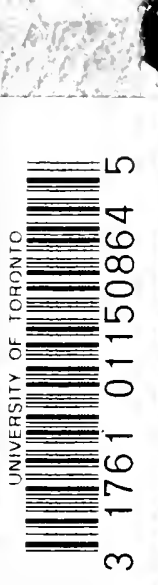

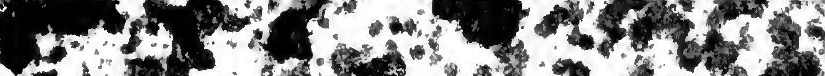

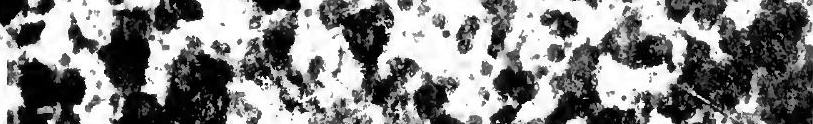
H. 5 .

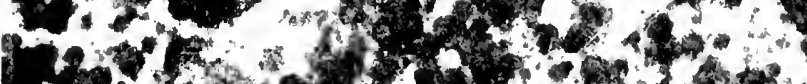

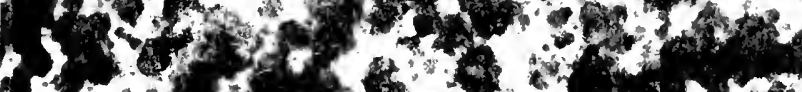

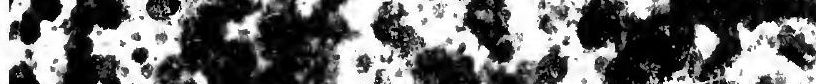

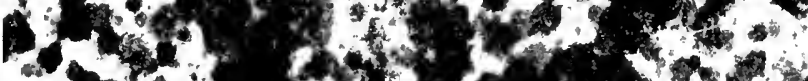

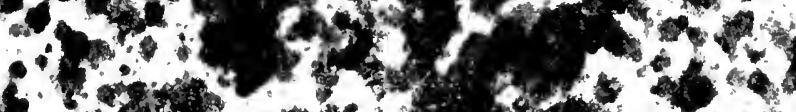

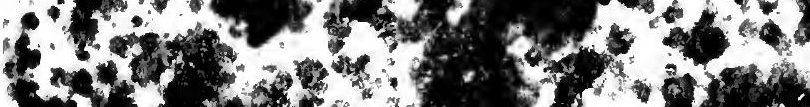

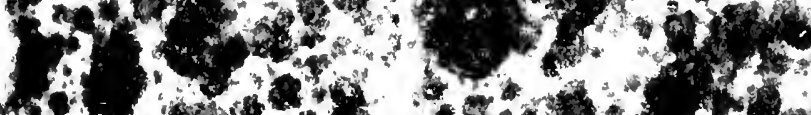
a.s.

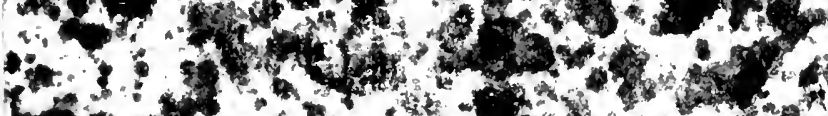
-

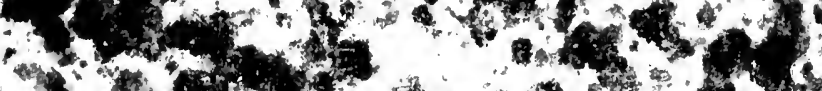
$3 x^{2}+4$

$3-100$

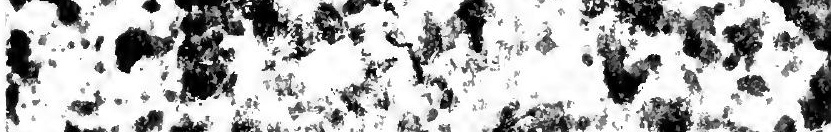

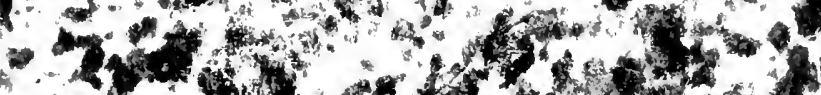

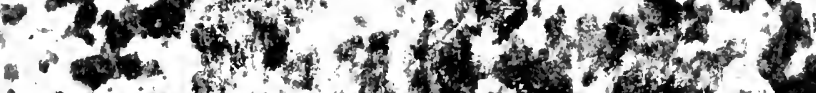

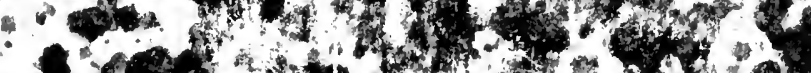

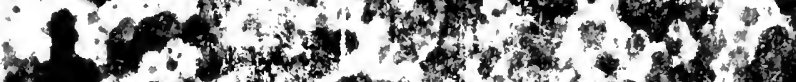

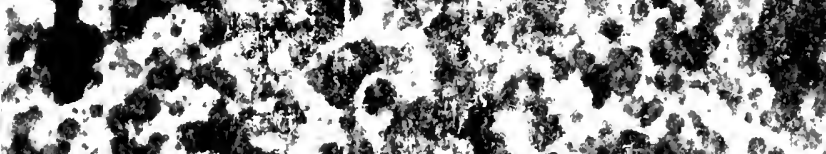

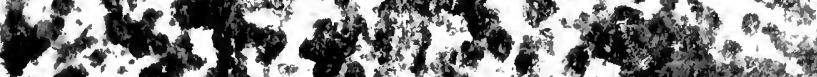
(6) (1) a

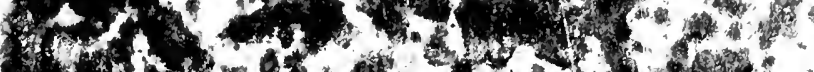




$$
\text { 芽尘 }
$$






\title{
IIISTOIRE
}

\author{
L L L A
}

IIILISITION

CONTEMPORIINE

EN FRANCE

PAR

\section{ALFRED RAMBAUD}

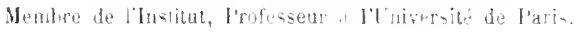

$$
\text { 9. ÉDITION }
$$

mise à jour jusqu'en 1912

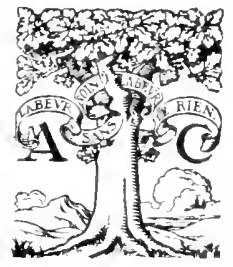

Librairie Armand Colin

Rue de Mézières, 5, PAIIS 



\section{IISTOIRE}

II E L.I

CIYILISATIOS CONTEVPORAINE

EX FRINGE 


\title{
OUVRAGES DE ALFRE RAMBAUD
}

\author{
LIPRAIRIE ARMAND COLIN
}

Histoirede la Givilisation française (Elition reliste pl mise is jom)

I. Memis les origines jusplic la fromle. In-18. Jir..4 4.

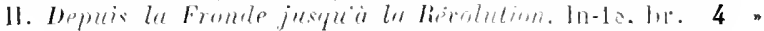

Histoire de la Civilisation contemporaine en France Edilion

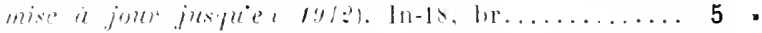

Petite Histoire de la Civilisation française lepui- its urigines

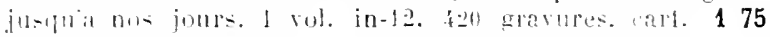

Etudes sur IH Histoire Byzantine. In-18. Inteht....... 350

Histoire gènérale du IV $^{*}$ siècle à nos jours. pulbliés sous la

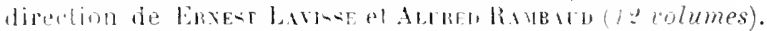

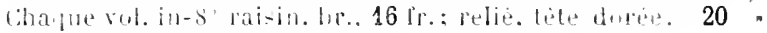

La France coloniale Emui,j.

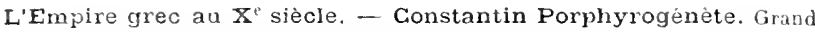

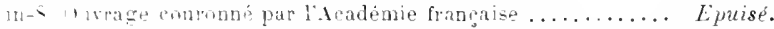

La Domination française en Allemagne. - Les Français sur le Fhin. - La Convention de Mayener, la liepulilique ristrénane, l'or-

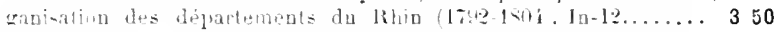

La Domination française en Allemagne. - L'Allemagne sous Napoléon $I^{e r}$. - La Confuleration du Lhin. le Royame de Westplialie,

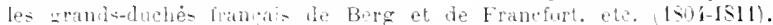

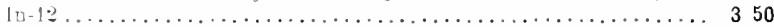

La Russie épique. - Étulp sur los chamano hepriqques de lo Russie,

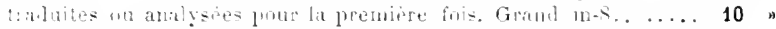

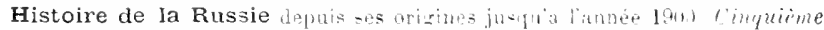

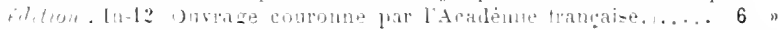

Français et Russes. - Moscou et Sérastopol 1 12-15. finguirme

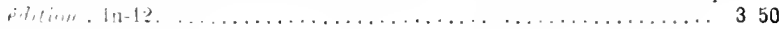

Russes et Prussiens. - La Guerre de Sept Ans. Ir-.... 7 n

Instructions aux Ambassadeurs français en Russie.? volumes.

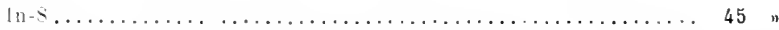

Histoire de la Révolution française $(17,1,1)$. Onvife notenant

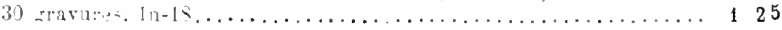

Jules Ferry 19:3!. 


\title{
HISTOLRE
}

DE LA

\section{CIVILISITIOS COITEIIPORIILE}

\section{EN FRANCE \\ P.IR}

\section{ALFRED RAMBAUD}

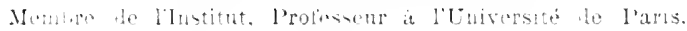

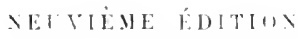 \\ $1415 \%$ at jour juquen $191 \%$
}

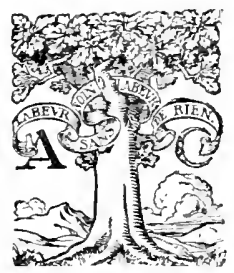

LIBRAIRIE ARIANO COLIX

RUE de MÉZIÉRES, J, PARIS

$$
1912
$$


$D C$

$3=$
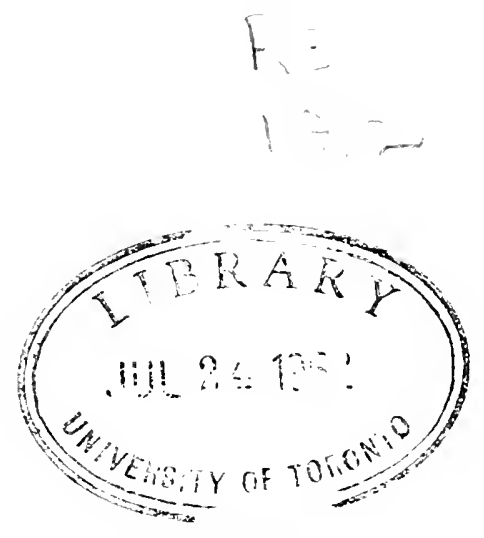

503151 


\section{PRÉFACE}

\section{DE LA PREMIÉRE ÉDITION}

(1888)

Les deux volumes de mon Histoire de la civitisation française ont obtenu du public un accueil qui a dépassé mes espérances; c'est ce qui ma encouragé à lui présenter ce troisième volume, qui en est la suite naturelle.

Je m'étais arrêté à la veille de la Révolution, j'avais seulement, dans un appendice en une trentaine de pages, donné un tableau de notre civilisation contemporaine, me bornant " à en indiquer les grandes lignes, à en mettre en lumière les caractères incontestables, à montrer ce que la France nouvelle tient de l'ancienne France et en quoi elle en diffère ". Le présent volume n'est que le développement de cet essai.

Ce qui m’avait d'abord fait hésiter à le publier, ce sont surtout les diffieultés inhérentes à la période tout à fait contemporaine. 
A aucune époque de nolre histoire, le génie français n'a été plus vivant, plus agissant, plus fécond, en toutes les branches de la liltéralure, de l'art, de la science, que dans les cinquante dernières années qui viennent de s'écouler.

Au théâtre, dans la poésie, dans le roman, dans la critique littéraire, dans la philosophie, dans l'histoire, dans l'érudition, que de noms et que d'ouvres I Comment être juste pour tous? Comment oser préjuger les appréciations de l'avenir sur chacun? Comment rester impartial entre les écoles rivales? Comment se défendre des passions et des sentiments qui dominent la grénération à laquelle on appartient et qui ne seront peut-êlre pas ceux de la postérité? Quand on voit combien de jugements des contemporains de Corneille, de Racine, de Vollaise, de Chateaubriand, de Balzac, ont été réformés, comment se hasarder à juger el à classer, à louer celui-ci, à laisser dans l'ombre celui-là?

Parmi les centaines de nos contemporains qui manient avec distinction l'ébauchoir, le pinceau, le burin, ou qui nous eharment de leurs œurres lyriques, quels sont ceux que l'avenir établira solidement au Pantheon artistique el qu'un autre Delaroche peindra dans un autre Hémicycle?

Même pour les sciences et les applicalions des sciences, qui pourra apprécier, avant trente ou quarante ans, la portée réelle de telle ou telle découverte, que nous ne pouvons que noter au passage el qui est peut-ètre le point de départ de merreilleux développemenls? 
Notez qu'il s'agit d'auteurs vivants, envers lesquels nous sommes tenus à tous les égards qu'on doit à des vivants, et dont l'œurre n'est mème pas achevée.

Nous sommes précisément au point oủ l'histoire se confond arec la chronique quolidienne, celle-ci n'étant que la prẻparation liàtive, tumultuaire, hasardeuse, de celle-là.

J'ai cependant espéré me tirer de tant de périls à force de sincérité, de scrupuleuse attention, d'indépendance, en même temps que de respect pour tant d'illustres contemporains qui, après tout, sont sur le grand chemin de la gloire, et dont te pire destin sera d'aboutir simplement à une brillante renommée.

La partie politique de cette histoire, c'est-à-dire l'exposé de nos trop nombreuses constitutions, des divers régimes républicains ou monarchiques, parlementaires ou autoritaires, que nous arons subis depuis plus de cent ans; de nos systèmes électoraux et de-notre développement social; de nos institutions administratives, judiciaires, ecclésiastiques, militaires, scolaires, etc., présente aussi ses difficultés.

Şil est relativement aisé d’ètre impartial à l'égard de Philippe le Bel, Louis XI, Henri IV, Louis XIV, est-il possible de l'être au même degré envers la Constituante, la Convention, le Directoire, Napoléon, la Monarchie de 1814 et de 1830, la République de 18.18, le second Empire, enfin pour les institutions et les hommes qui nous gouvernent aujourdhui?

On le peut aszurément, si l'on applique à l'étude des faits contemporains la même méthode qu'à l'étude des faits plus anciens. 
L'histoire contemporaine, sans doute, ne se sépare point de la politique; mais la politique même n'est pas uniquement, comme certains semblent le croire, affaire d'opinion, de préjugés, de passion et de nerfs. Bien comprise, elle est une science; elle fait même partie des sciences dites expérimentales; à ce titre, elle comporte, comme elles, des conclusions encore incertaines, des hypothèses; mais elle doit aboutir, si on la traite avec un esprit vraiment scientifique, à des lois aussi certaines que celles de la physique, de la chimie ou de la physiologie.

Ceux qui, en politique, s'emportent à des conclusions hâtives et violentes prouvent simplement qu ils n'ont pas observé ou pas observé avec assez de patience, ni tenu assez compte des observations et des expériences accumulées par leurs devanciers, c'est-à-dire des enseignements de l'histoire.

Ou bien ils ont cru pouvoir appliquer à la politique une méthode qui n'est applicable quaux sciences mathématiques; au lieu d'observer, ils ont posé des axiomes, vrais ou faux, tiré des deductions plus ou moins logiques et abouti à des conclusions qui ne sont exactes que sur le papier; oubliant que, suivant le mot de l'impératrice Catherine II, " le papier souffre tout, mais que la peau humaine est autrement sensible $»$.

En politique, l'ardeur des passions est en raison inverse de l'éducation scientifique. Les violents sont presque toujours les ignorants. Autrement verrionsnous tous les jours se produire des systèmes qu'on nous présente comme noureaux, mais qui sont, 
depuis longtemps, condamnés par l'expérience la plus concluante. On voudra, par exemple, nous imposer, comme choses nouvelles et excellentes, ou la propriété collective, ou le gouvernement d'une assemblèe unique, ou l'élection des juges par les justiciables, ou le système religieux des Hébertistes: nous n'avons qu’à renvoyer aux experiences déjà faites, comme nous renverrions à l'explosion de la poudrerie d'Essonnes (1788) ceux qui s'offriraient, avec l'air d’inventeurs sûrs de leur fait, à charger nos canons avec la poudre Berthollel.

L'histoire, même contemporaine, possède, comme le disait 11 . Vietor Duruy dans son Instruction du 24 septembre 1863, " une grande vertu d'apaisement ".

L'éminent ministre de l’instruction publique, l’éminent historien, ajoutait : "Aussi suis-je convaincu que l'étude, faite avec bonne foi, des épreuves que nous avons subies depuis quatre-vingts ans, est plutot de nature à apaiser les esprits, en les éclairant, qu'à les irriter ".

Dans mon examen des divers régimes que nous avons essayés, on verra que je ne méconnais aucun de leurs bons côtés : ni les idées généreuses et humaines de la Constituante, ni l'énergie patriotique de la Convention, ni le génie organisateur de Napoléon, ni la probité parlementaire de nos deux monarchies constitutionnelles, ni lardent esprit de justice sociale qui animait la seconde République, ni les grands progrès matériels accomplis sous le second Empire. 
En même temps je crois qu'il résultera de ces éludes qu'à aucun moment, sous aucun de ces régrimes, on n’a réalisé complètement lidéal, à la fois de liberté, d'égalité, d'ordre public, que tous les partis dignes de ce nom doivent avoir en vue.

Arriver à constater cette double vérité, n'est-ce pas une condition d'apaisemenl? Si l'on veut sincèrement atteindre cet idéal, ce n'est donc pas vers le passé qrill faut se retourner : c'est vers l'avenir qu'il faut regarder. Il ne sert à rien de renouveler les querelles d'autrefois : c'est à un effort combiné qu'il faut tendre. Aristophane nous montre, dans une de ses comédies, les peuples de la Grèce, naguère ennemis, unissant enfin leurs bras pour tirer la stalue de la Paix du fond d'un puits où leurs discordes l'ont plongée. Ne pourrait-on imaginer les divers partis de France s'inspirant chacun du meilleur de leurs traditions respectives et tirant fraternellement sur les câbles pour achever de mettre hors du puits cette statue radieuse d'une France libre et égalitaire, prospère et puissante, qui est le rêve, l'éblouissement et l'espérance de tous?

\section{A. R.}

Après douze ans écoulés, cet ourrage exigeait une revision totale et des additions assez considérables. J'ai revu, complété et corrigé, quand il y avait lieu, tous les chapitres; $j$ ”ai refondu entièrement le livre IlI. L'ensemble, mis à jour jusqu'en 1900, se trouve ainsi augmenté d'environ 80 pages.

\section{Ilars 1901.}

A. R.

Cet onvrage a été de nouveau revisé, complété et mis à jour pour la neuvieme édition. 


\section{PLAN DE LOUVRAGE}

Le présenl ouvrage se divise en trois parties:

De 1789 à 1814, les Gouvernemexts révolutionatres (Constituante, Législative, Convention, Directuire, Consulat, Empire);

De 1814 à 1848, les Gouversenexts de seffrage RESTREINT (Restanration et Monarchie de Juillel ;

De 1848 jusqu'a nos jours, les Gouversements de suffrage universel (seconde République, second Empire, troisième République).

Pour cíacune de ces trois périodes le plin reste identigue :

D’abord les constitutions, le régime électoral, les libertés publiques, l'administration, les finances, les cultes, l'armée, la marine, les colonies, l'instruction publique;

Puis les chapitres de civilisalion proprement dile: lettres, philosophie, histoire et les autres sciences morales et politiques; beaux-arts; sciences, applications des sciences; développement économique (agriculture, industrie,commerce, crédit); la vie publique et privée. 


\section{HISTOIRE}

DE LA

\section{GIVILISATION}

\section{CONTEMPORAINE}

EN FRANCE

\section{LIVRE PREMER}

LES GOUVEREMENTS RÉVOLUTIONNAIPFS

LA lútulution - LE CONSUlat - L'biphe (1789-1814)

\section{CIIAPITRE PIEMIER}

LES PRINCIPES DE 1799 ET LA RETOLUTION ${ }^{1}$

L'cuvre aceomplio par lancienne numarchie. - L'ancienne monarchie a rendu de grands services au pays: on peut dire qu'elle a lait la France. Nos rois, far leurs luttes contreles dynasties lëodales, contre les nations rivales, sont arrivés à grouper successivement autour de leur tròne la plupart des provinces qui faisaient partie de la vieille Gaule. Ils se sont substitués, pendant le xu1 siècle, aux anciens souverains du Languedoc, de la Champragie; fendant le $x v^{e}$, à ceux du Dauphiné; pendant le xve, à ceux de la Provence, de l'Anjou, du Haine, de la Bourgogne, de

1. Nous n'avons pas à raconter l'histoire de la Révolutiun : auus rous proposons seulement de dire quelle a été son cuvre.

R. Civil. contemp. 
la Picardie; pendant le xvıe, à ceux de l'Auvergne, du liourbonnais, du comti de Fois, du Béarn, de la Bretagne; pendant le xvme, à ceux de la Lorraine et de la Corse. A l'Angleterre, les Capétiens ont repris la Normandie et l'Aquitaine; à la maison de Bourgogne, devenue la maison d'Espagne, les Bourbons ont repris l'Artois, la Flandre, le Roussillon, la Franche-Comté, et à la branche autrichienne de la mème maison, l'Alsace.

Par l'action incessante de leurs officiers d'administration, de justice, de finances, par leurs prévóts, leurs baillis, leurs gouverneurs, leurs intendants, par leurs tribunaux inférieurs et par leurs Parlements, par leur Chambre des comptes et leur Conseil d'État, par la diplomatie et par la force des armes, par les influences ecclésiastiques et par les séductions de leur cour, nos rois ont travaillé, pendant près de huit siècles, avec tant de persévérance qu'à la fin tous les pouvoirs du passé perdirent leur souveraineté et furent subordonnés à une autorité unique.

D'un chaos de provinces, de duchés, de comtés, de baronnies, de républiques municipales et de principautés ecclésiastiques, ils ont fait sortir l'État moderno avec ses organes essentiels, ses moyens d'attaque et de défense, une armée, une llotte, une diplomatie, des finances.

En alliant la l'ermeté au respect, ils ont peu à peu diminué la prépondérance autrefois exclusive de l'Église, assuré l'indépendance des pouvoirs temporels, permis aux lettres et aux sciences de s'źmanciper graduellement de la théologie, en un mot constitué l'État laïque.

Pour accomplir cette œuvre, sontre la féodalité guerrière et contre l'Église féodale, ils on dù faire appel à une classe jusqualors humiliée : le tiers étăt. Ils ont lavorisé l'émancipation, sinon politique, du moins civile, des villes, poussé à l'affranchissement des paysans, opposé, dans les Etats généraux, les députés de la bourgeoisie à ceux des classes autrefois souveraines, recruté parmi les bourgeois leurs intendants, leurs conseillers ifEtat, leurs ministres.

L'ouve accomplie par la Révolution. - A ce point de vue, la liévolution n'est pas venue détruire l'œuvre de la royauté, mais au contraire la compléter et l'achever. Elle respecta et renforça la centralisation administrative. 
Elle maintint intacte l'autorité souveraine et sa préponlérance sur les individus, se bornant à la faire passer les mains du roi dans celles de Ia nation. Elle fortilia l'unité matérielle et créa l'unité morale: des provinces réunies par les rois, elle forma une nation. Louis XIV et Louis XV, en parlant des habitants de la France, disaient encore : "Nos peuples". La Révolution a fait le peuple.

Les rois n'avaient poussé la destruction de la puissance temporelle ecclésiastique, de la féodalité, des autonomies provinciales et municipales, que jusqu'au point précis où ces puissances du passé cessèrent d'être un obstacle à leur autorité. La Révolution poussa jusqu'au bout cette destruction : car l'égalité démocratique, qui était son but, exigeait nécessairement un nivellement complet.

L'œuvre qu'on pouvait attendre de la royauté, elle l'avait accomplie; mais il n'était pas de son essence mème, comme puissance d'origine féodale et ecclésiastique, d'achever la destruction des privilèges ecclésiastiques et féodaux. Or les privilèges du clergé et de la noblesse étaient un obstacle invincible à un bon système d'impôts, à un bon système d'armée, à un bon système de justice et d'administration. La rovauté n'ayant pas la force ou la volonté de les supprimer, elle dut faire place à la Nation.

La royauté française n'avait pas été assez forte pour réaliser l'égalité; elle l'était trop pour pernettre la liberté. Timide à l'égard des droits historiques de l'Église et de la noblesse, elle avait été tyrannique à l'égard des sujets : elle avait anéanti jusqu'au dernier vestige de représentation nationale; elle n'avait respecté ni la liberté de conscience, ni la liberté d’écrire, ni la sécurité des personnes el des propriétés. Les conséquences du despotisme de Louis XIV pesaient encore d'un poids énorme sur toute la vie nationale; près d'un nillion de sujets français, à cause de leurs convictions religieuses, restaient hors du droit commun. Ses successeurs, de caractère plus modéré, maintenaient cependant intacts le principe et les pratiques les plus détestables du gouvernement absolu.

L'œuvre de la royauté pouvait se résumer en ces trois points: elle avait créé l'unité et la srandeur de l'État francais; e'le avait abattu la puissance des anciennes classes 
dominantes, mais en laissant subsister leurs privilèges; elle avait détruit les libertés publiques et élevé sur leurs ruines le pouvoir absolu. Sur le premier point, la Révolution maintint l'ceuvre de la royauté; sur le second point, elle l'aclıeva; sur le troisième, elle la détruisit. Son œurre à elle peut se résumer en ces trois mots : unité, égalité, liberté.

La Révolution n'est pas un accident dans notre histoire. Elle a été préparée et amenée par un passé de huit siècles. Au xne siecle, avait commencé l'émancipation des villes; au $x m^{*}$ siecle, celle des paysans; au $x v^{*}$ sierle, la renaissance des lettres, des sciences et des arts; au xue siècle, les idées de liberté religieuse. L'influence des philosophes et des économistes, au xvme siècle, avait été lécisive. "Depuis quarante ans, écrivait Rœderer en 1789 , cent mille Francais s'entretiennent avec Locke, avec Rousseau, avec Montesquieu. Chaque jour, ils recoivent d'eux de grandes lecons sur les droits et les devoirs de l'homme en société; le moment de les mettre en pratique est arriví. "

Laz Hévolntion anratelle pu etre évitec: - Les autres nations de l'Europe ont eu, comme la France, le pouvoir absolu et l'ètat social de l'ancien régime; cependant, chez la plupart d'entre elles, le prouvoir absolu a fini par faire place au régine parlementaire, et l'état social issu de la féodalité, a un état social plus voism de l'égalité. Aucune n'a dù acheter cette transformation par une crise aussi violente que l'a étéchez nous la Révolution. Pourquoi notre pays seul, au lieu de procéder par voje de réformes pacifiques, a-t-il dù subir un bouleversement?

C'est d'abord parce qu'il a été le premier à entamer lis lute contre toutes les torees du passé.

Ensuite, il a été victime dun concours funeste de circonstances. Si Louis XVI avait été plus intelligent et plus résolu, il aurait pu prendre l'initiative d'une révolution nécessaire, et alors l’accomplir par les voies légales; mais tout son règne, même avant la Révolution, n’a été qu'une série de fausses mesures; toutes ses réformes se sont produites trop tard ou bien ont élé reprises apres aroir été octroyées. Il ne convoque les Etats ténéraux qua la dernière extrénité, lorsyüil y est contraint par la détresse 
de son trésol' il concède au tiers état une double représentation et lui refuse le vole par tête qui en était la conséquence logique. Après s'ètre aliéné l'armée par une série d'édits, il essaye de recourir aux soldats pour dissoudre une assemblée dont l'armée comme la nation attendent uniquement le redressement de leurs griefs.

L'Assentlée, qui allait assumer le rôle que le roi navait pas su prendre, était composée d'hommes pleins de bonne volonté, de patriotisme, d’idées élevées et humaines; mais ils n'avaient pas eu le temps d'ébaucher leur éducation politique dans les assembles provinciales, Jrécisément parce que celles-ci avaient été créées beaucoup trop tard, moins de deux années avant la Révolution.

Enfin le peuple, qui allait intervenir dans les événements pour les précipiter, n'avait reçu sous l'ancienne monarchie aucune sorte d'instruction, et sa misère avait été accrue par une série de mauvaises récolles; il devait done apporter dans ses interventions des passions violentes, et les émeutes parisiennes furent aussi souvent dirigées contre les représentants de la uation que contre l'autorité royale.

Le caractère du roi Louis XVI, l'éducation incomplete de l'Assemblée, les années de famine qui exaspérèrent les souffrances du peuple, ce sont autant de circonstances désastreuses qui tirent que la France, au lieu de se régénérer par une évolution pacifique, fut lancée dans les périls d'une révolution.

La royauté n'ayant su ni prévenir la crise par des réformes opérées en temps utile, ni accepter de bonne grûce celles que lui proposèrent les représentants de la nation, celle-ci n'avait que le choix entre la continuation de lancienne servitude ou la lutte à main armée.

Les députés de la nation, à peine assemblés, sentirent leur force; ils s’indignèrent quon prétendit, au prix de réformes insignifiantes, obtenir d'eux les moyens financiers de perpétuer l'ancien régime; ils refusèrent d’admettre qu'ils fussent réunis uniquement pour voter de nouveaux inpòts. D’autre part, il était impossible de réformer les finances sans réformer tout l'état politique et social. Par le serment du 20 juin, les députés formulèrent leur programme : donner une constitution, à la fois politique et 
sociale, à la Frince. Dans la séunce royule du 2.3 Juin, le roi formula le sien : ne toucher ni à la division en ordres, ni au clerğí, ni a la noblesse, ni au système militaire. Entre ces deux programmes, nulle conciliation ne semblait possible : le roi essava d'employer la force contre l'Assemblée; le peuple de Paris employa la force contre la royauté. La prise de la Bastille (14 juillet 1789) mit fin a la monarchie absolue; la journée du 10 aoùt $1792 \mathrm{mit}$ fin à la monarchie mème tempérée.

Les principes de 1 z89. - La transformation de la France ancienne en une France nouvelle a été accomplie par trois assemblées nutionales : $1^{\circ}$ la Constituante; $2^{\circ}$ la Législative; $3^{\text {o }}$ la Convention. Les Conseils législatifs du Directoire ont peu ajouté à l'œurre de ces grandes assemblées.

Elles édictèrent des milliers de lois et de décrets qui modifièrent toutes les branches de la vie nationale. De ces actes innombrables, les uns furent des lois de circonstance et de combat; les autres furent des lois de fond et de durée, qui nous régissent encore aujourdhui. Celles-ci ne sont que les déductions, les corollaires et les conséquences des principes de 1789. Ils ont été formulés en 1791 dans la Déclaration des droits de l'Homme et du Citoyen ', cette pare de raison et de justice, " la plus grande, a dit Victor Cousin, la plus sainte, la plus bienfaisante qui ait paru depuis l’Évangile ". Les adversaires mêmes de la Rérolution linvoquent chaque jour comme la grande charte de leurs droits civiques.

Souveraineté nationale. - Louis XIV et Bossuet ont donné la théorie de la royauté absolue. Voici celle que lui oppose la Déclaration de 1791: "Le principe de toute souveraineté réside essentiellement dans la nation. Nul corps, nul individu, ne peut exercer d'autorité qui n'en émane expressément. "C'est la négation non seulement dune

1. Il existe d'autres Déclarations. Celle qui fut rédigèe en juin 1793 sous l'inspiration de Robespierre. dans ses traits essentiels, difere peu de la première: elle se borne à y ajouter certains principes, comme le droit a linsurrection. el à ed accentuer certains autres, comme la souverainaté pationale. Nous parlerons plus loin de la Déclaration de 1795. En étudiant la Lincluration des droils de l'Homme et du Citoyen, nous citons le terto de $17 \% 1$. 
royauté de droit divin, mais aussi de toute autorité indépendante que prétendrait exercer ou une elasse d'hommes ou un corps judiciaire. A la souveraineté du roi, aux droits historiqucs du clergé et de l'aristocratie, on oppose nettement la souverainelé nationale.

Le roi de droit divin faisait seul la loi : il était la loi vivante. "La loi, dit la Díclaration, est l'expression de la volonté générale: tous les citoyens ont droit de concourir, personnellement ou par leurs représentauts, à sa formation."

Le roi règne désormais par la volonté nationale. Il n'est plus le propriétaire de la France, maitre absolu des biens de ses sujets et des finances publiques : on lui fixe sa liste civile. Il n'est plus que le ch'f du jouvoir exécutif et le premier magistrat de l'Etat. Les Français ne sont plus des sujets, mais des citoyens. Après la constitution monarchique de 1791. d'autres constitutions supprimeront le roi, et alors apparaitra plus clairement ce fait nouveau : la nation se gouvernant elle-même.

Principes nouveanx de liberté. - Les libertés publiques, tant de fois violées par lancienne monarchie, sont affirmées par la Déclaration: "Nul homme ne peut être accusé, arrêté, ni détenu que dans les eas déterminés par la loi et selon les formes qu'elle prescrit; ceux qui sollicitent, expédient, exćcutent ou font exécuter des ordres arbitraires doivent ètre punis. "C'est la condamnation des lettres de cachet, des commissions extraordinaires, de toutes les juridictions exceptionnelles qui enlevaient le citoyen à ses juges naturels.

Les persécutions religieuses étaient encore présentes à toutes les mémoires, et beaucoup des contemporains en avaient personnellement souffert. " Nul, proclame le droit nouveau, ne doit ètre inquiété pour ses opinions, mème religieuses, pourvu que leur manifestation ne trouble pas l'ordre établi par la loi."

La presse était jusqu'alors soumise à une censure vexatoire et à des lois pénales très rigoureuses. "La libre communication des pensćes et des opinions, porte la Declaration, est un des droits les plus précieux de l'homme; tout citoyen peut donc parler. écrire, imprimer librement, saut 
à répunlre de l'abus de cette liberté dans les cas oéterminés par la loi. "En conséquence, la Constitution de 1791 garantit "la liberté à tout homme de parler, d'écrire, d'imprimer et publier ses pensées, sans que ses écrits puissent ètre soumis à aucune censure, ni inspection avant leur publication".

La mème Constitution garantit " la liberté aux citoyens de s'assembler paisiblement et sans armes, en satislaisant aux lois de police".

Les propriétés, sous l'ancien régine, nétaient guère mieux assurées que les personnes: "La Constitution garantit linviolabilité des propriétés, ou la juste et préalable indemnité de celles dont la nécessité publique, légalement constatée, exigerait le sacrifice. "Une loi instituera les jurys d'expropriation, composés eux-mèmes de propriétaires, qui statueront sur cette indeminité.

Principes nouveaux d'égalité. - Le trait caractéristique de l’ancienne société française, c’était l'inégalité entre les personnes. La Révolution a pour principe l'égalitè. "Les hommes naissent et demeurent libres et égaux en droit, dit la Délurution. Les distinctions sociales ne peuvent ètre fondées que sur lutilité commune. "

En conséquence, "il n'y a plus ni noblesse, ni pairie, ni distinetions héréditaires, ni régime féodal, ni justices patrimoniales, ni aueun des titres, dénominations et privilèges qui en dérivaient, ni aucun ordre de chevalerie, ni aucune des corporations ou décorations pour lesquelles on exigeait des preuves de noblesse ou qui supposaient des distinctions de naissance, ni aucune autre supériorité que celle des fonetionnaires publics dans l'exercice de leurs fonctions. La Constitution garantit comme droits naturels et civils : $1^{\circ}$ que tous les citoyens sont admissibles aux places et emplois, sans autre distinction que celle des vertus et des talents; $-2^{\circ}$ que toutes les contributions seront réparties entre tous les citovens également, en proportion de leurs facultés; $-3^{\circ}$ que les mêmes délits seront punis des mêmes peines, saus aucune distinction des personnes." "

C'est la fin d'un état social qui avait existé chez nous de tout temps, car la vieille Gaule arait eu ses druides, ses che- 
valiers, ses clients; la Gaule romaine avait eu ses nobles, ses colons, ses esclaves; la France du moyen àge avait eu son Église féodale, son aristocratie, ses vilains et ses serfs.

Voici comme un père de famille, au lendemain de la prise de la Bastille. expliquait à son fils, le jeune Étienne Delécluze, le sens de la Révolution : "Qu'est-ce donc que la Révolution'? demandait l'enfant. - Il est bien difficile de te répondre, disait le père. Si tu étais plus grand!... Tiens, je ne puis mieux faire qu'en te disant que la Révolution détruit toutes les distinctions entre les hommes. Désormais, il n'en existera plus qu'une seule : celle que la science et l'instruction meltront entre les ignorants et les savants. Aussi, travaille bien, si tu veux te distinguer. Il n'y a plus d'autre noblesse. "

Les privilerged des provinces et des villes abolis. - Dans la nuit du \& aoùt, ce n'étaient pas seulement les privilèges du clergé et de la noblesse qui avaient été supprimés: c'étaient aussi ceux des provinces et des villes. Pour anéantir jusqu'au souvenir des rivalités locales et des haines d'autrefois, on suppiima la division en provinces. La France fut partagée en départements, désignés par des noms empruntés à leurs cours d'eau, à leurs montagnes, à leurs particularités géographiques. Il n'y eut plus des Bretons, des Flamands, des Provencaux, mais des Francais habitant la Loire-Inférieure, le Nord ou les Bouches-du-Rhóne. Tous eurent les mèmes devoirs et les mèmes droits. Il n'y eut plus des cités, des bourgs, des villes, des villages, mais des communes soumises aux mêmes principes d'organisation administrative.

En retirant aux provinces et aux villes leurs privileges, c'est-à-dire les vieilles libertés incomplètes et exclusives, on leur assura la liberté. Les départements, les districts, les communes ne furent plus administrés que par des autorités et des assemblées élues.

Principes nouveaux de justice et de législation. - La Constituante supprima les Parlements, qui ètaient restés les citadelles des privilégiés; elle supprima également les juridictions extraordinaires du roi, toutes les justices seigneuriales, ecclésiastiques, municipales. Elle mil fin au droit que s'arrogeaient les individus de rendre la justice, 
soit qu'ils l'eussent acheté au roi, soit qu'ils l'eussent trouvé dans l'héritage de leurs ancêtres.

Au lieu du chaos des coutumes provinciales, les Assemblées édictèrent une série de lois applicables à tous les points du territoire français, réglant l'état civil du citoyen, la constitution de la famille, les relations d'obligation et de contrat, supprimant toute subordination d'une terre à une autre, abolissant lancienne procédure criminelle et l'ancienne législation pénale.

Principes nonveaux d'ormanisation militaire. - Dans l'armée, jusqu'alors instrument du pouvoir absolu, où lc noble s'arrogeait plus exclusivement que partout ailleurs le privilège du commandement, pénètre le principe de liberté et d'égalité. Plus de titres de noblesse exigés, plus de vénalité des grades, plus d'exploilation du soldat par ses chefs, plus de chàtiments corporels. Le service militaire est à la fois un devoir et un droit. On verra ce peuple français, qui manifestait naquère tant dhorreur pour le service militaire, s'éprendre tout à coup de passion pour la gloire; au lieu des iniquités de l'ancien racolement et de l'ancienne milice, c'est l'appel de la patrie á tous ses enfants qui fait sortir du sol les légions révolutionnaires; le fusil de munition, si redouté autrefois du paysan, est devenu l'insigne le la liberté reconquise et sa garantie.

On verra, pendant vingt-trois ans, une race nouvelle de guerriers issue du vieux sol gaulois, ardente, intrépide, sobre, patiente au mal, conquérir et affranchir les pays voisins, promener son drapeau nouveau, le drapean aux trois couleurs, dans loutes les capitales de l'Europe et sous tous les climats des deux mondes, affronter les frimas de la Russie ou le ciel de leu de l'Egypte, accomplir une épopée militaire qui éclipse les exploits de l'antique chevalerie et les victoires de Louis XIV.

Principes nouveaux d'organisation financière. - "Pour l'entretien de la force publique et pour les lépenses d'administration, dit la lécluration, une contribution commune est indispensable: clle doit ètre également rípartie entre tous les citoyens, en raison de leurs facultis.

"Tous les citoyens ont le droit de constater par euxmèmes ou par leurs représentants la nécessité de la con- 
tribution publique, de la consentir librement, d'en suivre l'emploi et d'en déterminer la quotité, l'assiette, le recouvrement et la durée. "

Le changement même des mots indique le changement des idées; le mot d'impót, qui semblait emporter l'idée d'un tribut imposé par un maitre ou un conquérant, lait place à celui de contribution, qui rappelle à la fois la légitimité de la quote-part demandée à chaque citoyen et l'utilité publique qui est sa destination. Ce n'est plus le roi qui fixe arbitrairement les perceptions et les dépenses : ce sont les représentants de la nation qui votent la contribution, qui en surveillent l'emploi, qui contractent les emprunts. Plus de privilèges devant l'impòt: le pauve ne payera plus pour le riche.

Principes nouveaux d'enseignement national. - " I] sera crée et organisé, porte la Déclaration, une instruction publique commune à tous les citoyens, gratuite à l'égard des parties d'enseignement indispensable pour tous les hommes." Ainsi il y aura une éducation publique, c'està-dire une éducation nationale. Instıuire les citoyens est maintenant la chose, non du clergé ou des corporations, mais de l'État, qui est le premier intéressé, car il est la communauté des citoyens. Plus d'écoles où l'on n'entre qu'arec des quartiers de noblesse. Un vaste plan pour les études va ètre élaboré; et, comme il laut que le plus pauvre citoyen puisse apprendre ce qui lui est indispensable pour la connaissance de ses droits et de ses devoirs de citoyen, on entend que cette part d'éducation, qu'on appelle aujourdhui l'enseignement primaire, soit gratuite.

Principes nouveaux d'assistance publique. - La Constitution de 1791 a érigé en devoir national l'assistance "des pauvres infirmes et des pauvres valides manquant d'ouvrage "; l'assistance publique, comme l'éducation publique, c'est une des principales applications du principe de Fraternité, inscrit dans la devise de 1789.

Ainsi partout, dans toutes les manifestations de la vie sociale, dans toutes les branches de ladministration publique, la Révolution a substitné à l'arbitraire la liberté; au privilège, l'égalité; au désordre, résultant du conflit des 
institutions anciennes avec les nouvelles, l'ordre et la régularité modernes.

Expansion des principes de 1 g89 dans le monde. La civilisation française, au $x v_{11}{ }^{e}$ siècle, avait un caractère universel ou cosmopolite : la Révolution eut le même caractère. Elle ne fut pas seulement un fait français, mais un fait européen. Notre langue, si répandue dans tous les pays civilisés, servit de véhicule aux principes de 1789. Ils se propagèrent surtout dans les pays dont létat social était le plus rapproché du nôtre. La Belgique, la Hollande, l'Allemagne du Khin, la Suisse, l'Italie furent révolutionnées de fond en comble. L'Angleterre et l'Écosse s'agitèrent, l'Irlande opprimée appela les Français. Quand Napoléon, après avoir dompté la liévolution en France, se fut emparé de sa direction en Europe, les principes de 1789 furent alors appliqués, au moins en partie, dans toute l'Allemagne, en Espagne, en Pologne, en Illyrie, en Dalmatie, aux îles Ioniennes. Les serfs mêmes de la Russie tressaillirent au mot nouveau pour eux de liberté. Pour résister à l'empereur de la Révolution, les rois eoalisés furent contraints de faire appel aux peuples et de promettre des réformes: les vieilles dynasties des Hohenzollern, des Habsbourg, des Romanofi, parlèrent de liberté et d'égalité.

Quand Tapoléon suecomba, la réaction qui suivit sa chute s'étendit sur l'Europe entière; mais partout les idées qu'avait semées le passage des armées françaises commencèrent à germer. De 1821 à $182 \%$, quand la France elle-méme était en repos, la Révolution continua à cheminer par le monde : elle éclata dans l'Amérique espagnole et portugaise, en Espagne, à Naples, en Piémont, en Grèce, jusqu'en Russie, où les associations libérales livrèrent bataille a l'empereur Nicolas.

Après nos journées de Juillet, les États du pape, la Polorne, la Belgique s'insurgèrent, les États secondaires de l'Allemagne demandèrent des constitutions, et l'oligarchie anglaise dut consentir à la réforme parlementaire de 1832 .

En 1848, l'agitation prit des proportions encore plus vastes, car le roi de Prusse et l'empereur d'Autriche furen chassés de leurs capitales; les Allemands se formèrent en congrès à Francfort, les Slaves en congrès à Prague; la 
Hongrie prolongea son insurection pendant deux années; l'Italie se leva tout entière de Venise à Palerme; la Valachie et la Moldavie renversèrent leurs hospodars; des meetings anglais réclamèrent le suffrage universel.

Dès lors, l'ancien ordre européen ne put jamais se reconstituer tout entier. En Russie mème, douze ou treize ans après notre journée de février $18 \$ 8$, les paysans furent affranchis par l'empereur Alexandre II. Ainsi les peuples de l'Europe ou de l'Amérique mirent un temps plus ou moins long, suivant leur tempérament ou leur degré de maturité, a réaliser les principes de 1789: tous y sont venus. Ceux qui, au temps de la Convention ou de Napoléon, ont combattu avee le plus d'acliarnement la Révolution française, ont fini, les uns vingt ans, les autres trente ans, les autres cinquante ou soixante ans après, par en adopter toutes les maximes. Les serfs de Russie, armés en 1799 contre le Directoire, ont recueilli, en 1861, le bénéfice de leur défaite par les soldats de Masséna. La prédiction de Lafayette, qui annonçait, en 1789, que le drapeau tricolore lerait le tour du monde, s'accomplit chaque jour sous nos yeux. Si donc nous avons soutenu une lutte terrible contre toute I'Europe monarchique et contre une partie mème de la France pour le triomphe des Droits de lhomme, si le sang français a coulé a flots sur tant de champs de bataille, le peuple français a du moins la gloire, chirement acquise et unique, quaucun peuple, si victorieux qu'il soit, ne peut lui disputer, d'avoir combattu non seulement pour son émancipation, mais pour celle du genre humain, et d'avoir été le missionnaire et l'apòtre de la régénération universelle. Ainsi il a continué, sous un autre étendard, le rỏle qu’on lui assignait au moyen àge, celui de soldat de Dieu. Aux Gestes de Dieu par les Franes se sont ajoutées des pages immortelles. Si nous n'avons plus combattu pour un Sépulcre vide, nous avons combattu pour le Dieu vivant, pour la Justice, pour le Droit, ce "souverain du monde ", comme le définissait Mirabeau. Ce n'est pas pour nous seulement, mais pour tous les hommes, dans l'avenir comme dans le présent, pour nos ennemis comme pour nos amis, pour les noirs comme pour les blancs, que nous avons brisé le pouvoir despotique, l'or- 
ganisation en castes, le servage de la glebe, tous ces vestiges de l'ancien état social asiatique; que nous avons mis fin à l'ignorance et à l'explostation des travailleurs, à la férocité de la procédure criminelle et à la barbarie des supplices, aux chàtiments corporels dans les armées et dans les écoles, à l'intolérance et aux persécutions religieuses; que nous avons rendu libres l'homme, la famille, la terre, les métiers, la presse, la conscience; que nous arons enfin, du monde royal, sacerdotal et féodal, fait sortir le monde moderne.

Ouvnages a consulten. - Documents : - Réimpressiondu lloniteur uninersel. - Arche's parlementares depuis 1757. - Conllection des documents pulliés, tant par le minister de l'Instr. Publ. que par le Conseil munic. do Paris, sur la Révol, - Ilimtoires de la Revol. Frane: Thiers, Mirnet, Nichelet, Louis Blans, Ed. Guinet. Hanel, de Sybel, A. Kamhaud, ete. - A. Anlard, llist. Polit.

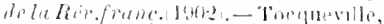

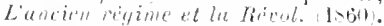
- Taine, Les origimes de lie Finute contemporicine lsis-185. - Henri Martin, lolitique de lir liprol. Anu, Challamel, Mistoine-musre de la livol. frame. (18is)

A. Bardous, La bouryeoisie frane. (1789-18's), (1886). - Laferrière, Hist. des principes, des institut. et des lois pendantlie Rév. (ranc. (1850). - Janot, Philos, de la liév. (IST). Chassin, Le yenie de la Rér. (1869). Champion, Esprit te la Rive (18si). - Giaret, Les bienfaits de la Rév. (1.sisto) - Aulard, litultes et lecons sur lit hive frunc. (déjit is séries).

Burke, Riflerions surla Riv. frane. (17mb. - Narlintosh. A polowie de la hiv. frame (1791). - Thrmas Piynf, Les Droits de lhomme (179117\%2. - Ces ouvrates sont lis a des Anglais, le promier enmemi, les deux autes partisans de la liévolution.) . Fichte (le philosophe allemand), Considisations sur la liev. frubr. (1793. - Mme de Stä̈l Consillerations sur la Rer. franc. (1บis).

('h. de Remusat, L'Angletere au X Ville siecle (1856). - A. Giffroy, Gustare 111 et lic coum le France (1sfo). - G. Avenel, Anacharsis Clonts (1905) et Lundis rérolutionnaires (1855). - A. Rambiud, Les

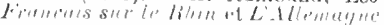
sous liz. ler (1SB3). - L. I incaud.
Les Francais en Russie el les Russes en France (1886). - Furnepon, llist. gén. des émigrés (1S84). - E. Daudet, Histoire de l'Emyration pend. la Rév. franc. (1904-i). - Albert Sorel, L'Europe et le Rev. frant: (1887-1905). - Torres-Caleedo, Les principes de 1789 en Ameirique 1869

H. Walion, Hist, dic tribunal rétolut. (1.S:) et La kit. "tu St mai et le férléralisme de 1793 (1886). - d'llerivault. La hiv. de Thermidor (1876). - Clarelie, Camille Dosmoulans (1875) et Les demiers Munlamards (1067). - Hamel, Hist.de Rubespierre (1867). - Boustart. Duntem 1851. Rohinet, Iroces des Dantonistes (1875)et Janlon homm d Etat (1589). Seingmerlet, Strusboury pend. la Rèv. (1ธ21). - Bouvier, Les Vosyes id. (1855) - A. Babeau, Troyes id. (1S74). - A. Denis, Toul id. (1R90). - G. Bussiere, La Rév. en Périgord(1S77-1903). - Pocquet. La Rév. en Bretayse (1S85). - P. Vidal, Histoire de la Rer. franc. dans les Pypinces-Orientales (185;-89); F. Rouvière, dans le Gurd (182)? Arnaur, dans lidring (1904); L. Guillemant, dons le Lomhuntis (IS.t. 1903 ; E Pionnier, di Terdun (1906). - M. Wahl, Lespremières annies de la Riv. a Lyon (184- - M. Lam-

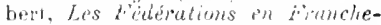
Comté (1890). - J. Viruler, Les debuls de la Rév. en Provence (1895). - Brmeau. Id. clans les dejart. du Cheret de londre(1502). - I. Saluzay, Hust. de la persécution rirolutionnutre dons le boubs (1801-73). -

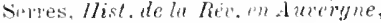
et dimles de f. Mere sur la mone region, ite.

Ciunpliter avee shap. I a iv el vi du t. Vlll de J"Histore y rale de Lavise et Rambaud. 


\section{CIIAPITRE II}

LES CONSTITUTIONS, LE DROIT ELEGTORAL

\section{La Constitution de 1791.}

Priacipes fondamentaux de nos Constitutions. - Tous les gouvernements de la France depuis la Révolution, à l'exception d'un seul (la Restauration), qu'ils aient porté le nom de Royauté, d'Empire ou de République, ont reconnu formellement qu'ils avaient pour origine la volonté nationale. La Restauration elle-niême n'a pas eu la prétention de gouverner despotiquement.

Donc tous les gouvernements qui ont suivi la Révolution se distinguent de ceux qui l'ont précédée par ces traits caractéristiques : ils ne sont plus absolus; ils gourernent avec le concours de représentants de la nation; ils obéissent à ure loi fondamentale qu'on appelle la Constitution.

Seulement la France a eu, depuis un siècle, bien des espèces de Constitutions. Nous avons mème eu jusqu'à dix-sept Constitutions: celle de 1791, qui était monarchique; celles de 1793, de l'an III, qui ètaient républicaines; celles de l'an VIII, de l'an X, de l'an XII, qui organisèrent le Consulat et l'Empire; la Charte de 1814, l'Acte additionnel de 1815 , la Charte de 1830 , qui étaient parlementaires; la Constitution républicaine de 1848; la Constitution bonapartiste de 18:2, modifiée par les Actes de 18\%3, 1860, 1867, 1869; enfin la Constitution républicaine de 1875. Outre ces régimes, qui ont tous pour bise des actes écrits, nous en avons eu qui furent seulement hes gouvernements de fait, ne reposant pas sur une Constitu- 
tion: la dictature de la Constituante, celle de la Législative, celle de la Convention, celle du gouvernement provisorre de 18 '8, celle de Louis-Bonaparte en décembre 185\%1, celle lu gouvernement de la Défense nationale de 1870 , celle de l'Assemblée nationale de 1871 .

La Constituante. - La première Assemblée de la RévoJution, après avoir été les Étuts finiraux de 1789, devint l'Assemulée nationule lors de la réunion des trois ordres; elle prit le nom de Constituante parce qu'elle s'était assigné pour mission, conformément au Serment du Jeu de Paume, de donner une Constitution à la France.

En attendant que cette Constitution fût votée, l'Assemblée laissa au roi le pouvoir exicutif, mais elle s'attribua le pouvoir législatif et le pouvoir constituant ${ }^{1}$. En 1791, après la fuite du rui à Varennes, elle le frappa de suspension, c’est-à-dire quelle lui interdit d'exercer le pouroir exécutif. Jusqu'au moment où elle le releva de cette déchèance, l’assemblée réunit tous les pouvoirs : elle légiféra et elle gouverna.

Elle donna au pays la constitution promise : c'est la Constitution de 1791 , la première quait eue la France?.

La Constituante n'avait pas été embarrassée pour rédiger la Déchuration des droits : elle n’eut quà s̈inspirer des idées élaborées par les philosophes et de ses propres sentiments de justice et de générosité. Il était plus difficile de rédiger une bonne Constitution; car, pour une telle cuvre, il faut beaucoup d'expérience politique, et c'est précisément ce qui manquail à nos pères: pour en acquérir, le temps leur avait manqué et leur manqua.

\section{Exemple que nous offrait la Constitution anglaise. -} On aurait pu profiter de lexpirience acquise par une nation roisine, le premier des grands peuples européens qui st fût mis en possession de la liberté politique. La Constitution anglaise n'avait pas été rédigée par une assemblée constituante : elle était l'œuvre du temps et de l'expé-

1. Quand ses decrets touchaient aux matières légisiatives, on demandait la san tion du roi; quand ils touchaient aux matières constitutionnelles. le roi n'arait pas a les sanctionner, mais simplement a les pronulguer.

2. Elle porte la date du 3 stptembre 1701, et comprend 213 articlos. 
rience. C'est pär une suite de transformations insensibles, presque sans que les Anglais en eussent eu conscience, que la Grande Charte du xue siècle était devenue cette Constitution que Montesquieu avait admirée et que Delolme avait décrite. luans ses lignes essentielles, elle garantissait si parfaitement à la fois l'ordre et la liberté que tous tes peuples qui, au xıxe siècle, ont voulu être libres s'en sont inspirés. Arec quelques modifications, elle est devenue celle des llollandais, des Belges, des Portugais, des Espagnols, des ltaliens, etc. Foyons ce qu'elle était en réalité.

La constitution britannique reconnaissait au roi d'Angleterre les pouvoirs les plus étendus, comme de nommer a toutes les charges ecclésiastiques, judiciaires, civiles, militaires, comme de décider la paix et la guerre, de rendre la justice et de faire gràce, de conférer la noblesse et de créer des pairs du royaume. Seulement il ne lui était permis dexercer tous ces pouvoirs quavec le concours de ses ministres et avec le contre-seing de l'un d'eux. Or ces ministres étaient responsables de tous leurs actes derant le Parlement, c'est-a-dire devant les Chambres, et celles-ci pouvaient, en refusant un impòt ou en rejetant une loi proposés par le gouvernement, renverser les ministres.

11 fallait bien que le roi choisit pour ministres des hommes qui eussent la confiance des Chambres: mème il ne les choisissait que dans leur sein, parmi ceux qui avaient le plus d'influence sur elles et le plus de popularité dans lo pays. Il avait à considérer quel était le parti dominant dais le Parlement et, s'adressant à un des chefs de ce parti, il le chargeait de désigner les autres ministres. Celui qui arait formé le ministère prenait le titre de premier lord de la trésorerie, c’est-à-dire de premier ministre, et il était le président du conseil des ministres. Ses collègues formaient, sous sa présidence, un conseil ou cabinet. Ils se considiraient comme solidaires et se retiraient tous ensemble si un vote défavorable des Chambres venait à les frapper. Cette solidarité les rendait plus lorts pour opposer à une volonté déraisonnable du roi une résistance ferme et respectueuse. Dans la pratique, il y avait peu d'exemples que le roi eût osé congédier un ministère qui fût en possession de la confiance des Chambres. C'est seulement 
quand le ministère et le Parlement se trouvaient en désaccord que le souverain pouvait intervenir. Il avait alors le choix entre deux procédés : ou bien souscrire au vœu exprimé par le Parlement, congédier ses ministres et s'adresser à un autre chef de parti; ou bien garder ses ministres, dissoudre la Chambre des communes et en appeler aux électeurs. Si les électeurs réélisaient la mème Chambre, il n'y avait pas d'exemple, depuis cent ans, que le roi eut refusé de tenir compte de leurs volontés.

On voit que le roi d'Angleterre, en principe, était toutpuissant; en lait, il ne pouvait qu'exécuter les volontés du pays, qu'elles lui fussent indiquées par les ministres, ou signifiées par un vote des Chambres, ou dictées par le suffrage des électeurs.

Les ministres s'intitulaient " les conseillers de sa Très Gracieuse Majesté "; en réalité, ils étaient les hommes du Parlement, les hommes du pays. C'était le roi qui paraissait déclarer la guerre, proposer les lois, nommer les évêques et les fonctionnaires; en réalité, qu'il le voulut ou non, il ne déclarait la guerre que parce que le Parlement la voulait; il ne proposait que les lois que celui-ci était disposé à voter; il ne nommait, mème aux offices de cour, que les fonctionnaires proposés par les ministres et acceptés par le Parlement.

Les Anglais, qui avaient subi la tyrannie de Henri VIII et de Charles Ier, avaient donc trouvé un moyen pratique de concilier leur respect inné pour les droits du monarque et leur ferme résolution d'assurer le gouvernement du pays par le pays.

I'autre part, au temps de la révolution de 1648, ils avaient eu à subir la tyrannie d'une assemblée populaire, le Long Purlement. Soucieux de prévenir le retour du despotisme sous cette autre forme, ils ne voulurent plus entendre parler d'une Assemblée unique. Le Parlement restait donc partagé en deux Chambres. D'abord, une Chambre haute, ou chambre des lords : elle était composée de seigneurs, qui étaient nommés par le roi à titre héréditaire, mais toujours avec l'assentiment de ses ministres. En second lieu, une Chambre basse, ou Chambre des communes : elle était composée de députés élus par les comtés 
et les bourgs du royaume. Ces deux Chambres se surveillaient mutuellement et se faisaient contrepoids : une loi n'était valable que lorsqu'elle avait été votéc par toutes deux et lorsqu'elle avait été sanctionnée par le roi. La Chambre des lords était la première en dignité et ses membres s'intitulaient les pairs du royaume; mais la Chambre des communes était la plus importante, car, dans la pratique, on admettait qu'un ministère ne pouvait ètre renversé que par elle. Dans la confection des lois, la Chambre haute pouvait arrêter un élan irréfléchi de la Chambre basse; mais elle ne pouvait lui résister sérieusement, lorsque celle-ci se sentait appuyée par le corps électoral. De mème que la Chambre basse pouvait ètre dissoute par un appel du roi aux électeurs, il y avait un moven pour vainere une résistance déraisonnable de la Chambre haute: les ministres obtenaient du roi la nomination d'un certain nombre de nouveaux pairs, et ainsi la majorité s'y trouvait ehangée. Ce moyen était si efficace que rarement la Chambre haute attendait quon en vint à cette extrémité : avant quon eùt fait la fournée de pairs dont on la menaçait, elle se rúsignait presque toujours à eéder.

En réalité, e’ètait la Chambre basse, préeisément parce qu'elle sortait du suffrage des éleeteurs, qui menait tout le monde : le roi, en lui imposant le choix de ses ministres; les ministres, par le droit qu'elle avait de leur refuser un impòt ou une loi; la Clıambre haute, en la faisant menacer par les ministres d'une fournée de pairs.

Cependant le roi et les lords, bien qu'ils ne fussent que les parties décoratives de la Constitution, avaient une réelle utilité : ils jouissaient dans le peuple d'une énorme eonsidération: ils pouvaient, les lords en refusant de voler une loi, le roi en relusant à cette loi sa sanclion, retarder les décisions quils jugeaient funestes, obliger la Chambre des communes à délibérer de nouveau, donner aux éleeteurs le temps l'agir sur leurs représeutants.

Dans cette Constitution, il n'y avait pas antagonisme entre le roi et les représentants de la uation, mais plutôt équilibre et harmonie. Le pouvoir exécutif, figuré par le roi, le pouvoir légrislatif, figuré par les representants, n'étaient pas séparés. Ils avaient l'un sur l’autre une 
action mutuelle. Le pouvoir exécutif avait le droit de proposer les lois, et aucune n’était valable sans qu'il l'eùt sanctionnée; le pouvoir législatif, à son tour, avait une grande influence sur l'exécution des lois, puisqu'il imposait au roi le choix de ses ministres et qu'il pouvait lui refuser ou les lois ou l'argent dont il avait besoin pour gouverner.

Ponequoi on n'a pas alopté la Constitution anglaise. Peu de Français, à cette époque, étaient en état de se rendre un compte exact de ce qu'était réellement la Constitution hritannique, et, parmi les Anglais éclairés, beaucoup nen avaient pas encore une idée très nette. On était frappé de certains vices de cette Constitution, qui d'ailleurs ont été corrigés ou atténués depuis. Ces vices, c’ètaient surtont la corruption électorale qui dépouillait la représentation nationale de toute sincérité, la corruption parlementaire dont les ministres étaient les principaux agents, les intrigues des chefs de parti qui se disputaient le pouvoir et amenaient des crises ministérielles trop fréquentes, enfin le pouroir peessif que le roi de cette époque, George III, avait réussi, par tous ces mojens, à s'arroger. Celte constitution semblait trop compliquée à des esprits qui étaient alors affumés de simplicité, de clarté, et qui entendaient fonder la société sur la raison pure. On ne tenait comple alors que des principes, et non de l'expérience. On croyait que, jusqu'à 1789, aucun peuple n'avait eu d’idées raisonnables sur la constitution d'un État. On nadmettait pas qu'il fùt possible de concilier le dogme nouveau de la souveraineté nationale avec des pouvoirs un jen itendus altribucs an roi. On se figurait le pouvoir executif et le pouvoir higislatif comme deux êtres distincts, entre lesquels on ne pouvait établir une séparation trop marquée. Surtout on se défait trop du caractère de Louis XVI, de ses relations avec les mécontents, avec les émigrés, avec les puıssances étraugères, pour consentir à lui conserver les attributions essentielles d'un monarque mème parlementaire. On craignait trop de fortifier l'aristocratie pour consentir à la création d'une Clambre haute.

Dans le Comité de Constitution, nommé par l'Assemblée en aout 1789, ensuite à la tribune Je l'Assemblée, les institutions britanniques trouverent done peu de partisans, 
saut parmi les membres de la droite. Voici la Constitution qui sortit de ces délibèrations.

La Constitution de 1 99. - Le pouvoir exécutif appartenait au roi. Il l'exerçait à l'aide le ministres. Tout acte du pouvoir exé utif était signé par le roi, mais devait étre contrecime par un des ministres.

Les ministres étaient nommés et révoqués par le roi.

Le roi n"était pas personnellement responsalle. Lorsque l'Assemblèe blàmait un des actes du pouvoir exécutif, c'étaient les ministres qui encouraient le blàme: même ils pouvaient être poursuivis levant un tribunal suprême, qu'on appelait la Haute Cour. La personne du loi, par une fiction constitutionnelle, était invinlabit.

On avait retiré au pouroir exécutif une de ses attributions principales : le roi ne pouvait ni déclarer la guerre, ni conclure la paix. "Le droit de la paix et le la wuerre appartient à la nation ", porte la Constitution. En conséquence, la guerre ne pouvait êtro tholmpo que par un décret de l'Assemblée, sur la propusition du roi le rol signait les traités, mais ils devaient etre ratifiés par l'Assemblée.

Le roi ne nommait pas les juges, quoique la justice fùt rendue en son nom, et navait pas le droit de grace.

Nous verrons que toutes les institutions administratives, judiciaires, fiuancières, militares, ecclesinstigues de la Constituante, reposant sur le systeme Plectif, auront pour conséquence de dépouiller lo roi du droit de nomination a la plupart des emplois.

Lá Constituante avait hésité d'abor entre le système d'une Chambre unique et le systeme des deux Chamlires.

Vainement Lally-Tollendal, Clermont-Tonnerre, Younier, Malouet, Dupont de Yemours, Sievis, invoquerent non seulement l'exemple de l'Angleterre, mais celui des Éats-Unis, oủ le Parlement est aussi partagé en deux Chambres. Vainement ils dépeignirent les entrainements auxquels devait s'abandonner une Assemblée unique, privée de tout contrepoids; les usurputions de pouroir auxquelles elle pouvait se livrer; les conflits a préroir entre le pouroir exécutif et le pouvoir législatif ainsi organise; limpossibilité de résoudre pacifiquement ces contiits, en 
l'absence d'une Assemblée qui pût servir de modératrice.

Les chefs du parti dit populaire, Mirabeau ', Thouret, Treilhard, Pétion, Rabaut-Saint-Ėtienne, opposèrent aux arguments tirés de l'expérience des raisons d'un caractère plutòt philosophique et métaphysique : le peuple étant souverain, sa volonté ne devait pas rencontrer d'obstacles dans une assemblée qui ne sortirait pas directement de lui; le peuple étant un, il ne devait pas y avoir de dualité dans sa représentation; la volonté nationale étant une, il répugnait à la raison de lui donner des organes différents. On fit loon marché de l'exemple tiré de l'Angleterre et de l'Amérique, bien qu'ils fussent les seuls grands peuples libres à cette époque; on affirma que, s'ils avaient conservé une Chambre haute, c'est qu'ils avaient compté avec les préjugés aristocratiques.

La raison la plus sérieuse était que l'on craignait de trop fortifier l'aristocratie en lui ouvrant une Clambre haute et de trop fortilter la royauté en lui attribuant la nomination des membres de cette Chambre.

Pour écarter cette objection, le Comité de Constitution avait proposé que le roi ne pût les nonmer que sur une liste de caudidats proposés par les départcments; que ces membres ne fussent pas hẻréditaires, mais à vie, ou mème nommés seulement pour dix ans; que cette assemblée prit le nom de Sénat, dénomination républicaine, puisqu'elle était employée aux États-Unis. Mounier avait mẻme proposé que les sénateurs fussent nommés directement par les assemblées départementales et que leur mandat fùt seulement de dix années.

Malgré tout, les représentants, le 10 septembre 1789, par 499 voix contre 89 , établirent une Chambre unique. Elle devait prendre le nom d'Asscmbléc législative. Elle ferait les lois, voterait les impôts, fixerait le chiffre des armées de terre et de mer, déclarerait les guerres, ratifierait les traités de paix et de commerce, poursuivrait devant la Haute Cour les ministres et autres agents du pouvoir

1. Mirabeau appuya tantót les idées du parti populaire, tantót, à la fin de a carrire, les idées des constilutionncls à la manière anglaise. Il voulait une Chambre unique; mais il demandait pour le roi l'exercice du droit de paix el de zuerre, le veto absolu, le droit de dissoudre la Chambre. 
exćcutif. Chaque Assemblée législative siégerait pendant deux ans.

Le roi n'avail qu'une faible part dans le pouvoir législatif : les lois votées par l'Assemblée législative n’étaient exécutoires que lorsque le roi les avait sanctionnces; il pouvait refuser sa sanction et opposer son veto ${ }^{1}$; mais il ne pouvait maintenir son refus que pendant la duréc de deux assemblées, c'est-à-dire pendant quatre ans; si une troisième assemblée persistait dans les mèmes idées, le veto du roi tombait, et la loi devenait exécutoire de plein droit. Son veto n'était done pas absolu, comme celui des rois d'Angleterre, mais simplement suspensif.

Le veto suspensif, entre les mains de Louis XVI, était une arme à la fois inefficace et dangereuse : inefficace, puisqu'au bout de quatre ans il était oblig'́ de subir une loi qu'il désapprouvait; dangereuse, car son refus de sanction irritait la cluambre et la ruation.

En refusant au roi le droit de dissoudre l'Assemblée et d'en appeler à la nation, la Constitution rendait insoluble tout conflit qui pourrait s'élever entre le roi et l'Assemblée. Il liallait donc, pour le trancher, que le roi reeourìt à la violence contre l'Assemblée, ou l'Assemblée contre le roi.

La Constitution interdisait au roi de prendre ses ministres dins l'Assemblée : n'étant pas membres de l'Assemblée, ils ne pouvaient avoir aucune influence sur elle, ni celle-ci aucune action sur eux. Ils élaient nécessairement les hommes du roi et devinrent, non sans de justes raiso:s, suspects à l'Assemblée et à la nation ${ }^{2}$.

1. Yeto, en latin, signifie : je m'oppose. Lo peuple se passionna d'autant plus contre le veto qu'il comprenait moins. Un homme disait a un autre : "Tu manges ta soupe. Le roi te dit: Renverse lon écuelle; et il faut que tu la renverses. C'est ça le veto."

2. L'interdiction faite aux membres de l'Assemblée d'accepter les fonctions de ministre du roi dénotail une profonde inexpérience des conditions du régime parlementaire. Un ministère choisi dans l'Assemblèe, c'est le pivot méme de ce régime. Les ministres on beau ètre nommés par le pouvoir exécutif : c'est de l'Assemblèe qu'ils dépendent; ils ne subsistent que par ses votes de confiance ou ses votes de finances; ce sont ses indicalions qu'ils suivent et ses rolontés qu'ils exécutent; tous les moyens d'action, tous les moyens d'information que donne l'exercice du pouvoir, c'est à sa disposition qu'ils les mettent. La conséquence de cette interdiction fut que les chefs de la majorite restèrent privés des moyens de faire leur éducation politique par l'esurcice du pouvair, de renseigner exactement la Chambro 
La Constituante aurait donc mieux fait de supprimer absolument la royauté et de faire une Constitution républicaine : malheureusement, tout en se défiant de Louis XVI, elle était profondément monarchique. Les hommes de 1791 crurent faire une Constitution monarchique: ils en f́rent une qui n'était ni monarchique, ni républicaine; elle neitait même pas une Constitution parlementaire.

La Constitnante commit une dernière faute : par un lésintéressement mal entendu, sur la proposition de Robesfierre, elle décida qu'aucun de ses membres ne pourrait :aire partie de la prochaine Assemhlée législative: elle laissait à des lommes nouveaux, encore plus inexpirimentés qu'elle-même, le soin de mettre en pratique la Constitution votée jar elle.

La Législative. - Asssi la Constitution de 1791 n'eutelle qu'une existence courte et tourmentée. La nourelle Assemblée législative et le pouvoir royal entrèrent en lutte presque anssitôt. Le roi conspira contre l'Ascemblée : l'Assemblée laissa le peuple de Paris insulter la royauté, dans la journér lu 20 juin, et la détruire, dans la journée du 10 aout (1792).

\section{Les Constitutions républicaines.}

La Convention. - Il fallut penser à faire une autre Constitution et, à cet effet, réunir une nouvelle Assemblèe constifuante : ce fut la Convention. La Constitution que celle-ci avait à rédiger devait être républicaine. La Convention fit comme la Constituante : en attendant que la Constitution fut rédigée, elle gouverna senle le pays.

Le gouvernement le la Convention fut autrement énersique que narait ite celui de la Constiluante. Il n'y avait

sur la pulitique royale, de la protégrer a la fors contre les vsines terreurs et les dangers sérieus; et, dautre part, le roi put se compromettre dans de dangerous complots et compromettre avec lui ses ministres, dont, par la suite, plusieurs périrent sur l'échafaud. Il n'y a qu'une seule de nos Constitutions qui ait ensulte reproluit cete disposition : e'est cello de 1852. Louisrapoléon prit alors ses malstres hos des Chambres, précisement nour awoir

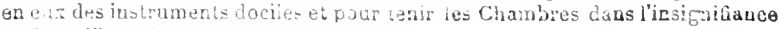
at dias l'impuissance. 
plus de roi et la République avait été proclamée dès sa première séance. L’Assemblée se saisit donc de tous les pouvoirs. Elle eut à la fois le pouvoir législatif, car elle fit les lois qui complétèrent l'ouvre de la Révolution; le pouvoir exéculif, car elle gouverna, déclara la guerre aux puissances étrangères et organisa les armées qui repoussír nt l’iuvasion; le pouvoir judiciaire, car elle fit leur proces a i.uu $\therefore \mathrm{XVI}$ et à plusieurs de ses propres membres. Cetle Assenblée eut donc une autorité aussi absolue que celle qu'avait possédée Louis XIV. Au lieu du despotisme l'un homme, ce fut le despotisme dune Assemblée. Nulle autre qu'une Assemblée despotique n'aurait pu décréter la dévastation de la Vendée et la démolition de Lyon, substituer la justice révolutionnaire à la justice régulière, suppıiner, par la lui des suspects, tonte sécurité pour les citoyens et, par la loi de prairial, lonte garantie pour les accusés.

Saus doute, certaines de ces mesures étaient justifiées par l'extrême danger de la patrie : il fallait une dictature pour vaincre à la fois la coalition européenne et les lébellions de l'intérieur; mais ce n'en est pas moins lexemple d'un pouvoir absolu exercé par une Assemblée.

Rien ne se faisait que par les lois et les décrets de la Convention. Pourtant il etait impossible qu'une Assembíe de huit cents membres pût réeltement gouverner et administrer. Aussi la Convention avait-elte tiré de son sein une quinzaine de Comités qui soccupaient du gouvernement, de la législation, des finances, de la guerre. de la marine, des travaux publics, de l'instruction publique. Les deux plus célèbes sont le Connité de Sulut public ${ }^{1}$, qui était

1. Le Comité de Salnt publie, au 6 avril 1793, se composait de Barère, Delmas, Brénd, Cambon, Jein Jebry, Guyton-Morveau, Treilhard, Delacroix. 11 était nomne pour un mois. les Girondius en ont ète exclus en juin. Le 10 , ulllet, on y tronve Barère, Lindat, Jean Bon Saint-André, Hérault de Séchelles, Prifur de la Marne, Gasparia, Thuriot, Saint-Just, Couthon. Puis les amis de hamun en sont exclus. Le 27 juillec, hubteplere y entre, et, lo 14 août, Cirnot. En septentra, il se compose de douze membres. Carnot, Lindet, Prieur de la Cote-J'Or, chargés surtoni de la guerre, Jean Bon SaintAndré, de la marine. Cambon, des finances, Prieur de la Marne, y forment le eroupe dos gens dexamen. Barere, Collot-dllerbois, Eiliad-Varennes, le trio des gens révolutionnaires; Robespierre, Saint-Just, Couthon. Le trio des Robespierristes, ou gens de la hate main, rui dirigent et doninent tout le reste, Quoique soumis tous les mus a la rectection jar l'Asamblee, on no 
investi du pouvoir exécutif, et le Comité de Sureté générale, qui ètait chargé de poursuivre les conspirateurs et de les livrer au Tribunal révolutionnaire".

Par le décret du 12 germinal, 1er avril 1794, les ministères furent supprimés, comme étant " une institution monarchique ${ }^{2} "$. Les six ministres furent remplacés par douze commissions composées d'un ou de deux membres, sauf la commission des linances, qui en comptait cinq. Les commissuires touchajent un traitement de 12000 livres par an. Ils étaient subordonnés au Comitè de Salut public, qui chaque jour se faisait rendre compte de leur travail et prenait les décisions núcessaires.

Les Comités, à commencer par le Comité de Salut public, les commissions, les représentants en mission, tous dépendaient de la Convention, qui les nommait et les révoquait, et qui jamais, mènte en face de Robespierre, ne se désarma

renouvelle plus ce Comité : on le continue indéfiniment jusqu'à la chute de Robespierre. Ce terrible Comitè avait sous sa main tous les corps constilues, tous les fonctionnaires, les représentants en mission, les ministres, quand i] y en avait, la diplomatie, les opérations militaires, la politique générale.

1. Le Tribunal révolutionnaire fut constitué par decret du 10 mars 1793, sar la proposition de Dauton, qui, plus tard, en lemanda "pardon á Dieu et aux hommes". C'est ce tribunal qui envoys a l'échafand les plus illustres victimes do la Terreur, Girondins, Dantonistes, lleberlistes. En septembre 17y:3, il ne se composait plus que de Robespierristes : Herman . président; Dumas, vice-président; Coffinhal, juge ; le menuisier Duplay, l'imprimeur Nicolas, le peintre Topino-Lebrun, ete., jurés; Fouquier-Tinville, accusateur public. La lai de prairial 1:93 acbeva de supprimer toutes garanties pour les accuses, et les députés eux-mèmes furent soumis a celte juridicion. A prín Ia chute de Robespitrre, il fut renoivelé, et la plupart do ses membres robespierriste's enroyes a l'échalaud par leurs successeurs thermidoriena. C'est encore ini qui frappa, en mai 1795 , ceux quon a appelés les derniers Montaymards.

2. En 1791, il y avait six ministres. Le 10 aoùt 1792 , la Lérialntive sar. rogua le droit de les nommer. Jusqu a leur suppression, en arril $179 \mathrm{i}$, ils formaient le Conseil expcutif provisoire. Les principaux furent, de 1791 à 1794: 1. sux atfaires etrangères, Delessart, Dumouriez, de Chambonnas, Bigot do Sainte-Crotx, Lebrun-Tondu, de Forgues; $2^{\circ}$ a la guerre, Narbonne, Servan, Dumouriez, l'ache, Beurnonville, Bouchotte, Beauharnais; $3^{\circ}$ a la justice, Danton. Gurat, Gohier; a l'intérieur, Roland, Gara!, Ilerman; $5^{\circ}$ aux finances, Chaviere; $6^{\circ}$ a la marina, Dubouchage, Monge. - Quant aux mentres des commissions instituees en 179:, l'un de ceux de la commission des affaires étrangères était un certain Buchot, ancien abbẻ ou instiluteur, très imnorant. et si besocneux que, lorsqu'i! fut remplacé par un homme de mérite, Vint de Mélito, il lıi demanda une place de garcon de burean. Le rôle prépmatrant du Cumite de Salut publie explique linsiguitance d'une partie de ces commis:aires. 
de son autorité souveraine. La loi du \& décembre 1793 poste que "la Convention nationale est le centre unique de l'impulsion du gouvernement ". Sa volonté est la loi : lout pouroir émane d'elle; elle décrète d'accusation tout a runt qui lui semble suspect, mème les plus puissants de inus, fussent-ils membres de l'Assemblée.

Le gouvernement de la Convention rappelait, dans s traits essentiels, celui des rois absolus. Le Comite ile Salut public répondait assez bien au Conseil d'en haut: le Comité de Súreté générale. au lieutenant de police; l'armée révolutionnaire, à la maréchaussée; le Tribunal révolutionnaire, aux commissions de Richelieu et de Louis XIV; les represscntants en mission et les agents nutionaux, aux intenilants et aux subdélégués. Sans |resque s’en rendre compte, tout en continuant a professer les mèmes théries libérales que la Constituante et les Girondins de la Convention, les Montagnards en étaient arrivés à reconstiluer le pouvoir le plus absolu et la centralisation la plus énergique. Avec des moyens qualifies de ribolutionnrires, en apparence désordonnés et anarchiques, ils refirent lordre et mème le despotisme. Ils cherchaient à se faire illusion en protestant que ce régime était tout exceptionnel; que le gouvernement révolutionnaire neètait que provisoire; qu'il ne devait durer que jusqu'a la mise en vigueur de la Constitution.

La Constitution de 1793. - La Convention avait une Constitution à rédigrer. Elle en fit deux, l'une en 1793, l'autre en 1795. Elles furent très diffirentes l'une de l'autre, parce que la Convention s'inspirait de tout autres idées en 1793 et en 1793 .

La Constitution de $1793^{1}$ faisait résider le pouvoir souverain non dans l'Assemblée, mais dans le peuple, réuni en ses assemblées primaires ou rémnions électorales: il y avait, dans chaque canton, une assemblée primaire par deux ou trois cents électeurs.

L'Assemblée nationale, composée d'une seule Chambre, s'appelait Corps législutif. Elle n'était élue que pour un an.

1. 24 juin 1793. Elje comprend $12 i$ articles, sans compter les $3 \dot{t}$ articles de la nouvelle Déclaration des droits de l'fomme et du Cituyea. 
Elle avait deux fonctions : rendre des décrets et proposer des lois. Les décrets ne se rapportaient quaux matières de gouvernement et d'administration. Les lois proprement dites étaient simplement proposées par l'Assemblée : elles étaient acceptées par les assemblées primaires : celles-ci étaient réputées les avoir acceptées si, dans la moitié des départements plus un, le dixième d'entre elles n'avait pas réclamé. Il y arait donc la des espèces de plébiscites, mais le plus souvent tacites.

L.e pouroir exécutif était confié à un Conseil ex\&cutif de vingt-quatre membres : il était nommé par l'Assemblée sur une liste dressée par les électeurs des départements, à raison d'un nom par département.

Jamais il ny eut de Constilution aussi démocratique que celle-lá, puisque le peuple tout entier non seulement nommait les députés, mais encore rotait les lois el proposait les candidats pour le Conseil exécutif. Le pouvoir législatıf ètait faible, puisque l'Assemblée était rééligible tous les ans; le pouvoir exécutif était faible, puisquil dépenlait à la fois des électeurs et de l'Assemblée; composé de vingt-quatre membres, comment aurait-il été capable de gouverner?

La Constıtution n’était même pas définitive : elle pouvait ére sounise à la revision par les assemblées primaires, dès que le dixième de celles-ci le demandait.

Sa mise en vigueur eùt été l'anarchie en permanence, l'impossibilité pour la France de résister aux révoltes intérieures et à l"invasion étrangère. Cette Constitution, sounise à l'acceptation des assemblées primaires, votée par 1801918 oui contre 11610 non, fut déposée, derrière le fauteuil du président de la Convention, dans un coffre en bois de cèdre, de forme artistique, ressemblant à l'arche d'alliance des lébreux, et dont le peintre David arait dessiné le modèle. Elle n'en sortit pas et ne fonclionna janais.

La Constitution de l'an IHI'. - La Constitution de

1. 5 fructidar an $11 !-22$ aout 1795 . Elle comprend 377 articies. Eile es: précédée d'une Déclination des droits.

Daunou s'était oppusé a ce que l'on consacràt de nouveau le droit à l'insurrection, ne voulant pas faire do la nouvelle Déclatatiun des druils u ua 
l'an III, ou Constitution directoriale, est en réalité notre première Constitution républicaine. Rédigée à un moment où les partis avancés avaient été vaincus, elle était beaucoup moins démocratique que celle de 1793.

Les assemblees primaires perdaient toute importance: elles n'avaient plus le pouvoir législatif et les députés n'étaient mème plus nommés par elles.

Le pouvoir législatif se partageait entre deux Assemblées 1 : le Conseil des Cinq-Cents, dont les membres devaient avoir trente ans, et le Conseil des Anciens, dont les membres devaient en avoir au moins quarante. Ils se renouvelaient par tiers tous les ans. Le Conseil des CinqCents proposait les lois : elles devaient être approuvées par le Conseil des Anciens.

Le pouvoir exécutif était confié à cinq Directeurs : tous les ans, un le ces Directeurs, désigné par la voie du sort, était remplacé par un nouveau membre désigné par le le Conseil des Anciens, sur une liste de dix noms dressée par le Conseil des Cinq-Cents. Le Directoire nommait et réroquait les ministres, car les ministres avaient été rétablis : il nommait les généraux, les ambassadeurs, et tous ceux les fonctionnaires qui n'étaient pas électifs. Il exerçait ḋ peu près toutes les attributions d'un roi constitutionnel.

La Constitution nouvelle était mieux conçue que celle de 1791 : elle aurait eu des chances sérieuses de durée, si

arsenal pour les factieux ". En outre, dans cette Déclaration, on énumèro les devoirs du citoyen en mème temps que ses droits.

1. En 1795, on a'en était plus, comme en 1791 ou 1793, \& dédaigner les leçons de l'expericuce, pour se guider uniquement sur des axiomes de métaphysique politique. Le rapporteur du nouveau projet de Constitution, Borssy D'Axglas, dans son rapport du 23 juin, invoque les exemples dn passé : "Nous avons devant nous lhistaire de plusieurs peuples, nous arons la nótrc... "Il reconnait, pour les aroir éprouvés, les incouvénients et les dangers d'une Assemblée unique : "Toul impose done la nécessité d'apposer une digue puissante à l'impétuosité du Corps législatif... Cette digue, e'est la division du Corps législatif en deux Chambres... La première portera plus d'attention à ses décisions, par cela seul qu'elles devront subir une revision dans la seconde; la seeonde, avertie des erreurs de la première et des causes qui les aurant produites, se prèmunira d'avance contre ua jugement errané dont elle connaitra le principe... Tous les pouvoirs émanent du peuple... mais, puisquil ne peut les exercer, it faut qu'il les délegue de cacon qu'aucun d'eux ne lopprime. * 
elle n'arait présenté deux défauts assez graves. Le premier, c'était que le pouvoir exécutif, au lieu d'ètre confié, comme en Angleterre ou en Amérique, à une seule personne, était partagé entre cinq.

Le second défaut, c'est que, par crainte de subordonner le pouvoir législatif au pouvoir exécutif, on les tenait rigoureusement séparés. Le Directoire ne pouvait choisir ses ministres parmi les dérutés: il n'avait aucune part au pouvoir législatif, ni la proposition des lois, ni la sanction, ni mème la promulgation. Il ne pouvait ni dissoudre ni proroger les Conseils, et les Couseils ne pouvaient pas déposer les Directeurs. En cas de conflit entre les deux pouvoirs, la Constitution n'ofrait donc aucun moyen de consulter les électeurs, ni aucun autre moyen légal de sortir de la crise. Or, comme il se produisit des conflits, il fallut, de part et d'autre, recourir à des coups î́tat: le lirectoire en fit deux contre les Conseils, celui du 18 fructidor, qui frappa les partis monarchistes, et celui du 22 floréal, qui frappa les partis avancés; les Conseils en firent un contre le Directoire, celui du 30 prairial.

Ce qui montre combien le pouvoir exécutif était faiblement organisé, combien il était exposé à s'énerver par scs propres livisions, c'est qu'il n'y eut pas moins de conflits entre les cinq personnes collectivement investies du pouvoir qu'entre le Directoire et les Conseils. Au 18 fructidor, trois des Directeurs se liguèrent contre leurs deux collègues, Carnot et Barthélemy, et les firent déporter. Au 30 prairial, ce fut le tour de Laréveillère-Lépeaux, que ses collègues foreèrent à donner sa démission. A la fin de 1799, nous voyons deux Directeurs, Sieyès et Roger-Ducos, conspirer contre deux autres, Moulin et Gohier, et préparer les voies à l'usurpation de Bonaparte, tandis que le cinquième, Barras, se tient soigneusement à l'écart.

Le coup drat de Bonaparte, au 18 brumaire, emporta d̀ la fois les Directeurs, les Conseils et la Constitution.

Le mours parlementaires perdant la période violente de la Révolution. - La Constituante complait parmi ses membres, outre les déléqués du clergé et de la noblesse, les plus riches, les plus influents et les plus instruits du tiers état. En somme, elle représentait la grande pro. 
priété, noble ou roturière, ecclésiastique ou laïque. Mème après qu'elle eût été décimée par les premières émigrations, sa composition restait aristocratique. On s'en apercoit rien qu'aux ménagements qu'elle garda dans la question des droits féodaux. La composition le la Législative, après l'exclusion prononcée par la Constituante contre ses propres membres, dut être fort différente. Les votes des électeurs se portìrent sur les représentants de la moyenne et le la petite bourgeoisie; ils nommèrent beaucoup de médecins, d'avocats, de procureurs, et aussi des hommes ayant appartenu aux congrégations religieuses. Ces déclassés ne se montrèrent pas les moins exaltés : il sulfit de citer l'ex-capucin Chabot. Le caractère démocratique s'accentua encore dans la Convention : Paris surtout élut alors des hommes de la très petite bourgeoisie, de la bohème littéraire ou artistique, et quelques ouvriers

La composition de ces trois Assemblées explique la différence des mœurs parlementaires aux différentes époques.

Les discussions de la Constituante, souvent lumulteuses, sont toujoura décentes. Elles sont plus agitées dans la Législative et surtout dans la Convention. Le costume des bourgeois de la Constituante, tout noir, grave dans sa simplicité, fait place, en 1793, à un certain négligé populaire, dont Marat donue l'exemple. Si Robespierre affecte un soin minutieux dans sa toilette, d'autres députés inaugurent le pantalon, la carmagnole, le bonnet rouge, les bottes à retroussis ou mème les sabots. Les orateurs de la Gironde maintiennent le débat à une certaine hauteur, ont une éloquence recherchée, un peu déclamatoire : les Montagnards affectent, en général, une langue plus populaire; avec le tutoiement et l'appellation de citoyen, ils prodiguent voloniiers les gros mots et traitent couramment leurs adversaires de voleurs, de pourris, de traitres, d'imbéciles et d'aristocrates. Si l'éducation sociale des nouveaux venus laisse à désirer, leur éducation politique est encore plus défectueuse. Le peuple français, mème dans son élite, navait pas les habitudes de la liberté, quoique tout le mnnde eût ce mot a la bouche. Il faut un long apprentissage du régime parlementaire pour quion sache soufirir la contradiction, respecter ses adversaires, admettre la 
liberté pour eux comme pour soi. Or l'intolérance politique, résultat fatal du passé monarchique, atténuée chez les Constituants par des moeurs plus douces et plus polies, éclate violemment chez leurs successeurs. Entre qualifier ses adversaires de traîtres et leur infliger le supplice des traitres, il n'y a qu'un pas. Ce pas fut franchi avec une extrème facilité. On vit des orateurs brandir des poignards à la tribune, en menacer leurs adversaires, ou les tourner, avec de grands gestes pathétiques, contre leur propre poitrine. Beaucoup de députés avaient des pistolets à leur ceinture. A dater de la proscription des Girondins, une arme plus redouiable, le couteau de la guillotine, apparait dans les harangues comme argument, comme menace ou comme conclusion. Surtout dans les discours de Robespierre ou de Saint-Just, elle jette de sinistres reflets. Les Hébertistes en furent frappés, puis les Dantonistes, jusqu'au moment ou elle se retourna contre Robespierre luimème. Les discussions du Parlement devenaient de véritables batailles, dont la vie des vaincus était parfois l'enjeu. On s'habitua à considérer la mort sur l'échafaud avec une troide intrépidité, et les hommes politiques en vinrent à ne pas plus redouter la guillotine que des soldats, dans la mélée, ne redoutent un coup de sabre.

Ce qui contribua à rendre plus orageuses les séances des Assemblées révolutionnaires, c'esi d'abord que ces assemblées étaient beaucoup trop nombreuses; que la plupart des membres étaient très jeunes, que le sang y était chaud, les passions ardentes et les haines implacables; que l'absence d'éducation politique, le gout très vif alors pour la rhétorique, les grandes phrases. les mouvements pathéliques, exposajent les légistateur's à des entrainements; et quenfin il n'y avait pas une seconde chambre pour reviser les décisions de la première et donner aux passions le temps de se calner.

En second lieu, ce fut l'inlluence des tribunes. Aujourd'hui les séances de nos Assemblées sont publiques : mais les tribunes réservées aux spectateurs doiveul rester absolument silencieuses: quiconque se permettrait d'y élever la roix serait i liustant expulsé par les huissiers. A cette époque, au contraire, elles regorgeaient dune foule tur- 
bulente, agitée des mêmes passions que les députés, qui applaudissait, sifflait, huait, provoquait les orateurs, intervenait dans le débat.

A lout moment, les séances étaient interrompues par l'entrée de quelqne députation, qui, sous le premrer prétexte venu, exigeait son admission à la barre de l'Assemblée; là, ses meneurs morigénaient l'Assemblée, insultaient les députés du parti contraire, les menaçaient de la colère du peuple, ou entretenaient les représentants des intérts les plus frivoles ou les plus égoïstes.

Enfin la population parisienne, qui, après sa victoire du 10 aoùt, avait été autorisée à défiler toute sanglante dans l'enceinte de l'Assemblée législative, reparut plus d'une rois en armes dans la Convention. Elle lui présenta des pétitions au bout d'une pique. Elle la cerna de ses canons pour l'obliger à proscrire les Girondins $(31$ mai et 2 juin 1793). Elle viola l'enceinte parlementaire dans les journèes de floréal et prairial ( ${ }^{\mathrm{e}_{\mathbf{r}}}$ avril et $20 \mathrm{mai} \mathbf{1 7 9 5}$ ).

Tout cela découlait d'une fausse application du principe de la souverainelé nationale. Dans les partis exaltés, on prétendait que le peuple est toujours libre d'abréger la durée du mandat de ses représentants, mème de se substituer à eux, de pénétrer dans leur salle d'assemblée, de s'asseoir sur leurs bancs, de voter à cúté d'eux ou à leur place. Or le peuple, ce n'était pas la nation tout entière, mais simplement le peuple de Paris, ou seulement une fraction de la populace parisienne. Une poignée d'individus, qui ne représentaient qu'eux-mêmes, s'arrogeait le droit de faire la loi aux représentants de vingt-cinq millions d'hommes, de leur parler comme le maitre peut parler a ses serviteurs, et de proscrire, comme on fit au 31 mai, les députés de trente départenents français.

Il eût suffi, pour faire justice de ces dangereux sophisnes, de se reporter à l'article 3 de la Décluration des droits de 1791, qui est ainsi conçu : " Le principe de la souveraineté réside essentiellement dans la nation: nul corps, nul individu ne peut exercer d'autorité qui n'en émane expressement. " Malheureusement la Déclaration des droits de 1793, tout en constatant de nouveau " qu'aucune portion du peuple ne peut exercer la souveraineté du peuple entier ", 
avait ajouté un article 35 ainsi conçu : " Quand le gouvernement viole les droits du peuple, l'irsurrection est, pour le peuple et pour chaque portion tu peuple, le plus sacré des droits et le plus indispensable des devoirs. " Or, la Convention ayant reconnu le droit a l'insurrection, il n'est pas étonnant qu'elle ait été trois fois insultée.

Sous le Directoire, les tribunes sont rigoureusement surveillées et les perturbateurs expulsés; les deux Conseils, de mème que le Directoire, ont une grarde pour leur sûreté; In costume spécial, un peu trop thédral, la toge romaine et la toque à plumes, est imposé aux députés, afin qu'on n’ait plus le spectacle le cette tenue débraillée qu'avaient affectée les Héberlistes.

\section{Les constitutions napoléoniennes.}

La Constitution de lan VIII'. - La Constitution consulaire ne fut pas l'œuvre llune Assemblée : elle fut élaborée par deux hommes, Sieyès et Bonaparte.

On s`était plaint de la faiblesse du précédent gouvernement: on rendit celui-ci beaucoup trop fort. En quittant l'Égypte, Bonaparte avait dit: "Si j’ai le bonheur de mettre le pied en France, le règne du bavardage est fini. ” Par bavardage, il entendait toute discussion libre.

Le pouvoir exécutif était confié à trois Consuls élus pour dix ans; mais le Premier consul avait toute l'autorité.

Le pouroir législatif était partagé entre trois assemblées: le Conseil d'Etat, le Corps législatif, le Tribunat. Le Conseil d'État préparait les lois; puis trois membres du Conseil d'État et trois membres du Tribunat renaient les discuter devant le Corps législatif : celui-ci ne prenait aucune part à la discussion; il rotait silencieusement : c'était une assemilée de muets. C'étiit, dit Thibaudeau, un corps " sans langue, sans yeux, sans oreilles".

Ainsi le Tribunat discutait les lois, mais ne les volait pas; le Corps législatif les votait, mais ne les discutait | as.

1. 22 frimaire an VIII - 13 décembre 1799. Elle compread 95 articles ot a'est pas précédée par une Déclaration des droits. 
C'est la plus singulière conception que puisse présenter lhistoire des Constitutions.

Le soin de maintenir la Constitution était confié à une assemblée appelée le Sénat conservateur. Quoique le Sénat n'eût aucune part à la confection des lois, il avait à décider si telle ou telle loi était conforme ou non à la Constitution et aux principes de 1789. Les décisions du Sénat s'appelaient sénatus-consultes.

Le Conseil d'État était nommé par le Premier consul sur les listes de notatilités. Les numbres du Corps législatif et du Tribunat étaient choisis par le Sénat sur les mèmes listes : ils se renouvelaient par cinquième ${ }^{1}$.

Le Sénat se trouvait ainsi le grand électeur des prétendus représentants de la nation. Il importe de savoir comment lui-mème se recrutait. Daprès le texte de la Constitution, à l'avenir, il devait choisir chacun de ses membres sur une liste de trois noms, présentés l'un par le Premier consul, le second par le Corps législatit, le troisième par le Tribunat. 11 étail à prévoir qu'on n'oserait guère écarter le candidat du Premier consul ou qu'il serait également le candidat des deux autres pouvoirs. En réalité, jamai ce mode de recrutement ne fonctionna. Comme il fallait établir d'abord un noyau de Sénat, il fut convenu que 31 membres seraient nommés par une commission composce de 4 personnes: Sieyès, Roger-Ducos, Cambacérès, Lebrun, les trois derniers absolument dévoués à Bonaparte. Donc, ce premier noyau de Sénat fut nommé presque entièrement sous l'influence de celui-ci.

Ce qui était le plus fortement organisé, dans la nouvelle Constitution, c'était le pouvoir du Premier consul. Les deux autres Consuls n'avaient que le droit de lui présenter des observations et, au besoin, de les consigner sur un registre spécial. Bonaparte exerça tous les pouvoirs d'un roi : il eut le droit de nommer et révoquer les ministres, ambassadeurs, fonctionnaires de tout ordre. Il eut la nomination des juges, à l'exception des juges de paix et des membres du Tribunal de cassation. Il eut le comman-

1. Un membre du Corps législatif tocehsit alors 10000 francs; du Tri. bunat, 15000; du Sénat, 25000. 
dement des forces de terre et de nue. Il eut le soin de la sûuté générale, avec faculté de lancer des mandats d'arrêt et des mandats d'amener contre les conspirateurs et les suspects. Il fut chargé des relations extérieures, négrociations, déclarations de guerre, traités de paix et d'alliance, avec cette seule restriction que ces actes seraient soumis aux délibérations du Corps législatif. Quand nous étudierons l'organisation administrative, judiciaire, militaire, ecclésiastique de cette époque, nous verrons que la conception du pouvoir exécutif, en 1800, est diamétralement opposée à celle de 1791 .

On avait marchandé à Louis XVI, puis au Direstoire, une part dans le pouvoir législatif : or Bonaparte s'en emparait presque entièrement, et c'était lui en réalité qui faisait les lois. En effet, la confection d'une loi supposait alors six opérations : l’initiative, la préparation, la discussion, le vote, la confirmation, la promulgation. Limitiutive des propositions de loi appartenait an Premier consul; la préparation, au Conseil d'État, nommé directement par le Premier consul; la discussion, le vote, la confimution, au Tribunat, au Corps législatif, au Sénat, nommés indirectement par le Premier consul; la promulgation, au Premier consul. Ayant l'initiative, il pouvait retirer la loi à l'une quelconque de ces étapes; mème confirmée par le Sénat, il pouvait se dispenser de la promulguer : elle restait alors lettre morte.

Le Premier consul avait done la haute main sur les légisłateurs et sur la loi. La Constitution, les Assemblees, les deux autres Consuls, ne servaient qu'a masquer ce que son pouvoir avait déjà de trop absolu.

Pour s’assurer lobéissance passive des fonctionnaires, il avait inséré dans la Constitution le fameux urtiole 75 , qui les mettait hors du droit commun : aucun cituyen ne pouvait leur intenter une action sans aroir obtenu l'autorisation du Conseil d'Etat.

Il arait eu soin de soumettre la Constitution à l'acceptalion du peuple, qui s'était prononcé aflrmatirement par un plétiscite ${ }^{1 .}$

1. La Constitution de 93 , soumisa éghement a l'acceplation du peuple,

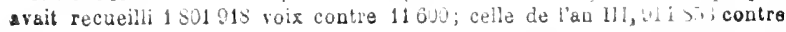


La Constitution de l'an VIII une fois promulguée, les Consuls s’installèrent aux Tuileries, le Sénat au Luxembourg, le Corps législatif au Palais-Bourbon, Ie Tribunat et le Conseil d'Etat au Palais-Royal.

Le Tribunat, présidé par Daunou, et qui comptait parmi ses membres Chénier, Andrieux, Ginguené, Tienjamin Constant, essaya de prendre au sérieux son rỏle de tribun du peuple. Plusieurs des mesures du gouveriement $y$ furent vivement critiquées; le projet du Code civil y fut soumis à un examen que Bonaparte trouva outrecuidunt. Bien que sur 80 membres il ne se révélât guère que 26 opposints, le Premier consul s'en irrita. Il fit persifler les tribuns dans des articles de son .Moniteur. Il lui échappa de dire : "lls sont là douze à quinze métaphysiciens bons à jeter à l'eau : c'est une vermine que jai sur mes habits: mais je suis soldat, enfant de la Révolution, et je ne souffrirai pas qu'on m insulte comme un roi! "Il trouva moyen. tràce à la complicité du Sénat, d'expulser 20 membres du Tíbunat, et les autres se tinrent pour avertis.

La seule assəmblée qui auraitpu tenir tète à Bonaparte, c'était le Sénat. Ses membres étaient nommés à vie, inamovibles; ils étaient à l'abri de la séduction comme de la crainte, la Constitution ayant déclaré la dignité de súnateur incompatible avec les fonctions publiques. Par son droit de nommer les membres du Tribunat et du Corps législatif, il pouvait avoir une grande action sur ces denx corps. Et pourtant ce Sénat, qui aurait pu ètre le rival du Premier consul, se fit son complaisant.

La Constitution de lan $\mathbf{x}$. - Apres le complot de la machine infernale, ee fut le Tribunat qui prit l"initiative dune proposition tendant à donner "au général Bonaparte un gage éclatant de la reconnaissance nationale ". Le Corps législatif sétait borné à mettre Boniparte au-dessus de Solon et d'Alexandre, le Sénat à offrir une prolongation de ses potwoirs pour dix ans. Dans celte lutte d'alulation, la palme resta au Conseil d'État : il prit un arrèté décidant que le peuple français serait consulté sur la nomination

il s92; cellede l'an VIII, 3011007 contre 1562; celle de laa X. 355\$ 259 contre 16374 ; celle de l'an XIl 3572323 contre 2309.

R. Civil. CONTEMP 
de Ronaparte comme consul à vie. Le Sénat déclara qu'on avait parfaitement interprété sa pensée, et les deux autres corps firent adhésion. Le plébiscite de juillot $i \delta 09$ conféra au vainqueur de Marengo le consulat à vio; le Sénat, par le sénatus-consulte du 16 thermidor an $X^{1}$, remania la Constitution pour la faire mieux caurer avec l'autorité, désormais souveraine, de Bonapirte.

Le Conseil d'Etat perdit ses attributions politiques et devint une sorte de Conseil privé du Premier consul. Le Tribunat tut réduit à cinquante menbres. Le Corps législatif perdit le droit de voter les trailés de paix et d'alliance, ne gardant que celui de voter les lois civiles, les impôts, les contingents mililaires. Le Sénat s'arrogea sur ees deux assembles le droit de dissolution et leur retira le droit de présenter des candidats aux postes vacants du Sénat. Il leur enleva la nomination de leurs presidents et de leurs bureaux pour se l'attribuer.

Tous ces changements semblaient se faire au profit du Sénat; mais voici que le Sénat lui-mème se metlait à la discrétion de Boniparte. Les nominations sénatoriales continuaient à se faire par le Sénal, mais sur une liste de trois noms, tous présentés par Bonaparte. Au fond, c'était lui qui nommait. La haute Assenulée serait désormais présidée par les Consuls, qui indiqueraient les jours et heures de ses séances. L'interdiction du cumul des fonctions de sénateur avec toute autre fonction. cette garantie de la vertu des sénateurs, était supprimée : ils pourraient etre Consuls, ministres, membres de la Légion d'honneur, inspecteurs de I'Université, chargés de missions rétribuées. Le Sénat perdait donc la liberté de son recrutement, l'indépendance de son résime intérieur, le renom d'incorruptibilit, de ses nembres. Un an plus tard, Bonaparte achèvera le le corrompre, en créant des sintoreries, riches dotations de 25 à 30000 francs de revenu, qu'il pourra distribuer à ses fidèles.

Non seulement le sénatus-consulte de l'an X consacre le Consulit à vie, mais il autorise Bonaparte à lésigner

1. Sénatus-consulte du 16 thermidor sn $\mathrm{X}-4$ aoit 1602. - C'est une

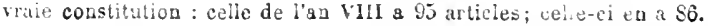


son successeur : c'est une sorte d'hérédité. Par là aussi, Bonaparte se distingue plus encore des deux autres Consuls. A l'arenir, ceux-ci seront nommés, sur sa présentation, par le Senat. Enfin, le Premier consul acquiert le droit, vraiment royal, de faire grice aux condamnés.

Il n'aurait tenu qu’à Bonaparte d’avoir dès lors l'hérédité formelle, car on en lit la proposition. Il refusa, avec de grandes jhrases: "Comment concilier i'hérédité de la premiere magistrature avec la souverainete du peuple? Comment persuader que cette magistrature est une propriétes? "Cela voulait dire que le moment ne lui semblait pas encore venu. Il en étiit de la Constitution comme de cette colonne le la place Vendỏne, érigée par arrèlé des Consuls, et que devait surmonter la statue de Charlemasne. La colonne et la Constitution allaient ètre acherées suivaut le vœu secret de Bonaparte. On avait déjà l'kmpire: il suffisait de changer un mot pour avoir l'Empereur.

La Constituation de ran XI. - La Constitution de l'an Vlil et le sénatus-consulte de l'an $\mathrm{X}$ sont les deux premiers actes de la piece: voici le troisième acte. Après le complot de Cadoulal et l'exécution du duc d'Enohien, le Sénat offrit. a mots couverts, le rótablissement de la monarchie. Le Conseil d'Elit se prononça pour l'heredité par 20 voix contre 7 . Le Tribunat ne voulut pas se laisser devancer : il applaudit la proposition curée, et tel lut l'empressement de tous ses membres a se signaler uril se prononca dix-neuf discours en laveur de l'Enpire. Le Sénat rendit alors un nouveau sénalus-consulte.

Le sínutus-consulte de l'an XII ${ }^{1}$ débute par cet article premier, d'ane rédaction si sinculière: "Le gouvernement de la République est confié à un empereur qui prend le titre d'Emperenr des Francais ${ }^{2}$. " Les autres articles établissaient lhérédite de la comonne, de mâte en male, par ordre de primogéniture, dans la lamille Bonaparte; détrmmaient

1. 28 floréa an XII - 18 mai 180 i. - 142 aricies.

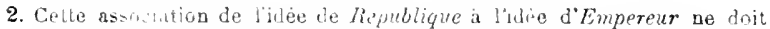
pas nous etonul. Napoleon savait que Rome avait eu ses Cesars sans cesser d'ètre ofliciellemeat la Kepublique romaine. Comme Auguste, il conserra longtemps certaines apparences, certaines formules républicaines. Sur sey monnaies, jusqu'a l'annee $\$ 50 \%$, on lit d'un củte : Republique francaise, eq de l'autre: Tizolion Emperent. 
les titres et les droits des membres de la famille imperiale; organisaient la réfgence en cas de minorité; créaient les yrunds dignitaires le l'Empire (grand électeur, archichancelier de l'Empire, archichancelier d'État, architrésorier, connétable, grand amiral) et les grands officiers de l'Empire (les seize maréchaux, les grands officiers civils, etc.). L'Empereur devait prèter serment de fidélité à la Constitution; mais tous les fonctionnaires, méme les simples électeurs, étajent tenus de jurer "obéissance aux Constitutions de l'Empire ${ }^{1}$ et fidélité à l'Empereur ".

Le Sénat perdit, par le mème acte, le peu d'indépendance qui lui restât. L'Empereur y tit entrer les princes de la famille impériale, les grands dignitaires de l'Empire et, en général, les citoyens qu'il "jugeait convenable d'éleverà la dignité de sénateur ". C’en était fait du libre recrutement de la haute Assemblée. Désormais son président fut nommé par l'Empereur. Or, comme c'est par un Sinat ainsi composé que les membres du Tribunat et du Corps législatif continuaient à ètre nommés, on peut juger du peu d'importance de ces Assemblées.

Cependant, comme on voulait donner le change à l'opinion, le sénatus-consulte de l'an XII établit qu'il serait. formé dans le sein du Sénat deux commissions, chacune de sept nembres, intitulées, l'une, commission sénatorinle de la liberté individuelle; l'autre, commission sénatoriale de la liberte de la presse. Lorsqu'il apparaitrait que l'une ou l'autre de ces libertés aurait reçu une atteinte, sur le rapport de ces commissions, le Stnat pourrait deider : "Il y a de fortes présomptions que $\mathrm{N}$. est détenu arbitrairement "; ou bien : "Il y a de fortes présomptions que la liberté de la presse a été violée ". Pas une seule fois, en dix ans, le Sénat ne fit usage de cette prérogative.

Le Corps législatif reçut aussi une consolation. On l'autorisa à avoir deux espèces de séances : les séances ordinaires, où il continuerait à être muet comme par le passé; les comités généranx, ou ses membres pourraient discuter a huis clos.

1. On appelail Constitutions de l'Empire la Constitution consulaire de I'an VIII, le sénatus-consulte de l'an $\mathrm{X}$, celui de l'an XII, plus une série d'actes ultétieurs, parmi lesquels l'Acte additionel de 1815. Tous ces acter formaient le pacte constitutionnel. 
Avec ces Assemblées si dociles, avec un certan appareil d'élections et de collèges électoraux pour les fonctions sans importance, avec certaines apparences de souveraineté nationale, avec tout ce décor d'institutions représentatives, comme le Sénat ne lui refusa jamais un sénatus-consulte, ni le Corps législatif une loi, ni le Peuple un plébiscite, Napoléon fut, en réalité, plus puissant que Louis XIV.

Suppression du Tribuuat. - Napoléón ne sut même pas respecter ces formes qui avaient l'avantage de masquer son absolutisme et qui en gênaient si peu l'exercice. Le Tribunat l'importunait, moins par la liberté de ses discussions que par les souvenirs républicains que son nom rappelait. En 1807, il le supprima. Les tribuns furent versés dans le Corps législatif. Des commissions élues par celui-ci remplaçaient, pour la discussion des lois, les sections du Tribunat. Tribuns et législateurs votèrent des remerciements à l'Empereur. Fontanes, présilent du Corps législatil, fit un discours pompeux : "La majesté des Assemblées nationales va renaître sous les auspices d'un grand homme... Rendons-nous dignes d'un tel bienlait. "

Abus des sénåus-consultes. - En réalité, il n'y avait que deux corps politiques qui eussent quelque importance $^{1}$ : le Conseil d'État, parce qu'il élaborait les lois; le Sénat, parce qu'il mettait ses sénatus-consultes au service de l'ambition impériale. Napoléon abusa des sénatus-consultes pour enlever au Corps législatif ses dernières attributions politiques. Dès 1805 , profitant de ce que cette Assemblée était en vacances, il s'était fait autoriser par le Sénat a lever des conscrits pour sa campagne d'Austerlitz. Le Sénat accorda, le Corps législatil se tut, et l'Empereur éigea cet expédient en systime. De septembre 1812 à octobre 1813, il obtint du Sénat 840000 hommes, plus tard 300000 . C'est par des sénatus-consultes qu'il organisa la garde nationale de facon à pouvoir mener à la guerre móme les jères de famille. C’est par des sénatus-consultes qưil opéra ses annexions les plus impolitiques et les plus

1. Aussi le Moniteur, en 1SOS, assigne-t-il au Corps législatif le dernier ran - parmi les corps de l'É'at. "Le Corps législatif. inuproprement appelé de u norı, devrait èlre appelé Conseil législatif, puisqu'il n'a pas la faculté de faire des lois n'en arant bas la proposition. 
dangrereuses : celles de liome, de Hambourg, Brême, Lubeck, du Hanovre, de l'Oldenhourg. Il viola constamment l'article 50 de la Constitution de l'an VIIl, qui exige que toute déclaration de guerre soit " discutée, décrétée et promulguée par une loi ". Il commit, une violation bien plus éclatante des droits du Corps législatif: après les désastres le Russie et d'Allemagne, cette Assemblée ayant manifesté quelques velléités dopposition. Napoléon en prononça l'ajournement, régla lui-mème le budgret, établit de nouveaux impòts. C'est ce qu'aucun pouvoir n'avait osé depuis 1789 .

Despotisme impérial. - Le vrai nom de ce régine, cest le despotisme militaire ou le cesarisme. La France navait plus aucune garantie, ni pour les levées de deniers, ni pour les levées de conscrits. Il n'y avait plus ni élections libres, ni liberté de la presse, comme nous le verrons plus loin. Il n'y avait plus de liberté personnelle, car la police impériale mullipliait les emprisonnements ${ }^{1}$ et les exils. Xapoléon, en mars 1814, rendit le fameux décret sur les prisons d'Étut ${ }^{2}$. En 1813, il fit amuler par le Sénat le verdict d'un jury, celui d'Anvers, renvova devant une autre cour d'assises les accusés et même les jurés. Il ny avait plus de garanties pour la propriété, car Capoléon avait maintenu la confiscation ${ }^{3}$, que la Coustituante arail abolie et que la Convention avait rétablie. Il n’y avait plus de sécurité des correspondances, car il avait reconstitué l'ancién Calinet Noir.

Iastabilité des institutions imperisales. - Tapoléon, en

1. Des espèces de lettri's de cachet ètaient mises au service mème d'animosités privées. Un présideul ayant eu à se plaindre des légéretés de sit femme, celle-ci, un jour qu'elle revonait de la promenade. Lrouva sa cour remplie de gendarmes, ful enlevee par eux et conduile dans un hospice.

2. Elles élaient au nonbre de huit: les chaleaux de Saumur, Ham, If, Lanskrow, Pierre-Chàtel, Fénestrelle, Campiano, Vincennes. Ce n'ćtait pas la peine d'avoir, en 17S9, démoli la Bastille.

3. Napoléon, qui croyait avoir des griefs contre le poète dramalique Lemercior, ordonna de démolir, sous prilexle d'élargissement de la voie publique, une maison que son père possédait rue de Rivoli, et qui formait ?es deux tiers de sa fortune. Une escouade de magons s'abattit un jour sur la nıaison et mit tant d'entrain à la démolition que les habitants eurent a neine le limps de lévacuer. Le gouvernement impérial refusa toute indemnité a lewerier. 
asservissant ainsi les corps politiques, avait affaibli son propre pouvoir : lEmpire reposait non sur les institutions, mais sur un homme. Lui-même avait pu sentir les dangers de cette situation : en 1512 , sur la fausse nouvelle que l'Empereur était mort en Russie, le général républicain Malet, par un coup de main, s'empara lu trésor, de l'hôtél de ville, de la préfecture de police, du ministère de la police, et, gràce à la docilité machinale des fonctionnaires, a l'obéissance passive des troupes, au manque d'initiative des pouvoirs constitués, à l’indifférence des citoyens, faillit opérer une révolution. Napoléon fut à la fois effrayé et indigné : "Un homme est-iì donc tout ici? Les institutions, les serments, rien?"

A qui la faute si un homme élait tout et les institutions rien? A Napoléon lui-même. Encore en 1813, devant lopposition du Corps légrislatif, il lui disait: "Au nom de qui parlez-vous? C'est moi qui suis le seul, le vrai représentant du peuple. "On ne parlait pas autrement au temps de Louis XIV et de Bossuet.

Aussi, quand l'invasion commence, partout où Yapoléon n'est pas présent de sa personne, rien ne résiste. L'impératrice, qu'il a établie comme régente à Paris, son frère Joseph, qu'il lui a donné comme appui, sont les premiers à fuir. Ses ministres, Fouché, Talleyrand, s'empressent de nówocier avec l'étranger, avec les Bourbons. Quand il est bien décidément vaincu, alors seulement le Sénat, se souvenant de son titre de conservateur, sémut des violations répétées de la Constitution. Il les rassemble et les énumère dans les considérants de ce dernier sénatus-eonsulte ${ }^{1}$ par lequel il proclame la déchéance de l'Empereur. Il lui reproche d'avoir décrété arbitrairement la peine de mort contre les partisans du drapeau blanc, d'avoir illégalement déclaré des guerres ${ }^{2}$, anéanti la responsabilitio des ministres, detruit lindénendance de la justice, confondu tous les pouvoirs, violé la liberti individuelle et la liberté de la presse. Ces reproches étaient fondés: il était seulement fàcheux que le Sénat eùt

1. Du 3 avril 181 í

2. Le Senat a encore la pudeur de ne pus parler des levées illegales d'hommes et d'impóts. 
attendu si longtemps pour les adresser à l'Empereur. l.e Corps légistalif s'empressait, le même jour, de s'associer à ce décret et à ses considérants. Le despotisme succombait sous le poids accumulé de ses fautes.

\section{Le droit électoral.}

Les élections de 1989. - Les élections aux États généraux de 1789 ont été faites par ordres. Ainsi les ecclésiasques ont été invités à élire les députés du clergé; les gentilshommes, à élire les députés de la noblesse; les roturiers, à élire les députés du tiers état.

Louis XVI avait déclaré vouloir "que ses sujets fussent tous appelés à concourir aux élections des députés ". Tous les membres du clergé et de la noblesse prenaient part a la nomination de leurs représentants respectifs. Dans le tiers état, pour être membre des assemblées primaires, il suffisait de remplir ces trois conditions: ètre âgé de vingtcinq ans, être domieilié dans la commune, être inscrit au rôle des impositions. Les pauvres étaient donc exclus. Cependant il faut remarquer que Louis XVI a été très libéral pour l'époque: jamais, avant lui, on n'avait étendu le droit de voter à une si grande masse d'électeurs. Ce nétait pas le suffrage universel, mais personne alors n'y songeait ou ne s'en souciait.

Les députés du tiers n'étaient pas élus directement. Les assemblées frimaires nommaient un délégué par cent maisons. Les délígués se réunissaient au ehef-lieu de bailliage ou de sénéchaussée, où ils formaient l'assemblée des électeurs: là, ils rédigeaient les cahiers et élisaient les députés aux Élats généraux. Il y arait donc une double élection par les nssemblées prinaires et par les assemblées d'électeur's: le suffrage n'était pas direct, mais à deux degrés.

Čest ainsi que fut élue, sous le nom d'Ėtats généraux, l'Assemblée qui commença la Révolution française.

Système électoral de la Consituante. - Quand elle devint l'Assemblée constituante, elle eut à décider comment se feraient à lavenir les élections. Les membres de la droite demandaient qu'on n’accordàt le droit électoral 
qu'aux citoyens qui payeraient 60 francs de contributions directes. Cette proposition fut combattue par les membres de la gauche, Mirabeau, Grégoire, Pétion, Robespierre ${ }^{1 .}$

Pourtant on établit un certain cens électoral, et de plus l'élection ne fut pas directe. On réserva la qualité de ciloyens actifs aux Français qui rempliraient les conditions suivantes : être àgés de vingt-cinq ans, ètre domiciliés depuis un an dans la commune, n'ètre pas domestiques, être inscrits au ròle de la garde nationale, enfin payer une contribution équivalente à trois journées de travail. Trois journées de travail, c'est-à-dire une valeur de 3 a 6 lranes, ce nétait guère; cela suffisait cependant pour exclure du droit de suffrage des millions de citoyens.

Les citoyens actifs formaient les assemblees primuires, dans lesquelles ils élisaient les véritables électeurs, à raison d'un électeur par cent citoyens actifs. Pour ètre électeur et prendre part á l'élection des députés, il fallait payer un cens encore plus élevé ${ }^{2}$. Ainsi on reconnaissait à tous les Francais le titre de citoyen; mais il fallait jouir dune certaine aisancc pour ètre citoyen actif et encore plus pour être électeur. Tout citoyen actif pourait ètre élu député.

Il n'y avait en 1791 , pour tout le royaume, que $4298360 \mathrm{ci}-$ toyens actirs.

Les èlecteurs formaient des assemblées délccteurs : on y nommait non seulenent les députés, mais les memlin: des administrations locales et les magistrats.

C'est de ce système électoral que sortit la Législative.

1. Voici un passage du discours de Robespienze demandant le suffrage aniversel : "Tous les citoyens, quels qu'ils soient, ont le droit de prétendre a tous les degrés de représentation. Rien n'est plus conforme à votre Déclaration des droits, devant laquelle tout privilère, tuute distinction, toute exception doivent disparaitre. La Constitution établit que la sonverainelè réside daus le peuple, dang tous les individus du peuple. Chaque individu a donc droit de concourir à la loi, par laquelle il est obligé, el à l'administration de la chese publique, qui est la sienne. Sinon il n'est pas vrai que tous les hommes sont égaux ep droits, que tout homme est citoyed. Si celui qui ne paye qu'une imposition équivalente à une journeje de travail a moins de droit que celui qui paye la valeur de trois journées de travail..., celui qui a 100000 lives de iente a donc cent fois autant de droits que celui qui a'a que 1000 livres de revenu? "

2. La loi du 22 décembre 1789 exige qu'on paye une contribution de dis jounne de Iravail; la Constitution du 3 septembre 1 i9l exige un revenu foncier de la valeur de ccot cinquante à deux cents jourdées de travail. 
Systène électoral de la Législative. - Celle-ci, le 11 aout 1792 , c'est-à-dire au lendemain du renversement de la royauté, décréta que toute distinction serait effacie entre les citoyens actifs et les autres; que tout Français àgé de vingt et un ans, pourvı quil ne fût ni assisté par la charité publique, ni domestique, serait admis dans les assemblées primaires, en prètant le serment civique. Elle abolissait toute condition de cens; mais elle laissait subsister le suffrage à deux degrés. Elle imagina un moyen assez compliqué pour répartir les 745 députés à élire : 24 devaient être élus par les départements a raison de l'étendue territoriale de eeux-ci; 249 à raison de la population; 249 à raison du montant de la contribution directe payée par le département.

La Convention nationale fut élue sous ce régime.

La Convertion nationale; son prenuien système électoral. - La Convention, par la Constitution de 1793, maintint le suffrage universel et établit le suffrage dircet. Les assemblées primaires comprenaient tous les citoyens et élisaient elles-mèmes les députés à raison d'un représentaut par 40000 habitants. Elle laissait subsister les anciennes assemblées d'électeurs, mais seulement pour l'élection des administrateurs et des magistrats.

Cette Constitution n'ayant jamais été appliquée, par conséquent, jamais, pendant toute la période révolutionnaire, on ne vit fonctionner le suffrage universel et clirect.

Son deuxiène système electoral. - La Convention, beaucoup moins imbue didées démocratiques à la fin de sa carrière ', revint au systime du suffrage à deux desrés pour les élections de représentants. En vertu de la Constitulion de lan III, les assemblées primaires, composées des

1. Ses vues, en 1795 , sont developpes dans le rapporl de Borssy DiAnGLAS. qu'il faut mettre en regard du discours de Rohespierre sur le sufrage universel : "si vous donnez à des hommes sans propriéte les droits politiques sans réserve, et s'ils se trouvent jamais sur les bancs des législaleurs, ils exciteronl ou laiseeront exciter des agitations sans en craindre l'effel; ils élabliront ou laisseront établir des taxes funestes au commerce el à l'agriculture, parce qu'ils n'en auront senti ni redouté les déplorables résultals; et ils nuus préripiteront enfin dans ces convulsions violentes dont nous sorions a peine et dont les douleurs se feronl sentir si lonertenups sur toule la stríace de la France. Un pays gouverai nar les proprietilles esi hatio lordre social; celti oủ les zon-proprietaires gevvernent est dans létut de nature. 
citoyens domiciliés dans le canton, recommencèrent à élire des électeurs à raison d'un représentant par cent citoyens, les assemblées d'electeurs à nommer les membres de la législature. Pour être électeur, il fallait posséder une propriété donnant un revenu de cent cinquante à deux cents journées de travail. On maintenait donc, en principe, le suffrage universel; mais on l'entourait de telles restrictions que la Convention se trouva, en réalité, beaucoup moins libérale que n'avait été Louis XVI en 1789.

Gystème électoral de Ia Constitution de I'an vil. La Constitution de l'an VIII respectait aussi, en principe, le suffrage universel; mais, en fait, elle l'annulait, grâce à une série de combinaisons ingénieuses et compliquées.

D'abord elle admettait que tout Français âgé de vingt et un ans était électeur. Tous les citoyens doniciliés depuis un an dans un arrondissement se réunissaient au chel-lieu de canton, élisaient le dixième d'entre eux et formaient ainsi la liste de notabilité communule. Les citoyens portés sur cette liste se réunissaient au chef-lieu d'arrondissenient, désignaient à leur tour le dixième d'entre eux et formaient ainsi la liste de notubilité départementale. Enfin les citoyens portés sur cette liste se réunissaient au chef́-lieu de département, choisissaient encore le dixième d'entre eux et formaient ainsi la liste de notabilité nutionul'.

En supposant qu'il y eût alors 6 millions de eitoyens, Ia liste communale comprenait 600000 noms, la liste dejurtementale 60000 et la liste nationale 6000 .

Il y avait trois espèces d'assemblées électorales qui devaient se réunir plus ou moins fréquemment : celles de canton, d'arrondissement, de lépartement.

A quoi servaient toutes ces listes? Sur la liste communale, le gouvernement choisissait les maires et les conseillers municipaux, les sous-prélets et les conseillers darrondissement, les juges de première instance, etc. Sur la liste départementale, il choisissait les préfets, les conseillers généraux, les magistrats des Tribunaux d'appel, etc. Sur la liste nationale, le Premier consul choisissait les ministres, les conseillers d'État; le Sénal y choisissait les députés du Corps législatif et du Tribunat les nagistrats du Tribunal de cassation, ete. 
Ainsi le simple citoyen avait son vote et sa part d'influence pour la nomination non seulement des députés, mais des prefets, des ministres, des magistrats. Seulement son vote passait comme par trois cribles: il était si bien tamisé qu'il n'en restait rien.

Dès lors, le vote du simple citoyen a si peu d'importance qu'il s'en désintéresse; il néglige d'aller exercer dans les assemblées primaires une part de souveraineté tout à fait dérisoire.

\section{Systène électoral du Consulat a vie et de l'Empire.} - Bonaparte trouva que le peuple avait encore trop d'action sur les élertions. Par le sématus-consulte de l'an $\mathbf{X}$, il compliqua ce système. Il institua trois espèces de corps. électoraux: $1^{\circ}$ l'assemblée de canton, composéc de tous les citoyens portés sur la liste de notabilité communale et domiciliés dans le canton; $2^{\circ}$ le collège électoral d'arrondissement; $3^{\circ}$ le college électoral de département.

Le collège électoral d'arrondissement se compose de 120 à 200 membres; celui de département, de 200 à 300 nembres choisis parmi les plus imposés du département. Tous ces membres sont nommés par les assemblées de canton; mais, connme ils sont nommés à vie, celles-ci n'ont a faire que de rares élections partielles; quant au simple électeur qui vote pour la liste communale, devenue la liste de lassemblée de canton, il a encore bien moins à se déranger.

Comme si l'action du gouvernement n'élaii pas déjà excessive sur les électeurs, le Premier consul s'est réservé le droit de nommer les présidents des assemblées de canton et les présidents des collèges électoraux. Il s'est réservé le droit d'adjoindıe 10 membres de son choix à chaque collège d'arrondissement, 20 membres à chaque collège de département.

A quoi servent ces collèges? Le collège électoral d'arrondissement présente 2 membres pour chaque place vacante au Tribunat; celui de département 2 menbres pour chaque place vacante au Sénat; ils présentent chacun 2 membres pour chaque place vacante au Corps législatif. C'est le Sénat qui choisit, après ces présentations, les membres du Tribunat et du Corps législatil; c'est le Pre- 
mier consul, le Tribunat et le Corps législatif qui choisissent les membres du Sénat. Ce n’est pas beaucoup s'avancer que de résumer ainsi cette organisation si compliquée : le Premier consul nomme les sénateurs, et ceuxci nomment les léputés et les tribuns.

Bientôt les assemblées de canton ne sont plus réunies pour des élections. Elles interviennent seulement lorsque le pouvoir a besoin d'obtenir un plétiscitr. Or, un plitiscite ne peut être l'expression libre et sincère du sentiment national. Ciest le gouvermement qui formule la question, et il peut la formuler de telle facon que le puple soit forcé de sanctionner à la fois ce qu'il approuve et ce qu il désapprouve; le peuple ne peut ni demander d'explications, ni proposer de modifications, comme le ferait une assemblée; à des questions très complexes il ne peut répondre que par un oui ou par un non. Un gouvernement qui redoute la discussion par des assemblées libres preterera donc toujours consulter le peuple par le moyen d'un plébiscite. Le régine plébiscitaire est le contraire du réçime parlementaire, et le gouvernement le plus absolu peut très bien s'en accommoder.

Ainsi Napoléon ne permet à la souveraineté nationale de se manilester que pour faire des actes d'abdication entre ses mains. Il peut se dire alors "l'élu de la nation ", et mépriser les représentants. Il peut prétendre, comme les Césars romains, que le peuple sourerain lui a remis tous les pouroirs : lui aussi est la nation incarnée, le peuple fait homme, la loi virante.

Duraages a consulter. - Dicticnnaire de la constitution et du gure'ruement frumenis, Anonymo (1791). - Fanstin Halie. Les Cunistitutions te th Frane lisit. - Did-

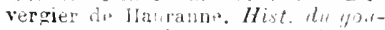
vernement purt montule $105-72$

- Troplong. Du prancipe d'autorile depuis 1789. - Audirannr, llist. electorate de la Jrance demis la convocation des Ehats quntrauc (Isi1). - A. Challamel, Mist. de lie liberte en France depuis $7 \% 59$ (1Syb. -G. Dodu. Io Inatrementarisme et les Parloménides asus lis lis. 911). -
Gros, Le Comitederielat Public 1. 4).

A. Vandal, Latemente de limu-

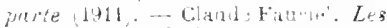

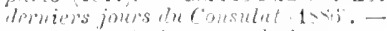
De-marets. fllidere ans de hute po-

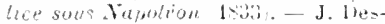
trem, Las deportalions du Cionsulat f't de l'Empite 1Ss5t.

Mares de Saint-llibitre, Kippotion an conseil ditut lvi3. - low

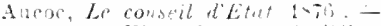

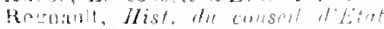
1Yis, diu-lre - H. Troubllart. Le Senat conservitur die rons. it itu Ior Einl. 10!1. 


\section{CHAPITRE HI}

\section{LES LIBERTÉS PUBLIQUES}

Ce quion entend par les libertés publiques. - Le droit de suffrage assure aux citoyens qui sunt électeurs une action efficace sur la direction des affailes publiques. Mais comment pourraient-ils imettre un vote raisonné s'ils nont pas le moyen de séclairer par la libre discussion?

D’autre part, mênc dans les pays où n'existe pas le suffrage universel et qui sont cependant des pavs libres, comme en Angleterre, on n'a pas cru que les citoyens non électeurs dussent ètre privés de tout droit à faire connaitre leur opinion sur les affaires publiques.

Pour les uns, conmme pour les auties, la liberte de la presse, la liberte de rénion et d'association, le druit de pétition, constituent les libertés politiques, ce que M. Thiers appelait sous Napolén III les libertés nécessaires.

Entin jl est une seconde catégorie de libertés et de garanties qui sont pour ainsi dire de droit naturel, et qui doivent appartenir mème aux habitants qui ne sont pas ciloyens, même aux femmes, même aux étrangers : ce sont la liberté et la sécurité de la personne, l'inviolabilite du domicile, la liberté lie conseienee, la liberté de travail.

Tous ces droits, libertés politiques et libertés naturelles, sont inscrits dans la Décluration des droits: ils ont eté garantis par la plupart de nos Constitutions el reconnus, au moins en termes généraux, mòne par celle de 1852.

Nous n'avons a nous occuper ici que du droit de pétition, du droit de réunion et d'association, de la liberlé de la presse. 
Le droit de pátition. - C'est le droit d'adresser aux pouvoirs publics des plaintes ou des voux, de leur signaler les abus, de leur indiquer des rélormes.

Ce droit a été largement exercé pendant la Révolution. on en a mème fait un usage tumultueux et séditieux.

Aussi la Constitution de l'an III décida que les pétitions devaient ètre individuelles, que nulle association n'en pourrait présenter de collectives, et que les pítitionnaires " ne devaient jamais oublier le respect dù aux autorités constituées".

Celle de l'an VIII renouvela l'interdiction des pétilions collectives. Parmi les Assemblées, elle désigna le Tribunat comme devant spécialement recevoir les voux des citoyrns. Celle de l'an XII permit d'adresser au Sénat, mais non au Corps législatif, les pétitions relatives à la liberté individuelle et à la liberté de la presse. Il fut interdit d'apporter les pétitions a la harre du Tribunat et du Sínat.

Le droit dassociation et de réurain:- - Le droit d'association est le droit de former des sociétés organisées, soit en vue d'ure action politique ou religieuse, soit tout simpiement avec un but scientifique, littéraire, commercial, industriel, philanthropique.

Le droit de réunion est le droit de se réunir à un moment donné, sans organisation permanente.

Ce double droit est exercé en Angleterre, en Amerique, en Belgique et dans d'autres pays libres sous les formes les plus diverses.

Il n'a presque jamais eu en France la mème latitude. Jusqu'au temps piésent, et sauf dans les périodes troublées, les Français, mème électeurs, n’ont jamais joui aussi largement de ce droit que les Anglais, meme non électeurs.

Il est vrai qu'il a été surtout exercé. chez nous, ou par les partis révolutionnaires ou par les partis de réaction.

Son histoire: Pendant da mésolution. - Pourtant il a été proclané par la Constitution de 1791: mais l'exercice en a été d'abord interdit aux ouvriers pour affaires concernant leur profession.

Il se forma des associations célèbres, comme le club des Feuillants, le club des Corleliers, surtout le club des Jacobim: de Paris, qui avait des clubs affilies dans toutes les villes 
et mème dans quantité de villages, et qui constitua une puissance rivale des Assemblées nationales.

Eı 1792, La Fayette, au nom des " soldats de la liberté ", demandait qu'on supprimât les clubs.

La Constitution de 1793 ne reconnut que le " droit de se réunir en sociétés populaires ". Un décret de la Convention, en juillet 1793, édicta les peines les plus sévères contre les autorités "qui empêcheraient les sociétés populaires de se réunir on qui tenteraient de les dissoudre ".

Il n'y a de liberté réelle que lorsqu'elle appartient à tous les citoyens : or, pendant la Terreur, si les Jacobins jouissaient du droit de s'associer et de se réunir, les royalistes et même les républicains modérés ne purent en jouir. De même, lorsque ceux-ci, après la chute de Robespierre, se trouvèrent les plus forts et purent former des clubs, à leur tour, ils provoquèrent la dissolution des clubs où se réunissaient leurs adversaires et les dispersèrent violemment.

La Constitution de l'an 111 interdit à toute societé particulière, se proposant un but politique, de correspondre avec d’autres sociètés, de s'affilier à elles, de faire porter à ses membres un signe distinctil. Cependant les partisans de Babeuf formèrent le Club du Panthion ou des Egaux; les royalistes formèrent le Club de Clichy. Le gouvernement, menacé également par les deux parlis extrêmes, se défendit. La loi de thermidor an $Y$ prohiba toutes les associations politiques et leur appliqua les peines portées contre les attroupements.

* Sous le Comsulat et lEmpire. - Ce n'était pas Bonaparte qui pouvait restaurer une liberté mutilée par la Convention et anéantie par le Directoire. Les Constitutions consulaires et impériales se gardent, même daus leur préambule, d'en faire mention. Sous le Consulat, la qualité de membre ou ancien membre de sociétés populaires fut un titre a la déportation.

Sous l'Emprire, le Code pénal de 1810, dans les article. 291 i $29 \%$, limite étroitement le droit de réunion et d'association: mème si des citoyens se proposent de traiter de qüestions non politiques, ils ne peuvent se réurir à plus de vingt personnes sans l'autorisation du gou'ernement. 
Ces articles ont une grande importance, car ils sont restés, jusqu’à nos jours, la base de la législation sur la matière.

La liberté de la presse. - La liberté de la presse a toujours été chez nous beaucoup plus appréciée de l'opinion, mais tout aussi redoutée des gouvernements.

Elle n'a été sérieusement pratiquée que pendant les quatre premières années de la Révolulion française, pendant quatre ou cinq années de la Restauration, sous la uonarchie de Juillet, sous la République de 1848 et sous la République actuelle. A part ces périodes assez courtes, les gouvernements l'ont toujours plus ou moins combattue. IIs n'ont pas voulu admettre que la presse, précisément parce que son rôle est de contrôler et de criliquer les gouvernements et d'assurer contre eux les droits du citoyen, doit être indépendante : ils ont essavé de faire de cette liberté une tolérance du pouvoir.

C'est contre les journaux, bien plus encore que contre les livres, qu'ils se sont armés de rigueur, et nos lois d'autrelois sur la presse sont comme un arsenal de moyens fiscaux, préventifs et répressifs plus ou moins ingénieux ${ }^{1}$.

1. Ces moyeas peuvent ètre classés en plusieurs catégories:

1. Il y a d’abord les moyens fiscaux, destinès a rendre trés coùteuses la fondation et la publication des journaux. Alors les citoyens tres riches peuvent seuls en creer, et les classes ouvrières ne peuvent les lire. C'est ainsi quon a ćtabli le cautionnement, obligation imposée aux fondateurs de jourraux de déposer une somme considerable qui ré;ondra pour les amendes qu'ils peuvent encourir; l'impot du timbre, qui augmente le prix de chaque numéro; l'impot sur le papier, qui augmenle les frais d'impression.

2 Les moyens préventifs sont destinés a prévenir les écarts de la presse. Tellcs furent, à certaines époques, l'obligation d'obtenir du gonvernement une autorisation prealable avant d'établir un journal; l'obligation imposée aux rédacteurs de signer leurs arlicles, mesure qui a aussi pour conséquence d'alfuiblir l'autorite du journal, puisque les articles scmblent l'expression de l'opinion individuelle des rédacteurs et oon plus celle de la doctrine d'un parti; lobligation de cunstituer un gérant responsable sur qui tomberont les amendes ei la prison; et eufin la mesure la plus grave de toutes, celle qui scumet les artirles ou les lives, avant qu'ils soieut imprimés, a l'exanon de censeurs nummés par le gourernement.

$3^{\circ}$ Les moyens répressifs sont destinés à punir les dẻlits ou prétendus délits ea frappant lesimprimeurs, gérants ou rédacteurs, de pénalités plus ou moius rigoureuses, telles que l'amende, la prison, la perte des droits eiviques. Les amendes ont surtout pour but de ruiner le jourval; la prison et la perte des druits eiviques, de décourager les journalistes.

Le regime répressif est plus ou moins rigoureur, suivant que ces peinex 
Son histoire : oous la Constitunare. - La Constitusion de 1791, rompant arec les traditions d'arbitraire de l’ancien régrime, fait cette déclaration en son article 11: "Tout citoyen peut parler, ecrire, inrprimer librement, sauf à répondre de l'abus de cette liberté dans les cas détermines par la loi. "

Or la Constituanle elle-mème, apres l'affaire du Champ de Mars (17 juillet 1791), sévit contre les journaux et les journalistes républicains. Toutefois les principes posés par elle assurèrent pour quelque temps la liberté légale de la presse.

Nous disons: la liberté légule, car, en fuit, elle fut violée souvent. L'éducation politique du pays n'était pas laite et Thabitude de la liberté de la presse n’était pas entrée daus les mours. A cetle ćpoque, déjà si troubléc, les citoyens s'arrogeatient le droit d"interdire ce que permettait la loi. On voyait les pntriotes, en novembre 1790 , faire une démarche auprès des journaux rovalistes, "à l'eflet de les ramener dans le bon chemin par des paroles de paix ", assuraient-ils. En réalité, ils malmenèrent les journalistes qu'ils rencontrèrent chez eux et, chez les absents, saisirent les manuscrits et les imprimés. Chaque parti, devant la porte du café qu’il fréquentait habituellement, faisait des autodafés des journaux hostiles.

Sous la Constiluante, il y eut de très nombreux jour-

sont appliquées, ou par l'administration, qui est ainsi juge et partie, ov par les tribunalx correctionnels, qui ne sont pas totijonts assez indejpendants da pouvoir et qui ont une tendance a appliquer la loi dans toute sa rigueur, ou par le jury, qui est plus disposé a teuir cumpie des circonstances atleubantes, mais qui s'inspire souvent des mines passious politiques que l'eerivain.

Les lois et rirlements restrictifs de la liberté de limprimeur et du libraire appartiennent au système préventif. L'interdiction de la rente sur. la voie publique, par simple mesure administrative, tient a la fois du système fiscal, préventif et répressif. La proclamation, en cer'ains cas, de l'état de siege qui soumet les joumaux a la jurulictiou des tribunaux militaires tient a la fois des deux derumers syolimes.

Noublions pas qu'it certaines épocines on a dédaignè ces noyeus romme n'ètant pas assez expedilifs, qu'on a suplrimé les jouraux et puni les journalistes demprisonaements arbitraires, de la déportation, mème de la peine de mort. Ces moyens ont été surtout employés sous les récime: exceptionuels, comme la Terreur (1793-94), le conp ditat the is fructido. 1797, le coup l'Etal du is trumaire (1709), lo coup d'Etai de dacentore (1551). 
naux. Outre ceux quavait légués l’époque précédente. tels que le Vercure de France, la Guztte de France, le Journal de Paris, le Joumal de l'Europe, etc., on vit naitre le Courrier de Provence, rédigé par Mirabeau, les Rérolutions de Paris, par Prudhomme et Loustalot, avec un tirage de 200000 numéros. La Sentinclle, par Louvet, la Bunche. de Fer, par l'abbé Fauchet, le Patriote, par Brissot. sont déja des leuilles républicaines, d'une nuance relatirement modérée, qui sera ensuite celle des Girondins. Au parti avancé, qui s'appellera plus tard le parti monlagnard, appartiennent lOruteur du Peuple, par Fréron; les Ricolutions de France et de Brabunt, par Camille Desmoulins; le Point du Jour, par Barère; l'Ami lu Peuple, par Harat. II y avait alors un Père Duchéne, qui nettait un lintage grossier et orlurier au service de la liberté et du roi constitutionnel, et qu'il ne faut pas confondre avec celui que rédigera plus tard Hébert.

La presse royaliste, largement subventionnée par la cour, était représentée par les Actes des Apótres, do Peltier, Rivarol, Champcenetz; I'Ami du Roi, de l'abbe Royou; la Lanterne majique nationale, de Mirabeau-Tonneau; le Journal de la Cour et de la Ville (appelé aussi le Petit Gautier), de Gautier; la Gazette de Paris, de de Rozoy; la Fenille du jour, de Parisot; le Journal des Hulles, le Journui it dour liards, le Journal de Louis XVI et de son Peuple, etc. Quelques-uns des journaux royalistes, comme les Aetrs des A pótres et le Journal de Suleu, égalaient Marat en violence et en grossièreté : ils attaquaient surtout les modérós.

zo Sous la dépislative et la Convention - Apres la chute de la royauté (10 aoùt 1792), il n'y a plus de liberté de la presse pour les rovalistes : le 12 aoùt, la Commune de Paris, usurpant sur les pouvoirs de l'Assemblée nationale, décrète que " les empoisonneurs de l'opinion publique seront mis en prison et que leurs presses, caractieres et instruments seront distribués aux imprimeurs patriotes ". En conséquence, Gorsas hérite des jresses de l'Ami du Roi. Le rédacteur de la Gazette de Puris, de Rozoy, est condamné à mort et exécuté.

Déjà à co moment les Girondins et les Montasmards, ¡usqu'alors confondus dans le parti républicain, se divi- 
sent: les premiers ont le Courrier des départements, de Corsas, le Bulletin des Amis de li Verite, la Chronique de Paris. Les Montagnards, outre les fenilles qu'ils avaient léjà, fondent le Joumal des hommes libres, le Journal de la Montagne, le Joumal de la Convention, l'Anti-Brissotin, l'Anti-Fédéraliste, le Bulletin du Tribunal révolutionnaire'. Ils sont les plus forts et les plus violents: en mars 1793, le journal de Gorsas est mis a sac par une bande de 200 hommes, et ses presses, celles qu'il tenait de l'Ami du Rori, sont hriséps. Mèmes exploits à l'imprimerie de la Chronique de Paris.

Après le 31 mai, il n'y a plus de liberté de la presse pour les Girondins, décimés par l'exil ou par l'échalaud. Pendant la domination les Robespierristes, il n'y en a plus pour les autres fractions du parti montagnard : le Vieux Cordelier de Camille Desmoulins est brûlé solennellement an club des Jacobins, puis Desmoulins périt sur l'échafaud. Le poète André Chénier, rédacteur du Journul de Puris, a le même sort. Après le 9 thermidor, il n'y a plus de liberté pour les Jacolins. Pendant tout le reste de la Révolutiou, les partis subissent tour à tour le régime qu'ils ont fait peser sur les autres, et celte liberté que Mirabeau avait proclamée comme étant " de droit naturel " levient un privilège des factions victorieuses.

D'abol l cette proscription des journaux adverses s'était faite sans loi, par mesure révolutiommaire, en invoquant le sulut publie. Puis on édicta les premières lois.

Un lécret de la Convention (29 mars 1793) porte la peine de mort contre tout écrivain qui aura provorgué soit au menrtre ou à la destruction des propriétés, soit au rétablissement de la royauté. L'ex-capucin Chabot déclarait que "la presse arait élé nécessaire pour amener le régime

1. Il est impossible dëaumérer tous les juurnanx de la Révolutton, car i] y eut une infinité d'Annales, de Chroniques, de Courriers, d'Lichos. d'()rateurs. de Patriotes, de Défenseurs et d'Amis le toutes sortes de ehoses. Il y eut le Journal des Sans-Culottes, le Postillon de la Liberte, la Lorijnolle de l'Enchanceur .Merlin, le Babillard, le Menteur. It y cut des joumaux vivant de scandales, comme le Compere Mathieu, dautres qui riaient de tout, comme l'Espiègle, et d'autres qui ne se soueiaient de rien, comme le Je m'en f... - Le Journal de Bonaparte et des hommes vertueux. qui dura vingt jours, en ventóse an V (janvier 1797), annonee deja uno autre lendanee. 
de la liberté; mais, une fois le but atteint, il ne fallait plus de liberté de la presse, de peur de compromettre la liberté elle-mème ". C'est le fond de la pensée de presque tous les Français de ce temps : la liberté de la presse est bonne quand elle défend leursidées personnelles, mauvaise quand elle les discute. Cela n'empèche pas la Constitution de 1793 (23 juin) de proclamer, une fois de plus et solennellement, que "le droit de manifester sa pensée et ses opinions, soit par la voie de la presse, soit de toute autre maniere, ne peut c̀tre interdit ".

Après la chute de Robespierre, il fut question de faire une nouvelle loi sur la presse. Les Montagnards s'y opposèrent, invoquant la Déclaration des droits. Cambon et Bourdon de l'oise la réclamèrent, invoquant les dangers du royalisme. La Convention, pour la troisième fois, proclama, dans la Constitution le lan III, les principes de liberté. Elle manifesta bien l'intention de faire une loi sur la presse, mais elle se sépara sans l'avoir rédig̨ée.

3. Sons le Bincetoire. - Le Directoire, attaqué a la fois par le parti royaliste et les anciens terroristes, obtint des deux Conseils la lo $i$ de $1796^{1}{ }^{1}$; elle portait la peine de mort ${ }^{2}$ contre quiconque aurait provoqué au rétablissement de la royauté ou de la Constitution de 93.

Elle était trop rigoureuse pour ètre appliquée : le jury préférait acquitter les coupables que de les marquer jour l'échafaud; il acquitta constamment les terroristes, comme Lebois, les royalistes, comme Michaud. Richer-Serisy, rédacteur de l'Accusateur public, fut une première fois acquitté par le jury de la Seine; le Tribunal de cassation byant cassé le jugement, il fut renvoyé devant le juty de Seine-et-Oise, qui acquitta encore. Le gouvernement se trouva désarné. A cette époque, sur 70 journaux parisiens, il n'y en avait pas quatre, assure Lacretelle, qui fussent républicains. Bonaparte, ému des langers que les royalistes faisaient courir au gouvernement, écrivit au Directuire une lettre irritée: "A ppelez les arnées!... Faites briser les

1. 27 germinal an IV -- 16 avril 1706.

2. Si le jury accordait les circonstances atténuantes, la peine sera t celle de la déporlalion. 
presses des journaux vendus à l'Angleterre, plus sanguinaires que ne le fut jamais Marat."

Alors eut lieu le coup d'Etat du 18 fructidor. On supprima cinquante-quatre journaux, lont les propriétaires et rédacteurs, au nombre de 67 personnes, furent déportés à l'ile d'Oléron. Parmi eux, Laharpe et Fontanes, du Mémorial; Geoffroy, de la Quotidienne: Bertin de Vaux, de l'Éclair; Fiévée, de la Gazette de France: Richer-Serisy, etc. Toutes les publications périodiques durent ètre soumises, pendant un an, à la surveillance de la police.

C’étaient là des mesures révolutionnàves : ce n'était pas une loi. On fit la ioi de $1797^{\prime}$, qui imposait aux journaux un double droit de timbre. Elle ne suffit pas au gouvernement. Le 26 frimaire an VI, il supprima $\in$ neore seize journaux royalistes, parmi lesquels le Bulletin de la République et les Tablettes rélublicaines, qui n'étaient autres que la Quotilitnne et le Hémorial, sous dautres noms; le 22.2 gerninal, il supprima deux journaux jacobins, le Journul des Hommes libres et l'Ami de la Patrie: le 20 messidor, quinze autres; le 23, une nouvelle loumée; le 28 , le Joumul des Francs, qui n'était autre que le Journal des Hommes litres, ressuscité sous un autre titre.

C'était de l'arbitraire et du plus violent, qui ne pouvait s'excuser que par la violence nème de cette presse; mais les Conseils, tout en autorisant la prolongation de ce régime à titre exceptionnel, refusaient obstinément de faire une loi restrictive de la presse. Vainement le Directoire proposa une surtaxe sur le papier, un nouveau droit de timbre, un droit de patente. l'our se venger, il laissait la police bàtonner les colporteurs de journaux hostiles. Les Conseils tinirent uctme par rapporter la loi de 1797. Le Directoire, interprétant abusivement un article de la Constitution, supprima encore, apres le coup d'Etat le prairial, 11 journaux. Il n'y avait pas de loi sur la presse, mais la presse expirati sous l'arbitraire.

4 sous le Consuat et rimpire. - Bonaparte, par le deeret du 17 janvier 1800 , détermina nominativement les journaux qui pourrajent continuer à paraître : éétait lire 
qu'il supirimait d'autorité tous les autres. Quant à ceux qui subsistaient, au nombre de treize seulement ${ }^{1}$, leurs propriétaires devaient renir chez le ministre de la police justifier de leur qualité de citoyens francais et promettre fidélité à la Constitution. Au premier article hostile, ils devaient être supprimés.

En 1803, Napoléon exigea que les propriétaires de journaux lui présentassent des hommes sùrs comme rédacteurs. Quelques-uns des journaux conservés durent itre rachetés par les plus prospères, ce qui réduisit encore leur nombre. Il imposa aux Bertin de changer le titre le Journal des Dibuts ${ }^{2}$ en celui de Journul de l'Empire.

En 1810, il étudia, en son Conseil ditat, un moaveau projet de décret sur la presse, dans le dessein, assurait-il, de mettre fin au régine arbitraire. C'est alors qu'il licclara que la profession de journaliste était " wise fonction publique ». On devait donc attendre des écrivains la mene docilités que des fonctionnares. Par le deret de 1510 , l'Empereur rétablit la censure de lancien rógime, réluisit le nombre des imprimeurs et librares, les oblicea a prenure un trevet et a prêter le serment de fidélité.

En outre, il s'arrogea le droit de nommer et réroquer les

1. C'étaient le .Moniteur universel. le Journal des Dituats, le Joumal de Paris. Je Bien inf.rmi, la Publicite. qui appartenait a Suarả el a Dipons de Nemours. 1". An dos lois, la Clef diu cabinet des souvrains, le Cutoyen francuis, la Guzute de Frane, le Jourral des Hommes libres, le Journal du sour, lo Journal des defenseurs de la patrie. la Decade phlosophique. Bonaparte avait eacore excepte de la mesure de suppression lcs feuilles qui soccupaiout exclusivement de sciences, arts, litterature, commere, andonces, etc.

2. Le Journal des Dehats et des Dicrets avait ete fondé en 17s9, pas quelques depites. il fut wehete, en 1799 , pour la somme de 20000 francs, par les deux frères Bertin, et, sous le titre de Journal des Debass el Lois di. pouvoir leyisiatif et des actes in gourernemem. parut en format in-to. 1: etait deja inprime. comme aujond'hu, rue des Prétres-Saint-Germainl'Anxerrois. Le récime nupoléonien, en supprimant beancoup de ses coneurrents, lai fut dahord favorable. Il avait 12000 abonnes. chifre énorme pour lèjoque, et fulsat $: 0000$ francs de bénéfices annuels. 11 arait des tendarees classi pues. myla istes. catholiques, hustiles à la Revolution et a la phlobophie du xvío swele. Il louat surtout Bonaparte davoir releve les antels. Il ralliait done autour de lui plusleurs categories de eonservateurs u de mécontents. Il eut pour ennemi implacable le ministre de la police. Fonche, qui se croynit un adepte de la philosopie voluirienne.

Avec Geotroy, avee Étienne, le Journal des Débats inaugura dés lórs les fecilletons de critıque littiraire et thedrale. 
journalistes, de ne laisser passer aucun article qui n'eût été soumis au ministre de la police; d'insérer lui-mème dans les journaux des nouvelles, plus souvent fausses que vraies; le leur imposer, sous le nom de directeurs, de véritables censeurs, payés par eux; de les obliger à servir des pensions à tel ou tel courtisan; de mettre la main sur une partie de leurs actions.

En février 1811, le Journal de l'Empire fut enlevé aux Bertin, qui se virent ainsi dépouillés de leur propriété: leurs créanciers, pas plus qu'eux-mèmes, ne reçurent d'indemnité. Roderer et le duc de Bassano perdirent de la même manière la propriété du Journal de Paris. "Considérant que les produits des journaux.... ne peuvent être considérés comme une propriété qu'en conséquence d'une concession expresse faite par Nous... ", l'Empereur se croyait tout permis à leur égrar.

Le décret si rigoureux de 1810 n'arait done pas mis fin a l'arbitraire. Napoléon trouvait les journaux toujours trop nombreux et trop indépendants. Il décida qưil n'y aurait plus qu'un seul journal par département, Paris excepté, et que ce journal unique serait publié sous l'autorité du préfet. Enfin, le $2 S$ décembre 1811, le Journul de l'Empire publia cette note : "A compter du 1"r octobre prochain, il ne paraitra plus à Paris que quatre journaux quotidiens s'occupant de nourelles politiques (il n'osait pas dire : de politique), saroir: le .Honiteur, le Journal de l'Empire, la Gazette de France et le Journal de Paris. "Un moment, l'Empereur songea à n’en laisser subsister qu'un seul : le Moniteur. Quant aux journax de province, ils ne furent plus que des feuilles d'affiches, d'annonces et d'avis divers.

La presse française, méprisée du public, n'existait plus que de nom ${ }^{1}$ : personne en France ne sarait la vérité sur ce qui se passait en Europe. La presse des pays étrangers, lorsqu'ils étaient occupés par Napoléon, était sounise a un récime de terreur : en 1803, il arail lait fusiller le libiaire allemand Palm. Les journaux de Brène, de Hambourg, des petits Etats d'Allemagne, reçurent des avertissements me- 
naçants, et beaucoup furent supprimés. Pour trouver une presse libre, il fallait aller dans le seul pays qui bravàt encore la puissance impériale, dans un pays qui était l'ennemi mortel du nòtre, c'est-à-dire en Angleterre.

Aussi, à la chute de l'Empereur, la presse releva la tête, et le Journal des Débats, ayant repris son ancien nom, écrivit: "Il est temps de faire connaitre que Buonaparte ne s'appelle pas Napoléon, mais Nicolas : cet homme roulait paraître extraordinaire en tout, et jusqu'en son nom!"

Les livres n'avaient pas été mieux traités que les journaux : comme ceux-ci, ils étaient soumis à la censure et ne paraissaient qu'avec les suppressions qu'elle exigeait des auteurs. Encore la censure ne les garantissait pas des poursuites: le censeur Esménard, ayant examiné à Ia loupe l'ouvrage de Mme de Staël sur l'Allemagne, avait donné le permis d’impriner; l'ourrage était déja tiré à dix mille exemplaires quand lédition fut saisie par le ministre de la police et envoyée au pilon : l'auteur recut l'ordre de sortir de France.

Lit pourtant l'article 64 de la Constitution de l'an XII arait institué une commission sénatoriale de sept nuentbres, chargee de veller à la liberté de la presse. Il est vai qu'il ajoutait : "Ne sont point compris dans son attribution les ouvrages qui sompriment et se distribuent par abonnement à des époques périodiques o. Cétait excepter tous les journaux.

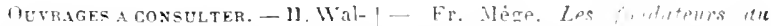
Ion. II ctorice du bibunal révolutionnuive Inst-k. - Campardon, meme titre (1,os). - G. Lenótre. Le tribuanl rivolut. 1908 - Challiamel. Hist. de la liburtien Frumedepicis

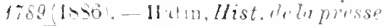
en France 15.0-61. - II. Avent.

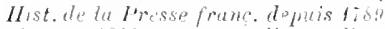
lispos. 1900 - Marellun Pellet. Elysire tonstulut on les lierolutions te Peris I- -2 et Les Actes des tpotres 11272 - L. Grthois. Hist. des jombure de lin lierolmtion. Ch. Brunet, Lel lem linchesne 185.

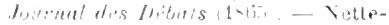
munt, Hist. du duminal des Dibats

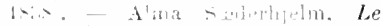

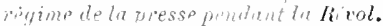
(tiv). - Ghamplientr. Hist de la

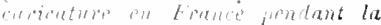

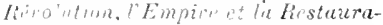
hon 1-íl. - Grand-Carteret, Les

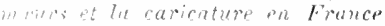
In. - 1'. Porllet, Les institutions

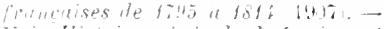

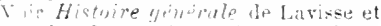
Ratabind, t. V111, p. 115 et suiv.
} 


\section{CHAPITRE IV}

\section{L'ADMINISTRATION DEPARTEMENTALE ET COMMUNALE}

Problèmes que soulève cette adminisántion. - Lne bonne organisation départementale et communale doit d'abord résoudre un double problème : 10 assurer aux départements et aux eommunes une certaine autonomie, et cependant réserver le droit supérieur de l'État français: autrement il n'y a plus d'unité nationale, mais une simple collection de provinces et de villes comme au temps de la féodalité ou de la Ligue; $2^{\circ}$ dans chaque départenuent, dans chaque commune, assurer aux citovens un droit de contròle et míme de participation dans la gestion de leurs intérèts, et cependant y constituer une autorité assez forte pour y faire exécuter les lois de l'État et les décisions des conseils locaux. Tel est le double problime auquel les divers gouiernements issus de 1789 ont eu à donner une solution.

système de la Constituante : 10 Bepartements et dis. tritu. - Notre première Assemblée nationale trouva, fonctionnant a côté des intendunts, soit les anciens Etats provincinur, soit les Assembles provinciales instituées par l'édit de 178\%. Dans les villes, elle trouva les dernières libertés commmales anćanties par l'édit fiscal de $17 \%$ et la cité admini-trée par des agents qui avaient achete leur office. Dans les villages, elle trouva soit le conseil municipal créé par l'édit de 178\%, soit l'ancienne assemblée prroissiule, l'un et liaulre en possession délire les olticiers municipaux, mas gralement soumis a l'arbitraire des intendants.

Par la loi de 1789 , l'Assemile divisa la France en 
départements et les départements en districts, cantons et communcs. Les districts et les cantons d'alors étaient beaucoup plus nombreux que les arrondissements et les cantons d'aujourd'hui 1 .

Au chef-lieu de chaque département fut instituée une administration de dépurtement; au chel-lieu de chaque district, une administrution de district.

Ladministration de département se composait de trente-six membres: sur ces trente-six, huit formaient le directoire de diurtement, les autres le conseil genéral de departement.

Ladministration de district se composait de douze membres : sur ces douze, quatre formaient le directoire de district, les autres le eonseil géméral de district.

Le président du directoire de département ou de district était en même temps président du conseil yénéral, c'està-dire de toute ladministration.

Les directoires étaient en fonetions toute l'année; les conseils généraux se réunissaient une fois par an.

Un procureur-géneral-syndic était attaché au départe. ment et un procureur-syndic au district: ils avaient mission de requérir l'application de la loi el de provoquer les actes politiques ou administratifs des autorités.

Tous ces membres des administrations étaient élus par les seuls électeurs du second degré.

Ils étaient renouvelables par moitié tous les deux ans, sauf les procureurs, qui étaient nommés pour quatre ans et rééligibles seulement après quatre autres années.

Le gouvernement n'avait pas le droit de les réroquer.

Les atributions des administrations de département étaient de deux sortes : 1o sous l'autorité du pouvoir législatil, elles étaient chargées de l'assiette, de la répartition, de la perception de l'impòt et du payement des dépenses; 2o sous l'autorité du roi, elles étaient chargées de l'assistance publique, des encouragements à l'agriculture, à i industrie, au commerce, de la gestion des forets, de la 
viabilité et des travaux publics, de l'organisation et de l'emploi des milices et gardes nationales, ctc.

On voit que les administrations de département et de district correspondaient à nos conseils généraux et d'arrondissement; mais : $1^{\circ}$ rien ne correspondait à nos préfets ct sous-préfets; ce sont les directoires de département et de distriet qui en tenaicnt la place: l'Assemblée nationale avait concu une telle méfiance contre les intendxnts et les subdélégués qu'elle les supprima, sans les remplacer; $2^{\circ}$ les directoires étaient chargés de centraliser limpòt, d'abord à la caisse de district, puis à celle de département, oftice aujourd'hui confié à des receveurs spéciaux; $3^{\text {n }}$ les directoires de département étaient chargés d’organiser la garde nationale; plus tard, ils seront chargés de lorganisation des volontaires et de la levée des conscrits.

2. Inniripalités. - Par les lois de 1789 1, la Constituante supprima dans les municipalités tous les anciens noms et anciens privilèges de personnes ou de corporations. Elle décida que les cités, bourgs, villes ou villages de France, sans aucune des distinctions d'autrefois, formeraient des communes ou mumiripulités. A la tête de chaque nunicipalité, il y aurait: $1^{\circ}$ un maire; $2^{\circ}$ un corps manicipal, composé de trois membres dans les plus petites communes et de vingt et un daus les plus grandes (Paris restail a part) ; $3^{n}$ un conseil général de la commune, composé à la fois les membres du corps municipal et de notubles ${ }^{2}$ en nombre louble de celui de ces membres; $4^{\circ}$ un procureur de li commune, assisté dans les grandes villes d'un substitut lu procureur; $0^{\circ}$ un secréluire yreffer: $6^{\circ}$ dans les localités les plus importantes, un trésorier.

Le mare était chargí seul du pouvoir exécutif dans les municipalités où le corps municipal ne se composait que de trois membres; dans les autres, il partageait ee pouvoir avec un buren où entrait le tiers du corps municipal.

Le corps mmicipal assistait le maire dans son administration quotidienne et s'assemblait au moins une fois par

1. Lni du 1'́t el loi du 2 ? decemlire 179

2. IIs correopondent aur habitants les plus imposes que la lui de 1831 edioiguait. dan- certains cas, a nos conseils manicipaur. 
mois; il veillait à la répartition et à la perception de l'impôt et à l'exécution des travaux d'utilité publique.

Le conseil général de la communc était conroqué pour toutes les affaires importantes : acquisitions et aliénations d'inmeubles, impositions extraordinaires, emprunts, tra vaux à entreprendre, etc.

Le promureur de la commune avait à peu près les mèmes attributions que ceux de département et de district.

Le maire, le corps municipal, le conseil général, le pro. cureur, son substitut, étaient élus par tous les citoyens actifs : ils levaient donc avoir un esprit plus démocratique que les administrations le département ou de district.

La durée le leur mandat était de deux ans.

Le burcan était nommé, pour un an. par le corps muni. cipal. Le greffer et le trésorier étaient nommés par le conseil général de la commune.

Parmi les attributions conférúes aux municipalités, on distinguait comme aujourd hui : $1^{\circ}$ celles qui sont propres au pouvoir municipal; 20 relles qui lui sont déléguées par l'Élat, comme la répartition et la perception de l'impòt, le recrutement militaire, ete.

C'était à peu près l'organisation municipale d'aujourd'hui, avec ces différences : lo le maire n'avait pas d'adjoints dins les petites communes, et, dans les plus grandes, c'était le berean qui lui en tenait lieu; $2^{\circ}$ il $y$ avait, pour ainsi dire, deux conseils municipaux; $3^{\circ}$ le pouroir municipal était chargés non seulement de répartir limpòt entre les habitants de la commune. ce qu'il fait encore aujourd'hui, mais de le percevoir et de verser les sommes percues à la caise th district, office aujourd'hui confié à des percepteurs; $\dot{t}^{0}$ la municipalité pouvait requérir la garde nationale et les autres forces publiques; כo elle ne pouvait ètre dissoute; $6^{\circ}$ elle était subordonnée aux administra. tions de district et de département.

Ineonvénieñs de ee système. - Ainsi l'État confiait les deux services qui intéressent le plus la défense nationale, c'est-d-dire la perception de l'impòt et le recrutement de l'armée, ì des autorités locales, celles du département, du district, de la municipalité, autorités entièrement indé. pendintis du golwernement central, que celui-ci n'avait 
pas nommées et qưil navait pas le droit de discoudre ou de révoquer.

Les autorités loeales eurent une tendance marquée à agir comme des pouvoirs indépendants; toutes les administrations s'arrogeaient le droit d'opposer des remontrances aux ordres du gouvernement, à l'instar des anciens Parlements, d'en modifier les dispositions et d'en suspendre l'exécution.

De plus, si ces administrations n'avaient pas les mémes idies politiques que le gouvernement, ellos ne pouvaient manquer de lout entraver. C'esi ce qui arriva. Quand le gouvernement devint républicain, les administrations étaient encore monarchistes; quand il devint jacobin, elles étaient encore girondines. Beaucoup ne tenaient aucun compte des ordres venus de Paris.

On avait voulu hter au gouvernement toute action sur les administrations, et il n'en avait aucune. Les levées d'hommes ne se faisaient pas régulièrement; l'impôt n’arrivait plus au 'rrésor; les lois, par exemple les lois sur la vente des biens nationaux, ne s'exécutaient pas. L'Assemblée Constituante avait voulu, en supprimant les intendants et subdélégués, garantir l’indépendance des administrations élues, mais elle n'avait pas pris soin de garantir le droit supérieur de l'État. Eile avait voulu fonder la liberté : elle ne créa que l’anarchie.

Syctème de 1933. - L'anarchie amena, a son tour, le despotisme. La Convention, qui arait l'invasion étrangère ̀̀ repousser et les rébellions intérieures à dompter, entendit être obéie à tout prix. La loi ne lui permettait pas de révoquer les administrateurs négligents ou hostiles: elle les fit guillotiner. Le régime de la Terreur s'explique en grande partie par l'impossibilité où la Constituante avait mis les futurs gouvernements de se laire obéir par les moyens legaux. Tandis qu'aujourd hui une administration régulière assure la levée de l'impòt et le recrutement de l'armée, la Convention ne put obtenir ce rés.ultat que par les moyens révolutionnaires. Le 21 mars 1793, elle établit dans chaque conımune un comité de surveillance, formé des républicains les plus ardents, et qui devint ensuite le comité révolutionnaire. Partout il se lorma des sociétés 
ropulaires, des clubs de Jacolins, affiliés a vec le club des Jacobins de Paris, et qui se donnèrent pour tâche de surveiller et de dénoncer sans reliche les administrateurs.

Pourtant la Convention restait dans les mêmes idees de décentrilisation que la Constituante; elle ne songea pas à rétablir un pouvoir analogue a celui des intendants; elle se borna à sévir contre les individus sans toucher à l'autonomie municipale ou départementale. Elle n'abrogea pas les lois de 1789. Par la loi du 4 décombre 1793, elle courut au plus pressé. Elle supprima les procureurs de commune et de district, qui ne servaient à rien, et les remplaẹ par des agents nationaux de commune et de district. Ceux-c1 eurent pour mission spéciale " de requérir et de poursuivre l'exécution des lois, ainsi que de lénoncer les négligntees apportées dans cette exécution ". Ils purent, mais nar une mesure qualifiée de provisoire, ètre nommés et réroqués par la Convention. Celle-ci supprima aussi les consoils généranx de département, ainsi que les procureurs-généranxsyndics; elle ne laissa subsister que les directoires; charjue membre en aurait la présidence à tour de rôle. Par lá, clle rendit la responsabilité plus efficace en la faisant porter sur un plus petit nombre de tètes.

Enfin, au-dessus des agents nationaux, comme autrefois les intendants étaient au-dessus des subdélégués, on vit apparaitre, dans les départements les plus récalcitrants, des reprisentants en mission, qui disposèrent de l'ermée. révolutionnatire, du tribunal révolutionneire et de la guiliotine. La Constituante avait poussé ì l'excès la décentralisation: la Convention refit un moment la centralisation par la Terreur.

Toutes ces mesures ont un caractère provisoire, car la loi du 4 décembre est précisément celle qui organise le gouvernement récolutionnaire; or il ne devait durer que jusqu'a la paix générale. Avec la dictature du Comité de Salut public, le pouvoir des représentants en mission, l'action des agents nationaux, on espérait, sans toucher aux principes mèmes de l'organisation administrative, obtenir assez de docilité chez les autorités locales prour assurer la défense du territoire et l'obéissance aux lois.

Système de Man nir. - La Constitution de l'an III sup- 
prima les administrations de districts et les districts euxmèmes. L'administration du département resta composée uniquement d'un directoire départemental: il était formé de cinq membres, tout comme le Directoire national. Comme celui-ci, il était renouvelable, par cinquième, tous les ans.

Toute commune d'au moins 5000 àmes conservait sa municipalité propre, composée de cinq à neur officiers municipanx. Toute commune dont la population excidait 100000 âmes était divisée ell municipalités de 30000 à 50000 àmes. En revanche, les communes dont la population était inférieure à כo00 àmes étaient groupées pour former une municipalite de canton.

La Constitution, pour atténuer l'inégalité entre les communes, divisait donc les grandes, groupait les petites, mainterait les moyennes. Le nombre de toutes les municipalites de France se trouva réduit d'environ $\$ 1000 \mathrm{com}$ munes a environ 5000 .

Toute commune faisant partie d'une de ces municipalités collectives élisait au moins un agent municipal et un adjoint: c'était la réunion de ces agents municipaux qui formait la municipalité de canton, sous la présidence de l'un d'eux.

La création des municipalités de canton n’était pas une innovition lnuphse : si petite que soit une commune, elle a intirit à ce que ses fonctionnaires municipaux habitent sur place, afin de résoudre immédiatentent les dil'iicultés; sil faut aller chercher la municipalité hors du village, les choses trainent en longuenr; enfin, les affaires de ces petiles communes sont des aliaires de famille, ou l'on naine pas á mèler des étrangers.

Il n'y eut plus de maires nulle part, mais senlement des officiers ou des agents municipaux.

Notons une tendance nouvelle à subordomer un peu plus les administrations locales au pouvoir central. Les membres des directoires de dipartement et des municipalités peuvent ètre suspendus ou destitués par le gouvernement. Auprès de chaque administration départementale ou municipale, il y a un commissaive, nommé et réroqué par lni, et qui "surveille et requiertlexécution des lois"; 
seulement le commissaire doit ètre choisi parmi les citoyens domiciliés depuis un an dans le pays. Il est formellement interdit aux autorités locales de modifier les actes du gouvernement, d'en suspendre l'exécution, de s'immiscer dans les affaires étrangères à leurs attributions.

La Constitution de l'an III maintenait la nomination des municipalités aux électeurs prinaires, et celle des direc. toires départementaux aux électeurs du second degré.

Système du Consulat et de I'Empire. - La loi dc pluviòse an IIII I supprima les municipalités de canton, rétablit les anciennes communes, divisa le département, non plus en districts, mais en arrondissements. Partant de cet axiome, posé par Sieyes, "arrir est le fait d'un seul, délibérer est le fait de plusieurs", elle établit à chaque degré un fonctionnaire exécutif et une assemblée délitérunte. En conséquence, dans chaque département il y eut un préfé et un conseil général; dans chaque arrondissement, un sous-prifet et un conseil darrondissement; dans chaque commune, un mire, assisté l'un ou plusieurs adjoints, et un conseil municipul. Le préfet et le sous-préfet étaient uniquement les agents du gouvernement; le maire était à la fois le pouvoir exécutif de la commune et l'agent llu pou. voir exécutif central.

En outre, le prélet était assisté d'un conseil de préfecture, clıaré de la justice administrative : on appelait de ses décisions au Conseil d'État. Ainsi les trihunaux arministratifs, que la Constituante avait formellement abolis, se trouvaient restaurés.

Lagent national de 1793 et le commissaire de l'an III devaient ètre pris parmi les citoyens domiciliés dans le pays; au contraire, le préfet et le sous-préfet de l'an VII sont étrangers au pays qu'ils administrent; nommés et révoqués par le gouvernement, ils peuvent être aussi transférés d'un bout à l'autre de la France.

L'agent nutional et le commissuire se bornaient à requérir et à surveiller l'exécution des lois. Le préfet, le souspréfet, le maire de l'an VIII, exécutent les lois. Ils sont essentiellement des agents d'exécution.

1. Loi du 29 pluviuse an VIII - 17 février 1 vion. 
Les préfets, agents supérieurs du gouvernement central, ont li haute main sur les municipalités. Dans les communes de moins de 5000 àmes, ils peurent suspendre les maires, les adjoints, les conseillers municipaux; dans les autres communes, ce droit est réservé au Premier consul. La tuteile administrative qu'avait excrcée sur les communes lïntendant de l'ancien régime reparait; les communes sont des mineures, et le préfet est leur tuteur. Elles ne peuvent vendre, acheter, agir en justice, sans son autorisation.

Le conseil général répartit l'impôt entre les arrondissements, le conseil l'arrondissement entre les communes, le conseil municipal entre les particuliers; mais les conseils municipaux, généraux et d’arrondissement sont débarrassés du soin de percevoir l'impôt. Is n’ont plus à faire le recrutement; les communes ont seulement lobligation de dresser annuellement la liste des conscrits. Tous ces corps doivent se renfermer dans des attributions purement administratives et ne jamais soccuper de politique.

Dans le mode de nomination, il n'y eut d'abord aucune différence entre les maires et les conseillers municipaux, entre les sous-préfets et les conseillers d'arrondissement, entre les préfets et les conseillers généraux. Tous, en vertu de la Constitution de l'an Vli, sont écalement nommés par le pouvoir. A la vérité, ils sont nommés soit sur la liste de notabilité communale, soit sur la liste de notabilité lépartementale; mais ou sait quelle latitude ces listes laissaient au choix tu pouroir.

A partir du sénatus-consulte de l'an $\boldsymbol{X}$, les listes disparaissent. Les conseillers municipaux, dans les communes au-dessous de 5000 àmes, sont nommés par l'assemblée de canton, sur une liste des cent plus imposes. Dans les communes de population supérieure, ils sont nommés par le Premier consul ou l'Empereur, sur une liste de deux noms pour un, présentée par l'assemblée de canton. Les conseillers d'arroudissement et les conseillers généraux sont nommés par lui sur une présentation semblable, soit du college darrondissement, soit du college de département. Les maires et aljoints, comme agents du pouvoir 
exécutif, restèrent toujours à sa nomination, aussi bien que les prélets et sous-préfets.

Mème sous l'ancien régime, jamais le pouvoir central "I avait exercé une telle autorité sur les affaires locales. ses préfets étaient au moins aussi absolus que les intendants d'autrefois. Les conseils de département et d'arrondissement devaient moins à l'élection que les anciens Etats provinciaux, et beaucoup moins que les Assemblées provinciales de l'édit de 1787. Autrefois les officiers municipaux qui avaient acheté leurs offices à Louis XIV ou Louis $\mathrm{XV}$ en étaient propriétaires, et, jusqu’à un certain point, restaient indépendants du pouvoir : maintenant ils sont nommés par lui et entièrement à sa discrétion.

Lorganisation de lan VIII est exactement la contrepartie de l'organisation de 1789. Si les lois de la Constituante avaient méconnu les droits de l'autorité, celles du Consulat et de l'Empire ne tenaient aucun compte des droits de la liberté. Celles-là avaient conduit à l'anarchie; celles-ci organisaient larbitraire. Les citoyens n'avaient nlus aucune action sur ladministration de leur village, d. leur ville, de leur département: les intérèts qui les wuchaient de plus près dépendaient du bon plaisir du préfet, agent docile du pouvoir, et dont les maires et les conseils n'ètaient que les dociles subordonnés.

Pour rentorcer encore l'action administrative, dans toute ville au-dessus de 5000 àmes, on instille un commissure de police, agent direct du ministre de la poiice. Paris est divisé en douze muniripalites ou arrondissements, danschacun desqueis il y a un maire et des adjoints, plus un commissaire de police. Les douze mairies sont subordonnées aa préfei de lie Stine, et les donze commissaires de police sont placés sous les ordres du prefet de police. Ces deux ioncionnaires ont succédé au préiót des marchands et au lieutenant de police de l'ancien régime. Les douze arrondissements de Paris nont mène pas de conseils municipaux : c'est le conseil général de la Seine qui en tient la place. Paris revenait done au régime exceptionnel sous lequel l'avait maintenu lancienne royaté.

On peut dire quaucun des gouvernements de la période révolutionnaive et napoléonienne n’a résolu le problème de 
l'arministration locale : les uns ont péché par excés de décentralisation, les autres par.abus de centralisation.

L'assistance publique. - La Commune de Paris, même dans sa période hébertiste, a racheté une partie de ses violences par le zèle avec lequel elle se consacra à l'assis. tance des malheureux, à la réforme des hospices et des hòpitaux. Le service de santé fut perfectionné. Nous verrons les services rendus par le médecin piNel aux aliénés. L'abbé sicard, qui faillit périr dans les massacres de septembre, fut le digne élève et le continuateur de l'abbé de l'Épée : il trouva moyen d'enseigner aux sourús-muets le catéchisme, la grammaire et les éléments des sciences. vaLintin Haüy (1740̈-1822) fonda à Paris, en 1806, un établissenent où il instruisait les jeunes aveugles au moyen de signes en relief, perceptibles au simple toucher ${ }^{1}$.

La Convention, malgré d'excellentes intentions, avait failli tarir les ressources de l'assistance publique : confiante a lexcès dans sa création d'une Caisse de prévoyance et d'un Grand-Livre de la Bienfuismce, qui devaient ètre la:grenent dotés par le budget, elle avait autorisé, en juillet 1794, la vente des biens des hospices. Elle tut obligie d'y surseoir, treize mois apris, car la pénurie du budget avail laissé vide la nouvelle caisse. Napoléon rendit aux hospices tous leurs biens qui n'avaient pas été vendus et leur assura une allocation sur le budget.

Olvages a consurter. - Fauslin Hẻlit. Le's Constitutions de la Frarce. - Mantice Blowk, Dictrommire de l'administrution / rancaise (aveesupplenents. - A.llesse, Ludm, provinciale et communale en France et en Europe, 1785-1870 (1571). - Girardot, Les administrations électives ef collectives 1537 . - Dupnni- Whil., is liberte politique considerse dans

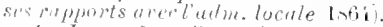

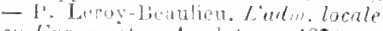

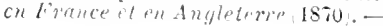

M. Block, Le's communes thit liberl,

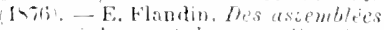

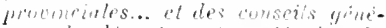
rand des dipurtements. Hasimedu

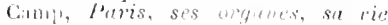

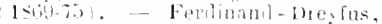

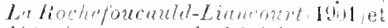

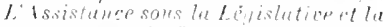

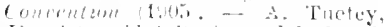

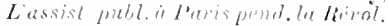
laty? - I. de linman de Laborie. luars sous Vipolion en cuur, t. I et $\mathrm{V}$. 
CHAPITRE Y

LES TRIBUNAUX ET LES LOIS

\section{Les tribunaux.}

Oranisation des tribunaux par la Constituante. Lorsque la Constituante s'occupa de la réforme judiciaire, elle supprima les innombrables juridictions royales, seigneuriales, ecclésiastiques, municipales, qui maintenaient dans notre pays la confusion et le chaos. Pour la première fois, on vit les tribunaux établis sur un plan rationnel '.

Pour la justice civile, dans chaque canton, l'Assemblée institua un juge de paix; dans chaque district, un tribunal de premiere instance.

Le juge de paix avait une double mission : d'abord il jugeait toutes les causes, sans appel, jusqu'à la valeur de cinquante livres, et, à charge d'appel, jusqu'à la valeur de cent livres. En outre, aucune cause plus importante ne pouvait être portée devant le tribunal de première instance avant que les plaideurs eussent été cités à comparaitre devant le juge de paix, assisté de six citoyens, formant son bureau de paix, afin qu'il essayât de coneilier leurs prétentions et de prévenir le procès. C'est surtout à raison de cette mission de eonciliation qu'on l'appela juge de paix. Par là beaucoup de conflits pouvaient ètre étouffés dans leur germe, au grand avantage des plaideurs. Cette juridiction toute paternelle, peu coùteuse, simple dans sa

1. Ce plan se dessine dans la loi du 30 avril 1790, la loi du 16 aout 1790 , 1. Constitulion de 1791 et la loi du 16 septembre 1791.

R. Civil. CoNtemp. 
procédure, a été críée tout exprès pour le paysan et l'ou. zrier, ruinés autrefois par ia multiplicité des tribunaux et la rapacité des gens de loi.

La Constiluante établit aussi, pour les contestations entre mari et femme, entre parents et enfants, entre membres de la mème fanille, ce qu'on appelait des arbitres de farnille. Ce tribunal domestique se composait uniquement de parents, d’amis, de voisins, choisis en nombre égal par les deux parties. Ce n'était pas un tribunal au sens propre du mot : il était précisément destiné à empècher que certains débats ne fussent portés devant les tribunaux.

Par la justice de paix, par le bureau de paix, par les arbitres de famille, par les juges de commerce, on roit que le but de la Constituante était de réduire le plus possible la juridiction des tribunaux proprement dits.

Les causes que ni les arbitres ni le juge de paix n'avaient pu concilier et celles qui dépassaient la compétence de celui-ci étaient portées devant le tribunal du district, composé en général de cinq juges, sous la présidence de l'un d'eux, car il n'y avait pas de président en titre. Ils jugeaient sans appel jusqu'à mille livres.

Au-dessus de mille livres, quand un des plaideurs n'était pas satisfait du jugement, la cause était portée en appel. Seulement, il n'y avait pas alors. comme aujourd hui, de cours d'appel : c'étaient les tribunaux de district qui en tenaient lieu les uns à l'égard des autres, d'après un système assez curieux. Pour les appels de chaque tribunal de district, on dressait une liste de sept autres tribunaux, choisis parmi les plus roisins. Sur ces sept, chacun des deux plaideurs avait le droit d'en récuser trois : restait le septième, qui devenait alors trilunal d'aprel.

Cette organisation avait un défaut. Quand des plaideurs font appel d'un jugement, c'est qu'ils espèrent comparaitre devant des magistrats d'une capacité réputée supérieure. Or, en 1790, on les renvoyait d'un tribunal de district à un autre tribunal de district, qui n'olfrait apparemment pas plus de garantic de savoir que le premier.

Pourquoi done la Constituante navait-elle pas voulu établir de réritables cours d’aprel? C’est que, frappée strtout de l'opposition que les Parlements avaielit faite aux 
réformes, elle ne voulut pas les rétablir sous un autre nom; elle craignit de voir les anciens parlementaires rejrendre leur siège et leur influence sous le nom de juges d'appel.

Pour la justice pénale, la Constituante distingua trois degrés : la justice de simple police punit les simples contraventions; la justice correctionnelle punit les délits; la justice criminalle punit les crimes. Les contruventions sont des transgressions aux lois et règlements de police et qui n'entachent pas l'honneur; les délits sont moins graves que les crimes, et les peines qui leur sont appliquées portent le nom de correctionnelles parce qu'on se propose moins de punir le délinquant que de le corriger, dans l'espérance qu'il s'amendera et reviendra au bien.

La justice de simple police ${ }^{1}$ fut attribuée aux autorités municipales ${ }^{2}$, devant lesquelles le procureur de la commune était chargé de poursuivre les contrevenants; la justice correctionnelle, au juge de paix, assisté de deux de ses collègues ou de deux assesseurs: la justice crininelle, au tribunal criminel de chaque département, qui siégeait une fois par mois.

Le tribunal criminel se composait d'un présilent, assisté de trois jugres pris dans les tribunaux de district; un accusateur public était chargé de soutenir l'accusation, et un commissaire du roi veillait à l'exacte observalion des lois.

Quand un citoyen était accusé d un crime, il était d'abord cité devant un jury d'uccusution, présidé par un jugge du tribunal de district appelé directeur du jury. Ce jury, composéau moins de huit citoyens, décidait s'il y avait lieu de mettre en jugrement l'accusé. S'il se prononçait en ce sens, l'accusé comparaissait devant le tribunal criminel, assisté d'un jury de jugement composé de douze citoyens. C'était ce jury qui prononçait sur le fait, c'est-à-dire qui décidait si laccusé était coupable ou non; les jugres du tribunal criminel n'avaient plus qu'à appliquer la loi en conséquence.

Tous les électeurs du second degré ponciient ètre jurés; mais le procureur-général-syudic du département, tous

1. Pour les délits pouvant entrainer de trois a huit jours de prison.

2. Ou plutèt à un tribunal de trois membres du corps aunicipa!, choisi. par leurs colleguex. 
les ans, dressait une liste de deux cents noms; sur ces deux cents noms, tous les mois, le président du trihunal civil tirait au sort douze jurés pour la session mensuelle.

Ce n'étaient donc plus des juges de profession, comme sous l'ancien régime, mais les citoyens eux-mêmes qui décidaient d'abord de la mise en accusation, puis de la culpabilité. L'introduction en France de cette magnifique institution du jury, dont les Anglais étaient déjà en possession depuis des siècles, fut due principalement à ADRras DUPORT.

En matière correctionnelle, les deux assesseurs qui assistaient le juge de paix formaient, en réalité, une sorte de jury correctionnel.

La Constituante avait même songé à établir le jury en matière civilc. Ce projet fut soutenu notamment par Charles Lameth, Røderer, Robespierre; il fut combattu par Regnier et Tronchet. On y renonça, vu la difliculte de distinguer, dans les causes civiles, le point de fuit du point de troit et de faire décider le point de droit par des citoyens étrangers aux études juriliques.

La Constituante avait supprimé tous les tribunaux administrutifs de lancien régime : les citovens qui ètaient en proces avec ladministration s'adressaient, suivant les cas, soit aux autorités municipales, de district, de département, soit aux tribunaux civils ordinaires.

lians les principales villes commercantes, il y eut un tritumal de commerce. Sa compitence reçut une grande cxlension.

Au sommet de toute cette organisation judiciaire, la Constituante plaçait le Tribunal de cussution. Celui-ci ne jugeait aucune affaire quant au fond, mais il cassait les jurements qui lui étaient délérés dans les deux cas suivants: si les formes de la procédure n'avaient pas été observées on si la loi n'avait pas été exactement appliquéc; i) renroyait alors les plaidenrs devant un autre tribunal. Quand deux fois pour la méme affaire il arait uś de son droit de cassation, il devait s'adresser au législateur pour lui demander dinterpréter la loi et cette interprétation s'imposait. A partir de $1800^{-}$, ce fut l'Einpereur, en Conseil d'Étrit, qui donna cette interprétation. 
En l'an II, fut créé le Bulletin des lois, qui assura l'exacte publication et constata la promulyation des acles législatifs.

La Constitution de l'an III apporta quelques molifications à l'œurre de la Constituante. La plus importante fut la suppression des tribunaux de district, que remplaęait un seul tribunal civil par département, siégeant au cheflieu, et composé de vingt juges.

Organisation des tribunaux par vapolcon. - Vapoléon, comme Premier consul ou comme Empereur, remania du fond en comble lorganisation judiciaire. Il fixa les principes sur lesquels elle repose encore aujourd'hui.

Dans chaque canton, il y eut un juge de paix, juge unique, qui avait des suppléunts, mais n'avait plus d'assesseurs; dans chaque arrondissement, un tribunal de premiere instance; enfin des tribunule d'appel. Bonnjarte ne craignit pas de les établir de prélérence dans les villes qui avaient autrelois possédé les Parlements. Au sommet de la hiérarchie, il maintint le Tribunal de cassation. Les tribunaux d'appel et le Tribunal de cassation reçurent de lui, en 180 , la déromination toute monarchique de Cour's'.

Pour la justice pínale, il attrilua la justice de simple police au juge de paix; la justice correctionnelle aux tribunaux de premiere instance; la justice crimine!le à un tribunal criminel qui, à partir de 180', s'appela la cour de iustice criminelle, et plus tard, la cour d'ussises. Ce tritunal était lormé, dans chaque département, frar trois maz-trats du tribunal d'appel dans le ressort duquel était situé le département.

Le jury d'uceusttion, d'abord maintenu, fut supprimé en 1908: son ròle lut attribué à une section de ia cour d'apret.

Xipoléon ne maintint que le jury de jugement, comnosé de douze ciloyens. Encore celui-ci lut-il en péril; l'Empereur lui était peu farorable. Dans les discussions du Conseil dEat, Bigot, Cambacérès, Portalis, cédant à cette influence, ne le defendirent que fablement : ce fut BERLIEA qui, lans un discours plein de force et de raison, le sauva.

1. Les Cours d'appel se sont appelíes aussi, suivant les époqies, Cours royales ou Cours imperiales. Les juges de la Cour de cassation et des Cours dapel prirent le titre de conseillers. 
On alla aux voix el la majorité du conseil se déclara pour le mantien du jury. Miot de Nélito raconte que l'Empereur, qui présidait, leva brusquement la séance. En l'an XIII, il suspendit le fonctionnement du jury lans le cas de haute trahison. En 1813, nous avons vu quil cassa un verdict du jury d'Anvers.

\section{Recrutement des magistrats : 10 Systène de la Con-} stituante : l'élection. - Sous l'ancien régime, les seigneurs justiciers étaient propriétaires du droit de rendre la justice : les juges du roi étaient dans le méme cas, puisqu'ils avaient acheté leurs charges.

La Constituante ayant aboli cette confusion de la justice et de la propriété, il s'agissait de savoir comment seraient recrutés les juges des nouveaux tribunaux. Il n'y avait que deux partis à prendre : ou bien les faire nommer par le roi, ou bien les faire élire par les citoyens. La Constituante se décida pour le principe de l'élection. La justice fut rendue au nom du roi, mais il n'eut aucune action sur le personnel judiciaire.

Les juges de paix étaient élus par tous les citoyens actifs du canton, réunis en assemblée primaire.

Les juges des tribunaux de district étaient élus par les electeurs du second deyré, c'est-à-dire ceux qui élisaient les députés. Nul ne pouvait ètre élu s’il ne remplissait certaines comlitions, par exemple d'avoir été pendant cinq ans juge de paix, ou juise des anciens tribunaux, ou homme de loi exerçant publiquement auprès d'un tribunal.

Les juges de commerce étaient élus par les notables commereants.

Le president du tribunal criminel et l'accusateur public étaient lus par les électeurs du second deyré.

Seul le commissuire du roi était nommé par le roi.

Les juges du Tribunal de cassation étaient élus pour quatre ans, renourelables par moitié, et pouvaient ètre réélus. Tous les quatre ans, les électeurs de la moitié des départements de France étaient convoqués et nommaient, dans chaque département, un juge au Tribunal de cassation; a l'élection suivante, c'était le tour des quarantedeux autres départements.

Le principe de l'élection, posé par la Constituante, resta 
en vigueur sous la Législative, sous la Convention et sous le Directoire.

Avantages et inconvénients de l'élection. - Les électeurs firent assurément des choix excellents : beaucoup des hommes qui plus tard se distinguèrent dans la carrière juridique furent appelés aux fonctions de juges de paix ou de juges des tribunaux par les électeurs de $1790^{1}$.

Ce système, rive la Constituante avait adopté surtout par défaut de confiance envers le roi, présentait cependant des inconvénients. Pour que l'impartialité du jugge soit assurée, il faut qu'il ne soit pas dans la dépendance des justiciables : or, le juge de paix dépendait des électeurs du canton, le juge de première instance de ceux du district, le président du tribunal criminel de ceux du département. Il était bien difficile à ces magistrats de rester absolument impartiaux entre ceux qui avaient fait leur élection ct ceux qui l'avaient combattue. Le mal eut été moindre si le juge avait été élu à vie, c’est-à-dire s’il eût été inamovible; mais le juge de paix était rééligible au bout de deux ans, le juge de première instance au bout de six : comment n’auritent-ils pas été tentés de ménager les justiciables influents qui pouvaient assurer leur réélection? Les élections de juges n’étaient pas plus exemptes de passions, de brigues, dintrigues, de violences, que les élections de députés 2. Dans les départements royalistes, on élisait des juges d'opinion conservatrice; dans les départements jacobins, des juges d'opinion avancée; or, leurs adversaires politiques, quand mème la justice eût été impartialement rendue, croyaient avoir tout à craindre d'eux. On en revint bientôt à penser qu'un juge doit rester en dehor's et au-dessus des partis et que le pouvoir central,

1. Ainsi. aux élections parisiennes de novembre 1790 , les six présidents des six tribunaux de Paris sont: Frétenu, Thouret, Target, Dupont, Merlin de Douai, Treilhard, tous jurisconsu'tes distingues, et les deux derniers destinés à collaborer plus tard à la rédaction de notre Code civil. Parmi les juges, Lepelletier de Saint-Fargeau, ancien président au Parlement de Paris, Tronchet, plus tard le défenseur de Louis XVI. Dans la Dordogne, Malleville. Plus tard, en l'an V1Il, Bigot de Préameneu. Ces trois derniers devaient collaborer à la redaction du Code civil.

2. En 1793, les élections a Paris furent viciẻes par les intrigues des partians de Marat. En 1791, a Colmar, elles furent troublées par les royalistes. 
précisément parce qu'il est étranger aux coterıes locules, est mieux placé pour faire des cloix impartiaux.

Quant à ceux qui avaient voulu l'élection des juges dans l'espoir de créer une magistrature dévouée aux idées nouvelles, ils se trouvèrent déçus. Dis 1791, on signale le "mauvais esprit " des juges élus ${ }^{1}$. La Convention se vit contrainte, pour faire cesser cet etat de choses, d'ordonner" des élections nouvelles pour 1793, sans attendre le terme légal de 1796, et de renoncer aux garanties professionnelles exigées par la Constituante. Par une série de décrets, elle suspend des tribunaux, elle cite des juges à sa barre ${ }^{3}$. Par le décret du 25 février 1793, elle annule en masse tous les jugements rendus par les tribunaux sur des faits d'émigration et leur défend d'en connaitre à l'avenir. Par le décret du 10 mars, pour suppléer à la justice trop indulı̨ente des juges élus, elle crée le tribunal révolutionnaire. Elle se met à casser les juges - ce qui était illègit - et les nomme elle-même : d'un seul coup, en janvier 1793, clle nomme כ̆ juges de cassation, 73 présidents, juges ou suppléants des tribunaux de district.

La situation empira encore pendant la réaction thernidorienne, puis en 1796 et 1797 : beaucoup de juges, dans le Midi, pactisaient avec les chauffeurs et les brigands, sérissaient contre les républicains, les entassaient dans les prisons, les envoyaient à l'échafaud *

Ainsi l'élection des juges n'avait donné aucun des résul-

1. Presque partout, en 1792 , on les accuse de faire cause commune arec les émigrés el les prètres réfraclaires, deutraver la vente des biens nalionaux, d'exciter et encourager les émeutes, d'empiéter sur loules les autres autorités, d'ignorer les lois ou de les violer audacieusement, de prendre un espril de corps orgueilleux el tyrannique. "Ils sont prèts, s'éeriait Condorcel, en 179.2, á recréer, sous jes formes judiciaires, les lettres de cachet et les bastilles. De jures des citoyens, ils s'érigent en juges des pouvoirs publics, el, sous prêtexte de les juger, bientót ils sauraienc les dominer et les remplacer. "

2. Décrel du 13 oclobre 1792.

3. Dans les Ardennes, les Bouches-du-Rhòne. l'Eure, les Basses-Pyrénées, le Pas-de-Calais, les tribunaux poursuiraient et emprisonnaient les démocrates, aequittaient les fabricants de fausse monnaie et de faus assignals.

4. En l'an Vll, François de Neufcháteau, esprit très modéré, accusiit les tribunaus d'avoir ouvel une tombe immense. "Elle contient déjà, s'écriait-il, les ossemenis de trente mille républicains assassinés par les royalistes de l'intérieur. * 
tats qu'on en avait espérés, ni au point de vue l'une justice impartiale, ni au point de vue politique. La Constituante, par son organisation judiciaire comme par son organisation administrative, se trouvait avoir préparé à la fois la Terreur rouge et la Terreur blanche.

$\boldsymbol{2}^{\circ}$ Gystème napoléonien : la nomination par le pouvoir. - La Constitution de l'an VIII, pas plus pour les nominations de juges que pour celles le diputés, ne supprima le principe de l'élection : en fait, elle l'annula.

Le juge de paix continua bien à ètre nommé par les électeurs du canton et les jugres le commerce frar lus négociants; mais les jugres de première instance et cux d'appel furent nommés par le Prenier consul, plus tard par l'Empereur; les juges de cassation le furent par le Sénat: ceux-la sur lés listes de notabilité comnunale et départementale, ceux-ci sur la liste de notabilité nationale. Il en fut de même pour les proeureurs généráux auprès des tribunaux d'appel et de cassation, pour les procureurs auprès des tribunaux de prenière inslance, pour leurs substituts, etc. En oulre, les présidents et riceprésidents de tous les tribmnaux lurent désignés, frarmi les magistrats de ces tribunaux, par le chef de l'Etat, sauf les présidents du Tribunal de cassation, qui étaient élus par leurs collégues. Bientôt les juges de cassation furent nommés par le Sénat sur la présentation du Premier consul ou de l'Empereur : au fond, e'est le pouroir exécutif qui désormais les nomma.

Inamovibilité des nugisbrats. - Le nouveau régime, qui supprimait ou qui allait suppriner l'élection, devait aux justiciables une garantie de l'indépendance et de l’impartialité des magistrats. Cette garantie ne pouvait être que l'inumovitilité des juges. La Constitution de l'an VIII statua qu'ils conserveraient leurs fonctions à vie, à moins qu’il= ne fussent pas maintenus sur les listes de notabilité ou qu'ils fussent condamnés pour forfaiture. C'était l'inanovibilité, mais subordonnée a une condition qui dépendait du corps électoral.

Bonaparte ne se souciait pas de donner la véritable inamovibilité à des juges qui seraient les arkersaires de 
son pouvoir. Deux actes lui permirent, sans toucher a principe, de renouveler le personnel judiciaire.

La loi du $1 S$ mars $1 S 00$ déclarait supprimés tous les tribunaux créés par la Constitution de l'an III, et en installait d'autres à leur place : en conséquence Bonaparte put choisir les juges de ces nouveaux tribunaux.

Puis, le sénutus-consulte du 12 octobre 1807 déclara: $1^{\circ}$ qu'avant d'instituer les juges d'une façon irrévocable, il serait procédé à une épuration du personnel judiciaire; $2^{\circ}$ qu’a l'avenir l'inamovibilité ne serait conférée qu'après cinq annes d'exereice.

Quant aux juges de paix, ils furent nommés, dès 1802, par le chel du pouvoir exécutif, sur une présentation de deux noms par l'assemblée de canton, puis sans présentation. Ils n'eurent jamais l'inamovibilité, paree qu'ils étaient censés èlre toujours nommés sur présentation.

De cette façon, Napoléon créa un corps de magistrature absolument dévoué à sa cause : $1^{\circ}$ parce que le personnel avait subi plusieurs épurutions; $2^{\circ}$ parce qu'aueun des nouveaux juges n'avait obtenu l'inamovibilité sans avoir donné pendant cinq années des garanties de dévouement à la dynastie; $3^{\prime \prime}$ parce que les procureurs généraux et les premiers présidents des cours d'appel répondaient au gouvernement du bon esprit de leurs subordonnés.

Léorganisation dn miniatere public. - Le nouveau maitre le la France assura une répression plus énergique des erimes et délits et une discipline plus forte dans la magrstrature en réorganisant le ministère public.

La Constituante avait fait une distinction entre le ministère public, représenté par le commissaire du roi, et l'accusation, représentée par l'accusatcur public.

Niapolion réunit les deux services. C'est le ministère public qui fut chargé de l'accusation. Il comprenait auprès de chaque cour d'appel un procureur genéral; auprès de chaque tribunal de première instance, un procureur 1. Devant le tribunal de simple police, e'est-à-dire devant le juge de raix, c'était le commissaire de police ou le maire

1. Co procialur, impérial depuis 1904. s'est aussi appelé, suivant les régimes, procureur rojul ou procureur de la Republique, 
du chef-lien de canton qui faisait (et il le fait encore), l'office de ministère public.

Le procureur général est assisté d'un avocat général et de substituts; le procureur, de substituts. Le procureur est subordonné au procureur général.

Le ministère public s'appelle aussi le parquet : il y a le parquet du procureur général et le parquet du procureur. On l'appelle encore la magistrature detout, par opposition aux juges proprement dits, qui sont la majistrature assise, ordinairement inamovible.

Tandis que la Constituante avait décidé que l'accusateur public serait élu par les électeurs et que le commissaire du roi, quoique nommé par le roi, ne serait pas révocable, un autie principe prévalut avec Bonaparte: les magistrats du ministère public lurent non seulement nommés par le gouvernement, mais devinrent révocables par lui : étant considérés comme ses agents, ils l'urent placés dans sa dépendance.

Le procureur général est, dans le ressort de la cour d'appel, ce que le préfet est dans son département : le représentant le plus élevé du pouvoir central. C'est à lui que le gouvernement s'adresse pour avoir des renseignements sur tous les magistrats du ressort : c'est sur ses propositions, combinées avec celles du premier président de la cour, que se font les nominations dans la magistrature. Par la nouvelle organisation des parquets, Napoléon et tous les gouvernements qui lui ont succédé ont eu sur la direction des affaires judiciaires une action plus directe et plus efficace que ne l'avaient eue la monarchie absolue et surtout les premiers gouvernements de la Révolution '.

Les avocats et les officiers ministeriels. - La Constituante, lorsqu'elle abolit les corporations, avait compris dans la suppression celles des avocats, avoués, notaires, huissiers, commissaires-priseurs. "A cet ordre des avocats, dit M. Bardoux, asile de la science, de la probité, de l'indépendance et de l'honneur, avait succédé une tourbe de

1. Toute cette orcanisation de la magistrature impériale se trouve dans la Constitution de l'an VIll, les senatus-consultes de l'an $\mathrm{X}$ et de l'an XII, la loi du :- ventuse an Vill, le sematus-consulle du 12 octobre 1807 , et finalement dans une loi qui coordone tous ces acles, celle du 20 avril 1510. 
défenseurs officicux, qui, nés dans l'anarchie, profitaient de la désorganisation de la compagnie pour envalir; sans instruction et sans titre, lentrée de la justice. "Napolion rétablit lordre des avocats, exigea d'eux le diplòme do licencié en droit et l'inscription au tableau (1804). Il remit à leur tète le bitonnier, leur donna un conseil de discipline, les placa sous l'autorité du tribunal auprès duquel ils étaient élablis, les soumit à des lois rigoureuses (1810). Leur liberté lui déplut souvent'. "Ce sont des factieux, disait-il, des artisans le crimes et de trahisons...; je veux qu'on puisse couper la langue à uu avocat qui s'en sert contre le gouveruement. "Les avocats a la cour de cassation et les avocats au conseil d'État durent étre nommés par l'Empereur. Les avoués durent subir un examen de droit et faire un stage de cing ans. Le nombre des notuires et les limites de leurs circonscriptions respectives furent déterminés par le gouvernement : ils durent justifier de certaines conditions d'ige, de nationalité, de stage, produire un certificat de moralité et le caj)acité, fournir un cautionnement, prèter un serment. Ils furent soumis, dans chaque ressort de tribunal, à une chambre de discipline. Avoués, notaires, huissiers, commissaires-priseurs, devinrent des officiers ministeriels: ils purent rendre leur charge, ınais à la condition que leur successcur serait agres par le garde des sceaux, ministre de la justice.

\section{Les lois.}

La Révolution : 1 Léggislation civile. - La Révolution a modifié la législation comme lorganisation des tribunaux. D’innombrables lois, édictées par la Constituante, la Législative, la Convention, les Conseils du Directoire, ont créé un nouvel ordre de choses. Les actes de l'état civil, sécularisés par la Constituante, ont été organisés par la Légilative 2 . L’égalité de partage a été établie entre les enfants ${ }^{3}$ et, a leur délaut, entre les lrériliers du même

1. En 1S01, sur 200 avocats inscrits au barreau de Paris, 3 seulement rotèrent pour l'établissemeat de l'Empire.

2. Décret du 20 septembie 1792.

3. Decret de la Constituante du S avril 1:31. 
degré. Les droits ${ }^{1}$ d'aînesse et de masculinité, les majorats, substitutions, fidéicommis, le retrait lignager conıme le retrait féodal, les renonciations imposées aux filles par contrat de mariage, ont pris fin. On a limité le droit de tester, afin d'assurer l'égalité de parlage, et pour empècher qu'il ne servit, au détriment des enfants et des lıéritiers légitimes, à reconstituer les grandes fortunes nobiliaires ou les grands domaines ecclésiastiques. Le mariage a cessé d'ètre uniquement un sacrement pour devenir aussi un contrat civil. Il n'a plus été indissoluble : on a admis le divorce. Les époux ont obtenu plus de facilitis pour se faire des avantriges mutuels. Les eitogens sans enfants ont pu en acquérir, gràce à l'adoption ${ }^{2}$. La puissance paternelle s'est adoucie : la majorité a été lixée à vingt et un ans, et on a permis aux enfants, parrenus à l'àge de vingt-cinq ans et moyennant certaines formalités respectueuses, qui suppléent au consentement des parents, de se marier librement.

La terre a été affranchie des servitudes féodiles ou domaniales.

Sur certains points, les assemblées qui succéderent à la Constituante ont dépassé la mesure. Dans son désir de favoriser la "liberté naturelle ", la Convention a par trup affaibli la puissance paternelle et relàché les liens de la famille. Elle a, par exemple, supprimé le droit des parents à hériter de leurs enfants quand ceux-ci laissaient des frères ou des sœurs, des nerewx ou nièces. Elle est allée jusqu’à supprimer presque entièrement la faculté de disposer de ses biens par testament ou par donations entre vifs ${ }^{3}$. Elle a permis aux tils, dès l'àge de quinze ans, aux filles, dès l'ige de treize ans, de se marier avec le consentement du père, en se passant de celui de la mère. Enfin elle a aboli toute distinction entre les enfants légitimes et les enfants naturels ": ces derniers pouvaient

1. Voyez notre Histoire de la civilisation française, t. II, parges 145 et suivantes.

8. La Cenventien donna elle-mème l'exemple en adoplant la fille de Lepelletier de Saint-Fargeau, assassiné par un royuliste, puss les sis enfanto de Richer, etc.

3. Décrel du 7 mars 1793.

4. Décrel du 12 brumaire an II (2 novembro 1795). 
succéder non seulement à ieurs parents naturels, mais aux parents de ceux-ci.

La Législative eut le tort, en maintenant le divorce, d'interdire ${ }^{1}$ la séparation de corps, le seul mode de dissolution du mariage qu'acceptassent les catholiques. Elle donna des facilités abusives pour le divorce ${ }^{2}$ : quand les époux étaient daccord, après une simple formalité de comparution devant une réunion de six parents ou amis et après un délai d'un mois (de deux mois, s’il y a des enfants), ils obtenaient le divorce par-devant l'officier de l'état civil. La Convention alla plus loin : elle accordait à l'homme divorcé la faculté de se remarier immédiatement, à la femme divorcée le droit de se remarier, quel que fût le motif du divorce, dans un délai de dix mois ${ }^{3}$.

Une innovation très utile date du Directoire: c'est la création du système des hypothéques , qui permet au propriétaire loncier d'emprunter en laissant prendre sur son bien, pour garantie, une hypothèque.

a Lécislation pénale. - La Constituante mit fin à une procélure criminelle qui rappelait celle de linquisition. Elle entendit que l'accusé fût présumé innocent jusqu’à sa condamnation, abolit la torture, confia la mise en accusation ei le jugement à des jurys de citoyens, prescrivit la publicité de la procédure, pourvut l'accusé d'un défenseur, ordonna de lui communiquer les pièces et de confronter avec lui les témoins, enjoignit au juge de motiver clairement sa sentence, ouvrit au condamné une voie de recours auprès du Tribunal de cassation. Elle abolit les supplices barbares de l'ancien temps, le fouet, la marque, la mutilation, le carcan, restreignit l'application de la peine de mort, adopta le mode d'exécution capitale qui lui sembla le moins inhunain : la décapitation ${ }^{5}$. En un

1. Décret du 20 septembre 1792.

2. Décret du :0 septembre 1792.

3. Loi de nivóse an II.

4. Lo1 da 11 brumire an VII (1er novembre 1798).

5. Guillotin, médecin distingué et plilanthrope conraincu, avait fait ndopter, en 1791, par l'Assemblée, le principe d'une machine à décapiter : on l'appela l'abord Lonisette, du nom du célèbre médecin Lours, que la Constituante avail chargé d'en surveiller la construction, puis guillotine, du nom de celai qui en avait eu la première idée. Les malfaileurs l'ont bap- 
mot, tous les principes qu'avaient formulés les sages du xvıne siècle, Montesquieu, Voltaire, Beccaria, Filangieri, prirent corps dans les lois nouvelles de la France.

Legislation apolénienne : les codes. - Ce sont ces lois de la Révolution que Napoléon, comme Premier consul ou comme Empereur, a entrepris de reviser et de coordonner de facon à en former des Codes. Il commenca par le Code civil.

Le 9 août 1793, CAMBACÉRes avait déjà soumis à la Convention un projet de Code civil. Sous le Consulat, Bonaparte nomma une commission, composée de portalis, TRONCHET, BIGOT DE PRÉAMENEU, MALLEVILLE, TREILHARD, BERLIER. Il la chargea de prendre à la fois dans le droit romain, dans les anciennes coutumes, dans les travaux des juris-

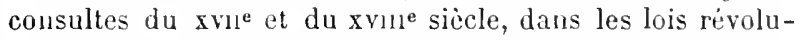
tionnaires, les dispositions qui paraitraient les plus conformes au nouvel état de la société. Au droit romain, on emprunta l'adoplion. Pour le régime du mariage, on prit à la fois au droit romain le réfine dotal et aux coutumes le régime de lu communauté des biens. Des lois révolutionnaires, on garda l'organisation des actes de l’état civil, le principe de l'égalité des partages, une linitation plus rigoureuse lu droit de tester, le régime hypothécaire. On leur prit le divorce, dont on corrigea les abus, tout en reprenant à l’ancienne législation chrétienne la sépuration de corps. Bonaparte eut une part imporlante dans les discussions de la commission. Le projet fut adopté par le Conseil d'Etat, qui, contradictoirement avec le Tribunat, le disenta devant le Corps législatif. Celui-ci lui donna la sanction législative en 180'. Le Code civil, le premier que nous ayons eu (car le Code Louis n'était pas un Code civil), a pris en $180 \%$ le nom de Code Napoléon. Il a repris ensuite son premier nom de Code civil, car il est l'ourre moins de Napuléon que de la Révolution, dont il consacre les principes.

L'Empereur devait porter atteinte à l'un des principes

tisè aussi du nom d'abbaye de Monte-da-regret. Guillotin, emprisonné pendant la Terreur. fut sur le point d'experimenter son invention philanthropiqua : il se fut sauré que par la chute de Robespierre. 
révolutionnaires de son Code civil quand, en 1806, il rétablit une espèce de droit d'ainesse et constitua des majorats, afin de favoriser la formation d'une nouvelle noblesse.

Sous l'Empire, parut, en 1806, le Code de procédure, qui régularisait la marche ả suivre devant les tribunaux civils, mais qui se ressent encore trop du formalisme et des complications de l'ancienne procélure.

La mème année, le Code dinstruction criminelle détermina la procédure pour la recherche des crimes et délits, la tenue des tribunaux de police et correctionnels, des cours d'assises, la cassation et la revision des jugements.

En 1807, le Code de commerce vint régler la compétence et la procédure des tribunaux de commerce, la législation sur les sociétés commerciales et industrielles, la Bourse, les lettres de change, les faillites, les banqueroutes, pour lesquelles Napoléon se montra d'une rigueur excessive.

En 1810, le Code pénal rétablit quelques-uns des usages barbares abolis par la Constituante: l'exposition, le carcan, la marque, l'amputation du poignet pour les parricides. Il rétablit la peine de mort pour beaucoup de crimes que les assemblées révolutionnaires n'avaient puni que des fers. Dans ses articles 103 et suivants, renouvelant une disposition tyrannique des lois des empereurs romains, de Louis XI et de Richelieu, il punit quiconque ayant eu connaissance d'un complot n'en fait pas, dans les vingl-quatre heures, la révélation au gouvernement.

Ouvrages a consulter. - Paul Viollet, Precis de l"hist. du droit francais. - A. Desjardins, Les caliers des Etats Gérerux et ta ligislation criminelle (143). - Serin, Etudes sur les arigines rivolutionnaires des cordes Tapoltion (1879). - Portalis, Discours, rapports et travaux inedits sur le Code civil (184í). - A. Madelin, Le Premier consul léfislateur (1S95). - Rondonneau, Napoléon le Grand consid. comme législuteur $(1008)$. - Pérouse, Nap. et les tois ciriles (1S66). - L. Auso:, Le Conseil (lEtat 1876). - Hiver, Hist. critinue des inst. judic. de la France (we ti89 i 1848), 15is ). Em. Marco de Saint-IJilaire, Vapoléon au conseit d'Etat (1813). - Valette, De la duris nersistante de l'ensemb!e du droit rieil fourctis pendant et apres la Rerolution 1982. - Seruzuer, Pretcis historique su' les codes francuis 18.1. - De Frisuet, Precis dihust. des sontres du druit franças (litil). - H. Planiol, atl. Cole civil dans li frante Lncyplopillie, I. XI. - Esmein, IIist. de la procedure friminelle ch France 18ve. - Ph. saruac. La Ligi.l. cilile de la Rév. four. 1sas - Lecentemaireducodc cicil pref de A. Sorel). - Wallon Is so-s. Campinton 14t2, Hist. du tribunal rifolut. - A. Douarche, Lestribunaux cirils de l'aris pend. lu liev. 1905-7. - Jules Roche, Disconos a la rh. des deputes 16 et Io janvion $18<3$ sur l'́lection des mayistrats et le fonctionnement des tribunaur. - C. A. Waban, Les prisomsde Paris sones la Rrolution (18:0). - Louis Madelin, Fonchi, 1901. 


\section{CHAPTTRE Ví}

\section{LES FINANCES}

Confributions directes. - Les seules contributions directes, sous Ia Révolution, lurent : la contribution foneiére, qui porte sur les immeubles; la contribution persomulle et mobiliere, calculée d'après le revenu apparent des citoyeus; la contribution des portes et fenetres; les patentes, paries par quiconque exerce une industrie.

Le principe de l'égalité de l'impòt figure dans la Díclaration des Droits. Il fut confirmé par lá loi de 1790 (1er décembre), qui établit la contribution foncière. Cette loi autorisa les ciloyens à s'acquitter, au moins partiellement, en nature. La Convention ${ }^{1}$ maintint cette faculté et indi jua la proportion : moitié en nature, moitié en argent. l'uis, vu la rareté du numéraire, elle permit ${ }^{2}$ de s'acquitter, pour les trois quarts, en grains. Comme les grains se détérioraient en magasin et qu'une partie lu produit se dépensait en frais de garde et de transport, le Directoire rétablit le payement intégral en argent ${ }^{3}$.

Pour assurer l'égalité de la contribution, il eût fallu établir le cadastre, comprenant l'arpentage et l'évaluation des biens-fonds. La Constituante renonça à une entreprise qu'elle jugeait, avec raison, très compliquée et de très longue durée. La Convention se borna à la décréter en principe. Le Consulat, trouvant trop difficile l'opération

1. Loi du 2 thermidor an $11-20$ juillet $1: 95$.

2. Loi du 'í fruetidor an III - 10 septembre 1795.

3. Loi du 3 frimaire an VII -23 norembre 1793. 
du cadastre par parcelles de terre, préféra s'en tenir à la compatraison entre les masses de cultures : on établit la moyenne des évaluations sur la comparaison de 1300 communes tirées au sort pour toute la France. Un ministre des finances de l'Empire, Gaddin, en revint à la méthode du cadastre parcellaire (1807), et l'entreprise fut poursuivie avec activilé. Au 1०r janvier 1812 , environ $10000 \mathrm{com}$ munes avaient vu leur terriloire arpenté; pour 6000 d'entre elles on avait fait l'expertise.

Les impôts établis sur le revenu des citoyens présentent des inconvénients; car on ne peut se baser que sur le revenu apparent, manifesté par un certain train de dépenses; il $\mathrm{y}$ a toujours, ou arbitraire dans les évaluations, ou inquisition vexatoire si l'on veut préciser, entin inégalité des charges entre lavare qui se prive et dissimule sa richesse et le citoyen qui ne craint pas de la laisser voir. C'est pour ces raisons que Vecker, en 1777, avait supprimé la taille d'industrie. Puis Loménie de Brienne avait exprimé cette idée que le signe le plus apparent de la fortune d'un citoyen, c'est le logis qu'il occupe, le loyer qu'il paye, le luxe le mobilier qu’il déploie. La Constituante reprit cette idée $^{1}$ : outre la cote personnelle, qui était tixe et équivalait uniformément à la valeur de trois journées de travail, elle établit la cute motilière et dhabitation, qui était variable et se calculait sur la valeur du mobilier et du loyer ${ }^{2}$. Ce sont ces impôts qui forment encore actuellement la contribution personnelle et mobilière. Le Directoire ${ }^{3}$, abanlounant l’élément d’appréciation tiré de la valeur des meubles, s'en tint uniquement, comme on le fait aujourd'hui, à la valeur locative du logis occupé.

La contribution des portes et fenêtres fut crée par le Directoire *. La Convention avait d'abord cherché à établir une taxe sur les feux, e'est-à-dire sur les cheminées et les poiles. Elle donnait lieu a une inquisition ficheuse dans le domicile mème des citojens, car les poủes, par

1. Loi du 13 février 1791.

2. Dans le méme ordre d'idées, la Constituante taxa anssi, comme signes de la foriune présumee. les domestiques, chevaux, mulets, etc.

3. Loi du ter aotit 1797 .

4. Loi du '2' novembre 1798 - an VII. 
exemple, ne pouvaient ètre aperçus du dehors. Au contraire, les portes et fenètres étaient parfaitement visibles de la rue ou de la cour des maisons. C'est ce qui décida le Directoire à préférer cet élément de taxation et à créer une contribution qui n'avait pas de précédent dans notre histoire financière, à moins qu'on ne remonte à l'ostiarium de l'époque gallo-romaine". Le tarif de la loi fut d'abord très modéré : 20 centimes par fenêtre, dans les communes de moins de 5000 âmes; daus celles de plus de 100000 àmes, 60 centimes pour les fenêtres des deux premiers etages et 25 pour les autres. Il est vrai que le Directoire, daus la suite, doubla par deux fois l'impôt et parvint à en tirer 16 millions: il rend aujourdhui environ 30 millions ${ }^{2}$.

Le nouvel impòt rencontra une vive opposition, et il faut citer, comme spécimen de l'éloquence parlementaire à cette époque, le discours d'Huguet, député aux Cinq-Cents : "Ne pourrait-on trouver un impôt moins rebutant et moins odieux?.... Quoi! si pour adorer la divinité, au lever du soleil, je veux ouvrir une fenètre à l'orient, il faudra payer un impôt. Quoi! si pour réchauffer le corps débile de mon viẹx père, je veux faire percer une fenètre à l'aspect du midi, il faudra payer un impòt! Quoi, enfin! si pour me garantir des chaleurs de thermidor, je veux ouvrir une fenètre au nord, il fatıdı́a encore payer un impòt!"

La Constituante, par la loi de mars 1791, en mème temps qu'elle abolissait les maitrises et jurandes, ainsi que les droits qu'elles rapportaient au roi, créa la contribution des paterites. Elle prit pour base la valeur locative des boutiques, magasins, ateliers, répartit ces locaux en trois classes, et, correspondant à chaque classe, établit trois degrés de taxation : 10, 12 et demi, 15 pour cent du prix du loyer. Son tarif ne tient pas plus de quatre lignes; celui d'aujourd'hui ne tient pas moins de cent pages. Cet impòt se décomposa ensuite ${ }^{3}$ en un droit fixe et un droit pro-

1. Voir notre Histoire de la Civilisation francaise, t. $1^{\text {er }}$, pare 49.

2. Des adoucissements furent apportés à cette loi, d'abord par une loi do l'an $\mathrm{Xl}$ en faveur des fenetres des manufactures, puis par la ioi de 1832, pour favoriser l'assainissement des habitations.

3. Loi du 6 fruclidor as IV -23 aoùt 1796 , sous le Directoire. 
portionnel. On affranchit de la taxe ${ }^{1}$ les citoyens qui sravaillent chez eux pour autrui, mais qui n'ont ni ouvriers ni boutiques : cette exemption s'est maintenue ${ }^{2}$.

Contributions indirectes. - La Révolution arait donc conservé, sous d'autres noms, sauf la corvée royale des routes, tous les impots directs de l'ancien régime; elle ne conserva aucun des gros impòts indirects. Ils étaient par trop impopulaires; ils rendaient trop peu, gràce à la contrebande que l'anarchie avait développée; enfin ils étaient condamnés par la plupart des économistes, qui croyaient que l'impôt foncier devait suffire à tout. Ainsi aides, gabclle, monopole du tabac, furent supprimés. L'État perdit d'un seul coup plus de la moitié de ses revenus.

En 1799, le Directoire proposa un impot sur l'extraction du sel: les Conseils le repoussèrent avec indignation, comme s'il se fut agi du rélablissement de la gabelle. Bonaparte lui-mème n'osa d'abord pas l'établir. C'est seulement en 1806 (décret du 16 mars) qu'il frappa le sel, à l'extraction, d'un décime par kilogramme, porté bientôt à deux décines ${ }^{3}$.

Il l'ut plus hardi pour les impoits sur les consommations, dont aucun des gouvernements rérolutionnaires n'avait tenté le rétablissement. En 1804, il établit un droit fixe de 40 centimes sur chaque hectolitre de vin; en 1806, un droit de circulation et un droit de détail ; en 1Sos, un impòt sur la bière.

Toutes ces taxes formerent ce qu'on appelait alors les Droits réunis 4 .

En supprimant le monopole sur le tabac, en sacrifiant ainsi 30 milliuns que la Ferme payail à l'Etat, la Constituante avait essayé de se dédommager avec des droits de douane sur cette denrée, mais seulement sur le tabac fabriqué. Le Directoire mit un impòt sur la fabrica-

1. Loi du 9 frimaire an $\mathrm{V}-29$ novembre 1796.

2. Cet impöt, qui ne renlait pas plus de 68006 y lirres en l'an $1 \mathrm{~V}$, en a rondu 20 millions en 1820,42 en 1843,132 en 1900.

3. Cet impót, quí s'est maintenu depuis, rendait déja 46 millions en 1814, 70 en 1847, et, grace aux réductions de tarif en 184 et en 1876 , seulement 33 millions en 1955 , un peu plus de 9 millions en 1900.

4. Ces divers impóts, qui produisaient, en 1780,90 millions, en donnent aujourdhui pris de 660 , y compris la taxe sur le sel et quelques autres. 
tion du tabac en France mème: il en tirait environ 1200000 francs. Le Prenier consul l'augmenta, y ajouta une licence de fabrication, et tira plus de 20 millions tant de ces taxes que des domanes. Devenu Empereur, il rétablit l'ancien monopole. On raconte qu'il aurait vu dans un bal une bourgeoise richement parée et couverte de diamants; qu'il se serait informé et aurait appris qu'elle était la femme d'un fabricant de tabac; que c'est ce qui lui aurait domné l'idée de réserver à l'État une source aussi importante de revenus. Ce qu'il y a de sùr, c'est que, par le décret de 1810 (29 décembre), il rétablit le monopole de l'Etat; mais, au lieu de l'affermer conme avait fait l'ancienne monarchie, il le mit en régie. Il soumit la culture du tabac indiqène à une surveillance, ne l'autorisa plus que dans luit départements, réserva à la régie le droit exelusif d'acheter les produits de cette culture, comme aussi de les manufacturer et de les vendre ?

Parni les petits impóts indirects, le droit de marque sur les matieres d'or et l'argent, les taxes sur les huiles et savons, papier, voitures publiques, cartes à jouer, etc., avaient été maintenus par la Constituante, ou, après une courte disparition, avaient été rétablis. Par exemple, la Constituante maintint le monopole royal des messageries et le mit en adjudication; mais elle ne put le défendre contre une concurrence audacieuse. Le Directoire le remplaça par un impòt sur les voitures publiques ${ }^{2}$. Li régie des cartes à jouer avait été supprimée en 1790 : la fabrication était devenue libre. En l'an Vl, le Directoire atteignit cette industrie par son impòt du timbre; puis il rétablit la régie, qui fut organisée avec une extrême rigueur par Napoléon (1807). Quant à la fabrication et à la vente des poullres, le Directoire en avait déjà attribué le monopole à l'État.

Euregistrement et timbre. - Les anciens droits de contrôle, insinziation, centiène denier, scel, greffe, etc., furent abolis par la Constituante ${ }^{3}$; mais elle les recon-

1. Résultat : en 1816 , le monopole rend 33 millions, en $183 \dot{x}$, plus de 50 , on 1900 , plus de 413 millions.

2. En lian VI.

3. Loi du 19 décembre 1790. 
stitua aussitôt sous d'autres noms : le contrôle s'appela enregistrement; l'insinuation devint la transcription; le centième denier fut transformé en sept pour cent et se trouv ainsi sextuplé. Le service nouveau fut organisé sous le Directoire par une loi très bien faite, très compliquée et très savante, qui, encore aujourd'hui, est restée presque tout entière en vigueur. Par la loi de l'an VI ${ }^{2}$, l'ałministration reçut le droit, en cas de déclaration jugée insuftisante, d'exiger une expertise ${ }^{3}$.

Il y avait, sous l'ancien régime, un droit de formule, qui rapportait 6 millions. Il n'arait pas cours dans certaines provinces et ne frappait qu'une partie des objets que le timbre atteint aujourd'hui. La Constituante le maintint * sous le nom de droit de timbre; mais, comme il ne frappait ni les journaux ni les autres imprimés, il arriva que, pendant toute la Révolution, tantôt le produit ne payait pas la dépense ảu papier, tantôt il faisait place à un énorme délicit. Le Directoire réorganisa ce service ${ }^{5}$; le timbre frappa les pétitions adressées aux administrations, les journaux et autres périodiques, les affiches, le papier de musique, les cartes à jouer. En 1797, il atteignit les avis imprimés qui se distribuent dans la rue ${ }^{6}$.

Hode de perception des impioss. - Les contributions indirectes ont toujours été percues par des administrations spéciales, tandis que les contributions directes ont passé par différents régimes.

D'après les lois de la première Constituante, le corps municipal était chargé de perceroir l'impôt direct sur les habitants de la commune; il le versait à la caisse de l’administration de district, celle-ci à la caisse de l'athinisiration de département, celle-ci au trésor public.

Pendant toute la Révolution, ce service fut fait par les

1. C'est la loi du 22 frimaire an VIl (12 décembre 1798).

2. Loi du 9 vendémiaire an VI -30 septembre 1797.

3. Ces droits rendirent, en l'an V1, 69 millions; anjourd'hui 525 millions, plis d'un demi-milliard.

4. Loi du 13 février 1791.

5. Lois du 9 rendemiaire an VI (1797) et 13 brumaire an V1l (3 norembre 1:98).

6. En las Vil, le timbre produit 15400000 francs; en 1810, 25 millions; en 1300, 184 millions et deni, non compris l'Algérie. 
autorités élues avec une extrême négligence : la Constituante, la Législative, la Convention, le Directoire ne réussissaient pas à faire rentrer les impots. Les contribuables devaient parfois plusieurs années d'arriéré ${ }^{1}$.

Quant à la répartition, le pouvoir législatif, en mème iemps qu'il votait l'impot direct, le répartissait entre les départements. Les assemblées départementales le répartissaient entre les districts, les districts entre les communes, et les communes entre leurs habitants. Cela se pratique encore aujourd'hui.

Organisation du service des contributions directes. Le Premier consul comprit que les impòts ne rentreraient régulièrement que lorsqüils seraient perçus par des agents rétribués, nommés et révoqués par l'État. Il créa l'administration des contributions directes ${ }^{2}$.

Par chaque groupe de communes, il établit un percepteur. Les fonds recueillis par celui-ci étaient centralisés, au chef-lieu de chaque arrondissement, par un receveur particulier. Dans chaque chef-lieu de département, un receveur général concentrait les fonds, et un payeur général versait les sommes affectées aux divers services publics. Tous ces fonctionnaires devaient, comme garantie de leur gestion, verser un caulionnement.

Un directeur et un inspecteur par département, 5千0 contróleurs dans les arrondissements, devaient préparer les ròles, c'est-à-dire les listes des propriétés et des personnes, et déterminer la part afférente a chaque contribuable.

La Cour des comptes. - L'ancienne Chambre des comptes

1. Dès 1791, on signale, pour la contribution foncière, des retards, un déficit croissant. Sur 300 millions, 165 seulement ètaient, non pas rentrés au Trésor, mais seulement répartis eutre les contribuables. On proposa d'affcher, dans la salle des séances de l'Assemblée, la liste des administrations retardataires: elle eủt été trop longue. En 1792, sur 40911 municipalitès, $5 \% 18$ sealemeat avaient commencé le travail de répartition, 2500 seulement l'avaient terminé. En 1796, Ramel constatait que l'arriéré, pour cette anné ou les précédenles, montait à 300 milions. Les départements ne daignaient mème pas répondre aux letires pressantes et rèitérées du ministre. "On ve peut se dissimuler, déclarait Bénard-Lagrave, que, depuis quelques années, on a voulu s'habituer à ne plus payer d'impóts. "En l'an VII, il manque eacore des roles de contribution pour l'an V, il en manque :000 pour l'an Vl, 11 g'y en a aucun de terminé pour l'an V'll. Mème tableau l'annèe suivanto.

2. Organisée par Bonalarte dés le 21 novembre 1799. 
de la royauté avait été supprimée en 1790, et remplacée par un Bureau de comptabilité composé de quinze commissaires. Napoléon, en 1807, rétablit l'ancienne institution, mais sur des bases nourelles et avec un nom nouveau. Elle s'appela dès lors Cour des comptes. Tous les agents comptables de France sont tenus de lui soumettre leur gestion. Elle prononce en appel sur les décisions des conseils de préfecture en matière de gestion financière.

Les budgets. - En 1790, la Constituante avait inauguré la publication annuelle d'un tableau des recettes et des dépenses, telles qu'elles étaient votées par le pouvoir législatif. Malheureusement, pour les causes que nous avons indiquées, pendant toute la durée de la Révolution, le déficit resta l'état normal.

C'est ce qui explique que, pour nourrir au moins les soldats, la Convention et le Directoire furent obligés de recourir à des expédients ou tyranniques ou ruineux : confiscations ordonnées parfois au hasard; réquisitions à outrance sur le sol français comme sur les pays conquis; émission abusive d'abord des assignuts, puis des manduts territoriaux; emprunts forcés sur les riches en 1793, en 1795, en 1799; banqueroute partielle en 179i, sous le nom d'opération du tiers consolidé. La vente des biens nationauz se faisait lentement et celle des biens mobiliers des églises ne donnait pas ce qu'on en avait attendu.

L'Empire eut un budget à peu jrès en équilibre, sans que le pays souffrit trop du poids des impôts. Ses grandes guerres, ses immenses armements furent surtout soldés aux frais des pays conquis. Il pratiquait cette maxime du grand condottière allemanu du xvile siècle, Wallenstein : "La guerre doit nourrir la guerre ". Mais, en 1814, la guerre fut reportée sur notre territoire, et, à la chute de l'Empire, il $y$ eut des comptes à rendre aux vaincus de la veille. Les contributions de guerre, les indemnités de toute origine que la France dut alors subir pesèrent et pèsent encore sur nos budgets.

Ourrages a consulter. -- Em. Tixier, De lassiettede limpot foncier (15:5). - be Nervo, Les finunces francoises sous lancimme monarchie, la Remublique, le ronsulat et l'Empire 1Nos. - Wubror. Hist. de lit dette publique en france Isso - René
Stourm, Les finanes de l'ancien régime et de la revol. (1885), et Les finances atu Consulat 190:)- Belloc.

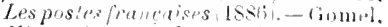
Hist. firtuc de la Constituante (1896), de la concention (1901). 
CiIAPITRE VII

LES CULTES

\section{Le clergé catholique sous la Constituante.}

Fòle an elergé au début de la hévolution. - Avant la Révolution, le clergé catholique avail en France une situation prépondérante: sa religion était une religion d'Etat; il formait le premier des deux ordres privilégiés; il était le plus grand propriélaile du pays, ayant un domaine d'une valeur de trois milliards et d'un revenu denviron 70 millions; il percerait pour environ 80 millions de dimes sur tous les autres propriétaires; il levait des droits féodaux; il avait son organisation, ses assemblées, ses justices ecclésiastiques et ses justices féodales.

Comme il comptait dans son sein des privileriés et des sacrifiés, une aristocratie et une plèbe, un Iraut clergé et un bas clergé, il ne fut pas unanime dans la résistance à la Rérolution. Dès le 13 juin, trois curés du Poitou, Jallet, Ballard, Lescève; le 14, six curés, dont le Lorrain Gréggoire, curé d'Embermesnil; le 15, trois, dont Marolles, se rallic̀rent au tiers état. Le 19, 127 membres du clergé contre 133 se prononcèrent pour la réunion des trois ordres, qui devait conduire à la suppression des ordres privilégiés. Le 20, ils se trouvèrent 149 et prirent part au serment du Jeu de Paume. Le 22, ils firent ouvrir à l'Assemblée, chassée de toutes les salles de réunion, l'église Saint-Louis. Grâce à une notable fraction de ses membres, le clergé cessa, en fait, d'ètre un ordre pour s'absorber dans la nation.

Premières réformes de la Constituante. - Dans la nuit du. aout, le clergé déclara consentir au rachal des dimes, 
et des curés offrirent le sacrifice du casuel. L'évèque d’Uzès, peut-ètre sans mesurer toute la portée de ses paroles, dit que le clergé ne pouvait disposer de son lomaine, parce qu'il avait reçu des mains de la nation ses droits et ses titres, et qu'elle seule pouvait les détruire. Le tiers état recueillit cet aveu et lui donna aussitôt une sanclion.

Le 6 aout, Buzot fit cette déclaration : "Les biens ecclésiastiques appartiennent a la nation ". Le 8, comme l'Assemblée cherchait quelle garantie elle pourrait offrir pour un emprunt de 30 millions reconnu nécessaire, M. de Lacoste, député du Calvados, renouvela la déclaration le Buzot et $y$ ajouta ces propositions : $1^{\circ}$ les biens du clersé sont la propriété de la nation et servent de garantie à ses emprunts; $2^{\circ}$ à partir de 1790 , toutes les dimes sont supprimées; $3^{\circ}$ les ordres religieux seront abolis. En échange de ses biens, le clergé, d'après la proposition de Mirabeau, devait recevoir un traitement sur le budget : désormais, suivant l'expression de l'orateur, "la nation salarie les officiers de morale et d'instruction ". Une partie des députés ecclésiastiques fit bon accueil à ces propositions. Les curés déposèrent un acte de renonciation. L'archevèque de Paris fit cette déclaration : "Nous remettons tous dans les mains de la nation toutes les dimes ecclésiastiques, et nous nous confions à sa sagesse : que l'Evangile soit annoncé, que le culte divin soit célébré avec décence et dignité; que les églises soient pourvues de pasteurs vertueux et zélés; que les pauvres soient secourus."

Le décret $d u \quad 12$ aoùt abolit sans indemnité les dimes ecclésiastiques et déclara rachetables les dimes inféodées. Le décret du $\mathbf{2}$ novembre mit les biens de l'Eglise à la disposition de la nation " à la charce de pourvoir, dune manière convenable, aux frais du culte, a l'entretien de ses ministres et au soulagement des paurres ${ }^{1}$ ". Ces biens durent servir de garantie au nouveau papier-monnaie, les assignats. Le décret du 19 déctmbre en ordonna la vente jusqu'à concurrence de 400 millions ${ }^{2}$ et décida,

1. Le mėme dẻcret fixa à 1200 livres le traitemenl annuel des curés, - outre la jouissance des presbytires et des jarlins qui en dépendinat.

2. En férrier 1790, Bailly proposa de les alienor aus municipalitès, qui 
en mėme temps, l'émission de $\mathbf{4} 00$ millions d'assignats. Dès septembre 1789, l'arcrenterie et l'orlëvrerie des églises, évaluées alors à 140 millions, furent mises à la disposition de l'Assemblée.

C'est ainsi que le clerré cessa d'être grand propriétaire pour devenir un corps salarié, comme le roi lui-mèmc. sur le budget de l'Etat.

les lois sur l'organisation judiciaire mirent fin à sa situation de justicier; l'abolition de tous les droits féodaux mit fin à ceux qu'il possédait. Un ordre de choses qui remontait aux empereurs romains, aux Mérovingiens, à Charlemagne et aux premiers Capétiens disparut ainsi pour jamais.

Cette transformation de l'Église de France est, en matière ecclésiastique, l'ouvre durable de la Constituante. Acceptée par le clergé, elle a survécu à toutes les révolutions ultérieures. Si li Constituante s'en était tenue là, la paix reỉgieuse n'eût jamais été compromise.

Le Comité ecclésiastique. - Malheureusement, il y eut un parti dans la Constituante qui voulut aller plus loin. Le Comité tcclésiastique de l'Assemblée, qui fut formé le 20 août 1789, se composait de quinze membres, dont cinq ecclésiastiques, parmi lesquels les évêques de Luçon et Clermont. Parni les laïques, il y avait danciens magistrats ou avocats des Parlements, esprits modérés à d'autres égards, très savants en droit canonique, mais imbus des idées gallicanes et mème jansénistes ${ }^{1}$. Ce comité se proposa le remaniement des institutions ecclésiastiques pour les mettre en harmonie avec les nouvelles institutions politiques. On voulait enlever au roi la nomination des érêques, conme celle des magistrats, des fonctionnaires, des officiers. Cest ce qui fit voter la Constitution civile du clergé.

seraient chargées de les vendre en dètail ; le décret du 14 avril confia l'opération aux direcloires de departement et de distrıct.

1. Par exemple Lanjuinais, ancien avocat au parlement de Rennes, Mar. tineau, Treilhard, Dupaty de Courteille, et surtout Durand de Maillane, auteur de l'Histoine du droit canonique, du Commentaire des Institutes de Lancelot, du Dictionnaire du droit canonique. du Recueil des libertés de l'Église gallicane. Plus tard, les ecclésiastiques du Comité furent dom Gerle, dom Breton, Expilly, Massieu. Gassendi, Thibaut, les quatre derniers destines à être meubres de l'épiscopal constitutionnel. 
La Constitution civile du elergé. - Cette loi, dont les principales dispositions furent votées le 12 juillet 1790, abolissait le Concordat de François $I^{\text {er }}$ et de Léon $X$. Ses disposilıons essentielles peuvent se ramener à quatre points principanx ${ }^{1}$ :

$1^{\circ}$ Elle établissait une nouvelle division ecclésiastique de la France : au lieu de 116 évêchés et 18 archevêchés ${ }^{2}$, elle ne gardait que 83 sièges, à raison d'un par département; elle supprimait donc 59 sièges anciens et en créait 8 nouveaux. Les sièges conservés ou crés prenaient le nom d'un département. On ne disait plus : l'évêque de SaintDié, mais : l'évèque des Vosges.

Des 83 sièges, 10 étaient chefs-lieux de métropole; donc, 8 des anciens archevèchés devenaient de simples évèchés. Les sièges épiscopaux metropolitains prenaient le nom d'une région ${ }^{3}$.

Par la suppression des anciennes dénominations, on s'attaquait aux vieux souvenirs historiques, aux traditions qu'elles rappelaient, à tout ce qui restait de l'aneienne division en provinces romaines, conservée en grande partie dans la division ecclésiastique de la France ${ }^{4}$.

Enfin la juridiction des évéques belges sur les paroisses du Nord, de l'archevèque-électeur de Trèves sur les TroisÉvèchés et sur les évèchés de Nancy et de Saint-Dié, de

1. Elle comprend qualre titres : le premier, en 27 articles, est inlitulé des offices; le deuxième, en 44 articles, traite de la nomination aux bénéfices; le troisième, en 12 articles. fixe le traitement des évéque:, curćs et vicaires; le qualrième, en 7 aricles, traite de la résidence.

2. Dans ce nombre de 18 archevẻchés ne sonı pas compris celui d" Tarantaise (Savoie), ni ceux de Mayence et de Trèves, qui avaient pour suffragants six évéchés français de la Lorraine et l'Alsace, ni ceux de Pise et do Gènes, qui avaient pour sufragants les cinq évèchés de la Corse.

Dons ce nombre de 116 évèchés ne sont pas compris les évèchés belgeg de Tournai et de Namur, dont les diocèses comprenaient nombre de jaroisses françaises; ni les évẻchés de Bâle et de Lausanne, qui étaienl sufräranls de Besancon; ni les évèchés de Savoie; ni les cinq évẻchès du département actuel de Vaucluse, le Comtat d'Avignon n'ayant élé réuni à la Franco qu'en $1: 91$.

3. Rouen était métropole des Cótes de la Manche: Reims, du Nord-Est; Rennes, du Nord-Ouest; Besançon, te l'Est; Paris, de Paris; Bourges, du C'entre; Bordeaus, du Sud-Ouest; Toulouse, du Sud; Aix, des Cates de la Méditerrané; I.yon, du Sud-Est.

4. Voir notre Histoire de la civilisation francaise, t. I, page 66, ot t. Il, piges $3 \overline{7}$ et suivantes. 
l'archevêque-électeur de Mayence sur l'évêché de Strasbourg, de l'évéque de Bàle sur une partie de la Franche-Comté, des archevêques de Gênes et de Pise sur les évèchés de Corse, était abolie. Les frontières de l'Église de France devaient concorder exactement avec celles de la France.

Une nouvelle circonscription des paroisses devait ètre établic par une entente entre les évêques et les administrations de district. Toute paroisse où siégeait un évèque ne devait avoir d'autre curé que lui. Dans toute ville audessous de 6000 àmes, il n'y aurait qu'une paroisse.

Tous les titres et offices ecclésiastiques autres que ceux d'évèque et de curé étaient abolis. Il n'y aurait donc plus ni chapitres, ni chanoines, mais seulement, pour assister les évèques dans leur administration et former leur conscil épiscopal, des vicaires épiscopaux, en nombre variant de 12 à 16 . Il ne devait subsister qu'un seul séminaire par diocèse.

$2^{\circ}$ Avant 1790, les évèques étaient nommés par le roi; les curés, présentés par les patrons et institués par les évêques.

Désormais les évèques seraient élus par les mėmes électeurs qui nommaient les députés, les juges au tribunal de première instance et les administrateurs de département. On exigeait, pour la nomination à l'épiscopat, quinze années de ministère sacerdotal.

Les curés seraient élus par les mèmes électeurs qui nommaient les administrations de district. Leur élection devait ètre proclamée par le président du corps électoral, à l'église de la paroisse, avant la messe solennelle, en présence du clergé et du peuple.

$3^{\circ}$ Les évèques ainsi élus ne pourraient s'adresser au pape pour obtenir de lui, comme autrefois, une bulle de confirnation; mais ils pourraient lui écrire comme au chef visible de l'Église et en témoig̨nage de l'unité de communion qu'ils entendaient entretenir avec lui. La confirmation, ou installation canonique des évéques, se ferait par le métropolitain de la région; à son refus, par les autres évèques de la circonscription métropolitaine. Celle du métropolitain se ferait par le plus ancien ivique da ressort. Dans tous ces cas, le confirmant ne pourrait exiger du 
nouveau prélat qu'une simple profession de la religion ca. tholique, apostolique et romaine.

Le curé élu devait demander l'installution canonique à son évèque. Si ce prélat la refusait, l'élu devait avoir recours à la puissance civile.

C'étaient de graves atteintes à la hiérarchie.

Robespierre aurait voulu aller plus loin; i] avait demandé l'abolition de toute hiérarchie supérieure, la suppression des métropolitains et le mariage des prètres.

4. Après leur installation, l'évèque ou le curé élus devaient prêter, en présence des officiers municipaux, le serment solennel de bien remplir leurs devoirs pastoraux; d'ètre fidèles à la nation, à la loi, au roi; enfin de maintenir de tout leur pouroir la Constitution.

Les auteurs de la Constitution civile du clergé prétendaient avoir pour eux l'autorité des Pères et des conciles et les anciennes traditions de l'Église de France : $1^{\circ}$ les empereurs romains, les rois francs ou français, avaient eu autrefois le droit de changer les circonscriptions épiscopales et d'en établir de nouvelles, car, si le dogme est immuable, les limites des diocèses ne le sont pas; $2^{\circ}$ l'élection des évèques et des autres pasteurs avait été la règle de la primitive Église; la Pragmatique-Sanction de Charles VII en avait prescrit le rétablissement; $3^{\circ}$ il est vrai que le Concordat de 1516 avait fait nommer les évêques par le roi au lieu de les laisser à l'élection des chapitres; mais la souveraineté du peuple ayant remplacé celle du roi, il était naturel que cette prérogative, par la voie de l'élection, revint au peuple; $4^{\circ}$ la nomination par le corps électoral ne semblait pas plus contraire à la foi que la présentation des curés par les patrons laïques d’autrefois, qui pouvaient ètre des non-catholiques; $\tilde{3}^{\circ}$ nos législateurs citaient des canons des anciens conciles qui exigeaient de l'évèque, non pas sa confirmation par le pape, mais sa consécration en présence des évèques de la province; $6^{\circ}$ ils alléguaient l'autorité de certains Pères, qui déclaraient que tous les évêques, y compris celui de Rome, étaient égaux, et qui affirmaient l’indépendance de l'autorité épiscopale à l’égard du pontife romain.

Les partisans de l'ancien ordre de choses sefforçaient 
de réfuter ces doctrines. Remanier les circonscriptions épiscopales, supprimer des évêchés, en créer de nouveaux, c'était, assuraient-ils, toucher aux matic̀res spirituelles. Ils soutenaient qu'un Concordat régulièrement conclu avait mis fin en France à l'élection des prélats; quant aux curés, ils n'avaient jamais été élus : l'élection tendait à supprimer leur subordination à l'égard des évéques. D'ailleurs, en admettant le principe électif, le clergé avait eu, au temps de la primitive Église, une part prépondérante dans les élections, tandis que la Constitution civile ne parlait que d’électeurs laïques. Il était inadmissible que les pasteurs de l'Église catholique fussent nommés par des électeurs qui pouvaient ètre juifs, protestants, déistes ou mème athées ${ }^{1}$. Interdire de demander au pape les bulles de confirmation, c'était constituer l'Église de France à l'état d'Église schismatique. Une Église où les curès ne dépendent plus des évèques, ni les évêques du pape, n'était plus une Église catholique: son organisation devenait celle de l'Église protestante presbytérienne.

\section{hésistances opposées al la Constitution civile. -} L'ouvre de l'Assemblée ne pouvait se passer de la sanction du roi. Louis XVl s'était montré lort inquiet pendant cette longue discussion de six mois. Le ler août, il avait écrit au pape une lettre où il déclarait ne pouvoir refuser plus longtemps sa signature. Après beaucoup d'lésitations, il se décida, le 24 aoùt 1790, sous la pression des circonstances, à sanctionner la loi.

Le pape en témoigna, par une lettre adressée le 22 septembre à Louis XVI, une surprise douloureuse. Le 28 octobre, la congrégation des cardinaux déclara que "le souverain pontife manquerait essentiellement à son devoir et porterait un coup mortel au catholicisme s'il approuvait, tels qu ils sont, les décrets concernant le clergé de France ". Pourtant elle estimait encore que le pape pouvait exhorter le roi et les évèques de France à chercher, pour tranquil-

1. Ce qui ètait grave, c'est qu'un amendement de Grégoire, tendant à co que les seuls catholiques fussent électeurs, fut repoussé, sous prétexte que " ce serait composer avec les principes de la Constitution el etab.r une inquistion $*$ 
liser les consciences, un moyen d'accorder eette législation: sur les points principaux, avec les règles canoniques.

L'épiscopat de France se montra moins conciliant. Le 10 octobre, Boisgelin, archevèque d'Aix, publia une critique de la Constitution civile. 30 prélats-députés, puis 110 évêques français ou évêques étrangers ayant juridiction en France adhérèrent à ce manileste. C'était une protestation en masse de l'ériscopat. Quantité de chapelains, de curés, surtout en Bretagne, s'y associèrent. En attendant, dans la pratique, les évèques ne tenaient aucun compte de la loi nouvelle, ni des nouvelles circonscriptious. Par toute la France, il y eut un trouble profond dans les consciences et des divisions très vives.

Cependant, s'il y avait du mécontentement, il n'y avait pas de lutte ouverte. Il n'existait pas encore de signes extérieurs de ces divisions, pas de formules opposées l'une à l'autre, pas de noms de guerre. Le trouble élait latent. Une nouvelle faute de l'Assemblée le fit éclater.

Décret qui impose le serment constitutionnel. - La Constitution civile, article 21, n'avait parlé que d'un sernent de fidélité à la Constitution : cela pouvait s'entendre de la Constitution de l'État, et un serment purement civique n'avait rien qui put alarmer les consciences. Le dieret du 27 novembre 1790 précisa. Il obligea tous les ecclésiastiques "fonctionnaires publics " à prèter le selment suivant: "Je jure de maintenir, de tout mon pouvoir, la Constitution francaise, et notamment les décrefs relatifs à la Constitution civile du clergé. "Le serment devait être prèté le dimanche, à l'issue de la grand'messe. Ceux qui le reluseraient seraient considérés comme démissionnaires, et il serait pourvu à leur remplacement. Ceux qui, après l'avoir prèté, le violeraient, ceux qui s'opposerairnt a l'exécution du décret, seraient poursuivis comme rebelles a la loi, privés de leur traitement, déchus de la qualité de citoyeus actifs.

Ce décret allait avoir pour effet immédiat de partager les ecclésiatiques en deux catégories : cemx qui préteraient le serment et ceux qui le reluseraient; les "ssermentés ou constitutionnels, et les insermentés ou réfructuires; les jureurs et les non-jureurs. 
Le roi, après des hésitations bien plus grandes, assailli par les députations de l'Assemblée et redoutant des dangers plus graves pour le clergé, sanctionna encore ce décret (26 décembre).

Exécution des décrets. - Le 27 décembre, les députés ecclésiastiques furent mis en demeure de prêter le serment à la tribune de l'Assemblée. (irégoire fut le premier qui prononça la formule: il dil qu'il agissait ainsi paree qu'il entendait que l'Assemblée n'avait pu avoir l'intention de " porter la main sur l'encensoir... de porter la moindre atteinte au dogme, à la hiérarchie, à l'autorité spirituelle du chef de l'Eglise ". Parmi les jureurs, il y avait deux prélats: Talleyrand, évèque d'Autun, et frobel, évêque in partibus de Lydda. Leur nombre šeleva à 98, dont quelques-uns, dans la suite, se rétracterent. Ce n’était qu'une minorité dans l'Assemblée, car il y avait sur ses banes 300 ecclésiastiques.

Le 7 janvier, Bailly, maire de Paris, se rendit a NotreDame pour recevoir le serment des ecclésiastiques de la cité. En somme, sur 52 paroisses de Paris, 29 curés cédèrent, 23 résistèrent; sur 666 prêtres, 430 relusèrent. Les professeurs ecclésiastiques de la Sorbonne déclarèrent la Constitution " hérétique, schismalique, et vraiment oplosíe à l'esprit du christianisme ". En province, mêmes divisions, mèmes troubles : les deux tiers des membres du clergé refusèrent le serment.

Le nouveau elergé constitutionnel. - La grosse difficulté, pour l'Assemblée, c’était de recruter le nouveau clergé. Il fallait avoir d'abord des prélats pour consacrer les prètres; les premiers évéques constitutionnels nouveaux furent Expilly et Marolles, élus prélats de Quimper et de Soissons : ils furent consacrés par Talleyrand, assisté de Gobel et d'un autre évêque in partitus. Gobel, élu évêque de Paris par 500 électeurs sur 66 t votants, prêta son serment au bruit des salves d'artillerie et des cloches des églises : il consacra neuf évêques à sa messe d'instillation. Parmi les anciens prélats qui acceptèrent la Constitution, se trouva Loménie de Brienne, archevêque de Sens, qui, olàmé par le pape, lui renvoya le chapeau de cardinal. L'épiscopat constitutionnal lid bientót presque au complet 
'Tronhe profond apporté par les décrets. - Le pape, qui avait observé une réserve excessive tant que durèrent les discussions de l'Assemblée, montra une rigueur non moins intempestive quand les décrets furent en voie d'exécution. Le 10 mars 1791, il écrivit aux prélats de ''Assemblée pour condamner la Constitution civile; le 13 avril, un bref déclara les élections illégitimes et sacrilèges, cassa et suspendit les èlus ainsi que leurs conséerateurs, enjoignit à tout jureur de se rétracter dans les quarante jours. Le pape et l'Assemblèe semblaient d'accord pour placer dans la plus cruelle situation les ecclésiastiques qui, en présence du silence de la papauté, avaient cru pouvoir prêter le serment. Ils se trouvaient partąés entre leurs sympathies pour la Révolution et leur respect pour le chef suprême de l'Église. On en vit alors beaucoup, parmi les esprits les plus libéraux, parmi les meilleurs citoyens et les meilleurs Français, refuser le serment ou le rétracter. Ils se trouvèrent confondus, sous la dénomination commune de réfractaires, avec ceux qui haïssaient foncièrement la Révolution et ne voyaient dans l'affaire du serment qu'un prétexte pour provaquer au désordre.

Les troubles religieux donnaient partout un nouvel aliment aux discordes civiles. Les historiens, suivant le parti auquel ils se rattachent, relèvent plus volontiers, ceux-ci les violences des insermentés contre les constitutionnels, ceux-là les violences des populations révolutionnaires contre les prêtres insermentés. Tantòt, comme à Paris, les églises et les couvents étaient envahis par le peuple; tantôt, comme à Caen ou en Alsace, les assermentés, qualifiés d'intrus, étaient maltraités, assommés, par les nobles et leurs domestiques en armes.

Dernier decret de ia Constituante. - Pour calmer le zèle emporté de certaines administrations, qui, comme le directoire de la Seine, commençaient à interdire aux insermentés l'entrée des églises et à mettre en vente les édilices qui n'étaient pas indispensables au culte constitutionnel, l'Assemblée, sur la proposition de Talleyrand, rendit le décret du 7 mai 1791. Conformément à la Déclaration des droits, elle proclamait la liberté des cultes. Les prêtres insermentés gardajent le droit de dire la messe dans toute 
église ou sanctuaire consacrés au culte national: le refus du serment ne les dépouillait que de leur office d'évèque ou de curé de paroisse. Ils avaient également la liberté d'ouvrir des églises particulières : seulement celles-ci seraient fermées si l'on s'y permettait des attaques contre la Constitution du royaume et notamment contre la Constitution civile du clergé. Ce décret, destinè à prévenir la guerre religieuse, était sage; mais il venait trop tard. La Constituante léguait aux Assemblees suivantes une situation grosse de périls.

\section{Le clergé catholique après la Constituante.}

Décrets de la késrislative. - Les troubles dans l'Ouest et le Midi avaient déjà commencé et l'approche de la guerre étrangère les rendait plus menaeauts. On y retrouvait partout la main de prètres insermentés. La Législative, saus distinguer entre ceux qui restaient paisibles et ceux qui s'agitaient, sévit contre tous les prêtres réfractaires sans distinction. Par réfractaires, elle entendait seulement ceux qui refuseraient le serment civique. Elle remonçait donc à appliquer à la rigueur le décret du 27 novembre.

Par le decret du 29 novembre 1791, les réfractaires devaient ètre privés de tout traitement ou pension et "réputés suspects de révolte et de mauvaises intentions envers la patrie". Le decret du 27 mai 1792 les rendit passibles de la déportation, si elle était demandée par vingt ciloyens actils. Le refus de sanction qu'opposa Louis XVI à cette mesure fut une des causes de la journée du 20 juin, suivie bientôt de celle du 10 aoùt. Après la chute de la royauté, l'Assemblée, par le décret d'aoút 1792, prononça la déportation à Cayenne contre tout prêtre qui aurait refusé ou rétracté le serment, s’il n’èvacuait le territoire dans les quinze jours, après avoir demandé des passeports. Comme toujours, la Commune de Paris alla plus loin: elle ne donna aux insermentés que vingt-quatre heures pour sortir de la ville; après ce délai, ils devaient être mis en dépòt aux Carmes ou à l'Abbayc. Combien ce dépôt était peu sûr, les massacres de septembre le montrèrent. 
Décrets de la Conveation contre les réfractafres. Sous la Convention, les mesures de rigueur continuèrent contre les insermentés. Le décrct du 17 mars 1793 substitua à la déportation la peine de mort. Le dicret du 12 mai 1794, prenant en considération la situation de ceux que l'àge ou la maladie empêchaient de quitter le territoire français, condamna les infirmes et les sexagénaires à la réclusion dans leurs départements respectifs. Le décret du 12 germin:l prononça la peine de mort contre quiconque recélerait un prêtre réfractaire.

l.'. a la nouvelle Église, elle avait été considérée par les deux Assemblées précédentes comme l'Église nationale, et elle avait joui de sa dotation et du respect des autorités constituées. Sous la Convention, elle commenca à itre en butte à l'esprit d'hostilité qui se manifesta dans l'Assemblée, sous la forme, tantôt du déisme professé par Robespierre, tantôt de l'athíisme aliché par la munjcipalité parisienne.

A Paris et dans beaucoup d'autres communes, on voulut obliger les prètres constitutionnels à se marier. Le décret du 19 juillet 1793 prononça contre les évêques qui s'y opposeraient la rérocation et la déportation.

Les membres les plus célébres de l'épiscopat constitutionnel, outre ceux que nous avous déjà cités, furent Grégoire, évêque de Loir-et-Cher, qui, aux jours les plus sombres de la Terreur, osa siéger sur les bancs de la Montagne en costume de prélat catholique; Fauchet, évèque du Calvados, qui, l'un des preniers, dans la Bouche de Fer, en 1791, avait demandé la République; Lindet, évèque de l'Eure, frère du célèbre membre du Comilé de Salut public, et qui protégea son département compromis dans l'insur. rection grirondine; Thibaut, évêque du Cantal; Gay-Vernon, de la Haute-Vienne; Lalande, de la Meurthe; Huguet, de la Creuse; Massieu, de l'Oise; Saurine, des Landes. Ces neuf prélats, ainsi que six autres, furent membres de la Convention. Hors de l'Assemblée, citons Charrier de la Roche, métropolitain de Rouen, et Lamourette, de Lyon.

Quelques-uns ont mérité le bel éloge qu'a fait d'eux lally-Tollendal. "Les nouveaux èlus, dit-il, ont prêché, de parole el d'exemple, l'étude de la religion, la régularité 
des mœurs, la pratique de la charité et tous les devoirs sacerdotaux. Dans les temps de la Terreur, on a vu de ces pasteurs schismatiques braver les plus grands dangers pour conserver le souvenir d'une religion, pour secourir, consoler, sauver ce qu'ils appelaient leur troupeau, nème sans différence d'amis ou d'ennemis. On en a vu qui, traînés à l'échafaud, ont reçu le coup de la mort avec courage et religion. "

L'Église constitutionnelle allait traverser, en effet, de cruelles épreuves: plusieurs de ses évêques furent atteints, non pour cause de religion, mais comme adhérents les partis que les vicissitudes de la politique vouèrent successivement à la proscription. Fauchet fut exéeuté avec les chefs du parti girondin. Marolles, Martin, Expilly, Gouttes, Roux, moururent également sur l'échafaud. Gobel, qui apostasia, n'en périt pas moins. Plusieurs furent emprisonnés ou obligés de se cacher. D'autres, comme Lindet, Massieu et sept autres, se marièrent, autorisèrent le mariage de leurs prêtres et firent ainsi un schisme avec leurs collègues. Six abaiquèrent pendant la Terreur, entre autres Huguet, qui fut ensuite fusillé comıne complice de Bateuf, en 1796.

\section{Le culte de la Raison et la persécution hébertiste. -} A un certain moment, les vues de la Commune de Paris, inspirée par Chaumette, dominèrent l'Assemblée ${ }^{1}$. C'est l'époque où le parti hébertiste, après avoir obtenu le décret sur le mariage des prêtres, fit adopter par la Convention, le 24 octobre 1793 , le calendrier républicain, avec la substitution du décadi au dimanche, et, en novembre, le culte de la Raison. L'Assemblée se prêta d'abord aux idées des novateurs : elle reçut les vases sacrés, statues des saints, châsses, chrasubles, que le peuple enlevait aux églises et

1. Jusqu'alors le culte catholique constitutionnel avait été libre dane Paris. En 1792, les processions de la Fète-Dieu se déroulèrent dans lez rues pavoisées, au son des musiques militaires. En décembre 1792, Nanue: t la Commune ayant voulu interdire la messe de minuit, le peuple? s'ameuta et força les curès à la dire. En 1793, cinq mois après l'exécutior du roi Louis XंvI, il y eut encore les processions de la Fète-Dieu. En novembre 1793, quand Manuel allait à l'échafaud comme modéré, il fut insulté par des fruitières et par des blanchisseuses qui criaieat : " C'est bien fait! c'est lui qui nous empéchait d'allez à la messel n 
lui amenait par charretées en dansant la carmagnole, revèlu dhabits sacerdotaux. Le 7 novembre, elle accueillit Gobel, érèque constitutionnel de Paris, qui, accompagné des " citorens ses vicaires ", vint déposer ses lettres de prêtrise sur le bureau du président et abjurer le culte dont il était le ministre. Le 13 novembre, elle laissa célébrer, dans Notre-Dame profanée, le nouveau culte avec une actrice en robe blanche, en manteau bleu, en bonnet rouge. Quand la déesse eut été amenée, sur un char de triomphe, à la Convention, le président se leva et, au nom du peuple français, lui domna l'accolade 1. A Reims, le député alsacien Ruhl brisait la sainte-ampoule. A Nevers, Fouché ordonnait la destruction des croix dans les cimetières. A Paris et dans mainte alitre commune, on anéantissait les croix et autres insignes placés à l'extérieur des églises. Le 21 nuvembre, sur la proposition d'Anacharsis Clootz, la Commune décida que "les ossements et autres guenilles "trouvés dans la chàsse de Sainte-Geneviève seraient brùlés en place de Grève. Le 23, elle ordonna que tous les sanctuaires, aussi bien protestants et juifs que catholiques, seraient fermés : l'exercice de tout culte fut interdit et quiconque demanderait la réouverture d'un templc ou d'une église serait arrêté comme suspect.

1. " Dans les départements, raconte une voyazeuse anglaise (1:94), lorsqu'on doil célébrer la féte de la Raison, un député arrive quelques jours arant la cérénonie, accompagné de la déesse (si la ville ne peut pas ellemème en fournir une convenable). On la pare d'une tunique romaine en satin blanc, empruntée au théatre; sa tète est couverte d'un bonnet rougo orne de feuilles de chène; un bras est appuvé sur une charrue, l'autre saısit une lance; son pied pose sur un globe, et elle est environgee des emblemes mulilés de la féodalité. Ainsi équipeée, la déesse arec ses appendiccs est portée sur les épaules de Jacobins en bonnet rouge; elle est escortée par la garde nationale, le maire, les juges, toutes les autorités constiluées, qui, amusés ou indignés, sont forcés de garder extérieurement une gravitè respeetueuse. Quand toat le cortège artive au lieu designé, la déesse est placéo sur un autel érigé pour celle oreasion: de la, elle harangue le peuple, qui, eu retour, lui offre ses adorations et chaute la Carmagnole et dautres hymnes républicains de la mème espèce. La procession se rend ensuite dans le méme ordre à l'église princialale, el on renouvelle la mème cérémonie dans le chœur. On táche de se procurer un prétre qui abjure publiquemeatsa foi et declare que le christianisme tout entier est une imposture; puis la fẻle se termine par un autodafé général de livres le frièes, do saints, de confestiunnaux, enfin de loutes les choses appropritees au culto public." 
Robespierre, homme politique et homme d'autorité avant tout, ne put admettre que des décisions aussi graves, tendant à la destruction de tous les cultes et à l'anéantissement de la liberté de conscience, pussent être prises par des autorités municipales. Dès le 17 novembre, il avait dénoncé à la Convention les exagérés; le 20, il arait prononcé aux Jacobins un grand discours contre l'athéisme. Il se rapprocha de Danton, et celui-ci, dans son discours du 26, flétrit à la Convention les "máscarades religieuses" " La Commune de Paris, intimidée de ce rapprochement, revint le 28 sur son arrété du 23. Cependant les églises n'en restèrent pas moins fermées jusqu'en 1795. Dans le reste de la France, le mouvement irréligieux, d'abord toléré par la Convention et encouragé par quelques représentants en missior, se propageait. Le 11 décembre, Robespierre déclarait à l'Assemblée que, dans beaucoup de communes, " on trouve mauvais que les autorités ou la force armée ordonnent de déserter les églises et meltent en arrestation des ministres du culte, à cause de leur caualité seule ". Il fit rendre un décret interdisant toutes violences ou "meriaces contraires à li. liberté des cultes". Ce déeret ne fut pas observé : en arril 179', il ne restait pas en France 150 communes où l'on dit publiquement la messe.

Aux Jacobins, on avait d'abord voulu layer les érèquesdéputés de la liste des socićtaires: Robespierre les y fit maintenir, et, itu contraire, en fit rayer $A$ nacharsis Clootz, "l'apôtre du s,enre humain " et le fanatique ennemi des prêtres. En miırs 1794, le:s llébertistes furent envoyes à léchafaud; parmi eux, Clootz, el plus tard, Chaumette. Gobel périt avec eux, le 13 arril, tandis que Grégoire, qui était resté attaché à ses convictions, fut respecté.

Robespierre et le culte de liktre suprème. - Robespierre, après avoin frappé les pontifes du culte de la Raison, se fait lui-mème le pontife d'un autre culte. A la religion municipale de Chaumelte, il substitue la religion nationule de l'Étre suprème; à l'athéisme de d'Holbach, le déisme de son maitre Jean-Jaeques Rousseau.

Il fait renúre à la Convention le decret du 7 mai, aux termes duquel "le peuple français reconnait l'existence de l'Être suprême et l'immortalité de l'àme ". Le 18 juin, 
il célèbre en grande pompe la Fête de l'Étre supreme. Cependant, tout en déclamant contre les prêtres, "qui sont à la morale ce que les charlatans sont à la médecine ", il autorise la célébration du dimanche. Le décret du 7 mai, qui établissait un nouveau culte officiel, avait proclanné en mème temps, mais inutilement, la liberté des cultes ${ }^{1}$.

1. On peut suirre, dans les eurieux Mémoires de l'abbé Dumesnil, curé do Guerbaville (Seine-Inferieure), les effets produits, jusque dans les villages les plus reculés, par les divers décrets des Assemblèes. En 1791, les munizipaux de sa paroisse lui défèrent ie serment: il le prète avec une restriction : un tumulte s'élève dans l'èglise: les uns veulent que le serment soit bon, les autres qu'il soit nul; les Lunicipaux se retirent ot dressent proces-verbal. Cependant, non seulement i: reste en sa fonetion, mais il l'exerce dans les paroisses voisines qui n'ont plus de pasteurs légitimes. En 1793, va club do Jacobins se forme dans le village : ils veulent enlever au curé certain gobelet dont il fait usage, c'est-a-dire le calice. A eet.te proposition, il rèpond par une lettre indignée: elle est sommuniquée aux Jacobins de Rouen et au représentant Guimberteau, qui la fait passer au Lomité de Salut public. Quelques semaines après, on le mande à la municipalité : "Là, on me dit qu'il fallait remettre sur-le-ehamp lı clef de l'église, ma lettre de prètrise, renoneer a nes fonctions, à ma religion, et que, décormais libre, je devaiz penser à faire le choix d'une épouse. On voit que Guerbaville en ètait alors a la periode hébertiste. Dumesnil livre la clef et la lettre de prétrise, mais refuse evergiquement d'abjurer et de se marier. Ii trouve prudent de fuir, de se eacher dans les bois ou chez las fidèles, de mener pendant plusieurs mois la vie d'un proserit et d'un nowade, eraigrant de tomber entre les mains du terrible représentant Siblut. Las d'errer, it rentre $h$ Guerbaville. y trouve son eglise dérastee, le culte de la Raison installé, l'observation du dimanche interdite. On l'arréte, on le conduis a Yretot, chef-lieu du distriet, et on l'emprisonne au chateau de Combles. Puis des ordres étant arrivés de Paris, - e'est l'époque oủ Robuspierre fait décréter la liberté des culles, - le cure Dumesnil est mis en liberté. Le $9 l$ hermidrs n'anène puint sa réintégration dans son église : il a méme le ehagrin d'y voir installer lo buste de Marat, sous un arbre de liberte qui a remplacé l'autel. Après linsurrection de germinal à Paris, on lui rend son église, ?es Jacobius de Guerbaville sont dissous : il peut de nouveau prècher et dire la messe. Le parti avaneé reprend le dessis, à la suite du 18 fructidor : mais désormais il se. contente d'empẻcher le euré de sonner les cloches et de porter le eostume sacerdotal dans la rue: à la suite d'une conträrention, il est de nonveau arreté, puis lelàehé sous caution. puis eondamné par le jury à huit mois do prison, 300 livres d'amende et les frais d'affichage du jugement tans $150 \mathrm{com}$ munes. Ses adversaires politiques essayèrent mẻme de le fairo déporter a l'ile de Rè. Cejuendant, eomme il n'y avait plus de messe a Guerbaville, personue n'y venait les fëtes et dimanches, et les cubaretiers, mëme jacobıns, commencaient a se plaindre. Libèré a l'expiration de sa peine, Dumesnil ne fut plus iuquiéte, mais nosa cẻlebrer le culte. Enfin, deux ans après, l'avènement le Bonaparte lui rendit la sécurité, comme aux autres prètres, ot le préfot de la Seine-Inferieure, malgrẻ l'hostilité beaucoup plus terace des autorites locales, linvita formellement a reprendre ses fonctions, aprè qu'il out fait la promesse d'étre fidèle à la Constitution. 
Derniers temps de la Convention : la liberté des caltes. - Par le décret de septembre 179', lá Convention déclare que "la République francaise ne paye jius les frais ni le salaire d'aucun culte ". Par le décrt du 21 fivrier 1795, elle affirme de nouveau la liberté des cultes et porte des peines contre quiconque troublerait leur exercice; mais elle statue que l'Etat ne fournirait de locaux ni pour le culte, ni pour le logement de ses ministres; féfend aux communes d'en acheter ou d'en louer; interdit toule cérémonie sur la voie publique, toute sonnerie de cloches, tous signes extéricurs sur les édifices, tout costume particulier pour les prètres.

La Convention se montra plus libérale lorsque, par le décret du $30 \mathrm{mai}$, elle restitua au culte les édifices non aliénés; rien qu'a Paris, douze églises; mais, par le décret du 29 septrmbre 1795 , elle renouvela l'interdiction des signes extérieurs.

Le décret du 21 février 1795 ne distinguait pas entre les assermentés ou les insermentés : le peuple linterpréta donc à sın gré; en tel pays, ceux-ci étaitnt reçus dans les églises; en tel autre, on continuait à les exclure et à les arrèter.

On pouvait s'attendre à ce que la Conventinn fit connaitre sur ce point sa volonté; mais sa législation varia suivant les vicissitudes de la politique : tantôt, surtout a l'occasion de noureaux troubles, elle renouvelle les tois précédentes dans toute leur rigueur; tantòt, surtout dans les moments de calme, elle incline à la tolérance. Ainsi, le 1er mai 1795 , elle enjoint à tous les condamnés a la déportation ou déportés revenus en France de quitter le sol de la République dans le délai de deux mois. Le 30 mai, elle déclare n'exiırer des prètres qu'une simple promesse de soumission aur lois. Le 10 septembre, elle statue de nouveau le bannissement à perpétuité des réfractaires et l'arrestation immédiate de tous cenx qui ont repris leurs fonctions sans avoir souscrit l'engagement exigé par la loi précédente. Le 2 actobre, ehe prononce que les lois contre les réfractaires seront exécutées dans les vingt-quatre heures.

En résumé, d'une part, la Convention se montrc plus large, sur la formule du serment, que ne l'avait été la Cons- 
tituante; d'autre part, elle dépouille le culte, mème constitutionnel, de toute subvention et lui interdit toute manifestation extérieure. Pendant cette dernière année, tout ecclésiastique, en prenant simplement l'engagement général d'obẻir aux lois, sans prèter le serment exigé en 1790, est assuré d'une large tolérance au moins dans l'enceinte du sanctuaire.

Politique du Directoire. -- Sous le Directoire, en thèse générate, il y eut beaucoup plus de tolérance à l'écard des insermentés. Ceux-ci reparaissaient partout. Beaucoup d'églises servaient aux deux cultes. Le Directoire ne se montra intraitable que sur la question des signes extérieurs : en avril 1796, une loi destinée à "réprimer l’abus des sonneries de cloches "édicta la peine d'un an de prison et, en cas de récidive, de la déportation. En juin 1797, le député Jordan fit une motion pour autoriser les sonnories: il échoua aux Cinq-Cents, mais à une faible majorité, et $y$ gagna le surnom de Jorlan-Cari,lon ou Jordum-les-Cloches. La loi du 24 aout 1797 abrogea les lois contre les réfractaires.

Cenendant il faut citer une nouvelle tentalive de religion officiclle et un nouveau retour aux pratiques de violence.

Quelques diciples de Rousseau essayèrent encor's de constituer une religion de déisme pur. Ils avaient fondé, dès 1792. la secte des Théoandrophiles ou Théophilanthropes. (Amis de Dieu et des hommes). Vers la fin de 1796, par la protection d'un de leurs adeptes, le Directeur Laréveillère-

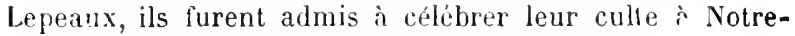
Dame, concurremment avec le culte catholiqus.

Après le coup d'État du 18 fructidor, on sévit de nouveau contre le clergé, cette fois sans distinction untre assermentés ou insermentés. Tout prêtre put ètre, à la discrétion du gouvernement, frappé de la déportation : 193 furent dépol'és soit à l'île de Ré, snit, mais en très petit nombre, à Cayenne. Tous les projets de loi proposés, ou en vue de rendre le régime plus rigoureux, ou en vue de l'adoucir, éclouerent également.

A la fin du Directoire, près de 40000 églises avaient déjà été rendues au clergé; les autorités locales ne faisaient plus aucune distinction entre les constitutionnels et les 
réfractaires; les premiers voyaient même, partout, les populations les abandonner pour retourner à l'aucien culte. Cependant, en 1797, un concile national du clergé constitutionnel s'était tenu à Paris.

\section{Le clergé catholique sous Napoléon.}

Politique de Bonaparte. - L'œuvre du Premier consul est donc bien moins d'avoir rétabli la liberté de conscience que d'avoir essayé de reconstituer une Éclise d'État. Quand il se fut emparé du pouvoir, il se trouva en présence de deux cultes et de deux hiérarchies catholiques. Il se garda d'exiger le serment qui avait créé le schisme et se contenta de la simple promesse de soumission aur lois. La cour de Rome refusail d'autoriser même cette promesse: en sorte que, parmi les anciens insermentés eux-mêmes, il y eut deux catégories de prètres : ceux qui aviient pris cet engagement et ceux qui avaient refusé de le prendre. Il y avait dono le clergé qui avait juré, le clergé qui arait promis, et le clergé dont on n'arait pu obtenir ni serment ni promesse.

Le Premier consul avait à choisir entre plusieurs politiques: $1^{\circ}$ laisser les choses en l'état, c'est-à-dire continuer à ne subrentionner aucun culte et ne pas intervenir dans le confiit des divers clergés; $2^{\circ}$ rétablir la situation privilégiéc du clergé constitutionnel, traiter en ennemi le clergé réfractaire, et reconstituer une Église française, qui ne dépendrait que de l'État; $3^{\circ}$ s'entendre avec la cour de Rome pour rétablir les choses sur le pied où elles étaient apres les.rétormes essentielles de la Constituante, mais avant la Constitution civile du clergé.

Il écarta la première de ces politiques: le gouvernement ne pouvait rester indifférent en présence des troubles excités par l'animosité des ciergés rivaux qui se disputaient les édifices du culte, car elle pouvait mettre en péril l'ordre public. Dailleurs, s'il ne payait plus le clergé, il fallait lui permettre de lever sur les tidèles des contributions volon. taires qui seélèveraient à une somme probablement supérieure à celle que pourrait lui accorder l'Etat. Le Clergé 
réfractaire, dont le culte était beaucoup plus suivi que celui des constitutionnels, ferail de cet argent un emploi que le gouvernement ne pourrait pas contrôler et peut-être dangereux pour la sécurité de l'État. Enfin le peaple de France n’était pas préparé au système en rigueur aux États-Unis, où le gouvernement reste indifférent entre les diverses éclises et n'en subventionne aucune; car, en fait, le catholicisme restail la religion de l'immense majorité des Francais.

Bonaparte écarta la seconde de ces politiques : il ne voulait pas revenir au système de persécution précisément contre le clergé qui avail les sympathies du plus grand nombre. La Coustituante avait échoué dans sa tentative de constituer une Église indépendante de Rome : le nouveau gouvernement n'aurait pas un meilleur succès. Bonaparte se refusait, comme certains de ses conseillers l'y engageaient, à pousser la France; au protestantisme pour mieux l'éloigner du pape. Quant à tenter, après Chaumette, après Robespierre, après Laréveillère-Lepeaux, la création d'une nouvelle religion, e'était relomber ou dans la tyrannie, ou dans le ridicule ${ }^{1}$.

Tous ces systèmes écartés, il fallail en revenir à un accord avec la cour de Rome. Le pape seul disposait du pouvoir spirituel, puisque le peuple ne voulait reconnaitre que les prêtres qui étaient en cemnunion avec lui. On ne pouvait done rien fonder sans lui. En revanche l'Etat, qui a la responsabilité de l'ordre public, avait le droit d'ètre entendu lorsqu'il s'agissait de tracer la linite des diocèses, de choisir les prêtres et les évêques, de leur preserire certaines règles de conduite.

Le Concordat de 1801. - Ces principes avaient été reconnus une première fois lors du Concordat signé entre François Ier el Léon X (1516). C'était un nouveau Concordal qui devait intervenir entre Bonaparte et le pape Pie VII. Il fut signé à Rome le 15 juillet 1801. En voici les dispositions essenticlles :

1. La secle des théphilanthropes fut exclue, par arı été consulaire du 21 octobre 1s01, de l'usage des édifices nationaux consacrés au culte. Puí elle fut interdite. 
Le catholicisme n'ètait plus une religion d'État; mais le gouvernement de la Réfublique le reconnaissait comme "la religion de la majorité des Français". Son culte devait ètre libre et public. Les évèques et les prêtres devaient recevoir un "traitement conrenable "; mais le gouvernement ne s'engageait à doter ni les chapitres ni les séminaires.

Toutes les églises métropolitaines, cathédrales, paroissıales, les autres édifices religieux qui n’auraient pas été vendus et qui seraient reconnus nécessaires au culte, seraient mis à la disposition des évêques. Le gouvernement permettrait aux fidèles de faire des fondations en faveur des églises. En échange, le pape rassurait les acquéreurs de biens nationaux, si souvent inquiétés par les prédications et les menaces du clergé réfractaire.

Les archevèques et évèques seraient nommés par le chef de l'État; mais ils devaient recevoir du pape l'institution canonique. Les curés seritient nommés par les évéques, mais ils devaient ètre agréés par le gouvernement. Tous, avant dentrer en fonctions, devaient prèter un serment '. Dans les prières publiques, devait ètre récitée la formule ${ }^{2}$ : Domine, salvam fac rempublicam, etc.

Enfin une nouvelle circonscription des diocèses serait itablie de concert avec le pape.

Les articles organiques. - Le Concordat est un truite conclu entre l'État français et la cour de Rome; les articles organiques sont un réglement dans lequel le pape n'a pas eu à intervenir. Le Concordat et les articles organiques forment cependant un tout indivisible, car c'est le mème acte ${ }^{3}$ qui les a mis en vigueur sur le territoire framcais et qui les a érigés en lois de l'Etat.

1. Voici la formule de ce serment: a Je jure et promets à Dieu, sur les saints Évangiles, de garder obeissance et fidelité au gouvernement étibli par la Constitution de la Pépublique francaise. Je promets aussi de navoir sucune intelligence, de n'assister à aucun conseil, de n'entretenir aucune ligue, soit au dedans, soit au dehors, qui soit contraire a la tranquilité publique; et si, dans mon diocèse ou ailleurs, japprends qu'il se trame quelque chose au préjudice de l'État, je le ferai savoir au gouvernement.

2. Remplacée sous l'empire ou sous la monarchie, par la formule : salvum fac imperatorem nostrum Napoleonem ou salun fac regem nostrum. Sous le Consulat, elle était suivie des mots: Salios fac Consules.

3. La loi da 18 germinal an X (\$ avril 1S02). 
Les articles organiques règlent: 10 les rapports de l'Église et de l'administration civile; $2^{\circ}$ la hiérarchie et la disci. pline du clergé catholique; $3^{\circ}$ le mode de célébration du culte; $4^{\circ}$ la nouvelle circonseription des diocèses et des paroisses; $\breve{5}^{\circ}$ le traitement des ministres du culte.

$1^{\circ}$ Aucune bulle, aucun acte émranant de Rome, aucun décret de conciles étrangers ou de conciles généraux ne pourrait être publié en France, aucune personne se donnant pour nonce, légat, vieaire, commissaire apostolique ne pourrait y exereer d'autorité, aucun concile ou synode, national ou provincial, ne pourrait y être tenu sans l'autorisation du gouvernement.

Pour réprimer les abus, excés de pouvoir des évèques contre les prètres, violations des lois et règlements, atteinles aux franchises et coutumes de l'Eş̧ise gallicane, attaques aux citoyens du haut de la chaire, on a emprunté à l'ancien régime l'appel comme d'abus. La plainte est portée devant le Conscil d'État, soit par la personne intéresscé, soit par le préfet du département. Le Conseil d'État, si la plainte est fondée, prononce qu'il y a xbus.

$2^{n}$ Les prêtres; chargés du soin des cures sont soumis aux éréques dans l'exercice de leurs fonetions. Un petil nombre d'entre eux seulement portent le titre de curés : dans les campagnes, il n'y a plus qu'un curé frar canton; on l'appelle le curédoyen; tous les autres sont des desservants. Les curés et les desservants de certaines paroisses sont assistés de vicaires. Il y a cette différence entre les curés, d'une part, et les desservants et vicaires, d'autre part. que les premiers sont inamovilues et que les seconds sont révocalles à la volonté de l'évêque.

Il est interdit aux évêques de faire aucune ordination sans que le nombre des personnes à ordonner ait été approuré par le gouvernement; car le Premier consul ne se soucic pas que le nombre des prètres puisse ètre augmenté arbitritrement, au détriment des finances publiques et peut-itre du recrutement militaire. Aucun étranger ne doit etre employé dans le ministère ecclésiastique sans la permission de l'État.

Un article, abrogé depuis, interdisait mème aux évèques d'ordonner aucun ecclésiastique qui ne justifierait pas 
d'une propliété produisant au moins 300 livres de revenu. C'eñt été le sacerdoce censitaire.

Les prêtres qui seraient désignés par les évèques pour donner l'enseignement dans leurs diocèses devaient souscrire une adhésion aux maximes de $168 \%$.

$3^{\circ}$ Il ne devait y avoir qu'une liturgie et un catéchisme pour toutes les églises catholiques de France : cette disposition n'a pas survécu à Napoléon. Le dimanche était officiellement reconnu comme jour de repos pour les services public. Aucune fête, à l'exception du dimanche, ne pouvait être établie ${ }^{1}$, aucun oratoire ou chapelle ne pouvai être ouvert, sans la permission du gouvernement. Bien que le culte fùt public, aucune cérémonie religieuse, dans les villes où il y a des temples consacrés à différents cultes, ne pouvait avoir lieu hors des églises. Il ne pouvait ètre fuit au pròne aucune publication étrangère au culte, à part celles qui étaient prescrites par le gouvernement. La bénédiction nuptiale ne pourrait ètre donnée qu'aux personnes justifiant du mariage contracté devant l'officier civil.

Les articles organiques déterminaient le costume que levaient adopter, en dehors des cérémonies religieuses, les ecclésiastiques : tous devaient porter l'habit noir à la française : les évèques se distingueraient seulement par la croix pastorale et les bas violets. Les prélats ne pouvaient ajouter à leur nom que l'appellation de monsieur, mais non celle de monseigneur.

$4^{\circ}$ Les archevèchés ètaient au nombre de dix, les évêchés au nombre de cinquante. Il y avait au moins une paroisse par canton, ayant à sa tète un curé : les autres églises étaient des succursales.

$5^{\circ}$ Le traitement des archevêques était fixéà 15000 francs; celui des éveques à 10000 ; celui des curés, à 1500 pour ceux de première classe, à 1000 pour ceux de seconde classe. Aucun traitement n'était attribué aux desservants et vicaires : comme les évêques étaient tenus de les choisir parmi les prêtres pensionnés par ies dérrets de la Constituante, le montant de ces pensions et les otilations, c'est-à-dire le casuel, devaient suffire à leur entretien.

1. Des innombrables jours fériés de l'ancien régime, quatre seulement étaient conservés : Noël, Ascension, Assomption, Toussainl. (Bref pontifical du 9 avril 1802 et arrèté consulaire du 12 avril suivant.) 
nise à exéention du Concordat. - La paix fut ainsi rétablie dans l'Église. Le pape avait demandé leur démission à tous les anciens titulaires des sièges épiscopaux, les seuls qu'il regardât comme légitimes. Il prit une formule différente pour amener les constitutionnels a démissionner également. Dans la nomination aux évèchés nouveaux, une part très faible fut faite aux anciens prélats constitutionnels : le pape consentit seulement à instituer parmi eux deux archevêques et dix évèques; les quarante-huit autres sièges furent attribués à des insementés. L'abbé Bernier, qui avait été autrefois un des agitateurs de la Vendée, mais qui était devenu je promoteur de la réconciliation et l'un des négociateurs du Concordat, devint évêque d'Orléans: le Premier consul négocia même pour le f́aire nommer cardinal. Plus tard, Napoléon se piqua dobtenir pour son clergé le plus grand nombre possible de chapeaux.

Comparaison de la situation du clerge sous le nonvean Concordat et sous l'ancien rémime. - La situation que le Concordat et les articles organiques faisaient à l'Ëglise catholique différait, sur quelques points essentiels, de celle que Iui avait maintenue l'ancienne royauté. Elle avait cessé d'ètre une Érlise d'État: elle était astreinte, dans son enseignemert public et dans ses cérémonies, à tenir compte de la liberté des autres cultes. Au lieu de posséder le cinquième du terriloire francais et de percevoir la dime, elle toushait une subvention sur le budget de l'État et recevait de celui-ci les édifices nécessaires au culte. Les actes de l'état eiril passaient des mains des ecclésiastiques à celles des fonctionnaires läques et ie mariage civil devait précéder le mariage religieux. Les prètres étaient soumis plus étroitement quautrefois aux évêques, car tous étaient nomimés par ceux-ci; en outre, grâce à la distinction faite entre les curés et les autres prètres, l'immense majorité d'entre eux, sous le nom de vicaires ou desservants, était révocable à volonté.

Sous tous les autres rapports, l'Église se retrouvait dans la mème situation à l'égard de l'État: les évêques étaient nommés par lui; le clergé était lié envers lui par un devoir de déférence, constaté par lobligation de prèter 
un serment, de mentionner la République et le chef de l'État dans les prières publiques, de lire au prône les actes de l'autorité civile. L'État exerçait sur les ecelésiastiques, par l'appel comme d'abus, un droit de répression; seulement il l'exerçait non plus, comme autrefois, par les Parlements, mais par le Conseil d'État.

L'Église restait romaine par le droit d'institution canonique réservé au souverain pontife; elle restait gallicane par l'obligation d'enseigner dans les séminaires les principes de 1682 et par les restrictions apportées à la publication des bulles du pape et aux pouvoirs de ses envoyés.

Appreciation du Concorat. - Pour le spirituel, l'Église était done indépendante. Pour le temporel, elle subissait une dépendance que compensaient les avantages matériels que lui faisait l'Etat sous la forme de traitements à ses ministrès, subventions pour lıs édilices du culte, honneurs de toutes sortes rendus à ses chels, exemption du service militaire pour tous ses menbres.

Cefte dépendance se justifiait dans un pays où la religion catholique est celle de l'immense majorité des citoyens et où l'État a le droit de veiller à ee que l'on n'y crée pas des mouvements dopinion hostiles à son principe. L'Etat protège l'Église, mais c'est à la condition que l'Eglise ne tourne pas contre lui les ressources financièes et morales qu'il met à sa disposition, et qu'elle se soumetle aux lois qui assurent l'ordre public.

Le Concordat et les articles organiques ont été une œurre de sagesse. Aussi tous les gouremements qui ont succédé á celui du Premier consul les ont-ils maintenus. Ancun n'a pris sur lui de dénoncer le traité conelu en 1801 avec la cour de Rome ou de renoncer aux garanties qu'assurent à l'État les articles organiques ${ }^{1}$. Tout autre régime conduirait à l'oppressioñ de l'Eglise par l'État ou à une indépendance de l'íglise qui pouruait mettre en péril la séeurité de l'État.

Politique de Napoléon à l'égard de la papanté. Bonaparte, en signant le Concordat, n'avait pas en vue

1. Ou n'a laissé tomber en désuètude que certains articles, ceur qui sont relalifs au costume, a l'appellation de monsieur, a la rente de 300 francs. C’àge de vingt-cing ans, requis d'abord four lia consécration les prèires. 
seulement la paix des consciences. S’il rendait à l'Église une partie de sa puissance, c'était à la condition qu'elle contribuerait à affermir et à élever la sionne. Comme Clovis, Pepin et Charlemagne, qu'il aimait à invoquer comme "ses augustes prédécesseurs ", il avait protégé l'Église : cornme à ces princes, l'Église lui devait une récompense. Ses prédications, son influence devaient préparer les peuples à la fondation d'un noùveí état politique. Quand l'Empire fut établi, Napoléon exigea que le pape fit pour lui ce qu'il n'avait jamais fait pour aucun souverain : qu'il quiltit la ville éternelle et vint dans la capitale. du nouvel empereur, non pas pour le couronner, mais pour assister à son couronnement, et couvrir la monarchie nouvelle du prestige antique de la papauté.

Une fois empereur, Napoléon se regarda comme l'héritier des droits qu'avaient possédés autrefois, à l'égard de la papauté, les empereurs romains, Charlemagne et les empereurs allemands. Il cousidéra le pape comme un vassal du nouvel empire, comme tenant de hi en fief les Elats romains. "Votre Silinteté, écrivait-il à. Pie VII, est souveraine de Rome, mais j'en suis lempereur. "Quand le souverain pontife essaya de résister, il n’hésita pas à le traiter en sujet rebelle. " Il faut agir à Rome, écrivait-il à Murat, comme jagirais avec l'archevèque de Paris. "Il fit enlever le pape Pie VIl et le fit transporter successivement à Grenoble, puis à Savone, el enfin à Fontainebleau. Il transféra en masse le Sitcré.College à Paris, y fit apporter la tiare, l'anneau du pêcheur, tous les autres insignes de la papauté, les archives mèmes du Vatican. C’était à Paris, sous son protectorat, que devaient se traiter désormais les affaires du saint-siège avec les puissances européennes. Paris devenait la métropole religieuse du catholicisme comme les victoires de Napoléon tendaient à en faire la capitale du monde. La " captivité d'Avignon " semblait recommencer pour la papauté.

- élé réduit à vingt-deux ans en 1810. Le traitement des évèques et des curés a élé aurmenté; les desservants el les chanoines en ont reçu un. Des bourses de séminaire on été fondées (Napoléon en créa 2400 par décret do $1807)$. On a fait un fonds de subvention pour la construclion ou la réparation des édifees du culte. La loi du \& février 1810 a réglé l'organisation des fubriques. 
Les États du pape avaient été réunis à l'limpire et organisés en départements franȩais. Rome n'était plus que le chef-lieu du departement du Tibre. Quand un fils naquit à Napoléon, il le décora du titre de roi de Rome.

En 1813, il conclut avec le pape, prisonnier à Fontainebleau, un acte qui lut appelé aussi concorlat, mais qui ne portait que sur la nomination a certains sièges épiscopaux. La clute le l'Empire annula cette convention.

Politique de Rapoléon à l'égard de lrigglise de Franec. - Si Napoléon raitajt avec si peu de ménagements le chef du catholicisme, on peut imaginer ses exigences à l'égard du clergé francais. L'Église était pour lui un instrument de rìgne. Son rôle, comme celui de l'Université, c’était d'enseigner la fidélité à l'Empereur et a sa dynastie. Napoléon fit rédiger un catéclıisme qui devait être enseigné dans toutes les paroisses de la France 1. La

1. Voici un extrait de ce nouvea catéchisme :

Lecon VII, - Suite du quatriène commandement.

D. - Quels sont les devoirs des chrétiens à l'égard des princes qui les gouvernent, et quels sont en particulier nos devoirs envers Napoleon ior, notre empereur?

R. - Les chrétiens doivent aux princes quiles gouvernent, et nons devons en particulier à Najoléon lar, notre empereur, l'amour, le respect, l'oléissance, la fidelité, le service militaire, les tributs ordonnes pour la consprvation et la défense de l'empire et de son trône; nous lui devons encore des prieres ferventes pour son salut et pour la prospérité spirituelle et temproclle de l'Élat.

D. - Pourquoi sommes-nous tenus de tous ees devoirs envers notre empereur?

R. - C'est, p'emièrement, paree que Dieu, qui crée les empires et les distribue selou sa wonte, en eomblant notre empereur de dons. soit dans la paix, soil dans la guerre, l'a étaoli notre souverain, l'a rendu le ministre de sa puissance et son image sur la terre. IIonorer et servir notre empereur est donc honorer et servir Dieu lui-mème. Secondement, parce que N. - - . J. -C., tant par sa doctrine que frar ses exemples, nous a enseigné lui-mème ce que nons devons à notre souverain.....

D. - N'y a-t-il pas des motifs particuliers qui doivent nous attacher phus fortement à Napolicon Ies, notre empreseur?

R. - Oni, car il est celui que Dieu a suscité, dans les circonstances difficiles, pour rétablir le culte public et la religion sainte de nos pères, et pour en ètre le protecleur. Il a ramené et conservé l'ordre public par sa sazesse profonde et active; il défend l'État par son bras puissant; il est devenu l'oint du Seigseur par la consécration qu'il a recue du souverain pontife, thef de l'Éghise universelle.

D. - Que doiton penser de ceux qui manqueraient à leur devoir envers notre empereur?

R. - Selon l'apòtre saint Paul, ils résisteraient à l'ordre établi de Dieu mème, et se rendraient dignes de la damnation éternelle. 
fète de l'Empereur se confondit avec celle de l'Assomption de la Vierge, le 15 aoùt ${ }^{1}$. En revanche, il recevait les prélats à la cour, faisait entrer les cardinaux dans son Sénat. donnait le pas aux évêques sur les généraux. Il choisissait de préférence pour l'épiscopat les prètres titrés, nême anciens émigrés; nommait M. de Boulogne parce qu'autrefois il avait prèché le carème devant Louis XVI; đésignait Boisgelin, archevèque d'Aix, pour prêcher le jour de la publication du Concordat, précisément parce qu“il avait parlé au sacre de Louis XVI; se plaisait à renouer les anciennes traditions de l'Église monarchique, et, comme Louis XIV, goủait les louanges tombées de la chaire. ll se montrait mème plus difficile que le grand roi : à l'occasion de la naissance du roi de Rome, M. de Rroglie, érèque d'Acqui (Italie), n’arait rien trouvé de mieux que de copier ce qu'avait dit Bossuet à la naissance d'un petitfils de Louis XIV : Napoléon trouva que c'était insuffisant.

Portalis ${ }^{2}$, conseiller d'Etat charçé des cultes, fut comme un ministre des affaires ecclésiastiques. Les mandements épiscopaux furent, comme les journaux, soumis à une sorte de censure: d'abord on engatgea les évèques à communiquer leur prose aux préfets; puis ils ne purent faire imprimer qu'a l'imprimerie préfectorale. Le préfet exigeait parfois des modifications ou des suppressions. Il se produisit des faits singuliers. Tel préfet, appelé à censurer un mandement, pouvait ètre protestant ou libre penseur. Souvent un évèque, dont le diocèse comprenait deux départements, recevait de ses deux prefets descritiques contradictoires. Ces fonctionnaires avaient une tendance à empiéter

1. Guand on fonda la Saint-Napoléon, les prélats furent trés embarrassés pour decouvrir la légenile du nouveau saiat. L"èvéque de Naney écrit qu'à "la honte des bibliothegrues de Nancy, vainement, nous arons feuilleté tous les volumes qui pouvaient nous insiruire ". Le cardinal Caprara, légat du pape, s'avisa enfin qu'il y arait eu un ehrétien martyrisé en Égypte, sous le réze de Diocletien, ef qui s'appelait Neapolis nu Neapolas. On a'hésila pas a y reconnitre le Napnlén eherché, el on l'inserint dans le calendrier.

?. Aprés Austerlilz, Porlalis, reprenant un usage de l'ancien régime, avait eu l'idee de fare lire en chaire par les eures les bulletins de vietuire. Napoleon se ravina : s'il y avail de mauraises nouvelles, nétait-ce pas les sutoriser a les communiquer en ehaire? a Je vous ai deja fait conatitre, écrivitil à Portalis, que je ne désirais pas qu'on fil sortir les prètres de leurs fonctions et quon leur donntit trop d'importance cirile... C'est un grand mal de leur faire sentir qu'ils ont une importance politique. 
sur le domaine spirituel : celui de l'Aveyron se trouvait "déconsidéré aux yeux de ses administrés", parce que son évèque ne permettait pas, comme ceux des diocèses voisins, l'usage des aliments gras à certains jours.

Napoléon faisait surveiller les prélats par la gendarmerie, recevait des rapports sur eux. Il essaya de les transformer eux-mėmes en auxiliaires de la gendarmerie, les invitant à appuyer les mesures de recrutement, surtout dans l'Ouest et en Belgique, à prècher contre i"Angleterre, en insistant sur la persécution des catholiques irlandais. II exigea qu'ils dégradassent les prètres compromis dans les complots. Certains se prêtaient aisérnent à ce ròle : Bernier, par exemple, dénonçait les menées de ses ancienscomplices, les chouans, et Napoléon l'invitait à en faire arrèter deux. Il disait volontiers : "Mes évėques et mes gendarmes. "

Ce clergé si docile, Napoléon trouva moyen de le pousser à bout. Après qu'on eut enlevé le pape de Rome, il essaya, comme Louis XIV en 1682, de couvrir ses actes de l'autorité de l'Église de France. Il convoqua donc un comité, choisi panni les plus dévoués du haut clereí. ct composé du cardinal Maury, de cinq évèques et de labbe Emery, supérieur de Saint-Sulpice. Il les invita à se prononcer sur des questions fort embarrassantes pour cux : à savoir, si, pour mettre le pape à la raison, il ne convenait pas de réunir un concile; si l'on ne devait pas placer Pie VII sous la tutelle d'un conseil d'évèques de tous les pays; s'il n'y avait pas des mesures à prendre pour prévenir l'excommunication qu'il pouvait ètre tenté de lancer. Les membres du comité se bornèrent à dire qu'une excom. munication serait "un abus de pouvoir "; ils évitirent de s'expliquer sur le reste. L'Empereur dut se borner a édicter le décret de 1810 (Qü férrier), par lequel it remettrait en vigueur les maximes de $\mathbf{1 6 8 2} \mathbf{2}$ et en prescrivait de nouveau l'enseignement dans toutes les facultés de thèologie et dans tous les séminaires. L'année suivante, il se décida à réunir le concile national de 1811 (du 1 j juin au כ̆ août), où figurèrent 106 évéques dont 31 de son royaume d'Italie. Un certain nombre dentre eux réclamèrent la mise en liberté du saint-père. Les promoteurs de cette démarche, les éréques de Troyes, de Tournai, do 
Gand, furent arrêtés et enfermés à Vincennes. 88 prélats consentirent à approuver le décret de 1811, en vertu duquel " si, dans les six mois, le pape refusait l'investiture épiscopale (aux nouveaux évèques), elle serait donnée par le métropolitain ".

Bientôt Napoléon se trouva engagé, comme les Assemblées révolutionnaires, dans la voie de la persécution. Il avait entrepris de révoquer et de remplacer les trois prélats arrètés : cela fit un sehisme dans les trois diocèses. A Tournai, comme le nouvel évèque se préparait à officier, les séminaristes refusèrent de paraitre dans le chœur : le préfet arrêta leur supérieur et leurs professeurs et livra ces jeunes hommes au recrutement militaire; Napoléon les fit incorporer dans les régiments d'artillerie de Wesel, où plusieurs moururent de chagrin ou de maladie.

Ambitions impolitiques de Napoléon. - Plus tard à Sainte-Hélène, Napoléon énonçait ainsi ses vues sur l’Église: “ Quel levier! Quel moyen d'influence sur le reste du monde!... J'aurais fait du pape une idole; il fât demeuré près de moi. Paris fût devenu la capitale du monle chrétien, et j’aurais dirigé le monde religieux aussi bien que le monde politique... J'aurais eu mes sessions religieuses comme mes sessions législatives. Mes conciles eussent été la représentation de la chrétienté : les papes n’en eussent été que les présidents. "Le système que rèrait Xapoléon eut été la confusion du pouvoir spirituel et du pouvoir temporel. L'Empereur ent été à la fois un chef politique et religieux, comme les empereurs païens de Rome, comme les killalifes arabes et les sultans ottomans. C'eùt été un retour au despotisme asiatique.

Le Concordat de 1801 valiat mieux que la politique de 1811. Aussi a-t-il survécu à Napoléon.

\section{Les congrégations religieuses.}

Décrets de la Constituante. - Sous l'ancien régime, les congrégations avaient eu dans l'Église catholique une situation particulière. Au point de vue religieux, sovvent elles étaient indépentantes des évèques dans le diocèse 
desquels elles avaient leurs établissements : c'est ce qu'on appelait " n'être pas soumis à la juridiction de l'ordinaire ". Au point de vue politique, elles ne pouvaient se fonder sans une autorisation du roi.

L'Assemblée Constituante, avant de statuer sur leur existence, commenȩa par prendre une mesure provisoire : par le décret du $2 S$ octobre 1789 , elle interäit, jusqu’à nouvel ordre, de prononcer des vœux monastiques.

Puis elle rendit le décret du 13 février 1790, dont le premier article est ainsi conç : "La loi ne reconnaitra plus de veux monastiques solenneis de personnes de l'un et de l'autre sexe : en conséquence, les ordres et congrégations roligienx dans lesquels on fait de pareils rœux sont et demeurent supprimés en France, sans qu'il en puisse être élabli de semblables à l'avenir. "

Ce décret ne se bornait pas, comme on l'a dit, à ouvrir les portes du couvent à ceux qui voulaient rentrer dans la vie civile, tout en permettant à ceux qui auraient le goût de la vie religieuse d'y entrer comme par le passé. En réalité, il supprimait les couvents, puisqu'il interdisait de prononcer les vœux monastiques. D’ailleurs, un décret antérieur n'avait-il mis les biens des communautés à la disposition de la nation ${ }^{1}$ ?

Sans doute, l'Assemblée tenait compte des scrupules ou des intérêts de certains reliquieux. Bien que leurs associations fussent dissoutes, l'Assenublée les autorisait à terminer leurs jours dans une maison de leur ordre, et prescrivait, à cet effet, de réunir plusieurs maisons en une seule. A l'égard des religieuses, elle usait encore de plus de ménagements, les autorisant à vivre dans les maisons mèmes qu'elles occupaient. Leurs congrégations n'en étaient pas moins dissoutes, puisqu'elles ne pouvaient plus recruter de novices.

Autrefois les religieux et religieuses, en prononçant des vœux, mème contraints et forcés, avaient. par cela mème, renoncé à tout héritage. L'Assemblée crut devoir, en leur permettant de rentrer dans le monde, leur interdire de

1. Jusquä nouvel ordre, les établissements consaerés a l'instruction publique et aux hópitaux étaient autorisés à subsister. 
revenir sur le passé. En dédommagement des biens et héritages qu'elle ne les autorisait pas à réclamer, elle leur assurait une modeste pension dont l'Etat ferait les frais. Cette pension fut fixée à un chiffre variant de 700 à 1200 livres.

Qu'allaient devenir les biens immenses des monastères supprimés? Qui en était le propriétaire? Ce n’étaient pas les religieux eux-mèmes, car les anciens fondateurs des couvents ne s'étaient pas proposé de faire la fortune particulière des moines. Les seuls propriétaires, c’étaient les ordres religieux. Or, un ordre était une personne morale. S'il était dissous, on pouvait dire que la personne morale mourait. Elle mourait sans héritier, et dès lors l'Etat pouvait occuper ses domaines par droit de déshérence. C'est en vertu de cette théorie que les biens du clergé régulier, comme ceux du clerge: séculier, furent déclarés biens nationaux.

bicrets de la Législative. - En supprimant les congrégations religieuses, la Constituante s’était réservé de statuer sur les congrégations vonées, soit au service de l'enseignement, soit au service des hópitaux.

Ce fut le Comité de l'Instruction publique, sous la Législative, qui demanda la suppression des premières, alléguant que leur existence nuisait à la réorganisation de l'enseignement.

En conséquence, le décret du 18 août 1792, qui suivit de huit jours la chute de la royauté, prononca la dissolution de toutes ces communautés. Il se terminait ainsi : "Toutes les congrégations séculières d'honmes et de femmes ${ }^{1}$, ecclésiastiques ou laïques, même ${ }^{2}$ celles uniquement vouées au service des hôpitaux et au soulagement des malades, sous quelque dénomination quelles existent en France, sont éteintes et supprimées."

La compagnie de Jésus avait été dissoute sous Louis XV; les autres ordres le furent par la Révolution. Alors disparurent les bénédictins, qui remontaient aux rois mérovin-

1. Aubert-Dubayet, qui fut plus tard un des défenseurs de Mayence, avait. sans sucrés. proposé une exception en faveur des couvents de femmes.

2. Le Comité d'Instruction publique avait, sans plus de suecès. proposé ce sexte: "Autres que celles uniquement vouées au service des bojpitaux. " 
giens, les dominicains, qui, au xure siècle, avaient établi l'Inquisition dans le midi de la France, les franciscains, dont la branche la plus populaire était les capucins, et tant d'autres ordres si célebres dans notre histoire. Leurs biens furent confondus dans les biens nationaux, leurs abbayes livrées au marteau des spéculateurs, leur costume proscrit, leur souvenir presque effacé.

Législation eousulaire et impériale. - Quand Bonaparte rétablit le culte catholique, le Concordat ne fit même pas mention des congrégations: indirectement, il consacra leur dépossession en donnant des garanties aux acquéreurs de biens nationaux. Les articles organiques, sans nommer les congrégation's, semblèrent les abolir une fois de plus : car, en permettant aux évêques d'établir des chapitres et des séminaires, ils ajoutèrent: "Tous autres établissements sont supprimés. "

Napoléon autorisa seulement, trois conyréyutions d'hommes: lazaristes, missions élrangères, Saint-Esprit. Il autorisa, comme corporutions enseignuntes, les frères des écoles

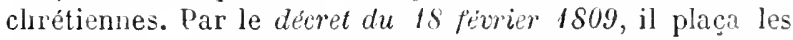
congrégations de femmes vouées à l'assistance publique "sous la protection de Madame, notre très chère et très honorée mère ". Mais quand les jésuites essayèrent de se reconstituer sous les noms de Pères de la loi, Adorateurs de Jésus, Paccanaristes, le décret dc messidor an XII consacra de nouveau leur abolition. "Sont pareillement dissoutes, ajoutait le décret, toutes autres agrégations ou associations formées suus prétexte de religion, et non autorisées." "

\section{Les cultes non catholiques.}

Les protestants et la Rhévolution. - La Révolution rendit aux protestants la liberté de conscience. La Constituante, par le décret du 2.4 décembre 1789, leur assura les mêmes droits politiques qu'aux autres citoyens. Par le décret du 10 juillet 1790 , elle restitua aux héritiers des proscrits les biens qui avaient été confisqués. Elle fit plus : soucieuse d'effacer jusquau souvenir de la Révocation et de ramener de la terre étrangère, s'il était possible, les des- 
cerdants de ceux qui avaient fui les barbaries de Louis XIV et de Louis XV, elle rendit le décret du 15 décembre 1790 : tout descendant d'un Français ou mème d'une Française expatriés pour cause de religion serait, de plein droit, s'il revenait en France et y pretait le serment civique, admis à jouir de la qualité de Français.

Le culte protestaut ne fut inquiété qu'un moment à Paris, sous la Commune hébertiste. Le régime de la liberté des cultes, sans subvention pour aucun, qu'avaient adopté la Convention et le Directoire, portait préjudice au clergé catholique, qui était jusqu'alors en possession d'une riche dotation et de nombreux éditices : il n'en portait aucun au culte protestant.

Les protestants et Napoléon. - Bonaparte appliqua aux deux communions protestantes, c'est-à-dire à la confession luthérionne ou d'Augsbourg et à la confession calviniste ou de Genève, qu'on appelle aussi réformée, la même politique qu'à l'Église catholique. Leur situation fut réglée par les Articles organiques des cultes protestants (2 avril 1802).

Il assurait un traitement aus pasteurs, mais il réglait l'organisation des églises. Il trenait à leur égard les mèmes précautions qu'avec l'Éclise eatholique : s'il veillait à ce que celle-ci ne fủt pas trop dépendante du pape, il savait quelles inquiétudes lorganisation buguenote avait autrefois données à Henri IV et Louis XIII. Le là ces dispositions: "Les églises protestantes, ni leur's ministres, ne pourront avoir de relations avec aucune puissance ni autorités étrangères. "Nul ne pourra exercer les fonctions du culte s'il n'est Français.

Les églises réformées étaient groupées en consistoires, et leurs consistoires en synodes; les églises luthériennes, en consistoires, et ceux-ci en inspections, au-dessus desquelles élaient les consistoires généraux. Les synodes et les consistoires ne devaient s'assembler qu'avec l'autorisation du gouvernement. Bonaparte créait des séminaires (plus tard des facultés) pour l'instruction des pasteurs; mais il se réservait la nomination des professeurs. Les pasteurs étaient élus et révoqués par les consistoires, mais leur élection et leur révocation devaient être approuvées par 
le gouvernement. Les pasteurs, avant d'entrer en fonctions, devaient prèter le mème serment que les prètres catholiques. Dans les temples, on devait prier pour la République et pour les Consuls.

Les Juifs et Ia Révolution. - La question juive fut posée, à la Constituante, par Mirabeau et l'abbé Grégoire. Le premier avait, en 1787, publié un livre intitulé : "Mendelssohn et la réforme politique des Juifs ". Le second élait fort lié avec le poète israélite Moïse Ensheim et avait présenté autrefois à un concours de l'Académie de Metz un mémoire sur la même question. Le 3 aoủt 1789, Grégoire fit à la Constituante un tableau des persécutions que venaient encore de subir les Juifs en Alsace, ajoutant que, "comme ministre d'une religion qui regarde tous les hommes comme frères ", il venait défendle " un peuple proscrit et malheureux ". En septembre, on reçut une pétition des Juifs, demandant que l'Assemblée décidât sur leur sort et leur accordât le titre de citoyens; qu'ils pussent demeurer dans toutes les villes; qu'on abolit les taxes spéciales qui pesaient encore sur eux (par exemple, à Metz, au profit de la famille de Brancas); enfin, que l'on reconnut le libre exercice de leur culte. Le 14 octobre, on entendit leur délégué, Isaac Berr, auquel l'Assemblée accorda les honneurs de la séance. Leur requète fut combattue par Rewbell, la!'sé Maury, l'évèque de Nancy; elle fut soutenue par le comte de clermont-Tonnerre. "Il laut, dit celuici, tout refuser aux juifs comme nation; il faut tout leur accorder comme individus; il faut qu'ils soient citoyens. " Robespierre intervint aussi en leur faveur. "Leurs vices, dit-il, naissent de l'avilissement dans lequel vous les ávez plongés; ils seront bons quaud ils pourront trouver quelque avantage à l'ètre."

L'Assemblée montrait de l'hésitation. Dèjà, en accordant les droits politiques aux protestants, elle avait réservé sa décision sur les Juifs. Puis, le 28 janvier 1790, elle Ies avait accordés aux Juifs d'Avignon et de Bordeaux, mais non à ceux d'Alsace et de Lorraine, qu'on regardait comme moins civilisés, enclins au lanatisme et à l'usure. Près de deux ans après, en septembre 1791, on trouve encore Rewbell, député de Colmar, combattant leur admis- 
sion. Il fit d'abord voter la liquidation de leurs créances particulières, puis la liquidation des communautés juives qui, en Alsace et en Lorraine, exerçaient sur leurs membres une autorité despotique.

Enfin le décret du 27 septembre 1791 accorda les mèmes droits aux Juifs d'Alsace et de Lorraine qu'à ceux du Midi; mais, par une dernière manifestation de défiance, il les accordait à ceux-là seulement qui prêteraient le serment civique : on voulait que, par un acte formel, ils cessassent d'appartenir à la nation israélite pour faire partie de la nation francaise; on voulait qu'au moment où ils seraient affranchis de toute loi d'exception, ils renonçassent aux avantages et aux contraintes de leur organisation religieuse.

Les Juifs et Napoléon. -- A propos de nouvelles affaires que les Juifs s'étaient attirées en Alsace, en vendant aux paysans les biens nationaux et en poursuivant avec trop d'àpreté le remboursement, une discussion s'engagea, en 180今, au Conseil d'Etat, sous la présidence de l'Empereur. Celui-ci, par un premier décret, suspendit pour un an lexécution des jugements obtenus par les Juifs contre leurs débiteurs.

Par le décret du 30 mai 1806, Napoléon conroquait à Paris une assemblie de notables isrálites. Elle eut pour mandat de " délibérer sur les moyens d'améliorer la nation juive et de répandre parmi ses membres le goût des arts et des métiers utiles". Elle se composait de cent onze délégués, choisis par les préfets, tant en Italie qu'en France. Des commissaires impériaux, Holé, Portalis, Pasquier, furent chargés de diriger ses travaux. On posa aux délégués un certain nombre de questions: par exemple : "Les Juifs, nés en France et traités par la loi comme citoyens, regardent-ils la France comme leur patrie et se croient-ils obligés de la défendre?" - Réponse : "Oui, jusqu’à la mort. "Sur les indications des délégués, une nouvelle assemblée fut réunie, beaucoup plus nombreuse, avec plus d'appareil et d'éclat, sous le nom de grand sanbédrin. Elle ratifia les décisions des notables. Elle posa en principe que la loi mosaïque renferme à la fois des dispositions reliyienses, qui sont immuables, et des disposi- 
tions politiques, qui n'ont pas le méme caractère et qui doivent varier comme les conditions politiques où se trouvent les fils d'Israël. La loi civile des Juifs pouvait donc se confondre avec la loi civile des Francais. La polygamie, prohibée par leur sỵnode de Worms au xie siècle, n'ètait plus pratiquée depuis des sièeles. Pour le mariagre et le divorce, ils se conformeraient désormais aux dispositions du Code Napoléon. Les mariages mixtes, e’est-à-dire entre Juifs et chrétiens, ne seruier t pas bénis par le rabbin, mais ne seraient plus frappés de l'anathème. Les Juifs considé reraınt les Français comme leurs coneitovens, avee obligation de les aimer, de les secourir. Ils regarderaient la France comme leur patrie et lui rendraient le service militaire : pendant la durée de ce service, l'observation du sabbat et des autres pratiques incompatibles avee lui serait suspendue. Hs encourageraient leur jeunesse aux arts et aux métiers utiles, s'interdiraient l'usure, acquerraient des propriétés foncières. Le décret du 2 murs 1807 sanetionna les décisions du grand sanhédrin. Un autre décret obligea les Juifs à adopter, ce qu'ils n'avaient pas encore, des noms de fimille.

Le déertet du 17 mars 1808 les plaça, pour dix années encore, sous un régime exceptionnel. Durant ee clélai, ils ne pourraient faire le commerce des immeubles, ni prendre une hypothèuue, sans l'autorisation du préfet. Les Juifs étrangers aux départements d'Alsaec et de la rive gauche du Rhin ne pourraient s'y établir, ni eeux de cette récrion s'établir dans le reste de la France, sinon comme agriculteurs. La faculté de prendre un remplaçant dans le service militaire était suspendue pour eux.

C'était un déeret bien dur : il avait pour objet de faire l'édueation civique des Juifs d'Alsace et le Lorraine; aussi ceux de Paris et de Bordeaux furent-ils exceptés de ces dispositions. Comme il ne fut pas renouvelé, lors de son. expiration en 1818, les Juifs furent alors placés de plein droit sous la loi commune.

Organiqation du culte ismélite. - Ce mème déeret, puis le decret du 11 decembre $1 S 0 S$, donnèrent aux Juils leur organisation religieuse. Tapoléon établit une synagogue consistoriale et un consistoire israélite dans tout 
département ayant au moins deux mille àmes de population juive : les départements qui auraient une population juive inférieure à ce chiffre seraient groupés ponr former la circonscription d'un consistoire. Dans le ressort de la synagogue consistoriale pourraient s'établir, si le consistoire le jugeait utile, des synagogues particulières: à la tête de celles-ci serait un rabbin; à la tète de celle-là, un grand rabtin. Un consistoire se composerait d'un grand rabbin et de notables laïques. A Paris, il $\mathrm{y}$ aurait, pour tout l'Empire, un consistoire central, composé de trois grands rabbins et de notables.

Aucune élection de rabbir, de grand rabivin, de notable, ne serait valable sans l'autorisation dı gouvernement. Les rabbins étaient astreints à prèter le serment, avant d'entrer en fonctions, et à prier pour l'Empereur. Ils devaient " rappeler en toute circonstance l'obéissunce aux lois, notamment et en particulier à celles relatives à la défense de la patrie, mais y exhorter, plus spécialement encore, tous les ans à l’époque de la conscription, depuis le premier appel de l'autorité jusqu“à la complète exécution de la loi ".

Napoléon exigeait donc tout autant du clergé israćlite que des autres clergés; mais il ne le payait pas. Ses décrets fixaient bien les traitements; mais ce n'était pas l'État qui fournissait l'argent : c'étaient les contributions des fidèles. Les consistoires étaient chargés d'en répartir et d'en percevoir le montant. Cet état de choses dura jusquà 1831.

OTYHAEs A CONSULTER,-L.Sciont. Hist. de la Constitution civile du rler-

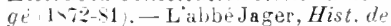
THelise de France pendant la hivel. (17).1792, 1,52. - Labbé Nleric, W. Limery el l'Eqlise de France pendant lu liée. 1905\%-Chrssin, Les cahiers les cures en 1789), (188:). Ernouf. Mim. d'un curéde campugne (le crite Dumesnil). - De Pressenné, L'Eulise et lu Rev. (15y0). - Gazier, Etudes sur llist. relig. le la Rév.fr.

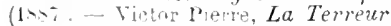
sousle lirectoirplisi, - A. Aulard, Le culte de la finison et le culte de lEhe Suj, phe 1 La Theophilunthropie et le culte decadaipe 1903) et La Revol. et l'Eglise (1910. - P. de la Gures. Hist. reliy. de la liet. fr., t. 1 1909. - L abhe belare, LEgliso de I'aris perdunth

\begin{abstract}
Kir. 1799-181, 18\% - Labbe Pisani. mime titre, lass-10). Labbe cirente. Le culte collolinue is Puris, de la Terren au Consulat 1903, continne Delare. - CrétineanJoly, Bunapurte et le Concordat 1 186: - L. Séché, Les origines dru Concurdut 1-9ti. - Dibaussonvilte, L'Eulise rumaine et lo premier Empire 1 19014, 1 1868-j0). - Welsehmgar. L l'npe et l'Empereur 14)i1.5. 1:46.

Th, Reinach. Hist. les Israilites depuisleurlispersion, 19H1, - Lahbe Liman. Lentree des Isirulites duns la socilie/rancaise lavis et Napoleon jer et les Ismililes 1S:1. L. Brun, La comdition des Juils en France demais fish $19010 .-1$.h. Silcrnac, dans Revate h.st worl, et cout.

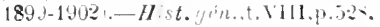




\section{CHAPITRE VIII}

LE DROIT DEs GENS, L'ARMÉE, LA MARINE, LEs COLONIES

\section{Le droit des gens.}

Le droit des gens pendant la hévolution. - La Constitution de 1791 consacre un principe nouveau en matière de droit des gens: "La nation française renonce à entreprendre aucune guerre dans la vue de faire des conquètes, et n'emploieri jamais ses forces contre la liberté d'aucun peuple. "C'est la négation du droit violent d'autrefois, du droit du plus fort, du droit de conquête, qui venait de s'affirmer encore d'une façon si scandaleuse dans le premier partage de la Pologne. Comme corollaire du dogme de la souveraineté nationale à l'intérieur, la France professe le respect de la souveraineté des autres nations. Pour ètre sûre de n’èire pas amenée à violer ce principe, malgré les objurgations de Mirabeau, elle désarme la royauté du droit de paix et de guerre et le remet aux représentants du pays.

La Constituante s'imposait seulement de ne pas nuire aux autres peuples : la Convention, emportée par les idées généreuses des Girondins, rend le décret de 1792 (19 novembre) : "La Convention nationale déclare, au nom de la nation française, qu'elle accordera fraternité et secours à tous les peuples qui voudront recouvrer leur liberté. " Déjả, au lendemain du manifeste de Brunswick, quand la France se trouva en face d'une nécessité inéluctable, la guerre pour la défense du territoire, Robespierre avait dit: 
"Allons! il faut que le peuple fritncais soutienne le poids du monde. Il taut qu'il soit parmi les peuples ce qu'llercule fut parmi les héros."

Alors commence la guerre de propagande, la guerre pour l'affranchissement des nations, la guerre pour l'expansion des Droits de l'Homme. C'est aux acclamations des libéraux de la Savoie, de Nice, de la rive gauche du Rhin ${ }^{\mathbf{1}}$, de la Belgique, de la Hollande, c'est précédés par des légions de volontaires savoisiens, italiens, rhénans, belges, bataves, que nous entrons dans ces pays. Nous acceptons la lutte contre tous les rois pour la cause de tous les peuples. Dans la proclamation aux armées ( 21 février 1793 ), la Convention propose à leur valeur le but le plus noble pour lequel jamais soldats aient combattu : "Si vous êtes vainqueurs, c'en est fait des tyrans. Les peuples s'embrassent, et, honteux de leur longue erreur, ils éteignent à jamais le flambeau de la guerre. On vous proclame les sauvenrs de la patrie, les fondateurs de la République, les régénérateurs de l'univers. "Pent-ètre y avait-il là une utopie; mais quelle espérance que la régénération universelle, que la paix perpétuelle! et quelle force morale elle donnait à une armée et à une nation!

La lutte devient si lourde pour nous, si menaçante pour notre existence mème, qu’il faut bientôt renoncer à ces vastes pensées et consacrer tous nos efforts à la défense de notre propre territoire. La politique plus étroite, mais plus pratique de Robespierre prévaut. La Conslitution de 1793 consacre bien ce principe : "Le peuple français est l'ami et l'allié naturel des peuples libres "; mais elle ajoute

1. Le grand poète allemand Gathe, dans Hermann et Dorothes, raconte ainsi notre arrivée parmi les populations de la rive gauche du Rhin : "Les Francais arriverent, mais ils semblaient n'apporter que l'amitiè. Et ils l'apportèrent en effet, car ils avaient tous l'àme exaltèe. Ils plautaient ave allëgresse les joyeux arbres de liberté, promettant à chacna son droit, à chacun son gouvernement national. Les jeunes gens, les vieillards se félicitaient, et les danses joyeuses commencérent autour des nouveaux ételsdards... Il est beau le temps où, avec son amante, le fiancé prend l'essor it la danse, en attendant le jour de l'union souhaitée; mais il était plus mor gnifique le temps où le premier des biens que l'homme puisse rèver noas sembla proche et aciessible: la liberté ! Toutes les laugues élaient déliées : vieillards, hommes faite, jeunes gens, exprimaiont hautenteat des pensèes et des sentiments sublimes. 
aussitôt ce correctil" : "Il ne s'immisce point dans le gouvernement des autres nations; il ne souffre pas que les autres nations s'immiscent dans le sien."

Avec le Directoire, on revient à la grande politique de propagande des Girondins. Partiout où les patriotes opprimés réclament l'appui de nos armes, les soldats français interviennent : à la République batave, fondée sous la Convention, s'ajoutent la République cisalpine (HauteItalie), la République ligurienne (Gênes), la République helvétique, la République romaine, la République parthénopéenne (Naples). Elles forment à la démocratie française comme une ceinture de démocraties armées.

La Révolution n'a pas fait de sonquètes au sens propre du mot. Tous ces pays, occupés par nos troupes, gardent Jeur indépendance sous la forme: républicaine. Quant aux pays réunis à la France pour reconstituer la vieille Gaule dans ses limites naturelles, ils ne l'ont été que du consentement des peuples: le comtat d'Avignon, par le vote populaire de 1791; la Savoie, par le vote du 14 octobre 1792; la rive gauche du Rhin, par le décret de la Convention de Mayence, réunion des députés cisrlıénans, le 21 mars 1793; la ville libre de Nulhouse, par le plébiscite de 1798. La Belgique fut annexée après lia bataille de Fleurus, qui l'afrianchissait de l'Autriche et lui rendait la libre navigation de l'Escaut.

L'Europe, qui nous faisait alors une guerre implacable, pratiquait plus que jamais la politique de conquète : les puissances du Nord essayaient de démembrer la France, tout en procédant au deuxième et au troisième partage de la Pologne. On violait contre nous et contre nos alliés toutes les règles du droit des gens. L'Autriche retenait en prison La Fayette, qui était allé lui demander asile; elle arrêtait en Suisse nos diplomates Maret et de Sémonville (1793); elle faisait assassiner à Rastadt, en 1798. nos plénipotentiaires pour leur voler leurs papiers. La Russie retenait prisonnier notre amlassadeur à Varsovie. L'Angleterre inondait nos rivages de faux assignats, suscitait ou soudoyait la trahison de Toulon, la guerre civile en Vendée, le brigandage en Bretagne, les assassinats à Paris, envoyait des émissaires incendier nos ports et nos arse- 
naux, traitait le blé comme contrebande de guerre et essayait d'affamer nos provinces. C'est seulement en représailles que la Révolution prit des mesures qui ne pouvaient être justifiées que par l'ancien drcit des gens. La Convention ordonnait, par les décrets de 1793 (9 septembre et 8 octobre), l'arrestation des sujets britanniques sur le sol français, déclarait (26 mai) qu'il ne serait plus fait de prisonniers anglais et hanovriens et que toute garnison étrangère qui se défendrait dans une place française serait mise à mort.

Bonaparte livrait Venise et son territoire à l'Autriche (1797), en punition du massacre de nos blessés dans les hòpitaux. En Syrie, il faisait tuer les prisonniers musulmans. On peut reprocher au Directoire d'avoir abusé des réquisitions et contributions de guerre en pays conquis et d’avoir mis la main sur le trésor de Berne (1798).

Le droit des gens sous le Consulat et l'Empire. Avec Napoléon on en revint à la politique de conquète. On annexa des territoires sans consulter les peuples. Le pouvoir exécutif, après avoir dépouillé le Corps législatif du droit de voter la guerre et la paix, se montra aussi violent qu'au temps de Louis XIV : ainsi furent réunis à la France le territoire de Gênes, la Toscane, l'État romain, les cantons suisses de Genève et du Valais, plusieurs villes allemandes de la rive droite du Rhin, le littoral allemand de la Baltique, arec les villes hanséatiques de Hambourg, Brème et Lübeck. Pour la réunion de la llollande (1810), Napoléon se contentaii d’aỉéguer que ce pays n'était qu' " une alluvion des fleuves de l'Eñpire n. Il partageait et repartageait les peuples conmme des troupeaux, les donnant et les repre. nant à ses alliés ou à ses vassaux, livrant, par exemple, le Tyrol, pays foncièrement autrichien, au roi de Bavière.

A l'ancienne royauté, il n'empruntait pas seulement la politique de conquète, d'agrandissement, de convenance, mais aussi la politique dynastique. Après ses conquêtes, il installait des membres de sa famille sur les trònes de l'Europe. Il a donné la Hollande à Louis Bonaparte; la W'estphalie à Jérôme; Naples à Joseph, puis à Nurat; l'Espagne, malgré la résistance obstinée de ses habitants, à Joseph; Francfort à Eugène de Beauharnais, Lucques et 
Piombino à sa sœur Élisa, Guastalla à sa swur Pauline, etc. C'est l'idée du pacte de famille qui reparait, mais sinculièrement agrandie et menaçant d'englober l'Europe entière

Dans sa lutte acharnée contre les Anglais, Napoléon rivalise avec eux de mépris pour le droit des gens. Ils soudoient contre lui le complot de la machine infernale et le complot de Georges Cadoudal; en réponse, il viole le territoire de Bade pour en enlever le duc d'Enghien et le faire lusiller à Vincennes (1804); il viole le territoire hambourgeois pour en enlever l'envoyé anglais Rumbold.

Les Anglais bombardent en pleine paix, et par deux fois, Copenhague (1801 et 1807). Xapoléon riposte en décrétant l'arrestation de tous les sujets liritanniques en France et dans les pays soumis à ses armes. Haitres de la mer, ils déclarent en état de blocus toutes les còtes de la France et de ses alliés (1806) et font observer ce blocus fictif comme sil était effectif. Maitre clu continent, Napoléon leur répond par le blocus continental (décrets de Milan, 1806, de Berlin, 1807, de Paris, 1508). Il confisque, il fait brûler les marchandises anglaises partout où il peut les saisir, même dans les pays neutres. Il capture les navires, mème neutres, dès qu'ils ont touché le littoral anglais ou subi la visite des vaisseaux britanniques. C'est pour assurer l'exécution du bloces qu'il envalit le Portugal, les États du pape, qu'il annexe la Hollande et le littoral allemand, et qu'il finit par rléclarer la guerre à la Russie. Jamais les principes du droit des gens, proclamés avec tant d'éclat par la Constituante, n'avairnt été plus audacieusement foulés au pied, soit par Najuléon, soit par ses ennemis. Bien des années se passeront avant que l'esprit de 1789 réagisse de nouveau sur les relatious internalionales.

\section{Il. L'armée pendant la Révolution.}

Ministres de la guerre. - Pendant la période révolutionnaire et impériale, les ministres de la guerre ont été le comie de Puységur, nommé en 1788; le duc de Broglie, qui le remplaça pour organiser le coup l'État de juillet 1789, mais ne resta que vingt et un jours; la Tour du Pin, 
du Portail, Narbonne, qui administrèrent sous la Constituante; de Grave, Servan, Dumouriez, sous la Législative; Pache, Beurnonville, Bouchotte, sous la Convention. Quand les ministères furent supprimès, Carnot cut une influence prépondèrant? dans les Commissions exécutives de la guevre ${ }^{1}$ comme au Comité de Salut public. Sous le Directoire, on eut pour ministres de la gucrre: Aubert-Dubayet, Pctiet, Schérer, Millet-Mureau, Bernadotte; sous le Consulat : Dubois-Crancé, Berthier, Carnot, Lacuée; sous l'Empire : Lacuée, Berthier (1807), Clarke (1807-1814). A côté du ministère de la guerre il y eut, à partir de 1802 , un ministère de l'adminisiration de la guerre, avec Dejean, Lacuée, Daru. Le ministre de la première Restauration fut Dupont et celui des Cent-Iours le maréchal Soult.

Idées nouvelles sur larmée. - A la fin du xvin ${ }^{e}$ siècle, le système de l'armée permanente avait été attaqué par les philosophes et les économistes : la milice surtout avait été dénoncée comme tyrannique et ruineuse. Les cahiers de 1789 demandèrent, en général, la suppression de celle-ci et la réduction de celle-là. En même temps, on préconisait l'armement de tous les citoyens.

Pouvoirs du roi sur ha force armée. - La Constituante maintint à Louis XVI un attribut essentiel du pouvoir exécutif : le roi restait le (hef suprème de l’armée; mais l'Assemblée garda un attribut non moins essentiel du pouvoir législatif : celui de voter annuellement les sommes nécessaires à l'entretien de l'armée: ce qui entramait le droit d'en déterminer !'effec'if.

La force armée se composait alors de trois éléments : la garde nationale, l'armée résulière, la gendarmerie, spécialement réservée au service de l'intérieur.

Il ne pouvait ètre introduit dans le royaume aucun corps de troupes étrangères qu'en vertu d'un acte du pouvoir législatil. On voulait empècher que le roi, en augmentant le nombre des régiments suisses, allemands, irlandais, qui étaient lléjà à sa disposition, ne pủt en laire un instru-

1. Ces commissions, destinées à remplacer l'ancien ministère, élaịnt au nombre de deux : I $^{\circ}$ Organisation et mourements des arnees: 20 Alpro risionnements. La Commission des Travaux publics avait hérité aussi do cerlaines atributions du ministère de la guerre. 
ment de despotisme. C'est surtont avec ces troupes étrangères que la cour essaya à deux reprises, en juillct et en octobre 1789, de faire un coup d'État contre l'Assemblée; c'est avec les gardes suisses qu'elle livra au peuple de Paris le décisif combat du 10 août 1792, après lequel les gardes suisses et les régiments suisses furent dissous.

L'institution de la garde nationaie entrainait la suppression de la milice ainsi que du tirage an sort. La Constituante, par le décrét de 1789 (16 décembre), n'admit d'autre mode de recrutement que les engagements volontaires.

La garde nationale. - La Constituante, dès le 13 juillet 1789, avait demandé la formation de gardes bourgeoises; le roi essaya de s'y refusier; mais elles s'organisèrent spontanément sur toute l'étendue du territoire. En août, elles prirent le nom de gardes nationales. A Paris, il y eut alors 60 bataillons de district, comprenant chacun une compagnie spéciale, appelée compagnie du centre, et qui faisait un service permanent. Ces 60 compagnies permanentes furent recrutées des gardes-françaises, passés à la cause de la Révolution, et de quelques militaires qui avaient abandonné leur corps. Ensemble, elles constituaient une force, très sérieuse pour ce temps, de 6000 soldats. La garle nationale de Paris prit l'uniforme des gardes-françaises : les grenadiers eurent le grand bonnet à poil et les fusiliers le tricorne. Elle comprenait aussi de l'artillerie, des gardes à cheval, des vétérans, des carabiniers, des cuirassiers avec le tricorne et la cuirasse. En province, luniforme offrit une variété infinie : habit rouge, ou blanc, ou bleu. La Fayette fut nommé " commandant général des gardes nationales du royaume " et devint, par là, un des personnages les plus considérables de l'État, l'arbitre du roi et de l'Assemblée. A la fète de la Fédération (14 juillet 1790), il y eut à Paris des délégués de toutes les gardes nationales de France : ce fut surtout le fète de la milice nouvelle.

La loi de 1790 (6 décembre) appela au service de la garde nationale tous les citoyens en âge de porter les armes; elle déclara que cette garde r'était ni un corps militaire, ni une institution dans l'État : " Ce sont les citoyens euxmèmes appelés an service de la force publique ". L'orgaaisation devait être déterminée par le roi; la discipline et 
l'uniforme seraient les mèmes partout; les officiers étaient ćlus à temps et ne pouvaient ètre réélus qu'après un intervalle de service comme simples soldats. Cette dernière disposition achevait de détruire torte discipline dans une milice où l'on n'était déjà Gue trop disposé à discuter.

Cette loi avait statué que nul ne pouvait commander la garde nationaie de plus d'un district : elle mettait fin a la dictature militaire de La Fayette. Les lois de 1791 (23 septembre et 14 octobre) décidèrent que les bataillons se formeraient seulement par district et par canton : elles supprimaient toute organisation départementale. Chaque bataillon se composerait de compagnies ordinaires et d'une compagnie de grenadiers. Huit ou dix bataillons se groupaient pour former uue légion. Il pouvait y avoir des compagnies à cheval et même des sections d'artillerie, à raison de deux pièces pour chaque bataillon à pied.

Sous la Législative, la loi de 1792 (8 mai) organisa à part des canonniers de la garde nationale. Elle créa des compagnies de vétérans (àgés de plus de soixante ans) et d'élèves àgés de moins de dix-huit ans). En rendant le service universıl, elle autorisa les ministres, députés, employés, prêtres, magistrats, à payer une taxe de remplacement.

Le drapean tricolore. - Les drapeaux ofrraient jusqu'alors une variété infinie, les trois couleurs étant disposées en triangles, en losanges, en croix, etc. Désormais il n y eut qu'un seul drapeau tricolore, le bleu adhérant à la hampe, avec une double inscription. D'un côté : "le Peuple francais debout contre les tyrans"; de l'autre: "la Liberté ou la mort ".

L'armée régulière sous la comstituante. - Quant à l'armée, la Constituante se borna d'abord à y introduire quelques réformes. La vénalité des grades était supprimée. nul ne pouvait devenir officier saus aroir débuté comme soldat ou sous-officier. On ne pouvait être promu à un grade supérieur qu’après avoir passé quelque temps dans le grade infërieur. Les soldats devaient prèter entre les mains de leurs officiers, et les officiers devaient prèter publiquement le serment d'ètre "fidèles à la nation, à la loi, au roi el à la Constitution ". On espérait faire ainsi de l'ancienne armée royale une armée vraiment nationale. 
Les noms des anciens régiments, Navarre, Piémont, Champagne, Picardie, qui rappelaient tant de souvenirs de gloire, furent supprimés et remplacés par des numéros d'ordre ". On abolit les états-majors généraux, gouvernements, lieutenances; on réduisit de 16 a 6 les maréchaux de France, de 216 à 34 les lieutenants généraux; on remplaça la dénomination de bas-officier par celle de sous-officier; on établit des règles pour les examens et l'avancement.

La loi de 1790 (22 septembre) réorganisa les cours martiales, les composa de juges militaires et de juges civils, y introduisit la procédure publique, la faculté de se défendre par avocat, les jurys d'accusation et de jugement, la sentence motivée. La loi de 179: (30 septembre) ${ }^{2}$ édicla un Code des délits et des poines militaires, qu'on trouva bien sévère à cette époque, mais qu'on n'a pas modifié depuis.

Tout militaire, après seize ans de service, jouirait des droits de citoyen actif'.

Pendant longtemps, l'armée permanente fut régligée: toute la faveur de l'opinion se portait vers la garde nationale. On s'enorgueillissait du chiffre énorme de cette milice, et il n'etait bruit que des 2571000 baïonnettes qu'elle pouvait opposer à I'Europe coalisée. Quelques-uns parlaient même de quatre millions.

Pourtant, quand on eut à délendre la frontière, on s'aperçut qu'une garde nationale, composie d'hommes de tout àge et de toute profession, si nombreuse qu'elle lùt, n'était pas en état de lutter contre les vieux régriments de la Prusse et de l'Autriche. Une armée permaneute était seule capable de tenir tète à des armées permanentes.

Malheureusement, l'armée royale était désorganisée par l'émigration de 2000 officiers nobles, affaiblie par la désertion de 30000 soldats. Pour la reconstituer, on r'avait plus la ressource du tirage de la milice, et l'on r'avait pas

1. En 1791, le chapeau à cornes est remplacé par le casque en feutro noir verni. Les grenadiers et les carabir.iers sontiauent a porter le bonnet a poil.

2. Jusqu'en 1796 , les tribunaux militaires ne sont pas permanents, et il n'y a pas de recours contre les jugements. En 1796, apparaissent les Conseils de guerre permanents et les Conseils de revision, appelés à réformer las jugements. 
encore celle de la conscription. En 1791, la Constituante décida de renforcer l'armée de 100000 gardes nationaux volontuires; ils devaient servir un an : chaque département devait fournir un contingent déterminé. En réalité, la levée ne fut que de 60000 hommes.

La Législative : les enrölements volontaires. - En 1792, devant les menaces d'invasion, on proclama la patrie en danger, et partout, sur des estrades en plein air, on ouvrit des bureaux d'enrôlement. Contre l'Europe et les émigrés, qui prétendaient rélablir l'ancien régime, détruire les libertés nouvelles, dépouiller les acquéreurs des biens nationaux, rétablir la dime et les diroits féodaux, les campagnes s'armèrent comme les villes. Dans tous les départements s'organisèrent les bataillons de volontrires. Ceuxei furent autorisés à élire leurs officiers ${ }^{1}$ : beaucoup de leurs choix furent excellents. C'est alors que des hornmes qui, sans la Révolution, seraient restés dans les carrières civiles ou auraient végété comme sous-officiers dans l'armée, obtinrent l'épée d'officier par le sulfrage de leurs camarades. C'est alors que les Hoche, les Marceau, les Desaix, les Joubert, les Championnet, les Kléber, ces futurs généraux de la République; que les Masséna, les Augereau, les Moncey, les Davoust, les Macdonald, les Lannes, ces futurs maréchaux de l'Empire; que ies Marat et les Bernadotte, ces futurs rois de Naples et de Suède, furent élus capitaines ou chefs de batailion.

A côté des officiers plébéiens, comme Sébastiani, fils d'un artisan; Drouot, fils d'un boulanger; Murat, fils d'un aubergiste; Lannes, teinturier; Bessières, perruquier; Jourdan, mercier. il y a quantité d'ofticiers de l'ancienne noblesse: Biron, Custine, Montesquiou, la Bourdonnaye, Canclaux, Dumouriez, Ditgobert, de Fontenilles, Dugommier, Desaix, Dommartin, Clarke, Macilonald, Grouchy, Marmont, Bonaparte. Beaucoup d'anciens nobles restèrent fidèles à la

1. Les soldats de l'ancienue armèe désapprouvaient cette innovation: ceux de Dumouriez declaraient aux commissaires de la Législative que "ćtail le plus grand malheur qui pủt arriver n. Pourtant, a une époque où le patriotisme primait tous les sentiments et où les grades n'élaient pas ambitionnés avec autant dardeur quaujourd'hui, ce système ne produisit pas trus les inconvenients qu'il aurait pu produire en d'autres temps. 
patrie sous ses nouveaux étendards. Le royaliste Dommartin écrivait: "C'est à l'armée qu'est la place de tous les gens de bien ", et La Tour-d'Auvergne s'écriait: "Quand mème toute l'armée émigrerait, je resterais en France. » A tous, la pénurie du Trésor réservait de dures privations et de cruelles épreuves ${ }^{1}$.

Les forces réunies à la frontière se composaient donc de deux éléments bien différents : l'ancienne armée, désorga-

1. On connait ce mot de La Tour d'Auvergne, à qui un représentant du peuple faisait ses offres de service : "Eh bien, dit La Tour d'Auvergne, si vous éles tout-puissant, demandez pour moi.... - Quoi? un rériment? Non I une paire de souliers."

Quand on songe qu'en 1793 et 179 tes $^{\prime}$ officiers, les généraux mèmes, a u témoignage de Soult, ne touchaient en argent que 8 francs par mois, on se demande quel devait ètre le dénuement de's soldats.

Une estampe allemande, que $\mathrm{N}$. Loredan Larchey a reproduite duns son édition du Journal du sergent Fricasse, représente une revue de soldats français à Manlieim en 1795. Toutes les variétés possibles de vètements, de coiffure et de chaussure y sont représentées : la veste étriquée et l'ample cedingote a la propriétaire, les pantalons de cotonnade rayée et les culottes de drap, les casques à chenille, les tricornes et les bonnets de peaux de bètes. Les uns semhlont avoir conservé quelque vestige d'un costume de petit-maitre, y compris les escarpins et les bas de soie; les autres sont la tels qu'ils sont arrivés du village, avec leurs grands chapeaux ronds de paysen, leurs guétres encore rouges de la glèbe des champs et leurs blouses rustiques : tout cela fripé, rapiècé, dẻchiré, frangé, effiloché, lamentable à voir. Certains ont des restes de bottes, quelques-uns des débris de souliers rafistolès arec des ficelles; d'autres vont pieds nus.

Pour douner une idée de l'esprit qui animait ces volontairos, je citerai ls Priere d" soldat republicain francais du sergent Fricasse :

"Dieu de toute justice, $\hat{E} t r e$ éternel et suprème souverain, arbitre de la destinée de tous les hommes, toi qui es l'auteur de tous biens et de toute justice, pourrais-tu rejeter la prière de l'homme vertueux qui ne te demande que juistice et liberté?

" Ab! si notre cause est injuste, no la défends pas l La prière de l'impie est un second péché; c'est t'outrager toi-méme que de to demander ce qui n'est pas conforme à ta rolontè sainte.

" Mais nous te demandons que la puissance dont tu nous a revélus soit conforme à ta volonté. Prends sous la protection sainte uue nation généreuse qui ne combat que pour l'égalilé. Ote à nos ennemis détestables la force criminelle de nous nuire; brise les fers des despotes orgueilleux qui veulent nous les forger. Bénis le drapeau de l'union sous lequel nous voulons tous nous réunir pour obtenir notre indépendance. Bẻnıs les généreur citoyens qui exposent leur rie et leur fortune pour défendre leur patrie. Bénis les méres respectables de ces vertucux enfants de la patrio qui to prient de leur accorder victoire. Ouvre les yeux de ceux qui sont égarés dans nos foyers afin qu'ils rentrent à la raison, pour jouir avec nous des prérieux fruits de l'ègalité el de lic liborté, et chanter avec nous les cantiques ot les louanges dédiés à l'Êtro suprémo. v

R. Civil. contemp. 
nisée et un peu découragée, mais ayant l'expérience et l'instruction militaires, et ces bataillons nouveaux, encore inexpérimentés, indisciplinés, turbulents, mais qui apportaient un patriotisme ardent, un dévouement à toute épreuve, un enthousiasme indomptable. " J'en ressens encore, écrira plus tard Marmont, la chaleur et la puissance à cinquante-cinq ans, comme au premier jour."

Les anciens soldats domnèrent aux nouveaux venus l'exemple du sang-froid et de la discipline, et ceux-ci leur communiquèrent l'enthousiasme qu'ils apportaient de leurs villes et de leurs villages. Des succès éclatants, la victoire de Valmy, la prise de Mayence, la conquète de Nice et de la Savoie, jetèrent sur cette armée déjả républicaine le premier refiet de gloire.

La Convention : l'amalgame. - Sur la proposition de DoboIs-CRANcE, par les décrets de février $1793^{1}$, on supprina les anciens régiments et jusqu'au nom de régiment. On associait un bataillon d'anciens soldats et deux bataillons de volontaires pour en former une demi-brigade. C'est ce qu'on appelait faire l'amalgame 2. "En récompense de leurs services, portait le rapport de Dubois-Crancé, les braves soldats des troupes de ligne doivent être considérés tous comme volontaires nationaux, ètre réunis à leurs frères d'armes et ne plus faire avec eux qu'un seul et mème faisceau contre les ennemis de la patrie. "Les anciens soldats échangèrent l'habit blanc des troupes royales contre l'habit bleu des volontaires, obtinrent, comme ceux-ci, le droit d'élire leurs officiers, le droit de se marier, les droits politiques. On assura aux soldats, pour les retenir sous les drapeaux, des gratifications en argent, des lacilités pour acquérir les biens nationaux, des secours pour leur famille, des pensions pour les hlessés. Un vieux capitaine arouait à La Fayette qu il naimait pas la Févolution, mais

1. Dẻcrets du 7 el du 12 février 1793.

2. L'opération de l'amalgame s'effectua lentement et dura de la fin de 1793 su commencement de 1795. Voici, par exemple, comment se formerent les trois premières demi-brigades: - 1. $1^{\text {or }}$ bataillon du 10r régiment ColonelGénéral, bataillon de la Butte-des-Moulins de Paris. - II. 2e bataillon du mème régiment, $4^{\circ}$ bataillon de la Somme, $5^{\circ}$ batxillon de Paris. - $111.1^{\circ}$ bataillon du $2^{*}$ régiment de Picardie, $5^{*}$ baiaillon de l'Aisne, $5^{*}$ bataillon do la Cote-d'Or, $1^{\circ}, 2^{\circ}$ et $3^{\circ}$ bataillons du district de Lille. 
qu'il se battrait pour elle parce qu'elle lui domnait la retraite que lui refusait l'ancien régime.

La réquisition, la levée en masse. - Quand il fallut résister à toute l'Europe coalisée et à la Vendée insurtuée, l'enròlement des volontaires fut insulfisant pour recruter les quatorze armées qu'organisait Carnot. La Convention mit alors en rérquisition les gardes nationanx de 18 à 25 ans; le remplacement ètait autorisé. En lévrier 1793, elle put ainsi lever 300000 soldats. Elle recrutait les armées avec des réquisitions d'hommes, elle les nourrissait avec des réquisitions de vivres. Le 23 aont 1793 , elle proclama la levée en masse : tous les Français furent en réquisition permanente pour le service des armées. Le remplacement fut interdit. Les citoyens valides furent partagés en quatre classes; les non mariés ou reufs sans enfants, de dix-huit à vingt-cinq ans, devaient marcher les premiers. On porta le chiffre total des armées a près de 1200000 hommes.

La Convention maintint le système de l'election des officiers, mais en le restreignant. Pour tous les grades audessous de général de brigade, un tiers se donnait a l'ancienneté, un tiers était à l'élection, un tiers était à la nomination par la Convention (plus tard par te Directoire). Tous les emplois de généraux de brigade et généraux de division étaient conférés par le gouvernement.

Le Directoire : la conseription. - Sous le Directoire, on ent à défendre non seulement le territoire français, mais celui des républiques organisées sur le modèle de la nôtre, à résister à l'Europe sur une ligne immense qui allait du golfe de Zuydersée (Hollande) au golfe de Tarente (Italie). Il fallut songer it organiser le recrutement d'après un système plus régulier que l'expédient rérolutionnaire de la levée en masse et de la réquisition.

Sur le rapport de jodrdan, le vainqueur de Fleurus, lut votée la loi de $1799^{1}$ qui organısa la conscription. Tout Français était tenu de servir de vingt à vingt-cing ans. La jeunesse formait, en conséquence, cinq classes. Le gouvernement devait commencer par la class de vingt ans et lever successivement les suivantrs, à mosure que le service

1. Loi de fructidor an Vl. 
l'exigesait. Au bout de cinq ans, le conscrit était libéré du service ordinaire; mais, en cas de danger, le gouvernement conservait le droit d'ordonner la levée en masse.

Creation de nouveanx corps. - La Législative avait comblé une lacune dans les réformes de Gribeauval : elle créa, en 1792, l'artillerie à cheval. La Convention organisa en un corps de pontonniers les compasnies de " matelots révolutionnaires français" qui s'étaient spontanément formées à Strasbourg et à Mayence. Elle attribua au service du génie les compagnies de mineurs et sapeurs de nouvelle formation: il y eut, dès lors, des troupes du génie. En 1799 furent créées les troupes du train d'artillerie.

Les troupes êtraugères pendant la Révolution. - La Constituante avait naturalisé français les régiments étrangers, et la Législalive avait licencié les régiments suisses.

Il se forma bientôt d'autres corps étrangers, mais sous linlluence d'idées toutes nouvelles. Il ne s'agissait plus denviler des merenaires, mais d'appeler les étrangers eux-mêmes à la défense de la cause commune, la aause des peuples et de Ia liberté. Par la loi de 1792 (3 aoùt), la Législative invita les sous-olficiers et soldats des armées ennemies à servir dans les troupes françaises, leur promit des indemnités et des pensions, leur déléra le serment cıvique et les recommanda " à la sollicilude des fonctionnaires publics et à la fraternité des ofliciers et soldats irançais ". La loi de 1793 (2 décembre) mit fin à ces pratiques. La Constitution de l'an III n'admit dans nos armées que les étrangers qui auraient fait " une ou plusieurs campagnes pour l'établissement de la République ".

En 1792 figurèrent dans nos rangs une légion ${ }^{1}$ liégcoise, une légion belge, une légion batave. La dernière était commandie par les chefs du parti libéral en Hollande, Daendels, de Winter, Kock ${ }^{2}$, etc., et devait être notre avantgarde dans la campagne entreprise pour l'affranchissement des l'ays-Bas. Une légion germanique, lormée en 1792 à la

1. Une légion était composée à la fois dinfanterie, cavalerie et artillerie.

2. Le père du célèbre romancier, Paul de Kock : il fut plus tard enveloppé dans la disgràce des Hébertistes et envoyé à l'échafaud (mars 179') aveo oux et avec Anacharsis Clootz, "l'orateur du genre humain 
demande d'Anarcharsis Clootz, et pour laquelle il avait composé en allemand des chants républicains, devint plus tard, en 1799, la légion des Francs du Nord, nom qu'on donnait alors aux habitants de la rive gauche du lihin. Dans l'invasion de la Savoie, nous fûmes guidés, en 1792, par la légion franche allobroge, commandée par le vaillant Dessaix et le médecin Doppet ${ }^{1}$. Plus tard, les sujets du roi de Sardaigne nous donnèrent deux brigales piemontaises et une légion vuudoise, levée par Masséna. En 1799, la France. prit à son service les troupes de la République Cisalpine et forma une légion italique, ouverte non seulement aux Cisalpins, mais aux Romains, Toseans, Napolitains. On eut, en 1796, une brigade irlandaise, qui fut licenciée après l'échec des expéditions tentées en Irlande, et dont il resta un bataillon. Une partie des Suisses licenciés après le 10 août formèrent, avec d'autres, la compagnie frunche genevoise et les chasseurs suisses. Les Suisses, au service de la Sardaigne, furent organisés en deux légions helictiques. En 1798, à la suite d'une capitulation conclue, sur le type de celles de l'ancien régime, avec la nouvelle République helvétique, $1 \mathcal{S} 000$ Suisses entrèrent à notre service. $A$ près le troisième partage de la Pologne, de vaillants réfugiés constituèrent, avec l'autorisation du général Bonaparte, deux légions polonaises: c'est Dombrowski qui les commandait. On vit Zaïontchek suivre Bonaparte en Egypte, Kniaszewicz arborer le drapeau tricolore au Capitole de Rome, Jablonowski combattre à l'île Saint-Domingue.

Bonaparte, aprés la prise de Malte, forma, avec la gardo du grand maitre et les deux régiments de l'ordre, une légion maltaise. Lin Égypte, il créa une légion cophte, recrutée d'Égyptiens, une légion grecque et un corps de mumelouks.

Enfin, avec les esclaves nègres enlevés aux Anglais, on créa un bataillon de piomiers noirs ${ }^{2}$.

1. Dessaix, qu'il ne faut pas confondre avec Desaix, figrra plus tard à la hataille de la Moskova. Doppet prit part au siege de Lyou en 1793.

2. Il passa plus tard au service de Joseph, roi de Naples, et forma lo Royal-Africain. 


\section{L'armée sous Napoléon.}

Abus de la conseription sons l'Eapire. - D'apris la loi de 1798, on levait les classes tout entières; par exemple, quand on levait la classe de vingt ans, tous les Francais àgés de vingt ans partaient pour l'armée. Napoléon, en 1804, décida que, pour chaque classe, il y aurait un tirage au sort: les conscrits qui avaient amené les plus faibles numéros élaient seuls incorporés. On pouvail s'exonérer du service militaire en fournissant un remplaçant : c'était une satisfaction donnée à la bourgeoisie. Ce système était plus équitable, moins rigoureux que celui de Jourdan : il devint désastreux par l'abus qu'en fit l'Empereur.

Les guerres devinrent si fréquentes et si prolongées, il se fit une telle consommation d'hommes sur les champs de bataille, que les classes, à la fin, étaient levées tout entieres : il n'y avait plus de bons numéros. En 1813, on leva mếne la classe de 1815, c'est-à-dire les jeunes gens de dix-huit ans, et l'on remonta jusqu'à celle de 1803 pour prendre les hommes de trente ans.

Ceux qui avaient obtenu un bon numéro, et qui se croyaient libérés, finissaient par ètre appelés comme les autres. Ceux qui avaient fini leur temps étaient garlés sous les drapeaux. Ceux qui avaient fourni un remplaçant étaient Corces de servir en personne ou d'en fournir un nouveau. Des jeunes gens que leurs familles avaient rachetés plusieurs fois lurent, à la fin, obligés de partir.

La conscription devenait ainsi la mise en coupe réglée des générations françaises. Le désespoir était dans toutes les familles : les jeunes gens se sauvaient dans les bois pour échapper au recrutement; il y eut bientòt des milliers de réfructuires qui se formaient en bandes et livraient bataille à la gendarmerie.

La grade nationale sous r'Empire. - La Constitution disposait que la garde nationale serait organisée par une loi. L'Empereur obligea le Sénat à commettre une nouvelle usurpation sur le Corps législatif : le sénatus-consulte de 1805 statua que la garde nationale serait organisée par decret de l'Empereur. Le décret de 1806 appela tous les 
Françis de vingt à soixante ans au service de la garde nationale; elle fut divisée en légions, subdivisées elles-mèmes en cohortes. Puis un sénatus-consulte de 1812 (13 mars) la répartit en trois bans : de vingt à vingt-six ans, de vingt-six à quarante ans, de quarante à soixante ans. Tous les gardes nationaux du premier ban furent mis immédiatement à la disposition de l'Empereur pour la défense des frontières. Ils se battirent bien et se distinguèrent notamment au combat de la Fère-Champenoise, en 1814, où, avec le général Pacthod, ils se firent écraser par l'artillerie prussienne. Ainsi, mème ceux qui avaient échappé, comme par miracle, au service de l'armée permanente, étaient repris par la garde nationale et envoyés à la bataille.

\section{Les grades, la légion Whonneur, ies datations. -} Dans l'armée, comme dans la garde nationale, Napoléon avait absolument supprimé l'élection : tous les grades étaient conférés par lui, soit au choix, soit à l'anciennetè.

La Révolution avait supprimé toutes les décorations: puis l'usage s'était introduit de distribuer aux soldats les plus braves des armes dhonneur. Napoléon institua la Légion dhonneur : il fit en 1804 la première distribution de croix.

Premier consul, mème Empereur, Bonaparte se faisait un devoir d'entrer dans les casernes pour sassurer que les soldats, surtout ceux de la garde, étaient bien nourris, bien couchés '. Jusqu'a 180', il invitait à sa table, parfois au nombre de deux cents, les militaires ou les marins qui avaient obtenu des armes d'honneur, fusils, sabres ou haches d'abordage ${ }^{2}$.

1. Le eapitaine Coignet, dans ses Cahiers, raconte une de ces visites. Le Premier consul vinl surprendre les soldats al lit : "Les couchettes, dit-il a Launes, sont trop courtes pour mes grenadiers. Vois-lu? il faut réformer tout le coucher de ma garde. Prends note. "Il se fit donner du pain. "Ce n'est pas eela, dit-il; je paye pour du pain blanc, je veux en aroir lous les jours, tu ezteuds, Lannes? Tu enverras mou aide de camp chez le fouruisseur pour qu"il vienue me parlor. "

2. Il recommandait d'entremêler les simples soldats avec les colonels et les généraux. Contre son habitude, i] laissait le repas se prolonger. II se montrait d'une amabilité parfaite, s'efforgail de meltre à l'aise les plus humbles de ses convives. "Rien n'ètait plus dróle, raconte le valet de chambre Constant, que de voir ces bous trouriers, se tenant à deux pieds de la table, n'osant approcher ni de leur serviette, ni de leur pain, rouges jusquaux oreilles et le cou teudu du cúté do leur général, comme pour recevoir le mot dordre. Le Premier consul leur faisait raconter lo baut fait 
C'est ainsi qu'il s'assurait le dévouement de l'armée, le principal appui de son pouvoir en France comme en Europe.

Pour les colonels, pour les généraux, Napoléon gardait d'autres moyens de séduction. Il les nommait barons, comtes, princes, ducs, leur distribuait de grosses pensions, de riches gratilications, leur assignait des domaines lans les provinces conquises. Plus précieux que tout était le bàton de maréchal, dignité rétablie en 1S04: un maréchal de Napoléon se cousidérait comme plus qu'un roi. Et puis il n'était pas sans exemple qu'un maréchal füt devenu roi : Murat le fut à Naples, Bernadotte en Suède, Davoust espéra l'ètre en Pologne.

Lorganisation et l'armement. -- L'Empire, pas plus que la Révolution, ne modifia rien à l'ancien armement. Toutes leurs victoires furent gragnées avec les fusils à pierre modèle de 1777 , et les canons à âme lisse modèle de 1765, qui avaient figuré dans les guerres de la monarclie. Napoléon fit mème disparaitre la carabine rayée que portaient certains corps d'élite sous l'ancien régime ${ }^{1}$.

Le système d'artillerie de Griheauval fut légèrement madifié par le système de l'an Xx. (1503): le Prenier consul supprima les canons de 4 et de 8 de canıagne, allégea le calibre 12 , introduisit le calibre 6 , précisément pour utiliser les pic̀ces et les projuctiles conquis sur l'artillerie autrichienne. Il adopta la formation en balteries de six pièces. Napoléon ne cessa d'accroitre la proportion de l'artillerie dans les armées : il eut jusqu'à 4 jièces par 1000 hommes. Ses batailles d'Eylau, Friedland, Essling, Wagram, la Moskowa, furent d'effroyables canonnades, ou

qui leur valait la récompense nationale, et riait parfois aux éclats de leurs singulières narrations. Ii les engageait a bien manger, buvaut quelyucli, a leur santé; mais, pour quelques-nns, ses eucourugements échouaient contı e leur timidité, et les valets de pied enlevaient successivement lours assiettes sans qu'ils y eussent touché. Cette contrainte ne les empèchait pas d'ètre p'eins de joie et d'enthousiasme en quittant la table. "A revoir, mes braves, Jeur disait le Premier consul, baptisez-moi bien vite ces nouvean-nés-la n (montrant du doigt leurs sabres d'honneur)! Dieu sait s'ils s'y épurgnaient. *

1. Les noms de carabiniers, chasseurs, grenadiers, dont il distinguait les différents corps, ne doivent pas nous faire illusion: il n'y avait pas plus de carabines que de grenades, et tout le monde avait le mème fusil. 
il se proposa surtout de " démolir " les solides carrés de l'ennemi.

En 1807, il créa les bataillons du train des équipages et les compagnies de boulangers de munition; en 1809, les compagnies d'infirmiers.

11 rétablit les régiments et créa les corps d'armée.

Comme ses campagnes étaient des " campagnes de Imanœuvre " et que ses soldats faisaient la guerre, comme. ils disaient, autant avec leurs jambes qu'avec leurs bras, il s'efforça de clonner plus de mobilité à tous les corps.

Dans les bataillons d'inlanterie, il y avait déjà une compagnie d'élite, celle des grenadiers, composée des hommes les plus grands et les plus robustes; il créa, en 180 t, une seconde compagnie d'élite, celle des voltigeurs, composée d'hommes petits et agiles, exercés à la marche rapide, à la course, à la gymnastique, marchant au clairon et non au tambour. Dans chaque bataillon, on distingua dès lors la compagnie des grenadiers, celle des voltigeurs, celles lu centre : on les reconnaissait à la couleur des épaulettes. En 1809, Napoléon créa des régiments entiers de voltigeurs : en 1814, il en eut dix-neuf. On distingua, dès lors, entre les régiments d'infanterie légère et ceux d'inl'anterie de liyne.

Napoléon maintint à la cavalerie, même à la grosse cavalerie, un ròle prépondérant. A Eylau, Murat lança sur l'armée russe d'épouvantables charges de 80 escadrons. Les cuirassiers, à la Moskova, enlevèrent des redoutes; à Waterloo, enfoncèrent les carrés d'infanterie anglaise. Comme l'Empereur avait à sa disposition toutes les ressources de l'Allemagne, il put monter sa cavalerie des plus beaux chevaux de l'Europe. La Convention lui avait légué 86 régiments à cheval, dont 2 de carabiniers, 1 de suirassiers, 24 de cavalerie proprement dite, 21 de dragons, 20 de chasseurs, 14 de hussards. La cavalerie proprement dite disparut sous l'Empire. En 1814, il y avait 83 régiments à cheval : 2 de carabiniers, 4 de cuirassiers, 24 de dragons, 30 de chasseurs, 14 de hussards, 9 de lan. ciers : car Napoléon avait, en 1809, reconstitué des corps armés de la lance, à l'imitation des Polonais.

La garde impériale. - La Constitution de l'an III avait créé une garde directoriale et une garde des ronseils. 
Bonaparte eut sa gurde consulaire. Elle devint ensuite la garde impériale. On distingua la vieille garde, constituée avant 1807 , et la jeune garde, formée depuis cetle époque. La garde s'éleva, en 1813, à 92000 hommes: c’était toute une armée, toute de soldats d'élite, aguerris par vingt batailles, touchant une haute paye, ne combattant que sous les yeux de l'Empereur, tenus en réserve pour donner les grands coups. Elle était commandée par des héros incomparables, comme Dorsenne, général des grenadiers à pied, Lepic, des grenadiers à cheval, Lefebvre-Desnouettes, des chasseurs à eheval, Drouot, de l'artillerie. Napoléon y distribuait libéralement les croix et, mème aux simples grenadiers, des dotations. Aussi, du dernier fusilier jusquaux généraux commandants, tous étaient fanatiques de l'Empereur, lui étaient dévoués jusqu'à la mort. Ils avaient gardé à son égard la familiarité des campagnes d'Égypte et d'Italie, l'appelaient volontiers le petit caporal ou le petit tondu, et, comme ils murmuraient tout en obéissant, il les avait surnommés ses grognards.

L'infanterie de la garde se composait: de 4 régiments de grenudiers à pied, une élite dans l'élite, dont un régiment hollandais; de 3 de chusseurs à pied, 1 de fusiliersgrenadiers, 1 de fusiliers-chasseurs, 1 de flanqueurs-grenadiers, 13 de tiraillcurs, 13 de voltigcurs; des pupilles de la garde et des vétérans de la garde.

La cavalerie comprenait les yrenadicrs à cheval, les plus beaux cavaliers de l'armée, imposants sous le grand bonnet à poil, célèbres par leurs charges d'Austerlitz et d'Eylau; les dragons de l'Impératrice, qui, en 1805, avaient juré a Joséphine de revenir victorieux de l'Autriche; les chasseurs ì checul, anciens guides de l'armée d'Égypte; les mamelouks, à l'équipement oriental, turban à aigrette, grandes culottes rouges, cimeterre asiatique, selle à haut pommeau, étriers à la turque, étendards à queue de cheval, mais dans les rangs desquels l'élément européen commeneait à prédominer; les lunciers polonais; les lanciers rouges, recrutés de Hollandais et de Français; les quatre régiments des gurdes dhomeur, formés en 1813, équipés et montés a leurs frais, lous lils de lamilles riches; enfin la genturmerie dilite. 
L'artillerie et services annexes comprenaient 1 régiment à cheval, 2 à pied, 3 du train, 1 compagnie de sapeurs.

Il y avait même dans la garde un corps de marins, avec un uniforme très peu maritime : le grand shako à plumet et le dolman rouge à brandebourgs.

Louis XIV et Louis XV n'avaient rien eu de plus magnifique que les uniformes de celte garde, où l'on avait prodigué les passementeries, cordons, aiguillettes, ganses, tresses, broderies, brandebourgs, les plumets, placues, chabraques, sabretaches : le tout très incommode, mais splendide, arec un ruissellement d'or pour les officiers. Les grenadiers à pied portaient des boucles d'argent à leurs souliers, des bas de soie, la queue poudrée à frimas. Leurs tambours, lifres, musiciens, étaient éblouissants. Un de leurs tambours-majors, un nommé Sénot, avait $1^{\mathrm{m}}, 898$ de haut : il élevait à deux mètres et demi le prodigieux panache de son énorme bonnet à poil.

Comme la garde était un objet d'envie et d'émulation pour tous les soldats de l'armée de ligne, Napoléon les tenait tous par l'espoir d'y être un jour admis.

Les troupes etrangères sous limpire. - 11 faut distinguer, parmi les troupes étrangères que Napoléon eut à sa disposition : $1^{\circ}$ celles qui étaient recrutées dans les départements récemment annexés à la France; $2^{\circ}$ celles qui venaient du dehors et qu'il prit directement à sou service, $3^{\circ}$ celles que lui fournissaient les Etats vussuux de son Empire: 4" celles qu'il exigea des États alliés.

$1^{\circ}$ A la première catégorie appartiennent les soldats levés non seulement en Belgique et sur la rive gauche du Rhin, mais en Hollande, Genève et Valais, Piémont, Toscane, Etats romains, Illyrie, littoral allemand du Nord, iles Ioniennes, quand ces pays eurent été réunis par Napoléon à la France. Ils étaient tous considérés comme des solduts français. L'llyrie fournit 6 régiments d'infanterie croate, 6 de chasseurs illyriens, 1 régiment dalmate, etc. Les îles Ioniennes donnèrent les chasseurs a cheval ionions, le bataillon septinsulizire, etc.

$2^{\circ}$ A la seconde catégorie se rattachent les Suisses, qu'une nouvelle capitulution, conclue en 1803, mit au service de la France, au nombre de 16000 ; la légion hanovrienne, formée 
par Mortier, en 1803, après Ia conquète du Hanovre; les deux legions du Nord et les deux légions de la Vistule, commandées par Joseph Poniatowski, Zaïontchek, Chlopicki, et toutes composées de Polonais; les lanciers polonais de la garde et deux autres régiments de lanciers polonais; le régiment d'infanterie lithuunienne et les gardes d'honneur polon'tis, levés en 1812. A partir de 1807, il y eut une légion portugaise et deux régiments espagnols. Napoléon eut non seulement des Mamelouks, mais un escadron de Taturs, levé en 1812, un régiment albanais et un bataillon de chasseurs grees.

$3^{\circ}$ Il eut à sa disposition les armées de tous les États allemands de la Confédération du Rhin, Hesse, Bavière, Wurtemberg, Bade, Saxe, etc., et spécialement du royaume de Westphalie et du grand-duché de Berg; l'arnée du royaume de Hollande, qui devint francaise a l'annexion de ce pays; celle du royame ditalie (Italie du Nord, celle du royaume de Naples (Italie du Sud), celle du grandduché de Varsovie (Pologne).

$4^{\circ}$ Il exigea le concours armé du Danemark et de l'Espagne en 1807, de la Russie en 1809, de la Prusse et de l'Autriche en 1812.

Les troupes de la troisième catégorie étaient aussi complètement à ses ordres que celles des deux premières. Les princes héritiers de Bade et de Hesse-Darmstadt, Deroy, le généralissine des Bararois, surtout Poniatowski, "le chef des Polonais ", le servaient avee autant de zèle que les rois français Jérơme et Murat. 11 enflammait ces soldats ètrangers de ses proclamations, les récompensait avec ses croix d'honneur, décernait à leurs chefs des titres de comtes et de princes. Les Polonais lui restèrent fidèles jusqu'au bout et formaient encore sa garde à cheval lans l'ile d'Elbe. Les Allemands, quoiqu'ils se fussent tournés contre lui en 1813, conservèrent de lui un souvenir profond et, encore aujourd'hui, en Allemagne, il y a des associations de "vétérans de la Grande Armée ".

Napoléon utilisait à son gré les services de tous ces soldats étrangers : il envoya combattre les Espagnols sur la Baltique, les Polonais et les Westphaliens en Espagne. En 1812, la Granle Armée qui envahit la Russie se composait de 306000 Francais et de 322000 étrangers : or, comme il 
faut comprendre parmi ces Françuis, les Hollandais, les Belges, les Allemands et les Italiens des pays annexés, plus de la moitié de cette armée était composée d'éléments exotiques. Jamais l'ancienne monarchie n’avait fait un si large emploi des troupes étrangères.

\section{La marine et les colonies.}

La marine. - De 1789 à 1814, on a peu innové lans notre organisation maritime telle qu'elle avait été fixée par l'orlonnance de 1786. La Constituante, par sa loi de 1791, avait supprimé les élèves et les volontaires de la marine, aiusi que les écoles navales, prétendant que l'état-major de la flotte se recrutàt dans la marine marchande. Puis la Convention rétablit les écoles navales. Le corps des officiers de marine, suppriné le 1 er mai 1791, fut réorganisé le 13 du même mois. Les appellations de lieutenunt général ct de chef d'escadre disparurent; celles d'amiraux, de vice-amiraux, de contre-amiraux furent maintenues. Sous la Convention, on donnait aux officiers généraux de la marine le titre de généruzıx. Beaucoup d'officiers étaient si hostiles à la Rérolution que ceux de Toulon, en 1793, livièrent la flotte et le port aur Anglais.

Les ministres de la marine fureut La Luzerne, yui avait succédé en 1787 à Castries; Fleurieu, Thévenard, Delessart, sous la Constituante; Bertrand de Molleville, Lacoste, Dubouchage, sous la Législative; le savant Honge et Dalbarade, sous la Convention. Pendant une année environ (179女-1795), la marine fut administrée par une Commission. Truchet, Pléville Le Pelley, Bruix, Bourdon, furent ministres sous le Directoire; l'ingénieur Forfait, sous le Consulat; Decrès, pendant la plus grande partie du Consulat et sous l'Empire (1801-1814), puis pendant les Cent-Jours.

En 1789 , on avait 72 vaisseaux de ligne portant ensemble วั371 canons, 63 frégates, 36 corveltes, 18 culters, 4 galiotes à bombes: au total, 261 bâtiments de tout rang, portant 8632 bouches à feu. Au 13 janvier 1793, la Convention ordonna de construire 23 vaisseaux de ligne, 20 frégates, 20 corveltes, 6 galiotes i bombes. Le 31 jaivier, on autorisa les armements en course. 
Le personnel de la marine fut très éprouvé par l'émigration ou par la Terreur : d'Estaing, Grimoard, Kersaint furent guillotinés; Morard de la Galle, Kerguelen, Latouche-Tréville, Bruix, Lacrosse et d'autres furent destitués ou emprisonnés; mais quelques-uns de ceux-ci reparurent ensuite à la tête des escadres.

En 1794, Jean Bon Saint-André avait fait décider la suppression des régiments d'artillerie et d'inlanterie de marine, se fondant sur ce que les principes d'égalité ne permettaient pas d'accorder à ces corps le droit exclusif de délendre la République sur mer, honneur que réclamaient également les autres régiments : "Pourquoi les vainqueurs de Landau, de Toulon, ne pourraient-ils pas aller sur nos flottes montrer leur couraye à Pitt et faire baisser le pavillon de George III?" L'artillerie de la marine fut rétablie en $179 \%$ et portée à un effectif de 25000 hommes.

Nos flottes, privées par l'émigration de presque tous leurs officiers, compromises par les passions et les dissensions politiques, écrasées bientòt par la supériorité de la marine anglaise, ont livré une série de combats, le plus solvent malheureux, tonjours glorieux: la bataille de prairial (1er juin 179'), où s'illustıa le Tengeur; Aboukir (1798) et Tralalgar (1805), où notre flotte de la Méditerranée fut anéantie. Quant aux marins de la garde impériale, ils se sont distingués surtout dans les batailles de terre, à Lützen, à Leipsig. Les vaisseaux continuèrent à être construits d’après les procédés et par les ingénieurs de la période précédente, surtout par Sané et rorfarr. Napoléon, en 1808 et 1811, pour le service de la flotte créa les bataillons de marins, divisés en équipages de haut bord el en équipages de flottille. Nos corsaires des ports de Dunkerque, le Havre, Saint-Halo, Nantes, la Rochelle, Toulon, Marseille, des Antilles et de la Guyane, de lile de France et de l'ile Maurice, se signalèrent, jusqu'à la fin de l'kmpire, par une guerre acharnée contre la marine marchande de l'Augleterre.

Les colonies. - Les principes de la Révolution ${ }^{1}$ péné-

1. La Révolution ne semble pas avoir attaché plus d'importance aux eolonies que la royauté du $\mathrm{xvuH}^{\circ}$ siècle. Delacroir, ministre du Directoire, négociant la paix avec l'envoyé anglais Malmesbury, lui disait en 1796:

* L'Azgleterre et la Frauce ont deux buts très difírents et très distiacts. 
trèreut dans nos colonies, comme dans le reste du monde. Dès le début, elles divisèrent la population coloniale en adversaires et en partisans des idées nouvelles. Aux premiers appartenaient ordinairement les grands propriétaires, les riches colons; au second, les blancs des autres classes, les hommes libres de couleur.

Par la loi du 28 mars 1792 , la Législative accorda à ces derniers les droits politiques. Par le décret du 22 aoút, elle donna une représentation dans l'Assemblée nationale à toutes nos colonies.

Cependant la lutte avait commencé partout : à la Martinique, les royalistes avaient pris les armes contre Rochambeau, envoyé de l'Assemblée, arboré le drapeau blanc, fait appel aux Anglais. A la Guadeloupe, ils avaient repoussé Lacrosse et n'avaient été soumis que par le général Collot. A Saint-Doningue, la lutte avait été encore plus vive : en février 1793, les royalistes de l'ile avaient signé à Londres un traité arec les Anglais; pour leur résister, les déléguès de l'Assemblée firent appel aux esclaves, accueillirent même les nègres marrons, leur promirent à tous la liberté, pourvu qu'ils continuassent à travailler sur les terres de leurs anciens maitres, et, avec leur aide, écrastrent les royalistes dans les journées de juin 1793.

La Convention, sur la proposition de Grégoire, avait, en 1793. aboli la prime pour la traite des nègres. Le 4 février 179.', elle décréta, par acclamation ${ }^{1}$, l'abolition de l'esclavage dans les colonies.

Votre empire, est le commerce; sa base est dans les Indes et dans vos colonies. Quant a la France, j'aimerais mieux pour elle quatre villages do plus sur les frontieres de la Républifue que l'ile la plus riche des Antilles. Et je serais mėne fáché de voir Pondichèry et Chaudernagor appartenir encore à la France."

1. Voici un curieux extrait du proces-verbal de cetle séance :

"Lacroix. - .... Les hommes de couleur ont, comme nous, voulu briser leurs fers; nous arons brisé les nòtres... Accorảons-leur le mème bienfait.

"Levasseur. - S'il était possible de mettre sous les yeux de la Convention to tableau dechirant des maux de l'esciavage, je la ferais frémir de l'aristocratie exercéc dans nos colonies par quelques blancs.

"Lacroix. - Président, ne soufre pas que la Convention se déshonoro par une plus longue discussion 1

"LiAssemblee entière se lève par acclamation.

* Le Président prononce l'abolition de l'esclavage, a milieu des appláa. 
Cet acte était à peine comnu dans les Antilles, qu'une puissante flotte britannique, en mars 179', apparut dans ces parages. Elle s'empara de Sainte-Lucie, força Rochambeau et Collot à capituler, l'un à la Martinique, l'autre à La Guadeloupe, mais ne put rien tenter à la Guyane et à Saint-Domingue. En juin de la même annéc, Victor Hugtues, de Marseille, commissaire de la Convention, débarqua à la Guadeloupe avec moins de 1200 hommes, proclama le décret d'abolition de l'esclavage, appela les noirs aux armes, chassa les Anglais, quoique supéricurs en nombre, reconquit lîle en entier, mais ne put reprendre les autres łles.

La conséquence de ces événements, c’est que l'esclavage resta aboli à la Guyane, à la Guadeloupe, où Victor Hugues se maintint contre toutes les attaques des Anglais, a SaintDomingue, ou les nègres se renlirent maitres du pays et presque indépendants de la France. Dans les autres Antilles, grâce à l'occupation britannique, il se maintint.

Lile de France et l'ile Bourbon ne passèrent point par les mèmes épreuves: la Révolution s'y opéra sans coùter une goutte de sang: le nom nouveau de la Réunion est resté comme un souvenir de la fédération des patriotes des deux iles en 1793. Le décret de 179' n'y fut pas promulgué et l'esclavage y subsista.

Bonaparte essaya de reconstituer un empire colonial dans les Antilles avec les iles restituées par les Anglais; avee Saint-Domingue, dont la cour de Madrid nous avait céde la partic espagnole; avec la Louisiane et la Floride,

dissements et des cris mille fois répétés de Five la Riqublique! Vïve la Convention! Vive la Montagne!

" Les deux députés de couleur sont à la tribune; ils s'embrassent.

"Lacroix les conduil au président, qui leur donne !e baiser fraternel.

"Ils sunt sueeessivement embrassés par lous les dejutés.

"Cambon. - Une cituyenne de conleur, qui assisle régulièrement aux séances de la Convention, et qui a partage tous los mourements rérolutionnaires, vien! de ressentir une jole si vive, cn voyant la liberté accordée par nous a tous ses frères, qu'elle a perdu entièrement connaissance. (On applaudit.) Je demande que ce fail soit consignè au procès-verbal, el que cetto citoyennt, admise à la séauce, recoive au moins celle récomperse de ses vertus civiques.

"Cetle proposition est décrétée.

"On voit sur le premier bano de l'amphithéatre, à la gauche du presideat, celte choyenne, qui essuie les larmes que cette scene alteudrissante fait couler de ses yeux. (On applandit.) * 
l'une restituée, l'autıe promise par l’Espagne. Er mème temps, il rétablit l'esclavage à la Guadeloupe et à la Guỹane et essaya de le rétablir à Saint-Domingue: mais l'insurrection de Saint-Domingue, dirigée par Toussaint-Louverture, amena la destruction d'une armée française et la perte de cette grande ile. A la fin de l'Enıpire, toutes nos colonies staient occupées par les Anglais.

Dans l'intervalle, on y avai introduit les nouveaux codes: l'ile de France, quoique tombée au pouvoir des Anglais en 1810, est encore en possession du Code Napoléon.

Quant à la traite des noirs, malgré le décret de 1793, alle continua encore longtemps; Napoléon, pendant les Cent-Jours, dans l'espérance de se conciiler les sympathies de l'opinion anglaise, proclama de nouveau l'abolition de cet odieus trafic.

Ouvrages a consulten. -- A. Sorel, L'Lurope et la Rév. franc. (18571905). - F. Mssson, Le departement des aff. êtrang. penel. La Reve. (1572). - De Rayneval, Dela liberté des mers (1811). - Lecrand, La Riv. franc. en Hollande (1894). - De Lanzace de Laborie, La dom. frane. en belyigice (1895).-A. Rambaud, Ladom. fretic. en Allemagne 1 83 . -Gatfarel.Bonaparte et les republiques itatiennes

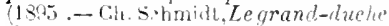
de berg (190:) - E. Driault. Napoleon en Italie $(1900)$. - Voir Hist. le la civil. fr., t. 11, p. 233 .

C. Rousset, Les volontaires, 17911794 (1882). - Fr. Nère, Les bataillonsdevolontaires (Auvergue), IsSO). - Michelet, Les solda ts de la Rév. Chassin, L'arméo de la Rév. (1865).Colonel Lung, Dutrois Crancé(1-Si) et Bonaparte (1881). - Sainte-Chapelle, Hist. generale des instit. nilit. pend. la Iiér. - G. Poisson, L'armée et la garle nationale $1789-95)$ (1802). - E. Deprez, Les volontaires nationaux (1908). - Chassin el Hennet, weme titre (documents, depuis 1\%89).

A. Chuquet, Serie de volumes sur l'histoire mititaire de la Revolution depuis 18v6i.

York de Wartenbure, Napnlion chef d'armee, trad. de l'all., (18:19. C. Roussel, La grande anmee de 1-13 (187). - Fieffé. Vapoleion Ier et la yarle imp. Messin-de Raffel) (1x,0). - Loredan-Lareliey, Jomrial du sorqent Fricrsseet C'iliers du crap. Coigret. - Nemores de Junot, So alt,
Marmont, du Ct Parquin, sergent Bumprogne, col. de Gunneville. de

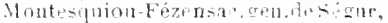
Thicbault, Marbot, de Brande fulonais, Pepe (italitn), Ledem d do bler (hoilandaio), etc. - Charras. Hist. de

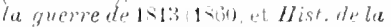

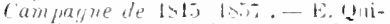

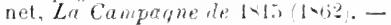

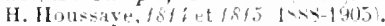
- Nonograbhies sur Kloluer (Einoni, 1867: Pajol, 18:2. Horhe imspre\%,

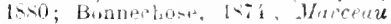
(Maze. 1890; Noñl Parfat. 1549), Desaix (l)esprez. Issif, Lither Debrecagaix, 1905 . Dheoust $11 \mathrm{mr}$ de B hot: quevile, 18-0. La Tuar ll Anergue simond, lwo, Lunnes Thoumas, 1s91, Championnet de sam!-11bin, 1,80. Massena (Gacbot, en crurs), Ney Bonnal, en cours a, cete - Sur les contingents etraugers: Fieffé, Choizko Polonait. Buppes Esparnols, Croates), Sanzy (Allemands). Chaquel (legion germanaque).

Jurien de la Graviere, Guerres maritimes (1851) - E. Chevalier, Hist. de la marme francuise sous la prem. hip. et Sous le Consulat et l'Empire $(1-8)$. - L. Levy, Jeanbon Suint. André (1901).

La Livion dhonneur, 180:-1900. Léon Deschamps, La Constituante et les colonies (1s98). - Castonnet des Fosser, La Révolution à Saint-Dominque (1893) - Barbé-Marbois, llist. ile la Lusisiane (1829). - H. I'renwont, L'lle de France sous Decren 1901 , $\because$ ci-dessous chap. Xxill. 


\section{CHAPITRE IX}

\section{L'INGTRugtion PUblique}

\section{L'instruction publique pendant la Révolution.}

Projets de la Convention. - La Révolution, dès son début, se préoccupa d'établir en France, sur un plan rationnel, un enseignement national. Les deux premières Assemblées n'eurent le temps de rien londer : Talleyrand avait pourtant préparé, au nom du Comité de Constitution, un rapport adressé à la Constituante; ConDorCET, au nom du Comite ce instruction publique, avait présenté à la Législative un plan comprenant des écoles de tout ordre.

La Convention entendit également le rapport de Romme sur un plan d'études, celui de Rabaut-Sant-Étienne sur les fètes publiques, qu'elle considérait comme un moyen d'éducation nationale et républicaine, celui d'Arbogast sur les livres élémentaires, celui de Bancal sur les écoles primaires et les écoles centrales.

La Convention, avant d'ètre une grande créatrice, avait été une grande destructrice: elle prononça la réunion au domaine des biens de toutes les corporations scientifiques ou enseignantes, et supprima celles-ci : elle se proposait de doter sur le budget ses nouvelles créations, mais la pénurie du Trésor faillit tout compromettre.

lo Enseignement primaire. - Pour l'enseignement primaire ${ }^{1}$, qu'il semblait le plus urgent de constituer, puis-

1. On sait qu'il y a lieu de distinguer en France trois ordres d'enseignement: l'enseignement primaire, pour les notions tout à fait ćlémentaires: 
qu'il s'adresse à la masse de citoyens, la Convention discuta successivement plusieurs projets : celui de BARĖRE, avant la chute de la Gironde; celui de pomme ${ }^{1}$, et celui de BodQUIER ${ }^{2}$, à l'époque de la plus grande puissance des Jacobins; celui de lakanal, ${ }^{3}$, après la chute de Robespierre.

Les plus démocratiques étaient ceux de Romme et de Bouquier. Le premier décidait qu'il y aurait au moins une école par commune de 400 habitants; il divisait les écoles primaires en trois catégories et dressait pour chaque catégorie des programes rationnels et conplets, peut-c̀tre trop complets ${ }^{4}$. Le second établissait que l'enseignement serait obligatoire et gratuit.

Pour constituer dans toutes les communes de France un enseignement primaire, surtout obligatoire et gratuit, il aurait fallu disposer de beaucoup de temps, de beaucoup d'argent, d'un nombreux personnel. En effet, on n'a pas le droit de décréter que l'enseignement sera obligatoire si I'on n'est pas en mesure de mettre à la disposition des enfants une école et un instituteur; il n'est pas possible d'établir la gratuité si l'on n'a pas les fonds nécessaires pour assurer au personnel enseignant le traitement qui doit lui tenir lieu de la rétribution scolaire. Or, pour créer peut-être cinquante mille écoles, trouver soixante ou quatrevingt mille instituteurs et institulrices, s'assurer de leur capacité, leur constituer un traitement et un logement suffisants, l'argent et le temps manquèrent à la Convention.

Elle-mème, dans sa dernière loi, celle de trumaire an $I V^{5}$, inspirée par DaUNod, renonce au principe de l'obligation et de la gratuité, renonce à créer une école par

il se donne aujourd'hui dans les écoles primaires el les écoles primaires supérieures; l'enseignement secondaire, qui prépare aux carrières dites libérales, et qui se donne aujourd'hui dans les lycees el collegts; l'enseignement supérieur, destiné a former une élite, el qui se donne aujourd'hui dans les facultés, dans les établissements scientifiques (tels que le Collège de France, le Muséum, ete.) et dans certaines écoles spéciales (comme l'Écalo normale, l'École polytechnique, etc.).

1. Volé le 30 vendemiaire an II - 21 octobre 1793.

2. Volé le 29 frimaire an II - 19 décembre 1793.

3. Voté le 27 brunaire an III - 17 novembre 1794.

4. Ils comprenaient la géographie, l'histoire des peuples libres, les élémeats des sciences, la gymnastique et les exercices militaires.

5. 3 brumaire an IV -25 antobre 1795. 
commune et même par mille habitants, renonce à assurer un traitement fixe aux instituteurs (il avait d'aborl été question de 1200 livres, puis de 900 livres), renonce aux vastes programmes qu'elle avait rèvés. Elle se borne à demander qu'on enseigne à lire, à écrire et à compter.

Toutefois, c'est la gloire de la Convention d'aroir eu pour l'instruction populaire, pour le bien-ètre des maitres, pour les programmes d'ensejgnement, de hautes ambitions. L’idéal qu'elle se proposait était trop élevé pour les ressources dont on disposait alors : jusquà la République actuelle, aucun des gouvernements qui ont succédé à la Convention, et qui jouirent de ressources et d'une tranquillité qu'elle n'a pas connues, n’ont tenté de réaliser ses plans. Quoiqu'elle ait échoué dans sa tâche, elle a marqué le but à atteindre et posé les principes.

2o Enscignement seeondaire : les écoles centrales. La Convention a créé les écoles centrales, destinées à remplacer les anciens collèges, à raison d'une par département. A Paris, il y en eut trois : celle du Panthéon (aujourd'hui lycée Henri IV, celle de la rue Saint-Antoine (aujourd'hui lycée Charlemagne), celle des Quatre-Nations, alors installée au Palais-Mazarin. Ce qui caractérisait le nouvel enseignement, c'était la place qu'on $y$ avait faite aux mathématiques, à la physique, à la chimie, au dessin, et aussi à la philosophie, à l'histoire, à la législation, à la grammaire comparée. C'était un grand progrès sur les enseignements précédents, presque entièrement consacrés aux lettres et aux langues anciennes. Malheureusement, beaucoup de ces écoles végétèrent: on en avait confié la suryeillance aux autorités départementales, qui manquaient de zèle ou de compétence; les professeurs n'étaient pas assez nombreux ou assez capables; les élèves, laissés libres de choisir les cours qu'ils entendaient suivre et n'ayant à redouter aucun examen qui contrôlàt leurs études, négligeaient des parties essentielles de l'enseignement. Les écoles centrales qui réussirent le mieux furent les trois écoles de Paris, et celles de Besançon, Toulouse, Montpellier

30 Enseignement supérieur. - Dans l'enseignement supérieur, la Convention n'eut pas le temps de préparer une organisation d'ensemble: il y eut alors deux écoles de 
droit, à Paris ${ }^{1}$, et trois écoles de sante, à Paris, Moutpellier et Strasbourg, où se trouvèrent réunis, pour la première fois, les médecins, les chirurgiens, les chirurgiens militaires et les apothicaires, devenus les pharmaciens.

L'œuvre capitale de la Convention, pour l'enseignement supérieur, fut la création de nos grandes écoles spéciales et de nos grands établissements scientifiques et artistiques.

4. Créations scientifiques, littéraires, artistiques. La Convention a créé : $1^{\circ}$ l'École normale ${ }^{2}$, inaugurée en 1794, pour le recrutement des maîtres. Elle comprenait alors 1200 élèves, fui n’étaient pas astreints à l'internat. Elle comptait parni ses professeurs les hommes les plus éminents de l'époque : Lagrange, Laplace, Monge, pour les mathématiques; Haüy, pour la physique; Daubenton, pour l'histoire naturelle; Berthollet, pour la climie; Thouin, pour l'agriculture; Volney, pour l'histoire; Bernardin de Saint-Pierre, pour la morale; Laharpe, pour la littérature; Sicard, pour la grammaire générale; Garat, pour l'analyse de l'entendement; Vandermonde, pour l'économie politique; Buache pour la géographie. Les élèves devaient être choisis par les municipalités à raison d'un par 200000 lıbitants : c'était une sorte de conscription. Les seules conditions requises étaient d'avoir au moins vingt et un aus, et de " réunir à des lumières un patriotisme éprouvé et des mours irréprochables ". Les instituteurs ou professeurs de l'École " leur apprendront d'abord à appliquer à l'enseignement de la lecture, de l'écriture, des premiers éléments du calcul... les méthodes tracées dans les livres élémentaires adoptés par la Convention et publiés par ses ordres ". En réalité, l'École normale de 179' était destinée à former des instituteurs, et non des professeurs.

$2^{\circ}$ L'École centrale des travaux publics, constituée par décret de $1794^{3}$, est devenue bientòt après l'École poly-

1. C'étaient deux êcoles liâres : l'Academie ae législation, rue de Vendome, et l'Liniversité de jurisprudence, dans l'ancien college d'Harcourl, rue Laharpe.

2. Créée par décret du 9 brumaire an 111 - 30 octobre 179.4, organisée par décret du 8 décembre 1794 .

3. 7 vendémiaire an $111-2$ oclobre 1794. - L'école comprenait alor 400 élèves; les études duraient trois ans; on y entrait après des examens passés dans $2 z$ vules désignees; linstruction était gratuite, et les élèves 
technique. Trois des comités de la Convention, ceux de Salut public, d'Instruction et des Travaux publics, s'entendirent pour la constituer. Elle compta parmi ses fondateurs Lamblardie, Monge, Fourcroy, Lagrange. Elle eut pour professeurs ces trois derniers, plus Prony, Berthollet, Chaptal, Vauquelin, Guyton de Morveau.

$3^{\circ}$ Le Jardin du Roi fut translormé, par décret de 1793 (10 juin), en Muséum d'histoire naturelle : Geoffroy Saint-Hilaire y ouvrit, en 1794, notre premier cours de zoologie. Il y eut pour collègues Brongniart, Cuvier, Jussieu, Lacépède, Lamarck.

$4^{\circ}$ L'École spéciale des langues orientales, "d'une utilité reconnue pour la politique et le commerce ", lut fondée en mars 1795. Langles y enseignait le persan et le malais, Silvestre de Sacy l'arabe littéraire et l'arabe vulgaire, Venture le turc et le tatar, Millin l'archéologie et (sous le Directoire) d'Anse de Villoison le grec moderne.

$5^{\circ}$ Le Bureau des longitudes fut eréé, en juin 1795, pour les ètudes d'astronomie nécessaires à la navigation.

$6^{\circ}$ Le Conservatoire des arts et métiers, fondé en octobre 1794, est resté notre école supéricure d'industrie.

$7^{\circ}$ Le Musée du Lourre, en juillet 1793, fut formé des tableaux recueillis dans les palais royaux, bientòt enrichi des tableaux conquis en Hollande et en ltalie, et destiné $\dot{a}$ faire l'éducation artistique du peuple.

$8^{\circ} \mathrm{La}$ Bibliothèque nationale eut pour premier noyau lancienne Bibliothéque du Roi: la loi de 1793 sur le tépót légnl l'a enrichie de toutes les publications imprimées en France.

9० Dans les Archives nationales fondées en 1794, vinrent se centraliser tous les documents anciens dispersés daus les châteaux et les monastères et que la Convention, sur la proposition de Grégoire, avait interdit de détruire.

$10^{\circ}$ Le Musee des monuments français, formé en février 1793, réunit les morceaux de sculpture et les fragments les plus précieux de l'ancienne architecture du 
moyen âge. La Convention avait interdit de mutiler les anciens monuments " sous prétexte d'en faire disparaitre les insignes de la féodalité ei de la royauté ". C'est un gouvernement révolutionnaire qui a eu l'idée de recucillir pieusement ces précieux restes du passé : c'est la monarchie légitime, sous la Restauration, qui a dispersé ce musée.

$11^{\circ}$ Le Conservatoire national de musique, ouvert en novembre 1793, réunissait 600 élèves et comptait parmi ses professeurs Gossec, Grétry, Méhul, Lesueur, Cherubini.

$12^{\circ}$ Le Musée dartillerie fut organisé par Pétiet, en juillet 179ă, et installé d'abord à Saint-Thomas d'Aquin, sous la surveillance du Comité d'artillerie.

C'est la Convention qui a convoqué le premier jury national des beaux-arts. Mème au milieu des dangers mortels de l'invasion étrangère et de la guerre civile, elle organisait des expositions de peinture.

La Convention donna une organisation nouvelle à des établissements déjà existants :

$1{ }^{\circ}$ Elle rétablit en 1795 l'École des mines, fondée en 1783, supprimée en 1790.

$2^{\circ}$ Elle réorganisa l'École des ponts et chuussées.

$3^{\circ}$ La Constituante avait eréé 34 écoles de navigation pour l'instruction de notre marine; la Convention en créa deux nouvelles; elle fonda trois écoles spéciales d'aspirants dans les ports de Brest, Toulon, Rochefort. C'est l'origine de notre Ecole nuvale.

$4^{\circ}$ La Convention, pour le recrutement des olficiers de l'armée de terre, établit au camp des Sablons l'Ecole de Mars, qui ne dura que cinq mois.

$5^{\circ}$ Elle transféra à Hetz l'École du génie, réorganısée par la Constituante. C'est aujourd'hui l'École d'application de Fontainebleau, pour le géliie et l'artillerie.

$6^{\circ}$ Elle réorganisa, en 17903 , le Collège de France, fondé par François Ier, et qui a pour mission d'enseigner les sciences et les langues qui n'ont pas eneore trouvé place dans le programme des facultés.

Il est un homme, Laganal, dont le nom est associé aux principales réformes de la Convention : c'est lui qui fit voter la dernière loi de cette assenblée sur les écoles pri- 
maires, présida à l'organisation des écoles centrales, à celle de l'École normale et du Muséum. Il fut un des premiers membres de l'Institul. Son caractère était à la hauteur de son intelligence. Il refusa de reconnaître le coup d'Elat, fut éliminé de l'Institut et n'eut d'autre moyen d'cxistence que son traitement de professeur à l'école centrale du faubourg Saint-Antoine (lycée Charlemagne). Sa devise était : "Un peuple ignorant ne peut être libre."

50 L'Institut de France. - Au sommet de ce magnifique ensemble d'écoles et d'enseignements, comme pour résumer tout le mouvement scientifique et artistique du siècle, fut placé l'Institut national, en octobre 1793̈. Déjà, sous la Constituante, Mirabeau avait proposé de supprimer les anciennes Académies, " ces écoles de servilité et de mensonge ". L'Académie française, qui comptait dix de ses membres dans l'émigration, fut, en effel, dissoute; les autres Acalémies furent réorganisées sur un plan rationnel et devinrent des classes de l'Institut. La première classe était celle des sciences physiques et mathématiques (ancienne Académie des sciences); la seconde, celle des sciences morale's et politiqucs, véritable création de la Convention, était consacrée aux sciences nouvelles, à la philosophie, à la morale, à la législation, à l'économie politique, à l'histoire; la troisième classe était celle de littéaturc et beaux-arts (ancieunes Académie française, Académie des inscriptions et belles-lettres, Académie de peinture et de sculpture, Académie d'architecture).

Le nouvel Institut fut instal]é au Louvre en 1796. Plus tard, on le trausféra aux Quatre-Nations (quai Vollaire).

sous le Ibircetoire. - Le Directoire n'a rien ajouté aux créations de la Convention. Il prescrivit en 1797 de surseoir à la vente de tous les édifices autrefois consacrés à l'enseignement. Il exigea de tous les citoyens qui solliciteraient une fonction publique la preuve qu'ils avaient étudié dans une des écoles de la République, et, s'ils étaient pères de famille, qu'ils faisaient instruire leurs enlants.

En 1798, François de Neufchâteau, ministre de l'intérieur, créa un Conseil de l'instruction publique, origine de notre Conseil supcrieur. 


\section{L'Instruction publique sous Napoiéon.}

Fondation de rUniversité. - Napoléon, par la loi cì 1806, décide qu'il sera formé un corps " chargé exclusivement de l'enseignement et de l'éducation publique dans tout l'Fmpire " : c'est l'Université impériale. Les décrets de 1808 en règlent l'organisation et la discipline. A la tête de l'Lniversité, il y a un grand muitre, assisté d'un Conseil de l'Université. La France est divisée en acudémies, à la tète de chacune desquelles il y a un recteur, assisté d'un ou plusieurs inspecteurs d'actémie et d'un conseil acudémique, tous nommés par le grand maitre.

L'Université comprend : $1^{\circ}$ des fueultés, "pour les sciences approfondies et pour la collation des grades "; $2^{\circ}$ des lycées; $3^{\circ}$ des collèges; $4^{\circ}$ des institutions purticulicres, dont l'enseignement se rapproche de celui des colleges; $5^{\circ}$ des pensions ou pensionnuts d'un ordre moins élevé; $6^{\circ}$ des petites écoles; c'est le nom qui remplace l'appellation, jugée alors trop révolutionnaire, d'écoles primaires.

Tous ces établissements prendront pour base de leur enseignement : " $1^{\circ}$ les préceptes de la religion catholique; $2^{\circ}$ la fidélité à l'Empereur, à la monarchie impériale, dépositaire du bonheur des peuples, a la dynastie napoléonienne, conservatrice de la France et de toutes les illées libérales proclamées par les Constitutions impériales ". Le grand maitre prête serment à l'Empereur: il s'engage à former "des citoyens attachés à leur religion, à leur prince, à leur patrie, à leurs parents ".

Nul ne peut enseigner s'il n'est membre de l'Université ou s'il ne se soumet à ses règlements et à ses principes : c'est ce qu'on appelle le monopole de l'Université.

Les instituteurs primaires n'appartiennent que nominalement à I'Université, car ils dépendent, avant tout, de la hiérarchie administrative : maires, sous-préfets, préfets.

Le premier grand maitre de l'Universite fut $\mathrm{M}$. de Fontanes, qui se distingua surtout par ses apologies, en beau style acadénique, du génie de l'Empereur.

1 - Enseignement primaire. - Sous le Directoire, l'argent avait toujours manqué pour créer des écoles: les 
communes, que l'État avait chargées du traitement des instituteurs, ne les payaient pas ou les payaient mal ${ }^{1}$.

Napoléon abandonne la nomination des instituteurs aux maires et aux conseils municipaux. Les communes ne doivent aux maitres que le logement. Leur traitement est constitué par la faible rétribution que payent les élèves. L'État n'alloue aucuns fonds pour ce service. Tout le budget de l'instruction primaire consiste en une somme de 4250 francs que l'Empereur attribue au noviciat des ćcoles chrétiennes. En 1810, Fontanes approuve les statuts de ces écoles : leurs maîtres doivent ètre brevetés de l'Université et leurs supèrieurs peuvent en être membres. Lenseignement leur est livré presque entièrement. Liinstruction se réduit alors à la lecture, à l'écriture, au calcul, an catéchisme; les châtiments corporels et les punitions humiliantes, que la Convention avait voulu interdire, reparaissent.

Le décret de 1808 avait prescrit la création d'écoles normales auprès de chaque académie, à l'intérieur des lycées et collèges; mais il ne s'en fonda alors qu'une seule, celle du Bas-Rhin (1811), sous le préfet Lezay-marnésia.

a Ensciguenent secondaire : Ies lyeées et collèges. L'enseignement des lycées et collèges, qui ont renplacé les écoles centrales, est un retour au passé : les ètudes scientifiques cèdent de nouveau le pas aux belles-lettres et aux langues auciennes, enseignées suivant la méthode mise en honneur, au $x v_{1}$ siècle, par les jésuites. Le régine intérieur de ces établissements tient à la fois du couvent et de la caserne: les proviseurs, censeurs, principaux doivent être célibataires; les élèves sont astrents a l'unilorme, à une

1. In document curieux donnera une idèe des obstacles qu'opposaient á la cirínion de l'instruction les préjugés el la routine.

Le 9 thermidor 1795, 42 habitants de Saint-Leger.de-Fougeres (Nièrre) adressent a la Convention nationale une pétition dont foici un extrat : - Ciloyens représentants... Les écoles primaires sont des etablissements très coúteux à la République. Elles sont inutiles dans uos eampagnes par l'imJussibilité où nous sommes de nous passer de nos enfants ou de les envoyer a une école distante de nos domiciles sourent de plus duue lieue. Nous n'avons pas besoin d'avocats à la charrue, et, pour labourer, il nous est inutile de savoir lire et écrire... Nous n'avons vu clisparaitre de nos camparnes la bonne foi et l'union que lorsqu'on a voulu nous rendre sçavants et philosophes. "Suivent 9 signatures, dont la plupart sont informes. La piece se termine par cefte mention : "Les autres pretitionuaires ue savent signer." (Documeut inedit communiqué par M. Gazter.) 
discipline toute mécanique et militaire, et règlent tous leurs mouvements sur le tambour. Le lycée ou le collège est, avant tout, l'apprentissage du régiment.

$3^{\circ}$ Enseignement superieur : les facultés. - Napoléon porte à neuf, pour toute la France, le nombre des facultés de droit. Il transforme les "écoles de santé " de la Convention en facultés de médecine, au nombre de trois. Il crée les facultés de théologie catholiques, au nombre de neuf, et deux frcultés de théologie protestrntes, une à Strasbourg pour la confession d'Augsbourg, l'autre a Montauban pour la confession de Genève : plus une à Genève, alors que cette ville était française. Enfin il institue les facultés de lettres et de sciences, chargées de faire tes cours publics et de conférer le bacculuaréat et les autres grales universituircs.

Les facultés de lettres et de sciences nont pas encore de personncl à elles : elles se composent de professeurs empruntés au lycée de la ville où elles sont établies : son proviseur et son censeur en font nécessairement partie. A Paris, la faculté des sciences est forméc par des professeurs du College de France, du Muséum, de l'École polytechnique et de deux professeurs des lycées; la faculté des lettres est formée par des professeurs du Collège de France ou des lycées. Dans chaque faculté, un des professeurs porte le titre de loyen.

4 R Rounes et créations diverses. - L'École normale de la Convention devient le Pensionnat normal: les élèves, très réduits de nombre, sont astreints à l'internat et suivent les cours du Collège de France, du Nuséum et de l'École polytechnique. Ils n'ont pas de professeurs spéciaux.

L'ícole poly technique, en 1804 , fut écalement astreiıte à l'internat. Elle fut soumise au régrime militaire. Elle uccupait déjà l’ancien Collège de Navarre.

Napoléon, dans ses guerres continuelles, faisait une consommation effrayante d'officiers. Un de ses premiers soins, comme Premier consul, avait été de fonder une École militaire, établie d'abord à Fontainebleau, puis transférée à Saint-Cyr, sa résidence définitive ${ }^{1 .}$

1. C'est cette école qui a donné à la France 5 maréehaux, 289 génèraux de division et $40 . \dot{i}$ généraux de brigade. - Dès le début de l'école avaient commencé les brimades, rudes et grossières eomme les mours da 
L'ancien couvent du Val-de-Gràce devient notre grand hôpital militaire et un centre d'études pour la chirurgie et la médecine des armées.

$5^{\circ}$ LInstitut de France mutllê. - Napoléon porta la main sur l'Institut de la Convention, dont il avait été membre. En 1803, il supprima la classe des seiences morales et politiques, auxquelles il appliquait dédaigneusement le nom d'idéologie, mais qui lui semblaient dangereuses pour le pouvoir absolu. Par la suppression de celte classe, des hommes éminents qui s'étaient distingués dans la politique ou dans la science, Sieyès, Merlin de Douai, Lakanal, Garat, etc., se trouvèrent éliminés de l'Institut.

lemps. "On suspendait, nous raconle l'historien de l'école, les malheureux conscrits au plafond dans des sacs à distribution; on leur volait leurs fouschettes pour les empêcher de manger'; on les faisait aller à l'exercica 'o tête nue en cachant leur bonnel de police, el mille autres vexalions qui devaient former le caractère des noureaux venus et leur apprendre à obéir avant de pouvoir commander. Cette manie de tourmenter les conscrits devenait une véritable rage quand le nouvel arrivé recevait pour numéro malricule le numéro 1000 ou un de ses multiples. A Fontainchleau, le malheureux qui entra et prit le numéro 2000 fut jeté par les fenèlres. Pourquoi? Parce qu'il était trop conscrit! " Cette belle raicon avait tant do poids qu'on fut obligé plus tard de faire accompagner plusieurs jours, partout où il allait, l'élévo qui entra avec le numéro 3030 .

a Naturellemcnt, parmi celte bouillante jeunesse, le noint d'houneur élait porté à un degré exiraordinaire, et les duels furent nombreux... Une parole ımprudente de Napoléon, lors d'une de ses visites à l'École, ne fit qu'accroitre cette fureur. L'Empereur demanda s'il y avait des duels. - Je vondrais bien voir qu'on se baltit a l'École ! s'exclama le générai baron Bellavène. - De mon temps, à Brienne, nous nous battions, ajonta l'Empereur. Cette parole, tombant de la bouche de celui qu'ils consideraient comme un demi-dieu, fut recueillie comme un encouragenent lacite par les élèves, qui se battirent de plus belle, prenani, pour suppleer aux armes qu'on leur enlerait, des baguettes de fusil préalablement aiguisées."

Ouvalges a consulter. - Buis- noir et le musée des monuments sun, Dictionnaire pédagogique, arti- fruncais (18T). - Dupuy, L'Lcole cles Constituante, Convention, no:malesuperieure(1s9.).-G. Pinet, France, ete. - J. Guillatume, Procéverbaux du Comité d'Inst. publ. „a Convemion. - Cumpayre. H... critique des doctrines diducation en France $(1879)$. - Issaurat, La peidagogie, son irolution et son histoire (1si6). - A. Bibcan, L'école du village pendant la Rirol. (1585. - Hij)peau, L'inst. primaire en France perdant la Révol. (1881-83).-A. Duruy, L'inst. publique et la Révol. (ISs2). -

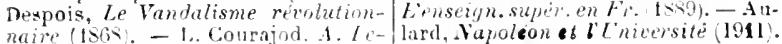
Hist. de l'Ecole polytechnique tos). - In ancien Saint-lyrinn, Hist. de lecole de Suint-1"y 18>0. - Lt(Col. Titens, sitint-ryr et licole spec milh. - De Franuduville, Le iremier sipcle de linstitut 1896 . L. Auro", L'Institut (1\$\$9). - P. Mesnard, Ifist de l'. I cad. franc. 1257)J. Bertrand (IS6S. Maindron (IN88), L'Acal des sciences. - Delenze, Mist. du Wuseam I tash. - Liard, Linsergn. superr. en Fo t\$89). - Anhard, sapoleon et te niecrsite (1911. 


\section{CHAPITRE $\mathbf{X}$}

\section{LES LETTRES}

\section{Caractères géréraux.}

Infuence de la Révolution sur l'esprit frangais. - La Révolution fut un déchainement prodigieux de forces destructrices et de forces créatrices. Elle agit sur l'intelligence francaise comme sur l'état politique et social.

Puisque nous avons compté les victimes que fit la monarchie, surtout à l'époque des persécutions religieuses, parmi les lettrés, les savants, les artistes, nous ne pouvons oublier celles que fit la Rérolution, surtout à l'époque de la Terreur. Sur ses échafauds périrent les poètes Houcher et André Chénier, Fabre d'Eglantine, le fécond auteur dramatique, et, successivement, les plus brillants orateurs, les plus hardis polémistes des partis monarchijues, puis de la Gironde, puis de la Montagne. A la Terreur l'histoire demande compte de Bailly, une gloire des sciences comme des lettres françaises, l'auteur de "l'Histoire de l'Astronomie"; de Condorcet, grand mathénaticien et grand philosophe, qui esquissa d'une main si ferme le "Tableau des progrès de l'esprit humain "; de Lavoisier, le créateur de la chimie noderne et le rénovateur de la physiologite; de Bochart de Saron, qui avait complété la grande découverte de Herschel en montrant qu'Uranus était une planète et non une comète; de Morand, l'éminent architecte de Lyoll. Elle poursuivit Rouget de l'lsle, l'immortel auteur de la "Marseillaise ", et Philippe de Girard, qui rendit tant de 
services à la science et à lindustrie. Et combien d'autres furent jetés dans l'émigration, proscrits, déportés! Cependant, dans le mème temps. la Révolution donna naissance à des formes et à des genres littéraires jusqu'alors inconnus : elle enfanta un théatre d'une audace et d'une fécondité quon n’avait pas revues depuis les républiques grecques; elle dressa en France une tribune et y fit entendre les voix les plus éloquentes que le monde cùt jamais entendues depuis Dimosthène et Cicéron; elle lança dans la rue des centaines de journaux et nous donna notre première presse politique; elle ouvrit des horizons infinis aux sciences morales, politiques et religieuses; elle imprima un caractère de grandeur inouï aux productions des arts plastiques, de l'architecture et de la musique. Pour nous en tenir a la litterature, ce sont les genres militants, ceux qui s'adressent à la foule, qui furent le plus profondément renouvelés, car la littérature de cabinet fut à peine modifiée.

Sur le rapport de son Cumité dinstruction publique, présenté par Grégoire, la Convention avait dècrété (18 oclobre 1794) qu'une somme de 100000 écus serait annuellement consacrée aux " encouragements, récompenses et pensions à accorder aux savants, aux gens de lettres et aux artistes dont les taleuts sont utiles à la nation ". Ainsi l'Assemblée régicide reprenait une des plus nobles traditions du grand roi.

milnence de l'mpire. - Quand Napoléon fut devenu le maitre de la France, il pacifia le théâtre, la tribune, la presse. Il imposa silence à ces mille voix que la Révolution avait éveillées. Il n'épargna que la littérature inoffensive et presque insignifiante. Ses faveurs furent pour les Fontanes et les François de Neufchàteau; ses rigueurs pour Chateaubriand et madame de Staël. Comme Napoléon le disait à Fontanes: "Jai pour moi la petite littérature et contre moi la grande."

Napoléon a élé moins tyramnique, par conséquent plus heureux, arec les artistes et les savants qu'avec les lettrés et les philosophes.

Pour ses conceptions grandioses en architecture, il trouva d'admirables interprètes en Chalgrin, Percier. Vignon, Brongniart. Les peintres Darid et Gros, en leurs 
vastes compositions, donnèrent la splendide illustration de ses fètes et de ses batailles.

Les musiciens Méhul et Gossec trouvèrent des accents dignes des gloires de l'époque.

Les découvertes des savants justifiaient le fier langage que Napoléon tenait à l'Institut, après la lecture des fameux lirpports sur l'état des sciences: “J'ai voulu vous entendre sur les progrès de l'esprit humain dans ces derniers temps, atin que ce que vous auriez à me dire fủt entendu de toutes les nations et fermàt la houche aux détracteurs de notre siecle, qui, cherchant à faire rétrograder l'esprit humain, paraissent avoir pour but de l'éteindre. J'ai voulu connaitre ce qui me restait à faire pour encourager vos travaux, pour me consoler de ne pouvoir plus concourir autrement a leurs succès."

Napoléon, en effet, ne se borna pas à protéger les savants: il s'enorgueillissait d’ètre l'un d'eux, et tint à conserver, devenu Empereur, ce titre de membre de l'Institů qui avait été décerné au général de l'armée d’Égypte. S`il nassistait plus aux séances de ce grand eorps, il orlonnait la publication de ces Rapports sur les sciences et les lettres, rédigés par Delambre, Curier, Joseph Chénier, et qui sont comme l'inventaire des richesses de l'esprit humain à cette époque. Il fondait les prix décennoux avec une libéralité qui eût étonné Colbert : c'étaient des prix de 100000 franes. Sur la poitrine des lettrés, des artistes, Ies savants, des inventeurs, il attachait cette étoile si enviée des héros, pour laquelle ses soldats se ruaient sur les canons et les drapeaux de l'ennemi; il les élevait aux plus hauts gratles de cet ordre de la Légion d'honneur, dont ¿es souverain. de l'Europe ambitionnaient les insignes. II 'tisait que, si Corneille avait vécu de son temps, il l'aurait fait prince: du moins, il faisait comtes et barons des sivants comme Lagrauge, Laplace, Monge, tout comme ses colonels et ses généraux victorieux. Il ouvrait son Sénat à Lagrauge, Laplace, Monge, Lacépède.

Rivalisant avec Louis XIY, le surpassant même en magnificence, la protection qu'il exerçait sur les intelligences eut quelques-uns des défauts de celle du grantl roi. Elle fut parfois exigeante, égoïste, et certaines injustices furent 
encore aggravées par son humeur brusque et despotique, car il ne savait pas se contenir comme le souverain de Versailles. Il désespéra Cherubini ${ }^{1}$ par des rigueurs que celui-ci s'était attirées par un peu trop de franchise. Si Gay-Lussac dut à sa libéralité les moyens nécessaires pour poursuivre de couteuses recherches, on voit, par l'exemple de Lamarck, que ses boutades n'étaient pas moins à redouter pour les savants que pour les ambassadeurs des puissances européennes ${ }^{2}$. Il protégeait l'Institut, mais il le mutilait; il ne lui laissait aucune liberté, et il s'arrogeait le droit d'en nommer parfois les membres en dehors des suffrages de leurs futurs collègues, comme il fit pour le statuaire Bosio.

Caractère classique de Ia littérature. - La France fut une République comme Sparte et Athènes; elle fut ensuite, comme Rome, la capitale d'un Empire. Rien d'étonnant si le caractère classique, légué par le xvi et le xvıe siècle, s'accentue dans les lettres. La plupart de nos dramaturges reviennent sans relàche aux sujets grecs et romains, avec Joseph Chénier, avec Legouvé, avec Arnault. Raynouard lui-mène écrit un "Caton d'Utique ". Collot d'Herbois, ce pourroyeur du tribunal révolutionnaire et de la guillotine, tient à nous donner le "Procès de Socrate ". Chénicr se fait inierdire un "Timoléon ", et Lehoc un "Pyrrhus ". Les Grees et les Romains dominent,

1. Un jour Bonaparte, alors Premier consul, critiquait devant Clerubini ses accompagnements, qu'il trouvait trop sonores, citait des airs de Zingarelli, louait la musique de Paisiello, qui, disait-il, le herçait doucement. "J'entends! répondit Cherubini, vous aimez la musique qui ne vous empèche pas de songer aux affaires de l'État. " Mot trop spirituel que le maitre n'a jamais pardonné.

2. Arago, dans l'Histoire de sa jeunesse, raconle une scène qui eut lieu, en 1509, lors d'une présentation des membres de l'hustitut. L'Empereur s'arrèta tout à coup devaat Lamarek, déja illustre par tant de belles déceuvertes. Le vieillara lui présenta un livre : "Qu'est cela? dit brusquement Napoléon. C'est votre absurde météorologie, e'cst cet ouvrage dans lequel vous faites concurrence a Mathieu Lænsberg, eet Annuaire qui dẻshonore vos vieux jours! Faites de l'histoire uaturelle, et jo rocevrai vos productions avec plaisir. Ce volume, je ne le prends que par considération pour vos ehereux blancs." - "Teuez!..." Et il passa le livre a un aide de eamp. Le paurre Lanacck, qui, a chacune de ces paroles offensantes, essayait inutilement de Jire: "C'est uu livre d'histoire nalurelle que je vous présento " -ut la faiblesse de fondre en larmes. * 
plus que jamais, dans l'art dramatique comme dans les tableaux de David, comme dans la statuaire, comme dans l'architecture, comme dans les motifs d'ameublement et dans le costume, comme à la tribune et mème dans la presse, comme dans les constitutions et les lois. "Prenez n'importe quel discours, lisez n'importe quelle proclamation, ouvrez au hasard un journal, feuilletez un pamphlet : vous y trouverez, quatre-vingt-dix fois sur cent, des allusions directes à l'expulsion des Tarquins, à la mort de César, à l'héroïsme de Brutus, à l'inflexibilité de Lycurgue, a la sagesse de Solon, au dévouement de Cynégyre, à la conspiration de Catilina, au supplice de Manlius, à la rigidité de Marius, à la folie de Xerxès, au sacrifice de Léonidas, à la condamnation d'Aristide, au jugement de Socrate. " (Welschinger.) Puis, sous Napoléon, les noms de dignités et d'institutions nouvelles, Consul, Empereur, Sénat, Tribun't, Sénatus-consulte, Plébiscite, Comices, Légions, Cohortes, tout n'est-il pas romain?

\section{Lo théâtre.}

Le théâtre de la hévolution. - Par le décret du 13 janvier 1791, la Constituante avait mis fin aux monopoles, proclamé la liberté des théàtres, aboli la censure royale. Paris, à lui seul, eut alors quarante-cinq scènes dramatiques ou lyriques. La mème assemblée émancipa les comédiens et, après une célèbre discussion, ou Røederer, Clermont-Tonnerre, Robespierre parlèrent en leur faveur et où l'abbé Maury se fit rappeler à l'ordre en les combattant, leur reconnut le droit électoral.

Les théâtres, ainsi multipliés, peuplés d'acteurs qui, pour la plupart, étaient patriotes, entrèrent aussitôt dans le mouvement de la lévolution. Ils saisirent au vol l'actualité et, de même qu'à Athènes, transportèrent sur la scène les événements du jour. On pourrait, rien qu'avec la liste des tragédies, drames, comédies, opéras, opéras-comiques, pantomimes, reconstituer la suite des journées de la Révolution. Celle du 14 juillet inspire quatre pièces. La chute de la royautè est saluée par "la Journée du 10 Août 1792 " 
et par “ la Réunion du 10 Août, sans-culottide dramatique dédiée au Peuple souverain ". Après la fuite de la famille royale et son arrestation à Varennes, on représente "la Ligue des Fanatiques et des Tyrans" et "la Voyageuse extravarante corrigée ".

Le procès de Louis XVI, celui de Marie-Antoinette, qui semblaient annoncer un sort pareil à tous les souveriuis de l'Europe, inspirent une série de pièces où respire une haine furieuse contre les monarques : "le Jugement dernier des Rois ", par Sylvain Maréchal, où l'on roit le pape, l'impératrice de Russie, l'empereur d'Allemagne et les rois, déportés sur une île volcanique, se lamentant, se querellant et se battant, et finalement anéantis par une éruption du volcan; "les Potentats foudroyés par la Montagne et la Rilison, uu la Déportation des rois de l'Europe ", par le citoyen Desbarreaux; "les Peuples et les Rois au tribunal de la Raison ", par Cizos-Duplessis; "la Folie de Guorges ou l'ouverture du Parlement d'Angleterre ", par le peintre Lebrun-Tossa, où l'on voit les Anglais mettre leur roi dans une cage, le conduire it l'hospice des fous et fraterniser avec les Français aux cris de Vive la Nation! " le fràteau des Rois ", par Destival et de Valcour, où les potentats tirent la fève sur les ruines de la Bastille ${ }^{1}$.

Les ordres privilégiés, dès le début de la Révolution, n'ont pas été plus épargnés que la royauté. La noblesse est bafonée dans "la Destruction de laristocratisme"; dans " le Conspirateur confondu "; dans " le Convalescent de qualité ou l'Aristocrate "; dans " l'Aîné et le Cadet "; dans " les Émigrés aux terres australes "; dans le "Brigand ", qui est une sorte d'apologie du Tribunal révolutionnaire; dans " les Crimes de la Noblesse ou le Rérrime féodal "; dans "Alisbelle ou les Crimes de la Forblité "; dans " le Noble roturier "; dans "Monsieur le Marquis ".

Le clergé est attaqué dans quantité de pièces dont les

1. La tragique destinée de Louis XVI et de Marie-dnloinette insp ra plus de pilié a Aignan el Berthevin, dans la Mort de Louis XVl, et à un auleur anonyme, dans le Martyre de Marie-Antoinette, reine de France. mais de ces deux pieces aucune ne fut représentée, et la seconde fut imprimée à l"étranger. 
titres sont assez significatifs : " la Partie carrée "; "Encore un Curé "; "l'Esprit des Prètres ou la Persécution des Français en Espagne "; " le Prélat d'autrefois "; "le Clergé dévoilé ou les Etats génèraux de 1303 "; " Au retour ", pièce où se trouve la chanson du "Curé patriote "; " la lète de la Raison "; " les Amours de dom Guerle "; " la Papesse Jehanne "; " la Journée du Vatican ou le Mariage du pape "; "l'Auto-da-fé "; "les Vietimes sauvées ou les Horreurs de l'Inquisition "; " la Dévote ridicule "; "le Couvent ou les Vceux forcès "; "les Victimes cloîtrées "; "Fénelon ou les Religieuses de Cambrai ", de Joseph Chénier; " les Visitandines ", de Picard; "les Dragons et les Bénédictines ", de PigaultLebrun, etc.

En revanche, les gens du peuple sont exaltés, adulés, parés de toutes les vertus. Voyez "la Nourrice républicaine ", " les Salpètriers républicains ", " l'Epoux républicain ", " le Vrai Patriote ou le Congé de vingt-quatre heures ». Un certain Cange, commissionnaire de son métier, a remis 100 livies en assignats à un malheureux, prisonnier pour deites à Saint-Lazare. Les dramaturges s'emparent de cette bonne action, et il n'y a pas moins de cinq pièces qui la gloritient, et pas moins de einq théàtres qui se disputent l'honneur d'avoir ce brave homme et sa famille à leurs premières représentations.

L'armement des gardes nationales, l'appel des volontaires, la guerre contre la coalition et la Vendée donnent naissance à toute une série de pièces patriotiques: "le Corps de garde national "; " la Caserne ou le Départ de la première réquisition "; " le Départ des volontaires villageois pour la frontière"; "les Volontaires en route ou l'Enlèvement des cloches "; " le Siège de Thionville "; "la Patrie reconnaissante ou l'A pothéose de Reaurepaire "; "le Naufrage du Vengeur"; deux pièees sur le siège de Lille; quatre sur la reprise de Toulon; deux sur l'héroïsme du jeune Bara; une sur "Agricol Viala ou le Jeune héros de la Durance "; plusieurs sur la guerre de Vendée; et quantité d'autres destinées à eélébrer la bravoure des soluats franẹis : "Amour et Valeur "; " la Vraie Bravoure "; "Au plus brave la plus belle ". 
Une des dernières pièces militaires, c’est " la Descente en Angleterre ", de Mithié (1797).

L'éloge de la Révolution et de la Convention se retrouve dans toutes les pièces de 1793 et 1794, surtout dans " la Liberté et l'Egalité rendues à la Terre "; "la parfaite Egralité avec les $t u$ et toi "; " les Montagnards "; " la Fète de l'Ètre suprème ".

Cependant mème les années 1793 et 1794 n'ont pas produit uniquement des pièces jacobines. Plusieurs furent dénoncées comme peu patriotiques. "L'Ami des Lois ", de Laya, fut représenté le 2 janvier 1793; le public y applaudit de nombreuses allusions à la tyrannie jacobine; elle fut signalée à la Convention et interdite par la Commune de Paris. "Les Assemblées primaires ou les Élections ", de Martainville, furent interdites en 1794 et de nouveau en 1797. On peut citer aussi des œuvres moins courageuses, car elles parurent après la cliute de Robespierre: "Arabelle et Vascos ou les Jacobins "; " le Souper des Jacobins "; "l'Intérieur des comités révolutionnaires; "les Boites ou la Conjuration des Mouchoirs"; "Charlotte Corday ou la Judith moderne "; "le Terroriste "; "On respire "; "Nous respirons ".

La dernière pièce politique de la période rérolutionnaire est destinée à glorifier le coup d'État de Bonaparte : c'est " la Journée de Saint-Cloud ou le 18 Brumaire ", vaudeville de Léger, Chazel et Armand Gouffé, où l'on trouve des airs comme ceux-ci : la Fanlare de Saint-Cloud, - le Pas de charge, - la Croisée, - Allez-vous-en, gens de la noce! - Eh! mais, oui dà, On ne saurait trouver de mal à ca!

da censure sur le thêtre pendant la Revolution. La Constituante avait donné la liberté aux théàtres. Cette liberié fut singulièrement restreinte. Le 2 aoùt 1793, la Convention, considérant que les thèatres " ont trop souvent servi la tyrannie ", décrète qu'ils domneront, trois fois par semaine, des " pièces dramatiques propres à entretenir les principes d'égalité et de liberté ". Le décret ajoute: "Tout théâtre sur lequel seraient représentées des pièces tendant à dêpraver l'esprit public et à réveiller la honteuse superstition de la royauté, sera fermé, et les directeurs 
seront arrètés et punis suivant la rigueur des lois. " La censure, déjà rétablie en pratique, le fut expressément par arrêté du 14 mai 1794. Elle fut exercée, au nom de la Convention, par la Commission de l'Instruction publique. En trois mois, sur 151 pièces examinées, 33 sont rejetées et 20 sont soumises à des changements. Nous avons vu interdire " l'Ami des Lois " et "les Assemblées primaires". François de Neufchàteau avait fait jouer, en aoùt 1793, "Paméla ou la Vertu récompensée "; cette pièce, comme les deux précédentes, donna lieu à un grand débat lans la Convention; on l'aceusait de glorifier les Anglais et de " tendre à faire regretter les privilèges de la noblesse "; elle fut interdite; les artistes de la ci-devant Comédie-Lrançaise, ceux du moins qui passaient pour nourrir des sentiments inciviques, furent arrètés et faillirent périr.

Les théàtres n'eurent pas seulement à craiudre la censure gouvernementale : les comités de gardes nationaux, le club des Jacobins, les assemblées de district, surtout la Commune de Paris, s'arrogèrent le droit de dénoncer et d'interdire les pièces. Les lanatiques des divers partis en interrompaient violenment la représentation. En 1792, dans un calé du Palais-Royal, on brûla "Richard Cocur de Lion ", lopéra de Grétry. Quand les lacobins dominaient, leurs partisans imposaient aux acteurs de couper la soirée par le chant du "Ca ira " ou de " la Carmagnole ". Quand leur pouvoir décrul, la jeunesse dorée fit chanter le "Réveil du peuple ". A presque toutes les époques, sauf lorsque les opposants étaient réduils à se cacher, les allusions patriotiques ou antipatriotiques étaient salsies au vol, applaudies par les uns, sifflees par les autres. Il y avait bien peu de représentations où l'on ne se battil au parterre.

Comme la direction générale, sauf un instant après Tlıermidor, resta révolutionnaire, les théâtres durent se conformer à l'esprit dominant. L'Opéral, ancienne Académie royale de musique, devint, en 179', le Théatre de la République. L'ancienne Comédie-Française s'appela successivement Théatre de la Nation, Théatre du Peuple, Théatre de l'Egalité. Le théàtre Molière prit le iitre de Théfitre des SansCulotes. On eut le Thécitre patriotique, le Thétre de la 
Liberté, le Théritre de la Montagne, le Portique français ou Club de la Révolution, le Théatre des Comédiens républicains, le Thédtre des Victoires nationales. On eut même le Théatre de la Pantomime nationale, dont le directeur écrivait, en 1798, au ministre de l'Intérieur : "Il faut nationaliser la pantomime."

Les acteurs en scène, qu'ils jouassent des rôles de Grecs, de Romains, d'Assyriens, de sauvages, durent porter la cocarde; et "Phèdre ne déclara sa flamme à Hippolyte que la poitrine ornée d'une large cocarde tricolore ".

Une pièce de 1766, "Guillaume Tell ", tragédie de Lemierre, devint "Guillaume Tell ou les Sans-Culottes suisses ", mais, malgré ce changement de titre, ne trouva pas grâce devant la censure. Les pièces de Corneille, Racine, Molière, Regnard, Voltaire, furent revues avec soin : la plupart furent rejetées comme mauvaises; les autres furent corrigées. On changea le dénouement du "Brutus" de Voltaire et de sa "Mort de César". Son "Mahomet " fut tantôt interdit, vu que liahonset était un " chef de parti ", tantôt mutilé ${ }^{1}$. Un patriote retoucha "Tartuffe". Joseph Chénier fut contraiut, en présence de Robespierre et de Barère, de brûler lui-même sa tragédie de "Timoléon ${ }^{2}$ ". La censure de li Commune de Paris fut encore plus rigoureuse que celle de la Convention : celle-ci se contentait de républicaniser le théàtre, celle-la entendait inaugurer l'hébertisme des arts.

Le 26 avril 1794 , les administrateurs de police adressèrent aux directeurs de théâtre une circulaire où on leur enjoirnait de faire disparaitre sur-le-champ de toutes leurs pièces de théàtre, soit en vers, soit en prose, les

1. On retrancha ces deux vers, qui prètaient à'l'allusion :

Exterminez, grands dieux de la terro oú nous sommes,

Quiconque avec plaisir répand le sang des homules.

8. On comprendra la proseription dont Timoléon fut l'objet en relisan: les vers que prononce un personnage de la pic̀ce :

Sougeons que la terreur ne fait que des esclaves...

La tyrannie altière et de meurtres avide,

D'uu masque réréré couvrant son front livide,

Usurpant sans pudeur le nom de liberté,

Roule au sein de Corinthe un char ensauglanté. 
titres de luc, buron, marquis, comte, monsieur, madame, et autres qualifications proscrites, " ces noms de féodalité émanant d'une source trop impure pour qu'ils souillent plus lontemps la scène française ". Dans le "Menteur " de Corneille, on estropie un vers, afin de renplacer la place Royale par la place des Piques. On voudrait supprimer le not rois dans "Athalie " de Racine. Dans une pièce intitulée "le Bourru bienfaisant ", l'acteur, jouart aux échecs. s'écriait : "Echec au roi! " Il lui l'ut enjoint de dire désormais: "Echec au tyran!" "Dans le "Déserteur " de Sedaine, le déserteur dut porter, au lieu de l'ancien uniforme royal, le nouvel uniforme national. Le Directoire, après le coup d'État de fructidor, revint à ces puérilités ế enchérit encore. Dans "Alexis ou l'Erreur d'un bon père " (1798), un personnage avait à donner 2's louis. "Pourquoi, dit un rapport de police, pourquoi cette monnaie, qui rappelle aux royalistes leur idole? L'acteur ne peut-il donner tout simplement une bourse? " Lamoureux, dans "Léon ou le Chàteau de Montenero ", reçoit défense de sappeier Louis. Une pièce intitulée "Minuit " est censurée paree qu'on y souhaite la bonne année: c'est un usage aboli par le calendrier républicain. Les titres féodaux ne doiven: plus etre donnés qu'a des personnages jouant un rôle ridicule ou odieux. On ne fera plus paraitre d'Anglais ou d'An. glaises que dans ces mêmes rôles. Plusieurs pièces le Voltaire, entre autres "Zaïre", sont interdites parce qu'elies expriment des sentiments religieux. Les pièces a sujets chrétiens. devront être modifiées et le sujet reporté dans les siècles antérieurs au christianisme.

Ces tracasseries manquaient leur but; la censure avait beau faire la chasse aux allusions: les artistes ou le public savaient en faire naitre. Tel acteur mettait un panache blanc à son chapeau; telle actrice, ayant à parler d'une somme de 2000 écus, ajoutait malignement : " en numéraire ". Et les logres d'applaudir.

\section{liegine du theadre sous le Consulat et l'Empire. -} En janvier 1796, Bonaparte, alor's général en chef de l'armée de lintérieur, adressait au nuinistre de la police des rapports sur les théatres. Il exeréait ainsi le ròle do censeur powr le compie du Diretoire. Bientit il lexerça 
pour son propre compte. Devenu le maitre, il facilita la tâche de sa police en rétablissant le privilege des principaux théâtres, ce qui amena la suppression des autres. L'histoire le la censure impériale offre moins de traits ridicules que celle de la censure révolutionnaire : e'est simplement parce qu'elle sut étouffer les pièces au berceau et que la production dramalique fut énormément diminuée. Parlant de "Tartuffe ", le chef-d'cuvre de Molière, Napoléon faisait cet aveu: "Je n'hésite pas à dire que, si la pièce eût été faite de mon temps, je n'en aurais pas permis la représentation ". Son gouvernement interdit " la Jeunesse de Richelieu ", "Édouard en Écosse ", "Guillaume le Conquérant ", "Struensée ou le ministre a'État ", trois pièces de Duval : la première, parce que Bonaparte voulait ménager les nobles, auxquels il rourrait ses antichambres; la seconde, parce que les spectateurs royalistes y avaient relevé et applaudi certaines allusions; la troisième, parce qu'il y était question de personnages vivants. On interdit " les Etats de Blois ", de Raynouard, et "Pyrrhus ", de Lehoc. Duval arait écrit une pièce sur Charles II, roi d'Angleterre : on lui enjoignit de changer de sujet, et la tragédie s'appela "la Jeunesse de Henri l" ", un autre roi d'Angleterre, plus vieux de leux cent cinquante ans. Briffaut avait composé une pièce à sujet espaznol, "Don Sanche "; mais, l’insurrection d'Espagne étant survenue, il dut transporter la scène en Assyrie et fit " Xinus Il ". La plupart des tragédies de Joseph Chénier ne furent pas représentées, paree que son "Cyrus " avait déplu. Népomucène Lemercier surtout fut persécuté à outrance '. Ni son "Charlemagne", ni son "Clovis", ni son "Baudoin empereu" ", ni si "Démence de Charles VI ", ni son "Louis IX en Ėypte" ne trourérent gråce. Deux de ses pièces seulement, "Plaute " et "Cliristophe Colomb ", arrivèrent à la scène : encore la première fut-elle interdite dès qu'on y découvrit des allusions qui avaient d'abord échappé à l'œil vigilant des censeur's.

La trackédic. - La plupart des pièces qui parurent pendant la Rérolution nont pour nous aucun intérèt; impro-

1. Vuir ci-dessus, page 42 , une autre vengeance qua tira de lut Najoléon. 
visées parfois en quelques jours, elles devaient tout leur succès aux passions du moment ${ }^{1}$. Nous ne nous occuperons ici que des œuvres qui présentent quelque mérite littéraire.

Parmi les auteurs de tragédies, le vieux Docrs continue à vulgariser chez nous le théàtre de Shakespeare et, en 1792 , donne un "Othello ".

JoSEPB CHÉNıER, pendant la Révolution, donna "Charles IX"s qui parut en 1789, avec une dédicace à Louis XVI, " Ilenri VIII ", où l'imitation de Racine est surtout sensible; "Caïus Gracchus ", dont un vers fit sensation en $1793^{2}$; "Timoléon ", où il osa flétrir la Terreur. Sous l'Empire parurent " Cyrus ", "Brutus et Cassius ", "Philippe Il ", " Tibère ", "OEdipe roi ", "OElipe à Colone ", "Electre ".

RaYNoUaRd est surtout connu par "les Templier's" (1805) et "les Etats de Blois" (1810.

soor, qui avait fait la guerre dans les Indes et qui avait assisté à la chute de Tippo-Saëb, sultan de Mysore, tué à l'assaut de sa capitale par les Anglais, transporta le sujet sur la scène dans son "Tippo-Saëb".

LUCE DE LANCIVAL, professeur de l'Université et qui célébra en latin le mariage de Napoléon avec Marie-Louise, donna un "Hector " : l'Empereur, qui crut se reconnaitre dans ce héros troyen, accorda à l'auteur une pension de 6000 livres.

Est-il nécessaire de mentionner les tragédies d'Arnault, Laharpe, Gabriel Legouvé, Baour-Lormian, Néponucène Lemercier?

Aujourd'hui on ne lit guère ces, pièces. En général, elles sujvent de très près le tỹpe de la tragédie classique française, déja dégénérée entre les mains de Voltaire et qui achève de mourir aux mains de ses imitateurs. Ce sont des ceuvres taillées sur un patron commun et daprès une recette qui est à la porlée de tous les talents. La tragédie

1. Le Moniteur lui-mème, le 18 nivòse an 11 , en présence de uctle irruption barbare douvrages pitoyables dont nos thétres sont inondés depuis quelque temps, croit devoir dénoncer une conspiration payée par Pitt e: Cobour' pour faire tomber dans l'avilissement le theatre français n.

2. Des lois et non du sang !... Ve souillez point vos mains. Romaius, oseriez-vous égorger des Romains?

Un spectateur osa interrompre et crier: "Du saug, et non des lois!" 
des "Templiers" n'est qu'un tissu de scènes dialoguées et de longs récits; Jouy, qui a vu mourir Tippo-Saëb, n’a pas su introduire un peu daction dans sa pièce. Népomucine Lemercier, d'après Jullien lui-mème, qui est un critique de 18 ' $千$ et qui juge ces œuvres surannées d'après des règles également surannées, n’a donné que des tragédies médiocres. On se soucie si peu de la couleur locale, que Brilfaut n'éprouve aucune difficulté à faire de sa pièce espagnole une pièce assyrienne et Duval à transformer son Charles II en un Henri $V$ d'Angleterre : il est vrai qu'il lui laisse ses pistolets et sa montre, bien que ces objets ne fussent pas inventés au $x r^{\mathrm{c}}$ siècle. C'est toujours le même alexandrin, monotone et plat, pauvre de rimes, alourdi d'épithètes oiseuses, respectant la césure et s’interdisant comme un crime tout enjambement et tout rejet, ayant l'horreur du mot propre et le culte de la périphrase, se traînant dans une phraséologie incolore, et souveut, mìme chez Raynouard, d'une langue yeu correcte. C'est cependant cette tragedie que le grand acteur Talma animait de son génie ${ }^{1}$. Napoléon s'en tenait pour satisfait et la faisait admirer à tout un "parterre de rois". La génération d’alors était tellement imprégnée du gout pseudo-classique, que les spectateurs de 1792 ne purent supporter le mouchoir d'Othello, et que les plus fougueux dramaturges de 1793 osaient à peine appeler par leur nom la poudre ou le canon ${ }^{2}$.

Le drame. - Il semble que lorsque les auteurs peuvent renoncer aux personnages grecs et romains, ou lorsquils osent s'affranchir de l'alexandrin, leurs ceuvres prennent aussitôt plus d'originalité et de vie. C'est qu'alors on n'a plus la tragédie, mais le drame. D’après Jullien, qui juge d’après ses idées de vieux classique, "le drame ne diffère

1. Parmi les autres artistes de la Comédie-Françise, il faut citer SaintPrix, Fleury, Montel, Mmes Raucourt, Contal, Duchesoois. Les débuts de Miles Mars et Georges datent de celle époque.

2. Dans la Patrie reconnaissante ou l'Apothéose de Beaurepaire, opero héroique de 1793 , on lit ees rers: 
de la tragédie que par deux particularités : $1^{0}$ les personnages, au lieu d’ètre des rois et des hẻros, sont pris dans la classe commune, ou du moins se trouvent en relations avec des gens de cette classe, ce qui permet plus de variétés dans les ressorts et dans toute l'intrigue; $2^{\circ}$ le drame; comme la comédie, n'est pas essentiellement écrit en vers ". On peut ajouter que le drame n'est point assujetti a la règle des trois unités; il n'est point condamné a ètre continuellement noble dans le choix des situations, dans le dialogue, dans le style; il admet, comme la réalité ellemème, le mélange des éléments dramatiques et comiques; il a une liberté, un mouvement, une action, que se refusait à admettre la tragédie classique.

Le drame peut ètre poussé au noir et atteindre au maximum de l'horreur théatrale; il peut aussi continer à la comédie par une certaine façon de concevoir les caractères et par le choix de dénouements moins sanglants, tout en conservant dans son ensemble une allure pathétique. Au drame on peut rattacher le mélodrame, la tragédie bourgeoise, la comédie historique, la comédie dolente ou larmoyunte. C'est donc un genre très vivant, dont le domaine est très étendu, mais dont une critique étroite a souvent refusé d'admettre l'existence, sous prétexte que, n'étant ni la tragédie ni la comédie, il ne devait pas aroir de place dans la littérature. Le drame a pris son essor chez nous à la fin du $x^{\prime} w^{e}$ siècle et au commencement du $x \mid x^{\theta}{ }^{1}$.

C'est Diderot qui a formulé la théorie du drame, en mėme temps qu'il en donnait au théatre deux spécimens: "le Fils naturel" et "le Pire de Famille". Beaumarchais, qui ne négligeait aucune veine de nouveauté, fit jouer, déjà sous lancien régime, son "Eugénie " (1767). Mercier, le célèbre auteur du "Tableau de Paris", fut également un fécond écrivain de théàtre : on l'a mème surnommé le dramaturge, pour les nombreuses pièces qu'il fit paraitre de 1778 à $178 \dot{\dot{x}}$, et qui sont souvent dune langue peu correcte. Noublions pas qu’à celte époque l’influence du

1. Cependant il u'est pas absolument inconnu au xvil siècle : les traglcomédies de Corneille (Nicomède, Don Sanche), le Don Juan de Molière,

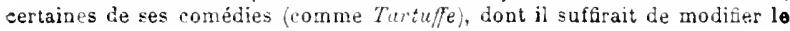
déouement, sont presque des drames. 
drame de Shakespeare était devenue dominante en Europe et que presque tout le théàtre allemand de cette époque, le premier grand thèâtre qu'ait eu l'Allemagne, celui de Gcethe, de Schiller, de Lessing, appartient plutót au type du drame quà celui de la tragédie. Or les drames shakespeariens étaient bien connus en France et les dıames d'Allemagne n'y éfaient pas inconnus : "les Brigal ıds ", de Schiller, par exemple, qui sont de 1782, pièce d'une fougue juvénile et presque déréglée, ont été imitès de très près, en 1793, par lamartellière dans son " Robert, chef te brigands $)$.

Sous toutes ces influences, le drame a été très flor issant chez nous pendant la période révolutionnaire et impóriale. Les pièces qu'il a enfantées sont pour nous beaucoup plus lisibles que les tragédies de la même époque, et, au fond, elles ont une valeur littéraire plus grande. Jullien n'hésite pas à reconnaitre que la "Mélanie " de LABARPe, représentée en 1791, est supérieure à toutes ses tragédies. Le "Calas " et le "Fénelon ou les Religieuses de Cambrai w, de JOSEPB CEÉNIER, ont plus d'intérêt que mème son "Tibère " et son "Timoléon ".

Un survivant de la période précédente, BEadmarchais, a douné en 1797 " la Mère coupable ". Il aboutissait au drame en partant, non de la tragédie, mais de la comédie; car ce sont les personnages mèmes de ses pièces précédentes qui reparaissent, non plus jeunes et pimpants comme au temps de " la Folle Journée", mais chargés d'ans et quelques-uns vieillis par les fautes commises. C'est mème une entreprise assez singulière que d'avoir essayé de laire pleurer le public du Directoire en lui présentant, cette fois en cheveux gris, Figaro, le comte Almaviva, la conitesse Rosine.

Parmi les dramaturges de l'époque, on peut citer FENOdLlOT DE FALBAIRe, dont " l'Honnete Criminel " fut représenté en 1790; ARNAUd DE BACULARD, qui fit jouer la mẻme année "le Comte de Comminges ou les Amants malheureux "; Boully, qui donna dans la sensiblerie au point de méritei le surnom de poète lacrymal, et dont "l'Abbé de l'Épée ", "Madame de Sévigné ", "Fanchon la Vielleuse " charmèrent le public du Consulat. 
Le plus fécond de tous fut alexandre Doval, directeur de lodéon en 1808 et membre de l'Académie en 1812. Il affectionna les pièces à personnages historiques, mais écrivit surtout en prose. A part " la Jeunesse de Richelieu ou le Lovelace francais ", qui est de 1796, tous ses drames à succès datent de l'époque consulaire et impériale. Ce furent notamment "Édouard en Écosse ou la Nuit d'un proserit ", dont le sujet est emprunté au récit de Voltaire sur l'expédition du prétendant Charles-Edouard; "Guillaume le Conquérant ", dont la représentation coïncidait avec les préparatifs d'une nourelle descente en Angleterre; " le Menuisier de Livonie ou les Illustres Voyageurs ", où figurent Pierre le Grand et Catherine, voyacreant incoguito; "Shakespeare amoureux ou la Pièce à l'étude "; "les Hussites ou le Siège de Naumbourg "; " la Princesse des Ursins ou les Courtisans ", etc. Un de ses livrets d'opéra-comique a pour sujet les aventures de Beniowski à Madagascar. Alexandre Duval, qui s'entendait merveilleusement à "charpenter une pièce ", peut, à certains égards, ètre considéré comme un précurseur d'Alexandre Dumas père.

N'oublions pas piXĖnécodrt et CaIgniez, qui firent verser tant de larmes, lun avec le "le Chien de Montargis" (1814), l'autre avec “ la Pie voleuse »(1815).

La comédie. - La conédie de caractère n'a pas repris alors son grand éclat du svne siècle. L’époque révolutionnaire et impériale n'a guère connu que la comélie d'intrigue, celle qui procède de Beaumarchais et de Marivaux, vive, spirituelle, pimpante, une des gaietés de l'époque et le charme de l'esprit l'rançais dans les jours les plus sombres. En aucun temps elle n'a été asservie aussi étroitement que la tragédie aux prétendues règles édictées par les "législateurs du Parnasse ". Elle a pu fuir les théàtres ofliciels, se rélugier sur les scènes secondaires, rester en contact avec le grand public et $y$ gagner tout autant de liberté et de vitalité que le drame.

beadmarchats, ici encore, lorme un trait d'union entre la France dancien rígime et la Frince nouvelle : en 1790, il écrit un libretto d’opéra-comique, "Tarare ", qui est bien une comédie. 
De la mème année date la pièce, si populaire encore aujourd'hui, de Desforges : " le Sourd ou l'Auberge pleine ". Notons que cette comédie, qui a eu tant de représentations, fut payée à son auteur cinquante francs.

collin D'Barleville a donné surtout “ le Vieux Célibataire», représenté en 1792 , qui passe pour son chef-d'œuvre.

FABRE D'Églantine, qui représenta en 1790 "le Philinte de Molière ", se proposait, a-t-on dit, de traduire sur la scène Robespierre en personne lorsque celui-ci trouva moyen de l'envoyer à l'échafaud.

andriedx, dont le chef-d'œuvre, "les Etourdis ou le Mort supposé ", date de 1787, Andrieux, le spiritnel et mordant orateur que Bonaparte tint à expulser du Tribunat, se consola en donnant " Holière avec ses amis ou la Société d'Auteuil ", "le Trésor ", " le Vieux Fat ", etc.

NÉPOMUCENE LEMERCIER se vantait d'avoir créé la comédie historique : ses pièces de "Pinto ou la Journée d'une Conspiration ", "Plaute ou la Comédie latine ", "Christophe Colomb ", se rapprochent des drames historiques de Duval.

ALEXANDRE DUVAL s'est fait une place dans la comédie comme dans le drame : on lui doit "le Tyran domestique", "la Tapisserie ", "le Chevalier l'industrie ", sans compter "la Manje des grandeurs " et "la Fille d'Honneur ", qui datent de la Restauration.

PICARD, un comédien qui, phus heureux que Molière, fut de l'Académie, est le plus fécond et le plus gai de toute cette génération de comiques: il a composé plus de 80 pièces en tout genre, dont 66 comédies. Ses contemporains le comparaient à Molière, dont il a la verve comique, le don de saisir les travers, mais non la prolondeur de conception ni la langue énergique et éloquente. Les plus conmues de ses pièces sont "le Conteur ", " le Collatéral ", "la Petite Ville ", "les Provinciaux à Paris", "les Marionnettes " (1806), "les Capitulations de conscience ".

Après ces princes de la comédie, il y a encore une place honorable puur Patrat, Demoustier, Dumaniant; Etienue, plus célèbre comme critique, mais atuteur des "Deux Gendres " (1810); Iloffman, dont on joue encore "les Rendez-vous bourgeois " et "te Roman d'une heure"; 
Planard, dont "le Curieux", qui passe pour son chefl'œurre, date de 1807.

Quelques-uns de nos types populaires, Mine Angot, Nicodeme, M. de Crac, Cadet-Roussel, ont été créés à cette époque. Mme Angot, la poissarde parvenue, figure pour la première fois, en 1796, dans un opéra-comique de Maillot : Aude, dans un drame-tragédie-farce-pantomime joué en 1800 et qui eut 200 représentations, la fit voyager au sérail de Constantinople. Nicodème dut le jour au cousin Jacques (Beffroy de Reigny), auteur de "Nicodème dans la Lune ou la Révolution pacifique " (1790). On eut ensuite "Nicodème dans le Soleil ", puis "Nicodème à Paris ou la Décade et le Dimanche " d'Armand Gouffé. Collin d'Harleville représenta en 1791 "Monsieur de Crac dans son petit castel ". Aude, l'auteur de la chanson de Cadet-Roussel, composée contre l'avocat Roussel, fit jouer en 1798 "Cadet-Roussel, professeur de déclamation", et, l'année suivante, "Cadet-Roussel barbier à la Fontaine des Innocents".

\section{Les autres genres littéraires.}

La poésie Iyrique. - S'il y eut des événements capabłrde remuer les àmes et d'inspirer au poète des stropheailées, ce furent assurément ceux de la Révolution et de l'Empire. Pourtant ils semblent plutôt avoir écrasé qur surexcité le don poétique: c'est à la génération suivante. quand on fut a distance d'une réalité trop accablante, qu'éclata dans les vers de Victor Hugo ou de Lamartine la magnifique poésie qu'ils recélaient. Le premier chant vraiment lyrique de la période révolutionnaire, "la Marseil laise » de ROdGET DE L'ISLE, parut quand la France, à l'approche de l'invasion, tressaillit tout entière d'un élan patriatique. Il faut citer ensuite "le Chant du départ". que composa Josepr chénier, et "le Camp de Grandpré ", qu'il fit paraitre a la veille de Valmy pour encourager les volontaires de 1792. La fète de l'Ètre suprême inspira au mème auteur un chant qui fut mis en musique, et a l'abbé Delille son "Dithyrambe sur l'immortalité de l'àme ", 
que Robespierre ne jugea pas à propos de faire chanter en public ${ }^{1 .}$

Chaque génération a son lyrique attitré : celle de la Révolution et de l'Empire eut ÉcoucBard-LEBrun, comme la génération précédente avait eu J.-B. Rousseau. Il eut les qualités et les défauts de l'emploi : de la majesté et un peu de froideur. Il sintitulait et on le eroyait volontiers le poète national. Il chanta tour à tour les fastes de la Monarehie, de la République, de l'Empire. Il avait reçu de Louis XVI une pension, le la Convention un logement au Louvre, de Napoléon une pension et de nombreux bienfaits. On peut relever de belles strophes dans son ode sur le combat du Vengeur. Puis il fit, sur la Descente en Angleterre, une ode où la perfide Albion fut comparée à Tyr et Bonaparte à Alexandre.

Il troura des coneurrents : MiLlevoye chanta la bataille d'Austerlitz, un autre sebron (Pierre) la bataille d'Iéna, Lelliard d'AVRigny la eampagne d'Autriche et la eampagne de Prusse. Cependant les plus éelatantes vietoires de l'Empereur ont inspiré, en leur temps, moins de beaux vers lyriques que les premier's combats de la République. La guerre avait sa poésie à elle, dont la grandeur sauvage tuait la poésie des poètes.

Chose singulière, eette génération si guerrière aima la poésie sentimentale, presque maladive. millevoye fut surtout célèbre par ses élégies, dont la plus larmoyante et la plus connue est "la Chute des Feuilles". On peut en rapprocher " la Pauvre Fille " de soumet (1814).

La poésie descriptive. - La déeadenee des genres elassiques se marque surtout dans ceux dont Boileau, cent cinquante ans auparavant, avait formulé les lois. Les poètes descriptifs du siècle précédent tiennent encore la tête; ear l'abbé Delille, en 1803, publie son poème de "ia Pitié ", en 1806, son poème de "l'Imagination ", composé en 1794.

1. Labbé Delille y avait introduit des strophes où les puissants du jour araient pu rulever des allusions. Il poursuit les tyrans de ses inrectives :

O vous qui, de l'Olympe usurpant le tonnerre.

Des éternelles lois renversez les autels,

Låches oppresseurs de la terre,

Tremblez, vous èles immortels $\mathfrak{l}$ 
Le cardinal de berivis, ancien ministre de Mme de Pompa dour, nous lègue en mourant (179:) sa "Religion vengée".

Sur leurs pas se précipitent une foule de disciples : Esmènard chante la Navigation, Ricard la Sphère, Gudin l'Astronomie, Boisjolin la Botanique, Saint-Victor l'Espérance, Chaussard la Poétique sccondaire, Cournaud les Styles. Aimé Martin versifie des "Lettres à Sophie " sur la Physique, la Chimie et l'Histoire naturelle. I.e plus grand nombre prétend ne pouvoir s'arracher aux beautés de la campagne: François de Neufchàteau sattaque aux Vosges, Castel à la Forèt de Fontainebleau, Fontanes à la Maison rustique, Campenon à la Maison des champs, HoudanDeslandes à la Nature sauvage et pittoresque, Lalanne au Potager et aux Oiseaux de la ferme. A ces cuvres, généralement insipides, on préférera sans doute "la Gastronomie " de Berchoux ou "l'Art de diner en ville " de Colnet, pour ne point parler de poèmes par trop humoristiques.

Dans la tourbe des leseriptifs, LEgodvé s'est fait un nom avec "le Mérite des Femmes ", chénedoldé avec "le Génie de l'Homme ", où l'on voit poindre une inspiration plus haute et une versification plus pure, qui font de cet auteur un des précurseurs de Lamartine.

La poésic épique et héroi comique. - Cette génération qui vit s'accomplir cette merveilleuse épopée de cent victoires, terminée par une catastrophe auprès de laquelle pàlissent les inventions des plus sublimes poètes, n'enfanta pas un vrai poème épique. Tous ceux qui prétendirent nous doter de ce genre littéraire, où le xvule et le xvul siècle avaient si complètement échoué, tous, qu'ils écrivissent en alexandrins ou en vers de dix syllabes, se trainèrent dans les mêmes errements. Népomucène Lenuercier donna un Moïse, un Homère, un Alexandre, une Atlantiade, qui sont unis par un lien téuu, de manière à former une tétralogie. Flins chanta "Agar et Ismaël "; Campenon, " l'Enfant prodigue "; Denne-Baron, "Héro et Léandre "; Luee de Lancival, "Achille à Scyros "; Fontanes, "la Grèce sauvée "; Dumesnil, "Oreste ", en quinze mille vers.

Nos poètes épiques, s'ils sortent des sujets bibliques ou mythologiques, n'en restent pas moins dans le cercle de sujets où s'étaient enfermés les contemporains de Boileau. 
Tardieu de Saint-Marcel chante "Charles Martel ou la France délivrée ". Charlemagne inspire jusqu'à quatre poèmes épiques : celui de Théveneau, celui de Millevoye, celui du prince Lucien Bonaparte, enfin la "Caroléide ", de d'Arlincourt, qui mêle de la plus étrange façon les dieux des Germains et les saints du christianisme. Aux périodes les plus obscures des annales, Millevoye va emprunter le sujet d" "Alfred"; Briffaut, celui de "Rosamonde". Masson célèbre les "Helvétiens ", c'est-à-dire la guerre des Suisses contre Charles le Téméraire. Le seul de ces poèmes qui ait eu alors un grand retentissement, c'est " la Bataille d'Hastings ", de Dorion, parce qu"on y releva des allusions aux projets contre l'Angleterre ".

Rien de moins épique que toutes ces épopées: le sens des mœurs barbares, qui est vraiment le sens épique, y fait absolument défaut. Toutes ces œuvres ne sont qu'une imitation ou une compilation plus ou moins savante de tous les poèmes connus, depuis "l’Ėnéide " jusqu’à la "Jérusalem délivrée ${ }^{2} "$.

$\mathrm{Au}$ fond, nos lettrẻs ne croient pas à leurs sujets : la mythologie de la Grèce ou de la Germanie les laisse aussi froids que les légenles bibliques ou les légendes chrétiennes. Ils rédigent une épopée de la mème plume dont ils écriraient une élégie, une tragédie en cinq actes ou un raudeville. Le souffle du xvir ${ }^{\mathrm{e}}$ siècle a desséché en eux tout enthousiasme poétique aussi bien que toute croyance religieuse. Ils sont tout prêts à verser dans la

1. Et le seul qui ait noe valeur réelle, e'est la Chevalerie de Crenzé de Lesser, dont nous parlerons plus loin.

2. Comme le merveilleux chretien et le merveilleux paien sont éralement rebattus, l.emereier essaye, après Voltaire, d'inventer des divinités nouvelles. 11 tombe dans des allegories encore plus froides que celles de la Hrnviade. Les divinités de son Atlantiade s'appellent Théose, c'est-à-dire Lieu luiméme, quon n'ose pas nommer par son nom? Psycholie, qui est l'intelligence universelle; Barythee, qui est la foree d'attraction; Probablene, qui est la force centrifuge. Ceux-ei sont enfants d'une loi générale. Ia gravitation universelle, qui s'appelle Nomogène. Un autre de ses fils, Curgire, préside a la course elliptique des astres. Les déesses Syngénie, Lampelie et "yrophyse representent l"aftinité, la lumière, le calorique. Les nymphes Bune et Electrone personnifient la force vitale et l'ćlectricité, et celle-ci a pour époux Pyrotone, le feu du tonnerre. La chimie vient ajouter a ce panthén lo nymphe Sulphydre. Voila qui est propre a faire regrelter les dieux do lÖlymo grer, et méme la . Kollesse de Boileau ou la Discorde de Voltaire. 
parodie, même dans la parodie licencieuse, de l'énopée. Parny, qui a consacré un millier de vers à chanter, sous le titre bizarre d' "Isnel et Asléga ", les exploits et les a mours tragiques de héros scandinaves, est bien plus à snn aise dans "la Guerre des Dieux " et autres pièces analngues, où la mythologie paĩenne et les légendes chrétiennes ne sont plus que des prétextes à polissonneries. Népomucène Lemercier, après sa tétralogie de poèmes sérieux, écrit une "Mérovéide ", où sainte Geneviève est presqua aussi maltraitée que Jeanne d'Arc l'a été par Voltaire. Viennet consacre vingt-cing ans à rimer une froide plaisanterie, sous le nom de poeme héroï-comique: "la Philippide ", qui n’a pas moins de vingt-six chants. Pour sciever à l'épopée, il manque aux hommes de ce siècle d'abord le respect de leurs héros.

La satire, la chauson, la romance. - Si lon écrit des épopées, comme Voltaire, on fait des satires, comme Boileau; mais, a part les iambes énergiques ${ }^{1}$ qu écrivit ANDRÉ c日E்ier à la veille de monter à l'échafand, dans la prison de Saint-Lazare; à part quelques pièces originales de JosEPB chÉNIER, comme " les Nouveaux Saints " ou le "Discours sur la calomnie ", on s'écarte à peino des molèles légués par le $x$ vio $^{\circ}$ siècle. Il suftit de renvoyer aux pièces de Vigée, Despases, Baour-Lormian, Viennet. Celui-ci ne pouvait manquer de rimer également des firres : ellss sont adressées à Morellet, à Raynouard, à Capoléon, et cela seul nous avertit qu'elles ne datent pas de louis XIV.

Un genre bien plus vivant, tonjours francais. c'est la chanson. Le xvme siècle l'avait perfectionnée : vers 1729 s'était fondée, dans une cave du carrefour Bucy, la so:iéte.

1. C'e-t là qu'il flétrit, avec un courage qui allait être promptemeut expie.

. Ces porte-plumets, ces commis de earnage,

Ces noirs accusateurs Fouquiers,

Ces Dumas, ces jurés, horrible arépage

De voleurs et de meurtriers.....

Ces bourreaux barboulleurs de lois,

Ces vers cadavèreux de la trance asservie.

A Saint-Lazare, il cerivit aussi, s'inepirant de sa propie restince, aveo une grace poetique et une perfection rle forme qui font le petio pirca son chef-d'aurre, l'ode de la Jeune Captive qui "ne veut point mourir encore". 
$d u$ Caveau, qui, après avoir jeté un vif éclat et répandu autour d'elle une raielé communicative, disparut en 1739 . Elle se reforma vingt ans après, avec une autre génération de joyeux compères. La Révolution ne put étouffer la voix légère de la chanson : les journaux étaient pleins de couplets, que des chanteurs ambulants colportaient dans les carrefours.

Enfin, en 1806, se constitua le Caveau moderne, qui lıérita de la popularité de ses aînés. Il compta parmi ses membres Barré, de Boufflers, les deux Ségur, Desprez, Armand Gouffé, Jouy et les plus célébres de tous, Désaugiers et Béranger.

ALEXANDRE DE SÉgur est l'autcur, entre autres ceurres, de la jolie chanson sur le Temps et l'Amour ${ }^{1}$.

ARMAND GOUfré lit " le Corbillard" et "Plus on est de lous plus on rit ".

Jouy a chanté " la Sagesse " ave: ce refrain: "L'excès en tout est un défaut".

DÉSAdgIERS a pour ainsi dire immortalisé "Monsieur et Madame Denis ", "Jean qui pleure et Jean qui rit ", etc.

BÉRANGER n'appartient á cette période que par ses débuts. En 1810, il publiait son premier recueil de poésies; en 1812, "la Chanson des Gueux "; en 1813, "le Sénateur ", une jolie satire, et "le Roi d'Yvetot", où le public malicieux ne manqua pas de saisir le contraste entre les ambitions napoléoniennes et les gouts modestes du bon petit roi au bonnet de coton. Puis vinrent "l'Académie et le Caveau ", comparaison irrévérencieuse entre les deux institutions. Les événements de 1814 et de 1815 inspirèrent à Béranger "Vieux habits, vieux galons!" " le Nouveau Diogène ", " la Politique a l'usage de Lise ", " Plus de politique ", qui allaient engager la chanson française dans les voies tout à fait nouvelles.

Ainsi, deux genres surtout se sont développés pendant les tragiques années de la Révolution et de l'Empire : ce sont précisément la comédie-vaudeville et la chanson. Les Picard et les Armand Gouffé furent les concemporains de 
Robespierre el de Napoléon! Ils gardèrent, à travers tous les drames de la politique, les traditions de la gaieté française. Ils sont aussi nécessaires pour donner à cette période étrange sa vraie physionomie que les tribuns de la Montagne et que les maréchaux d'Austerlitz.

La romance sentinuentale et plaintive se partageait avec la chanson joyeuse et même libertine les sympathies populaires. "Il pleut, il pleut, bergère "! a été composé en 1790 par Fabre d'Églantine, musique de Simon de Hetz. C'est dans le fracas des batailles napoléoniennes que l'on commença à roucouler "Fleuve du Tage ", et "Pauvre Lise ", qui ont survécu au règne de l'épinette, du clavecin et de la harpe. Chateaubriand lui-même, avec sa romance "Combien j’ai douce souvenance ", joignit sa voix à ce concert d'innocente poésie.

Le roman. - Le même contraste se manifeste dans le roman. Le public a du goùt pour le roman de sentiment, le roman moral: il tait bon accueil à une des dernières œuvres de bernardin DE SAINT-PIERRE, "la Chaumière indienne", qui est de 1790; aux curres morales de Mme DE GENLIS; à celles de riévée, qui est de l'école de Bernardin de SaintPierre et qui nous a donné deux jolis romans, "la Dot de Suzette " (1798) et "Frédéric " (1799). Et ce mème public fait également bon accueil aux romans de PigaultLebrun, dont les premiers parurent en 1792 et où l'on retrouve la verve licencieuse et inpie des poèmes de Parny.

Un phénomène assez curieux, c'est qu'à cette éproque le roman est presque entièrement aux mains des femmes. Les deux chefs d'écoles sont Mme de GeNLIS et Mme DE STAEL. Celle-là ne nous a pas laissé moins de cent volum 's, dans lesquels on retrouve avec quelque plaisir "les Veillées du Chàteau "(1784) et "les Petits Énigrés " (1798). Celle-ci nous a donné "Delphine " (1802) et "Corinne ou l'Italie" (1807). Et voici me corrin avec ses romans, qui ont peu de naturel, peu de style, aucune observation du réel, mais dont la sensibilité exaltée caractérise bien cette époque; Mme DE CBARRIÈRE, d'origine hollandaise, dont les œuvres ont beaucoup de naturel, mais sont empreintes de désenchantement et mêne de pessimisme; Mme DE KRUDENER, 
d'origine livonienne, qui enchanta les femmes de France avec sa "Valérie "(180k), avant de séduire l'empereur de Russie par sa tendresse mystique; Mme DE soozA, d'abord comtesse de Flahault, que l'échafaud rendit veuve de son premier mari et à qui nous devons "Adèle de Sénanges " (1794), " Eugène de Rothelier ", " Eugène et Mathilde ", deux romans où l'on trouve une peinture assez vivante de la noblesse ralliée à l'Empire; Mme DE RÉMOSAT, plus connue aujourd'hui par ses Mémoires et ses Lettres publiés de nos jours, mais qui fut célèbre alors, grâce à "Charles et Claire ", aux "Lettres espagnoles " et à son livre sur l'Éducation des femmes; Mme Gorzor, alors Pauline de Meulan, auteur des "Contradictions " et de "la Chapelle d'Ayton "; Mme DE DURAS, avec ses deux romans d' "Ourika " et "Édouard", qui portent déjà l'influence visible de Chateaubriand; Mme sophIE GAY, qui osa exprimer, avant George Sand, des idées assez hardies sur le role de la femme dans la société.

La plupart de ces romans féminins se recommandent par les qualités précieuses dans l'analyse des passions et des sentiments, par une observation assez exacte de la société contemporaine, par une sensibilité très vive et un certain naturel dans le style. Ils annoncent le grand renouvellement qu'une autre femme, en notre siècle, allait produire dans ce genre littéraire.

Déjả s'opérait daus le roman une première rénovation, on pourrait presque dire une révolution.

CHATEAdBRIAND donnait, en 1801, "Atala ": en 1802, "René"; en 1809, "les Martyrs". Le style d'Atala n'a pas la simplicité élégante des romans de Bernardin de Saint-Pierre et les caractères sont moins vrais. Cependant les imaginations de nos grands-pères furent séduites par la peinture de cette nature exotique, de ces caractères primitifs de Peaux-Rouges, que l'infatigable voyageur avait empruntés à l'Amérique. Cette langue pittoresque, colorée, de tons parfois excessifs et parfois faux, cette précision, au moins apparente, dans les descriptions, étonna et ravit les contemporains. Encore aujourd'hui les grâces de la jeune Indienne et la sauvage bonhomie du vieux Chactas nous tiennent sous le charme. "Atala " doit beaucoup à "Paul 
et Virginie "; "René ", au contraire, procède du "Werther " de Gothe. C'est la fatalité dans l'amour, e'est le pessimisme allemand, en même temps que la vague málancolie du siècle nouveau, qui assombrit cette ouvre. Clateaubriand est un de nos premiers romanciers qui ait choisi pour sujet d'analyse un cas exceptionnel et presque anormal dans la passion; il a voulu attrister mortellement le lecteur comme le héros même du récit. Il a introduit dans la nouvelle école française une note de mélancolie, de désenchantement et de désespérance ${ }^{1}$. ll n'en a pas moins créé chez nous le roman personnel, qui fait de l'auteur luimême, sous un nom d'emprunt, le héros du récit. "Les Martyrs ". c'est le dèbut de notre roman historique: Chateaubriand a placé les amours d'Eudore et de Cymolocée, à l'époque des persécutions contre le christianisme, dans le splendide décor du monde antique à son déclin et du monde barbare qui s'agite dans les marais du Nord; si sa couleur locale est souvent fausse, il a du moins le sens des âges héroïques, et son récit est animé d'un souffle épique.

A côté de lui, quoique à un degré inférieur, il convient de placer Xavier DE MAISTRE et charLes NODIER.

Si les facultés d'imagination ont pu être surexcitées en Chateaubriand par ses voyages dans les deux mondes, des bords du Mississipi aux bords du Jourdain, elles ont été aiguisées en Xavier de Maistre par les pérégrinations de l'émigré, en Nodier par les hasards d'une vie mèlée, à ce qüil prétendait, aux conspirations contre le Directoire ou l'Empire et tracassée par la police. Aussi leurs nuvres en ont-elles gardè ce caractère viril qui manque un peu aux romans des helles dames de l'epaque.

Xavier de Maistre cependant n'est pas un révolté comme Chateaubriand: c'est plutôt un résigné, un doux philosophe, un humoriste aimable. En 1794 , il s'enferma d'abord chez lui et publia le charmant "Voyage autour de ma chambre». En 1811 parut son "Lépreux de la Cité d"Aoste".

1. L'œuvre la plus désespérée de l'époque, c'est le poème inachevè et en prose de Gnainville, qui périt par le suicide, en 1805. Il est intitulé le Dernier Homme, et nous montre, à la fin des temps, la mort triomphant du dernier couple humain, le soleil s'éteignant, et, sur les dèbris du monde, se levanl "l'aurore de l'éternité n 
Son séjour en Russie lui inspira " les Prisonniers du Caucase " et " la Jeune Sibérienne ".

Nodier débuta, sous la Révolution, par ses "Proscrits"; sous IEmpire, il fit le "Peintre de Salzbourg" et "Stella". II a contribué à mettre à la mode chez nous ces récits très courts, où la brièveté ajoute à l'intensité de l'effet produit, et qu'on appelle nouvelles : un genre où les Français ont gardé une supériorité sur tous les autres peuples.

La coitique littéraire. - JOSEPH CHÉNIER, dans son " Tableau de l'état et des progrès de la littérature française depuis 1789 ", se montre un classique convaineu, parfois arriéré; impartial et bienveillant, mème pour ses ennemis personnels, s'ils appartiemnent à la mêne école que lui; mais réservant toutes ses rigueurs et presque toutes ses fureurs pour Chateaubriand, par qui a commencé la révolution rommtique.

LABARPE publie, de 1799 à 1805, son "Cours de littérature ", oú il s'inspire de principes aussi étroits, montre une profonde inintelligence de la littérature antique, une ignorance complète de celle du moyen àge, des préjugés mesquins quand il lui faut apprécier celle du xvme siècle et celle de l'époque contemporaine.

Une critique plus originale, plus indépendante, plus large, apparait dans trois ouvrages de Mme DE STAEL : "l'Essai sur les Fictions " (1793), "le Livre de la Littérature " (1800), entin "l'Allemagne" ( $\mid 810)$, où l'auteur nous révèle les chets-d'œuvre de la littérature d'outre-Rhin.

Dans la presse, qui n'est plus qu'une presse officielle, c'est la critique elassique qui domine. Dans le Joumal des Débuts, devenu le Journal de lEmpire, geofrnoy a créé le feuilleton littéruire. Il guerroie à lat fois contre les tendances romantiques et contre la philosophie du xvm siecle. Il est si hostile à Voltaire philosoplue, qu'il s'en prend mime à son théàtre, qui reste pourtant le type du théàtre classique. horrman est un ennemi passionné de drame moderne, de l'initation allemande, des "Martyrs", qu'il déclare "le manvais ouvrage d'un grand talent ", en un mot de tout ce qui est nouveau. Dossaubt, champion plus médiocre des "saines doctrines ", n'ose s'attaquer à Cluateaubrianı, mais déclare les livres de Mme le Staèl «lons à mettre au pilon". 
Les origines du mouvement romantique. - J'ai déjà employé plusieurs fois ces mots de classique et de romantique, destinés à passionner et à diviser, comme des noms de guerre, la génération suivante. Par eux-mèmes, ils n'ont pas un sens très précis, et on peut leur attribuer plusieurs significations. lls servent surtout à désigner deux tendances dans la littirature, deux influences très diverses qui s'exercèrent, à diverses époques, sur l'esprit français. Notre civilisation procède à la fois d'origines grecques et latines, et d'origines celtiques et germaniques; dans ses périodes de renouvellement, elle se tourne tour à tour vers le Midi ou vers le Nord. Quand notre littérature s”inspire surtout des origines grecques et latines, quand elle subit surtout l'influence des littératures du Midi, italienne ou espagnole, on peut dire que le courant classique domine chez nous. Quand elle s'inspire surtout des origines germaniques et celtiques, quand elle subit surtout linfluence des littératures du Nord, anglaise, allemande, scandiuare, on peut dire que c'est le courant romantique qui l'emporte. Or la période révolutionnaire et impériale, dans les lettres comme dans les arts, est surtout classique: on pourrait dire psendo-clussifue, car elle n'a qu'une entente bien inparlaite des civilisalions antiques. Cependant on vit se préparer dès lors et s'accentuer le mouvement rommtique. C'est d'abord vers le nord celtique qu'on se tourna: on s'éprit des poésies des bardes de la Grande-bretagne, retrouvées, arrangées, mème inventées par l'Ecossais Macpherson. Il les arait publiées en 1762 ${ }^{1}$, en les plaçant sous le nom d'Ossian, un barde qui aurait été fils de Fingal, roi de Morven, aurait défendu sa patrie cuntre les Romains, et, comme l'Homère des Grecs, aurait perdu la vue. Ce fut la génération impériale surlout qui se passionna pour cette poésie un peu nébuleuse, et la plus classique des intelligences de ce temps, le plus Romain des Franciiis d'alors, Napoléon, partagea l'engouement général pour Ossian et les beautés ossianiques. Il fit traduire, ou plutót

1. Dès $17 \% 6$, Letourneur en avait donné une traduction francaise. Puis, en 1796, Arnault avait donné une tragédie intitulée: "rsar, fils dOssian associant bizarrement un nom scandinave a un nom ceitique. 
imiter, l'wuvre de Macpherson par Baour..Lormian, qui nous donna ses poésies galliques (1801). Il félicita le musicien Lesueur, qui, en 1804, fit représenter à l'Académie nationale de musique son opéra des "Bardes "; il estimait cette cuvre "brillante, héroïque et vraiment ossianique"; il admirait surtout la musique du second acte, qu'il qualitiait, sans songer à mal, d'inaccessible. Il lit don au compositeur d'une tabatière en or avec cette inscription : "L'Empereur des Français à l'auteur des Bardes ". Méhul, vers la mème époque, composa "Uthal" sur un libretto ossianique. Les peintres s'en mêlèrent : Girodet exposa au Salon de 1802 un tableau où l'on voyait Fingal et Ossian accueillant les ombres des guerriers francais; Gérard peignit en 1809 un Ossian qui fut acheté par le roi de Suède et perit en mer avec le vaisseau qui le portait. Ossian tit aussi la conquète de Mme de Staël, qui, à la grande indignation de Geoffroy, assurait le préférer à Homère.

Linfluence des poèmes celtiques dura peu : bien plus profonde fut celle de la littérature anglaise avec Shakespeare, avec Villon, dont l'abbé Delille paraphrasait “ le Paradis perdu "; de li littérature allemande, avec Schiller, dont on imitait "les Brigands" et dont Benjamin Constant traduisait "Wallenstein "; avec Gœethe, que la Convention avait fait vitoyen français en mème temps que Schiller; avee tous ces éerivains allemands, si originaux, Wieland, Klopstock, Werner, Jean-Paul Richter, dont Inme de Staël dounait des analyses el des extraits dans son "Allemagne ". Alme Neeker de Saussure, en 1814, traluira le a Cours de littérature dramatique " de Schlegel, où l'on trouve uue critique originale de nos grands tragiques. Rien de divertissant comme les fureurs de Geoflroy, s'armant en guerre contre celte " nouvelle invasion des Barbares " el contre "la Melpomène anglo-tudesque ".

Eutin une nouvelle so rce de romantisme souvre avec CRECZÉ DE LESSER. Il reírouve nos siècles féodaux et la grande poésie des chansons de gestes, oubliées depuis tant de siècles sous la poussière des bibliothèques. Dans son épopée de " la Chevalerie " réapparaissent le roi Artlıur, la Table ronde, le Saint-Graal, Lancelot et Gauvain, Tristan ot la belle lseult, et iout le cycle des épopées bretonnes; Char. 
lemagne se dresse, environné de ses paladins, et le val de Roncevaux revoit l'hérö̈sme de Roland et la trahison de Ganelon; Amadis de Gaule et les autres vaillants de la légende parcourent le monde à la recherche des aventures. combattant les chevaliers félons, les païens et les Sarrasins, les dragons et les monstres, les enchanteurs malfaisants. Au romancero espagnol, l'auteur emprunte "le Cid et ses exploits eontre les mécréants. Ce poème de la Chevalerie, en 50000 vers, est donc une première résurrection de notre moyen âge.

Non seulement on retrouve le moyen ige, mais on cherche a l'inventer. Le capitaine DE sURviLlz, un émigré qui fut ensuite fusillé (1798), avait déjà, avec la complicité de l'éditeur Vanderbourg, mis au jour les prétendues poécies de sa prétendue aĩeule du $x v^{e}$ siècle, Clotilde de Surville.

Par les influences anglaises et allemandes, par la résurrection d'Arthur, d'Amadis, de Roland, du Cid, des héros de l'àge féodal, tous les éléments de la future révolution romantique sont dẻjà préparés.

Bécondité littéraire de la période révolutionnaire ê imperiaie. - Aujourd'hui on sourit volontiers quand on entend parler des poèmes descriptifs, des poèmes épiques et des tragédies de cette période : et, en effet, dans ces cuvres, nous voyons s'aceomplir la décadence des anciens grenres littéraires. Les dernier's héritiers de Voltaire poète achèvent de dissiper l'héritage. Nais, en dehors d'eux, que de créations originales et que de germes vivaces! Avec Alexandre Duval, e'est le drame historique; avec Picisd, c'est la comédie historique; avec Chateaubriand et Mme de Staël, c'est le roman moderne qui commence. Chênedollé annonce de loin Lamartine, et Creuzé de Lesser "la Légende des Siècles " de Victor Hugo. La chanson ouvre ses ailes avec Désangiers et Béranger. Nous allons voir plus loin quel élan fut alors donnè à l'éloquence, à la philosophie, à l'histoire, aux sciences politiques, aux études orientales, à l'étude des religions. Comment admettre encore que, mème dans les lettres, cette période d'un quart de siecle ait été intéconde? 


\section{La tribune et la presse.}

L'éloquence politique. - Le fait capital de cette époque, capital dans l'histoire littéraire comme dans l'histoire politique, capital dans l'histoire du genre humain comme dans l'histoire du peuple français, c'est qu'il y a chez nous des assemblées nationales, et qu'une tribune s'y éleve. A ce moment, il n'y a dans l'univers entier que trois grands peuples libres: la France, l'Angleterre, l'Amirique. Or, a la tribune de Londres ou de Pliladelphie, les orateurs ne débattent que des intérèts anglais ou américains. La supériorité a la fois glorieuse el tragique de la tribune française, c'est qu'on y discute moins des intérêts que des principes: les droits qu'on y entend proclamer ne sont pas seulement les droits du citoyen français, mais les droits le l'homme. Nos orateurs de la Constituante, de la Législative, de la Convention, des Conseils du Directoire, ont tous les délauts de leur temps et quelques défauts qui leur sont propres. Ils sont trop imprégnés de souvenirs classiques; ils sont enclins ia la pompe théâtrale et à la déclamation; ils tombent volontiers dans les lieux communs de la sensibilité et de la philunthropie; ou bien leurs discours se ressentent de la violence des passions populaires et des fureurs de la ruc. Considérons cependant que les idées qui nous sont aujourd'hui familières avaient alors tont l'éclat de leur formilable nou. veauté, qu'elles répandaient au loin l'espérance parmi les peuples et la terreur sur les trónes. C'est avec ces discours, qui nous semblent aujourd'hui emplnatiques, que nos ora. teurs surent se faire entendre jusquaux extrémités du monde, qu'ils rassemblèrent la nation francaise dans un élan presque unanime potir la conquête de la liberté et la délense lu territoire, qu'ils imprimèrent aux armées l'en. thonsiasme qui enfinta les victoires, qu'ils tinrent l'Europe sous le charme ou sous l'épouvante de leur parole

Tous les partis entre lesquels se disputa te pouvoir eurent leurs orateurs éminents. Dans la Constituante, la droite eut labbé Maury et le capitaine Cazales; les partisans de la Constilution britannique curent Clermont-Ton- 
nerre, Lally-Tollendal, Malouet, Mounier; le parti populaire eut Sieyès, Bailly, Barnave, Duport, les deux Lameth, surtout mirabead. Il est le plus grand de tous, le plus puissant parce qu'il se soucia le moins de la forme littéraire, parce qu'il joignit à l'élan et à la fougue, au pittoresque du langage, à la lorce des arguments, ce que les orateurs des républiques antiques estimaient par-dessus tout: l'action. Qui n'a présents à la mémoire sa foudroyante apostrople au marquis de Dreux-Brézé; les fic̀res paroles qu'il chargea les dèlégués de l'Assemblée de porter au roi après le 14 juillet ${ }^{1}$; ses discours sur la banquesoute, "la hideuse banqueroute "; sur l'intolérance religieuse et le balcon du Louvre à la Saint-Barthélemy; sur l'érgoïsme nobiliaire, sur cette poussière lancée au ciel par les Gracques mourant et dont naquit Harius; et enfin tant d'autres harangues, tour à tour passionnées ou profondément habiles, où il délendit, suivant les nécessités et les périls du moment, tantòt le principe de la souveraineté nationale, tantòt les prérogatives essenticlles du pouvoir exéculif.

Dans la Léurislative, dans la Convention, ce qui domine d'abord, c'est l'éloquence, colorée de passion méridionale, des orateurs girondins: Buzot, Brissot, Guadet, Fauchet, Barbaroux, Pétion, Condorcet, Lanjuinais. C'est Isnard, qui, en 1792, brandit l'épée de la révolution universelle et montre la terre entière tressaillant au cri poussé par la France et se couvrant de combattants. C'est Gensonné, dénonçant la conspiration cles rois contre les peuples. C'est surtout vergNiAdD, avec ses discours d'un patriotisme exalté jusqu'au sacrifice de sa vie et de celle de ses amis, faisant " rentrer, au nom de la loi, lépouvante et la terieur dans ces palais dont olles sont sorties, dans les temps antiques, au nom du despotisme "; appelant les hommes du 14 juillet et du 10 aoút "à piocher la fosse" des envahisseurs du territoire; ou bien préchant la concorde à une Assemblée déjà malade de ses divisions et s'écriant: "Périsse l'Assemblée, pourvu que la Frince soit libre!..."

Puis, c'est la Montagne et la furieuse éloquence des jours de grands périls : DaNTon prèchant l'audace, et, dans ses

1. - Dites-lui bien, dites-lui que les hordes etrang-ires... . " 
périoles entlammées, laisant rugir "le canon d'alarme " et tomner " le pas de charge contre les ennemis de la patrie "; Robespierre, en contraste si frappant avec Danton, rhétem froid et déclamateur, mais d'une logique si redoutable, répandant tour à tour la terreur sur les tètes des modérés ou sur celles des exagérés; Saint-Just, à la parole métallique et tranchante comme le fer de la guillotine; Barère, le rapporteur violent et souple des plus terribles mesures; Grégoire, l'évêque de la Montagne, le chrétien du jacobinisme; Tallien, dont l'amour pour Thérèse Cabarrus chauffait ì blanc l'éloquence vengeresse contre le tyran de la Convention.

Mais peut-on leur appliquer les règles de la critique littéraire, à ces discours tragiques que pouvaient interrompre la balle de l'émeutier ou la maju sanglante du bourreau? Et comment juger avec les préceptes de la rhétorique ces paroles qui soulevaient et apaisaient les tempetes?

Il faudrait aussi entendre ces harangnes brèves, concises, dignes de Spartiates et de Romains, que les représentants en mission et les généraux de la République faisaient retentir sur le front des troupes, sous le feu des batteries ennemies. C'est Custine ou Merlin de Thionville annonçant la fraternité aux Allenrands de la rive gauche; c'est Hoche offrant la paix à la Vendée dévastée; c'est Kléber entrainant ses troupes au delà du Rhin pour la lélivrance de l'Europe; c'est Bonaparte montrant du haut des Alpes l'Italie à ses soldats; ou, à bord de la flotte, leur annonçant la conquête de l'Egypte; ou, sur les rivages du Nil, prenant à témoin les 'yramides.

Un moment vint où un homme stul eut le droit de parler, et, dans le silence de la tribune asservie, étonna l'Europe de ses ordres du jour, de ses bulletins de victoires, de ses arrêts de mort contre les vieilles dynasties, les Habsbourg ou les Bragance, de ses atrèts de résurrection en fiveur des peuples déchus, l'blyrie ou la Polosne. NAPOLEON, que le monde écoutait dans la stupeur, fut assurément l'orateur le plus étrange qu'il eut entendu depuis Mahomet. "Bonaparte, disait alors Chénier, ne créa pas seulement un nouvel art de la guerre, mais une éloquence 
dont il sera toujours le modèle; qui donc a jamais su parier comme lui à des soldats?" Plus tard. Timon (Cormenin) lui fit une place à part dans son Lirre des Orateurs: "Sa manière de haranguer n'a rien de semblable chez les modernes, ni dans l'antiquité. Il parle comme s'il etait, non sur un tertre ordinaire, mais sur une montagne. On dirait qu'il a lui-mème cent coudées de haut... Son armée n'est pas une simple armée, c'est la Grande Armée. Sa nation n'est pas une simple nation, c'est la Grande Nation. Il raye les empires de la carte. Il scelle du pommeau de son épée les nouveaux royaumes qu'il institue. Il prononce sur les dynasties, au milieu de la foudre et des éclairs, les arrêts du destin."

La presse, la polénigue. - Parmi les journalistes, deux surtout eurent une valeur littéraire. Dans le parti royaliste, c'est Rivaror, un fougueux Languedocien, avec la verve endiablée du Midi, écrivain brillant, causeur étincelant, polémiste fin, élégant, caustique, auquel les "Acies des Apòtres "durent en partie leur succès; dans les partis démocratiques, e'est camile desmoolins, l'ardent Picard, si éloquent et si patriote dans "la France libre" de 1789, où il montre le grand réveil de la nation; si violent et si haineux dans ses publications de la période suivante, où il sattaque àprement non seulement au roi, à la reine, aux royalistes, aux constitutionnels, mais aux républicains des autres écoles, avec tant d'acharnement qu'il y gagna le surnom de "procureur général de la lanterne "; plus réfléchi, plus h'tmain, presque héroïque, dans "le Vieux Cordelier ", où il osa flétrir la tyrannie de Robepierre, fit un appel si audacieux a la clémence, répara si noblement une partie de ses torts et mérita de périr sur l'échafaud de $1799^{\prime}$ dans la catastrophe du parti dantoniste et dans l'extermination des indulyents.

Parmi la multitude des pamphlets du temps, l'histoire ne peut oublier celui de sieyès, qui fut non seulement un écrit. mais un acte, le manifeste et le début de la Révolution; ni ceux dont rivaror harcela Necker; ni l' "Histoire des Brissotins " de camile desmoulins, factum meurtrier dirigé contre les Girondins.

Sous l'Empire, les écrivains politiques n'ont de liberté 
que dans l'exil; et, comme les armées impériales s'étendent des rives du Tage à la mer Baltique, il faut aller chercher l'exil bien plus loin que ne firent les protestants sous Louis XIV. Par moments, il ne leur restait guère que la Grande-Bretagne et la Russie. C'est en Angleterre que Mroe DE STAEL écrivit "Dix années d'exil ": où sa haine contre Napoléon va jusqu'à souhaiter le succès de la coalition. C'est pourtant à Paris mème, en 1807, que chateadbriand avait publié dans le Mercure l'article qui commence par ces mots: "Lorsque dans le silence de l'abjection..." Napoléon se contenta de confisquer la part que l'écrivain avait dans le journal. Puis, quand l'Empereur lui-mème eut ouvert à Chateaubriand l'Académje française, celui-ci prépara un discours de réception si hardi qu'il ne put être prononcé. Napoléon se borna encore a lui dire : "Sortez de mon Empire, si mes lois ne vous conviennent pas ". La censure continua à se montrer d'une clémence relative pour les œurres de Chateaubriand. Son plus violent pamphlet, "Bonaparte et les Bourbons ", porte une date qui lui ôte le mérite du courage: 1814 . Il y traite Napoléon de " parvenu, faux grand homme, Moloch, Gensérie, Attila ". Il ose mėme, oubliant le pont d'A reole, l'accuscr de làcheté.

\section{Les sciences morales et politiques.}

Nous empruntons à l'Institut de la Convention, pour désigner à l'avenir certaines branches de nos études, la rubrique désormais officielie de sciences morules et politiques. Ce sont celles qui ont pour objet l'homme considéré, soit comme individu, soit comme membre des sociétés humaines. Les principales sont la philosophie, l'histoire, ia science des religions, la politique, la sociologie, la législation, l'économie politique ${ }^{1}$.

La philosophie. - La génération de la Révolution et de lEmpire, en philosophie, appartient presque entièrement à l'école qui fait dériver les illées de la sensation. Les dis-

1. Pour la législation nous renvoyons au chapitre v, et pour l'économio politique au chapitre xur. 
ciples de Locke et de Condillac, ceux qu'on appelle les sensualistes, ce sont alors Destull de Tracy ${ }^{1}$, Morellet ${ }^{2}$, Volney, Garat, Laromiguière. Comme ils faisaient profession d'indépendance en politique, Napoléon avait peu de sympathie pour eux. "Je n'aime pas les ilkologues ", disait-il. Il est vrai qu'il confondait avec eux tous ceux qui pensaient librement. C'est en haine de l'idéologie qu'il supprima la classe des sciences morales et politiques à l'Institut. Une autre variété d'idéologues, pour Napoléon, c'étaient ceux que nous appellerions les matérialistes : cabanis, le plus célèbre d'entre eux, publia, en 1802, ses "Rapports du plysique et du moral de l'homme ${ }^{3}$ ".

Napoléon, dans le Journal des Débats, laissa Geoffroy et Dussault guerroyer contre la philosophie du xvis ${ }^{0}$ sicele. Son règne coincida, d'ailleurs, avec une renaissance des idées spiritualistes et eartésiennes.

On doit au baron DE GÉRANDo, sous le titre d" Histoire comparée des systèmes de philosophie " (180'), une vaste enquète sur les philosophies contemporaines à létranger, notamment celles de l'école écossaise et de l'école allemande. Mme DE STAEL, dans son livre "De l'Allemigne", appela égalenent l'attention sur kant, un restaurateur du spirituatisme, et sur Fichte et Schelling, les l'ondateurs du panthéisme idéuliste.

MAINE DE BIRAN, qui avait éfé garde du corps de Louis XVI et qui fut sous-prélet de Napoléon et député de son Cosps législatif, renonça aux thóries de Locke et de Condillac, qu'il avait d’abord prolessées. Il fut un spiritualiste et revint à la métaphysique, longtemps délaissée. Cependant il ne lut pas un pur cartésien; il eut un système ussez original, fondé sur l'importance qu'il donnait à la volonté, dont, suivant lui, ni Deseartes ni les idćologues n'avaient tenu assez de compte. Descartes avait donné pour base à sa philosophie le fameux : "Je pense, done je suis ";

1. Destutt de Tracy a publie les Moyens de fonder la morale (179S). Ses Eléments d'idéologie (1S17-1S1S) appartiennent à la période suivante.

2. L'abbè Morellet publia, en 1790, son Apologie de la philosophie contre ceux qui l'accusent des maux de la Révolution.

3. Plus tard, sous la Restauration. il devait revenir aux doctrines spiritualistes sur Dieu et l'áme : en 152 $i, 11$ publiera la Lettre sur les causespremières, qui est une sorte de palinodie. 
Maine de Biran disait plutôt: "Je veux, donc je suis ". D’après lui, " ètre, agir, vouloir, sous des noms différents, c'est une seule et même chose ".

RoYer-Collard, nommé professeur à la Faculté des lettres de Paris en 1809, restaura le spiritualisme dans l'enseignement de la Sorbonne. Il se donnait volontiers pour un disciple de Maine de Biran. "C'est notre maitre à tous ", disait-il. En réalité, il dut beaucoup, comme plus tarı Cousin, aux pliilosophes de l'école écossaise, Reid et DugaldStewart ${ }^{1}$ : ceux-ci avaient fait de la psychologie leur étude principale et avaient porté à un regré jusqu'alors inouï la précision dans l'analyse des phénomènes de l'âme, idées, sentiments, volontés. Royer-Collard a peu écrit, mais il eut une grande influence sur la jeune génération : il fut le maître de Cousin, Jouffroy, Damiron.

Au-dessous des hautes régions métaphysiques de la philosophie, il faut signaler deux auvres remarquables de bernardin de SAINT-PIERRE : " la Nature de la Morale " (1798), et surtout le beau livre des "Harmonies de la Nature" (1796), qui, à certains égards, est un brillant développement de l'argument si cher à l'ancienne école spiritualiste, celui des causes finales.

L'hisioire. - Les périodes de la Révolution et de l'Empire ne furent guère favorables à l'histoire : pendant la yremière, on vécut une histoire si terrible que peu d'hommes se soucièrent de remonter dans les siècles écoulés: pendant la seconde, on n'eut pas assez de liberté : Napoléon accusait Tacite d'avoir calomnié les empereurs romains, et il ne se souciait pas de voir un Tacite grandir sous son règne.

On fit peu de voyages en Grèce, et on ne songeait pas encore à y exécuter des fouilles. C'est aux Allemands, à Lessing, à Winckelmann, qu'on laissa la gloire de renouveler l'archéologie hellénique. De même, c'est un Allemand, Niebuhr, qui, en 1811, dans sa magnifique "Mistoire romaine ", appliqua sa critique sagace et ingenieuse aux origines de Rome. On ne peut guère citer chez nous, pour

1. Reid avait publié, en $\mathbf{1 7 6 4}$, ses Rerhorches sur l'entendement humain; en 1785-1788. son Essai sur les facultes de i iumme. Dugaid-Stewart avait donné, en 1792, sa Philosoptie de l'esprit humain; en 1793, sa Philosophic morale; et 1810 , ses Essais philosophiques. 
les études classiques, que l'" Histoire critique de la République romaine " (1807) de LÉvesade et les " Recherches sur l'histoire ancienne "(1814) de volnsy.

De même la Révolution, en dispersant les ordres religieux, avait interrompu le vaste travail d'enquête sur nos origines nationales qu'avaient commencé les bénédictins, et l'Institut de France n'était pas encore en mesure de le reprendre. On se ne souciait pas d'exhumer les vieilles chroniques, de déchiffrer les chartes. Une certaine indifférence, uême un certain dédain, planait sur ces siècles, consilérés comme infectés de royauté, de féodalité et de monachisme. On n'avait point le goût des recherches patientes et désintéressées de l'érudition; on préférait les généralités philosophiques et politiques. Cependant il faut signaler: de DAdNod, l'“ Essai sur la puissance temporelle des papes" (1810); de sisnond, l' "Histoire des républiques italiennes ", commencée en 1807, et l'" Histoire des littératures du midi ", commencée en 1813; de GINGUENE, l" Histoire littéraire d'Italie" (1811-1819); de michado, l" Histoire des Croisades ", dont le premier volume parut en 1811, en uême temps que les premiers fascicules de sa "Biographie universelle "; de lacretalle, l' "Histoire de France pendant fes guerres de religion (1814); de Jay, "le Ministere du "irdinal Richelieu»(1815).

Lhistoire du xvme siècle, qui, pour nos pères, était de l'histoire presque contemporaine, attira bien plus leur attention. JAY et DAONOO en retracèrent le tableau littéraire (1810), et lacretelde, professeur à la Sorbonne, les événeuchts politiques (1808). PH. Dr ségor raconta le rène de Frederic-Guillaume $\boldsymbol{I}$, roi de Prusse (1800), et michadD " "Histoire de l'empire de Mysore ", alors très populaire chez nous, à cause des luttes soutenues contre les Anglais ! rar nos alliés les sultans Ilyder-Ali et Tippo-Saëb. RolHière rublia, en 1796, ses "Anecdotes sur la révolution de Russie ", dont l'ancien gouvernement, à la prière de Catherine II, avait interdit l'impression, et fit "IHistoire Se l'anarchie de Pologne" (1807). On pourrait de ces deux (nvrages rapprocher ceux de Lescr : "Tableau des progrès ¿ la puissance russe " (1807) et " Histoire des Cosaques" $(\$ 14)$, si les préoccupations politiques ne l'avaient emuorté 
chez lui sur la véracité de l'hisiorien et s'il n'avait commis un véritable faux en insérant dans le premier de ces ouvrages le prétendu Testament de Pierre le Grand.

Ce qui a le plus occupé cette génération, c'est ellemème. L'histoire de la Révolution s'ébaucha pendant les années mèmes de la Révolution. En 1790, deux amis de la liberté tracent une esquisse de ses débuls. L'“ Almanach historique de la Révolution française pour l'année 1792 " y ajoute quelques scènes. En I793, un poème épique du citoyen Pagès la célèbre en dix chants et Lorenz la raconte en latin d̀ Strasbourg. En 1796, Fantin Désodoards a la prítention d'en donner une "Histoire philosophique ", qui est tout imprégnèe des idées girondines, et le poète Pagès en écrit "l'Histoire secrète ".

L'histoire le cette grande époque a donné naissance à des cuvres plus célèbres; mais ce sont des apologies, non des récits; ceux qui les ont écrites sont avant tout royalistes, constitutionnels, girondins, etc.; et, pour la plupart, ils les ont publiées dans l'èmigration ou dans l'exil. Dans le camp royaliste, nous avons les "Considérations sur la Révolution francaise ", de MALLET DU PAN (1793), et les "Considérations sur la France ", de JOSEPB DE MAISTRE (1796). MOUNIER exprime les désillusions des constitutionnels de l'école anglaise dans ses "Recherches sur les causes qui ont empêché les Français d'ètre libres " (1792). Garat, organe des déceptions girondines, publie ses "Considérations et mémoires sur la Révolution "(1792-1793). Un peu à l'écart des partis, Necker donne son traité "De la Révolution française " (1796). chateadbriand esquisse son "Essai sur les révolutions " (1797). Mme DE STAEL, dans plusieurs écrits de circonstance, prélude à ses "Considérations sur la Révolution française ", qui ne pourront être imprimées qu'en 1818.

En 1801, il se fait une tentative sérieuse pour raconter ces annales si récentes : Lacretelle, Beaulieu, Toulongeon, Bertrand de Molleville, publient chacun une " Histoire de la Révolution ".

A partir de l'année 1801, on ne voit presque rien paraitre en France sur ces événements. Les acteurs dı grand drame se recueillent dans leurs souvenirs, leurs regrets ou leurs remords, ou, s'ils rédigent leurs Mémoires, les tienneut 
seerets. On sent que le nouveau gouvernement est peu favorable à toute tentative de ce genre: en 1810, le convenílonnel Paganel s'étant avisé d'imprimer ses Mémoires, l’édition est saisie et mise au pilon. Dès lors, le silence se refait pour près de vingt années.

Pour l'histoire militaire, on ne peut guère eiter chez nous quine Lettre de paUl de ségor sur la campagne de Macdonald (1802) et l'importante "Histoire des guerres de la liúvolution " par Jomins (t806). L'Empereus, iei encore, prétend être le seul historien comme le seul orateur et presque le seul acteur. Ceux qui voulaient s'instruire de nos frloires militaires n'avaient qu'à lire ses Bulletins.

Les ctudes orientales. - Si nous avons fait peu de progrès, à cette époque, dans la connaissance de l'antiquité grecque et romaine, il n'en est pas de mème pour les antiquités de l'Orient. En 1795 s'est fondée l'École des langues orientales. En 1798, une armée française a mis le pied sur cette terre d’Égypte, si mystérieuse encore et que, dès l'antiquité, on appelait la "mère des religions". Nous avons occupé jusqu'en 1801 l'ancien empire des Pharaons. Les savants de notre Institut d'Égypte ont exploré en tous sens notre conquète, et, sans pouvoir encore déchifrer les caraetères hiéroglyphiques, ont copié beaucoup d'inseriptions et collectionné de curieux monuments, comme le famenx Zodiaque de Denderah. En 1803, sylvestre de SACY avait commencé à ètudier los caractères cunéiformes de la Perse. Il avait publié, en 1799, les "Prineipes de grammaire générale ", douné en 1810 sa Grammaire arabe, fait connaitre les géographes arabes Ibn-Haukal et Abd-Allatif, le fabuliste hindou Kidpaï. Le sanscrit, eette langue sacrée de l'Indoustan, faisait la préoecupation de nos érudits : chézy traduisait, en 1814, un fragment du grand poème siuscrit, le Rimiyma. Toutes ces vieilles eivilisations ne faisaient encore que s'entr'ouvrir pour nous, et on ne pouvait même pressentir les magnifiques progrès que deviai accomplir, en notre sièele, la science de l'Orient.

La science des religions. - Le peu que l'on connaissait déjà des eultes et des civilisations anciennes permettait te traiter la question de Jorigine des religions avee plus de priecision et de méthode que n’avait pu le faire Voltaire; 
mais c'était toujours l'esprit du xvme siècle qui dominait dans ces études, c’est-à-dire un esprit hostile au catholicisme. En 1791, volney, fort de ses voyages en Orient et de ses études sur les langues orientales, publiait " les Ruines ", où, dans le décor imposant des citès mortes, il lait comparaitre les fondateurs de toutes les religions, se plait à les mettre en contradiction et à montrer l'infinie division les eroyances en sectes rivales. En 1793, comme pour abroger la morale chrétienne, il formulait celle de " la loi naturelle ". En 1795, Dupurs. dans son "Origine de tous les cultes ", assignait à tous, même aux rites et aux symboles du culte catholique, une origine astronomique, royant jusque dans la tonsure des prêtres une imagge du soleil et dans la vie du Christ une série de mythes solaires. En 1806, il essayait une explication du Zodiaque de Denderah : il tendait à reculer dans une antiquité prodigieuse les débuts de la civilisation égyptienne et à infirmer ainsi la chronologie de la Bible. A peu près dans le même espril, DESTUTT DE TRACY, en 1804 , faisait paraitre un ouvrage qui porte le mème titre que celui de Dupuis, et Dulaune (18031806) entreprenait "l'Histoire des différents cultes".

C'est pourtant presque dans le mème temps, entre l'ípoque où Bonaparte proclama la liberté du culte catholique et celle où Xapoléon fit bénir sa couronne par le pape, que chateadbriand publia "le Génie du Christianisme" (1802). ll révèla presque aux croyants eux-mèmes leür religion. L'enseignement religieux du $x v^{e}$ siècle arait été un peu étroit et sec, comme la critique de son ennemi Voltaire : Chateaubriand fut un apôtre et un artiste; il sut légager la haute poésie, à la fois sublime et touchante, que recèlent les dognes, les symboles, les pompes du catholicisme : i) nous attendrit avec la description des processions et des fètes de village.

Les Dupuis, les Volney, les de Tracy, pour nier l'originalité du christianisme, s’étaient étudiés à montrer la coïncidence des fètes chrétiennes avec les époques de l'année astronomique; Chateaubriand s'empara de leurs observations, mais pour donner aux pompes de la religion des origines plus augustes, une majesté plus imposante et en sens plus profond : il entoura la Fète des trépasses de 
toutes les tristesses de l'équinoxe d'automne, convia l'âme assombrie par la mort de la nature à saluer dans le berceau de Noël à la fois la naissance du divin Enfant et la naissance de l'année nouvelle, entoura la Pàques triomphante du Christ de toutes les splendeurs d'avril, le mois des fleurs et des chants d'oiseaux. Il fit du christianisme une chose qui enveloppe et pénètre l'homme, fait vibrer en lui toutes les fibres morales et physiques, l'émeut à la fois par les mystères d'une religiọn révélée et par les prestiges d'une religion de la nature. Par son livre, Chateaubriand devenait le collaborateur de Bonaparte dans la restauration des autels; celui-ci rouvrait les églises et celui-là les emplissait de fleurs et les inondait de lumière; le poète donnait une àme populaire à ce culte dont le conquérant voulait refaire un culte ofticiel.

Les theories politiques. - La Révolution avait proclamé la souveraineté populaire, et Napoléon, en restaurant un tròne, affectait de le fonder sur celle-ci. D'autres poursuivaient une restauration plus complète du passé, ou plutut, en restauraut les institutions d'autrefois, ils entendaient leur donner une logique, une rigueur, un caractère absolu qu'elles n'avaient jamais eus. A la souveraineté populaire, mème à toute monarchie fondée sur elle, mème à l'ancienne monarchie de droit divin, limitée, en théorie, par une sorte de droit national, ils opposaient une monarchie où le droit divin développait toutes ses conséquences; car ce mème principe, qui soumettait les sujets au roi, soumettait le roi au pape, le "vicaire de Dieu sur la terre ". A la papauté limitée par le droit des conciles, ils opposaient la papauté. absolue et infuillitle. A l'ancienne Église gallicane, hésitante entre ses deux chefs, le pontife de Rome ei le roi de rrance, ils opposaient une Eglise uniquement soumise au premier et purement ultrumontuine. Ce sont ces principes que JOSEPA DE MAISTRE devait plus tard formuler avec tant. d'éclat. Ils sont dejjà en germe dans les écrits de BoNalD "la Théorie du pouvoir politique et religieux" (1796), "les Lois naturelles de l'ordre social " (1800), la "Législation primitive « (1802), et dans les premières œuvres de Joseph de Maistre Iui-mème : "Considérations sur la France " et - Principe générateur des constitutions" (1810). C'est en 
plein triomphe de la démocratie, soit sous la république lu Directoire, soit sous le césarisme plébiscitaire, que se formulait ainsi la restauration d'une monarchie plus logiquement despotique que celle de Louis XIV, et d'une papauté telle que l'ont imaginée, sans pouvoir jamais la réaliser, les plus ambitieux des grands papes du moyen àge. L'alsolutisme en politique, l'ultramontmisme en religion, la raison, cette orgucilleuse, humiliée sous le joung de l'autorité: tel est le dernier mot de cette nouvelle école politique.

Les théories sociales. - Pendant la Révolution, yuand des catégories nombreuses de propriétés étaient atteintes par la loi, il n'est pas étonnant que le principe même de la propriété ait pu être mis en discussion. Les uns, sous l'influence des souvenirs de la république égalitaire de Sparte et des rẻveries égalitaires de Platon, les autres, obéissant simplement à leurs convoitises, à leurs appétits, à l'envie de ceux qui ne possèdent pas contre ceux qui possèdent, parlaient d'un nivellement général. Brissor, le futur Girondin, l'avait justifié d'avance dans ses "Recherehes philosophiques sur le droit de propriété et le rol ", publiées en 1780. Un autre Girondin, RABACT, dans la Chronioze de Paris, proposait en 1792. comme le but final de toutes les lois révolutionnaires, d'obtenir un partage égal des fortunes; pour prévenir le rétahlissement de l'négalité, on aurait tixé le maximum de ce qu'un citoyen ponvait posséder. REDERER, dans le Journal de Paris, combattit ces doctrines comme tendant a établir, non pas " l'égalité dans l'abondance, dans la richesse, dans la prospérité générale, mais l'égalité dans la misère, l'égalité dans la famine, l'égalité dans la ruine universelle ". Elles furent discutées ardemment dans les clubs. Le superflu d to riches devait leur ètre enlevé pour former le nécessaire des pauvres. C'est par une sorte d'application de ces thenries qưà trois reprises la Convention ou le Directoire décrétèrent les emprunts lorcés sur les riches.

Cependant la Convention recula devant les conséquences des principes formulés par quelques-uns de ses membres. Cette assemblee, qui avait augmenté en France le nombre des proprićtaires, ne pourait renser à détruire la propriété. 
Le décret du 18 mars 1793 porta la peine de mort contre quiconque oserait proposer une loi agraire. La Constitution de 1793 définissait ainsi la proprièté : " le droit qui appartient à tout citoyen de jouir et de disposer de ses biens, de ses revenus, du fruit de son travail et de son industrie ". Dans celle de l'an III, on lit: "C'est sur le maintien des propriétés que reposent la culture des terres, toutes les productions, tout moyen de travail, et tout l'ordre social. "

Babeuf et les Babouvistes. - Les idées que nos Assemblées refusaient d'appliquer furent reprises par quelques sectaires. BABEUr avait emprunté son prénom de Gracchus à un célèbre agitateur romain, et la plupart de ses théories au "Code de la Nature " de Morelly. Il s'associa avec des hommes du parti terroriste, laissés sans direction après la chute de Robespierre et dont les doctrines dépassaient étrangement celles des Jacobins. C'étaient surtout Darthé, le Toscan Buonarotti, Antonelli, ancien juré du tribunal révolutionnaire, Sylvain Maréchal, l'auteur du "Dictionnaire des Athées " et du "Dernier Jugement des Rois". Avec eux, il publia des journaux socialistes, fonda le Club du Panthéon ou Société des Égaux, groupa autour de lui les débris des factions robespierriste et hébertiste, et conspira contre le Directoire. Après avoir renversé celui-ci, on devait exterminer les opposants, distribuer gratuitement les vivres sur les places publiques, partager entre les "défenseurs de la patrie " les biens des "ennemis du peuple ", loger dans les maisons de ceux-ci les citoyens sans asile. Ensuite on mettrait en commun toutes les propriétés, en vertu de cet axiome : la terre n'est à personne, les fruits sont à tout le monde. Tous les citoyens mangeraient à des tables communes. Cette conspiration fut découverte. Babeuf et Darthé furent exécutés, cinq de leurs complices déportés. Les idées socialistes disparurent de la scène, et ce n'est pas sous Napoléon qu'elles pouvaient relever la tête.

Autres écoles socialistes. - Cependant deux chefs des écoles socialistes du $\mathrm{x}_{1} \mathrm{X}^{\mathrm{e}}$ siècle étaient déjà à l'œuvre. FOURIER, né à Besançon en 1772, publiait, en 1808, son premier ouvrage: "La théorie des quatre mouvements et des destinées sociales ". Le comte DE SAINT-SIMON, né à Paris

R. Civil. contemp. 
en 1760, écrivait, sous l'Empire, plusieurs ouvrages ${ }^{1}$. Toutefois les écoles fouriériste et saint-simonienne n'ont encore pris aucun développement.

Le Halthusianisme. - A l'histoire des théories sociales, on pourrait rattacher l' "Essai sur le principe de la population ", publié en 1798 par l'Anglais malthus et bientôt traduit chez nous. Malthus, attribuant tous les maux de l'humanité à l'excès de population, engageait ses contemporains à y remédier en diminuant les mariages.

Ouvaages a consulter. - Outre les Histoires gènérales sur la littérature francaise, nolamment Petil de Julleville, t. VI et VII :- M. J. Chénier, Tableau de la litterature francaise (1815). - Merlet, mème titre (1876). - Geruzez, La litt. sous Ia Rev. francaise (1861). - Jullien, Hist. de la pósie au temps de l'Empire (18:4). - Paul Albert, La litt. française au XIX siecle, les origines du romantisme i\$884). - Welschinger, Le theritre de la Rivolution (18y7) el La censure théatrale sous le $I^{\mathrm{er}} \mathrm{em}$ pire $(18>7)$. - Jauffret, Le theitre sous la Rivolution (1S69). - Alfred Copin. Talma et la. Révolution (1S85). - Vaulaier, Essui sur Nepomucine Lemercier (IS\&ri!. - Lamartine, Les hommes de la línolution. Mirabeau, Veryniaud, Danton. - Aulard, Les orateurs de la Constituanle, de la Lrgislative. de la Convention Q inttion, 190(j). - Neton, Siryis 1900. J. Clarelie, Camille Desmualins (1875. - Cormenin, Le live des Orateurs 1848. - De Lanzac de Labnrip. Mouner (J\&si). - E. Faquet. A. Chemier (190\%). - SulnueBenve, Chateaubiumal et som "roup? littirire sums l'Empire livol, el Pur. truts. Landis, Foureane lundis. J. F. Bossonnade, La critivate litti- raire sous le premier Empire (1863). - Cuvillier-Fleury, Etudes historques et littérares, 3 séries 185 -59). - P. Gaulier. Madtme de Stael et Tapolion $(1502)$. - J. Ilarmand, Wu"Janue de Genlis 1912. - L. Ilenry Leromte, Vapoléon et l'art dramatiqne 1912.

P. Jinnet, Hist, des sciences politiques (1872). - Cousin, Cours dhist. de hathilosophie moderne (lecons do 1815-201. - Franck, Dictionnaire des sciences philosophiques, - Damiron. Essui sur l'hist. de la philos. (1829). - Thurot, Introd. il l'étude de la. philos. (1530\%. - J. Gerard, Maine de Firan (1876). - Picavet. Les Ideologues 1890 . - L. Cahen, Condorcet et la Rev. franc. 190t). - A. Sudre. llist. Nu communisme $155 \mathrm{j}) .-\mathrm{Ad}$ velle. Bubcufet le babouvisme (158'. - Am. Le Finre, Le socinlisme pondant la Rivol. fr. 1857. - P. Janet. Les origines du sociulisme contemforain : la propritéte prurlant la $R e^{i-}$ culution frameaise (18sa. - E. Fawuet, Yuestions politiouses et probleme's polatipues due temps present 1:100). - G. el 11. Bourara, le sorialismp frencuis ale fisq "lsta 1912 . - Ch. Bonnet, Le Babanvisme (1907). - Lobiquet, Buonuroti 1910).

1. Tels que la Lettre d'un habitant de Geneve. l'Introduction aux traruux scientiluzes, la Science de llomme, la Gravitation universelle, la Réorgar nisatio: de la société europienne. 


\title{
CHAPITRE XI
}

\author{
LES ARTS
}

\section{L'architecture, la sculpture.}

Caractère elassique. - Pendant la Révolution, on a peu construit : on n'avait ni le temps ni les ressources nécessaires. C'est sous l'Empire que les tendances artistiques communes à toute la période de 1789 a 181 t ont pu se manifester par des œuvres. Ces tendances sont avant tout clussiques. Si l'on connaissait encore mal les monuments de la Grèce, on avait étudié avec soin les débris de l'art romain et gréco-italien à Rome, à Pompéi et Herculanum, à Pæstum, dont le magnifique temple à colonnade dorique était un but de pèlerinage pour nos architectes. Aussi, tout est romain chez nous : l'église Sainte-Geneviève, de Soufflot, est devenue le Panthéon, ouvert aux mànes des grands hommes; celle des Invalides est devenue le Temple de Mars; Napoléon commencera un Temple de lit Gloire. On demandera à l'antiquité romaine des modèles d'ares at de colonnes triomphales.

\section{Caractère de grandeur : vastes projets de Napoléon.} - On vise au colossal ${ }^{1}$ : on rêve de monuments prodigieus

1. Le goủt du colossal était aussi bien celui de la Révolution que celu; de l'Empire; le décret de la Convention du 15 novembre 1795 porte :

Art. $I^{\text {eq. }}$ - Le peuple a triomphé de la tyrannie et de la superstition. La monument en consacrera le sourenir.

II. - Ce monument sera colossal.

III. - Le peuple y sera représenté debout par une statue.

IV. - La victoire fournira le broaze.

V1. - La statue aura quinze mètres ou quarante-six pieds de hauteur.

Notons le décret du 10 janvier 179', rendu sur la proposition de Grégoire, et ordounant que desormais les inscriptions des monumeats publics ne seroa plus en latin, mais en frauçais. 
comme les idées de la Révolution ou les guerres de l'Empire. On n'a qu'un mot à la bouche : grand. On est la Grande Nation, la Grande Armée, et Napoléon dessine un plan de la Grande Capitale, dont la réalisation n'est pas complète après quatre-vingts ans de richesse et de travail. Il voulait faire de Paris la métropole du monde, "quelque chose de fabuleux, de colossal, d'inconnu jusqu'à nos jours ". Il traçait une avenue, la Voie impériale, qui, en ligne droite, allait de l'arc de triomphe (en projet) de la barrière du Trône à l'arc de triomphe (en construction) de l'Étoile. Il voulait édifier un palais, celui du quai d'Orsay (depuis, la Cour des comptes), qui eût été comme une splendide caserne pour les ambassadeurs de tous les pays. Il eût voulu que tous les rois, le pape lui-même, eussent à Paris un palais, comme Louis XIV avait amené tous les grands seigneurs à se constıuire un hôtel à Versailles. Ses musées auraient pris la place de tous les musées de l'lurope, dépouillés à leur profit de leurs chefs-d'ouvre. Le palais de son fils, le roi de Rome, eut été comme une ville immense, une résidence babylonienne ou pharaonique, s'étendant de l'Étoile au bois de Boulogne, couvrant de ses édilices les hauteurs de Passy et de Chaillot, la plaine de Vaugirard et de Grenelle: la Seine y eût joué le ròle d'un ruisseau dans un parc princier; les anciennes demeures royales n'auraient été que les communs du palais nouveau : la Muette eût été sa vénerie et Bagatelle son rendezvous de chasse. Pour réaliser ces plans, auprès desquels ceux de Louis XIY eussent paru mesquins, il a manqué à Nảpoléon ce qui a été si largement accordé à Louis XIV : le tenups.

Parmi les architectes dont l'Empereur put disposer, on trouve au premier rang Percier, Fontaine, Raymond, Chalgrin, Lepère, Gondouin, Vignon, Poyet, Brongniart, Bonnard, Gauché, Beaumont, Cellerier.

Les ares de triomple, les colonnes. - PERCIER et FONTAINE étaient des hommes nouveaux. Ils avaient étudié ensemble à Rome et en étaient revenus enthousiastes de l'antiquité. De retour à Paris, en 1792, ne trouvant aucune commande de monuments, ils se résignèrent à faire des dessins pour un fabricant de meubles, et c'est alors qu'ils créèrent, sur 
des modiles antiques, le mobilier républicain, qui fit fureur non seulement à Paris, mais en Espagne, en Allemagne, en Pologne, en Russie. Connaissant à fond la théorie aussi bien que la technique de leur art, ils publièrent le "Recueil des décorations intérieures ". Ils crurent un moment toucher au but de leurs plus hautes ambitions: dans un concours ouvert pour la construction d'une salle d'aısemblée nationale, leur projet fut classé le premier. L'Empirc en empêcha la réalisation. Bientôt Napoléon leur offrit un magnifique dédommagement: il les chargea de restaurer les Tuileries, de continuer le Louvre, de faire disparaitre ce dèlale de ruelles et de masures qui encombrait lespace entre les deux palais, de percer la rue de Rivoli, de réparer les châteaux de Fontainebleau, d'achever ceux de Saint-Cloud et de Compiègne, d’ériger la fontaine de Desaix sur la place Dauphine, et enfin d'élever l'A ${ }^{\circ} \mathrm{c}$ de triomphe du Carrousel, dédié "à la gloire de nos armées", et sur lequel devaient figurer les chevaux de bronze enlevés à Saint-Marc de Venise. Ils conçurent cet arc comme une copic presque exacte de l'arc de Septime-Sévère à Rome. Ils furent, à eux deux, comme le Mansart du nouveau Louis XIV: on leur demanda les projets de décorations et de fêtes pour le sacre de l'Empereur et son mariage avec Maric-Louise. C'étaient eux qui levaient construire le palais du roi de Rome.

Un décret de 1806 ordonna l'érection d'un autre are, l'Are le triomphe de l'Etoile, celui-ci dans des proportions colossales, en un point qui domine à la fois la plaine de Paris et la plaine de Boulogne et qui devait éire le centre d'une étoile de boulevards et d'avenues. L'exécution fut confiée à RAYMOND et cHALGRIN. Ils s'entendirent sur la forme générale de l'édifice, mais non sur le motif de décoration. Le premier voulait entourer le monument de colonnes supportant des statues; le second entendait réserver les surfaces planes pour y appliquer des bas-reliefs. Chalgrin resta seul chargé des travaux: à sa mort, en 1811, le monument se dressait déjà à la hauteur de 5 mètres $\mathbf{4 0}$. Goust, qui continua l'ouvre jusqu'en 1814, l'éleva jusqu'à la naissance du grand cintre. Puis, à la Restauration, pendant neuf années, les travaux restèrent interrompus. 
En 1806 fut décrétée l'érection de la Colonne Vendome, dont le bronze fut fourni par les canons pris à l'Autriche. LEPĖRE et GONDOUIN s'inspirèrent de la colonne Trajane à Rome. Autour de la colonne montèrent en spirale, dans une suite de bas-reliefs, les bataillons victorieux, jusqu'aux pieds de la statue, qui représentait Napoléon en costume de législateur, sous le manteau d'hermine, et le laurier au front. En 1810 eut lieu l'inauguration du monument.

A Boulogne-sur-Mer, Labarre avait commencé, en 1804, la Colonne de la Grande-Armée, qui ne fut achevée qu'en 1841.

Le Temple de la Gloire. - En 1806 encore, le 2 décenbre, dans un décret daté de Posen (Pologne), Napoléon ouvrit un concours d'architectes pour le Temple de la Gloire. "A l'intérieur, portait le programme rédigé par l'Empereur, seront inscrits sur des tables de marbre les noms de tous les hommes, par corps d'armée et par régiment, qui ont assisté aux batailles d'Ulm, d'Austerlitz et d'Iéna, et, sur des tables d'or massif, les noms de tous ceux qui sont morts sur les champs de bataille. Sur des tables d'argent sera gravée la récapitulation, par département, des soldats que chaque département aura fournis à la GrandeArmée. Autour de la salle seront disposés des bas-reliels où seront représentés les colonels de chacun des régiments de la Grande-Armée, avec leurs noms. Ces bas-reliefs seront faits de manière que les colonels soient groupés autour de leurs généraux de division et de brigade, par corps d'armée. Les statues en marbre des maréchaux qui ont commandé des corps ou qui ont fait partie de la Grande Armée seront placées dans l'intérieur de la salle." Cent vingt-sept projets furent adressés à l'Institut. Napoléon se les fit envoyer à Tilsitt, où il dictait alors des lois à la Russie et à la Prusse. Il fit choix du projet de vignon, bien qu'il n'eût pas été classé par l'Institut en pre mière ligne. Il répondait mieux à l'idée romaine que l'Enı. pereur s'était faite de l'édifice. " C'est un temple que j'avais demandé, disait-il, et non une église. "Du camp de Finckenstein, il complètait ainsi ses instructions à l'architecte : "Dans un temple qui doit durer des milliers d'années, écrivait-il, il faut chercher la plus grande solidití 
possible. "En fait de matériaux, il ne voulait pas de bois, mais du fer et du granit pour l'extérieur, du marbre pour l'intérieur. Sur le fronton devait étinceler cette inscription : "L'Empereur Napoléon aux soldats de la GrandeArmée ". On sait que cet édifice se compose d'une partie massive, qu'on appelle la cella, entourée de 5'x colonnes de quinze mètres de haut. En 1814, Ia celia et les colonnes étaient presque terminées; il ne manquait que la frise, le fronton, la toiture, quand survint la Restauration. Elle fit du Temple de la Gloire l'église royale de la Madeleine.

Palais et édifices publies. - Pour faire pendant, de l'autre côté de la Seine, à la colonnade de ce temple, POYET, en 1807, lut chargé de terminer le monument du Corps législutif. Gisors et Lecomte en avaient construit la salle; Poyet éleva le large perron et les douze colonnes monumentales qui supportent le fronton triangulaire.

C'est encore un temple antique, avec une colonnade, cette Bourse que Brongniart fut chargé de construire sur l'emplacement du couvent des Filles de Saint-Thomasd'Aquin. Il mourut en 1813, et eut pour successeur labarRE. Le monument ne devait être inauguré qu'en 1826.

En 1810, un concours fut ouvert pour l'érection des deux palais du quai d'Orsay: l'un pour les Affaires Etrangères, l'autre pour loger les ambassadeurs des puissances : c'est BoNNard qui fut chargé de la construction; mais les travaux, interrompus en 1810 , ne furent achevés que sous Louis-Philippe ${ }^{1}$.

En 1808, sur les terrains appartenant autrefois à l'abbaye Saint-Victor, Gauchí éleva l'entrepòt des vins de Bercy. En 1810, un décret prescrivit la construction de cinq abattoirs à Paris: Gauché se chargea de celui de Grenelle; les autres furent bâtis par Petit-Radel, Poitevin, Happe et Vautier, Leloir.

En 1801, BEAUMONT avait construit, au Palais-Royal, la salle des séances du Tribunut. cellerier avait commencé l'appropriation de l'hòtel Soubise, qui devint le palais des

1. De ces deux édifices, l'un est aujourd'hui le palais des Affaires Étrangères; l'autre, qui renfermait la Cour des Comptes et le Conseil d'État. a étó beendié par la Commune en 1871. 
Archives nationales. Le mème architecte dota Parıs, en 180\%, du théatre des Vuriétés, où reparait, dans des proportions plus modestes, la colonnade. Il éleva le théatre dt Dijon. PEYRE, en 1800, avait construit le théatre de la Gaieté.

Les seulpteurs français. - Le retour à la statuaire classique, inauguré sous Louis XVI par Roland, s’accentua naturellement à la période suivante. RoLANd fit, en 1793, un "Peuple terrassant le Fédéralisme". michalıon fut son émule dans le sujet de "Caton d'Utique ": les statues colossales qu'il éleva en plàtre pour les fẻtes de la Convention ne leur ont pas survécu. mortre sculpta, en 1789, "la Patrie couronnant les vertus civiques"; en 1798, "la France appelant ses enfants à sa défense "; puis les statues ou les bustes de Bonaparte et de ses généraux, les basreliefs de la colonne de Boulogne. Giraud traita le sujet d'Achille mourant (à Aix), du liaigneur endormi, du Soldat laboureur : nembre de l'Académie depuis 1789, possesseur d'une immense fortune, il voyagea en Italie, visitant des musées et 'aisant exécuter de nombreux moulages. Napoléon a été souvent modelé, notamment par Ramey, Bosio, Espercieux, Cartellier. Les chefs-d ceuvre de cartellier, ce sont le groupe de la Vigilance et de la Guerre, la statue de la Pudeur, celle de la Gloire, la Capitulation d'Ulm, qui est un des bas-reliefs du Carrousel. Pour le même arc de triomphe, ESPERCIEUx exécuta le bas-reliel des Clefs d'Ulm; pour le Corps législatif, la Victoire d'Austerlitz. Jacques Dumont fit la statue de la Liberté en 1796, le général Marceau en 1804, la Clémence et la Valeur, en 1808, pour l'arc du Carrousel. chaddet fit le Napoléon législateur de la colonne, et le fronton du Corps législatif. Bosio entoura la colonne de ces vingt bas-reliefs qui l'assiegent de leurs batailles d'airain. Parmi ses chefs-d weuvre, citons "l'Amour lançant des traits ", et surtout "l'Amour séduisant l'Innocence ". Statuaire de Napoléon et de sa famille, il le fut ensuite de la famille royale après le retour des Bourbons. DUPATY, qui était parti comme volontaire en 1790 et qui fut membre de l'Institut en 180I, s'est signalé surtout par son "Ajax poursuivi par la colère de Neptune ". Lemot sculpta, en 1808, un fronton du Louvre qui a été détruit depuis, plaça sur le Carrousel le char triomphal attelé des chevaux de 
Venise, en attendant que la Restauration lui donnàt à exécuter Henri IV sur le Pont-Neuf et Louis XIV à Lyon.

Les grands senlpteurs étrangers. - Il ne faut pas oublier linfluence qu'exercèrent sur notre école française l'ltalien Canova et le Danois Thorwaldsen, plus célèbres alors qu'aucun des sculpteurs français de ce temps, et combien leur existence fut mêlée à notre histoire.

canova, qui passa sa vie à Rome, dans d'immenses ateliers, entouré de nombreux élèves, assailli par des commandes venues de l'Europe entière, a laissé des chefsd'œuvre d'élégance et de grâce toutes classiques : "l'Amour et Psyché ", "Thésée vainqueur du Minotaure ", "Madeleine pénitente ». Il sculpta Napoléon et représenta deux de ses sœurs: Pauline Borghèse en Vénus victorieuse, et Elisa Bacciochi en Polymnie. C'est lui qui fut chargé, en 1815, de reprendre dans nos musées les chefs-d œuvre qu'y avaient accumulés nos victoires. THORWALDSEN, dont l'ceuvre capitale est peut-ètre "l'Entrée d'Alexandre à Babylone ", a exécuté les statues ou les bustes d'un grand nombre de personnages illustres ae la France et de l'Europe, notamment de Poniatowski.

Caractères de la seulpture. - Le goùt étant au classique, Canova, Thorwaldsen, mème les sculpteurs français, lorsqüils avaient à représenter, par exemple, un général d'artillerie, n’hésitaient pas à le déshabiller en Romain, jambes nues, casque en tète et le glaive court au còté.

En somme, la révolution elassique de la sculpture avait été faite à la période précédente; la révolution romantique ne fera ıue l'effleurer même à la période suivante. Ce qui domine dans la statuaire de l'époque impériale, c'est la science du dessin, une vigueur tempérée, une correction un peu froide.

\section{La peinture, les arts du dessin.}

Filiation de nos écoles de peinture. - L'ancien régime avait légué à la période révolutionnaire et impériale tout un groupe de grands peintres ${ }^{1}$ : David, Regnault, fètes galantes, et mème de la peinture de genre, que les tab!eaux de Watteau, 
Lethière, Prud'hon, Carle Vernet. Regnault fut, pour la nouvelle génération, le maître de Guérin et de Géricault. David fut le maitre de Gros, d'Isabey l'ancien, de Gérard, de Girodet, des ateliers desquels devait sortir clus tard une troisième génération, celle où dominèrent les romantiques. Il fut mème le maitre d'une quatrième génération : Ingres, Granet, Schnetz, Léopold Robert, David d'Angers.

\section{Première génération : David, Regnault, Lethière,} Prud'hon, Carle Veruet. - Louis david (1748-18?ö) exerça non seulement sur ses disciples, mais mème sur ses égaux en âge, une grande influence. L'école davidienne fut presque entièrement maitresse pendant vingt-cinq années. David eut, dans cette période, un rôle presque aussi considérable que celui qu'avait eu Le Brun sous Louis XIV. Son tempérament, qui fut autrement fougueux que sa peinture, le jeta dans toutes les luttes de la politique. Il šinspira d'abord des idées de 1789. Puis il fut un ardent montagnard, un fanatique partisan de Robespierre; il parla mème de "boire la ciguë arec le juste ", mais il le renia après Thermidor. Il fut ensuite le peintre attitré de Bonaparte, consul ou empereur. A la rentrée des Bourbons, il fut banni comme régicide et mourut en exil (1825). Pendant la Révolution et l'Empire, il fut l'ordonnateur de toutes les fêtes, organisa les cortèges de la Convention et les pompes du récrime impérial, dessina les costumes pseudo-classiques dont se décorèrent les élèves de l'École de Mars, les législateurs du Directoire, les courtisans de Napoléon.

Sa peinture est essentiellement classique; mais il ne faut pas entendre ce mot dans le sens étroit et injurieux qu'Y ont attaché ensuite les romantiques. David s'appliquait avant tout à la correction du dessin : quelque costume qu'il dùt ensuite donner à ses personnages, il les dessinait d'abord nus. Le reproche qu'on lui a fait d'ètre statuaire dans sa peinture it une part de vérité pour ses tableaux à sujets antiques, comme "Brutus après la mort

de Boucher, de Fragonard sont parlout relégues dans les greniers. Greuzo meurt dans l'obscuritè et la miséé, et son curps est jeté à la fosse commune (1805). On ne voulait plus que de la peiutute classigue, dramatique, bèroique. 
«e ses fils ", "les Amours de Pâris et d'Hélène " (1789), comme les Sabines, qu'on peut considérer comme le plus typique dans cette catégorie de ses tableaux, comme "Sapho et Phaon ", comme Léonidas aux Thermopyles (1814), comme "l'A mour et Psyché ", comme " la Colère d'Achille ", comme "Mars désarmè par Vénus". C'est vrai, également en partie, pour son "Bonaparte au mont Saint-Bernard", où le héros, escaladant les Alpes sur un cheval fougueux, a une attitude par trop théâtrale. Mlais, quand il traite les grandes scènes contemporaines, comme le Serment du Jeu de Paume (1790), le Couronnement de l'Empereur (1808), la Distribution des aigles, sa peinture a un caractère de sincérité et de réalité. Les romantiques euxmêmes auraient pu y admirer quelques-uns des mérites qu'ils revendiquaient exclusivement pour leur école: la modernité de la conception, la richesse des costumes et des draperies, le soin des accessoires. David n'est guère plus que Le Brun un coloriste, ou plutôt il l'est à sa manière; il se borne à appliquer sur son tableau la teinte qui convient; il ne songe pas à ces jeux de lumière, à ces effets de contraste que l'on obtient en associant curieusement les couleurs, en avivant leur éclat par les contrastes des tons, en cherchant même l'harmonie dans la discordance. Les critiques qu'on a pu adresser à une certaine école classique ne peuvent s'appliquer à David : cest un très grand peintre, un artiste de tempérament autant que de science, qui sinspire de la nature et non de receties d'atelier, fort au-dessus des mesquineries d'école. Son génie a plus d'un aspect : de la correction un peu raide de ses tableaux romains, de la pompe un peu théátrale de ses tableaux où figure l'Empereur, il faut rapprocher son portrait de Mme Récamier, si gracieux, et son portrait de Pie VII, si profond et si fin, où il semble être allé jusqu'à l'àme du pontife italien.

REGNAdLT (17\%4-1829), depuis eette toile de "l'Éducation d'Achille " qui avait fait sensation au Salon de 1783, n'a point produit d'œuvres de premier ordre. Il a plus de naturel et de facilité que David, mais il n'a pas cette ampleur de conception et le don des grandes compositions. Il a payé son tribut à la Révolution par deux tableaux : 
" l'Acceptation de la Constitution " (1789) et " la Liberté ou la Mort " (1793); à l'Empire, par une "Bataille de Marengo ", qui est à Versailles.

LETHière (1760-1832), un créole de la Guadeloupe, a le talent de la grande composition, mais peu de naturel. On posrrait le qualifier d'ultra-classique el d'ultra-davidien. En 1795 , il fit l'esquisse de "Virginius poignardant sa fille "; mais le tableau ne fut exposé qu'en 1831, en pleine révolution romantique. En 1801, il peignit, dans le mème style, "la Mort des fils de Brutus "; en 1806, "les Préliminaires de Léoben ${ }^{1}$ ".

PRUD'HON (1758-1823) échappa complètement à l'influence de Darid. Treizième fils d'un maçon de Cluny, privé d'abord de tout enseignement, dans ses essais d'adolescent, il réinventa pour ainsi dire la peinture à l'huile. Plus tard, il eut pour maitre un artiste dijonnais, Desvoge. Il avait une telle facilité de conception, qu'un jour, à diner, entendant citer un vers d'Horace, il quitta la table et, en un quart d'heure, fit l'esquisse de son fameux tableau : " Caïn ou la Justice et La Vengeance poursuivant le Crime ". Au salon de 1808, l'Empereur en fut si frappé, que, s'approchant de l'artiste, jusqu'alors ignoré, pauvre, délaissé, il lui remit la croix, puis le nomma professeur de dessin de Marie-Louise. Pourtant ce n'est ni dans cette toile, ni dans son "Christ en croix ", que se révèlent les qualités maitresses de Prud'hon: le naturel, la gràce, et quelque chose de profond qui rappelle Poussin. Ciest plutôt dans telle scène d'intérieur, comme la "Famille malheureuse "; c'est dans le portrait de sa fidèle amie, Mlle Mayer; c'est dans ses tableaux mythologiques, comme "Psyché enlevée par les Zéphyrs", "l'Innocence séduite par l'Amour ", "Vénus et Adonis ", "Zéphyre se balançant". C'est là qu'il fait ouvre de dessinateur impeccable, de coloriste savant et fin, d'artiste "gracieux comme le Corrège et tendre comme Le Sueur " (Charles Blanc).

CARLE Vernet (1738-1836), fils du célèbre paysagiste et

1. Sous la Restauration, il produisit, outre le tableau de Virginius mentionné plus haut, Philoctète à Lemnos, Homère chantant, le Jugement de Paris, une Messe dans les catacombes. 
père du célèbre peintre de batailles ${ }^{1}$, célèbre lui-mème depuis son "Triomphe de Paul-Émile" (1787), a été l'illus. trateur de l'épopée impériale par ses Batailles de Millesimo, de Mondovi, de Marengo, de Lodi, de Mantoue, de Rivoli, d'Austerlitz, de Wagram, le Passage du mont Saint-Bernard, le Bombardement de Madrid, la Revue du Carrousel, le Mameluk au combat, compositions savantes, dont la plupart décorent aujourd'hui notre musée de Versailles. Il a èté aussi un merveilleux caricaturiste dans ses "Incroyables et Merveilleuses" de 1797. C'est encore le peintre des courses et des chasses, car il connaissait le cheval et le chien comme personne.

Denxième génération : Isabey, Gërard, Gros, Girodet, Guérin. - J.-B. ISABEY, ou Isabey l'ancien (1767-185̋3), élève de David, ne procède de lui que par les côtés graeieux. Dans sa "Barque " de 1798, il y a un groupe de famille ravissant. Sa "Revue des Tuileries " (1801), "Bonaparte à Rouen ", "Bonaparte chez l'industriel Oberkampf", forment l'œuvre d'Isabey comme peintre d'histoire. C'est surtout comme portraitiste qu'il excella. Il fit le Premier consul à la Malmaison 2, Napoléon Empereur, l'impératrice Joséphine, le Roi de Rome, qu'il remit à Napoléon lors de son retour de l'ile d'Elbe. Il fut le peintre des jolies femmes, des merveilleuses de la République et des maréchales de l'Empire, de 1 mes Tallien, Récamier, d'Abrantès.

GĖRARD (1770-1837), autre élève de David, se recommande par un dessin correct, un coloris harmonieux, une grande vérité d'expression. Il peignit peu de batailles, sauf celle d'Austerlitz; mais des tableaux bibliques, chose assez rare à cette époque, comme "Joseph reconnu par ses frères " (1789), "Daniel défendant Suzanne " (1790); des tableaux mythologiques, comme "l'Amour et Psyché " (1796), qui est son chef-d'œuvre, et "Flore caressée par Zéphyre " (1802); des tableaux d'histoire classique, comme

1, 11 se croyait inféricur a son père et à son fils, et disait en mourant : - C'est sintrulier comme je ressemble au grand Dauphin, fils de roi, père de roi... et janais roi!"

2. Sous la liestauration, il fut nommé dessinateur du cabinet du roi : il peignit, en 1817, la Confërence de Vienne, et fit la décoration du sacre de Charles $x$. 
"Bélisaire " et "Marius rentrant dans Rome " (179ă); surtout dinnombrables portraits: toute la famille impériale, les maréchaux de l'Empire, les rois et reines de l'Europe. Nous avons de Gérard, au Louvre, une merveille, son "Portrait d'Isabey et de sa fille "(1796). La partie la plus brillante de sa carrière appartient peut-être à la période suivante ${ }^{1}$, quand, après l'exil de David, il se trouva en France le représentant le plus en vue de l'école davidienne. C'est alors, en attendant l'explosion du romantisme, qu'on put lui donner les surnoms de peintre des rois et de roi des peintres.

GRos (1771-1834) fut le plus original peut-être des davidiens. Laissons ses toiles de début et arrivons de suite à ses Batailles : Combat de Nazareth, Bataille d'Aboukir, Bataille d'Eylau, Reddition de Madrid, Bataille des Pyramides, Entrevue de Napoléon et de l'empereur d'Autriche après Austerlitz, esquisse de la Bataille de Wagram. Quand, au Salon de 1804, il exposa les Pestiférés de Jaffa, ce fut une émotion prodigieuse : les artistes et le public couvrirent de couronnes et de palmes la bordure du tableau. La couleur, cette couleur qu'ont adorée ies romantiques, y éclatait avec toutes ses séductions; le soleil éblouissant de l'Orient inondat certaines parties du tableau, en laissant des ombres tranchées. C'était un art nouveau qu'annonçaient ces nus d'une puissante anatomie, ce contraste des draperies asiatiques et des uniformes français, cette simplicité et cette dignitè d'attitude du général en chef au milieu des corps convulsés par l'agonie. La Bataille d'Aboukir fut un autre succès. Sous l'éclat des

1. La carrière de Gérard a été coupẻe en deux par la chute de l'Empereur, et, quoiqu'il n'ait plus été dans le mouvement à l'époque qui suivit, c'est ici le lieu de parler d'cuvres assurément aussi grandes que celles qui les on: précédées. En 1817, il peignit le magnifique tableau de l'Entrée de Henri IV a Paris, puis Louis XVIII dans son cabinet (1S23), Louis XIV teclarant ro d'Espagne son petit-fils (18\%4); le Sacre de Charles X (1829); après la révolulion de Juillet, Napoléon dans son cabinet aux Tuileries (1831), le duc d'Orleans acceptant la Constitution, l'Enrôlement des volontaives en 1792. Ces deux derniers tableaux sont de 1834, de mème que la Peste de Marseille. En 1832, il peignit quatre belles allégories pour les pendeatifs du Danthéon : la Mort, la Patrie, la Justice, la Gloire. N'oublions pas 'deux toiles mythologiques, Daphnis et Chloe (1823), Hylas et la Nymphe (1826). ot un tableau romain, Brutus après la mort de Lucrèce (1834). 
couleurs, sous l'opulence des draperies, il y avait une vérité si frappante de dessin que l'ambassadeur turc s'écria :

:Quand tous ces personnages seraient nus, on reconnaitrait facilement, ici des Turcs, là des Albanais, là des Français. " La Bataille d'Eylau étonna surtout par la tristesse de son ciel bas et gris, ses plaines de neige semées de cadavres ou zébrées de colonnes en marche, ses blessés aux chairs verdàtres, la richesse des fourrures contrastant avec l'usure des vètements fatigués par une longue campagne, enfin l'expression mélancolique du conquérant, assombri lui-même d'une telle boucherie. Gros est le précurseur des romantiques dans l'orientulisme. Un des premiers, il sut dessiner des mosquées et non des temples, des cimeterres et non des glaives, des chevaux arabes et non des coursiers du Parthénon. Ce sont déjà les "Orientales " de Victor Hugo traduites en peinture; ce sont déjả les "Massacres de Scio " d'Eugène Delacroix et la "Smala " d'Hlorace Vernet. Gros est aussi le précurseur des romantiques par sa façon de traiter les sujets tirés de nos siècles à maillots de soie et à manteaux de velours : c'est déjà un tableau à la Delaroche que "François Ier et Charles-Quint visitant les tombeaux de Saint-Denis" (1812). Gros est un moderne et mème un moderniste. Charles Blanc a dit de lui : "Le premier, il osa remplir ses tableaux d'uniformes, de gibernes, de chapeaux à plumes, d’épaulettes, de sabres et d'épées; mais ces objets prirent sous son pinceau je ne sais quelle tournure... Il a su les retrousser, les agiter, les tourmenter au besoin, pour leur faire jouer un ròle optique et jeter ainsi de la variété jusque dans l'uniformité de l'uniforme. " - Et, le comparant à Horace Vernet, le critique ajoute: "Laissez à Vernet les eugagements d'avant-postes, les combats de tirailleurs, la reconnaissance, l'escarmouche, la bataille familière et bien française; mais a lui, Gros, la bataille héroïque, celle où se donnent les grands coups, celle où les peuples se rencontrent sous l'œil des conquérants, où se décide le destin des empires et le sort des idées puissantes que la marche des armées répand dans le monde! Chez Vernet, on se bat en riant et avec esprit, comme au siège de Lérida ou à Fontenoy, et il me semble que les bons mots du soldat volent avec la mitraille. Chez 
Gros, la bataille en impose; elle a des proportions homériques; ses héros sont, à leur manière, aussi beaux que les guerriers de l'lliade ou les cavaliers d'Ossian. La bataille d'Horace est un bulletin; celle de Gros est une épopée ${ }^{1 . " ~}$ GIRODET (1767-182'), élève de David, un des plus soumis à son influence et qui arait cependant l'illusion de ne lui ressembler en rien, dut sa première notoriété à “ l'Assassinat de Tatius ", qui est de 1788. Il a donné successivement a Joseph reconnu par ses frères" (1789), "le Sommeil d'Endymion (1792), "Antiochus et Stratonice ", "Hippocrate refusant les présents d'Artaxercès " 11793), "Danaé " (1798), une "Scène du déluge ". ll sortit un instant des sujets bibliques et classiques pour traduire une page de Chateaubriand dans ses "Funérailles d'Atala " (1808), et raconter deux épisodes de l'épopée napoléonienne dans "Napoléon recevant les clefs de Vienne " (1808) et " la Rérolte du Caire " (1810). Dans ce dernier tableau, il règne une opulence de draperies et une vivacité de mouvement qui rappellent les tableaux de Gros ${ }^{2}$.

Pierre Guغ́rin (177t-1833), élève de Regnault, est le type le plus caractérisé de l'école classique. Il en a la correction et la pureté de dessin, avec un coloris faible, une grande froideur, une pauvreté extrême dans la décoration et les accessoires. Ses sujets sont presque exclusivement antiques : "le Corps de Brutus rapporté à Rome " (1797);

1. Gros a donné le beau Portrait du gènéral Lassalle (1812). La mèmo annèe, il commença les peintures de la coupole du Panthéon, achevées seulement en 1824, œuvre colossale, représentant les fondateurs de nos qualre dynastics, mais où la fortune a donné à Louis XVllt la place réservée d'abord a Napoléon. Pour ia Restauration, il a peint la Sortie du roi des Tuileries au 20 mars 1815 et l'Embarquement de la duchesse d'Angoulême. Au salon de 1S22, il eut Saül et David, d'une opposilion si saisissante d'ombre et de couleur et d'une inspiration si tragique. Puis son gćnie parut décliner avec le Portrait de Charles X. En 1835, it peignit Hercule et Diomede, dont le sujet est classique, mais dont l'exéculion esi ultra-romantique par la fougue sauvage de l'action et la vigueur de la musculature: seulement la couleur on est détestable. Gros fut assailli de critiques passionnées et s'en déses. péra : avec une énergie incroyable dans le suicide, il alla se noyer dans un étang, sous quatre pieds d'eau!

2. A la période suivante, Girodet revint à la mythologie et à l'allégorie avec Pygmalion et Giluthie(1819), qui est au Louvre, avec l'Hymen et la Fécondite, la Force, l'Eloquence, tous destiucs à décorer le chateau do Compierne. 
* Caton d'Utique "; " Marcus Sextus " (1799), histoire d'un banni romain, à laquelle les émiglés ou parents d'émigrés firent un grand succès; "Offrande à Esculape "; "Phèdre accusant Hippolyte devant Thésée " (1802); "Aurore soulevant Céphale"; "Andromaque implorant Pyrrhus " (1810); "Didon et Énée ". Il ne sortit de ses sujets ordinaires que pour peindre "Bonaparte pardonnant aux révoltés du Caire" ".

Il faut signaler dans oette période les débuts de GRANET (1775̆-1849) el de GÉricadlt (1791-1824), qui donna ses deux belles figures du "Chasseur de la Garde impériale " (1812) et du "Cuirassier blessé " (1814) ${ }^{2}$.

INGRES (1780-1867) se révélait déjà par ses portraits du Premier consul et de l'Empereur, par ses tableaux "d'OEdipe et le Sphinx " (1808), "Raphaël et la Fornarina ", la "Chapelle Sixtine ", "Virgile lisant l'Énéide ", "Françoise de Rimini ", "Roger délivrant Angélique ${ }^{3}$ ".

On voit que la peinture de l’époque révolutionnaire et impériale eut un tout autre éclat que la statuaire.

La gravure. - Il y a peu de chose à dire de la gravure à cette époque. Le plus célèbre des graveurs de la Révolution fut DEBucourt, qui, au moyen de tirages superposés, sul obtenir des eflets qui ressemblaient à ceux du coloris, et Sergent-Marcead. Par sa nature mème, la gravure devait être, plus que la peinture, soumise à certaines influences de l'école de David. Elle ne produisit d'abord que des ceuvres froides et compassées. Puis elle se régénéra par l'étude des maitres graveurs italiens du $\mathrm{xv}^{\boldsymbol{\theta}}$ siècle. Alors parurent les belles estampes de DESNOYers (1779-1857), qui grava les premières ceuvres d'Ingres et celles des maîtres italiens;

1. Sa Clytemnestre poussé par Égisthe au meurtre d'Agamemnon est le 1817; mais sa période d'activité est comprise presque tout entière dass la période révolutionnaire et impériale.

2. Au retour des Bourbons, móns par vocation militaire que par vocation artistique, par goút des chevaux et des costumes étincelants, il entra dans les mousquetaires, dont l'uniforme rouge et or séduisait son cil de peintre.

3. Ingres eut des commencements trés durs. "Granet a'a conté, nous dit M. Jean Gigoux, une visite qu'il lui ft a Florence. M. Ingres, lui ourrant ia porte lui-mème, ètendit le bras pour l'empècher d'entrer : " Oh: n'entre pas ici, tu trouverais la misère. "Sa première femme l'aidait à vivre du produit de son aiguille. Lui-mème faisait par-ci par-là quelques petits portraits au rrayou. dans des occasions, du resle, assez rares. 
de Bervic, si habile que, d'un tableau médiocre de Callet, le portrait en pied de Louis XVI, il fit une gravure excellente; de TARDIEU, dont la facilité apparente cachait un savoir profond et une patience laborieuse. Le grand peintre PRUD'HON fut aussi un graveur sur cuivre. Il eut pour élèves Louis copIa et Barthélemy ROGER.

\section{La musique.}

Les compositeurs de la génération précédente. Grétry, Devienne, Dezède, Deshayes, Dalayrac, terminaient leur carrière et continuaient, dans l'opéra-comique, les traditions de notre théàtre du xvile siècle, régénéré sous linfluence des Italiens et sous celle de Mozart.

Le génie de GRÉTRY avait donné tout ce qu'il pouvait dans "Richard Cœur de Lion" (1785). Quand Glück, Méhul, Cherubini introduisirent chez nous une harmonie plus savante et une instrumentation plus puissante, Grétry essaya de se hausser à la musique nouvelle. Dans "Pierre le Grand ", "Lisbeth ", "Guillaume Tell ", "Elisca ", il perdit quelques-uns de ses mérites sans acquérir ceux de ses rivaux. Ce compositeur, dont les royalistes avaient pris pour chant de ralliement les airs de "Richard Cœur de Lion ", écrivit des pièces patriotiques : "la Rosière républicaine " (1793). "Callias ", "Denys le Tyran " (1794), "Joseph Barra ", et l'Hymne pour la plantation des arbres de liberté. Il avait collaboré, en 1793, à la musique du " Congrès des Rois ", avec Dalayrac, Méhul, Cherubini, Deshayes, Devienne, etc.

DEVIENNE, qui est mort fou en 1809, a vait écrit la musique des "Visitandines" (1792) et "les Comédiens ambulants" (1798).

DEZĖDE était mort en 1792. DESHAYES donna un " Mariage patriotique (1793). DALAYRAC fit exécuter, en 1789, "Raoul sire de Créqui et Fanchette "; puis "la Soirée orageuse ", "Vert-Vert ", "Philippe et Georgette ", "Camille ou le Souterrain ", "Roméo et Juliette ", " Gulnare " (1798), où il y a une jolie romance, "Léon ou le Chàteau de Monteaero " (1799), bref, une vingtaine d'opéras comiques. Ш 
paya son tribut à la Révolution par " le Chène patriotique ou la Matinée du 14 juillet" (1790) et par l' "Hymne à la Liberté " (1792), paroles de Gyrey-Dupré ${ }^{1}$.

Cet hymne, d'après le titre gravé sur l'édition originale, avait été chanté " avant le 10 aout 1792 par les patriotes qui conspiraient pour la République pendant que le comité autrichien conspirait aux Tuileries pour le despotisme". L'air en avait été emprunté par Dalayrac à son opéra de "Renaud d'Ast" (1787) : aussi, en dépit des paroles, n'a-t-il pas un caractère très militaire.

Dalayrac traita en opéra le même sujet que Gossec : "la Reprise de Toulon ". Républicain peu farouche, il reçut de Napoléon la croix de Légion d'honneur. Sous l'Empire, quoique la science de la composition, sous l'influence italienne, eût fait de grands progrès, il eut encore de belles journées: "Maison à vendre " (1800), " liulistan ou la Halle de Samarcande " (180כ), opéra tiré des Mille et une Nuits, "Lina ou le Mystère " (180\%), "Koulouf ou les Chinois ", "le Poète et le Musicien ", sa dernière pièce, dont le labeur hâta sa mort (1809).

Les compositeurs de la génération révolntionnaire. Une uouvelle transformation allait s'opérer dans l'art, et amener en vue des hommes nouveaux. La musique subit l'empreinte de la Révolution aussi bien que les arts plastiques. D'abord celle-ci lui permit de créer un genre inconnu : les chants nationaux et patriotiques. Puis, en décrétant la liberté des théàtres, elle ouvrit la carrière à des talents ignorés et permit de créer des formes inédites de l'art. Enfin, elle contribua à imprimer à la musique des hymnes et des opéras un caractère plus classique, plus fier, des accents plus énergiques et plus máles : elle développa la grande déclamation lyrique.

1. Cet hymne commence par ces vers :

Veillons au salut de l'empire

Veillons au maintien de nos droits;

Si le despotisme conspire,

Conspirons la perte des rois.

Liberté! Liberté! Que tout mortel te rende hommago!

Plutót la mort que l'esclavage,

C'est la devise des Français. 
Parmi les compositeurs éminents de l’époque révolutionnaire et impériale, citons d'abord deux Français de l'ancienne France : Mغ̇нol, de Givet (1763-1817), et LESUeuR (1763-1837), des environs d'Abbeville. cEerubini (1760-1842), né à Florence, avait déjà eu des succès en ltalie, quand, à la veille de la Révolution, il vint s'établir à Paris. Sans perdre ses qualités natives, il francisa à tel point son génie, qu'on doit le regarder comme un des nôtres. Très en faveur sous la République, il déplut à Napoléon, qui ne goùtait point sa musique. Il n'eut la Légion d'honneur qu'en 1815, des mains de Louis XVIII. cossec (1733-1829) était Belge, mais sa vie se passa en France, et son génie est également tout français.

Les chants patriotiques. - Tout le monde connait " la Marseillaise " de ROJGET DE L'ISLE, dont le couplet a un tel accent tragique et le refrain un si grand élan.

Peu de personnes ont entendu le "Chant du Départ", musique de ме́нus, paroles de Joseph Chénier, ou du moins l'ont entendu exécuter comme il doit l'ètre, avec ses chœurs de guerriers, de vieillards, de femmes, d'enfants, d'une mélopée si imposante, mais qui n'aurait pu remplacer sur les champs de bataille Pardente Marseillaise de Rouget. Moins connus encore sont d'autres morceaux de Méhul : "Hymne à la Raisan ", paroles de Salverte, "Chant des Victoires ", paroles de Chénier, et d'autres curres qui parurent après la chute de Robespierre, telles que "Hymne sur la mort de Férand ", "Hymne des vingt-deux Girondins ", "Chant du Retour ", "Chant pour l'anniversaire du 9 thermidor".

gossec a écrit le "Chant du 14 Juillet " et le "Chant patriotique pour l'inauguration des bustes de Marat et Leprlletier $"$.

cherubini a composé l" "Hymne funèbre pour la mort de Hoche" (1797), ponctué par le glas des cloches et le grondement lointain du canon, d'un grand caractère tragique.

LESUeur a donné également plusieurs hymnes, entre autres l' "Hymne sur le 9 thermidor ", qui fut chanté à la Convention nationale en 179 ว.

L'opéra. - Les grands opéras de MéHul souffrirent un peu de la vie agitée du théàlre à cette époque. Ce qui 
nuisit aussi à leur succès, c'est que les liv'ets qu'Hoffman ou Alexandre Duval fournirent à l'auteur manquaient d'intérèt. "Alonzo et Cora " (1791) réussit peu. "Stratonice " (1792) présente de magnifiques morceaux. "Le Jeune Henri " (1797) fut déchiré, à la première et unique représentation, par les applaudissements des royalistes et les sifflets des républicains, non que la musique les passionnât à ce point, mais parce qu'il s'agissait de la jeunesse de Heuri IV. L'ouverture de cet opéra est encore très admirée. Puis viurent "Horatius Coclès " et "Adrien ", pièce à grand spectacle, où cet empereur recevait à Antioche les honneurs du triomphe : malheureusement, le public crut reconnaitre, attelés au char du César, des chevaux qui avaient appartenu à Marie-Antoinette et se mit ḋ siffler. Le peintre David déclara qu'il mettrait le feu à l'Opiéra plutôt que d'y voir triompher des tyrans. Sous les régimes suivants, mais pour dautres motifs, la piece fut plusieurs fois interdite. Méhul fit une ouverture et des choeurs pour le "Timoléon " de Clıénier : c’était la première fois, depuis les pièces sacrées de Racine, qu'on voyait la tragédic classique admettre des parties musicales. Le grand succès de Méhul, ce fut Joseph (1807), pièce biblique, qui a été reprise en 1831 et qui a été souvent jouée depuis. La musique de ce maitre a de la grandeur el de la puissance: symphoniste de génie, il comprit l'importance du coloris instrumental et sut donner ḋ la partition de chacune de ses pieces une sorte de couleur locale. On a dit de lui qu'il excellait á " peindre en musique".

cherubin avait débuté, chez nous, par un opéra emprunté au "Démophon " de Marmontel (178S) : la froideur du livret compromit le succès de la musique, qui présente ccpendant de beaux morceaux d'ensemble. Puis vinrent "Lodoïska ", demi-opéra ou comédie héroique, représenté en 1791 à la salle Feydeau; "Médée " (1797), à laquelle certains critiques reprochèrent des imitations de Héhul, mais dont Méhul lui-mème proclama hautement l'originalité; le ballet d" "Achille à Scyros " (1804), où il y a une bacchanale ravissante, mais auquel les spectateurs de l’époque ne pardonnèrent pas d'avoir osé présenter le héros travesti en femme; "Faniska ", qui fut représenté à Vienne en 1805̆, 
et qus excita l'admiration de Haydn et de Beethoven; "Pygmalion ", opéra en italien, qui fut exécuté sur le théâtre des Tuileries; "les Abencérages " (1811), dont on a retenu l'air d'Almanzor '.

Napoléon ayant euscité à Cherubini des difticultés pour le théâtre, celui-ci s'était consacré à la musique religieuse : sa Messe du Sacre, le Kyrie et le Credo de sa Messe en fa comptent parmi ses chefs-d'ceuvre.

La musique de Cherubini se recommande par le charme et la suavité quill tenait de l'école napolitaine, en mème temps par des qualités de foree et de vigueur qu'il emprunta à l'école française, par la richesse de l'instrumentation, la science des effets harmoniques, l'ampleur de ses morceaux d'ensemble, la pureté et la correction du style.

FRANÇOIS LESUEUR (1773-1830), musicien savant, qui avait étudié le système des Grecs, réussit peu au théâtre, beaucoup par la faute du public, car Lesueur fut un novateur, un précurseur du rérolutionnaire Berlioz. Le médiocre suceès de sa "Mort d'Adam ", dont Beethoven disait pourtant: "Elle semble guérir tous mes maux ", le fit revenir à la musique religieuse. C'est lui qui composa la Messe du sacre impérial. On cite encore de lui deux opéras: "les Bardes", et "Alexandre à Babylone ", resté inédit, mais dont on joue encore des fragments.

CATEL fut aussi un musicien savant, auteur d'un "Traité d'harmonie", qui voulut innover dans la théorie des accords, mais qui paya de la chute de son grand opéra, "Sémiramis" (1802), l'honneur d'avoir voulu devancer la révolution musicale.

Copéra comique. - Le début de mémul avait été " Euphrosyne et Corradin ou le Tyran corrigé " (1790), qui produisit une impression prodigieuse sur les contemporains. Grétry se fait l'écho de l'émotion qui s"empala d'eux quand il écrit que "le duo d'Euphrosyne est peut-ètre le

1. La liste des operas de Cherubini se termine avec l'Empire : cependant, sous la Restauration, il collabora, en 1814, à Bayard a Mezières, et, en 1S21, à Blanche de Provence ou la Cour des Fées, opéra composé par Berton. Boleldieu, Cherubini, etc., a l'occasion du baptème du duc de Bordeaux. Il écrivit aussi la Messe de Requiem pour lanniversaire de la mort do Louis XV1 et la .Hesse du sacre de Charles X. 
plus beau morceau d'effet qui existe " et qu'il ajoute: " Je n'excepte mème pas les plus beaux morceaux de Glück... Ce duo vous agite pendant toute sa durée. L'explosion, qui est à la fin, semble ouvrir le crâne des spectateurs arec la voûte de la salle. "L'Irato ou "l'Emporté " de Méhul est une bouffonnerie musicale qu'il s'amusa à publier sous un pseudonyme italien. De 1802 à 1806, il composa encore "Une folie ", "le Trésor supposé ", " loanna ", "l Heureux malgré lui ", "les Aveugles de Tolède ", avec des airs espagnols.

CherdBin donna "Élisa ou le mont Saint-Bernard " ( $179 k$, où l'on remarque une imitation des cloches et le Chœur des religieux portant secours aux égarés, qui est encore exécuté aujourdhui par la Société des concerts du Conservatoire; "l'Hòtellerie portugaise" (1798), où il y a un trio qui est un chef-d'œurre; "les Deux Journées " (1800), où il faut signaler l'air du Petit Savoyard, le Chœur des Soldats, la Marche du deuxième acte; enfin "Anacréon ou l'Amour fugitif " (1803), dont l'insignifiance du livret compromit le succès musical ${ }^{1}$.

LESUEUR a composé " la Caverne " (1793), dont un ehœur est resté classique; "Paul et Virginie " (179'ł), où l'on admire un hymne au Soleil; "Télémaque " (17:6), dont il faut citer le Chœur des nymphes et le duo de Télémaque et d'Eucharis, dans lequel intervient Calypso trahie et furieuse. Ces trois pièces sont plutỏt des drames lyriques que des opéras-comiques.

Enfin il faut au moins eiter les noms de JADIN, soliÉ, ténor très applaudi el compositeur fécond; GaveadX. autre ténor, mort fou en 1825, dont "le Bouffe et le Tailleur" (180') et "Monsieur Deschalumeaux" (1806) ont été repris; CATEL. qui écrivit "les Artistes par occasion ", "l'Auberge de Bagnères " (1807), "la Bayadère " (1817) et "Wallace ", où il devança Boieldieu en nous faisant entendre des airs écossais; RREUTZER, violoniste, auteur de "Lodoïska » (1791); BERToN, dont le caquetage des nonnes dans "les Rigueurs d" clnitre " (1790) a été imité dans " le Domino noir ", et

1. A soixante-treize ans. en 1833, Cherubini composa encore, sur un live de Scribe et Mélesville, Ali-Baba ou les Quarante Voleurs. 
dont "Aline, reine de Golconde " (1803) a été reprise avec succès en 1847; DELla maria (1768-1800), né à Marseille d'une famille italienne, auteur du "Prisonnier ou la Ressemblance" (1798), dont on chante encore la romance: "Il faut des époux assortis"; DJgAzon, qui fit avec PRADHer " le Chevalier d'industrie "; Nicolo ISOUARD, d'origine maltaise, qui écrivit la musique des "Rendez-vous bourgeois" (1807), si suuvent replésentés de nos jours, de "Cendrillon " (1810), de "Joconde ", de "Jeannot et Colin " (1814). Mentionnons les débuts de Boreldieo avec "Zoraïme et Zulnare " (1798), "Beniowski " (1800), "le Calife de Bagdad", "Ma tante Aurore "; avec plusieurs pièces composées pendant son séjour en Russie (1803-1810), par exemple les "Voitures versées " (1807); avec "Jean de Paris" (1812) et le "Nouveau seigneur du village " (1813).

L'éducation musicale du peuple français n'était pas encore faite à cette époque. Bien que, dans les représentations gratuites de la Révolution, on eût joué devant lui les chefs-d'ocuvre des diverses écoles et qu'il eût pu former son goût par la comparaison, il pensait comme Mme de Motteville $\mathrm{au} \mathrm{xv}_{1}{ }^{\mathrm{e}}$ siècle: le moindre pont-neuf, la moindre mèlodie populaire, faisait bien mieux son affaire. De là le succès des romances sentimentales, d’une musique simple, rudimentaire, banale. Grétry lui-même crut devoir se soumettre à ces exigences du public : dans son "Guillaume Tell ", il introduisit une ronde.

Infuenee des Allemands et des Italiens sur la musique française. - Les cuvres de mozArt commençaient à ètre connues chez nous: on joua en 1807 "les Noces de Figaro", et, en 1811, "Don Juan ".

En 1793, on avait exécuté à Paris la "Création" de HAYDN,

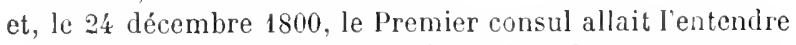
à l'Opéra quand éclata la Machine infernale.

WEIGl, un Allemand de l'ècole de Salieri, nous donna, en 1812, à la prière de Marie-Louise, "la Vallée suisse ".

REIcHa, né à Prague (Bohème), mais dont l'éducation mu. sicale fut surtout allemande, auteur de savants traitis sur la mélodie et la composition musicale, d'opéras, de quintettes, s'était fixé à Paris en 1809 et devint ensuite professeur au Conservatoire. 
L'intluence principale appartient aux Italiens, dont l'histoire, gràce à nos fréquentes interventions dans la péninsule, gràce à la fondation de républiques par le Directoire et de royaumes à dynasties françaises par Napoléon, a été alors si étroitement inêlée à la nôtre. Le goût personnel de Napoléon, homme de race italienne, contribuait à propager cette influence.

paisielio, dont Bonaparte, en 1797, a l'armée d'Italie, fit jouer "l'Hymne funèbre en l'honneur de Hoche ", de préférence à l'hymne de Cherubini, fut, après la proclamation de la république parthénopéenne, nommé directeur de la musique nationale à Naples. Il fut appelé à Paris en 1802 par le Premier consul. On lui donna un appartement richement meublé, un carrosse de la cour, 12000 francs d'appointements, 18000 francs d'indemnités de voyage et de séjour, le titre de directeur de la chapelle des Tuileries. Il avait collaboré, en 1801, à un hymne " à la Paix ", et composé l'opéra de "Proserpine ". Joseph Bonaparte, nommé roi de Naples par Napoléon, y fit revenir Paisiello. Nurat, successeur de Joseph, maintint au vieux maitre tous ses emplois. L'Empereur lui conserva sa faveur et lui accorda 4000 livres de gratification pour un morceau composé à l'occasion de son mariage.

zINGARELli, autre Napolitain, se montra d'abord plus rebelle aux séductions napoléniennes. A l'occasion de la naissance du roi de Rome (1811), l'Empereur lui demanda un Te Deum. Zingarelli, qui avait sur le cœur la captivité de Pie VIl, refusa. On le traita comme un pape : le préfet de Rome le fit enlever et conduire à Paris. Là, il fut si bien traité qu'il s'humanisa un peu et consentit à composer une Hesse pour la chapelle des Tuileries.

viotri, violoniste piémontais, donna des concerts en 1803 à Paris; en 1819, nous le retrouvons directeur de l'Opéra.

Paer, de Parme, fut rencontré à Dresde (Saxe) par Napoléon (1806), qui fut charmé de l'audition de son "Achille». L'Empereur l'emmena avec lui à Posen et à Varsovie, le ramena à Paris, le nomma directeur de sa musique particulière, maitre de chant de l'impératrice MarieLouise, directeur de l'opéra-Bouffe, puis directeur de l'Opéra-Italien. Il jouit ensuite de la même laveur auprès des Bourbons. It composa chez nous plusieurs opéras. 
Spontini, de la M 1 arche d'Ancône, le célèbre auteur de " la Vestale ", fit jouer à Paris, en 1804, "Julie ou le Pot de fleurs ", " la Petite Maison ", "Milton ". Napoléon le nomma directeur de la musique de l'impératrice Joséphine. La représentation de "la Vestale " aux Tuileries (1811) lui valut les compliments de l'Empereur. Quand on entreprit de la jouer à l'Opéra, les mèmes cabales, les mèmes luttes qui avaient signalé autrefois la guerre des Bouffons ou la guerre des Coins, se reproduisirent: le succès n'en fut pas moins éclatant. Deax ans après, il donna “Fernand Cortez ". L'Empereur, en faisant représenter cet opéra, poursuivait un but politique : flétrir le fanatisme des Espagnols. Au contraire, les applaudissements des loges éclatèrent précisément parce qu'on était sympathique à ce peuple, alors armé pour son indépendance. En 1810, Napoléon, qui avait déjà fait décerner à Spontini un de ses prix décennaux, le nomma directeur de l'Opéra-Comique. Le maëstro venait de contracter un mariage français en épousant la fille d'Érard, le célèbre facteur de pianos ${ }^{*}$.

En 180', salieri, qui avait fait en 1787 la musique du “Tarare o de Beaumarchais, fut directeur de la chapelle impériale et composa chez nous plusieurs opéras.

Si nous occupions militairement l'Italie, on roit que les Italiens prenaient une sorte de revanche artistique sur les scènes françaises.

Ouvrages a coseutter. - L. Courajod, Alexandre Lenoir et le musée des monuments francais 18\%. Le comte Delaborde, LAcadémie des Beaux-Arts dep. la fond. de l'Institut de Fr. 1891). - E. Despois. Le Tandalisme révalution. (1868. - J. Renouvier, Hist. de lart pend. la Rév., considére principal.dans les estampes (1563) - Fr. Benoit. L'art fr. sous la Rev. et l Emp. (1897) - T. C. Bruun Neercaard, Sur la situation des beaux-arts en France, Lettres d'un Danois Paris, an I.X). - Guizot, Le Salon de 1810. - S. J. Delecluze, Louis David, son école pt son temps (1855 . - J.L. David (1880), Ch. Saunier 1904). L. Rnsenthal (1904), David. - E. Chesneau, Les chefs d'école 1953. - Cb. Clémenl, Prudhon 1880. - Tripier le Franc,

Hist. du baron Gros (1550). - Ch. Clément. Géricault (1868.- Adam, L'cuxre du baron Gèrard (1852-57). - Quatremére de Quincy, Canova (1831). - André Michel. La peinture frunc. de David a Delacrois: (1890). A. de Montaiglon et G. Duplessis, A. Houdon Rerue universelle des Arts. 1. 1\% - P. Marmottan, LEcole franc. de peintuse ( $1789-1830$ (1856).

11. Lawoir, La Musique frunc.Pierre Constant). Sarrette et les origines du Conservatoire; les Hymres et Chansons de la Rér. (1905).Tiersol. Rouget de l'Isle (1892). A. Coipuard. La musique en Fr. depuis Rousseun 1891).-Pougin, Méhul 1893) et Boieldieu 1875). - M. Brenet 158i, 11. de Curzon 19us Gretry. - Soubies et Malherbe, Preicis hist. de l'Opera-Comique 1857

1. Avec cette insouciance de la fidélité politique qui se rencontre si souvent cbez les artistes, il composa, pour la :entrée des Bourbons (Arril 1814). - Pélare, ou le Roi et la Paix". 


\title{
CIIAPITRE XII
}

\author{
LES SCIENCES
}

Services rendus par la science à la défense nationale. - La France, menacée en 1793 par une formidable coalition, bloquée à la fois sur tous ses rivages par les flottes britanniques et sur toutes ses frontières par les armées européennes, privée de toute communication avec le reste du monde civilisé, dut en grande partie son salut à ses savants.

Le télégraphe aérien. - Nos pères de la Révolution tressaillirent d'ètonnement et de joie quand les deux frères Chappe, en 1793, réalisèrent le télégraphe aérien. De distance en distance, sur une ligne de hauteurs, on élevait des tours: surces tours on établissait un appareil composé de pièces mohiles : chaque mouvement, chaque combinaison de ces pièces formait un signe, qui était répété successivement par tous les appareils de la ligne. Le

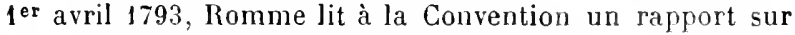
"ce moyen ingénieux d'écrire en l'air ". L'Assemblée ordonne l'établissement d'une ligne allant de Paris à la frontière du nord. Le 11 avril, Barère annonce dans un nouveau rapport que "les communications se font avec la rapidité de l'éclair et que les ordres du Comité de Salut public arrivent mème à travers une armée assiégeante ". Le $1^{\text {er }}$ septembre 1794 , les bras de tous les appareils formant la ligne du nord sont en mouvement; ils transmettent à Paris un grand succès des armées francaises: " La ville de Condé est restiłuée à la République; la reddition a eu lieu ce matin à six heures. "Le mème jour, la 
Convention adressait à l'armée un télécramme de félicitations et recevait la réponse des chefs. Dans les années suivantes seetablirent les lignes de Paris it Strasbourg, de Paris à Brest; en 1805 , celle de Paris à Turin, alors cité française; en 1813, de Paris, par Metz, à Mayence, ville également lrançaise à celte époque.

Ierostation milituire, eanons, aciers, poudres, salpètre, ete. - L'aérostation militaire date du ballon captif du capitaine courelle à la bataille de Fleurus (179't).

On n'avait pas assez de canons et on ne pouvait faire venir le cuivre d'Allemagne; nos savants trouvèrent moyen de fondre des canons ${ }^{1}$ avec les cloches des églises, avec lis statues : de celle de Jeanne l'Arc à Orléans on tira des pièces qui portèrent les noms de Jeanne et de la Pucelle. Monge publia, par ordre du Comité, son livre, introuvable aujourd'hui, intitulé "Description de l'art de fabriquer les canons".

L'acier manquait, nous ignorions mème le secret de sa confection, et on ne pouvait en demander à l'Angleterre. Fourcroy inventa des procédés rapides de fabrication; et l'on fit des baïonnettes, des épées, des sabres, avec l'acier français.

Lit poudre manquait; on navait plus, pour en fabriquer, le salpètre de linde; on n'avait plus le temps de construire des moulins à poudre; le Comité de Salut public demandait dix-sept millinns de livres de ce produit, et la régie déclarait ne pouvoir en fabriquer plus de trois millions de livres. Nos savants montrèrent comment on pouvait, en lessivant le sol des étables et le plàtre des murailles, extraire le salpètre ${ }^{2}$, non plus à raison d'un million de livres par an, ainsi qu'on le faisait autrefois, mais à raison de douze millions en neuf mois; comment on pouvait, par des procédés jusqu'alors incon-

1. Dans nos foncleries, on suivaıt cneore le procédé très long du moulage en argile : le Comité de Salut public, à la recherche de procédés plus expéditifs, ordonna de mettre en ceuvre celui du moulage en sable.

2. Pa: 1 rdre du Comité de Salut publis, il fut élabli, dans chaque département, un prépo é chargé d'instruire les a_ents qui devaient rechercher le salpètre. Le décret de la Convention (4 décenbre 1793) fut accompagné d'une Instruction claire, précise, a la portée de ehaque citoyen, oú l'on Indiquait les principales opérations de la fabrication du salpétre. 
nus, le purifier et le sécher en quelques jours; comment on pouvait, avec des tonneaux que des hommes faisaient tourner, fabriquer la poudre en douze lıeures. Alors se vérifia cette assertion audacieuse d'un membre du Comité de Salut public: " On montrera la terre salpêtrée, et, cinq jours après, on en chargera les canons. "

"Par son arrêté du 14 pluviòse, nous raconte Monge, le Comité de Salut public appela de chaque listrict de la République des citoyens choisis parmi les canonniers de la garde nationale, pour y apprendre, dans des cours révolutionnuires, l'art d'extraire le salpètre, le procédé nouveau du raffinage de cette substance, la nouvelle manière de fabriquer la poudre, enfin la l'abrication des canons de bronze pour le service de nos armíes de terre, et de fer coulé pour larmement de nos vaisseaux. Il chargea de ces cours les citoyens Fourcroy, Pluvine, Dufourny, pour le salpêtre; Guyton, Carny, Berthollet, pour la poudre; Hassenfratz, Monge, Perrier, pour les canons. "Chaque section de Paris eut son atelier.

Quand ces cuurs furent terminés, la Convention convia les citoyens à la Fête du Sulpetre, le 30 ventòse an II (mars 1794). On y exposa les produits des industries nouvelles, canons, poudres, salpêtres. "Cette fète fut, dit Monge, une des plus belles de celles qui ont eu lieu sous la Révolution. Toutes les sections $y$ assistèrent, portant l'hommage de leurs travaux en salpètre qu'elles avaient fait cristalliser sous des formes patriotiques, toutes très aimables, et la plupart très ingénieuses. " C'est alors que fut mise en vogue la "Chanson républicaine du Salpêtre ${ }^{1}$ ", où l'on trouve une indication sommaire des procédés nouveaux, et que répétaient en chœur les élèves du salpètre.

Armand seguin inventa un procédé rapide pour le tan-

1.

\footnotetext{
Descendons dans nos souterrains,

La liberté nous y convie;

Elle parle, Républicains,

Et c'est la voix de la Palrie!

Lave la terre en un tonneau;

En faisant èvaporer l'eau,

Bientot le nitre va paraitre!

Four visiter Pitt en bateau,

Il ne nous faut que du salpètre.
} 
nage des cuirs destinés à la fabrication des chaussures et autres objets d'équipements militaire: la Convention luı décerna une récompense nationale (1795).

La Convention avait fait, comme nous l'avons vu, beaucoup pour la science; la science fit alors beaucoup pour la patrie. La révolution scientifique vint au secours de la révolution politique et sociale.

\section{Les mathématiques et l'astronomie.}

uathématiques et mathématieiens. - Les mathématıciens de cette époque ont été mèlés à la politique comme à la guerre. Les services rendus par eux à la cause de la défense nationale n'ont pas été inférieurs à ceux des physiciens et des chimistes. Le parti constitutionnel s'enorgueillit de Bailly, la Gironde de Condorcet, la Montagne de Carnot, Monge, Arbogast, le Sénat consulaire ou impérial de Lagrange et de Laplace. C'est un mathématicien, Carnot, qui renouvela la tactique et fut l' " organisateur de la victoire "; c’est un autre mathématicien, Bonaparte, qui inaugura la grande guerre.

La carrière scientifique de BaILly est antérieure à la Révolution : il avait achevé en 1787 son "Histoire de l'astronomie ancienne et moderne " et publié, en $177 \%$, ses "Lettres sur l’origine des sciences".

La dernière cuvre de condoncet avait été ce magnitique "Tableau des progrès de l'espril humain ", dont la Convention nationale ordonna l'impression aux frais de la République. En 1801 commence, par les soins de Garat et de Cabanis, la première édition de ses œuvres complètes.

P0RRo, de Besançon, publia, en 1779, son "Algèbre selon les vrais principes $n$.

La mème annće, arbogast, de Müntzig (Alsace), présentait à l'Académie des sciences son "Essai sur de nouveaux principes de calcul différentiel et intégral ». Nembre de la Convention, il rédigea le "Rapport sur l'unitornité et le système général de poids et mesures ".

Les principaux travaux de trembley, de Genève, parurent, de 1793 à 1800, dans les mémoires de l'Académie de Berlin. 
Il contribua au perfectionnement du calcul intégral et du calcul des probabilités.

lagrange, de Turin, ful membre de la commission que l'Académie des sciences chargea d'examiner et de récompenser les inventions, membre de la commission qu'elle institua pour l'étude du système décimal, professeur à l'École polytechnique, à l'organisation de laquelle il avait pris une si grande part. Napoléon, qui admirait en lui a la haute pyramide des sciences mathénatiques $\mathrm{b}$, le fit sénateur, grand officier de la Légion d'honneur. Ses principaux ouvrages de mathématiques pures, dans cette période, sont la "Théorie des fonctions analytiques" (1797), les "Leçons sur le calcul des fonctions " (1806) et le "Traité de la résolution des équations numériques à tous les degrés "(1808). Delambre terminè ainsi son éloge de ce savant : "Gràce aux travaux de Lagrange, la science mathématique est aujourd'hui comme un vaste et beau palais dont il a renouvelé les fondements, posé le faite, et dans lequel on ne peut faire un pas sans trouver avec admiration des monuments de son génie. "

LAPLACE fut, en 1794, professeur d'unulyse muthématique à l'École normale. Après le 18 brumaire, il fut ministre de l'intérieur, sénateur et chancelier du Sénat, comte, grand officier de la Légion d'honneur. Il a publié la "Théorie analytique des probabilités" (1812), le "Calcul des fonctions génératrices ". Ses leçons à l'École normale (179') ont douné naissance à l' "Essai philosophique sur les probabilités " (1819).

MONGe devient, en 1792, ministre de la marine; puis il se consacre à la création des ressources scientiliques pour la défense nationale. Ardent jacobin, il est, après la chute de Robespierre, dénoncé par son portier comme un partisan de la loi agraire et n'échappe que par la luite à une poursuite devant le tribunal révolutionnaire. En 1795, il prend part à l'organisation de l'École polytechnique, où il devient professeur, et de l'Institut de France, dont il devient membre. Chargé d'une mission en Italie, il contribue à la proclamation de la république romaine. Aidé de Berthollet, il recrute le personnel de l'Institut d'Égypte, déharque avec Bonaparte devant Alexandrie, et il faut un ordre formel 
du général en chef pour l'empêcher de figurer dans les colonnes d'assaut. De retour en France, il est fait sénateur, comte de Péluse, grand officier de la Légion d'honneur, directeur de l'École polytechnique. La Restauration lui retire tous ses emplois, le chasse de l'lnstitut, licencie l'École polytechnique. Il meurt dans la misère en 1818.

Avec ce tempérament arlent, dans une carrière si tourmentée, il a rendu de grands services aux mathématiques. On peut le considérer comme un des créateurs de la géométrie descriptive. Sa "Géométrie descriplive " et son "Analyse appliquée à la Géométrie" sont restées des livres fondamentaux.

Carnot, officier du génie, fut député a la Législative, puis député à la Convention et membre du Comité de Salut public, puis l'un des cinq Directeurs. Chargé principalement de l'organisation des armées, il assistait Jourdan à la bataille de Wattignies (1793), et c'est lui qui plaça Bonaparte à la tête de l'armée d'Italie. Proscrit par ses collègues du Directoire après le coup d'État de fructidor, il n'échappa à la déportation qu'en se rélugiant en Allemagne. Après le 18 brumaire, Bonapaste le rappela et lui confia le ministère de la guerre; l'Empire le rendit à la vie privée, d'où il ne sortit qu'en 181 ŏ pour organiser la défense d'Anvers. La Restauralion, qui ne lui pardonnait pas d'avoir voté la mort de Louis XVI, lui infligea un nouvel exil : il mourut à Magdebourg (Allemagne), en 1823.

Comme Monge, Carnot fut surtout un géomètre. Dans son premier exil, il avait publié sa "Métaphysique du calcul intégral ". Après sa disgràce sous Napoléon, il publia sa "Géométrie de position " el son "Essai sur la théorie des transversales ".

meusnier, olficier du génie, devenu général sous la Convention et qui périt en défendant Mityence contre les Prussiens (1793), fut non seulement un physicien distingué, qui avait perfectionné les aérostats, inventé un appareil pour distiller l'eau de mer, et mis Argant et Quinquet sur la voie d'un nouveau système d'éclairage, mais aussi un géomètre de premier ordre, qui, sur certains points, avait devancé Monge.

Lancret, membre de l'Institut d'Egyple, mort en 1807, à 
trente-trois ans, complète les travaux de Monge et Meusnier sur les courbes $\dot{a}$ double courbure.

LEGENDRE est surtout célèbre par ses "Éléments de géométrie " (1794) et sa "Théorie des nombres " (1798); poinsot, par ses "Éléments de statique " (180'); нachetre, un des savants de l'expédition d'Égypte, par sa "Correspondance sur l'École polytechnique ", qu'il commenç en 1804 ; l'abbé вossut, par son " Histoire générale les mathématiques " (1810).

L'astronomie. - De 1789 à 1793, l'Allemand schroeter poursuit ses belles observations sur Vénus : il établit que les montagnes de celte planète atteignent 44000 mètres d'altitude, c'est-à-dire qu'elles sont cinq fois plus hautes que les plus hauts sommets de notre globe, mème ceux de l'Hinalaya.

Képler, en poursuivant ses calculs sur le monde planétaire, avait émis l'hypothèse qu'il devait exister une planète entre Mars et Jupiter. Les astronomes allemands, lans leur foi au génie de leur compatriote, s'étaient, pendant un siècle et ćemi, ingéniés à la déconvrir. C'est le lor janvier 1801 que, suivant l'expression de Delambre, "un hasard extrèmement heureux, mais préparé par un travail immense ", fit apercevoir à l'Italien piazzı. dans la région indiquée par képler, une étoile inconnue. Il la suivit avec soin, constata gu'elle n'était point immobile, et en conclut que c'était une planète. Il la nomma Cérès. Dans les mèmes parages, Pullas lut lécouverte par olbers, de Brème, en t 802 ; Junom, par harding, de Gottingen, en is04; Testa, par Olbers, en 1807 . Bien d'autres ont été depuis découvertes. On les appelie astéroides ou petites planetes. Certains astronomes ont émis l'hypothèse que ces astéroüles, visibles seulement au télescope, sont les débris d'une planète primitive, projetés dans l'espace par quelque explosion, ef qui continueraient, à une certaine distance les uns des autres, à suivre des orbites distinctes, mais assez rapprochées de l'orbite primitive.

Pour l'astronomie physique, les Anglais conservent leur supériorité avec wiLlam Herschel, qui continue son exploration du ciel, et JоHN MITchell, qui itudie les amas stelluires et les rébuleuses (1797). 
L'astronomie mathématique resta le domaine des Français. En 1790, mécBin et DELAMBRe furent chargés par l'Académie des sciences de mesurer le méridien terrestre entre Dunkerque et Barcelone. Cette opération, qui devait servir à constater scientifiquement la longueur du métre, base de tout le systéme décimal, fut exécutée au moyen d'instruments et de méthodes beaucoup plus parfaits que ceux qu'avaient pu mettre en œuvre les astronomes du xvue siècle. En 1803, Méchin se proposait de prolonger ce méridien jusqu'aux îles Baléares: il mourut au cours des travaux.

Le grand nom français de l'époque, c'est laplace. Dans ses deux cuvres capitales, Exposition du système du monde (1796), qu'il dédia au Conseil des Cinq-Cents, et Traité de la mécanique céleste (1799), il confirma les lois de kiépler et le système de Newton en leur donnant un degré de certitude qu'ils n'avaient pas eu aux yeux mêmes de leurs auteurs, et une précision que ceux-ci n'avaient pu leur assurer.

lalande publia, en 1801, son "Histoire céleste " et, en 1803, sa "Bibliographie astronomique ".

\section{La physique et la chimie.}

Physique : les gaz. les aérostats. - GaY-LUSSAC, élève de l'Ecole polytechnique en 1797, fut le suppléant de Fourcroy à la mème école et l'ami de Berthollet. Il a attaché son nom au psychromètre, instrument destiné à mesurer l'humidité avec plus de précision qu'on ne pouvait le faire avec l'hygrométre, inventé par Saussure.

Il a dû sa grande réputation de physicien à ses recherches sur la compressibilité des gaz et à ses expériences d'aérostation.

Depuis la bataille de Fleurus (1794), il y eut de nombreuses ascensions militaires : dans les quatre mois qui suivirent, Fourcroy en signale jusqu'à trente-cinq. D'autre part, les aéronautes civils rivalisaient avec les militaires '.

1. La première ascension accomplie avec un but d'observations scientiGques fut faite en 1503, à Hambourg, par Robertson et Lhoest. 
Gay-Lussac les dépassa tous en audace : de plus, il fit servir ces témérités à des recherches scientiliques. Le 20 août 1804, dans une ascension entreprise avec Biot, il s'éleva à 4000 mètres. Le 16 septembre de la même année, il atteignit une altitude, constatée par le baromètre, de plus de 7000 mètres : le thermomètre accusait une température de 9 degrés et demi au-dessous de zéro, tandis que la température relevée à l'observatoire de Paris était d'environ 28 degrés au-dessus de zéro: c'était une différence de plus de 37 degrés. A ce changement si brusque de tempéra¿ure se joignait une autre épreuve pour l'aéronaute : une difficulté très grande à respirer. De ce voyage périlleux, ray-Lussac rapporta de précieuses observations sur les oscillations de l'aiguille aimantée et la composition de l'air atmosphérique à ces hauteurs.

On commença à faire des ascensions un attrait des fètes publiques : en 180;, Garnerin, le jour du couronnement de l'Empereur, s'enleva sur la place Notre-Dame à Paris; le lendemain, il débarquait à Rome. L'art nouveau avait déjà des victimes à enregistrer : Olivari à Orléans (1802), Mosment à Lille (1806), Bittorf à Manheim (1812), Zambeccari à Bologne (la mème année). Les célèbres mathématiciens Monge et Meusnier s'étaient déjà préoccupés de la direction des ballons.

C'est à GARNERIN que remonte l'invention du parachute (1797); il osa se confier à ce fragile appareil et làcher son ballon à une hauteur de 1000 mètres : il descendit heureusement au milieu de l'émotion inexprimable des spectateurs.

La lumière, l'optique. - Les théories de Newton sur la na. ture de la lumière, son hypothèse de l'émission, dominaient encore dans la science. Ce fut l'Anglais wolLaston qui, vers 1800 , revint le premier à l'hypothèse de Huyghens sur les ondulations. En 1807, malus, ofticier du génie, qui avait fait la campagne d'Égypte, publia son "Traité d'optique analy. tique " et son " Mémoire sur le pouvoir réfringent des corps opaques". Les newtoniens virent d'abord dans ces travaux une confirmation de leur théorie : Arago n'eut pas de peine à démontrer le contraire. De 1808 à 1810, Malus publia ses recherches sur la polarisation de la 
lumière et sa "Théorie de la double réfraction ". En 1811, arago, appliquant son génie à cet ordre de phénomènes, lécourit la théorie des couleurs complémentaires. Voilà donc toute une branche de l'optique que les siècles prócédents n'avaient pas connue, et qui se trouve constituée dès cette époque.

Lorsque la lumière du soleil passe par un prisme, elle se décompose et projette ce spectre solaire dont Newton avait déjà donné la théorie. Mais certains rayons, à droite et à gauche des sept couleurs, ne sont pas colorés : ils sont invisibles, et cependant ils conservent des propriétés chimiques, par exemple celle d'altérer certaines substances, telles que le chlorure d'argent et l'iodure bleu d'amidon. Les expériences faites à cette époque par quelques savauts français ou étrangers, notamment par GAY-LUSSAC el THÉNARD, démontrèrent qu'au spectre solaire ou coloré se superpose un spectre chimique, beaucoup plus étendu.

La chaleur. - Sur la nature de la chaleur, les savants étaient partagés, comme sur la nature de la lumière, entre deux hypothèses : les uns la considéraient comme un fluide, c'est-à-dire comme une chose matérielle et même pondérable; les autres ne voyaient en elle qu'une variété du mouvement. En 1798, l'Américain Romfond lit, en Bavière, une observation importante : il remarqua que le forage des canons produit dans le bronze une forte élévation de température. Il en conclut que c'esl le mouvement de la machine à forer qui se transforme en chaleur: la chaleur n'est donc que du mouvement. Dès lors, l'hypothèse de la chaleur-mouvement l'emporta sur celle de la chaleur-matière. C'est, d'ailleurs, un retour à la théorie antique soutenue par Héraclite.

Les premiers travaux sur la chaleu rayonnante sont dus à Prévost (1809), B. de Saussure, Rumford. Celui-ci démontra que les rayons calorifiques traversent le vide.

La vapeur. - En 1790, BËTANCOURT avait lu un mémoire à l'Académie " sur la force expansive de la vapeur d'eau ". Les applications de cette force furent alors tentées, non par des Francais, mais presque uniquement par le plus jeune des peuples civilisés, les Américains des Élałs-Unis. Olivier Ewans, dans sa manulacture de Pittsburg, cons- 
truisit des machines a hate pression, et, en 1800, fit circuler dans les rues de Philadelphie une espèce de chariot $\dot{a}$ vapeur. En 1801, les Anglais trevithick et vivian avaient introduit dans leur pays ces machines à haute pression, qui devaient rester encore longtemps inconnues chez nous.

Un autre inventeur américain, rolton, se proposa, dès 1793, de construire un navire mù par la vapeur. En 1797, il proposa au Directoire deux de ses inventions : la torpille sous-marine et un bateau sous-marin, quil appelait le Nautilus. Assez froidement accueilli, il s'arlresse, six ans après (1803), au Premier consul : il fait naviguer sur la Seine un bateau à vapeur. Bonaparte ne semble pas avoir compris alors tout le parti qu'il aurait pu tirer de ce nouvel engin pour ses projets de descente en Angleferre. Éconduit pour la seconde fois, Fulton retourne en Amérique, construit un bateau qui fait le service sur la Delaware. C'est en 1814 que le Congrès américain, alors en lutte contre l'Angleterre, fait construire le prenier navire de guerre à vapeur, destiné à tenir la haute mer : c'était une simple frégate.

L'électricitc. - Le xvm siècle, jusqu'en 1780, n'avait connu que l'électricité statique, obtenue par le frottement. Avec les expériences de GaLvani sur sa grenouille (17S0) commence l'électricité dynamique, que l'on appela longtemps grlwanique. Galvani niait que ces deux électricités fussent identiques. Il voyait dans celle qüil avait découverte une électricité d une nature particulìe, qu il appelait animale; il croyait avoir trouvé un fluide nouveau, le fluide nerveux; il supposait qu'il était sécrétė par le cerveau et que les muscles, réservoirs de ce fluide, agissaient comme de petites bouteilles de Leyde, dont les nerfs seraient les fils conducteurs. Ses expériences furent répétées partout en Europe. Une commission, nommée par notre Académie pour étudier ce phénomène, se trouva divisée d'opinion.

Un autre Italien, vouta, de Pavie, tenait pour l'identité des deux électricités; il estimait que les organes animaux, dans les phénomènes galvaniques, étaient non des générateurs, mais simplement des conducteurs du fluide. Il remarquait que ces phénomènes ne se produisent guère lorsqu'on ne met en contact avec les organes animaux

R. Civil. CO: TEMP. 
qu'un seul métal. Il formulait ainsi le principe du voltaisme : "Lorsque deux métaux différents sont en contact l'un avec l'autre, il y a dévcloppement d'ëlectricité. "Une rondelle de cuivre appliquée sur une rondelle de zinc provoque le phénomène: mais si une paire de ces rondelles dégage un peu d'électricité, beaucoup de paires semblables, séparées l'une de l'autre par une rondelle de drap imbibée d'eau, développeront beaucoup d'électricité. C'cst ainsi que Volta, en 1799, construisit l'appareil qui porte son nom : la pile de Volta. C'était, en effet, une pile de rondelles, en forme de colonne, ayant un fil métallique à ses deux extrémités : par un de ces fils se dégage l'électricité qu'on appelle positive; par l'autre, l'électricité négative. Une paire de roudelles, l'une en cuivre, l'autre en zinc, s'appelle un couple ou un élément de la pile.

La disposition en colonne avait ses inconvénients : elle ne permettait pas de multiplier indéfiniment le nombre des éléments, c'est-à-dire la puissance de l'appareil, puisque le poids des rondelles superieures fait sortir le liquide des rondelles de drap. L'Anģais cruikshank plaça les couples dans une colonne de bois, où chacun était maintenu par des crans. Puis on magina de les coucher l'un à côté de l'autre dans des auges en bois remplies d'eau, et de leur donner la forme de plaques carrées; on conserva à l'appareil son nom de pile, bien qu'il n'en eut plus la forme. Telle fut la pile à auges, inventée également par Cruikshank. Alors on put multiplier le nombre des éléments, donner aux plaques de cuivie et de zinc de grandes dimensions; c'est ainsi que fut construite la grande pile de wollaston, à l'Institution royale de Londres, en 1807, et la grande pile de l'Ecole polytechnique, construite en 1813 par ordre de Napoléon. Celle-ci comprenait 600 éléments ou couples placés dans 60 auges de bois, les plaques de zinc et de cuivre ayant 9 décimètres carrés; la batterie, c'est-à-dire l'ensemble de ces éléments réunis par des fils métalliques, occupait 54 mètres carrés. Depuis lors la pile a pris bien des formes différentes.

Mème, avant ces perfectionnements, elle donnait des résultats considerables. En 1800, NICHOLSON el CARLISLE avaient montré qu'en plongeant dans l'eau les fils qui sont aux 
deux póles, c'est-à-dire aux deux extrémités de la pile, l'eau se décompose en hydrogène et oxygène. cruiksank montra que presque tous les corps sur lesquels on fait agir à la fois les deux pỏles de la pile se décomposent. Davy expliqua scientifiquement cette action chimique de la pile, et, quoiqu'il fût Anglais et que les deux nations fussent en guerre, Napoléon, en 1807, lui fit décerner par l'Institut le prix de 60000 francs qu'il avait fondé en 1801 pour encourager les travaux sur l'électricité.

En 1793, six ans avant que la pile füt inventée, à l'aide d'un arc métallique composé de deux métaux, le chirurgien LARREY avait provoqué des contractions musculaires sur une jambe récemment amputée. En 1798, à l'aide du mème appareil, le physiologiste віснат galvanisa des cadavres de suppliciés. En 1818, cette fois avec une pile puissante, le médecin oRE, ḋ Glasgow, épouvanta l'assistance en rendant à un cadavre toutes les apparences de la vie.

Une curieuse application de ces découvertes, ce fut le télégraphe électrique, inventé en 1811 par søMmering, de Francfort, qui devint alors membre correspondant de l'Institut.

L'Américain Coxe en avait eu la première idée : elle consistait à produire, à distance, au moyen de fils électriques, des décompositions des substances chimiques: chacune des décompositions obtenues correspondait à un signe. Sœmmering se bornait à une seule décomposition, celle de l'eau en bulles d'hydrogène et d'oxygène. A cet effet, il employait $3 \check{5}$ fils, correspondant aux lettres de l'alphabet ou à d'autres signes : ces 35 fils plongeaient daus un baquet d'eau. Celui d'entre eux par lequel passait le courant électrique dégageait une bulle d'hydrogène et une bulle d'oxygène : on notait le signe correspondant à ce fil. C'était assurément fort ingénieux, mais 3ò fils constituaient un appareil bien encombrant.

Chimie. - L'échafaud révolutionnaire avait interrompu, en 1794, la carrière de Lavoisien, dont les "Mémoires sur la chimie " furent publiés en 1805 .

GUYTON DE MORvead, qui fut membre de la Législative, de la Convention, des Cinq-Cents, directeur de l'École polytechnique et administrateur de la Monnaie, n'écrivit, dans 
cette période, que quelques mémoires de chimie et son "Traité sur les moyens de désinfecter l'air " (1801).

BERTHoLLET ${ }^{1}$, organisateur et membre del'Institut d'Égypte, publia, en 1789, son "Mémoire sur la nature de l'acier "; en 1791, ses "Éléments de l'art de la teinture "; en 1801, ses " Lois de l'affinité ", où il traita surtout des sels et formula ce qu'on appelle les lois Berthollet; en 1803, son "Essai de statique chimique". Il s'est occupé beaucoup de la chimie industrielle, de la fabrication des poudres, de l'emploi du chlore pour le blanchiment des étoffes. Ce procédé de blanchiment s'est appelé alors berthollage : de là encore les mots de bertholler et bertholleur.

Fodrcroy, qui fut membre de la Convention, du Comité de Salut public, du Conseil des Cinq-Cents, puis, sous le régime suivant, conseiller d'État et directeur général de l'instruction publique, avait présidé à l'organisation de l'École polytechnique, des écoles de médecine et de droit, des écoles centrales. Il publia " la Médecine éclairée par les sciences physiques "(1791), "la Philosophie chimique" (1792), son "Procédé pour extraire la soude " (1795), son "Tableau synoptique de chimie".

vadouelin est le premier chimiste qui ait dégagé le chrome, du plomb spathique de Sibérie (1797), et le glucinium, de l'émeraude et du béryl (1798). Il s'occupa surtout de l'analyse des matières organiques et, avec Roвiauet, découvrit l'asparagine, un alcaloìde extrait de l'asperge, il analysa la matière cérébrale, la laite des poissons, le chyle de plusieurs animaux; etudia l'action du vin, du vinaigre et des acides sur les vases de plomb et d'étain; fabriqua l'alun et le laiton. Il est un des fondateurs de notre chimie médicale, comme de notre chimie industrielle.

Celle-ci dut également d'importants progrès à cBaptal, ministre de l'instruction publique sous le Directoire, ministre de l'intérieur sous le Consulat, ministre d'État pendant les Cent-Jours. Il publia deux ouvrages; où les préoccupations d'utilité pratique s’affirment rien que par les

1. Berthollet est le premier qui ait expérimenté, vers la fn du xvul siẻcle, une poudre, la poudre Berthollet, où le chlorate de potasse remplaçait lo sulpétre, et qui était plus brisante que la poudre ordinaire. De là l'explo3.20 de la poudrière d'Essonues, oủ il faillit pẻrir avec Lavoisier. 
titres: "la Chimie appliquée aux arts " (1807), et "la Chimie appliquée à l'agriculture ${ }^{1}$, (1823).

GAY-LUSSAC, à l'aide d'une pile colossale, parvint à isoler plusieurs corps simples. De l'acide borique il dégagea le bore; du bleu de Prusse, le cyanogene (1815). Celui-ci, bien que composé lui-même de carbone et d'azote, agit cependant comme un corps simple et entre dans plusieurs combinaisons, telles que l'acide prussique. Les recherches de Gay-Lussac sur le solium, celles sur le potassium, qui faillirent lui coûter la vue, ont une grande valeur. Il inventa l'alcoomitre, le chloromètre, l'alcalimètre. Dans l'analyse des monnaies, il substitua la voie humide à la coupellation. Enfin, la philosophie de la chimie lui doit la loi des volumes.

Dans plusieurs de ses travaux, Gay-Lussac eut pour collaborateur le baron Thénard, avec lequel il publia, en 1811, ses "Recherches physico-chimiques".

Le baron THÉNARD avait commencé, en 1800, ses recherches sur les conıbinaisons de l'arsenic et de l'antimoine avec loxygène et le soufre, sur les oxydes et sels de mercure, les phosphates, les tartrates, les éthers. Avec les sels de cobalt, il fabriqua le bleu de Thénard. Plus tard (1818), il inventera une eau oxyçénée dont il proposera l'emploi pour le nettoyage des tableaux à l'huile. On roit que ses travaux ont principalement porté sur la chimie industrielle. De 1813 a 1816 parut son célèbre "Traité de chimie ".

Il est nécessaire de dire quelques mots de quatre chimistes étrangers de cette période : les Anglais ${ }^{2}$ Humphry Davy, Wollaston et Dalton, le Suédois Berzélius.

Humphry DAvY avait d'abord été apprenti chez un apothicaire, qui l'estimait " un pauvre sujet ". A vingt ans cependant il démontrait la décomposition de l'air par les plantes marines (1798). Le protoxyde d'azote, ou " oxyde nitreux " de Priestley, était considéré comme un gaz mortel, dont l'inhalation tuait à de très faibles doses : Davy osa le respirer pur (1799) et constata qu'il donnait

1. Un procédé inventé par Chaptal, en 1\$23, pour augmenter la force des vins en alcool, s'appelle encore la chaptalisation.

2. Un autre Anglais, Howard, inventi, en 1800, la poudre Howard, qui eat? le fulminate de mercute. 
des sensations tellement agréables et étranges, qu'il l'appela gaz hiltrant. Il fit un usage plus constant qu'on ne l'avait fait avant lui de la pile, et découvrit plusieurs corps simples dont Lavoisier avait deviné l'existence : le potassium dans la potasse, le sodium dans la soude, le calcium dans la chaux, le barium dans la baryte, le strontium dans la strontiane. Il essaya aussi d'isoler le fluor de l'acide huorhydrique, mais ne put obtenir à l'état libre ce redoutable gaz. Il montra ce qu'avait d'incomplet la théorie de Lavoisier, qui croyait que l'oxygène entre en composition dans tous les acides: il prouva que le chlore peut jouer parfois le mème ròle et quil en est de mẹme de l'hvdrogène. Davy distinguit donc entre les oxacides, ou acides d'oxygène, et les hydrucides.

L'invention de la lampe des mineurs ${ }^{1}$ (1815); la démonstration que l'emploi des clous de fer dans les doublages en cuivre provoque la décomposition des doublages; l'emploi de réactif's chimiques pour rendre lisibles les manuscrits de Pompéi et d'Herculanum, ont rendu Davy célèbre dans tous les mondes.

Son nom se rattache à notre histoire par une circons. tance notable: en 1811, bien que l'Angleterre füt en guerre avec nous, Napoléon autorisa Davy à traverser la France; c'est dans ce voyage qu'il examina une substance noire, qui se rencontre dans la cendre des plantes marines, qui corrode les chaudières, et qui avait attiré l'attention du salpêtrier Courtois. Il découvrit que cette substance était un corps jusqu'alors inconnu et susceptible d'importantes applications : l'iode. La découverte en fut faite, presque en mème temps, par Davy et Gay-Lussac, si bien que la question de priorité reste encore indécise.

wollaston dut, comme Davy, à l'emploi de la pile, qui fut perfectionnée par lui, d'importantes découvertes : par exemple, du pulludium et du rhodium (1804), qu'il tira de ce mème minerai de platine dont Tennant, l'année précédente, avait déjà extrait l'iridium et l'osmium.

1. Cette invention est fondèe sur la propriété qu'ont les toiles mètalliques d'isoler les flammes et d'empécher eelle d'une lampe, emprisonnéo dans un cylindre de toile métallique, de meltre le feu au grisou ou gaz ingammable des mines de houille. 
Dalton fut le créateur d'un nouveau système de philosophie chimique. Dès 1801, il émit l'hypothèse que la matière est composée de particules infiniment petites, insécables, invisibles : ce sont les atomes des philosophes grecs. Chaque espèce de matière aurait ses atomes propres, ayant une forme et un poids spéciaux. C'est ce qui explique les différences entre les corps simples. Lorsque des atomes de nature différente entrent en combinaison, ils se juxtaposent sans se confondre.

Cette idée a été reprise, en 1814, par AMPĖRE, qui au mot atome substitua celui de molecule. Depuis, la science a admis les deux expressions : la molécule, invisible ellemème, est un agrégat d'atomes.

Proust avait formulé la loi des proportions définies, GayLussac la loi des volumes; Dalton compléta ces données par la loi des proportions multiples.

BERzÉLios est surtout célèbre par les progrès qu'il a fait faire à la méthode chimique. Pour désigner une combinaison quelconque, il ne suffit pas, comme on sait, de désigner les corps qui y entrent, il faut encore désigner la proportion dans laquelle y entre chacun d'eux.

C'est Berzélius qui a employé, le premier, des lettres et des chiffres pour traduire ces combinaisons. Berzélius a donc complété l'œuvre de Lavoisier, le créateur de la nomenclature chimique, en donnant à la science une langue plus brève dans sa concision. Berzélius a émis, pour expliquer l'action de la pile sur les combinaisons et les décompositions chimiques, une hypothèse qui est encore en vigueur aujourd'huı: il suppose que chaque molécule a leux pôles qui sont électrisés diversement : une combinaison de molécules serait en mème temps une combinaison d'électricités '.

1. Signalons encore la découverte de plusieurs corps simples, outre ceux que nous avons dejjà indiqués : da titane, par Gregor et Klaprolh (1791-1794); du silicium et du sélénium, par Berzehus; du cérium, par Berzélius ot Hésinger; du zirconium, par Klaproth et Berzélius (1805). 


\section{Les sciences naturelles}

Voyagres de naturalistes. - Bien que la période rérolutionnaire et impériale, tout entière occupée par les guerres anglaises, n'ait pas laissé aux savants français la faculté de courir le monde, il faut signaler cependant la fin des voyages scientifiques de LA BILLARDière en Océanie, de RICHARd à la Guyane, la mission de dombey dans l'Amérique du Sud ${ }^{1}$ et surtout l'expédition entreprise, de 1800 à 1802 , lans toutes les mers africaines, par les trois navires le Gégraphe, le Naturaliste et la Casuarina : ils étaient commandés par le capitaine Baudin et son lieutenant Freycinet. BORY DE SAINT-VINCENT était le directeur scientifique de l'expédition; il était accompagné des deux zoologistes Péron et Lesueur. Comme le constate l'historien allemand Carus, " les entreprises des Français furent les premières " et elles allaient être bientôt " les plus fécondes".

Zoologie. - C'est dans cette période que lacépède donna une suite à ses précédents travaux en publiant l'Histoire des Reptiles. en 1789; celle des Poissons, de 1798 à 1803; celle des Cétacés, en 1804.

LATREILle publie, en 1796, ses travaux sur les crustacés, et, en 1806, son livre sur les Insectes.

LELORGNE DE SAVIGNY, qui avait voyagé en Chine et qui fut membre de l'Institut d'Égypte, est connu par sestraraux, encore aujourd'hui classiques, sur la bouche des insectes; il est un des fondateurs de l'anatomie philosophique.

LAMARCE, professeur de conchyliologie au Muséunı (1793) ne s'est pas seulement occupé des espèces à coquilles. II montra l'importance capitale de la division des animaux en vertébrés et invertébrés. Il constata une des grandes lois de l'histoire naturelle : la dégradation progressive des organes, lorsquion va des animaux les plus parfaits aux moins parfaits, jusquà l'entier anéantissement de ces organes. C'est lidée maítresse de ses " Recherches sur l'organisation des corps vivants" (1806), où l'on trouve son

1. Interrompue par sa capture (il fut pris par les Anglais) el par sa mort (iis). 
magnifique "Tableau du règne animal ". Dans sa "Philosophie zoologrique " (1809), il jeta les bases de la doctrine de l'évolution et fut ainsi le précurseur de Darwin.

LEVALlant publia, de 1796 a 1804 , le résultat de ses précédents royages, et fut surtout l'historien des oiseaux de l'Afrique et de l'Amérique.

DUTRoceEt, en 1812, sépara nettement des infusoires ces fameux rotifères qui avaient tant occupé le xvine siècle.

Louis DUvernoy, à partir de 1802, se consacra aux Reptiles, notamment aux serpents venimeux, caméléons, crocodiles.

C'est de cette époque aussi que datent les premiers travaux de Frédéric Cuvier et Constant Duméril.

ÉTIENNE GEOFFroY SAINT-HILAIRE, en 1792 , avait été assez heureux pour arracher son maitre Haüy et onze autres prêtres aux massacreurs de septembre. En 1793, nous le trouvons professeur de zoologie au líuséum. s'employant activement à en enrichir les collections. Il suivit Bonaparte en Égypte, et, lors de la capitulation d'Alexandrie, réussit à sauver les collactions fiançaises '. En 1808, il fut chargé d'une mission scientifique en Portugal, et, en 1809, prit possession de la chaire de zoologie à la Sorbonne. Ses travaux, qui sont pour la plupart des monographies, réunies plus tard dans son grand ouvrage, ont un earactère philosophique : il tient, comme nous le verrons, pour l'unite de composition dans les ètres animés.

georges covirn, le plus grand zoologiste du siècle, devint sous l'Empire conseiller de l'Université et conseiller d'État. Il avait professé à l'école centrale du Panthéon, au Collège de France, au Muséum. Avec Saint-Hilaire, il publia le "Mémoire sur la classification des Mammifères" (179\%),

1. Voici comme Dumas, daus son Éloye du fils de Geoffroy, raconle cet episode. Un savant anglais, Hamilton, avait fait inserer dans la capitulation un article en vertn duquel les collections de toutes sortes rassembiées frour l'Institut d'É:zpte seraient lirrées. Geoffroy, indigné des exigences et de la dureté de l'Anglaic, s’écria : "Non! nons n'obéirons pas. Votre armée nentre à Aeraudrie que dans deux jours. Eh bien, d’ici la, le sacrifice sera consommé. Nous brùlerons nos rirhesses, vous disposerez de nos personnes.... Oui: nous le ferons. C'est à la cẻlébrité que vous visez? Comptez sur le souven de l'histoire. Vous aussi, rons aurez brùlé une bibliothèque à Alexandrie. "Hamilton, qui. après tout, aimait les lettres et

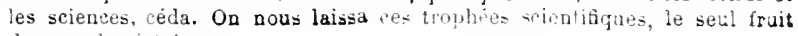
de taut de victoires 
une nouvelle classification des animaux à sang blanc et les "Tableaux élémentaires de l'histoire naturelle des animaux " (1798). Il acheva, après quelques tàtonnements ' , de déterminer la classification des animaux, à peu près telle que nous la pratiquons encore aujourd'hui.

Paléontologie. - En 1800, cuvier commença ces leçons d'anatomie comparée qui devaient donner de si surprenants résultats. En effet, c'est grảce à l'anatomie comparée qu'il fonda la paléontologie, c'est-à-dire la reconstitution des espéces perdues ou cspéces fossiles. Des ossements épars d’animaux fossiles avaient été recueillis au Muséum sans quon eût pu encore déterminer à quelles espèces ils appartenaient. Vers cette époque commencèrent les fouilles dans les carrières de plàtre et de gypse à Montmartre. Dès 1796, à propos des éléphants fossiles comparés aux éléphants vivants, Cuvier affirmait que l'on pouvait établir les mêmes comparaisons pour les rhinocéros, les ours, les cerfs, et un grand nombre d'animaux, dont le sol recouvre les espèces fossiles et dont nous avons sous les yeux les espèces vivantes. Il affirmait qüil avait existé, avant la création actuelle, toute une création, peut-être toute une série de créations, qui avaient été détruites par les révolutions du globe.

"Que l'on se représente, dit Flourens, ce mélange confus de débris mutilés et incomplets, recueillis par Cuvier; que l'on se représente, sous sa main habile, chaque os, chaque portion d'os, allant se réunir à l'os, à la portion d'os à laquelle elle avait dú tenir; et toutes ces espèces d'animaux, détruites depuis tant de siècles, renaissant ainsi avec leurs formes, leurs caractères, leurs attributs; et l'on ne croira pas assister à une simple opération anatomique : on croira assister à une résurrection!"

Cuvier, pour opérer cette résurrection prodigieuse, s'appuyait sur la loi de la corrélution des formes. Telle dent appartient evidemment à un carnivore, mais c'est le seul débris qu'on possède de lui; cependant Cuvier lui attribuait avec certitude telle constitution de la màchoire, du

1. Par exemple, en 1797 encore, Curier classait les crustacés homards, écrevisses, crevelles, etc.) avec les insectes et les arachnides. 
cråne, de la colonne vertébrale, des membres antérieurs et postérieurs, des ongles ou des griffes. Telle autre dent, au contraire, est d'un ruminant : Cuvier n'hésite pas à dessiner cet herbivore fossile avec une màchoire, un crâne, un estomac triple, des pieds fendus, bref, toute une structure générale. Donc il suffisait à Cuvier dune dent ou du plus petit os pour reconstruire un squelette entier. Et, lorsque le hasard des fouilles amène au jour un squelette entier, on s'aperçoit avec stupeur que le savant ne s'est pas trompé d'un détail. C'est ainsi qu'il remet sur pied, après des milliers et des myriades d'années, toute la tribu de pachydermes antédiluviens, mastodonte, rhinocéros à narines cloisonnces, hippopotame fossile, palaotherium, anoplothérium, lophiodon, anthrucotherium, chxropotinne, adapis; toute la tribu des herbivores, depuis le grand cerf d'Irlande jusqu'au daim gigantesque de la vallée de la Somme; toute celle des carnassiers, ours arctoïde, ours à dents comprimées, ours des cavernes, grand félin des cavernes; toute celle des grands reptiles, ichtyosaure, plesiosaure, mégalosaure, salamandres ou crocodiles gigantesques, pterodactyles ou lézards ailés.

Ce n'est pas tout: Cuvier constate que ces animaux fossiles, depuis les plus anciens jusqu'aux plus récents, se trouvent dans des couches de terrain différentes; que chaque série animale correspond à un état particulier du globe, roches anciennes ou terrains plus ou moins récents; qu'avec les premières couches qui formèrent le lit des océans primitifs apparaissent seulement des zoophytes, des mollusques, des crustacés, des poissons; que sur les premières terres émergées du chaos pataugièrent, comme dans un immense marais, les reptiles colossaux; que sur le sol un peu raffermi ont vagabondé les grands pachydermes; que les forèts et les prairies qui survinrent ensuite permirent aux carnassiers et aus ruminants d'apparaitre. Et alors, interprétant les couches du sol par leurs habi. tants, il publie, en 1813, ses deux ouvrages capitaux : le Discours sur les révolutions du globe, et les Recherches sur les ossements fossiles.

Botanique. - Les principaux travaux sur la botanique furent alors ceux de LAURENT DE JUSSIEd, qui fit paraitre la 
dernière feuilie de ses Genera plantarum le jour méme ou fut prise la Bastille; - de Lamarck, qui, en 1789 , commença son "Dictionnaire de Botanique ", en 1802 , publia la troisième édition de sa "Flore générale de France ", et qui contribua à la réorganisation du Jardin des Plantes (1793); - de du petit-thodars, qui, dans ses "Essais sur la végétation "(1809), s'occupa spécialement du mode de développement des bourgeons; - de Brissead-Mirbel, auteur d'un "Traité d'anatomie et de physiologie végétales " (1802), d'une "Théorie de l'organisation végétale " (1808), des "Éléments de botanique et de physiologie végétales ", et qui a publié, en collaboration avec Lamarck, de 1802 à 1826, sa grande "Histoire naturelle des végétaux".

Géologrie. - L'Allemand Werner, qui, en 1791, publia sa "Théorie des Filons ", avait concilié les deux écoles vulcanienne et neptrnienne. Il avait fait leur part au système de la formation des roches par le feu et au système de la formation par les dépôts de la mer. Il avait divisé l'écorce terrestre en deux étages, séparés par un terrain de transition : un étage inférieur, constitué avant lapparition des êtres organisés, et où l'action ignée était évidente; un étage supérieur, où les débris d'êtres organisés apparaissaient et qui ne pouvait aroir été constitué que par les sédiments. Cette théorie de Werner était encore incomplète: son compatriote LE்OPOLD DE BUCH, qui visita les Alpes en 1797 et le Puy-de-Dóme en 1802, prit constater qu'elle ne rendait pas compte de tous les faits géologiques. BÉnÉDict DE SAJSSURE, dont les excursions alpestles vont de 1780 à 1796, se trouva aux prises avec les mêmes obscurités. CuVIER et aleXANDre broNgniart " mirent en évidence l'existence d'un troisième ètage formé de sédiments déposés au sein des eaux, celui des terrains tertiaires ". C'était un grand événement; mais " à ce service rendu à la scrence s'en joignait un autre. Les terrains tertiaires ne forment point des masses homogènes; ils se subdivisent en couches distinctes et nombreuses. Pour caractériser chacune d'elles, il fallut créer une méthode; et celle-ci vermit non seulement de les classer, mais de mieux définir les coupes des terrains secondaires plus anciens; de reconnaitre l'existence de terrains quaternaires plus récents; 
de démontrer, enfin, que les couches sédimentaires forment une série continue, commençant aux terrains de transition et finissant aux alluvions actuelles... Dans le sol des environs de I'aris, Cuvier et Brongniart constatèrent l'œurre distincte de trois mers qui, après l'avoir occupé chacune au cours de longs siècles, l'araient abandonné pendant des périodes non moins prolongées. (Dumas.)

Or, comnent reconstituer cette histoire des couches terrestres, qui apparaissait si compliquée? Ce fut l'œurre surtout de Brongniart. Les coquillages et les ossements fossiles lui fournirent les points de repère. Il apprit à les considérer " comme autant de médailles capables de fournir la date de leur dépôt ". C’est sur ces données qu il publia (1808, en collaboration avec Cuvier, sa "Deseription géologique des environs de Paris ".

Pour la minéralogie proprement dite, signalons le "Traité de ninéralogie " publié ell 1801 par нaüy.

\section{Les sciences médicales 1 .}

Anatomie. - Un des plus grands anatomistes de cette périude. ce fut bichat, qui, en 1797 , ourrit un cours privé

1. Cuvier (Éloge de Corvisart) constate que l'enseiquement médical de lo Faculte de Paris séłait peu amélioré à la veille de la Révolution. "Tous ses nembres recevaient, avec le tilre de docteur, le droit d'enseigner, mais ils n'en contralaient pas le devoir ". Elle n'avait done pas de professeurs en titre : les jlus jeunes doeteurs passaient dans les chaires a tour de röle, D'y re-taient pas l, lus de deux ans, " se hatant de s'aequitter de celte corvè pour acquerir le titre de doeteur-régent. " 11 n'Y avait toujours pas de cltnique ou lestns publiques au lit des malades : les jeunes medecins ne pouvaient se former qu'en accompagnant les anciens dans leurs tournées do risite. En somme, le siège du progrès médical n'élait point a la Faculté, mais a l'Academie de médecine et dans les chaires du Collége de France.

"Les hábiludes et l'txtèrieur des médecins, continue Cuvier, n"ètaien" guère moins antiques que le récime de la Faculte. Si holiere leur avait fait quitter la robe et le bonnet pointa, ils avaieut au moins garde la perruque a marteau, que personne ne portait plus, et était dès leur entree en fonetions qu'ils devaieut s'en affubler. On assure que $\mathbf{3 1}$. Corvisart et M. Hallé ont été les premiers à donner le scandale de ne point la prendre, et qlis cette legereté. comme on l'appelait, leur duisit beacoup. "Le premier, qui était candidat a la direction d'un húpital qu'une grande dame vezait de fonder, en fut écarté, ear la fondatrice, u dés le premier mot, lui dèlara que son hỏjital n'aliait jamais ua medecin sans perruque .. 
à Paris. En 1801, il fut médecin à l'Hòtel-Dieu, et fonda la Société médicale d'émulation. Travailleur infatigable, on le voyait manger et coucher à l'amphithéàtre et faire jusqu'à 600 dissections en un seul hiver. Chose singulière, il dédaignait, dans ses études sur les tissus, le microscope, "dont la physiologie et l'anatomie, disait-il, ne me paraissent avoir jamais retiré un grand secours, parce qu'on regarde dans l'obscurité : chacun voit à sa manière et suivant qu'il est affecté ". C'est cependant l'emploi du microscope qui devait achever son œuvre, car, en notre siècle, l'anatomie sera surtout l'histologie '. Ses principaux travaux dans cette branche de la science sont le "Traité des Membranes " (1800), "l'Anatomie générale appliquée à la physiologie et à la médecine "(1801), le "Traité d'Anatomie descriptive " et "l'Anatomie pathologique ", qui parurent après sa mort (1802). Il semble avoir eu, de son vivant, moins d'influence sur les anatomistes que sur les médecins : parmi ceux-ci, il peut se glorifier d'avoir eu pour disciples Broussais, Corvisart, Laënnec.

Physiologie. - Les " Recherches physiologiques sur la vie et la mort " (1800) assurent également à BIcHat le premier rang parmi les physiologistes du temps. Il appartenait à l'école vitaliste ${ }^{2}$, dont Bordeu avait transporté les théories de Montpellier à Paris. Le chef de l'école était alors Barthez (mort en 1806).

Les théories dites matérialistes, en médecine, eurent pour principal représentant caBanis ${ }^{3}$.

LEgallois, médecin à Bicêtre, publia, en 1812, ses “ Expériences sur le principe de la vie, notamment sur celui des mouvements du cœur, et sur le siège de ce principe ".

Dotrochet, d'une famille ruinée par la Révolution, fut d'abord obligé, pour gagner sa vie, de servir comme médecin militaire dans la guerre d'Espagne. Nommé ensuite mélecin du roi Joseph (1808), puis devenu tout à coup riche vers trente-quatre ans (1810), il put se livrer à ses recherches physiologiques. En 1S06, il avait donné une

1. Étude microscopique des lissus.

2. Voir notre Hist. de la Civilisation frangaise, tome 11, pages $197-\mathbf{1} 98$.

3. Voyez ci-dessus, page 209. 
"Nouvelle théorie de la voix ", et, en 1810, une "Nouvelle théorie de l'habitude et des sympathies ". La plupart de ses travaux appartiennent à la période suivante ${ }^{1}$. Il appartenait, comme la plupart des illustres de ce temps, à l'école vitaliste.

PRosT s'est signalé par son "Essai sur la sensibilité " (1805) et ses "Trois coups d'œil sur la folie " (1S06) ².

Thérapeutique. - La thérapeutique, ou médecine proprement dite, eut alors d'illustres représentants.

BRoossars, merveilleusement doué au physique et au moral, d'une force herculéenne, d'un esprit brillant, d'une parole éloquente, fut d'abord soldat sous la Révolution, puis médecin de la marine et médecin militaire pendant les campagnes de la République et de l'Empire,

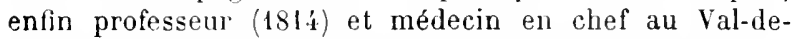
Gràce ${ }^{3}$. C'est un des noms les plus populaires de ce temps. En réaction contre le stimulisme de Brown *, il plaçait le germe de toutes les maladies dans l'inflammation des tissus; il préconisa la méthode antiphlogistique, destinée à calıner cette irritation, et en revint aux émollients, aux saignées, aux purgations. Ses principales œuvres de cette période portent des titres assez caractéristiques: "llistoire des phlegmasies ou inflammations chroniques" (1808), et "Examen de la doctrine médicale généralement adoptée "(1816).

corvisart fut, sous la Convention, professeur à l'École de Santé de Paris (1795); sous l'Empire, médecin de Napoléon; sous la Restauration, chef du service médical. Sa principale æuvre, dans la période qui nous occupe, c'est son " Essai sur les maladies et les lésions organiques du cœur et des gros vaisseaux "(1806). Un des premiers, il mit en pratique la méthode de percussion, qui consiste à frapper avec le doigt la cavité pectorale pour découvrir les lésions des organes. Il traduisit mème l'ouvrage de l'alle-

1. Notamment, Recherches anatomiques et physioiogiques sur la stricture intime des végétaux et des animaux (1834), et l'Agent immediat du principe vital dévoilé dans sa nature et son mode d'action (1847).

8. Le dernier ouvage de Prost fut son Traité du choléra morbus (1832).

3. En 1831, il devint professeur à la Faculté de Paria.

4. Voir nolre Hist. de la Civilisution francaise, tome II, page 198. 
mand Auenbrugger sur cette méthode, qu'il employait d'ailleurs concurrenment avec celle de l'auscultation ".

Le breton LAËNNE avait commencé par être médecin militaire daus les campagnes contre les chouans du Morbihan. Il s'occupa des maladies des organes pectoraux, telles que l'anévrysme, les tubercules, et des maladies des organes abdominaux, telles que la péritonite. Il perfectionna la méthode dauscultation en inventant le stéthoscope, une sorte de cornet acoustique qu'on applique sur la poitrine du sujet et qui permet d'entendre tous les mouvements les organes et de reconnaitre ainsi les altérations quils ont pu subir. C'est un jeu d'enfants qui lui aurait suggéré l'idée de cette invention. Laënnec put dès lors établir avec précision les différentes phases d'évolution dans les affections pulmonaires.

bayle fut d'abord théologien, puis légiste, puis médecin militaire : en 1803 , il fut nommé médecin à la Charité. Ses principaux travaux ont porté sur les tubercules des poumons (1803) et sur la phtisie pulmonaire (1810). Longtemps après sa mort (1816), on publia ses " Recherches sur les maladies cancéreuses ".

Les écrits de portal ont porté sur la rage (1779), la phtisie pulmonaire (1792). le rachitisme (1797), la petite vérole (1799), l'apoplexie (1811), les maladies du foie (1813), et sur ce qu'il appelle les muladies de fumille (1808).

THOdRET est surtout célèbre pour avoir introduit en France (1801) la pratique de la vaccination, inventée par Jemuer, et pour avoir, de concert avec La Rochefoucauld-Liancourt, formé des comités destinés à propager et vulgariser les mesures de préservation.

HALLE். qui fut professeur en 1790 à l'École de santé de Paris, s'occupa aussi de propager la vaccine. Il est le créateur, en France, de l'enseignement de l'hygiène, sur laquelle il publia, en 1806, un traité de premier ordre.

Marc, qui fut plus tard médecin de Louis-Philippe, peut être considéré comme le fondateur, en France, de la módecine légale, celle qui met à la disposition de la justice les ressources de la science pour la recherche des crimes. 
Pratiquée, depuis le xvie siècle, devant les tribunaux d'Italie et d'Allemagne, elle était restée à peu près inconnue en France, avant la publication, en 1793̈, du livre de Marc sur les poisons considérés au point de vue judiciaire.

En Angleterre, Dalton (1798) et roung (1807) constataient et définissaient cette affection de la rétine qui consiste en une perversion du sens des couleurs et qu'on a appelée le daltonisme.

Psychiatrie. - Une branche importante de la science, c'est la psychiatrie (médecine de l'àme), qui a surtout pour objet les maladies mentales. Elle avait été pratiquée dans l'antiquité, puis oubliée au moyen àge. C'est depuis la Renaissance surtout qu'on s'était montré dur pour les aliénés; dans beaucoup d'hospices, les médecins dédaignaient de s'en occuper, les abandonnant aux soins plus ou moins éclairés des moines. Les malades tranquilles étaient livrés à eux-mêmes; les malades agitès étaient cruellement traités : on les chargeait de chaînes, on les enfermait dans des prisons, dans des cachots, dans des cabanons, dont on montre encore un à la Salpètrière. On les laissait dans la malpropreté, les privations, la misère la plus affreuse. On cherchait à dompter à force de coups la révolte de leur sysième nerveux que létraquait la folie. "On auradit dit autant de criminels voués d'avance aux supplices de l'enfer. " Les Anglais out eu l'honneur de précéder toutes les nations dans une méthode plus humaine de traitement. Ils avaient, depuis 1347, l'asile de Bedlam; depuis 1751, l'hospice Saint-Lucas à Londres ${ }^{1}$. La Grande-Bretagne possédait aussi de nombreux établissements privés. A Paris, nous avions Bicètre et la Saljêtrière, où les fous étaient confondus avec les criminels et les vagabonds ${ }^{2}$, et où les vieilles et barbares pratiques étajent encore en vigueur.

En 1791, l'Académie de médecine mit au concours ce sujet : " Des moyens les plus efficaces de traiter les ma-

1. Il est vrai qu'encore eu 1770 on montrait les fous furieux pour do 'argent et qu'on laissait les autres mendier auprès des visiteurs.

2. L'ancieu point de vue sur les maladies mentales était encore si uicrédité, que le Code pénal de 1810, article 475, confond dans un méme article répressif tous ceux qui laissent divaguer "des inseusés ou furieux, ou den animaux malfaisants ou féroces". 
lades dont l'esprit est devenu aliéné ". Le lauréat de ce concours fut pinel. Il est le premier chez nous qui ait étudiè méthodiquement les maladies mentales, collectionné les cas, dressé des tableaux des causes et des effets. Il arriva ainsi à cette conviction que, dans beaucoup de cas, " la manie est une maladie passagère, qui se guérit, comme la fièvre, pour peu qu'on ne la trouble pas dans sa marche ". Nommé médecin, en 1792, de Bicêtre, en 1794, de la Salpètrière, il obtint que les aliénés fussent séparés des criminels. Au grand étonnement du rude conventionnel Couthon, il osa se rendre au milieu des aliénés les plus dangereux, fit tomber leurs chaînes, interdit aux gardiens tout mauvais traitement en actes ou en paroles, et, par la douceur. obtint des résultats surprenants.

Pinel a publié la " Nosographie philosophique " (1789), qui a eu cinq éditions en vingt ans et a été traduite trois fois en allemand, le " Traité médico-philosophique sur l'aliénation mentale " (1801), et la "Médecine clinique de la Salpètrière " (1802).

Il eut, en 1811, pour successeur tans cet établissement ESQUIROL, qui a comme lui bien mérité de l'humanité. C'est lui qui, en 1817, créera la première clinique psychiatrique. Tous ses travaux, jusqu'à 1838, ont eu pour objet les maladies mentales. Dès 1805 avait paru son livre «Des passions considérées comme causes, symptòmes et moyens curatifs de la manie ${ }^{1}$ ".

Chirurgie. - Les longues et sanglantes guerres de la Révolution et de l'Empire n'ont donné que trop d'occasions aux chirurgiens de se perfectionner. Non seulement ils avaient à relever sur les champs de bataille d'Essling, de Wagram, de la Moskova, de Leipzig, parfois 60000 ou 100000 blessés; mais, dans l'encombrement des ambulances et des hòpitaux, ils avaient à lutter contre cette suite des blessures plus meurtrière que les blessures ellesmèmes: la gangrène ou pourriture d'hópital. Nos chirurgiens acquirent alors une habileté de main, une rapidité

1. Le premier, il distingua ces maladies en cinq groupes principaux : mélancolie, ou délire partiel sans excitation; monomanie, ou délire partiel avec excitation; manie. ou délire général; demence, ou folie proprement dite; idiotisme, ou affaissement des facultés. 
d'exécution merveilleuses; peut-ètre furent-ils un peu trop enclins aux opérations radicales, le temps et les ressources leur manquant pour une chirurgic plus expectante et plus conservalrice. Ils avaient en Europe une grande renommée : l'établissement, en 1806, d'un concours pour les professcurs de chirurgie, malheureusement supprimé en 1810, avait donné une vive impulsion aux études.

Le $x$ vuse siècle nous avait légné un chirurgien éminent : SABATIER, mort en 1811, qui fut médecin en chel des Invalides, qui publia, de 1796 à 1798, son fameux "Traité ", et dont les disciples s'appelèrent Desault, Larrey, etc.

DESAULT, mort en $179 \%$, fonda chez nous l'enseignement clinique chirurgical. Il fut le maître de Bichat, de Larrey, de Richerand. Sa principale œuvre, "les Maladies chirurgicales ", est de 1789. Il excella surtout à traiter les anévrysmes, les luxations, les fractures. Il fut un des premiers à pratiquer rationnellement la ligature des vaisscaux.

Pierre Lassos, mort en 1807, fut professeur à l'École de Santé, puis chirurgien consultant de Napoléon. Son "Traité élémentaire de médecine opératoire " date de 1794.

PELLETAN, renommé par son éloquence comme professeur, a publié, en 1810, sa "Clinique chirurgicale ".

Dans la chirurgie civile, on doit encore citer Francois CHOPARD, mort en 1795, qui s'occupa surfout des lésions internes, el RICHERAND, qui traita, en 1799 , des fractures du fémur. Passons aux chirurgiens militaires.

BOYER, qui avait d'abord été apprenti barbier à Uzerches (Corrèze), devint professeur el chirurgien à l'llỏtel-Dieu, médecin en chel de la Charité, premier chirurgien de Napoléon, membre de l'Académie des Scieuces. Son a Traité complet d'anatomie commença à paraitre en 1797 , et son - Traité des maladies chirurgicales on 1814 .

PERCY, qui avait débuté en 1776 comme médecin militaire, qui suivit en cette qualité les campagnes de la République et de l'Empire, el dont Napoléon fit un baron, a contribué à organiser le service de secours aux armées. Chirurgien en chef dès 1792, il établit un bataillon de soldats d'ambulance et une compagnie de brancardiers. Plus tard, avec Larrey, il s'occupa d'organiser les ambulances mobiles. On lui doit le Manuel du chirurgien d'armèe, 
(1792), et la "Pyrotechnie chirurgicale" (179'), où il traite de l'emploi du feu dans les opérations.

heURTELOdP, qui mourut en 1812, chirurgien en chef des armées et baron de l'Empire, s'est signalé par un travail sur le tétanos (1792).

Le plus illustre des médecins militaires de l'époque, c’est LARREY (1766-1842). Son histoire, c'est presque celle des guerres de ce temps. En 1792, nous le trouvons aide-major à l'armée du Rhin; puis chirurgien en Italie, en Égypte, en Espagne, en Allemagne. A la suile de la bataille de la Moskova, il lui faut exécuter de ses propres mains 200 amputations par jour. Après avoir fait vingt-cinq campagrnes, il se retrouve encore à Waterloo, où il est blessé et pris par l'ennemi. L'empereur Napoléon, à Sainte-Hélène, lui fit, par testament, un legs important, comme à "l'homme le plus vertueux que j'aie rencontré ». Nul n'était plus digne d'avoir sa statue dans la cour du Val-de-Gràce, devenu notre grand hòpital militaire. La Restauration, après l'avoir mis en disgrâce, fut bien obligće d'avoir recours à ses services ". Nombreux sont ses ouvrages : "Mémoires sur les amputations des membres à la suite des coups de feu " (1797); "Relation historique et chirurgicale de l'armée d'Égypte "; " Mémoires de chirurcie militaire " (1812-1817). Larrey, cette providence de nos soldats dans les grandes guerres de ce temps, s'est ingénié à perfectionner les instruments et les pansements. Une de ses plus heureuses innovations, c'est lemploi de la méthode d'irrigation: gràce à un filet d'eau continu, il parvenait à faire cesser l'inflammation des plus cruelles blessures et à rendre parfois l'amputation inutile.

Déja commençait la carrière de Dopurtren, fils d'un pauvre avocat d'une bourgade de la Haute-Vienne. En 1801 , il entrait conme prolesseur à l'Ecole de médecine; en 1812. il succédait à Sabatier comme premier chirurgien à HHôtel-Dieu; en 1803, il fonda la Société anatomique, qui ne tarda pas à se dissoudre, pour reparaitre en 1826 Nous reviendrons plus loin sur ses travaux.

1. Larrey mourut en 1842 à la suite d'une iaspection dans les hòpitaux de l'Aigerie. Il a encore laissé des travaux sur la fièvre janne (1821), une notice sur le chotera (1S31), un grand travail avec atlas sur la clinique chirurgicale et une Relation nédicale des campagnes de 1815 à 1840 . 
Cette période de l'histoire chirurgicale vit commencer ane série de curieuses tentatives. En 1800, Lucas, médecin de l'armée des Indes, introduisit en Europe ces opérations plastiques, que les Orientaux connaissaient depuis longtemps, et qui consistent à refaire avec la chair vive telle partie du visage. Lucas avait vu le sultan Tippo-Saëb faire couper un nez, et un médecin indigène recoller ce nez au patient et le faire reprendre; il avait vu aussi refaire des nez avec la peau empruntée au front. C'est ce procédé qu'il nous fit connaitre sous le nom de rhinoplastre. Après lui, chOPART refit des lèvres. Une autre opération plus hardie encore, c'est celle de la cransfusion du sany: elle fut pratiquée d'abord sur des animaux; mais, en 1792, l'Anglais russell osa infuser du sang de mouton à un jeune homme atteint d'hydrophobie.

Pharmacie. - Dans la pharmacie, le plus grand nom de l'époque, c'est celui du chimiste bounLON-LAGRANGe, élève de Rouelle, médecin de l'impératrice Joséphine $(1 \$ 06$ et directeur de l'École de pharmacie. Il donna, de 1790 à 1813, plusieurs ouvrages très estimés.

\section{En 1803, furent fondées les Ecoles de pharmacie.}

Ouvrages a constlter. - Hoefer, Hist. des mathematiques; Hist. de lastronomie; Hist. de la physique et de la chimie; Hist. de la zoolngie; Hist. de la botannque et de la géologie (collection V. Durny.) - Rapports de Delambre, Cuvier, ete., sur les progrés des sriences (1808).

Faye, Théories cosmogoniques des anciens et des modernes. -- Dumas, Lecous de philosuphie chiminue(1837). - Carus, Hist. de la zoolunie (tr. 1 - G. Cuvier, Hist. des proyres des sciences nuturelles depuis $7789(183,4)$ - I adenburg. Hist. du dévelo/. de la chimir depnis Lawoisier (1910).

Joseph Bertrand, L'Academie trs sciences et les academiciens de tibti a 1793 (1858). - Naindron, L'Aculimie des scrences (1848). - Biot, Essur su" l"hast. génerale des sciences put dant lic Revolution (1s03). - Payeu Les sciences perdant la Révoluition (Revuc des Leu.c. Hondes, 15 juin 1866 . - Ch. Dupin, Essai hist. sur Gaspard Monge 1S19). - Arago, Biogruphic de llonge (1xios et Biographip d. Camot (1860); Hist. de ma jeuness" (1)i) - Lonel, Bioar. de F'. Arag (15i3. - Flourens, Travaus de Cir- vier (1811). - Jaubert, Yotice sur Biot (1862). - Buisson, Proels sur Bichat (1892). - Curier. Eloyes do Daubenton, Adanson, Ch. Bonnet, Bénédict de Sausstre, Werner, liäy, Berthollet, Lacepeide, etc. - E. Griminx, Lamisier, 176-1794 (1588).

Maxime Helène, La poulre a cunon et les nouveant corps replosifs (15×6).

llaremberg, Hist. des sciences medicales, t. I1 (1,70). - Hreser, Hist. de la médecine (en alleman1) (NŚs). - Cabanis, Coup d'ifil sur les revulktions de la médecine 180 - 1 -F. Lonz, Hist. des progrès delumélecine mentale. - Rochard, Hist de lachinurgie francaise au NI. $\mathbf{I}^{\mathrm{e}}$ siecle (15i). Sabatier, Recherches historiques sur la Farulté de mislecine.

E. Pariset, Hist. des membres ae l'A cadèmie de médecine (1515-50). Cuvier, Eloges de Lassus, Tenon, Hallé, Corvisart, Pinel. - Corvinart, Notice sur Bichat. - Duliois, Eloge de Bronssais. - Leroy-Duple, Larrey, chirurgien en chef de la GrandeArmé (1860).

Chappe, Hist. de la titégraphie (1524). - J. Turgan, Les bullons, hist. de la locomotion aérienne IS51). 


\section{CHAPITRE XIII}

Lagriculture, L'industrie, Le Commerce, LE Crédit

\section{L'agriculture.}

Lois agraires de la Constituante. - Les célèbres décrets de la nuit du 4 aoùt avaient aboli la féodalité; mais il ne suffisait pas de décréter cette abolition, il fallait la réaliser. C'était une opération difficile et compliquée : il latlut s'y reprendre à plusieurs fois.

La Constituante s'était avisée d'établir une distinction entre les droits seigneuriaux, qui témoignaient de l'ancien asservissement du paysan, et ceux qui avaient été, assurait-on, librement consentis entre les propriétaires nobles et les roturiers. Elle établissait done deux catégories de ces droits : ceux qui procédaient de la féodalité dominante et ceux qui procédaient de la féodalité contractante.

Les premiers devaient être supprimés sans indemnité : ainsi disparurent le servage et le droit de mainmorte; les droits de chasse, colombier, préage, ravage; les droits de déshérence, de bàtardise, d'aubaine, d'épave; la corvée et la taille seignenriales; les banalités de pressoir, de moulin, de four; les péages seigneuriaux sur les routes, les ponts, les rivières, les marchés, etc.

Les seconds étaient supposés avoir été consentis par le paysan, en échange de terres concédées par le seigneur ou de services rendus par lui : parmi ceux-ci, le cens ou rente seigneuriale, les lods et ventes, ou droits de mutation. Ils 
ne devaient ètre abolis que moyennant une indemnité, rente ou somme d'argent, payée au propriétaire noble.

C'étaient donc les impôts les plus lourds qu'on laissait subsister. Le paysan continuerait à payer, comme droits fonciers, les mêmes rentes qu'il payait autrefois comme droits féodaux; ces charges pèseraient sur la terre et devienIraient mème plus lourdes à mesure que la valeur des biens ou le rendement du sol augmenteraient; elles assureraient it l'ancien seigneur une part de tous les bénéfices que le paysan pourrait réaliser par les perfectionnements apportés à sa culture; elles seraient toujours là pour décourager le laboureur de toute amélioration et maintenir l'agriculture dans son enfance. Le paysan français se serait trouvé à peu prìs dans la même situation que le paysan anglais ou irlandais d'aujourd'hui, qui ne subit ni servage, nı corvée, ni banalités, mais qui s'épuise en rentes et en droits de mutation. La fortune immobilière resterait toujours aux mains de l'aristocratie, et tout essor de la démocratie serait arrêté.

Cepcndant la Constituante ne pouvait guère aller plus loin : non seulement elle se composait encore, pour moitié, de privilégiés, mais beaucoup des députés bourgeois avaient acheté des fiefs et des terres nobles; beaucoup d'autres, comme avocats, procureurs, intendants, vivaient de la noblesse : ils étaient, suivant l'expression du temps, des valets de seigneurie.

Lois agraires de la Législative. - L'Assemblée suivante, par le décret du 18 juin 1792, déclara abolis sans rachat "les droits connus sous les noms de quint, requint, treizième, lods et treizains, lods et ventes et issues, mi-lods, rachapts, ventroles, reliefs, relevaisons, plaids-aeapte, arrière-acapte et autress, sous quelque dénomination que ce soit, qui se percoivent à raison des mutations qui surviennent dans la propriété ou la possession d'un fonds, sur le vendeur, l'acheteur, les donataires, les héritiers et tous autres ". C'était supprimer toute distinction entre la féodalité dominante el la féodalité contractante.

Pour les autres droits, appelés droits casuels, que l'As. semblée consent à maintenir, ce sera au propriétaire à fournir la preuve qu'il y a eu contrat: or, comme le plus 
souvent on ne peut produire de titres, soit parce qu'il n'y en a jamais eu, soit parce qu'ils se sont perdus, la loi nouvelle est toute en faveur du paysan. La Législative abolit quelques banalités qu'avait réservées la Constituante sous prétexte qu'elles étaient la rémunération de services rendus par le seigneur.

Lois agraires de la Convention. - La Convention va encore plus loin. Elle abolit mème les droits casuels qui auraient été le prix ou la condition d'une concession de terre. Elle ne se préoccupe pas de déterminer quel est exactement le droit du propriétaire noble et celui de lancien vassal; elle dénie tout droit au premier; elle ne se soucie pas d'ètre juste, pourvu qu'elle favorise le paysan. Avant tout, elle poursuit un but social : la destruction de l'aristocratie et le triomphe de la démocratie dans les campagnes. Dans sa haine contre la féodalité, elle n'admet pas qu'elle ait jamais été contractante; elle entend abolir jusqu'à son nom et à sa mémoire; pour empêcher qu'on puisse jamais revenir sur cette abolition, elle décrète "que tous les fitres féodaux devront être déposés dans les trois mois au greffe des municipalités et qu ils seront brûlés en présence du conseil municipal et de tous les citoyens".

Le 7 septembre 1793, nouvelle loi, encore plus impérative, qui semble vouloir poursuirre par delá les frontières et par delà les mers la féodalité vaincue : " La Convention nationale décrète qu'aucun Français ne pourra percevoir des droits féodaux et des redevances de servitude en quelque lieu de la terre que ce puisse être, sous peine de dégradation civique. "

Ainsi la Constituante, dans sa tentative pour faire la part du noble et du paysan, avait conservé une certaine partialité pour le premier; la Législative cherche à ètre juste pour tous deux; la Convention favorise le paysan jusqu'à l'injustice envers l'ancien propriétaire. La Constituante n'avait affranchi le paysan que des droits les plus oppressifs; la Législative l'affranchit de tous ceux qui ne sont pas fondés en justice; la Convention l'affranchit même de ceux qui pouvaient se justifier. Avec le systeme de la Constituante, le paysan restait, sous d'autres noms, le tenancier des anciens maitres; la Législative l'en rend pleinement indé- 
pendant; la Convention l'enrichit mème à leurs dépens. Ainsi, tandis qu'en Angleterre, en Allemagne, en Russie, le paysan n'a pu recouvrer la libre disposition de sa terre qu'en payant aux seigneurs, en échange de leurs anciens droits, de larges indemnités, la Révolution a donné gratuitement au paysan français l'affranchissement. Ce que les rois et les nobles, dans leurs bons jours, lui avaient vendu en détail et chèrement, elle le lui donna en bloc et gratuitement. La liberté du sol fut, pour le campagnard, la “dot de la Révolution".

Multiplieation des propriétés rurales. - La Révolution a eu d'autres conséquences. Non seulement le cultivateur devint le maitre de sa terre, mais il put l'agrandir.

Les biens dits communaux étaient alors beaucoup plus étendus qu'aujourd'hui : ils étaient comme un vestige le l'ancienne organisation agraire, qui subsiste en Russie encore de nos jours, et dans laquelle la terre reste indivise entre tous les habitants d'un village. Ces terres, appartenant à tous, étaient mal cultivées et rendaient fort peu. De plus, les seigneurs avaient fait consacrer, par l'ordonnance forestière de 1669, les usurpations qu'à la laveur du droil de tiers ou de triage ils avaient commises sur cette propriété commune, accaparant ainsi les bois, les pâturages, les landes, les marais. La Constituante abolit pour lavenir le droit de triage. La Législative, donnant à cetle mesure un effet rétroactif, autorisa les communes à ressaisir tous les terrains qui avaient été occupés sans titre. Dans le cas où le seigneur pouvait opposer des titres à ceux des communes, les titres les plus favorables à celles-ci devaient être préférés. Les communaux ainsi reconstitués, on autorisa les communes à les partager entre tous les habitants, à l'exception des bois. La Législative rendit ce partage obligatoire. La Convention le rendit de nouveau facultatif (10 juin 1793), mais ordonna qu'il aurait lieu dès que le tiers des voix dans la commune le demanderait: il se ferait par tête d'habitant, sans distinction d'àge ou de sexe. On remarque que les communes les plus riclies aujourd'hui sont celles qui ont effectué ce partage.

Les biens dont l'Église avait été dépouillée, les biens qui furent confisqués sur les nobles coupables davoir pris 
les armes contre la République ou simplement d'avoir émigré, furent déclarés biens nationaux et mis en vente. Le paysan put les acquérir à vil prix, avec du papier-monnaie tombé en discrédit. Les soldats qui avaient combattu pour la liberté devaient aussi recevoir, à titre de défenseurs de la patrie, des dotations en terres. Nombre de chàteaux et d'abbayes furent démolis; les forêts seigneuriales et abbatiales, les grands parcs, les vastes prairies, furent morcelés, dépecés, et ceux qui avaient été si longtemps les sujets du château ou de l'abbaye se partagèrent leur dépouille. Sans doute, les gros capitalistes, les spéculateurs, les gens de la Bande noire, prirent souvent les devants sur le paysan, achetèrent en gros et lui revendirent en détail, s'enrichirent du profit que, plus avisé ou plus hardi, il aurait pu réaliser lui-mème; mais la terre n'en finit pas moins par lui revenir, et des milliers d'hommes arrivèrent ainsi à la propriété ${ }^{1}$.

Il se forma ainsi une classe nombreuse de citoyens, ardents au travail comme autrefois, mais fiers de la liberté conquise, plus attachés que personne aux principes de 1789 et plus hostiles à toute tentative de retour vers le passé. C'est la démocratie rurale de France, la plus puissante qu'il $y$ ait dans le monde.

Cette démocratie rurale sort tout à coup de son humilia tion séculaire; elle, qui n'a point de passé, point d'aïeux, s'en crée tout à coup: elle joue sur la scène du monde le plus grand rỏle qui ait jamais été dévolu à aucun peuple: des députés-paysans siègent sur les bancs de nos assemblées; des armées de soldats-paysans, conduites par des généraux-paysaus, font la conquète de l'Europe.

Progrès de lagriculture. - L'agriculture se développa rapidement. De vastes espaces furent ensemencés en blé;

1. "Les fermiers, écrivait une voyacreuse anglaise en 1792, sont les plus satisfaits de la Révolution, et ils ont leurs raisous pour cela. En ce moment, ils refusent de vendre leur blé autrement que pour de l'argent, tandis qu'ils payent leurs fermages en assignats... On les encourage beaucoup aussi a acheter dos proprietes nationales, et cela, me dit-on, peut devenir dangereux pour l'agriculture, car, daus leur ardeur pour acquérir de la terre, ils se privent des moyens de la cultiver.... La rage de l'émigration, que les approches de la guerre, l'orgueil, la timidité et la vanité augmentent chaque jour, a engagé beaucoup de nobles à vendre leurs terres; avec celles de la courone et du clergé, elles forment une grande masse qui a été jetèe, pour ainsi dire, dans la circulation générale. * 
500000 hectares furent plantés en pommes de terre; la culture de la vigne, de la garance, du pastel, de l'œillette, se développa; celle du lin fut encouragée par les prohibitions ou les droits sur l'importation du coton; celle de la betterave, par l'interdiction des sucres coloniaux. Les greniers, les étables, vidés ou dépeuplés par les réquisitions de la Convention, se remplirent de nouveau quand un gouvernement régulier s'établit. La terre, cultivée par le paysan à son propre profit, produisit davantage. Une preuve incontestable des progrès du bien-ètre dans les masses rurales, c'est, malgré la fréquence des guerres, le nombre croissant des mariages et le chiffre croissant de la population ${ }^{1}$. Celle-ci, surtout dans les campagnes, s'augmentait d'une manière continue et dans une proportion beaucoup plus rapide qu'aujourd'hui.

La Societe d'agriculture de France, qui remontait à 1761 . fut réorganisée en 1804 .

\section{L'industrie.}

L'industrie pendant la Révoiution. - La Constituante ne s'ètait pas bornée à émanciper l'industrie des liens des corporations par la loi de 1790; par celle de 1791, elle créa les trevets d'invention et assura ainsi la propriété industritle.

Malheureusement, il survint des années de crise terrible qui empêchèrent le travail de profiter de ces réformes. Toutes les industries de luxe, articles de Paris, meubles, vaisselle, furent tuées par l'anarchie, l'émieration, la Terreur, les emprunts forcés sur les citoyens riches. La politique en plein air, les discussions des clubs, le service de la garde nationale ou de l'armée, firent déserter les ateliers. L'insurrection de Lyon, puis la sévère répression qui suivit, anéantirent l'industrie de la soie (1793).

1. En 1800, il y eut 198000 mariages et 903000 naissances; en $180 \mathrm{i}$, 214000 mariages et 912000 naissances; en 1809,267000 mariages et 933000 naigsances; en 1814, les mariages se réduisent a 193000, mais il y a 991000 nilissances, 11 n'y eut de légères disettes que dans les années 1802 à 150\%, 1807, 1811 a 1814 . Au contraire, les années 1809 et 1810 furent une époque do belles récoltes et de grande prospérité. 
Les ouvriers, dès 1791, avaient formé des coalitions ế pétitionné pour faire augmenter le prix des salaires. La municipalité parisienne essaya vainement de les apaiser en invoquant la liberté qui doit présider aux transactions entre ouvriers et patrons et les principes immuables de l'économie politique. La loi de $179 /$ (14 juin) interdit ces associations sous peine d'amende et de prison. "Sans doute, disait le député Chapelier dans son rapport, il doit etre permis à tous les citoyens de s'assembler, mais il ne doit pas ètre permis aux citoyens de certaines professions le s'assembler pour leurs prétendus intérèts communs... Les caisses de secours sont inutiles, car c'est à la nation à fournir des travaux à ceux qui en ont besoin pour leur existence, et des secours aux infirmes. "Ainsi la Constituante, en méme temps qu'elle refusait une liberté nécessaire, patronnait la dangereuse utopie du droit an travail.

Comme le chómage était devenu général, on ouvrit des ateliers nationaux; mais, comme ils ne servaient qu'à décourager ceux des ouvriers qui persistaient à travailler comme autrefois, on les ferma. Beau oup, pour avoir du pain, s'enrôlèrent dans les armées des frontières ou dans l'armée révolutionnaire de l'intérieur.

Le travail ne reprit un peu que sous le Directoire. Pourtant, plusieurs millions alors accordés à Lyon ne réuscirent pas à relever son industrie. A Paris mème, on constatait que les ouvriers des Gobelins neetaient pas payés. Pour stimuler un peu la production. François de Veufchìteau, ministre de l'intérieur. imagina de réunir au Champ de Mars la première exposition nationale de l'industrie française. Soit que celle-ci fût encore trop éprouvée, soit qu'on n'eìt pas été prévenu à temps, il ne se présenta. que 111 exposants, auxquels on distribua douze médailles. Cependant on y remarqua le développement de l'industrie métallurgique du Creusot et des essais de filature mécanique qui annonçaient l'avènement prochain des machines.

L'industrie sous Napoléon : la réglementation. Napoléon, Premier consul ou Empereur, eut pour premier souci de rétablir une certaine discipline parmi les classes ouvrières. Il dépassa la mesure, et. sur certains points, son préfet de police, par une réglementation minutieuse 
et tracassière, en revint presque à reconstituer l'ancien régime. Les boulangers de Paris, au nombre de 641, les bouchers, au nombre de 4วั0, réduits ensuite à 300, furent réunis en corporations et soumis à une rigoureuse surveillance. Ce qui prouve, cependant, que ces mesures n'étaient pas absolument contraires à l'opinion de l'époque, c'est que les marchands de vin sollicitèrent, en 180', la mème réforme: ils ne furent pas exaucés. La police dez halles, des marchés. fut à peu près celle de la monarchie. Les colporteurs, commissionnaires, porteurs de charbon, reçurent une médaille avee un numéro; leur nombre fut rigoureusement limité. Les forts de la halle durent ètre commissionnés par l'administration. Les imprimeurs furent réduits à 60 ; en 1811 , ce chiffre se releva à 111. Comme les libraires, ils furent astreints à lobligation du brevet et au serment.

Une loi de 1903 interdit les coalitions d'ouvriers, en vue de cesser le travail. Elle ne s'expliquait pas sur les coalitions de patrons. Le Code pénal de 1810 fut un peu plus équitable: il ne punit que les ouvriers coalisés pour faire cesser le travail. Il visa aussi les coalitions de patrons; mais ceci n'était qu'un trompe-l'œil, car les patrons n'ont pas besoin de s'attrouper pour arriver à une entente.

Le livret d'ouvrier, mesure utile en soi, devint une mesure vexatoire, car on l'assujettit aux mêmes formalités que le passeport; l'administration le faisait payer 7o centimes à l'ouvrier; celui-ci devait le déposer entre les mains du patron qui l'embauchait, et, par là, se trouvait à sa discrétion. Le Code civil (dans son article 1781) contient une disposition assez peu équitable: "Le maitre est cru sur son affirmation pour la quotité des gages, pour le payement du salaire de l'année échue, et pour les acomptes donnés sur l'année courante. "

Une création utile fut l'établissement, en 1806, des conseils de prud'hommes dans 26 villes de France; mais l'organisation en était aristocratique; la moitié de chaque conseil était bien composée de patrons, mais l'autre moitié, au lieu de se composer d'ouvriers salariés, ne comprenait que des contremaitres et des ouvriers patentés, c'est-à-dire de petits patrons. La loi de $1 S 10$ conféra aux conseils de 
prud'hommes des attributions de justice correctionnelle, les autorisant à punir d'un emprisonnement qui n'excéderait pas trois jours les délits tendant à troubler l'ordre et la discipline des ateliers. Toutes ces lois constituaient donc une sorte de revanche des classes bourgeoises contre la dictature des classes populaires en 1793.

Progrès de l'industrie. - En 1801, Chaptal, Monge, Conté, Fourcroy, Berthollet fondèrent la Société d'encouragement pour l'industrie nationale, qui rendit d'éminents services. Un des caractères de notre histoire industrielle à cette époque, c'est le rỏle qu'y jouent les savants et le progrès accompli par les applications pratiques de leurs découvertes.

Napoléon emprunta à François de Neufchâteau l'idée des expositions nationales. Elles eurent alors beaucoup plus de succès. Celle de 1801 compta 229 exposants; celle de 1802, 540; celle de 1806, 1422.

Alors se signalèrent, parmi les industriels français, CBOpitel, serrurier, qui inventa une machine à découper les pièces Iaminées, de manière à fabriquer des fenètres toutes prètes à recevoir la vitre; BERNARD et CANDÉRE, qui trouvèrent un vernis contre la rouille; TREPPOz, qui importa en France la fabrique orientale de l'acier et produisit des rasoirs aussi bons que ceux d'Angleterre; ALBERT, qui imagina les scies sans fin; conté. l'inveuteur des crayons de mine de plomb, chimiste et métallurgiste si habile que, l'armée francaise en Égypte ayant perdu ses outils et ses machines, il y improvisa des fabriques d'étoffes. d'acier, de canons, d'instruments de chirurgie et de précision; LEBLANC, qui avait créé en 1791 la première fabrique de soude artificielle, mais qui s'était ruiné; segoin, qui s'enrichissait dans la tannerie; BESSON (1793) et CBAMPION (1811), qui fabriquaient le caoutchouc; nollerat. qui, s'inspirant des recherches de Vauquelin et Fourcroy, produisait le vinaigre de bois; Edouard aDAM, qui distillait l'alcool avec une perfection jusqu'alors inconnue; DARCET, qui, arec la gélatine extraite des os, obtenait une colle supérieure; BORDIERMarcet. qui inventa la lampe astrale, à couronne et suspendue, dont la lumière tombait d'en haut et ne portait point d'ombre; carcel, qui, en 1803, ajouta aux lampes un 
mouvement d'horlogerie pour faire monter l'huile régulièrement. Deux fabriques de maroquin avaient été établies, l'une à Choisy-le-Roi, depuis 1797, l'autre à Paris. CADET DE VAUX, chirurgien en chef du Val-de-Grice, fabriquait de la gélatine avec les os ou en tirait des engrais pour l'agriculture. Rochon imitait la corne transparente avec de la colle de poisson.

Les produits chimiques, après les recherches de Thénard, Berthollet, Fourcroy, etc., devinrent une branche importante de l'iudustrie nationale : on améliora la fabrication de l'acide nitrique; on créa celle des acides chlorhydrique et sulfurique, de l'ammoniaque, du blanc de céruse, de l'alun purifiè, des sulfates de fer et de magnésie. On employa le chlore pour le blanchiment des toiles, tandis que l'ancienne méthode, l'exposition sur le pré, exigeait des mois. chaptal l'employa aussi pour les chilfons destinés à la fabrication du papier.

Bucher, de Strasbourg, et Mlle sonthonax, de Nantua, fabriquaient des nankins; MonTagrin, de Tarare, des mousselines; Camille PERNoN, des brocards; GRÉGOIRE et VAJCBELET, des velours; MatiÉ, des satins. L'ébéniste Jacob DESMaLTer créait un mobilier nouveau. Dans l'orfèvrerie se distinguaient BIENNAIS, AUGUSTE et ODIOT; dans le bronze, thomine et ravrio. On disputait à l'Italie la fabrication des camées et mosaïques, alors fort en faveur chez nous.

Le luxe de la cour consulaire, de la cour impériale, des uniformes militaires, fut un sérieux encouragement à nos industries du vêtement.

Les meubles fabriqués dans le faubourg Saint-Antoine continuaient à s'exporter au loin.

L'usine métallurgique d'Essen, alors française, si célèbre depuis comme usine prussienne, naquit en 1810. La manufacture de Bischwiller donna des faux d'acier fin; celles de Moulins et de Langres, des couteaux et des ciseaux; celles de Thiers, des couteaux à bon marché ${ }^{\text {. }}$.

La fabrication du papier à la mécanique fut inaugurée à Essonnes, par LÉGER DIDOT. En 1799, un ouvrier, appelé

1. Par exemple, les eustaches, couteaux-sifflets de deux sous qu'admirait l'Anglais Fox à l'exposition de 1806, et dont il remplit ses poches pour les distribuer a ses amis de Londres. 
LOuis ROBERT, y inventa la machine à production continue, qui donne le papier sans fin.

PRIEOR, de la Côte-d'Or, ancien membre de la Convention et du Comité de Salut public, retiré en Bourgogne, montait une fabrique de papiers peints et renouvelait l'industrie inaugurée par RĖveILLON.

L'horlogerie de Besançon offrait des montres à tou prix, mème à 13 francs. La typographie parisienne, avec les дірот, la lithographie, avec Lasteyrie, de Paris, et Engelmann, de Mulhouse, donnaient des produits admirables.

Pour suppléer à la rareté du sucre colonial, ACBARD, un Prussien d'origine française (1796), DEROSNE (1904), PROJST et Pierre figdier (1810), bonmatin el Drapiez (1811), PERPère (1812), perfectionnaient la fabrication du sucre de betterave. Delessert fondait l'usine sucrière de Passy (1812) et CRESPEL-DELISSE celle de Lille (1812).

ALEXANDRE BRONGNIARD fut nommé, en 1800, directeur de la manufacture de Sèvres, poste qu'il occupa jusqu'en 1847 : il y rendit de grands services, car il y fit revivre la peinture sur verre, y perfectionna les émaux, y développa le Iusée de céramique, trouva moyen de fixer le vert de chrome.

En 1790 se fondait la verrerie de Saint-Louis (Lorraine).

Philippe Lebon. - Lebon, né à Bruchay (Haute-Marne) en 1769 , fut sur la voie d'une grande découverte. Il distilla le bois, en obtint un gaz d'éclairage et construisit les thermolampes, qui donnaient à la fois de la chaleur et de la lumière. Il prit un brevet dinvention et obtint de l'Empereur la concession de la forèt de Rouvray (Seine-Inférieure), qui devait fournir les bois à sa distillation. En 1805, il mourut à Paris, d’une façon mystérieuse. Son invention, portée en Angleterre, appliquée à la distillation de la houille, est l'origine de l'éclairage au gaz.

Eichard-Lenoir. - Richard, qui s'appela Richard-Lenoir, du nom de son associé, Lenoir-Duf́resne, était né à Épinay (Calvados), en 176. A dix-sept ans, il avait quitté son village en sabots, s'était fait garçon limonadier dans la ville voisine, ensuite à Paris, au café de la Victoire. Il avait monté ensuite un petit commerce et y avait si mal réussi qu'il fut prisopnier pour dettes. En 1797, il s'était associé 
avec Lenoir-Dufresne, d'Alençon, qui mourut en 1806, et avait commencé de vastes entreprises de filature de coton et de laine. Pour suppléer au coton d'Amérique et du Levant, dont les croisières anglaises privaient nos manufactures, il en avait semé dans le royaume de Naples. Napoléon, qui, par ses lois de douanes entre l'Italie et la France, nuisait beaucoup à cette industrie naissante, lui vint en aide en lui prêtant 1500000 francs. Richard fonda jusqu'à $\mathbf{4} 0$ filatures de laine et de coton, de nombreux ateliers de lissage, employa des milliers d'ouvriers, perfectionna les machines, amassa 1 ' millions, fut un des principaux champions de l'industrie nationale contre lindustrie britannique. Il se montra courageux citoyen lors de l'invasion: en 1814, il se signala à la bataille de Paris, et, en 1815 , se fit inscrire parmi les fédérés du faubourg SaintAntoine, levés à la voix de l'Empereur et au chant de la Marseillaise. Il mourut en 1839.

Philippe de Girard. - Né en 1775, au chàteau de Lourmaran (Vaucluse), Girard passa quelques années dans l'émigration. Ensuite, à vingt ans, il occupa la chaire de physique et chimie à l'École centrale des Alpes-Maritimes; à vingt-quatre, il professait un cours de physique à Marseille; il fut plus tard élève de Monge à Paris. Il joignait la science du théoricien à l'expérience de l'homme d'affíires. Rentré dans l'industrie, il fut le grand inventeur du temps. Il fonda, à Marseille, des savonneries, des usines de sel; à Paris, une fabrique de soude artificielle, une manufacture de tỏle vernie. 11 ajouta le systeme modérateur aux lampes Carcel, créa ainsi la lampe Girurd, fabriqua pour l'éclairage privé les globes en verre dépoli. Il imagina une lunette achromatique sans le concours du flintglass anglais, construisit la machine à vapeur à cylindre unique et à mouvement rotatoire sans balancier, qui fut aussitôt adoptée en Angleterre. Napoléon, qui voulait opposer à lindustrie britannique du coton une industrie française du lin, comprenant que le succès ne serait obtenu qu'à la condition de rèunir la modicité du prix à la perfection de la fabrication, rendit le fameux decret du 11 mai 1810. Il proposait un prix d'un million à quiconque, Français ou étranger, inventerait la meilleure machine à filer le lin, et 
ordonna de traduire ce décret dans toutes les langues. Soixante-sept jours après, Girard prenait son brevet. Il fit construire à Paris, par l'habile ouvrier Laurent, la première machine à douze broches, capable de tirer d'un kilogramme de lin 100 à 130000 mètres de fil. En 1813, il avait deux flatures de lin, l'une à Paris, l'autrc à Charonne. La chute de l'Empire l'empêcha de toucher le million promis et de donner à sa découverte toute l'extension prévue. Plus tard, en 1826, quand il visita la Grande-Bretagne, il eut la mortification de trouver les Anglais en possession de ses propres dessins et faisant fonctionner, à l'aide de sa machine, deux usines colossales ${ }^{1}$.

Jacquard. - Joseph-Marie Jacquard était né à Lyon en 1752. Son père et sa mère étaient des ouvriers de fabrique. Entré dans le commerce, il fit des affaires médiocres, fut proscrit après la révolte de Lyon en 1793, se fit oublier en se battant bravement à l'armée d'Alsace. Dès 1790, il cherchait à perfectionner la machine à tisser : le premier engin qu'il établit, quoique fort imparfait, obtint une médaille de bronze à l'exposition de $1801{ }^{2}$.

Cette invention, successivement perfectionnée, est devenue le fameux métier à la Jacquard, qui permet à un seul ouvrier de tisser une étoffe du dessin le plus compliqué. Elle fut cédée par lui à l'État, moyennant une rente viagère de 3000 francs, et tomba ainsi dans le domaine public. Elle ne devait donc pas enrichir son auteur. D’abord, les ouvriers de Lyon, irrités comme ils l'étaient tous alors, en Angleterre et en France, contre les machines, I'avaicnt persécuté : ils le jetèrent, un jour, dans le Rhòne; sa machine fut brisée publiquement par sentence du conseii des prud'hommes. A la fin, il eut la satisfaction d'assister au triomphe de son idée : en 1812, il y avait à Lyon, dont la fabrique s'était relevée par sa découverte, 12000 métiers à la Jacquard, et quand il mourut, en 1834, 30000 .

L'avènement des machines. - Avant la Révolution, notre industrie avait négligé d'emprunter à l'Angleterre

1. Il mourut de misère à Paris, en 1845 , lui qui avait eu, avant la Révolution, une fortune de 6 à 700000 livres.

2. En mėme temps, il inventait une machine à fabriquer dos filets pour la pèche maritime, et obtint une médaille d'or à l'exposition de 1804. 
les machines nouvellement découvertes, dont les Anglais interdisaient d'ailleurs l'exportation et dont ils gardaient le secret comme un secret d'État. La longue guerre de vingt-deux ans, qui se continua presque sans interruption, de 1793 à $181 \%$, entre les deux pays, les empècha de profiter, aussi promptement qu'ils le font aujourd'hui, de leurs inventions respectives.

C'est le moment où l'Angleterre commence à être en possession de son outillage industriel, où elle exploite sérieusement ses mines de fer et de houille, plus précieuses que les mines d'or et d'argent de l'Amérique espagnole; où WATt lui donne la machine à vapeur; où AREWRIGHT la dote de la machine à filer ${ }^{1}$; où la production des fils et tissus de coton va devenir mille fois plus grande ${ }^{2}$; où celle du fer et de l'acier va décupler; où Davy, en 1815, va introduire dans ses houillères la lampe du mineur. Pendant linterruption des relations entre les deux pays, RichardLenoir, Girard, Jacquard, qui furent vraiment des inventeurs, ont octillé cependant la France de telle sorte qu'à la reprise les relations commerciales elle se retrouva en état de soutenir la lutte.

Une conséquence de l'avènement de la vapeur et de la machine, ce sera bientôt une transformation totale dans les conditions du travail industriel et dans la situation des classes ouvrières. A la quenouille et au rouet, au métier du tisserand, va succéder la machine; à l'atelier va se substituer la manufacture. Le petit travailleur va tomber en la dépendance du grand capitaliste, et, dans les classes ouvrières, démesurćment accrues, va se développer le prolétariat industriel. Cette conséquence, déjà visible en Angleterre, ne peut encore ètre entrevue en France. Voilà pourquoi, pendant la Rívolution, il y a eu des émeutes d'ouvriers, mais pas de question sociale ouvrière.

1. Kay a inventé la narette volante; Hargreaves, en 1768 , le métier appelé Spinning-Jenny (Jenny la fleuse); Richard Arkwright, en 1769, la filature à cylindres ou Mull-Jenny (le moulin Jenny), qui ruina l'invention d'llargreaves el le ft mourir de misère; Cartwright, la machine à peigner et tisser la laino.

2. En Angleterre, avant l'invention des machines, on ne comptait pas plus de 5000 tileuses au rouet el 3000 tisseurs d'étoffes de coton, en tout 8000 : quarante ans après, il y en aura $\$ 00000$. 


\section{Le commerce.}

\section{Le régime donanier : $1^{\circ}$ Pendant la Révolution. -} La Constituante avait opéré, en 1790, la suppre-sisn des douanes intérieures, vainement proposée par Calonne en 178\%. Il n'y eut désormais plus de douanes qu'aux frontières, avec un tarif unique et uniforme. Ce tarif, décrétè en 1791, conservait encore des prohibitions dentrée (sur les médicaments composés, dorures et fils d'or faux, poudre et salpêtre, eaux-de-vie autres que de grains, verrerie fine, etc.) et des prohibitions de sortie (effets militaires, munitions, armes, espèces d'or et d'argent). Sur toutes les autres marchandises, on maintenait un droit d'entree variant de 5 à 15 p. 100 . Il y avait plus de sécurité en France pour la fortune et les économies des étrangers : le droit d'aubaine avait été aboli en $1790^{1}$.

A l'approche de la guerre, la Législative leva les prohibitions d'entrée sur les objets nécessaires à la défense nationale, mais établit des prohibitions de sortie sur les céréales, fourrages, cotons, cuirs, bestiaux, chevaux, etc., et en général sur les objets nécessaires à l'équipement des troupes et à l'alimentation publique.

L’Angleterre avait déjà violé le traité de commerce de 1786 en interdisant l'exportation de ses grains en France. Après la déclaration de guerre, on en revint à une lutte de tarifs plus acharnée qu'an temps de Colbert. La Convention déclara annulés tous les traités de commerce avec les puissances alors en guerre contre la France. Elle étendit les prohibitions de sortie aux savons, soudes, combustibles, aciers, papiers, draps et tissus de tout genre,

1. La Constituante, daus les considerants de son décret du 6 aout 1790 , disait: que le droit d'aubaine est contraire aux principes d'humanite qui doivent lier tous les hommes, quels que soient leur pays et leur gouvernement; que ce droit, établi dans des temps barbares, doit ètre proserit shez on peuple qui a fondé sa constitution sur les droits de l'homme et du citoyen, et que la France libre doit ouvrir son sein à tous les peuples de la Łerre, eu les invitant à jouir, sous un gouvernenent libre, des droits sacrè et inaliènables de l'humanité..... n Le Code Napoléon ne maintint l'abolitioa du droit d'aubaine qu'à l'égard des nations qui nous accorleraient la reaprocite. Une lot de 1819 l'abolit de uouveau sans restriction. 
sous peine de dix ans de fer. Elle décréta la peine de mort contre tout exportateur de grains. Elle prohiba ${ }^{1}$ l'entrée de toutes marchandises anglaises, sous peine de vingt ans de fers contre quiconque en aurait importé, vendu ou acheté. Elle déclara suspect quiconque en ferait usage. Sous des peines moins graves, les marchandises des autres nations en guerre avec nous étaient également frappées d'interdit. Ce qui semble prouver que la Convention ne se proposait pas seulement de nuire à ces puissances, mais qu'elle en était revenue aux principes colbertistes de protection et de prohibition, c'est que les nations mèmes qui étaient en paix avec nous virent prohiber l'entrée de beaucoup de leurs produits.

Le Directoire redoubla de rigueur contre l'Angleterre, dont il espérait ruiner l'industrie, et renouvela la terrible loi de 1793. Certaines marchandises, qu'on tenait à écarter de notre marché, étaient, quelle qu'eu fủt l'origine, réputées anglaises. Mème à l'égard des nations amies ou alliées, la plupart des droits furent rehaussés. Ce système rétrograde eut son effet ordinaire et inévitable : l'élévation des droits assurait une prime à la contrebande et la rendait plus active. Une loi de 1799 déclara que les procès-verbaux dressés en matière de contrebande seraient réputés vrais jusqu'à preuve judiciaire du contraire.

$2^{\circ}$ Sous le Consulat et l'Empire. - En 1800, Chaptal, ministre de l'intérieur et chargé du commerce, proposait au Premier consul un système plus libéral : on supprimerait les prohibitions et l'on n'imposerait que des droits modérés sur les matières premières nécessaires à notre industrie. En 1802, on signait avec l'Angleterre la paix d'Amiens et l'on eut à se demander si on lui offrirait ur: nouveau traité de commerce. Bonaparte y répugnait, et le haut commerce anglais était tout entier à sa jalousie de voir l'industrie française se relever et 1500 navires mar. chands promener sur les mers le pavillon tricolore. La rup. ture de la paix d'Amiens fut amenée, en grande partie par la rivalité économique des deux nations.

Nous avons déjà parlé des violences auxquelles se por- 
tèrent les deux belligérants, du blocus maritime et du blocus continental. Ce qui montre mieux à quel point Napoléon était acquis au système protecteur 1, c'est que, même à l'égard des autres nations, il releva les tarils dans des prcportions telles qu'ils équivalaient à une véritable prohibition quand on ne l'édictait pas formellement. Les tissus et fils de coton restèrent prohibés (1806). Bientòt ce fut le tour des savons et des soudes. Mème le coton brut, quand Napoléon voulut encourager l'industric du lin, fut frappé de droits énormes : ceux du Levant, des États-Unis, du Brésii. ceux de Riclıard-Lenoir dans le royaume de Naples. durent payer des taxes de 400 à 800 franes par 100 kilog. Les denrées coloniales, comme elles ne pouvaient plus nous arriver que par l'intermédiaire des Anglais, furent frappées à outrance : d'abord une taxe de 100 francs par 100 kilog. sur les sucres, de 150 sur le poivre et le café, de 200 sur le cacao; puis, apris l'annexion de la Ilollande, une taxe équivalant à 50 p. 100 de leur valeur, quelle que fût leur origine. Les délits de contrebande furent jugés, non plus par les tribunaux ordinaires, mais par des cours prévótules ou cours martiales. Quant aux tissus et denrées conlisqués, on s'était borné d'abord à les vendre au profit du Trésor : pour donner plus d'éclat à la répression, Napoléon, à partir de 1810, ordonna de les brùler publiquement. On en détruisait ainsi pour des millions de franes aux yeux de populations qui en éprouvaient un grand crève-cœur, car elles ètaient cruellement privées. Elles ne connaissaient plus que de souvenir les denrées des colonies; elles en étaient réduites à substituer au café la chicorée, au thé les feuilles de certaines [!antes. Pour frapper plus surement l'Angleterre, pour faire observer partout le blocus continentai, Napoléon fut obligé d'envalir et de tyranniser tous les Etats de l'Europe, d'engager enfin contre la Russie une lutte gigantesque, et on peut dire que c'est sous le poids de ce monstrueux système économique qu'il a fini par succomber.

1. On n'eu saurait douter quand on le voit interdire la réimpressior du Traite d'economie politique de J.-B. Say, dont la première éditıon avail para sa 1803, et dont les théories étaient favorables au libre-echange. 


\section{Régrime intérieur du commerce : 10 Pendant la Révo-} Iution. - Dans l'histoire de notre commerce intérieur, nous allons assister à des violations aussi éclatantes des lois énoncées au $\mathrm{xv}^{\ominus}{ }^{\ominus}$ siècle par les physiocrates et économistes français. La Convention ne se contentait pas de punir de mort l'exportateur de grains : elle sévit également contre cenx qui en faisaient des approvisionnements et qu'on traitait d'accaparcurs. Comme l'insécurité générale et la baisse des assignats faisaient hausser le prix de toutes les denrées, cette Assemblée autorisa les directoires de départements à fixer le muximum des prix auxquels pourraient être vendus certains oljets parmi les jlus nécessaires à la vie : le blé, le pain, les boissons, les combustibles. Puis elle appliqua cette loi du maximum mème aux tissus, aux métaux, etc. La conséquence, c'est que les marchands cessirent de vendre, les labricants de fabriquer. Alors on déclara suspects ceux-ci comme ceux-là. Ils durent vendre, fabriquer, même à perte, même en se ruinant, car la ciénomination de suspect était un brevet de guillotine. Toutes ces mesures allaient contre leur but : la disette prit des proportions jusqu'alors inconnues. On ne réussit mème pas à donner au peuple du pain. Le Comité de subsistances dépensait inutilement 300 millions par mois pour maintenir les grains à un prix raisonuable. On en vint, en février 1794, à proposer un caréme civique : les citoyens devaient jeüner une fois par mois pour épargner les subsistances. On n'osait plus poudrer les perruques.

La Convention se convainquit enfin de son erreur: la " loi du maximum " fut rapportée dix mois après sa promulgation. Une crise presque aussi grave que celle qui avait signalé ses débuts suivit son abolition. L'agiotaye sur les denrées prit des proportions fabuleuses. Puis, peu à peu, le cours naturel des choses n'ètant plus contrarié, l'équilibre ne tarda pas à se rétablir. Le birectoire reconnut de la façon la plus explicite les vérités économiques quela Convention avait méconnues: "Le commerce, rendu à lui-mème, est seul en état de rétablir l'équilibre des prix dans les marchés" (9 juin 1797).

2o Sous le Consulat et l'Empire. - Napoléon, qui, à plusieurs reprises, interdil l'exportation des grains, faillit, 
pour le trafic des céréales a l'intérieur, retomber dans les erreurs de la Convention. En 1812, ému d'un commencement de disette, il créa un Conseil de subsistance et ordonna d'amener des grains pour la réserve de Paris. Aussitôt, par l'effet mème de ces achats, les blés haussèrent énormément. Alors Napoléon taxa le pain au-dessous du cours, essaya de forcer les paysans à amener leurs grains, fixa un prix maximum. L'État, en outre, dépensa 12 millions : en pure perte, comme on l'avait fait en 1793. Depuis, aucun gouvernement n'a renouvelé ces tentatives.

Unité des poids et mesures. - La Constituante réalisa l'ancienne idée de Louis XI en mettant fin à cette diversité des poids et mesures qui était une des grandes entraves du commerce. Pour obtenir le mètre, qui, avec ses multiples et ses sous-multiples, devait servir de base à toutes les mesures de longueur, de surface, de capacité et de poids, les savants mesurèrent un arc du méridien terrestre. Cette opération ne fut terminée qu'assez tard, et c'est seulement sous le Consulat que le nouveau système put être mis en vigueur (10 décembre 1799).

Routes, ponts, canaux. - Necker, à la veille de la Révolution, avait supprimé, à l'exemple de Turgot, la corvée royale sur les routes. Il fallait cependant pourvoir à leur entretien, et, en même temps, se préoccuper des autres chemins : ceux-ci furent laissés à la charge des paroisses qu'ils desservaient : celles-là durent ètre entretenues sur le budget de l'État et souffrirent de la pénurie du Trésor. En décembre 1792, le ministre de l'intérieur, invoquant " cette ardeur de bien faire qui échauffe les àmes devenues libres et républicaines ", proposait une corvée volontaire et civique d'environ six journées de travail pour chaque citoyen. C'était un retour déguisé à la corvée royale : il ne séduisit personne. En 1797 (10 septembre), le Directoire avait fait voter une loi établissant sur les routes des barrières à pér ge : c'était un retour aux anciens procédés féodaux : les campagnards s'abstinrent de circuler et restèrent plus que jamais chez eux.

Tous les expédients ayant échoué, les routes se trouvaient, à la veille du Consulat, dans le plus déplorable état. Bonaparte, par un arrété consulaire de 1802 ¡23 juil- 
let), mit les chemins vicinaux à la charge des communes et invita les conseils municipaux à proposer soit une taxe en argent, soit des prestations en nature. Quant aux routes nationales, le budget de l'État, désormais alimenté par des perceptions régulières, put subvenir à leur entretien. En 1806, on supprima les barrières à péage, qu'on ne rencontre plus aujourd'hui qu'à l'ètranger.

Sous le Consulat ou sous l'Empire, des ponts furent partout construits ou réparés. Le canal de l'Ourcq, celui de Saint-Quentin furent creusés.

A travers les Alpes fut ouverte la magnifique route du Simplon : on étudia celles du mont Saint-Bernard, du mont Cenis et du mont Genèvre. Jusqu'en Dalmatie et en Illyrie, un moment soumises à notre domination, celle-ci a laissé une tráce impérissable : les routes construites par nos régiments victorieux.

Moyens de locomotion : diligences, fiacres. - En 179', la Convention proclame la liberté des diligences. En 1805, Napoléon soumet cette industrie à l'autorisation préalable et à des droits onéreux. Beaucoup de compagnies succombent, et les Messageries ci-devant royales subsistent seules, comme avant la Révolution. Plus tard se fondèrent les Messageries Laffite et Caillard et la Compagnie des diligences françaises ${ }^{1}$. Napoléon déclarait qu'on " peut mesurer la prospérité publique aux comptes des diligences ". Qu'aurait-il dit du mouvement de nos voies ferrées?

En 1790, l'exploitation des fiacres ou voitures de louage devint une industrie libre. En 1797, on la frappa d'une taxe de 50 à 75 francs par voiture. En 1800, le tarif des fiacres est fixé au taux actuel : 1 fr. כ̆0 la course et 2 francs l'heure. Vers 1800 apparurent les premiers cabriolets (du mot cabri), qui ne démentaient pas leur nom, car, sur le pavé de Paris, ils sautaient comme des chèvres.

1. On peut se figurer ce qu'étaient alors les diligences par l'ordonnance de $1 \$ \Omega \delta$, qui a fxe plus lard leurs dimensions et leur mode de construction. Celles de première classe contenaient alors vingt et un voyageurs, dont trois à limperiale et dix-huit dans les trois berlines: c'ètaient les plu. lourdes et les plus lentes. Celles de seconde classe contenaient seize voyageurs, dont trois dans le coupé, six dans l'intérieur, quatre dans la rotonde et trois sur la banquette 


\section{Le crédit.}

Les assignats. - La Révolution faillit retarder encore, par des combinaisons malheureuses, l'établissement du crédit, déjà vainement tenté, en 1716, par la Banque royale de Law, en 1776, par la Caisse d'Escompte. Quand les propriétés de l'Église et des émigrés furent déclarées biens nationaux, on émit des assignats, un papier-monnaie à l'aide duquel l'acheteur de biens nationaux était autorisé à payer ses achats. Si la Convention avait pu mettre quelque modération dans l'émission, comme firent la Constituante et la Législative, qui se bornèrent à en émettre, l'une pour 1800 millions, l'autre pour 900, les assignats auraient pu conserver la valeur qu'on leur attribuait, et auraient joué à peu près le rôle du billet de banque. Malheureusement on en fabriqua de telles quantités qu'ils se déprécièrent rapidement. La Convention eut beau décréter le cours forcé de ce papier-monnaie et la peine de mort contre quiconque refuserait de l'accepter en payement: le moment vint, en 179', où Dubois-Crancé avouait qu'on fabriquait pour cent millions dassignats par jour et que cela ne sulfisait pas pour la déptnse quotidienne. Depuis qu'on en avait jeté sur la place pour plus de 48 milliards, il n'était pas étonnant qu'un louis d'or füt estimé 7200 francs en papier : ce qui supposait une dépréciation de $993 / 4$ p. 100.

Les mandats territorianx. - En 1797, le Directoire cessa d'émettre des assignats. Il les remplaça par les mandats territoriaux, dont les biens nationaux continuaient à former la garantie et qu'on powvait employer a acheter des terres. Au lieu de 24 milliards d'assignats, on eut pour 2 milliards 400 millions de mandats territorianx : un tiers de ceux-ci furent consacrés ì racheter les assignats au trentième de leur valeur, et la planche aux assignats fut brisée; les deux autres tier's furent consacrés aux dépenses du gouvernement. Trois mois après, le mandat de 100 livres valait 7 livres 10 sous, et, en février 1799, 1 livre.

Le Grand-Livre. - L'État restait surchargé d'une dette énorme, car à la dette de l'ancienne royauté étaient venus s'ajouter les emprunts contractés par les gouvernements 
révolutionnaires et le prix du rachat de toutes les charges de financiers, magistrats, officiers ministériels, ol'ficiers militaires, maitrises de corporations, etc., abolies par suite des réformes.

En 1793, sur la proposition de Cambon, la Convention institua le Grand-Livre de la dette pululique.

Le tiers consolidé. - Loin qu'on füt en état de payer toute cette dette, on ne pouvait mème pas en servir l'intérêt. En 1799, le Directoire prit une mesure radicale: il la réduisit des deux tiers, mais garantit de nouveau l'autre tiers, qui prit le nom de tiers consolidé. Les intérèts s'élevaient encore à 40 millions par an : on fut obligé de payer les créanciers de l'État en bons d'arrérages.

Cette banqueroute partielle, qui rappelait celles de l'ancien régime, fut la dernière qui ait compromis le crédit du pays. Le tiers consolidé est resté le noyau de notre dette publique; les rentes inscrites au Grand-Livre ont été sacrées pour tous les gouvernements qui se sont succédé depuis 1799, et pas une seule fois on n'a omis d'en payer, à jour fixe, l'intérêt. Dès lors les rentes sur l'État ont été considérées comme les plus solides des valeurs mobilières.

Le crédit public sous Napoléon. - Le Directoire, en prenant sur lui l'odieux de cette mesure, avait l'acilité la tàche de ses successeurs. Bonaparte n'eut pas de peine à inspirer contiance aux détenteurs de rentes sur l'Etat. L.e taux de ces valeurs s'éleva rapidement; mais, sous l'Empire, il n'atteignit jamais le pair, c'est-à-dire qu'un titre de rente à 3 p. 100 n'atteignit jamais au taux de soixante francs, ni un titre de rente à à p. 100 au taux de cent francs. C'est seulement sous la monarchie de Juillet que le pair fut atteint et dépassé.

La Banque de France. - La Convention, qui avait proscrit les compagnies de commerce, proscrivit également les associations de capitalistes ${ }^{1}$. Les rares banques particulières que nous avait léguées l'ancien régime périclitèrent. Le Mont-de-Piété disparut. Sous le Directoire, quel-

1. La loi du 25 octubre 1795 ayant décrèté la liberté de l'iutérèt, les partiouliers prètèrent a 12 et à 20 p. 100 par mois, ne se hasardant guère à prèter - l'année : c'était une usure de 14 á $210 \rho .100$. 
ques maisons sérieuses se constituèrent, comme la Caisse d'escompte de commerce, la Caisse des comptes, le Comptoir Jabach, etc. Il n'y avait toujours pas de Banque d État.

Bonaparte fut le créateur de la Banque de France. En 1800 , il détermina un certain nombre de banquiers parisiens, dont le plus notable était Perregaux, à s'associer et à former un capital de 30 millions. Lui-même, les membres de sa famille et ses principaux dignitaires furent au nombre des souscripteurs. Il accordait à l'association le droit d'émettre des billets de banque. La Banque de France est donc une compagnie d'actionnaires se réunissant pour former un capital, faire des opérations de Banque, énettre un papier payable à vue et au porteur. En 1803, l'État lui garantit un privilège, celui d'émettre seule des billets, mais pour Paris seulement ', et lui imposa une nouvelle constitution. La Banque, aux termes de cette mème loi de 1S03, était gouvernée par un comité de trois membres, élus parmi quinze régents et trois censeurs formant le conseil général, nommés eux-mèmes par les actionnaires. En 1806, Napoléon garda le conseil général, mais substitua au comité trois gouverneurs nommés par l'État. Pendant la durée de l'Empire, la Banque se montra très timide dans ses opérations : elle se borna à établir hors de Paris les deux succursales ou comptoirs de Rouen et de Lyon.

Ouvrages a CONGltater. - Rougier de la Bergerie, Hist, de l'urviculture franeaise 1810 . - 11. Honiol. La Révol. fr. et la fiorlalit's 1803 at Les classes rurules en France 1865 . - Baudrillart. Les populations agricolvs de la Fraure 1\$93). - A. de Foville, Lumprollement ide la terre 1855). - M. Varion (1908), A. Vialay 1905). La vente des biens nationaur. - Chaptal. loe lindustrie francaise 1819/; Soutenirs. - D'Avenel, La fortune prive it travers sept siècles $1085 .-$ A. Blanqui, Hist. do l'economie politique I $>37$ - - F. Rougier, La liberti commerciale (1878.Bathie, Hist. Mu cridit populaire 1S6i. - Richard-Lenoir, Memoires. - Baudrillart. Vir de facquaril IN6io - - Silvestre 1-36), Ch. Dupin 1830 . Noticessur thilippe de Girard.
- Figuter, Exposition et Hist. des prillcipales deronertes moderues et Les Merceilles de limbstrie. Thurston. Hist. de la macline it rapenr 1879. - A. de Foville. La lionnaie 1906 . - Biollav. Les prix en 1790. - A. Courtais. Hist. de la Banque de France. - V. de Swarle, Les ringt prem. annies de la Banque de France. - Himoirps. Mollien. Gaurlin. - Levansenr, Hist. des classes oumieres en France depuis 175.7 (1903-4. - DAvenel, Puysans et oumiers [S99]. - O. Noê]. Hist. du commerce. t. II] 1906). - De Lanzas. de Lahorit. o. c..t. V1. - Collection, en cours, de documeuts sur l'Histoire économ de la Revol. franc.

MĆÉEs a VISITER : Conservatoire des arts et métiers a Paris, le Insie d'art ei d'mdustrie a Lyon.

1. On craicnait qu'en province le souvenir des assignats n'etit frappé d'un trop grand discreilit tout papier-monnaie. Il n'y avait pas alors de lillets au-dessous de 500 francs. 


\section{CHAPITRE XIV}

\section{LES USAGES ET LES MOEURS}

\section{Pendant les premières années de la Révolution.}

La vie dans la rue. - La Révolution arracha tout Paris aux salons, aux écoles, à la boutique, à l'atelier, à l'échoppe, et le fit vivre dans la rue, sur la place publique, comme les cités de l'antiquité. Quand on n'était pas à son club ou dans les tribunes de l'Assemblée, on emplissait le jardin du Palais-Royal, les promenades publiques, les cafés, transformés eux-mèmes en clubs. On discutait, on pérorait, on commentait les nouvelles et les papiers publics, tandis que, répandus par milliers dans les rues, les crieurs de journaux et de pamphlets assourdissaient les oreilles et emplissaient la ville d'une rumeur continue. Puis il fallait courir aux élections: élections de députès, d'administrateurs, de juges, d'èvèques, de curés, d’officiers de la garde nationale.

Tout citoyen était devenu soldat, portait le fusil et les buffletteries, manœuvrait, patrouillait, couchait au cor pss de garde. Les royalistes se moquaient de ce zèle militaire et faisaient des jeux de mots sur patriotisme et putrouillotisme.

"Les hommes, dit M. Viollet-le-Duc, dans le premier transport où les mit la création de la garde nationale, ne quittent plus l'uniforme qui vient de leur ètre attribué et qu'ils tiennent pour la plus glorieuse des conquêtes. Le marchand derrière son comptoir, l'homme de loi se ren- 
dant au Palais, le bourgeois en promenade, ont sur le dos l'luabit bleu à revers blancs, et sont chaussés de guètres longues."

"Tous les valets du roi, dit Mme Campan, de la dernière classe, lurent transformés en lieutenants et capitaines. Presque tous les musiciens de I: chapelle osèrent paraitre, un jour, à la messe du roi en costume militaire, et un soprano ditalie y chanta un motif en uniforme de capitaine de grenadiers. Le roi en fut très offensé, et défendit à ses serviteurs de se montrer en sa présence dans un costume aussi déplacé. "

Au début de la Révolution, malgré quelques journées sauglantes, on était tout à l'entlousiasme, à la joie, à l'espérance de la régénération; on n’éprouvait que sentiments de fraternité pour ses concitoyens; on ne parlait que de liberté, égalité, bien public, et l'on commençait à remplacer l'appellation de monsieur par celle de citoyen. On dansait, sans distinction de classes, sur la place où s'était élevée la Bastille. Le patriote Palloy, un industriel avisé, se faisait une spécialité et une fortune en débitant les pierres de la forteresse abhorrée sous la forme de réductions de la Bastille envoyées aux 83 départements, de tutles de la loi, de bonbonnières, de tabatières, de camées, etc. Plus de laquais ni de domestiques: on n'a plus que des fréres servants, des officieux. Plus de livrées, plus d'armoiries au front des vieux hôtels, aux panneaux des carroses : le marteau, le grattoir commentent le décret de l'Assemblée qui a déclaré la noblesse abolie.

En 1789, la mode est aux sacrifices patriotiques, prèchés par les orateurs de la Constituante : sur l'autcl de la patrie ou à la barre de l'Assemblée, les femmes apportent médaillons, colliers, pendants doreilles, boites à mouches, boittes à rouge; les hommes livrent les boucles d'argent de leurs souliers.

Lo costume, le mobilier. - Les femmes portent des bijoux à la constitution, appelés aussi rocamboles; des bagues où est enchàssée une pierre de la Bastille; des pendants d'oreilles en simple verre, sur lesquelles est inscrit le mot patrie. Elles se parent de bouquets a la nation, c'està-dire aux trois couleurs; leurs rubans, leurs écharpes, la 
cocarde de leurs bonnets, leurs souliers mèmes sont aux trois couleurs. Elles affectent la simplicité des modes anglaises et américaines, ou bien le négligé à la patrivte, la toilelte constitution, la redingote nationale, les bonnets aux trois ordres réunis, à la Bastille, à la citoyenne.

Cependant les opposantes, du moins celles qui n'ont pas émigré, résistent, et il faut signaler la coiffure à la reine et la toilette à la contre-révolution.

Mlle Bertin fut ruinée par ce progrès de la simplicité civique ou plutôt par le dérangement de toutes les fortunes. Plusieurs de ses élèves émigrèrent et allèrent londer dans les capitales étrangères, à Londres, à Berlin, à SaintPétersbourg, des magasins de modes. En novembre $1790^{2}$ le Cabinet des Modes constatait avec un mélange de tristesse et de fierté civique que " nos mœurs commencent à s'épurer : le luxe tombe ". Pour remplacer la elientèle dispersée, ce journal essaya de s'en faire une autre. proposa des toilettes civiques et des toilettes pour les religieuses sorties du cloitre, leur proposant des robes $\dot{a} l_{\alpha}$. Vestale en linon. II tomba avec le luxe ${ }^{1}$

Mème en costume civil, tous les hommes portent la cocarde au chapeau, et il n'est pas toujours facile de distinguer l'aristocrute du patriote. La cravate de couleur, garnie de dentelles, forme un énorme nœud sur le cou. On a des culottes de casimir ou de daim, très collantes, à l'écuyère, un habit à grand collet, des bas rayés en long, des souliers sans talons ou des bottes à revers, des gants en étoffe rayée aux trois couleurs, une canne à épée.

Les perruquiers restèrent d'abord aussi importants que jamais. Leur métier était une charge qui s'achetait fort cher. Quand l'Assemblée nationale, reprenant l'idée de Turgot, abolit les corporations, elle jugea a propos de rembourser le prix des maitrises. Dans la somme à payer pour ces remboursements, soit 120 millions, la part des perruquiers montait à 22 millions. Cependant, cette haute

1. Les rédacteurs de journaux de modes émigrèrent aussi. Harlem (IIo:lande) eut son Cabinet de la mode, en 1793; Londres, sa Galerie de la mode. en 179.́. 11 gst à remarquer que, mėme à Saint-Pétersbourg, sous l'impératrice autocrate Catherine 11 , les toilettes révolutionnaires et les toilelles a la contre-réolution se dispulèreal les sympathies de la plus baute sociéló. 
situation sociale fut une des premières que menaça la Révolution. Dès 1789 , le cri du peuple s'élève contre l'abus de la poudre : on l'accusait de contribuer à augmenter le prix des farines. Les patriotes jugent convenable de se poudrer plus modérément : Brissot donne mème l'exemple de ne plus se poudrer du tout. En revanche, les partisans de l'ancien régime abusent de la poudre plus que jamais : ils contribueront à la faire proscrire définitivement. Bientôt les perruquiers sont ruinés par le courant continu d'émigration qui leur enlève leurs meilleurs clients, par le changement qui se fait dans les modes, par le retard que la pénurie du Trésor apporte au remboursement du prix de leurs charges. Léonard, le coiffeur de la reine, prendra part à la fuite de Varennes, et, par ses minuties d'artiste, compromettra l'évasion de la famille royale. Le peuple insulte à la déconfiture des merlans. Ils sont forcés de déposer l'habit noir, le chapeau à plumet, l'épéc à poignée d'acier, toute leur défroque de gentilshommes. Une histoire tragique, c'est celui de l'ancien perruquier de Mme de Lamballe '.

Dès 1792 , les patriotes avancés adoptent un costume qui rappelle celui des auvriers : une carmagnole ou jaquette, une houppelande ou vaste redingote à collet de peluche rouge. Au lieu de culottes, ils inaugurent le pantalon : c'est ee qui les fait appeler sans-culottes. Dès 1792, les bretelles apparaissent. Les plus zélés se coiffent du bonnet rouge.

Le mobilier est débaptisé, et l'on couche dans les lits patriotiques ${ }^{2}$, ou à la Fédération, ou à lu Révolution. L'acajou, " qui joue dans l'ordre des bois le rôle du tiers état

1. Lors des massacres de septembre, quelques-uns des assassins imaginò rent de se rendre chez lui et de lui présenter au bout d'une pique la tète ensanglantée de son infortunée cliente, avec injonction d'avoir à la coiffr $r$ à la dernière mode. Il obéit, mais éprouva un tel saisissement qu'i] en devint fou.

2. Mème enthousiasme dans les campagnes. "Chaque village, chaque chaumière, dit une voyageuse anglaise, nous salue du cri de live la Nation! Le cabaret vous invite à boire de $\ln$ bicrn $\dot{\alpha}$ la nation et vous affre un logement $\dot{a}$ la nation. Le marchand de chaudelie offre de la poudre a cheveux et du tabae a priser à la nation, et il y a mème des barbiers patriotes dont les enseignes vous annoncent que vous pouvez vous faire couptr les cheveux et arracher les dents à la nation." 
dans l'ordre des classes ", tend à supplanter les bois aristocratiques, ébène et bois de rose. Les papiers peints à sujets patriotiques, sortis de la fubrique républicaine de Dugoure, tendent à détrỏner les tapisseries et tentures de l'époque royale. Les assiettes, les plats, toute la faïencerie de Strasbourg, de Sarreguemines, de Rouen, surtout de Nevers, reproduisent des sujets patriotiques : les insignes des trois ordres, le garde national à bonnet à poil, entouré de cette devise: "Mourir pour la patrie ", le tombeau de Mirabeau, bientôt le bonnet rouge sur le faiscean de piques. Nos nappes, nos serviettes, vont jusqu'à l'étranger raconter la Prise de la Bastille ou la Fédération de 1790.

Les plaisirs. - Malgré la disette et les inquiétudes du lendemain, on joue gros jeu au Palais-Royal, très fréquenté alors par les escrocs et les femmes perilues. On court les bals, les concerts publics, les théàtres. Les calés, qui se divisent aussi en patriotiques ef en contre-révolutionnaires, voient doubler et tripler leur clientèle d'oisifs. "On juge l'opinion d'uu homme, dit slle Boudon, par le café qu'il fréquente, comme vous savez que l'on jugeait à Athènes qu'un citoyen professait les sentiments d'Aristote ou de Zénon, suivant qu'il fréquentait le Lycée ou le Portiq:ie." Les cafés sont la presse parlée de l'époque ".

Le noble jeu de l'oie devient le Jéu de la Révolution, et les Parlements y prennent la place des oies. Sur les cartes, on remplace les rois, les reines, les valets par des Libertés, des Égalités et des Génies.

Les duels. - Dans les premiers temps de la Révolution, la manie des duels avait repris de plus belle. On se battait pour les principes, pour un mot, pour une cocarde. En 1790, Talma et Naudet se battent; Rivarol blesse au cou son adversaire; M. de Bouillé tue $\mathbf{M}$. de La Tour-d'Auvergne d'un coup de pistolet. Gervais, maitre d'armes en renom, n'est occupé qu'à préparer, la nuit, les duellistes

1. Les aristocrates fréquentent le café de Foy; les feuillantins, celui de Valois; les patriotes, celui de Corazza (Palais-Royal), où les Jacubins continuent toutes les nuits les séances de leur club, celui de Procope (alpelé alors café Zoppi), celui des Arts (rue de Tournon), celui de la Vicloire (rue de Sèves), celui de la Monnaie (rue du Roule), celui de Manoury (rue de l'École), etc. 
pour le combat du lendemain. Cette fureur sérit aussi parmi les militaires : à Toulon, deux régiments se déciment sur les remparts, dix contre dix, pendant plusieurs jours, "sans trop savoir pourquoi n. On se bat au pistolet bien plus souvent qu’à l'épée : e’est une importation anglaise, qui, malgré les protestations philanthropiques et philosophiques de Mercier, s’est implantée chez nous.

Les royalistes s'attaquent surtout aux députés populaires. Vainement la presse et l'opinion se soulèvent; vainement les sections pétitionnent à l'Assemblée; vainement le patriote Boyer, contre les spadassins, enrôle son bataillon de cinquante spadussinicides, qui se vouent à la défense des députés. Mais bientòt l'émiğration décime les duellistes, et l'on se battra plus à Coblentz qu'à Paris. D'autres hommes, d'autres idées prennent le dessus. Camille Desmoulins, insulté, peut refuser de se battre. "Qu'on maccuse de làcheté si l'on veut ", répondait-il. Et il ajoutait ces paroles prophétiques : "Je crains bien que le temps ne soit pas loin où les oceasions de périr plus utilement et plus glorieusement ne nous manqueront pas. "La Terreur allait inaugurer, dans l'acharnement des partis, le duel à la guillotine. Les académies de maîtres d'armes étaient dissoutes, et Fouquier-Tinville, envoyant à l'échafaud Rousseau, le professeur des enfants de Louis XVI, lui dira ironiquement: "Pare-moi celle-là. "

\section{Pendant les années sombres de la Révolution.}

La vie pendant la Terreur. - Survinrent la guerre, le procès et l'exécution du roi, les insurrections, la Terreur. On eut à passer alors des moments difficiles. Qu'on se figure l'existence d'un petit bourgeois de Paris à cette époque. Plus de rentes, car l'État ne peut plus s'acquitter; plus de canons, car les fermiers se dispensent de payer; plus de revenus du commerce ou de lindustrie; plus de numéraire; les assignats en baisse constante. Chaque matin il allait s'informer des cours du jour, et l'achat de son déjeuner était compliqué d'une spéculation financière. Plus de café, plus de sucre, puisque la mer nous était 
fermée par les Anglais et les frontières par les armées coalisées; tout le reste hors de prix. Si paurre qu'on füt, on pouvait être dénoncé comme un riche par quelqu'un de plus pauvre, dont les entrailles criaient la faim, et le mot même de Robespierre qu'on "n'est pas un bon citoyen quand on a plus de trois mille livres de rente" ne suffisait pas à rassurer. De tous côtés des nouvelles sinistres : les Autrichiens à Condé et à Valenciennes, les Anglais à Toulon, Lyon révolté, la Normandie, la Bretagne, la Vendée en feu. Il ne s'agissait plus de jouer au soldat : il fallait l'ètre pour de bon. Ceux qui n'étaient pas partis comme volontaires étaient pris par les réquisitions : un immense drapeau flottait à l'Hôtel de ville en signe du danger de la patrie, et le canon d'alarme tonnait au Pont-Neuf et à l'Arsenal. On faisait des visites domiciliaires dans toutes les maisons pour rechercher les suspects; on en faisait pour découvrir les accaparements de blé; on veillait à ce qu'on ne recélàt pas do marchandises anglaises, à ca que la loi sur le maximum fủt exactement suivie, à ce qu'on n'insultàt pas, par de folles dépenses, à la misère du peuple ${ }^{1}$. On entrait dans les caves pour en lessiver le sol et en extraire le salpètre. On réquisitionnait le plomb, le cuir, les vêtements, les chaussures, tout ce qui pouvait servir à l'armée. Non seulement on réquisitionnait les hommes pour l'armée, mais les femmes pour les ate. liers nationaux, où elles cousaient guêtres, habits, tentes, sacs, pour les défenseurs du pays. Les tricoteuses leur tricotaient des bas, tout en assistant aux séances de la Convention et des elubs ou même aux exécutions.

Tandis que Robespierre se coiffait encore en ailes de pigeons, portait l'habit de drap fin, le jabot de batiste, la culotte de nankin, les bas de soie, les souliers à boucles, Chaumette et les municipaux de Paris avaient mis à la mode les sabots, pour laisser les souliers aux soldats. Plus de luxe, plus de carrosses, plus de perruques poudrées. Tous ceux qui autrefois " faisaient marcher le commerce"

1. " Il serait nécessaire, disail Couthon aux Jacobins, de faire des visiles chez les traiteurs, les restaurateurs, les aubergistes, afin de savoir quels sont ceux qui onl fait des repas à 100 livres par téte : ceux qui font de pareils repas at ceux qui les donnent sout écalement suspeets. " 
étaient en fuite ou en prison. On voyait les hôtels des nobles changés en hôtels garnis; leurs riches mobiliers, leurs collections artistiques, leurs précieuses bibliothèques, dispersés ou mis aux enchères; la moitié des églises et la Sainte-Chapelle elle-mẻme, transformées en magasins. Plus de cloches : ces " breloques monstrueuses du Père éternel ", " nanan des oreilles religieuses ", étaient parties pour la fonderie. Tous se traitaient de citoyens et tous se tutoyaient.

Comme on voulait effacer toute trace du passé, on changeait les appellations, non seulement des théàtres, mais des rues et places de Paris. On eut, au lieu de la rue Bourbon-Villeneuve, la rue Neuve-Égalité; au lieu des rues de Monsieur-le-Prince, de Condé, de Saint-Louis-en-l'Hle, les rues de la Liberté, de l'Égalité, de la Fraternité. La place de la Bastille devint la place de la Liberté et le Palais-Royal le Palais-Égalité. Après le meurtre de Marat, plus d'une ville eut sa rue Marat. Des bourgs, des villes changeaient de nom : Égalité-sur-Marne, Val-Libre, Rochers de la Liberté, Mont-Égalité. Bourg-la-Reine devint Bourg-Égalité. Après leur reprise, Lyon devint Commune-affranchie, Toulon Port de la Montagne et Condé Nord-Libre. Les prisons, par une sorte de dérision, parlaient de liberté : l'une d'elles, à Paris, s'appelait Port-Libre.

On ne lisait plus que les journaux montagnards; au théàtre, on n'entendait plus que des pièces du plus pur sans-culottisme; on ne chantait plus seulement la "Marseillaise " et le " Chant du Départ ", mais la "Carmagnole " le " Ca ira ".

Il fallait veiller sur ses paroles; car, s'il n'y avait plus de police, il y avait partout des observateurs qui rapportaient tout au Comité de Sủreté générale. On n'osait plus sortir le soir sans un certificat de civisme.

On n'entendait parler que d'aristocrates, de conspirateurs, de suspects, de traîtres. Le petit bourgeois était dans l'affolement de tout ce qu'il apprenait. Traitre Bailly, qui avait fait prèter le Serment du Jeu de Paume; traitres les Girondins, qui avaient pourtant fondé la République; traitres Danton et ses amis, qui avaient pourtant fait condamner le roi; traîtres Hébert et ses partisans, qui avaient pourtant saccaǵé les églises; traitues non seulement les 
émigrés, mais les généraux qui les avaient vaincus : Biron, Custine, Houchard, Beauharnais. Tout ce monde était jeté dans les prisons, traduit devant le tribunal révolutionnaire. Tous les soirs, le Parisien pouvait lire dans son journal, au-dessus du programme des théâtres, la liste des personnes condamnées par ce tribunal, et parmi lesquelles il avait souvent à pleurer, mais en se cachant, un parent, un ami, une connaissance. Tous les matins, par les rues les plus vivantes et naguère les plus commercantes de Paris, dans la rue Saint-Honoré, par exemple, on entendait rouler et crier les fatales charrettes ", avec leur chargement de nobles et d'hommes du peuple, de femmes et mème de jeunes filles. Après un prétendu attentat sur Robespierre, cinquante-quatre personnes, revêtues du manteau rouge des parricides, emplissaient trois voitures. Le sol de la place de la Révolution était imprégné de sang et exhalait une odeur cadavérique; les cimetières de la Madeleine, les fossés de la rue d'Anjou, regorgeaient : il fallut ouvrir de nouvelles nécropoles. Puis on transporta la guillotine à la ci-devant place du Trône, parce que le faubourg Saint-Honoré ne voulait plus voir ces funèbres convois.

Il n'y avait qu'un homme qui, surement, ne füt pas un traître, c'était Robespierre, l'incorruptible Maximilien, qui, au comble de la puissance, continuait à habiter chez le menuisier Duplay. Celui-là ne se laissait séduire, ni par les pleurs des femmes, ni par la gloire des généraux. Sans relâche, il dénonçait tour à tour et les modérés et les exagérés. C'était par amour du peuple qu'il faisait peser sur toutes les têtes ce terrible régime, et c'était par humanité qu'il ètait obligé de se montrer si sévère. Avec l'aide

1. Étienne Delécluze a raconté une des plus vives impressions de ses souvenirs d'enfance. Un jour qu'il se promenait, alors ảgé de douze ans, avec sa mère, arrivé près de la place Dauphine, il sentit sa mère qui l'entrainait vivement. "Pourquoi marcher si vite? demanda l'enfant. - Les charreltes! les charrettes! balbutia-t-elle en se hatant encore davantage. Entends-tu le bruit? Viens! viens! courons vite! n Malgré leur diligence, l'enfan! et sa mère se trouvèrent arrètés par la foule, à la descente du Pont-Neuf, au moment où sept charrettes, remplies de condamnés, défilaient devant eux. Se sentant défaillir, la pauvre femme fit un mouvement pour se couvrir los yeux et s'appuya contre le parapet. Un homme, simplement vètu, s'approcha d'elle et lui dit à voix basse : "Contraignez-vous, madame, car vous étes entourée de gens qui interpréteraient mal votre emotion.. 
de son ami Saint-Just, il finirait bien par régénérer le pays et par faire triompher la vertu. Or, jugez de l'étonnement du bourgcois parisien lorsqu'un beau jour il apprit, par ses journaux, que Robespierre, lui aussi, était un traitre, qu'il visait à rétablir la monarchie, que la Convention avait ordonné son arrestation, et qu'on allait le guillotiner avec vingt et un de ses amis, pour commencer!

Le calendrier républieaiu. - On avait un nouveau calendrier. Le 5 octobre 1793, Romme avait proposé la réforme décimale du calendrier, qu'il avait préparée avec les mathématiciens Lagrange et Laplace. Le littérateur Fabre d'Eglantine avait inventé les noms poétiques des mois révolutionnaires. Ils s'appelaient maintenant messidor, thermilor, fructidor, etc. Au lieu de noms de saints, les jours portaient des noms d'animaux, de légumes ou d'instruments utiles. Au lieu du dimanche, on avait le décadi. Tout allait par dix, et l'on fabriquait des montres où la journée était partagée en dix heures.

Cérémonies, fètes. - Les baptèmes, les mariages se faisaicnt à l'Autel de la Patrie. Le cercueil des citoyens, drapé d'un grand drapeau tricolore, s'en allait, sous l'escorte de leur section, par une route bordèe le jalons tricolores, au champ de repos, le nom nouveau des cimelieres.

Les fètes de l'ancien culte, entachées de superstition, avaient été remplacées par des fêtes républicaines. Celles-ci devaient contribuer à l'éducution civique de la jeunesse, lui inspirer la liaine des tyrans et le culte de la vertu. On avait les Fêtes de la Fondation de la République, de la Jeunesse, des Époux, de la Reconnaissance, de l'Agriculture, des Vieilları, sans parler des Fètes décadaires, sans parler de la fête de la Raison, imaginée par les Hébertistes, sans parler de la fite de l'Ètre suprème, crééc par Robespierre. Les solennités consistaient en chants patriotiques, discou's sur la morale civique, banquets fraternels. A Paris, on voyait figurer dans d'interminables cortèges les membres de la Convention, les corps constitués, des troupes de soldats, des chours de vieillards, d'enfants, de jcunes filles habillées de blanc et couronnées de lleurs. On brủlait, au pied de la statue de la Liberté, les insignes de la Monarchie et de la Féodalité ou bien le mannequin de l'Athéisme. 
Pour ajouter à l'éclat de ces solennités, le grand peintre David avait dessiné un costume étrange qu îl proposait aux citoyens : une tunique, un manteau court, un pantalon collant, des bottines et un bonnet surmonté d'une plume.

Les prisons, l'échafaud. - Dans les prisons, à la Conciergerie ${ }^{1}$, à Saint-Lazare, à Sainte-Pélagie, aux Madelonnettes, à l'Abbaye, au Luxembourg, on royait les ci-devant nobles, les ci-devant ministres, conseillers d'État, magistrats des Parlements, mélés aux députés et atıx généraux de la Convention; les nobles dames de la cour mèlées aux actrices et aux grisettes. Décimés tous les matins par l'appel des condamnés, toujours placés sous le couteau de la guillotine, ne pouvant jamais compter sur le lendemain, ils n'en refaisaient pas moins une apparence de société élégante. Dans les deuils les plus cruels, sous les dangers les plus terribles, ils faisaient assaut de politesse, d'esprit, de belles manières, de galanterie. lls composaient des vers, des bouts-rimés, parfois improvisaient des concerts ${ }^{2}$. On tinissait par se familiariser avec la mort ${ }^{3}$. Un jeune homme rima des couplets sur la gtillotine ${ }^{4}$.

1. "Cetle maison est l'antichambre de la mort, écrivait un prisonnier de la Conciergerie. Nous vivons avec elle. On soupe, on rit avec des compagnoas d'infortune; l'arrét fatal est dans leur poche, on les appelle le lendemain au tribunal; quelques heures après, nous apprenons leur condamnation; ils nous font faire des compliments, en nous assurant de leur courage. Notre train de vie ne change point pour cela; c'est ua mélange d'horreur sur ce que nous voyous, et d'une gaicté en quelque sorte féroce; car nous plaisantons souvent sur les objets les plus efrayants, au point que nous démontrions l'autre jour à un nouvel arrivé de quelle manière l'exécution se fail, par le moyen d"une chaise à qui nous faisions faire la bascule."

2. Mème spectacle dans les prisons des départements. Une Auglaise, détenue dans celle d'Amiens (1793), rsconte : J'ai vu ce matin, au corps de garde, un âne chargé de violons el de musiques, el une prisonnière n’arrive jamais sans sa boite de rubans. Étouffés comme nous le sommes par lo nombre, nous n'en subissons pas moins une importation de bichons, qui forment une part aussi importante de la communauté dans une prison que dans le plus superbe hòtel. "

3. Quand la priacesse de Monaco dut monter à l'échafaud, elle clemanda du rouge : " Si la nature l'emporte, el que j'aie un moment de faiblesso, employons l'art pour le dissimuler."

4.

... Demain l'on me jugera ;

On fixera ma destinée

Et le tribunal mouvrira

La porte... ou la croisce (bis).

La croisee, c'est la lunetla de la guillotine. 
On jouait aux cartes, aux dames, au tric-trac. Quand Danton arriva au Luxembourg, il trouva un de ses amis, destiné à mourir dans la même fournée que lui, l'ancien président de la Convention, Hérault de Séchelles, qui jouait au bouchon. "Après tout, qu'est-ce que la guillotine? disait Lamourette: une chiquenaude sur le cou. "Bailly, dont on avait différé le supplice, se frottait les mains et répétait : "Petit bonhomme vit encore."

Sur l'échafaud, les victimes, sans distinction de parti, montraient une intrépidité sereine.

Les royalistes mouraient en criant : Vive le Roi! Les gentilshommes affectaient de tutoyer le bourreau comme autrefois leur valet de chambre. Ils le chargeaient d'envoyer des boucles de leurs cheveux à leurs amis et amies.

Le 11 novembre, par une froide matinée d'automne, on amenait au Champ de Mars, pour expier le sang versé en ce lieu même au 17 juillet 1791, l'homme du Serment du Jeu de Panme, Bailly. Comme les mains du vieillard tremblaient : "Tu trembles! lui dit un des assistants. Mon ami, répondit paisiblement Bailly, c'est de froid. " Les Girondins allèrent à l'échafaud en chantant la Murseillaise. Quand on amena Danton et Camille Desmoulins, ils voulurent s'embrasser. Le bourreau s'y opposa : "Imbécile! lui dit Danton, tu n'empêcheras pas nos têtes de s'embrasser dans le mème panier ". Quand ce lut son tour, il dit à l'exécuteur: "Tu montreras ma tête au peuple, elle en vaut la peine. "Même les Hébertistes, après avoir déshonoré la Révolution par leurs excès, honorèrent l'échafaud. " Ce qui me tue, disait Hébert, c'est que la République va périr. - Non! répondait Ronsin, les mains liées derrière le dos; elle est immortelle! " Plus tard, les suprêmes paroles de Duroy, un des derniers Montagnards, furent : "Unissez-vous tous : c'est le seul moyen de sauver la République. "

Les femmes, Charlotte Corday, la reine Marie-Antoinette, Mme Roland, mouraient aussi intrépidement que les hommes. Une seule pleura et se roula sur l'échafaud; et cela fit tant d'effet sur le peuple que les tricotcuses ellesmèmes faillirent empècher le supplice · c'était Mmodu Barry, la dernière favorite de Louis $X V$. 


\section{Après thermidor.}

La réaction thermidorienne. - Dès le lendemain de la mort de Robespierre, on vil reparaitre les carrosses. Il y eut de nouveau des maitres et des domestiques. Quand la loi du maximum fut abolie, et surtout quand le Directuire eut succédé à la Convention, les magasins se signalèrent par leurs étalages. Un bourgeois, qui, en 1797, admirait celui d'un confiseur, disait : " Il y a trois ans, le maitre de cette boutique eût été guillotiné. "

Au lendenain de la Terreur, les français sortis des prisons ou revenus de l'exil, ou simplement las de l'austérité jacobine et du régime spartiate qui avait pesé sur eux, se jetèrent avec emportement dans tous les plaisirs. Trente ou quarante théâtres, 644 bals publics, faisaient recette. Parmi ceux-ci, il y avait les bals des victimes, où n'ètaient admis que ceux qui affirmaient avoir perdu des parents par l'échafaud, où l'on dansait en habits de deuil, et où l'on saluait d'un coup sec de la tète, comme si elle eùt été frappée dı couteau de la guillotine. Dans les théàtres, on applaudissait les allusions qui semblaient avoir trait au jacobinisme, à la tyrannie; la jeunesse dorée, les muscadins, ainsi nommés parce que le parfum du musc et celui. de la muscade faisaient alors fureur, applaudissaient les allusions hostiles à la République. Le " Chant du Réveil du peuple ", qui passait pour réactionnaire, retentissait partout. Le chansonnier Ange Pitou colportait dans les rues et les carrefours des chansons contre le Directoire.

Le costume. - La jeunesse à la mode adopte un costume singulier. Les hommes, élégants, muscudins, merveil. leux ou incroyables, portent les cheveux abattus le long. des tempes, en oreilles de chien, et relevés par derrière avec un peigne, de manière à figurer un chignon et à rappeler la toilette des condamnés à mort; aux oreilles, d'immenses anneaux; sur le nez, d'énormes lunettes, ou bien, devant les yeux, un énorme binocle à long manche, comme s'ils étaient affectés de myopie; une prodigieuse cravate, qui semble cacher un goitre ou des écrouelles; un habit à grand collet, faisant une gibbosité sur le dos, comme s'ils 
eussent ete bossus; des culottes de nankin mal ajustées et faisant paraitre leurs genoux cagneux; des bas chinés, tirebouchonnés sur la jambe, comme s'ils eussent été dépourvus de mollets. Non contents de paraitre myopes, contrefaits et malingres, ils affectaient un zézaiement ridicule, évitaient de prononcer les $r$, disaient ma paole supéme, incoyatle, hoible, etc. '. Mais, si étiolés qu'ils voulussent paraitre, ils ne sortaient qu'avec un énorme gourdin, noueux ou en spirale, qu'ils appelaient leur pouoir exécutif, et dont ils se servaient pour traquer et rosser les Jacobins. En signe de ralliement, ils avaient adopté la perruque blonde et le collet noir : ce qui amenait des rixes continuelles, soit avec les collets rouges démocratiques, soit avec les soldats républicains.

Parmi les femmes ${ }^{2}$, les merveilleuses prétendirent s'habiller ou plutôt se déshabiller à la grecque ou à la romaine, ne se vêtirent que d'étoffes légères et mème diaphanes, se chaussèrent de cothurnes ${ }^{3}$, de sandales attachées au-dessus de la cheville par des rubans entre-croisés ou des lanières garnies de perles. Elles portèrent des bagues aux doigts de pied et des cercles d'or aux jambes. Tantôt, sur une vaste perruque blonde, elles arboraient des chapeaux immenses; tantòt elles portaient les cheveux courts et frisés, comme ceux des bustes romains. La mythologie, l'anti quité étaient à l'ordre du jour : on eut des tuniques a la Cérès et il la Minerve, des redingotes à la Galathee, des robes à la Flore, à la Diane, à l'Omphale. Comme ces robes étaient trop collantes pour qu'on pût y faire des poches, on imagina de porter le mouchoir dans un sac qu'on appela, d'un mot grec, balantine, ou, d'un mot latin, réti-

1. Dès 1795 , le Journal de Paris, décrivant cette maladie nouvelle qu' semblait sévir sur la jeunesse, et, commo les muscadins prononçaient sexa a lieu de qu'est-ce que c'est que ccla, l'appelait la "maladie du sexa ".

2. Carle Vernet a donné, dans ses caricntures d'Élégants de 1795, d'Incroyables et de Merveilleuses du Directoire, de curieux spécimens du costume des classes oisives.

3. C'est Coppe qui fabrique alors le cothurne, et qui le fait "d'un coloris, d'une fraicheur, d'une èloquence, d'une pocsio "jusqu'alors inouie. Seulement ce n'est guére solide. Si on hi rapporte la chaussure déchiré, l'artiste après avoir longtemps médité, seécrie, comme frappe d'un trait de lumièro, * Ah! parbleu! Je gage cinquante louis que madame aura marché. * 
cule: d'oủ nous avons fait ridicule. Les reines de la mode sont alors Mme Tallien, qu'on appela "Notre-Dame de Thermidor ", Mme Hamelin, qui poussa le plus loin l'audace dians la nouveauté, Mme Riécamier, dont David a laissé un i ravissant portrait. Mme de Staël et Mme Raguet, que l'on complarait à Minerve et à Junon.

L'amiotage. - Les assignats tombant chaque jour davantage, on paye 2700 livres un chapeau, 3000 une paire de bottes, 200 une cravate, 625 un paquet de chandelles, 60 une livre de pain, 120 une livre de viande, 50 une tasse de café avec le petit verre. L'agiotage s'exerce dans des proportions colossales: les femmes les plus ćlégantes se mettent à accaparer la chandelle, le savon, le tabac, les épices, les tissus. Dans les salons repeuplés, on ne s'entretient que de la baisse les suifs ou de la liausse des cuirs. Des fortunes énormes poussent comme des champignons. Aux fermiers généraux, décimés par l'échafaud révolutionnaire, succède une race nouvelle de financiers, plus avides d'argent et de jouissances, plus grossiers parce qu'ils sont plus vite parvenus, raillant la gêne de la vieille bourgroisie française et la corrompant par leurs exemples.

Mariages et divorees. - Avec le divorce, sans garanties et presque sans formilités, il y a de telles facilités pour se soustraire aux obligations du mariage qu'ou ne craint plus de se marier. Dès 1794, Liardot avait ouvert, rue de la Tixanderie, la première agence matrimoniale que nous ayons eue, et publié son Indicateur des Mrriages. Un autre fouda une espece de pension de demoiselles à mitrier, où, trois fois par semaine, il y avait bal et concert pour attirer les épouseurs. Beaucoup s’indignaient de ces innovations. "Ce n'est pas ainsi, écrivait un citoyen, que dans Athcones ou montait les marches du temple de l'Hyménée et qu'ou se préparait à donner le jour à des Aristides et à des Miltiades. "

Les plaisirs. - Les jardins d’été s'ouvrent de toutes parts. On déserte le Palais-hoyal, un repaire de filous, et les Tuileries, où les sentinelles arrêtent les coiffures antipalriotiques. On va à Bagatelle, au bois de Boulogne, aux pelouses de Monceaux, au jardin de la rue Saintlazure, a 
l'Élysée du faubourg Saint-Honoré; à Biron, rue de Varennes; au Jurdin de Virginie, faubourg du Roule; au pavillon de Hanovre, où il y a des tentes turques et des kiosques chinois; à Frascati, éclairé par des verres de couleur; ou bien un peu plus loin, au Colistée et au jardin anglais de la plaine des Sablons; au wauxhall de Passy ou de Saint-Germain-en-Laye; au clos Griel de Saint-Cloud. Ruggieri inaugure Tivoli, qu'il illumine de ses feux d'artifice: puis, exilé de Tivoli par ses associés, il fonde Idalie, qui rivalise avec Tivoli d'illuminations et de fusées, de concerts, d'exhibitions curieuses, d'ascensions aérostatiques. Les royalistes se réunissent de préférence au PetitCoblentz, rue Grange-Batelière.

En 1798, Velloni, le premier glacier napolitain qu'on ait vu à Paris, ouvrit au coin de la rue Taitbout le café connu depuis sous le nom de Torton.

Séraphin, avec ses ombres chinoises, le théâtre Mareux, avec ses acteurs enfants, Franconi, avec ses chevaux, font concurrence aux théâtres.

Les tireurs de cartes et diseurs de bonne aventure reviennent à la mode. C'est alors que fleurissent le citoyen Martin, qui sait prédire " quand les mariages doivent avoir lieu, de mème que les divorces ", et Mlle Lenormand, qui eut alors beaucoup de clients: sans parler de cette devineresse de la Martinique qui avait prédit à Joséphine qu'elle serait " plus que reine 1 ".

Paris pendant la Révolution. - Sous la Révolution, Paris, a vec ses 600000 habitants, avait peu changé. Il continuait à ètre assez malpropre: les rues étaient infectées par des amas d'ordures qui s'entassaient au coin des. bornes. Leur pavage, que le ruisseau traversait par le milieu, se détériorait et formait des trous fort dangereux. Le soir, elles étaient obscures, surtout quand l'éclairage des magasins cessait, et fort peu sùres. En 1793, on faisait paitre d'immenses troupeaux de moutons aux ChampsElysées. Les autres promenades, pas plus que les boule-

1. Napoléon lui-mėme croyait à son étoile, et Josèphine profitait de cette idée superstitieuse pour détourner l'Empereur de lidée d'un divorce. "On parle de ton étoile, lui disait-elle, mais c'est la mienne qui influe sur la tienne; ćest à moi qu'il a été prédit une haute destinée. n 
vards, n'étaient pavées et entretenues. On lélicita le ministre Garat pour avoir fait placer les premiers bancs qu'on ait vus dans le jardin des Tuileries.

\section{Sous le Consulat et l'Empire.}

La cour. - Napoléon, Premier consul 1, mais surtout Empereur, modela peu à peu sa cour sur celle des anciens rois ${ }^{2}$. Il s'efforea de discipliner ses compagnons d'armes et leurs femmes, dont quelques-unes, comme la maréchale Lefèvre, duchesse de Dantzig, étaient renommées par leurs excentricités; il imposa une étiquette de plus en plus rigoureuse ${ }^{3}$; il interdit la moustache aux généraux courtisans *. Un certain Despréaux, qui avait été maitre de danse de la reine, vint apprendre ou réapprendre aux dames à marcher et à faire la révérence. D'autre part, Napoléon attirait à sa cour les membres de l'ancienne noblesse, disant insolemment que " ces gens-là seuls savent servir". Il donnait à l'impératrice Joséphine, comme dame d'honneur, une duchesse de La Rochefoucauld, quoique celle-ci fut bossue, et, comme dames du palais, Mmes de Rémusat, de Chevreuse, de Montmorency-Matignon, de Mortemart. Il fit servir Marie-Louise par des dames de familles encore plus anciennes, qui s'empressèrent d'accourir auprès d'une archiduchesse d'Autriche, d'une nièce de Marie-Antoinette. Lui-même s'entoura d'anciens nobles.

"Les Tuileries, raconte un page de Napoléon, étaient devenues leur ail-de-tœuf. Point de conloirs, de petits

1. La cour consulaire, au mains à la Malmaison, se diverlissail parfois à des jeux populaires. On jounit aux barres, el Mme Bonaparte, sa fille Hortense, son fils Eugène, Lauristan, Bourrienve, Rapp se partageaient en deur camps qui se faisaient des prisonniers. Bonaparte lui-méme s'en mèlait, tombait souvent et se relevait en riant aux éclats. On donnait aussi les comédies de société. On jouait mème à des jeux innocents, comme le gage touché, et le Premier consul se laissait prendre comme les autres.

2. L'imitation des usages de l'ancienne caur fut poussé si loin que, do mème qu'on avait connu autrefois des étoffes appelées caca Dauphin, on eut, après la naissance du fils de l'Empereur, des ètaffes caca roi de Rome.

3. En mai 1804, l'appellation de citoyen fit place officiellement á celle de monsieur. Le titre de madame avajt déjá été restitué aux femmes à la cous du Premier consul.

4. "Gèeraux sur le champ de balaille, leur disait-il, sayez grands sejgaeurs autour de moi. " 
escaliers dérobés, d'antichambres où on ne les rencontràt déjà. "Le bureau du secrétariat de la maison de l'Empereur " se trouvait encombré de demandes, de placets, de suppliques; dans les trois derniers mois qui précédèrent le sacre, ou en compta jusqu'à cinq mille, dont plus de trois mille avaient été faits par l'élite de la noblesse de France... L’un voulait ètre écuyer, l'autre chambellan. Celui-ci demandait une place pour sa femme auprès d'une des princesses sœurs de l'Empereur; celui-là réclamait pour son fils l'honneur d'entrer dans les pages. "

Napoléon, en effet, voulut avoir des pages pour faire le service auprès de lui et de IImpératrice. Ils formèrent l'ceole des pages et eurent des professeurs de mathématiques, de latin, de français, etc., même de musique, de danse, d'escrime, de natalion. A vingt ans, on ieur donnait un emploi dans l'armée.

Parmi les noms illustres, hommes et femmes, qui figurèrent dans le service de la chapelle, du palais, des écuries, on rencontre encore ceux des Rohan, des Broglie, des d'Osmond, des Talleyrand, des Bouillé, des Colbert, des Xaintrailles, des Cossé-Brisac, des Villeneuve, des Clermont-Tonnerre, des Fontanges, des Lur-Saluces, elc. "En ouvrail l'Almanach imperial, on aurait cru tenir l'ancien Amuaive de la cour de Versailles. " Quand l'Empereur eut pris la couronne d'Italic, aux vingt-quatre dames du palais de l'Impiratrice il ajouta douze dames italiennes, choisies dans les plus grandes familles.

Il avait conserré, de son origine presque plébéienne et de son éducation militaire, des façons qui n’étaient guère de cour. Il laissait volontiers échapper des b... et les f..., tout comme un jacobin. Il était brusque, fantasque, même brutal. Une de ses manies, en ses moments de bonne humeur, élait de pincer l'oreille à ses familiers ou de donner de pelits souffets. Sa brutalité pouvait aller jusqu’à la violence : it cingla un jour de sa cravache un écuyer, qu'il accusait d'avoir mal tenu son cheval. Au camp de Boulogne, il en menaça l'amiral Bruix, qui n’arait pas exécuté un de ses ordres; mais l'amiral recula d'un pas, mit la main sur la garde de son épée et dit: "sire, presez garde!" Un jour qu'il arait grossièrement apostrophé Talleyrand : 
- Quel dommage, dit celui-ci en se retirant, quel dommage qu'un si grand homme ait été si nıal élevé! o

Avec les dames, il n'était pas toujours aussi poli que Louis XIV. La maréchale Lannes, à laquelle il faisait de fréquentes observations sur sa toilette, disait, les larmes aux yeux: "Je ne sais quelle est la fatalité qui me place toujours sous les yeux de l'Empereur dans les moments où il a de l'humeur; car je ne pense pas qu'il ait l'intention de me dire des choses désagréables, et cependant cela lui arrive irès souvent. "

La princesse Dolgorouki, femme de l'ambassadeur de Russie, résumait ainsi son impression sur la cour impériale (1804) : "On trouve là une bien grande puissance, mais ce n'est pas là une cour."

Le costume Empire. - L'habit, la culotte courte, les souliers à boucles avaient reparu. On poitast mème la perruque. Hais, déjà en Egypte, Bonaparte y avait personnellement renoncé : pendant longtemps il était resté le seul général de la République qui fut sans perruque: anssi les soldats l'appelaient-ils le petit tondu.

Les costumes de cour de l'époque napoléonienne ne manquent pas de caractère. Il faut voir, dans les portraits du temps, les grands dignitaires en cravates de dentelles, habit, gilet, bas de soie; les femmes coiffées à l'antique, couronnées de diadèmes de perles et de hrillants, avec de grandes collerettes ḋ la Marie de Médicis, les bras nus presque jusqu'aux épaules, les épaules nues: jamais les femmes n’avaient bravé avec autant d'intrépidité les refroidissements. La taille était placée très haut: ce qui donnait plus d'ampleur aux plis de la robe. La jupe de dessus faisait par derrière une longue et majestueuse queue. Tout ce monde resplendissait des reflets de la soie, du satin, du velours, de l'éclat des pierreries et des diamants.

Les ressources pour la toilette étaient un peu limitées par l'obligation qu'imposait l'Empereur aux dames de sa cour de ne pas porter de tissus anglais. "Ce soir, écrit l'une d'elles, Napoléon était déchainẻ contre toutes les femmes. Il nous a dit que nous n'avions point de patriotisme, point d'esprit national; que nous devions rougir de porter des mousselines; que les dames anglaises nous donnent 
l'exemple en ne portant que les marchandises de leur pays; que cet engouement pour les mousselines anglaises est dautant plus extraordinaire que nous avons en France des linons-batistes qui peuvent les remplacer et qui font les robes beaucoup plus jolies; que, quant à lui, il aimerait toujours cette étoffe préférablement à toute autre, parce que, dans sa jeunesse, sa première amoureuse en avait une robe." "

On continuait à se parfumer beaucoup : l'impératrice Joséphine emplissait de musc son cabinet de toilette, et Napoléon s'inondait d'eau de Cologne.

Le mobilicr Empire. - La période impériale est signalée par un véritable style dans le mobilier : c'est le meuble Empire, qui, à certains égards, continue le meuble Louis XVI, car il s'inspire, comme lui, du goût classique et antique. L'école d'ébénisterie de l'époque précédente avait été dispersée par la tourmente révolutionnaire : on ne songea pas à demander les services des survivants, de Gouthière, qui était tombé dans la misère, de Riesener, qui consumait ses dernières années dans l'inaction. On laissa se perdre, se disperser et se détruire les restes des ameublements de Versailles, Trianon, Saint-Cloud. On fit du nouveau avec des hommes nouveaux, mais on perdit les traditions de mesure et de bon goùt qui avaient caractérisé l'ancien régime. On s'abandonna avec trop peu de retenue à une imitation plus ou moins habile de l'antiquité. Le mobilier affecta une raideur de formes et une lourdeur extrêmes. L'architecte Percier fut chargé de collectionner une immense quantité de dessins, de copies de meubles grecs, romains, et mème égyptiens, car Denon avait exécuté de ces dessins à Thèbes (Égypte). Parmi les pièces les plus célèbres de l'époque, il faut citer la toilette et la psyché de l'impératrice Marie-Louise, le berceau du roi de Rome, offerts par la ville de Paris, exécutés par les orfevres odrot et THOMIRe, enrichis de peintures par Prud'hon. Desmalter, qui acquit une célébrité européenne, fabriquait des meubles où la figure d'Isis, divinité égyptienne, fournissait le trait d'ornementation le plus caractéristique. AUGUSTE inventa des matrices à frapper en bosse les ornements. BIENNaIs. orfèvre-tabletier, exécutait les beaux nécessaires de voyage 
que l'Empereur emportait dans ses campagnes, des pièces d'orfèvrerie pour les impératrices Joséphine et MarieLouise. Parmi les ébénistes en renom, on peut encore citer BAODON-GOJBACD, qui employait l'orme noueux et enrichissait ses meubles d'ornements en bronze doré; FRICHAT. qui exécutait des marqueteries de cuivre, d'argent et d'or à l'emporte-pièce; GARDĖRE, qui moulait ses ornements en carton peint et verni.

Lart culinalre. - Un gastronome de cette éprrue, GRIMOD DE LA REYNIÈRE, caractérisait d'un not l'époque precédente : "Pendant les années désastreuses de la Révolution. il n'est pas arrivé un seul beau turbot à la halle. "Sous l'Empire revinrent les beaux jours de l'art culinaire. Napoléon n’y entendait rien : il mangeait en quelques minutes; mais les diners de Talleyrand et de Cambacérès furent célèbres. Le premier eut pour cuisinier l'illustre CARÈme (1794-1833), qui plus tard se sépara de lui "pour des motifs politiques ", et qui ensuite quitta le roi d'Angleterre, parce quil l'estimait "un mangeur vulgaire ${ }^{1}$ ".

Les plaisirs. - Un des divertissements les plus à la mode, c’était le bal masqué de l'Opéra. Napoléon aimait ces sortes de bals et se déguisait volontiers; mais on le reconnaissait du premier coup, car il ne pouvait s'empêcher de croiser ses mains derrière son dos.

Parmi les restaurants en renom, il faut citer les Frères provençaux, fondés, en 1\%86, par trois Provençaux qui nétaient nullement frères, chez lesquels Barras et le général Bonaparte s'attablèrent plus d'une fois, et qui firent fortune en 1808, quand les officiers de larmée d'Allemagne traversèrent Paris pour se rendre en Espagne. Parmi les cafés, le café Lemblin, qui resta toujours un café bonipartiste, et qui s'était fondé, en 1805̆, au Palais-Royal: le café du Caveau, alors fréquenté par les officiers de li garde impériale, plus tard par les artistes; le café de hi Rotonde, où une inscription, sur une table de ruarbre, rappelle qu'on y ouvrit une souscription pour la première ascension des frères Montgolfier; le calè des Mille-Colonnes, 
présidé par Mme Romain, la belle limonadière; le café de Chartres, où Murat, alors grand-duc de Berg, aimait à déjeuner avec ses officiers et où le poète Berchoux et Grimod professaient la gastronomie.

Au café Tortoni, Spolar attirait les clients par ses magnifiques parties de billard. Un jour, Talleyrand paria sur lui 40000 francs et les gagna. Spolar fut même nommé en 1809 professeur de billard de la reine Hortense.

Lopinion. - Le bourgeois de Paris était saturé de fêtes qui contrastaient avec celles de l'époque précédente : on le fit assister au couronnement de l'Empereur, se courber sous la bénédiction du pape, s'enthousiasmer au baptème du roi de Rome. La vie politique, la vie de la rue disparurent entièrement; plus de journaux ou des journaux insignifiants; une censure rigoureuse sur les théatres, une police toujours en éveil, les règlements à l’infini. Mais le bourgeois était plus heureux qu'à l'époque précédente; les impôts n'étaient pas trop lourds, la sécurité de la rue était assurée, les affaires reprenaient.

Il eut bientòt d'autres sujets de souci : le blocus continental lui imposait presque les mêmes privations que les lois révolutionnaires; la conscription se faisait de plus en plus lourde et menaçait toutes les familles. Au commen. cement, il était fanatique du génie de l'Empereur et ne rẻvait que gloire, victoires et conquêtes. Il s'en latigua vite. On a peine à se figurer aujourd'hui a vec quelle indifférence, à partir d'Austerlitz, la génération d'alors accueillit les bulletins de victoires, lus publiquement sur le théâtre, et les salves de canon aux Invalides '. Cette froideur s'expliquait par beaucoup d'inquiétude sur les suites de tant de témérités et par une certaine lassitude d'une autorité par trop personnelle. Napoléon lui-même le sentait. "Savez-

1. Napoléon, après la paix de Tilsitı, en convenail lui-mème : "La gloire militaire s'use vile chez les peuples medernes. Cinquante balailles ne produisent guére plus d'etret que einq on six. Je suis et je serai toujours pour les Frangais bien plutơl l’hemme de Marengo que celui d'léna el de Friedland. n - On disait déjá, après chaque bulletin de victoire : "La guerre, toujours la guerre, voila done oủ nous sommes réduits. n - Mme de Rémusat ajoute : "L'impression des victeires s'usait de plus en plus, et des yenx exercés auraient dès lors deviné que ce n'étaient plus les suecès de ce genre qui devaient exciter chez les peuples un enthousiasme durable. 
vous ce qu'on dira quand je n'y serai plus? denandait-il un jour à Mme de Rémusat... Eh bien, on dira : Ouf! "

Paris capitale d'un Empire. - Napoléon conçut pour Paris de vastes projets et en réalisa quelques-uns. Il fit construire des égouts, porter à 10000 le nombre des réverbères, jeter sur la Seine les ponts de la Cité, des Arts, d'Austerlitz, d'Iéna, prolonger les quais, déblayer les places de la Bastille, du Châtelet, du Carrousel, de la Concorde, de l'Étoile, percer les rues de Rivoli et de Castiglione, élever de magnifiques monuments.

Les abattoirs, dont Napoléon avait ordonné la construction dès 1810, ne furent terminés qu'en 1818. Jusqu'alors, tout comme dans l'ancien Paris, chaque boucher avait son abattoir : on tuait partout, et, raconte Hercier, "le sang ruisselle dans les rues: il se caille sous vos pieds, et yos souliers en sont rougis. "

En Vendée, se fondait la ville de Napoléon-Vendèe; à Lyon, se bâtissait la place Bellecour. Non seulement les grandes villes de France, mais Bruxelles, Anvers, Turin, s'agrandissaient et s'embellissaient: Napoléon bâtissait à Milan l'are du Simplon et $y$ construisait des arènes immenses sur le modèle romain.

Ouvrages a consulter. - Quicherat, Hist. du costume en France (185\%). - be Champeau, Le meuble, t. II (1885). - Viollet-le-Dnc, lict. du mobilier fr. - Ilavard, Dict. de lamenblement et de la dreoration. Champtleury, Hist. des faitences patriot. sous la Riv. (1566). - Du Camp, Paris, ses organes (1869-75). Des Cilleuls, Hist. de ladmin. parisieme au IIK s., t. I (1902) - De Lanzar de Lalonie, l'uris sous Napolson Fr en conrs). - Bouchot, Le luxe fr. sois l'Emp. (190i). - Lafond. Lart dicnrat if et le mobilier sous la Rep. et l Emp. (1900). - G. Lenotre. Paris indutionnaire. - Memoires de Inte Campan, Beurnot, Nme de liemusal, Villemin; Lettres de Norier, de Mme Rolind: Journal de Gouverneur Mnrris Amerirain. Véron, llem.d'un bouryeois de Paris. - Lockroy, Jommal d une bourgeoise pendant la lievo-A. Rochas, Hist. l'un bourgeois de Talence (1501). Soun. ft jommal d'un bourgeois "Evren. (1), - Besnard, souc. d'un nonusfenaire. - Ad. Schmidt,
Tubleaur de li hive fir mpjorle de

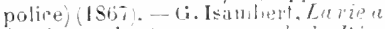

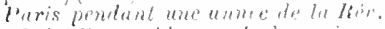
1791-9.9). - Amanach des prisons juar lian III). - Nichalet. Les Femmes de la llev. (185i) - b. Lairtullier. Les Fummes celebres de 1789 it t795 (15\%. - F. Ruenguin, Etat de la Fronce au 18 brmative, ralports (Ari). - De cioncourt, La rocilite finncaise pendant la Rivol. 1Nie): lil soc. franc. sous le birecloim liso). - Gilbert stenger, La rucièt finur. pent. le romsulit (1903 et sm:. - E. Herriol, Madame Récrmier et sos amis (1905). - ChampHenry. Hist. de la caricature sous

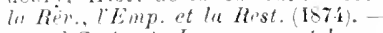
cirand-Carteret, Les momers et la curiruture en Frunce (IXS) - Itenain. llist. numism. dir la Reve. (140). Ruerer Peyre. Napolion et som temps (198x). - Naze-Sencier, Les fowmissoirs de Vup. (1s93) - F. Mascon, Vup. et les fimmes (1893) ol Nill. ihe zlui Is9í.

Musie : Musce Cornavalet a Paris; La Nalmaison. 


\section{LIVRE II}

\section{LES GOUVERNEMENTS DE SUFFRAGE RESTREINT}

\section{LA RESTAURATION - LA MONARChIE DE JUILlET (1814-1848)}

\section{CHAPITRE XV}

ZES CONSTITUTIONS, LE DROIT ELECTORAL, LES LIBERTES

\section{Les Constitutions.}

Caractères des deux monarchies. - Entre la Restauration et la Monarchie de Juillet, il $y$ a des différences notables. Louis XVIII et Charles $\mathbf{X}$ portaient l'ancien titre de roi de France et de Navarre, faisaient dater de la mort de Louis XVII l'origine de leur royauté, régnaient uniquement par la grice de Dieu, prétendaient avoir octroyé la Charte, s'appuyaient principalement sur l'aristocratie et le clergé. Louis-Philippe s'intitulait roi des Francais, datait son règne de la victoire des insurgés de juillet, régnait par la gráce de Dieu et la volonté nationale, avait accepté la Charte votee par les Chambres, s'appuyait sur la bourgeoisie et refusait au clergé toute influence dans les affaires publiques.

Cependant les deux monarchies eurent des caractères communs : elles étaient parlementaires. De plus elles s'appuyaient, non sur la masse du peuple, mais sur des classes dirigeantes; leur système électoral était le suffrage restreint. 
Par ces deux derniers caractères, elles diffèrent essentiellement des trois gouvernements qui suivirent: Républiques ou Empire.

Ces différences dans les institutions politiques imprimèrent à la période monarchiste (1814-1848) de notre civilisation contemporaine certains caractères qui la distinguent profondément de la période suivante. La domination des classes dirigeantes se fit sentir dans toutes les lois administratives, judiciaires, militaires, économiques, et mème dans la politique extérieure; elle se fit sentir aussi dans les lettres, dans les arts, dans les mœurs, même dans le costume et dans l'ameublement.

La Charte de 1814. - La Restauration ne prétendait pas, comne l'Empire, avoir pour base la souveraineté populaire. Louis XVIII ne songeait pas à faire ratifier par un plébiscite la constitution nouvelle qu'il donnait à la France. Pourtant la Charte du \& juin 181/4 garantissait effectivement les libertés publiques et organisait un contrôle effectif par une représentation nationale. Elle établissait une Chambre des pairs et une Chambre des deputés.

Les pairs étaient nommés par le roi : la pairie était viagère ou héréditaire : cette hérédité de la pairie pouvait choquer le sentiment égalitaire; mais, sous une monarchie, elle est une garantie nécessaire de l'indépendance de la Chambre haute à l'égard du pouvoir royal.

La Chambre des députés était élue par un nombre trop restreint d'électeurs et dans des conditions qui ne permettaient l'accès de la Chambre qu'à de très riches propriétaires; mais enfin elle était élue, tandis que le Corps législatif impérial avait èté, en réalité, nommé par le gouvernement.

Les pairs et les députés ne pouvaient être l'objet d'une poursuite judiciaire, pendant la durée des sessions, qu'après autorisation préalable de leur Chambre.

Ces deux Assemblées présentaient donc des garanties sérieuses d’indépendance.

Les ministres pouvaient ètre pris dans les Chambres : ils étaient responsables; ils pouvaient être mis en accusation par la Chambre des députés et jugés par la Chambre des pairs. 
Aucun impôt ne pouvait être perçu sans avoir été voté par les Chambres, et l'impôt n'était voté que pour un an.

Les lois étaient proposées par le roi, c'est-à-dire par ses ministres : elles devaient être votées par les deux Chambres et sanctionneses par le roi.

La responsabilité des ministres, le vote de l'impôt et le vote des lois par les Chambres, mettaient le pouvoir exécutif dans une certaine dépendance du pouvoir législatif.

La Charte garintissait la plupart des conquêtes de 1789: liberté individuelle, des cultes, de la presse, sécurité des propriétés, même des propriètés dites nationales.

La Charte de 1814 était donc une constitution monarchique, mais libérale et parlementaire. D'ailleurs, elle était presque copiée sur la constitution anglaise, qui avait pour elle la consécration d'une longue expérience.

L'Acte additionnel de 1815. - Quand Napoléon revint de l'île d'Elbe, il donna au pays une constitution presque semblable à la Charte de 1814. Lui aussi établit une Chambre des pairs, avec la garantie de l'hérédité, et une Chambre des députés, avec la garantie de la libre élection. Lui aussi établit la responsabilité ministérielle : ce qui était la renonciation au pouvoir personuel. Seulement il ne voulut pas avoir l'air de domner à la France une constitution absolument différente des anciennes constitutions impériales : il atténua en quelque sorte l'importance de la réforme en donnant à cette Charte le nom d'Acte additionnel aux constitutions de l'Empire (27 avril 1815). N'ayant pas la prétention d'octroyer une Charte, il fit ratitier l'Acte addititionel par un vote populaire et conroqua l'assemblée dite du Champ de mai, où 5000 délégués des collèges électoraux lui apportèrent les résultats de ce plébiscite, qui ne donna d'ailleurs que 1303000 oui: tant fut énorme le nombre des abstentions!

L'Empire libéral ne dura que trois mois: il succomba en mème temps que l'Empereur à Waterloo. L'ancienne dynastie revint et la Charte de 1814 fut remise en vigueur.

Hodifications a la Charte de 1814. - Plusieurs lois modifièrent les conditions du fonctionmement des deux Cliambres. L'ordonnance du 19 aout 1815 déclara liéréditaires tous les sièces de la Chambre des pairs et attucha 
à tous des titres de duc, marquis, comte, vicomte ou baron. La Charte de 1814 avait établi que les députés seraient élus pour cinq ans et renouvelables tous les ans par cinquième. Pourtant, en 1816, la " Chambre introuvable ", qui inquiétait le roi lui-mème par l'exagération de son royalisme, fut dissoute intégralement et remplacée par une Chambre nouvelle ${ }^{1}$.

On trouva que des élections annuelles agitaient trop le pays et que les Chambres n'avaient pas assez de durée pour suivre une politique conservatrice. La lo $i$ de $182 \mathbf{4}$, sous le ministère Villèle, décida que la Chambre des députés durerait sept années et serait renouvelíe intégralement dans la septième année.

La Chambre qui vota la septennalité se déclara ellemème septennale. Elle fut d'abord une assemble de riaction : elle ne comptait, au début, que dix-sept députés de l'opposition; c'est elle qui vota, par exemple, la loi sur le sacrilege. Elle finit cependant par faire de l'opposition à ce même Villèle, qui avait tant compté sur elle. Flle fut dissoute en 1827, n'ayant duré que trois ans.

La nouvelle Chambre, également septennale, montra encore plus d'indépendance : elle renversa le ministìre Villèle et vota l'adresse des 221 contre le ministère Polignac. Elle fut dissoute en 1829, ayant duré moins de deux ans. Les élections ramenèrent des députés encore pius hostiles. Alors le roi Charles $\mathrm{X}$ fit un coup d'Etat: par les ordonnances du 25 juillet 1830 , il cassa les élections, modifia la loi électorale, supprima la liberté de la presse. Il prétendait justifier ces actes par l'article 14 de la Charte, qui altribuait au roi le droit de faire " des règlements et ordonnances pour l'exécution des lois et la sûreté de l'État "; mais cet article 14 ne pouvait attribuer au roi le droit de faire des ordonnances pour la violation des lois. Prétendre régler au

1. La Chambre royaliste de 1814 n"élait aulre que le Corps législatif de Napoleon, conservé par la royauté. Elle fut dissoute au relour de Nagroléon, qui couvoqua une nouvelle Chambre. Celle-ci, bien qu'elle eúc consenti à rappeler Louis XV111, fut dissoule par lui en 1S15. C'est alorg qu'elle fut remplacée par la Clambre dite introuvable, composée des plus ardents royalistes parmi les grands propriélaires fonciers. La Chambre inIrouvable ayanl éce dissoute en 1816, cela fail trois dissolutions en deux . ans. 
moyen des ordonnances ce qui ne pouvait ètre réglé que par la loi, c'était remplacer la monarchie constitutionnelle par la monarchie absolue. Le pays répondit à cette prétention en renversant la royauté de droit divin (Révolution de juillet 1830).

Après la victoire du peuple, les députés dont les élections avaient été cassées par Charles $\mathbf{X}$ se formèrent en Chambre des députés, et offrirent la couronne à Louis-Philippe.

La Charte de 1830. - La Charte de 1814 devint alors la Charte de 1830. La Chambre l'amenda seulement sur quelques points, dans un sens plus libéral ou plus démocratique. Le funeste article 1'́ ful supprimé, l'hérédité dans la Chambre des pairs abolie, la durée de la Chambre des députés réduite à cinq ans avec renonvellement intégral, le cens électoral abaissé.

La nature du pouvoir royal, par cela même, fut un peu modifiée : le roi n'octroyait plus la Charte, il l'acceptait, et il n'était roi que parce qu'il l'avait acceptée. De nouveau, le principe de la souveraineté nationale se substituait au dogme du droil divin.

La Charłe de 1814 avait été si bien conçue au point de vue parlementaire,que les quelques modifications apportées par la Révolution de 1830 assurèrent pour dix-huit années le jeu régulier des institutions.

Pourtant la .Ionarchie de Juillet avait un vice originel. Les députés dont les élections avaient été cassées par l'ordonnance illégale de Charles $\mathrm{X}$ avaient le droit de siéger comme membres d'une Chambre des députés ; mais avaientils le droit de s'emparer, comme ils firent, du pouvoir constituant? Avaient-ils le droit de modifier la Charte et de disposer de la couronne? N'avaient-il a pas le devoir de convoquer une assemblée constituante chargée de donner à la France une constitution et un gouvernement? Ce fut la thèse que soutint, pendant dix-huit ans, l'opposition bonapartiste et républicaine.

La Restauration s'était appuyée sur les propriétaires fonciers. La Monarchie de Juillet s’appuya principalement sur la bourgeoisie commerçante. Elle lui maintint le monopole du droit electural, malgré les réclamations des lettrés et des classes populaires; elle rétablit la garde 
nationale, supprimée par Charles $X$, et la recruta dans la bourgeoisie aisée: c'était aussi par les jurés de la classe moyenne que les adversaires du gouvernement étaient jugés. Mais ni les votes, ni les baïonnettes, ni les verdicts de la bourgeoisie ne purent, à la fin, sauver la royauté bourgeoise. La question de la réforme électorale amena la Révolution du 24 février 1848.

\section{Le droit électoral}

Système de la Restauration. - La Restauration trouva en vigueur le système des collèges électoraux de département et d'arrondissement. La Charte de $1814 \mathrm{y}$ introduisit des modifications d'un caractère à la fois plus libéral et moins démocratique. Désormais, ces collèges élurent directement les membres de la Chambre des députés. Les députés avaient deux origines différentes : les uns étaient élus par les collèges d'arrondissement; les autres, par les collèges de département. L'élection des membres de ces collèges par les électeurs du canton fut supprimée et ces corps devinrent permanents.

Le principe du cens fut rétabli. D’abord un cens d'éligibilité. Nul ne pouvait ètre élu député s'il ne payait une contribution directe de 1000 francs (et s'il n'était àgè de quarante-ans); mais, s'il ne se trouvait pas dans le département 50 citoyens remplissant ces conditions, ce nombre de 50 serait complété au moyen des plus imposes.

Puis un cens d'électorat. Nul ne pouvait ètre électeur s'il ne payait une contribution directe de 300 francs. L'àge électoral était de trente ans.

L'Acte additionncl de 1815 maintint les deux espèces de collèges: il statua qu'ils seraient renouvelés par les assemblees de canton au moyen d'élections annuelles; mais, à la chute de Napoléon, on en revint au système de 1814 .

La loi de 1817 (15 février) maintint les conditions d'àge et de cens pour les électeurs et pour les éligibles. Elle supprima la distinction en députés des arrondissements et députés du département. Il n'y ent plus, dans chaque département, qu'un seul collège. 
Puis, par la loi de $18 \mathbf{2 0}$, les collèges d'arrondissement sont rétablis et nomment 258 léputés. Ces mêmes électeurs d'arrondissement désignent, sur la liste des citoyens les plus imposés du département, dans la proportion d'environ un quart, des électeurs qui, réunis en un collegge de département, nomment encore 172 députés. C'est ce qu'ou appelle la loi du double vote, destince à assurer un double suffrage aux électeurs les plus riches.

Il n'y avait alor's en France que 90000 citoyens remplissant les conditions pour étre électeurs et 15000 remplissant les conditions pour ètre éligilles.

De plus, l'article 19 de cette loi, maintenu après 1830 , statuait que les députés ne recevraient ni traitement ni indemnité; le monopole des fonctions législatives était donc assuré aux riches.

Système de la Monarehie de Juillet. - La royauté issue des barricades de 1830 crut faire assez pour le peuple en abaissant de 300 à 200 francs le cens électoral et de 1000 à 500 francs le cens d'éligitilité. Elle abaissa même le cens électoral à 100 francs pour les membres de l'Institut et les officiers. Elle réduisit à trente ans l'âge pour être èlu et à vingt-einq l'àge électoral. Elle supprima le double rote. Les départements furent subdivisés en circonscriptions électorales ou collèyes, dont chacun nommait un député.

Le nombre des électeurs s'éleva de 90000 à 200000 . En 184í, par le progrès de la richesse publique, il y en eut 241000 . Ce n'était guère four une nation d'environ 35 millions d'àmes. En outre, il était absurde que la grande majorité des professeurs, des médecins, des avocats, des ingénieurs, en un mot des citoyens les plus instruits ${ }^{1}$, fussent exclus du corps élecloral.

En résumé, sous Louis-Philippe, deux classes de citoyens furent adnises à la vie politique : les riches propriétaires fonciers et les patentés da commerce et de l'industrie.

1. Dans le projel présenlé en 1812 pour l'aljonction des capacités figuraient: les fonclionnares nommes par te roi, mais exerçant des fouctions gratuites, les ofticiers en retraite des armets le terre et de mer, les docteurs el licenciés des facultés de droit, sciences el leltres, les docteurs en mélecine, les membres el correspondants de l'Institut, les membres do atres sociétés savantes reconnues par le roi, les nolaires, olc. Co projet. qui faisait une part si modeste aux capacités, fut repoussé! 
“ Certes, s'écriait un jour Dufause, je respecte autant que personne le principe sacré et puissant de la propriété. Mais ne l'élevons pas au-dessus de tout. Pour parvenir aux honneurs dans ce pays, il faut donc devenir riche? Votre système électoral pousse donc tout le monde à chercher la fortune?... J'admire votre sécurité!"

\section{La question de la réforme électorale et parlemen-} taire. - Le gouvernement finit par ne plus tenir compte de la nation. A ses yeux, le pays était remplacé par le pays légal, c'est-à-dire par les électeurs censitaires. L'opinion publique, pendant dix-huit années, demanda vainement une extension du droit de suffrage, l'abaissement du ceus électoral, l'adjonction des capacités.

Le nombre des électeurs étant si restreint, réduit dans certains collèges à $150^{\circ}$, il n’était que trop facile aux candidats d'acheter leurs suffrages par des dons et des promesses ${ }^{2}$. Ces députés, après avoir dépensé des sommes énormes dans leurs élections, cherchaient à se dédommager en briguant les faveurs du potsvoir au profit de leurs entreprises industrielles ou financières ${ }^{3}$.

Les huit années du ministère Guizot (1840-1848) furent les plus paisibles du règne : le moment eût été favorable pour tenter une réforme. On aurait pu procéder comme en

1. L'inègalité de nombre entre des collèges qui nommaient également un député était choquante. Duvergier de Hauranne, dans son discours pour la réforme électurale, en 1847, montrait que les collèges d'Embrun, de Bourganeuf, de Saint-Palais ne comptaient que 150 electeurs, tandis que le deuxième collège de Paris en avait 3000 . Il prouvait que, dans la Chambre, i) y avait 10 députés nommès par 1500 électeurs, et 10 par $16000 ; 20$ nommés par 3400 électeurs, et 20 par 34000 . Sur 469 députes, 177 étaient nommés par 139000 électcurs, et 282, c'est-à-dire la majorité de la Chambre, par 102000 seulement.

2. Vèron, dans les Vouveaux mémoires d'un bourgeois de Paris, rapperte deux anecdotes caractéristıques. Un candidat offre un jour à un électeur influent une prise de tabac. " Nonl répond celui-ci; pas une prise: un bureau! n Un autre candidat, très riche, parie avec un de ces électeurs induents qu'il ne sera pas elu; il parie 20000 francs; l'électeur tient le pari. Le candidat est élu. N'élait-ce pas une manière spirituelle d'acteter 20000 francs la voix et l'influcace d'un électeur?

3. Véron raconte que, sous la Reslauration, lorsqu'un député paraissait dans les bureaux des ministères, les employés accouraient pour le regarder " comme une chose curicuse ". Sous la Monarelie de Juillet, on ne vit que députés dans les hureaux. De 1915 à 1830, ajoute Véron, "les élections e faisaient par un courant d'opinion et de croyances n; de 1830 à 1848, - par un courant d'interéts. 
Angleterre, où, par les rél'ormes de 1832, 1867, 1884' 1, on a successivement appelé au droit de suffrage des masses de plus en plus nombreuses de citoyens, à mesure que l'instruction se répandait parmi eux. En France, le gouvernement de Juillet, qui s'était annoncé comme libéral et démocratique, s'obstinait à maintenir un système électoral beaucoup plus étroit que celui qu'avaient demandé les royalistes de 1789 lorsqu'ils proposèrent un cens de 60 francs, beaucoup plus étroit que celui qu'avait établi la Constituante. Cependant l'instruction avait fait, depuis 1789, de grands progrès dans la nation, et les citoyens capables étaient bien plus nombreux.

Un autre abus du régime parlementaire d’alors, c'était le trop grand nombre de députés-fonctionnaires. Si un système trop exclusif à ce sujet a l'inconvénient d'éloigner de la Chambre les hommes compétents, un système trop complaisant risque d'òter à la Chambre son indépendance à l'égard du pouvoir. De Rémusat, en 1847, demandait au moins l'exclusion des officiers et fonctionnaires des maisons militaires et civiles du roi et des princes : sa proposition fut repoussée par 279 députés contre 170: sur les 279, 139 étaient fonctionnaires!

On appelait alors réformc parlementaire l'exclusion des députés fonctionnaires ou la réduction de leur nombre; réforme electorale, l'extension du droit de suffrage. La première, de 1830 à 1847, fut l'objet, à la Chambre, de dixhuit propositions. La seconde fut demandée trois fois. Le ministère Guizot, dédaignant les revendications les plus légitimes de l'opinion, se reposant sur une Chambre et un corps électoral également complaisants, se refusait à toute concession.

La journée du 24 février 1848 réveilla tout le monde. On n'avait pas voulu d'une réforme, on eut une révolution. Au lieu d'une extension progressive du droit de suffrage, on fut lancé dans cet inconnu redoutable : le suffrage universel. Pour avoir refusé l'admission des capacités, on se trouva avoir livré les custinées de la France à la sagesse

1. Par la réforme anglaise de 1832, le nombre des électeurs fut porté de 500000 à 1200000 ; par celle de 1867, à 2792000 ; par celle do 1884, à 5 millious. 
problématique de dix millions d'électeurs, nullement préparés alors à cette haute mission, et qui, après trente-cinq ans de liberté et de régime parlementaire, allaient nous ramener le gouvernement personnel.

\section{Les libertés publiques.}

Le droit de petition. - Le droit de pétition, sous la monarchie parlementaire, put s'exercer non seulement auprès du roi, des ministres, des administrations, mais auprès des deux Chambres.

La liberté d'association et de rénnion. - La Restauration, qui était pourtant une monarchie parlementaire, la royauté de Juillet, qui se piquait d'ètre plus libérale que la Restauration, même les gouvernements de suffrage universel qui suivirent, n'ont pas abrogé les articles du Code pénal de Napoléon qui subordonnent le droit d'association et de réunion à l'autorisation du gouvernement. Celui de Louis-Philippe, menacé par l'hostilité des associations politiques, a même aggravé ces dispositions.

La loi de 1834 (10 avril) eut précisément pour objet de rechercher dans le Code pénal les lacnues qui avaient pu échapper à l'œil vigilant de Napoléon, de déjouer les expédients à l'aide desquels on aurait pu échapper à l'action de la loi, d'étendre et de renforcer les pénalités.

Ainsi Napoléon n'avait eu en vue que les associations ou réunions de plus de vingt personnes : la loi de 1834 atteint les associations qui, pour éluder la loi, se sont divisées en fractions de moins de vingt personnes, si le total de ces fractions excède ce chiffre.

Napoléon n'arait pensé qu'aux associations qui se réunissaient "tous les jours ou à certains jours marqués "; la loi de 1834 supprime cette restriction.

Napoléon n'avait frappé que "les chefs, directeurs ou administrateurs de l'association "; la loi de 1834 frappe les simples membres.

Napoléon s'était contenté d'édicter une amende de 16 à 200 francs; la loi de 1834 édicte une amende de 50 à 1000 francs, un emprisonnement de deux mois à un an; elle statue que ces peines seront portées au double en cas 
de récidive, et que les condamnés seront ensuite placés sous la surveillance de la haute police.

\section{La liberté de la presse : 10 Sous la Restauration. -} La Charte de 1814, elle aussi, proclama la liberté de la presse 1 ; mais presque aussitôt la loi de 18142 rétablit la censure pour les journaux et brochures, les soumit à une autorisation préalable, et obligea tout libraire ou imprimeur au brevet et au serment. Cette loi, que l'abbé de Lamennais qualifiait de napoléonienne, n'était d'ailleurs votée que pour une année.

Napoléon, revenu de l'ile d'Elbe, put se donner pour un libéral. Il abolit la censure et attribua la connaissance des délits de presse au jury. Il prit pour collíborateur dans la rédaction de l'Acte additionnel un journaliste, Benjamin Constant, qui l'avait violemment attaqué. Il toléra les acerbes critiques du Conseur.

La seconde Restauration, pendant ses quinze années d'existence, oscilla perpétuellement entre la rigueur et l'indulgence à l'égard de la presse. L'ordonnance d'aoút 1815 décida qu'aucun journal ne pourrait paraitre sans l'autorisation du gouvernement, et organisa une commission de censure. La loi de 1815 créa le délit de provocation indirecte. La loi de 1817, qui n'était votée que pour un an, maintint l'autorisation préalable, qui impliquait pour le pouvoir le droit de suspension ou de suppression. C'est alors que le Constitutionnel fut frappé ${ }^{3}$. Puis, la loi de mai 1819 revint aux vrais principes: elle supprima la censure et l'autorisation préalable; elle attribua au jury la connaissance des délits de presse; elle ne punit le journaliste qui aurait provoqué à un crime que si la provocation avait été suivie d'effet; elle l'admit à faire la preuve de la

1. Article 8. - " Les Français ont le droit do publier et de faire imprimer leurs opinions, en se conformant aux lois qui doivent réprimer les abus de cette liberté. $n$

2. Loi du 21 octobre 1814 .

3. Il s'appelait alors l'Indépendant. Il fut supprimé pour un article sur le Salon de 1817, ou il était question du portrait d'un enfant avec des fleurs bleues. On crut que c'ètait une allusion su roi de Rome; or le portrat élait celui d'un petit Bavarois. Louis XV1II, en hommc d'esprit, répara cette injusie rigueur et haplisa le journal, à sa réapparition, du nom de Constiutionnel, qui lui resta. 
diffamation contre les fonctionnaires publics, mais non contre les particuliers, voulant que la vie privée restàt en dehors des débats publics ${ }^{1}$.

Cette loi, vraiment libérale, fut suivie de la loi de juin 1819 , qui établissait le cautionnement et le droit de timbre ${ }^{2}$ : car les riches propriétaires qui siégaient alors à la Chambre des députés, et qui formaient une véritable oligarchie, admettaient bien une presse pour les classes aisées, mais non pas une presse à bon marché pour le peuple. Ces mesures fiscales, assuraient les démocrates, pouvaient se résumer en ces trois mots : "Silence aux pauvres!"

Une réaction suivit l'assassinat du duc de Berry, bien que la presse, si modérée à cette époque, ne fủt absolument pour rien dans le crime de Louvel. L'ordonnance de 1820 rétablit la censure préalable, l'autorisation préalable et donna au gouvernement le droit de suspendre pendant six mois la publication d'un journal. Cette mesure était d'ailleurs donnće comme temporaire. Une nouvelle loi devait ètre présentée.

Ce fut la loi de 1822, beaucoup moins libérale que la loi de 1819. Elle supprimait la censure, mais maintenait l'autorisation préalable. Elle édictait la peine de la suspension et même de la suppression. Elle créait le délit de tendance : si les termes mêmes d'un article étaient inattaquables, les intentions du journaliste ou la ligne générale du journal-pouvaient justifier une accusation.

Tandis que la loi de 1819 punissait seulement les “ outrages à la morale publique et religicuse et aux bonnes

1. Dans cette période, une forme nouvelle de journalisme apparait: ce sont des recueils semi-périodiques, des espèces de revues, comme le Censeur, le Conservateur, de Chateaubriand, la Minerve, d’Étienne, etc.

C'est l'èpoque des procès par interprétation, intentés par le fameux avocat général Marchangy, ancien magistrat de l'Empire, qui fit condamner Béranger et les quatre sergents de la Rochelle. Il poursuivit le Censeur, dont deux rédacteurs, Comte et Dunoyer, furent conduits à La Force; Fiévée, un des censeurs napoléoniens, à qui Fouché avail offert la dircetion de la censure bourbonnienne, fut condamné a trois mois d'emprisonnement.

2. Les droits de timbre et de paste étaient alors fort élevés : dix centimes pour le timbre et cinq centimes pour la poste. Le Constitutionnel, qui avait alors le tirage lo plus èlevé, qui complait 20000 abonnès, ol qui réalisait une recette brule de 1133000 francs par an, payait à l’État $\mathbf{4 5 0} 000$ frarcs pour le timbre el 230000 francs pour la poste. 
mœurs", celle de $\mathbf{1 8 2 2}$ punissait les attaques "à la religion de l'État et aux autres cultes reconnus".

La loi de 1819 autorisait la preuve de la diffamation contre les fonctionnaires : celle de 1822 l'interdisait.

D'après celle de 1819, les attaques contre les Chambres levaient ètre jugées par les tribunaux; d'après celle de 1822, par les Chambres elles-mêmes, devenues ainsi juges dans leur propre cause.

La loi de 1819 attribuait au jury le jugement des délits de presse; celle de 1822 l'attribuait aux tribunaux correctionnels, et, en appel, aux cours royales ${ }^{1}$.

La censure fut rétablie par l'ordonnance du 15 aoút 1823 : elle fut supprimée à l'avènement de Charles $\mathbf{X}$.

Le ministère ne se trouvait pas suffisamment armé : en 1827, de Peyronnet proposa aux Chambres une loi draconienne, vantée imprudemment comme une " loi damour et de justice". Elle fut repoussée par la Chambre des pairs ${ }^{2}$.

Sous le ministère Martignac, un certain progrès fut accompli dans le sens libéral; par la loi de $1 \mathcal{2} \mathbf{S}$, la cen-

1. La loi de 1 S2? fut loccasion de nombreuses poursuites contre la presse: Y'avocat Magalion, rédacteur de l'Album, fut enchainé á un galérien galeus pour aller de la prison de Sainte-Pélagie à la maison centrale de Poissy. Le Constitutionnel et le Courvier français furent poursuivis pour des articles contre la Congrégation. En mème temps, le ministère s'efforçait d'acheter les journaux. Ces mesures ne firent que déconsidérer la presse dévouée a la couronne. Eu 1824, on calcule que les six principales feuilles bourbonniennes, Moniteur, Journal de Paris, Étoile, Gazette de France, Drapeau blanc, Pilote, ne réunissaient que 14344 abonnés; les six principales feuilles d'opposition, Constitutionnel, Journal des Debats, Quotidienne, Courrier francais, Journal du commerce, Aristarque, en comptaient 41330 . A cette époque, la Quotidienne avait été momentanément entrainée dans l'opposition. A la veille de 1830, Thiers, Mignet, Armand Carrel fondèrent le National.

2. Elle exigeait un dépot de cinq jours à dix jours pour toute publication : de sorte qu'un journal ne pouvait publier une nouvelle qui ne fút vieille d'au moins cinq jours. Elle imposait un droit de 1 frane pour la première feuille de toute publication et de 10 centimes pour les feuilles suivantes: ce qui mettait tout numéro de journal à un prix sujérieur à 1 franc. Chateaubriand la flétrit du surnom de loi vandale; Casimir Périer la résumait en ces mots : " L'imprimerie est supprimée en France au profit de la Belgique n; Royer-Collard l'écrasait dans un de ses plus éloquents discours; l'Académie française faisail une démarche en corps auprès du roi, ce qui amena la disgruce des academiciens Lacretelle, Villemain et Michaud. La loi fut votée, à la Chambre des Députés, par 233 voix contre 134, mais l'accueil de la Chambre des Pairs fut tel que le ministère jugea prudent de retirer son projet. A cctte nuuvelle, Paris illumina. 
sure et l'autorisation préalable furent supprimées, le cautionnement réduit, les délits de tendance abolis.

Charles X, dans ses funestes ordonnances de 1830, prétendit revenir au régime de 1814 et à la censure. Aussi ce furent les journalistes, M. Thiers et le National en tête, qui donnèrent le signal de la révolution.

$\boldsymbol{2}^{\circ}$ Sous la Monarchie de Juillet. - La royauté nouvelle, issue de cette révolution, ne pouvait se montrer rigoureuse envers les écrivains. "Il n'y aura plus de délits de presse ", avait déclaré Louis-Philippe. La Charte de 1830 abolit formellement l'autorisation préalable et la censure, et rendit au jury la connaissance des délits de presse.

La presse jouit sous ce régime d'une véritable liberté.

Elle la poussa jusqu'à l'abus. Les journaux hostiles publièrent des excitations à l'émeute, mème à l'assassinat du roi ${ }^{1}$.

Après les insurrections de Lyon et de Paris en 1834, après l'attentat de Fieschi en 1835, le gouvernement revisa la législation sur la presse et fit voter la loi du 9 septembre 1835.

Cette loi, si décriée à cette époque, n’était pas précisément une loi de réaction : elle ne touchait pas à la juridiction du jury, elle ne parlait ni de censure, ni d'autorisation préalable. Seulement, le taux du cautionnement fut èlevé; l'échelle des pénalités aggravée; les excitations à des crimes contre la sủreté de l'État assimilées à ces crimes. La loi atteignait des délits non encore classés ou moins sévèrement punis : l'apologie par la voie de la presse de faits qualifiés crimes, l'outrage à la personne du roi, ies attaques contre le principe du gouvernement, la publication des comptes rendus pour les procès eu diffamation (publication qui aggravait la diffamation), la publication des noms des jurés, qui ex posait ces derniers à l'intimidation ou aux vengeances, les souscriptions ouvertes dans les journaux pour payer les amendes encourues par eux, etc.

t. Les feuilles républicaines ètaient alors surtout la Tribune, rédigéo par Marrast; le Reformateur, par Raspail ; le Bon Sens, par Cauchois-Lemaire; l'Avenir, par Lamennais, Lacordaire, Montalembert. Les feuilles bonapar. tistes étaient la Révolution, le Capitole, etc. La presse ministérielle était surtout représentée par le Constitutionnel, la Charte, le Globe, etc. 
Les feuilles à caricatures seules étaient soumises à une sorte de censure; aucun dessin ne pouvait être publiẻ sans autorisation préalable. En somme, le gouvernement n'excédait pas son droit de défense : la presse restait encore très libre, et elle le montra par l'acharnement qu'elle déploya contre cette mème loi.

\section{Développement de la presse sous les monarchies} parlementaires. - La presse est une puissance politique qui, depuis un siècle, n'a cessé de grandir. A mesure que l'instruction, le goût de la lecture ont pénétré dans les couches profondes de la nation, le livre, la brochure, la revue, le journal, ont pris une influence plus considérable.

Sous la Révolution, les journaux étaient innombrables; mais, à part les Révolutions de Paris, feuille qui d'ailleurs n'était pas quotidienne, ils avaient un faible tirage; ils étaient criés et vendus dans la rue par les colporteurs, mais ils avaient peu ou point d'abonnés; ils étaient rarement quotidiens, à peine périodiques, la plupart paraissant quand il y avait une nouvelle à répandre, un acte du gouvernement ou des assemblées à critiquer. Ils ressemblaient aux brochures de 1789, dont ils avaient pris la place, bien plus qu'à nos journaux d'aujourd'hui. Ils formaient des cahiers de 12 à 40 pages, de format indouze ou in-octavo, rarement in-quarto. Les périodiques du premier Empire et de la Restauration ne se vendaient pas au numéro; ils ne servaient que leurs abonnés. L'abonnement coutait fort cher. Aussi le Journal des Débats, sous l'Empire, avec ses 12000 souscripteurs, le Constitutionnel, sous la Restauration, avec ses 15 ou 20000 , araient le plus fort tirage.

Dès l'Empire, les journaux politiques étaient devenus quotidiens, de format in-quarto ou petit in-folio pour la plupart, et ne comprenaient plus que quatre pages.

En dehors des articles et nouvelles politiques, le seul agrément que présentassent les journaux de la Restauration, c’étaient les feuilletons de critique littéraire et théătrale. Ils n'avaiènt presque pas d'annonces, et l'arlicle Bourse se bornait à donner le cours de la rente.

Outre le prix élevé des journaux et le petit nombre des lecteurs, une raison qui cmpèchait le développement de la 
presse, e'était l'imperfection du matériel d'imprimerie. Avec la presse à bras de la Révolution, qui imprimait d'abord le recto, puis le verso, on ne pouvait pas tirer à l'heure plus de 450 numéros d'un journal de quatre pages. Or, une transformation s'était opérée en Angleterre. En 1811, køNIG, d'Eislcben, en Saxe, établissait la première presse rapide, mue par la vapeur. En 1814, il l'introduisit à Londres dans les ateliers du Times. En 1816, il la perfectionna de façon qu'on pût imprimer en même temps les deux côtés du journal ${ }^{1}$.

Ce fut ÉmiLe DE GIRARDIN qui opéra dans la presse francaise une transformation : il en fut le grand révolutionnaire. En 1836, il créa un journal : la Presse. Qualifiée d'universelle, la Presse devait publier chaque jour un article militaire, naval, judiciaire, administratif, médical, industriel, commercial, littèraire, artistique, par conséquent " donner vingt journaux en un seul ", ne plus s'adresser seulement à l'homme politique, mais au militaire, à l'homme de loi, à l'administrateur, au savant, au médecin, au littćrateur, à l'artiste, au négociant, au manufacturier, etc. (Manifeste du 1er juin.)

Pour retenir cette nombreuse clientèle, Girardin diminuait le prix de l'abonnement afin d'augmenter le nombre des abonnés; son premier bénéfice, c’élait la diminution des frais généraux. Il inséra dans la Presse des annonces payées, procédé que les journalistes de l'ancienne école flétrirent comme antilittéraire et mercantile ${ }^{2}$. Il donna une bourse et une mercuriale, qui, répondant au développcment nouveau des affaires, lui assuraient de nouveaux lecteurs et de nouveaux bénéfices. La Presse, en trois mois, compta 10000 abonnés et put recueillir pour 150000 francs d'annonces. Au bout de deux ans, elle avait 40000 abonnés. Sur les mèmes données, également en 1836, Dutarco créa le Siècle, qui eut bientôt 38000 abonnés.

1. Notons l'invention de machines a composer, ayant la forme de claviers de piano, et dont la première idée remonte au philosophe Ballanche (1815), alors imprimeur à Lyon, et l'invention de la machine $\dot{a}$ distribuer, perfectionnée chez nous par Gavbert.

z. Ce ful la cause te son duel avec Armand Carrel, duel qui coúta la vio à celui-ci. 
Ces journaux séduisirent les lecteurs, surtout des classes populaires, en insérant des romans-feuilletons : c'est alors qu'Alexandre Dumas fit paraitre, dans le Siècle, les "Trois Mousquetaires ", "Vingt ans après ", " le Vicomte de Bragelonne ", et tint la France entière sous le charme. La Presse publia les romans de Balzac, d'Eugène Sue, de Léon Gozlan, et, en 1845, "la Reine Nargot ", de Dumas.

D'autres journaux imaginèrent les primes. Il y en eut de singulières. Ainsi le Bien-Être assurait à ses abonnés une pension de retraite après trente ans d'abonuement, un enterrement de seconde classe, en cas de décès, et une indemnité de cent francs à la veuve ou aux héritiers. D’autres offrirent les montres, des pendules, des livres, etc.

L'Époque arbora la première un format qui est celui des journaux d'aujourd'hui, mais qui parut alors immense et démesuré : les caricaturistes représentaient les abonnés de l'Époque obligés de monter sur des échelles pour la lire ou s'en servant comme d'une couverture de lit.

Cependant ces journaux ne se préoccupaient toujours que de l'abonné et négligeaient un public qui devait devenir chaque jour plus nombreux : celui des acheteurs au numéro. Le numéro coùtait alors de 25 à 50 centimes.

Le Charivari, fondé par pHILıPpoN en 1832, commença la vogue des journaux à caricatures.

La Revue des Deux Mondes fut créée, en 1831, par Francois BOLOz et compta parmi ses collaborateurs presque tous les illustres de l'époque.

Ouvrafies a consulter. - Histoires de la liestamation, par Vaulabelle, Lamartine, Vieil-Castel, Nettement, Hamel, Dareste; - de la Wonarchie de Juillet, par Lous Blane, Elias Regnanlt, de Nouvion, ThureauDangin. - Villemain, Sourenirs contemporains. - Fleury de Chaboulon. Soucenir's des rent-Jours. - Benjamiu Constant. Lettres sur tes CentJours. - Beurnot, Mémoires. t. II. - E. Daldet, Li Terreur Blanehe (1578). - Thureau-Dangin, Le parti liberal sous la liestauration (1876).

Giaizot. Limoires pou" sermo " l'Histoine de mon temps 155-68). Veron, Hemoires d'un bourgeois de
Paris. - Duc de Broglie, Souvenirs. - Doudan. Correspondance. - De Rèmusat, Currespondance. - Victor Jlugo, Choses vues. - Thiers, Dis. cours.

Duvergas de llanranne, Hist. du goncernement parlementaire (18577.2). - Nwhon, Le guavernentent partementaire sons la Ristention 1904). - Bardoux, La bourgeoisie fiammise, 1759-1845 (1856). - Fanstin Hélie, Les Constitutions de la France. - Hatin, Hist. de la presse en France (1859-6) - Netlement,

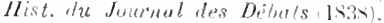
- Cirradoau, La me'ssé périoderue $1866)$. 


\title{
CHAPITRE XVI
}

\author{
L'ADMINISTRATION, LA JUSTICE, LES FINANCES \\ LES CULTES
}

\section{L'administration}

Caractères de notre organisation dans la période contemposane. - La génération révolutionnaire et impériale montra une singulière incapacité à résoudre le problème d'une bonne constitution politique. En revanche, on peut dire que toute notre organisation administrative, judiciaire, financière, religieuse, universitaire, même militaire et maritime, se trouve fivée, en ses traits essentiels, à la fin de cette période. C'est surto'st la Constituante qui a eu les idées novatrices; c'est surtout Napoléon qui a fait les créations.

C'est de Napoléon que procèdent la hiérarchie administrative et judiciaire, l'organisation financière et militaire, l'Église concordataire, lUniversité. Tout ce système, au moins dans ses cadres et dans ses lignes extérieures, lui a survécu. Les générations suivantes n’ont eu qu’à faire rentrer dans cet imposant édifice l'esprit de 1789, auquel l'Empereur n'avait fait qu'une part trop limitée. Elles n’ont eu qu'à admettre dans les conseils locaux le principe électif, dans l'enseignenent le principe de liberté, dans l'armée le principe du service universel. Le système napoléonien, remis en harmonie avec les tendances de la société nouvelle, se mainticnt depuis bientôt quatre-vingt-dix ans.

Un caractire qui distingue les institutions départementales ct municipales en notre siècle des institutions provinciales et communales de l'ancienne France, c'est l'uni- 
formité. Autrefois, il y avait une diversité infinie : dans les provinces, il y avait des pays d'États et des pays d'élec. tion, des bailliages, des sénéchaussées, des prévôtés, des clâtellenies; dans les villes, des maires, des échevins, des jurés, des capitouls, des syndics, des bourgmestres, des consuls, des viergs. Depuis la Révolution, ce sont partout les mêmes noms, les mèmes fonctions, le mème mode de nomination. Les institutions varient suivant les temps; elles ne varient jamais suivant les lieux. Si la mode est aux directoires, conme sous la Constituante, tous les départements, tous les districts ont un directoire. Puis, en 1800, le même jour, il y a autant de préfets que de départements et autant de sous-préfets que d'arrondissements. En 1831 et 1833, c'est le système électil qui règne partout. Cette similitude des noms et des choses est le signe frappant de l'égale action de la loi sur tous les points du territoire. L'uniformité n'est ici qu'une manifestation de l'unité.

\section{L'administration départenentale et municipale.}

L'organisation autoritaire de l'administration locale survécut à l'Empire ${ }^{1}$. Elle dura trente et un ans pour les communes et trente-trois ans pour les départements et les arrondissements. La Restauration, dans ses dernières années, pensa à la modifier; le ministère Martignac proposa un projet de loi qui fut repoussé par la Clsambre des députés. La Monarchie de Juillet reprit la question.

Dans la loi de 1831 (21 mars) sur lorganisation municipale, les maires et adjoints furent considérés surtout comme agents du pouvoir exécutif : aussi furent-ils nommés, dans les communes au-dessus de 3000 àmes, dans les chefs-lieux d'arrondissement, quelie que fût leur population, par le roi; dans toutes les autres communes, par le préfet. Pourtant, comme ils sont aussi les représentants de la commune, le pouvoir n'avait le droit de les choisir que dans le conseil municipal. Quant au conseil municipal, il est uniquement la représentation des habitants : aussi était-

1. Napoléon, lors de son retour de l'ile d'Elbe et sur les instances da Carnot, avait accordé que les communes de moins de 5000 àmes nom. meraient leurs maires. Cette concession fut annulée par la Restauration. 
il élu. Il était élu par un corps électoral spécial, comprenant les habitants les plus imposés de la comniune et ccrtaines catégories de fonctionnaires, de magistrats et de lcttrès.

La loi de 1833 (22 juin) rendit aussi à l'élection la nomination des conseils généraux et d'arrondissement. Les préfets, les sous-prélets et les conseils de prélecture restaient, comme de raison, à la nomination du pouvoir.

Pourtant la réforme était encore bien timide. Il semblait qu'on redoutât encore les excès d'indépendance qui avaient suivi la loi de 1789 . Le conseil grénéral, qui se réunissait une seule fois par an, n'exerçait aucun eontrôle efficace sur l'administration dı département; aucune de ses décisions n'était valable sans l'approbation du gouvernement; ses séances n'étaient point publiques; il ćtait interdit à tout conseil général de publier aucune adresse, de se mettre en correspondance avec d'autres conscils généraux ou des conseils d'arrondissement; et pourtant certaines affaires de routes, de canaux ou de chemins de fer dépassent les limites du département et intéressent toute une région.

L'influence du régime censitaire se faisait sentir dans le mode d'élection : les conseillers généraux et d'arrondissement étaient élus par une assemblée composée des citoyens les plus imposés; nul ne pouvait ètre conseiller général s'il ne payait au moins 200 francs de contribution dans le département.

La loi de 1834 maintint la division de Paris en arrondissements, mais lui donna un conseil municipal de $36 \mathrm{mem}$ bres, dont le président et les vice-présidents étaient nommés par le roi. Le préfet de la Seine, considéré comme chef de la municipalité parisienne, et le préfet de police assistaient aux délibérations du conseil. Lyon fut aussi placé sous un régime d'exception.

La loi de 1838 détermina les attributions des conseils généraux et d'arrondissement.

En somme, les idées de décentralisation administrative n'étaient point en faveur dans la bourgeoisie, qui était alors la classe dirigeante et qui n'était point revenue de son admiration pour l'œuvre du Premier consul. Aux partisans de ces idées, M. Thiers répondait : "Yous voulons faire abonder la vie sociale au centre de l'Élal; nous 
voulons réaliser ce grand phénomène moderne : celui de faire vivre le corps social dans une grande unité... Savezvous pourquoi la Restauration, en nous faisant un mal moral et politique immense, n'a cependant pas frustré les intérêts matériels? C'est qu'elle a respecté la vieille administration de l'Empire, qui en savait plus qu'elle, et qu'elle a laissé aller... Ce n'est pas nous qui sommes rétrogrades, c'est nous qui défendons la Révolution vivante. En affranchissant les grandes communes, vous détruisez l'unité; vous portez un coup de hache au pied de l'arbre. "

La police. - A Paris, sous la Restauration, furent créés les sergents de ville, recrutés parmi les anciens militaires, et qui étaient encore trop peu nombreux. En 1817, fut organisée la brigade de sủreté, ou police secrète, dont le premier chef fut Vidocq, et le second Coco-Lacour. C'étaient deux criminels graciès, qui recrutèrent leur brigade de forçats libérés; on les croyait plus aptes que personne à rechercher ceux qui avaient fauché le pré avec eux. En 1832, le préfet Gisquet s'émut de ce scandale, ne voulut plus tolérer que des agents qui n'eussent subi aucune condamnation et licencia les anciens, qui, naturellement, se refirent voleurs.

Une ordonnance de 1832 ( 15 juillet) enjoignit aux logeurs de tenir un registre de leurs locataires.

Reforme des prisons. - La Constituante, en 1791, avait cru devoir distinguer, comme on fait aujourd'hui : 10 les maisons d'arrêt, où les accusés et prévenus attendent leur jugement; 20 les prisons pénales criminelles, comprenant les maisons de force et les bagnes; $3^{\circ}$ les prisons pénales correctionnelles; $4^{\circ}$ les maisons de correction, destinées aux enfants âgés de moins de douze ans ou détenus à la demande de leurs parents. En 1810, Napoléon, en même temps que les prisons d'État, créa les maisons centrales.

Cette législation, en opérant un classement plus rationnel des prisons, ne changeait rien à leur régime intérieur. Les détenus continuèrent à être exploités par leurs gardiens, à coucher sur des litières de paille souvent humide ou infecte, à recevoir une nourriture insuffisante ou malsaine, et, s'ils obtenaient d'aller à l'infirmerie, à coucher 
trois ou quatre dans un lit. Imagine-t-on que l'Etat ne se croyait point obligé de nourrir les prisonniers, que ceux-ci devaient vivre à leurs frais, et qu'une circulaire de 1800 recommande " de ne procurer le pain et la soupe aux détenus qu'en cas d'indigence absolue et constatée n?

La Restauration s'émut de cette situation. Lin 1819, une ordonnance royale institua une Société ies prisons, composée de publicistes, de jurisconsultes, d'administrateurs, de députés. Sur sa proposition, on reprit l'œuvre de Malesherbes : on supprima les punitions inhumaines, les agglomérations dangereuses pour la sauté; on veilla à ce qu'il y en̂t plus d'air et de lumière, à ce que le détenu ne souffrit plus de la faim et du froid; on renouvela le natériel de literie. Cependant, la Restauration ne s'inspira que des idées d'humanité : elle ne s'occupa que de l'amélioration mutérielle.

La Monarchie de Juillet šinspira d'idécs plus élevées : elle se proposa l'amélioration morale. Or, la promiscuité entre les détenus de toute calégorie était une source de corruption. La réforme qu'on se proposa d'opérer reposait sur deux principes : $1^{\circ}$ séparer l'une de l'autre les diverses catégories de criminels; $2^{\circ}$ pour chaque détenu, obtenir un isolement complet, dans lequel il pourrait, par le travail, par la réflexion, par les exhortations morales de tout ordre, revenir à de meilleurs sentinents. C'est ce qu'on appelle le système cellulaire.

Le préfet de la Seinc, Delessert, le mit en pratique à la Petite-Roquette, destinée aux jeunes détenus et aux enfants subissant la correction paternelle. En 1838, il y prescrivit le régime de l'isolement, du travail, de l'instruction élémentaire donnée par des professeurs. Il constata que ce régime ne donnait plus qu'un récidiviste sur quarante, au licu d'un récidiviste sur quatre. En 1840, le mème système fut pratiqué à la Grunde-Force, prison réservée aux criminels adultes. La loi de $1 \$ 44$ l'étendit à toutes les prisons; mais, faute de fonds suffisants, elle ne put ètre appliquée que dans quelques-unes.

En 1850, sur le plan nouveau, se construira la prison de Mazas.

En 1817, le travail des détenus fut affermé à des entre- 
preneurs, qui ne leur laissaient que la moitié du produit. En 18 2, il fut mis en régie ${ }^{1}$.

L'assistance publique. - Le service de l'assistance avait été reconstitué en 1801 . Le Premier consul avait créé un conseil général et une commission alministrative des hospices ${ }^{2}$. Ces deux corps furent remplacés, seulement en $18 \dot{49}$, par un conseil de surveillunce et un directeur général de l'assistance publique, organisation qui subsiste encore.

En 1829, on comptait à Paris 62700 assistés sur une population de 816150 habitants : soit 1 indigent sur 13 personnes; en 1838, cette proportion est réduite à 1 sur 15; nn 1847, année calamiteuse, elle se relève à 1 sur 14. Elle est aujourd'hui de 1 sur 18.

Les bureaux de bienfaisance, établis auprès de chaque mairie parisienne, datent de 1791.

En 1816, un arrèté établit que les pères et mères indigents ne pourraient être inscrits au bureau de bienfaisance que s'ils avaient fait vacciner leurs enfants et les curoyaient aux écoles gratuites.

En 1830, Monthyon laissa aux pauvres de Paris une rente le 5312000 francs.

En 1831, Michel Brezin, ancien forgeron mécanicien, anrichi sous la République et l'Empire, fonda l'hospice de in Reconnaissance pour les vieux ouvriers.

En 1814, la maison des Enfants trouvés, fondée par saint lincent de Paul, fut séparée de la Bourbe, réservée au service de Maternilé. Sa réorganisation en maison des finfants assistés avait été opérée par le Directoire (1796) et IEmpire (1811). En 1836, on y réunit les Orphelins du fau-

1. En 18:8, on abolit le travail forcé dans les prisons, ce qui semble uno prreur morale el économique; en 1819 et 1852, on le rétablil. En 1856, on revint au système des entreprises, ce qui est une autre erreur économique pt morale, ne laissant subsister la régie qu'a Clairvaux.

2. Des huit hópitaux généraux de Paris, six datent de l'ancien régime : lEótel-Dieu, qui romonle au $\times u^{\circ}$ siecle, la Charite (1602), la Pitié (1612), Necker $(17 \% 6)$. Cochin (1780); deux de la Révolution : Beaujon et SaintAntoine (1795); un de la Monarchie de Juillet, La Riboisière (1839-1854).

l'armi les hópilaux spècialement consacrès à telle ou telle maladie. SaintLouis a élé fonde par lfeuri IV pour les pestiférés, et afTeelé depuss aux maladies cutanees et aux opérations chirurgicales: la Maternite date de 1795 ; le Midi, de 1792: les Enfants malades, de 1802; Lourcine, de 1\$32; 1.: Cliniques, de 1834; Sainte-Eugenie, de 1853. 
bourg Srint-Antoine, dont la fondation remontait à 1674 . On donna un développement plus vaste aux constructions '.

Bicêtre, autrefois họpital, hospice, prison, asile d'aliénés, avait été remis, en $18 \%$ à l'administration des hospires. C'est seulement depuis 1836 qu'il a cessé d'ètre une prison pour les jeunes détenus et qu'il est devenu exclusivement un hospice pour les vieillards, les infirmes et les aliénés du sexe masculin. Bicètre couvre 21 liectares de superlicie et a une population de plus de 3000 ìmes, supéricure à celle de beaucoup de villes de France.

Une autre cité encore plus vaste, c'est la Salpêtrière, l'ancien Hópital général de Louis XIV : elle a une jopulation de 5000 âmes. En 1802, on en avait éloigné les dètenus pour en faire un hospice consacré exclusiventent aux femmes, vieilles, indigentes, infirmes, aliénées. Ciest surtout des années 1832 à 1849 que datent les améliorations matérielles, morales et médicales.

Réforme des postes. - En 1791, il y avait en France 1419 bureaux de poste : en 1829 , il n'y en avait que 1799 , tant le progrès avait été lent! En 1829, on signalait à la tribune 3 ă 587 communes entièrement dépourvues te relations directes arec la poste. Il fallait alors se rentre au chef-lieu de canton, souvent même au chef-lieu d'arrondissement, pour retirer ses lettres. Mème dans les villes, lorsque la population n’atleignait pas 4000 àmes, elles n'étaient pas portées à domicile, ou bien le l'acteur exigeait une surtaxe de cinq centimes. Cet abus ne disparut qu'en 1830. ''endant toute la Restauration, il n'y eut pas en France un seul facteur rural.

Pendant tout le règne de Louis-Philippe, la France resta divisée en trois zones postales : dans la plus rapprochée du lieu d'envoi, le port était de 20 centimes; dans la plus éloignée, de 1 fr. 20.

La loi de 18.66 (3 juillet) apporta quelques perfectionnements à ce service. Le nombre des bureaux de poste atteignit 2395 en 1838. Les facteurs ruraux furent alors créés.

1. En 1850 , on essaya, avec ces enfants, de fonder la colonie acricole do Ben-Aknoun (Alcérie) : elle fut dissoute en 1858. D'uutres colonics furent fondées en France, dont la plus connue est celle de Metlray. 
On ignore si la Révolution de 1830 a mis fin à l'existence du Cabinet noir : en 1847, les fonds secrets servaient encore 60500 francs de pension aux " employés de l'ancien Cabinet noir ".

\section{Les tribunaux et les lois.}

Nomination des magistrats. - Le système napoléonieu avait été, en résumé, la nomination des magistrats par le pouroir. Les juges de paix, les magistrats du parquet, les magistrats des colonies restant seuls révocables, les autres magistrats jouissaient de l'inumocibilité.

Arec l'inamovibilité, la Restauration aurait èté obligée de vivre avec la magistrature impériale, le gouvernement de Juillet arec celle de la Restauration, le second Empire avec celle de Louis-Philippe et de la République de 1848. Or, un gouvernement peut-il subsister avec une magistrature hostile à son principe?

Tous ces gouvernements, en affirmant respecter le principe d'inamovibilité, surent éluder la difficulté. Louis XVIII déclara que les magistrats seraient inamovibles, mais ceux-là seulement qui seraient nommés par le roi : on ne conserva donc que ceux qui furent institués à nouveau. Après la Révolution de 1830 , on se contenta dexiger des magistrats le serment de fidélité à Louis-Philippe : cela suffit pour qu'un certain nombre d'entre eux, plutòt que d'abjurer leur foi de légitimistes, quittassent leurs sièges. La Rérolution de 1848, après avoir d’abord déclaré l'inamoribilité incompatible arec la République, tinira par la consacrer de nouveau. Le second Empire, pour exclure ses adversaires, leur imposera un serment de lidélité ${ }^{1}$.

Le principe de l'inamovibilité, même avec ces dérogations, n'en est pas moins une garantie de leur indépendance pour les magistrats, de justice impartiale pour les justiciables. Que le juge soit nommé par le gouvernement ou

1. La République actuelle, par la loi du 30 aout 1S\$3, supprima un certain nombre de sieges dans les cours d'appel el les tribunaux : on put faire porter les mises á la retraite sur les magistrats qui passaient pour les plus bostiles a ia démocratie. 
qu'il soit élu par le peuple, il faut qu'il n'ait plus rien à craindre ni de l'un ni de lautre; or, le seul moyen de lui lonner cette sécurité, c'est qu'une fois en possession de son siège il ne puisse le perdre, à moins d'indignité constatée par les tribunaux ${ }^{1}$.

Importance nonvelle de la cour de Cassation. En vertu de la loi du 1er avril 1837, quand la Cour de Cassation a fait deux fois acte de cassation pour la même affaire, le tribunal qui en est ensuite saisi est obligé d'appliquer sa jurisprudence. En 1800 avait commencé le recueil de SIREY; en 1839 conımence celui de DaLloz sur les arrêts constituant jurisprudence.

Esprit de la magistrature. - Sous la Restauration surtont, la magistrature reprit ses anciennes traditions de lutte contre les doctrines ultramontaines et, quoique sincèrement royaliste, de résistance à l'arbitraire.

En 1826, la cour d'appel de Paris, saisie de la question des jésuites par M. de Montlosier, tout en se déclarant ıncompétente sur cetle question, donna, dans ses considérants, raison à l'écrivain.

En aoùt 18:9, le Journal des Débats, traduit devant les tribunaux pour ses attaques contre le ministère Polignac, fut condamné en première instance, mais acquitté par la cour de Pari:. En juillet 1830, quand les lameuses ordonnances de Charles $\mathbf{X}$ suspendirent la liberté de la presse, limprimeur du journal le Commerce, craignant pour son brevet, se refusait à l'imprimer : le président du tribunal civil de la Seine. Debelleyme, rendit une ordonnance enjoignant à l'imprimeur de remplir ses engagements. (Le président du tribunal de commerce, Ganneron, faisait la même injonction à l’imprimeur du Courrier français.)

L'esprit de la magistrature était donc, en bonne partie, gallican et libéral.

Les avocats s'inspiraient de sentiments eucore plus vils. En 1822, le garde des sceaux Peyronnet leur avait enleve

1. Il faudrait aussi que, n'ayant rien à craindre, il n'eút également rıen z espérer;mais il est difficile d'òter au magistrat l'espérance d'un avancement sans nuire en mème temps à la bonne organisation du scrvice judiciare. An reste, la mellleure garantie, en cette matière comme en toute autre, e’est la liberté générale et la responsabilité ministérielle. 
l'élection directe des batonniers et du conseil de discipline en assemblée générale. Ils la recouvrèrent après la Révolulion de 1830.

La législation civile. - Aux cinq codes napoléoniens s'est ajouté, en 1827, le Code forestier.

La législation ne peut être, chez les peuples modernes, fixée à jamais par des codes; car la société, aux besoins de laquelle elle a mission de pourvoir, est en transformation perpétuelle. Aussi d'importints changements ont-ils été introduits.

Dans le Code civil, le divorce a été aboli, sous la préoccupation d'idées religieuses, par la Chambre dite " introuvable "; la loi de 1816 ne laissa subsister que la séparation de corps.

La situation des étrangers en France, surtout pour le droit de succession, a été améliorée par la loi de 1819.

La contrainte par corps, en matière civile, qui peuplait les prisons de détenus pour cause de dettes, avec tant d'inconvénients pour eux et si peu d'avantiśres pour leurs créanciers, et qui a rendu si fameuse la prison parisienne de Clichy, a été limitée par la loi de 1832 (17 avril).

Le Code de Commerce a été modifié surtout par la loi de 1838 sur les faillites et banqueroutes, conçue dans un esprit plus libéral que les lois de Napoléon. Le développement de l'activité industrielle et commerciale dans notre pays a provoqué en outre d'autres modifications dans le Code de procélure et le Code de commeree, en vue de simplifier l'un et de compléter l'autre.

La legislation pémale. - Cette législation (Code d'instruction et Code pénal) a été adoucie par la grande loi de 1832 (28 avril). Celle-ci a supprimé le carcan, lo marque, lamputition du poignet pour les parricides, qui costunuent seulement à marcher au supplice nu-pieds et la tète enveloppée d'un vóile noir. Elle a supprimé la peine de mort dans onze cas pour lesquels le code napoléonien l'avait maintenue ou rétablie. Elle a abrogé les articles de ce code qui punissaient la non-révélation des complots. Enfin, le nouvel article 463 du Code pénal a établi les circonstances atténuantes. Quand celles-ci sont accordées à l'accusé par le jury, le juge est autorisé à abaisser 
d'un ou de deux degrés la peine prévue par le Code : par exemple, si cette peine est la mort, il peut appliquer, soit les travaux forcés à perpétuité, soit les travaux forcés à temps.

Depuis l'établissement des circonstances atténuantes, les exécutions à mort ont diminué dans une proportion notable. Sous la Restauration, de 1826 à 1830, dans une période de cinq ans, il y a eu 360 exécutions'. De 1831 à 1833 , il n'y en cut plus que 154 , soit moins de la moitić ${ }^{2}$.

Cette même loi de $\mathbf{1 8 3 2}$ avait exigé que, pour la condamnation, huit jurés au moins sur douze se fussent prononcés pour la culpabilité. La loi de 1835 (9 septembre) réduisit à sept le nombre des suffrages exigés : c'est-à-dire que la simple majorité suffisait pour la condamnation.

La confiscation générale des biens du condamné, conservée par l'ancien régime, avait été abolie par la Constituante, rétablie par les gouvernements suivants, et finalement supprimée par la Charte de 1814. La confiscation ne subsista çue pour certains objets déterminés : engins prohibés, marchandises de contrebande, etc.

Rappelons qu'en 1831 le député Destutt de Tracy, désireux de sauver la tête des ministres ae Charles $X$, fit une motion pour l'abolition de la peine de mort, et que Victor Hugo n'a cessé de présenter, sous toutes les formes possibles, le mème vou.

\section{Les finances.}

Les impôts. - En ce qui concerne l'impòt loncier, il est à noter que le cadastre de la France, commencé en 1811, fut achevé vers le milieu de ce siècle. En 1830, il restait encore 15788 communes oú ce travail n'était pas fait. Il fut achevé, pour la France continentale en 1850 , pour la Corse en 1858. On n'obtint pas pour cela l’égalité absolue.

1. Dans la période de 1816 à 1820 , il y a eu 1986 condamnations à mort; on ignore combien ont été commuees, mais on ne se tromperait guère on comptant 1000 ou 1200 exécutions pour celte période de cinq ans.

2. De 1560 à 1565 , il n'y on eut que 63 . Le nombre a encore diminué do nos jours. 
c'est-à-dire la péréquation de l'impôt entre tous les citoyens français. La loi de 1821 se borne à l'exiger dans l'intérieur de chaque commune; mais elle n'existe ni d'un département à l'autre, ni même d'un arrondissement à l'autre ${ }^{1}$.

En général, on n'a pas modifié les impòts directs, sauf l'adoucissement apporté à celui des portes et fenètres par la loi de 1832, afin d'empêcher que les maisons d'ouvriers et les manufactures ne fussent privées d'air et de lumière.

L'impôt du timbre s'est étendu à des catégories d'actes de plus en plus nombreuses.

Les impôts sur les consommations, rétablis par Napoléon sous le nom de droits réunis, étaient naturellement impopulaires. Quand les Bourbons revinrent en 1814, ils furent salués par les cris : "Plus de droits réunis!" Après les avoir abolis, le nouveau gouvernement fut obligé de les rétablir. Il est vrai que ce fut sous un autre nom, celui de contributions indirectes (boissons, sel, sucre) ${ }^{2}$.

Le budget de l'État. - Le budget, sous le premier Empire, ne présentait qu'un aperçu très incomplet des dépenses et des recettes : ce qui laissail une large part à l'arbitraire du gouvernement. La Restauration eut l'honneur de dresser un budget complet et sincère.

Les ministres, dans chaque ministère, étaient libres, en pratique, de ne pas tenir compte de la division du budget en chapitres, et de faire ies virements d'un chapitre à l'autre: en 1817, on les obligea à respecter ces divisions, et, en 1831, sous la Monarchie de Juillet, on en fit une loi ${ }^{3}$.

Le budgef des départements et des communes. - Les lois de 1831 et 1833 et autres lois qui ont établi une certaine autonomie des communes et des départements ont établi leur budget sur un plan analogue à celui de l'État.

1. A Vanderland (Seine-et-Oise) l'impôt foncier s'élève à 21 p. 100 du revenu net, tandis qu'il ne s'élève qu'à 0,61 p. 100 dans la commune de Saurelerre (Gironde) : co sont là les points exlrèmes dont l'écart a souvent eté signalé.

2. Ils produisent aujourl'hui, en y comprenant le monopole des tabscs, plus du double des contributions direcles : 1100 millions contre 420.

3. Le second Empire, après l'avoir abrogée, finit par y revenir. Sous la République actuelle, une loi de 1871 a formellement interdit les virements d'un chapitre à l'autre : ce qui assure sur le budget un contrôle plus efficace du Parlement el de la Cour des comptes.

4. Lois de 1871 sur les conseils géneraux, de 1884 sur les municipalités. 
De même que l'État, la commune et le département ont leurs dépenses; il faut donc qu'ils aient leurs revenus.

Les communes ont pour recettes : $1^{\circ}$ le revenu de leurs domaines, car beaucoup d'entre elles ont des lorèts, des terres, des valeurs mobilières, et quelques-unes sont fort riches; $2^{\circ}$ les octrois, ou taxes imposées par les villes sur les objets de consommation qui entrent chez elles; $3^{\circ}$ divers produits, comme l'impôt sur les chiens, la part afférente aux communes sur la délivrance des permis de chasse, le prix des concessions dans les cimetières, etc. $; 4^{\circ}$ les centimes additionnels : ce sont des impôts qui s'ajoutent, sur la cote du contribuable, à l'impôt principal, c'est-à-dire à l'impôt direct de l'Etat; pour chaque franc que le contribmable verse à l'Etat, il verse un certain nombre de centimes attribués au budget de la commune.

Les départements n'ont pas de domaine qui produise des revenus. Aussi leur recette se compose-t-elle presque uniquement de centimes additionnels départementaux.

Ainsi, dans la cote payée par chaque contribuable, il y a la part de l'État, de la commune, du département.

Liorganisation financière. - On n’a presque rien innové dans l'organisation créée par Napoléon. En ce qui concerne les contributions directes, la loi de 1817 a ainsi organisé le service de contrainte à l'égard des contribuables : d'abord un avis personnel, aussitót les rôles d'impôts confectionnés; puis, une sommation sans frais et une sommation avec frais; puis les poursuites judiciaires, commandement de payer, envoi de grarnisaires chez le débiteur en retard; finalement, saisie et vente.

\section{Les cultes.}

La pratique du Concordat. - Sous la Restauration, on laissa d'abord toute liberté aux membres les plus ardents du clergé. Ils persécutèrent les évêques qui avaient fait autrefois partie de l'Église constitutionnelle; ils organisèrent des missions qui agitèrent le pays ${ }^{1}$; ils recommencè-

1. On fit une obligation aux fonctionnaires, aux soldats de remplir leurs devoirs religieux, et l'on vit les maréchaux incrédules de Napoléon accompagner le roi, cierge en main, dans les processions. 
rent à inquiéter les acquéreurs de biens nationaux. Plus tard se forma, sous la direction des jésuites, une association célèbre, la Congrégation, plus politique que religieuse, qui inspira quelques-unes des mesures les plus funestes de Charles $X$ et le conduisit enfin à sa perte.

En 1817, un nouveau Concordat fut préparé par le gouvernement de Louis XVIII, en vue d'abroger celui du Pre. mier consul et d'en revenir à celui de François Ier. Le pape consentit à signer ce traité, mais le gouvernement n'osa pas affronter la discussion dans les Chambres, et le quatrieme concordat fut annulé. On se borna, par une loi de $\mathbf{1 8 2 4}$, à augmenter le nombre des diocèses ${ }^{1}$.

C'est la dernière tentative qui ait été faite pour revenir sur le Concordat de 1801.

Esprit du elergè. - Avant la Révolution, les membres du clergé français se divisaient en gallicans et ultramontains. Les premiers professaient les maximes de 1682, altirmaient la supériorité des coneiles cecuméniques sur le pape : ils faisaient de la papauté une sorte de monarchie constitutionnelle, contrólée par les assemblées générales de l'Église. Les seconds rejetaient la déclaration de 1682 et affirmaient la suprématie du pape sur les conciles: ils faisaient de la papauté une monarchie absolue. Nous avons vu que Bonaparte s'était proposé d'assurer la prépondérance à l'opinion gallicane en exigeant qu'on enseignàt les principes de 1682 dans les séminaires.

Depuis qu'aux " rois très chrétiens " ont succédé des gouvernenents d'origine plus ou moins révolutionnaire, tenus à traiter tous les cultes reconnus avec une égale bienveillance, les sentiments que Bossuet avait professés à l'égard de la royauté n’ont pas subsisté au mème degré, à l'égard des régimes nouveaux, dans le cour du clergé. Comme il ne pouvait plus se grouper autour du "trỏne de saint Louis ", il a tendu à se grouper autour du siège pontifical. La suppression des tribunaux ecclésiastiques en France avait fait du pape le juse unique. On avait vu, en 1801, le pape signer un Conıordat, destituer des évêques; jamais, le SaintSiège n'avit encoro fait en France de pareils actes d'auto-

1. Il y eut dès lors 17 arrovevechés et 67 évèchès. 
rité. Tout cela portait le clergé français à admettre plus complètement qu'autrefois les vues et les doctrines de la cour de Rome. Le journal religieux l'Avenir, fondé en 1831 par Lamennais, Lacordaire et Montalembert, a marqué les ¿lèbuts de cette grande évolution. De 1842 à 1849, l'histoire ecclésiastique de Rohrbacher se substitue, dans les séminaires, à celle de Fleury, conçue dans l'esprit gallican.

Lois religieuses sous la Restauration. - Sous la Restauration, il y eut une tendance à revenir à toutes les traditions de l'ancienne royauté de droit divin. On voulait que le bras séculier intervint de nouveau pour imposer comme obligations civiles des pratiques qui ne sont obligatoires que dans la conscience des lidèles, ou pour punir comme crimes de droit commun des actes qui ne sont des crimes que pour le croyant.

Ainsi la loi de 1814 (18 novembre) interdisait tout trafic et tout travail pendant les dimanches et jours fériés. Les contrevenants étajent punis d'une légère amende pour la première fois, et, en cas de récidive, passibles de quinze francs d'amende et de cinq jours de prison.

Cette loi, sans avoir jamais été abrogée en fait. n’est plus exécutèe. L'État, considérant qu'il faut au moins un jour de repos dans la semaine et qu'il est avantageux de faire coincider ce jour avec celui que consacre la loj religieuse du plus grand nombre des citoyens, a maintenu le dimanche et les autres fẻtes fériées conme jours de repos pour les administrations, les tribunaux, les écoles. Les travaux entrepris pour son compte sont, eu général, suspendus ce jour-là. Cependant il ne se croit pas le droit d'imposer l'observation du dimanche aux particuliers qui ne s'en font pas un devoir de conscience.

La loi de 1826 sur le sacrilège punissait de mort le vol avec effraction dans les églises et la profanation des vases sacrés. Le ministère avait mẻme, dans son projet de loi, inséré une disposition, qui fut rejetée par la Chambre des Pairs : on aurait appliqué au coupable la peine du parricide, c'est-à-dire la décapitation précédée de l'amputation du poignet. La loi fut votée dans les deux Chambres; mais elle senblait tellement contraire à l'esprit du siècle, que la Restauration elle-même n'osa pas l'appliquer '.

1. La loi civile, en effet, doit punir les crimes de droit commun, mais 


\section{Politique de Louis-Philippe à l'égard du clergé. -}

La Monarchie de Juillet, en tenant le clergé exclu de toute ingérence dans la direction politique, lui rendit un grand service. L'attitude d'une partie du clergé pendant la Restauration l'avait rendu impopulaire; lorsqu'éclata la Révolution de 1830 , les prêtres, par prudence, au moins dans les grandes villes, durent quitter leur costume. Une manifestation imprudente amena le sac de l'archevèché (1831). Les Chambres rayèrent de la Charte les mots de religion de l'Etat, pour les remplacer par ceux de religion de la majorité des Français, et réduisirent le budget des cultes. Elles exclurent de la pairie les évèques nommés par Charles $\mathbf{X}$ : les autres évèques-pairs durent même s'abstenir de siéger. Le ministère des affaires ecclésiastiques fut supprimé. L'image du Christ fut retirée des cours d'assises.

Bientôt une attitude plus réservée ramena au clergé les sympathies. Le Christ fut replacé en 1837 dans la salle des assises; on rétablit la subvention des cardinaux; le budget affecta des sommes considérables à la construction ou à la réparation des églises et des presbytères. Les églises n'offrirent plus le spectacle de l'hypocrisie officielle ou de communions sacrilèges, dictées par la peur, l’intérêt ou le désir de l'avancement, mais elles se repeuplèrent d'une foule recueillie et vraiment croyante. Un signe éclatant de ce revirement fut qu'après la Révolution de février le peuple victorieux invita les prêtres à bénir les arbres de liberté et les tombes de ses morts. Lacordaire fut élu représentant du peuple et put siéger à l'Assemblée nationale en robe blanche de dominicain.

Les congrégations. - Sous la Restauration, les congrégations commencèrent à se reformer de toutes parts; mais une différence subsistait entre elles. Les unes se reformèrent en sollicitant l'autorisation du gouvernement, les autres sans la demander ${ }^{1}$. Il y eut donc à distinguer

noz les crmes religieux, qui sont dü domaine de la conscience. Elle frappe le voletar d'un vase sacré, non comme sacrilège, mais comme voleur. Si la loi admettait un crime de sacrilège, il n'y aurait plus de motifs pour ne pas admettre un crime d'bérésie.

1. Les congrégations qui se refusent à demander l'autorisation entendent affirmer par là leur indépendance à l'ëgard de l'État: elles se proposent aussi d'ecarter lout cont óle de l'État dans leur gestion financière. 
des congrégations antorisées et des congrégations nou autorisées. Les plus puissantes de celles-ci étaient la Compagnie de Jésus, les maristes, les chartreux, les franciscains, les capucins, les dominicains, les trappistes. Mème distinction parmi les congrégations de femmes.

Les congrégations autorisées sont des personnes morales, reconnues par la loi, c'est-à-dire qu'elles peuvent légalement posséder; elles peuvent acquérir et recevoir des libéralités; elles peuvent aliéner, mais seulement avec une autorisation du Conseil d'État. Elles sont à l'égard de l'État. dans une sorte de tutelle, comme les communes urbaines et rurales.

Les congrégations non autorisées nont pas le droit de posséder, ni d'acquérir. Elles possèdent et acquièrent seu lement en éludant la loi, au moyen de personnes interposées qui prennent la qualité de propriétaires.

Jusqu'à 1817, les congrégations d'hommes pouvaient êre autorisées par simple décret ou ordonnance royale; mais une loi de 1817 n'attribua le droit d'acquérir qu'à celles qui seraient reconnues par une loi : dès lors elles ne furent plus autorisées que par un vote du Parlement ${ }^{1}$. Quant aux cougrégations de femmes, la loi de 1825 n'exige un vote du Parlement que dans des cas exceptionnels; dans tous les autres cas, elles sont dùment autorisées par un simple décret. Cette facilité amena leur multiplication.

Les congregations autorisées ont eu, depuis la Révolution, une existence assez paisible. Les congrégations d'hommes non autorisées, celle des jésuites surtout, ont soulevé de vives discussions. A l’époque de la Restauration, les jésuites, dont la maison mère était à Montrouge (Paris), non seulement s'étaient reconstitués ${ }^{2}$, mais, au mépris du

1. Il a'y a que quatre congrégations d'hommes qui aient été autorisées : les Lazarisles, les Missions étrangères, le Saint-Esprit, les prètres de SaintSulpice. Quant aux frères des Écoles chrètiennes, frères de la Doctrino chrétienne, frères de l'lnstruction chrétienne, frères de la Socièté de Marie, petits frères de Marje, etc., ils ont été autorisés non comme congrégations religieuses, mais comme associations vouées à l'enseignement. En revanche, les congrégations łe femmes autorisćes sont très nombreuses.

2. Ou sait le rỏle que jouent les jessuites de Montrouge dans le fameux roman d'Eugène süe, le Juif Errunt. 
monopole universitaire, avaient ouvert en France sept collèges, dont le plus célèbre fut celui de Saint-Acheul. Or, la Restauration elle-néme ne pouvait reconnaitre leur existence comme légale, et une ordonnance (16 juin 1928) signée du dévot roi Charles $\mathrm{X}$ et de $\mathrm{Mgr}$ Frayssinous, évêque in partibus d'Hermopolis et alors grand-maitre de l'Université, ordonna la fermeture de ces établissements ou leur soumission au statut universitaire. En 1845, après l'interpellation de $\mathbf{M}$. Thiers, et à la suite d'une négociation avec la cour de Rome, ils furent de nouveau fermés.

Les deux monarchies parlementaires n'ont donc jamais accordé à ces congrégations qu'une existence de fuit, et non pas de droit.

Les protestants et les juifs. - Rien d'essentiel n'a été changé à la situation des églises protestantes, qu'elles lussent de la confession de Geneve ou de la confession d'Augsbourg.

Les juifs, à l'expiration du délai de dix ans prévu par le décret de 1808, c'est-à-dire en 1818, se sont trouvés affranchis de toute restriction, en pleine possession des mèmes droits civils et politiques que les autres Français.

En 1831, Laffitte, ministre de Louis-Philippe, fit admettre le culte israélite à participer, comme les autres cultes reconnus, aux subventions de l'État. La France était alors la seule nation en Europe qui eût donsé anx israélites l'égalité absolue. En Angleterre même, ils n'ont été admis qu'en 1858 à siéger comme députés au Parlement.

Ouvrages a consurten. - Cronier, Histoire du pouvoir municipal et de ses variations depuis la Restauration jusqu' 2 18:8. - Maurice Block, Dictomairc de ladministration francaike et Les Communes et la liberté (15i6). - A. llesse, L'administration procinciale et municipale en France et en Furupe (15i1). - DupontWhile, La liberté politique considérer dans ses rapports acec l'adminisfration locale (1864). - P. LeroyButulieu, L'administration locale en France et en Angleterre. - Flandin, Des assemhleses provinciales... et des Conseils griniraux et de département. - Marine du Camp, Paris, ses orzanes, ses fonctions (1869-75.

Lueas, Dusysteme penal 1527); De la reforme des prisons 1530 - we
Molènes, De l'humanite, dans les lois criminelles (1830). - 11. Bonnevilte, De lameliar de la loi crimin. (1\$35). - Collard, Du systeme des circonstances attimuantes 1840.- Rossi, Traité de droit pénal (1872). Levieil de la Marmonnière, Hist. de la contrainte pror corps (1843).

René Stourm, Le budget, son hisloire et son mécanisme (1906). Wührer, Hist de la dette publique en France (1856:- - Sudre, Les funances de la France an $\mathbf{M I}^{\circ}$ siecte (1583).

An. Leroy-Beaulieu, Catholiques liberaur; l'Eqlise et le liberalisme depmis 1830 (IS-5). - Théodore Reinach, Itist. des israélites (1901). Sur loulez les matières ecclésiastiques, Bibling. dans l'Hist. Ginérale, t. $1 \mathrm{x}$, p. $291,1 . \mathrm{x}, \mathrm{p} .7 .5$ 


\section{CHAPITRE XV'II}

LE DROIT DES GENS, L'ARMEE, LA MARINE, LES COLONIES

\section{Le droit des gens.}

Les congrès de 1815 à 1823. - Le congrès de Vienne en 1815, pour la première fois, a montré les représentants de toutes les arandes puissances curopéennes réunis pour aviser à résouclre, par des moyens pacifiques et diplomatiques, une série de questions dont la moindra, cinquante ans auparavant, aurait suffi pour mettre en feu l'Europe et le monde. Il est vrai que toutes les puissances étaient épuisées par vingt-trois ans de guerres sanglautes, et qu'à tout prix il fallait assurer la paix.

A cette date, on était trop près des trois partages de la Pologne et des violentes conquêtes de Napoléon pour que les diplomates réunis à Vienne eussent un grand respect du droit des peuples. Aussi, dans leur remaniement de la carte de l'Europe, nous les voyons partager pour la qualrième fois la Pologne, démembrer la Saxe, livrer la Norvege à la Suède, le Holstein au Danemark, la Belgique à la Hollande, l'Italie du nord à l'Autriche, les pays catholiques du Rhin à la Prusse protestante.

Ils ne tinrent compte ni des caractères nationaux des peuples qu'ils séparaient ou réunissaient ainsi sans les consulter, car la théorie des nationalités était alors inconnue, et la Révolution elle-même avait subordonné l'idée de nalionalité à celle de liberté; ni des "aspirations des peuples ", car les diplomates représentaient tous le principe le plus opposé à celui des souverainetés nationales : celuj des monarchies de droit divin. La Révolution avait rêvé la 
ligue de tous les peuples contre tous les rois; la Restauration entra dans la Sainte-Alliance des quatre grands souverains du continent ${ }^{1}$, et vainement Béranger chantait "la Sainte-Alliance des peuples".

Après le congrès de Vienne, on eut le congrès diAix-laChapelle, où les puissances s'entendirent pour hâter l'évacuation de la France; les congrès de Laybach et de Troppau, où elles décidèrent l'intervention de l'Autriche pour détruire les constitutions que les Napolitains et les Piémontais avaient arrachées à leurs rois; le congrés de Vérone, où elles confièrent à la France le soin d'accomplir la restauration de l'absolutisme en Espagne.

Pendant plusieurs années, l'Europe en revint à la politique de l'ancien régime: celle des affaires des rois et des intérêts des calinets. Jusqu'à 1848 , les seuls grands États européens qui aient été en possession d'une Constitution, et chez lesquels l'opinion publique ait influé sur la politique des cabinets, ce furent la France et l'Angleterre.

Les guerres de la Restauration. - La Restauration fit dabord une guerre dynastique, une guerre de famille: celle d'Espange (1823). L'expédition avait pour but de res. tituer au Bourbon de Madrid le pouvoir absolu dont ses sujets l'avaient dépouillé. Elle semblait une application de l'ancien système du Pucte de famille, en mème tensps que de la politique nouvelle, celle de la Sainte-Alliance.

Cependant la Restauration elle-mème fit une guerre dopinion : elle envoya une flotte et une armée pour rendre à la Grèce son indépendance (1826), tout comme Louis XVI avait envoyé une flotte et une armée pour assurer l'indépendance des États-Unis d'Amérique (1778).

La politigne ètrangère sons Louis-Philippe. - La Monarchie de Juillet se trouva en présence de deux politiques tout opposées, entre lesquelles il fallait choisir. L'opinion publique se manifesta d'abord énergiquement pour une politique de propagande; elle demandait que la France intervint en faveur des révolutions qui avaient partout éclaté à la suite de la nòtre: en faveur de la révolution italienne contre le pape et l'Autriche, de la révolution polonaise contre la Russie.

1. France, Russie, Aulriche. Prusse. 
Louis-Philippe comprit que la France n'était plus assez puissante pour reprendre le grand rôle qu'elle avait joué sous la Convention et le Directoire. Il rompit avec le ministère Laffitte, qui inclinait vers cette politique, et forma le ministère Casimir Perier; celui-ci tenait pour l'ancienne politique d'équilibre européen. Ce fut celle de la plupart des ministères qui suivirent jusqu'à 1848 .

On laissa donc écraser la révolution polonaise. On se contenta, pour faire équilibre en Italie à l'Autriche, qui occupait les États du pape, d'occuper Ancòne. Dans les affaires de Belgique, qui intéressaient l’équilibre européen et la sécurité de notre frontière, on n'intervint que de concert avec les grandes puissances. La conférence de Londres montra, une fois de plus, l'efficacité du concert européen. C'est de ses délibérations que sortit l'organisation des provinces belges en royaume de Belgique.

C'est également le concert européen qui empêcha la France de soutenir le vice-roi d'Égypte contre son suzerain le sultan (1840), et qui, ensuite (1841), ordonna la clôture du Bosphore et des Dardanelles aux navires de guerre européens.

Caractère essentiellement pacifique do la période parlementairc. - Ainsi, de 1814 à 1848 , pendant toute la durée de la monarchic parlementaire, l'armée française n'a agi en Europe que dans quatre occasions : l'intervention en Espagne (1823), l'intervention en Grèce (1826), l'occupation d'Ancone (1832), enfin l'intervention en Belgique, qui a été marquée par la prise d'Anvers (1832). Or, en Espagne, en Grèce, en Belgique, nous n'avons agi qu'avec l'assentiment des puissances : nous n'avons pris Anvers que pour obliger le roi de Hollande à se soumettre aux décisions de la conférence de Loudres. Donc, pendant trentequatre ans, nous n'avons pas fait en Europe ${ }^{1}$ une seule frinde guerre et nous n’avons pas ajouté un village à aotre territoire.

Il en est de même de toutes les autres puissances europeiennes : elles se sont armées quelquefois pour réduire

1. Hors d'Europe, nous avons fait la conquẻte de l'Algérie et des expéditions peu importantos au Mexique (1S38), au Maroc (1844)et aux iles Tahiti $(1846)$. 
leurs sujets révoltés; mais, sauf l'annexion de la ville de Cracovie à l'Autriche (1846), on ne peut signaler une seule acquisition faite en Europe par aucune d'elles.

C'est donc une période essentiellement pacifique, on pourrait dire conservatrice, dans l'histoire européenne. Les gouvernements parlementaires, comme ceux de France et d'Angleterre, et les gouvernements autoritaires, comme ceux de Prusse, d'Autriche et de Russie, se sont trouvés d'accord pour maintenir le statu quo et éviter les conflits. On a employé à cet effet deux procédés : d'abord, les congrés et conférences, ensuite les neutralisations. Atin de supprimer mème pour l'avenir les causes de guerre, on a neutralisé des pays ou des passages qui avaient été ou qui auraient pu ètre disputés : ainsi la Suisse, en 1815, la Beigique, en 1832, les détroits des Dardanelles et du Bosphore, en 1841, ont été déclarés neutres. Cette neutralité a été garantie par toutes les puissances.

La monarchie parlementaire, et plus particulièrement la monarchie bourgeoise, a contribué à cette pacification de l'Europe, que nous avions tant agitée au temps de la Rérolution et de l'Empire. Véron raconte, dans ses Mémoires, qu'un ancien ministre de Louis-Philippe l'arrèta un jour devant le palais des Tuileries et lui dit : " II y a là un homme d'esprit et de beaucoup d'expérience; c'est un grand malheur qu'il n'aime pas la gloire. " Ce n'était pas seulement Louis-Philippe qui n'aimait pas la gloire, sachant par une dure expérience ce qu'elle pouvait coûter; c'étaient aussi les classes dirigeantes d'alors, dans leur grande masse, la majorité des deux Chambres, la plupart des ministres, Thiers aussi bien que Guizot. Ils firent à la paix du monde de gros sacrifices d'intérèt ou d'amour-propre, comme dans l'affaire de Belgique, l'affaire d'Egypte, l'affaire de l'indemnité Pritchard. Les seules satislactions qu'ils accordèrent à l'humeur belliqueuse de la nation et à son enthousiasme pour les gloires nupoléoniennes, ce furent des paroles et des monuments. Ils applaudirent au "Rhin allemand " d'Alfred de Musset ct achevèrent l'Arc de triomphe. Un dérivatif plus sérieux, ce furent les longues guerres d'Afrique, qui ne nous fiaisaient courir aucun danger sérieux: elles lument une surte de 
roman militaire qui consola la France de ne pouroir - retremper ses armes dans le Rlin, ainsi que l'y invitaient Béranger et les autres poètes. Sans ètre partisans, comme on les en accusait, de la paix à tout prix, les politiques sentaient que les forces réelles de la France et la situation générale de l'Europe n'étaient plus celles le 1793 ou de 1805 , et qu'elles nous interdisaient les aventures. Ce n'est pas eux qui auraient aidé à faire l'unité allemande ou l'unité italienne: ils comprenaient qu'une bonne part de la puissance relative et de la sécurité de la France reposait sur l'indépendance de ces petits États qui entouraient notre frontière, sur l'organisation fédérale de l'Allenagne, sur l'équilibre des deux grandes puissances germaniques. Ils saviient que la politique des nationalités, dont les assourdissait l'opposition, ne pouvait point nous ètre favorable, et que, dans l'incertitude de l'avenir, le stalu quo était encore ce qu'il y avait de moins désavantageux pour nous. C'était une politique qu'on pouvait qualifier de terre à terre, mais qui eut l'avantage de laisser la France plus puissanto en 1848 qu'en 1814, sans dininution de son territoire et sans augmentation du territoire de ses rivaux.

\section{L’armée.}

L'armée sous la Restauration. - Quand l'Empire tomba, la conseription napoléonienne avait tellement fatigué et épuisé la nation que Louis XVII crut répondre au cri de lopinion en inscrivant dans la Cluarte de 1814 ces mots : "La conscription est abolie."

La plus grande partie de l'armée napoléonienne fut dissoute: une foule d'officiers qui avaient conquis leurs grades sur les champs de bataille virent leur carrière brisée et furent mis à demi-solde; l'exil et les supplices décimèrent les généraux de l'Empereur. Louis XVIII, qui n'avit pas conliance dans ce qui lui restait d’armée, créa une garde royale', commandée surtout par des émigrés.

1. Elle comprenait 2 divisions dinfanterie, 2 de caralerie, 2 régiment. d'arlillerie, l'un a cheval, l'autre à pied. 
Il enrôla, comme ses prédécesseurs du $x v^{e}$ au $x v ı u^{e}$ siècle des régiments suisses ${ }^{1}$.

En dehors des Suisses, le seul corps ètranger fut la légion de Hohenlohe, formée des débris de huil régiments étrangers, levés par Napoléon pendant les Cent-Jours.

On avait une telle horreur du système militaire de l'Empire, qu'un moment on supprima les régiments pour les remplacer par des légions départementales. Elles devaient se recruter, au moyen d'engagements volontaires ${ }^{2}$, dans les départements qu'elles occupaient, et en porter le nom.

Bien que l'armée eût été réduite à 240000 hommes, les engagements volontaires furent bientòt insuffisants pour maintenir ce chiffre. Alors le maréchal Godvion SAINT-cYR fit voter la loi de 1818 (10 mars), qui rétablissait partiellement et, en quelque sorte, timidement la conscription. Les engagements volontaires restaient le mode principal de recrutement pour l'armée; les appels de conscrits ne devaient en ètre que le mode accessoire. En réalité, ils furent la ressource princrpale. La loi fixait le contingent annuel, une fois pour toutes, à 40000 hommes. Tout conscrit " tombé au sort " pouvait fournir un remplaçant. La durée du service était de six ans. En outre, les sous-officiers et soldats devaient, en temps de guerre, sous le nom de vétérans, faire un service territorial de six ans.

La loi de 1924 vint modifier la loi de 1818 : elle éleva le contingent annuel à 60000 hommes, porta la durée du servicc à huit ans et supprima le service territorial des vétérans. Les régiments furent rétablis peu de temps après.

En juillet 1829 , on donna le pantalon rouge à l'infanterie.

C'est avec cette armée qu'on fit les expéditions d'Espagne, de Grèce et d'Alger.

La garde nationale sous Ia Restauration. - La garde nationale fut maintenue, mais seulement dans certaines

1. Deux régiments dans la ligne et deux régiments dans la garde, plus les Cent-Suisses. - Le 10r juin 1816, une nouvelle capitulation fut signè arec les cantons suisses.

2. Elles furent formées diabord avec les militaires licenciés et renvoyé dans leurs foyers, mais qui n'avaient pas encore fini leur temps de servico. 
villes. Une commission de recensement, composée du maire et de notables choisis par le préfet, dut choisir les citoyens qui en feraient partie. On ne prenait que ceux qui, par leur fortune ou leurs opinions, offraient des garanties de dévouement à la dynastie. C'est pourtant cette garde nationale, si soigneusement triée, qui se laissa gagner par l'esprit libéral. Celle de Paris, en 1828, a une revue passée par Charles $X$, fit entendre les cris : "Vive la Charte! Vive la liberté de la presse! A bas Villèle! „Elle lut licenciée, et les gardes nationaux parisicns ne reparurent en uniforme que sur les barricades de juillet et dans les rangs des insurgés.

L'armée sous la Monarchie de Juillet. - Pour l'armée permanente, la loi de $\mathbf{1 8 3 2}$ (21 mars), proposée par le maréchal soout. établit la conscription comme le mode principal de recrutement. Elle accrut le contingent annuel, qui fut porté à 80000 hommes. Elle nainlint le tirage au sort, avec laculté pour les conscrits porteurs de mau. vais numéros de se faire remplacer ou de négocier avec un conscrit du même canton la substilution d'un numéro à un autre. La durée du service, soit pour les conscrits, soit pour les engagés volontaires, fut fixée à sept ans. Les soldats qui avaient fait leur temps pouvaient contracter un rengagement pour une durée de deux à cinq ans, et les rengagés touchaient une haute paye. L'armée atteignit ainsi sur le papier le chiffre de 500000 hommes; une partie seulement était présente sous les drapeaux : le reste était envoyé en congé et formait la réserve.

Les Suisses avaient été licenciés ${ }^{1}$; mais de nombreux réfugiés italiens, espagnols, belges, allemands, surtout polonais, chassés de leur pays par les événements qu'y provoqua la révolution de Juillet, vinrent chercher un asile sur une terre qu'rls regardaient comme celle de liberté. On en forma, en mars 1831, une première légion étrangère qui fut aussitòt envoyéc en Afrique et qui, en 1835, fut cédée a l’Espagne. Une seconde légion étrangère, formée également en 1831, fut envoyée en Afrique et y est restée.

1 Le corps de Hohenlohe fut naturalisé en masse et forma désormais un regıment français: le $21^{\circ}$ léger.

R. Civil. Contemp. 


\section{La garde nationale sous la Monarchie de Juillet. -} Louis-Philippe, en sa qualité de monarque bourgeois et sans faste, n'eut pas de garde royale. La garde nationale lui suffisait. Il lui rendit l'élection des sous-ol'ficiers et des officiers au-dessous du grade de capitaine: au-dessus, ils étaient nommés par le roi sur une liste de dix candidats. Seulement l'obligation de l'uniforme, imposée à cette milice, en écarta lélément populaire : elle se recruta uniquement dans les classes bourgeoises et devint le soutien de la nouvelle dynastie. Les citoyens les plus aisés y formèrent des compagnies d'élite, grenadiers, voltigeurs, et composèrent surtout l'artillerie. Il fut ètabli qu'en cas de danger une partie de la garde nationale pourrait être mobilisee. Plusieurs fois par an, le roi la passait en revue, soit aux Champs-Élysées, soit sur les boulevards '. Comme elle avait conservé l'habitude de pousser des cris sous les armes, les revues étaient presque toujours l'occasion de manifestations dont le roi tenait grand compte. C'élait aussi une occasion de distribuer des croix ${ }^{2}$. Du reste, cette milice montra du dévouement et de la bravoure dans la répression des émeutes ${ }^{3}$, notamment celles de 1832 (6 juin)

1. $11 \mathrm{y}$ à une lettre trẻs curieuse de Louis-Philippe à La Fayette, après la revue de la garde nationale au 29 aoil 1830: "Témoin de la fédération de 1790 dans ce méme Champ-de-IJars, témoin aussi de ce grand élan de 1792, lorsque je vis arriver à notre arméo de Champagne quarante-trois bataillons que la ville de Paris avait mis sur pied en trois jours et qui contribuèrent si èminemment à repousser l'invasion, que nous eúmes le bonbeur d'arreter a Valmy, je puis faire la comparaison; et c'est avec transports que je vous dis que ce que je viens de voir est bien superieur à ce qu'alors j’ai trouvé si beau et que nos ennemis trouverent si redoutable."

2. Les caricatures du temps représentent Louis-Philippe laneant à pleine pelle les croix sur les gardes nationaux, dont beaucoup en nnt déjà cinq ou six sur la poitrine: il puise avec sa pelle à un grand monceau, qualimente une file interminable de charrettes pileines de croix.

3. Après les émentes des 5 et 6 juin 1832, dans lesquelles roi, ministres et soldats bourgeois déployèrent tant de bravoure, voici ce que la fille d'un des négociants importauts de la rue Saint-Martin érivait à son frère, qui habitait Roued: "Dès que le rappel a battu, nous avons fermé le magasin. Papa s'est habille pour aller joindre le bataillon, place des Petits-Péres. II a embrassé maman et moi en disant: "Il faul en finir aves ces nuisérables!" Jamais je ae l'ai vu si en colère. Dans la journée d'avant-hier notre inquiétude a été mortelle, nous n'osions pas sortir. Nous enlendions le canon, qui ébranlait les vitres. Des voisins nous apportaient les nouvelles, nous ne mangions plus.... Enfin, papa est arcive tout pâle, couver de poussière. Nous avuns sauté à son cou. 11 ne pouvait pas parler. "

Telles étaient les épreuves auxquelles se soumettait le bourgeois de Pario 
et 1834 (16 avril). Quelque chose de l'esprit belliqueux que nous avaient légué la Révolution et l'Empire revivait en elle. Plus de 2000 gardes nationaux, pour la plupart pères de famille, chefs dindustrie, riches commercants, propriétaires aisés, succombèrent dans les émeutes de Paris et de Lyon et scellèrent de leur sang leur fidélité à la royauté qu'avait londée la bourgeoisie.

A la fin, la garde nationale se laissa gagner, elle aussi, à la cause de la réforme électorale, et condamnait l'obstination du cabinet Guizot. C'est pourquoi elle refusa, en grande majorité, de combattre les insurgés de février 1848 . Cette défection contribua à òter tout courage à Louis-Philippe. Plus tard, dans son exil, il écrivait : "Lorsque jappris que la garde nationale, cette force sur Jaquelle j'étais si heureux de m'appuyer, la garde nationale de Paris, pour laquelle j'ai toujours eu tant de bénévolence, qui m'avait porté au tróne, qui mavait defendu dans l'émente, et au profit de laquelle on m'avait si souvent reproché d'avoir gouverné, abandonnait ma cause; lorsque j'appris que pas une de ces mains que j'avais si souvent pressées dans les miennes ne se levait en ma laveur, alors j'ai senti que mon règne était terminé, puisque l'opinion s'ètait retirée de moi et que j’avais cessé d'ètre apprécié. Je n'aj pas voulu verser des flots de sang pour une cause qui avait cessé dètre celle de la nation."

Un corps délite de 3000 hommes, soit à pied, soit à cheval, fut créé pour la sécurité de la sapitale. Il fut appelé, à cette époque, garde municipale, puis, en 18:8, garde républicaine, puis, après 18.51, garde le Puris, et il est redevenu la garde républicaine.

Progrès de Iartillerie. - Après le sýstème Vallière, le système Gribeauval, le système de l'an XI, nous avons eu le système de 1827. Comme pièces de campagne, on ne garda que deux canons, calibre 12 et calibre 8 , et leux obusiers. Les premiers servaient toujours à lancer les boulets pleins et avaient une portée plus longue: les seconds étaient réservés aux projectiles creux et avaient une portée quotidienne du boutiquir censiloire, et il défeudait raillamment, le fusil i la main, son privilége electeral. 
plus courte. On allégea encore le poids des pièces, celui des affuts, et l'on remplaça, pour l'attelage, la limonière par le timon. On emprunta aux Anglais le shrapnel, boulet explosif et plein de balles.

En 1822, fut constituée l'artillerie de montagne: il sulfisait de dix-huit mulets pour transporter une batterie : pour chaque canon, un mulet portait la piece, un autre l'affut, le troisième le caisson.

En 1829, on organisa des régiments d artillerie comprenant à la fois des batteries à pied, des batteries à cheval et des batteries d'artillerie montée, où les servants, assis sur les caissons, sont transportés avec la mème rapidité que les pièces.

Pour mettre le feu au canon, l'étoupille fulminante remplaça, sous la Restauration, l'ancienne lance à feu.

Perfectionnement du fusil. - Le fusil du modèle de 1777, le fusil à pierre, est resté en usage pendant les guerres de la Révolution el de l'Empire et jusqu'à une époque assez rapprochée de nous. Heux grands perfectionnements furent successivement apportis : $1^{\circ}$ Le fulminate de mercure, inventé en 17ź par bayen, fut employé en France dès 1819 par l'arquebusier DEgodBers à la fabrication des capsules pour lusil de chasse; en 1840, toute l'armée française fut armée du fusil a cupsule ou fusil à percussion. 20 En 1826, Gustave Delvigne, alors sous-lieutenant d'infanterie, inveuta une curabine rayée à balles forcées ${ }^{1}$. On en arma d'abord en 1838 le bataillon de tirailleurs de Vincennes. Elle fut perfectionnée par Ponchara, Minié, Tamisier, Nessler ${ }^{2}$.

Corpgs nouveaux ou modification des anciens. - En 1838, furent constitués les tirailleurs de Tincennes, qui, après la mort de leur fondateur, le duc d'Orléans ('842),

1. C'était un progrès sur les carabines qu'avaient gardées certaines troupes étrangéres, les chasseurs tyroliens, par exemple. Dans celles-ci, il fallait que le tireur fút muni d'un maillet pour enfoncer les balles; dans celle de Delvigne, la haguette en fer suffisait.

2. Avant Minié et Tamisier la portée de la carabine élait plus courle que celle du fusil, le tir étant seulement plus précis. Alors on avait conné a quelques tireurs de grosses carabines, d'une grande portée et d'une grande précision, mais d'un poids énorme. Láadoplion de la carabine Minié en 1842 permit de les supprimer. 
s'appelèrent chasseurs dorléans, et, depuis la chute de la dynastie, chasseurs de Vincennes ou chasseurs a pied.

En 1831 on constitua le premier bataillon de zouaves, nom emprunté aux Zouaoua, tribu kabyle d'Algérie. On le recruta, d'une part, de Turcs, Kabyles, Arabes, d'autre part, de Parisiens qui avaient combaltu aux barricades de Juillet et qu'on appelait volontaires de la Charte, en troisième lieu. d'ètrangers. Puis on versa les Parisiens dans un régiment de ligne, les étrangers dans la légion étrangère. Le corps re fut plus composé que d'indigènes algériens avec des cadres francais et un uniforme d'un caractère tout oriental. En 1841, au contraire, on n'y trouve plus que des Francais avec de rares indigènes. Ceux-ci disparurent bientôt pour aller dans les tiraillurs algériens. Les zouaves ne furent plus qu'un corps francais avee un uniforme oriental. Ils étaient destinés uniquement au service d'Algérie.

La guerre d'Alrique donne naissance à d'autres corps équipés pour combattre sous ce climat: dans la cavalerie, les chasseurs d'Afrique; dans l'infanterie, la légion etrangère; des bataillons d'infonterie légère d'Afrique, composés de soldats ayant subi cerfaines condamnations avant leur arrivée au corps: ce sont ceux auxquels on a donné le sobriquet de joyeux ou de zéphyrs; enfin des compagnies de pionnicrs ou de disciplinuires, composés de soldats ayant conmis des fautes graves contre la discipline militaire.

Parmi les indigènes, on a recruté la cavalerie des spahis au inanleau rouge, les goums, sorte de garde nationale à cheval, Ia gendarmerie indigéne; comme troupes de pied, les " tirailleurs indigènes ", qui datent de 18\&1 et qui s'appelèrent ensuite tirailleurs algériens.

\section{La marine et les colonies.}

La marine. - Les bataillons de marins, eréés par Napoléon, supprimés à la Restauration, furent reconstitués, en 1822, sous le nom d'équipages de ligne ${ }^{1}$. Depuis lors, ils sont répartis en einq divisions, correspondant aux cinq préfectures maritimes : Cherbourg, Prest, Lorient, Rochelort,

1. En 1856 , ils ont pris le nom d'équipages de la flotte. 
Toulon. Ils comprennent les gabiers brevetés, des matelotscanonnier's, des murins-fusilier's, des matelots-timoniers.

Comme forces auxiliaires de la flotte, l'infunterie de marine a élé réorganisée en 1831; l'artillerie de marine, en 1822; les disciplinures de la marine, en 182'; les ingénieurs hydrographes, en 1814.

La hiérarchie maritime comprenait alors, comme aujourd'hui : aspirant de deuxième ou première classe, enseigne de vaisseau, lieutenant de vaisseau, capitaine de frégate, capitaine de vaissean, contre-amiral, vice-amiral, amiral. Les officiers de marine se recrutent parmi les aspirants sortis de l'Ecole polytechnique ou de l'Ecole navale, parmi les premiers-maitres ayant subi un examen, parmi les auxiliaires munis d'un brevet de capitaine au long cours dans la marine marchande.

Parmi les écoles rattachées au service de la marine qui furent alors créées, citons l'École navale, fondée à Brest en 1816; l'École de l'artillcrie de marine, à Lorient, en 1844; celle de pyrotechnie, it Toulon, en 18'0; celles de maistrance, à Brest, Rochefort, Toulon, en 1819.

Les colonies. - Notre empire colonial sest reconstilué lentement. Nous devons à la Restauration la prise d'Algrer; à la Monarchie de Juillet, la conquête de l'Algérie. En outre, celle-ci a occupé les archipels de Tahiti, Marquises, Pomotou, Tubuai; le Gabon (1839), les postes de Grand. Bassam et Assinie (1843); plusieurs iles voisines de Madagascar et un territoire sur la côte nord de l'île (1840-42).

La traite des négres avait été déclarée abolie par les Américains au congrès de Philadelphie, en 1776; par la Convention nationale de France, en 1793; par le Parlement britannique, en 1803 et 1807; par Napoléon, en 1815. Pour empécher la prolongation de ce trafic, il a fallu, sous la Monarchie de Juillet, soumettre les navires de commerce à la visite des vaisseaux de guerre français et mème anglais.

Quant à l'esclavage, il se maintint dans les colonies européennes jusqu'à une époque assez rapprochée de nous : en Angleterre jusqu’à 1833, en France jusqu’à 1848 .

Ouvrages a consulter. - Voyez la bibliogr. du chapitre xxvi. 


\section{CHAPITRE XVIII}

\section{L'1NSTRUCTION PUBLIQUE}

Sous la Restanration. L'Université. - La Restauration était si hostile à l'idée mème de l'Université impériale, qu'en 1815 on avait projeté de la supprimer. Tout au moins on supprima le grand maitre de l'Université, " considérant, dit l'ordonnance royale de 1815 , que le régime d'une autorité unique et absolue élait incompatible avec nos intentions paternelles et avec l'esprit libéral de notre gouvernement ". Les académies universitaires prirent le nom d'universités : il y en avait alors dix-sept. L'autorité du grand maitre était remplacée par celle d'un conseil royal de l'Université, composé d'un président et de onze conseillers nommés par le roi. Ce conseil royal, un moment supprimé en $181 \%$, avait dù être rétabli. Le titre mème de grand maitre reparut en 1822 et, depuis cette époque, s'est ajouté à celui du ministre de linstruction publique, créé en 1820. Gràce à la conservation de son monopale, à son droit de surveillance sur les établissements privés, à l'obligation de présenter un certificat d'études universitaires pour quiconque se présentait aux examens, à la permanence d'une autorité centrale (le grand maitre ou le conseil royal), au maintien de la licérarchie des recteurs, inspecteurs généraux, inspecteurs d'aca dénie, l'Université resta sous la Restauration une corporation très puissante. Animée en général d'un esprit liberal, elle était attaquée par ceux qui révaient de restaurer la domination du clergé dans l'enseignement.

Dans la lutte engagée sur le terrain de la liberté de l'enseignement par le parti ultramantain, l'Université, harcelée 
par la presse ultra-catholique ${ }^{1}$, lut soutenue par ia ma cristrature. On crut revoir les grands combats du xvin siècle entre magistrats et jésuites, gallicans et ultramontains. A la tête de la campagne contre l'Université se plaça la Compagnie de Jésus. Celle-ci essuya une défaite quand ses sept collèges furent fermées par la fameise ordonnance de juin 1 828 . qui assura, suivant l'expression du Journal des Débats ${ }^{2}$, "la victoire de lordre légal ".

Enseignemer primaire. - L'ordonnance de 1816 établit dans chaque canton, pour surveiller l'instruction primaire, et surtout linstruction religieuse, un comite de churité. Le curé du canton et le juge de paix en étaient membres de droit. Lin catholique, pour ètre instituteur, devait d'abord obtenir du maire et du curé des communes qu'il avait habitées un certifucat de bonne conduite; il était ensuite examiné par ordre du recteur, qui délivrait, s'il y avait licu, un diplôme. Quand une école communale devenait vacunte, il fallait ètre présenté par le maire et le curé de la commune, agréé par le comité de charité et par le préfet, nommé par le recteur.

Lordonnance de 1824 enleva au recteur la nomination pour l'attribuer, dans les écoles communales, à un comité dont l'èvêque était président et dont deux membres sur cinq étaient des ecclésiastiques désignés par lui. Le recteur navait plus à nommer que les instituteurs protestants.

Cette ordonnaace ne créait d’ailleurs aucun londs pour établir des écoles là où elles faisaient défaut, assurer l'existence des maitres, permettre aux indigents de faire instruire gratuitement leurs enfants.

La Restauration, comme l'ancienne monarchie, semble ne pas considérer l'instruction primaire comme une chose

1. Lamennais, le futur démocrate, slors fougueux ultramontain, écrivait dans le Draperu blanc que la tolérance en matière religieuse élait une violation de la loi divine. Il y signait des Lettres a Mgr l'evéque d'Zermopolis, où on lisait: "Sous la protection d'un nom respecté. les enfants sont élevés dans l'athéisme pratique et dans la haine du christianisme; un compte terrible sera demande à l'Université de ces jeunes àmes que Dien appelait en sain."

2. "Le sreptre de l'Inquisition est brisé n, écrirait le mẻme jourual. En revanche, la frazette de France s'écriait: "Il ne reste plus qu"à consommer l'avènement de la République et l'éreciion des autels de la Raison.. 
d'Etrit : elle s'en remet à la bonne volonté des communes et compte avant tout sur les congrégations religieuses. Celles-ci se multiplient : à l'association des Ecoles chrétiennes, autoricie par Napoléon, viennent s'en ajouter un rrand nombre d'autres. Linstituteur congréganiste a sur l'instituteur laĩ que tous les avantages. La lettre d'obédience que lui délivre son supérieur lui tient lieu du dipióme que le laïque est obligé de conquérir par un examen. Il est protégé, soutenu, encouragé. Au contraire, le laïque est tracassé, humilié, traité en suspect par les autorités ecclésiastiques : or, il les retronve partout devant lui, s'il veut obtenir un certificat, s'il veut être présenté, puis nommé aux places vacantes, et c'est sous leur surveillance qu’il est tenu d'enseigner, surtout le catéchisme.

Le budget de la Restauration pour l'instruction primaire fut seulement de cinquante mille fruncs.

Pourtant, c'est alors que se fondent, pour le recrutement des instituteurs, les Ecoles normales primaires. De la Restauration daten: celles du Loiret, de la Moselle, du HautRhin, des Vosges, de la Côte-d'Or, de la Corse, de la SeineInférieure, les plus anciennes après celle du Bas-Rhin.

En 1826, la première salle d'asile est fondée à Paris. La Société pour l'enseignement élémentaire, qui devait tant contribuer au perfectionnement des livres et des méthodes, se constitue. La mèthode d'enseignement mutuei était alors fort en laveur.

Enfin la loi de 1818 sur l'armée accorde la dispense du service militaire aux instituteurs et professeurs qui ont contracté l'engagement de servir pendant dix ans dans l'enseignement public.

Autres ordres denseignement. - Il n'y eut pas d'autre3 changements dans les lycées que l'adoption du nom de collége royul, la substitution de la cloche au tambour pour régler les mouvements, celle du chapeau à haute forme au tricorne napoléonion, et une place plus grande donnée aux exercices religieux.

En 1816, on supprima trois facultés de sciences (Besançon, Lyon, Metz) et dix-sept facultés des lettres. De cellesci, il ne subsista que huit : Paris, Besancon, Djon, Aix, Strasbunrg, Touluuse, Angers, Ajaccio. Les autres 
furent remplacées par de simples commissions d'examen.

Les cours de Cousin et de Guizot, à la Sorbonne, furent supprimés, l'un en 1821, l'autre en 1823.

On fit disparaitre l'histoire de la philosophie et l'histoire moderne du programme des facultés.

Dans les collèges, l'histoire fut reléguée dans les classes inférieures et devint un pur exercice de mémoire; l'enseignement de la philosophie fut mutilé et réduit à celui de la logique.

L'Ecole normale, en 1822, devint suspecte et fut supprimée. Puis on la rétablit en $1 \$ 26$ sous le nom d'École préparutoire : elle n'eut pas de directeur spécial, mais fut placée sous l'autorité du proviseur du lycée Louis-le-Grand, dans les bâtiments duquel elle était installée. En 1828, on lui donna pour directeur le savant Guignaut.

L'École polyterhnique, également suspecte, fut un moment supprimée, puis rétablie, mais enlevée au ministère de la guerre pour être rattachée au ministère de l'intérieur.

En 1825, aux agrégations de lettres et de grammaire s'ajouta celle de philosophie, et cette science reprit alors quelque faveur.

De la Restauration date la création: $1^{\circ}$ de l'École des Chartes (1821), destinée à l'étude de nos antiquités nationales, et qui complétait heureusement la fondation des Archives nationales par la Convention; $2^{\circ}$ de l'École forestière, où nos futurs agents forestiers vont faire leur éducation théorique; $3^{\circ}$ l'École centrale des arts et métiers, fondée en 1829, par lavaliéE, et destinée à former des ingénieurs civils. Elle était alors et est restée une école libre.

Les classes de l'Institut reprirent l'ancien nom d'académies, qui semblait plus monarchique : on eut l'Academie francaise, l'A cadémie des inscriptions et belles-lettres, l'Académie des sciences, l'Académie des beux-arts.

Sous la Ionarchie de Juillet Enceignement primaire. - GUIZT, ministre de l'instruction publique de 1832 à 1834, ordonna une enquète dont les résultats ont élé recueillis dans le livre de P. Lorain, "Tableau de l'instruction primaire en France ". L'auteur cite un arrond ssement où quatre maires ne savent pas signer leur nom, ne 
parlent que le patois, trouvent l'instruction inutile aux enfants, estiment que ceux-ci feraient mieux d'aller curer un fossé que d'aller à l'école. A Terny (Oise), l'instituteur offre d'enseigner gratuilement : on refuse. Ailleurs le curé propose de l'argent aux parents qui laisseront les enlants fréquenter l'école : on n'en veut point. La plupart des instituteurs sont profondément ignorants; dans le canton de Belpech, où il n'y en a que quatre en tout, trois sont illettrés. Dans les Landes, en général, ils ne savent mème pas lire: ils se bornent à garder les enfants. Le métier d'instituteur était la ressource des infirmes, des misérables, des inoccupés : on en cite un qui vient du bagne. lls cumulent cette profession avec celles de laboureur, fermier, valet de charrue, sabotier, cordonnier, cabaretier, etc. Le plus sonvent, l'instituteur n'a qu'une seule pièce, où il couche, mange, soigne ses enfants, fait la cuisine, verse à boire aux clients; ou bien il enseigne dans une salle de danse. sous le porche de l'église, dans une cave, dans une grange, souvent dans une écurie, pour avoir plus chaud. L'un d'eux tient son pourceau dans la classe.

La loi de 1833. - La loi du 22 juin 1833, élaborée par Guizot, constitua vraiment en France l'instruction populaire. Sans revenir aux grandes visées et aux vastes plans de la Convention, elle donna au moins le nécessaire.

En vertu de cette loi, toute commune est tenue, soit par elle-mème, soit en se réunissant à une ou plusieurs communes du voisinage, d'entretenir au moins une école primaire. Les chefs-lieux de département et les communes de plus de 6000 àmes doivent, en outre, entretenir une école primaire supérieure. La loi indique avec précision les ressources financières à l'aide desquelles ces écoles seront créées et entretenues et les instituteurs payés. Chaque commune devra s'imposer une taxe spéciale de trois centimes par chaque franc inscrit à ses contributions directes; si cetı. ressource est insuflisante, le département vient en aide a la commune; en cas d'insuffisance des centimes communaux et départementaux, l'État intervient.

Il y a désormais un budget de l'instruction primaire: il s'élèvera en 1847 à près de 3 millions.

Auprès de chaque école, il y a un comité communal de 
surveillance; au chel-lieu de chaque arrondissement, un comité d'arrondissement.

Quant aux instituteurs, le conseil municipal, après avoir pris l'avis du comité communal, les présente; le comité d'arrondissement les nomme; le ministre les institue.

Pour ètre instituteur, il faut ètre àgé de dix-huit ans, produire un certificat de moralité délivré par le maire de sa commune et être pourvu soit du trevet élémentaire, soit du brevet supérieur. Ces diplômes continuent à être suppléés, pour les institutrices congréganistes, par la lettre d'obélience; la loi exige le brevet des instituteurs congréganistes, mais il sulfit qu'un frère, dans une école, ait le brevet, car alors les autres lrères ne sont considérés que comme des adjoints, et la lettre d'obedience leur suffit.

Les ecclésiastiques ont encore place daus les comités scolaires; mais le clergé cesse d'exercer sur les destinées des maitres une inlluence prépondérante.

La loi assure désormais à tout instituteur communal : to un locul pour son habitation et la salle de classe; $2^{\circ}$ un traitement fixe, dont le minimum est de 200 francs pour les écoles élémentaires, de 400 pour les écoles primaires supérieures; $3^{\circ}$ une rétribution mensuelle dont le taux est déterminé par la municipalité, et qui est perçue par le percepteur; $4^{\circ}$ une retraite, constituée par lne retenue de ciny pour cent sur son traitement, et servie sur les fonds d'une Caisse d'épargne et de prévoyance.

La loi n'avait pas organisé l'enseignement des filles; mais celles-ci pouvaient ètre reçues dans les écoles de garçons.

Elle n'établissait ni l'obligation, qui eût été prématurée, puisqu'il n'y avait pas encore partout des écoles, ni la gratuité, qui était limitée aux enlants indigents. Elle fut cependant un immense progrès, et M. Guizot, quelles qu'aient été d'ailleurs les erreurs de sa politique, restera, de ce chef, un des bienfaiteurs du peuple.

Progrès réalisés. - La loi Guizot donna une impulsion énorme à l'enseignement primaire. En 1833, il n'y avait en France que 42000 écoles, fréquentées par deux millions d'élèves; 7 ou 8000 communes en étaient absolument dépourvues: il y avait des cantons où l'on ue comp- 
lait qu'une école pour 15, pour 23 communes, et où la jeunesse végétait dans l'antique barbarie. En 1848, il y a 63000 écoles, fréquentées par trois millions et demi d'élèves, et le nombre des communes dépourvues d'écoles tombe au-dessous de 2000 .

Les nouveaux règlements permettent encore de mettre les élèves à genoux, mais statuent qu'ils " ne pourront jamais être frappés ".

Les Ecoles normules dinstituteurs s'étaient multipliées: déjà en 1833 on en comptait 38 nouvelles.

Les premières Écoles normales d'institutrices allaient être constituées par le ministre Villemain en 1842 : il y en avait onze à la fin du règne de Louis-Philippe.

L'ordonnance de 18.35 établit les inspecteurs dés écoles primaires, à raison d'un au moins par arrondissement.

Enseignement secondaire. - Le nombre des colléges royaux (aujourd'hui lycées) fut porté de 40 à 54 : ils étajent fréquentés, en 18ł7, par 23000 élèves.

Le monopole qu'avait assuré Napoléon à l'Université de France fut alors attaqué plus vivement que jamais. Montalembert et Lacordaire, revendiquant la liberté de l'enseignement, se faisaient poursuivre pour l'ouverture illégale d'une école, et plaidaient éloquemment leur cause devant la Chambre des Pairs. Le chanoine Desgarets, dans son pamphlet intitulé " le Nonopole universitaire ", les journaux l 1 mi de la religion et la Gazette de France, attaquaient violemment l'Université ${ }^{1}$. La bourgeoisie libérale la défendait, comme la représentation la plus complète de ses idées êt de ses goùts littéraires, et comme une des créations les plus admirées de Napoléon. Quoique la liberté de l'enseignement eût été promise dans la Charte, elle n’en voulait point entendre parler.

1. "Il y avait dans ces atlaques, dit M. Guizot (Memoires), beaucoup d'injustice et quelque ingratitude. Le gouvernement de l'Université, grand maille ou conseil royal, ministre ou président, avait toujours usé de son pouvoir avec une grande modération : à la fois rival et maitre dos établissements partieuliers d'enseignement secondaire, il les avait surveillés sans jalousie et sans riqueur, les antorisant partout où ils offraient des chances de léritine succés, et ne portant jamais, sans de puissants motifs, atteinte à leur stubilité ou à leur liberlé. C'était, au milieu du desprotisme général et d'une iscilution despotique elle-mème, une alministratiou juste et libérale. 
On prépara cependant, sous les ministères de Guizot (1836) et de Villemain (1841 et 1844), trois projets de loi pour accorder cette liberté dans l'enseignement secondaire. Aucun de ces projets n'aboutit : la haute bourgeoisie, qui a tant clıangé depuis, refusait obstinément de porter atteinte au droit de l'Université.

Enseignement supérieur. - salvandy, deux fois ministre de l'instruction publique (1837 et 1843 ), rétablit la plupart des facultés des sciences et des lettres qu'on avait supprimées et leur assura une existence distincte et un personnel séparé de celui des lycées.

A Paris, la Faculté des lettres, avec les professeurs Guizot, Cousin, Villemain, la Faculté des sciences, avec Biot, Thénard, Gay-Lussac, Geoffroy Saint-Hilaire, jetèrent un vif éclat.

L'École normale supérieure reprit son titre, après 1830 , et fut installée rue d'Ulm, avec 18 maitres de conférences. On créa une quatrième agrégation littéraire, celle d'histoire. On divisa celle de sciences en agrégation des sciences mathématiques et agrégation des sciences physiques ${ }^{1}$.

Des chaires nouvelles furent créées au Muséum, au Collège de France, où s'illustrèrent alors Michelel, Edgar Quinet, le grand poète polonais Mickiéwicz.

Salvandy fonda, en 1846, l'École française d'Athènes, pour l'étude de la laugue et des antiquités grecques.

A l'Institut, Guizot rétablit, sous le nom d'Académie des sciences morales et politiques, la classe que Bonaparte avait supprimée en 1803. Il y lit rentrer les douze survivants de l'époque révolutionnaire, parmi lesqueis Sieyès, Merlin de Douai, Daunou, Garat, Lakanal.

Sur l'initiative du duc de la rochefodcadld-liancodrt, des Écoles d'arts et métiers furent constituées, par l'ordonnance de 1832, à Angers et à Chàlons-sur-Marne (calle d'Aix est plus récente). Elles sont destinées à lormer des chelis ulateliers : elles ont donné aussi des candidats pour les écoles Polyiechnique et Centrale et fourni de bons oliciers à l'artillerie.

Ouvrages a consulter. - Voyez la bibliogr. du chap. xxvit.

1. Total, six agrégations : lellres, grammaire, philosophie, histoire, sciences mathématiques, sciences physiques. 


\title{
CHAPITLE XIX
}

\author{
LES LETTRES
}

\section{Caractères généraux.}

Le siècle de victor Hugo. - Si le xvule siècle peut s'appeler le siécle de Voltaire, le xıx s'intitulerait non sans raison le siècle de Victor Hugo. Le grand poèle est né presque avec lui, en 1802 : à dix-sept ans, il publiait ses premières odes; à quatre-vingt-trois ans, l'année de sa mort (1885), il mettait la main à ses dernières ceuvres. Il a vu les jours suprêmes du grand Empire, vécu sous les deux monarchies, parlé à la tribune de la seconde République, souffert dix-huit ans d'exil sous le second Empire, et, sous la troisième République, après avoir siégé à l'Assemblée nationale et au Sénat, il a eu des funérailles triomphales qu'a suivies un peuple entier. Il a traversé toules nos révolutions politiques et toutes nos révolutions littéraires : il a eu sa part dans toutes, et de toutes son génie porte la trace. Il s'est exercé dans tous les genres, théàtre, épopée, poćsie lyrique, roman, pamphlet, histoire, éloquence politique, et dans tous il a été supérieur. Personne n'a suscité des haines aussi ardentes et des admirations aussi passionnées. Il a vécu assez pour voir le goût public se transformer sous son action et accepter les audaces qui avaient provoqué les plus violentes tempètes. Disciples ou adversaires, il n'est guère un écrivain de ce siècle qui n’ait plus ou moins subi son influence. Il a été, pendant trois générations humaines, le producteur toujours fécond et dont l'œuvre nouvelle formait l'entretien du jour. I] 
a remué tant d'idées et dimagges pendant trois quarts de siecle, que nous ne pouvons avoir une idée poètique sans quelle se formule aussitôt dans quelqu'un de ses vers. Il est à tel point la persomnification de la poésie française, yue Thédore de Banville a cru pouvoir justifier par des exemples tirés de lui toutes les règles de la poétique nouvelle et qu'il l'apjelle simplement le poète ${ }^{1}$.

La langue. - Pour une littérature nouvelle s'est formée une langue nouvelle. Elle n'a plus la raideur ou la pruderie de celle des derniers classiques; elle a renoncé à l'horreur du mot propre, au préjugé des vocables nobles ou non nobles, aux subtilités des grammairiens, qui avaient appauvri notre idiome; elle s'est enrichie sans scrupule de mots empruntés au vieux français, aux parlers populaires, à la technique même des arts et des métiers; elle est lihre, vivante, colorée, variée comme la vie même. Chaque lettré s'est iıgénié à la sculpter, à la ciseler, à l'assouplir, à la briser, pour lui faire exprimer tous les aspects de la réalité, toutes les nuances du sentiment et mème de la sensation. Cette langue nouvelle a pu être harmoniense et musicale dans les poésies de Lamartine, pittoresque et brillante dans celles de Victor Hugo, incisive et mordante dans les pamphlets de Courier, vive et alerte dans les récits d'Alexandre Dumas, tendre et passionnée dans les romans de George Sand, chaude de couleur, étincelante comme les mille facettes d'un diamant, dans les Ninvelles de Théophile Gautier ou de Prosper Mérimée, pleine de trouvailles ingénieuses, d'effets saisissants, mais parfois gàtée par une recherche excessive, dans certaines cuvres contemporaines. Victor Hugo est l'un des premiers qui aient eu l'honneur de la mettre en ceuvre ${ }^{2}$.

1. Exposer le role de Victor Hugo, ce serait presque faire l'histoire d'un siécle de littérature, et il m'en coute de disperser en plusieurs chapitres cette ruve immense.

2. Ce qu'a été cette révolution dans la langue frangaise, c'est Victor Hugo lui-mene qui nous le dira :

Les mots, bien ou mal nés, vivaient parqués en castes;

Les uns, nobles, hantant les Phèdres, les Jocastes,

Les Héropes, ayant le décoram pour loi,

Et montant à Versailles aux carrosses du roi : 
La versification. - Les deux siècles classiques avaient étrangement réduit nos ressourees poétiques. Ils s'étaient privés de cette variẻté de vers, de rythmes, de strophes, dont Ronsard et mème les anciens trouvères faisaient si bon usage. Victor Hugo risqua des vers de toute mesure ${ }^{1}$, des strophes de toutes formes. Il rompit les entraves dont les législateurs du Parnasse avaient, sans raison sérieuse, garrotté le poète. Le vers sur le vers osa enjamber; sa césure se déplaça au gré du rythme; il eut des rejets comme celui des poètes latins; il se fit souple, ondoyant, avec une mobilité infinie d'artieulations. Le pivot du vers, ce fut la rime que Victor Hugo voulut très riche, très pleine, très sonore, inattendue, imprévue ${ }^{2}$.

Les autres, tas de gueux, drôles patibulaires, Habilant les patois, quelques-uns aux galères Daus l'argot; dévoués à tous les genres bas, Déchirès en haillons dans les halles; sans bas, Sans perruque; créés pour la prose el la farce : Populace du style au fond de l'ombre éparse...

Alors, brigand, je vins, je m'écriai : Pourquoi Cetux-ci loujours devant, ceus-là toujours derrière?

Et sur l'Académie, aïeule et douniriene, Cachant sous ses jupons les tropes elfarés, Et sur les balaillons dalexandrins carrès, Je tis souffler un vent révolutionnaire. $\mathrm{J}$ e mis un bonnet rouge au vieux dictionnaire. Plus de mot sénateur! plus de mot roturier l Je fis une tempète au fond de l'encrier...

1. Voyez par exemple la pièce des Djinns.

2. D'autres allèrent plus loin dans celte voie, se montrèrent à la fois plus sévères et plus independants. Banville proserit ces inversions maladroites, paures expedieuts qu'on appelail autrefois des licences roéliques, comme s'il était permis d'écrıre plus nẻgligemment dans la langue des dieux qu'en vile prose. II voudrait que le rythme et l'harmonie fussent la régle suprème du vers, et que celui-ci ne fút pas seulement de la prose dont on a compté les syllabes, mais une musique, comme elle le fut cliez les anciens. "Il pouvait, dit Banville ea parlant de Viclor Ilugo, il pourait, lui, de sa puissante main, briser tous les liens dans lesquels le vers est enferme et nous le rendre absolument libre, machant seulement de sa bouche écumante le frein d'or de la rime..... J'aurais voulu que le poc̀te, dèlivré de toules les conventions empiriques, n'eủl d'autre maitre que son oreille Jélicate, subtilistie par les plu wouces caresses de la musique..... Ce que n'a pas fail le géant, nu! ne le fera! " 


\section{Le théâtre.}

La révolution du théatre. - Les premiers vers de l'école romantique suscitèrent des colères très vives parmi les classiques ${ }^{1}$. Pourtant, tant qu'elle ne produisit que des odes et des ballades, la lutte, si acharnée qu'elle fût, resta circonscrite dans les salons et dans les feuilletons littéraires. Il n'en fut pas de même quand les novateurs osìrent aborder la scène dramatique. Voltaire, ses disciples, ses procédés, son école, y trônaient encore. En 1819, si le "Saint Louis " de Népomucène Lemercier était tombé sous une cabale, on avait applaudi des tragédies coulées dans le même moule : le "Louis IX " d'ancelot ou "les Vêpres siciliennes " de casimir delavigne. La "Marie Stuart " de PIERRE LEBRON (1820), qui,bien que le sujet eủt été emprunté à Schiller, était conçue et versifiée dans la manière classique ${ }^{2}$, peut être considérée comme formant une transition entre les deux écoles. Classiques encore étaient " le Paria " de Casimir Delavigne, "les Macchabées " de Guiraud, la "Clytemnestre " et le "Saül " de Soumet (1822). La tragédie se soutenait surtout grâce au génie de l'acteur Talma : or, il mourut en 1826.

La Préface de Cromwell. - L'année suivante (182i), Victor Hugo écrivit son drame de Cromwell. Lui-même reconnaissait qu'il était trop long et trop touffu pour être joué, mais que, si les circonstances devenaient plus favorables, "on pourrait extraire de ce drame une pièce qui se hasarderait alors sur la scène ". Aussi, libre ale toute préoc-

1. Nèpomucène Lemercier écrivait alors :

$$
\text { Avec impunité les Hugo font des vers. }
$$

2. Dans Harie Stuart, l'auteur faisait dire à la reine d'Écosse :

Prends ce don, ce mouchoir, ce gage de teadresse,

Que pour toi de ses mains a brode ta maitresse.

Mouchoir et brode semblèrent trop fort au comité de lecture de la Comédie-Française, et l'auteur dut se résoudre à remplacer ces ver par les deux suivants :

Prends ce don, ce tissu, ce gage de tendresse

Qu'a pour toi de ses mains embelli ta maitresse.

Mouchoir nobtint droit de cité au théatre quaprés la représentition do 1'Othello de Shakespeare, traduit par Alfred de Vigny, en 1829. 
cupation du còté de ces deux ennemies mortelles de l'art nouveau, la censure théâtrale et la critique théatrale, l'auteur avait charpenté son drame à sa fantaisie. Il avait montré dans Cromwell le mélange de l'ambitieux de génie et du sectaire étroit; jeté à travers laction les fous du Protecteur se gaussant de leur maitre, son épouse bourgeoise lui faisant des scènes domestiques, les cavaliers ardents aux plaisirs et mêlant aux complots les madrigaux, les puritains avec leurs têtes rases et leurs noms bizarrement entortillés de versets de la Bible, Rochester déguisé en ministre indépendant et forcé d'épouser une duègne, le juif Manassès, usurier et prophète, le tapissier Barebone, républicain farouche et boutiquier sans scrupule, vendant très cher à Cromwell le tròne sur les marches duquel il veut lui percer le cœur, a la fin dénonçant le complot pour que ses belles étoffes ne soient pas gàtées par le sang du tyran. Ce drame est une cuvre tour a tour bouffonne et lyrique, grouillante d'une multitude de personnages, en contraste avec la sobriété de mise en scène des tragédies. pleine de vie et de mouvement, et qu'on ne peut s'empecher de trouver surprenante, surtout quand on songe que l'auteur n'avait pas alors vingt-cinq ans.

Ce qui était plus grave que ce drame, c’était la prélace du drame. Victor Hugo y exposait toute une poétique nouvelle. Aux œuvres pseudo-classiques, il opposait les œuvres vraiment classiques des grands tragiques grecs. Il se réclamait de la Bible, de l'Iliade et de l'Odyssée, d'Eschyle et de Sophocle, de Dante et de Shakespeare. Il revendiquait les droits de la réalité contre la tyrannie des genres littéraires, montrait le comique et le grotesque intervenant, comme dans la vie mème, dans les chefs-d'cuvre les plus siblimes du passé. Il demandait compte au faux Aristote, à Chapelain, à Scudéry, à Boileau, de la contrainte arbitraire qu’ils avaient imposée aux génies, des " plumes d'aigle retranchées à Corneille et à Racine " pour nous donner en échange Campistron. Il affirmait que de la prétendue règle des trois unités il ne devait subsister que la règle primordiale de l'unité de l'action; qu'en " croisant l'unité de temps à l'unité de lieu, comme les barreaux d'une cage ", on avail mutilé les lommes et les choses, fait grimacer 
l'histoire, tué la vérité et la vie : si bien que ie plus souvent " la cage des unités ne renferme qu'un squelette".

Zuataille dHernani. - La Préface de Cromwell, c'était le manifeste de la nouvelle école : son entrée en campagne, ce fut la représentation d'Hernani, ou plutôt ce qu'on a appelé la Batuille d'Hernani. Cette bataille, livrée à l'absolutisme classique, précéda de six mois la bataille de juillet 1830 , livrée à l'absolutisme royal. Elle eut pour théâtre la Comédie-Française. Elle mit en présence deux armées littéraires, deux sociétés, aussi différentes que celles que nirent aux prises les révolutions de 1789 et de 1830. Aux conservateurs, corrects, bien gantés, bien pensants, qui se retranchaient, armés de sifflets, dans les fauteuils de balcon et dans les premières loges, elle opposa un parterre de jeunes gens aux costumes étonnants, aux crinières mérovingiennes, aux têtes échevelées comme leurs idées, parmi lesquels s'étalait, comme le drapeau rouge d'une guerre sociale, le gilet écarlate de Théofhile Gautier. Les bourgeois aux mentons glabres virent avec elfroi ces tribus étranges, ces hordes de barbares, ces Ihuns du nouvel Attila, campés dans la maison de Racine. Dans les cafés du quartier latin, dans les ateliers d'artistes, on demandait trois cents Spartiates décidés à mourir pour fermer aux Philistins les Thermopyles de l'art. On y parlait couramment d'exterminer l'hydre du perruquisme; on menacait de couper les tètes pour avoir les perruques; on criait : " A la guillotine les genoux! "Les conservateurs n'étaient pas moins enragés : Armand Carrel, libéral en politique, conservateur en littérature, comparait les héros d'Hernani à des échappés de Charenton. Duvergier de Hauranne, également libéral en politique, prononẹait en ces termes la sentence de la nouvelle école: "Le romantisme n'est pas un ridicule; c'est une maladic, comme le somnambulisme ou l'épilepsie; un romantique est un homme dont l'esprit commence à s'aliéner. "Baour-Lormian déclarait synouymes ces deux mots : fripon et romantique. Sept acadéniciens, parmi lesquels Arnault, Jouy et Étienne, présentaient au roi une requête tendant à interdire la Comédie-Française a toute pièce infectée de romantisme ${ }^{1}$.

1. C'etait a propos de Henri III et sa caur, d'Alexandre Dumas. Le roin 
La fureur guerrière gagna la province : a Toulouse, un jeune hcmme fut tué en duel. Quelqu'un disait a victor Hugo : "Il y a en France deux hommes bien détestés, M. de Polignac et vous ". Son propriétaire lui signifiait son congé. Des lettres anonymes le menaçaient de mort. A la Comédie-Française, c'ètaient des scènes teribles. Sur les mêmes morceaux, sur les mêmes vers, à propos d'une césure déplacée, d'un rejet ", d'une tirade, d'une épithète, les sifflets et les applaudissements se croisaient, étouffant la voix des acteurs. On sifflait, on applandissait, sans entendre ${ }^{2}$. Il y eut cuarante-cinq représentations, quarantecinq combats. Chaque soir, Mme Victor Hugo, qui n'osait sortir de chez elle, demandait : "Est-on allé jusqu'au bout? "Pas une scène, pas un vers n'éclıappa aux silitlets.

Quelques années se passèrent. Quand on reprit " Hernani ", les siffleurs des prenières représentations s'étonncrent d'avoir tant à applaudir. Cette vive entrée en action, ces sentiments si chevaleresques exprimés dans une langue si colorée, le magnifique monologue de Chitrles-quint, le duo si poétique d'Hernani et dona Sol, la lantastique invention de cet appel du cor qui vient jeter la note tunèbre dans l'ivresse des deux amants, tout cela, comme des choses toutes nouvelles pour eux, les surprit ef les ravit. "Ce n'est pas étonnant, disaient-ils pour s'excuser: il a changé tous les vers. " Ce n'était pas les vers qui étaient changés : c’était le goût public.

Le théatre de victor Hugo. - Le poète donna successivement "Marion Delorme " (1831); " le Roi s'amuse ", qui, ayant été interdit par la censure de Challes $X$, ne fut représenté qu'en 1832; "Lucrèce Borgia ", "Marie Tudor " (1833), "Angelo, tyran de Padoue " (1833), " Ruy lilas "

mieux inspiré el plus libéral en lillérature qu'en politique, avail répondu : "Que voulez-vous? je n'ai comme vous qu'une place au parterre."

1. Voici un rejet qui fit fureur dans les deus seus :

Serait-ce déjá lui? C'est bien à l'escalier Dérobé.....

2. Cilons une anecdote bien caractéristique. A un certain momenl, Hernani dit à Ruy Gomez : "Vieillard stupide! " Deux spectaleurs, au partirre, entendirent et comprirent: "Vieil as de pique! " Le prenier se levat en fureur en criant : "C'est abominable! n - « C'est sublime, monsieur! , cria lo second, en se levant aussi. 
(1838). La pièce des "Burgraves " (1843), où les personnages sont des géants, où les vieilles légendes de l'Allemagne sont revêtues d'une poésie que l'Allemagne ellemème n'avait pas inventée, où se dressent les figures colossales de l'empereur Barberousse et du burgrave plus que centenaire, n'était pas faite pour la scène ${ }^{1}$.

Le théatre de Victor Hugo a une puissance dramatique incomparable. La donnée en est siuvent d'une fantaisie étrange : comment admettre qu'une reine d'Angleterre aime un bijoutier et une reine d'Eswagne un laquais, que Charles-Quint soit caché dans une armoire à la merci d'une duègne, que le fou Triboulec rit à sa discrétion la vie d'un roi de France et les destinées de l'Europe? Ces caractères et ces situations exceptionnels, Victor IJugo les fait presque accepter par le charme d'une langue colorée, pleine de prestiges et de séductions.

Il prouva qu'avec un le ces personnages obscurs, quauraient dédaignés Voltaire et son école, on peut créer des siluations aussi trayiques que s'il s'agissait de demi-dieux ou de rois, ces favoris de la tragédie. Les derniers classiques concevaient trop souvent leurs personnages tout d'une pièce, absolument bons ou absolument mauvais, étant absolument le héros ou le traitre. Viâtor Hugo sait que l'homme réel, cet ètre double, cet ètre multiple, ne cesse de se donner à lui-même d'éclatants démentis. Au fond des pires natures peut descendre le rayon divin : au fond de Lucrèce Borgia, perdue de crimes et de luxure, l'amour maternel; de Triboulet, un monstre au physique et an moral, l'amour paternel; de Marie Tulor, la reine singlante, et de Marion Delorme, la courtisane perverse, l'amour chaste, doux et humble, fait de pureté et de dévouement.

Influence du théatre etrangen. - Shakespeare, après les audaces de Viclor Hugro, n’avait plus besoin d’ètre

1. Plus récemment on a hré d'un roman de Victor Hugo le drame do Notre-Dame-de-Paris, et l'on a extrait de ses papiers celui de Torquemada. Rappelons que le thètre de Victor Hugo a inspiré à Verdi Rigoletto (tire du drame le tioi s amuse) et Emuni, a Donizeuti sa Lucrezia Borgia: de mème que ses udes ont inspiré d'admirables mélodies à Weckerlein, Saint-Saëns, Gonnod, Massenet, Bizet. 
mutilé pour paraître sur notre scène. On linissait par comprendre chez nous et gouter son charme sauvage. On sait que Villemain et Lamartine ont publié des étıdes sur Shakespeare, et qu'un de nos plus grands poètes, Victor Hugo, après un de nos plus grands historiens, Guizot, a patronné une traduction de ses œuvres. ALFRED DE VIGNY, dans son "More de Venise ", nous donnait alors un "Othello" tout shakespearien (1829). ALEXANDRE Dumas traduisait et faisait représenter "Hamlet " (18.48). D'autres révéleront au grand public "Macbeth ", " le roi Lear ", "Roméo et Juliette ", "le Songe d'une nuit d'été " ".

Au thèàtre espagnol, Pierre Lebrun empruntait le sujet du "Cid d'Andalousie ", et Alexandre Dumas de "Don Juan de Marana " (1836). De Barante avait traduit Schiller. Rappelons que dès les lébuts de la révolution romantique avait été publiće la "Collection des chefs-d'œuvre des théâtres étrangers ", qui, en même temps que Shakespeare, Schiller et Goethe, nous rendit familiers Calderon et Lope de Vega.

Les dernières tragédies. - La vieille tragéılie classique n'a pas survécu aux coups terribles qu'on venait de frapper sur elle. De " la Bataille d'Hernani " elle est sortie mourante. On a revu encore des tragedies à la scène : car une partie du public persistait dans ses goùts, et les excès mèmes des romantiques ne pouvaient qu'amener une réaction; mais ce n'étaient plus vraiment des tragédies classiøues. Mème dans les pièces qui s`intitulaient tragélies, comme une "Fète de Néron " de soomet (1829), comme la "Lucrèce " (1843) de PONSARD, comme "la Fille d'Eschyle " (1848) de Joseph adtran, linfluence de la révolution, de l'émancipation romantique, est visible.

Acteurs et actrices célèbres. - Si Talma n'était plus, il s'était formé une génération nouvelle : Hígnier, Samson, Beauvallet, dont la voix faisait trembler la salle quand il poussait le cri du vieil Horace : Qu'il mourut "! Mlle Rachel, dont nos pères ne parlent encore qu'avec enthousiasme, Mlle Georges, Mlle Mars, quoique de l'ancienne école, avaient fini par comprendre l'alexandrin romanlique. Bocage et

1. Les compositeurs s'emparèrent de ces magnifiques sujels: MM. Ambroise Thomas et Gounod nous ont donné les opéras de Hamlet et de Roméo et Julie:te. 
Mme Dorval contribuèrent brillamment au succès des nouveaux drames.

Le drame historique. - Dès 1829, c’est-à-dire entre la Pléface de Cromwell et la Bataille d'Hernani, alexandre Dumas avait donné le drame de "Henri III et sa cour ", et casimir delavigne le drame de "Marino Faliero ". Dès lors, les pièces de ces deux auteurs alternent avec celles de Victor Hugo. Le premier donne successivement "Stockholm, Fontainebleau et Rome ", c'est-à-dire le drame de Christine de Suède et de Monaldeschi (1830); "Antony ", dont le héros est un beau ténébreux (1831); "Charles VII chez ses grands vassaux ", où le rôle principal, chose inattendue, appartient à un Arabe; la "Tour de Nesle" (1832), restée le plus populaire de nos drames historiques, et vingt autres pièces, toutes de franche facture, au dialogue bien coupé et de vive allure, comme les romans dont ils sont tirés pour la plupart ${ }^{1}$.

Casimir delavigne, dans une donnée un peu plus rapprochée de la tragédie, renonçant à la gène des unités, mais se gardant de la couleur un pen violente des romantiques. fait représenter "Louis XI " (1832), " les Enfauts d'Édouard " (1833), "IJon Juan d'Autriche " (1835), " une Famille au temps de Luther ", "la Fille du Cid " (1839), "Charles VI ". ALFRED DE VIGNY nous donne "la Maréchale d'Ancre " (1831) et "Chatterton " (1835). Scribe et LEgodvé racontent les amours tragiques d'Adrienne Lecouvreur (18'9).

Le drame bourgeois. - Le drame tu boulevard ${ }^{2}$, le drame bourgeois, le mélodrame, ainsi appelé parce qu'il admet quelques mélodies à l’orchestre, ne fîl-ce que le tremolo des violons dans les situations les plus émouvantes, sinspire surtout des événements de la vie commune. Ses jersonnages, bons ou mauvais, héros ou traitres, sont des gens du peuple. C'est ce lrame surtout qui, interprété par le grand acteur populaire Fréléric Lemailre, mouilla les yeux et les mouchoirs des spectateurs sensibles. Le type le plus connu de ces sortes de pièces, c'est le mélodrame de DJCANGe: "Trente ans ou la Vie d'un joueur" (1827).

1. Pour la plupart aussi, avec la collaboration d'suruste Maquet.

2. Ce drame est si noir de meurtres que le boulevard oủ s'éleve le théátre de la Popte-Sant-Martiu ca a pris le uom de "boulevard du Crimen. 
L'auteur le plus fécond en ce genre, c'est DENnERY, qui a enfanté plus de deux cents pièces, dont les plus cèlèbres sont " la Gràce de Dieu " (18'1), "les Bohémiens de Paris " (1843), le "Marché de Londres" (1845). On doit mentionneı aussi " la Closerie des Genêts " de frébéric soullé (1846); " le Juif errant " d'edgène sue (1849); "Gaspardo le Pécheur " (1837) et "Lazare le Pàtre " (1840), de Boochardy; "la Vénitienne " (183ł), "Latude " (1834), " Héloïse et Abélard " (1836), " la Mendiante " (1843), d'anicet-BodrGEoIs, auteur de près de deux cents pièces de théàtre; "Jeanne de Naples " (1837) et " la Justice de Dieu " (1843), de pad fodcher; - les "Deux Serruriers" (1841) et "le Chiffonnier "( 1847 ), du célèbre démagogue réLIX PYAT.

La comédie historique. - Il est une variété de la comédie qui se conlondrait aisément avec le drame historique : elle n'en diflère que par la nature du dénouement, mais les mêmes grands intérèts, sous les noms historiques les plus retentissants, $y$ sont agités. Parmi les chefs-d'œuvre du genre, il faut citer " Mademoiselle de Belle-Isle " d'alexandre domas (1839); " le Verre d'eau " de SCRIBE (1842), où les personnages s'appellent la reine Anne, lady Marlborough, Bolingbroke, l'ambassadeur de France, et où il s'agit de savoir si l'Angleterre se retirera de la coalition sous laquelle succombe notre pays.

La comédie-proverbe. - ALFRED DE mUSSET s'est fait, une place à part avec ses comédies-provertes (de 1840 à 18.30), qui ont peu d'action, mais un dialogue vif et étincelant, et dont la grâce mièvre et délicate rappelle Marivaux. On joue et on juuera longtemps encore "les Caprices de Marianne ", a On ne badine pas avec l'amour ", "Il ne faut jurer de rien ", "Il laut qu'une porte soit ouverte ou fermée ", etc.

Le vaudeville. - Les générations contemporaines de la monarchie parlementaire ont été aussi éprises que leurs devancières du vaudeville, de ses intrigues parfois enfantines autant que compliquees, et de ses joyeux couplets. Sur le vaudeville, un genre consacré depuis longtemps et étranger à leur débat, classiques et romantiques étaient d'accord : ils se réconciliaient dans un goutt commun pour ce genre que Boileau assure avoir été créé par a le Français né 
maliu viennet, un classique convaincu, a encouragé les débuts de Dovert. Celui-ci eut surtout pour collaborateur ladzanne. Nous leur devons "les Cabinets particuliers" "1831), "l'Omelette fantastique ", "le Supplice de Tantale, "En revenant de Pondichéry ", "Ce que femme veut " (1847). Mais quels noms, parmi près d'une centaine, quelles pièces surtout, parmi plus d'un millier, pourrions-nous signaler? Il est d'autant plus difficile de s'y reconnaitre qu'un vaudeville est rarement l'œuvre d'un seul écrivain : il y a presque toujours plusieurs collaborateurs, l'un apportant l'idée, l'autre les bons mots, un troisième les couplets, chacun payant son écot d'esprit et de bonne humeur à ia tache commune. Il suffit de rappeler que BAYARD, dans ce genre, a collaboré à près de 200 pièces, Brazien et Xavier-SAINTINe à un nombre à peu près égal, Do mersan a 300 , MÉLESVILLE à 350 ; etc.

C'est Do mersan et varin qui ont représenté, en 1838, la comédie-parade des "Saltimbanques ", dont tant de mots, comme sauvons lit caisse! celte malle doit être à nous! sont restés proverbiaux. Elle a immortalisé le type populaire de Bilboquet. antien, dans "lAuberge des Adrets " (1824) et dans "Robert Macaire" (1836), a créé deux autres types non moins célèbres, illustrés à celte époque par la caricature : c'est Robert Macaire et son fidèle acolyte Bertrand.

\section{Les autres genres littéraires.}

La poésie lyrique et épique. - Le poète $d u$ xixe siècle s'est hardiment laucé dans des régions que ses devanciers n'osaient mème pas explorer. Des influences jusqu'alors inconnues sont venues vivifier son génie. La poésie d'autrefois était plutôt impersonnelle : le poète moderne a pris comme son sujet le plus fécond son propre moi, ses douleurs et ses joies d'amour, ses doutes religieux, ses angoisses philosophiques, ses élans vers quelque chose qui est au deli de ce qu'on voit avec les yeux du corps, ses aspirations tourmentées vers l'idéal et vers l'infini, le cruel contraste entre l’immensité des désirs de son cœur et de son esprit et la brutale contrainte qu'impose le réel. Voilà ce qui remplit les "Méditations " et les "Harmonies " de 
Lamartine; les "Feuilles d'automne", les "Chants du Cré. puscule ", les " Rayons et les Ombres ", les "Contemplations ", les "Chansons des rues el des bois ", de victor \#0GO; "Rolla " et les " Nuits " d'alFred de MUSSET.

Puis le poète a eu la nature, non plus une nature composée d'arbres et de rochers comme celle qu'analysaient les descriptifs, une nature inerte et pour ainsi dire passive, mais une nature vivante, qu'il a comme animée de ses propres sentiments et de ses propres passions, qui, dans l'ceil rêveur de la bête, dans le frémissement de la plante, dans le bouleversement des océans, dans le scintillement des étoiles, semble n'avoir qu'une seule àme partoul présente. C'est ce qu'on appelle la conception pintheiste de la nature. Celle-ci, pour le poète, se confond avec Dieu, ou plutôt n'est autre que Dieu lui-même, dont la personnalité immense embrasse et absorbe tous les êtres, à commencer par nous-mémes, et de sa vie nous fait vivre. Cette inspiration panthéiste, nous la retrouvons, à commencer par "le Lac ", dans maintes pièces de Lamartine, qui est pourtant le plus chrétien de nos trois grands lyruques. Nous la retrouvons surtout dans la plupart des cuvres de Victor Hugo, par exemple, dans son "Pan " de " la Légende des Siècles ".

En troisième lieu, le poète dégage des grands èvénements de l'humanité la poésie qu'ila recèlent. Les scènes glorieuses on tragiques de la Révolution, les prodigieuses batailles et la suprème catastrophe de l'Empire, Austerlitz, Moscou, Waterloo, avaient à peine lait vibrer les lyres contemporaines de la Révolution et de l'Empire. lls enflammèrent la génération (fui suivit. Que de fois Napoléon, en qui se personnifie et s'absorbe alors toute l'épopée révolutionnaire et impériale, Napoléon à cheval au milieu des débris de sa garde ou debout sur le rocher de SainteHélène, viendra hanter les strophes de Victor Hugo, de Lamartine, de Béranger!

Puis, sous la monarchie parlementaire, quand les misères du prolétariat commencèrent à émouvoir les àmes généreuses, d'autres voix montèrent au cœur de l'artiste: la grande plainte des pauvres, des malheureux, des déshérités, le gémissement ou le cri de colère qui s'élève de la 
manufacture, du puits de mine, de la grève battue par les flots et veuve de ses marins. Et le poète prêtera sa lyre aux " revendications sociales ".

En un mot, rien d'humain ne lui est étranger : le domaine de la poésie s’est étendu à l'infini : aux profondeurs du ciel comme à celles du cœur humain, aux gloires de la patrie comme aux souffrances de l'humanité tout entière.

Un trait caractéristique de la poésie au xıx ${ }^{\mathrm{e}}$ siècle, plus accentué à mesure qu'on se rapproche de l'époque contemporaine, c'est que la distinction entre le lyrique et l'épique, si profonde dans les théories de Boileau, tend à s'effacer. Le poète est hanté par les souvenirs du passé en mème temps que soulevé par les passions du moment : tour à tour, presque en même temps, il évoque les uns, il s'abandonne aux autres. Qui pourrait faire exactement le depart des deux genres dans les chefs-d'curre de Victor Hugo? Il n'y a jlus désormais une poésie lyrique et une poésie épique : il y a la poésie. Elle s'attaque à tous les sujets et met en œuvre tous les rythmes. Elle emprunte aussi volontiers l'alexandrin que la strophe : Alfred de Musset. dans son "Espoir en Dieu ", raisonne en alexandrins sur les systèmes philosophiques ou religieux, puis s'élance, avec le vers lyrique, en une ardente supplication.

La poésie française ne se résume pas uniquement dans ces grands noms de victor hogo, LAMartine, mosset. Le $x^{r v 1}{ }^{e}$ siecle mème ne compte ni tant de poc̀tes, ni si divers. l'resqu'au premier rang encore ALFRED DE vignY, dont les c Poèmes antiques et modernes s (1826) et a les Destinées D (posthumes) sont, dans leur pessimisme sombre, la première expression d'une poésie philosophique. Puis Casimin Delavigne, avec ses a Messéniennes »(1817), la poésie la plus classique de l'âge romantique, où respirent toutes les douleurs de la Patrie; AUgdSTE BARBIER, avec la vigueur satirique de ses a Iambes \(1830), qui maudissent a le Corse aux cheveux plats o ou exaltent cette Liberté qu'il faut embrasser avec des bras rouges de sang $\triangleright$; BARTHÉLEMY et MÉRy, avec leur épopée, parfois chaude et colorie, de " Napoléon en Égypte " (1828); Mme Desbordes-valmore, avec ses ldylles, ses Elégies, ses Pomances; adguste Maduet, qui, revenant à l'inspiration de 1792 , a composé, à la veille 
de la Révolution de 18:8, le "Chant des Girondins "; BRIZEUX, qui a retrouvé le charme de l'idylle antique dans son poème de " Marie ๖ (1826) et ses scènes champètres des a Bretons \$ (1843); VICTOR DE LAPRADE, enthousiaste de la nature dans ses "Odes et Poèmes o (1843), et satirique véhément dont s'inquiéta la police du second Empire; SAINTE-BEOVE, d'une versitieation si savante et si ralfinée dans "Poésies s, a Consolations s, "Pensées d'août , (1829-1830); Henri murger, le type du bohême dans le second quart de siècle, auteur des a Ballades et Fantaisies s et des « Nuits l'hiver" (1861); ThËophILE Gautier, qu $i$ a curieusement eiselé ses a Poésies ๖ (18103).

La chanson. - Le grand poète populaire, béranger, n'a pas seulement chanté, comme ses devanciers, Lisette ou la dive bouteille. Il s'est élevé parfois à la grande poésie. Il a su dire, en traits touchants on énergiques, les gloires de la République et de l'Empire, peindre le vétéran des grandes guerres au berceau de ses petits-enfants, secouer la poussière du drapeau aux trois couleurs, faire revivre, dans les souvenirs du peuple, l'Empereur " qu'un pape a couronné ". La chanson politique, exprimant les passions du peuple de France, quadruplant l'ntensité de ses effets par le retour du refrain, volant en strophes aériennes parmi les ateliers et les tonnelles, a été en ses mains une arme meurtriere contre la Restauration.

Le roman. - Des romanciers de la génération révolutionnaire et impiriale, deux surtout ont conservé un rang dans la génération suivante : CHateadBriand publie, en 1826 , "le Dernier des Abencérages ", et, en 1828, "les Natchez s'; CHARLES NoDier poursuit la série de ses Nouvelles de 1818 à 18:36, "Sbogar מ, “ Smarra ", “ les Contes d.

victor BUG0 avait déja commencé cette suite de romans, qui devait s’étendre jusqu’à nous. En 1823, à vingt el un ans, il publia l'histoire fantastique de a Han d'Islande ; puis a Bug-Jargal $\triangleright$, récit de l'insurrection des nègres; "les Lerniers Jours d'un condamné », son premier

1. Morten 154s, il devait occuper encore la génération qui suivit avec ses Mémoires d'outre-tombe, publiés de 1849 a 1850 , rú sa personnalité impérieuse prend une place plus grande que jamais, mais où jamais aussi la langue n'a été plus belle et plus vigoureuse et le récit plus attachtat. 
plaidoyer contre la peine de mort; "Notre-Dame-de-Paris " (1831), qui cría chez nous ce que Walter Scott créait alors en Angleterre: le roman du moyen âge; enfin "Claude Gueux " (1834). Ce sont ses œuvres de la première manière, de la manière romantique.

LaMARTine nous a donné des espèces de romans poétiques : "Jocelyn " (1836), "Raphaël, pages de la vingtiènse année " (1849), "Graziella " (1852). ALFREd DE MUSSET s’épanche dans " les Confessions d'un enfaut du siècle". qui est à la fois un roman et une autobingraphie, s'égaye dans deux volumes de jolies nouvelles, telles que "la Mouche ", "Mimi Pinson ", "le Merle blanc ". ALrRed oE vigny publie "Cinq-Ilars" (1826), roman historique. "Stello ", "Grandeur et servitude militaire " (1835). zDGAR QUINET nous donne une épopée en forme de roman : - Aliasvérus " (1533) ou la légende du Juif errant. Tout à fait at part stendal (Ilenri Beyle), avec a la Chitrtreuse de Parme ", et surtout a Le Rouge et le Noir \$ (1830); ses lervents voient en lui l'initialeur du réalisme.

Les deux plus grands noms du roman français, au xixe siecle, sont ceux de Balzac et de George Sand. Hs ont fondé chez nous le roman de mours. llonoré DE BALzAC, dans sa carriére relativement courte (1799-1850), a entassé une prodigieuse quantité d'œurres. Un conte fantastique, la "Peau de chagrin s (1831) le mit en lumière. Dans son ambition démesurée, soutenue par une puissance merveilleuse de travail, il avait conęu un vaste plan de romans embrassant tous les aspects de la vie. Plus tard, il groupa ses reurres sous ce titre général : la Comédie humaine. 11 les divisa en scènes de la vie privée, de la vie de province, vie de Paris, vie politique, vie militaire, vie de compagne. Très enclin à s'enfermer dans son cabinet, il n'a pu réellement obsereer tout ce qu'il raconte; il a beaucoup devine par une sorte d'intuition. Ses seènes de la vie de Paris n’ont pas une réalité aussi intense que la maus saderie de ses petites villes. Il a pourtant créé des types vivants, étonnants d'énergie et de couleur, types de déclassés, d'ambilieux sans scrupules, d'usuriers, d'escroes, de forçats, de manieurs d'argent et de consciences, et il a pressenti quelle génération de brasseurs d'alfaires allait 
appeler au jour le progrès rapide de la richesse et des entreprises. Son génie, qui a quelque chose d'inégal, de brutal, d'excessif, d'intempérant, qui affectionne les caractères outrés et les situations forcées jusqu'au lantastique, a été ainsi caractérisé par Victor Hugo : "Il saisit corps à corps la société moderne: il arrache à tous quelque chose: aux uns lillusion, aux autres l'espérance. "

GEORGe SAND ${ }^{1}$, qui a débuté en 183 I avec "Rose et Marie" et qui est morte en 1876 en pleine activité, forma son génie sous les influences les plus diverses. Elle subit celles de Rousseau et de Chateaubriand, celles d'Alfred de Musset et de Lamennais, avec lesquels elle fut étroitement liće. Elle se créa un style original, qui rappelait la chaleur de Rousseau, la couleur de Chateaubriand, mais avec une chaleur contenue, une couleur discrìte, une souplesse toute féminine, qui se prêtait à l'analyse la plus délicato des sentiments, et parfois une énergie toute virile.

Elle se mit hors de pair par "Indiana " (1832), dont la donnée hardie et l'inspiration ardente étonnèrent, scandalisèrent et ravirent les contemporains. Puis se succédèrent les grands romans de mours et de passion: "Valentine ", "Lélia ", "Jacques ", "Leone Leoni " " Consuelo ", " Teverino ". Puis elle découvrit un filon nouveau : elle prit pour décors les parsages du Rerry, du Limousin, de l'Auvergne, qu'elle connaissait si bien, mit en scène les gens des campagnes, qu'elle nous rendit à la fois réels et idéalisés, mèla à l'action du roman le charme de l'idylle, l'anima du reflet des légendes et des superstitions populaires, dégagea la saine poésie de la vie des champs. Alors parurent "la Mare au diable " (1846), " la Petite Fadette " (1848), "Francois le Champi " (1850), " les Maitres sonneurs " (1853)! De temps à autre elle faisait une excursion dans le roman historique : ainsi "Mauprat " (1837), peinture des rudes mœurs féodales qui, encore au début de ce siècle, dans les recoins perdus des montagnes, perpétuaient les traditions de l'Auvergne, des Grands-Jours. Génie très soupla,

1. Mlle Aurore Dupin, baronne Dudevant, prit le nom de Goorgo sind a cause du pseudonyme de Jules Sand dont ful signé le roman de $=$ Rose - Marie ", écrit en collaboration avec Jules Sandeau. 
ouvert à toutes les idées du siècle, sous l'excitation de la propagande révolutionnaire après 1830, sous l'influence surtout de Pierre Leroux, elle se passionna pour la libre pensée, pour les revendications sociales, et fit des romans $\dot{a}$ théses qui ne sont pas ses meilleurs au point de vue littéraire. Dans les "Lettres d'un voyageur ", dans "Elle et Lui " après sa rupture avec Musset, elle fit du roman autobiogruphique, commenté par "l'Histoire de ma vie". Elle fut, par sa vie, un des personnages originaux, et, par tant de chefs-d'œuvre, un des grands prosateurs du siècle.

ALEXANDRE DOMAS, dès 1833̈, avait inauguré par "Isabelle de Bavière " la série de ses romans, qui, pour la plupart, empruntent leurs sujets à nos annales nationales, et qui, mème lorsqüils ont beaucoup de chemin à laire et beaucoup de volumes à remplir, vont d'une allure si vive et si gaie. Bientôt paraissent "les trois Mousquetaires" (1834), qui se continuent par "Vingt ans après " et le "Vicomte de Bragelonne "; puis "Monte-Christo " (1844), "la Reine Margot " (1845), "Joseph Balsamo ", (1846), " le Collier de la Reine ", "les Quarante-cinq ", "les Compagnons de Jéhu " (185\%7). Chemin laisant, lauteur écrit pour les enfants le conte du "Casse-noisette " (18'4)

Alexandre Dumas avait pour ainsi dire inauguré le roman-feuilleton, qui est presque nécessairement un roman d'aventures, et dont les récits interminables, occupant le rez-le chaussée des journaux. tiennent sans cesse en éveil la curiosité du lecteur par la promesse de " la suite au prochain numéro ».

En mème temps que lui ou sur ses pas, d'autres s'adressent à ce public, plus curieux d'aventures émouvantes que des raftiuements du style. edgẼNe sue publie ses " Hystères de Paris " (1842-43), qui ont rendu si populaires les types du Prince Rodolphe, du Maitre d'école, du Chourineur, de Tortillard, de la Chouette, de Fleur-de-Marie, et son "Juif errant ", avec le bon vétéran Dagobert et le louche jésuite Rodin. PAdL FĖVal attache ou terrifie ce bon public avec "les Mystères de Londres " (18, ${ }^{\prime}$ ) et " les Tribunaux secrets "; FRĖDĖRIC soulí, avec les "Mémoires du Diable " (1837); LÉON gozlan, avec a les Nuits du Père-Lachaise (18:0). 
Un fait qui montre combien étaient neuves les intelligences auxquelles le roman populaire aurait à s'adresser, combien elles étaient promptes an rire comme à l'émotion, c'est le succès obtenu, entre 1843 et 1871, par lé romans comiques de PADL DE KOCK, pétillants d'une grosse gaieté, $t \dagger$ d'ailleurs plutot gaulois qu'immoraux.

La eritique litténaire et artistique. - La critique de l'âge précédent, celle des Laharpe, des Geoffroy, des Étienne, avait une infirnité : elle se fondait sur un système littéraire et condamnait tout ce qui s'en éloignait; elle appliquait les mèmes règles d'esthétique à Homère, Dante, Shakespeare, et aux auteurs contemporains. Er 1828, trois hommes inaugurèrent une critique plus large et plus équitable. Elle est historique et éclectique, comme la philosophie de Cousin.

SaINTE-BEUVE donne son "Tableau de la poésie française et du théàtre français au $\mathrm{xv}^{\circ}{ }^{\circ}$ siècle ", que suivront l'“ Histoire de Port-Royal " (1840) les "Portraits ", les "Causeries du lundı "(1851). Il s'étudie à replacer une œurre donnée dans son milieu, à son époque, dans le pays qui l'a vue naitre; il l'explique en nous faisant connaitre lauteur et son temps.

SAINT-MARC GIRARdin publie son "Tableau de la littérature française au xvıe siècle", que devaient suivre le "Cours de littérature dramatique ", les études sur La Fontaine, sur J.-J. Rousseau. Il dégage les lois supérieures de l'art par la comparaison de types dramatiques choisis dans les œuvres les plus diverses, antiques ou modernes, francaises ou étrangères, tragédies ou drames, comédies ou romans.

villemain commence son "Cours de littérature ", qui comprendra le moyen àge et le xvin ${ }^{\otimes}$ siècle français. Il s'attache surtout à montrer l'influence des institutions politiques et sociales sur la production des ceuvres littéraires.

Dans la presse quotidienne, se distinguent gUSTAVE PLANCHE, qui un jour soutint à la pointe de l'épée ses théories et se battit en duel pour les romans de George Sand, et Joles Janin, que l'on saluait alors comme le Prince de la critique.

La critique d'art, qui avait débuté avec THers et son "Salon de 1822", nous a valu les (: Peintres et sculpteurs françzis "du grand artiste DELAGRoix 
La polémique. - Les honmes de la Restauration retrouvaient en présence les écoles politiques et religieuses de l’àge précédent.

Joseph De maistre publie " le Pape " (1829), "l'Eglise gallicane ", " les Soirées de Saint-Pétersbourg" (1821), les "Lettres sur l'Inquisition ", où il accentue encore les tendances ultramontaines de ses premières cuvres.

montalembert, dans une série de brochures passionnées, clıerche à organiser le parti catholique libéral; essaye de concilier les idées modernes avec la tradition, en apparence immuable, de l'Église; ramène à son point de vue orthodoxe les appréciations des évén monts contemporains : si bien qu'en même temps il approuvera les insurrections polonaises et condamnera les insurrections italiennes.

L'abbé de LAMenNaIS, qui s'est placé au premier rang dans l'école catholique par son "Essai sur l'indifférence en matière religieuse" (1817), voit le pape condamner ses "Paroles dun croyant "(1833). Alors il passe dans le camp de la Révolution. Il attaque la papauté dans "les Affaires de Rome "(1836), l'ordre politique et social dans sa "Politique à l'usage du peuple ", " le Livre du Peuple ", "L'Esclavage moderne ", "le Pays et le Gouvernement " (1840). Rome l'a interdit comme prêtre : les juges de Louis-Philippe le condamnent à la prison. Il continue la guerre contre la société par "Amschaspands et Darvands " et " Une voix de prison ". Il siégera à la gauche de l'Assemblée de 1848 et mourra sans s'être réconcilié avec l'Église.

Avant que cette éloquente recrue ne vint renforcer ses rangs, le parti libéral avait produit un des premiers pamphlétaires du siècle : Paul-lodis courier. On connait sa "Pétition aux deux Chambres" (1816), le "Simple discours de Paul-Louis, vigneron ", contre la souscription pour l'achat du château de Chambord, la "Pétition à la Chambre des dépulés pour des viliageois qu'on empèche de danser " (1822), la "Gazette du village ", le "Pamphiet des pamplilets ". Il mourut assassiné en 1825 .

Alors des rangs opposés se détacha un nouveau combattant. montlosier, d'un royalisme éprouvé, d'un catholicisme fervent, mais fortement teinté de jansénisme, par son " Mémoire à consulter sur un système religieux tendant 
au renversement de la religion " (1826), commença la guerre contre les jésuites et les mit en accusation devant les Chambres et l'opinion.

La Monarchie de Juillet eut surtout à conıter avec les pamphlets de Timon, pseudonyme du vicomte DE CORMENIN : "Lettres sur la liste civile ", "Très humbles remontrances de Timon ", "Questions au sujet d'une dotation".

C'est alors qu'EDgar QDINET se révéla comme un polémiste de premier ordre avec son "Avertissement au pays " (1841), ses brochures contre les jésuites, et que, en collaboration avec michelet, il publia " le Prêtre " et "le Peuple".

Le journalisme, alors si puissant et si vivant, a compté des maitres illustres : ARMand carrel, plutót républicain que démocrate, ÉmiLe de GIRARDIN, le grand remueur d'idées, THIERs et mignet, les collaborateurs de Carrel au National.

L'éloquence. - L’éloquence de la chaire a eu ses jours de splendeur avec le jésuite de Ravignan, le dominicain LACORDAIRE, qui, à propos du général Drouot, nous a presque rendu l'oraison funébre du xvise siècle.

Le barreau a été illustré par BerRyen, qui, en 1815, voulant épargner à la royauté qu'il aimait une tache sanglante, se fit l'avocat du maréchal Yey; dopin ainé, autre défenseur du maréchal, et qui plaida pour le Journal des Débats en 1830; MAOGdIN, MÉRILHOD, HENNEQUIN, ODILON-BARROT.

Le théâtre priacipal de l'éloquence française $2 \mathbf{u} \times \mathbf{x}^{\mathrm{e}}{ }^{\mathrm{e}}$ siècle, c'est la tribune politique. Sous la Restauration, elle a mis aux prises les de SERRE, les laiNé. les decazes. les villèle. ministres de la royauté; BENJAMIN CONSTANT, un redoutable logicien; ROY£r-COLlaRd, qui, à propos de la liberté de la presse, appelant à son aide les grandes vues du philosophe, donnait au débat une élévation inconnue; le général roy, nourri des grands orateurs de l'antiquité, rayonnant du prestige de la Grande Armée, dénonçant les mesures prises contre ses compagnons d'armes comme "un coup de canon échappé de Waterloo "; Mandes, d'une passion ardente et opiniàtre, que les ministres osèrent faire arracher à son banc de député par la main des soldats; martignac, si séduisant qu'un de ses adversaires, furieux de se sentir persuadé, lui criait un jour : \& Tais-toi, sirène! ,

Sous la Monarchie de Juillet, BERrYer, avec le respect 
qu'imposaient sa probité et sa modération, à force d'élever le débat au-dessus des passions du jour, en se tenant dans la région sereine des principes, réussissait à faire écouter l'apologie de la royauté déchue. montalembert le secondait de son éloquence passionnée, chaude, un peu déclamatoire. LAMARTINE, avec sa parole harmonieuse, ses grands effets oratoires et ses images poétiques, plaida tour à tour la cause de la légitimité ou celle de la démocratie. casmin PERIER, à la parole brève et impérieuse, aux apostrophes foudroyantes, aux boutades redoutées, défendait la politique de résistance contre les séductions révolutionnaires de LAFFitTe et de LA FAYETTE. GUIZot tenait la Chambre sous le charme d'une parole austère et élégante, de raisonnement serré, mais colorée et vibrante, soutenue d'une dignité hautaine. THIERs se révélait un merveilleux orateur d'ấfaires, plein de faits, de chiffres, d'arguments, excellant à rendre limpides les questions les plus obscures et gagnant ses auditeurs par le plaisir inattendu qu'ils éprouvaient à tout comprendre. cousis intervenait avec sa langue expressive, noble et véhémente; viluEMarn avec ses allusions malicjeuses et son élègance académique; le duc DE BROGLIE avec son tact et sa dignité de grand seirneur; DE REMUSAT avec sa bonne grâce un peu railleuse; DUVERGIER DE HAURANNE avec sa ténacité à reproduire les motions de réforme et ses avertissements prophétiques; DUFAure avec sa dialectique ef ses bontades; Dopin avec sa verve mordant et ses reparlies si redoutées; ODILON-BARRot avec sa collviction raide; LEDRO-ROLLIN avec ses lieux communs pathétiques.

Ouvrages a consulter, - Outre les histoires rénerales de la littérature lrancaise (Pelut de Julle ville, t. V11/: - Nettement, Hist. de la litt. franc. sous la Restauration. Paul Albert, La litt. franc. au $\mathrm{N} / \mathrm{X}^{\mathrm{\theta}} \mathrm{s}$. et les Oigines du romantisme (188i). - Theophile Galitier, Hist. du romantisme (1455); Portraits contemp.; Hist. du theitre contentp. - Sainte-Beuve, Portratts, Lundis, Nouv. Lundis. G. Planche, Portraits litteraires (1853-54).-J. Lamaitre, Portr. litter. - Brunetière, Histoire et littérature; Evul. de la porsic lyrique; Etudes critiques. - Faguet, Etudes lilter. sur te $\mathrm{XIX}^{\mathrm{e}}$ s. - Larroumut, Etudes de litt. et d'art. - Lacretelle, La-

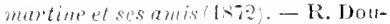
mic, Lamnrlite 1912. - Paul de Mussel. Riographip dA de Whsset. - Analole Franee (IVG); A. Lauvriére 1910 , A. de Viqny. - Em. Berferat, Th. Guntier (1nj9) - Barbon: Bire; Rivel, Virtor Ilugo. Mme Viclor Ifnen, Fictor llujo raconte per un téntrón de sa vio (1863). - P. Stapfar. Rurine at lirtor Hugo (18xi). - Le Breton. Bulauc, llomme

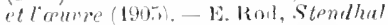
(1802) - A. Cinguet, Stendlut-beyle 1901 - - Vilirtuan. La tribune moderne lss?), - Curmenn. Le licre desforaleurs (18is). - Cimpleter avec la Bibl. de l'Hist. Ginerale, 1. x, p. 512. 


\section{CHAPITRE $\mathbf{X X}$}

LES SCIENCES MORALES ET POLITIQUES

\section{La philosophie et le droit}

L'école éclectique. - Dès le premier Empire, nous avons vu Maine de Biran et Royer-Collard inaugurer le retour aux idées spiritualistes. Ce spiritualisme n'avait pas repris les allmres dogmatiques d'autrefois; il ne visait pas à constituer de toutes pièces une doctrine nouvelle, comme celles que les philosophes allemands, Schelling, Fichte, Hegel, continuaient à édifier. De son passage par la philosophie du xvme siècle, l'esprit français avait perdu la croyance à l'infaillibilité des théories; il en avait contracté un certain scepticisme, c'est-à-dire des habiludes de doute et de critique. Aucun des systèmes élaborés dans les siècles précédents ne le satisfaisait entièremenl. Aussi la nouvelle école spiritualiste, fermement attachée à quelques points essentiels, tels que l'existence de Dieu et l'immortalité df l'âme, se mit à rechercher dans tous ces systèmes les arguments que chacun d'eux pouvail lui fournir à l'appu: de sa thèse. La philosophic cartésienne fut le fond de son enseignement; mais elle la contrôta el la compléta par des emprunts à celle des Grecs et des Romains, à la scolastique du moyen àge, aux grandes ouvres anglaises sur la psy. chologie ct allemandes sur la métaphysique. Cette tendance. à comparer, à concilier, à choisir, s'appela l'éclectisme.

Lc fondatcur de la philosophie éclectique en France ful victor coosin (1792-186\%). Investi des plus hautes fonc-

R. Civil. CONTEMP. 
tions dans l'Université et dans l'État, tour à tour prolesseur dans les lycées de Paris, à l'École normale, à la Sorbonue, conseiller d'État, conseiller de l'Université, titre qui laisait de lui une sorte de ministre de la philosophie, inspecteur général, directeur de l'École normale, pair de France, ministre de l'instruction publique (1840), sa grande situation, non moins que son admirable talent d'exposition, fit de sa doctrine la doctrine officielle. Elle passa dans les programmes des écoles, s'imposa dans les chaires de l'Étal comme dans celles des écoles libres : elle est restée, jusqu'à une époque très voisine de nous, le fond même de l'enseignement philosophique. Victor Cousin la marqua si bien de son empreinte queles éclectiques s'appellent aussi cousiniens.

L'éclectisme ne pouvait se fonder que sur ane connaissance approlondie de tous les systemes philosophiques. Un des plus grands services qu'ait rendu Victor Cousin, ce fut de provoquer une vaste enquête sur les vucs des penseurs de tous les temps et de tous les pays. L'école cousinienne fut une grande école d'histoire philosophique. "Publier des systèmes, et des systèmes tirer la philosophie, a dit Jouffroy, tel était le plan de II. Cousin. "

Lui-mème traduisit les cuvres de Platon et de Proclus, fit connaitre l'école platonicienne et néoplatonicienne, commenta la "Métaphysique" d'Aristote (1836), édita les "Ouvrages inédits d'Abélard", publia ses "Études sur Pascal " et son "Cours d'histoire de la philosophie au xvı" siècle ", se livra à une critique sćrieuse des philosophes allemands, Leibnitz, Kant, Schelling, Hegel, comme des psyclıologues écossais, Reid, Dugald-Stewart, Mackintosh, comme des sensurtistes anglais ou français, Locke et Condillac. Il se fit donc traducteur, éditeur, critique, historicn. Son ceuvre capitale, dans laquelle il essaya de donner un corps à ses doctrinas, c'est le livre célèbre "Du Vrai, du Beau et du Bien ", tiré de ses cours de 1815 à 1820 , plusieurs fois remanié par lui, et qui prit une forme définitive en 18333 .

Cousin, au moins à ses débuts, était un libéral en politique ${ }^{1}$, comme en philosophie. Il devint, par la suite, plus

1. C'étail lui qui, à vingrt-cinq ans, défnissail ainsi ls. morale : "La vraie morale est celle qui conduil à la liberté folitique; la fausse morale est celle qui conduil au desuotisme et a l'acbitraire. 
conservateur dans les deux ordres d'idées ${ }^{~}$. Après avoir eté un éclectique, il chercha à réduire son système en dogme.

De la mème période il faut citer les travaux d'un des plus éminents disciples de Cousin, Thèodore joufrroy, sur la théorie du beau et sur les théories morales (Cours de broit Naturel, 1835). Charles DE RÉmusat publia ses "Essais de philosophie " (1842), "A bélard ", un " Rapport sur la phi?osophie allemande " (1845) et l' "Histoire de la philosophie en Angleterre " (1875).

L'école positiviste. - Se tenaul en dehors, et se préten- Iant au-dessus du conflit des écoles métaphysiques, une autre école s'est furnée : l'école positiviste. Elle part de ce principe que l'inlelligence de l'homme est hors d'état de résoudre jamais ces hautes questions de l'existence et de la nature de bieu, de la nature et des destinées de l'àme humaine. Elle estime qu'il est plus sage de se borner a l'étude de ce que nos sens et notre raison peuvent atteindre de la réalité. Elle renonce à la métaphysique et se borne aux notions positives. Si le mot est neuf, la chose ne l'est pas tout à fait : l'abbé de Saint-Pierre et Voltaire, qui assignaient pour but à la philosophie de rendre l'humanité meilleure et plus heureuse, étaient assurément des po:itivistes. Ce qui caractérise l'école nouvelle, c'est une plus forte culture scientifique et une étude plus patiente des faits.

Ses théories ont pour base l'idée du proyrés daus le développement du genre humain à travers les ìges. Sa morale consiste surtout à lavoriser ce progrès. Elle a manifesté souvent des tendances socialistes et internationales assez accentuées, car le progrès ne peut se réaliser que par l'émancipation des classes laborieuses et par l'abaissement des barrières qui séparent les peuples. Née dans la première moitié du siècle, elle a gardé une teinte religieuse et mystique qu'on retrouvera aussi dans les écoles purement socialistes. Elle a un culte; elle a même eu des rites et des

1. Après la Rivolution de février, il Iui échappa de dire a M. de Rémusal : "Conrons nous jeler dans les bras des éréques; eux seuls peuven" nous sauver aujourd'hui. " Mais, dans la discussion de la loi de $1850 \mathrm{st.}$ l'instruction publique, il défendit courageusement la cause de l'Universilt. Il fut mis à la retraile aprés le coup d'Etal de 1851 . 
cérémonies; mais son culte s'adresse, non pas au Dieu des spiritualistes, inaccessible à notre intelligence comme à nos sens, mais à l'humanité elle-même, dont eỉle a fait, en quelque sorte, son Dieu.

Le fondateur de l'école, c'est auguste comte (1798-1857), dont le renom est plus grand aujourd'hui à l'étranger que chez nous. Il fut un mathématicien de mérite, examinateur a l'École polytechnique, l'auteur de la "Géométrie analytique " (1843). il avait des connaissances vastes et variées, cornane le prouve son "Cours de philosophie positive "(1839-42), où il donne le résumé et la théorie de toutes les sciences humaines. Séduit un instant par les doctrines de Saint-Simon, il se sépara de ses disciples pour professer le positivisme pur. C'est en 1828 qu'il formula les principes essentiels de son école dans le "Système de philosophie positive ".

Le dresit. - Notre droit actuel a pour base les codes préparés par la Révolution et rédigés sous le Consulat et l'Empire. Cependant on n’oublie pas qu'il procède du droit coutumier et lu droit romain, celui-ci étant même plus important que celui-là, parce qu'il n'a pas cessé d'être la raison écrite et qu'il y a toujours profit à s'y reporter pour éclairer ou même interpréter et développer le droit actuel. Aussi les études juridiques comprennent-elles chez nous trois branches principales: le droit actuel, le droit romain, l'ancien droit francais.

La mise en pratique de nos codes, surtout du plus important de tous, le Code Civil, devait, au commencement de ce siécle, à une époque si voisine de leur rédaction, soulever de nombreuses difficultés d’interprétation. Pour les résoudre, on a eu, d'une part, la jurisprudence des Tribunaux, des Cours d'appel et de la Cour de Cassation; dautre part, les travaux des jurisconsultes. Parmi ces travaux, ii faut signaler les grandes publications de Toultien (depuis 1811), de PROdDEON (1823-1839), de DURanton (1826), de duvergier (1846), d'aubry el rad (1843-1846), píolesseurs ì Strasbourg, sur le Code Civil; de faustin héliz et chauvead, sur le droit pénal; de pardessus, sur le droit commereial; de CORMENIN (1826), DE GÉRANDO (1829), MACARE (184), vivien (1846), sur le droit administratif; de DJFIN, 
1814-1848. - LES SCIENCES MORALES ET POLITIQUES 401 sur les libertés de l'Église gallicane (182:); de Rossi, sur le droit constitutionnel (183ว). En 1824, DALLoz, avocat i la Cour de cassation, avait conmencé son immense Repertoire de jurisprudence, dont la nouvelle édition (1845-1865) comprend 44 volumes in-quarto.

Les études du droit romain nous ont valu l" Explication historique des Institutes de Justinien " (1827), par ontclan; et plusieurs ouvrages de LABOULAYE.

Les études sur notre ancien droit francais se sont développées surtout dans la période qui suivit : il faut signaler cependant les études de l'historien michelet (1837), le ParDESSUS et du professeur Charles GIRAdD (1845).

\section{L'histoire, les langues, la géographie.}

Idées nouvelles sur lhistoire. - Une des gloires du $\mathbf{x I x}^{\mathbf{e}}$ siècle, c'est le magnifique développement des iturles historiques. Après la grande secousse de la hívolution, qui semblait avoir brisé tout lien qui nous rattachàt à nos origines, la France s’est éprise de son passé, et de son passé le plus lointain, le plus mal connu, et même le plus dédaigné des générations précédentes. En mème temps, comme la Révolution l'avait mis en contact avec presque tous les peuples, sa curiosité, une fois éveillée, est devenue universelle. Enfin l'histoire, qui était autrefois un passe-temps de lettré ou une curiosité d'érudit, a paru ce qu'elle est en effet: la maitresse de la vie, la lumière qui éclaire le présent et mèn c l'avenir par les expériences du passé, le guide nécessaire de la politique et l'un des ressorts lu patriotisme. A tous les degrés de l'enseignement, à commencer par l'école primaire, l'histoire est donc devenue, ce qu'elle n'était pas au xvu1 siècle, une des bases de l'éducation nationale.

Elle a progressé à la fois comme art et comme science. D'une part, elle a cessé d’ètre, comme elle était "ncore avec l' "Histoire des croisades " de Hichaud (1811-18:2) ou l' "Histoire des ducs de Bourgogne " de Barante (182:4), un récit plus ou moins intéressant, une sorte de paraphrase des chroniques. Elle a formé une des branches les plus brillantes de notre littérature; elle a donné des chefs- 
"'icurre de style, comme "la Conquête de l'Angleterre par les Normands " (18:2:), "Dix ans d'études historiques" (1835), ou "les Récits mérovingiens " (1840) d'AoGuSTIN THIERRY ; comme I" "Histoire de la civilisation" (1839) de GoIzoT; comme l' "Introduction à l'histoire universelle " (1831) et le "Précis d'listoire moderne " (1833) de MichelEt, qui commença en 1833 son "Histoire de France".

D'autre part, dans sa recherche ardente de la vérité, elle a perfectionné ses méthodes, accru ses moyens d'investigation, appelé à son aide toutes les sciences auxiliaires, archéologie, palégraphie, numismatique, épigraphie, etc. Quand on entreprend de laire connaitre le passé d'un peuple, on ne se borne plus à raconter les guerres, les traités et tous les événements de sa vie extérieure, mais on veut rendre compte de son état social, de ses institutions, de ses croyances religieuses, de ses industries et de son commerce, des lettres, des sciences, des arts.

Ainsi comprise, l'histoire ne saurait être l'œurre de quelques hommes de génie. Il faut une armée de travailleurs explorant à la fois tous les points de son domaine, chacun d'eux se confinant dans une spéciulité et se résignant à ne dégager souvent qu'une parcelle de vérité. C'est de nombreuses fouilles archéologiques et de patientes rechrrches dans la poussière des archives et des bibliothiques, que se compose le monument colossal de l'histoire universelle. Pour le construire, il a fallu une organisation du travail et une division du travail.

Les àges classiques. - La première moitié du siècle a été signalée par une brillante renaissance des études d'érudition. C'est l'époque où boISSONNADE, Base, victor Le CLera, publient leurs éditions savantes d'auteurs classiques; où villemain traduit les fragments de "la République" de Cicéron, que le cardinal Angelo Maï a retrouvés, en 1822, dans un palimpseste; où M. Désiré NISARd dirige la publication, avec traduction française, des écrivains latins (1839); ou lit maison Didot commence la collection, avec traciuction latine, des classiques grees; où DUGAS-MONTBEL donne ses études sur les poésies homériques (1831), WALCKENAER sur le poite Horace (1840), patin (1811-1843) sur les tragiques grees, EgGER sur les historiens du siècle d'Auguste (1844). 
1814-1848. - LES SCIENCES MORALES ET POLITIQUES 403

RAOUL ROCHETTE (1815̆) et BRDNET DE PRESLE (1840ั) étudient les colonies grecques; victor Le cLerc, les journaux chez les Romains (1838); NAUDET, les magristratures romaines; GOIGNIAOT, les religions de l'antiquité (1821); DUREAD DE LA MaLLE, l'économie politique des Romains (1840).

Michelet, en écrivant son "Histoire de la république romaine " (1831), et M. VICTOR DUROY son "Histoire des Romains " (1843), ont vulgarisé chez nous les résultats des recherches de Niebuhr et des grands érudits allemanıls.

C'est en 1820 que le marin DUMONT D'CRville découvrit à Milo, une des îles de l'Archipel, l'admirable Vénus de Milo, la merveille de notre Musée du Louvre.

Cependant la période de la Monarchie parlementaire n'est pas encore celle des grandes découvertes dans le domaine de l'histoire et de l'archéologie grecques et romaines. Elle a une autre gloire qui lui est propre.

Le moyen àge français. - Les services que l'École française d'Athènes devait rendre aux études grecques, l'École des Chartes, fondée en 1821, les a rendus aux études sur le moyen âge français: la Bibliothéque de l'École des Chartes, recueil périodique inauguré en 1830, forme une collection des plus précieuses.

Les travaux entrepris au siècle précédent par les bénédictins de Saint-Maur ont été repris sous les auspıces de l'Institut de France. C'est ainsi qu'on a pu continuer le "Recueil des historiens des Gaules et de la France "; l' "Histoire littéraire de la France ", qui a compté parmi ses collaborateurs Victor Le Clerc, Renan et Littré; "la Gaule chrétienne "; le "Recueil des historiens des croisades "; le "Recueil des ordonnances des rois".

En 183', M. Guizot a créé au ministère de l'instruction publique le Comité des travaux historiques, chargé d'éditer le "Recueil des documents inédits ", qui comprend aujourlhui plus de 150 volumes in-quarto ${ }^{1}$. Presque en même temps s'est constituée la Socit́té de l'histoire àe

1. C'est dans celte collection qu'Augustin Thierry a publié les Documents relatifs a l'histoire die tiers etat, Michelet le Procès des Templiers. Mignet. les Papiers relatifs aux négociations de la succession d'Espagne, le général Pel=t les Documents relatifs i l'histoire de la guerre de la succession d'Es. pagne, etc. 
France, qui a déjà publié plus de 200 volumes. Il ne s’agissait pas seulement d’éditer des chroniques, mais aussi des chartes, des comptes, des polyptiques ou registres terriers. L'archéologie du moyen âge ne comprend pas seulement l'épigraphie, la numismatique, la paléographie, mais encore la sigillographie ou étude des sceaux, car les sceaux jouent, au moyen àge, un rôle considérable, qui les rend précieux au point de vue historique et même artistique.

Une des découvertes les plus importantes de cette pérode, c'est celle des chansons de gestes ou épopées francaises du moyen àge, commencée en 1831 par EDGar Quinet, et poursuivie depuis par J.-J. Ampère, Raynouard, Victor Le Clerc.

C'est alors aussi qu'ont été publiées, outre les grands travaux de Guizot, Augustin Thierry, Michelet, "les Institutions mérovingiennes " et "les Institutions carolingiennes"

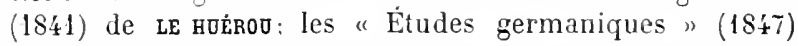
d'ozanam; la "Collection des chroniques nationales" (18\%4) de Bucron et ses "Recherches sur les États fondés en Grèce par les croisés (18:3-18:6); l' "Histoire de sainte Élisabeth de Hongrie " (1836) et l' "Histoire de saint Anselme " (1844), de Montalemeert; l" "Histoire de saint Dominique ", de LACORDAIRE (1840). SIMONDE DE SISMONDi publie, en 1832, son "Histoire des républiques italiennes" et achève en 1844 son " Histoire des Français ". HENRI MARTIN commence, en 1847, sa grande "Histoire de France".

L'histoire des temps modernes. - L'histoire des temps modernes a une méthode un peu différente : elle demande de vastes recherches dans les archives pour en extraire les papiers d'État, correspondance des rois et des ministres, instructions diplomatiques, rapports de généraux et d'ambassadeurs. Comme les rapports entre les nations devinrent, à partir du $x^{e}$ siècle. chaque jour plus fréquents, ce nest pas seulement aux archives de France qu'il faut chercher les sources de l'histoire de France.

Dans cet ordre de travaux, mignet se place au premier rang avec son "Introduction aux négociations relatives à la succession d'Espagne "(1836), ses "Notices et mémoires "(1844), son livre sur "Antonio Perez et Philippe II " (18; ) : villemain, avec ses "Études d'histoire moderne " (1846); GUIzoT, avec 
son "Histoire de la Révolution et de la République d'Angleterre "(1827-1828) et sa "Vie de Washington" (1841); SAINTEadbatre, avec son "Histoire de la Fronde " (1827); pIERRE CLĖMENT, avec son "Histoire de Colbert et de son administration (1846); SAINTE-Beove, avec son " Histoire de PortRoyal " (1840-1860).

L'histoire de la thévolution et de l'Empire. - Après le long silence imposé par l'Empire, puis par la Restauration, sur ce sujet brùlant de la Révolution, il semblait que la France eùt oublié complètement cette histoire ou qu'elle en eùt honte. On avait élevé à Louis XVI un monument expiatoire, et une simple allusion de Hanuel a 1 /93 avait suffi à le faire expulser de la Chambre. Les libéraus, dans leurs luttes contre la royauté, nosaient invoquer ces souvenirs terribles et faisaient plutót appel à ceux du Consulat et de l'Empire. Il semblait que Napoléon personnitiàt à lui seul la grande époque et que les victoires de la République lussent perdues dans la splendeur d'Austerlitz et d'iéna. Ce fut triers qui mit fin à ce long silence quand il publia, en 1823, le premier volume de son "Histoire de la Rírolution ". Cette œuvre, remarquable par une rédaction limpide et alerte, est, pour le fond, encore bien insuffisante. L'auteur n'avait eu à sa disposition que l'ancien Moniteur, quelques Mlémoires inédits et la conversation des témoins oculaires. Surtout dans les deux premiers volumes. consacrés à la Constituante, il semble ne pas saisir toute la complexité des questions qu'il effleure. HIGNET, son ami, donna, en 182t, une petite histoire de la Rérolution, remarquable par la concision, la netteté, et l'élégance du style.

Ces deux ouvrages rompirent le charme : c'est alors que commencèrent à paraitre les Mémoires des Constituants, des Conventionnels, des émigrés, des généraux de la République et de l'Empire. Le public témoigna pour ces publications une telle curiosité qu'on lui donna mème des Mémoires apocryphes. Après 1830, commença la réimpression du Woniteur universel de la Rérolution. Buchez et roox publièrent leur "Histoire parlementaire de la Rísolution " (1833). Ces deux collections mirent sous les yeux du public, sinon le texte même, au moins le résumi authen- 
tique des discours dont avait retenti la tribune nationale aux jours de Mirabeau et de Danton.

Quand les idées socialistes itaient à leur maximum de puissance, Lodis blanc. en 18千6, commença son "Histoire de la Révolution ", si forte de recherches et si remarquable de style, mais où il exaltait Robespierre et les Jacobins, exagerait la diversité entre les aspirations du peuple et des bourgeois de la Révolution, prèlait aux personnages de 1789 et de 1793 les idées de sa génération et de sou parti.

LAMARTine, en 1847, d'un style imagé, mais un peu décla. matoire, avec peu de critique des textes et des laits, avec un souci visible de faire l'apologic de la Révolution et de la mettre en contrastc avec ce qu'on appelait "les petitesses du temps présent ", publia sa poétique " Histoire des Girondins ", qui produisit une grande sensation et contribua, dit-on, à la révolution de février.

la mème année, mickelet commençait son "Histoire de la Révolution ", oì il montra la mẻme faculté d'intuition historique, la mème puissance de résurrection, la même chaleur patriotique, les mimes vues larges, humaines, généreuses, que dans son "Histoire de France ". Il s'efforça de comprendre et de faire comprendre tous ces hommes, Feuillants, Girondins, Montagnards, indulgent pour tous, excepté pour Robespierre, qui les avait tous envoyés à l'échafaud, et particulièrement favorable à Danton, le grand homme daction et le grand indulgent.

Pour la période contemporaine, Vaulabelle commence, en 1847, son "Histoire des deux Restaurations ", et Louis Blanc, en 1841, son "Histoire de dix ans ", qui comprend la première période du règne de Louis-Philippe.

Les provinces nouvelles de lhistoire. - Nous avons suivi jusqu'à présent ce qu'on pourrait appeler le courant classique de l'histoire : la Grèce, Rome, la France, l'Europe au moyen àge et dans les temps modernes. Nous ne pouvons oublier qu'il y a des civilisations plus anciennes que celles de la firèce el de Rome, et d'autres qui sont restées presque étrangères à la nôtre. Dans ces autres provinces de Ihistoire universelle, la science francaise s'est acquis des titres impérissables.

Etudes égypticnnes. - Sur les monuments rapportés 
d'Egyite par l'armée française, cHAmpoLlion avait entrepris des t'avaux de déchiffrement. L'inscription trilingue de Rosete, en caractères hiéroglyphirques, en caractères démotique el en grec le mit sur la voie: le texte grec de l'inscriptsn lui donna la traduction des deux autres. Il constata ensue que les anciens Égyptiens se servaient concurremmende trois alphabets : l'écriture hieroglyphique; l'écriturehiéralique, également réservée aux prêtres, et qui est omme la lorme abrégée de la première; l'écriture déntique, c'est-à-dire populaire. Il publia, en 1821, son "Moire sur l'écriture hiératique ", et, en 1824, son "Systèr hiéroglyphique ". A force de tàtonner, il déchiffra defragments chaque jour plus nombreux d'inscriptions efit d'importantes publications. Il mourut en 1832, Lant à ses continuateurs sa "Grammaire égyptienne ", c fut éditée l'année suivante.

1 eut des diseiples : en Allemagne, comme Lepsius, ıgsch, Bunsen; en Hollande, comme Leenıns; en Anglere, comme Birch et Goodwin. Il en eut en France:comme n frère, cBampollion-rigeac, qui étudia l'éeriture démotique publia, dans la collection de l'Univers pittoresque, l'Égypte ancienne et moderne " (1850); comme LETronNE, élèbre par ses travaux sur l'histoire de l'Égypte, sur le sélèbre colosse musical de Memnon, sur les inscriptions grecques et latines de la vallée du Nil (1832); comme PRISSE D'AVESnes, qui publia en 1836 un "Choix de monuments égyptiens ".

C'est en 1836 que l'ut amené à Paris le fameux obélisque de Louqsor, enlevé aux ruines lu temple d'Ammon, dans l'ancienne cité égyptienne de Thèbes. Notre musée du Louvre s'enrichit de nombreux monuments égyptiens.

\section{Etudes assyriennes, babylonienuex, persiques, médi-} ques. - Le centre d'une civilisation presque aussi vieille que celle de l'Égypte. c'est la vallée du Tigre et de l'Eu phrate, comprenant l'aneıenne Assyrie, l'ancienne Baby lonie, l'ancienne Perse, l'ancienne Médie. Là aussi, on se trouvait en présence d'inseriptions jusqu'alors indechiffrables; elles sont gravées, non plus en hiéroglyphes, mais en earactires cunéiformes (qui ont la forme de elous). On s'aperçut que ees caractères servaient d'alplabet à de; 
langues très différentes: les unes sémitiques, comne l'azsyrien; les autres indo-europénnes, comme le pers et le mède; d'autres scythiques, c'est-à-dire finnoises ou turques, comme le plus ancien babylonien. Vinrent EUGENE BRNOOF, qui, dès 1836, déchiffra les inscriptions de Hamadan Ecbatane), et l'Anglais rawlinson, qui expliqua l'insciption monumentale de Bélistoun, où sont relatés les explits de Darius, et dont SAulcy a donné la traduction.

En i845, BoTTa, notre consul à Mossoul, avait retroré les ruines de Ninive et le palais de Khorsabad. C'est alo que les taureaux gigantesques à tète d'homme, couronnéle la tiare sacerdotale et royale, furent transportés au nsée du Louvre. Les Anglais rivalisèrent avec nous et fouillont, toujours sur l'emplacement de Ninive, les ruines deimroud, qui rappelle le nom de Nemrod, et de Koyourik. En 1840 avaient commencé les missions d'Eugène FLAN. et COSTE; en 1845̆, celle de FERRIER. Ils explorèrent les ruinge Babylone, où sont les restes de la fameuse to ur dite de $B_{4} l$, ies ruines de Persépolis et de Ctésiphon, anciennes mypoles de la Perse, d'Ecbatane, ancienne capitale de la MC.

On a fait plus que retrouver les anciens monuments, la Perse. On a retrouvé sa Jangue ancienne, le Zend, et livre sacré, le Zend-Avesta, attribué à son grand légis teur Zoroastre ( $\mathrm{xvl}^{\mathrm{e}}$ siècle avant Jésus-Christ). Ce livre ar disparu de la Perse avec la langue zende, après la co quête musulmane: il ne se rencontrait plus que chez 1 Parsis de l'Inde, descendants des Perses, et, comme eu adorateurs du feu. En 1771, Anquetil-Duperron avait donr. la traduction du Zend-Avestr. En 1829, EugÉne BuRnouf tra duisit le Vendidad Sade, également attribué à Zoroastre.

Eudes sémitiques. - Les civilisations sémitiques son celles des régions habitées par les descendants de Sem : Phénicie, Judée, Syrie, Arabie, ainsi que des divers pays que les Arabes ont envahis et conquis à la loi de Mahomet.

Les Phéniciens n'ont pas habilé seulement les cités fameuses de Tyr et Sidon; ils ont fondé Carthage en Afrique; ils ont fondé, avant les Phocéens, une colonie à Marseille. En 1845, on a trouvé la fameuse inscription phénirienne de Marseille.

Les études hébräques et syriaques sont en relation 
intime avec les études sur nos origines religieuses, qu'intéressent à un haut degréles textes hélraïques ou syriaques de la Bible, du Talmud, des Evangiles. Il faut citer les belles traductions de DABLER (1820), de s. CABEN (1830), de MoNk, auquel nous devons, en outre, un livre remarquable sur la Palestine (1846). En 1843, M. FRANck, le célèbre auteur $\mathrm{du}$ "Dictionnaire des sciences philosophiques ", publiait "la Kabbale, ou philosophie religieuse des Hébreux".

Plusieurs ouvrages d'historiens ou de géographes arabes ont été traduits, comme la Géographie d'Aboul-Fèda par REINADD et DE SLANE (1840). Le Kioran a été traduit par raSIMIRSRI (1840), auteur d'un dictionnaire arabe.

L'histoire de cette branche des peuples sémitiques a été renouvelée par les "Lettres sur l'histoire des Arabes avant l'islamisme ", de FULGeNce de FRESNel (1838); par l' "Essai sur l'histoire des Arabes avant Mahomet ", de CAUSSIN DE PERCEVAL " (1847); par l' "Histoire des incursions des Arabes en France" (1836), de ReINADD; par les recherches sur les sciences des Arabes, de Sinillot.

Ctudes persanes et arméniennes. - La Perse du moyen âge et des temps modernes, la Perse musulmane, est profondiment différente de la Perse antique, celle de Zoroastre et lu Zend-Avesta; mais, bien qu'elle professe une autre religion, on retrouve dans ses traditions nationales les traces de son àge héroïque. Depuis sa conversion à lislamisme, la Perse, au temps des khalifes de Bagdad ou de ses rois particuliers, a eu d'illustres poètes, comme Tirdousi $x^{e}$ siècle), Férid (xue siècle), Sadi (xun siècle).

SILVESTRE DE SACY, qui est encore ici le grand initiateur, avait traduit, en 1819 , le Pend-Nameh de Férid. GARcin DE TASSY traduisit le a Langage des Oiseaux " du méme auteur. mozL entreprit une ouvre colossale, la traduction du Shuh-Timed ou "Livre des Rois", la srande épopée persane de Firdousi (1838-1835). DEFnemeny a écrit llisioire de la dynastie samanide de la Perse (18 $\% 3$ ). Un magnifique recueil, la Collection orientalo, a été entrepris aux frais du gouvernement français. Amédée Jaubert en a donné des extraits dans ses "Chrestomatlies orientales". Nous dofons à M. Alexandre ceonzko le "Théitre persan " (18 $x^{3}$ ) et plusieurs ourrages sur la poésie persane. 
L'arrivée à Paris de l'Arménien Zohrab, en 1818, a donné chez nous l'élan aux études sur son pays. Parmi les Français qui ont le plus contribué à en faire connaître la littérature et l'histoire, il faut citer Bnosser, établi en Russie et membre de l'Académie de Saint-Pétersbourg, auteur de savants mémoires sur la Géorgie et l'Arménie.

Il faut mentionner aussi les travaux de saunt-mantnr.

Etudes indicnues. - Un monde dont la découverte scientifique a exercé une influence encore plus grande sur l'ensemble de nos études, c'est l'Inde. Avec ses Védas, qui sont les plus anciens poèmes de notre race; avec ses colossales épopées, comme le Ramayana et le Mahabarata; avec ses poèmes cosmogoniques, comme le Bhagavata-Pourana, ses recueils de contes, comme le Punichatantra, ses drames lyriques, comme Sukountalu; arec ses nombreux idiomes, pàli, hindoui, hindoustani, dont le plus ancien, qui n'est plus aujourd'hui que la langue sacrée des brahmanes, s'appelle le sanscrit; avec ses deux grandes religions, le brahmanisme et le bouddhisme; avee son art étrange et original, l'Inde nous a beaucoup appris sur les origines les plus lointaines de notre civilisation.

C'est l'étude du sanserit qui nous a fait toucher du doigt la parenté des langues qui se parlent et des races qui habi. tent dans la plus grande partie de l'ancien monde, depuis l'Indoustan jusqu'à l'Irlande, y compris les races persane, germanique, slave, latine, grecque, celtique. C'est alors qu'on a compris toules ces langues et toutes ces races sous une dénomination commune : indo-germaniques ou indoeuropénnes. C'est une des plus grandes dícouvertes de notre siècle.

En 1815, Antoine DE chÉzy oecupa la chaire de sanscrit au Collège de France, qui fut alor's fondée et qui fut la première qu'on ait eue en Europe. Il eut pour disciples Burnouf, Langlois, Bopp, Lassen. Il a traduit des fragments du Ramayana, le drame de Sakountala. edgéne boRnodf a publie, dès 18:6, son itude sur le pàli, antre langue sacrée de l'Indoustan. Dès 18\%0, il a traduit le Bhagavata-Pourana. GARCIN DE TASSY donne en 1839-1847 son Histoire de la litterature hindoue. 
Etudes tarares, turques, chinoises, japonaises. - De l'autre còté des montagnes qui forment au nord les frontières de l'Inde et de la Perse, commence un tout autre monde. C'est la région des peuples finnois, tatares, tures, mongoliques, menaçant éternellement les pays occupés par les peuples de race indo-européenne. Ils ne se sont guère signalés dans l'histoire que par leurs campagnes dévastatrices, sous les ordres de ces fléaux de Dieu qui s'appellent Attila (ve siècle), Gengis-Khan (xme sièele), Tamerlan ( $x v^{e}$ siècle).

ABEL RÉMUSAT et REINAUD nous ont appris la curieuse histoire des relations de nos rois avec les princes mongols, du xine au xye siècle.

Un des peuples de la race jaune, le plus nombreux de ious ceux qui couvrent la surface du globe, a possédé une civilisation brillante et complète, infiniment plus ancienne que la nòtre et qui, à certains égards et en cerłains temps, lui a été supérieure. C'est la Chine, que, depuis trois cents ans déjà, étudient nos missionnaires et nos savants. La connaissance de la langue, de la littérature, des sciences, des arts de la Chine a fait, en notre siècle, de grands progrès.

Ils sont dus surtout à ABEL RÉMUSAT, qui, à vingt-six ans, occupa la chaire de chinois créée en 1814 au College de France et traduisit le roman des "Deux cousines "; à stanislas Jolien, qui a traduit le philosophe Meng-Tseu, la comédie du "Cerele de craie ", le drame de "l'Orphelin de la Chine ", le roman-féerie des "Deux couleurres-fées" (1834), enfin les auteurs chinois qui se sont occupés de l'élève et des maladies du ver à soie, ainsi que de l'art de fabriquer la porcelaine; à TEÉodore pavie, qui nous a révélé les contes chinois, le roman intitulé "Histoire des trois royaumes " (1845), le "Laotseu " ou philosophie de Confucius; à ED. BIOT, qui s'est occupé surtout des sciences de la Chine; à GAILLARD D'ARCY, qui a enrichi de nombreuses traductions notre bibliothèque française-chinoise.

ABEL RÉMUSAT est le premier, en France, qui se soit occupé de la littérature japonaise.

Géographie, voyages. - Les découvertes maritimes des trois derniers siecles n'avaient laissé sur la carte du 
globe que querques taches blanches, indiquant l'absence de notions précises sur certaines régions. L'exploration des régions đu pôle nord a coûté la vie, en 1833, à un explorateur français, Jules De blosseville, et a provoqué l'expédition GAYMARD, de 1833 à 1840 ; mais, de ce còté, nous arons laissé zgir surtout les Anglais et les Américains, qui ont eu à déplorer la perte de beaucoup de vaillants hommes et de plusieurs navires. Les voyages maritimes de LA PLACE. DOMONTDURVILLE, DUPETIT-THODARS, CÉCILLE (1827-1840) ont achevé de nous faire connaitre locianie, sur plusieurs points de laquelle nous avons depuis planté notre pavillon.

En Afrique, sur les rivages de laquelle nous occupions déjà certains points et qui présente à son centre de si rastes régions inconnues, il y a eu d'importantes explorations francaises. Les contrées du haut Nil et l'Abyssinie ont été explorées par BRUN-ROLLET, VAUDEY, qui $y$ périt, D'ESCARAC, LEFÉvRe, les frères D'ABBADIE. En 1846, MAIZAN fut assassiné sur la côte de Zanguebar. Partant de nos établissements du Sénigal, perRolet et Lefel (1833), CAILle et BUART 1840), RAFFenel (18\$4), ont passé du bassin de ce fleuve dans celui du Niger. En 1828, René carlé, déguisé en Égyptien, était parvenu du Sénégal à Tomboutou : de Tombouctou, à travers le Salıra, il avait pu regagner le Maroc et l'Europe (1828) : voyage si hardi et si perilleux que les Anglais refusèrent d'y croire.

Il faut encore signaler les voyages du colonel vialla (1819) au Honténégro, alors absolument barbare; de вorTa et EResnel, dans la vallée du Tigre et de l'Euphrate; de Jacouemont, dans l'Inde (1822); de l'évèque BRUguiène, d'Auguste WALlin et de Léon roche, en Arabie; d'Alcide d'orbigny (1826), dans les régions inconnues du bassin de l'Amazone.

Dè 1821, s'est fondée à Paris la Socite de Grographie, émule de celle de londres. La collection de "l"Livers pitcoresine ", celle des "Annales des voyages ", de MalteBrun, ont contribué à vulgariser la connaissance du globe. Au Dépòt de la guerre, au Dépòt de la marine, nos militaires et nos marins ont rivalisé avec les ingénienrs civils pour la confection des cartes. La Géographie de Malte-Brun arait été commeneée en 1810. 


\section{L'économie politique et la sociologie.}

L'économie politique. - Les doctrines du libre-change, professées par les physiocrates du xvme siècle, puis par l'Anglais Adam Smith, puis, sous Napoléon, par JEAN-BapTISTE SAY ${ }^{1}$, furent reprises en notre siècle par BASTIAT ${ }^{2}$, MICHEL CHEVALIER ${ }^{3}$, ROSSI ${ }^{4}$, ADOLPHE BLANQUI ${ }^{5}$. Elles trouvèrent peu d'écho dans les Chambres des deux monarchies parlementaires, mais firent beaucoup de chemin dans lopinion.

Les théories communistes et collectivistes. - Le comte de SAINT-SIMON était mort en 1823̆, après avoir résumé ses doctrines industrielles, sociales et religieuses dans son "Nouveau cliristianisme ", et fondé pour les soutenir une feuille périodique : le Producteur. Ses disciples, les Stintsimoniens, dont les principaux étaient alors ENFanTis et BAZARD, commencèrent à prêcher, rue Taranne, la foi nouvelle et publièrent une autre feuille : lorgunisateur. Suivant eux, l'histoire de l'humanité avait été jusqu'alors "l'exploitation de l'homme par l'homme"; il fallait y substituer "l'exploitation de la nature par l'homme associé à l'homme". La cause de tous les maux dont souffraient les classes lahoricuses, c'était la concurrence : il fallait détruire la con inrence. Le travail était asservi au capital: il fallait detruire le capital. Pour l'empècher de se reformer, il fallait abolir l'hérédité : a la mort de chaque proprictaire. ses immeubles, ses capitaux, ses instruments de travail, feraient retour à

1. Say a publié un Traité d'économie politique (1S01), un Catéchisme d'économie politique (1815) et un Cours d'economie politique (1815.

2. Bastiat fit connaitre (18'5) les efforts que faisaient, en Angleterre, Cobden et la Ligue de Hanchester pour combaltre les lois sur les céréales ot tout l'ancien systeme douanier. 11 a publié les Sophismes economiques (1846-1851) et les Harmonies économiques (1850-1851).

3. On doit à Michel Cheralier, d'abord saint-simonien, plus tard sénateur du second Empire, le livre intitule : Interêts matériels de la France (1838), et beaucoup d'autres ouvrages.

4. L'Italien Rossi fut ministre du pape Pie $1 \mathrm{X}$ en 18 is: il péril assassiné par des fanatiques. En 1833, il aviit élé appelé par Guizot a professer i'économie politique au College de France et publia son Cours, en $1=33$. 1841.

5. Blanqui, qu'il ne faut pas confondre avec le démagogue du mème nom, fut un disciple de J.-B. Say. Il publia son Cours fait all Conserenturre dez $\Delta r t s$ et Metiers (183i) et ane Hisivire de l'economie politique (155i). 
la communauté. Celle-ci les répartirait entre les travailleurs. Il n'y aurait plus de propriétaires, mais des serviteurs de l'État, qui serait le seul propriétaire du sol, le seul industriel, le seul commercant, mais qui nourrirait tous les travailleurs. Et d'abord l'Etat ancien, l'Etat aristocratique et bourgeois, devait disparaitre : les Saint-Simoniens le remplaçaient par la communauté. Pour préparer l'émancipation de celle-ci, ils s'étaient déjà groupés en une famille ou église, pratiquant la vie en commun, ayant sa hiérarchie de dignitaires, ses degrés d'initiation, ses mères et ses pères, et surtout son père suprèmc ou son pape. Le pape était alors en deux personnes: Enfantin et Bazard. Il y avait un culte saint-simonien, avec offices, sermons, fêtes, baptèmes, confessions publiques ou secrètes, communions spirituelles. Ghaque membre de la famille portait un costume déterminé par les règlements. Les Saint-Simoniens formaient si bien un clergé qu'ils se refusaient au service de la garde nationale et príféraient aller coucher au poste. La Révolution de 1830 donna l'essor à la nouvelle église. Le journal le Globe, acheté par les sectaires, adopta ce sous-titre: "Journal de la doctrine de Saint-Simon ". Ils s imposirent à l'attention du public par un délugre de brochures, une multitude de cours, conférences, prédications, offices au temple de la rue Taitbout. Ils organisèrent des missions dans les provinces et $y$ fondèrent cinq églises. Ils se vantaient d'avoir 40000 adlicrents et comptaient dans leurs rangs des hommes d'une haute valeur et célèbres depuis à divers titres : le poète Sainte-Bcuve, le financier Pereire, le publiciste Guéroult, l'économiste Michel Chevalier, le musicien Félicien David. Ils professaient un profond mépris pour le régime parlementaire, et ces trois mots, libéral, bourgeois et égoiste, étaient pour eux synonymes.

Un schisme naquit parmi les adhérents lorsqu'Enfantin, développant certaines de ces doctrines, se proclama la loi vivante, appela les femmes dans l'église, prêcha leur émancipation et les unions libres, se proposa de confier le pouvoir suprême à un couple-prétre, donna au Globe un nouveau sous-titre: "L'appel aux femmes ". Bazard fit scission en protestant contre l'immoralité de ces doctrines. La fumille, reforméc sous l'autorité unique d'Enfantin, mena 
d'abord joyeuse vie rue de Monsıny; puis, accablée de dettes, se retira sur les hauteurs de Ménilmontant, où l'on vit les frères se rendre mutuellement les scrvices de la domesticité, faire la cuisine, brosser les habits, cirer les bottes, cultiver eux-mèmes la terre de leur petit jardin, en chantant les hymnes composés par Félicien David.

En jauvier 1832, les Saint-Simoniens, accusés d'outrage à la morale publique, furent traduits en cour d'assises. Ils y parurent en tunique bleue, pantalon blanc, ceinture de cuir verni. Enfantin portait sur la poitrine, en grosses lettres, ces mots : Le Pére. Il attesta qu'il était la loi vivante, irrita les magistrats par un pathos inintelligible et sa prétention d'essayer sur eux "la puissance de son regard". Trois des accusés furent condamnés à un mois de prison. Les autres se sécularisèrent, c'est-à-dire se dispersèrent, et allèrent porter dans les arts, l'économie publique, la finance, un levain d'idées parfois fécondes et originales. Enfantin, toujours à la recherche de la Mère, c'est-à-dire de la femme iléale qui devait compléter le couple-prétre, voyagea on Orient. Plus tard, le duc d'Orléans fit offrir à l'héritier de Moïse, de Jésus et de Nahomet, tombé dans l'isolement et la misère, une place de sous-préfet.

Les idées de rourier ont été professée dans ses livres intitulés "Traité de l'association domestique agricole " (1822), "le Nouveau Monde intellectuel ", "l'Harmonie universelle " (1849), et dans ses journaux, le Phalanstère et la Phalange. Ses œuvres ont été publiées en 1841-184วั.

Fourier abolit presque entièrement la propriété : tout est à tous, sauf les instruments de travail, qui restent personnels. Les travailleurs sont divisès en phalanges de 1600 à 2000 persounes, de tout sexe el de tout age, exploitant un établissement agricole ou industriel, appelé le phalanstère. Ne croyez pas qu'aucun d'eux refusera de travailler: Fourier a fait du travail, qui est un devoil fàcheux, un plaisir attrayant: les heures d'ateliel sont tres réduites, les occupations variées, égayées par ure agriable compagnie et par de la musique. L'art culinaire, élevé à la hauteur d'une science et devenu la gastrosophie, assure aux ourrier's, assis autour de tables communes, une nourriture abondante et recherchée: Fourier craint même qüils tu 
deviennent obèses. Il supprime toutes les entraves que des lois et une morale surannées apportent aux inclinations du cœur, ainsi que les soucis et les charges résultant de la paternité : les unions sont libres, et les enfants sont élevés par le phalanstère.

Fourier essaya inutilement de réaliser son phalanstère à Condé-sur-Vesgre et mourut en 1837. Ses disciples, les Fouriéristes, ont été fort nombreux. Is attendaient beaucoup de la mise en pratique de ces théories : ils pensaient mème que, dans un régime de vie aussi rationnel, l'ètre humain pourrait se perfectionner, acquérir des facultés et mème des organes nouveaux, par exemple, un œil de plus, comme l'admettait tel de ses disciples.

CABET, dans son "Voyage en Icarie ", publié en $18 \pm 1$. présente le tableau enchanteur d'une société idéale, établic dans l'ile imaginaire qui a pour capitale Icara. Il respecte le mariage et la famille; mais, entre tous les habitants ¿'Icarie, il y a une communauté absolue de biens et de travaux, de droits et de devoirs, de bénéfices et de charges. Cest l'Etat qui fait fabriquer et qui vend, qui administre les chemins de ler et qui règle les fẻtes. qui prescrit les meilleures méthodes de culture et les machines les plus perfectionnées, qui détermine la coupe du vètement et le menu des repas. Aussi est-il fortement armé contre les insubordonnés : il n'y a qu'un journal en Icarie, le Journal offiriel; l'histoire y est rédigée par des historiographes officiels, d'après les sentences rendues par un tribunal sur le mérite et le démérite des personnages historiques.

PIERRE LEROOX s'était séparé d'Enfantin en mème temps que Bazard. Dans ses livres sur l'Eqalité (1838) et sur IHumanité $(18 千 0$ ), il mèle aux idées sociales des idkes mrstiques et religieuses, identifie l'homme avec l'humanité, Dieu avec le monde, nie la vie future et se perd dans des rèveries sur la triade et sur le circulus, sur le cylindre, qui Loit ètre le symbole de la liberté, et sur le cöne. qui est celui de la fraternité, comme la sphere est celui de l'égalité.

LOUIS BLANC, dans son "Organisation du travail " (1841), dans son "Catéchisme des socialistes " (18:9), roit, lui aussi, dans la dirersite des intérèts. la cause de tous les mulux. Il veut substuer à la concurence l'association, 
l'harmonie, la fusion. S'il respecte la famille, il supprime l'hérédité, d'abord en ligne collatérale, et plus tard en ligne directe. Il tend à faire ahsorber par l'Etat tous les établissements industriels, toutes les propriétés agricoles, de façon à anéantir toute industrie et toute agriculture privées, les tuant d'abord par la concurrence officielle, afin de détruire plus surement ensuite toute concurrence. Mis par la Révolution de 1848 en possession du pouvoir, ce sont ces idées, à peine mitigćes, qu'il développe aux ouvriers de Paris, dans ses fameuses conférences du Luxembour'. En attendant mieux, il proposc que l'Etat subventionne un certain nombre d'ateliers socioux ${ }^{1}$.

Toutes ces doctrines se ressemblent par un caractère: c'est le communisme ou le coliectivisme. A l'activité individuelle, elles substituent toutes l'activité collective. Pour annihiler l'indivirlu, en vue d'assurer son bonheur, elles confèrent toutes à la puissance collective, qu'elle s'aprelle le Couple-prètre, le Phalanstère, l'État icarien ou l'Etat français réformé, une autorité absolument despotique.

Les thénries amarehistes. - PRODDHON ${ }^{2}$ se sépare nettement de ces écoles. Sans doute, lui aussi est l'ennemi de la propriété. En 1841, paraît sa brochure intitulée: "Qu'estce que la propriétí?" A cette question, il répond par le mot célèbre de Brissot de Warville: "C'est le vol ". La propriété n'est pas juste, car elle crée l'inégalité; or, la justice, c'est l'égalité. Tous ont '́galement le droit d'octuper la terre: donc nul n'a le droit de la posséder. Tous ont igalement le droit de vivre en travaillant; donc, nul n'a la propriété exclusive des instruments de travail. Le capital n'est pas quitte quand il a payé à l'ouvrier son salaire : celui-ci conserve un droit naturel de propriété sur les objets que son travail a crés. La rémuníration de tous les travaux de durée égale doit ètre égale : done la journée d'un ingé-

1. Sa proposition, d'ailleurs défguree, aboutit aux ateliers nationauc do 1848, ou se préparèrent les jouruées de juin.

2. Né à Besançon en 1809, mort à Paris en 1865. 11 a publié : Qu'est-ce que la probriéte, 1811 ; Création de l'ordre dins l'humanite, 1343 ; Contradictuns économiques, 1846: Confession d'un Révolutionnaire, 1849; La Révolution sociale demontrée par le coun d'Etat, 185\%; D! la justice dans la Fievoution et dans l'Eglise, 1855 ; etc. C'est un economisto très savaist et uz - crivain de premier ordre. 
nieur ne doit pas être payée plus que celle d'un manouvre.

Proudhon combat le communisme avec la mème ènergie que la propriété. Nul n'a réfuté avec autant d'esprit et de force Saint-Simon, Fourier, Cabet, Leroux. Il montre a quel point les instincts primordiaux de l'homme répugnent à la vie commune, à la propriété commune, à la famille commune. Il n'est pas moins sévère pour les socialistes mitigés, comme Louis Blane, qui demandent des ateliers nationaux, c'est-à-dire la ruine de l'industrie privée, ou une organisation du crédit par l'État, ce qui entraine la suppression du capital privé et frappe de stérilité l'épargne, cette grande force économique.

Loin qu'il attende rien de l'État pour l'organisation du travail, il regarde tout État comme le principal obstacle au progrès. Il voudrait l'anéantir, avec ses frontières, sa diplomatie, ses armées permanentes, ses tribunaux. La seule force organisatrice de l'avenir, c'est l'association libre des travailleurs. A la réforme par l'État, Proudhon oppose la réforme par l'anarchie, qu'il définit " la négation de toute autorité ".

Sans entrer plus loin dans l'étude des sectes socialistes, on voit que celles qui s'agitent sous nos yeux, et qui se divisent en deux grands groupes, les collectivistes et les anurchistes, procèdent toutes soit du communisme pur de Saint-Simon, Fourier ou Cabet, soit du collectivisme mitigé de Louis Blane, soit de l'anarchisme de Jroudhon. La différence principale consiste en ce que les unes attendent tout de l'Élat, et que les autres veulent commencer par. détruire les États.

\footnotetext{
Dlvrages a conzulter. - Voyez la bibliogr. du chapitre xxi et, puir lit se h n 111 , celle du chapitre xxxul.
} 


\section{CIIAPITRE XNI}

LES ARTS

Nos victoires avaient enrichi nos musées. Epargnés lors de la première entrée des alliès à Paris (1814). ils furent dépouillés à leur seconde entrée (1815). Suivant l'expression du Régent d'Angleterre, ces trophées artistiques de nos gloires " ne pouvaient manquer de faire vivre lans la nation française le souvenir de ses anciennes conquètes et d'entretenir son esprit militaire et sa vanité ". C'est alors que cette magnifique statue antique, la Vínus de Médicis, et bien d'autres merveilles nous furent enlevées. Le moment était venu où les artistes français allaient produire assez de chefs-d'cuvre pour combler les vides produits dans nos collections par ces revendications à main arméc.

\section{L'architecture, la sculpture.}

Larchitecture de la Restauration. - La Restauration fut une époque de médiocrité et de stérilité pour l'architecture mème religieuse. On avait renoncé à l'art classique, et on ne comprenait pas encore l'art chrétien du moyen âge, car la Restauration dispersa le musée d'antiquités nationales créé par la Convention. La révolution romantique, si brillante dans la littérature et dans la peinture, ne produisit que tardivement ses eflets en architecture.

En fait de monuments publics, on se borne à continuer ceux qu'avait laissés l'Empire. En 1823, on reprend lcs travaux de l'Arc de triomplie, qu'on veut dédier à l'armée 
qui venait d'opérer la contre-révolution en Espagne.' vignon reste chargé de l'achèvement de son monument, très embarrassé de laire de ce temple une église. On inaugure la Bourse en 1826. Sur la Colonne de la place Vendòme, à la place de la statue de Napoléon, renversée en 1814, flotte le drapeau blanc. Toutes les églises construites à cette époque sont d'un pauvre style: Notre-Dame de Lorette, par LEBAS (1824): Saint-Vincent de Paul, par LE PÉRE et son gendre hittom; la Chupelle expiatoire, par fontaine. alavoine prétend achever la catedrale de Rouen, mais il lui donne, par on ne sait quelle fàcheuse inspiration, une flèche en fer.

DEstallleurs commence le Ministère des finances, construit l'Hospice de Saint-Mandé et le Pussuge Jouffroy. La mode est alors aux passages : rohadut de fleury batit le Passage du Saumon, mazors le Passage Choiseul et le Passage Saucede. Tout cela n'a rien à voir avec le grand art.

Larehitecture de Ia Monarehie de Inillet. - Sous le régime qui suivit s'achève l'Arc de triomphe, dont les travaux sont confiés à воуот, puis à BLODET. Restitué à la gloire de la Grande Armie, orné des quatre grands bas-reliefs de Fude, Cortot, Elex, et d'autres bas-reliefs de Cortot, Lemaire, Feuchère, Chaponnière, décoré à l'intérieur d'inscriptions qui reproduisent les noms des batailles, les noms des armées républicaines et impériales, les noms des généraux. il est inauguré en 1836 . On peut alors admirer l'imposante conception de Chalgriu, ces proportions colossales, la simplicité de ces grandes lignes, se développant magnifiquement sur l'horizon de Paris, et dont l'efiet est doublé par cette large avenue des Champs-Elysées et toutes ces arenues, aux noms retentissants de généraux et de batailles, qui rayonnent alentour. Sur la Colonne, on place le Napoléon populaire ef militaire, au grand chapeau, i la redingote grise. La Nadeleine est inaugurée en 1842. On achève les églises de la Restauration. LAconnée termine le palais du quai d'Orsay (Conseil d'Etat et Cour des comptes), commence le Paluis les Beaux-Arts, achève le Mnistère des Affaires étran!jẻres. LÉon vaudoyer restaure l'église et l'abbaye de Saint-llartin, qui deviennent le Conservatoire des Arts et Metiers. On construit la fontaine Molière, le pont du Carrousel, la prison de Mazas, la gulerie d'Orléuns 
au Palais-Royal. Sur la place de la Bastille, où Napolíon avait fait élever par Alavoine le modèle en plàtre d'un éléphant colossal, alavoine et Doc érigent la Colonne de Juillet

gRILlon, sur la place de la Concorde, dispose les socles des villes de France, fait jaillir les fontaines, dresse l'obélisque égyptien de Louqsor. Hitronfr s'empare des Champs-Elysées, leur donue l'aspect qu'ils ont aujourd'hui, les dote de la Rotonde des Panoramas et du Cirque d'été. Il bâtit la Caserne des sapeurs-pompiers, la Mairie du Pınthéon, le Cirque d'hiver. visconn construit la Bibliothéque Royale (depuis 1825); les fontaines Gaillon (1824), Louvois (183\%), Molière (1841), Saint-Sulpice (1812); le Tombeau de Napoléon aux Invalides (1842). LaBrouste élève la Bibliothéque Sainte-Geneviève (1843), continue la Bibliotheque Nationale. RoHadLT DE FLeURy travaille all IIuséum d'histoire naturelle. Le Havre doit à BRUNET-DEBaINes ses principaux monuments. DALGABIo construit ceux de Saint-Étienne. DARDEL, à Lyon, restaure l'Hotel de ville, bàtit le Palais de la Bourse et dn Commerce, perce la rue Impériale; LĖon EEUCHère dessine les théatres de Toulon et d'Avignon; PENCHAUd est le grand architecte de Marseille; тніac. de Bordeaux. En somme, inalgré l'effet imposant de quelques-uns de ces monuments, il n'y a pas lá un art nouveau.

Chose singulière, ce n'est pas sous la Restauration, mais sous la Monarchie de Juillet, si peu dérote, que conmence la renaissance de l'architecture religieuse. Elle s'accomplit par le retour aux modèles que nous a lègués le moyen àge, ees rieilles églises que Montalembert, Prosper Mérimée, Victor Hugro, signalaient à l'admiration du public et qu'ils défendaient contre le vandalisme. La fondation de la Societé d'archéologie par Caumont, du Comité les arts et monuments par le ministre Salvandy, les lois votées pour protéger nos anciens monuments, attestent le revirement qui s'est opéré dans les esprits. Lenorr restaure l'Hótel de Cluny (183\%), qui devient le Musée de Cluny; Baltard restaure, a Paris, Saint-Germuin des Prés, Suint-Séverin, SaintEustache: Lassus restaure Suint-Germain l'Auxerrois (1836), la Suinte-Chavelle (18:0-1856), Notre-Dame de Paris (184518:i), la cathédralt de Chartres (18千3). On ne néglige pas 
nos antiquités romaines, car LENOIR restaure à Paris les Thermes de Julien; DURAND et GRANGENT, la Maison Curvéc de Nîmes; QUESTEL, l'amphithétite d'Arles.

A l'étranger, montrernand dotait Saint-Pétersbourg de cette magnifique cathédrale Saint-Isaac, où il a prodigué le bronze, le marbre, la malachite, le lapis-lazuli. et qui restera un des plus beaux spicimens de l'architecture dite byzantine (1814-1831).

\section{Caractères généraux de la sculpture franģaise. -}

La révolution romantique a beaucoup moins influé sur la sculpture que sur la peinture. La statuaire, en effet, est soumise à des conditions matérielles qui limitent les caprices de la fantaisie. Celle-ci ne peut se mettre en révolte contre les lois de l'équilibre apparent, contre certaines exigences esthétiques, comme la nécessité de présenter une cuvre belle de quelque côté qu'on la regarde. La statuaire ne peut s'accommoder des attitudes tourmentées, qui donnent quelquefois leur originalité aux figures peintes : sa beauté a toujours quelque chose de calme et de reposé.

On peut signaler, en notre siècle, quatre tendances entre lesquelles se partagent les artistes de la sculpture: la tendance classique, qui cherche a tout prix la beauté idéale, même aux dépens de l'exacte réalité; la tendance romuntique, qui fait saillir les muscles et veut avant tout du " caractère" dans les physionomies, comme ont fait MichelAnge et Puget; la tendance maniérée, qui est un retour aux traditions du xvıı siècle et qui vise uniquement au joli; la tendance réaliste, qui pousse l'artiste, par un respect exagéré du vrai, à copier les mod’̉les d'atelier, e'est-i-dire, suivant l'expression de M. Eugène Guillaume, à " rendre telles quelles des natures obscures, dépourvues de caractère moral et, à plus forte raison, de beauté ".

De ces diverses tendances, les deux premières surtout se sont disputé les artistes dans la première moitié du siècle; les deux autres ont agi concurremment avec celles-là, surtout dans la seconde moitié 1

1. Il est difficile de marquer exactement la limite entre ces deux époques; mais, dans la premiere, nous placerons les sculpleurs qui ont recu les lecono des maitres de l'épnque révolutionnaire ou impériale, des Ramey, des Lemot, des Cartellier. des Bosio, des Cauova; dans la seconde, ceur 
Les scuipteurs. - RUDE, de Dijon (1784-1855), peut passer pour le type du révolutionnaire romantique en sculpture. Il a produit telle ceuvre où l'attitude est violente à l'excès, le geste peu naturel, l'ensemble dépourvu de beauté, comme la statue du muréchul Ney au carrefour de l'Observatoire; en revanche, il a rencontré la force, la fougue, l'élan, l'énergie heureuse, comme dans son chef-d'œuvre, cette Varseillaise de l'Arc de triomphe (1838) qui, d'un geste si emporté et d'un cri si retentissant (car on croit l'entendre crier), soulève pour la guerre d'indépenılance les vieux guerriers aux forts biceps et les jeunes héros aux membres élégants. Il $y$ a une beauté plus sereine et plus classique dans d'autres de ses cuvres: son "Mercure rattachant ses talonnières" (1827), son "Jeune pêcheur napolitain" (1833), "l'Amour dominateur ", "Hébé et l'aigle de Jupiter ".

DAvid D'ANGers (1784-18506) a été un élève de Roland 1, de Canova, du peintre David. De l'évolution romantique, il n'a guère gardé que le caractère moderne de ses types et de ses draperiss. Il a de la dignité, de la grandeur, du naturel. Son œuvre immense, ses statues, ses bustes, surtout ses médaillons, font revivre tous les hommes illustres de l'époque. 11 a laissé peu de groupes. On lui doit cependant le fronton du Panthéon.

PRADIER (1790-1852) fut un élève du classique lemot. Les qualités maitresses de son génie sont la pureté, la grâce, le fini. Parmi ses chefs-d’euvre mème, il faut laire un choix et se borner à citer "Psyché " (1824), "les Trois Grâces " (1832), "Nyssia ", le "Printemps ", la "Toilette d'Alalante ", "Sapho " (1852).

Cовтот (1787-1843) a modelé "le Soldat de Marathon "

qui oul ręu les onseignemnts de cerx-là ou de leurs élèves. En général, les œuvres des premiers sont exposées au musée du Louvre el les œuvres des seconds au musée du Luxembourg, saus parler de celles qui sont dispersées dans les édifices publics ou privés.

1. "David a eu des commencements bien difficiles, raconte M. Jesn Gigoux dans ses Canseries. Il m'a conflé là-dessus des choses d'un intérćl poignant que je n'ai jamais divulguées pendant sa vie... Écoutez donc, jeunes gens qui vous plaignez si souvent. David m'a conté que sa pénurie était si grunte quand il était a l'atelier de $\mathbf{M}$. Rnland, qu'il en était réduit, pour vivre, a ramasser les croúles de pain des camarades quand celax-ci elaient partis! il les mettail tremper dans le baquet pour sa aourrituro de la jolruce! * 
(1822), "Daphnis et Chloé " (1827), "le Triomphe de Napoléon "à l'Arc de l'Étoile, le fronton du Corps législatif.

CHARLes Nanteull (1792-186ö), élève de Cartellier, a donné un "Ajax mourant" (1817), "Eurydice piquée par un serpent " (1822), les frontons de Saint-Vincent de Paul et de Notre-Dame de Lorette.

On doit à henry. LEmaIre, né en 1798 et élève de Cartellier, " la Jeune fille au papillon ", le "Laboureur ", " la Jeune fille piquée par une vipère ", le fronton de la Madeleine.

ALEXANDRE DUMONT, né en 1802 , fils, petit-fils et arrièrepetit-fils de sculpteurs éminents ${ }^{1}$, est l'auteur de "l'Amour tourmentant l'àme ", de "Leucothoé el Bacchus " (1832), du Génie de la Liberté sur la colonne de Juillet, du Napoléon militaire et populaire sur la colonne Vendòme, des figures lu pavillon de Lesdiguières au Louvre, d’une infinité de statues. Il fut plus illustre encore par les iminents élèves quil forma : un grand nombre des artistes de la seconde moitié du siècle sont sortis de son atelier.

Clésinger, né à Besançon en 1841, gendre de George Sand, fut un artiste puissant, d'une grande vivaciti de mouvement et d'expression. mais peu maître de lui-même, inégal et incomplet, souvent défectueux dans l'exécution. Son ceuvre ressemble à cette statue de François Jer qu’il devait dresser dans la cour du Louvre, quil avait concue colossale et qui n'a point été achevée. Chose singulière, c'est par quelques ceuvres gracieuses, la "Femme piquée par un serpent ", " la Bacchante ", " Rachel en Phèdre ", " la Tragedie ", que ce rude génie passera à la postérité.

On peut encore citer de cette génération GatTeaux ${ }^{2}$, pour son "Triptolème " et sa "Ninerve" (1836); roman, pour son "Nisus et Euryale "; Allien, pour son "Aliane ", sou "Viala ", son "Philopœemen "; royatien, pour son "Spartacus " (1827); les deux dantan, Antoine et Jean-Pierre; Jaley, pour ses statues de "la Prière " (1833) et de "la

1. Arrière-petit-fils de Francois Dumonl (tis lui-nène de P. Dumont, illustre sculpteur du $x \mathbf{v i}^{*}$ siecle), auteur du Titan foudroyé (1712): petitfils d'Edme Dumont, qui, en 1768, fit Milon de Crotone essayant ses forces; tils de Jacques Dumont, dont il a été question au chapitre $x$, et qui, avec Cartellier, fut son mailre.

2. Son atelier fut, en $187 t$ incendiè par les insurgès de la Communo. 
Pudeur "; Triquetr, pour son " Pétrarque lisant ses vers à Laure "(1839) et pour ses belles portes de la Madeleine; DURET, pour son "Jeune pécheur dansant " (18.38), son "Vendangeur ", sa "Vénus au bain ", son fronton du Louvre (1852), son groupe de la fontaine Saint-Michel (1866); Jourfrox, pour son " Caïn maudit " et son "Ingénuité " (1839); sIMART, pour son "Gladiateur mourant ", son fronton du pavillon Denon; BARYe, le grand sculpteur animalier, dont on peut admirer les groupes de bêtes en bronze verdâtre du jardin des Tuileries et du musée du Luxembourg et son "Thésée combattant le Minotaure".

\section{La peinture, les arts du dessin.}

Les révolutions de la peinture. - La peinture dispose de bien d'autres ressources que la sculpture : elle n'est pas enfermée dans le contour d'une statue; elle a pour elle la marrie de la couleur, les illusions de la perspective, la faculté de multiplier les plans, de grouper des foules dans un espace étroit, de nous donner sur une surface plane des profondeurs infinies, d'y enfermer la mer sans bornes et le ciel sans limites. Il n'est pas étonnant que, de tous les arts plastiques, elle ourre la plus vaste carrière à la fantaisie, à l'initiative individuelle, aux rivalités d'écoles, aux renouvellements incessants. Aussi a-t-elle pu avoir autant de révolutions que la littérature elle-même, être tour à tour classique, romantique, réaliste, impressionniste.

Essayons de grouper par générations les principaux peintres de ce siècle. Celle de la Restauration a eu pour chefs Eugène Delacroix, Géricault, Ary Scheffer, Sigalon, Léopold Robert, Paul Delaroche, Ingres, Picot, Leion Cogniet. Elle a vu les brandes batailles des classiques et des romantiques.

Celle de la Monarchie de Juillet a compté parmi ses illustres Horace Vernet, Alfred Johannot, Decamps, Ies deus Devéria, Auguste et Hippolyte Flandrin, Jean Gigoux, Couture, Lehmann, Ziégler, Karl Girardet, Philippoteaux, Josepb Robert-Fleury, Amaury-Duval, Gudin, Roqueplan, Marilhat. Brascassat. 
Cette génération a été témoin de la fusion, de la pacification, de la pénétration mutuelle des écoles, en lutte si ardente à l'époque précédente.

\section{Les peintres de la Restauration : classiques et} romantiques. - Parmi les peintres de l'âge précédent, nous en avons distingué qui, tout en s'intitulant classiques, ont échappé cependant par la puissance de leur génie à toute mesquinerie d'école : David lui-même, surtout dans ses portraits et ses tableaux d'histoire contemporaine, Regnault, Prud'hon, Carle Vernet, Isabey l'Ancien, Gérard. Gros. D'autres sont des classiques au sens strict du mot : Lethière, Girodet, Guérin. Ce qui caractérise ccux-ci, c'est le choix presque exclusif de sujets antiques, un dessin correct, mais froid, un coloris pauvre et monotone. Prenons quelques-uns des tableaux les plus typiques de l'école : "Phèdre accusant Hippolyte ", ou "Andromaque implorant Pyrrhus ", qui sont de Guérin. Rien ne ressemble plus à une tragédie classique du xvıne siècle : deux ou trois personnages principaux, auxquels on adjoint parfois un confident; pas d'action, mais des attitudes de thêtre, des gestes convenus d'acteurs; aucun caractère dans le costume, qui a la prétention d'ètre antique, mais qui n'est que du faux antique; un fond négligé et vague, un mobilier paure et quelconque; l'action se passe n'importe où, en un lieu qui peut être Athènes aussi bien que Rome. C'est du bas-relief colorié plutòt que la peinture. La peinture ainsi réduite aux ressources de la sculpture, appauvrie comme la langue des tragédies de Voltaire, n'a ni chaleur, ni vie. Or, les classiques de génie et les classiques de procédé, un Gros aussi bien qu'un Guérin, si différents qu'ils fusscnt entre eux, se croyaient tous de la mème écolc, celle de David '. Comme ils occupaient les sièges de l'Ins-

1. Lne anecdole montre le remords singulier dont furent pris les élèves de David, ceux qui étaient le plus émancipés de l'influence davidienne, qurad éclata la révolution romantique avec toutes les exagérations, les brulalilés, les injustices, mėme les fẻrocités d'une école qui se lève. En 1S2i, comme Gérarl et Gros paraissaient trés affectés de la mort de Girodet : "Que no le remplacez-vous! dit à Gérard un peintre de l'ancienne écule. Et que ne vous levez-vous pour remettre l'école dans la bonne voie, puisque David est exile? - C'est ¿s que je devrais faire, dil Gérard, mais je confesse que jo ne m'en sens pas la force : jen suis incapable. - Puur moi, s'ecria 
titut, formaient le jury des salons de peinture, inspiraient la critique d'art dans les journaux, recevaient les commandes de l'État ou les faisaient donner à leurs élèves, il n'y avait plus de place au soleil pour ceux qui cherchaient d'autres voies ${ }^{1}$. Ceux-ci s'indignaient de ne voir partout que Grecs et Romains à jambes nues; ils aspiraient à laire éclater sur leurs toiles les brillantes symphonies des coloristes vénitiens. Une jeunesse ardente grandissait, en révolte aussi bien contre la peinture de Guérin que contre la poésie de Baour-Lormian.

"Nous étions, raconte M. Paul Mantz, en présence des derniers représentants de l'ćcole de Davil, prêtres d'un culte abrogé, qui, pour bien des raisons, n'inventaient plus et dont les froides réminiscences nous glaçaient jusque dans les moelles. Ces peintres avaient peut-être du talent, une sorte de propreté graphique qui faisait de quelques-uns d'entre eux d'estimables professeurs d'écriture. Mais notre état mental ne nous permettait pas d'apprécier les mérites de ces sages. On devine notre lassitucle et notre écœurement. Ces calligraphes attardés, élevant l'art à la hauteur du pensum, nous paraissaient les plus ennuyeux du monde. Nous avions des mépris superbes pour leurs recettes monotones et artificielles. Les personnages qu'ils mettaient en scène, sur un théàtre mal meublé, nous faisaient l'effet de mannequins d'autant plus coupables qu'ils étaient déclamatoires. Delacroix vint, et il nous montra des hommes. "

tout a coup Gros, dont les yeux étaient rouges et la voix allérée, non senlement je n'ai point assez d'aulorilé pour diriger l'école; mais je dois m'aciuser encore d'avoir été l'un des premiers à donner le mauvais exemple que lon a suivi, en ne mellant pas, dans le choix des sujets que j'ai trailés et dans leur exéeution, cette sévérité que recommandail mon maitro ot qu'il n’a jamass cessé de montrer dans ses ouvrages. "Touchante humilité chez deux peintres de génie el singulière méconnaissance de leur propre originalité ?

1. "Un jour, raconle M.Jean Gigoux, que je montais la rue de Tournon, je rencontrai Delacroix, qui la descendait. Dès qu'il m'aperçut, il leva les bras eu s'écriant : " $A$ h! mon cher, dix-sept de refusés! "C'utait le maliu de l'ouverture du Salon. Dans ce temps-là on présentait autant de tableaux qu'on voulait, mais le jury en refusait tant qu'i] voulait aussi. Pour changer le cours de ses idees, je parlai à Delacroix d'un petil hérilage qu'il venail de faire, et il me répondit: "Dui, au moins avec cela je suis sủr do ne pas mourir portier. 
EUGENE delacroix (1798-1863), le chef de l'école romantique, était cependant un élève non seulement de David, mais de Guérin. Son premier tableau épouvanta celui-ci (1822). Il représente “ Dante et Virgile»; les deux poètes sont promenés sur la barque infernale par Charon, qui, d'un geste furieux, à coups d'aviron, repousse et assomme la foule grouillante des morts, le tout d'une couleur éclatante, assombrie d'ombres tragiques. Puis vinrent les "Massacres de Scio " (1824), tableau qui fut un événement à la fois artistique et politique, protestation à la fois contre la tyrannie des peintres pseudo-grecs et contre l'abandon des insurgés grecs par les despotes de la Sainte-Alliance. C'était une scène orientale comme celles de Gros, mais avec plus de fougue dans le mouvement, plus d'éclat dans les tons, plus de soleil.

La lutte était déjà commencée, ardente, implacable, avec des injustices et des cruautés presque égales de part et d'autre. Les jeunes gens, en passant devant les tableaux classiques, affectaient de relever le collet de leur habit, comme s'ils eussent été frappés d'un froid soudain. Les classiques accusaient Delacroix de ne pas savoir dessiner, de barbouiller ses toiles avec un "balai ivre ".

Puis vinrent le "Combat du Giaour et du Pacha" (1826), la "Mort de Marino Faliero ", "Milton dictant le Paradis perdu ", la "Mort de Sardanapale " (1827), la "Liberté guidant le peuple " (1831), surtout la "Mort de l'évêque de Liège ", une scène inspirée de Walter Scott, dans un tumulte de figures féroces et de costumes truculents, à la lueur vacillante et rouge des torches. Chose singulière, Delacroix, le grand coloriste, n'a jamais été à Venise. D'abord il s'est épris des fraìclres couleurs de l'école anglaise de cette époque, lans les portraits de Lawrence, dans les paysages de Constable, dans les aquarelles de Varley et des deux Fielding. C'est en Africue, en pleine lumière du soleil, qu'il alla compléter son éducation. De son voyage au Maroc et en Algirie datent "les Femmes d'Alger " (1834), " une Noce juive au Maroc ", "la Chasse aux lions ". Son "Entrée des croisés a Constantinople "(1S+1), dans le fond bleu du ciel oriental, dans le panorama infini de la metropole du Bosphore, dans l'éclat et le contraste 
des armures franques et des riches draperies byzantines, est une adnirable page d'histoire. Sa "Médée " (1838) montra comme il était possible de rajeunir et de renouveler les sujets même classiques.

Delacroix, comme Victor Hugo, avait gagné sa bataille : il fut presque le peintre officiel de la Monarchie de Juillet, qui livra à son pinceau les murs et les plafonds du Corps législatif, du Luxembourg, de l'Hôtel de Ville, etc.

GĖRICAOLT (1791-1824). dont nous avons vu les débuts sous Napoléon, autre élève de Guérin, n'avait pas moins étonné le maitre. Il commença la révolte plus tòt que Delacroix, bien qu'il n'ait pas gardé le premier rang parmi les insurgés. Son "Naufrage de la Méduse ${ }^{1}$ ", exposé au Salon de 1819, ne se prètait pas à la coloration éclatante. Au contraire, pour donner à cette scène toute son horreur, il a fallu forcer les tons de bitume pour le radeau, le màt, la voile, les cordages, pour les chairs et les draperies des personnages, pour la mer et le ciel, également menaçants et implacables aux naufragés. Ce dessin hardi, ces raccourcis audacieux, ce fouillis de morts et de mourants, furent sévèrement jugés par les classiques, qui prétendaient que les personnagres de Géricault ressemblaient à des hommes comme une boîte de violon ressemble à un violon. Géricault était un génie puissant qui avait le goût du gigantesque. Quand ses amis, devant cette toile immense, lui disaient : "Voilà de la grande peinture! - De la grande peinture, cela! répondait dédaigneusement l'artiste. Mais c'est un tableau de chevalet! Ah! la grande peinture, c'est de la peinture avec des baquets de couleurs sur des murailles de cent pieds. "II connaissait le cheval à merveille : on sait qu'il s'était engagé dans les mousquetaires, et que, plus tard, il est mort d'une chute de cheval. Ses derniers tableaux, c'est le "Hussard chargeant " et le "Postillon faisant boire ses chevaux".

Un troisième élève de Guérin, ARY SChEFrer (1795-1858),

1. Le gouvernement ne se montrait guère gẻnéreux pour les artistes: il paya 6000 francs seulement à Géricault la grande tolle du Vaufrage de la líduse. Pourtant Louis XVIII, en lui remettant lui-mème la médaille du Salon, avait dit à l'artiste : "Monsieur Géricault, vous venez de faice cin Danfrage qui n'en est pas un pour vous. 
compléta la stupeur du maitre quand, à ce mème Salon qusi avait vu "Dante et Virgile " de Delacroix, il exposa ses "Bourgeois de Calais ". La " Mort de Gaston de Foix " et les "Femmes Souliotes" (1827) suivirent de près. Quoique lrès français par la perfection du goût et la netteté de l'idéc et du dessin, Ary Scheffer tenait de son origine hollandaise quelque chose de la rèverie du nord. Aussi a-t-il emprunté beaucoup de ses sujets, comme ses Marguerites de Faust et sa "Mignon regrettant sa patrie", aux légendes et la liltérature d'outre-Rhin. Dans "Françoise de Rimini " (1835), "Dante et Béatrix ", les scènes de la vie du Christ (la Tentation, le Baiser de Judas), "Monique et saint Augustin " (1846), "les Douleurs de la terre ", on retrouve la mème originalité de conception et la mème profondeur de pensée.

Il est un romantique de la littérature plutôt que de la peinture; il est romantique plutôt par sa passion pour Dante et Gœthe que pour ses procédés d'exécution. Il n'a rien de la fougue, du fier coloris de Delacroix. Sa peinture vit surtout par l'expression et le sentiment. Ary Scheffer est un peintre philosophe et un philosophe spiritualiste. Sigalon (1788-1837), un quatrième élève de Guérin, étaił né peintre; il avait d'abord été son propre maitre et s'ètait fait lui-mème. Il eut d'abord à lutter contre la mauvaise fortune. A l'époque où il peignit "la Courtisane " (1822), qui est au Louvre, un chel-d'cuvre tant de fois reproduit par la gravure, il vivait avec quinze sous par jour. Un soir, il se passa de diner pour entrer à la ComédieFrançaise. Trois vers du Britannicus de Racine lui inspirèrent "Locuste essayant ses poisons sur un esclave " (1824): rentré chez lui, il en traça l'ébauche en quelques heures. Ce tableau, pas plus que son "Athalie faisant massacrer ses enfants " ou sa "Vocalion de saint Jérôme " (1827), n'est daus la manière classique. Il y a, en toutes ses œuvres, une science du nu, une inergie dans la musculature qui rappellent ce Michel-Ange dont il copiait, quelques années plus tard, " le Jugement dernier ".

LĖOPOLd ROBERT (179'-183\%), né en Suisse, est cependant un des maitres de l'école francaise. Elève de David et de iros. il est surtout un coloriste. Il a vécu à Venise, à 
Riome, à Naples. C'est l'Italie elle-même, avec son ciel éclaiant, sa chaude lumière, ses beaux types humains, qu'il a transportée sur ses toiles : "Improvisateur napolitain" (1824), "Retour de pèlerinage ", "Moissonneurs des marais Pontins " (1830), "Départ des pècheurs de l'Adriatique " (1835), etc. Amoureux de son art comme on savait l'ètre alors, c'est au sentiment de son impuissance à reproduire l'idral sur la toile, tout autant qu'a une passion malheureuse pour une fille du roi Joseph, qu'il faut attribuer sa mort volontaire.

GRANET (1775-1849) continuait ses études de monastères. II avait tant fréquentí les moines qu'il en avait conservé quelque chose de monacal dans son costume, ses manières et son genre de vie un peu sauvage : "N'a-t-il pas l'air d'un vrai capucin? " disait un jour Louis XVIII, en regardant sa calotte noire. Granet a peint surtout des intérieurs d’églises et de monastères. "Il est le premier, mème avant Delacroix, qui ait deviné les tons ", dit M. Jean Gigoux.

PAdL DElaroche (1797-18ว̌6), élève de David et Gros, mais débutant vers 1822 en plein mouvement romantique, suivit d'abord ce mouvement, puis se fit une manière à lui. En lui se réalise la fusion des écoles rivales. Aussi n'a-t-il point la puissante originalité de Delacruix : il est un romantique atténué comme Casimir Delarigne en littérature. Il est, en peinture, comme Cousin en philosophie, un éclectique. Les fanatiques le dénonģaient volontiers comme un bourgeois, un notaire, Je Scribe de la peinture. Il a gardé de la révolution artistique le goùt des sujets modernes, de la draperie, de l'accessoire. Sa première grande toile, la "Mort d'Elisabeth, reine d'Angleterre " (1827), semble, dit Charles Blanc, " un bazar d'étoffes voyantes, un étalage immodéré de soie, de velours, d'hermine et de brocart, de rideaux ramagés, de coussins brochis d'or et de pompeuses tentures ". Au second rang comme coloriste, mais dessinateur correct, il a commo personne l'entente des grandes compositions, l'instinct du dramatique, le labeur à la fois acharné et facile, la science du costume, du mobilier et de toute l'archiologie. Il était né pour être le grand peintre d'histoire ct comme le Le biun de la Monarchie constitutionnelle. 
Aussi quelle magnifique série de vivante histoire que la "Scène de la Saint-Barthélemy " (1826), la " Mort du président Duranti ", la "Prise de la Bastille " (1830), "les Enfants d'Edouard ", cette pathétique illustration du drame de Casimir Delavigne; " Richelieu descendant le Rhône " " Mazarin mourant ", Cromwell ouvrant le cercueil de Charles Ie" " (1833), le "Supplice de Jeanne Gray", "Galilée étudiant le mouvement de la Terre ", "le Meurtre du duc de Guise " (183ð), "François de Guise et Ambroise Paré sur le champ de bataille de Metz ", "Charles Ior insulté par les soldats ", "Strafford marchant au supplice ", "Bonaparte franthissant les Alpes ", " le Dernier adieu des Girondins "! Rien qu'à parcourir cette galerie, on voit que Delaroche est contemporain de la grande résurrection de l'histoire par les Thierry, les Guizot, les Michelet. Il était si consciencieux que, pour ses tableaux " du Baptême de Clovis " et du "Couronnement de Charlemagne ", il visita Venise et Ravenne afin d'y étudier les monuments de style roman, qui sont ceux de l'époque qu'il avait à étudier. En 18:1, on lui donna à peindre l'hémicycle du palais des Beaux-Arts; là, sur une longueur de vingt-sept mètres, il représenta plus de soixante-dix personnages, les grands artistes de l'antiquité, du moyen àge et des temps modernes, présidés par leurs maîtres à tous: lctinus, Phidias et Apelle.

Pendant que l'école romantique s'exaltait avec Delacroix ou s'assagissait avec Delaroche, dans le camp de ces classiques si dédaignés, un artiste maintenait les traditions des maitres qui l'avaient formé, Regrault et David. Seulement, en retenant d'eux un dessin correct et un coloris tempéré, INGREs (1780-1867) s'appliquait à colriger certains défauts de l'école par une étude encore plus consciencieuse de la nature, mais dans ses lormes les plus suaves et les plus idéales. En face de l'école opposée, il resta un des grands peintres du siècle. Ingres, dout nous avons déjà signalé les brillants débuts, donna son "Odalisque " (1819), son "Vœu de Lous XIII" (1824), son "Martyre de saint Symphorien " (1827), qui furent en butte à une critique acharnée 
Dès lors a cessa d'exposer, mais non de produire. Son "Apothéose d'Homère " a servi de modèle à Delaroche pour son hémicycle. Sa "Jeanne Darc ", sa "Vierge à l'hostie ", sa "Naissance de Vénus ", "Jésus au milieu des docteurs ", "Molière et Louis XIV ", " la Source " (1861), "l'A pothéose de Napoléon " (brûlée en 1871 avec l'Hòtel de Ville), ses beaux portraits de Cherubini, Molé, Bertin (du Journal des Débats), attestent la fécondité de sa vieillesse.

PICOT (1786-1868) est le grand décorateur des plafonds vers 1830. On a de lui au Louvre " le Génie. es arts dévoilant l'Égypte à la Grèce " et "Cybèle protégeant les villes contre le Vésuve ".

LÉon COGNIET (1794-1880), élève de Guérin, a donné, sous la Restauration, son "Marius sur les ruines de Carthage " et son "Massacre des Innocents ". Par son cuvre principale, "Tintoret peignant sa fille morte " (1843), et par ses Batailles du musée de Versailles, il appartiendrait à la génération suivante. Ce furent encore ses élèves qui brillèrent dans les Salons des àges suivants.

Les peintres de la Monarehie de Juillet. - La plupart des maitres que nous venons d'énumérer restèrent, sous le régime qui suivit, en pleine possession de leur génie, ainsi que des honneurs publics. Ils eurent pour rivalux ceux qui sortirent alors de leurs ateliers.

La Monarchie de Juillet montra plus de libéralité pour les artistes que le régime précédent. Le chàteau de Versailles, qu'aucun roi n'avait liabilí depuis les journées d'octobre 1789, fut transformé, en 1537, en un vaste musée que Louis-Philippe dédia " à toutes les gloires de la France". Dans la famille royale mème, la princesse Marie était un sculpteur distingué. Le duc d'Orléans fut l'ami d'Horace Vernet et le protecteur de Barye, qu'il tira de l'obscurité et de la misère en lui faisant obtenir ses premières com. mandes.

HORACE VERNET (1789-1863) fut intimement lié avec les fils de Louis-Philippe. Il les accompagna, dans plusieurs de leurs

Diaz furieux, en frappant le plancher de sa jambe de bois. Horace Vernet montrant une Vierge a l'hostie, commandée a lngres par l'empercur Nico!as, disait : "Quand on pease que voila soixante ans quil nous debe dez bleus comme cela!" 
campagnes, sous luniforme d'officier de la garde nationa'e. Il est si bien de l'époque orléaniste qu'il avait adopté l'anachronisme à la mode : il s'ètait fait une tète de grognard de Napoléon Ier. Quoiqu'il ne fût pas autrement militaire, il avait la passion des chevaux, des uniformes, des scènes guerrières.

Déjà sous la Ricstauration, il avait peint les soldats de la grande époque, la Nort de Poniatowski, etc. Ces sujets ne plurent pas au gouvernement d'alors : le jury de peinture refusait obstinciment ses tableaux. Alors Vernet ouvrit une exposition privéc, où il produisit une cinquantaine de toiles: entre autres, la "Bataille le Jemmapes", la "Défense de la barrière de Clichy ", la "léfensu d'Huningue ", le "Soldat de Waterloo", la belle composition du "Massacre des Mameluks par le vice-roi d'Égypte " et ce tableau, si curicux pour les moenrs artistiques d'alors, qui représente IJorace Vernet et ses amis daus son atelier, peignaut, faisant des armes, battant du tambour, etc.

Il fut le peintre de batailles de la monarchie libérale. De son pinceau brillant, vif, alerte, il illustra la conquête de l'Algérie: surtout par cette immense toile de la "Prise de la Smala ", si amusante dans le détail et qui témoigne d'une si profonde connaissance des types, thes costumes et des paysages algériens. Il peignit aussi le "Siège d'Anvers ", plus tard, le "Siege de Rome", plus tard, la "Bataille de l'Alma ". Les sujets bibliques et orientaux l'attirèrent: il donna " Judith et Holopherne ", "Judas et Thamar ", "Rebecca et Eliézer ", " Mazeppa ", etc. On a de lui d'intéressants portraits, comme celui dı Frère Philippe.

Parmi les autres peintres d'histoire, il faut citer alfred JoBANNot, pourson "Ent rée de Mlle de Montpensier à Orléans" (1833); Decamps, un peintre orientaliste, pour sa "Halte de cavaliers arabes ", sa "Sortie de l'école turque ", et aussi pour quelques jolis tableaux de genre; EUGÉne DEvérIa, pour sa "Naissance de Henri IV", et achille Devéria, pou" ses tableaux religieux, auxquels a succédé, en 1850 , "Périclès chez Aspasie "; adgdste rlandrin, pour snn "Savoiarole prêchant à Florence "(1840); HIPPOLYTE FLANDRIN, pour son "Dante et Virgile ", son "Napoléon legislateur", pour son pénétrant portruit de Napolion III, pour ses fresques à 
Saint-Germain des Prés et dans d'autres églises; JEan GIGoux, pour sa "Mort de Léonard de Vinci ", son "Héloïse recevant les restes d'Abélard ", sa "Mort de Cléopàtre ", sa "Veille d'Austerlitz" (18ว7); couture, pour ses "Romains de la décadence " (183̃); zIÉGLer, pour sa décoration intérieure de la Madeleine; godin et Nestor rogdeplan, pour leurs études de marines; marilat, qui, dès 1832 , avait commencé a voyager en Orient, pour ses Scènes et Paysages de Syrie; Karl GIRARdet, pour ses "Protestants surpris au prêche " (18'2); Philippotzadx, pour son "Dernier banquet des Girondins" (1850); JOSEPB ROBERT-FLEURY, pour sa "Scène de la Saint-Barthélemy (1833), son "Colloque de Poissy " (1840), son "Pillage d'une Juiverie ", son "Charles-Quint au couvent de Yuste" (186i); AmadRY duval, pour ses peintures de Saint-Merry, de Saint-Germain l'Auxerrois, du chàteau de Saint-Germain.

BRASCASSAT a mis en scène les combats entre les laureaux, leurs batailles contre les loups, et nous a intéressé au paysage italien, en attendant que nous nous intéressions au nòtre.

Les dessinateurs. - CRARLET (1792-18.45), élève de Gros et disgracié par la Restauration, produisit plus de trois mille dessins. Il fut, plus encore que les artistes du pinceau, l'interprète des regrets et des tiertés de ce peuple de lirance qui avait recruté les légions de la Grande Armée. Il lui raconta son épopée querrière en scènes familières, humoristiques, parfois tragiques : "la Garde meurt ", "Vous ne savez - donc pas mourir ", "l'Aumône du soldat ", "Episode de la retraite de Russie ", "l'Empereur et sa garde ". Charlet était grand, avec une tète éncrgique, et ressemblait luimème à ses plus beaux grenadiers.

RAFFEt (1804-1860) traita presque les mèmes sujets. Son chef-d'œurre, c'est cette page fantastique, traduction en gravure de la célèbre ballade de Zedlitz, la "Revue nocturne ", où l'on voit l'ombre de l'Empereur, entourée des ombres de ses marechaux, passer en revue ses cavaliers dont les crànes ricanent sous les casques et ses fantassins qui, de leurs bras de squelettes, lui portent les armes.

Parmi les caricaturistes, notamment ceux du Charivari, qui ne connait GAVARNI (1802-1866), ses lorettes, actrices, étudiants, Bals de Paris, Enfants terribles, Parents terribles; 
cham, pseudonyme d'Amédée de Noé (1819-1879), élève de Delaroche et de Charlet, qui exécuta les piquantes séries des Souvenirs de garnison, Impressions de royage. Soulouque et sa cour, Représentants en vacances, et qui fit la première Revue comique du salon; DAomien (1808-1879), qui a dessiné ces types réalistes de Bourgeois censitaires, de Loeataires et Proprictaires, de Gens de justice, de Philanthropes du jour, de Robert-liacaire et de ses émules; BERTAll, auteur de tant de jolies charges; GRANDVILle (180318:\%, qui illustra les Scènes de la vie des animaux, les Petites mis̀̀res de la vie humaine, les Fleurs animées, La Fontaine, Béranger, les voyages de Gulliver.

Les artistes graveurs. - Il laut retenir les noms de DIEN, qui interpréta les Batailles de Gérard; de FORSTER, qui traduisit les maitres italiens; de HENRIQOEL-DOPONT, qui grava les œuvres des peintres contemporains et popularisa l'Hémicycle de Paul Delaroche.

Les progrès de la gravure sur bois ont permis d'éditer les journaux illustrés, comme le Magasin pittoresque (1830), le Musée des Familles, l'Illustrution, le Monde illustré. Ils ont donné l'essor à cette imagerie d'Épinal, de Metz, de Pontà-Mousson, si populaire dans nos villes et nos campagnes.

les artistes lithographes. - Aux procédés de la gravure sur cuivre ou sur bois, au burin ou à l'eau-forte, sont venus s'ajouter ceux de la lithographie, inventie, en 1793, par Senefelder, et de la lithochromie ou chromolithographie, devinée par lui, mais réellement fondée par Engelmann(183i).

Le romantisme a rérolutionné la lithographie. Les grands peintres Giricault, Ary Scheffer, Horace Vernet, furent aussi des artistes lithographes, de mème que les grands dessinateurs Chrlet, Raffet. Gavarni, etc.

Le élébre paysagiste rrançaIs fut d'abord un admirable lithographe. Delacroix, dont il reproduisait la "Barque de don Juan ", se montrait, en examinant son propre tableau, très affligé des défauts qu'il y découvrait. "Que roulezvous! dit-il au graveur. Faites comme vous pourrez. Est-ce qu'Audran a copié Le Brun littéralement? Il l'a recalé. Eh bien. "tealez-moi aussi!"

Citons encore J. P. Sudre, Aubry-Lecomte, et le peintre Charles Muller. 


\section{La musique.}

Progrès de lämusique an XXX sièele. - Des trois pays qui avaient été la patrie de la musique au siècle précédent, l'Italie, au $x x^{e}$ siècle, perd un peu de terrain. Sa grande école napolitaine est presque ćpuisée. Ses maitres nouveaux doivent autant à l'influence française que la France avait dû naguère à l'influence italienne. Si l'Allemagne conserve son rang et son originalité pour la musique religieuse et la symphonie pure, c'est cependant à Paris que le génie de ses grands compositeurs dramatiques, à l'exception d'un seul, vient s'achever et se consacrer. Le génie français, retrempé aux sources de sa double origine, à la source italienne comme à la source germanique, est alors en pleine possession de sa force et de son originalité : les maitres français ne le cèdent à personne, ni pour la grâce de la mélodie, ni pour la science de la symphonie et la puissance de l'orchestration. Au reste, les diverses écoles de musique théàtrale se sont fondues en une grande école européenne, dont Paris est le chef-lieu. Remarquons encore que, parmi les nations qui s'étaient jusqu'alors tenues au second rang, il en est une alors, à l'extrémité orientale de l'Europe, qui commence à se révéler: avec guinka et son opéra de "la Vie pour le tsar " (1836), la Russie est entrée en lice. Une corde nouvelle s'est ajoutée à la lyre européenne.

Un phénomène aussi remarquable, c'est que la race juive, à peine émancipée de l'humiliation séculaire, a révélé le grand don musical qu'elle semble tenir de ses ancêtres bibliques. Elle nous a donné Halévy, Mendelssohn, Meyerber.

Une des supériorités de la musique dramatique fíancaise, ou composée sous l'influence française, c'est le livret. On sait à quel point un libretto bien fait concourt au succès d'une ceuvre lyrique et combien les Grétry, les Méhul, les Cherubini, ont eu à se repentir d'avoir accepté des textes dénués d'intérèt. Le créateur, chez nous, du livret dopéra et d'opéra-comique, c'est scribe (1791-1\$61), que les romantiques appelaient dédaigneusement a Monsieur Scribe ๖. Bourgeois si l'on veut, car il était fils d'un marchand de soieries et avait débuté dans une étude d'avoué; incorrect et plat quelquefois, car des vers ineptes déparent ses meil- 
leures pièces; mais doué d'une merveilleuse entente de la scène, connaissant à fond ce que la musique doit exiger de la poésie, Scribe, fécond auteur auquel nous devons plus de quatre cents pièces de théàtre, rendit d'éminents services à l'école musicale française. Il suffirait à sa gloire d'avoir donné à Auber les livrets du Macon, de la Muette de Portici, du Cheval de bronze, de l'Ambassadrice, du Domino noir, des Diamants de la couronne, de Haydée; à Boïeldieu, celui de la Dame Blanche; à Adam, celui du Chalet; à Halévy, celui de la Juive; à Neyerbeer, ceux de l'Étoile du Nord, de Robert le Diable, des Huguenots, du Prophète; à Rossini, celui du Comte Ory.

La musique, surtout la partie d'instrumentation et d'orchestration, doit beaucoup de sa puissance nouvelle au perfectionnement des instruments. Il s'est accompli surtout en France et en Allemagne. En 1823, stclzel invente le piston. Vers 1827, aste. dit BaLARY, invente le bugle et spontin introduit chez nous l'ophicléide. En 1822, weIndinger, de Vienne, fabrique la trompette $a$ clefs. En 1829 , le cornet $\dot{a}$ pistons est inventé par périnet; en 1836 , le cor a pistons par bluBMEL et le trombone à pistons par LABBaye. En 1839, toute la famille des tubas et bass-tubas doit sá naissance à MORITz et WIEPRECHT et, a partir de 1838, toute la tribu des saxhorns à sax. Voilà pour les instruments à vent. Quant aux instruments à cordes et à clavier, l'orgue expressif est inventé par GRENIER. Les pianos, harmoniums, mélodiums, doivent des perfectionnements inconnus à Camille plerel, BALKBRDNNer, ERARD ${ }^{1}$, à Fourneaux, Mercklin-Scluultze, Muller. Martin de Provins, Debain, Mustel, Alexanıre. Gràce à eux, le piano n'a plus la voix grèle de l'antique épinette et du piano d'autrefois : il est à lui seul un orchestre.

Pour preparer un auditoire aux nouveaux chefs-d'ouvre, des sociétés musicales se sont organisées. La Société des concerts du Conservatoire s'est fondée en 1828. La critique musicale a repris faveur, dès le règne de Charles $\mathbf{X}$, avec les chroniques de castiL-Blaze dans le Journal des Débats.

1. Sébastien Erard, sous l'Empire, construisit le piano organisé aveo double virter, l'un pour l'orgue, l'autre pour le piano; en 1808 , le piano a queur: en 1811 , la harpe í Zcable mouvement; il coustruisit le grand orgue do la clapelle des Tuileries. 


\section{La musique allemande et son infuence sur la uòtre. -}

Les compositeurs allemands eurcnt un trop grand ròle dans notre éducation musicale pour qu'on puisse les oublier dans une histoire de la civilisation francaise.

BEETHOven, de Bonn sur le Rhin (1770-1827), est peutêtrc le plus grand musicien du sic̀cle. Il a le génie des sonorités, la puissance symplıonique en mème temps que mélodique, le don magique d'ouvrir à l'auditeur les horizons infinis. Bien qu'il ait composé un opéra, "Fidelio " (1803), son cuvrc est plutôt épique que dramatique. Ses neuf Symphonies ont recu de l'admiration universelle les noms des neuf Muses. Il avait composé en l'honneur de Bonaparte une Symphonie héroique; mais il en supprima la dédicace quand son héros eut usurpé la couronne impériale. En 1813, il célébra par une autre Symphonie la défaite des Français à Vittoria.

Schubert. de Vienne, mort à trente et un ans (1797-1828), est un mélodistc incomparable. Dans ses Lieder, mélodies populaires de l'Aliemagne, il n'a pas de supérieur, pas même Beethoven. Ses contemporains n'ont pas su l'apprécier à sa valeur : c'est après sa mort sculement qu'on l'a remis à sa vraie place.

mendelssonn, de Hambourg (1809-1847), a composé des Symphonies, des Oratorios, des Sonates, des lieder, des Romances sans paroles, des Ouvertures d'opéras, des Chœurs pour "Athalie" de Hacine, une partition pour "le Songe d'une nuil d'été " de Shakespeare.

WEBER (1786-1826), du Holstein, a fait la musique des chansons patriotiques que le poète Kœrner lançait contre la Grande Armée. Il fut le poète de la nature et des légendes de l'Allemagne. C'est par le choix original de ses inspirations, par l'horreur des noires forêts de sapins et des vieux chàteaux en ruine, par le prestige de la magie et des eusorcellements, par le cor enchanté d'Obéron et les balles enchantées du Frcyschütz, surtout par cette mélodie, d'un charme plus efficace que tous les sortilèges, qu'il nous séduisit si complètement, à l'époque de notre ivresse romantique. Son "Freyschütz " (1819) fut d'abord représenté chez nous sous le titre de "Robin des hois". sP0zR, de Brunswick, par son opéra de "Faust " (1818), 
MARSchner, par son opéra du "Vampire " (1828), accentuèrent chez nous l'invasion du fantastique allemand.

Chopin (1810-1849), Français et Nancéien par son pére, Polonais par sa mère, fut Allemand par sa vie entière et par son éducation musicale. "Le génie de Chopin, a dit George Sand, est le plus profond, le plus plein de sentiments et d'émotions qui ait jamais existé. "Il règne ell maitre sur nos pianos par ses Nocturnes, Etudes, Préludes, Impromptus, Ballades, II azurkas, Valses, Polonaises.

Il partage cette royauté avec le Saxon schomann (18101836), auteur de tant de belles œuvres symphoniques et de l'opéra de "Geneviève".

La musique italienne et son infuence. - ROSSIN (17921868) est né à Pesaro (États romains), mais il a passé la plus grande partie de son existence en France et il est mort à Passy. Son père était artiste corniste et sa mère chantait dans les théàtres: il eut de naissance la passion de la musique et l'instinct de la scène. A dix-huit ans, il composait un opéra comique. Dès lors, presque chaque année apporta son cuvre. Dans le grand opéra : "Tancrède " (1813), "Othello " (1816), "Moïse " (1818), " la Dame du lac " (1819), "Mahomet II " (1820). Dans l'opéra comique, "l'Italienne à Alger " (1813), "le Turc en I1alie "(1814), le Barbier de Séville (1816), "Cenerentola " ou Cendrillon(1817).

Tous ces ouvrages furent d'abord peu appréciés du puhlic italien et restèrent presque inconnus en France. C'est en 1823 qu'il vint à Paris, qu'il s'y fit connaître et, en mème temps, qu'il acquit un sens si merveilleux du goùt français. En gardant la gràce, la simplicité, la vivacité, la science instrumentale dont témoignait déjà son " Barbier de Séville ", il se défit de quelques défauts italiens: une tendance à refaire pour tous les opéras la même ouverture, un certain manque de goût qui lui avait fait insérer dans son Moïse une polonaise, enfin quelque banalité dans la mélodie. Ou peut dire qu'à partir de ce moment, ce qu'il produisit, ce furent des œuvres françaises. Son "Mahomet II " devint, sur la scène de notre Académie royale, le "Siège de Corinthe " (1826), auquel les événements d'Orient assuraient un succès d'allusion et d'actualité. Puis parurent successivement son "Moise " remanie, "le Comte Ory " (1828), "Guillaumo 
Tell ", (1829), sans parler de son Stabat Mater et de tant d autres chefs-d'œurre de musique religieuse. Alors aussi il prit une influence énorme sur nos compositeurs français, et c'est l'honneur des meilleurs d'entre eux que d'avoir su échapper à l'imitation rossinienne.

Bellin, né à Catane (Sicile), en 1806, et mort prématurément à Puteaux, près de Paris (1835), fut un disciple de Pergolèse. Quand il vint en France, il avait déjà composé le "Pirate " (1827), "L'Étrangère " (1829), "la Somnambule " (1831), et surtout "Norma " (1831), son chef-d'auve. C'est chez nous qu'il écrivit " les Puritains " (1835).

DonizetTi, né et mort à Bergame (Italie du Nord) (1798-1848), mais qui a passé une partie de sa vie en France, est un rossinien. Il eut une facilité et une sûreté merveilleuses de travail ; car il composait jusqu’à onze actes dans une année et n'a pas écrit moins de trente-six pièces. On l'a défini “ le plus étonnant des improvisateurs italiens du $\Sigma i x^{e}$ sièclen. A la période de son séjour en Italie appartiennent "Lucriee Forgia " (1833) et "Lucie de Lammermoor " (1835). Le premier de ces sujets est emprunté à Victor Hugo, le second à Walter Scott. De la période française de sa vie datent "la Fille du régiment ", "la Favorite" (1840), "Don Pasquale ", "Don Sébastien de Porlugal ".

Les compositenrs français. - Le génie de Boieldieo, dont nous avons vu les débuts, est alors à son apogée. Son chef-d'œuvre, dans cette seconde moitié de sa carrière, c'est " la Dame Blanche " (1825) dont le lihrelto est inspiré de "Guy Mannering ", le roman de Walter scott.

Il s'y révéla mélodiste élégant et gracieux, habile à tirer parti des airs nationaux de l'Écosse, ingénieux dans son orchestration, et enfin d'un goût exquis et d'un charme soutenu, qui font de cette pièce une suite ininterrompue de morceaux ravissants. Il ne se laissa pas trop séduire par Rossini; il resta Francais et fut original.

auber (1782-1871), né à Ciaen, mais qui vécut à Patis et ne voyagea guère plus loin que le bois de Bonlogue, fut, dans sa première manière, un élève de Mozart, Cherubini, Boïeldieu. C'est alors qu'il produisit plusieurs opéras comiques, dont le meilleur est " le Maçon " (1825). Puis il devint un rossinien tout en gardant sa forte originalite : 
c'est l'époque de " la Muette de Portici v, grand opéra (1828, et des opéras comiques, "Fra Diavolo " (1830), "le Philtre ", "la Fiancée ", " le Dieu et la Bayadère ", "le Cheral de bronze " (1835), l'Ambassadrice" (1836), "le Domino noir ", "les Diamants de la couronne" 18't. "Haydée " (1847), et enfin "le Premier jour de bonheur " (1868). Il fut surtout un mélodiste fis, varié, élégant, spirituel. Ses airs, d'un joli dessin, se gravent aisément dans la mémoire. Il plut aux Français; il leur rendit le service, à cette époque où leur éducation était encore incomplète, de leur faire comprendre et aimer la musique. On a dit d'Auber que c'était " Rossini mis à la portée de tout le monde $"$.

BÉROLD (1791-1833), un Parisien de sang germanique, un élève de Méhul, ayant beaucoup royagé en Italie et en Allemagne, tient beaucoup de Weber et fort peu de hossini. Parmi de nombreux opéras comiques, œurre dune carrière féconde, mais prématurément brisée, on compte surtout deux chefs-d'cuvre : " Zampa ou la Fiancée de marbre " (1831), d'un fantastique si puissant, d'une symphonie si chaude et colorée, et le "Pré aux Clercs » (1832), où il y a tant d'airs spirituels, mélancoliques ou passionnés. Hérold mourut à 42 ans. Une de ses dernières paroles fut : "Je pars trop tôt, je commençais à comprendre le théàtre."

Adolphe ADAM (1803-1836), un autre Parisien, élève de Boïeldieu, excellait à recueillir et à développer les airs populaires. Il composa une soixantaine de pièces: des bajlets comme "la Fille du Danube " (1836), "Giselle " (184!), "le Corsaire " (1856); et toute une série d'opéras comiques: "le Chalet" (1834), qui a eu plus de mille représentations, le "Brasseur de Preston " (1838), le "Postillon de Longjumeau " (18 46 ), "le Toréador " (18千9), "Giralda " (1850), "Si j’étais roi " (1852), "le Sourd ou l'Auberge pleine ", "le Bijou perdu " (183̆3).

Les compositeurs que nous venons d'énumérer ont été surtout des mélodistes et ils ont produit surtout des opéras comiques. Pour pouvoir renouveler le grand opéra, il fallait approfondir les lois de l'harmonie, appeler à son aide, pour accompagner et renforcer le récitatif ou les 
chœurs, toutes les sonorités de l'orehestre, toutes les ressources de coloris qu'offrait la variété croissante des instruments. L'homme qui nous donna les premiers chefsd'œuvre en ce genre, ce fut Joachim Beer, ou Giacomo mererbeer (1794-1864). Il était né à Berlin; mais un juif de Berlin, en 1794, était à peine un Alleınand. Son génie a un caractère fort différent du génie tudesque; son éducation musicale ne fut pas exclusivement germanique : s'il fut élève de Vorgel et condisciple de Weber, il reçut aussi les leçons de Salieri et subit d'abord l'influence rossinienne. C'est aux Français, à Seribe surtout, qu'il dut l'entente de la scène, le sens dramatique, l'art de tirer parti des accessoires. Son génie se ressent de cette éducation cosmopolite : il est un éclectique en musique. II n'est d'aucune école et toutes viennent se fondre dans la puissante originalité de son ouvre. Il n'avait eneore produit que quelques opéras de valeur secondaire lorsqu'en 1826 il vint s'établir chez nous, pour ne plus jamais nous quitter et pour nous consacrer son génie. C'est pourquoi, juif et Berlinois, il est cependant un chef de l'école française. Il est le pre. mier qui ait su faire manœuvrer les masses chorales, commander aux légrons d'instruments de toute forme et de toute nature, narier le chant gracieux des violons et des flûtes au grondement des contre-basses, au rugissement des cuivres, au roulement des timbales. Il a su, tour à tour, comme un dieu des tempêtes harmoniques, déchaîner ou apaiser les orages de l'orchestre, nous charmer d'une vieille mélodie normande pour évoquer ensuite les clameurs de l'enfer ou la bacchanale de Robert le Diable (1831); passer des suaves harmonies de la prière ara: fureurs d'une foule ivre de sang, comme dans les Huguenots (1836); après la joyeuse kermesse du Prophète, nous épouvanter du fracas des palais s'abìmant dans les flammes (1849); après le sifflement des vents dans les agrès du vaisseau en péril, nous verser, comme un philtre mortel et doux, la symphonie du mancenillier de l'Africaine (1865); nous faire entendre les soupirs du géant Pierre le Grand dans lÉtoile du Nord (1854) ou les voix mélancoliques de son idylle bretonne, le Pardon de Ploörmel (1859). Il a su traduire en harmonies 
poignantes toutes les passions de l'âme : la colère, le fana. tisme, la jalousie, l'amour. Rien de plus beau, dans aucune pièce lyrique, que son duo d'amour entre Raoul et Valentine des "Huguenots ". Grand dramaturge, autant et mème plus que grand symphoniste, grand architecte dans la conception de ses œuvres, profond psychologue dans l'analyse des passions, possédant à fond tous les secrets des sons et des couleurs, il fut par excellence le maestro: le maítre.

HaLśvy (1799-1862), juif et Parisien, élève de Cherubini, subit l'influence d'Hérold et de Meyerbeer. Moins laborieux que ces deux maitres, enclin à un peu de négligence et de précipitation, il est peut-être inférieur à celui-là dans l'opéra comique, et certainement à celui-ci dans le grand opéra. Il fut aussi moins heureux dans le ehoix de ses livrets, sauf quand Scribe s'en mêla. Parmi ses nombreux opéras comiques, il faut citer, au premier rang. "l'Éclair " (1835), les "Mousquetaires de la Reine " (1846), "le Val d'Andorre " (1848), "la Fée aux roses " (1849), "Jaguarita l'Indienne " (1855), qui est d'une belle couleur orientale. Parmi ses opéras, "Ia Juive " 1835 ), avec le rôle magnifique d'Éléazar; "Guido et Ginerra " (1838), d'une teinte un peu sombre, mais dont le troisième acte est d'un effet terrifiant; "la Reine de Chypre " (1841); "Charies VI " 1843), qui nous a donné un de nos chants nationaux; "le Juif errant "(1852). On peut marquer comme l'apogée de son génie cette année 1835 qui vit paraitre à la tois "l'Éclair" et "la Juive ", ses deux chel's-d'œurre dans chacun des deux genres lyriques

BERLIOz (1803-1869), du Dauphiné, complète avec Beethoven, Mendelssohn et Schumann, le groupe des grands symphonistes dans la première moitié du siècle. S’il eut, plus que tous les autres, à lutter contre les préventions du public, c'est paree qu il s'adressait a des Français que leur éducation musicale inclinait vers la musique de théâtre, et qu'effarouchaient les innorations qu'il prétendait introduire dans l'expression musicale; c'est parce qu'il fit mcins de concessions au goût de son époque, et aussi parce que son génie ne disposa pas d'abord de toutes ses ressources. Au reste il $y$ a lieu de distinguer plusieurs póriodes dans sa carrière de compositeur. 
Dans la première, Berlioz, élève de Reicha et de Lesueur, mais prenant son point de départ dans la dernière manière de Beethoven, se cantonna dans la symphonie; il se lança dans la dangereuse utopie de la musique descriptive, voulant décrire et peindre arec des sons; presque exclusivement préoccupé du coloris instrumental, il négligea le style, qui resta toujours surchargé et pénible. Quand il fit son premier essai dans ce genre, sa Messe à Saint-hoch, exécutants et auditeur's s'accordèrent à déclarer cette musique absolument inintelligible. Il en fut do mème de sa "Symphonie fantastique ", de son poème symphonique de "Harold ", de son Requiem pour les funérailles du général Damrémont. Mème son opéra de " Benvenuto Cellini " éprouva un échec complet (1838).

"Roméo et Juliette " (1839), symphonie dramatique, c'est-à-dire symphonie accompagnée de paroles, mais sans les ressources de la représentation dramatique, sans costumes et sans décors, marqua un grand perfectionnement dans son style.

Quand il eut triomphé de la gène que son èducation incomplète apportait dans la réalisation de ses conceptions, il donna son chef-d'œuvre, la " Damnation de Faust ", symphonie dramatique, l'une des ceuvres les plus puissantes et les plus originales de la musique. Accueillie avec une extrême froideur à son apparition en France (1846), elle rencontra de vives sympathies en Allemagne; à la fin, en France mème, elle souleva un réritable enthousiasme lors de sa réapparition. Avec son oratorio "l'Enfance du Christ " et son opéra Béatrice et Bénédict, la manière de Berlioz change une dernière fois; le style prend la pureté et la perfection qui lui manquaient. Lopéra des "Troyens ", représenté au Théâtre-Ḷ̂rique en 1S6:3, fut un succès marqué qui montra à quel point líducation musicale du public s'élait complétée en mẻme temps que le talent du maitre.

Ouvrages a Consulter. - L. Ro- f française de 1815 a 1890 (1900). senthal, La peinture romantique; Toyez la bibliogr du chap. xxr. essai sur l'évolution dé la peinture 


\section{CHAPITRE XXII}

\section{LES SCIENCES}

\section{Les mathématiques et l'astronomie.}

Mathématiques. - Lagrange écrivait autrefois à d'Alembert, à propos des mathématiques : "La mine est déjà trop profonde et, à moins qu'on ne découvre de nouveaux filons, il faudra tôt ou tard l'abandonner. "La mine n'a pourtant pas été abandonnée; de nouveaux filons s'y sont révélés. Les mathématiques, dans leurs branches principales, analyse (comprenant le calcul intégral, l’algèbre, la théorie des nombres), géométrie et géométrie descriptive, mécanique, astronomie el physique mathématiques, n’ont cessé de progresser. L'Ecole polytechnique, l'École normale (section des sciences), l'École centrale, les diverses Écoles de génie militaire, maritime et civil, l'enseignement de la Sorbonne et du Collège de France, ont également concouru au développement des mathématiques. Les grands travaux publics, les vastes constructions métallurgiques, les machines compliquées, en un mot toutes les applications nouvelles de la science, n'ont cessé de ramener l'attention sur les hautes questions théoriques. Le monde est plus que jamais dominé par les mathématiques '.

Dans la génération qui précède 1830, et qui put recevoir les lecons des Carnot, des Monge, des Lagrange, des

1. Les limites de cet ourrage ne permettraient pas dexposer les résul. tats, trop spéciaux pour les lecteurs et pour l'auteur, de lant de travaux. I) faut donc nous borner a citer quelques noms. 
Laplace, se signalèrent surtout le baron Charles Dupin, Cauchy, Mlle Sophie Germain, le général Poncelet, Sturm, Bobillier, Michel Chasles. La période suivante, de 1830 à 1848, est celle des grands travaux de Joseph Liouville, Lamé, Constant Dulıamel, Binet, Alfred Serret, Bienaymé, Joseph Bertrand.

Astronomie. - En astronomie, on est arrivé à un€ connaissance plus exacte des variations de la Lune. Dès 1820, Laplace avait fait mettre au concours, par l'Académie des sciences, "la formation, par la seule thérie, de tables lunaires aussi parfaites que celles que l'on a formées par le concours de la théorie et des observations".

ENCEE, de Hambourg, en 1842, a estimé la masse du Soleil

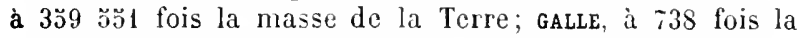
masse de la Terre et de toutes les planètes réunies.

Encke a en outre établi que la densité du Soleil n'est que le quart de celle de la Terre.

Les astronomes du xvine siècle avaient reconnu que lt Soleil n'est point immobile, mais qu'arec son cortège de planètes, de satellites, de cométes, il se meut dans l'espace. bessel en 1839, BRavaIs. en 1841, ont établi qü̈l se déplace arec une vitesse d'au moins 6190000 kilomètres par jour, c'est-à-dire plus que double de la vitesse arec laquelle la Terre tourne autour du Soleil. ARgeLANDER, directeur de l'observatoire de Bonn (Prusse rhénane), et STRUVE, directeur de l'observatoire de Poulkova (Russie), ont même précisé le point vers lequel le Soleil semble se diriger : il est situé dans la constellation d'Hercule. Il semble qu'il y ait aussi un point autour duquel il décrirait cette courbe prodigieuse, peut-ètre une étoile qui commanderait son orbite et qui serait le soleil de notre Soleil. On n'a pu encore déterminer ce point avec certitude: les uns, comme Maedler, l'ont eherché dans la constellation des Pléiades, et d'autres, comme Goldschmidt, dans la constellation d'Orion.

Les planètes du système solaire ont été l'objet d'études très suivies de la part de le verrier. Celui-ci a pu dresser les tables de Mlercure, de Vénus, de Mars. boovard avait établi, en 1821 , celles d'Uranus.

La découverte la plus considérable de ce siècle, c'est 
celle de Neptune, en 1846, par LE verRIER. Le savant astronome, avant de l'apercevoir au télescope, l'avait deviné. Les perturbations qu'il observait dans la marche de la planète Uranus ne pouvaient, pensait-il, s'expliquer que par l'existence d'une autre planète, encore inconnue. Quand Le Verrier en eut, par une série de calculs, précisé la position astronomique et qu'il ent annoncé au monde savant l'existence d'une planète que ni lui ni personne n'avait encore aperçue ${ }^{1}$, il reçut d'un savant de Berlin l'avis que celui-ci venait de la reconnaitre au télescope. "Les astronomes, disait à ce propos Arago, ont quelquefois trouvé, accidentellement, un point mobile, une planète, dans le champ de leur télescope, tandis que M. Le Verrier aperçut le nouvel astre sans avoir besoin de jeter un seul regard sur le ciel : il le vit au bout de sa plume. Il avait déterminé, par la seule puissance du calcul, la place et la grandeur d'un corps situé bien au delà des limites jusqu'ici connues de notre système planétaire, d'un corps dont la distance au Soleil surpasse 1200 millions de lieves et qui, dans nos plus puissantes lunettes, offre à peine un disque sensible. "

Lianneau de Saturne, où llerschel avait déjà découvert la bande herchélienne qui le partage en anneau extérieur et er anneau intérieur, a été encore subdivisé : ENCEE, en 1837, signala un nouvelle bande sur l'anneau extérieur, et vico, en 1838, en signala denx sur l'anneau intérieur: au total cinq anneaux, séparés par quatre bandes. On en a reconnu depuis jusqu'à onze.

En 1847, tout de suite après la grande découverte de Le Verrier, l'Anglais cassell dota Neptune d'un satellite. En 183̆1, il signala deux nouveaux satellites d'Uranus.

L'exploration du groupe des petites plamètes situées cntre Mars et Jupiter, après 38 ans d'interruption, étiit rejprise : en 1845, encre découvrait Astrée et, en 1847, Hébé.

On a catalogué aujourd'hui jusqu'à six cents comètes. Les plus intéressantes sont les périodiques. En 1818, on g'en connaissait qu'une seule, celle de Ilalley. Cette année- 
là, poss, à Marseille, en découvrit une seconde, qu'on appela comète d'Encke, parce qu'Encke en établit la périodicité. Puis vint celle qui fut observée à dix jours d'intervalle, en 1826, par l'Allemand BIÉLA et par Gambart, de Marseille, et qui porte l'un ou l'autre de ces noms. Puis FAYE découvrit en 18 '3 celle qui a gardé le sien.

En 1829, l'Anglais Forster eut l'idée singulière d'attribuer aux comètes périodiques les épidémies périodiques : il fut réfuté victorieusement par arago. En 1832, Damoiseau annonça que la comète de Biéla tomberait, l'année suivante, dans l'orbite terrestre. De là une terreur qui rappelait celles de l'ancien temps. Arago rassura encore les esprits en prouvant qu'elle passerait à plus de vingt millions de lieues de la Terre.

\section{La physique et la chimie.}

Plyysique : aconstique, lumière. - Les divers instruments connus dès le $\mathrm{xvI}^{\mathrm{e}}$ ou le $\mathrm{x}$ vinte siècle, baromètre, thermomètre, hygromètre, psychromètre, aréomètre, manomètre, etc., ont subi de nombreux perfectionnements et ont affecté les formes les plus diverses. Babiner, physicien en mème temps qu'astronome, a perfectionné la machine pneumatique.

L'acoustique a fait de grands progrès à la suite des expériences de CAGNIARD DE LATODR et SAVARD sur les cordes et sur les tuyaux.

La vitesse du son a été mesurée avec plus de précision. En 1822, une commission composée d'Arago, Bouvard, Prony, Gay-Lussac, A. de Humboldt, avait disposé des pièces d'artillerie sur deux points éioignés de 1861 mètres, à Montlhéry et à Villejuif. Les observateurs s'étaient partagés entre les deux stations, afin d'éviter les causes d'erreur produites par la direction du vent. On constata une vitesse moyenne de 340 mètres par seconde. En 1827, CoLLADon et STURM mesurèrent la vitesse du son dans l'eau. Biot mesura sa vitesse de propagation dans les corps solides.

Dès 1814, FRESNel avait commencé sur la réflexion et la réfraction de la lumière les travaux qui le conduisirent, en 
1820, a l'invention des lentilles $\dot{a}$ ćchelons. Avec arago, il inventa les lampes à méches concentriques, qui produisent une lumière équivalente à celle de trois ou quatre mille lampes Carcel. Le Phare de Cordouan, élevé en 1823, est le premier qui ait bénélicić de celte double découverte.

Les théories sur les couleurs sc rattachent à cette partie de la physique qui s'occupe de la lumière. chevredr, que nous retrouverons quand il s'agira de la chimie des coulcurs, s'en est aussi occupé au point de vue physique et physiologique. Il a signalé la loi du contraste simultané des coulcurs (1839), et la théorie des couleurs complémentaires : le vert par exemple est la couleur complémentaire du rouge, et c'est pour cela que les vues affectées de daltonisme ne peuvent pas les distinguer.

Nous citerons enfin deux curieuses applications des lois de l'optique. Le kaléiloscope fut inventé en 1817 par l'Anglais Bnewster. Le stéréoscope est fondé sur la théorie de la superposition de deux images vues en mème temps par les deux yeux, mais de chaque coté d'une cloison, et apparaissant alors en relief. Le stéréoscope à réflexion lut inventé, en 1839, par l'Anglais wuEatstone, et le stéréoscope à prisme ou à réfraction, celui dont nous nous servons aujourd'hui, par BREWSTER.

Electricité : les piles. - La pile électrique a reçu des perfectionnements importants. Les éléments, dans la pile du Hanovrien BUNSEN, inventée en $1843^{\prime}$, ont la forme de deux cylindres rentrant l'un dans l'autre. Seulement, au lieu du zinc et du cuivre qu'avaient employé Volta et ses successeurs, chaque élément se compose d'un cylindre de zinc et d'un cylindre de charbon. Au lieu de les immerger dans I'eau pure, comme autrefois, on les immerge dans un liquide acidulé, et la décomposition du métal sous l'action de celui-ci accélère le dégagement de l'électricité. Dans quelques piles, au lieu d'un seul liquide, on emploie deux liquides différents : c'est sur la décomposition de l'eau et l'oxylation des métaux que repose donc le principe des appareils nouveaux. On en a construit qui sont formés de 1000 , de 2000 éléments.

1. L'Anrlais Gru'e, dès 1839 , avait déjá utilisé le charbon pour la con. struetion de sa pile. 


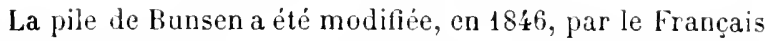
aRCHEREAd, qui plaça, comme avait fait Grave, le charbon au centre de son appareil cylindrique, et le zinc à l'extérieur : ce qui assure, avec une surface métallique plus étendue, un plus grand développement d'électricité.

L'action de ces appareils est tellement puissante, que les composés les plus réfractaires ont dû se dissoudre et livrer tes corps simples dont ils sont formés.

En décomposant les sels métalliques dans lesquels entrent le cuivre, l'argent, l'or, on amène les métaux à se déposer en particules impalpables sur les surfaces que l'on veut bronzer, argenter ou dorer. C'est eette industrie nouvelle, dont les principes ont été établis par spencer en Angleterre (1837) et JACOBI en Allemagne (1838), qu'on appelle galcanoplastic ${ }^{1}$.

Electro-magnétisme. - Un principe plus fécond encore que l'électricité dynamique avait été découvert en 1820 par le physicien danois arsted. Il constata que le courant électrique produit par la pile fait dévier l'aiguille aimantée d'unc boussole. Entre le phénomène de l'électricité et celui de l'aimantation, il y avait lonc une relation: le principe de l'électro-magnétisme était découvert. Presque en mème temps qu'OErsted, les physiciens français AMPÉRE et ARAGO constatèrent l'action qu'exercent l'un sur l'autre soit deux courants électriques, soit un courant électrique et un courant magnétique. Les lois qui gouvernent ces actions s'appellent lois d'Ampère. Ampère a montré encore que la Terre elle-meme agit " comme un faisceau de courants électriques ayant son siège dans le sein de la Terre, au sud de l'Europe, et dont le mouvement s'opérerait, comme la révolution diurne du globe, de l'ouest à l'est ".

Ampère a inventé le galvanométre. C'est cet instrumen: qui a permis à Seebeck de découvrir les courants thermoilectriques: a Fourier et OErsted, de reconnaitre la loi de rendement des sources électriques; à Pouillet, aux deux

1. Une curieuse application de ce procéde, c'est le bronzage ou piulót le cuivrage de la fonlaine monumentale de la place Lourois, à Paris. A l'aide de la gahranop'astie, en déposant une mince couche de métal sur des staluellos en fhitre, sur des feuilles, sur des fruits, mème de petils animaur, on lour coune !'aspect d'objels de brouze, de cuivre, d'argent, d'or. 
Becquerel, père et fils (César et Edmond), d'étudier la conductibilité des différents corps.

En 1820, ARAgo avait constaté qu'en entourant un petit barreau d'acier d'un fil par lequel circule un courant électrique, ce barreau devient un ammant. Quand le courant cesse, le barreau cesse d'ètre aimanté. Si l'on approche de ce barreau une plaque d'acier, cette plaque vient s'appliquer contre le barreau ou s'en éloigne, suivant que celuici est aimanté ou non, c'est-à-dire suivant que le courant électrique circule ou s'interrompt. Les mouvements ainsi imprimés à cette plaque peuvent servir à figurer des signes; ils peuvent mème constituer tout un alphabet. Ces mouvements lui sont imprimés au moyen d'un fil métallique, à une distance aussi grande qu'on voudra. Un observateur placé à Paris peut les transmettre à une plaque métallique installée, par exemple, à Bordeaux : il communiquera ainsi, au moyen de signes convenus, avec un observateur placé dans cette ville. C'est le principe de la télégraphie électrique.

Chimie : déconverte de nouveaux corps simples. La chimie, armée de piles de plus en plus puissantes, a fait de grands progrès dans la décomposition des substances. De nombreux corps simples ont été découverts ${ }^{1}$.

Parmi ces éléments nouvellement reconnus, deux surtout ont une grande importance. BALARD, rencontrant (1826), dans les marais salants, le brome associé au chlore et à l'iode, constata qu'il reproduit beaucoup de leurs propriétés, qu'il peut se substituer à eux dans les combinaisons, qu'ils sont ensemble comme trois éléments jumeaux ${ }^{2}$. C’est une

1. Le radmium, par Hermann el Stromeyer (1S17); le lithium, par ARFEedon (1817); l'yttrium, le glucinium, par Worater (1S27); le magnésium, par Bussy (1829); le thorium, par BERzélius (1829); le vanadium, par Selfstrom (1830); le lanthane (1830), le didimium, le terbium, l'erbium, par Mosanner (18.9-1843); le niobium, le pelopium, par Rose (184i); le ruthenium, par Claus (1845).

2. Pour montrer lanalogie, et ea mème temps la diversilé de ces trois subslances, prenons une de leurs combinaisons avec l'arcent, dun grand usage en photographie. "Le chlorure d'argent exige l'exposition au soleil, prolongée pendant des heures, des objets à reproduire; l'iodure d'argent, pendanl des minutes; faites-vous intervenir le brome, des secondes suffsent. et mème des centièmes et des millièmes de seconde. s'il s'agit de corps très éclairés." (Dumas.) La succession de ces trois corps répond donc 
découverte d'une grande importance, non seulement pour les applications industrielles, mais au point de vue de la philosophie de la chimie. Par elle, Balard a mis en lumière l'idée de l'existence de familles de corps simples, et jeté les bases d'une nouvelle classification chimique. "C'est par là, a dit Dumas, que la découverte du brome constitue le point de partage entre deux époques de l'histoire de la chimie; avant qu'il eut été signalé. les éléments étaient considérés comme independants les uns des autres; c'est surtout depuis qu'il est connu qu'on a vu, sans incertitude, qu'ils se rangeaient par familles naturelles, et que, lorsque celles-ci étaient encore incomplètes, on pouvait non seulement prévoir la découverte de l'élement ignoré dont la place restait inoccupée, mais en prédire toutes les qualités. " On pouvait prévoir, par exemple, que telle combinaison du brome avec l'argent aurait des propriétés analogues à la combinaison du chlore et de l'iode avec le mème métal; on pouvait prédire que cette combinaison rendrait des services à la photographie, quoique personne ne pùt s'attendre à ce qu’ils seraient si cousidérables. De mème, en pharmacie, les bromures sont venus faire concurrence aux chlorures et iodures.

L'Allemand weHLer avait bien decouvert l'aluminium (1827); mais il n'avait pu le produire qu'en petite quantité, par des procédés de laboratoire, au prix de 40000 lrancs le kilogramme!

La soude. - Balard remarqua que les sauniers, après avoir fait evaporer l'eau de mer dans leurs bassins, laissaient, une lois qu'ils en avaient extrait le sel marin, écouler l'eau qui avait déjà subi cette concentration. “ M. Balara s'était ému de voir perdre ce liquide, renfermant deux produits éminemment utilisables, la soude et la potasse, matières alcalines nécessaires à la fabrication du verre, a celle des savons, au dégraissage et au blanchiment des tissus... Il n'hésitait point à aftirmer qu'au lieu de retirer de l'eau des mers le sel marin et de rejeter les autres substances, on en viendrait à l'exploiter surtout pour retirer 
celles-ci en rejetant le sel marin. On ne saura jamais à quels durs travaux M. Balard s'était condamné pour arriver à résoudre ce problème. Les journées ardentes et les nuits glaciales qui chassaient tous les ouvriers étaient celles qui appelaient $M$. Balard sur ces plages redoutées que la fièvre habite. C'est ainsi qu'après vingt ans de travaux (1830-1850) il put réaliser le rève qui lui avait fait entrevoir la Méditerranée et l'Océan comme des sourees inépuisables de soude et de potasse. "

Les composés nouveaux. - Les corps simples, anciennement ou nouvellement reconnus, forment entre eux des combinaisons à l'infini, et il ne se passe pas d'année sans quon découvre quelque acide, quelque oxyde, quelque alcali, quelque sel, inédits et dont les applications dans l'industrie, dans les arts, dans la médecine sont innombrables. Pour désigner une si prodigieuse variété de substances, la nomenclature chimique de 1787 s'est Irouvè insulfisante, et il a fallu lui donner de nouveaux developpements.

La métallurgie a dù à la chimie, non moins qu'au perfectionnement des installations et des machines, d'importants progrès. Elle a pu employer de nouveaux fondants, de nouveaux alliagcs. Des aciers d'une résistance à toute épreuve, dont on a pu forger de prodigieux canons, ont été fabriqués.

Chimie organique. - C'est surtout dans létude des matières organiques, soit animales, soit végétales, que la chimie a accompli des progrès : la chimie organique est devenue comme une science a part '.

De l’inerte cellulose (coton ou moelle de sureau), traitée par l'acide azotique, on a extrait des substances redouta-

1. Toutes les substances organiques se rameneat, en somme. a trois eorpg simples, si elles sont vegetales, et à qualre, si elles sont animales : dans le premier cas, elles se composent de carbone, d'hydrocève, d'orygèoe; dans le second cas, elles comprennent, en outre, de l'azote. Mais ces quatre corps se combinent ensemble a l'infini. Ils forment, soit des acides organiques; soit des malières végélales neutres, comme la cellulose, le bois, l'amidon, la dextrine, les gommes, les caoutchoues, la gutta-percha, importée de l'Asie méridionale en 1844; soit des matières sucrees, comme les glueoses et les sucres; soil des alcools, des ethers; soit des alcalis organiques, ou eneore des alcalniles; soil des corps gras; soil des huiles colatiles, appelées aussi essences, ete. Sur lous ces domaines, dimportantes lécouverles ont élè réalisèes. 
bles. La découverte de la xyloidine, matière inflammable, par braconNot (1833), a conduit à celle de la pyroxyline, appelée aussi fulmi-coton ou coton-poudre, trouvéc par PELOoze (1838) et schanbern (1846), et qui a une puissance explosible et brisante très supérieure à celle de la poudre. Cette méme pyroxyline, dissoute dans l'éther, fournit le collodion ', qu'on emploie en chirurgie et en photographie.

Du bois et des goudrons de houille on a extrait par distillation la paraffine, qui entre dans la fabrication des bougies, et qui a été obtenue, en 1831, par reicrentach ${ }^{2}$.

Boucherie a trouvé le moyen de conserver indéfiniment les bois en les injectant de sels de cuivre ou de fer $(1840)$.

Les sucres ont été étudiés notamment par Pelooze. Il a montré aux manufacturiers comment ils pouvaient uti'iser les résidus des betteraves, jusqu'alors négligés par eux, et ainsi augmenter d'un tiers la production du suere.

En 1836, il a découvert l'éther onanthique, un des frincipes de l'arome des vins.

De l'alcool on a extrait le chloroforme, découver: en 1831 par soubeyran et analysé en 183' par Domas.

chevredu a pris à partie les corps gras. Il a montré comment ils se composent, en proportions variables, de stéarine, qu'on extrait surtout du suif, de miryarine, qu'on extrait surtout de l'huile d'olive, et d'oléine, yu'on peut extraire de la plupart des huiles. Ces trois corps donnent chacun naissance a trois acides egalement découverts par lui : stéarique, margarique el oléique. Ces acides, combinés avec la potasse et la soude, produisent à leur tour lcs divers savons. Avec l'acide síarique, Clinreul a créé lindustrie des bougies steariques (1811), pour lesquelles il avait pris un brevet, de concert avec Gay-Lussac, et qui ont remplacé avec tant de succès la chanlelle ou la cire d'autrefois. De l'acide margarique est nće l'industrie des beurres artificiels, dont la production se chiffre annuellement, dans le monde entier, par deux cents millions.

PElodze a étudié spécialement l'acide butyrique, un des

1. L'application du collodion à la chirurgie est due à MAQUaRD, de Boston, et son emploi on photographio à l'Anclais Archer.

2. Du bois distillé on a pu obtenir encore l'esprit de bois, qui es: un alcool, el le vinaigre de bois. 
principes du beurre naturel, déconvert par Chevreul, en 1819 , et en a tiré la butyrine.

Les acides organiques sont fort nombreux '. Ils forment les sels organiques appelés acétates, citrates, tartrates, etc.

L'acide turtrique ${ }^{2}$, important à bien connaitre pour la confection des vins, a été découvert en 1819 par restNer, de Thann.

On peut citer les travaux de BraconNot sur l'acide malique; de canours, sur l'acide amilique et ses dérivés; de Pelouze, sur les tartrates, les acides tartrique et pyrotartrique, l'acide formique, l'acide lactique, les acides gallique et pyrogallique (celui-ci employé en photographie et pour la teinture des cheveux), l'acide tannique. De la noix de galle, Pelouze a extrait le tunnin pur, appelé tonnin Pelouze, et a montré comment on pouvait l'utiliser pour la conservation des vins blancs et notamment des vins de Champagne, dont la fabrieation a été ainsi renouvelée par lui.

De certaines plantes dont on connaissait déja les vertus curatives, toniques ou toxiques, on a extrait des alcalis et alcaloïdes organiques qui possèdent soit les mẻmes vertus à un degré incomparablement plus grand, soit des vertus différentes, mais d'une intensité également remarquable. Ce sont, pour la plupart, des poisons violents, mais qu'on peut employer en médecine comme de puissants narcotiques ou des toniques très efricaces. We l'opium, Derosne, en 1804, extrait la narcotine; Sertuerner (180弓), la morphine, étudise ensuite par Robiquet et Pelletier; Robiquet, en 1831, la codéine. De mème, du pavot est sortie la nureéine; d'une colchique, appelée vératre ou véraire, la vératrine. grâce à Meissner (1818); de l'amande, gràce à

1. On pent citer l'acide oxalique, qu'on peut extraire de l'oseille; l'acide acétique, du vinaigre; l'acide formique, des fourmis rouges; l'acide tartrique, du jus de raisin; l'acide cutrique, du jus de citron; l'acide malique, de la pumme et d'autres fruits; l'acide amilique, de la pomme de terre; l'acide tannique, de l'écorce de chẻne; l'acide lactique, du lait, etc.

2. Le tartre, dont on extrait cet acide, était déjà connu de Paracelse; mais sa composition n'a été exactement donnée que par Scheele en $17 \% 0$. Les combinatsons de l'acide tartrique aver la potasse, la soude, l'antinoine, ont donnó narsance à des sels appelés tartrates qui, de nos jours, ont été l'objet dimpurtunts tiavaux. 
Robiquet et Boutron-Chalard, l'amygdaline (1830); du café, ou du thé, grâce à Runge, Pelletier, Robiquet, Oudry, la caféine (1820), qui est à peu près identique à la théine; de la noix vomique, gràce à Pelletier et Caventou, la strychnine (1818) et la brucine (1819) ' ; de la digitale, gràce à liomolle et Quévenne, la digitaiine; du tabac, gràce à Reimann et Posselt, la niectine; des solanées (mandragore, jusquiame, helladone), gràce à Brandes et Desfosses, la solanine (1821); du quinquina, gràce à Pelletier et Caventou, la quinine (1820) et la cinchonine, si précieuses contre les fièvres; de la ciguë, grảce à E. Simon, Giesecke, Geiger, la cieutine ou conicine, comparable en énergie toxique à l'acide prussique; de la belladone, l'atropine ${ }^{2}$, dont une très petite dose suffit à dilater la pupille de l'œi!' ‘.

Les huiles volatiles, ou essences, ont été étudiées surtout par Gerhardt, Laurent, Cahours. camours analysa celles qu'on tire du cumin, de l'anis, de la badiane, du fenouil (1841-184), et l'on voit quels services il a pu rendre à cette branche si importante de l'industrie française, spécialement de l'industrie parisienne : la parlumerie.

Les couleurs de teinture ont été l'objet de découvertes importantes. Robiquet a extrait de la garance l'alizarine (1826), de l'orseille l'orcine, deux splendides teintures rouges. Kopp a légagé de l'indigo l'indigoténe; de la mauve, la malvéine. Jacquelain du rocou d'Amérique a fait sortir la tixeine; Verdeil, du chardon, la cinureine. chevreus, attache pendant plus d'un demi-siècle à l'établissement national des Gobelins, y a renouvelé les procédés de la coloration. II a trouvé dans le bois de campêche l'hémacéine et a publié, en 1831, ses "Leçons de chimie appliquées à la teinture " ".

1. Les propriétés de ce poison avaient frappé Alexandre Dumas père, qui lui fait jouer un rôle important dans son fameux roman de Honte-Christo.

2. Ce nom vient de celui du genre atropa, famille des solanées. Linué nvait formé le mot d'atropa du nom d'une des Parques, Atropos, celle qui coupe le fil de la vie des hommes.

3. Le docteur Bèhier l'a employée, à doses infimes, en injections souscutanées, contre les névrilgies rebelles. - La liste de ces alcaloides n'a cessé de s'accroitre sous nos yeux : il suffit de citer la cocaune, extraite du coca du Péron, en 1856, el qui produil des phénomènes très curieux d'anesthésie locale, dont le chirurgien, le dentiste, peuvent tirer un excellent parti.

4. Plus recemment, il a donné cne Histoire des connaissances chimigues (1866), ou butót une introduction philosobhique a cette histnire. 
Il est à remirquer que, dans cette période, on a extrait surtout des végétaux les matières colorantes; de nos jours on les a demandées plutòt à la houille; mais les houilles elles-mèmes sont moins des minéraux que des végétaux fossiles.

\section{Les sciences naturelles.}

Voyages de naturalistes. - De 1817 à 1S20, Les zoologues QUOY, GAIMARD, GAODICHAOD, accomplissent un royage scientifique autour du monde, sur l'Uranie et la Physicienne, que commandait de Freycinet. Puis viennent les explorations de LESSON et GARNOT (1522-23), sur la Coquille, que commandait Duperrey; de Quoy et Gaimard (1826-27), sur l'Astrolabe, que commandait Dumont d'Urville; de nonbtor et Jacodinot (1837-1840), avec le même commandant, dans les îles océaniennes et les rigions du pỏle Sud. Le prince LuCIEN BONAPARTE va étudier l'ornithologie de l'Amérique, Agassiz ses tortues et ses méduses. Nous trourons th. Lefebvre, A. PEtit, Desjardins à l’ile Maurice; sganzin (1840), à Madagascar; odantinDILloN (1539-43), en Abyssinie. Une exploration scientifique de l'Algérie fut exécutée de 1840 à 1842.

Zoologie. - Trois des zoologistes de la période précédente occupent, encore dans celle-ci. le premier rang ${ }^{1}$.

LACÉPEDE public en 1827 son " Histoire naturelle de l'homme " et, en 1830, ses "Ages de la nature ". cuvier nous donne, en 1816, son "Règne animal "; en 1828, son Histoire naturelle des Poissons; en 1830, son Histoire des Sciences naturelles. Étienne GeofrRoy SAINT-BILAire, en 1818, dans sa "Philosophie anatomique ", précise sa théorie de l'unité de composition organique dans tous les animaux. Cette théorie l'engage dans une polimique avec Cuvier. Celui-ci, après avoir reconnu que, dans la variété infinie des formes extérieures, il n'y a qu'un petit nombre de

1. Larépède meurt en 1825 ; Curier succombe en 1832 , le jour mėme où il renail de clore, avee un trés grand éslat, son cours du Collère de France; Geofroy Saint-Hilaire termine en 184 une vie dont la fin fut ittristée par la récite et des infirmités courazeusement supportées, et, suivant l'expres. sun de son biographe, " descendit sans rien craiudre dans léternelle $=r$ ience $*$. 
plaus de strueture, s'en tient à cette pluralité, mais n'admet pas l'unité.

Ces trois hommes exercent une grande influence sur la science pendant le premier tiers du siècle, et ce sont, après eux, leurs diseiples et leurs collaborateurs qui l'ont surtout illustréc.

Achille valenciennes, qui collabora à l'Histoire des Poissons de Cuvier, s'occupa personnellement des Mollusques, Annélides, Zoophytes (1833). Pierre rloorens, qui avait été l'aide de Cuvier dans ses travaux anatomiques, fut d'ailleurs plutòt un physiologiste qu'un zoologiste. LAdrillard eut sa part dans les livres de Cuvier sur les Mammifères et sur l'espèce humaine. Blainville, professeur à la Sorbonne, ćcrivit son "Prodrome d'une nouvelle distribution méthodique du règne animal " (1816), dont les théories furent ensuite développées par son suppléant Maurice Laurent. Il publia sa "Faune française" (1821), son "Cours de physiologie générale et comparée ", et en 1850 son " Ostéographie ". Il s'occupa aussi des Mollusques. Isidore GerFroy SAINT-BILAIRE continua la réputation et les travaux de son pèrc et démontra l'existence des oiseaux gigantesques de Madagasear, les Epyornis, qui devaient être six fois plus grands que les autruches et qui ont disparu. Maurice LAORENT, qui avait aecompli un voyage autour du monde, se consacra aux Zoophytes, notamment à l'hydre et à l'éponge d'eau douce. agassiz, du pays de Vaud, s'oceupa des Purssons vivants et des Poissons fossiles, ainsi que des Échinodermes vivants et fossiles; Aleide D'oRBIGNy et Jules pictet, des Mollusques lossiles. Paul deshayes s'est surtout occupé des Invertébrés et des Mollusques.

Botanique. - Nous reviendrons plus loin sur les progrès de la botanique en ce siècle, parce qu'ils appartiennent plutòt à la période tout à fait contemporaine. Signalons seulement les travaux de Payer, Gaudichaud, Adrien de Jussieu, Adolphe Brongniart, Auguste Saint-Hilaire, Moquin-Tandon, les deux Bravais, sur les organes des plantes.

La célèbre elassification botanique de Linné et des Jussicu s'est trouvée assez vite insuffisante quand, de tous les points du globe, par milliers et par myriades, des espèces et des variétés nouvelles de plantes se sont révélées. Dès 
1824, PYRAME DE CANDOLLE essayait de rectifier et de compléter cette classification dans son "Prodrome d'un système du règne végétal".

Minéralogie, géologie. - La description des minéraux a fait l'objet des travaux de Dufrénoy et de Sénarmont.

La classification des minéraux avait été ébauchée par Haüy, qui avait tenu compte surtout des bases et alcalis qui entrent dans leur composition. Beddant (1824) et Alexandre BRONGNIART (1841) tinrent compte surtout des acides. DURRÉNOY (1845) est revenu, sur certains points, à la classification d'Haüy. Après les essais de LExmeric et d'adam, une méthode dite éclectique, adoptée par Delarosse (1846), a pris ses motifs de groupement, tantôt dans la composition chimique, tantòt dans le système de cristallisation.

La stratigraphie, ou étude des couches du sol, a été, en quelque sorte, créée par ÉlE DE BEAumont. De 1826 à 18千́, en collaboration avec Brochant de Villiers et Dufrénoy, il a dressé la carte géologique de la France, magnifique travail d'ensemble qui a été repris en détail, dans nombre le régions, par les ingénieurs départementaux. En 182\%, il a publié sa "Classification des roches" et, en 1833. son "Dictionnaire des espèces minérales".

C'est surtout à Cordier. Huot, Alcide d'Orbigny qu'est due la nomenclature des roches et des terrains, les dénominations de silurien, déconien, permien, jurassique etc.

charles Sainte-claire-Deville, le frère de lillustre chimiste, s'est consacré à l'étude des régions volcaniques. En 1831, il se rendait à la Guadeloupe et y constatait que la nature rolcanique de l'île a commandé toute sa structure topographique. En 1843, il assista au terrible tremblement de terre des Antilles, qui bouleversa la Guadeloupe, y renversa la ville de Pointe-à-Pitre et y fit 2000 victimes. Dans l'intervalle, il avait escaladé le pic de Ténériffe. Ensuite il étudia les phénomènes volcaniques du Vésuve, de l'Etna, des iles lipari, descendant dans les cratères, explorant les crevasses, y recueillant les soufres et les laves. analysant les caz, risquant à tout moment d'être asphyxié par les émanations infernales ou englouti dans quelque gouffre. Il constata les rapports qui existent entre les phénomènes éruptifs et certains phénomènes météorologiques. 


\section{Les sciences médicales.}

Anatomie, histologie. - Les grandes découvertes anatomiques avaient été faites du xvire au xvıle siècle. Loriginalité de notre époque a été, en premier lieu, la comparaison de la structure humaine avec celle des animaux; en second lieu, l'étude microscopique des tissus; en troisième lieu, l'étude des fonctions des organes. On a donc fait plus de progrès dans l'anntomie comparée, dans l'histologie, dans la physiologie, que dans l'anatomie proprement dite.

Cependant quelques savants de notre siècle se sont illustrés en cette branche de la science : BRESCHET (mort en 18:5), qui a étudié spécialement les vaisseaux lymphatiques, les canaux veineux des os. l'organe de l'ouie; ISIDORE Georror SAINT-BILAIRE, qui a recherché surtout les cas exceptionnels, les monstruosités, ce qu'on appelle les anomalies, chez l'homme et les animaux (1832); Pierre-Auguste béCLARd, l'auteur des "Éléments d'anatomic générale " (1832) et l'un des fondateurs du Nouveau journal de médecine; Antoine sours, qui a fait plus de cinq mille dissections. Au reste, la plupart des savants médecins dont nous allons rappeler les travaux ont été également des anatomistes distingués.

La ehuire d'anatomie pathologique, à la création le laquelle Dupuytren avait consacré 200000 francs par testament, fut occupée par d'illustres titulaires, notamment par CRUvellaier, a partir de 1835. N'oublions pas une autre création de Dupuytren : le Musée anatomique.

Mentionnons la réorganisation (1826) de la Societé anatomique, autrefois ébauchće par Dupuytren ".

Lhistologie a pu accomplir de très grands progrès, gràce à l'cmploi du microscope ${ }^{2}$, des réactil's chimiques et des injections colorées. En 1845, l'anatomiste LEBERT, se séparant sur ce point de Bichat, adjurait les médecins de faire grand usage du microscope. DonNé publiait (18441846) le "Cours et l'Atlas de microscopie ". Dès lors, on a pu non seulement analyser les tissus, mais arriver à ce

1. En 1820 , fut reconstituée I'Ácartémie de médecine

2. En 1824, l'ingenieur Chevalier construisit le premier misconose achromatique. Le microscope solaive a rendu aussi des rtrices, mais plulot a l'étude des animaux infusoires qu'a l'histologie. 
qui semble l'élément irréductible de tout organisme : la cellule, dont le nom semble avoir été prononcé pour la première fois en France par RaspaIL (1824).

Physiologie. - " L'influence des Français, dit l'historien allemand Haeser, se marqua de la façon la plus décisive sur le développement de la physiologie depuis le début de notre siècle, mais particulièrement depuis les années 1830 à 1840 ". En 1849 a été fondée la Société de Biologie.

La première génération de physiologistes français comprend ceux qui peuvent avoir été contemporains et même disciples de Bichat.

DOTROCHet a découvert, en 1828, le curieux phénomène de l'endosmose, ou pénétration des tissus par les liquides.

Magendie, qui fut professeur de physiologie au Collège de France, proclama que, dans cette branche les sciences médicales, comme dans toutes les autres, l'expérience, et l'expérience seule, doit faire la loi. Il contribua à mettre au rebut ces fameuses théories de l'animisme, du vitalisme, déjà fortement ćbranlées. Il étudia les effets produits sur l'organisme par les substances nouvellement découvertes, telles que la morphine, la strychnine, la vératrine, la quinine et autres dérivés du quinquina, l'iode, l'acide prussique.

Jean-Pierre flodrens dirigea ses recherches sur l'ovologie el l'emtryogénie (1836), sur les propriétés et les fonctions du système nerveux, sur la formation des os, sur la physiologie et l'anatomie comparées ${ }^{1}$, sur les propriétés anesthésiques des éthers et du chloroforme.

GERDy, qui fut membre de la Constituante de 1848, aussi célèbre comme médecin et chirurgien que comme physiologiste, a laissé une œuvre consilérable : " la Physiologie philosophique des sensations et de l'intelligence " (1846).

Therapeutique. - Parmi les célèbres médecins, il faut citer Bocilladd, membre de la Conslituante de 18 18 , qui étudia spicialement les inflammations du cerveau (1825), les maladies lu cour (1833), et, dans leurs relations avec celles-ci, les rlıumatismes ärticulaires (1840). PIORRY généralisa l'emploi du plessimètre, plaque d'ivoire employée pour faciliter

1. Plus reccmment il a publiè d'importants ouvrages sur la circulation da sanj et sur son histoire (195\%), sur les couditions de la longévilé bumaine. 
la percussion, et perfectionna cet instrument. сномеL, qui fut médeein de Louis-Philippe et ne voulut pas l'ètre de Napoléon III, commença la réaction contre les doctrines de Broussais et se consacra aux fièvres, aux maladics pestilentielles (1821), aux dyspepsies (1857). Alexandre Louıs. élève de Chomel, est célèbre par ses recherches sur toutes les variétés de fièvres (typhoïde, putride, bilieuse, muqueuse, ete.), sur la phtisie, sur les naladies et lésions inteslinales. Il fut un redoutable adversaire de Broussais. BRÉtonnead publia, en 1826, ses Recherclies sur la diphté ritc, plus connue sous le nom de croup. rostan traita des ruptures d'anévrysmes $(1820)$ et fut un des premiers à étudier " une maladie encore peu connue, qui a reçu le nom de ramollissement du cerveau "(1820). ANDRAL, élève, puis adversaire de Broussais, est, suivant Haeser, "le premier elinicien français des temps modernes ". Avec M. Gavarret, il s'est livré spécialement à l'étude du sang et de ses maladies (1842-1843). A]fred BECQUerel et ROBIN ont publié leurs "Recherehes sur la composition du sing dans l'état de santé et dans l'état de maladie " (1844). troussead, " celui des Français modernes, assure Haeser, sur lequel la médecine allemande a eu l'influence la plus visible ", a publié, avec Belloc, un "Traité de la phtisie laryngée " (1837). Il fut un des fondateurs du Journul des connaissances mélicales (1839). RAYER a traité de la morve, des maladies du rein; BIETT el aLiBERT, des maladies de la peau; ManTIN - SOLON, de l'albuminurie; VALLEIX, BAJdelocode des maladies des enfants; mulcent, LEBERT, de la serofule, les écruuelles de nos aïeux; GAUTIER DE CLAUBRY, FAdRE, CHAUFFARD, GODELIER, BARAILLER, du typhus et de la fièvre typhoïde; rORGET, des fièvres continues; grisolle, de la pneumonie.

En 1807, Bozzin, de Franefort, avait inventé le laryngoscope, pour l'exploration du larynx : CAGNIARD DE LA TOdR, vers $182 \%$, le perfectionna et en vulgarisa l'emploi.

En 183.t, HÉrIsson inventa le sphygmométre, colonne de mercure enfermée dans un tube gradué et qui, mise en contict ar. l'artère, rend compte exactement de la fréquence, du rythme et de l'énergie du pouls.

Matтeucci, professeur à Pise, semble le premier qui ait employí l'électricité en thérapeutique (1844). 
LOGOL est le premier en France qui ait fait usage de l'iode dans les hópitaux pour le traitement de la scrofule.

Homoeopathie. - mannemann, médecin allemand, préconisa de 1791 à 1843 une méthode de thérapeutique tout. à fait nouvelle. Il enseignait que la maladie est causée uniquement par une diminution de la force vitale. Il était inutile, suivant lui, de distinguer les maladies en locales ou générales, fiévreuses ou non fiévreuses, toute maladie étant nécessairement générale. La prétention de rechercher la cause du mal afin de la faire disparaître pour amener la guérison était également une chimère. On ne pouvait saisir et combattre que des symptòmes et non des causes; on ne pouvait guérir une maladie qu'en donnant au patient une autre maladie plus violente pour combattre la première : deux maladies ne pouvant coexister dans le même organisme, celle qu'on donnait artificiellement, et qu'il appelait maladie artificielle ou maladie médicamenteuse, chassait la première, ou plutôt c’étaient les symptômes du remède qui détruisaient les symptômes du mal, car de remonter à la cause interne de ce mal il n'y fallait pas songer. Ensuite la maladie artificielle était ellemême expulsée par les forces natives de l'organisme, revenues, au milieu de ce conflit, à leur maximum de puis. sance. De là le nom de son système : homaopathie, ou guérison par les semblables, en vertu de l'axiome latin : similia similibus. Il traitait ses adversaires d'allopathes, parce qu'ils cherchent à guérir par des principes contraires, en invoquant la devise d'Hippocrate : contraria contrariis.

Hahnemann, pour donner au patient sa maladie mélicamenteuse, recourait à une pharmacie aussi sincrulière que sa thérapeutique. Il prétendait qu'un seul remède, simple et primaire, un seul spécifique, sulfisait pour chaque maladie. Il n'employait que des substances très énergiques, même toxiques, comme l'arsenic, l'aconit, l'arnica, la helladone; mais il ne les administrait qu'a des doses infinitésimales. Le médicament une fois obtenu à son ètat de pureté absolue, il le diluait dans cent fois son volume d'eau ou le triturait dans cent fois son volume de sucre en poudre. Un grain de ce mélange était de nouveau mèlé à cent fois son volume. Puis l'opération était renouvelée jus- 
qu'à trente fois, de façon à ce que le médicament primitif ne formât plus dans la potion ou la pilule définitive qu'un décillionième. La thèse de Hahnemann était que, loin de l'affaiblir, ces mélanges successifs produisaient en la substance ainsi employée une dynamisation, c'est-à-dire une élévation de sa puissance.

L'homœopathie a fait, à cette époque, quelque bruit en France, et il y a encore chez nous des médecins et des pharmaciens homoopnthes; mais elle n'a recruté que peu de croyants dans le monde scientifique et n'y compte pas d'adhérents illustres. Elle n'a jamais eu chez nous, comme en Allemagne, accès dans les chaires publiques. Elle a éloigné la confiance par son mépris affecté pour les connaissances physiologiques, l'étude attentive des maladies, la recherche des causes, surtout par le caractère paraxodal de sa thérapeutique et de sa pharmacie.

Chirurgie. - Le siècle nouveau avait hérité de plusieurs des grands chirurgiens de l'époque impériale : Percy est mort seulement en 1825, Pelletan en 1829, Boyer en 1833, Larrey en 1842. Après le rétablissement de la paix, la suprématie passa de la chirurgie militaire à la chirurgie civile.

Le grand nom de l'époque, c'est Doportren 177\%-1835̆), l'élève favori de Bichat. Sa force et sa beauté physique, son labeur infatigable, ses profondes connaissances anatomiques et physiologiques, sa vaste expérience, son coup d'œil infaillible, le sang-froid et la dextérité qu'il déployait dans les opérations les plus difficiles, même sa richesse, sa générosité, son originalité, sa brusquerie de bourru bienfaisant, le reudirent non seulement célèbre parmi les hommes de science, mais populaire dans les masses. Louis XVIII le fit baron, Charles $X$ le nomma son premier chirurgiea. Il laissa en mourant une fortune de plusieurs millions, avec des legs qui servirent aux fondations scientifiques dont nous avons parlé. Ses principaux travaux sont postérieurs à 1828 : ils purtent surtout sur les hernies, l'opération de la pierre, les blessures.

RICHERAND, élève de Desault, fut le rival et le contradicteur de Dupuytren. Son "Histoire des progrès récents de la chirurgie" (1825) fourmille de traits piquants à l'adresse du grand opérateur. 
RoDx, condisciple de Dupuytren chez Bichat, n'en fut pas moins son adversaire. Ses recherches eurent surtout pour objet les résections, l'opération de la cataracte, la suture du voile du palais (1825).

Jacques Delpech fut, comme l'illustre Larrey, un élève du père de celui-ci, Alexis Larrey. C'est le plus grand nom de la chirurgie de ce temps après Dupuytren. Il avait débuté, en 1813, par un mémoire sur la pourriture d'hopital. Il enseigna, le premier, à redresser des membres en coupant les tendons trop courts, c'est-à-dire par la ténotomie (1829), Il mourut d'un accident assez rare dans l'histoire médicale : il fut tué par un patient qui avait à se plaindre du mauvais succès d'une opération.

LISFRANC fut un admirateur, puis un adversaire et mème un ennemi de Dupuytren. On nous le représente comme un habile opérateur et un professeur éloquent, mais d'un caractère difficile et querelleur.

velpeau fut un excellent chirurgien, qui eut presque la réputation de Dupuytren. Il publia, en 183\%, avec Béraud, son fameux "Manuel d'anatomie chirurgicale ", le premier que nous ayons eu. Anatomiste savant, physiologiste distingué, professeur clair et précis, le premier, depuis Desault, qui ait été médecin en même temps que chirurgien, il s'occupa spécialement d'embryologie et d'ovologie humaines. On lui doit d'importants travaux sur les maladies des yeux et les opérations du trépan.

JOBERT DE LAMBALLE, savant anatomiste et histologiste, opérateur d'une merveilleuse adresse, a traité des plaies d'ar'mes à feu, des fistules, de la chirurgie plastique.

On peut encore citer, vers le milieu du siècle, Lallemand, de Hetz, élève de Dupuytren; Pétrequin, qui, le premier, employa l'électricité au traitement des anévrysmes, et qui écrivit sur l'histoire et la philosophie de la chirurgie; Sanson, Blandin, Chassaigne, Bonnet, Marjolin, Récamier, qui osa tenter, un des premiers, l'ablation de l'utérus.

Caractères nouveaux de la chirurgie : les anesthé. siques. - La chirurgie du $\mathrm{xix}^{\mathrm{e}}$ siècle se distingue nettement de celle des deux siècles précédents, si cruelle et si empressée de lecourir au feu et au fer : elle est bien plus conservatrice. Elle se préoccupe des suites de l'opération autant 
que de l'opération elle-mème; aux amputations elle a commencé par préférer les résections, destinées à régulariser la blessure. "Plus je vieillis, disait Velpeau, moins j'ampute. " "Si j'avais la jambe cassée par un coup de feu, ajoute Malgaigne, je ne me laisserais pas amputer. "

La pratique de l'irrigation, inaugurée par Larrey, préconisée ensuite par sEUTIN, velpEAd, BĖRARD, a donné les plus heureux résultats ${ }^{1}$. L'opération de la taille (pour la pierre), si souvent mortelle, a été presque abandonnée : en 1822, LEROY D'ÉTIOLLES inventa l'appareil pour la lithotritie, c'est-à-dire le broiement de la pierre, et amussat un brisepierre. La lithotritie a été perfectionnée par civiale, HedRTELOOP, sÉgalas. On est mème parvenu à guérir les malades par le seul emploi de certaines eaux minérales.

On a renoncé aussi à cette diète hippocratique, si rigoureusement prescrite aux blessés, et qui avait pour conséquence d'achever de les affaiblir moralement et physiquement, et de les livrer sans défense aux assauts du mal. On se fondait sur la crainte de la fievre traumatique, qui pouvait naitre des blessures si le malade conservait toute sa vigueur. La réforme fut commencée, en 1842, par MaLGalgNe. 11 prescrivit les aliments, le vin, l'alcool en quantité modérée, et les malades ne s'en trouvèrent que mieux.

La chirurgie moderne s'est montrée aussi plus humaine, parce que, plus heureuse que sa devancière, ella a pu faire usage des anesthésiques, destinés à atténuer, ou mème a supprimer la douleur. Les opérateurs, dans les grandes guerres de la République et de l'Empire, n'avaient rien le pareil à leur disposition : il leur fallait trancher dans la

1. Sous l'influence du courant d'eau continu, "les douleurs s'apaisent, linflammation tombe, la fièvre cesse; le calme, la confiance, la gaieté mème, renaissent au cœur du malade, et le plus souvent la guérison marche plus rapidement. Les parties déchires se soudeut, de noureaus tissus se forment, et, sauf quelques lambeaux délachés au moment de l'accident tout reprend sa place. Le chirurgien qui assiste à ce spectacle laisse à la nature tout l'honneur de la guérison... D'un blessé que l'accident dont il a été victime menaçait de transformer en un malade, l'irrigation refait un sujet bien portaut, à sa blessure près; dune plaie qui allait devenir le foyer te désordres pathologiques les plus graves, elle fait le siège des phénomenes les plus réguliers el les plus habituels de la vie. "(Dumas, Éloge d'Auguste Bérard.) Berard a eu la hardiesse, le premier, de permettre à un blessé, fracturé de la jumbe, de se lever le troisieme jour et de fairt quelques pas a l'aide de bequilles. 
chair, souvent parmi les cris et les convulsions du patient. Encore en 1829 Velpeau déclarait que vouloir supprimer la douleur " c'est une chimère 1 ". Or, cette année-là, CLOQUET proposa d'insensibiliser le malade au moyen de l'hypnotisme. C'est à partir de 1840 que plusieurs anesthésiques puissants lurent successivement adoptés. En 1844, le dentiste Ewans employait, à Paris, le protoxyde d'azote. En 1847, Longet ei Malgaigne préconisaient les inhalations d'éther sulfurique. La mème année, le chloroforme était nis en ouvre par Simpson, à Edimbourg, et recommandé par Dumas et Flourens. Après sa découverte par Balard (1844), on essaya aussi de l'amylène ou hydrogène carboné, mais on ne put constater assez sûrement son caractère inoffensif. La morphine, découverte par Sertuerner (des 1803), étudiée ensuite par les chimistes français, n'est devenue d'un usage général qu'à une époque assez voisine de nous, depuis les expériences de Claude Bernard.

Les pansements, dont la complication plaisait à Desault et Boyer, ont été simplifiés. Pour empècher le sang de couler, Larrey et Lisfranc recouraient à la torsion des artères : on s'en tient aux ligalures. Pour cautériser, on ne connut longtemps que le feu et les acides: on a emprunté aux Allemands l'emploi du galvanisme, c'est-à-dire la galvanocaustique, dont Félix palaprat et admussat donnèrent la théorie. On inventa les appareils fixes destinés à maintenir les nembres fracturés plus sùrement que les attelles d'autrefois : dès 1814, on commença à employer en Europe les appareils en plàtre, connus depuis longtemps en Orient; Larrey se servait d'un enduit composé de blanc d'cuf', l'einu de plonb, d'esprit de camphre; Seutin, en. 1829, inagrina les bandages amidonnés; plus tard, on a employé la gutta-percha.

Les infirmités connues sous le nom de pied bot, strabisme, bégayement, certaines déviations de la taille, ont été guéries

1. Cependant, dès le m $^{\circ}$ siècle, la chirurgie des Chinois faisait usage du cannabis indica, connu en Europe sous le nom de hachisch. Au xit siècle, Nicolas le Preposé, à Silerue, recommandait certains onguenls destines a remplir le méme office. Comme moyen purement mécanique, on peut citer aussi une forte compression des vaissenx du cou : elle avait été pratıo quée, dims l'antiquité, par les Assyricus. 
par la ténotomie. Dès lors, l'orthopétlie a fait de grands progrès, gràce surtout à Jules Gó̇rin et pRAvaz.

La chirurgie plastique consiste à refaire certains organes en empruntant à d'autres parties dı visage ou du corps la peau et mème les muscles. La rhinoplıstie, ou rúfection du nez, en est une branche. En 1817, Werneck refait une bouche; en 1825, Lisfranc refait un nez gelé ılans la campagne de Russie; Blandin et Jobert de Lamballe refont des paupières (1835); Dupuytren corrige les hecs de lièvre. On refera des larynx, des palais, des joues.

Branches diverses de la médecine et de la chirurgie. - Le service des Maternites avait été réuni par la Convention nationale aux Écoles de santé : il le fut ensuite aux Facultés de médecine. C'est là que s'illustrèrent Leroy, Baudelocque, Antoine Dubois, Beneux, qui fut médecin de la duchesse de Berry, Désormeaux, Moreau, Paul Dubois, qui, plus tard, fut médecin de l’impératrice Eugénie.

L'ophtalmologie est la médecine des yeux. Parmi les ophtalmologistes ou oculistes les plus distinsués de cette époque, citons demodrs, qui fut oculiste de Louis XVlll et de Charles $\mathrm{X}$; carron do villards. qui fonda l'Ecole spéciule d'ophtalmologie; saroN, qui inventa un appareil appelé les images de Saron (1837) : c'est l'origine de l'ophtulimosrope.

Pour le traitement des maladies mentales, Pinel et Esquirol ont eu de dignes successeurs : Georget, Leuret, Fabrel. Morel, surtout ferros, qui, en 1838, inspira le règlement concernant les asiles d'aliénés et recommanda pour eux la vie tranquille des champs, au besoin dans des colonies agricoles.

ORFILA fouda en France l'enseignement de la médecine Zegale, dont Marc avait pose les principes.

HALLE et MICHEL LÉVY se signalèrent comme hygienistes.

Pharmacie. - Il suftit de rappeler les noms et les découvertes mentionnées ci-dessus de Robiquet, Pelletier, Caventou, professeur à l'École de pharmacie de Paris, Boutron-Chalard, Brandes, Desfosses, etc., enfin les travaux de BOUCHARDAT, pour qu'on puisse mesurer les progrès accomplis par la pharmacie française dans cette période.

Ouvaages a consulter. - Voyez la bibliogr, da chap, xxxin. 


\section{CHAPITRE XXIII}

\section{La Transformation ÉconomiQue}

\section{Les grandes applications des sciences.}

La vapear. - Deux forces surtout ont contribué à transformer le monde moderne et à lui domner son caractère: la vapeur et l'électricite out amene, au $\mathrm{x}^{\mathrm{e}}$ siècle, une révolution aussi profonde que la découverte de la poulre à canon et de l'imprimeric au début des temps modernes. Seutement la poudre à canon a surtout changé les conditions politiques; l'imprimeric a surtout agi sur le mouvement intellectuel; la vapeur et l'électricité ont modifié toutes les conditions matérielles et morales de la vie des peuples ${ }^{1}$.

Un Américain, Olivier Evans, apporta de nouveaux pertectionnements aux engins créés par James Watt et construisit des machines a haute pression. En 1819, il mourut désespéré après un incendie qui détruisit son lablissement de Pittsburg. Son cuvre lui survécut: les mécaniciens anglais trevituicr et vivian reprirent ses idées. Cependant, c'est seulement de 1823 à 1830 que ces machines se multiplièrent en Angleterre.

L'Angleterre devait être la vraje patrie des machines à vapeur, car elle possède, avec une ahondance exceptionnelle, les deux éléments essentiels d̀ la construction et à l'alimentation de ces machines : le fer et la houille.

1. Jusqu'à frésent, nous en avons parlé aus chapilres sur les sciences pysiques : depuis qu'elles sont sorlies des labolalores pour entrer dans lit pralique, elles appartiennect à l'histoire économique du siècle. 
Pourtant linvention nouvelle continuait à végéter dans une demi-impuissance, lorsqu'un ingénieur français, marc SEgUIN, d'Annonay, en 1828, it une découverte importante. Les anciennes chaudières produisaient trop peu de vapeur, parce que la surface chauffée était insuffisante; on aurait pului donner plus d'étendue en donnant plus de dimension à la chaudière, mais alors celle-ci eût été démesurée. Seguin trouva moyen daugmenter la surface de chauffe sans augmenter les dimensions de la chaudiere. Il fit passer à lintérieur de la chaudière un grand nombre de tubes creux, qu'cmplissait l'air chaud du foyer et qui contribuaient à vaporiser l'eau : c'est ce qu'on appelle le système tubulaire. Dès lors, une simple chaudière percéc de quarante, puis de quatre-vingts, puis de cont vingt de ces tubes, produisit des quantités énormes de vapeur. En même temps, Seguin inventait un système de ventilution destinée à activer la flamme du foyer.

La vapeur prenait done possession du monde. Elle allait le révolutionner par son emploi dans trois applications principales : $1^{\circ}$ les machines industrielles; $2^{\circ}$ la locomotion par eau; $2^{\circ}$ la locomotion par terre.

Les maehines industrielles a vapeur. - La premièrc machine à vapeur qui ait été construite cn France figura à l'Exposition de 1806. Depuis cette époque, la rapeur a été appliquée à tous les usages possibles. L'agriculture s'en cst emparée pour ses batteuses, ses charrues à rapeur; l'industrie, pour ses machines à tisser', à filer, pour ses usines métallurgiques, ses scicries, papeteries, imprimeries. En 1839, il y avait en France 2400 machines à rapeur, d'uwe force de 33308 cheraux; en 1839, if y en avait 13691 , d'une force de 169166 cheraux ${ }^{1}$. Une seule machine a vapeur, dans une usine, peut mettre en monvement une infinité de machines-outils, depuis le tour du tourneur jusqu'à l'énorme marteau-pilon, si puissant et si docile. qui peut forger des pièces dacier de vingt à trente mille kilogrammes et casser une noisette sans l'écraser.

La navigation à vapeur. - L invention de la navigation a vapeur, trois fois écartée de France par les malheurs de

1. En 1982, il v en avait 46289 d'une force de 611859 cheraux. 
Papin, l'émigration de Jouffroy d'Abbans, le refus opposè à Fulton, eut, comme nous l'avons v'u ${ }^{1}$, son triomphe définitif en Amérique. L'Angleterre fut ensuite la plus prompte à utiliser la nouvelle découverte : dans tous les progrès de la navigation a vapeur, elle nous a presque constamment précédés.

La Restauration sut gré à Joufrroy D'abBans de son dévouement et de son exil. Elle lui vint en aide : en 1816, il put lancer le Charles-Philippe à Bercy et l'arrèta sous les fenêtres des Tuileries pour recevoir les applaudissements de Louis XVIII. Il vit ensuite son privilège contesté par une entreprise rivale, la Compagnie Pajol. Il acheva de se ruiner et dut accepter en 1830 un asile aux Invalides, oì il mourut en 1832 .

Ce fut un capitaine français de la Compagnie Pajol, qui, en 1816, vint de Londres à Paris sur l'Élise, accomplissant ainsi la première traversée de la Manche. En mer, l'Elisr" fut assaillie par une tempète épouvantable qui fit périr beaucoup de navires à voiles et démontra la résistance dı nouvel appareil. Le bateau aborda au Havre, à la stupeur. des pilotes et marins du port. 11 remonta la Seine par une nuit obscure : "Les villageois se rassemblaient sur le: rives du fleuve, appelés par le bruit des roues et effrayés a la vue des étincelles et des jets de flamme qui s’échappaient du bateau. Cette espèce de torche sillonnant avec rapidité le cours du fleuve attirait de loin tous les regards et semait l'épouvante sur son parcours. Les cris sinistres : A u feu! au feu! le tocsin et les aboiements des chiens ne cessèrent, jusqu'au point du jour, de poursuivre la fantastique apparition. "En revauche, l'entrée a Paris fut triomphale : au milieu des applaudissements d'une multitude immense, l'Elise vint mouiller sous les fenètres des Tuileries, qu'elle salua de vingt et un coups de canon.

A la suite d'une mission confiée a l’ingénieur marestien et de son Rapport sur les progrès le la navigation à vapeur en Amérique, des services de bateaux sétablirent sur presque tous les fleuves de France. D'autres hateaux, dont le premier en date lut le Courrier de Caluis, lirent réguliè-

1. Voir ci-dessus, page 253. 
rement la traversée de la Manche. En 1835, les Chambres votaient l'établissement d'une ligne de bateaux à vapeur entre Marseille et Constantinople.

Il fallait oser plus, et traverser l'Océan. En 1819, le Savannah, bateau américain, faisait, en vingt-cing jours, c'est-à-dire en six jours de plus que les navires à roiles, la traversée de Savannah (Amérique) à Liverpool (Angleterre). En 1821, l'Enterprise, vaisseau anglais, opérait en quarantecinq jours le royage de la Grande-Bretagne aux Indes. En 1838, le Sirius et le premier Great-Western franchissaient en dix-sept jours l'Atlantique, d'Angleterre en Amérique. En 1842, le Iriver, bateau anglais, accomplissait le premier tour du monde à la vapeur.

Les Français se risquèrent plus tard. C'est seulement en 1830 que fut construit, dans les ateliers d'Indret, le Sphinx, le premier navire à vapeur de notre marine de guerre.

C'est seulement en 1840 que la Chambre des députés se préoccupa de créer un service de prquebots ou bateaux destinés à mettre la France en communication avec l'Amérique, et qu'on appelle transatluntiques. Elle vota 28 millions pour la construction de dix-huit bateaux, qui desserviraient les trois lignes du Harre à New-York, de Nantes au Brésil, de Marseille et de Bordeaux aux Antilles.

Une moditication importante avait été apportée à la construction des bateaux à vapeur. Au lieu de deux roues latérales, DALLERY, d'Amiens, dès 1803, avait proposé de liaire mouvoir le bateau au moyen d'une hélice placée à larrière. La modification était précieuse, surtout pour les navires de guerre, car l'hélice est moins exposée que les roues. Les travaux de Delisle et SAOVAGE, vers 1823, avaient confirmé l'importance de la découverte, et en 1838 les Anglais construisirent les premiers bateaux à hélice.

En outre, les Anglais avaient commencé à substituer le fer et l'acier au bois dans la construction des navires. Enfin la chaudière des machines, par l'adoption du systeme tubulaire, avait acquis une force d'impulsion et donnait une vitesse beaucoup plus considérables.

Les chemins de fer. - La locomotion à vapeur par terre a progressé moins vite que la locomotion par eau. Elle présentait des difficultés plus grandes, car elle suppose deux 
éléments : $1^{\circ}$ une route aplanie et munie de rails de fer ou d'acier; $2^{\circ}$ une machine roulante, mue à la rapeur et entrainant des voitures.

Dès 1696, dans les mines de houille de Newcastle, eı Angleterre, on facilitait la locomotion des chariots de minerai au moyen de rails en chène ou en sapin; puis on garnit de fer ces bandes de bois; puis on fabriqua des rails de fonte; puis on les fit de fer forgé ou d'acier.

Ces chariots de minerais étaient trainés par des chevaux. Nous connaissons la tentative faite par le Lorrain Cugnot, en 1769 , pour substituer a la traction par les chevaux la traction par la vapeur.

En 1800, evans réussit à laire marcher une voiture à vapeur dans les rues de Philadelphic et prit un brevet d'invention; mais personne ne voulut lui prêter d'argent pour l'exécution de ses plans. Trevitaick et vivian reprirent son idée en 1801. En 180', ils s'avisèrent de poser leur " diligence a vapeur " sur des rails de métal. Le principe du chemin de fer était trouvé! En 1813, l'Anglais BLAcketT écarta une difficulté qui avait jusqu'alors arrêté les ingénieurs: les roues des locomotives, tout en tournant, rlissaient sur place, et la machine n'arancait pas; vainement on avait cherché le moyen de faire mordre la roue sur le rail. Blackett indiqua la vraie solution, qui semblait alors paradoxale : c'était d'augmenter le poids de la locomotive.

Georges stephenson, a Newcastle, avait construit (1812) la première machine qui ressemblảt un peu à la locomotive d'aujourd'hui : Robert Stephenson avait eu l'idée l'activer le tirage en lançant dans la cheminée le jet de vapeur, après qu'il avait produit son effet sur le piston. Pendant une dizaine d'années, on se contenta d'employer ces machines à tirer des convois de houille, auxquels on adjoignit, vers 1825, des voitures de voyageurs. Les chaudières produisaient encore si peu de vapeur que l'on parcourait seulement une lieue et demie à l'heure. La vapeur donnait moins de vitesse que les chevaux!

Les ingénieurs anglais furent les premiers à introduire dans la construction des locomotives le systeme tubulaire (1828). Dès 1829, les stephenson construisaient une puissante locomotive, la Fusée, qui trainait un poids de 13000 kilo- 
grammes et parcourait six lieues à l'heure. Dès 1830 , fonctionne le premier chemin de fer anclais, entre Liverpool et Manchester.

Ici encore, les Français, peidant le bénélice de l'invention de Seguin, s'étaient laissés devancer, mais de deux années seulement.

Dès 1823, BEAUnier obtenait la concession d'une ligne de fer allant de Saint-Étienne à Andrézieux. Dès 1826, sEgurN obtenait celle de la ligne de Saint-Étienne à Lyon. En 1828 fut concédée celle d'Andrézieux à Roanne 1. Mais sur la première de ces lignes, cétaient des chariots de houille, uniquement trainés par des chevaux. Sur la seconde ligne, destinée également au transport de la houille et des marchandises, mais non à celui des voyageurs, les voitures étaient tantôt remorquées par une espèce de locomotive, tantót trainées par des chevaux, tantôt hissées par des cordages qu'une machine à vapeur immobile enroulait autour d'un tambour, tantôt, sur les pentes, abandonnées à leur propre impulsion 2. Nous n'avions pas encore un víritable chemin de fer. En 1832 seulement fut inaugurée chez nous la véritable locomotive. Les Américains, sur leur ligne de 24 kilomètres, ne remplacèrent qu'à cette mème date les chevaux par la machine. Seule l'Angleterre nous a précédés de deux années.

L'ingénieur PERDONNet, associé a I banquier péreIre, essaya vainement d'obtenir du gouvernement la concession d'une ligne allant de Paris a Rouen. M. Thiers, alors ministre des travaux publics, et qui revenait cependant d'Angleterre, refusa même de saisir les Chambres de cette question. " On me jetterait en bas de la tribune ", répondit-il. Il

1. La première ful ouverte en 1828 el avail 23 kilomètres de long; la seconde fut inaugurée en 1830 sur un parcours de 15 kilomètres.

Vinrent ensuite la ligne d'Épinac au canal de Bourgogne, concédéo en 1830 et ouverte en 1835; celle d'Alais à Beaucaire, concédée en 1833, etc.

2. L. Figuier raconte un voyage qu'il fit sur ce chemin de fer primitif : les voútes des tuunels étaienl si basses el si étroiles, les piliers des ponts si rapprochés, que le voyageur qui meltait la lète à la portière risquail do la perdre. Les wagons étaient des boites en sapin semblables à des diligences. " Nous eùmes le bonheur d'arriver a Sainl-Élienne sans encombro, ajoule le voyageur; c'élail toul ce que l'ou pouvait demander à notra embryon de chemin de fer." 
affirmait que les chemins de fer ne seraient jamais que des joujoux pour les Parisiens : jamais ils ne pourraient relier des centres de population séparés par de grandes distances : tout au plus pourraient-ils desservir des lignes très courtes aboutissant à de très grandes villes. Arago, lillustre savant, affirmait, en 1836, qu'il serait impossible de respirer dans les tunnels. D'autres prétendaient que quand deux trains, allant en sens contraire, passeraient l'un à côté de l'autre, l'air qui se trouverait entre eux serait si violemment comprimé que les voyageurs seraient aussitôt asphyxiés ${ }^{1}$.

Perdonnet et Péreire se rabattirent alors sur la concession d'une ligne allant de Paris à Saint-Germain, et longue seulement de 17 kilomètres. Elle fut votée par les Chambres en 1835 et inaugurée en 1837. C'est la sixième de nos lignes. L'expérience suffit pour que la cause des chemins de fer füt gagnée ${ }^{2}$.

En 1836, les Chambres votèrent l'établissement des lignes de Paris à Versailles et de Cette à Montpellier. L'année suivante commencèrent les discussions sur l'établissement d'un système d'ensemble, d'un vaste réseau ferré : elles aboutirent, en 1842, à une loi qui décidait la création de grandes lignes, dont l'exécution fut confiée a un certain nombre de compaynies, avec le concours des subventions et du crédit de l'État.

La loi de 18.45 régla l'exploitation et la police des chemins de fer.

$\mathrm{Au}$ début de cette exploitation, les wagons de voyageurs étaient fort incommodes, petits, mal aérés, mal éclairés. Les compagnies, par un souci mal entendu de la sécurité des voyageurs, les traitaient en enfants yu'on ne saurait

1. Les préventions contre les chemins de fer survécurent longtemps aux premiers essais. Wellinglon, le vainqueur de Waterloo, le Duc de Fer, ne se décida pas avant l'annèe 1842 à monter dans un wagon. Cavour, un des fondateurs de l'unité italieune, préférait, en 1558, venir en chaise de poste de Turin a Paris. Les paysans attribuaient à la fumèe des locomotives les pluies persistantes. Tel conseil municipal d'un chef-lieu de canton du Doubs demandiail que la ligne ne passál point par cette localité : cela ferait venir la maladie sur les pommes de terre.

2. I] frut citer, parmi les hommes à qui la France dut ces premiers chemins de fer, i'ingenieur Didton, qui fut membre de toutes les commissions chargées d'examiner ces questions. 
trop surveiller. Elles les enfermaient à clef dans les voitures : c'est pour cela que l'incendie du chemin de fer de Versailles, en 1842, fit tant de victimes, parmi lesquelles le célèbre navigateur Dumont d'Urville.

La télégraphie électrique. - Les premières tentatives pour communiquer a distance au moyen du courant électrique remontent, comme nous l'avons vu, à Marshall (1753), à Franklin (1756), à Lesage (1774), qui ne disposaient alors que de machines à frottement, ne dégageant qu'une trop faible quantité d'électricité. Enfin Sommering (1811) put utiliser la pile dans son télégraphe; mais il fallait encore autant de fils que de signes : trente-cinq. Puis, après les découvertes d'OErsted, Ampère, Arago, en 1838, l'Américain morse prend un brevet pour un télégraphe n'exigeant qu'un seul fil. Celui-ci, actionné par une pile, transmet des signes sous la forme de points et de lignes qui, à la station correspondante, s'impriment sur un papier. Morse crée vraiment la télégraphie électrique.

En 1845, l'ingénieur français BRĖGOET invente un nouvel appareil, où les signes de Morse sont remplacés par les lettres de l'alphabet.

En 1839, Wheatstone établit la première ligne télégraphique sur un chemin de fer anglais, le Great Eastern Railway. En 184'x. les États-Unis créent leur première ligne.

C'est en $\mathbf{1 8 4 5}$ seulement, sur le rapport d'Arago, que les Chambres françaises votent l'établissement d'une ligne d'essai sur le chemin de fer de Paris à Rouen : l'exécution en est confiée à For et BRÉGJET.

L'éclairage au gax. - Le gaz qu'avait obtenu Lebou, et, après lui, Murdoch, donnait une flamme obscure, qui répandait une odeur fétide. Il fallait trouver moyen de le purifier pour que l'usage s'en généralisàt. Dès 180t', l'Allemand wINSOR fondait en Angleterre une société industrielle pour l'éclairage des rues au moyen du gaz extrait de la houille. Des années se passèrent avant que cette innovation pùt pénétrer en France : en 1816, Winsor offrit au public français un spécimen d'éclairage au gaz dans le Passage des Panoramas et s'associa avec Darpentigny et $\mathrm{C}^{\mathrm{ie}}$ : l'essai fut interrompu par la déconfiture de ses associés.

En 1818 , le roi prit la nouvelle invention sous sa protec- 
tion; ils'inscrivit comme actionnaire d'une nouvelle société, créée par pauwels. Les gens de cour s'empressèrent de l'imiter. M. de Chabrol, préfet de la Seine, fit un essai à Paris. De là, le gaz s'est répandu dans les principales villes, puis a pénétré mème dans des bourgs et des villages.

La lampe de mincur. - Pour alimenter les machines, il faut de la houille, que vont chercher, parfois à huit cents pieds sous terre, les mineurs. Dans ces galeries souterraines, un danger terrible les menace : le gaz grisou qui s'enflamme à la lumière de leur lampe, et dont les explosions bouleversent la mine, brulant ou ensevelissant sous les décombres des centaines de victimes. DAVY, en 1815 , invente la lampe des mineurs, où la flamme est enveloppée d'un cylindre de toile métallique qui suffit pour empècher le grisou d'entrer en contact avec le feu. L'invention de Davy préserva la vie de milliers de travailleurs.

Les puits artésiens. - BĖRICART DE THURY et DEgousIE donnèrent la thíorie des puits artésiens ${ }^{1}$ et créèrent les appareils destinés à les creuser. En 1833, moLot creusait, à une profondeur de $5 \dot{4} 8$ mètres, le premier puits de ce type que nous ayons eu : celui de frenelle. Il ne fut terminé qu'en 1842. Il débite 4000 litres d'eau à la minute.

Progrès de Ia mécanique. - La science des machines a dû beaucoup, en France, à Chasles et ì Poinsot, qui ont surtout étudié la cinématique et la stıtique, deux branches de la mécanique; à Hachette (1806), à Lang et Bétancourt (1808), qui ont défini el classé les organes des machines; à Poncelet et Savary, qui ont donné la théorie des engrenages; à Dupuis (1837) et Morin (1842), qui ont calculé les frottements; à Darcy et Bazin, qui ont perfectionné la mécanique hydraulique; à Héron de Villefosse et Junker, qui ont construit les machines pour l'épuisement des mines; à Fourneyron, qui a établi les premières turbines.

Les travaux publics. - Les progrès des mathématiques ont permis de réaliser des projets qui eussent semblé chi-

1. Le mot d'artésien rappelle que c'est en Artois, à Lilliers (Pas-doCalais), que fut créé, en 1126 , sous le règne de Louis le Gros, le premier puits obtenu par le forage du sol. Mais ces puits, donl Bélidor, en 1729, donna la théorie, ne sont que l'enfance de l"art: jusqu'a notre siècle, la profoudeur des forageg ne dépassait pas 15 \& 20 métres. 
mériques aux ingénieurs des àges précédents. On a étudié avec précision les problèmes relatifs à la poussée des terres, à la résistance des matériaux, à la soliditè des voûtes. On a construit ces voùtes biaises, dont LEFORT a donné, en 1839, le premier spécimen, et qui sont plus étonnantes et plus solides que les constructions romaines; ces ponts suspendus, invention américaine qui, à partir de 1830, commence à se répandre en Fránce; ces ponts-viaducs, pour les voies ferrées, comme celui de la Nerthe, le premier en date chez nous, construit de 1844 à 1847, par Talabot et Gadeul.

Les travaux publics ont été favorisés, sous Louis-Philippe, par la loi de 1841 (3 mai) sur les expropriations pour cause d'utilité publique, qui a déterminé la compétence des jurys d'expropriation.

Sous la Monarchie parlementaire, des travaux importants ont été accomplis. Les ports de Dunkerque, Brest, Lorient, Toulon, ont été améliorés, celui de Clıerbourg a été presque achevé, celui d'Alger a été créé : c'est là que se sont signalés les ingénieurs Fouques-Duparcq, Raffaneau de Lille, Cordier, Lamblardie, Petot, Bernard, Noël, Reibell. On doit à Lamandé, Baudru, Coïc, Villars, Duleau, Brière de Mondétour, Vigoureux, Bonvalet, Lacordaire, Le Masson, Belanger, l'amélioration de notre réseau de canalisation ${ }^{1}$; à Deschamps, le pont de Bordeaux; à Kermaingant, les quais de Lyon; à Mallet, les nouveaux ponts et quais de Paris.

Les aérostats, la cloche a plongeur, l'air comprimé. - Les aérostats faisaient toujours fureur : en 1819, Mme Blanchard, dont le ballon avait pris feu, périt dans sa $67^{\mathrm{e}}$ ascension, écrasée sur le pavé de Paris.

La cloche à plongeur, connue des anciens, oubliée pendant le moyen âge, réapparut, bien imparfaite encore, en 1538 : elle ne servit alors qu'à une descente dans le Tage, à une faible profondeur. En 1721. Halley créa la promière cloche à plongeur qui ait été construite sur des données scientifiques, avec une provision suffisante d'air condensé pour assurer à un plongeur, à quelque profondeur que ce fát, la faculté de travailler nlusieurs heures. D'autres per-

1. En 1800, nous avions 1000 kilomètres de canaux. L'Empire en a ajouté 300 ; la Restauration, 900 ; la Monarchic de Juillet, 2000 ; le second Empire, seulement 500. 
fectionnements ont été apportés depuis par Spulding (mort en 1785, à la suite d'unc immersion trop prolongée), Smeaton (1786), Rennie (1812). En 1820, l'ingénieur BILLAUDEL employa cel appareil en France, pour la première fois, dans la construction des piles de ponts et donna l'exemple aux ouvriers en descendant le premier sous la cloche.

En 1840, andRand et TESSIE de motaY emploient l'air comprimé comme moteur dans leur petit chemin de fer de Chaillot.

Le daguerréotype et la photographie. - En 1813, le Français NIEPCE avait fait des expériences pour arriver à fixer liimage des objets sur une plaque enfermée dans une chambre obscure et recevant par une ouverture les rayons solaires. En 4829, il s'associa avec DagUrRRE. Ils employèrent des plaques de cuivre recouvertes d'un chlorure ou d'un iodure d'argent, substances très impressionnables à la lumière. Ce fut le daguerréotype : il donnait des images miroitantes et peu nettes. L'Etat acheta l'invention pour la livrer au public et favoriser les perfectionnements. Ceuxci ont été nombrenx : du daguerréotype est sortie la photogrophie sur verre. En 184 $\overline{7}$, Blanquart-Evrard trouva la photographie sur papier. Dès Jors, Jes plus pauvres purent avoir leurs portraits de famille.

\section{L'agriculture.}

Les résultats de la Révolution consacrés. - La restauration des Bourbons et les prédications du clergé avaient inquiété les acquéreurs de biens nationaux. Ces biens subissaient une dépréciation notable; elle cessa quand les Chambres eurent voté, en 1825, le milliard d'indemnité aux émigrés. Depuis le commencement du siècle jusqu’à la crise actuelle, les terres n'ont cessé de prendre de la valeur. Les forèts, qui étaient grevées d'anciens droits d'usage, ont été affranchies de ceux-ci par une multitude d'arrangements particuliers. Leur exploitation est devenue plus rationnelle, surtout depuis la fondation de l'École forestière. Les anciens propriétaires de lorêts sont plus riches aujourd'hui, avec le quart de ce qu'ils possédaient avant la Révolution, qu'ils ne l'étaient en 1789. 


\section{Proğrès de l'agrieulture : méthodes, instrunents. -}

A la culture routinière d'autrefois tendit à se substituer, en uotre siècle, une agriculture raisonnée. Au système des jachères, qui laissait inculte chaque année le tiers des terres labourées, se substitua, en beaucoup de pays, celui de l'assolement, qui, en exigeant de la terre une récolte tous les ans, ne lui donne le repos dont elle a besoin que par la variété des cultures. Le paysan, enrichi, put développer l'élève du bétail, qui lui assure plus de profit. qui a moins à craindre la concurrence du dehors, et qui fournit à la terre un engrais abondant.

A la charrue primitive se substitua bientỏ la charrue perfectionnée de mathied de dombasle, dont Grangé, Bonnet, Rozé, Vallerand, Valcourt, ont créé de nombreuses variétés. Au lieu du fléau, du van en osier, de la faulx, de la faucille, seuls connus du paysan dautrefois, on eut la machine à battre, mise en mouvement, soit par des chevaux tournant dans un manège, soit par la vapeur, les vans mécaniques, les faucheuses et les moissonneuses mícaniques. Pour les domaines plus étendus, on commença à employer la charrue à vapeur, inventée par Fowler. On a eu des scarificateurs, des extirpateurs, des buttoirs, des semoirs, des huche-paille. On a employé le rouleau pour étouffer les insectes et les larves qui, à l'approche du printemps, se rapprochent de la surface du sol; on doit à Dombasle un rouleau appelé squelette. La herse a été perfectionnée par Valcourt et l'Anglais Howard.

On a trouvé des méthodes et des appareils pour drainer les terrains humides ${ }^{1}$, irriguer les terrains trop $\operatorname{secs}^{2}$.

Institutions et enseigrnements agricoles. - Lagriculture doit à la Monarchie de Juillet la loi de $1 \$ 36$

1. Dès 1652, le capitaine anglais Walter Blight avait déjà traité du draínage. En 1S'3, furent présentés à la Société royale d'agriculture de Londres les premiers tuyaux de drainage. Ces tuyaux furent perfectionnes en France par le manufacturier Laurent. M. Poule a desséché le marais des Baux (Buuches-du-Rhủne).

2. Les plus beaux travaux d'irrigation ont été exécutés dans les Ardennes, les départements lorrains, les Pyrénées, la Loire, le Puy-de-loòme, le Doubs, Saỏne-et-Loire, etc. 
(21 mal) sur les chemins vicinaux, la loi de 1835 (29 avril) sur les irrigations ${ }^{1}$.

En 1830 fut créé le Ministère de l'agriculture; il avait alors dans ses attributions le commerce et les travaux publics, qui ont été confiés depuis à deux ministères spéciaux.

En 1831, le gouvernement institua un Conseil supérieur d'agriculture, composé de propriétaires instruits, et qui eut pour mission d'encourager les améliorations et de propager les nouvelles méthodes.

Dans beaucoup de cantons, dès la Restauration, sorganisèrent les Comices agricoles : ils provoquèrent des expositions annuelles de machines, d'animaux et d'autres produits; ils distribuèrent des récompenses aux agriculteurs, aux éleveurs, aux serviteurs agricoles. A un degré plus élevé, se fondèrent des Concours agricoles, dont le plus ancien est celui de Poissy (1844), avec des Expositions régionales.

Aux haras de Pompadour et du Pin (Orne), fondés par Louis XV, supprimés en 1790, rétablis par Napoléon, s'ajouta celui de Rosières (Meurthe), ouvert sous Louis XVIII, ceux de Saint-Cloud et de Meudon, ouverts sous Louis-Philippe.

Pisciculture. - Olivier de Serres ne fait-il pas rentrer parmi les travaux rustiques l'exploitation des cours d'eau? Or, la pisciculture, c'est-à-dire l'élève artificielle des poissons, était déjà pratiquée depuis longtemps en d'autres pays lorsqu'elle était encore inconnue en France, où le dépeuplement des cours d'eau devait nous rendre plus intéressants ses procédés. Deux pêcheurs des Vosges, REMY et GÉHIN, vers 1840, s'occupèrent de la fécondation et de l'éclosion artificielle des œufs de truite, et commencèrent à attirer sur leurs succès l'attention publique.

Leurs procédés furent suivis par berThor et DETzEM, deux ingénieurs du département du Haut-Rhin, qui fonderont, en 1851, l'établissement de pisciculture de Huningue. En 1852, coste, professeur d'cmbryogénie au Collège de France, créera, pour le compte de l'État, dans la mème localité, 
un vaste établissement qui fournira des milliards de jeunes poissons aux cours d'eau et aux étangs de la France entière.

\section{L'industrie.}

Les expositions nationales. - Les expositions nationales de l'industrie, inaugurées en 1798, par François de Neufchàteau, continuèrent, avec un nombre toujours croissant d'exposants, sous la Restauration et la Monarchie de Juillet. Elles se tinrent à des époques déterminées et revenaient tous les quatre ou cinq ans. Ces grandes revues de l'industrie française fournissaient des points de comparaison aux travailleurs, vulgarisaient les découvertes et les perfectionnements, répaudaient sur toute l'étendue du territoire l'esprit d'initiative et le gortt du beau. Les étrangers eux-mèmes profitaient de nos leçons.

L'exposiion de $\mathbf{1 8 1 9}$ compta $\mathbf{1 6 6 2}$ exposants (seulement 240 de plus que celle de 1806); celle de 1823 en eut 1642 ; celle de 1827, 1696. Sous la Monarchie de Juillet, le nombre s'éleva, en 1834, à 2247; en 1829, à 3281 ; en 1844, à 3960 .

L'industrie sous la Restauration. - De 1815 à 1830 , la métallurgie fait chez nous quelque progrès. Les grandes usines, les hauts fourneaux à hautes cheminées commencent à se multiplier, modifiant d'une façon imprévue le paysage français. A l'exposition de 1819, vingt et un départements envoient de l'acier. malluet, en 1819, par un alliage de cuivre, de nickel et de zinc, obtient ce métal imitant l'argent, qui de son nom s'appelle le maillechort.

Les mines de charbon des bassins de Saint-Étienne, de la Sarre, du Nord, sont largement exploitées: les mines d'Anzin font la fortune des Casimir Périer.

A Sarreguemines, Passy, Creil, on obtient une faience perfectionnce. Paris, Bayeux, Limoges, Saint-Yrieix, Nevers, renouvellent leur labrique de porcelaine. La cristallerie de Baccarat, fondée en 1822, celles de Saint-Quirin et Cirey, acquièrent une célébrité curopéenne.

Dès 18:8, il y a en France ว̌ 85 usines pour le suere de betlerave. 
A Lyon, Depodilly amende la machine Jacquard. On y produit la soierie à bon marché par le mélange de la soie ê du coton; on y fabrique le velours chiné, le gros de Naples. Saint-Etienne et Saint-Chamond rivalisent avec Lyon pour la rubannerie et la peluche de soie.

Celle-ci nous vaut le chapeau à haute forme. arbos invente le chapeau mécanique qui porte son nom.

Paris et Nimes fabriquent les châles brochés.

A Paris, la maison Ternadx, avec des toisons de Kazan, des poils de chèvre du Thibet, fabrique les chales cachemires, qui sont bientòt à la portée de toutes les bourses.

Rouen et Douai lournissent les tulles de coton, SaintQuentin et Tarare des mousselines. Rouen produit, à un bon marché inoui, les indiennes. L'Alsace, avec ses 27 manufactures de toiles peintes, livre par an 527000 pièces. La lilature du coton s'est tellement perfectionnée qu'au lieu de fil du numéro 80 , comme sous l'Empire, on obtient des fils du numéro 291 , c'est-à-dire le 291000 mètres au demibilogramme.

DIDOT SAINT-LÉger a réexporté d'Angleterre (1815) une industrie toute française, inaugurée en 1799 à Essonnes, et abandonnée à cause des imperfections de la machinerie : celle du papier à la mécanique. En 1814, se fonde la papeterie d'Annonay. De 1826 à 1837, Louis pIETte fabrique du papier avec de la paille, du foin, des écorces, des joncs.

La bougie stéarique de M. Chevreul tend à devenir d'un usage général.

L'industrie des pianos et autres instruments de musique se développe à Paris ${ }^{1}$.

L'industrie sous la Monarehie de Juillet. - L'industrie métallurgique, surexcitée par les commandes d'objets colossaux qu'on lui adresse, locomotives, chaudières, wagons, rails, grues, ponts de fer, décuple ses moyens d'action, s'arme de marteaux-pilons cyclopéens, de machines ingénieuses pour raboter, découper, river, tarauder, scier l'acier et le fer, conme on faisait auparavant du bois. Elle produit des socs de charrue, des faulx, des scies, des ressorts, des aiguilles, des toiles métalliques, 
des lits de fer, mais toujours avec une infériorité à l'égard de l'Angleterre au point de vue de l'exécution, et de l'Allemagne au point de vue du bon marché.

Une des plus précieuses inventions de l'époque, c'est celle de la machine à coudre, due à ThIMonnier, en $1840^{1}$.

L'usine des SchneIder, au Creuzot, prend, a partir de 183\%, un magnifique développement ${ }^{2}$.

heILMAN, en 1845, et SChLdMBerger inventent la pergneuse automulique pour la laine, la soie, etc.

Les impressions d'étoffes, à Saint-Quentin et Mulhouse, se perfectionnent grâce à la découverte de nouveaux mordants et de nouvelles teintures, comme le bleu d'outre-mer factice, qui coùte 200 fois moins que l'autre, la garancine, qu'a remplacée de nos jours l'alizarine.

Le tissage mécanique, à Saint-Quentin, en Normandie, en Alsace, se substitue au tissage a la main.

Les tapis communs, qui commencent à se répandre dans toutes les maisons, se fabriquent à Aubusson, Fellelin, Tourcoing, Abbeville, le Mans.

Les ternadx ouvrent à Paris, à l'enseigne du Bonhomme Richard, la première maison d'habits confectionnés.

A Paris, il y a déjà de vastes magasins, vrajes bonbonnières en comparaison de ceux qui ont grandi depuis, mais qu'on qualifiait alors de magusins monstres ${ }^{3}$.

La maison goibal et rattier, d'après les procédés de l'Américain Makintosh, file et tisse le caoutchouc. On en fait des manteaux et des chaussures imperméables. Ailleurs on fabrique le caoutchouc vulcanisé, inventé par l'Américain Goodyear et vulgarisé par l'Anglais Hancock, et la

1. Ellc est devenue depuis d'un usage universel : on en fabrique anauellemont plus d'un million. La fabrication francaise a un redoutable concurrent, la fabrication américaine.

2. Sa rivale, J"usine prussienne d'Essen, qui date de 1810, ne s'est guère dévelopjée qu'en mėme temps.

3. Le Chamvari montrait un étranger s'enquérant auprès d'un commis de l'endroit oú lon pourrait trouver le comptoir des bonnets de coton: * Au fond de la neuvième galerie à droite, répond le commis, puis la quatrième à gauche, et, une fois arrivé au quinziòme comptoir, vous demanderez les bonnets de coton; lia on vous indiquera parfaitement lo chemin que vous devez prendre pour y arriver... - Ah! sapristi! sècrie l'acheteur, je sus bien fáché d'aroir lajsé mon cabriolet à la porte da magasia. 
gutta-percha. rRanchot substitue à la lampe Carcel la lampe a modérateur, beaucoup plus économique. La savonnerie du Midi emploie l'huile de palmes, importée de la Guinée.

En 1836, elzampton importe la dorure et l'argenture par la pile; alors nait l'industrie des roolz el des christorle. nolot et collas inventent le procédé à réduire les statues. Avec le zine, on fabrique les bronzes à bon marché. En même temps, l'orfèvrerie de luxe se maintient avec les FROMENT-MEURICE, les MOREL, les VECHTE.

vICAT invente la chaux hydraulique ou artificielle (1817).

En 18'6, les allumettes à friction remplacent les allumettes simplement soufrées et les briquets à amadou, qui sont encore en usage dans les campagnes.

"L'impulsion donnée au mouvement industriel, dit M. Bardoux, ne se ralentissait pas: décorations, éloges officiels, places honorifiques, rien n'ètait négligé de ce qui pourait stimuler les efforts. Spectacle bien fait pour étonner! les mœurs industrielles transformaient. la société. "

Hodifieation dans le sort de la classe onvrière. - La machine à vapeur est, au $x^{\mathrm{e}}$ siècle, ce que l'artillerie a été

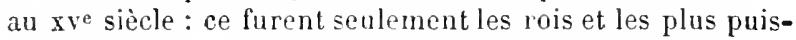
sants princes qui purent avoir des canons, et ils forcèrent les autres à se soumettre : ce sont seulement les capitalistes et les compagnies qui peuvent monter les puissantes usines à vapeur à l'aide desquelles elles font la loi sur le marché économique.

La grande industrie distribue cent fois plus de salaires que l'ancienne; elle fait vivre cent fois plus d'ouvriers; elle abaisse le prix de tous les objets manulacturés, et par la, met à la portée de l'ouvrier non seulement le nécessaire, mais ce qui eut été le luxe il y a cent ans. Cependant elle présente de graves inconvénients sociaux : elle écrase de sa concurrence le travailleur qui veut rester isolé et libre; elle réduit ceux qu'elle emploie à une dépendance étroite, les enrégimente et les caserne lans des usines sous une discipline presque militaire, leur impose sa loi en ce qui concerne le taux des salaires. Enfin, elle les met à la merci des bouleversements économiques. Que le coton manque aux manufactures de Normandie, conme il a manqué pentant la guerre d'Amérique; qu'un grand pays, 
jusqu'alors ouvert à nos produits, se mette à les fabriquer lui-mème et cesse d'acheter chez nous; qu'une crise quelconque arrite la consommation et amène l'encombrement dans les magasins : la manufacture cesse de produire autant ou ne produit plus rien. Elle réduit les salaires de moitié ou les supprime; elle congédie la moitié ou la totalité de ses ouvriers. Ainsi, parce qu'une guerre a éclaté en Amérique, parce que des banqueroutes ont eu lieu en Angleterre, roici que les pauvres ouvriers d'une bourgade de la Seine-Inférieure ou du Nord en subissent le contrecoup. Ces milliers d'hommes attachés au sort d'un seul patron peuvent être réduits au chòmage et à la misère. Ce sont ces conditions nouvelles de la vie industrielle qui ont donné l'essor aux théories et aux utopies socialistes.

Lois sur :e travail des enfants. - Certains patrons, afin d'obtenir la main-d'œuvre à bas prix, engageaient des enfants de dix, de neuf, de six ans. Ils leur imposaient un travail au-dessus de leurs lorces, les retenaient quinze ou seize heures par jour dans l'air empesté des ateliers, ne prenaient aucun souci de leur santé et de leur instruction. Les ourriers, dans l'espérance d'ajouter à leur salaire le maigre salaire de leurs enfants, se prêtaient à cette précoce exploitation de leur progéniture. Ils ne royaient pas que, en fournissant aux patrons du travail à vil prix, ils favorisaient l'abaissement de leur propre salaire. D'ailleurs ce labeur prématuré étiolait et déformait les enfants, exposait nos populations industrielles à une prompte décadence physique et morale, menaçait même le bon recrutement de l'armée. L'État crut de son devoir, dans l'intérèt des générations futures, de se substituer au père de famille imprévoyant ou égoïste; il résolut de protéger l'ouvrier contre l'avidité du patron tot sa froprefaiblesste latpremière loi pour la protection des enfants employés dans l'industrie date de $1841^{1}$. Aucun enfant, avant l'àge de douze ans révolus, ne peut ètre admis dans des manufactures, usines, chantiers, ateliers, mines, carrières; il ne doit pas, si on l'emploie de quelque autre manière, ètre astreint à plus de six heures de travail, divisées par un repos. A partir de

1. Elle a eté complétée par d'autres lois : voir ci-dessous, ch. xxxur. 
douze ans, le maximum du travail exigé des enfants est de douze heures, divisées par un repos. Le travail de nuit, plus épuisant, et qui peut présenter certains inconvénients au point de vue moral, est interdit pour les garçons de moins de seize ans et les jeunes filles de moins de vingt et un ans. Des inspecteurs spéciaux sont chargés de relever les contraventions, qui sont punies d'amendes.

\section{Le commerce et le crèdit.}

Les lois sur les céréales. - Sous l'ancien régime et sous la Révolution, on se préoccupait surtout d'assurer notre approvisionnement en grains : on permettait toujours l'importation des céréales, on en défendait quelquefois l'exportation. Tel est encore le sens de la loi de 1S14. A partir de 1819, on s'est préoccupé surtout d'empêcher l'invasion des blés étrangers, afin de maintenir les grains à des prix tels qülls assurent aux propriétaires et aux fermiers un bénéfice très élevé. Ainsi, en 1814, la loi était en faveur des consommateurs; en 1819, elle fut en faveur du producteur. Elle fit enchérir le prix du pain et aggrava les disettes causées par les mauraises récoltes.

Cette loi de 1819 établissait une échelle mobile; c'està-dire qu'elle taxait les blés étrangers plus ou moins lourdement, suivant que les prix des blés indigènes étaient en baisse ou en hausse. On voulait que l'hectolitre de blé ne coûtàt pas plus de vingt-trois francs et pas moins de seize francs. Dans certains cas, on prohibait absolument limportation.

La loi de 1832 supprima les prohibitions, mais conserva un droit d'entrée qui s’élevait de 1 fr. 50 par hectolitre, chaque fois que le prix à l'intérieur s'abaissait de 1 franc. Ce système était maintenu avec une extrême rigueur. Le peuple lui attribuait, dans les années de disette, comme en 1847, la cherté du pain. A cette époque, des émeutes éclatèrent en pluvieurs endroits, et notamment la fameuse émeute de Buzançais (Indre), qui amena une sévère répression et trois exécutions à mort.

Cette loi, qualifiée de provisoire, dura jusqu'en 1861. 
Le système dounier. - Autrefois, par l'établissement des lignes de douanes, on se proposait un double but : assurer un revenu au Trésor et protéger nos industries en frappant de taxes plus ou moins lourdes les produits de l'étranger,quel quefois mème en les prohibant absolument.

L’intérèt étroit du manufacturier français était que les produits étrangers fussent taxés si fortement qu'une fois entrés en France ils coùtassent plus cher que les produits nationaux. L’intérèt du consommateur français est tout autre : il consiste a acheter les meilteurs produits possibles au meilleur marché possible.

Jusqu'à une époque très récente, les gouvernements et les Chambres prenaient le parti du producteur contre le consommateur. Comme le traité de 1786 avec l'Angleterre avait été déchiré par la Révolution et n’avait pas été rétabli par la Restauration, on prohibait absolument l'entrée de certains produits. Il était défendu de faire entrer en France les cotons filés d'Angleterre, les cachemires de l'Inde, les suirs de Russie, les rhums et tatias étrangers, les dentelles et la plupart des articles d'horlogerie.

On meltait des droits énormes sur les autres produits étrangers, afin que le consommateur francais, s̈il persistait à les préférer, dût les acheter beancoup plus cher que les produits français de qualité égale ou inlérieure.

Les nations étrangères suivaient le mème système. Les Anglais, par exemple, dont on taxait lourdement les tissus de coton, les leers, les aciers, usaient de représailles en mettant des droits aussi lourds sur les vins et alcoots de France, les articles de Paris, etc. Ils prohibaient les soieries de Lyon.

Ainsi non seulement, chez nous, on sacrifiait le consommateur au producteur, mais, parmi les producteurs, on sacrifiait le viticulteur de Bordeaux, le fabricant de soieries lyonnaises, les industries parisiennes, au désir de protéger énergiquement les filateurs et tisseurs le livuen, de Lille, de Mulhouse.

Malgré les prédications des économistes, les Chambres de Louis-Philippe furent presque aussi décidément protectionnistes que celles de la Restauration.

Cependant le progrès des transactions, quoique lent, ne 
fut pas moins réel. Entre les années 1827 et 1847 , les in portations s'élevèrent de 414 à 933 millions; les exporta tions, de 507 à 720 millions.

Lc crédit. - Les institutions de crédit se dévelopjent, mais lentement, bien plus timidement qu'en Angleterre. Dès l'époque de la Restauration, la classe des financiers prend de l'importance. L'un d'eux, odvrard, pendant la guerre d'Espagne, remplaça à lui seul l'intendance désorganisée, nourrit l'armée française, fit abonder les vivres aux points qu'elle traversait et, pour vaincre la méliance des paysans espagnols, faisait étaler sur un manteau de soldit un monceau d'or, promettant le triple de la valeur au premier qui amenerait un bœuf, le double au second, et ailsi de suite. Ce fut lui qui, à coups de millions, mieux que le duc d'Angoulème à coups de canon, amena le gouvernement révolutionnaire de Cadix à transiger, à remettre le roi d'Espragne en liberté, à nous liver la place. Plus tard, Lafritre soutient de son crédit linancier la candidature de Louis-Philippe, et, à son tour, dans un moment d'embarras, trouve un appui dans son riche client.

La Banque de France était en pleine prospérité; mais elle avait des rivales dans celles de Ronen, Lyon, le Ilavre, Lille, Toulouse, Orléans. Marseille, Nantes, Bordeaux. Celles-ci émettaient des billets qui ne pouraient ètre payés qu'au comptoir qui les avait émis: ce qui limitait leur circulation ${ }^{1}$.

Les caisses d'épargne, qui datent de la Restauration, étaient au nombre de 13 seulement en 1820, de 159 en 1837. Les lois de 1834 (jnin) et 1837 (mars) facilitent leur extension.

L.es sociétés financières et industrielles se mulliplient, et, en même temps que le crédit, naissent les abus du crédit : l'agiotage et l'exploitation des actionnaires naïfs. Dans la comédie intitulce "l'Auberse des Adrets ", on voit que Robert-llacaire, son compère Bertrand, la bonne dupe Gogo, sont des types déjà populaires

\section{Ouvrages a consulter. - Vogez la bibliogr. du chap. xxxin.}

1. Cetétal de ehoses prit fu par les dícrets da gouvernement provisoiro de 19is, qui reuarent ces banques provinciales a la Baugue de france. 


\section{CHAPITRE XXIV}

\section{LES USAGES ET LES MOEURS}

\section{Le costume et le mobilier.}

Le costume. - Pour le costume, on peut distinguer assez nettement trois périodes : $1^{\circ}$ de 1814 a 1824 (Louis XVIII); $2^{\circ}$ de 182 ' a 1840 (Charles X et les dix premières annéts de Louis-Philippe); $3^{\circ}$ de 1840 à 1848 (toutepuissance de Guizot).

Sous Louis XVIII, ce sont presque les modes de l'Empire. Les hommes des classes dirigeantes n'ont encore complètement renoncé, ni aux bottes à retroussis, ni à la culotte courte, ni au jabot de batiste. Ils ont des habits a collet très remontant, en drap de couleur, à boutons dorés, ou des redingotes à cinq collets; le gilet à chale, en piqué; le pantalon très collant, ou bien froncé par en haut et par en bas et échancré sur le cou-de-pied; des chevenx frisés, chassés en avant des tempes, comme s'ils étaient fouettés du vent de l'inspiration lamartinienne ou byronieune. On porte des chapeaux ballon, tromblon, ou à la Bolivar; des chapeaux à poil e! des chapeaux de paille de la mème l'orme; parluss des iricornes, qui peuvent sc plier pour se porter sous le bras.

On fume peu, c'est de mauvais ton. En revanche, on prend un tabac exquis dins quelque tabatière Empire. On est soigneusement rasé, avec de minces cótelettes près des tempes.

Les femmes alfectionnent les robes à taille tris remon- 
tée, à jupe courte, avec des manches bouffantes au-dessus du coude. Les souliers, très décolletés, $\dot{a}$ cothurne, réduits presque à la semelle, se rattachent à la jambe par des lacets entre-croisés. La coiffure est très haute, un peu ébouriffée, formant de grandes coquilles sur les oreilles; le chignon, relevé sur la nuque, vient faire une touffe sur le sommet de la tête, où les boucles sont maintenues par des fils de fer; le tout ombragé de turbans, comme chez Mme de Staêl, ou de grands chapeaux à bords inmenses, surchargés de fleurs, comme chez la duchesse de Berry, ou de toques ombragées de plumes d'autruche et qui ressemblent à des diadèmes de rois saluvages.

La seconde période nous montre, pour les hommes, la redingote à très grand collet, à manches énormes, à jupes immenses, pincée à lc taille; de grands gilets a ramages au bas desquels pendent des breloques; le pantalon, tantót. très collant comme un unaillot du temps de Henri III et tendu par des sous-pieds; tantôt très bouffant, très large, a la cosaque, a la houssarde; on bien étriqué aux genoux, mais s'étalant en pieds d'éléphant sur la chaussure. On a conservé la manie toute militaire des boltes : ce qui entraine l'usage du tire-bottes, un meuble à peu près disparu aujourlhui. Les cravates prennent une grande impor. tance : chez les gens posés, elles font plusieurs fois le tour du cou, serrant un grand col de chemise qui leur scie les oreilles. Il y a les cravates à la romantique, à la mélancolique, à la gastronomie, à la cosaıue, à la Colin, à la Walter Scott. La coiffure devient celle qui caractérise les portraits de Louis-Philippe : a partir de 1830, le toupet devient une institution. Le bourgeois continue à ètre soigneusement rasé, mais avec de larges favoris au bas des joues. Les militaires, les artistes, affectent la barbiche à limpériale.

Pour les femmes, les modes sont l'exagération des molles de la période précédente, avec moins d'élégance et de goût. La touffe supérieure des cheveux, contournée de manière a former comme un craquelin, entrelacée de gros rubans, de grosses fleurs, de plumes, de rangs de perles, forme des ichafaudagres étonnants : e'est la coiffure a la girafe. Ou bien on se coiffe à la Vierge, arec des cheveux 
plats collés au front par une chainette d'or portant au milieu une féronniere. Ou bien, sous un bonnet de dentelles ou de rubans, comme en portent aujourd'hui les petites bourgeoises dans certaines provinces, les cheveux sont roulés en anglaises ou en tire-bouchons. Les manches $\dot{a}$ gigot sont énormes et plus grosses que le buste; les jupes s'étalent démesurément; les chapeaux semblent de grands auvents surchargés de fleurs, ou, sous le nom de capotes, affectent la forme de capotes de cabriolets. Les robes sont surchargées de bouillonnés. Il y a un joli détail, l'écharpe. Pour sortir, le châle est de rigueur, et le chàle cachemire, encore très coûteux à cette époque, a toutes les préférences. Les fourrures sont folt à la mode: on en garnit les manteaux; on en fait des bous pour mettre au cou; eu 1830, les manchons sont de proportions énormes ${ }^{1}$.

A partir de 1840 , les modes sont un peu plus artistiques.

Pour les hommes, la redingote perd son srand collet: elle se boutonne étroitement jusqu'en haut. Elle est fantaisiste et pincèe à la taille, comme chez les élégants; puritaine et doctrinaire, comme chez $\mathbf{H}$. Guizot; ample et longue, vraie redingote á lı proprietuire, comme celle dont $\mathbf{H}$. Saint-Marc Girardin a, jusque sous nos yeux, perpétué la tradition. On ne porte presque plus de ces immenses cravates, comme celle du docteur Véron, qui fit si longtemps la joie des caricaturistes.

Pour les lémmes, les manches à gigot disparaissent. On a des tailles pincées, des corsages fermés devant par un réseau de lacets. Les cheveux sont moins ébouriflés : il y a de charmantes coiffures avec des cheveux conrts, bouclés, comme on le voit par les portraits de Rosa Bonheur. La capote est plus pefite, mais enferme le visacte comme les œillères d'un cheval ${ }^{2}$.

1. Quand les bourgeois et les bourgeoises, qui se rendaient aux réceptious de Louis-Philippe, commençaient, dès trois heures de l'aprés-midi, à s'installer dass les fiarres et à prendre la file, raconte $\mathrm{M}$. Bardoux, a les jeunes élégants et les rapins, échelonnés sur le parcours, s'eo dounaient à cour joie : e'était à qui souléverait les stores des voitures ou enverrait des bouffées de tabac sur les toilettes $n$.

2. Sous le second Empire, le eostume des femmes fut carartérise par la crinoline. sorte de cage d'acier qui faisait énormenent boufter les jupes. En 1S56, on representa au Gymnase une pièce intitulée "les Toilettes tapa- 
En négligé, hommes et femmes se coiffent de madras. Les petits garcons portent de ces casquettes extraordinaires, à large fond plat, à soufflet, à gland, comme celle qu'a décrite Flaubert dans "Madame Bovary".

Le mobilier. - En pleine Révolution, c'est-à-dire en pleine époque de relour à l'antiquité classique, un alma. nach avait fait cette prédiction : "Nous avons tant éplu. ché les modes, tant ralliné sur les goùts, tant retourné les meubles et les ajustements, que, rassasiés, excédés de jolies choses, nous redemanderons le gothique comme quelque chose de neuf; nous l'adopterons, et nous voilà tout naturellement revenus au xive siècle. "Cette prophétie, qui s'était réalisée, dès le début de la Restauration, en littérature et en peinture, se réalisa aussi, sous le rénime suivant, en architecture et en ameublement. On délaissa le meuble Empire et le style classique pour en revenir aux dressoirs cliargés d'orfévrerie et de fal̃ence ancienne, aux chaises monumentales rappelant les stalles de chanoines. On tomba mème dans le bric-à-brac "gothique ", et l'on commença à collectionner les armures plus ou moins authentiques, les étoffes brochées d'or, chasubles, nappes d'aulel, voiles de calice, éclıapés au pillage révolutionnaire des églises. En un mot, on eut un mobilier moyen age, un mobilier romantique. Le gout des choses arabes, turques, égyptiennes, indieunes, chinoises, japonaises, ne s'est développé qu'ensuite; cependant, dès 1830 , un dessin de Charlet nous montre des amateurs dévalisant une boutique de bric-à-brac et emportant des massues, des casse-tète, des cimeterres, des fliches.

Les véhicules. - En 1817, il y avait à Paris 900 fiacres et 490 catriolets. A partir de 1830 , chaque cocher dut être porteur d'une carte portant son numéro d'ordre. En 1841, on établit des surveillunts auplès de chaque station

reusus $\%$. L actrice chargée du principal rôle imsina, pour mieux aucuser l'intintion satirique de l'auteur, de porter une jupe et une crinoline de dimensions exagerées. Le seul résultal de celte critique fut que, lo lendemain de la première représentation, une vingtaine de grandes dames demandèrent à l'artiste le patron de sa jupe el que la crinoline en acquit des dlmensions doubles. Les toiletles féminines de l'époque lout à fail conlemporaine semblent plus artistiques, avec une tendance à modeler les formes du coms. 
Sous la Nonarchie de Juillet apparurent des types nouveaux de voitures publiques : citalines, urtaines, latéciennes, dellas, cabriolets-compleurs, cubriolcts-mylords, thereses, cabs, coupés. Il y eut alors près de 4000 véhicules de ce genre dans Paris.

Londres avait repris, dès 1820 , cette idée géniale de Pascal : les omnibus. En France, ce n'est pas à Paris d'abord qu'ils se montrèrent, mais à Nantes, en 18:6: à Bordeaux, en 1827. La capitale n'en fut lotée qu'en 1828, sous l'administration du préfet de police Debelleyme. Une première compagnie, Baudry, Boitard et Saint-Céran, mit cent de ces véhicules à la disposition du public. Ils étaient lourds, attelés de trois chevaux, et ressemblaient à des gondoles. Le prix des places fut d'abord de cinq sous, comme au temps de Louis XIV, puis de trente contimes, comme aujourd'hui.

L'engouement du public fut tel que de nouvelles compagnies se fondèrent et promenèrent dans Paris des tricycles, qui n'avaient que trois roues, des fuvorites, des béurnaises, des dames blunches, des dames réunies, des constantines, des batignollaises, des béarnaises, des écossaises, des parisiennes, des excellentes, des ciladines, et d'autres formes d'omnibus que connaissent seuls aujourd'hui les archéologues. Ces diverses compagnies ne fusionnèrent qu'en $18 \%$ ว̆.

Outre les fameuses diligenes Lafitte et Caillard, qui ont amené à Paris tant de générations d'étudiants et de provinciaux, les accélérées, carabas, pots de chambre, gondoles, tapissières, coucous, mettaient Paris en relations avec la province. Le deruier coucou n'a disparu qu'en 1861: il allait de la Bastille à Vincennes; son coclıer, avec le carrick d'autrefois et les sabots fourrés de paille, avait fait peindre sur sa voiture ces mots : "Au coucou obstiné ".

Sur la Seine, les mouches étaient encore inconnucs : ce n'est qu'en 1866, à la veille de l'Exposition universelle, que se londa la première entreprise de bateaux à vapeur. Sous la Monarchie parlementaire, on avait encore les anciens coches d'eau; leur principale clientèle, c'étaient les nourrices, qui, de haute ou de basse Seine, venaient chercher un emploi à Paris ou y ramenaient leurs nourrissons. 


\section{La vie de société.}

Les salons. - Les møurs ne furent jamais plus polies et plus décentes qu'à cette époque où la noblesse, que les leçons du malkeur avait fort amendée, et la haute bourgeoisie, qui avait conservé ses anciennes habitudes de mesure et de tempérance, donnaient le ton à la société. Il est rrai que les dissentiments politiques, au lieu d'une société, comme dans la France du xvıne siècle, nous en donnèrent au moins deux : il y eut dès lors des salons royalistes et des salons libéraux. Quand la Chaussée-d'Antin ou le faubourg Saint-Honoré donnaient des lètes, on pouvait en conclure que le faubourg Saint-Germain avait des raisons de bouder et de s'abstenir.

Royalistes ou libéraux avaient de commun le goùt d'une élégance sans faste, l'amour de la vie de salon, la recherche de la société des femmes. La vieille conversation irançaise, avec sa galanterie respectueuse et spirituelle, vivait encore. Les habitudes contractées dans les cercles (ceux-ci ne se multiplièrent guère qu'à partir de 1840) ne l'avaient pas encore tuée. On retrouvait, dans les salons de 1820 et de 1840 . les mots ingénieux, jusqu'aux madrigaux de l'ancien régime. On y parlait aussi de politique, philosophie, art, littérature, mais on parlait fort peu des sciences, comme on le faisait avant la Révolution, car la période parlementaire est avant tout littéraire. Assurément, les drames de Victor Hugo, les toiles d'Ingres ou de Delacroix, les ceurres lyriques de Meyerbeer ou de Berlioz, tenaient plus de place dans la conversation que les découvertes d'Ampère ou d'Arago.

L'influence des classes dirigeantes dans la vie de société n'ètait paś encore menacée par celle des classes populaires : il était rare qu'on se permit, dans les conversations, de citer un mot d'argot. Elle n'était menacée que par les enfants perdus de ces classes, les artistes et surtout les rapins, les littérateurs et surtout la bohime littéraire, pour qui les idées, les modes, les goûts artistiques ou littéraires des classes censitaires étaient autant de motifs a bons mots et à caricatures, et pour qui le mot de bourgeois était synonyme de tout ce qu'on peut imaginer de plus arrièré. 
Cette société eut aussi ses travers. Par exemple, vers 1820, entiché qu'on était alors des poésies de Byron, du "Werther " de Gothe, du "René " de Chateaubriand, il fut de mode de se montrer désespéré et dégoùté de la vie. Des jeunes gens fort bien portants se posaient en poitrinaires. La poésie séraphique de Lamartine nous valut les femmes éthérées et frèles, qui, les yeux levés au ciel, affectaient de ne se nourrir que du parfum des roses.

La cour. - La cour de Louis XVIII fit peu parler d'elle : ce prince, studieux, lettré, classique, citant Horace et aiguisant des bons mots, d'ailleurs impotent et goutteux, n’aimait pas le monde. Quand sa belle-fille la duchesse de Berry, après la mort tragique de son mari, cessa de faire les honnew's du palais, il n'y eut un peu d'animation qu'à la cour du duc et de la duchesse d'Angoulème ou bien au parillon de Marsan, habité par le comte d'Artois. Lorsque celui-ci fut devenu le roi Charles $\mathbf{X}$, ses réceptions se limitèrent dans un cercle étroit de royalistes convaincus et de personres qui avaient fait leurs preuves de noblesse.

Louis-Philippe, qui tenait son tròne des efforts communs du peuple et de la bourgeoisie, s'acquittait envers le premier en chantant "la Marseillaise " au balcon des Tuileries et envers la seconde en lui ouvrant largement ses salons.

C'était un curieux spectacle, raconte M. Bardoux, que les premières soirées données par Louis-Philippe au PalaisRoyal. La tolérance du préfet avait permis aux omnibus d'entrer dans la cour, et les officiers de la garde nationale des qualtis commerçants et de la banlieue arrivaient en grande tenue, leurs femmes au bras, pour saluer familièrement le roi citoyen."

Les vertus privées du roi et de la reine, les manières simples et affables de toute la famille royale, plaisaient à la bourgeoisie. Elle leur savait gré d'autoriser le peuple à se promener dans le jardin des Tuileries, saus les fenêtres mèmes de ses appartements, de lui ouvrir ceux-ci à certains jours. Les visiteurs étaient touchés, en défilant dans les salons et mème dañs les chambres à coucher, de voir le lit du couple royal, de constater partout les indices d'un excellent ménage, d'une vie toute de famille et d'une simplicité civique. Ils savaient sar an roi mémede son parapluie, 
symbole d'économie et de prévoyance. Ils étajent touchés d'apprendre que, comme eux, il découpait à table, mème lorsqu'il invitait des ambassadeurs.

Les fils du roi reçurent l'éducation des fils de la bourgeoisie et fréquentèrent les lycées : lorsqu'ils avaient des succès au concours général, c’ètait fète aux Tuileries, et l'on invitait leurs camarades. Aussi aucun prince, mème sous l'ancienne monarchie, n'avait été pleuré comme le fut, après sa fin tragique (18:2), le duc d’Orléans.

Les plaisirs. - C'est pendant la Restauration que la harpe, qui faisait si bien valoir de belles mains et des doigts effilés, commença à ètre abandonnée pour le piano.

Des danses nouvelles nous arrivèrent d'Allemagne et de Pologne: la valse (on écrivait alors walse), la polka, la mazurka, avec le quadrille ou contre-danse, supplantèrent celles de la vieille France. Une des figures de ce quadrille rappelle encore la vogue de l'école saint-simonienne.

Les préférences de la bourgeoisie sont, en musique, non pour le Théâtre-Italien, car elle veut comprendre les paroles qu'on lui chante, mais pour le Grand-Opéra, où Monsieur Auber cherche a lui faire comprendre la musique nouvelle, surtout pour l'Opéra-Comique. Celui-ci est vraiment le théátre lyrique des familles. On s'y donne des rendez-vous, et plus d'un mariage s'y est ébauché.

En littérature, la bourgenisie abandonne le drame de boulevard au peuple, et, à la Comédie-Française, elle est d'abord effarouchée de l'invasion de Victor Hugo. Ses auteurs de prédilection furent alors Scribe et Musset.

Elle n'est point ennemie d'une certaine gaieté : dans les plus grandes maisons bourgeoises, après un diner opulent, on restait volontiers autour de la table a chanter des chansons de Béranger, dont on reprenait en chœur le refrain.

La bonne société fréquentait le bal masqué de l'Opéra; on y dansait soi-mème, on y rencontrait de vraies femmes du monde et on y uouait de vraies intrigues. Quand, par l'accroissement mème de la population parisienne, le caractère intime de ces bals fut compromis, quand leur public fut plus mèlé d'aventuriers et d’étrangers, quand l'administration enróla des danscurs soldés, quand Musard, avec sa nusique de cuivre, stridente et lipageuse, arec ses 
symphonies de coups de pistolet et de chaises cassées, avec son galop infernal, quand Chicard, avec ses gantelets, son casque et ses panaches extravagants, en eurent pris possession, la bourgeoisie déserta ces fètes '.

C'est de la Restauration que date la vogue du café Riche, du café Anglais et de la Maison Dorée.

La loterie. les jenx du hasard. - La Restauration, après l'Empire, avait maintenu la loterie d'État, supprimée en 1793 et rétablie en 1797. Celle-ci passionnait le peuple; on cherehait à deviner les numéros gagnants, à les voir en rẻve, à les obtenir des tireuses de cartes ou de somnim. bules plus on moins lucides. Il y avait cinq bureaux de loterie, à Paris, Bordeaux, Lille, Lyon et Strasbourg : cela faisait quinze tirages par mois.

On avait aussi établi une ferme des jeux de hasard: on jouait à Paris, sous le patronage de l'État. comme on joue aujourd'hui à Bade ou à Monaco. Cela n'empêehait pas les tripots clandestins.

La ferme et les établissements publics de jeu furent fermés en 1836, et la loterie supprimée comme "immorale " en 1839. On calcule que ces denx institutions coutaient à la nation près de 400 millions par an.

L'anglomanie. - On emprunta beancoup anx Anglais. Ce qu'on leur emprunta de mieux, à partir de 1814, ce fut l'hygiène du corps, les copienses ablutions, le goût de la propreté, qui assurément avait fait peu de progrès en ving̣t-cinq ans de campagnes, de bivouacs et de vie nomade. On se parfuma un peu moins, et l'on se lava beaucoup plus. Dans son intérieur, on rechercha moins la magnificence et davantage le confortrble, une chose et un mot anglais. La cuisine britannique, saine et simple, influa sur la nòtre, qui était par trop raffinée; on sut enfin, en France, ce que c'est qu'un bon bifteck.

On fut pris d'une passion extrème, à grand'peine contenue par les lois douanières, pour les tissus, les aciers, les mille brimborions que nous expédiaient les Anglais.

1. Les bals publics les plus célèbres sont alors le Prado, le ChriteauRouge, Hontesquieu, Valentino, Mabille, le Ranelagh, et, pour messieurs les etudiants, la Chaumiëre, tenue par "le papa Lahire n, que Henrı Heino - enteadu traiter de Pu'rgnac parce qu'il s'opposait a certains écarts. 
Chaussures ou vêtements, rasoirs ou aiguilles, rien ne semblait bon, ou beau, ou commode, que ce qui venait d'outre-Manche.

Le mot de mode fit même place à celui de fashion, et l'on se piqua d'ètre fushionable. On ne parla que de courses de chevaux, de banquettes irlandaises, de steeple-chase, de turf, de jockeys, de starters, de paris à la façon britannique avec book-makers, et les chevaux, même de sang franẹais, furent baptisés de noms anglais.

Le magnétisme animal et le spiritisme. - Les adeptes de Mesmer, confondus avec les illumines, ont fait peu de bruit sous la Révolution. Cependant, à Lyon, une femme en catalepsie, observée par le docteur Petétin, aurait prédit tous les événements du siège de cette ville en 1793. Sous la Restauration, les mesmériens formèrent plusieurs eercles, notamment celui que présidait la duchesse de Bourbon. Vers 1829, en Avignon, ils guérissaient les malades par le magnétisme et par le ehant du Veni crecior; ils conduisaient au moyen d'un tube de verre le fluide magnétique et l'esprit céleste sur les patients.

Bientôt il se forma deux écoles distinctes: les magnétistes fluidistes, qui croyaient à un fluide et qui étudiaient les faits avec une certaine conscience, et les magnétistes spiritistes.

Vers 1845 , en effet, commença la croyance au spiritisme, c'est-à-dire à l'existence d'esprits avec lesquels nous pouvons nous mettre en relations, qui peuvent se manifester à notre inte!ligence, à notre vue, à notre ouỉe, à nos autres sens, en empruntant des intermédiaires, tantòt des objets inanimés, tantôt des personnes spécialement douées pour communiquer avec eux et qu'on appelle des méliums. Allan-Cardec a été depuis, en France, le grand prètre de cette doctrine et a éerit de nombreux ouvrages pour la propager. Elle a eu du moins le mérite d'inspirer un des plus curieux romans de Théophile Gautier : "Spirite".

Dans les années qui précédèrent la révolution de 1848, on ètait très porté au merveilleux : aussi des pliénomènes mal observés ou mème de vulgaires mystifications causèrent-ils une certaine émotion.

Par exemple, vers 1846 , le pays entier fut très intrigué 
des phénomènes soi-disant électriques qui se produisaient chez une paysanne de l'Orne, Angélique Cottin. La même année fut signalée, à Paris, par la manifestation des esprits frappeurs dans la boutique du charbonnier Lerible. Vers 1850 , ce fut le tour des escargots sympathiques d'Allix, ou moyen de communiquer la pensée à de grandes distances au moyen d'escargots vivants. En 1852 commencèrent les expériences sur les tables tournantes, dont Agénor de Gasparin se fit lhistorien : ces tables répondaient aux questions posées par les assistants ou transmettaient les communications de Jules César, de Socrate, de saint Louis, de Jeanne Darc, etc.

Bien plus récemment, n'a-t-on pas vu une femme rechercher, avec une buguette magique à la main, les trésors prétendus enfouis dans le sol de la basilique de Saint-Denis?

On voit que notre siècle n'est pas moins avide de surnaturel que ses devanciers : les merveilles de la science positive ne suffisent pas a satisfaire notre amour du merveilleux; les anciennes superstitions reparaissent volontiers sous des formes nouvelles, sans parler de celles qui se conservent, sans se transformer, au fond des campagnes.

\section{La vie publique.}

Les haines de partis. - La seconde Restauration excita des haines inexpiables par sa rigueur envers les chefs de l'armée napoléonienne, par ses complaisances pour Trestaillon ${ }^{1}$ et les massacreurs du Midi, surtout par son alliance avec les envahisseurs ${ }^{2}$.

La fraction de la nation qui se montra le plus irréconeiliabie à la Restauration, ce furent les officiers de Napoléon

1. Le maréchal Brune est lachement assassiné par la populace royaliste d'Avignon; le géuéral Ramel, par celle de Toulouse. On connait la charson de Bèrangé sur " ce bon monsieur de Trestaillon n. Les excès de la Ter. reur blanche, dans le Midi, rappelèrent ceux de la Terreur de 1793.

2. Nos ennæmis étaient alors officiellement nos alliés, nos amis. "Vivent nos amis les ennemis! " disait ironiquement Séranger. Un capitaine a demi-solde fut arréte pour avoir appelé son cheval Cosaque. Le magistrat qui l'interrogeait tui dit : "Comment avez-vous pu donner à votre cheval un nom cher a tous les bons Français? 
qu'elle avait mis à demi-solde, tandis qu'elle prodiguait les grades aux émigrés revenus avec elle. Quelques-uns, avec le général Lallemand, s'en allèrent au Texas fonder une colonie militaire appelé le Champ d'asile, qui fut soutenue en France par une souscription nationale (1819); on lui donna le nom de Canton de Marengo, et le chef-lieu était Aigleville. D'autres, dans leur redingote boutonnée jusqu'au menton, avec leur chapeau à la Bolivar incliné sur l'oreille, la rosette ou le ruban rouge à la boutonnierc, se contentaient d'assister, sur les places d'exercices, a l'instruction des recrues: spectacle qui irritait en eux le sentiment de leur inaction et d'une disgràce imméritée. D'autres se lancèrent dans des conspirations et furent le principal danger de la dynastie.

Le café Valois était le club des légitimistes paisibles, des vieux émigrés, qu'on appelait les voltigeurs de Louis $\boldsymbol{X} l \boldsymbol{V}$. Le café Lamblin était cclui des bonapartistes : quand les garles du corps, en 1814, annoncèrent l'intention d'y venir inaugurer un buste de Louis XVIII, trois cents officiers de l'Empire y vinrent prendre garnison; il lallut l'intervention de l'autorité pour empècher une sanglante collision.

Après le retour de l'Empereur (mars 1815), le café Montansier (au Palais-Royal) fut le quartier général des officiers impériaux; ils avaient fait de l'estrade de ce caféchantant une tribune politique et, se substituant aux acteurs, débitaient des couplets injurieux pour les Bourbons. Après le second retour du roi, les mousquetaires et les gardes du corps, dans leur fureur de représailles, prirent ce café d'assaut, y brisèrent les glaces et la vaisselle, jetèrent par la fenètre l'argenterie et les meubles.

-En province, les anciens seigncurs de village, trop souvent coalisés avec le curé, inquiétaient les acquéreurs de biens nationaux, traitaient de haut en bas le maire et le conseil municipal, prétendaient siéger dans l'église à l'ancien banc seigneurial et recevoir avant tous le pain bénit. La satire et la caricature s'emparèrent de ces hobereaux prétentieux, de ces marquis de Curubas.

Il y avait en France comme deux nations, deux armées en présence. Les libéraux et les bonapartistes faisaient alors cause commune. A mille détails, le plus sourent futiles, on 
voyait éclater l'antagonisme. Les royalistes avaient mis à la mode un jeu de mots sur liberuux et libérés (forçats). D'un côté, on répandait les livres pieux, les brochures légitimistes; de l'autre, le libraire Touquet multipliait les éditions de Rousseau et de Voltaire, sous tous les formats, à tous les prix.

Le même Touquet vendait des tabatières libérales sur le couvercle desquelles se lisait le texte de la Charte; les royalistes en adoptèrent d'autres qui reproduisaient le testamerit de Louis XVI ou le portrait du roi-martyr. En 1819, on eut des cannes dont la pomme était mobile et qui, en s'ouvrant, laissaient voir la statue de Napoléon. On imagina de vendre des bretelles tricolores, de fabriquer des liqueurs alcooliques dont l'une s'appelait Liqueur des braves, et l'autre Larmes du général Foy. En 1815, le clergé refuse au cercueil d'une actrice, Mlle Raucourt, l'entrée de l'église Saint-Roch : les libéraux forcent les portes, brisent les grilles, installent le cercueil devant le maitre autel : Louis XVIII a le bon esprit d'envoyer un aumònier de sa maison réciter les dernières prières, et la foule menaçante se calme. Au Théàtre-Français, en 1817, libéraux et royalistes se colletaient à la représentation de " Germanicus ", une médiocre tragédie l'imault, uniquement parce que l'auteur était connu pour sa fidélité á Napoléon. De part et d'autre, les officiers tirèrent les sabrez. Il fallut appeler la garde. L'épilogue, ce fut, pour le lendemain, une demi-douzaine de duels.

Les duels. - Jamais on ne s'est autant battu que dans les premières années de la Restauration : officiers de l'ancienne garde impériale ou de la nouvelle garde royale s'alignaient tous les matins ${ }^{1}$.

1. La race odieuse des duellistes de profession reparut. Un de ces bretteurs entre au Café Français, et, jelant un regard dédaigneux sur les concommaleurs : "Je ne trouverai pas ici, dit-il, à qui donner le moindre coup d'épée. - Vous vous trompez! " répond en se levant un mousieur - lunettes. Échange de carles : le provocateur est un comte, l'autre un marquis. Le monsieur à luneltes, appelanl alors le garçon de cafó : - Tenez, lui dit-il, voici 2000 francs; allez aux pompes funèbres commander un enterrement de première classe pour monsieur, donl voici le nom et le titre. L'eaterremenl sera pour après-demain. Je veux que monsieur le comte soil enlerré comme un marquis. "Celte fois, le duelliste fut inti. midé, et l'affaire s'arrangea. 
Il y eut aussi des duels parlementuires, à la suite de discussions dans les chambres, comme celui du général Foy avec M. de Corday (1820). Pour ceux-ci, ordinairement, on se battait au pistolet : le premier qui tirait manquait, et l'autre, par courtoisie, tirait en l'air. Un des duels les plus célèbres de la Monarchie de Juillet, c'est celui où Émile de Girardin tua un autre journaliste, Armand Carrel, plus illustre alors que lui-mème (1836).

Les sociétés secrètes. - Les plus actives des sociétés de l’époque, ce n'était pas la franc-maçonnerie, bien que tous les libéraux s'y enrôlassent en foule. C'étaient d'un còté la Congrégation, dirigée par les Jésuites; de l'autre, le carbonarisme ou charbonnerie francaise, fondé par Buchez, alor étudiant en médecine. Les carbonari, mot italien qui sign ie churbonniers, s'étaient constitués chez nous à l’imitation de leurs contrères de la péninsule. Ils juraient sur un poignard "haine au roi et à la royauté " et versaient une cotisation d'un franc par mois. Ils étaient organisés en ventes (autre mot d'origine italienne), c'est-à-dire en vingtaines. Un seul mempre de chaque vente connaissait la vente par laquelle il avait été désigné pour en former une nouvelle. Ainsi elles naissaient les unes des autres, se reproduisant comme les polypes des coraux et des madrépores, enveloppant le pays et l'armée d'un réseau d'affiliations. Au-dessus de toutes était la vente supréme, dont les milliers d'affiliés, aussi bien que la police bourbonienne, ignoraient la composition. La charbonnerie envahissait les régiments, et l'on eut les conspirations militaires de Saumur, de Belfort, le complot du capitaine Vallé, la tentative insurrectionnelle du lieutenant-colonel Caron, en Alsace. Le plus célèbre des procès faits à cette occasion, c'est celui qui se termina par l'exécution des quatre sergents de la Rochelle (1822), Bories, Raoul, Goulin, Pommier, dont le peuple de Paris, tous les ans, couvre encore de fleurs le tombeau. Cette redoutable association disparut quand la haine contre les Bourbons commença à s'émousser.

Sous Louis-Philippe, d'autres sociétés, plus ou moins secrètes, comme celles des Amis du Peuple, des Amis le l'Égalité, de l'Union de Juillet, celle des Droits de l'Homme, qui réunis- 
sait en 1833 plus de 60000 adhérents ${ }^{1}$, celles de l'Action, des Saisons, des Familles, contribuèrent à organiser les émeutes et les insurrections, furent l'objet de poursuites judiciaires et provoquèrent la loi restrictive de 1833 .

Les complots sous Louis-Philippe. - Les exaltés des partis démocratiques ou socialistes attentèrent plus d'une fois à la vie du roi : Bergeron (1832), Alibaud (1839), harmès (1840), lui tirèrent des coups de feu. Le roi pouvait dire qu'il était le seul gribier dont la chasse fût ouverte en tout temps. Le 28 juillet 1834 , la machine infernale, montée par Fieschi, répandit la mort autour du roi et coucha sur la chaussée lu boulevard du Temple quarante morts ou blessés. Les légiimistes ne furent pas noins actils : la duchesse de Berry essaya de soulever une nouvelle insurrection royaliste dans l’Ouest et de réveiller la Vendée (1832).

Laporhense de Mapoleon. - Bien que Louis-Philippe fut en butte aux attaques des bonapartistes, aucun gouveruentent n'a plus honoré la mémoire de l'empereur mort à Sainte-liélène. Louis-Philippe, se souvenant qu'il avait combattu a Valmy et à Jemmapes, eut le culte des gloires militaires que la Restauration avait répudiées.

Or, comme les guerres de la République étaient alors presque oubliées el que les survivants des guerres de l'Empire étaient encore nombreux, toute gloire militaire semblait se personnifier en un homme, Napoléon. C'ètait lui que célébraient les orateurs à la tribune, que chantaient les poètes, it commencer par Victor Ilugo, Lamartine, Béranger, que glorifiaient les historiens, mène le républicain Lonis Blanc. On opposait cette grande èpopée guerrière à la. politique sagement pacifique de Louis-Philippe, que ses ennemis appelaient par dérision le "Napoléon de la paix ». On s'arrachait les Mémoires des généraux ou des serviteur's de l'Empire. On s'attendrissait en lisant le “ Mémorial de Sainte-Hèlène ». Un des livres les plus populaires à cette époque, cest celui de Guérin : "Victoires et Conquètes". Do nème que contre la politique dévote de la Restauration

1. Les noms de quelques-unes des sertions de cette société étaient sirnificalifs : Quatre-vinct-lreize, Montagnards, Guerre aux chileaux, Saint-Just, Babeuf, Marat. Coulhon, Robespierre, Ca ira, Niveau, Bonnet phrygien.

R. Givil. contemp. 
on avait ressuscité Voltaire, contre la politique pacifique de Louis-Philippe on s'ètudiait à grandir l'Empereur. LouisPhilippe, soit qu'il partageât ces admirations, soit par calcul et pour donner le change à l'opinion, cèdait à l'entrainement. C'est lui qui fit replacer la statue du conquérant sur la colonne de la place Vendòme, acheva les monuments à la gloire de la Grande Armée, négocia avec l'Angleterre la remise des cendres de Napoléon, envoya son fils, le prince de Joinville, les chercher à Sainte-Hélène, leur ménagea une marche triompliale à travers Paris, les fit déposer sous la voûte des Invalides. C'est dans l'intervalle des deux tentatives de Louis Bonaparte, à Strasbourg (1836) et à Boulogne (1840), que s'accomplit cette magnifique et dangereuse apothéose de Napoléon le Grand.

Ces anciennes associations d'onvriers. - L'ancien régime avait légué au nouveau un type singulier d'associations ouvrières. Le compagnonnage, laissant à part les ouvriers sédentaires, servait à grouper les ouvriers nomades qui allaient de ville en ville chercher de l'occupation, c'està-dire qui accomplissaient leur tour dc France. Dans chacune des villes du tour de France, le compagnon était reçu par les travailleurs qui faisaient partie de la société : ils soccupaient à lui procurer de l'ouvrage. En attendant. il était hébergé dans une auberge attitrée : elle était tenue par la mère des compaynons, et ceux-ci étaient ses enfants. Si le compagnon tombait malade, il était soigné par la mère, veillé par ses frères à tour de rỏle, et visité par le rouleur, un des dignitaires de l'association. S’il mourait, il était accompagné par enx au cimetière et enseveli à leurs frais.

Tous ceux qui faisaient partie d'une association de compagnonnage étaient initiés à certains mystères. Deux ouvriers qui se rencontraient échangeaient des formules et des signes de reconnaissance. Un rituel très compliqué déterminait la façon dont on devait porter la canne et les rubans dans les cérémonies publiques ou prendre son verre sur la table. Aux funérailles d'un compagnon, après l'cloge funèbre prononcé par l'un d'eux, les associés poussaient des hurlements rythmis, plaçaient sur la terre deux cannes en croix, et tous venaient successivement, deux à deux, en 
mettant le pied d'une certaine manière sur les angles de la fosse, s'embrasser d’après le rite.

Ces corporations avaient quelyues-uus des vices de celles de l'ancien régime. Le titre de compaguon devait s'acheter par un noviciat long et pénible. Les novices s'appeiajent aspirants, jeunes hommes ou renards. Les compagnons se plaisaient à les exploiter ou à les éprouver de nille maniirres. Ils prenaient pour eux-mèmes le meilleur de l'ouvrage, envoyaient les renards aux broussailles, c'est-à-dıre dans les faubourgs ou les villages, ne leur permettaient ni de coucher dans la mème chambre, ni de s'assenir au bal à còté d'eux. "Renard, cire-moi mes hottes ", disait le compagnon, et le renard était tenu d'obéir.

Les deux plus cèlèbres de ces associations au commencement du siècle, e'étaient celles des Enfunts de Salomon et des Enfunts de maitre Jucques. Les uns prétendaient que leur société avait été londée par Hiram, architecte de Salomon, qui aurait été assassiné dans le Temple par trois traitres auxquels il refusait de livrer le secret du compagnonnitge; les seconds se piquaient de remonter à maitre Jacques, un architecte provençal qui aurait été le collègue d'lliram, et qui, après son retour de Jérusalem en Provence, a arait été assassiné par un envieux.

Les "Enfants de Salomon ", qui se prétendaient plus anciens, étaient plus orgutilleux. Leurs rites n'avaient été conmuniqués qu'à quatre corps de méticss : les menuisiers, les loups ou tailleurs de pierre, les gurots ou serruriers, les renurds de liberté ou charpentiers. Ils accueillaient les ouvriers sans distinction de culte, et, pal consiquent, se recrutaient surtout parmi les protestants. Les "Enlants de maitre Jacques " étaient plus hospitaliers et avaient communiqué leur secret à un grand nombre de corps de métiers; mais ils ne recevaient que des ouvriers eatholiques. Ils s'appelaient encore les Compagnons du devoir ou devoirants ${ }^{1}$.

Ces associations étaient jalouses l'une de l'autre et se traitaient en ennemies. Les serruriers de Salomon ne sup- 
portaient pas, dans la ville où ils travaillaient, les serruriers de maitre Jacques. Souvent des batailles éclataien? entre gavots et dévoirants. A Sens, en 1842, un dévoirant eut l'idée de monter sur un àne et de passer devant les boutiques des serruriers appartenant à l'autre association, en criant: "Hue, gavot! " De là, une rixe sanglante. A Nantes, en 1845. les boulangers s'apprètaient à célébrer leur fète patronale arec des cannes et des rubans; les compagnons, furieux de cette usurpation de leurs insignes, tombèrent sur le cortège.

Dans d'autres occasions, les associations rivales en venaient a des transactions. Comne elles ne roulaient pas travailler dans la mème localité, elles proposaient de "jouer la ville ". On mettait au concours entre les deux partis la confection de quelque objet de leur industrie; celui qui aviit le mieux réussi restait maitre de la place et en expulsait ses concurrents.

Ces associations nuisaient donc à leur objel principal, qui ètait l'assistance mutuelle, par une affectation de mystère, par l'oppression qu'exercaient les compagnons sur les renards, par les haines et les querelles qui s’élevaient entre elies. L'ancien régine les avait proscrites; la Constituante les avait de nouveau prohibées par la loi de 1791; mais elles survivaient à toutes les défenses et entretenaient parmi les ouvriers des mours sauvages et turbulentes.

En 1823, les renards en révolte contre les anciens avaient fondé la Société des Indépendunts. En 1830, une autre révolte produisit un type nouveau et meilleur d'association. A cette époque, les préparatifs de l'expédition d'Alger avaient attiré a Toulon une énorme alfluence d'ouviers. La mère des compunnuns proposa aux anciens de permettre à des renards de coucher dans leur chambre. Les anciens se trouvirent offensés de cette proposition : ils quittèrent la mire et ordonuèrent aux renards de les suirre dans leur retraite. Ceux-ci refusèrent, secouèrent le jous et fondèrent la Sorité de l'Union. Celle-ci n'eut plus ni cannes, ni rubans, ni mots de passe ou de ralliement, ni chants de guerre. Elle n'était qu'une société de secours mutuels. Cétait ce type qui devait finir par prévaloir. Peu à peu l'ancien compagnonrage est tombè en désuétude. 


\section{Paris.}

Accroissement et cubellissements de Paris. - Le progrès de l'activité et de la richesse nationale eonmençait it réaliser, dans Paris, ce que Napoléon n’avait cru pouvoir accomplir qu'en dépouillant le monde entier à son prolit. Paris se développait rapidement: en 1816 , il comptait 710000 habitants; en 1826, 800000 ; en 1836, 909000 ; en 1846, plus d'un million ( 1053000 ).

Sous la Restauration, ont été jetés sur la Seine les ponts des Invalides, d'A rcole, de l'Archevèché, ont été dressées la statue de Louis XIII (place Royaie) par Cortot et Dupaty, celle de Louis XIV (place des Victoires) par Bosio, celle de Henri IV, fondue en 1818 avec le bronze des statues de Yapoléon et de Desaix, par Lemot. On a inauguré l'éclairage au gaz, le service des omnibus et linstitution des sergents de ville, dù au préfel de police Debelleyme.

Sous la Monarchie de Juillet, Paris dut beaucoup au préfet de la Seine, Rambuteau. C'est alors qu'on a construit les ponts Louis-Philippe et du Carrousel, percé la rue Rambuteau, aménagé la place de la Cuncorde avec l'obélisque de Louqsor et les statues des huit villes de France; élevé la Colonne de Juillet, terminé l'Arc de l'Étoile, restauré les deux merveilles de l'art ogival, Notre-Dane et la Sainte-Chapelle; achevé la Madeleine, le Panthéon, le Palais-Bourbon, les palais du quai dorsay; bàti l'Ecole des Beaux-Arts, l'École de médecine, l'École normale de la rue d'Llm; aménagé les places Louvois et Saint-Sulpice, celle-ci avec la belle lontaine de risconti ${ }^{1}$.

Enfin Thiers et Guizot ont donné à la capitale son mur d'enceinte et ses forts détachés (1841), que la presse opposante d'alors dénonça comme autant de bastilles que le despotisme armait contre Paris.

\section{Aspect de la camiale. - Cependant le Paris d'alors est}

1. Louis-Philippe, qu'on accusait d'avarice purce qu'il étail éconone, préleva sur sa liste avile trente millions pour la restauration des chateinax de Versailles, Fontainebleau, Pau, qu'ıl n'habita point cependant et qu'il ouvrit largement au public. Sur les meimes fonds, il fit ériger, parni les ruiues de Carthage (Tunisie), anx lieux ou était mort saint Louls, une chapelle commémorative 
bien loin encore a'avoir la physionomie de celui d'aujourd'huil.

bans le centre de Paris, les voies les plus larges étaient toujours les rues Saint-Denis et Saint-Martin. Il n'y avait alors ni avenue de l'Upéra, ni rue Turbigo, ni rue de Turenne, ni boulevard Saint-Germain, ni rue des Écoles, ni boulevard dEnfer. Les quartiers opulents qui se sont formés sur le parcours des boulevards Malesherbes, Haussmann, Pereire, avenues de Villiers, de Courcelles, sur le parcours des grandes voies qui s'étoilent autour de l'Arc d. triomphe; les quartiers populeux et ouvriers qui se sunt formés sur le parcours des bouleviads du nord et des boulevards du sud, n'existaient pas encore. Paris ne colmptait alors que douze arrondissements au lieu de vingt, les huit autres ayant été Cormés depuis par la réunion de communes suburbaines : ce qu'on appelait alors la banlieue. Qurnd les vaudevillistes du temps voulaient s'amuser aux dépens d'unions illégitimes, ils les trailaient de "mariages contractés à la mairie du Xllle arrondissement $n$.

l.es boulevards qui vont de la Madeleine à la porte Saint-Hartin, notamment celui des Italiens, đu'on appelait alors boulevard de Gand (d'où le nom de gandins pour désirner les élégants qui s'y promenaient), étaient encore bien peu vivants au début de la Restauration : de vienx Parisiens se souviennent d’avoir attaclé leurs cheraux aux irbres du boulevard pour aller laire leurs visites dans les maisons. Cette promenade s'anima dans les années suivantes, et alors naquit la race des toulevardiers.

II y avait encore dans Paris des dédales incxtrictbles de rues étroites, hautes, humides, parce que les rayons du soleil n’y pénétraient jamais : c'est dans un de ces pàtés de maisons, celui qui entourait le cloitre Saint-Merry, que les insurgés purent deux fois se retrancher et tenir en éclıec

1. Dés 1820, deux spéculateurs, Mignon et liagermann, présentent un plan de Paris où toscure le quartier de l'Europe, arec une place contrale sulumr de linguelle rayonnent de larges rues portant les noms des capitales. Dés 1835, le plan de Perrol marque le prolongement de la rue de Rivoli, par la ruc sainl-Antoine, jusqu'a la place de Bastille. Ces projets et bien d'autres n'onl été réalisés que sous le second Empire ou la troisiéme Républiq: 
toutes les forces de la garde nationale et de larmée de Paris. Un autre dédale continuait à occuper l'espace qui s'itend entre l'arc du Carrousel et l'ancien Louvre : il y avait là des ruelles, des masures, qui assiégeaient pour ainsi dire les Tuileries, et où les marchands de perroquets et autres oiseaux exotiques avaient dressé leurs échoppes.

Sous la Restauration, bien peu de rues a l'aris avaient des trottoirs, car en 1830 il n'y en avait que 16 kilomitres. Sous la Monarchie de Juillet, il s'en fallait de beaucoup que toutes en eussent, bien que le nombre les kilomètres se fùt élevé à 195. Ces trottoirs étaient souvent étroits et irréguliers. Dans les rues où ils manquaient, les passants ne pouvaicnt se protéger contre les voitures qu'en se collant aux murs el en ayant soin de se rapprocher des bornes qui s'accotaient aux maisons. Les maisons elles-mèmes étaient pour la plupart petites, étroites, quoique beaucoup eussent cinq ou six étages, avec des toitures de tuiles a forte inclinaison, et des gouttières qui venaient dégorger l'eau des pluies à la hauteur des mollets des passants. Aucune n'avait l'aspect colossal de nos immenses bàtisses à toitures d’ardoises. Les rues qui éfaient pavées ne l'útaient que de bloes de culcaire assez irréguliers et mal assujettis, qui faisaient la joie des entrepreneurs de barricades. Le murulam mème, inventé par l’ingénieur écossais John Loudon Mac-Adam (mort en 1836), n'est employé à Paris que depuis 1849. On doit au préfet Rambuteau l'installation des colonnes qui portent son nom. Nous n'avions que très peu d'égouts : en 1806, il y en avait 24297 mètres : le gouvernement de Louis-Philippe, surtout pendant la préfecture de Rambuteau, porta ce chiffre à 78675 mètres. C'est surtout sous le second Empire qu'a été construit le Paris souterrain '. Les commodités des maisons étaient donc installées alors comme elles le sont encore dans les campagnes. Rien d'étonnant si le choléra de 1832 a fait tant de victimes.

Les rues, au lieu d'ètre bombées, comme aujourd'hui, pour assurer lécoulement des eaux, étaient au contraire

1. Le dèveloppement des égouls, gråce surlout à l'ingénieur Belgrand. atleignit alors 7\%2 846 mètres. 
formées de deux plans inclinés vers le milieu de la rue, qui était occupé par le ruisseau. Le ruisseau de la rue du Bac, que Mme de Staël regrettait si fort mème en face du splendide lac de Genève, restait encore visible pour les contemporains de Louis-Philippe. Par les fortes pluies, pour aller d'un côté de la rue ì l'autre. il y avait donc un véritable torrent à traverser : des industriels d'occasion jetaient une planche par-dessus et, moyennant un sou, aidaient les promeneurs à passer à pied sec. Carle Vernet a représenté cette scène populaire dans une de ses estampes, avec cette légende : Pirsez, payez. Dans le milieu de la rue, de distance en distance s'ourrait une bouche d'égout recouverte d'une grille de fer, que siuvent les lourdes voitures brisaient. Ailleurs la bouche d'égout se dressait comme l'entrée d'une cave, avec une herse qui ne touchait pas terre : si bien que des enfants, jouant au milieu de la rue, roulaient dans le précipice. Cette situation fut un peu améliorée par l'ingénieur partiot (1830-1837).

Sur plusieurs ponts de Paris, il y avait encore Jes péages. Le canal Saint-Mlartin était alors a ciel ouvert. et les malfaiteurs, la nuit, pouvaient y jeter leurs victimes.

Ce Paris, si peuplé dans un espace si resserré, n'avait pas un square ou les habitants pussent aller respirer un peu d’air pur dans les fortes chaleurs de l'été.

On ne buvait guère, à Paris, que l'eau de la Seine: les provinciaux, qui n'y étaient pas habitués comme les Parisiens, lui payaient toujours leur tribut par quelque indisposition, plus ou moins grave. Il neetait pas question alors. dans les maisons, d'avoir de l'eau, pas plus que du gaz, at tous les étages : on n'avait que l'eau qu'on puisait dans les anciens puits ou à quelques bornes-fontaines, ou celle qu'apportaient dans les ménages les porteur's deau. De ceux-ci les plus fortunés avaient un cheval ou un àne attelé à un tonneau porté sur deux roues, pt allaient de maison en maison. Tous les Parisiens d'un certain àge se rappellent avoir ru les braves Auvergnats ${ }^{1}$, car presque tous les por-

1. L'Auvergnat porteur d'eau, marchand de charbon et de margotins, faiseur de commissions, etait un tỵpe cher au roman, à la chansm, an vaudeville du temps : voyez le Misanthrope et l'Auvergnat de M. Labiche. 
teurs d'eau étaient originaires du Centre, monter au matin les escaliers avec deux seaux qu'un cercle de bois tenait écartés, et aller servir leurs pratiques. Un seau coùtait un sou ou deux, et ce n'était pas le moindrétonnement des provinciaux que de voir qu'à Paris " l'eau mème coùtait quelque chose ".

Les halles et les marchés étaient peu nombreux : tout lapprovisionnement des petits ménages se laisait par d'autres industriels, poussant devant eux leurs charrettes à bras. Ils s'appelaient marchands des quatro suisms et avaient conservé la tradition des cris de l'ancien Paris.

Les devantures des boutiques, beaucoup moins nombreuses et luxueuses qu'aujourd'hui, ne se fermaient pas la nuit avec des garnitures métalliques nues par un récanisme ingénieux. Le boutiquier devait aller chercher. l'un après l'autre, les huit ou dix volets qui devaient proteger sa devanture, les accrochait par en haut, les assujellissicit par en has, au moyen de clacttes. Il n'était pas rare. Jorsqu'il débouchait de l'étroite allée de la maison, avee son volet sur l'épaule, qưil heurtàt violemment le promonmur sans méliance. Les sous-sols des boutiques souvraient an moyen de trappes, qui debouchaient au lehors : autre danger pour le passant.

Encore ḋ la tin du ràgne de Louis-Philippe, les deux procédés déclairage sont emplovés concurremment lans Paris : il y avait alors 2608 réverbères et 8600 lanternes à gaz. les temps moderres. - L walie, Hist. de Paris 1 15i. - th. L.telase. Les ancimnes maisons de f'uris lsii - Hoffbauer, Faris a traters lriscines (1s-2) - Vax du Cannp. Horis. ses orqunes, ses forctionset sa vie IKa! 75 . - Grand-Cirteret. Les marurse" la caricature en Frante lsw.

Consulter les journaur de morles. Jounal les Dames, le Costume partsien, le Bon genre, sous la Re=lin rirtinn; le Bon goüt, la Psyché, le do"'naldes marhands tailleurs. Ie I'rnorama fashionable, le Frofosseu on Jourmal raisonne des tailleurs. Io Soleil, le Lion, l'Eligant. la Pamilore. la Vourcauti, le Giont nouceur, sous Loum-Phiple; - saus oublier le Charieari. 


\section{LIVRE III}

LES GOUVERNEMENTS DE SUFFRAGE UNIVERSEL

LA SECONDE RÉPUBLIQUE - LE SECOND EMPIRE

LA TROISIEME RÉPUBLIQUE

(DEPUIS 18 is JUSQU'A NOS JOtrs)

\section{CIIAPITRE XXY}

LES CONSTITUTIONS, LE DROIT ÉLECTORAI, LES LIBERTÉS

\section{Les constitutions.}

Caracières générañ de cette période. - Assurément, entre les deux Républiques et le second Empire il y a des différences profondes. Les deux Républiques auront été des gouvernements libres; le second Empire a été un gouvernement personnel. Elles naquirent de l'acclamation populaire; il eut pour origine un coup d'État.

Ces trois gouvernements ont cependant un caractère commun : lous trois ont cherché à s'appuyer, non sur des classes dirigeantes, mais sur la masse du peuple; ils ont été des gouvernements democrutiques, des gouvernements de suffiage universel.

Sil est donné au régime actuel de se perpétuer, on s'apercevra, déjà dans une vingtaine d'années, que l'Empire n'a été qu'un accillent dans le grand courant démocratique de notre histoire. ll apparaitra comme le résultat d'une erreur passagère du suffrage universel dans l'exercice, encore nouveau nour lui, de sa souveraineté. Le 
règne de Napoléon III a duré assez pour qu'on ait commis dans nos relations extéricures des fautes colossales et irréparables, destinées à peser sur nos destinées ultérieures aussi lourdement que les erreurs mêmes de Napoléon Ier. Mais, en ce qui regarde l'histoire même de notre développement intérieur, il n'a retardè que de fort peu l'avènement définitif de la démocratie, et la logique de notre évolution en a été à peine altérée.

La période postérieure à 18 ' diffère profondément de la précédente. Le 24 février. qui mit fin au privilège électoral des classes bourgeoises, a eu ses conséquences dans toutes les branches de la vie nationale.

Le fait mème de l'existence du suffrage universel a imprimé un caractère nouvcan à toutes nos lois politiques: nous avons eu des constitutions tout autres que nous les aurions eues sans lui, d'autres conseils généraux, d'autres conseils municipaux, un autre jury; nous avons eu le service militaire universel et obligatoire, l'instrnction universelle, obligatoire et gratuite. Les lois qui régissent les rapports des ouvriers et des patrons, le droit d'association, le régime de l'assistance publique, le système de douanes et d'impots, l'agriculture, l'industrie, le commerce, en ont été modiliés. La politique extérieure elle-mème a pris une direction difrérente.

Les lettres n'ont pas attendu 1848 pour manilester ce caractère nouveau, car, dès 1830 , elles commencent à s'inspirer de l'esprit démocratique. Elles ont contribué à préparer 1848; elles n'ont fait, depuis lors, qu'accentuer leurs tendances. Il n'est pas une branche de la littérature, théâtre, roman, éloquence, polèmique, journalisme, qui ne témoigne visiblement de l'ascendant des classes populaires. L'architecture, la statuaire, la peinture, la musique, témoignent d'un goùt qui n'est pas tout à fait celui des anciennes classes dirigeantes. Les mceurs, le langage, le costume, l'ameublement, l'aspect de Paris et des grandes villes attestent, à leur manièe, la transformation profonde qui s'est opérée dans la société française ${ }^{1}$.

1. Je ne vois guère que l'histoire des sciences pour laquelle l'année 1818 ne marque pas une date importante; mais l'influence de la democratie reparail des qu'il s'agil des applications des sciences. 
Le grouvernement provisoire de 1848 . - Victorieux an 2: février, le peuple proclama la République et acclaına d'abord un Gouvernement provisoire. Celui-ci appela tous les citoyens au droit de voter, au droit d'entrer dans la garde nationale, au droit de faire partie du jury ${ }^{1}$. C'était l'avènement, plus d'un demi-siècle après la tentative de 1793 , des classes populaires à la vie politique. Ce gouveruement abolit les titres de noblesse, abrogea les lois qui restreignaient la liberté de la presse et le droit de réunion.

Quant à la mission de donner une constitution au pays, elle ne pouvait appartenir qu'à une Assemblée investie par les electeurs d'un mandat constituant.

La Constituante et la Constitution de 1848. - Alors fut èlue la Constituante de $184 \$^{2}$. Elle réunit les pouvoirs législatif et exécutif. Elle gouverna au moyen de ministres. Elle réprima les insurrections, dont la plus terrible fut celle de juin, et dirigea les relations cxtérieures de la France. En un mot, efle lut un gouvernement en même temps qu'une Constituante.

La Constitution de 18483 méconnut, comme celle de 1791, les véritables conditions du régime parlementaire. Dédaignantles lecons de l'expérience acquise en Angleterre. en Amérique ${ }^{4}$, en France mème, clle en revint à une Chambre unique. Elle établit une Assemble legislutive, élue pour trois ans, et un Président de la République, èlu pour quatre ans ${ }^{5}$.

Avec la Constitution de 1848 , les conflits entre le pouvoir législatif et le pouvoir exécutif étaient inévitables. Ils

1. La lei du 7 aoùt 1848 appelle tous les citoyens à faire partie du jury, pourvu qu'ils soient àgés au noins de trente ans, qu'ils sachenl lire et écrire, et qu'ils ne soient, comme serviteurs ou domestiques, aux gages de nersonne. - Comprer avee le systeme de la monarchie de Juillet (droit de sulfrage, garde nationale, jury) ex josé ci-dessus, p. 324́-3\%5.

2. Elle siégea du 4 mai 1845 au 27 mai 1849.

3. 4 novembre 1848 . -116 arlicles.

4. " N'est-il yas étrange, disait Duvergier de Hauranne, que l'autorilé du seul grand Étal moderue qui ait fleuri, grandi et prospéré sous la forme républicaine, soil ainsi écartèe et méconnne? " Les Élats-Unis ont, en elfel, un Sénat et une Chambre des represenlants, et chaque État de l'Union américane a son sénat et sa Chambre des représentants.

5. Elle élablissail aussi un Vice-Président, nommé par l'Assemblée sur une liste de trois noms présentée par le Présidenl. 
étaient insolubles, car l'Assemblèe n'avait pas le droit de déposer le Président, et celui-ci n'avait pas le droit le dissoudre l'Assemblée et d'en appeler aux èlecteurs.

Vainement un représentant, Jules Grévy, demanda qu'au moins le Président fût nommé ${ }^{1}$ par l'Assemblée : la Constituante décida qu'il serait élu par le suffrage universel. Elle vit dans le serment imposé au Président une garantie sulfisante.

Ainsi la Constitution de 1848 consacrait deux dispositions dont une seule eùt suffi pour assurer le renrersement de la République : une Chambre unique en face d'un Prisident, et l'élection de ce Président par le suffrage universel.

Cette situation fut encore aggravée par le choix des électeurs, qui, le 10 décembre 18 is, accordèrent 533 4 226 roix à un candidat qui portait le grand nom de Napoléon, et qui ne pouvait avoir d'autre idée que de reprendre la tradition de son oncle. Les élections pour l'Assemblée législative lurent tout aussi fàcheuses : elles donnèrent la majorité aux partisans de la monarchie, divisés, il est vrai. en légitimistes et orléanistes, sans compter les partisans de l'Empire.

Le Priner-President et Pssemblée Régislative. Entre l'Assemblée législative, dont la majorité révait le rétablissement de la royauté, et le Prince-Président, qui préparait le rétablissement de l'Empire, l'accord ne pouvait exister que tant qu'il s'agirait de détruire les institutions républicaines. Ils furent d'accord pour sévir contre la liberté de la presse, la liberté d'association, la liberté de réunion. lls s'entendirent pour renverser la République romaine et rétablir le pouvoir temporel du pape. Bientôt la République, en France, n'exista plus que de nom : le cri de Vire la Rejputlique fut puni comme séditieux; les républicains furent dènoncés comme rouges, e'est-à-dire dèmagogues, socialistes, anarchistes, etc. On ne choisit pour préfets, poul procureurs généraux, pour commandants militaires que des ennemis du gouvernement légal. Unis contre la République, I Assemblée et. le Président ne s'en regardaient pas moins avec une défiance mutuclle.

1. Il demandait, en outre, qu'il portat simplement le titre de Prisident du Conseil des ministres. 
L'une et l'autre songeaient à sortir te la situation; or, pour en sortir, la Constitution n'avait ménagé aucune issue lérale. Le Président, qui avait la force armée à sa disposition, fit un coup d'État contre l'Assemblée ( 2 décembre 1851). Un petit nombre seulement de républicains essaya d'y résister par les armes : les autres n'y virent que la dispersion d'une Assemblée impopulaire qui avait mutilé le sufrrage universel.

Le gouvernement de Louis-Napoléon, dans les deux mois qui suivirent le coup d'État, fut une véritable dictature, c'est-i-dire un gourernement sans contrôle. Il rendit des decrets-lois, cest-à-dire des décrets ayant force de loi.

La constitution de $1852^{\prime}$. - La Constitution élaborée par lui ${ }^{2}$ conservait le nom de la République. LouisNapoléon restait Président, non plus pour quatre ans, mais pour dix ans. Il se déclarait responsable, supprimant ainsi la responsubilite les ministres, qui est l'essence même d'un gouvernement libre.

Les assemblées du premier Empire reparaissaient avec leur ancien caractère :

Le Sénat se composait des cardinaux, des maréchaux, des amiraux, et de membres nommés par le Président.

Le Conseil d'État reprenait la prépondérance yu il avait eue dans les constitutions impèriales; nommé parle pouvoir exécutif, il avait la charge importante de préparer les lois et de les soutenir devant le Corps législatil.

Le Corps législatif était élu pour six ans; on supprimait la nomination au scrutin de département pour établir l'élection par arrondissement : elle favorisait l'influence des préfels sur le corps électoral, c’est-à-dire tendait à faire prévaloir la candidature officielle.

Ainsi les deux assemblées prépondérantes, Conscil d'État et Sénat, étaient à la nomination du gouvernement; le Corps législatif était élu, mais dans des conditions qui assuraient sur lui l'action du pouvoir exécutif.

\section{14 janvier $1852,-58$ articles.}

̊. Elle fut úlahorée sur les bases posées dans la proclamation du 2 décembre 1א̌l, approuvée par le plébiscite du 20 décembre: 7439216 oui contre 640737 non. L'armée prit part à ce plébiscite et donna $319: 69$ oui contie t: 187 non. 
Le Corps législatif conservait bien le vote des lois, mais il ne pouvait proposer aucun projet et ne pouvait introduire aucun amendement qui ne fùt accepté par le Conseil d'État, c'est-à-dire par le gouvernement. ll conservait le vote du budget, mais son vote était en quelque sorte forcé, ear, pour rejeter un crédit qu'il désapprouvait, il ètait obligé de rejeter tout le budget d'un ministère. La publicité de ses séances était fort restreinte; ses discussions n'étaient connues du public que par un procès-verbal très sec, rédigé par les soins de son président. Son président et ses viceprésidents étaient nommés, non par lui, mais par le chef de l'Élat. Les ministres, n'étant pas responsables, ne paraissaient pas dans les Chambres. Enfin, pour faire éclater à tous les yeux l'abolition du régime parlementaire, la tribune mème était supprimée, et chaque député parlait de sa place.

On avait laissé subsister la Haute Cour de justice, établie par presque toutes les constitutions précédentes, mais cette cour ne pouvait juger les attentats politiques que lorsqu'elle en était saisie par le Président de la Ripublique.

Encore, dans son message du 29 mars 1852 aux sénateurs et aux députés, le Prinee-Président disait : « Conservons la Republique; elle ne menace personne; elle peut rassurer tout le monde. D

Rétablissement de rempire. - La Coustitution du 14 janvier, malıgré son titre républicain, était si complètement monarchique qu'il suffit, au moyen d'un sénatus-consulte (7 novembre 1832), sanctionné par un plébiscite ${ }^{1}$, d'en modifier un seul article. Le Président de la République prit le titre d'Empereur des Francais. La dignité impériale fut déclarée hèrédilaire dans les mèmes termes que par la Constitution de l'an XII.

Un régime qui s'appuyait sur des assemblées dépendantes, sur un suftrage universel en tutelle, sur une administration toute-puissante ${ }^{2}$, sur la suppression des libertés,

1. Plébiscile du 21 nc vembre $1852: 7482863$ oui contre 238582 non. Dans ce lotal, les volrs de l'armée de lerre : "80 195 oui contre 11058 non; de l'armée de mer: 48263 oui contre 1361 non.

2. Gráce à l'article 75 de la Constilution de l'an VIII. 
sur la loi de süreté générale ${ }^{1}$, était bien un gouvernement absolu. Napoléon III put entreprendre, sans rencontrer d'opposition, les guerres de Crimée et d'Italie, signer les traités de commerce avec l'Angleterre, s'engager dans les expéditions de Chine, de Syrie, de Cochinchine, du Mexique, de Mentana, lavoriser la formation de l'unité de l'Allemarne par la Prusse et ruiner ainsi la prépondérance et la sécurité de la France en Europe.

Modifications apportées au régime impérial. - Un régime aussi absolu ne pouvait se perpétuer indéfiniment: chemins de fer, postes, télégraphes, nous mettaient en relations quotidiennes avec des nations jouissant des libertés parlementaires, et notamment l'Angleterre. La France avait vu faire la guerre de 1859 pour donner la liberté à l'Italie, et ne se résignait pas à en être elle-mème toujours privée; les alfaires de Rome avaient mécontenté les catholiques; enfin ce gouvernement dictatorial inquiétait l'Europe. Ceux que le souci de leurs intérêts arait laits ses partisans commençaient à ne plus se sentir rassurés. Il fallut apporter des moditications à la Constitution.

Décret du 24 novembue 8 89. - En 1860, l'Empereur exprima le désir de a donner aux grands corps de l'État une participation plus directe i la politique générale $\triangleright$. En conséquence ${ }^{2}$, revenant à un usage du gouvernement parlementaire, il autorisa le Sénat et le Corps législatil à voter tous les ans une adresse en réponse au discours de la Conronne. La discussion des termes de cette adresse permettait de passer en revue toutes les grandes questions de la politique. Les débats des Chambres devaient être reproduits in extenso par la sténographie. LEmpereur instituait des ministres spéciaux, appelés ministres sans portefuille, qui, tont en restant irresponsables vis-à-vis des Chambres, venaient y soutenir les propositions du gouvernement. On divisa le budget de chaque ministère en sections, aliu que le Corps législatil eat la possihilité de rejeter un crèdit sans repousser ce budget tout entier.

1. Volée en 1858 , elle autorisait le gouvernement à interner et à déporter oans jugement les citoyens qu'il jugeait dangereux pour l'ordre établi.

2. Dicret du 24 noveinbre 1860 , complété par plusieurs sénatus-consultes. 
Puis les conséquences de l'expédition du Mexique et les graves événements qui s'étaient passés cn Allemagne inquiétèrent encore plus l'opinion, ct le gouvernement se crut obligé à faire des concessions plus importantes.

Décret da 19 janvier 1867. - En 1867, on rendit aux deux Chambres une autre prérogative csscutielle du régime parlementaire : le droit d'interpellation. Elles purent questionner le gouvernement sur tout acte de sa politique extérieure et intérieure et émettre un vote sur ses explications. Les ministres a porteleuille purent itre charges, par délégation spéciale de l'Empereur, de représenter le gouvernement dans la discussion des interpellations, des projets de loi et des autres aflaires.

Sénatus-consulte du 8 septembre 1869. - Enfin le sénatus-consulte de $1 \$ 69$ modifia plus complètement encore la constitution impériale. Il attestait que le Senat avait recouvré le pouvoir constituant qu'il avait possédé sous le premier Empire. 11 donnait, concurremment, à l'Empereur et au Corps législatif l'initiative des lois. Le Corps legislatif recouvrait le droit de nommer ses présidents, vice-présidents et secrétaires; le budget des ministères devait ètre voté par chapitres; certaines restrictions au droit d'interpellation étaient supprimées, et tout membre des deux Chambres pouvait interpeller le gouvernement. Les ministres, quoiqu'ils continuassent a ne dépendre que de l'Empereur, devenaient responsabl ss et pouvaieut être mis en accusation par le Sénat; ils n'étaient plus, comme auparavant, cantonnés chacun dans les aftaires de son département, mais ils délibéraient en conseil, sous la présidence de l'Empereur. En apparence, ils formaient donc ce qu'on appelle un gouvernement de cabinet, ce qui est caractéristique du régime parlementaire; mais, en réalité, la volonté de l'Empereur restait toute-puissante.

Les libertés que II. Thiers appelait les libertés nécessaires avaient été restaurées dans une certaine mesure. La tribune avait été relevée dans les deux Chambres. Cette période nouvelle du gouvernement impérial constitue ce quion appelle l'Empire libéral.

Le sénatus-consulte de 1869 consacrait véritallement une constitution nouvelle. Elle fut soumise à la ratification 
populaire par le plébiscite du $S$ mai $18 \% 0^{1}$. Elle fut confirmée et développée dans le sénatus-consulte du 21 mai.

LEmpire liberal. - Malheureusement, lEmpire était né du coup d'État de décembre 1851, qui avait violé la Constitution jurée par le Prince.Président, dissous par force l'Assemblée, attenté à la personne des députés, versé le sang des défenseurs de la loi, emprisonné on déporté sans jugement des milliers de citoyens. L'Empire ne pouvait eflacer la tache de son origine.

La Constitution présentée à l'acceptation du peuple n'était pa s une Constitution vraiment parlementaire. L'Empereur, en établissant la responsabilité des ministres, maintenait le principe de la responsabilité du chef de l'État. Or, Je chef de l'Etal, restant responsable, pouvait ne pas tenir compte des volontés exprimées par les Chambres. En dépit des apparences constitutionnelles, le pouroir impérial restait personnel; il restait absolu dans son essence. Surtout depuis le plébiscite, l'Empereur était, à ses propres yeux, comme disait autrefois Napoléon Ier, a le seul, le vrai représentant du peuvle $\triangleright$. A ce titre, il se considérait comme supérieur à la représentation nationale; armé contre elle du Iroit d'en appeler à un plébiscite; libre, quand il le jurcrait convenable, de reprendre les concessions qu'il lui avait faites. Toujours il refusa d'admettre que les chels de la force armée, c'est-à-dire les ministres de la guerre et de la marine, fussent dépendants du Parlement. Il se réservait le droit de faire seul les traités et, seul, déclarer la guerre. Jamais il ne fut question de renoncer aux candidatures officielles, qui viciaient les résultats du scrutin et qui donnaient une majorité de députés absolutistes pour pratiquer le régime libéral. Par là, l’Emperenr autorisait les méfiances, et lui-mème se sentait pris de méfiance envers cette democratie autrefois asservie, et dont l'émancipation commencait. Peut-être a-t-il cherché dans sa déclaration de guerre à l'Allemagne un moyen de sortir d'embarras.

L'Empereur avait voulu rester personnellement respon-

1. En France (non comprise !'Algérie), 7347806 oui contre 1558123 non. L'armée ta marine avaient pris part au scrutin : elles donnèrent 306793 oui contre 54984 mon. 
sable. La nation le rendit persomnellement responsable des mallseurs de la guerre. Après le désastre de Sedan, la révolution du 4 septembre renversa l'Empire et proclima la République.

Le Gonvernement de la Défense nationale. -- La République qui, pour la troisième fois, prenait possession du pays, gouverna d'abord sans Assemblée. Comme il lallait avant tout résister à l'invasion, on we put que constituer le Gouvernement de la Défense nationale. Une partie de ses membres resta dans Paris assiege; l'autre s'était transportée à Tours, puis à Bordeaux, pour organiser les armées de province.

Après la capitulation de Paris, un décret du gouvernement convoqua les électeurs pour le 8 février 1871 , à l'effet de nommer une Assemblée nationale.

L'Assemblée nationale de 18g1. - Cette assemblé se réunit à Bordeaux le 13 février. Par la force des choses, comme la première Constituante, comme la Convention, comme la Constituante de 18 ' 8 , elle se trourat ctre le seul gouvernement. Elle se saisit de toute l'autorité, elle s'arrogeait à la fois le pouvoir constituant, le pouvoir législatif et le pouvoir exécutif. Elle délégıa celui-ci à I. Thiers, qui fut nommé Chef du pouvoir exécutif. Il gouverna, avec un conseil de ministres, fut chargé de conduire les négociations avec l'Allemagne et combattit la terrible insurrection de la Commune. Quant au pouvoir constituant, l'Assemblée se réserva de l'exercer plus tard : le seul usage qu'elle en fit d'abord fut, le $1^{\text {er }}$ mars 1871 , de a conlirmer la déchéance de Napoléon III, déjà prononcée par le suîrage unirersel o. Cetle assembléc ètait, en majorité, composée de monarehistes, que leur division en légitimistes et orléanistes réduisait à l'impuissance. Elle maintint la République, comme existant de fait, mais sans lui accorder la sanction du droit.

La Constitution Rivet. - Comme les diver's partis qui composaient la majorité ne pouvaicnt s'entendre, le 31 aout 1871, l'Assemblée, sur la proposition du dépulé Rivet, fit une sorte de Constitution provisoire : le Chef du pouvoir executif prit le titre de President de la République francaise. Il était responsable devant l'Assemblée. Le conseil des 
ministres et chacun des ministres étaient également responsables.

Le Septennat. - Le 2 ' mai 1873 , H. Thiers fut renversé, et, le même jour, le maréchal de Mac-Mahon lui succéda, avec le mème titre et les mèmes attributions. Seulement M. Thier's n'avait été nommé que pour la durée de l'Assemblée; Mac-llahon, par l'acte du 30 novembre, fut nommé pour sept ans. C'est ce qu'on appelle le scptennat.

Sous le nom de la République, la majorite de l'Assemblée fit un effort énergique pour réconcilier les partisans de la légitimité et ceux de la royauté de Juillet, en vue de refaire la monarchie. La teutative de réconciliation, ou fusion, échoua devant les scrupules du comte de Chambord. Alors cette Assemblée, en majorité monarchiste, fut obligée de voter une Constitution républicaine, celle du əs févilier 1875. Après avoir réuni un moment tous les pouvoirs, essayé, suivant l'expression d'un de ses ministres, de a liaire marcher la France s, et joué, comme disait llenri Martin, le róle d'une Convention blanche, elle ahdiquait devast le tlot montant de lopinion.

\section{La Constitution da $2 \bar{s}$ février 1875 et ses récentes} modifications. - La Constitution qu'elle vota est celle qui nous régit encore aujourd'hui ${ }^{1}$. Elle a été complétée ou modifiée par plusieurs lois ${ }^{2}$, dites oryaniques.

Elle a confié le pouvoir executil à un Prisiclent de la République; le pouroir législatif à deux Assenblées, le Sénat et la Chambre des deputés.

Le Président de la République est élu par les membres des deux Assemblées réunies en Congrès : il est nommé pour sept ans.

1. Cette Constitution se compose, en réalitè, de deux lois constitutionnelles : l'une, sur l'ortanisation du Sénal, 24 férrier 1875; l'autre, sur l'organisation des pouvoirs publies, 25 férrier 1875.

2. Loi du 16 juillet 1875 , sur les rapports des Pouvoirs publics. - Loi du 2 aoủt 1875, sur l'élection des sénateurs. - Loi du 30 novembre 1575 , sur l'èlection des dépulés. - Loi du 9 dècembre 1884 moditiant l'organisation du Sénat el la composition du corps èlectoral pour les elections des senateurs. - Loi du 16 juin 1855, qui relablit le sirutin de liste pour l’élection des députés. - Loi du 13 février 1809 rétublissaut le scrutin uniromiual. - Loi du 17 juillet 1889 , interibisant les candidatures mulsiples. 
Les députés sont élus au suffrage universel. La Constitution avait statué qu'ils seraient élus au scrutin uninominal ou scrutin d'arrondisscment, à raison d'un par arrondissement ou, si l'on a sectionmé les arrondissements, par circonscription électorale. La loi du 16 juin $1 \$ S 3 \ddot{~ r e ́ t a b l i t ~ l e ~}$ scrutin de liste ou scrutin de departcment. En présence du péril boulangiste, la loi du 13 fevrier $18 \$ 9$ revint au scrutin uninominal; celle du 17 juillet interdit les candidatures multiples. La Chambre est nommée pour quatre ans et se renouvelle intégralement.

La Constitution avait établi que, sur les 300 membres du Sénat, 225 seraient élus au scrutin de département, par un corps électoral spécial, composé des électeurs sénatoriaux, et 75 nommés par le Sénat lui-mème. Les 2203 seraient élus pour neuf ans, renouvelés par tiers tous les trois ans; les 73 étaitnt nommés $\dot{a}$ vie. Quant au corps électoral spécial, il se composerait des députés du département, des conseillers généraux et conseillers d'arrondissement, et des delégu's des communes. Ceux-ci étaient désignes par les conseils municipaux, à raison d'un pour chaque commune: une cité de trois millions d'àmes comme Paris nommait un délégué tout comme un village de 30 habitants.

La loi du 9 décembre 1884 a décidé que les 70 inamovibles seraient supprimés, mais seulement par voie d'extinction, et que les 300 sénateurs seraient également élus par le corps électoral sénatorial. Elle a modifié la composition de celui-ci : même les plus petites communes continuent à nommer un délégué; mais les communes plus considerables nomment un nombre de délegués qui est un peu plus en rapport arec leur population.

Les électeurs sénatoriaux se réunissent au chef-lieu du département et portent sur leur bulletin autant de noms qu'il y a de sénateurs à élire. Les électeurs des députés votent à la commune.

Le Président a toutes Ies attributions du pouvoir exécutif. ll les exerce au moyen de ministres nommés par lui; les ministres forment ungouvernement de cabinet; ils lélibèrent, tantôt sous la présidence du Président de la République, tantôt sous la présidence del'un d'eux, qu'on appelle president du Conseil. Le Président n'est respon. 
sable que daus le cas de haute trahison. Les ministres son $($ responsables devant les Chambres. Le Président peut dissoudre la cliambre des députés, mais sur l'avis conforme du Sénat. Alors les électeurs doivent être convoqués dans les trois mois. Le délai maximum est également de trois mois quand il s'agit de pourvoir a toute vacance d'un siège au Sénat ou à la Chambre.

Pour les crimes d'altentat à la sùreté de l'Élat, la Conslitution a prévu la formation du Sénat en Haute-Cour de Justice. La loi du 10 avril 1899 a précisé l'organisation de celle cour. Elle a fonctionné déjá deux fois : en 1889, lors de la conspiration boulangiste; en 1899-1900, sur des faits qui lui furent déférés par le cabinet Waldeck-Rousseau.

Tout projet de loi peut être proposé, soit par le gouvernement, soit par un membre de l'une ou l'autre Chambre. Pour devenir loi, il faut qu'il ail été voté par les denx Chambres : il est alors promulgué par le President. Les budgets et autres lois de finances se votent et se promulguent dans la même formo.

Les deux Chambres font elles-mêmes leur réglement et nomment leur bureau. Elles penvent discuter tous les actes du gonvernement, soil à l'occasion du vote du budget, soit au moyen d'interpellations. L'usage de discuter une adresse en réponse a un discours ou à un message du pouvoir exéculif a éé abandonué comme inutile.

Aucune modification ne peut ètre apportée à la Constitution que par l'accord des deux Chambres qui doivent alors se réunir en Congrès.

nuceanisme de notre Constitution actuehle. - Celle Constitution de 1875 , plusieurs fois amendee, est la meilleure de nos constitutions républicaines, comme la Charte de 1814, amendée en 1830, a été la meilleure de nos constitions monarchiques. Toutes deux se rapprochent beaucoup de la Constitution britannique, qui a fait la liberté et la grandeur de l'Augleterre. Le trail commun de toutes ces constitutions, cest qu'elles organisent le gouvernement de cubinet.

Le gouvernement de cabinet, en Angleterre somme en France, est celui d'un groupe de ministres, nomnes par le chel de l'État, mais dépendant en réalité du Partement, 
associés pour gouverner en commun sous la direction de l'un d'eux, et qui, en général, quittent le pouvoir tous ensemble. Ils gouvernent avec l'appui des deux Chambres, et déposent leurs portefeuilles quand cet appui leur est refusé. Dans la pratique, un vote hostile de la Chambre haute ne renverse pas le ministère; un vote hostile de la seconde Chambre l'oblige, ou ḋ se retirer, ou bien d demander au chel de l'Étal l'autorisation de la dissoudre. Un cabine ne se décide à dissoudre la Chambre que lorsqu'il croit ètre certain qu'elle n'est plus d'accord avec l'opinion publique, et que des élections sortira une assemblée favorable à la politique ministérielle.

On voit combien une telle organisation peut favoriser la sincère expression de la volonté nationale. Ce sont les électeurs qui nomment les députés, et ce sont les députés, en quelque sorte, qui élisent le gouvernement, puisque le chef de l'Élat ne peut nommer que des ministres dont les vues politiques soient celles de la majorité des deputis. Dans toutes les crises parlementaires, c'est toujours le corps électoral qui a le lernier mot; en France, où le corps électoral comprend l'universalité des citoyens, c'est donc la nation tout entière qui a ce dernier mot.

Le grand l'ouage de notre Constitution, celui qui donne l'impulsion à tout, c'est la Clambre des députés, précisément paree qu'elle est nomméc direstement par le sulirage univcrsel, tandis que le Sénat est nommé par un sutriage $\dot{a}$ deux degrès et le Président par le Conırès. Cependant, le Sénat et le Président sont indispensables comme pondérateurs: l'un a le droit de repousser les lois rotées par la Chambre, l'autre de nommer les ministres; it eux deux ils possèdent le droit de dissoudre la Chimbre. Or, ce droit de dissolution n'est point une menace pour la liberté; il est au contraire une précieuse garantie pour le pays; c'est la seule facon qu'on ait de consulter la nation en cas de crise parlementaire. Le droit de dissolution n'est que le droit d'appel aux électeurs ${ }^{1}$.

Presque toutes les $\Lambda$ ssemblées qui n'ont pas été sou-

1. En firit, on ne peut ciler en France, sots la lroizième Rupublique, qu'un seul cas de dissolution anticipée : c'est celle de mai $18 \pi 7$. 
mises à ce droit salutaire, ou bien ont usurpé sur les autres pouvoirs publics et mème sur les libertés nationales, ou bien ont été violemment dissoutes. La Convention s'est rendue omnipotente, l'Assemblèe nationale de 1871 a essayé d'imposer à la France une monarchie. Les Assemblées du Directoire ont commis ou subi une série de coups d'Etat; la Législative de 1849 a été dispersée au 2 décembre 1851.

La Constitution actuelle rend presque impossibles les conflits qui ont fait périr celles de 1791 et de 18千8. Aucuu des pouvoirs publics ne peut empièter sur les autres, ni méconnaitre longtemps la volonté nationale. Si la Chambre des députés sobstinait à voter des lois nuisibles, le Sénat les repousserait. Si elle se laissait emporter par ses passions, ou essayait de réunir tous les pouroirs comme a lait la Convention, le Sénat serait en mesure de la contenir; il pourrait mème s'entendre avec le Président pour la dissoudre et pour en appeler aux électeurs. Si le Sénat était animé d'un esprit de faction, il ne pourrait entraver la marche des afliaires, car l'existence du ministère ne dépend pas surtont de lui, et. dans un délai assez court, le tie:s de ses nembres aurait à répondre de cette conduite devant le corps électoral. Le Président ne pourrait conspirer contre la liberté, car ses ministres refuseraient de contresigner ses actes. les Chambres refuseraient de voter le budget; il we pourrait remplacer les ministres loyaux par des ministres factieux, car la Chambre les renverserait aussitot; il ne pourrait s'eu prendre à la Chambre, car il faut un aris conforme du Sénat jour la dissoudre; entin soll pouroir n'est pas viager, comme celui d'un roi, et, à supposer qu“il ne jugeât pas á propos de se retirer spontanément. Le moment de sa réélection finirait bien par venir. En 18\% \% on a vu le maréchal de Mac-Mahon obtenir d'un Senat complaisant la dissolution de la Chambre: mais, quand les électeurs eurent renommé les fameux 363 , il fallut bien que le Sénat et le Président s'inclinassent devant leur rolonté. En outre, comme le Président était intervenu d'une manière trop personnelle dans les élections, il comprit que les électemrs le condamnaient persommellement et. bien que son mandat ne fit pas encore expire, il quitta, de lui-mème, le pouvoir. Nous ñüsisterons 
pas sur des faits plus récents, comme la démission imposée au président Jules Grévy sous la pression des deux Chambres et de l'opinion publique ( 2 décembre $188 \pi$ ).

On roit quelles garanties assurent à la liberté la division de l'autorité entre trois pouvoirs, et le partage du Parlement lui-même en deux Chambres. Toutefois, la meilleure constitution ne vaut que par les hommes qui la mettent en pratique, chef d'État, ministres, sénateurs, députés. Ellene vaut inême que par ce que valent les électeurs.

\section{Le droit électoral.}

Le suffrage univensel décrété. - Uu des premicr: actes du Gouvernement provisoire de lévrier $18 \div 8$ fut de décréter le suffrage universel. On ne peut dire quil ait outrepassé son mandat: les restrictions apporices au droit de sulfrage par les lois consulaires et inperiales, par les Chartes de 1814 et de 1830, ne pouvaicnt survivre aux régimes qui les avaient établies. Le sulinage universe! n'était qu'un retour au droit commun, tel qu'il avait été défini par les principes de 1789.

Malheureusement le nouveau corps électoral. précisément parce quil se trouva porté tout à coup de 250000 électeur à 10 millions, précisément parce qu'il navait pas été préparé à sa haute mission, était accessible a tous les entrainements. Il élut d'abord une assemblèe en majorité républicaine, la Constituante; quand il eut à nommer un Président de la République, il dédaigna le candidat républicain, Cavaignac, et donna une immense majorité au prétendant napoléonien; enfin, il élut une assemblée en majorité monarchiste, la Législative. Ainsi, c’est la République de 18.8 qui a établi le suffrage universel, et ce sont les erreurs du suffrage universel qui liunt detruite.

Le sufrage universel menacé par losscublée légise Iative. - On pouvait certes regretter qu'on lût arriré si brusquement au suffrage universel, mais il était injuste et imprudent d'essayer de revenir en arrière. C'est pourtant ce que tenta l'Assemblée législative, bien qu'elle eût été élue par ce mème suffrage universel. Nosant pas lattaquer de front, elle essaya, par un moyen détourné, d 
restreindre le nombre des électeurs. La Constituante. qui était une assemblée républicaine, s'était bornée, par la loi du 13 mars 1849 , á exiger de tout électeur qu'il lüt domicilié depuis six mois dans la mẻme commune: la Législative, par la loi du 31 mai 1850, exigea trois ans de lomicile. Par lá, elle privait du droit de voter un très grand nombre de citoyens, principalement parmi les ourriers, que leur travail mème expose à de fréquents déplacements ${ }^{1}$.

Le sumpage universel réfabli par le coup d'Ént. Les ministres de Louis-Napoléon encouragèrent l'Assemblée à commettre cette faute. La faute commise, LouisTapoléon l'exploita contre l'Assemblée. Il accrut encore l'impopularité de celle-ci en lui proposant, l'aunée suivante, de rapporter la loi du 31 mai. Elle refusa, et, par là, s'aliéna irrévocablement les classes ouvrières. Quand le Président eut accompli son coup d'État, il n'eut qu'à faire afficher sur les murs de Paris ces simples mots : - Le suflrage universel est rétabli ๖; il désarma ainsi beaucoup de bras qui se fussent levés pour la Ripublinue.

Depuis cette funeste loi de 1850 , aucune Assemblée, aucun gouvernement n'a osé toucher au suffrage universel. L'Empire s'est contenté de le diriger, de le mettre en

1. Cette loi, qui attentait au suffrage universel, fut soutenue par Baroche, Montalembert. Thiers, qui fit alors sa fameuse sortie sur "la vile multitude v. Elle fut cumbattue ener riquement par tous les députés démocrates: Lamartine, Cavaigna\%. Fascal Duprat, Jules Grévy, Jules Favre, Vietor Hugo. Celui-ci prononca, dans la séauce du 90 mai 1850 , un admirable discours dont voiri quelques passages: "Voyez, messieurs, comme ce qui est profondément juste est, en mèue temps, profondèment politique. Le suffrage uviversel, en donnant un bulletin à ceux qui souffrent, leur òte le fusil. En leur donnaut la puissance, il leur donne le calme... Le suffrage universel dil a tous : Soyez tranquilles, vous ètes souverains... Ouoi ? deux morles d'action sont a votre disposilion, le droit du souverain ei le rủle du rebelle, et fous choisiriez le rỏle du rebelle! Ce serait une sottise el ce serait un erime... Messieurs, dissondre les animosités, désarmer les haines, laire lomber la cartouche des mains de la misère, relever l'homne injustement abaissé et a-sainir lesprit malade par ce qu'il y a de plus pur au monde, le sentiment du droit librement esercé; reprendre a chacun le droit de force, qui est le fait naturel, et lui rendre en ẻrhange la part de souveraiueté, qui est le fait social; montrer aux souffrances une issue rers la lumice et le hien-ètre: èloigner les èhéances révolutionnaires et donner à la société, avertie, le temps de s'y preparer; inspirer aux masses celte palienec forte qui fait les grands peuples : voila l'œuvre du suffrage universel, ourre éminemment suciale au point de vue de l'État, émigemment moraje an point le vue de l'udividu:" 
tutelle. Imposant ses candidatures officielles, employant les promesses et les menaces, mettant en œuvre toutes les forces de l'administration, il s'est appliqué pendant dixhuit ans à faire nommer par le peuple les députés qu'il jugeait devoir ètre le plus dociles. Il réussit à laire sortir du système le plus libéral de sulfragre le système le plus autoritaire de gouveinement.

Résumé de l'histoire de notre droit électoral. - Sous les gouvernements de la première Révolution, Constituante, Législative, Convention, Directoire, tantôl le suffrage n'est accordé qu'aux citoyens a actil's $\triangleright$; tantôt il est à̀ deux degrés: jamais il n'est à la fois universel et lirect.

Sous le Consulat et le premier Empire, d’ingénieuses combinaisons, tout en respectant le principe du suffrage universel, l'annulent completement dans son application : en réalité, les représentants du peuplc sont nommés par le gouvernement.

Sous la Restauration et la Monarchie de Juillet. le vote est direct, mais le droit de voter est riservé aux électeurs censitaires: le suffrage n'est pas universel.

Sulis le second Empire, le suffrage est universel et direct. mais il est mis en tutelle par le systeme des condidatures oficielles : il n'est pas libre.

Vitiat actuel du droit de sufrage. - Aujourd'hui, pour la première fois depuis cent ans (sauf quelques mois en $19+\$$, le suffrage est universel; il est dircet; il est libre. L’électeur a l'entière indépendance, mais il a l'entière responsabilité. Chaque électeur, en déposant son bulletin, doit se dire que les députés qu'il nomme auront à désigner les ministres au choix du Président de la Riepublique, et, riunis aux sénateurs, auront à nommer le Présiden: lui-mème. L'électeur a done une action directe et efficace sur la formation du gouvernement. sur la conduite de la politique intérieure et extérieure. Il dépend de lui que la France soit prospère au dedans, puissante au dehors, ou qu'elle soit livrée à l’anarchie et humiliée devant l'étranger. Il n'a pas à décider seulement des destinées de la génération actuelle; il engrage les destinées de ses enfants et de ses arrière-petits-culants; il sera responsable, devant la postérité la julus reculée, des consé fuences 
les plus lointaines de son vote. Il doit se souvenir que la France, ce n'est pas seulement la collection des hommes et des intérêts d'aujourd'hui, e'est aussi l'ancienne France, avec ses traditions de gloire, et la France luture, avec ses espérances d'avenir. En émettant son suflrage, il doit penser aux ancètres qui, pendant des siècles, ont souffert et combattu pour faire notre patrie grande et respectée; aux générations futures, qui trowveront la France telle que nous l'aurons faite. Nous ne sommes pas libres de voter au gré des intérèts, des passions, des caprices du moment. Voter, ee n'est pas seulement un droit qu'on exerce : e'est un grand devoir qu'on accomplit.

On peut calculer que sur environ 39 millions de Français, 17 millions sont nés sous la République, que 12 ou 13 millions d'autres sont arrivés sous ce régime à leur majorité. Chaque jour se rèduit le nombre de ceux qui ont connu d'autres régimes politiques. C'est là une condition très farorable à la stabilité de la Riépublique. Peut-être n'a-telle rien à redouter que des fautes commises par ses propres partisans. Yoir Suppl.)

\section{Les libertés publiques.}

Le droit de pétition. - Ce droit n'a pas fait beaucoup parler de lui dans la période contemporaine. Il ne s'est exercé, avec les formes tumultueuses qu'avaient autorisées ou subies les premières assemblèes nationales, que dans certaines journées de la Révolution de 1848 : par exemple, dans la manifestation du 15 mai en laveur de la Pologne. La constitution de 1852 r'autorisa que les pétitions au Sénat, et non au Corps législatif. Aujourd'hui on peut en adresser au Président de la République, aux deux Chambres, aux ministres, à toutes les autorités publiques. Elles ne doivent pas ètre apportées, mais adressées par écrit et signées. Les plus célèbres pétitions collectives sont celles qui lurent discutées au Sénat du second Empire en faveur de la liberté de l'enseignement et, plus récemment, le pétitionnement contre les lais Ferry.

¿án liberté d'association ct de réunion. - Sun histoire:

1 Sous la Repubrique de 1848. - La Révolution de 
1848 abolit toutes les lois qui limitaient le droit de réunion. Les clubs se rouvrent partout, et il laut arouer que ces clubs, comme ceux de la première Révolution, ne font rien pour réconeilier avec cette liberté les esprits modèrés ou timorés.

$\Lambda$ près les journées de juin, la lo $i$ de $181 S^{1}$ établit des restrictions que l'expérience des derniers mois semble rendre nécessaires : elle veut que l'ouverture d'un club soit précédée d'une déelaration anx autorités; elle exige que les clubs soient ouverts au public; elle leur délend le se constituer en comité secret; elle y fait entrer un agent de l'autorité revêtu de ses insignes.

En somme, cette loi n'interdisait que les socictés secrètes. Or, les societés secrètes, sous un gouvernement libre, ne peuvent être que nuisibles : on ne s'entoure pas de mystère quand on n'a pas de mauvais desseins.

La Constitution du 4 novembre is 4 (article 8) déclare encore que a les citoyens ont le droit de s'assucier, de s'assembler paisihlement et sans armes.... L'exercice de ce droit n'a pour limites que les droits ou la liberte d'autrui et la sécurité publique o.

La loi de 1849 a suspend celle du 28 juillet et antorise le gouvernement, pour une année, a interlire tout club el toute réunion publique qu'il jugerait de nature à compro. meltre la sécurité publique. Cette disposition fut ensuite renouvelée pour les années 1850 et 18531 .

$\mathbf{2}^{\circ}$ Gous le régime da comp detat. - Le coup d'État emporte cette liberté comme toutes les autres. Le décht de $1852^{3}$ rélablit le régine du Code pénal et de la loi de 183\%. De la loi de 1848, il ne garde que les dispositions contre les sociétés secrètes.

Désormais vingt et un citoyens ne peuvent se réunir, quel que soit le but qu'ils se moposent, sans une autorisation préalable. S’ils passent outre, ils s exposent à l'amende, à la prison, à la perte de leurs droits politiques, à la dégradation eivique, qui emporte avec elle la surveillance de la

2. 19 jum 1849.

3. 25 mars 1852 . 
haute police. Les réunions électorales elles-mèmes tombent sous le coup du décret : les citoyens sont privés du droit de se réunir pour examiner les candidatures; ils doivent voter sans entente préalable, sans discussion, à l'aveugle.

Cette législation n'empêcha pas les sociétés secrètes, principalement d'ouvriers démocrates, comme celles du Cordon sanitaire, des Consuls du peuple, des Deux-Cents, de la Commune revolutionnaire, de la Marianne, du SudEst, de la Hontagne, de recruter de nombreux adhérents.

Sous l'Empire, elle donna licu au procès des Treize, où furent inpliqués Garnier-Pagès, 11. Caruot, Dréo, llérold, Clamageran, Floquet, Jules Ferry, llérisson, etc. Bien qu'ils al'tirmassent s'être réunis à treize et non pas à vingt et un, ils lurent condamnés (1865).

:B' Sous l'Empire libéral. - Quand l'Empire s'essayait à devenir libéral, il autorisa la création de sociétés coopératives, la création de cours et de conférences, celle de la Ligue de l'Enseignement, londée en 1866 par Jean Hacé.

La loi du 6 juin 1865 autorisa les réunions publiques non politiques et les réunions publiques en vue de l’élection des députés. Chaque réunion devait ètre précédée d'une déclaration signće par sept personnes; un agent de l'autorité devait y assister, revêtu de ses insignes; il avait le droit de dissoudre l'assemblée si l'on y discutait des questions étrangères à l'oljet annoncé dans la déclaration ou si elle devenait tumultueuse. Les réunions électorales eı vue de l'élection des conseillers généraux, d'arrondissement et municipaux, ne bénéficiajent pas de la nouvelle loi. Elles restaient soumises à l'autorisation préalable, qui pouvait toujours ètre refusée. Le gouvernement ne voulait pas, disait-il, a troubler, par des concessions inopportunes, la liberté des citoyens $»$.

Sons le régime actuel. - Quel est l'état actuel du droit de réunion et d'association?

Le droit de réunion a reçu de nouvelles facilités frar la loi du 30 juin 1881. Les clubs demeurent interdits; mais toutes les réunions publiques sont permises, moyennant une simple déclaration signée par deux personnes. Un itrent de l'autorité y assiste; mais il n'a le lroit de dissudre la réunion que sil en est requis par le bu- 
reau ou s'il se produit des a collisions et voies de fait".

Quant à la liberté d'assuciation, elle doit toujours ètre, toujours prochainement, lobjet d'une loi générale. Une loi spéciale a réglé la liberté des associations syndicales ${ }^{1}$.

Les associations ayant un but philanthropique, économique, scientifique ou littéraire, la plupart les associations religieuses, jouissent, en fait, d'une entière liberté.

En revanche, la loi du 14 mars 1872 a proserit l'Association internationale des travailleurs, qui prétendait organiser les partis socialistes de tous les pays pour la desIruction de l'ordre social emropéen. La loi du 18 dicembre 1993 a sévi contre les Associations de malfaitetrs, c'est-àdire d'anarchistes pratiquant a la propagande par le fait $\triangleright$. Les derrets du 29 mars 1890 ont remis en vigueur les lois portées autrefois contre la compagnie de Jésus et les congrégations religieuses non autorisées ${ }^{2}$.

La liberté de la presse. - Son histoire : ${ }^{\circ}$ Sous la République de 18-18. - Le Gouvernement provisoire, par le decret de mars 1848 , abolit le timbre sur les journaux. On entendait donner l'essor à une presse vraiment populaire et démocratique : le suffrage universel étant proclamé, on voulait que la presse devint le moyen universel d'instruetion civique. La loi du 9 septembre 183. étail formellement abrogée. Les journaux se multiplièrent comme les clubs :.

Le décret du 9 aoùt $1 S 4 S$, rendu par l'Assemblée constituante, marque une première réaction contre ces ten-

1. Vuyez ci-dessous, chap. xxxin : la Transformation cconomique; vi, les classes ourrières.

2. La loi tu f.r juillet 1901 élablit le droit d'association "saus autorisation ni déclaration préalable ", (sauf en vue d'un objet illicite, contraire aux lois ou aux bonues mours); pour jouir de la capueite juridique, l'association duil ètre declaree. Seules les congrégations rehgieuses doivent élre autorisees par une loi.

3. Eu 1s48, comme à la première Révolution, il y ent un débordement de feniltes nouvelles: une foule de Republiques, parmi lesquelles la kemblique rouge cl mène la République napoléonienne; heaucoup de Peuples. et ootamment le Peuple souverain; toute une famile Duchène, le Pire Duchene, la Wère Duchène, le Pitit-fils du père Duchêne; quantite de Tribunes; phasieurs Verites, dont une Sans chemise; an Tribunal révolutionnaire; wa Pilori; une Guillotine. Prouhhon publie le Peuple; Raspail, l'A mi du I'eu't: Amédée de Céséna, le Triomphe du Peuple; Lacorlaire, l'Ere nouvelle. An reste, lit Resolution du 4 septembre et le régma de la Commuge ont vu reparaitre certains de nos plus sieux revenauls. 
dances. Il fixe le taux du cautionnement pour les leuilles quotidiennes à 24000 franes pour Paris, à 6000 pour les grandes rilles, à 3000 pour les petites. Il promet que le cautionnement sera aboli à partir du $1^{\text {er }}$ mai $18 \dot{1} 9$.

La mème Assemblée, par le décret du $1 /$ août, édicte des pénaliés contre les écrivains qui se seront attaqués aux droits et à l'autorité de l'Assemblée nationale ou du pouvoir exécutil, à la Constitution, au principe de la souveraineté du peuple et du suffrage universel, à la liberté des cultes, à la propriété, à la famille. Quiconque aura excité - à la haine et au mépris du gouvernement de la République o sera puni d'un emprisonnement d'un mois à quatre ans et d'une amende de 50 à 5000 francs.

L'Assemblée législative, par la loi du 27 juill:! 1949, Louis-Napoléon étant déja Président de la République, réédite presque toutes les dispositions de la loi de $1 \times 35$ et maintient l'obligation du cautionnement: le timbre seul reste aboli. La loi ilu 16 juillet 1850 exige que les articles soient signés; elle rétablit le timbre, à raison de cinu eentimes pour les journaux de Paris et de deux contimes pour les journaux de province : il est rai que le timbre leur tient lieu dafiranchissement et leur donne droit au transport par la poste.

$2^{\circ}$ Sons le régime du conp d'Star. - Le coup détat du 2 décembre a les mèmes conséquenees que celui de Brumaire : la plupart des journaux sont supprimés administrativement. Le decret du 31 décembre $18 \not ̈ 1$ eulève au jury la connaissance des délits de presse et l'attribue aux tribunaux correctionnels. Le système inauguré par le decret orgunique de février 19302 est le plus oppressif quait subi la presse franęaise depuis l'abolition de la censure : il aecumule contre la presse toutes les rigueurs du regime fise ul, du sustème précentif et du systime répressif ${ }^{1}$. Il élère le cautionnement a 50400 francs dans Paris, à 25 tim0 dans les grandes villes, à 15000 dans les plus petites. Le timbre est porté à six centimes pour les journaux de Paris, it trois centimes pour ceux des départements. Au droit de timbre s'ajoutent les frais de poste. En outre. nul journal ne 
pourra se fonder à l'avenir sans une autorisation préalable. A la répression des délits par les tribunaux correctionnels s'adjoint la répression alministrative. Tout journal peut ètre frappé d'un arertissement: si, dans l'espace de deux ans, un journal a recu deux arertissements, il est suspendu; šil a subi deux condamnations par les tribunaux, il est supprimé. Les tribunaux peuvent lui infliger soit la suspension, soit la suppression. S̈il a été suspendu judiciairement ou administrativement, il peut être supprimé par décret du pouvoir exécutif. D'ailleurs. celui-ci peut toujours le supprimer à sa volonté a par mesare de sûreté générale.

Ce décret ne parle que d'amendes, prison, suspension, suppression. Le moindre délit peut attirer une de ces pénalités. Or, désormais, c'est un délit que de rendre compte des procès pour délits de presse, un délit que de rendre compte des séances du Corps législatif autrement qu'en insérant le procés-verbal préparé par son président, un délit que de rendre compte des séances du Sénat autre. ment qu'en reproduisant les articles du .Honiteur, un délit que de publier des fausses nouvelles ou des documents fanx, c'est-a-dire les nouvelles et les pièces que le gouvernement declare fausses. Les ministres et les préfets ne sont pas seulement armés contre enx de ce redoutable droit d'uvertissement; ils ont encore le droit de communique : sous prétexte de répondre à une allégation quelconque dun journal, ils peuvent l'obliger à insérer en tête de ses colonnes une longue note officielle. Le Figaro s'attira un communiqué de ce genre pour avoir dit que les réverbères d'un boulevard n'étaient pas encore allumés à une certaine heure. Tout était interdit aux malheureux journalistes, tout leur était un danger. Si, désespérant de pouvoir, sans risque, parler des choses de France, ils s'occupaient des peupies étrangers. a de tels subteriuges ne pouraient tromper l'administration vigilante $\triangleright$ : ils étaient frappés pour avoir a cherché à dissimuler des critiques amères de la Constitution de 1852 en leignant de parlè üune consti\&ution étrangère ${ }^{1}$.

1. On sait que la plupart des journaux ne penvent faire leurs frais que gràce aux anaonces, surtout aux annonces judiciaires: or les préfets étnieut 
Les livres mèmes, du ton le plus modéré, pouvaient être saisis: ainsi fut saisie l'Histoire des princes de Condé, par le duc d'Aumale (1863).

Enfin, une rigourense surveillance excrcée à la frontière ne laissait passer ni livres ni journaux qui ne fussent agréables au gouvernement.

Tel fut le régime que subit, pendant seize ans, la presse d'un des pays les plus civilisés du monde.

$\mathbf{3}^{\circ}$ Sous l'Empire liberal. - En 1867, l'Empereur annonça, dans sa fameuse letre du 19 janvier, qu'une a loi serait proposée pour attribuer exclusivement aux tribunaux correctionnels l'appréciation des délits de presse ot supprimer ainsi le pouvoir discrétionnaire du gouvernement ๖. La juridiction des tribunaux correctionnels paraissait un progrès!

La loi annoncée fut la loi duf / mai 1868 . L'antorisation préalable fut remplacée par une simple déclaration préalable, indiquant les noms des propriétaires, du gérant responsable et de l'imprimeur. Le timbre fut ramené au taux de 1848. Les amendes pour simples contraventions ne pouvaient dépasser le tiers du cautionnement, mais comme il pouvait y avoir à la fois trois condamnés, le rédacteur, le gérant et l'imprimeur, une seule amende pouvail enlever la totalite du cautionnement. Un journal que les tribunaux condamnaient pour a crime s était supprimé; pour délit, suspendu.

Les tribunaux correctionnels appliquèrent rigoureusement cette loi. Dans les six premiers mois, ils prononcèrent pour 122000 francs d'amendes et pour sept ou huit années de prison.

40 Sous le ségime actuel. - La Révolution du 4 septembre amena encore la suppression du timbre et du cautionnement, et fit cesser l'obligation de la signature pour les rédacteurs. Il y eut un moment d'extrême liberté. Celleci lut tempérée bientôt après par le régime de l'état de siège qui, dans les pays où il est établi, confẻre à l'auto-

investis du droit de désiquer les journaux qui seuls pourraient reproduiro ces annonces, et de fixer le prix d'incertion. C'ètait une subveution que le pouvernement assurait aux journaux agréables et une ressource dont il privait les journaux suspects. 
rité militaire le droit d'interdire les publications et les réunions qu'elle juge de nature à exeiter ou à entretenir le désordre (loi de 1849), et qui attribue la connaissance d'une partie des délits de presse aux conseils de guerre.

La loi du $1 \dot{3}$ avril 1871 rétablit la compétence da jury pour la plupart des lélits, ne réservant aux tribunaux correctionnels que les délits contre les bonnes mœurs et la diffamation contre les particuliers (la dilfamation contre les personnes publiques devant ètre juggée par le jury).

La loi du 6 juill $t \mathbf{8 7 1}$ rétablit le cantionnement et la loi de septembre 1971 établit un impól sur le papier.

La loi du 29 decembre 18750 rendit aux tribunaux la connaissance des delits de diffamation contre toute personne, d'offense contre le Président de la République ou l'une des deux Cliambres, de publication de lausses nouvelles ou de pieces fabriquées, de provocation à commettre un crime ou un délit, d'apologie des faits qualifiés crimes on délits. Elle retirail à l'administration le droit d'interdire à un journal la vente sur la voie publique.

Celte loi était la plus libérale que nous eussions encore eue; cependant, comme le régime da 16 mai abusa de quelques-unes de ses dispositions, on voulut aller plus loin, et alors fut votée la loi du 29 juillet 1881. Ses dispositions peuvent se rattacher à ces trois priucipes: $1^{\circ}$ il ne reste aucune trace du régime préventif; 20 il ne reste aucune trace du régime fiscal; $3^{\circ}$ la répression se borne à frapper les actes qui sont considérés, mème en lroit commun, conme des crimes, délits ou contraventions. Sauf les exceptions qui seront notées plus loin, c'est le jury de la cour d'assises qui seul a qualité pour apprécier les faits.

Les journaux ne seront plus yoursuivis, ni pour excitation à la haine et au mépris du gouvernement, ni pour attafues à la Constitution, ni pour a apologie de faits qualifiés crimes s, ni pour attaques à la propriété, à la famille, aux cultes reconnus, ete. Les Chambres républicaines, beaucoup moins susceptibles que leurs devancières, n'ont mème pas voulu retenir le délit d'outragre aux Cliambres.

Jamais, à aueun moment, dans aucun pays, la presse 
n'a été aussi libre. C'est la liberté poussée jusqu'à l'excès. Bien que la loi édicte des pénalités contre les crimes ou délits politiques, il est certain qu'en fait, tous les jours, on peut impunément insulter et calomnier le Président, les ministres, les deux Chambres, l'armée, la magistrature, les fonctionnaires, provoquer à l'émeute et au coup d'État, au rétablissement de l'Empire ou de la Royauté, à la destruction de l'ordre social et à l'anéantissement des propriélés. Sans doute la loi édicte des peines sévères contre l'injure et la diffamation; mais presque seuls les particuliers injuriés ou diffamés se risquent à les poursuivre, car ils ont seuls le droit de les poursuivre devant les tribunaux correctionnels. Toute per'sonne revêtue d'une fonction, d'un mandat ou d'un caractère publics n'a de recours que devant le jury; or il est établi par de nombreux exemples que le jury a une tendance à respecter iusqu'au scrupule l'usage ou l'abus de la liberté de la presse et à reïuser les condamnations. Au surplus, on s'habitue aux violences et aux provocations : l'expérience, pense-ton, smble prouver leur inutilité; on se dit que ces inconvénients sont largement compensés par les avantages d'une publicité sans limites et qui porte la lumière partout.

La loi assure un droit de réponse à toute personne attaquée dans un journal; en ce qui concerne les personnes non publiques, elle ne permet pas au journaliste de redoubler la diffamation en ofirant d'en faire la preuve devant les tribunaux; elle défend aux jourmax de rendre compte des procès en diffamation dans les cas où la preuve n'en est pas admise.

Développencent énorme de la presse. - Les nouvelles machines ont contribué à donner au journalisme une force d'expansion inouïe. Remplaçant la presse à table de chariot, la presse $\dot{a}$ c!llindres fit son apparition à l'Exposition de 1867. Tandis que la première ne pouvait tirer que 6000 numéros à l'heure, la machine Marinoni, avec sept ouvriers seulement, en tire 24000 .

Le clichage, en multipliant les empreintes, permet de tirer la mème composition sur 24 machines il la fois : solt 14000 numéros it i'heure. 
Le clichage s'opère à l'aide d'une empreinte prise sur la composition, soit avec du blanc d'Espagne et du pajpier, soit avec de la gélatine, suivant le procédé Mlartin ${ }^{1}$. L'empreinte ainsi obtenue s'appelle matrice; il suffit d'y couler du métal d'imprimerie pour obtenir une composition aussi nette que la composition primitive.

Dans les dernières années du second Empire parurent les journaux à dix centimes; e'est encore Émile de Girardin qui en fit l'essai, avec sa Liberté. Le Petit Journal, fondé en 1863 par le banquier Moïse Millaud, lut le premier spécimen du journal à un sou, auquel une telle vogue était réservée; il ne tirait alors qu'à 60000 .

La télégraphie électrique assura aux journaux la séduction de la prompte information. Le Figaro, ressuscité en 183 ' par Villemessant, inaugura le reportage et ses indiscrétions : sa rédaction eut douze duels en dix ans, ce qui parut considérable pour l'époque.

Sous la République actuelle, les journaux, affranchis du timbre, du cautionnement, se sont multipliés prodigieusemeut. Il n'y a pas un chef-lieu d'arrondissement en France qui n'en possède un ou plusieurs, et cette puissance nouvelle de la presse de province, disputant ou mème arrachant a la presse parisienne la direction de l'opinion et la prépondérance dans les élections, est un des laits les plus importants de notre temps.

Vers 1837, il n'y avait pas, à Paris, plus de 300 publications périodiques, dont 21 seulement étaient des journaux politiques quotidiens : il n'y ell avait pas plus de 258 en province, dont 153 seulement étaient des journaux politiques, le plus grand nombre d'entre eux nétant point quotidiens. En 1899, il y avait à Paris environ 60 journaux politiques de grand format et une vingtaine de petit format, tirant ensemble à plusieurs millions de numéros par jour. Tel journal du matin, de grand format, dépasse 100000 numéros, et le Petit Journal a depuis longtemps lépassé le million.

1. Celui-ci permet mėme d'amplifier les types, en plaçant le moule dans l'eau chaude, ou il se gonfle, ou de les diminuer, en placant le moule dans l'eau froide, ou il se resserre. 
En province, il y a près de 1700 journaux, quotidiens ou non. Gràce à la télégraphie, mème au téléphone, qui leur permet de donner les nouvelles douze ou vingt-quatre heures avant les journaux de Paris, certains d'entre eux arrivent à un tirage énorme.

Si l'on ajoute aux journaux politiques les périodiques de toute catégorie, pour les sciences, les lettres, les beauxarts, les modes, l'industrie, la pèche, la clıasse, les sports, on arrive à un total de 6736 journaux et revues, dont 2685 d̀ Paris et 4051 dans les départements ${ }^{1}$.

Si l'on y ajoute les livres et brochures dont il s'imprime par all près de 20000 (dont 12000 à Paris), on aura une idèe de l'activité des presses irançaises.

Cette masse prodigieuse de papier imprimé répand dans toutes les classes de la société une infinité d'idées, d'impressions, de notions, de faits.

Il n'est pas un Français, quand il vivrait dans la solitude la plus prolonde, a qui ne parvienne un écho des grandes rumeurs de la presse. Le paysan le plus illettré, dans le hameau le plus reculé, finit par entendre quelque chose de ee qui se dit dans les journaux de Paris et se répercute dans les journaux de province.

La presse est comme l'air que nous respirons : elle est partout, elle nous entoure, elle nous pénètre. Elle nous éclaire et elle nous trouble. A personne elle ne reste étrangìre et indillérente. L'inventeur de l'imprimerie ne pouvait imaginer toute l'expansion que prendrait son idée : au lieu des lourds rolumes du $x v^{e}$ siècle, qui ne s'adressaient qu'aux savants, des livres délicats du xvile siècle, qui ne s'adressaient qu'aux lettrés, des journaux coûteux de la lestauration, qui ne s'adressaient qu'aux citoyens riches. voici des millions de feuilles volantes qui vont s'oflrir à toutes les intelligences et à toutes les bourses, qui chaque matin sortent des imprimeries, se répandent dans les rues, courent sur toutes les routes et que la poste va déposer au seuil de la chaumière la plus lointaine. Ces feuilles expriment toutes les nuances de l'opinion; à certains égards, clles fout l'opinion elle-même. Le journaliste, avec la 
plume et la presse, communique avec des millions die lecteurs, tandis que le plus puissant orateur ne peut parler qu'à quelques centaines ou quelques milliers d'auditeurs; mais les paroles de l'orateur, elles aussi, sont recueillies par la presse, et, si elles n'ont été entendues que par un auditoire restreint, elles arrivent aux lecteurs de la France et du monde entier.

C'est mème cette puissance rle la presse qui l'ait l'impuissance de toutes les mesures de coercition dirigées contre elle; c'est cette puissance de la presse, assurait Emile de Girardin, qui lait son impuissance, car l'impression causée par un journal peut ètre effacée par un antre journal, la fausse nouvelle répandue par celui-là étant démentie par celui-ci. Les pouvoirs publics ne pouvant rieu contre la presse, le journal seul pent combattre le journal. C'est la multitude des journaux qui les empóche de tyranniser lopinion, et qui fait deux, au contraire, les serviteurs de l'opinion. La presse est une force énorme et indomptablc comme celle de l'océan; mais, comme lui, elle troure en elle-mème son équilibre. Elle seule peut réparer les maux qu'elle cause, et Mirabeau la comparait déjà à la lance d'Achille, dont la rouille guérissait les blessures que sa pointe avait faites. Mlais cela, c'est un point de vue peut-être oplimiste.

OUVRages a CONSUlter. - Voir les Historres et les Mémoires sur la Monarchie de Jullet ci-dessus, p. 336. - IIstuires de la Révolution de 15is, par Daniel Sieru (la comtesse d'Agout), A. Delvau (se relaire de Ledru-Rollin), Normanby, Garnier-Pagès, E. Spuller, V. Plère, Pierre de la Gorce; - Mémoires rt Souvenirs de Canssidière, Odilon-Barrot (posthumes), de Tocquerille. - De la Hodde (un espion dans les societes secrètes, 18i8-1850), La naissance de la Repulitique (1850). - Tehernolf, Les associations, cercles et sociste's secrètes sous la beuxiène Ripublique (1905). - L. Blane, La Róvolution de Fevrier au Luxembourg (1870). A. Lucas, Les clubs ot les clubistes (1S51). - Ilistoires iu Coupd'Etat, par Victor Hngis, Grauter de Cassatrate le père, Lurine Ténot, Pascal lutprat, E. Spuller, Belouino; - du Se- cond Empire, par Taxile Delord, P. do lit Gorce; - de la Troisieme Reipublique, par E. Zevort, G. Ilanolaus, S. Denis, (en rours) Andro Daniel, $L$ 'anne politigue: depuis $1 \backslash 73$.

Thirria, Vapolsm III avant l'empire (1595). - Vassy-Beaumont, Ifist. intime du trecond Eimpire (147i). E. Ténort, Les suspects en $1 \$ 58(1-69)$. - E. Oilivier, L'Empire libéral (serie en cours). - II. Birton, Lérolution constitutionnell' du Second Empire (1901). - Darimon, Hist. de douze ans (1557-6.); Histoire ilun parti (les Cinq sous t'Empire): Le Tiers parti sous l'Empire; Les Hrriconcilirbles la sirrie d+ 1883 ar 1486).

Littre, L'etablis smment de la Troisieme hépublifus $188 \%$ - DrupontWhite, La politique actuelle (1)-8. - J. Simon, Le gounornement de 1. Thiers (1575), - Chessiplong, La campagne monarchique d'octobre 1873 
(1895. - E. Daudet, Trois mois ranne, Hist. du gowernement parleWhistoire contemporaine (1873). - mputaire (1857-72) - - Challamel, A. Lambatul, Jules Ferry (1903). Hist. de la libertè en France depuis Nemorres, Sonvenirs ou Corres- 1789 (1886). - Batbie, Droit public pondances de Véron (.Mémoires d'un bourgeois de Paris), Mèrimée. Odilon-Barrot. Proudhon, Viel-Castel, de Mauras. de Falloux. Maussmann, Persiguy, Deuormandie, maréchal Randon, maréchal de Castellane, gènéral du Burall. etc. et alministratif.

Hatin, Hist. de la presse en France (1861 - L Izambard, La presse parisienne de fevrier 1818 a l'Empire (1553). - E. de Girardin, Liberté de la presse et du commerce. - De Villemessint, Mémoires d'un journaliste. Faustin Hèlie, Les Constitutions - Hertor Pessard, Mes petitspapiere, le los France. - Duvergier de $\mathrm{Hau}-$ souvenirs diun journaliste. 


\title{
CIAPITRE XXVI
}

\author{
L'ADMINISTRATION, LA LÉGISLATION, LES FININCES \\ LES CULTES
}

Ladministration avant Isz 1. - Pour notre organisation municipale et départementale, signalons d'abord, après 1848, l'introduction du suffrage universel et la suppression du cens d'élıgribilité dans les élections locales.

A la fin du second Empire, les idées de décentralisation avaient pris faveur dans les partis d'opposition, puis dans le pays : de là, la loi du $1 S$ juillct $1 \$ 66$, sur les conseils généraux, et la loi du 24 juillet 1867 , sur les conseils municipaux : elles augmentèrent notablement les attributions conférées à ces assemblées. La loi du $2 \ddot{3}$ juillet 1870 rendit aux conseils généraux le droit d'étire leur bureau.

Ladministration depuis Isz1. - Sous l'Assemblée nationale, la loi du 18 août 1871, pour assurer un contròle permanent des conseils généraux sur l'administration, disposa que, dans lintervalle des sessions, une commission départementale, composée de quatre à sept membres, nommée par le conseil général, étudierait les affaires et aurait le droit de se laire donner par le préfet et les chef's de service tous les renseignements nécessaires. Les séances des conseils généraux furent rendues publiques. Ils purent se mettre en rapport entre eux pour les allaires intéressant plusieurs départements. Le droit reconnu au chef de l'État de dissoudre les conseils généraux fut limité. Les conseillers généraux et d'arrondisse. ment sont nommés pour six ans et renouvelables par moitié.

Les conseils gènéraux sont donc devenus un organe important dans le système de libre gouvernement. Aucune 
affaire intéressant l'administration départementale ne se décide sans leur participation. La loi de $18 \pi 1$ a résolu le problème dont la première Constituante et Napolion avaient méconnu chacun un élément essentiel. Elle respecte à la fois le droit supérieur de l'État et les libertés locales; sans affaiblir l'action administrative, elle l'a soumise à un sérieux contrôle.

L’organisation municipale a été également amendée dans un sens plus libéral. La loi du 12 aoút 1876 a statué que, dans toutes les communes qui ne seraient pas chelslieux de département, d'arrondissement ou de canton, les maires et les adjoints seraient élus par le conseil municipal; dans les communes chels-lieux, ils seraient nommés par décret du Président de la République.

Cette restriction a été supprimée par la loi du $2 S$ mars 1SS2. Aujourd'hui, tous les maires sont nommés par les conseils municipaux. La ville de Paris n'a pas de mairie centrale; le prélet de la Seine fait, en partie, loflice de maire; elle a un conseil municipal élu, de 80 membres. Les maires et adjoints des vingt arrondissements parisiens, dont les attributions principales sont celles d'officiers de l'étal civil, sont nommés par décret du Président de la République. Ce régrme exceptionnel, spécial à Paris, s'explique moins par le chiffre énorme de sa population que par sa situation privilégiée comme eapitale de la République et comme siège du Parlement et du pouvoir exéeutil.

La loi du 5 avril 1884 a coordonné et, dans un sens trés libéral, complété toute la législation municipale.

da légrislation eontemporaine : droit civil. - Le Sénat républicain, moins absorbé que la Chambre des députés par les péripéties de la politique quotidienne, a pris l'initiative de l'élaboration d'un Code rural, qui coordonnera les usages locaux, encore si difiérents l'un pays à l'autre, et dont la diversité rappelle un peu celle de la législation coutumière dans l'ancienne France.

Par la loi du 27 juillet 1884, votée sur l'initiative du député Naquet, le divorce, aboli en 1816, a été rétabli, avec des garanties et formalités analogues à celles dont l'avait. entouré le Code civil de Napoléon.

La loi du 25 murs 1896 détermina, dans des conditions 
plus libérales, le droit de successibilité des enfants naturels. Celle du 9 mars $1 \$ 91$ accorda au conjoint survivant une part dans la succession du conjoint décédé. Celle du 14 fevrier 1900 augmenta, dans une large mesure, la liberté de donation entre époux.

La naturalisation des étrangers a été rendue plus facile par le decret le $1 \$ 4 \$$ ( 28 mars), les lois du 22 mars et du 3 décembre 1849, la loi du 26 juin $1 \$ 89$, celle du 22 juillet $1893^{1}$.

La mort civile et ses effets ont été abolis par la loide 185.4.

La loi du 22 juillet 1867 a complèté l'ouvre de la loi de 1832 en abolissant totalement la contrainte par corps en matiere civile et commerciale; elle n'a laissé subsister ce mode de coercition que pour le recouvrement des amendes prononcées, au profit de l'État, par les tribunaux.

La loi du 24 juillet 1867 a réglé l'organisation des societés d'industrie, de commerce, de finance.

La loi du 23 janvier 1876 accorde aux femmes, chefs de maisons de commerce ou d'industrie, le droit de voter aux élections pour les tribunaux de commerce.

La loi du 7 decembre 1897 accorle aux femmes le droit d'ètre témoins daus les actes de l'état civil et les actes instrumentaires en général. Un projet de loi, non encore voté, propose d'assurer à la femme mariée le droit de conserver le gain qu'elle aura réalisé par son travail personnel. Entin, les femmes ont été admises à exercer la profession d'avocat (1900).

Droit peinal. - Un décret de 18.48 (6 mars), qui fut,

1. Le décrel de 1848 donnait aux étrangers la faculté de se faire naturaliser après cinq ans de résidence; la loi du 3 décembre 1849 exige dix ans, mais rèduit ce terme à une annèe " en faveur des étrangers quí auront rendu à la France des services importants on qui auront apporté en France soil une industrie, soit des inventions utiles, soit des talents distinqués ou qui auront formé de rrands établissements ". La loi du 29 juín 1867 réduisit à trois ans le dẻlai de dix ans. Toutefois les fernmes et les enfants nés avant le décret de naturalisation n'acquéraient pas, par ee décret, la qualıte de Francais. La loi de 1889 en facilita l'obtention a la femme et aux entants majeurs et l'accorda aux enfants mineurs, sauf le droit d’option qui leur est réservé à leur majorité. La loi de 1893 dispense de tout délai l'individu né en France d'un étranger, pourvu que, dès sa majorité, il déclare vouloit fixer son domicile en France et réclame la qualıté de Français. 
sur ce point, une sorte de revanche de la loi de septembre 1835, exigea une majorité de neuf voix, parmi les douze membres du jury, pour qu'une condamnation pît être prononcée ${ }^{1 .}$ Avec ce décrel, il devenait très difficile d'assurer la répression des crimes de droit commun. $\Lambda$ plus forte raison, à une époque où le jury avait à prononcer sur les délits de presse, il devenait impossible d'obtenir une condamnation contre les journaux. C'est surtout celte dernière considération qui amena l'Assemblée, par la loi de 1848 (18 octobre), à réduire à buil voix la majorité requise. La loi de 18.23 (9 juin), sous le Second Empire, en revint à la simple majorité, celle de sept voix : elle reproduisait les dispositions mèmes de la loi de 1833 et du Code pénal napoléonien.

La loi du 14 juillet $1860 \ddot{~ a ~ r e ́ g l e ́ ~ l e s ~ c o n d i t i o n s ~ d e ~ l a ~}$ inise en liberté provisoire des accusés. La loi du $S$ décembre 1897 statue que, dès son premier interrogatoire par le juge d'instruction, l'accusé ou le prévenu pourra se laire assister par son avocat. En 1899 la même disposition fut étendue à la procédure des conseils de guerre. Les lois du 8 juin 1895 et $f^{\mathrm{er}}$ mars 1899 ont organisé la procédure le revision des procès criminels. Celles du 3 juillet $18 \not \ddot{2}$, 14 août 1885,10 mars 1898 , 5 ant 1899 ont organisé la procédure de réhabilitation pour les condamnés.

La loi du 26 mars 1891 , dite a loi de sursis $\triangleright$ ou \& loi Bérenger $\triangleright$ autorise le juge, en cas de comdamnation it la prison ou à l'amende, si l'inculpé n'a pas subi de condamnalion antérieure, a ordonner qu'il soit sursis à l'application de la peine; au bout de cinq ans, si le condamné u'i pas encouru de nouvelle condamnation, la première sera considérée comme non avenue et mėme effacée de son casier judiciaire. Si, dans ce délai, il en encourt une seconde, les deux condamnations seront également exécutées.

La République de 18 t8 a complété la réforme pénale de 1832 en abolissant, par décrel du Gouvernement provisoire (12 avril), la peine de l'exposition publique ${ }^{2}$, der-

1. C'élait le chifre exigé par la loi de la Constituante (septembre 179I).

2. Considérant que la peine de l'exposition publique dégrade la dignité buma ne, nétrit a jamais le condamné el Jui ôte, par le sentiment de son infanie, la possibililé de la rébabililation; considéraul que eelte feine est 
nier vestige de l'antique pilori, et, dans la Constitution de 1848 , la peine de mort en matière politique.

L'ancien régime avait aboli, en 1748 , les galères, et les avait remplacées par les bagnes. Ceux-ci ont été supprimés par la loi de 1834 (mai-juin), et les condamnés furent soumis à la transportation dans les colonies pénitentiaires, d'abord sous le climat meurtrier de Cayenne, plus tard sous le climat salubre de la Nouvelle-Calédonie.

La loi du 27 mai 1885 a étendu cette peine, sous le nom de relégation, aux recidivistes.

La loi du 15 novembre $1 \$ 92$ décide que la durće de la détention préventive serait comptée dans la durée des peines prononcées. La loi du 4 février 1893 réorganise les prisons destinées à l'exécution des courtes peines.

L'assistance publique : enfants. - La loi du 24 firrier $18 \$ 9$ assure la protection des enfants maltraités ou moralement abandonnés. La loi du 19 aoht $1 \$ 9 S$ est destince à réprimer les violences, voies de faits el actes de cruauté commis envers les enfants.

Les finances. - Les impôts directs n'ont pas été augmentés, au moins en ce qui concerne le principal de ces contributions; car, dans certaines conmunes, les centimes additionnels sont arrivés à égaler, parfois mẻme à dépasser le principal.

Par la loi du 20 février 1849, a été créée une taxe foncière, appelée taxe ou impôt de mainmorte. Elle porte, non seulement sur les biens ecclésiastiques, mais sur ceux des départements, communes, hospices, etc. Elle est destinée à suppléer aux droits de mutation que ces personnes morales n'ont lieu qu'assez rarement d'acquitter. La loi de 1895, connue sous le nom de loi d'accroissement, détermine, d'une manière plus précise et peut-ètre plus rigoureuse, les conditions dans lesquelles devra s'opérer la perception de cette taxe sur les congrégations religieuses.

Comme taxes nouvelles, citons celles qui portent sur les

empreinte d'une odieuse inégalité, en ce qu'elle touche a peine le criminel endurci, tandis qu'elle frappe d'une atteinte irréparable le condamné repentant; considérant enfin que le spectaclo des expositions publiques éteint le sentimeut de la pitié et familiarise avec la vue du crime, - décrète, etc. 
vélocipedes, les automobiles, la taxe militaire sur les conserits qui ne font pas de service militaire ou ne servaient qu'un an (juillet 1889 et 13 avril 1898).

Les augmentations ont porté plutòt sur les contributions indirectes, dont la liste a été souvent modifiée ", ou sur le timbre, qui a été exigé pour des catégories d'actes de plus en plus nombreuses ${ }^{2}$. Depuis 1871 , on a créé un nouveau monopole de l'Etat. celui des allumettes.

Les revenus publies se sont accrus moins par l'augmentation du chiffre de ces imputts que par la plus-value dans leur rendement. Les revenus indirects, en y comprenant le monopole du tabac, le timbre, l'enregistrement, les douanes, les postes et télégraphes, produisent six lois plus que les impôts directs : en 1900, 2976 millions contre 516 .

Depuis 1862, par suite d'une réforme du ministre Fould, on distinguait dansle budget, trois burgets : 10 le budget ordinaire, qui comprend les dépenses courantes; $2 \circ$ le budget extruordinaire, pour les grands travaux publics et pour les imprérus résultánt le la guerre ou de quelque autre entreprise; $3^{\circ}$ le budget sur ressources spéciales, pour les dépenses locales soldées arec les ressources des départements et des communes. Sous la troisième République, le budget extraordinaire a été supprimé au moins en principe.

Le budget des dépenses, qui était en 1815 de 500 millions, dépassait déjà un milliard vers 1830,1500 millions en 1850 , deux milliards en 1860. Il est aujourd'hui d'environ trois milliards et demi. Notre dette nationale, singulièrement accrue par la guerre de 1870-71 et par la contribution de guerre payè à l'Allemagne, est d'environ trente milliards.

L'oranuisation financière. - Dans notre orsanisation financière, il n'y a que peu d'iniovations à relever. En

1. Ainsi, en 157\%, il y eul de nombreus dégrèvements sur les boissons, alcools, sucres, etc. Puis on a dú rétablir ou relever cerlaines laxes supprimées ou diminuėes à celle époque. Des surtaxes ont été imposées sur l'alcool. Une loi de 1899 a introduit le principe d'une réforme compléte des octrois par le dégrèvement des boissons dites hygléniques (vin, bière, cidres, etc.) et par une surtaxe de l'alcool.

2. 11 s'est appliqué, en 1850, aus bordereaux d'agents de change. aux actions et obligations des comprgnies francaises; en 1857. a celles des compagnies étrangères dont les coupons sont payés en France; en 1363 , aux rentes sur les convernements ctranters; en 1855, aux chéques. Une loi de 1871 a etabli le imbre molile pour les quithance el pour les recus. 
1863̆, l'ancien receveur général de lépartement a réuni à ses fonctions celles de payeur général, et a pris le titre de trésorier-payeur général.

Pour le recouvrement des impôts directs, qui s'opère, d'ailleurs, avec une facilité inoüe et une bonne volonté remarquable des populations, on a pu, en 1877 , renoncer à l'emploi des garnisaires.

L'exécution du Concordat. - Comme les gouvernements précélents, la République de 1848 , le second Empire, la République actuelle, n'ont pas cessé d'observer le traité conclu entre Bonaparte et Pie VII : le Président de la République exerce aujourd'hui les mêmes prérogatives que le Premier Consul.

L'État français a continué à traiter avec le souverain pontife comme avec une puissance jusqu'en 190't. Même après que le pape, en 1870 , eut perdu son pouvoir temporel et fut réduit à n'exercer sa souveraineté que sur une faible partie de Rome (le quartier du Vatican), la France entretint un ambassadeur auprès du Saint-Siège et la cour de Rome se lit représenter à Paris par un nonce apostolique ${ }^{1}$. Si le pape n'est plus un monarque temporel, il reste le chef spirituel des catholiques de France et du monde entier.

L'infaillibilité du pape n'a pas toujours èté un article de foi; il était permis aux fidèles de l'accepter ou de la rejeter; l'autorité spirituelle restait partagée entre le souverain pontife et les conciles. Toutelois, il est à remarquer que, depuis le concile de Trente (1545-1563), il ne s'était plus réuni de concile æcuménique. De même que la monarchie royale en France, de 1614 à 1789 , était devenue plus absolue par la suppression, en fait, des États généraux, de méme la monarchie spirituelle, dans le monde catholique,

1. Ce rérime a cessé d'exister en juillet 1904, date á laquelle le gouvernement frantais rompit dipiomatiquement avec le Saint-sige; cette rupture fut bientist suivie de la Siparation des eglises et de l'Etat, faite par la loi du b decembre 1905, qui supprime "Des budgets de l'Etat, des départements et des communes toutes depenses relatives à l'exercice des cultes ", el en attribue la charge, dans chaque commune, à une association qui devra se former sous certines condilions, qui sera contròlée par l'administration des Finances, et faute de laquelle les biens de l'établissement du culto seront attribués aux etablissements communaux d'assistance. 
avait profité de cette longue interruption dans les réunions des assemblées générales de l'Église. Elle ne rencontrait d'obstacle à sa toute-puissance, comme la royauté française elle-mème, que dans les privilèges des corporations ecclésiastiques, notamment dans les libertés de l'Église gallicane ou dans le caractère plus ou moins national des autres Églises. Depuis la Révolution de 1789, lidée de la souveraineté absolue du pape et de son inlaillibilité avait fait son chemin dans les clergés des divers pays, et les Jésuites ne s'étaient plus trouvés, comme jadis, presque seuls à la soutenir. Après un intervalle de plus de trois siècles, un concile ocuménique s'est réuni, en 1870, au Vativan, et, après de vives discussions, en dépit de sérieuses résistances, a consacré l'infaillibilité du pape, c'est-it-dire la concentration en ses mains de toute l'autorité spirituelle. La minorité opposante a dû faire sa soumission. Les privilèges des Eghlises nationales ont été abolis. En France, notamment, un coup mortel a été porté aux “ libertés de l'Église gallicane " et aux principes de 1682.

Depuis longtemps, d'ailleurs, ces doctrines avaient cessé d'être enseignées dans les séminaires, et, malgré les dispositions du Concordat, le gouvernement français parait avoir renoncé à en faire une obligation.

Il a mème renoncé à tout enseignement de la théologie catholique donné au nom de l'Etal, car, en 1886, la Chambre des députés a supprimé la subrention accordée aux facultés de théologie cathulique, et celles-ci, qui, depuis le xul siècle jusqu'à la Révolution et depuis Napoléon Ier jusqu'à nos jours, occupaient la place d'honneur en tète de nos Universités, se sont trouvées par cela même supprimées. Elles ont cessé de faire contrepoids aıx facultés libres de théologie, qui s’inspirent d'un esprit tout autre que celui de 1682 .

Cette transformation de l'ancienne « Église de France, a d'ailleurs coïncidé avec le développement de l'État dans un sens tout à fait laïque.

La Restauration, par ses deux lois sur le sacrilège et sur l'observation du dimanche, el par beaucoup d'autres imesures, avait tendu à rétablir l'ancienne confusion du spirituel et du temporel. La tendance de la société moderne, 
surtout depuis le triomphe de ses idées en juillet 1830, semble, au contraire, opposée à cette confusion. La Rérolution de 1789 a fail du mariage un contrat civil; des lois récentes ont émancipé l'école de toute tutelle ecclésiastiqıe; elles ont prescrit à l'instituteur de se borner à enseigner la science humaine, reservant au ministre du culte le soin d'enseigner les préceptes de la religion. Cette séparation du spirituel et du temporel, c'est la logique mème de notre histoire. Le mot de laicisation est peut-ètre nouveau, mais l'cuvre est ancienne; clle remonte très haut dans le passé, plus haut que Philippe le Bel ou Philippe Auguste, car, dès qu'il y cut un roi dans notre liance, il commença a distinguer entre les droits de sa couronne et les droits de l'Eglise.

Les congrégations. - Rien n'a été changé dans la situation des congrégations autorisées. Quant aux congrégations non autorisèes, aucun gouvernement, mème parmi les plus sympathiques à l'Église catholique, ne leur a restitué expressément ni le droit d'exister, ni surtout celui l'enseigner : la loi mème de 1850 sur la liberté de l'enseignement n'a pu les lavoriser qu'en évitant de les nommer.

Le gouvernement de Napoléon III, qui avait prolité, à ses débuts, de l'alliance du clergé, a suivi à l'ècrard de ces congrégations les mèmes principes que la monarchie absolue ${ }^{1}$ ou la monarchie parlementaire. Plusieurs fois, des ciablissements tenus par ces congrégations furent par lui lermés ?.

Les décrets du 29 mars 1880 ont renouvele les dispositions de toute la législation antérjeure.

Le premier de ces décrets enjoignait à la comparanie de Jésus de se dissoudre dans les trois mois; le second enjoignait aux autres congrégations non autorisées de se mettre, dans le méme délai, en mesure d'obtenir l'autorisation. Les trois mois passèrent, et les maisons des jésuites furent fermées, mème par la force, dans toute la France. Un nouveau delai avait été accordé aux autres congrégations

1. Voyez Histoire de la Civilisation française, tome II, page 51-j2.

2. En 1861 furent supprimés les eapucins d'Ilazebrouck, les rédemptoretes de Douai, Arras, Boulogne. En 1553, le collège des Jésuites de Montaud iul fermé. En 1500 , on interdit l'ouverture de eollèges de jesuiles a Bresl, au Mans, etc. 
pour donner satisfaction à la loi : ce nouveau délai écoulé, leurs maisons furent également fermées.

Quant aux congrégations de femmes, même non autorisées, elles n'ont point été inquiétées.

On peut affirmer que les ordres monastiques jouissent, en France, d'une liberté plus grande que dans la plupart des pays catholiques. Les religieux des deux sexes sont plus nombreux qu'avant la Revolution, et la fortune des communautés, reconstituée par les libéralités des particuliers, est redevenue considérable. En 1880, les congrégations d'hommes non autorisées comptaient $7500 \mathrm{mem}-$ bres, dont 1500 jésuites; les congrégations d'hommes autorisées comptaient plus de 22000 membres. Les congrégations de femmes non autorisées renfermaient 100000 religieuses : celles qui étaient autorisées en comprenaient environ $114000^{1}$.

Les cultes non catholiques. - Aujourd'hui, comme dans la première moitié du siècle, le catholicisme, le protestantisme, dans ses deux conlessions d'Augsbourg et de Genève, le judaïsme, sont, en France, les seuls cultes reconnus par l'État. Nous ne parlons pas de l'islamisme, du l,rahmanisme, du bouddhisme, ete., professés par les indigènes de nos colonies.

La France est, de toutes les nations européennes, celle qui a la première et le plus complètement accordé aux juifs l'égalité civile et politique. Elle les a même protégés au dehors. Par le décret du 24 octobre 1870 , elle accordait à ceux d'Algérie les droits électoraux : ce qui, d'ailleurs, contribua a provoquer la grande insurrection musulmane de 1871. Au congrès de Berlin, en 1878, elle a lait garantir par l'Europe entière la liberté de conscience à ceux de Roumanie, de Serbie, de Bulgarie. Elle est le siege d'une puissante association, l'Alliance israélite, qui, dans tout l'univers, protège les juifs. L'émancipation des israélites a

1. Cut étal de choses a cessé. La loi du for juillet 1909 relative au contrat dassociation obligea les congrégations religieuses non autorisées à faire dans les trois mois les démarehes pour l'ètre; ses conséquences furent. la suppresion de nombreases congregrtions dhommes et de femmes, et la ferueture de la jlupart des etablissement. La loi du 8 juillet 100 interdit aux congrérations toute espèe d'enseignement. 
commencé en France, et c'est par la France qu'elle s'est surtout poursuivie dans le monde entier.

Les cultes non reconnus ne recoivent pas de subvention, mais ils sont libres. Pour leurs assemblées, ils doivent se soumettre aux lois qui réglementent le droit d'association et de réunion. C'est sous ce régime que vivent six à sept mille anabaptistes dans nos provinces de l'Est, ainsi que d'autres communautés protestantes assez récemment fondées. L'Armée du Salut, association de protestants anglais, a pu, récemment, tenir chez nous ses assemblées avec une liberté qu'clle n'a pas rencontrée même en Suisse.

Ouvrages a consulter. - Voir du Vatican(1872). - E. de Pressense, la bibliogr. du chapitre xvi, p. 354 . Le concile du Tatican (1872). - M IT - C. du Puynode, L'administration des finances en is48-49 $(1819)$. De Nervo, Les finances de la France de 1850 a $1860(1801)$.

A. Dehiduar, Les rapports de l'Eglise et lEtaten France (1898). - Em. Ollivier, L'Eylise et l'Etat an concile du Vaticun 1879. - II tuet, La róno-

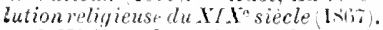
Maret, Du concile gpinéral et de la

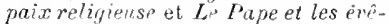
ques (1569). - J. Zeller, Pie I.I et Victor-Emmanuel (1:79.- L. Teste, Leon rill et le Vatican 1898 .Bonet-Ilaury, Hist. de la liberte de conscience en France... jusqu'a 1870 (1900). - A. Rambaul, Jules Ferry $1903)$.

- J. Wallon, La vérité sur le concile 


\section{CIIAPITRE XXVII}

LE DFOIT DES GENS, L'ARMÉE, LA MARINE, LES COLONiES

\section{Le droit des gens.}

Les nationalités. - La Révolution de 1848 , à Paris, eut pour contre-coup des révolutions dans tous les autres pays de l'Europe. Ces mouvements eurent un caractère à la fois liberal et national : ils tendaient $\dot{a}$ arracher aux princes des constitutions, mais aussi à constituer des agrglomérations nationales indépendantes. En Allemagne, Prussiens, Autrichiens, Hessois, Bavarris, exigeaient des constituiions plus libres, mais ils entendaient, en outre, fonder l'unité allemande. Les différents peuples italiens demandaient des garanties constitutionnelles, mais tous s'accordaient pour réclamer l'unité italienne. Les Hongrois et les Slaves de l'empire autrichien s'armaient pour la liberté, mais aussi pour la nationalité hongroise, tchéque ou illyrienne.

La question des nationalités fut alors chez nous à l'ordre du jour; des réfugiés de tous les pays accouraient sur notre terriloire pour se former en bandes armées et implorer le secours de la démocratie française; dans nos manifestations populaires, on promenait les drapeaux polonais, allemand, italien. Le Gouvernement provisoire de 18 is imita la circonspection de la royauté orléaniste à laquelle il succédait. Lamartine, chargé de la direction des affaires exterseures, fit une circulaire rassurante pour l'Ẹurope.

A la fin. le roi de Prusse, l'empereur d'Autriche, les princes allemands, avec le concours moral ou armé de l'empereur de Russie, parvinrent à comprimer dans leurs 
États tous les soulèvements. Louis-Napoléon et l'Assemblée législative, par l'expédition de Rome (18ł9), contribuèrent à dompter la révolution italienne. L'Allemagne retomba dans son impuissance, l'Italie dans son morcellement, la Hongrie et les autres peuples dans leur servitude.

Cependant les idées qu'avait suscitées la Révolution de 18 '8 ne périrent pas. Ce fut Louis-Napoléon lui-même, devenu empereur des Français, qui, par une politique aventureuse et incertaine, tour à tour favorisant et entravant l'unité italienne et l'unité allemande, en hâtá la formation. Par lui, ou malgré lui, elles se réalisèrent. La puissance de la France en fut atteinte d'abord indirectement, puis directement. Non seulement notre pays rit s'élever sur ses frontières, au lieu d'une Italie morcelée, d'une Allemagne divisée et nécessairement pacifique, deux puissantes monarchies militaires, mais la plus redoutable des deux, en 1870-1871, envahit la France et nous enleva l'Alsace et le nord de la Lorraine.

Le principe des nationalités, avec moins de dommage pour nous, a triomphé en d'autres pays. Dans l'empire autrichien, les Hongrois, les Tchéques, les Illyriens, les Polonais, ont fini par conquérir une certaine autonomie sous le sceptre de François-Joseph. Dans l'empire turc, par les armes ou la diplomatie de la Russie et de la France, les Roumains et les Serbes ont pu former des royaumes indépendants; le Monténégro est absolument libre; la Bulgarie forme une principauté autonome. Si l'on ajoute à ces peuples la Grèce, émancipée en 1828, la Belgique après 1830, les États de l'Amérique du Centre et du Sud, alliranchis, dès le début du xixe siècle, de la domination espagnole ou portugaise, on voit qu'en notre siecle une vingtaine de peuples sont arrivés á constituer des nations libres. Latlentat qui, au $x$ vil $^{\circ}$ siècle, a mis fin à l'existence de la Pologne, ne s'est pas renouvelé ${ }^{1}$ : beaucoup de peuples sont nés, aucun n'a péri de mort violente. Il faut constater, sur ce point, un certain progrès du droit des gens.

1. Cependant il est permis d'assimiler à ce crime la guerre de conquèto diricé par l'Angleterre contre les deux républiques bollandaises le l'Afrique Austrule (1899-1901). 
Drojt des peuples à disposer d'eux-mêmes. - Mème sous le second Empire, la France a soutenu cette thèse qu'on ne peut disposer des peuples malgré eux. Quand Napoléon 111 se fit céder Nice et la Savoie, il ne prononça leur annexion à la France qu'après avoir demandè, par la voie d'un plébiscite, le consentement des populations. Par ses conseils et sous son influence, le roi de Sardaigne n’a réuni en un royaume les peuples italiens quaprès avoir obtenu leur adhésion par un vote solennel. La Prusse n’a pas daigné ou n'a pas osé agir de mème quand elle annexait à l'Allemagne l'Alsace et la Lorraine en vertu du droit de conquéte.

La France, victime elle-mème de cette politique de conquète. et qui a lait du respect du droit des peuples à disposer d'eux-mimes un principe de sa politique, apparut plus que jamais, dans le monde entier, comme le champion du droit et de la justice internationale.

congrès. conférences, arbitrages, neutralisations. - Depuis 18'8, on a eu recour's plus fréquemment qu'autrefois, en grande partie sous l'inlluence de la France, à la pratique des congrès.

En 1856, quand la Russie vaincue refusait encore de plier devant l'Aogleterre et la France victorieuses. Je Congrès de Paris lui a fait admettre, arec l'autorité de l'Europe assem. blée, un état de choses que les vainqueurs n’auraient sans doute pas réussi à lui laire accepter saus une prolongation des hostilités. En 1867, quand la France et la Prusse furent sur le point de se déclarer la guerre à propos du Luxembour. la Confércnce le Londres amena chacune des deux parties aux concessions qui permirent de retarder la collision. En 1878, quand l'Autriche et l’Angleterre. coalisées contre la Russie, se préparaient à lui arracher le fruit de ses victoires sur les Turcs, lEurope intervint encore au Congrès de Berlin et obtint d Alexandre Il les sacrifices nécessaires au maintien de la paix. La Conférence de Berlin, en 1855, a posé de nouveaux principes de droit colonial et a partagé diplomatiquement, entre la France, le Portugal et l'Association internationale africaine (dont les droits ont passe au roi des Belges), la plus vaste région de l'Afrique centrale, cet immense Congo, dont personne ne connaissait 
encore les limites exactes. Le conflit soulevé entre l'Allemagne et l'Espagne à propos des îles Carolines a pris fin, sans effusion de sang, par l'arbitrage du pape Léon XIII. Des litiges qui s'étaient élevés entre la France et la Hollande, entre la France et le Brésil, à propos de leur délimitation en Guyane, le premier a été réglé par l'arbitrage du tsar Mlexandre III (1891), le second a été terminé, mais tout à notre désavantage, par l'arbitrage du président de la République hel sétique (1er décembre 1900). La guerre entre le Japon et la Chine a été abrégée par l'intervention concertée de la France, de la Russie et de l'Allemagne (1895). Des conflits aussi redoutables que ceux dont menaçaient la paix européenne, l'insurrection de la Crète et la guerre turco-russe ont été résolus grâce à l'action du a concert européen $\circ(1897)$.

Toutefois ce concert n'a pu ou voulu agir, ni lors des massacres d'Arménie (1894-1896), ni dans la guerre entre les États-Unis et l'Espagne, qui a perdu toutes ses colonies (1898), ni lors de l'agression anglaise contre les deux républiques de l'Afrique australe (1899-1901).

La neutralisation de la Suisse par le congrès de 1815, celle de la Belgique en 1839 constituaient des précédents qui n'étaient pas à négliger. En 1878 on a neutralisé le Danube qui, autrement, aurait pu ètre sillonné par les llottilles rivales de l'Autriche, de la Russie, de la Turquie, de la Roumanie, de la Serbie. En 1887, on a neutralisé le canal de Suez, que l'Europe entend maintenir ouvert à la marine de toutes les nations. Pendant et depuis la guerre de 1870-71, n'a-t.on pas rêvé de eréer, entre la France et l'Allemagne, une zone continue d'États neutres qui eutt rendu presque impossible le redoutable contact de leurs forces militaires?

Le droit des gens pendant la guerre. - Le traité de Paris, en 1856, a interdit la course; sans doute, les navires marchands des puissances belligérantes peuvent être encore saisis, mais ils ne peuvent l'être que par la marine de guerre, et non plus par des corsaires ${ }^{1}$. La Convention de

1. Deux puissnnces maritimes seulement, l'Esparne et les États-Unis, n'ont pas adbéré à l'abolition de la course. Au reste cette abolition est 
Genève, en 1864, à laquelle ont adhéré toutes les nations civilisées, prescrit que le personnel de santé militaire ne sera jamais traité comme prisonnier de guerre, qu'on no tirera ni sur les ambulances ni sur le matériel protégé par la croix rouge, qu'aucune distinction ne sera laite dans la manière de soigner les blessés. Elle stipule que tout blessé recueilli et soigné dans une maison lui servira de sauvegarde et que cette maison sera exempte des logrements militaires et des contributions de guerre.

D'autres résolutions, dont les plus importantes sont celles de la Conference de Bruxelles de 187\%, ont proscrit l'usage des engins qui infligent aux soldats qui en sont atteints des souffrances inutiles : elles tendent à prohiber l'emploi des balles explosibles, ainsi que les boulets à chaines ou boulets ramés; elles défendent d'empoisonner les projectiles, les puits, les fontaines, les provisions de bouche. Les almées en pays ennemi sont tenues de ne pas détruire inutitement la propriété privée, de respecter les habitants inoffensil's ${ }^{1}$, de ne réquisitionner que les objets nécessaires à leur subsistance, et, en ce cas, de délivrer des reçus qui permettront au réquisitionné de se faire indemniser par les puissances belligérantes.

L'alliance conclue entre la France et la Russie, maintenue et proclanée par les empereurs Alexandre IIl et Nicolas II, créa un puissant contrepoids à la Triple-Alliance (Allemagne, Autriche, Italie). Elle a contribué certainement au maintien de la paix rénérale. Nicolas II, hẻritier d'un empire à tradilions guerriores et conquérantes, s'est révélé, comme son père, résolûment pacifique. Le 24 aoùt 1898 , il signait une circulaire aux représentants de la Russie auprès des cabinets ètrangers, à l'effet l'obtenir de ceux-ci la réunion d'une conférence internationale, où l'on aviserait aux moyens l’assurer le maintien de la paix générale, de réduire, s'il se pouvait, "les armements excessifs qui

tout a l'avantage de la Grande-Bretagne, don la marine de guerre, si formidable qu'elle soit, serait impuissanle à protéger contre l'audace des corsaires les 35000 navires marchands qui sillonnenl les mers et les océans.

1. Plus d'une fois le bombardement avait frappé la population civile des places assiégées. Dans la dernière guerre, les Prussiens ont enlevé des otages dans nos villes, soil peur les fairo menter sur les locomotives, soil pour repondre des dommages causés par notre marine de guerre. 
pèsent sur toutes les nations s, qui “ atteignent la prospérité publique dans sa source ", détournent de leur application normale " les forces intellectuelles et physiques des peuples ". Cetle circulaire reçut des États les plus faibles un accueil enthousiaste; il en lut de mème en Autriche et en Italie; l'Angleterre et l'Allemagne se refusaient à tout désarmement; la France, tout en formulant quelques réserves, commandées par les dangers de sa situation, se prèta de meilleure gràce à l'examen des propositions du tsar. Celui-ci, tenant compte d'objections sérieuses et légitimes, précisa ses vues dans une nouvelle circulaire (11 janvier 1899), où il assignait à la conférence la tàclıe d'étudier les moyens de mettre un terme à l'accroissement progressif des armements de lerre et de mer; d'interdire l'emploi de certains engins ou de certaines substances par trop destruciives; d'étendre aux guerres maritimes les stipulations de la convention de Genève; de donner plus d'antorité aux déclarations de Bruxelles concernant les lois et coutumes de la guerre; de prévenir les conllits armés par tons les moyens paciliques dont peut disposer la diplo. matie. 11 fut alors décidé que la confúrence se réunirait a La Haye. Vingt-six Etats s'y firent représenter'. Sur la réduction des armements et budgets militaires, l'accord ne put se faire: on dut se borner à énoncer le prineipe qu'elle était " grandement désirable ". On fut d'accord pour proscrire l'emploi à la gruerre des balles explusives, des projectiles à gaz asphyxiants ou délétères, et, pour une durée de cinq ans, à interdire de lancer du haut de ballons des projectiles ou des explosifs. L'Angleterre relusa de renoncer à l'emploi des balles dum-dum. L,es stipulations de Genève furent étendues à la guerre maritime : des navires portant la croix de Genève étaient autorisés à intervenir dans les hatailles navales pour recueillir les blessés, les naufragés et les malades. L’Angleterre fit opposition a ce que les déclarations de Bruxelles, tendant

1. Les six grandes puissances : Allemarne, Antriche-Hongrie, France, Grande-Brelagne, Italie, Russie. - États secondaires de l'Europe : Belqique. Bulgarie, Danemark, Espagne, Grèce, Hollande, La embourg, Monténegro, Portugal, Roumanie, Serbie, Suẻde et Norvège, Suisse, Turquie. - En Amérique : Élats-Unis, Mexique. - En Asie : Chine, Japon, Siam, Perse. 
à protéger les villes ouvertes, les propriétés privées et les lignes ou càbles télégraphiques, fussent étendues aux guerres maritimes. La condition des prisonniers de guerre fut améliorée. Enfin il fut convenu qu'une Cour permanente d'arbitrage serait établie à la Haye et qu'en cas de conflit armé les puissances neutres seraient toujours autorisées à offrir leur médiation, sans qu'une telle démarche pût jamais être considérée par les belligérants comme un acte "peu amical ". Ces conventions, approuvées le 29 juillet 1899 par la conférence plénière, réalisaient, à léfaut de ce que les amis de la paix avaient pu espérer, un progrès très sensible dans le droit international. On recommande l'usage des Conventions d'arbitrage et des Commissions internationales denquétes (comme celle qui réglera l'incident anglo-russe de Ilull) (Voir Suppl.).

La diplomatie. - Il n'y a plus aucun État emropéen on les affaires étrangères soient conduites, comme autrefois, par la volonté des souverains et des ministres et sans ancune participation directe les peuples. Même en Prusse, en Russie, en Turquie, où la volonté du prince est restée prépondérante, les anciennes affities du roi sont devenues les affaires de la mution. Elles sont discutées au grand jour, par l'opinion, par la presse, par les assemblees. La diplomatie a cessé, chez les pemples lihres, d'ètre uniquement cette - ouvre de secret, de ruse, le duplicité, l'espionnage, que flétrissait Beaumarchais. En mème temps, elles'est déponillée de ce quil y arait d'excessil dans la pompe et la représentation d'autrefois; il n'y a plus de ces lours royages en grand appareil, de ces réceptions au son des cloches et du canon, de ces cérémonies théitrales, de ces éternels contlits de préséance. Les titres des aucents sont moins imposants; la France r'en entretient plus que neuf portant le titre d'ambussacleurs; ses autres représcntants a l'atranger se contentent du titre de ministres plénipotentiaires ${ }^{1}$. Les ÉtatsUnis d'Amérique, qui avaient donné l'exemple de ne se faire representer amprès des cours les phus importantes que par le simples ministres, y ont maintenant des ambas-

1. Nons avms encore des ambassadeurs à Londres, at Berlin, à Vienne, a Sant-Prtershourg, à Constantinople, a Madrio, a Washington, a Rome, aupres du roi d'trile. En mémoire des antiques relalion a avee la suisse, notre replésentant a Berne porte également le titre dambasadeur. 
sadeurs. Le personnel diplomatique, si nombreux autrefois, a diminué, surtout par l'unification de l'Allemagne ${ }^{1}$ et de l'Italie, et quoique des États nouveaux soient nés dans les deux Amériques et dans la péninsule des Balkans.

On ne saurait méconnaitre les services qu'est appelée a rendre la diplomatie ainsi transformée: elle dojt ètre l'habileté, la raison, le raisonnement, mis au service du droit et prévenant l'emploi de l'ultima rutio, qui est le canon.

Situation de la Franee en Europe. - La France, malgré la perte de l'Alsace et de la Lorraine, a un territoire plus étendu qu'à l'époque de Louis XIV, une population double de nombre, des linances infiniment plus prospères, une armee et une llotte intiniment plus redoutables. Sa puissance absolue est done incontestablement plus grande; mais sa puissance relative est beaucoup plus laible. Au temps de Louis XIY, il n'y avait que trois grands Etats européens : la France, l'Angleterre, lidutriche avec le Saint-Empire; ils avaient ensemble une population de 50 millions d'åmes, dont 18 millions pour la France : la France possédait, à elle seule, 36 pour 100 de toutes les forces européennes.

En Europe, il y a aujourd'hui six mands Etats : la France, la Russie, l'Allemagne, l'Antrletere, l'AutricheHongrie, l'Italie, avec une population totale de 292 millions d'âmes, sur lesquelles la France en possède 38 millions $1 / 2$; elle ne compte donc plus aujourdhui que lans la proportion de 1'́ pour 100. La proportion serait encore plus faible si, aux 33 ou 40 millions d'habitants de nos colonies on oppose les 300 millions qui peuplent les colo nies anglaises. Entin il faut laire entrer en linue de compte la population et la puissance militaire des Sitats-Unis (63 millions d'habitants).

Autant il était facile à Louis XIV de braver une coalition génèrale, autant eela nous serait aujourd'lui impossible, et ce serait d'ailleurs impossible pour chacune des autres puissances. Elles sont donc obligées d'avoir plus d'égards qu'autrefois les unes pour les autres. L'énormité mème

1. Le seul des États secondaires de l'Allemagne auprès duquel nous entretenione encore un chargé d'affaires, e'est la Bavière. 
des forces accumulées par elles doit devenir une garantie de la paix.

\section{L’armée.}

La garde nationale et l'armée après 1848. - La Révolution de février n'apporta aucune innovation dans l'armée. Dans la garde nationale, tous les officiers, mème les olficiers supérieurs, furent nommés à l'élection. Comme l'uniforme avait cessé, en fait, d'ètre obligatoire, les ouvriers y entrèrent en grand nombre ct en changèrent l'esprit.

La plupart n'avaient que l'équipement fourni par le gouvernement, c'est-à-dire le fusil, le sabre, la giberne et les buflleteries, mais pas d'uniforme; ceux des campagnes marchaient en blouse et en sabots. Les compagnies délite furent abolies : ce qui donna lieu, le 19 mars 18t8, à la protestation connue sous le nom de "manifestation des bonnets ì poil $\$$.

Le Gouvernement provisoire avait formé une garde nationale mobile, forte d'environ 900010 hommes, recrulée, par voie d'entólements volontaires, tans la jeunesse des classes ouvrières de Paris. On voulait constituer une force au service de l'ordre avee des eléments qui auraient pu tourner au désordre. Les gardes mobiles touchaient une payo de trente sous par jour. Aux journèes de juin, ce corps avait donné quelques inquiétudes, mais il fit tẻte à l'émeute; les gardes mobiles montrèrent même contre les insurgés une animosité qui les fit traiter par ceux-ci de "bouchers de Cavaignac ๖. En janvier 18\$9, on commença à dissoudre cette milice.

\section{La grarde nationale et lammée sons le second Empire.} - L'Assemblèe législative et le nouveau Président crurent devoir prendre celtaines précautions contre la garde nationale. Le 26 juin 183̋, un décrel de l'Assemblée la réorganisa, dans les départements, par communes; les communes ne pouvaient former des bataillous cantonaux que par décret du Président. Paris était organisé par arrondissements, et il était interdit aux arrondissements de se concerter entre eux. Le Président obtenait le droit de sus. pendre ou méme de dissoudre tous ces corps. 
Après le coup d'État, la garde nationale reçut une organisation conforme à un régime d'arbitraire. Elle ne fut maintenue que dans certaines villes; les préfets veillèrent avec soin à sa composition; l'uniforme redevint olligatoire, donc les classes ouvrières en furent exclues : tous les officiers furent nommés par le gouvernement. Il n'y eut plus de legions, mais seulement des bataillons, sans aucune relation entre eux. La garde nationale ne fut plus qu'une milice sédentaire, un corps de parade. Elle n'eut aucune influence politique.

Napoléon III, comme son oncle, constitua une garde impériale. Remarquons que l'existence de ces corps d'élite présente des inconvénients : ils excitent la jalousie du reste de l'armée; ils enlèvent aux régiments de lịne leurs meilleurs soldats et leurs tètes de colonnes.

La loi de 1832 continuait à fonctionner; mais, par la loi de 18.55, dite loi de dotation de l'armie, le remplacement direct fut interdit, excepté entre parents jusqu’au sixième degré. Les conscrits qui voulaient se faire exonerer du service devaient payer une somme déterminée, au lieu de fournir un remplaçant. Par la ils ètaient affranchis des responsabilités qui résultaient pour eux de la désertion de leur remplaçant ou de sa mauvaise conduite sous les drapeaux. Ou cessa d'employer cette expression a acheter un homme s, et l'industrie des marchands d'hommes, qui constituait une sorte de \& traite des blancs s, fut supprimée Les fonds versés par les exonérés formèrent la cuisse de la dotution de l'armíe. L'État devait les consacrer au rengagement des anciens soldats; mais le nombre des exonèrés dépassait celui des rengagés; le gouvernement employait à d'autres serrices les fonds de la caisse de dotation; les effectifs de l'armée s'abaissìrent notablement.

La faculté de s'exonérer à prix d'argent, en éloignant de l'armée les conscrits des classes bourgeoises et lettrées, tendait à abaisser son nirean intellectuel. L'argent mettait une inégalité choquante dans l'accomplissement d'un devoir sacré : les uns étant retenus au service par leur pauvreté, tandis que les autres se trouvaient assez riches pour envoyer quelqu'un se faire tuer à leur place. Les classes supérieures perdaient le gout de la profession militaire. 
L'armée formait, dans la nation, comme un corps à part. Ce système était d'autant plus choquant que la Prusse pratiquait, depuis 1808, le service militaire obligatoire pour tous les citoyens. Cela constituait pour nous une grosse inlériorité, car la Prusse pouvait disposer à un certain moment d'immenses contingents, tandis que l'armée française était toujours réduite à environ 300000 hommes.

La victoire de la Prusse sur l'Autriche, à Sadova (1866), donna enfin l'alarme. Le maréchal NIEL rédigea, en 1867, un projet de loi militaire dont l'adoption eùt sauvé le pays d'un danger dès lors imminent. Au lieu de n'appeler chaque année qu'une partie du contingent, laquelle devait servir sept ans, il proposait d'appeler la totalité de la classe. Cette classe eit été divisée en deux portions par la voie du tirage au sort : la première portion aurait servi cinq années dans l'armée active et quatre années dans la réserve; la seconde aurait servi qnatre années dans la réserve et cinq années dans la garde nutionale mobile. Des facilités étaient accordées pour se faire exonérer, soit de l'armée active, soit de la réserve, mais tout Français était tenu de servir au moins dans la garde mobile. Ce projet aurait porté l'armée française, sur le pied de guerre, à 800000 hommes, chitlre à peu près égal à celui de l'armée allemande.

Le Corps législatif, quoique recruté par la candiłature olficielle, n'osa braver l'impopularité qu'aurait pu lui laire encourir l'adoption de cette mesure de salut.

Par la loi de 1868, il réduisit le projet de Niel. Il persista à n'appeler au service actif qu'une portion du contingent, dispensa la seconde portion du service de la réserve et ne lui demanda que le service de la garde mobile. Dès lors, le chiffre total de notre armée ne pourait s'elever qu'à 540000 hommes. Elle se composait de deux parties tout à fait étrangères l'une à l'autre : une armée artive et une yarde mobile. Ajoutez à cela une garde nationale qu'on se proposait d'appeler à l'occasion, mais qui n'etait pas organisée, même sur le papier.

Encore cette loi ne fut-elle pas exécutée. On se contenta de nommer les offieiers de la mobile; on ne fit rien pour exercer leurs hommes. Quand la guerre survint, l'armée 
active fut écrasée par la supériorité du nombre. Elle fut prise presque tout entière, comme en deux coups de filets. à Sedan et à Melz. Puis les pauvres moblots, appelés en toute hâte, n'ayant ni instruction, ni uniformes, ni armes perfectionnées, ni confiance dans des ofliciers qu'ils ne connaissaient pas et qui n'étaient guère plus aguerris que leurs soldals, se trouvèrent, en lace de l'armée et même de la réserve prussiennes, dans des conditions désastreuses d'inlériorité. Quant à la garde nationale, reconstituée, elle anssi a la hâte, elle ne pul rendre que bien peu de services, sauf pour la délense de Paris et de quelques lorteresses.

cammée sons le régrme actuel. - La leçon nous coùtait cher; elle ne lut pas perduc. Un des premiers soins de l'Assemblée nationale lut de réorganiser l'armée.

La garde nationale, qui, depuis 1789 , s'était maintenue sous tous les régimes, mais qui, à Paris, avait été compromise en partie dans l'insurrection de la Commune, fut délinitivement abolie le 25 auth 1871 .

La loi du 27 juillet $\mathbf{1 8 7 2}$, complétée par de nom. breuses lois, dont les plus importantes sont celles des $1^{\text {er }}$ et 15 juillet 1889 et 21 mars 1905, établit le service obligatoire et unicersel. Tout Francais de vingt à quarante-cing ans doit le service militaire personnel. Nos forces comprement : l'armée actixe, la réserve de l'armée active, l'arméc territoriale, la reserve de l'armée territoriale.

Par la loi de 1872, personne n'était exempté que pour infirmité grave le rendant impropre an service. Le rempla. crment était supprimé. La première portion passait cinq ans sous les drapeaux; la deuxième, déterminée par tirage au sort, en raison de l'impossibilité fimancière l’incorporer pour cinq ans tous les citoyens valides, n’y passait qu'uu an. Les hommes non infirmes, mais de trop petite taille ou peu robustes, étaient classés dans les services auxiliaires.

D’autre part, la loi accordait dispense de tout service er temps de puix à certaines categories de jeunes gens : chefs de famille, soutiens de famille, jeunes grens qui s'engagent à rester pendant un temps déterminé dans les carrières qu’il importe à l'État de leur voir suivre. La loi instituait l'engagement conditionnel ou volontariut. II permettait aux jeunes gens pourvus de certains diplomes ou capables 
de satisfaire aux épreuves d'un examen, de se libérer en un an, mojennant le versement de 1500 rancs a liEtat, des obligations imposées en temps de paix par la loi militaire.

Tous les lommes du contingent, soldats de cinq ans, un an, conditionnels et dispensés devaient le service en cas de guerre de vingt it quarante ans. ils conslituaient, en lehors de l'armée active, une série de réserves : réserve de l'armée active, armée territoriale et réserve de l'armée territoriale. Les hommes de la réserve de l'armée active étaient astreints à deux périodes de vingr-lruit jours; ceux de l'armée territoriale à une période de treize jours.

La loi de $18 \$ 9$ consacrait l'obligution du semice persomnel.

La durée du service en temps de paix était ramenée de cinq ans à trois ans : cette durée s’appliquait au contingent entier, le volontariat était supprimé.

Néanmoins, la loi accordait des dispen-es partielles qu'on peut diviser en deux catigories: $1^{\circ}$ les dispenses au protit des familles; $2^{2}$ les dispenses au profit de ta société.

Elte laisait, en outre, une situation spéciale aux élèves de certaines écoles et créait une taxe militaire, à laquelle élaient assujettis tous ceux qui, pour une eause quelconque, bénéficiaient de tout ou partie de l'exonération du service militaire. Elle incorporait également les individus qui étaient exclus autrefois comme indignes.

La foi prolongeait jusqu'à quarante-cinq ans lobliıation du service en temps de gnerre. La durée du service était donc le vingt-cing ans : trois ans dans l'armée active, dix ans dans la réserve, six ans dans l'armée territoriale et six ans dans la réserve de l'armée territoriale; les lommes le la réserve de l'armée active étaient astreints à leux périodes de vingt-huit jours; les hommes de l'armée territoriale à une période de treize jours.

Comme dans la loi de 1872 , les hommes peu robustes étaient classés dans les services auxiliaires; ils ctaient assujettis à cinq appels.

La loi de 1905 est l'application intégrale di service personnel, obligutoire et égal pour tous.

La lurée du service en temps de paix est ramenée de trois ans à deux ans. 
Hors le cas d'incapaciti physique, le service ne comporle aucune dispense des deux années de service dans l'armie active. Des sursis peuvent ètre accordés, pour lincorporation, jusqu'à vingt-cing ans. Les pères de quatre enlants peuvent ètre dispensés d'accomplir les deux périodes de vingt-huit jours daus la réserve de l'arméc active; ceux de six enfants, la période de treize jours dans l'armée territoriale. La durée du service demeure de vingt-cing années.

La loi de 1903 a eu pour conséquence d'abaisser le chiffre de l'effectif actif; on espère combler le déficit avec des rengagés $(80000)$.

La France, au point de vue militaire, était naguere divisée en dix-huit régions; c'était l'Algérie qui tormait la dixneuvième. En 1896 , la $6^{\mathrm{e}}$ région (nord-est) a été subdivisée en $6^{\mathrm{e}} \mathrm{et}$ en $6^{\mathrm{e}}$ bis, qui a pris ensuite lo $11^{\circ} \geqslant 0$. Chacune d'elles est occupée par un corps l'armie. Les regiments de l'armie active, au moment de la mobilisation, sont completés surle pied de guerre au moyen de réscrvistes domiciliés dans la région. L'armée territoriale, avec sa réserve, forme comme une seconde armée, également divisée en régiments arec ses olficiers et ses cadres à elle. Sa principale mission est de délendre les places fortes, les cotes, les lignes stratégiques: elle peut aussi ètre appelée á combattre en rase cantpagne ${ }^{1}$. Ses régiments sont lormés uniquement d'hommes qui sont aussi du pays. Les soldats appeles sous les drapeaus riont plus besoin de courir d'un bout a l'autre de la France: cest dans la region mème quils habitent que se trouve le régiment auquel ils doivent s̈incurporer.

Sur le pied de paix, la force totale le notre armée est de 550000 hommes; sur le pied de gucrre, avec l'arnée territoriale et sa réserve, nos forces peuvent s'élever à 4350000 hommes : c'est-it-dire 25 classes à 230000 hommes chacune, déduction faite d'un déchet normal évalué à 23 pour 100. Au moment de la mobilisation, chaque com-

1. Larmée lerritoriale, en 1900 , formait 145 reciments d'infanterie, 7 bataillons de chasseurs a pied, 10 bataillons de zouaves (en Algerie), 18 escadrons de drazons, is de cavalerie legere, 6 de chasseurs d'Afrique Alcerie); un ou plusieurs gro upes d'artillerie rallachés a chacun des $\$ 0$ corps darmé et au gouv ernenifnt militaire de Paris, 21 bataillons du génie, 19 escadrons des equipages militaires. - On ratlache ausst i l'armie territoriale 37 bataillons de douaniers el 32 compagnies de chasseurs forestiers. 
mandant de corps d'armée a le droit de requérir, dans toute la région, les chevaux et mulets. Aussi a-t-on dressé un état de tous ces animaux, qui, chaque annee, sont passés en revne.

Les lois militaires de la troisième république sont les plus rigourenses de nos lois de conscription et en méme temps les plus égalitaires. La jeunesse française n'est plus divisée, comme autrefois, en deux catégories : ceux qui servent et ceux qui ne servent pas. La loi ne laisse subsister aucun privilège; le devoir de défendre la patrie est le même pour tous : tous sont égaux devant l'impôt du sang. Le régiment devient donc l'école par laquelle tout le monde aura passé, ou riches et paurres, savants ou ignorants, seront conlondus sous le même uniforme; il n'est pas seulement une école de discipline et de patriotisme, mais une école d'égalité. Il n'y a plus à distinguer désormais entre la nation et l'armée; l'armée, c'est la nation elle-meme, debout pour la défense du sol.

Tontes les nations européennes ont adopté un système analogue : l'Angleterre est le seul pays où les citoyens ne soient pas astreints au service personnel et où l'armée soit recrutée de soldats mercenaires; mais la Grande-Bretagne est une ile, que semblent protéger contre toute invasion la ceinture de l'océan et la ceinture de ses flottes de guerre.

Perfectionnement de lardillerie. - Une innovation capitale s'est produite dans l'artillerie. Autrefois, on ne lançait avec les cunons que de la mitraille ou des boulets sphériques et pleins. En fait de projectiles creux, on ne connaissait guère que la bombe, qui se lancait avec le mortier. Le mortier ne pouvait s'employer que dans les sièges, ou dans la marine avec des navires spéciaux, galiotes a bombes ou batteries flottantes. Pourtant, dès la guerre de Sept Ans, on voit appraraître. d’abord dans l’armée misse, des licomes ou obusiers, plus courts que le canon, plus longs que le mortier, et qui lançaient des projectiles creux, mais également sphériques. En 1822. Paixhans trouva le canon a bombes ou canon-obusier, canon en fer qui ne servit d’abord qu'à la marine et portait des projectiles creux, les obus, beaucoup plus loin que le mortier. Ces obus étaient eucore de forme ronde. Apris s'etre 
signalé, en 1853 , à la destruction de la flotte turque de Sinope par les Russes, le canon de Paixhans, réduit de proportions, put ètre employé dans les armées de terre. On n’arait done plus besoin d'avoir à la fois des canons pour les projectiles creux. Le canon-obusier sultisait à tout. Bientôt tout canon fut un obusier, et ce demier mot cessa presque d'ètre employé.

Dans la guerre de $18399^{1}$, Napoléon III employa les premiers canons-obusiers rayes, dont les rayures en spirale imprimaient it l'obus un mourement de rotation qui augmentait la précision du tir. L'obus éclatait par la combustion de sa fusée. On lui donnait la forme cylindroconique, qu'il a encore aujourd'hui et qui assure an projectile plus de masse pour un mème ealibre, plus de portée et de pénétration.

Le canon-obusier des armées de terre était en bronze; mais, en Angleterre, en Amérique. en Allemaqne, se manifesta un retour au canon de fer ou d'acier, rendu possible par le progrès énorme de la métalluruie. L'usine prussienne de RRUPP, à Essen, munie d'un martean-pilon du poids de 50000 kilogrammes, produisait un acier d'une grande résistance, avec lequel il put fabriquer des canons de toute dimension. A lexposition universelle de $186 \pi$, il exhiba son canon-monstre lorgé en acier, qui pesait 50000 kilogrammes et lancait des projectiles de 530 kilogrammes. II était destiné à l'armement des forts. L'armée prussienne fut la première, sur le continent, qui substitua l'acier au bronze pour le canon de campagne. En mème temps, elle admit la culasse mobile, qui permet de charger le canon par l'arrière. L'obus recut aussi d'importants perfectionnements; à la fusée fusante, difficile à régler, on substitua la fusée percutante, qui fait éclater l'obus au premier choc. Chargé de 200 grammes de poudre, creusé et strié à la surface pour régulariser les cassures de l'éclatement, l'obus prussien éclatait en vingt-quatre morceaux. Enfin les Prussiens revêtirent l'obus d'une enveloppe de plomb qui assurait son exacte adherence aux parois du canon et empecchait toute déperdition des gaz. Halheureusement, le

1. Pour élre exact. il faut sicnaler, dès 1858 , peudant lexpedition de Cochinchine, l'emploi de ces obusiers. 
canon d'acier à culasse ne fut pas alors introduit dans l'armée trançaise : la parcimonie des Chambres ne le permit pas; on dut se borner à transformer les anciens canons lisses en canons rayés; durant la guerre 1870-71, l'artillerie allemande avait sur la nôtre une supériorité dicisive.

C'est à la suite de nos désastres que l'on s'est mis à l'ouvre. Le canon se chargreant par la culasse était déjả en usage dans notre marine; il a pris position sur les remparts de Paris assiégé. Mais nous devons surtout le perfectionuement de notre artillerie de campagne, la labilication des pièces de 80 , 90 et 95 millimètres, du eanon de montagne de so, de lobus $\dot{a}$ balles, beaucoup plus menrtrier que l'ancien obus prussien, à DE REFFye de BANGE : le premier fabriquait les canons en bronze ( 1570 , le second les labriquait en acier (1877). De 189' a 189s l'artillerie francaise s'est encore transtormée, notamment par l'adoption du frein hydro-pneumatique qui supprime le reeul et permet un tir d'extrème rapidité, par l'emploi d'obus à mitraille, éclatant en l'air au-dessus du but, par l'mploi de nouveaux procedes de réglage du tir. Liusine francaise du Creusot rivalise avec celle de lirupp par la puissance de l'outillage, la perfection des produits, l'abondance des commandes dans le monde entier. C'est elle qui a lourni aux Boërs une partic les pieces qui leur permirent de lutter contre l'astillerie britamique.

A la veille de la guerre avec la l'russe, Napoléon III avait mventé la mitrailleuse, qui ne donna pas alors tous les résultats qu'on en espérait, puis vint le canon-revolver systeme Hotchkiss adopte d'abord par notre marine. De tir très rapide, il lancait un petit obus du poids de 500 grammes. Les mitrailleuses automatiques assez légères pour accompagner partout l'inlanteric et qui ont fait leurs preuves dans la guerre du Transvaal et dans la guerre Russo-Japonitise, sont en usage ou en essai dans presque toules les armées.

En 1853, on avait introduit dans l'artilierie francaise les fusces a la Congrive ${ }^{1}$, qui intimidaient l'ennemi, surtout la

1. Lingénieur anglais Congreve les avait inventées en 180i, ou plutòt i) les avait empruntees aux artificiers de l'Indoustan, où elles atuital convues depuis longlemps. 
garnıson des places assiégées, en laisant beautoup de bruit : de plus, elles portaient avec elles un petil obus on une petite bombe. Cet engin, dont le tir était fort incertain, a eté presque complètement dẻaissé depuis les progrès réalisés par l'obusier.

En 1883 , on a supprimé le train d'artillerie, dont les hommes, les chevaux et le matériel ontété versés dans l'artillerie. Il ne subsiste plus aujourd'hui que le train des équipages.

Perfectionnement dn fusil. - Après les perfectionne. ments apportés à la carabine rayée, on fabriqua le fusil rayé pour l'infanterie, la carabine rayée pour la cavalerie, le mousqueton raye pour l'artillerie. A la balle sphèrique on substitua la balle eylindro-conique. $A$ la baïonnette triangulaire on substitua le sabre-baionnette, puis l'épée-laïonnette, beaucoup plus rigide et plus légère. Les armes nouvelles furent en usage dans toute l'armée francaise à partir de 1858 , et firent leurs prenves dans la campanne d'Italie.

Depuis le xvie siècle, les armuriers avaient cherché un modèle de lusil se chargeant par la culasse. Quelıues essais avaient cté faits en Flance sous Napoléun ler et sous la Restauration : eelle-ci avait arné ses Cent-Suisses d'un fusil de ce type.

En 1827, l'armurier prussien DReysse inventa le fusil à aiguille: la cartouche était munie d'une pastille fulminante que venait frapper une pointe d'acier; mais le chargement par la culasse ne fut appliqué par Dreysie qu'en 1836. A partir de 1841, ce fusil fut arlopté par l'armée prussienne, qui, grice à la rapidité nouvelle du tir, bui dut unc partie de ses sucès dans la guerre contre le Danemark en 1so' t et contre l'Autriche en 1866.

Ce fut un avertissement pour la France. Depuis le lusil Chassepot, adopté en 1866 , jusqu'au lusit Gras, adopté en IS\%, le fusil rayé, à balle lorcée et eylindro-conique, se chargeant par la culasse, ne cessa de se perfectionner cliez nous. Nous arons maintenant le f'usil tebel (devenu lusil molèle 1886-93), très léger à porter, se chargeant avee une pouslre qui ne donne pas de lumée et d'une énergie extlème, envoyant une petite balle nickelée', d'une grande

1. Celte balle vient d'èlre remplacée par une balle loute en bronze, de forme très allongée, qui lui est bien supérieure. 
foree de pénétration. Cette arme est, en outre, un fusil $\dot{a}$ repétition, se rechargeant automatiquement, au moyen d'une série de eartouches contenues dans un magasin placé sous le canon. On connaissait déjà les fusils à répétition de spencer, de Winchester, de Kropatchek, ete. Celui-ci a été employé dans la marine française.

Le pistolet, dont la eavalerie était armée dans les anciennes guerres, a fait place au revolver.

Transformation de la tactique : la guerre scientifique. - Ces al'mes si redoutables et si précises ont dù morlifier la tactique. On ne se bat plus seulement en ordre compact, comme au $\mathrm{XvI}^{\mathrm{e}}$ siècle, en orlre mince, comme à la fin du xvir $^{c}$ siècle, mais surtout en ordre dispersé, e'est-à-dire avec des ligues de tirailleurs qui s'abritent de leur mieux pour donner moins de prise au feu de l'ennemi. Elles ont derrière elles des soutiens plus ou moins espacés et, en arrière encore, une reserve. On ne verra sans doate plus les charges décisives de cavalerie comme à Eylau ou à la Moskova; la cavalerie a maintenant pour rôle principal le service d'élaireurs, les reeonnaissances, les surprises.

La portée prodigrieuse des nouveaux canons, surtout des grosses pièces de siège, a amené également une transformation dans le système des places fortes. Les forteresses construites par Vauban, avec leur seule enceinte bastionnée, ne résisteraient plus au formidable effet du bombardement et des batteries de brèche. Pour maintenir l'assiegeant à une distance suflisante, on entoure les places de forts detachés, èloinnés quelquelois de huit ou dix kilomètres. Ladoption de redoutables substances explosives pour le chargement des obus ${ }^{1}$ oblige il bétonner les parajets et les casemates, i mettre l'artillerie sous des coupoles cuirassées.

La guerre est devenue scientifique : elle utilise toutes les inventions nouvelles. On a fondé ehez nous une Direction génirule des chemins de fer et des étapes et des Compagnies milituirs de chemins de fer (18s千); un service de la télégraptie militaire (1s74), comprenant la télégraphie électrique, la télégraphie optique, les tétéphones, la télégraphie sans fil; une Ecole daerostation militaire, at Chalais (bois de Ileudon), ou lon s'oecupe de recherehes sur la direc-

1. Voyez ci-dessous au chapilre des Seiences (Chimie). 
tion des aérostats; une administration inilitaire des pigeons vo!jageurs, avec colombiers centramx à Paris et à Langres. L'École superieure de guerre, fondée en $1876^{\circ}$, les Réunions dofficiers, les organes spéciaux comme la a Revue militaire de l'étrancer $n$, sont destinés à perfertionner l'instruction supérieure dans l'armée. Le Prytinée de la Fléche a ète réor@anisé en 1853; des Écoles de sous-olficiers destinés a lasser officiers, ont été fondées : à Saint-llaixent pour l'infanterie, à Saumur pour la cavalerie, i Versailles pour l'artillerie. Les écoles de médecine militare dn Valle-Grâce (Paris) et de Lyon ont été réorganisées. L'ṕrole de Vineennes a eté réée pour former les offoriers d'allministration. Il y a aujourl'hui des écoles diaviation Chotons.

Corps monvenux on modifieation des anciens. Pour repondre aux exigences de la nonvelle guerre, il a fallu modifier les anciennes armes et mème en créer le nouvelles. Depuis la dernière guerre, on a supprimé chez nous les lanciers ${ }^{2}$, bien que la Prusse ait gardé ses mhlans. Puis on a armé de lances une partie des dragors

Le second Empire ne conserva que deux résiments de arabiniers: il n'en existe plus aujourd'hui. Sur les 13 regiments de cuirassicrs. 6 avajent, pendant quelque temps, perdu la cuirasse: elle leur a été restituée. Le type jreféré de cavalerie, c'est le dragron (31 régiments), le chasseur (21 régiments), le hussard (14 regiments), anxquels il convient d'ajonter 6 régiments de chasseurs d'Alipique.

Les soldats d'infanterie ont cessé, depnis 18\%r. de se di-tinguer en yrenadiers, voltigeurs, compunies du centre, et les réginents en régiments de ligne et en rériments legers; car tous dorvent acquerir la mêne mobilité avec la mème suliditi. On compte 163 régiments d inlanterie.

Les deux corps d'élite créés sous la Monarchie de Juillet, zouaves et chasseurs a pied, ont subsisté. Les chasseurs à pied forment aujourd'hui 30 bataillons dont 12 alpins. En $18 \% 2$. l'effectil des zouaves fut porté à trois régiments,

1. Emule de l'dcalimie de guerre de Berlin.

2. La Rest:urám a ait réduit à un les rériments de lanciers et l'avait incorporé dans la girle. Le peuple, qui avait un faible pour cet uniforme, racontait que la Suntr-Alliance, redoutant ces sollats, avait imposé a la Restauration de n'en garder qu'un régiment. La Monarchie de Juiliet en eut jusqu'à huit (en 1838). 
auxquels sajouta bientit un regiment de zouares de la garle imperiale. Actuellement les regiments de zouaves sont au nombre de quatre (Alger, Oran, Constantine, Tunis).

En Algérie-Tunisie également, on a porté à quatre le nombre des régiments de spahis et à quatre le nombre des régiments de tirailleurs alyériens. On a créé les comparnies sahariennes (méharistes). L'infanterie légère l'Afrique comprend 5 bataillons; les compagnies de liscipline sont au nombre de 4. An Senégal, il y a les spalis et tirailleurs sénégaluis, créés en 1837 an Soudan, les spuluis et tiraillenrs soudanais ${ }^{1}$; à lladagascar, 3 régiments de tirailleurs malgaches; it la Nonvelle-Calédonie, les auxiliailes canaques; dans l'Indo-Chine, I rériment de tirailleurs amnamites, 4 de tirailleurs tonlinois, 1 bataillon de tirailleurs cambodgiens. à l'effectif total d'environ 30000 hommes.

Les troupes de la marine comprenaient en 1900. 20 régiments d'infanterie 2 et 2 d'artillerie. La loi du T juillet 1900. portant organisation de l'armée coloniale, les a fait passer. du ministere de la marine a relui de la gnerre : elles ont recu le nom d'infanterie coloniale el d'artillerie coloniale. Le nombre des régiments d'infanterie a sté liminué de i,

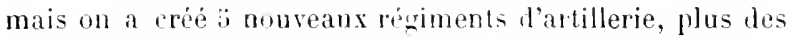
compagnies dourriers diartllerie. Les disciplinaires de la marine ont également passé sous les ordres du ministère de la unerre, ainsi que les régiments et corps indigènes. La Légion etrangere, partagre en 2 réments, a un effectif de 10 à 12900 hommes.

Limrtillerie a été récemment portée à 62 régiments ponr la France seule, et il $y$ a tonte une flotte aérienue de dirigeables et d'acroplanes.

\section{La marine.}

fiecrutemeut de l'armie de mer. - Larmée de mer se recrute: lo par les classes de linscription maritime; par $^{\circ}$

1. Il y a í rériments el plusieurs bataillons de lirailleurs sénégalais el soudanais : au Sénégal, au Soudau, au Congo, a llalagasrar, en Algérie, au Marue. Cist peut-etre le noyan d'une vertable "arme noiron.

2. Donze riginents liennent tramison en France; les autres au Tonkin, en Cochinchine, en Nourelle-Calédonie, a Minlanasear, au Stógal, en Chine. 
les engagés ou rengagés; $3^{\circ}$ par les jeunes gens qui ont sollicilé d'être affectés à ce service; $4^{\circ}$ à défaut d'un nombre sulfisant d'hommes de ces trois catégories, par des couscrits empruntés aux contingrents de l'armée de terre, et qui ont obtenu, lors du tirage au sort, les numéros les plus bas.

Nous nous occuperons seulement de l'inscription maritime, parce qu'elle constitue le mode de recrutement spécial à la marine. Elle a été régularisée et codifiée par la loi du 24 decembre 1896.

Tous les hommes se livrant à la navigation ou it la pèche sur les cótes de la France, et su les rivières jusquau point où la marée est encore sensible, sont inscrits, ¿̇ l'âge de dix-huit ans, comme matelots ct peuvent être requis pour le service de la flotte. Le temps de service dans l'armée de mer est fixé, par la loi de 1873 , a cinq années d'activité, quatre anuées lans la réserve, après quoi les lıommes passent dans l'armée territoriale. Mais les matelots libérés peuvent contracter des rengagements jusqu’à ce qu'ils aient atteint vingt-cinq aus de service et cinquante ans d'àge. Les inscrits sont au nombre de 80000 ; ils ne sont d'ailleurs leves qu'au fur et a mesure les besoins du service : on prend d'abord ceux qui n'ont pas encore fait de service, ensuite les autres.

L'inscription maritime assure aux inscrits des avantages sérieux : ils ont seuls le droit d'exercer la navicration maritime et la péche còtiere; moyennant une retenue sur leur salaire, ils ont droit, au bout de vingt-cing ans de travigation et à soixante ans d'dge, quelle que soit la durce de leur service sur la flotte, à une pension.

Parmi les eréations de cette période, il faut citer les Armuriers militaires de la marine (18.56); les Ouvriers civils de la marine (1864); l'École d'application de timonerie (1856); celle de pilotage (1865); celles des Hécaniciens de la marine, à Brest et à Toulon $(1860)$ et à Lorient (1900); celle des Mousses (1856) et celle des Pupilles de la marine (1862), à Brest; l'்́cole des torpilleurs, à Boyardville (Charente-Inférieure, depuis 1869); lécole de pyroteclınie de Toulou; l'école de Lorient, pour les fusiliersmarins et pour leurs officiers; l'école de canounare à 
Toulon, etc., à côté l'ancienne École navale s'est fondée une seconde ícole de Brest oú les sous-officiers peuvent acquérir le grade d'enseigne. Enfin une École supérieure de la marine, correspondant à notre École supérieure de guerre, s'est constituée, en 1896, à Paris, qui possède également le Laboratoire central de la marine.

Le nouvean matériel fottaut. - La guerre maritime n'a pas subi moins de transformations que la guerre sur terre. Les navires de bois, marchant à la voile, armés de soixante, de cent vingt canons, avee lesquels on a lutté contre les Anglais pendant les guerres de l'Empire et fait les expéditions de Morée et d'Algérie, ont été remplacés par les navires euirassés d'acier, mus par la vapeur, ne portant que très peu de pièces, mais d'une dimension et d'une portée énormes. C'est la transformation de l'artillerie par Paixhans, en 1822, qui a préparé la translormation de la marine. C'est en France que celle-ci a commencé.

A l'occasion de la guerre de Crimée, en 183 ', Napoléon III fit construire cinq batterics flottantes ${ }^{1}$. C'étaient des bâtiments à vapeur, qu'on ne destinait pas à tenir la haute mer, mais à se porter dans les bas-fonds. lls portaient chacın seize canons énormes et étaient protégés par une cuirasse de fer ${ }^{2}$. A 250 mètres de Kinburn (1854), ils résistèrent à toute la puissance de l'artillerie russe et rasèrent les forts.

Restait à construire de vrais navires, doués d'une grande vitesse, et également cuirassés. L'ingénieur DUPOY DE LOME ${ }^{3}$

1. La Congrève, la Dévastation, la Foudroyante, la Lave, la Tonnante. Ea 17s2, il y avait eu des balteries flotlantes au siego de Gibrallar, et Futon, en 1810, en avail consluit une; mais toutes navaienl que des murailles de hois.

2. Les Ançlais se hàlèrent d'en construire, mais arrivèrent trop lard.

3. Dupuy de Lòme, un des grands novaleurs du xtx sic̀cle, que M. Thiers appelait a un constructeur de génie ", a atlaché son nom à trois grandes innovations. 11 construisit chez nous le premier navire a coque de fer, le Caton (1811); le premier navire de guerre a hélice, le Napoléon (18亿́1852); le premier navire de guerre cuirassé, la Gloive (1858).

11 étail né, en 1S16, à Plocmeur, près de Lorient. Fils d'un ancien officier de marine, il entrait, en 1835, a l'École polytechniqute; en 1853, devenait ingénicur de [ $^{\text {re }}$ classe; en $185 \overline{7}$, directeur du matériel au ministère de la marine; en 1\$60, conseiller d'Etat en service ordinaire; en 1S66, membre de l'Académic des seieuces; en 1859, dęputé du Morbihan. Mort en 1855. 
construisit, en 185s, la frégate la Gloire. Elle était blindée de plaques de fer épaisses de 12 centimetres, qui avaient résisté à des salves de boulets tirécs à une distance de vingt mètres. De plus, la Gloire étail armée à son avant d'une étrave en forme de hache, dont le tranchant devait fendre les vaisseaux ennemis : cette étrave a pris, dans les constructions suirantes, la forme d'un eperon. a Ln seul navire de celte espèce, avait dit l'ingénieur, lancé au milieu d'une lotte entière de vaisseaux de bois, y serait, avec ses 36 canons, comme un lion au milieu dun troupeau de moutons. Puis vinrent trois autres frégates, dont une, la Couronne, avait, outre la cuirasse, une coque de fer. En 1859, le mème ingénieur construisit denx vaisseaux de ligne, le Solférino et le Mayenta. La France eut ainsi la premiere escadre cuirassée, et lut un moment maitresse de la mer, car l'Angleterre u'a mis le Warrior à l'eau qu'ca 1860, et les États-Unis leur Monitor qu'eu 1861.

Les autres nations suivicent notre excmple. La guerre d'Amérique vint lémontrer l'impuissance de la marine de bois contre la marine de fer : en 1862 un granul raisseau americain en hois, le Cumberland avait été coulé par le cuirassé le Merrimuc, dont les ravages ne furent arrités que par un autre cuirassé, le Honitor. Depuis trente ans a commencé a le duel du canon et de la cuirasse $\bullet$, les ingénieurs accroissant tantòt la force de pénétration du boulet, tantôt la force de résistance du blindagge. Un jour, c'ust l'altaque yui a l'arantage; le lendemain, cest la déleuse. On est arrivè à réduire à quatre, à deux, les pièces d'artillerie, alin de leur donner des dimensions phus grandes et d'assurer plus de force de pénćtration au projectile. On les abrite dans des tourelles mobiles d'acier qui lenr permettent de tirer dans toutes les directions. On domne aux blindares jusqu'd fŏ centimètres d'épaisseur.

Les flottes d'aujourd'luui, grands cuirassés de 1 f́5 mètres de loug, croiseurs-cuirassés, croiseurs, garles-côtes, contretorpilleurs, torpilleurs, cauonnieres, arec leurs sombres profils d'acier, leurs tourelles, l'absence presque totale d'agrès et d'ornements, leur artillerie réduite comme nombre, mais énorme de dimensions, leur équipage silencieux et presque invisible, diflerent étrangement de celles d'autre- 
fois, avec leurs hautes murailles de bois, leurs flanes percés d'une double ou triple ligne de sabords, leur màture compliquée, leurs voiles imnenses et innombrables, les sculptures dorées de leurs poupes à galerie, les pavillons flottant partout, leurs centaines de combattants perchés dans les hunes, dans les voiles, dans les cordages, le tumulte de leur branle-bas, le tonnerre de leur canonnade à portée de pistolet, la fureur des abordages le sabre ou la hache au poing. Alors un navire de bois pouvait recevoir jusqu'à deux cents boulets : aujourd'hui il suffit d'une torpille ou d'un obus bien dirigés pour pratiquer lans le plus robuste cuirassé une brèche irréparable (Voir Suppl.).

Torpilles, bateanx-torpillenrs, sous-marins. - Dans le long duel entre le canon et la cuirasse, un troisième adversaire est intervenu, infiniment plus redoutahle que les boulets rouges et les boulets ramés d'autrefois. C"est la torpille ${ }^{1}$, engin de ler bourré de fulmi-coton ou de mélinite, dont l'explosion peut anéantir le plus puissant navire. Autrefois, on se contentait de les semer le long des côtes, à l'embouchure des lleuves, attendant que le vaisseau ennemi los fit éclater en les heurtant. Puis au moyen de l'étincelle èlectrique, on a pu les faire détoner au moment voulu. Enfin, on a trouré le moyen de les diriger, de les amener jusque sous les flanes du navire cnnemi, au moyen de bateaux-torvilleurs, marchant arec une vitesse double ou triple de celle des cuirassés, montes par une douzaine d'hommes et porteurs de cinq à six torpilles. Dès lors un cuirassé, dont la construction aura duré sept ou huit années, coùté 20 ou 30 millions de francs, et qui sera monté par huit ou neuf cents braves, doit redouter un petit bateautorpilleur, conduit par douze hommes intrépides. Que la tornille le touche au défaut de la cuirasse, et il peut couler à fond avec tout son équipage. Contre cet engin, les blindagres les plus épais sorit inutiles, car on ne peut en proteger toutes les parties du vaissean. Le torpilleur, avant que de récentes expériences eussent un peu diminué son renom, paraissait donc appelé à faire une nouvelle révolution dans la construction navale. Un moment, il a été question le renoncer aux cuirasses el aux canons géants, de rédure les navires à des dimensions beaucoup plus 
modestes, et de se borner à leur donner les plus grandes vitesses possibles ${ }^{1}$.

Un autre ennemi redoutable du cuirassé est récemment apparu : c'est le sous-marin. Le Plongeur, en 1863, a été construit sur les plans de l'amiral Bourgeois. Puis sont venus (1895) le Gymnote de Zédé, le Goubet de Goubet, le Gustave Zède, le Morse, le Narval, etc.

Puissarec de la flotte frangraise. - Notre lloth do guerre se composait, en 1911 : de 20 cuirases d'escalle et de ly croiscurs "uirassés, ontre ceux qui sunt "en restrve",

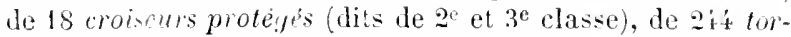
pilleurs on contre-torpilleurs, d'une quarantitine d'autres navies le querre et de 38 sons-marius fa plus belle fouttille du momle entier). Ello portait pres de 3600 bouches à feu et 56000 marins. Milheureusement notre lintte a souffert, en ces lernières annes, du manque de suite lans les programmes de construction. De terribles catastroplres se sont produites, dues, semble-t-il, à la conflagration spontanée de poudres $\mathbf{B}$ (Lena, Liberté).

Seule la Molle anghise oit. lus puissante que la notre: elle est montie par 82004 marins et 18000 lummes de troupes auxiliaires. Mais la llotte allemande ne cesse de saceroitre el nous dépasse déja, aiusi que celle des ÉtatsUnis, par le nombre et la force les cuirassés.

1. On connaiscait déjà, an $\mathrm{xv}^{\circ}$ siècle, les mines sous-marines. En 1624, Cornelius van Drebbel avait imaginé un appareil pour porter, au moyen d'un espar, aue boite de fer pleine de poudre sous le flanc d'un navire. Fulton, en 1797, proposa au Directoire lis torpille ancrée au fond de la mer : l'aniral Decrès la repotssa, disant qu'une telle invention étuit bonne pour des Algériens ou des corsalie . Froidemeut accueilli par le Premier Consul, il porta sa torpille en Angleterre, puis en Arrérique, où il fit sauter des uavires abandonnés ì ses expériences. En 1540, il publiait son TorpecioWar : La Guerre des torpilles. En 1815, il inventa un canon sous-marin pour lancer des projectiles. Ccpendant, pendant longtemps, on n'usa des torpilles que pour faire sauter les navires coulés qui encombraient les passes : en 1816, le prince de Joinvilie en usa contre une estacade, à la Spezzia. Deux inventions surtout vinrent leur ajouter une redoutable efacacité : d'une part, la bobine de Ruhmkorff et l’étincelle électrique; d'auıre part, la substitution d'autres explosifs a la poudre. La guerre de la Sécession, en Amérique, leur ofrit un champ nouveau d'uctivité - non-senlement les Sudistes semèrent de torpilles, appelées surprises du diable, les passos et les embonchures des fleures; mais ils corstruisirent des bateaux en forme de cigares, les bateaux-cigares, qui les apportaient sous les fanes des navires Nordistes, dont ils firent ainsi sauter une vingtaine. Ils inven'èrent eussi des canons sous-marins qui lançaient les torpilles et d'autres prọiec- 


\section{Les colonies.}

Aceroissements de notre empire colonial. - Le second Empire, tout absorbé dans ses combinaisons de politique européenne, n'a pas su profiter des précieuses occasions qui s'offraient à lui, notamment en Tunisie et à Madagascar, pour accroitre, avec beancoup moins de difficultés qu'on rien a rencontré depuis, notre domaine colonial. Cependant, la soumission de l'Algérie a été complétée, par la conquête de la Grande-Kabylie (185̈7), grâce à RANDon, et par de brillantes expéditions dans le Saliara. Grâce au général FAIDHerbe, nos possessions du Sénégal, jusqu'alors limitées au cours inférieur du fleuve et toujours très précaires, ont été consolidées et agrandies par la fondation de Médine sur le haut fleuve. Notre protectorat s'est établi, à la côte de Guinée, sur le royaume de Porto-Novo (1863). En Océanie, la Nouvelle-Calédonie et ses dépendances ont été occupées. La Cochinchine a été conquise en deux campagnes décisives, et le royaume de Cambodge, d'une étenduc presque égale, a été placé sous notre protectorat.

Sous la République actuelle, la France, dès qu'elle a pu assurer la défense et la sécurité de ses frontières, a travaillé plus énergiquement et, il faut le dire, avec plus de succès qu'aucun des régimes précédents depuis Colbert, à la reconstitution de son empire d'outre-mer. Elle a marché à son but avec une certaine ténacité et un certain esprit de suite, malgré toutes les incertitudes de la politique parlementaire, les divisions des partis, les défaillances mêmes de l'opinion. En moins de dix ans, l'Algérie s'est agrandie de plusieurs oasis dans le Sud, notamment par l'annexion du Mzab (1882). En 1900 a commencé la conquéte des oasis de l'Ouest (In-Salah, etc.). Par l'établissement de notre protectorat en Tunisie (1881), nos possessions dans l'Afrique du Nord, comme population et comme superficie, se sont accrues d'un bon tiers; elles ont acquis des ports excellents et une ligne de défense plus assurée. Du bassin du Sénégal nous avons

tiles. La réunion de toules ces infentions, c'est le torpilleur d'aujourdhui, muni d un appareil a projeter les torpilles entre deux eaux. 
pénétré dans le bassin du Niger supérieur, remporté avec Borgnis-Desbortes, Combes, Gallieni, Archinard, Audéoud, de brillants succès sur le sultan Ahmatou, héritier du conquérant El-Hadj-Omar, et sur Samory; occupé Tombouctou et les deux rives du Nigrer jusqu’à Sä̈; soumis le Fouta-Djallon, le Mossi, le pays de liong. En 18!8, la capture de Samory assura la pacification.

Sur le Congo, les conquêtes pacifiques de Savorgnan DE BRAzzA, la convention avec l'Association internationale afiricainc (188\%), les décisons du congrès de Berlin (1885) nous ont valu un territoire d'une étendue très supérieure à celle de la France, et d'une grande fécondité. Il fut encore doublé par les explorations de Crampel, Dybowski, Monteil, Mizon, par l'habile politique des administrateurs Liotard et Gentil, qui constituèrent nos colonies de l'Oubanghi et du lac Tehad. Avec l'appui du gouverneur de l'Oubanghi, le commandant Marchaud a pénétré dans l'ancien Soudan égyptien, occupé le Bahr-el-Ghazal, plauté le drapeau a Fachoda sur le Nil, battu les derviches (1898). Comme la guerre avec les Anglais menaçait d'éclater à ce sujet, une convention est intervenue avec eux : nous devions évacuer le Balır-el-Ghazal, mais la possession du Baghirmi, du Ouadaï, du Kanem et du Tibesti nous ètait reconnue (1899). Au commencement de 1900, la mission du Chari, la mission de l'Afrique Centrule, la mission saharienne, réunissaient leurs forces au Sud du Tchad, sous le commandant Lamy, et remportaient une série de victoires sur les troupes nombreuses, bien armées, munies d'artilleri, du marchand d'esclaves Rabah, qui fut tué; malheureusement Lamy périt lui-même au combat de lioussri (22 avril).

En Guinée, nous nous sommes heurtés a Behanzin, roi du Dahomey. Alrès une première guerre (1889), le général DoDds fut envoyé, battit partout les Dahoméens, occupa leur capitale, contraignit le roi à se rendre, établit sur tous ses États notre protectorat ou notre domination (1892).

Par toutes ces acquisitions, nos possessions du nord de l'Afrique peuvent communiquer, à travers le Sahara, avec nos colonies du Sénégal, du Soudan, du Dahomey el des autres Guinées, du Congo, de l'Oubanghi, du Tchad. Si nous avions pu commencer quelques années plus tôt, toute 
l'Mrique du Nord, de l'Ouest et du Centre, moins quelques enclaves, formerait le domaine de la France. Du moins, le Maroc vient-il d'être placé sous notre protectorat (1912), moyenuant la cession a l'Allemagne d'une partie du Congo.

Jans locéan Indien, en face de la côte orientale d'Mfrique, lî̀le de liadayascar, d'un tiers plus étendue que la lince 7:30 000 kilomètres carrés), a été l'abord soumise a notre protectorat nominal (1883), puis, après la conquete de 189; par les généraux duchesne et Hetzinger, à notre protectorat effectif; enfin, après l'expulsion de la reine Ranavalo, elle fut annexée à l'empire français (1897). Administrée et organisée par le général GaLlíni, l'ancienne ile Dauphine, l'arcienne France Orientule, but de tant

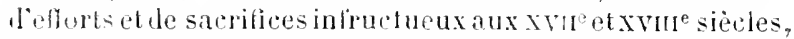
est enfin acquise d̀ la colonisation francaise.

Sur la mer Rougre, la colonie française d'Obock et Tadjourah a été constituée par une série de traités conclus avec les souverains ou tribus indigènes. Les relations d'amitié qui se sont établies avec l'empereur Ménélik assurent à cette colonie une grande importance commerciale. On travaille à la construction d'un chemin de fer qui, de notre port de Djihouti, pénétrera dans l'empire d'Slyssinie. Une compagnie marseillaise, de 1868 à 1871, acquit sur la côte d'Arabie le port de Cheïkh-Saïd; l'État francais n'en a pas encore pris effectivement possession.

En Océanie nous avons fait valoir et nous maintenons nos droits sur l'archipel des Nouvelles-Hébrides et sur d'autres iles.

Dans l'Indo-Chine, le Tonkin a été conquis après quatre annérs de laborieuses campagnes (1881-1885), lempire d'Aunam soumis à notre protectorat, le roi de Siam forcé de reconnaitre nos droits sur la rive gauche du llékong (1897). L’lndo-Chine françıise est déjà dotée de son premier résean de chemins de fer.

Par une série de conventions avec la Chine (1895-1897), nous avons obtenu d'elle la eession de la baie de Kouangtchéou-Ouan, voisine du Tonkin; l'extension de la concession francaise de Shang-haï; l'assurance que ni la grande ile de Haïuan ni les trois provinces chinoises limitrophes du Tonkin (Yunnan, Kouang-Si, Konang-Toung) ne seraient 
jamais aliénées, sous quelque forme que ce fût, à aucune autre puissance européenne (ce qui assurait l'influence et les droits éventuels de la France sur ces quatre pays): la promesse de contier à des infénieurs français la reconstruction de l'arsenal de Fou-tchéou, à un Français la direction générale de ses postes; enfin la concession de lignes de chemins de fer pénétrant dans le Yunnan et dans le Kouang-Si.

Ainsi lorientation coloniale que JULES FERRY, lors de ses deus présidences du conseil, avait, par ses interventions en Tunisie, au Congo, à Madagasear, en Indo-Chine, imprimée à la politique française, a été suivie de point en point par ses successeurs au pouroir.

Dans les Antilles, l'ìlot de Saint-Barthélemy, cédé par la France à la Suède en 1784, nous a été rétrocédé par celle-ci en 1877. Nous avons vu plus haut comment se sont réglés les conflits entre la France et ses voisins européens en Guyane. Entre la France el l'Angletere il subsiste toujours des liliges au sujet du French-Shore et des pêcheries de Terie-Keuve.

Abohition de leschange. - Depuis 1848 , trois grandes améliorations ont été effectuées dans notre empire colonial : au point de vue social, l'abolition de l'esclavage; au point de vue économique, la liberté des échanges; au poinl de vue politique, une large autonomie.

Par les décrets du 27 avril 1848, rendus sur' l'initiative de Schwelcher, l'esclavage, aboli une première lois par la Convention, a été définitivement supprimé dans nos colonies primitives, les anciens esclaves ont été admis à jonir de tous les droits des citoyens français; une indemnité a été accordée aux ancieus proprietaires. Cette seconde abolition, d'ailleurs prévue depuis longtemps, n'a entrainé aucun décordie.

Dans nos colonies récemment acquises, on a traraillé d’abord à supprimer le trafic des esclaves; puis à transformer peu a peu ceux-ci en travailleurs libres. A Madagascar, l'abolition de l'esclavage, très habilement opérée par le s'néral Gallieni, a été comme une conséquence néessaire te lannexion à l'empire colonial français.

Euaripation économique. - La Révolution et l'Em- 
pire n'avaient rien changé à l'ancien pactecolonial'. Sous les deux Monarchies constitutionnelles, il ne reçut que de faibles atteintes : on autorisa les colonies à ne pas apportcr toutes leurs denrées au marché métropolitain ${ }^{2}$, à recevoir certains prodıits de l'étranger ${ }^{3}$, à recourir à d'autres moyens de transport que la marine nationale *. Les traités de commerce de 1860 sapèrent par la base le pacte colonial; on ouvrait aux sucres étrangers le marché métropolitain, et dès lors les restrictions qu'on faisait peser sur l'industric et le trafic de nos colonies ne pouvaient plus se soutenir. Le sénatus-consulte de 1866 (4 juillel) les autorisa à modifier leurs tarils de douane. Certaines en vinrent à les supprimer : ce qui mit le commerce français avec nos colonies sur le mème pied que le commerce étranger. Les lois de 1866 (19 mai) et de 1967 (17 juillel) ouvrirent, sauf de faibles restrictions, l'Algérie au commerce de toutes les nations.

En 1898, la France faisait avec ses colonies et pays protégés un commerce de 825 millions de lranes se parlageant à pcu près également entre l'importation et l'exportalion. C'est à peu près la dixième partie du commerce que nous faisons avee le monde entier.

Emancipation politique. - Restait à donner à nos anciennes colonies l'èmancipation politique. Le sénatus-consulte de 1856 cluargea le Sénat de statuer sur la plupart des matières intéressant leur organisation. Tous nos Codes y avaicnt été ou $\mathrm{y}$ furent introduits. Unc colonie française eut, en général, un gouverneur, assisté de trois chels de service: l'ordonnateur, pour la guerre et les finances; le directeur de l'intéricur, pour l'administration locale; le procureurgeneral, pour la justice; plus rarement un commandant milituirc. On institua des conscils généraux ou coloniaux, des conseils municipaux ${ }^{5}$, qui reçurent peu à peu la mème

1. Voir notre IIstoire de la civilisation francaise, t. 11, p. 254 .

2. Arrèlé de 1817 , ordonnances de $18 \approx 6$ et 1816 .

3. Loi de 1815.

4. Acte de 1816; traité de 1822 avee des Élats-Unis, de $1 \$ 26$ avec I'Angleterre.

5. 11 y a 32 communes à la Guadeloupe, 24 à la Martinique, 12 à la Réunion, 1 à la Guyane (Cayenne), 4 au Senéral (Saint-Louis, Gorée, Daliar, 
organisation qu'en France. Souvent même, les premiers ont des attributions plus étendues. Dès ses débuts, la troisième République, au moins dans nos colonies anciennes, a établi le suflrage universel pour toutes les élections qui relivent de lui dans la mitropole. Les droits électoraux ont été, en beaucoup de pays, étendus aux indigrènes ou à des catègories d'indigènes ${ }^{1}$.

Representation coloniale. - La représentation des colonies françaises au Parlement, accordée par le décret de 1792, supprimée au 18 brumaire, rétablie en $18 \%$, supprimée au 2 décembre, a été de nouveau consacrée". Une large liberté de la presse lut concédée presque partout. Les colonies se déclarent prètes à accepter l'extension du service militaire universel et obligatoire à leurs habitants. En 189' le contingent ou régiment colonial de l'ile de la Réunion a concouru à la conquète de Madagascar. Les colonies sont, de plus en plus, des parties intégrantes du territoire francais. Une conception toute dillerente du régime colonial s'est donc substituée à celle de l'ancicnne monarchie.

En 1893 a été fondée l'École coloniale pour préparer les futurs administrateurs de nos possessions. Depuis, les établissements d'instruction coloniale se sont multipliés : Institut de médecine coloniale, École supérieure d'agriculture coloniale, Enseignement colonial aux Universités de l'aris, Bordeaux, Lyon, Nancy, Dijon.

Rufisque), 1 en Cochinchine (Saìgon), 1 à la Nouvelle-Calédonie (Nounèa), 2 à Saint-Pierre et Miquelon, 10 daus l'Indoustan.

1. A la Guadeloupe, à la Martinique, à la Réunion, à la Guyane, le droit de sufrage s'étend à tous les habitants dans les mèmes conditions qu'en Frauce. En Algérie, les Kabyles ou Arabes jouissant des droits politiques sont rares. Au Sénégal, tout indigène aequiert le droit d'électeur par un sejour de six mais dans une des quatre commuaes. Dans l'lndoustan, tont habitant cst électeur, mais on a dressé trols listes : l'une pour les lndous qui ont gardé leur caste, l'autre pour ceux qui y ont renoncé, la troisième pour les Européens, etc.; en 1899, la liste intermédiaire a été supprimee.

2. En 1871, an a donné 3 représentants à l'Algérie; en 1884, 6 dèpulés à l'Algérie; depuis 1875, 2 à la Réunion, à la Guadeloupe, à la Martinique, 1 à l'Inde, à la Guyane, au Sénègal, 1 a la Cochinchine. En 1875, on a donné 3 sénateurs a l'Algérie, I l la Réunion, a la Guadeloupe, à la Nartinique, a l'Inde. Total : 16 députés et 7 sénatenrs coloniaux. Les colonies trop petites ou trop peu avancées en organisation pour ètre représentées a 'varlement le sont au Conseil superieur des Colonies. 
OUVhages a Consulter. - C. Romsset, La conquéle d'Alger et de lilterie 157y-19xy et La guerre de irime $(1877)$ - - A. Delidour, Hist. Giplomaturue de lEurope (1891). Generai Truchu, Liamée firacaise en 1867. - Von der Goltz, Gambetta et ses armees (1877). - De Freycinel, La yue're en pronince (1Szt).Chanzy, Larme de la Lobe (1871). Chuquel, Histoire de la ykerre de 1570-71 (1596) - Ponr plus de dérails, les gramls onvrages du lieut.col. Kons-el, Lehautcourt (géneral Palat , heut.-col. Pioard, etc.-Genéral Vinoy. Lampe fire en $1873 .-\mathrm{Ge}-$ néral de 11 impf n, La nation armee (1870). - linc d'Almale, Les zouaces et les chasserts a pred 1859). - Hne, Hist. du for ry, de chesseurs d'A froque. - Lient. Viator Duray, Le ler rég. de timallours alguriens (1899). 6. de Susly, L'infonterie de marine (18901). - Naxime lleline, La poudre a canon th lis nomeraze corps explosifs (1s80). - Colouel Heunebert, L's nerieilles de l'artillerie. Comm. Borneque, L'aerostation militaire 1904. - C. Arter, LAviation militair 19!1). - Lieut.-col. Ch. Mangin. Lie forer notre (1910). - Lamir Jinien de la Graviere, La murine contenporaine. - X. Raymond, Les matimes de la France et de l'Alutrterpe $1 \leqslant 63)$. - Chevalier. Histoive die lie marine fratcaise foli-187i 190\%) - L. Firuier, Les mereeilles de l'industrie (la navigation a vapenr, les cuilassés).

1. Renard, Lat nacal (IS\&).

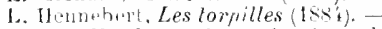
Farret, Ituris sur les operations de ynerre muritime de 1860 a 1883 . (i. Charmes, Les torpilleurs autonowes 1sci te Lu rifurme de la marine. - Congeard, La maine de guerre, sum fuisse el son avenir, cuirussés et torpilliurs (ISR), - E. Gan-

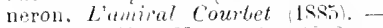
Etienne Trefen, Nosmerins liss. J. Lerrand, Lu lecont do Fachoda (1899. - E. Lockroy, La marine de guerre (189\%). - Cimmanłant Z... et H. Montechant, Riformes nardes et Les nuerres nurale's de demain. L. Peses, La matination sous-marine (Inou). - E. Bertin. La marine moderne 1.f11. - Comb Davelay, L'es. prit le la anere mavale (1909-10). - Rapume prarlementaires sur lo butat de lin uarine, notimment edai de bleury-lavirin (1901).
Duval, Les colonies et la politique coloniale. - Léon Desehamps. Hist. de la question coloniale en France. - A. Rambaud, La France coloninle (1893), Jules Ferry (19013). - Notices coloniales (officitlies) dis 1895 et 19410. - De Lanesuan, Lerpansion coloniale de la France (1886). - Ouvrares de P. Galfirel, L. Vignou, Mabel Dubois, E. Levassenr. sur les colomes francaises. - Paul Leroy-Beanlieu, La colonisation chez les poupls.s modernes (190:). - Andre Lebon, La politique de la France en A frique $(1896-1898)$ - P. Massou, Lil colonis. frate. au ilebut itt $\mathrm{XY}^{\mathrm{e}} \mathrm{s}$. (1906).

Voyanes ou rapports de BorgnisDesturides, Archumal, Gallieni, Bingnr, Monteil, ete., sur le Sondan. F. Dubois, Tombouctou la Hystiriense. - A. Mévil. Sanory. - Ciallieni, Rapport sur Madagasiar. Tonté, Da Dahomé ate Salara 11\$99\}. - F. Rorlget, Lerpansion culonicale an Conyo frameras (1990). - Prirr Mille. A u Congo belge (1.999). - Fuhert de Caix, Fachorta, la trance et lingleterve (isig). - V. Daville. Ṕartuge de ldprique. - H. Loria. Lidirque à lentré du XIo sipcle (1911) et L'A frique dil Nord (1909). - Lient. Gatelet, Hisi. de la conq. du Somilar frane: - V. Piqnet. Lis colonis, firne. lans lafirque du Nord (11:2). - M. Rondet-sant, LAdrigue équatarible frane. (1911).

J. Pinon et de Marrillite, La Chine qui s'ourre (1900. - Plerre LeroyBeantien, La finonation de l'Asie (1500). - De Lan:ssan, La Colonisation francuise "n Indo-Chine (1895). - Buginais et Paulus, La France en Indo-Chue (ISSij). - E. Courtois, Le Tonkin francais contemporain (1891). - Billut ancien ambassadear $\mathrm{r}$, L'affaire du Tunkin (ISS). - J. Llarmand, La petrailede Langson (18.2). - Jules Ferry. Le Tonkin et la wipro patrie (1890:- - Dommer. L'Intoihine frameis", Situation (196?); sonvenirs (1905).

Consulter ansi la Rerne maritime et coloniale, la lievee coloniald. is Bulletindu Comili, lel lirinue fian-

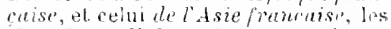
Ouestions riplomatiques et colommlis. ete.

Musées a risiter: Le murer d'altillerie (aux fovalides), le Muste de marine au Lonvre le dosed d'uthmoraphie (an Tromatero), le Husee Cinmet pres da Trucabero). 


\title{
CIIAPITRE XXVII!
}

\author{
L'INSTRUCTION PUBLIQZe
}

\section{Sous la seconde République.}

Projet Catuot. - Sous la Constituante, un projet de loi présenté par hippolyte carNot, ministre de l'instruction publique, déclarait l'enseignement primaire obligatoire et gratuit, relerait le traitement des instituteurs, les affranchissait de tout contrôle de l'autorité ecclésiastique. Ce ne fut qu'un projet.

C'est alors que fut créée l'Eeole d'administration, supprimée peu de temps après.

La République donua aux lycéens l'uniforme quasi-militaire qu'ils portent aujourd'bui. Les plus âgés lurent exercés au maniement du fusil.

Loi de \$850. - La Légrislative plaça les instituteurs sous la surveillance directe des préfets.

Elle vota. sur la proposition de DE FaLLodx, la célébre loi du 15 mars 1850, qui mit fin au monopole universitaire, proclama la liberté de l'enseignement secondaire et primaire, mais de manière à en faire profiter surtout le clerré et les congrégations, détruisit la hiérarchie universitaire, soumit ce grand corps aux influences ecclésiastiques.

Le Conscil de l'lniversite fut supprimé et remplacé par le Conseil superieur de l'instruction publique, on figuraient quatre areherèques ou évêques élus par leurs colleggues.

Au lien de l'ancienne division du territoire en quinze académies ayant à leur tète quinze reeteurs, on introduit 
la division en autant d'académies qu'il existe de départements. Comme il y a désormais $\$ 9$ recteurs, le recteur cesse d'ètre un personnage; il ne peut plus protéger ses subordonnés; lui-mème est soumis au contrôle du Conseil académique, où entrent l'évėque ou son délégué et un autre prétre. D'ailleurs, le recteur peut être choisi en dehors de l'Université, etl'on choisit assez souvent des ecclísiastiques.

L'inspection d'État cesse de s'étendre sur l'enseignement des établissements libres, car elle ne peut que s'occuper de la salubrité et rechercher si l'on n'y enseigne rien de contraire aux lois, à la constitution et aux mœurs s.

L'instituteur est de nouveau obligé d'enseigner le catéchisme : par là il subit de noureau le contròle du ministre du culte. Mème pour les autres parties de l'enseignement il n'en est pas exempt; car dans les nouvelles délégations cantonules, chargées de le surveiller, entrent en grand nombre les ecelésiastiques. L'instituteur n'est d'ailleurs plus nommé ni par le recteur, ni par le préfet : l'État semble se désintéresser de son sort. ll est nommé, soit par le conseil municipal, soit, à son defaut, par le conseil académique. Le recteur peut lui infliger toutes les peines, mème la révocation, sans qu'il ait aucun recours. C'est seulement sil s'agit d'une interdiction d'enseigner, mème comme instituteur libre, sur toute l'étendue du territoire, qu'il a recours devant le Conseil académique, et, en appel, devant le Conseil supérieur. Une brochure du temps résumait ainsi sa situation: "La funeste indépendance de l'instituteur vis-à-vis du curé disparait donc en mème temps que son inamovibilité."

La loi exempte formellement de l'obligation du brevet les instituteurs adjoints: or, l'immense majorité des instituteurs congreganistes portent ce titre d'adjoints. Ils n'auront à produire qu'une lettre l'obedience. D'autre part, la loi cherche visiblement à entraver le bon recrutement des instituteurs laïques; car elle autorise les conseils généraux a suppriner les écoles normales de leur département.

Dans la loi de 1830 , on ne peut relerer que quatre dispositions favorables au développement de l'instruction primaire, empruntées dailleurs au projet républicain dilippolyte Carnot : $1^{\circ}$ elle constitue l'enseignement des filles, en obli- 
geant toute commune de 800 âmes et au-dessus d'eatretenir une école de filles; $2^{\circ}$ elle établit un minimum de 600 francs pour le traitement des instituteurs; $3^{\circ}$ elle substitue une caisse des retraites garantie par l'État à leurs anciennes caisses d'épargne et de prévoyance $; 4^{\circ}$ elle cncourage les cours d'adultes, destinés aux personnes qui ont passé l'âge scolaire.

\section{Sous l'Empire.}

Régime da coup d'Éat. - La loi de 1850 avait eu pour but de subordonner l'enseignement à l'Église; le ministre ronTOOL' se proposa de l'asservir au pouvoir despolique issu du coup d'Etal.

Aux professeurs de tout ordre on imposa un serment de fidelité à ce pouvoir : refusant de le prèter, les plus illustres abandonnèrent leurs clıaires.

C'est alors que Villemain et Cousin furent mis à la retraite et que Michelet, Edgard Quinet, Mickiéwicz, Despois, Frédéric Morin, Barthélemy Saint-Hilaire, Vacherot, Jules Simon, Challemel-Lacour, Deschanel, Barni et bien d'autres, furent exclus de l'Université.

Le gouvernement mit aussi la main sur le Conseil supérieur, d'où il exclut Thiers, Beugnot, Orfila, Cousin, etc., aussi bien que sur les Conseils académiques, se réservant la nomination des membres qui naguère étaient élus. Il désorganisa l'École normale supérieure, supprima les agrégations d'histoire et de philosophie, réduisit l'enseignement de la philosophie à celui de la logique, bouleversa les programmes des lycées par la bifurcation. II anéantit les privilèges des grands établissements scientitìques, priva les professeurs de toutes garanties. Ceux des Facultés, du Collège de France. du Muséum, etc., qui étaient jadis inamovibles, furent rérocables par décret du Président; ceux des lycées furent révocables par simple arrêté du ministre; les instituteurs, par simple décision du

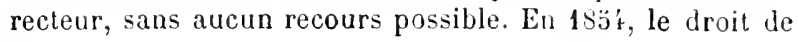


révoquer les instituteurs passa des mains du recteur à celles du préfet.

La seule mesure dont on puisse louer ce régime de violence, c'est le rétablissement des quinze académies sous leurs quinze recteurs ${ }^{1}$.

Le ministre RodLAND 2 répara une partie des maux causés par son prédécesseur : il releva l'École normale supérieure et rétablit a 600 francs le minimum du traitement pour les instituteurs.

Ministère de Vietor Durny ${ }^{3}: 1^{\circ}$ Mesures réparatrices. - victor DJROY rendit aux professeurs quelques garanties : ils ne pouvaient plus être révoqués sans avoir pu présenter leur délense ${ }^{4}$. En 1866, il fit autoriser la Ligue de l'enseigne. ment de Jean Hacé et, en 1868, les conférences publiques.

anseignement primaire. - La loi de 1867 établit une école communale de filles dans toute commune de š00 àmes, créa des écoles de hameaux pour les localités écartées, assura un logement et un traitement aux adjoints, accorda les primes aux instituteurs qui ouvriraient des cours pour les adultes, ajouta aux matières de l'enseignement èlémentaire l'histoire et la géographie, créa 10000 bibliothèques populaires annexées aux écoles.

a L'Empereur ne veut pas, éerivait ce ministre, qu'un seul enfant reste privé d'instruction pour cause d'indigence de sa famille s. En conséquence, il supprimait toute limitation budgétaire et accordait la gratuité à tous les enfants dont les familles seraient hors d'état de payer. Les commures eurent le droit d’ètablir dans leurs écoles la gratuité absolue, pourvu qu'elles votassent Jes fonds nécessaires.

Victor Duruy aurait roulu consacrer le principe de l'obligation, et il avait même gagné l'Empereur à ses vues : d'autres influences firent ajourner le projet.

3. Euseignement secondaire. - Une réforme léconde, ce fut l'iutrorluction dans les lycées et collèges de l'enseiwuement secondaire special (1865). Victor Duruy partait de cette idée qu'une faible partie de leurs élèves se destinent

1. Il $₹$ a aujourd'hui deux académies de plus : Chambéry ct Aiger.

2. Du 13 aoủt 1856 au 23 juin $1 \$ 63$.

3. Du 23 juin $1>63$ au 17 juillet $1 \$ 69$.

4. Le eret à 11 juiu 1863 . 
aux carrières de littérateurs, savants, médecins, arocats, etc., et que le plus grand nombre, au contraire, entend se préparer par une sérieuse instruction aux carières de l'industrie et du commerce. A ceux-ci il fallait offrir un programme où les études classiques et les langues anciennes feraient place à des connaissances pratiques : sciences appliquées, langue et littérature françaises, langues étrangires, géographie commerciale, notions de droit, économie industrielle et rurale. En conséquence, dans les lycées et collèges, les élèves furent partagès en deux catégories : ceux de l'enseignement classique et ceux de l'enseignement spécial. Certains établissements, dont le type fut le lycée de Mont-de-Marsan, se consacrèrent plus particulièrement aux nouvelles études. On créa l'École normale de Cluny pour leur former des professeurs, et l'on inslitua l'agrégation d'enseignement spécial.

Duruy avait projeté d'organiser l'enseignement secondaire des filles et avait crè des conlérences à leur usage; mais il lut énergiquement combattu par le clergé et faiblement soutenu par le gouveruement.

Il supprima la bifurcution, rétablit l'enseignement de la philosophie, introduisit celui de lhistoire contemporaine, restaura les agrégations de philosophie et d'listoire, créa celle de langues vivantes, organisa, pour les plus jeunes elèves, les petits collèges de Vanves, Bordeaux, Lyon, Marseille, Montpellier, etc.

Pour accroitre notre influence en Orient, il londa, daus un faubourg de Constantinople, le lycée de Galata-Sérai, ouvert aux élèves de toute race et de toute religion, et tenu par un directeur et des prolesseurs français.

4 - Enscignement supérieur. - Jusqu'alors les leçons les professeurs du haut enseignement s'étaient adressées surtout au grand public; ils avaient des auditeurs et non des élèves; il n'existait pas de laboratoires ni de conférences où ceux-ci pussent sinitier aux méthodes scientifiques, Duruy, pour opérer le rapprochement entre les maitres et les étudiants et leur donner les moyens de poursuivre leurs travaux en commun, fonda en 1867 l'École pratique des hautes études et créa de nombreux laboratoires au Collège de France, au Muséum, à İÉcole normale, dans les Facultés. 


\section{Sous la République actuelle.}

\section{Premières lois sur les Conseils et sur la liberto} de Ienseignement. - La loi du 19 mars 1873 sur le Conseil supérieur de l'instruction publique rendit à l'élection la nomination de quelques-uns des conseillers dont le chef de l'Etat, en 1852 , s'était réservé la nomination : il donnait cinq représentants élus an Collège de France et aux Facultés.

La loi 12 juillet $187 \dot{\partial}$ fut tout en faveur du parti qui, en réclamant la liberté de l'enseignement, entendait accroitre l'influence du clergé dans l'éducation. La loi de 1850 avait accordé cette liberté pour l'enseignement primaire et secondaire; la loi de 1875 accordait la liberté de l'enseignement supérieur. Les libéraux n'avaient aucun intérèt à cette loi, puisque les universités de l'État s'inspiraient du même esprit qu'eux-mêmes. Elle avait donc en vue un parti puissamment constitué, disposant des immenses ressources et de toute l'influence du clergé catholique, car elle ne faisait rien pour assurer la liberté des cours isolés, et naccordait que le droit de constituer des facullés et de les grouper en universites. Les établissements qui se créèrent en vertu de la nouvelle loi furent, en effet, des facultes catholiques et des universites catholiques.

Jusqu'alors l'État seul, par le ministère des lacultés créées par lui, avait le droit de conférer les grades de licencié et de docteur. Désormais les étudiants des facultés et universités catholiques ne seraient plus obligés de les demander à l'État : la loi créait, pour les examiner, des jurys mixtes composés par moitié de professeurs de lítat et de professeurs libres.

Eufin la loi, par son silence même, semblait reconnaitre aux jésuites et aux religieux des autres congrégations non autorisées le droit d'enseigner.

Dès 1877, il existait cinq établissements d'enseignement supérieur catholique : les quatre universités de Lille, Paris, Angers, Lyon, et la faculté de droit de Toulouse.

Il y eut une seule tentative pour constituer, en dehors du clergé, un enseignement supérieur libre : c'est la création de l'Ecole libre des sciences politiques, destinée à 
remplacer en partie l'École d'administration fondée en 1848 par Carnot. On y enseigne principalement l'histoire diplomatique, le droit constitutionnel et administratil, le droit international ou droit des gens, l'économie politique.

Lois Ferry sur les Conseils et la Liberté de lenseignement. - JULES FERRY, dans son premier ministère ${ }^{1}$, présenta aux Chambres deux projets de loi destiués à contenir dans de justes limites les ambitions de parti catholique.

Par une loi de $1880^{2}$, il réorganisa le Conseil supérieur de l'instruction publique : il en exclut les arehevêques et évèques et toutes les personnes étrangères au corps enseignant; le composa uniquement de membres appartenant à l'enseignement, à part cinq délégués de l'Institut; rendit à l'élection la nomination de tous les membres, à l'exception de treize qui étaient désiqués flar la loi ou nommés par l'État; y fit entrer, ce qu'on n'y avait pas vu jusqu'alors, des délégués des lycées, des colléges et de l'enseignement primaire. Le Conseil devint alors la large el libre représentation de l'enseignement tout entier. Au sein du Conseil reparut la section permanente, supprimée par la loi de 1850 et destinée à assister le ministre dans l'intervalle des sessions du Censeil.

Les Conseils académiques, dont les membres étaient, depuis 18ว22, nommés et réroqués par le ministre, reçurent une organisation analogue a celle du Conseil supericur.

Par une autre loi de $1880^{3}$, Jules Ferry confirma le principe de la liberté de l'enseignement supérieur, en etendit lapplication aux cours isoles, mais il interdit aux établissements libres de prendre les noms de facultes et d'universités, réservés à l'enseignement de l'État. Il abolit les jurys mixtes et rendit à l'État, représenté par ses facultés, la collation exclusive des grades. Ainsi un principe libéral, inserit dans la Charte de 1830 , recevait une nouvelle conlirmation; mais les empiétements d'un parti sur les droits légitimes de l'État étaient réprimés.

1. Du íferrier 1879 au 1 '́ novembre 1581. Jules Fesry fut une secunde tois ministre de l'instruction publique, du 30 janvier au 7 aoùt 185:?

2. Loi du 27 février 1580 .

3. Loi du 18 mars 1880. 
Un article du projet de loi avait été rejeté par le Sénat. C'était le célèbre article $7^{1}$, qui interdisait à tout membre d'une congrégation non autorisée de diriger un établissement ou d'y enseigner. Le rejet de cet article par le Sénat provoqua les decrets du 29 mars $1880^{2}$.

a kuseignement prinaire. - La troisième République eut l'honneur de reprendie les vastes plans ébauchés par la Convention en vue d'une instruction populaire et nationale : elle eut la fortune de les réaliser.

Les députés républicains avaient presque tous adopté pour programme l'enseignement primaire obligatoire, gratuit et laïque. L'école devait être obligutoire, car c'était le seul mojen de vaincre la résistance de parents aveugles ou ignorants; gratuite, car la distinction entre riches et pauvres, payants et non payants, ne devait plus exister sur les bancs de lécole, et la première leçon qu'on devail y recevoir était celle de l'égalité; laique, car l'école devait être ouverte aux cnfants de tous les cultes et de toutes les opinions, et l'on n'avait pas le Iroit de rendre obligatoire un enseignement qui aurait gardé le caractère contessionnel.

Le gouvernement républicain comprit qu'avant qu'on piit rendre l'enseignement obligatoire il lallait qu'il y eût. des étoles à la portée de tous les enfants. Les lois précédentes avaient rendu obligatoire pour toutes les commumes la création l'au moins une école; mais beaucoup d'entre elles n'avaient pas les ressour'es nécessaires. L'Étal leur vint en aide. BARDoux, en 1878, avait fait voter l'institution de la Caiss $\theta$ des écoles : cent vingt millions furent mis ¿ la lisposition des communes, moitié à titre de prèt, noitic à titre du subvention.

Lois berry sur l'enseignement primaire. - Jules Ferry fit ensuite adopter par les Chambres une série de dispositions l'́gislatives.

Lá loi de $1881^{3}$ sur les titres de capacité exigrea de tous les instituteurs ou institutrices, titulaires ou adjoints,

3. Lii du I6 juiu 1881 . 
laïques ou congréganistes, publics ou libres, la production du brevet élémentaire ou du brevet supérieur. Elle tit cesser l'injuste privilège de la lettre d'obédicnce, qui d'ailleurs abaissait le niveau de l'enseignement.

La loi de $1881^{1}$ sur la gratuité supprima la rétribution scolaire dans toutes les écoles primaires et daus toutes les salles d'asile dépendant des communes. L'Etat imposait à celles-ci de nouvelles obligations pécuniaires, mais en assumait de beaucoup plus grandes.

Laloi de $1882^{2}$ sur l'obligation interdit í tout instituteur public de Jonner l'instruction relıgieuse, désormais réservée au ministre du culte, l'affranchit de tout contrôle ecclésiastique, et donna à l'école un caraclère neutre, non confessionnel, laune. Tout père de famille lut oblige de faire donner a ses enlants l'iustruction primaire dans une école de son choix, publique ou libre, laique ou congréganist?, ou, s'il le prélérait, à la maison. Des commissions municipales scolaires étaient instituées pour assurer la fiéquentation de l'école. Quinze jours avant l'ouverture de celle-ci, la personne responsable de l'enfant est tenue de taire connaitre à la mairie de sa commune quel mode d'enseignement il cntend lui faire donner. S'il préfère l'école libre ou l'éducation domestique, la commission scolaire aura mission de s'assurer, au moyen d'examens, que l'enlant a reçu, en effet, les èléments de l'instruction. Contre leparents qui se relusent à exécuter les prescriptions de la loi, celle-ci a organisé des moyens de coercition : l'abord invitation au refiataire d'avoir à comparaitre devant la commission scolaire; puis affichage it la porte de la mairie; cufin citation devant le jugre de paix, qui appliquera les peines de police : l'amende et. au besoin, la prison.

Jules Ferry s'est appliqué activement à améliorer les progranmes, les métlodes d'enseignement, le recrute. ment des maitres. La loi de $1879^{3}$ a rendu obligatoire pour chaque département l'entreticn d'une école normale d'institutrices. Les écoles normales superioures de 
Saint-Cloud (garcons) et de Fontenay-aux-Roses (filles) préparent les professeurs pour les écoles normales. Les écoles primaires supérieures se sont multipliées ${ }^{1}$.

Larriculture, les notions d'industrie et de commerce, la gymuastique, les exercices militaires font désormais partie des programmes de l'enseignement primaire.

Ainsi, tout ce que les patriotes de la Convention avaient autrefois rèvé pour l'élucation du peuple s'est trouvé, en peu d'années, réalisé.

On a créé la Bibliothéque et le Musce pédagogique. Une chaire de pédagogie a été fondée à la Sorbonne.

Aufres lois sur venseignement primaire. - Sous le ministère de RENÉ GOBLET a été votée la loi du 30 octobre $18 \$ 6$ sur l'organisation de l'enseignement primuiro. Elle a étemlu aux Conseils departementaux le principe le lélection déjì en vigueur pour les autres conseils miversitaires.

Les représentants de l'enseignement primaire an Conseil supéricur sont élus, non plus senlement par les inspecteurs primaires et les professeurs des écoles normales, mais aussi par les instituteurs et institutriees élus euxmémes membres des Conseils départomentaux.

Nos écoles, lant materuelles que primaires, publiques ou privées son tau nombre d'environ 90000 , avec 162000 maîtres ou maitresses et 5 millions 600000 écoliers.

Des garanties sérieuses ont été accorlées aux membres du corps enseignant primaire : ils ne peuvent être ni révoqués, ni mème suspendus qu'en vertu d'un jugement du Conseil départemental.

lar les lois de $18 \$ 7,1889,1893,1900$, la siluation matirielle des inctituteurs a été notablement amíliorée.

3 Enseignement secondane. - La loi de $1880^{2}$ a fonlé l'enseignement secondaire des jeunes filles. Elle a permis, par le concours de l'btat. dus departements et les communes, la création de lycees et de colleyges de filles qui ne doivent être que des exprrmats. Cel enseignement noureau a sou Ĺcole normale supiriente à Sirres.

1. On trouvera plus loin au ehapitre Xxlll, liudiation des enseimemenls arrienles, inlustriels et eommereiaux.

8. Loi du 2I dinembre 1850 , sous le premier ministire do Jules Ianar. 
A còté des établissements officiels, comme les Lycées Fénelon et Racine à Paris, il y a des établissements libres, comme le Collège Sévigné, dans la mème ville.

L'enseignement secondaire des garçons a subi, en 1880 , une réforme profonde : le temps consacré à l'étude des langues anciennes a été réduit; l'étude du texte même des auteurs a pris plus l'importance; l'enseignement des sciences et des langues vivantes commence dès les petites classes. Sans renoncer à la haute culture classique, on s'est préoccupé des exigences de la civilisation moderne. L'enseignement spécial a été également renouvelé en I881.

En 1891 fut constitué par LE்ON BOURGEOIS l'enseignement secondaire moderne.

En 1899 la Chambre des députés forme une grande commission d'enquète qui, sous la présidence d'A. RIBot, siégrea plus de deux mois, enteudit 196 dépositions, non seulement de lettrés, de savants, de professeurs et de chels d'étiblissements, mais de délégnés de l'agriculture, du commerce et de lindustrie. Elle publia cinq énormes volumes de dépositions ou de statistiques. Elle maintint le principe de la liberté de l'enseignement, mais traça tout un plan de réorganisation pour l'enseignement secondaire de l'Ftat (mis en vigueur par les arrêtés du 31 mai 1902 : division du cours des études en reux cycles; baccalauréat à lormes diverses, mais conférant les mèmes droits).

1. Enseignement supérienr. - La loi de 1875 sur la liberté de l'enseignement avait eu au moins un résultat heureux. L'Élat prit à cœur de mettre son enseignement supérieur en état de lutter contre les concurrences que lui suscitait la loi. Il pourvut les facultes de chaires nouvelles, de bibliothèques, de collections, de laboratoires. Pour remplacer les facultés qu'on avait perdues avec Strasbourg, on créa deux nouvelles facultés de droit, quatre de médecine, deux écoles supérieures de médecine et de pharmacie. Le Musémm, le Collège de France, l'École des hautes études, l'École des langues orientales, virent accroitre le nonbre de leurs chaires. Cinq nouveaux observatoires en province, l'observatoire d'astronomie physique de Meudon, l'observatoire météorologique de Montsouris, les laboratoires de zoologie maritime de Roscoff, Concarneau, 
Banyuls, Marseille, furent fondés. Alsger fut doté de tout un ensemble d'Écoles supérieures destinées à former un jour l'Université el l'Institut africains. A l'École française d'Athènes s'adjoignit une nouvelle école d'histoire et d'archéologie chassiques, celle de Rome, et bientôt celle d’égyptologie au Caire. Une école d'Extrême-Orient s'organise.

Sous le ministère de RENÉ GOBLET, le décret de juillet 1895 donna aux facultés la qualité de personnes morales et la capacité de recevoir des lęs et des donations. Le lécret de décembre 18800 a groupé les facultés et écoles supérieures de chaque centre académique sous un Conseil général, l'ormé de trois représentants pour chacune d'elles, dont l'un est le doyen ou le directeur et les deux autres sont élus par tous les prolesseurs.

Les lois de finances de 1889 et 1893 , les décrets d'aoùt 1893, signés par R. PoIncaré, complétèrent cette organisation. Il lestait à laire voter une loi sur les universités. Un projet élaboré par L. Bourgeois avait échoué, en 189:, devant le Sénat, parce quil tendait à sacrifier les a petites universités s aux grandes. Enfin lut votée, sous l'administration d'a. Rambaud, la loi du 10 juillet 1896 qui lendit leur aneien nom d'Universités aux groupoments régionaux de facultés et d'écoles supérieures et leur assura une autonomie financière. Cette situation a encouragé les libéralités, sous forme de donations ou de less, en faveur de nos établissements; elles commencent à se chilfrer par millions.

Le service des voyages et missions scientifiques, organisè au ministere de l'instruetion publique et qui envoie ses missionnaires dans toutes les parties du monde, a donné d'importants résultats pour la géographie, l'archéologie, les sciences naturelles, et mème pour l'extension de notre domaine colonial. Une de ces missions, celle de Savorynan de Frazza, nous a valu tout un empire dans la région du Congo. La mission Foureau-Lamy, organisée en 1898, opéra la traversée du Sahara, se porta ensuite dans la région du lac Tchad, fit en mème temps l'exploration et la conquête de ce lays (1900). Une troisième mission, organisée par le même ninistere, avec le concours d'autres administrations, lut eelle du capitaine Cazemajou qui futtué à Zinder (1898). Ce ne fut pas le seul martyr de la science. Les miscion- 
naires de l'Instruction publique ont plus d'une fois payé de leur vie leur dévouement à la science. Crevaux avait péri dans la régrion de l'Amazone (1852), Crampel sur le Chari (1891), Dutreuil de Rhins au Thibet (1895). Parni les plus importantes et les plus récentes de ces missions scientifiques, citons encore celles de La Martinière au Maroc; Flamand dans les oasis de la frontière marocaine; Revoil au pays des Somalis; Sarzec, Dieulafoy, Jacques de Morgan en Perse; Bonvalot, Capus dans le Turkestan et le Pamir; Chafranjon dans la Mongolie; Bonin en Asie centrale; Faurie au Japon; Lionel Dècle, V. Giraud, Ed. Foa, à travers l'Afrique australe; Deflers lans le Yémen (Arabie); Wiener, Crevaux, Pinart, Clıarnay, Cessac, Olivier Ordinaire dans l'Amérique inconuue; etc.

C'est sous les auspices dı ministere de l'instruction publique et des beaux-arts qu'ont été entreprises la restauration de nombreux monuments en France, en Mlirierie, comme celle du Prætorium de Lambèse; en Algrérie, les fouilles de Timgad; en T:misie une partie des fouilles de Carthage; d'abord celles qu'exécutèrent Beulé. Falhe, Daux, qui fournirent ì Flaubert les éléments archéologiques de son roman de Salammbó; puis celles quont reprises, en 1877, Cailiet; en 188', S. Reinacls et Babelon; plus récemment, La Blanchère, Saladin, Poinssot, Carion, Cagnat, Diehl, Gauckier. En Grèce, les louilles de Tanagra, de Delos, de Deiphes.

5 Musées nouvearax. - Au palais du Trocadero se constituèrent le Iusee d'ethnographie, que devaient enrichir les collections rapportées par les voyageurs. et le Musee des monuments français, où figurent les reprouluctions des spécimens les plus importants de l'ancien art français, et yui réalise une idée vraiment nationale de la Cunvention.

Le Husée d'art, d'arehéologie et des religions d'Orient et d'Extrème-Orient, fondé à Lyon par Guimet, fut tran-féré à Paris.

$6^{\circ}$ Bndget de linstruction publique. - Les Chambres républicaines ont tcujours montré pour les besoins de l'enseignement une libéralité jusqu'alors inconnne. Le budget de l'enseignement primaire, qui était de 4250 tranes sous Napoléon, de 50000 francs sous la Restauration, de trois 
millions à la fin de la Monarchic de Juillet, de doüe millions à la fin llu second Empire, s’èlève anjourd'hui à près de 160 millions, sans compter les dẻpenses des départements et des communes qui atteignent presque 100 millions. Il faut y ajouter près de cinquante millions

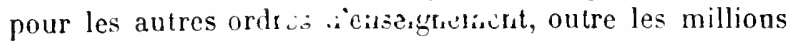
consacrés aux construclions des universités, des grands établissements scientifiques, des lycées et collèges, des écoles de tout ordre.

Olvages a consulter. - Buisson, lictionnaire pedagogique, notimbment larticle France. -- Miciel Broal. Onelques mots sur l'instruction gublignte. - II. Carnut, Le ministire de linstruction publique en 1548 (10.9\%) - Alwert Dumant, Notes et Discours (15i3-1't). - E. Lavisse. A propus de nos écoles I\$95): Eluders et etudiants (1S90); Qurstions d'enseivnement national (1855), ete. Joumlatm, Ranmort sur les proures de linstr. puthlune 1 1sij7). - Guzot, Mimaires, t. 11. - Julas Simon, Llicole IS65). - L. LinTI, Lenseignempet sup reur "a lrance 15.93 )

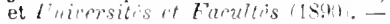

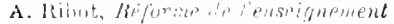

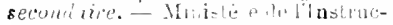
tion publique, stutslin $s$ et liap- ports sur les trois ordres d'enseignenent. - Narals de Beau hamp, liecueil des lois et reglements relatifs al"enseinnement sujérienr. - Greard, La legislation de l'enseignement primaire drp. 1759 (189i). - (Dupuy) Notiee sur l'Ecole normale. - Guizol, Villemain, Vi.tor Duruy, Bardons, Jules Ferry, Paul Beri, René Gohtet, L. Bourenois, R. Poincare, A. Ramband, G. J.evonec. Discours et Ery sis le projets de lui. - C. Rie, Lijceres ut collenges de jentres filles (Is)(i). - Le P. Didon, L'elucation presente(1si). - P. dis St-Arroman, Les misions fiamaises, caureries reosteghiques. - A. Rut haud. Ju-

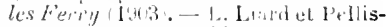
son, Instruction publigue dans Rappoi ls du jury uternat. Expos. 1900. 


\section{CHAPITE XNA}

\section{I.ES LETTRES}

\section{Le théâtre.}

Tendance a la confusion des genres dramatiques. -Entre le drame et la comédie, la barrière qui semblait séparer les genres n'a cessé de s'abaisser. Le drame admet les situations comiques, et les grandes comedies de notre temps, par le caractère de certains personnages, par la hauteur des thèses sociales qui les dominent, par la gravité des situations, souvent mème par la rigueur du dénouemenl, touchent au drame.

Entre le drame pur, qui fait verser tant de larmes aux théâtres du boulevard, et la comédie purc, qui n'excite que le rire, il y a une infinité d'intermédiaires, et c'est précisément dans ces genres mixtes que se placent les pièces les plus caractéristiques de ce siècle, celles que nos premières scènes ont inscrites comme les chefs-d'œuvre de leur répertoire. Souvent, faute de savoir comment les qualifier, on les appelle simplement des pieces. Il n'y a plus deux genres, comme au xvue siècle, le tragique et le comique, mais peut-être dix ou vingt genres dramatiques.

Le drame historique. - Pendant longtemps, les drames historiques de la première moitié du siècle, ceux de Victor IIugo, Ponsard ', Casimir Delavigne, A. de Vigny,

1. La Charlotte Corday de Ponsard (1850) est un drame avec une certaine lournure elassique, mais ce n'ost pas une tragédie. Ponsard a donné aussi le Lion amoureux (1866), dont le héros n'est autre que le général Humbert, qui, en 1798 , avec quinze cents hommes, faillit affranchir l'Irlande de la domination anglaise. Et ce n'est pas une tragédie. 
Alcxandre Dumas, défrayèrent presque seuls notre théàtre ', et il fant franchir presque une génération pour roir ce genre produire d'autres chefs-d'wurre.

LODIS BODILEET rima a la conjuration d'Amboise (1866). vicTORIEN SARDod fit jouer, en 1869. a Patrie s, sujet emprunté à la lutte des Belges contre l'Espagne; en 1875, la * Haine s, où les discordes des cités italiennes sont rendues avec viqueur; en 188't, "Théodora s; en 1887, " la Tosca s; en 1801, "Thermidor $\triangleright$, dont les révolutionnaires et partisans du blnc firent interdire les représentations; en 1895 , - madame Sans-Gêne $\triangleright$, amusante comédie taillée dans l'épopée napoléonienne. - HENRI DE BORNIER empruntait à notre épopée féodale a la Fille de Roland o (1875), et aux annales obscures des temps barbares a les Noces d'Attila . - LeCONTE DE LISLE, avec ses a Erynnies s, nous donnait une vraie tragédie grecque, non plus atténue et francisée comme celles dn $\mathrm{xvil}^{\mathrm{e}}$ siècle, mais dans la note crue des premiers tragiques d'Athènes. - FRANçors COPPÉE, le délicat auteur du a Passant o(1869), se révélait poète dramatique dans a Severo Torelli (188?), a les Jacobites \$ (1885), et a Ponr la couronne s (1893). - Joles lemaitre, tirait de son roman a les Rois o un drame palpitant de passion et d'action. - r'Dmond rostand s'est, d'emblée, placé au premier rang avee a Crrano de Bergerac o (1597) et a l'Aiglon $\triangleright(1900)$, deux drames à grande envolée lyrique; de versification exquise, souple, pittoresque; de rimes sonores, neuves, imprérues. On a pu dire qu'il nous rendait le drame en vers de Victor Hugo, mais en vers a revus par Théodore de Banville $\$$.

C'est surtout par le drame historique que s'est renouvelé chez nous lart de la mise en scène : on y voulnt. comme dans la pièce elle-mème, la couleur localc la plus exacte. Les auteurs et les directeurs de théâtre se firent archéologues, consultèrent les vieilles estampes ou les anciennes miniatures, envoyèrent des artistes dessiner, en pays lointains, les monuments, les parsages, les types humains. On fit revivre nos ancètres du moven àge dans leurs costumes, dans te décor des cathédrales, des chàteaux, des hôtels de 
ville. Quand la pièce fut égyptienne, indoue, américaine, la scène représenta des temples étudiés sur le Nil, des pagodes prises sur les bords mème du Gange, ou la nature exubérante des tropiques. Si, par un eas de plus en plus rare, on eut à faire parler des citoyens d'Athènes ou de Rome, on leur donna des costumes copiés sur les monuments antiques, au lieu des oripeaux pseudo-classiques. On déploya une magnificence inouie dans les accessoires; les plus fameux peintres furent chargés de brosser les décors; les costumiers les plus habiles reproduisirent les armures, les bijoux, les draperies. La décoration de - Théodora $\triangleright$, par exemple, fut une résurrection complète de la Constantinople de l'empereur Justinien, de son Hippodrome et de sou Palais impérial.

Le drame populaire. - Nous ne nous occuperons du drame bourgeois ou du drame populaire que pour signaler la continuation des succès de DENNERY, l'auteur de plus de cent pièces, parmi lesquelles : a la Gràce de Dieu "(1841), - les Bohémiens de Paris (18'3), a la Case de l'oncle Tom s (1853), tiré du fameux roman américain de Nme Beecher Stowe, a les Deux Orphelines d, a les Mrstères du vieux Paris s (1865) : Cette forme de drame, yui a inspiré a les Deux Gosses » de Decourcelles, conserve et conservera toujours un public; et, chose à noter, ce sont les pièces les plus anciennes, celles qu'on peut considérer comme étant l'entance de l'art, qui obtiennent auprès d'un auditoire populaire le plus éclatant succès et qui sont le plus souvent reprises.

La conédie de mcurs et de caractères. - La comédie de mours, c'est le triomphe de l'art français. Laissant $\dot{d}$ Molière les grands types éternels de l'Avare et du Misanthrope, auxquels on ne peut guère toucher après lui, elle a ètudiè les types secondaires, que présente l'infinie variété de notre civilisation si compliquée; les situations tragiques que fait naitre la lutte des mceurs et des lois; le conflit de la sociétí nouvelle issue de la Révolution et de l'ancienne socièté figée dans les idées d'autrefois : les unions mal assorties, les naissances irrégulières, source quotidienne de drames domestiques. Elle a fouillé arec une analyse pénétrante, une exactitude cruelle, les plaies so- 
ciales. Elle a agité les thèses les plus audacieuses et parfois les plus subversires. Elle s'est maintenue à une certaine hauteur classique; aussi emploie-t-elle l'alexandrin presque aussi souvent que la prose. Elle a été d'une telle lécondité que vraiment on ne peut songer a citer mème toutes les grandes œurres.

PONSARD nous a donné en ce genre a l'Honneur el l'Argent . (1853), et a la Bourse ๖ (1856); - Émile augier, a l'Aventurière ১ (1848), « Gabrielle ๖ (1849), a le Gendre de Monsieur Poirier o (1855, en collaboration avec Jules Sandeau),

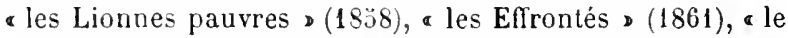
Fils de Giboyer ๖ (1862), a Maitre Guérin ๖ (186'), a Paul Forestier \(1868), Malane Caverlet \(1876), “ les Fourchambault (1879); - GEorge SAND, a le Mariage de Victorine (1851) et a le Marquis de Villemer (186:-); - OCTave FEULLLt, - Dalila (185i) et a le Roman dun jeune homme pauvre (1838); - joles sandead, « Mademoiselle de la Seiglière , (1834) et a la Maison de Penarvan - (1863); - CAMIlle Dodcet, - la Chasse aux fripons o (1846), a les Ennemis de la maison (18.00), a le Fruit défendu , (185\%); - Lara, a le duc Job D (1839); - Pailleron, a les Parasites \(1860), \& les Faux ménages • (1369), « le Monde où l'on s'ennuie , (1879); - alexandre domas fils, a la Dame aux Camélias , (1852), a le Demi-Monde ๖ (1855), a le Fils naturel (1858), - le Supplice d'une femme (1863), a les ldées de Madame Aubray D (1867), a la Princesse Gcorges จ (1871), "Monsieur Alphonse D (1873), a la Femme de Claude • (1873), - l'Érangère > (1876), a la Princesse de Bagdad ১(1887), - Franeillon (188\%); - les frères de Goncourt, Henriette Maréchal o (1864); - vacouerie, a Jean Baudry ๖ (1863).

VICTORIEN SARDOC, qui avait débuté par une pure comédie d’intrigue, a les Pattes de Mouche s, s'est élevé à la comédie de mœurs dans a Nos intimes D(1861), " les Ganaches , - la Famille Benoiton ग(1865), "Nos bons Villageois , (1866), “ Séraphine " (1868). Il a donné en 18\%:, dans "Rabagas ๖, un essai de comedie politique.

Il faut marquer une place très honorable aux pièces de LĖON GOZLAN, dont le clicf-d'œuvre est pent-ètre les a Faux bonsliommes D (1856); - d'HeNRY Becoue, d'observation intense et pessimiste : le Corbcau ๖, ‘ la Parisienne •; - 
de Joles lemaitre : " Révoltée ", " Mariage blanc ", " le Pardon ", "l'Aînée ", " le Député Leveau ", vigoureuse satire politique, "La Massière "(1905); - de JEAN RICHEPIN : "Par le Glaive ", "Le Chemineau " $(1897)$; — d'henri Lavedan : "le Prince l'Aurec", "le Duel "; - de Paul Ilervieu, PortoRiche, Eugène Brieux, Maurice Donnay, François de Curel.

Notons le succès, dans ces dernières années, du Théâtre Libre, dirigé, joué et parfois rédigé par Antoine, et la mise en scène de pièces à inspiration scandinave ou russe : d'Ibsen et de Tolstoï.

Le vadeville, la comédie fantaisiste. - Nous ne pouvons mème penser à signaler les innombrables comédiesvaudevilles, parfois simples levers de rideau, qui continuent les joyeuses traditions de la vieille France. Arrètons-nous, du moins, sur la comédie fantaisiste, qui n’a point la prétention de soulever des thèses sociales ou de tracer des caractères. Elle part d'une observation exacte des mours et des caractires, mais elle grossit, exagère, pousse tout au comique, parfois au grotesque, comme si elle ne visait qu'à exciter le rire. Elle a ses titres de noblesse dans le passé : on pent lui donner pour ancètre Molière avec ses - Fourberies de Scapin ๖. C'est là qu'a excellé Labiche (1815-1888), lui qui a su mieux que personne mêler l'observation et la fantaisie, qui a semé avec une telle richesse, dans les cent pièces qu'il a produites, les trajts de mours et les traits humoristiques, qui a fait entrer avec lui à l'Académie française la comédie du Palais-Royal. Qui ne connait Embrassons-nous, Folleville (1850), " le Chapeau de paille d'Italie s, Elgard et sa bonne (1852), - le Misanthrope et l'Auvergnat ๖, a l'Affaire de la rue de Lourcine D(1857), a le Voyage de Monsieur Perrichon , (1860), c la Cagnotte (1864), a les Trente millions de Gladiator D (1873)?

v. SARDOd a mis la main aussi à l'ocuvre et nous a donné une des meilleures comédies de ce type : « Divorçons $\triangleright(1880$ ).

Toutes ces pièces, qui eurent une si merveilleuse collection d'interprètes désopilants dans les acteurs Geoffioy, Ravel, Gil-Pérès, Ilyacinthe, Grassot, Brasseur, Lhéritier, Lassouche, Léonce, Dupuis, ont dejà fait rire, d'une gaieté saine et de bon aloi, deux générations de Français. 
Bien qu'elles se prètent difficilement à passer dans une autre langue, elles ont été traduites sur presque tous les theàtres étrangers.

Dans les mèmes donnèes. on ne peut oublier gondinet avec Gavaud, Minard et Cie $(1869)$, e le Chef de division D, \& le Pantche s, a les Convictions de Papa s; BENNEQUIN, FEYDEAJ, BISSON, dont les pièces, d'un mouvement en diablé et qui rappellent les anciennes pantomines, exigent un luxe inouï d'armoires où l'on se cache et de portes qui s'ourrent et se ferment sans cesse; - tout le théåtre de MEILHaC el BALĖvy, dune grâce si parisienne, et qui a fourni ses meilleurs livrets à Jacques Offenbach.

La féeric, la revue. - Un genre, qui n'a pas été inconnu des siècles précédents, car on peut $\mathrm{y}$ faire rentrer - le Songe d'une nuit d'été ๖ de Slakespeare, a l'Illusion comique de Corneille et a l'Amphitryon de Molière, mais qui a pris en notre siècle un développement extraordinaire, cest la féerie. On peut douter si, telle que nos contemporains l'ont concue, elle rentre encore dans le domaine de l'art : l'étude des caractères, l'agencement d'une intrigue bien ordonnée, la pureté du style, semblent être les moindres de leurs soucis. La meillenre part de leur succès revient assurément au décorateur, all costumier, surtou au machiniste, qui, pour donner une idée de la puissance des fées, des enchanteurs, des génies, ou de l'efficacité des talismans les plus bizarres, est obligé d'inventer sans cesse des trucs, des changements à vue du décor, des transformations à vue des persomnages. Comme il faut que ceux-ci soient mis en pieces par des explosions de chemins de ler. qu'ils voyagent au-dessus des nuées, au-dessous des caux, à trarer's les flammes, qu'ils prennent la taille d'ur. giant ou se rapelissent a celle d'un eufant, toutes les res. sources quoflie la science, feux de bengale, reflets magiques, lumière électrique, doivent être mis en jeu. Tous nous bornerons à mentionner les plus anciennes pièces de ce genre, un peu démodées aujourdhui et qu'on a dî rajeunir par de nouvelles inventions, comme a les Pilules du biable s et a le Pied de monton .

Le senre s'e-t releré, avec JULES VERNE quand la science et la géographie s'en sont mélées, quẹ la ténacité et 
l'énergie de l'homme se sont substituées à la vertu de la baguette magique et à l'infaillibilité des talismans: - Michel Strogof » et a le Tour du Honde en quatre-vingts jours sont des fécries par la magnificence et la fantaisie et de la mise en scène, mais presque des drames par le tragique de certaines situations et la robuste vaillance des héros.

La rerue est une autre forme de féeric; car, sous prétexte de nous dérouler les faits le plus piquants de l'année écoulée, elle nage aussi en pleine fantaisie et, pas plus que la léerie, ne peut se passer des changements à vue; mais relève-t-elle de la littérature?

\section{Les autres genres littéraires.}

La poésie épique et lýrique. - Le grand poète national, dans la seconde moitié du siècle comme dans la première, c est toujours victor BUgo. Il a peut-ètre encore grandi dans les vingt années d'exil qui ront des barricades de décembre à sa rentréo dans Paris menacé par les Prussiens.

Alors paraisseut a les Chatiments " (1853), a les Contemplations " (18:30), a la Légende des Siècles × (18:39), a les Chansons des rues et des bois o (1863), a l'Année terrible ๖ (15:3), la secunde partie de a la Légende des Siècles: (1576). Mais sont-ce des curres destinées à survivre que a l'Art d'etre grand-père s, a le Pape s, a l'Ane s, a la Pitie suprème s?

Les plus remarquables peut-être de ses poésies, ce sont celles qui ont le earactère militant. L'attentat de décembre, le parjure de l'ancien Président de la Réprublique, les massacres de la rue, loppression hypocrite ou riolente, lui ont inspiré les vers indignés des Châtiments. C'est ce qu'il y a de plus ajrect de plus sanglant parmi tous les pamphlets connus; et rarement linspiration de Victor Ilugo a été plus haute et la forme plus artistique. Du contraste des strophes idylliques et de la diatribe furieuse, comme dans a les Abeilles du manteau impérial $\triangleright$, du contraste entre les grands tableatix épiques et l'invective violente et sans trève, conme dass cette admirable piece qui s'appelle - l'Expiation s, il a su tirer les effets inattendus. 
Un autre altentat, linvasion du sol francais par les hor ies étrangères, lui a inspiré ce digne pendant des Châtiunents : - l'Année terrible d.

Outre théophile gautier, dont les a Émaux et Camées . (185:-1874) sont de cette période, il faut citer THÉodone de BANville, ce merveilleux artiste de style, qui, daus ses adelettes o et ses "Odes funambulesques $\triangleright$, joue et jongle avec les difficultés du vers; - Baddelaire, l'auteur des - Fleurs du mal (1857), le dernier venu et le plus turbulent de l'école romantique, qu'aucun sujet, si horrible et répugnant qu'il soit, ne fit reculer, mais dont Victor Ilugo disait qu'il avait créé a un frisson nouveau :; LECONTE DE LISLE, dont le vers a l'ampleur et la rudesse des poètes primitifs avec toutes les recherches de l'art moderne, et qui est allé chercher aux sources mêmes de la poésie ses a Poèmes antiques (1852) et ses a Poèmes barbares • (1862); 一 J. M. DE нÉRÉDIA, avec ses a Trophées », sonnets sans délauts, qui sont comme une Légende les siècles a en médailles ; - FRANÇOIS COPPÉE', SULLY-PRDDHOMME, CATULLE MENDÉS, JEAN RICHEPIN, Xavier de Ricard, Eugène Manuel, Jean Lahor (Cazalis), Jean Bertheroy, Maurice Bouchor, Dorehain, Haraucourt, Jean Rameau, Clovis Ilugues, llenri de Reguier, Albert Samain, Raoul Ponchon, etc., si différents de tempérament et de nature, mais ayant tous ce trait commun : la recherche anxieuse de sujets, de formes et de rythmes encore inédits.

Paul Verlaine et Stéphane Mallarmé ont passé pour des chefs d'école, pour les a princes ๖ des poètes symbolistes, esthètes et nème décadents, dont le nombre est légion. Ils sont en poésie ce que furent en peinture les impressionnistes. Ils suscitèrent les mêmes engouements et les mèunes dénigrements. Peut-être, sans avoir fait ouvre qui soit plus durable qu'une mode, ont-ils contribué à rendre la poésie plus libre, plus souple, plus mélodieusement vague, nuancée comme de la musique.

1. Francois Coppée figura, en 1866 , parmi les collaborateurs du Parnasse contemporain; il n'a pas seulement donnè le Reliquaire, les Intimités, les Poèmes morlernes (dans lesquels se trouve la Greve des Forgeronsl et d'autres recueils de poésies : nous venons de voir qu'il a su aborder aves succès le théătre. 
I'resque chaque province française a eu ses poètes amoureux d'elle. Pour la Bretagne, Brizeux, Le Goffic, Le Braz; pour les grives du Nord, Jules Breton; pour la Lorraine, André Theuriet; pour l'Auvergne, Marc, Fabié, Pierre de Nolhac; pour la Franche-Comté, Grandmougin, Frédéric Bataille, Henri Pauthier; pour la Bresse, Gabriel Vicaire; pour le Berry, Maurice Rollinat; pour la Provence, Paul Arène, Jean Aicard, Georges Gourłon, ete. La Bretagne a eu également ses poètes en langue bretonne: Luzel, Prosper Proux. Le Midi de la France a eu ses fellbres : Frédéric Mistral (" Mireille ১. 1850; l’Ode aux Catalans, 1861; a Calendau s; la tragedie de la "Reine Jeanne s); Joseph Roumanille; Fèlix Gras (Roumencero Prouvençal, 1888); Aubanel (le drame de a Lou Pan dou Pescat ). L'association du Félitrige, fondé en 155't, s'est donné des statuts dans la solennelle assemblée de 18\%6, en la grand'salle des Templiers d'Avignon.

La Chanson. - A còté de Béranger, dont la verte vieillesse était encore féconde, s'est élevé un autre chansonnier, PIERRE DOPONT. Plus éloigné que Béranger du xvile sièele el de sa joyeuse insoueiance, venu à un moment oủ, sous la Révolution libérale, commençait à gronder la Révolution sociale, Paul Dupont créa une clianson d'une inspiration grave, d'une poésie plus sincèrement populaire, quaccompagnaient non plus les airs connus el faciles diautrelois, mais une mélodie originale et forte. Quel charme agreste dans ses a bueuls s, dans la a Vigne s, dans le a Chant du Pain •, dans la « Chanson du Blé », dans la « Vache blanche $\triangleright$ ! Quelle inspiration élevée et parlois menaçante dans son a Chant des nations (1847), son * Chant des transportés ॰, son “Chant des soldats $\triangleright$ !

L'ouvre de GOSTAVR NADADD, donl le premier recueil parut en 1S 4 , se distingue par une philosophie douce et moqueuse, une bonliomie narquoise. C'est lui qui, dans ses - Deux gendarmes D. a créé le type immortel de Pandore. La chan-un de PAOL DÉROdLÉDE, un combattant de 1870, est d'iuspiration tunte guerrière : "Chants du soldat, " Harches et sonmeries ๖. Il a presque été pour nous ce que furent, en 1813 , les poètes soldats de l'Allemagne en révoute contre Napoléon. 
Et comment ne pas donner un souvenir aux poètes a de Montmartre s, à leur verve gouailleuse et a rosse s, pour laquelle ne furent jamais sacrés ni le Palais-Bourbon, ni l'llôtel de Ville, ni le peuple souverain, ni ses meetings et manifestations, pas mème, de quelque nom qu'il s'appelât, le chef de I'État.

Le roman. - Le roman n'est point, comme le théâtre, soumis à la censure officielle; il n'a point à compter arec certaines convenances, certains préjugés, qui s`imposent à un public dès qu'il est rassemblè dans une salle de spectacle; il n'est point aux prises avec les difficultès de la inise en scène. Il peut tout essayer, tout oser. Le roman exprime donc plus exactement et plus largement que le théàtre les évolutions ou les révolutions littéraires du xixe siècle. C'est là qu'on voit, le plus nettement, ḋ lécole classique succéder le romantisme, à celui-ei le réalisme et le naturalisme.

Le roman a pris toutes les formes imaginables : il a produit chez nous non pas des centaines, mais des milliers d'œurres. Dans le nombre, il y en a une infinité de remarquables et beauconp de tout à lait exquises. C'est dans ce genre que la supériorité littéraire de la France est le pilus incontestable, à tel point que trois pays seulement, l'Angleterre, les États-Unis, et, depuis peu, la Russie, peurent soutenir, mais de loin, la comparaison, et que nos romans sont lus depuis le far-eest américain jusqu'au fond de la Sibérie. Le difficile esi donc de faire un choix, et l'on conçoit que nous ne puissions mème nommer tous les écrivains de mérite, encore moins toutes les æuvres de quelque valeur.

Près de trente ans après son dernier roman d'inspiration romanti(jue, VICTOR HOGO est revenu au roman. II y est revenu avec une préoccupation plus vive des thèses sociales ou politiques, arec un style fort dillérent, beaucoup moins simple, intiniment plus travaillé, et subissant jusqu $\ddot{a}$ un certain point l'influence des nouvelles écoles. En 1862, paraissent a les Misérables , l'ouvre la plus importante de sa stconde manière, où il essaye de réhabiliter les victimes de l'injustice sociale : Fantine, la fille perdne, mais l'admirable mère; Jean Valjean, le lorcat vertueux; Gavroche, l'enfant abandonné, le gamin de Palis, un melange de per- 
versité et de générosité, spirituel, ingénieux, intrépide. Le jour même où parut ce roman à Paris, il était déjả traduit en neuf langues et affiché simultanément chez les libraires de Londres, de Madrid, de Berlin, de Saint-Pétersbourg, de New-York. Puis rinrent a les Travailleurs de la mer (1866), scènes de la vie populaire du littoral, drame à la fois réaliste et fantastique, que caractérise assez bien le combat de Gilliatt et de la pieuvre. Puis a l'Homme qui rit $>(1869)$, où les personnages sympathiques sont un saltimbanque défiguré par des pirates et qui se trouve ètre un pair d'Angleterre, une comédienne aveugle et un loup apprivoisé. Enfin, Quatre-vingt-treize o (1874), un épisode des guerres de Vendée, mélé de fraiche idylle et d'épopée titanesque.

Les stylistes de la poésie furent en même temps ceux du roman : THĖOPHILE GAOTIER, qui mit vingt années à ciseler son a Capitaine Fracasse ๖ (1863), et réussit à exprimer liimpalpable dans a Spirite o (1866); - PROSPER MÉRIMĖE, qui laisse des contes d'une brièreté élégante, d'une langue exquise, comme a Matteo Falcone $\triangleright$, a la Vision de Charles XI ๖, a l'Eulèvement de la redoute $\triangleright$, \& Colomba $\triangleright$, a la Vénus d'llle s, a Carmen s; - THÉodore de banville, un autre charmeur, dans ses a Esquisses parisiennes $>$, ses Contes héroïques, féeriques, bourgeois, etc.

D'autres se recommandent ou par l'analyse exacte, ou par l'intrigue ingénieuse, ou par la fantaisie originale: JULES SANDEAD, initiateur et collaborateur de George Sand; - octave fedillet, comme lui romancier avant d'ètre dramaturge, dont on lira toujours " le Roman d'un jeune homme pauvre (1858); - ALEXANDRE Domas fils, arec * la Dame aux Camélias > (1848), a le Roman d'une femme s;

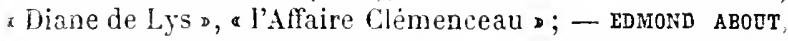
arec a Tolla (1850), a les Mariages de Paris ১, a les Mariages de province $\triangleright$, avec ses romans à donnée fantastique, a le Yez d'un Yotaire $\triangleright$, a le Cas de Monsieur Guérin $\triangleright$, a le: I urce ", "l'Homme à l'oreille cassée s; — GEORGES OBNET, qui a rencontré un facile succès avec sa série des a Batailles de la vie s; - cherbuliez, avec son a Comte Kostia $\gg$ et - l'Aventure de Ladislas Bolski s; - PIERRE Loti (Viaud), arec ses épisodes de la vie océanienne, indo-chinoise, sur-

R. Cinil. Cont. 
tout avec ce chef-dœurre, \& Pêcheur d'Islande s: FERDINAND FABRE, avec ses scènes de la vie cléricale, "l'abbé Tigrane $\triangleright(1873)$ et cucifer $\triangleright$, où il a su, sans y laire intervenir l'amour, ce grand ressort des romanciers, nous intéresser et nous passionner.

C'est l'analyse pénétrante de la passion amoureuse, une subtile intuition de la psychologie féminine qui caractérisent les romans mondains de PAOL BodRger : c Cruelle éniome ", "luglle tragique ", "Le Fantóme », "L'Elape" (1903, "Un dirorce " (i90): - danatole fraince: "Le Lys Rouge "; - de Marael PRÉvost : " liutumne d'une femme ", "les Demi-Vierges ", et a les Vierges fortes".

Comment énumérer les ouvres mème excellentes d'ANDRÉ Thedriet, qui entend le roman et l'idylle comme George Sand; - Jolfs Claretie, qui a réussi dans le roman contemporain, Monsieur le Hinistre $\triangleright$, aussi bien que dans le roman d'histoire, a le Beau Solignac s; - Lodovic Halévy, un conteur un peu gaulois, à qui un livre bien pensant, " l'Abbé Constantin s, a ouvert l'Académie; - hector malot, le roman. cier du lojer; - JEAN RICBEPIN, tour à tour de sentiment pro. fond " (La Glu o, " Madame André o) et de fantaisie débridée jusqu à la démence ( l'Aimé o, a Lagibasse o).

Il faut malquer sa place à l'école réaliste ou naturaliste. Lètude du récl est poussée bien avant déjà chez Balzac, George Sand et quelques-uns des auteurs cités plus haut. De nouveaux venus leur reprochèrent de s'ètre bornés a scruter l'homme moral. Il fallait s'attaquer à l'homme physique. Il s'agissait dexpliquer l'amour, la haine, la jalousie, la colère, par l'influence directe des choses sur son organisme, sur ses nerfs, sur ses sens. Il fallait analyser non seulement ses sentiments, mais ses sensations; non seulement ses aspirations, mais ses appétits; non seulement ses passions, mais ses maladies; le traiter non senlement par la psychologie, mais par la physiologie, mème par la pathologie. Le romancier ne dui pas se bolner à plonger dans les bas-fonds et les cloaques de la société, mais fréquenter les laboratoires, les eliniques, les salles d'anatomie. C'était, comme on le voit, la lutte des systèmes philosophiques transportée dans la littérature : le roman arait été spiritualiste, il tendait à devenir matérialiste. I 
avait considéré l'homme comme libre de ses actions, il allait exagérer l'influence de la fatalité physique, de la latalité héréditaire, de la fatalité des milieux. C'était la doctrine déterministe appliquée à la psyehologie. Le rôle de l'ho:nme diminuait, celui des choses devenait prépondérant. Etant donnés la complexion physique d'un personnage, le tempérament que lui avaient transmis les auteurs de ses jours, l'état plus ou moins électrique de l'atmospluère, le degré de température indiqué au thermometre, on derait préciser à l'avance ce qu'il ferait dans telle ou telle circonstance, à tel point, à telle heure. L'art consacrait toutes les ressources de la langue la plus riche à exprimer les couleurs, les sons, les odeurs. Surtout il devait tout oser: pour l'art noureau, la notion de l'indécent, de l'immoral, de l'immonde n'existait pas.

Il y a une quarantaine d'années que ces tendances saccentuèrent dans a Une Vieille maitresse, de BARBEY D'AUREvLLLY (1831); - dans a Madame Bovary o (1837), dans a l'Educalion Sentimentale o (1869) de rladbert; - plus encore dans - Fanny p (180̈8) de feydead. C'est done à peu près aux premières années du second Empire qu'on peut laire remonter les origines de la nouvelle école. Les rrais maitres, ce furent ensuite les Goncourt et Émile Zola.

- Renée Mauperin $\triangleright$, des frères DE Goncodrt, qui parut en 1864, est une étude presque pathologique. Leurs autres romans, depuis a Germinie Lacerteux o jusqu"d a la Faustin s, portent plus ou moins la marque de l'école.

Émine zola, à l'exemple de Balzac, donna un titre générique aux nombreux romans qu'il produisit, année par année, avec une régularité de bureaucrate. Ce titre, c'est - les Rougon-Macquart, histoire naturelle et sociale d'une famille sous le second Empire o. Tous ses héros sortent de cette lamille unique; il a dressé soigneusement leur généalogie, indiqué exactement de quelle allection morbide étaient atteints le père et la mère de chacun d'eux, tenu compte des faits d'atavisme, des infirmités, des tares qui peuvent sauter une génération. Tous, citadins ou paysans, prètres ou sollats, banquiers ou chemineaux, minis. tres ou ouvriers mineurs, artistes ou marchands de volailles, mères de famille ou courtisanes, souffrent donc 
de quelque névrose, c’est-à-dire de quelque lésion du système nerveux. Cela détermine presque tous leurs actes. Ces douze ou quinze romans nous montrent donc des gens qui, laisant le bien et le mal, ne sont ni bons ni méchants, car ils ne sont pas libres, subissant obscurément l'action des choses ou la fatalité du sang. C'est ce qui donne à tonte cette auvre un caractère sombre et pessimiste.

Ce qu'il faut admirer cependant, c'est la puissance de travail de l'auteur, l'activité qu'il déploya daus une enquête qui touche à tous les mondes, et qui tail que, après telle étude préparatoire à un de ses romans, il pourrait apprendre à un directeur de théàtre ce que c'est que les coulisses, à un inspecteur de la halle ce que c'est que la halle, à un forçat ce que c'est que l'argot, à un négociant ou à un ingénieur ce qui se passe dans les grands magasins de Palis ou dans les mines du Nord, à un médecin ce qu'est la tuberculose ou la neurasthénie.

Ce qu'il faut admirer encore, e'est l'opulence prodigieuse de cette langue, accrue de termes empruntés à cent métiers différents, renouvelée par des assacialions et des combinaisons de mots inattendues, qui vous fait entendre les sons, respirer les odeurs, soulfrir de la pesanteur de l'air, de la chaleur ou du froid. La palette du peinire-romaneier est si riche en couleurs qu'elle rendra aussi bien la vègétation luxuriante et fleuric dı paradou, les débris informes et fétides qu'on balaye aux Halles, les noires et étouflantes galeries des mines. Il semble que le beau et le lail. le splendide et le hideux, soient éganx devant l'œil indifférent de l'artiste : on dirait méme que le laid et le répuwllant aient pour lui quelque attrait spécial.

GUY DE MAUPASSAIT procede certainement de Flauberit, yui rut son parrain, et de Zola, dont il fut le commensal. Comme lauteur de Madanic Bovary et comme l'auleur de la Curée, il se pique de la précision naturaliste dans l'observation, et il ne voit pas l'humanité en beau. Les êtres ju'il met en seènes dans Bel-Ami, Nont-Oriol, les Contes de la Bicasse, etc., obéissent aveuglénent à leurs appétits purenent animaux, à leurs instincts de sordide avarice ou de basse volupté. Cependant, à la fin de sa carrière si prématurément terminée, il semble s'ètre lait en lui une 
réaction d’idéalisme, et ses romans de "Pierre et Jean ", "Une Vie ", Notre Cour ", et surtout "Fort comme la Mort ", trahissent en lui une sensibilité raffinée el une conception plus élevée de la vie et de l'amour. Le pessimisme de Flaubert est devenu chez Maupassant une lassitude et une désespérance : "La vie, si courte, a-l-il écrit, devient parfois insupportable. Elle se déroule toujours pareille avec la mort au bout... Il semble qu'on va mourir demain sans rien connaitre encore, bien que dégoùté de tout ce que l'on connaît. Alors on se sent écrasé sous le poids de l'éternelle misère de tout, de l'impuissance humaine et de la monotonie des actions."

CATULLE MENDÉs, dans ses contes et ses romans, se montre, comne dans ses vers, un maitre de la langue, avec une recherche de perversité. Dans "Gog " il s'est essayé au roman d'hisloire contemporaine.

PAUL ADAM ("La Force ", "Basile el Sophia ", "Au colcil de juillet ", "le Serpent noir "), A. Ilermant, Lucien Descaves, Léon Cladel, restent dans la note naturaliste : Je la violence, parfois outrée, mais une réelle vigueur.

ALPHONSE DAODET tient par certains còtés à l'école malu. raliste: sa vive nature méridionale, un goìt plus chàtié, une nature d'artiste moins puissante, mais plus exquise que chez Zola, l'ont préservé des exagérations. Il n'y a pas rien que du fatalisme dans son a Nabab s, éturle historique sur le duc de Horny, dans a Fromont jeune et Rissler ainé a, a Numa Roumestan ๖, « les Rois en exil », “ Sapho s. L'auteur des - Lettres de mon moulin $\triangleright$, des a Contes du lundi „, de - Tartarin de Tarascon ๖, de qui se dégage une gaieté si saine, n'est point un pessimiste.

Ce tableau du roman français au $\mathrm{xx}^{\mathrm{e}}$ siècle est encore bien incomplel, mais comment le suivre dans toutes les directions où il se lance : - le roman satirique, qui inspire à henri monnIER ses a Mémoires de Joseph Prudhomme • (1857); a EDMOND ABOUT, son a Roi des Hontagnes s (1836), un commentaire animé de sa a Grèce contemporaine s: à Édouakd DE LABOdLAYE, « Paris en Amérique d, critique de nos habitudes de routine (1863), et a le Prince Caniche s. satire des éducations princières; - le roman national, itre la riche collection des récits d'ERCKMANN-chatrian; -- le roman 
archéologique, qui, dans le a Roman de la Momie (1870) de THĖophiLE GadTier, nous rend l'Égypte des Pharaons et de l'Hébreu Joseph; dans la « Salammbô ๖ (1862) de FLAdBERT, ressuscite Carthage, ses oligarques sans scrupules, ses prètres féroces et dresse sur ses places la tragique idole de Moloch; avec JEAn BERTheroy ( « Cléopâtre ๖, a le Mime Bathylle $\triangleright$, " la Danseuse de Pompéi ") nous initie à l'élégante sensualité, parfois si étrangère au sentiment, de la vie antique; avec LÉON CAHON ( a le capitaine Magon „, "les Mercenaires ๖, « la Bannière Bleue „, « la Tueuse », - Hassan le Janissaire o) nous force à comprendre l'état d’àme des peuples les plus anciens et des hordes les plus farouches; avec ROSNY nous améne à sympathiser avec l'éveil des idées et des passions dans l'humanité préhistorique; - le roman scientifique, où, mè]ant les données les plus exactes de la science à la fantaisie la plus effrénée, JULES VERNE nous fait accomplir le tour du monde en quatrevingts jours, hiverner dans les glaces du Nord, visiter l'Afique en ballon, parcourir vingt mille lieues sous les mers, voyager au centre de la terre, aller dans la Lune et en revenir; où ANDRÉ LAORIE nous fait, avec ses a Naufragés de la Terre s, séjourner dans notre morne satellite; - le roman politique, avec MAURICE BARRÉs notamment dans ses « Déracinés D et a l'Appel au Soldat (1900); avec MELCHIOR DE VOGOE், dans les a Horts qui parlent \$ (1899), avec les frères Margueritte dans leur trilogie de l'Année terrible, dont le premier volume fut le "Désastre "; romans politiques anssi, puisqu'ils étudient l'âme alsacienne sous le régime allemand : "les Oberlé " de RENÉ BAzIN (1901) et "Au service de l'Allemagne " (1905) de Burrès, - le conte fantastique, où excella ErckmannChatrian (Contes du Rhin et de la Montagne, ete.); le conte pour les enfants. 'jai nous a valu les charmants livres d'Alired Assolant; les "Contes bleus " et les "Contes de tous les pays ", de Laboulaye; "les Braves gens " et "Nous autres ", du spirituel professem Girardin.

Le roman-feuilleton, qui est surtout le roman d'aventures et qui, à la génération précédente, a lait la joie de toutes les classes de la société, rencontre moins de favenr dans le public mn jeu cultivé. Aussi a-t-il décliné. Il sufit 
de constater que d'Alexandre Dumas nous sommes tombés à Ponson du Terrail et des "Trois Mousquetaires " aux aventures du forçat Rocambole (1859).

La eritique litteraire et artistique. - Des ceures magistrales des Villemain, des Sainte-Beure, des Saint-Marc Girardin. il n’y a aucune irrévérence à rapprocher "lllistoire de la littérature anglaise " de TAINE 186t, ou il explique la littérature anglaise par l'Anglelerre ellemème et par le tempérament britannique; les Lundis de FRANCISQUe SARCEy dans le jourual le Temps, où, ì propos d'une comédie ou d'un simple vauderille, il s'altachait à meltre en lumière les conditions essentielles et les règles permanentes de l'art dramatique; - les clironiques the trales de jules lemaitre, de larkoumet, Jémile fagoet, de René Toumic, celles d'A. Filon sur le théatre anglais.

$\Lambda$ près Guzot et ses études sur Corneille (185̆1) et sur Shakespeare, il y a encore une belle flace pour PAOL DE saint-victor, arec les a Femmes de Gocthe , et a les Deux Masques s, essai de critique appliquée à l'antiquité:PRÉVOST-PARANOL, ses a Études sur les moralistes lrançais o el ses a Essais de politique et de littérature $\triangleright$; J.-J. WEIss, et ses a Essais sur la littérature francaise \$; SaINte-becte, ses a Lundis s et a Kouveaux lundis $D ;-$ BERSOT, el ses atudes sur le XVII ${ }^{\ominus}$ siècle „; - BRDNETIC̀re, ses pénètrantes recherches et ses éloquentes conférences sur les grands écrivains de la France.

Dans la critique d'art, citons les a Études sur l'histoire de l'art ๖, de Louis vitet; l' " llistoire des peintres », de charles BLANC; "la Ihilusophie de l'art en Italie s de TAINe; les sulons du statuaire Guillaume, d'Edmond About, Pikul Mantz, Charles Bigot, Charles Yriarte, André Michel.

L'éloquence dn barrean. - Au barreau, notre génération a pu entendre plailer CHAIX D'EST-ANGE, dont le souple génie triomphait aussi bien dans les causes civiles, criminelles ou politiques; - Jules Favre, qui avail débuli, en 183ă, par sa défense des accusés d'Arril; - LAchaud, qui a parlé dans tant de causes célèbres el qui entreprit la tâche impossible d'innocenter Bazaine; - Marie, qui plaida dans le a Procès des Treize $\triangleright$; - Allou, si clair et si persuasif, lavocat de Prouthon, d'Émile de Girardin (1866), 
de Gambetla (18\%i): - Rousse, qui tour à tour disputa à la mort la tête des accusés de la Commune el défendit les congrégations atteintes par les décrets de 1880 ; - IALATEur, qui, en 1899-1900, dirigea la délense des accusés de la llaute Cour.

L'éloquence politique. - La plupart des orateur's des Chambres de Louis-Philippe se retrouverent dans les assemblées de la seconde République, où Victor llugo prononca ses magnifiques discours contre la loi de 1800 sur l'enseignement, contre l'expédition de Rome, ou pour la défense du suffrage universel.

Sous le second Empire, les ministres de Napoléon III n'eurent pas, d'abord, à se mettre en frais d'éloquence; mais, quand une opposition se forma et s'accrut, Billault el Baroche montrèrent certaines qualités d'orateurs; Rouher surtout, grâce à sa puissance de travail, sa verve intarissable, son art d'embrouiller les questions et de jongler avec les chif'fres. Dans l'opposition, se distinguèrent Jules Favre, avec sa parole puissante, parfois martelée, volontiers dédaigneuse ou amère; Ernest Picard, avec sa bonhomie rail. leuse; Emile Ollivier, avec sa lacilité abondante; Dufaure, rude et tenace logicien; Buffet avec sa parole mordante, parfois hargneuse, et sa profonde connaissance des chiffres.

La troisième République a vu grandir d'autres talents. LÉN GAMBETTA était né avec tous les dons de l'orateur, une facilité prodigieuse d’assimilation, qui lui donnait les apparences dune science encyclopédique, une mémoire riche et sûre, inépuisable de faits et d'images, une diction nette et vibrante, à lacuelle un reste d'accent du Midi ajoutait un charme musical, une voix puissante a dominer le tumulte de la rue ou les orages des Assemblées, une attitude et un port de tête imposauts, bien qu'il füt de taille moyenne, un geste dune ampleur étonnante. Pardessus tout, il était improvisateur. S'il élait obligé de parler sans avoir pu se recueillir, son début étail parfois lourd, embarrassé, même incorrect, car tout se présentait en mème temps à son esprit, le commencement et la fin de son discours, l'ordre dans lequel il fallait ranıer ses idées et les points qu'il fallait mettre en saillie. On ê̂t dit un oiseau énorme qui avail peine à s'enlever de terre. Après 
quelques instants, les idées prenaient leur essor, et alor's, sous l'action d'un feu intérieur, la parole s'éclaircissait, s'échauffait et vibrait; la phrase coulait de source, se retrouvant dans les tournures les plus compliquées, entraínant un monde d'expressions ingénieuses, de mots frappés et marqués pour durer, d'images poétiques et brillantes, d'apostrophes véhémentes et d'adjurations pathétiques, suppliantes, persuasives, et les applaudissements éclataient dans les rangs mêmes de ses adversaires. Sa puissance oratoire s'exerçait avec une intensité égale, qu'il eût à parler à des Assemblées ou à des foules. Nul ne s'est plıs rapproché que Gambetta de l'idée que nous nous faisons de Mirabeau, et nul n'a mieux rempli la condition essentielle que Démosthène imposait à l'orateur : De l'action!

JULES FERRY, dont on a dit quil avait a grandi au pouvoir $\triangleright$, a grandi encore plus dans l'impopularité que dédai ynait sa hautaine conscience, dans l' "ostracisme , qui suivit les ainées passées au pouvoir parmi les ardeurs de lit lntte. Orateur d'opposition sous l'Empire, il se révéla, pendant six années d'aciivite comme chef détat ou chef de parti (1879-1885), un puissant orateur dans la défense des idées de gouvernement et d'autorité. Sur lui porta tout le poids des discussions, dans les deux Chambres, a propos des lois d'enseignement et de la politique coloniale. Ses discours, fortement documentés, d'une dialectique seriée, parfois d'un grand mouvement oratoire, nous aplaraissent, hachés qu'ils furent par les violentes interruptions de droite et d'extrême gauche, comme la plus solide démonstration des illées maitresses sur lesquelles la démocratie française semblait appelée à vivre et à prospérer. Le discours par lecquel il prit possession de la présidence du Sénat (1893), dans une note plus apaisée, empreinte de résignation philosuphique, comme sous le pressentiment de la fin proclıaine, est encore dans toutes les mémoires.

L'éloquence de JULES SImon avait des ressources infinies, qu'il puisait dans le fonds le plus riche de littérature, de philosophie, d'histoire, d'expérience politique. Sa parole avait a la fois de la force, de la souplesse, et presque de la caresse. Il eut sur tous ses contemporains, sauf peutêtre Gambetta, la supériorité d'ètre un merveilleux impro- 
visaleur, d'une finesse athénienne, capable d'atteindre les plus grands effets oratoires, prèt à toutes les luttes, prompt à toutes les répliques et que nulle surprise ne pouvait déconcerter.

LÉON SAY, précis, clair, abondant, admirable orateur d'affaires, eut, comme M. Thiers, l'art de persuader “ à ses auditpurs qu'ils comprenaient les questions les plus obscures ».

CHALLEMEL-LACOUR avait de la hauteur dans les vues comme dans le caractère, de l'àpreté dans le débat ct une sincérité intrépide qui souvent brava l’impopularité.

Bardoux eût mérité d'être de l'Académie française, comme Jules Simon et Challemel-Lacour, tant il y avait de netteté, d'élégance littéraire et de charme dans tout ce quiil disait. Un de ses meilleurs discours est peut-être le dernier qu'il ait prononcé au Sénat (1896), sur la valeur ilucatrice des lettres classiques.

Nous ne parlerons pas des vivants, parmi lesquels il en est tant qui honorent la tribune française.

Au surplus, il se pourrait que l'èloquence fût en déclin dans les deux Chambres, grâce à la grossièreté des nouvelles mours politiques, la brutalité fruste de certains élus, leur manque d'instruction générale et d'éducation, leur impuissance á écouter pendant une heure la parole d'un ami et pendant cinq minutes la parole l'un adversaire.

iturafes a consulter. - Ginéralitis sur la litterature :- Rapport publié, à l'vecanion de l'Expositiun de 1867 (sur l'ólat des Jellues), par de Sacy, P. Féval, Th. Gautier, Aug. Thielry. - Voir ci-densus, p. 396 , lindiration d'ouvrages de Th. Gauticr, Sainte-Beuve, Paul Alberl, Jules Lemaitre, Brunelière, Larroumel, Facuet, dont une partio se rapporte a la période littéraire 18:18-1906. Petil de Julleville, Hist. de la langue et le la litt. francaisc, t. V11I. - Les frères Goncourt, Joumal et I'ages retroures. - René Doumic, Etudes sur la litt. fr. - G. Pellissier, Le

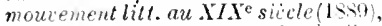
Essuis et nouveaux essais te lill. contomp. - An. France, La Vie littéraire. - A. David-Sanvageot. Le réalisme ot le naturalisme dans la litl. pt lint $(1850)$ - M. hesprez, L'Eolution naturaliste (185i. -
Virgile Rossel, IIist. de la litt. francaise hors de France (1855). - Voir les discottrs do réception a l'Academio Francaise.

THÉthe, - Jules Lemailre, Impressions de theatres (10 vol.). E. Fagurl, Notes sur le thédtre. Larrounet, Etudes de litt. dramaliyue. - R. Doamic, De Seribe à Ibsen (1893) et Essais sur le theilre contemporain (1897). - Aug. Filon, De Uumas i Rostand(1898). - Paul Hervieu, Discours de réeption (1900) sur Pailleron. - E. Zola, Le naluralisme au theatre et Nos auteurs dramatiques (1981).

PoÉste. - Jules Lemaitre, Les contcmporains (Ban?ille, Sulty-Prudllomme, Coppere, E. Gientier, Leconle Je Lisle, Heredia, Arm. Silvestre, Richepin, Baulelaibe, V'erlaine.Jean Lahor). - Brunticle, Symbolistes et dicadents. (IIist. et litt., l. III).- 
Doumic, nuv. rite, t. 11, Coppée, ele. naturnliste (1895). - P. Bourgel, - G. Paris, Etuite sur Sully-Find- Essais de psycholoy ie contemporaine. homme. - Calnlle Mendi.s, La lé- - R. Donnie, Portraits l'écrivains gente du Pamisse contemporain et Etwles sus la litt. contemp. (1N'1). - Viqu-Leneq, La poisie J. Lemaitre, Les Contemporains. contemporaine. - M. Spronck, Les R. Wuamic, Les Jeunes (18\%0. artistes litteraires. - F. Coppee, G. Deschamps, ta Vie et les lirms. Préface anx ouvres de Verlaine. - - E. Zola, Les rmanciers natureA. Mockel, stephane Mallarmi, un listes. - E. Fagnet, Flaubert 1902) hros (tris e nallarmiste"). - H. de orateurs. - H. Pelliszon, La Règnier, Etule sur Mullamp.

Romax. - Buneliere, Le roman $\begin{aligned} & \text { gia nos jours (1808). } \\ & \text { gia no }\end{aligned}$ 


\section{CHAPITRE XXX}

\section{LES SGIENGES MORALES ET POLITIQLES}

\section{La philosophie et le droit.}

Philosophie : récole éclectiquue. - Les contemporains et surtout les disciples de Victor Cousin complétèrent la vaste enquète ouverte par lui sur les diverses écoles philosophiques. Il faut citer les travaux de Charles Zévort, Charles Waddington, Théodore Jouffroy, Barthélemy SaintIilaire, Émile Saisset, Ravaisson, Thurot, Lévêque, Paul Janet, Ollé-Laprune, V. Brochard, sur la philosophie des Grecs; - Jules Simon, Vacherot, Nicolas Bouillet, sur celle des Alexandrins; - Cl. de Rémusat, Hauréau, Jourdain, sur celle du moyen àge chrétien (Abélard, saint Anselme, saint Thomas d'Aquin); - Bordas-Demoulin, Francisque Bouillier, Nourrisson, Saisset, sur Descartes et les écoles cartésiennes; - Bouillet et de Rémusat sur Bacon; Renouvier, Lachelier, E. Boutroux sur Kant; Nourrisson et Saisset sur Spinoza, ete. - L'horizon s'étendit encore par les travaux de Franck, l'éminent autenr du a Dictionnaire des scienees philosophiques », sur la philosophie des Hébreux; de Barthélemy Saint-Hilaire, sur les philosophies et religions de "Asie : a le Bouddha et sa religion o (1859), \& Hahomet et le Coran D (1865); de Renan, sur a Averroes et l'arerroïsme,$(185 \%)$.

La morale, c'est-à-dire la science du devoir, a inspiré les belles études de Jules Simon (la Liberté, le Devoir, la Ricligion naturelle), de Paul Janet, Ernest Bersot, Amiel, Duudan, Caro, Fouillée, Guyau.

La philosophic et les sciences. - Le point faible du 
système de Victor Cousin, c'est qu'il tendait à renfermer la philosophie en elle-même, à considérer l'homme uniquemenc comme un être intelligent et moral, à ne pas tenir assez compte de l'homme physique, à négliger le concours que la physiologie pouvait apporter à la psychologic. Il faut chercher la raison de ces vues incomplètes dans lèducation mème le Cousin, qui était un grand lettré et non un homme de science, et dans une certaine défiance de ces sciences de la nature dont l'influence sur la philosophie s'était surtout manifestée, au $x^{2} w^{e}$ siècle, par le développement des théories sensualistes ou matérialistes.

Cependant, on parvenait bien ainsi à esquiver les difficultés, mais non à les résoudre. Le problème capital des relations du moral et du physique dans l'homme se posait plus impérieusement que janıais, grâce aux récentes découvertes des physiologistes sur la nature et les lonctions du système nerveux. Le spiritualiste le plus éthéré ne pouvait nier que les phéuomènes de pensée ne fussent en relations étroites avec l'activité du cerveau, les phènomènes de la sensibilité et de la volonté avec le systéme nerveus. Ny avait-il pas lieu de rechercher ce quétaient ces relalions? Pourquoi et comment l'intelligence humaine subit-elle des éclipses ou des perturbations? Que devient la notion de la liberté et de la responsabilité de l'homme sous la pression des phénomènes physiques et physiologiques? Comment l'âme se comporte-t-elle dans les états de sommeil, de rève, d'hallucination, d'aliénation mentale? Que faut-il penser des systèmes qui, au siècle précédent, ont cherché à expliquer la vie, tels que l'animisme ou le vitalisme? De là une série de travaux, publiés les uns par des philosophes, les autres par des physiologistes; ceux de Lemoine, sur a Stahl et lanimisme „ (1858) et a l'Aliéné devant la science et la société; - de Lélut, sur a le Démon de Soerate „; - de Moreau de Tours, sur a la Psychologie morbide $\triangleright ;$ - d'Émile Saisset, sur a l'Ame et le Curps . (1802); - de Paul Janet, sur a le Cerveau et la Pensée. (1866); - d'llenri Joly, sur l'Instinct (1869), a l'Ylomme et l'Animal; - du docteur Bouchut, sur a la Tie et ses attributs ; - du docteur Fournet, sur a la Loi des deux substances $\triangleright ;-$ du docteur Chanllard, a Ame et Vie :- de 
Claude Bernard, a Introduction à l'étude de la médecine expérimentale s; - de Vulpian, a Leçons sur la physiologie du cerveau $\triangleright$; - d'Alfred Maury, sur le sommeil et les rèves; de Théodule Ribot, sur l'llérédité, les maladies de la Volonté et de la Mémoire; de G. Dumas sur a la Tristesse et la Juie »; de Bergson sur a le Rire »; de G. Le Bon, de Tarde sur la psychologie des collectivités et des loules; de G.-L. Duprat sur a les causes sociales de la folie $\triangleright$, etc.

Un Dieu críateur, c'est un des dogmes de l'école spiritralıste : or la question des génerations spontanées, débattue de 1858 à 1864 entre Pouchet et Pasteur; la quesiion de l'unité de l'espèce humaine ou de la pluralité des centres de création, résumée dans le beau travail d'A. de Quatrefages; les théories de Darwin sur l'évolution, sur le transformisme, sur la descendance quasi animale de l'homme, touchent par certains côtés au dogme de la création. Ainsi la philosophie, qui, au moyen âge, pouvait vivre sur sou propre fonds, est, dans les temps modernes, investie, assiégée, pénétrée de toutes parts par les sciences physiques, naturelles, médicales. C'est pour elle une nécessité, à chaque nouvelle découverte des savants, que de soumettre à un nouvel examen les solutions jusqu'alors admises.

Aussi les problèmes qui ont préoccupé les anciens Grecs, aux premiers débuts de la philosophie, reparaissent-ils sous des formes sans cesse rajeunies. Toujours l'esprit humain sera partagé entre des tendances opposées. Sur la question de Dieu, les uns continueront a lui attribuer une existence persomelle et une nature purement spirituelle, les autres à le confondre avec la matière vivante, avec le monde infini. Sur la question de l'àme, les uns inclineront vers les tendances matérialistes et les autres vers les tendances spiritualistes. Sur la question de la responsabilité de l'homme, les uns verront en lui un ètre libre, les autres le feront se determiner par des causes physiques, agissant presque fatalement sur lui, et soutiendront la théorie du déterminisme. Sur le problème du mal pliysique et du mal moral, les uns inelineront au pessimisme, formulé en système prar l'Allemand Schopenhauer (1788-1860), les autres à cet optimisme qui est dans le sang de notre race et dont 
Voltaire, tout en le raillant dans son a Candide s, s'est inspiré plus que personne.

L'école positiviste. - Auguste Com te avait développé ses idées de 182' dans une série d'œuvres : a Ordre et Progrès (1848), Culte systématique de l'humanité \$ (1850), đ Catéchisme positiviste (1852), a Synthèse subjective D (1856).

Comte eut la fortune d'avoir pour disciple un homme de génie, d'un savoir immense : l'érudit qui traduisit et commenta les OEuvres d'llippocrate (1839) et l'llistoire naturelle de Pline (1848); le savant qui refit avec Robin le grand Dictionnaire des sciences médicales de Nysten et publia les curieuses études intitulées a Médecine et Médecins , (1866); l'historien qui se récréa aux a Éludes sur les Barbares $\mathrm{D}$; le philologue qui écrivit a l'llistoire de la langue fraccaise $\triangleright(\mathbf{1 8 6 2})$ et acheva l'cuvre colossale du a Dictionnaire s: en un mot, ÉmLe LITTRé (1801-1881), ce philosophe doux, frugal. chaste et sobre, qui avait a l'air d'un vieux prêtre $b$ et dont la vie de quatre-vingts ans fut un labeur de toutes les minutes 1.

Littré ne se contentait pas de simples négations, comme firent trop souvent les philosophes du xvise siècle. II croyait peu scientifique de nier ce que la science ne peut encore prouver. Il réservait les droits de l'infini, de l'inconnu, de l'idéal. Il développa les idées de Comte, les

1. Dans une causerie eharmante de bonhomie, Comment jai fait mon dictionnuire, il nous raconte lui-mene cetle vie:

"Je me Je:ais a huit heures du matin; c'est bien tard, dira-t-on, pour un homme si pressé. Attendez. Pendant quion faisajt ma chambre á coucher, qui était en même temps mon eabinet de travail (vieille et petite maison, ai-je dit), je descendais au rez-de-chauszée, emportant quelque travall; c'est ainsi que, entre autres, je fis la preface de mon diclionnaire... A neuf heures, je remontais et eorrigeais les épreures venues dans l'intervalle, jusqu'au déjeıner. A une heure, je represais jlace a mon bureau, et la, jusqu'a trois heures de l’après-mıdi, je me mettais en règle avee le Journal des Savants, qui mavait èlu en 1855, et à qui javais a caur d'apporter régulierement ma eontribulion. De trois heures a six heures, je preuais le Dintlounare. A six heures, je descendais pour le diner. Une heure y suffsait enriron... Remonté vers sept heures du soir, je reprenais le diction. naire et ne le làchais plus. Un premier relai me menait a minuit. Le second me conluisail a trois heures du matin. Dordinaire na tiche quotidienne état finie. Si elle ne l'était pas, je prolougrais la veille, et plus d'une fois, durant les longs jours, jai éteint ma lampe et continué a la lueur de l'aube qui se levait. 
dégagea de tout mysticisme, en montra l'application à la politique el à la sociologie. Il exposa la doctrine avec une netteté lumineuse dans sa a Philosophie positive (18'́t5) et dans son a Application de la philosophie positiviste au gouvernement $\gg(1850)$. Il en retraça les origines et les développements dans a Auguste Comte et sa philosophie * (1863). Il lui donna un organe en fondant, avec le Russe Vyroubof, la « Revue positiviste ». En quels termes magrni fiques ne dégage-t-il pas la poésie de la science!

- J'ai rappelé, écrit-il, la magnificence du spectacle du ciel et combien les yeux se plaisent à considérer ces étoiles innombrables, ces globes semés dans l'espace, ces îles de lumière dont se pare la nuit, et je rappelle que, pour les yeux de lintelligence, le spectacle des lois mystérieuses et irrésistibles qui gouvernent les choses n'est ni moins splendide, ni moins attrayant. Le poète latin, quand il dissipe l'obscurité qui enveloppe son héros, lui fait voir, au milieu du tumulte d'une ville qui s'abime, les formes redoutables des divinités qui président à ce grand changement, numina magna deûm. Ainsi, au milieu du tumulte de la vie qui arrive et de la vie qui s'en va, au milieu del'évolution perpétuelle des êtres, apparaissent les lois redoutables que l'esprit humain ne peut contempler ni sans eflroi, ni sans ravissement. »

L'école positiviste rendit de grands services en rappelant les philosophes ḋ la rigueur de la méthole, en discrílitant la déclamation et la rhétorique, en modérant la lutte des écoles rivales, en leur inspirant les doutes sur les conclusions hâtives auxquelles elles s'abandonnaient volontiers, en préparant une sorte de coneiliation sur le terrain des laits inconlestés. Toutes les écoles philosophiques sont aujoud'hui plus ou moius imprégnées de positivisme et, en politique, tels de nos lommes d'État les plus distingués se font houneur d'être sortis de cette école, comme quelques-uns de ceux de la gérération précédente se laisaient gloire d'avoir appartenu á l'école de Saint-Simon. Seulement, tandis que le mysticisme dominait lans celleci, cest la rigueur de la méthode scientifique qui a fait la lorce de celle-là.

Parmi les philosophes indépendants, mais plus voins de lécole de Littré que d'aucuuc autre, il faut ciler Taine, 
pour ses ètudes sur l'Intelligence, sur la Volonté, sur les * Philosophes français au $x^{\circ}{ }^{\mathrm{e}}$ siecle s, et Théodule Ribot, fondateur de la a Revue philosophique ๖ et professeur de psychologie expérimentale au Collège de France.

dne branche movelle de la morale. - C'est au xvme siècle que le respect de la vie humaine a pris toute sa valeur aux yeux du moraliste et que l'homme cultivé s'est ému d'une sensibilité jusqu'alors inconnue, en présence des souffrances de son semblable. En notre siècle, un sentiment nouveau s'est fait jour également: une certaine compassion pour les souffrances des animaux. Il semble que nous ayons emprunté à ces Indous, dont la civilisation venait de nous èlre révélée, quelque cìose de leur respect pour ces ètres qu'ils regardent comme des frères infërieurs. Nous sommes arrivés à réprouver les eruautes inutiles qui leur sont infligées, non seulement parce qu'elles répugnent à notre cour ou parce qu'elles témoignent d'une nature dangereuse et perverse chez ceux qui tes exercent, mais parce que nous sentons qu'il $y$ a pour nous une sorte d'obligation morule, presque un decoir, a ne jas faire soulfrir les bêtes inutilement.

L'idée d'un devoir envers les animaux est aussi ètrangère que possible aux fondateurs des trois religions avee lesquelles nous avons le plus de contact (judaisme, ehristianisme, islamisme), aussi étrangère que possible aux moralistes de l'antiquite classique comme aux anciens morilistes franęais; car nous avons vu les Cartesiens prolesser, a l'égard des animaux, une doctrine qui n'était pas tendre. C'est donc là un fait nouveau dans notre civríisation : il s'y est alfirmé par des mesures législatives et par les œuvres de libre initiative. La loi Grammont, votee le 2 juillet 1850, sur l'initiative du député de ce nom, punit d'une amende de 5 à 15 franes, même d'un emprisonnement de un jour à einq jours, quiconque s'est rendu coupable de mauvitis traitements sur les aninadux domestiques ${ }^{1}$. 11 s'est constitué chez nous une Societi protectrice les animaux, reconnue d'utilité publique, et dont les membres ont le droit de requérir l'application de eette loi.

1. En Allemngne, des dispositions analognes ont été édiclées. Le nonveas Code peat alienand, du 31 mai 15:0, putit dune anende beauconp plus 
Enfin, il s'est fondé en France, tout comme dans l'Iude bouddhique, des hospices pour les animaux infirmes ou abandonnés. Voilà des faits qui assurément étonneraient Malebranche et réjouiraient le bon La Fontaine.

Le droit. - Parmi les commentateurs du Code civil, nous rencontrons en première ligne TROPLONG el DEMOLOMBE, dont les grandes œuvres (1833-1864 et 1845-1874) ont demandé chacune trente ou quarante années. Guillouard, professeur à l'Université de Caen, a repris et continué avec une méthode encore plus rigoureuse l'ouvre de Demolombe. Demante, Colmet de Santerre, Ch. Beudant, les deux Bufnoir se sont ėgalement distingués dans le droit civil. Faustin Hélie, déjà célèbre par sa a Théoric du Code pénal , (1835-1843), donnait le a Traité d'Instruction criminelle ? (1855-1860). Bravard-Veyrières publiait avec Demangeat le - Traité de droit commercial ๖ (1861). Celui-ci s’illustrait, ainsi que C. Accarias, par d'importants travaux sur le droit romain. Batbie, depuis lors député, sénateur et ministre, commençait en 1863 son grand a Traité de droit public et administratif ๖. Ducrocq avait publié le sien en 1861. Lyon-Caen s'est fait un nom dans la législation comparée comme dans le droit commercial, Chénon dans le droit constitutionnel, A. Desjardins dans le droit maritime, Renault dans le droit des gens, $A$. de Franqueville, Rodolphe Dareste, Léon Aucoc dans le droit administratif 1.

L'ancien droit francais a eu ponr historiens J. Laferière (1840̈-1858), puis Glasson, Paul Viollet, A. Gautier, A. Beaune, J.-D. Heyer, Esmein 2.

En 1869 a été fondée la Socièté de législation comparée, sous la présidence de Laboulaye, et, en 1876, le Comité de législation étrangère au ministère de la justice : ces deux institutions, l'une libre, l'autre officielle, ont été le point de depart d'études approfondies sur les lois des autres peuples et leur comparaison avec les nôtres.

forle et d'une peine équiralente à l'emprisonnemenl ceur qui maltraitent les animaux "publiquemenl et d'une mauière scandaleuse ".

1. L. Bequet a fondé (188\%), E. Laferrière a continué le grand a Réperloire de droit adminintratif".

2. Vuir. au tome 11 de notre Histoire de la civilisation française, la nolo bibliographique de la page $\mathbf{1 5 5}$. 


\section{L'histoire, les langues, la géographie.}

L'histoire. - Les grands noms de la période contemporaine sont d'aborl quelques-uns de ceux de la période précédente : ceux de mignet ${ }^{1}$, de michelet ${ }^{2}$, de thiers. Celui-ci, dans sa grande * Histoire du Consulat et de l'Empire s, commencée en 1846 , a montré comment il faut traiter les événements contemporains, dont l'exposé exige, non plus seulement des récits animés, mais une étude sagace des faits militaires, parlementaires, économiques, dont la complexité s'accroît à mesure que se complique notre civilisation.

Les àges elassiques. - Nos devanciers, pour écrire l'histoire de la Grèce ou de Rome, se bornaient presque à consulter les auteurs anciens, et ils tenaient pour exacts les textes qu'en avaient donnés leurs premiers éditeurs. On s'est aperçu qu'il y avait lieu d'y regarder de plus près, de rapprocher ces textes des plus anciens manuscrits, d'introdure des corrections qui allaient jusqu'à modifier le sens adopté jusqu'alors. On a eu les éditions savantes des Miller et les Benoist. Des textes inédits ont été retrouvés dans les bibliotlièques du Mont-Athos, de l'Escurial, du Vatican. Nous devons à nos professeurs de l'Université de bonnes traductions des auteurs anciens ${ }^{3}$ ou de savantes études sur ces auteurs .

On s'est apercu aussi que les textes soulevaient une foule

1. Mignet a publié, en 1851, I'Histoire de Marie Stuart; en 1858, CharlesQuint; en 1875, la Rivalité de Francois I'r et de Charles-Quint.

2. Miehelet a terminé, en 1853, son Histoire de la Révolution française; il est revenu a son Histoire de France et à ses six premiers volumes en a gjouté dix autres (1867); enfin il a donué trois volumes sur la période napoléonienue. Eu 1878, a paru son livre si populaire sur les Soldats de la Révolution.

3. Despois a traduit les satiriques latins; Talbot, les cuvres de Luciea, Xénophon, Sophocle, l'empereur Julian, Plutarque; Pessonneaux, celles d'Euripide; Cousin, eelles de Platon; Barthélemy Saint-llilaire, eelles d'Aristote; Poyard et Ch. Zévort, eelles d'Aristophane, etc.

4. Elades de fules Girard sur Thucydide (1860) et les orateurs grees (IS61 - 1574); de Taine sur l'historien romain Tite-Live (1854); de G. Boissier sur Cicéron el ses amis (1865); de C. Murtha, sur les moralistes latins (1965) et sur le poète Lucrèce (1869); d'A. Croiset, sur Xénophon (1973) et Pindare (1880): de P. Decharmesar Euripide 1893); d'A. Hauvette sur IÉrodote (1891). 
de questions qui ne pouvaient ètre résolues que par une connaissance approfondie de toute la civilisation des Grecs et des Romains. Celle-ci ne pouvait ètre bien connue quen consultant d'autres documents que les livres. On a donc étudié les monuments encore debout, les ruines des temples, des théàtres, des arènes, des ares de triomphe. On a recueilli les inscriptions dont les Romains ont été si prodigues, car, croyant graver ponr l'éternité, partout où ils sont passés, leurs empereurs, leurs magistrats, leurs légions victorieuses, ont voulu consacrer sur la pierre, sur le marbre, sur le bronze, le souvenir de leur action. 11 y a des milliers de ces inscriptions rien que daus l'Algérie et la Tunisie. Enfin il fallait étudier les institutions politiques ou administratives, la législation, la religion, les arts de ces leux grands peuples dont l'un, les Grecs, a été l'initiateur de la civilisation humaine, l'autre, les Romains, donna l'unité politique au monde connu des Anciens.

C'est surtout en Grèce, grâce à la foudation de l'École française d'Athènes, qu'ont eu lieu les fouilles archéologiques les plus importantes accomplies par des Français.

Beulé, en 1854, dégageait l'Escalier et les Propylées de l'Acropole d'Athènes. Wescher et Foucart exploraient le sol de Delphes. Heuzey parcourait l'Acarnanie et le mont Olympe. Georges Perrot copiait a Ancyre (Asie grecque) le Testament d'Auguste (1864), W. Waddington renouvelait l'épigraphie de l'Asie Mineure et toute la numismatique de l'antiquité. Champoiseaı rapportait de Samothrace la fameuse Victoire ailée (1863), qui est au Louvre. Rayet et Thomas, à Milet et à Héraclée (Asie Mineure, 1872), Haussoulier, près de Milet (1896-1898), Homolle, dans l'ile de Délos (1877-1885), faisaient des découvertes de premier ordre. A Tanagra (Béotie, 1870), on a mis au jour des figurines de terre cuite, d'un art imprévu et charmant, contemporain d'Alexandre le Grand. Pottier, Salomon Reinach et Veyries (1880-1882) ouvraient plus de mille tombeaux dans la nécropole de Myrina (près de Smyrne), et $y$ recueillaient d'autres statuettes, qui révèlent une branche presque inconnue de l'art hellénique. Les travaux et les fouilles de l'École d'Athènes ont été dirigés avec une granle distinction, de 187: it 1878, par Albert Dumont, 
lui-mème auteur de savants mémoires, principalement sur la céramique des Grecs. En 1895, sous la direction d'Homolle, ont commencé les fouilles de Delphes qui nous ont révélé des périodes anciennes et presque ignorées de l’art hellénique. Des archéologues et des artistes francais ont été appelés à consolider et restaurer les monuments de l'Acropole d'Athènes. Actuellement l'effort porte sur Détos. Dans l'Orient gree, nous avons rencontré des concurrents : l'Allemand Schliemann, en 1873, a mis à jour les ruines de Troie et ce qu'il appela le tressor de Priam; en 1878, un tombeau, quon croil ètre celui d’Agamemnon, à Mycènes. La mission allemande a pratique des foulles importantes à Olympie: une mission anglaise, à Cnosse (Crète); une mission autrichienne en Asie Mineure.

En Toscane, sous Napoléon 1Il, Alexandre François a exploré les anciennes cités étrusques. Notre Musèe du Louvre sest eurichi des curieuses antiquités de la collection Campana.

Diun antre côté, cette fois dans le monde latin et sur notre propre territoire, les fouilles d'Alise-Sainte-Reine ont mis fin à une longue polémique au sujel de l'emplacement d'Alesia (Alaise en Franche-Comté ou Alise en Bourogne), à laquelle ont pris part Napoléon III, Ie duc d'Aumale, Jules Quicherat, Auguste Castan, de Rellye. - Le P. de la Groix a retrouvé les Thermes de Sanxay (Vienne) et les Temples de Villeret; l'abbé Hamard, la néeropole de MonyBury; Castan, le Théâtre et les Arènes de Besançon. Uie société s'est formée pour la conservalion des Arènes de Paris.

Léon Renier, après avoir collectionné en France, en Algérie, en Roumanie, dans tous les pays latins, des milliers d’inscriptions, a presque fondé une science nouvelle: l’épigraphie romaine. Grâce aux inscriptions, on a pu déterminer plus exactement les titres des magistratures romaines et nous apprendre ce que fut l'administration des maitres dn monde.

La numismutique grecque ou latine a fait de grands progrès, gràce surtout à de Saulcy. François Lenormant, William Waddington, Sabatier, Schlumberger, Babelon.

Sous le nom de Napoléon III a paru la a Vie de César s 
(186\%), et c'est à celte occasion que s'est fondé, sous la direction d'Alexandre Bertrand, le précieux Muşe galloromain Sainl-Germain. Ernest Desjardins a publié sa - Gaule romaine » $(1870)$, Charles Tissot sa acographie comparée de la province romaine d'Afrique \ (1884-1888), Cagnat son a Armée romaine d'Afrique o (1892).

Les institutions romaines ont donné lieu aux travaux de Léon Renier, Fustel de Coulanges, Bouché-Leclercy, Mispoulet, P. Guiraud; la législation et les institutions grecques, à ceux de Brunet de Presle, E. Egcer ${ }^{1}$, Fustel de Coulanges ${ }^{2}$, G. Perrot, P. Guiraud. La religion des Grecs et des Romains a été éclairée par la a Nouvelle galerie mythologique " (1831) de Guignaut, "le Sentiment religieux en Grèce " (1868) de Jults Girarl, les travaux d'Allied Maury et P. Decharme sur la mythologie. L'économie politique de l'antiquité nous a valu d'importants ouvrages ${ }^{3}$. Nous arons vu plus haut avec quel soin avaient été étudiées la philosophic et les lettres antiques.

Les sciences de l'antiquité ont donné lieu aux travaux de Théodore-Henri Martin, Hoefer, Maximilien Marie, Faye, G. Milhaud, P. Tannery, Berthelot, sur les mathématiques, l'astronomic, la physique, la climie; de Littré et Daremberg, sur la médecine. Les arts plastiques des Grees, dout tant de monuments sont dispersés dans les musées de l'Europe ${ }^{4}$, ont inspiré de savantes théories développées

1. Études d'É. Egger (auteur de "l'Hellènisme en France" 1869), sur les traites internationaux ehez les Grees et les Romains (1S66), sur l'état civil et sur les honneurs publies ehez les Athéniens, sur le papier dans l'antiquitè (1860); de Georges Perrot sur le Droil public de lia rẻpublique athénienne $(186 \pi)$.

2. De Fustel de Coulanges, La Cité antique (186i); de G. Perrot, Essai sur le droit public et privé de la République athenismne 1408 ) el L'Éloquence politique et julicitire a Athines 1473 ; de Rodolihe Direste, La science du lroit en Grèce (1893).

3. Caillemer, par exemple, a publić des études sur les institutions commereiales, la lettre de change el les contrats d'assurance, le credit foncier, la proprití littéraire, etc., à Athènes; A. Dareste de la Chavanne, sur le Prêt à la grosse chez les Athéniens; P. Guiraud, sur la Main d'œurre industrielle et sur la Propriété foncière en Gréce.

4. A Londres, les frontons de la frise du Parthẻnon; à Munich, les statues d'Égine; à Berlin, les bas-reliefs de Pergame; à Vienne, les sculpLures de Gjol-Baschi (Lycie); à Paris, la Vènus de Milo, la V'icloire de Samothrace, les moulages de Delphes; a Floruce, les Niobide; a Rume, l'Apollon du Belvédére, le Laoeoon, la Véuns de Médicis. 
nolamment dans " la Sculpture avant Phidias" et " l'Art grec avant Péricles " (1868) de Beulé; dans "les Monuments de l'art antique" (1884) de Rayet; dans "l'Histoire de l'art dans l'antiqnité " de G. Perrol (depuis 1881), en collaboration avec l'archilecte Chipiez; dans " l'llistoire de la Scnlpture grecque" (1893) de Iaxime Collignon. BourgaultDucoudrày el Ch.-E. Puelle ont étudié la mosique des Grees.

Comme tentalives d'histoire générale, pour la Grèce, nous avons l'llistoire grecque de Victor Duruy; pour Rome, l'Histoire romaine à Rome de J.-J. Ampère (1855) ol l'llistoire des Romains de Victor Duruy, éclairée par toutes les découvertes récentes.

Le moyen âge français. - Non seulement on a donné de meilleurs textes de nos anciennes chroniques déjil connues; mais on a eu la fortume de découvrir des auteurs nouveaux : Robert de Clari, un des compagnons de Villehardouin dans la quatrième croisade; Jehan le Bel, qui fournit à Froissart le premier canevas de ses chroniques; Tlomas Bazin, l'historien de Louis XI, etc. C'est un Froissart presque inédit que nous a donné Simion Luce en publiant à la fois les rédaclions, si dillérentes entre elles, de ses divers manuscrits. Michelet a publié les pièces du a Procés des Templiers „, Jules Quicherat celles du a Procès de Jeanne d'Arc ^. Les Chartes et autres documents ont eu pour éditeurs Huillard-Brćholles, Bordier, Tardif, Boutaric, Chéruel, de Has-Latrie lans son a Trésor de Clironologie, d'histoire et d'archéologrie n, E. de Rozière, dans ses a Formulaires $>$.

La formation de la langue doc et de la langue d'oil, la philologie de l'ancien francais et de ses dialectes, doivent leur progrès à Littré, à G. Paris, P. Heyer, A. Darmesteter, Petit de Julleville, F'. Brunot, J. Gilleron (pour l'étude des patois); Thomas, Delboulle, L. Clidat, E. Etienne, F. Godefroy, auteur du grand a Dictionnaire de l'ancienne langue francaise $D$.

Les éditions et les travaux sur notre littérature du moyen âge ont été poursuivis par Gènin, qui, en 1850, donna la première édition de a la Chanson de Roland s; par Vitet, Littré, Paulin Pars, E. du Méril, Paul Meyer, etc. Gaston 
Paris. dans son * Histoire poétique de Charlemagne $\triangleright$, et Léon Gautier, dans ses a Épopées françaises $\triangleright$, en ont fait la eritique ou l'analyse. Nos Mystères, après avoir èté édités par Achille Jubinal, Trancisque Michel, Monmerqué, Gaston Paris, ont trouvé un historien en Petit de Julleville. On a publié. dans la « Bibliothèque gauloise », quelques-uns de nos plus anciens poètes lyriques. Le ministère de l'instruction publique a fait rechercher partout les textes et les variantes des chansons populaires.

Nous arons déjà ru à quels travaux ont donné lieu la philosophie du moyen àge et notre ancienne législation. Sa géographie a été renouvelée par A. Jacobs et Longnon; les sciences du moyen àge, par les mèmes auteurs que les sciences de l'antiquité ${ }^{1}$; l'architecture et de la sculpture, par de Caumont, Paul Lacroix. Seroux d'Agincourt. L. de Laborde, du Sommerard, Vitet. Didron, Prosper Mériméc, Lance. etc. ${ }^{2}$. Le savant et l'artiste qui a rendu le plus de serves à lhistoire des arts, c est violzet-le-duc, l'auteur du - Dictionnaire raisonné de l'architecture francaise ๖. du - Dictionnaire du mobilier ๖. La musique a fait l'objet des travaux de Coussemaker, d'Auriac, Gevaërt, etc. Les mours, le costume, le mobilier, ont été étudiés par P. Lacroix. J. Quicherat. de Champeaux. A. Darcel. de Lasteyrie, Müntz. Gerspach, Havard; l'histoire des classes laborieuses, de l'arriculture, de l'industrie, du commerce, par L. Delisle. A. Dareste de la Charanne, Levasseur, Depping, Thoniol, P. Clément, Germain, Pigeonneau, Fagniez.

Quant aux wurres d'un caractère plus général. outre celles de Michelet, il faut citer lllistoire des Gaulois et lllistoire de la Gaule sous la domination romaine, d'Amèlèe Thierry: « J'Eglise et l’Empire romain s, du duc de Broglie; a les Hoines dOccident $\triangleright$, de Montalembert: a Charlemane et sa cour $\triangleright$, d'Hlauréau: les travaux sur les institutions du moren age de Fustel de Coulanges, Boutaric, P. Clément. Cheruel, de Cherrier. Thérenin. J. Roy, G. Monod. A. Girt, A. Luchaire. Ch. T. Langlois, Coville: l' alli-toire Jes cointes de Champagne s, de d'Arbois de Jubainville;

1. Thir: notre Histoire de la eivilisation franęaise. Lome Ier, jare 379 , notice biblographique.

2. V.:., meme rolume, la notice bibliographique de la page 320. 
Ies recherches de Beugnot, Rey, de Ilas-Latrie, Riant, sur les États fondés par les croisés; lhistoire de Duguesclin, l'histoire de la Jacquerie, l'histoire de Jeanne d'Arc, de Siméon Luce; a Étienne Hareel », de Perrens; c les États généraux », de Georges Picot; l'Histoire de Charles VII, de Vallet de Viriville; a l'Histoire de la société française au moyen âge s, de Raoul Rosières, etc.

Nous serons plus sobres encore au sujet des travaux francais sur le moyen àge à l'étranger. Il faut cependant signaler : l' a Ilistoire d'Allemagne », de Jules Zeller; a l'llistoire de la formation territoriale des Etats de l'Europe centrale ", l'A. IImly; les études sur l'Empire d'Orient. l'A. Pambaud ( L'Empire gree au $\mathrm{x}^{e}$ siècle $»$ ), de Schlumberger ( Nicéphore Phocas s, a Basile Ie tueur de bulgares s), de Gasquet (Italie byzantine), de Diehl (Alique byzantine), de Labarte et Bayet (art byzantin); sur l'Angleterre, de II. Wallon, Jusserand, Bémont; sur la Bohème et sur l'Allemagne, d'E. Denis; sur l'ancienne Prusse, d'E. Lavisse; sur I'Italie, de J. Zeller, Perrens, E. Gebhart, E. Müntz, Ch. Yriarte, A. Baschet, G. Thomas, Ph. Monnier, Gauthiez; sur l’Espagne, de Morel-Fatio, Desdevises du Dizert, Mariéjol, Boissonmade; sur la Hongrie, d'Édouard Sayous.

Lhistoüre des temps modernes. - Parmi les travaux les plus remarquables sur la période moderne : l'Ilistoire de la ilicère au temps de la Fronde par Feillet (1862); celle de Louvois par Camille Rousset (1861); celle des prinees de la maison de Condé par le due d'Aumale; celles de Pichelieu par Fagniez, G. Hanotaux, d'Avenel; celle des grandes dames du xv! siècle par Victor Cousin; celle de la réunion de Ia Lorraine par d'Haussonville; celle de Frédérie Il par E. Lavisse; les travaux d'E. Bourgeois sur la Résence; du P. Baudılllart sur les Bourbons d'Espagne; du due de Broglie sur la rivalité de la France, de l'Autriche et de Ia Prusse au xvine siècle; d'A. Lel"evre-Pontalis et A. Waddington sur la Ilollande; d'A. Geoflroy, de Chr. Sehefer sur les États scandinaves; d'A. Fambaud, L. Lécrer, Waliszewski. E. Haumant, sur la Russie et sur les Slaves; ceux de Taine, limé Clérest, F. Rocquain, Doniol, Flammermont, sur la fin de lincion Regime. 
Sous le second Empire, les différences d'opinions qui divisaient les écoles démocratiques produisirent des histoires de la Révolution qui étaient plus ou moins partiales pour tel ou tel côté de la Convention; ainsi les livres d'E. Ilamel, a Histoire de Saint-Just \ (18ว̈9), « Histoire de Robespierre ๖ (1860̈), sont jacobins et surtout robespierristes; au contraire, les travaux de Robinet et Bougeart sont plutôt dantonistes.

Dans la mélée des opinions contraires, EDGAR QJINET intervient, en 1868, avec sa • Révolution •. Très sympathique aux hommes de la grande époque, exilé lui-mème, à ce moment, pour sa fidélité aux principes démocratiques, mais partant de ce fait indéniable que la Rérolution avait abouti au despotisme impérial, il en concluait qu'il y avait eu, dans l'œurre accomplie de 1789 à 1793 , quelque vice essentiel. Ce vice, ceétait que les jacobins, tout en détruisant le passé sacerdotal et monarchique, étaient eux-mémes des hommes du passé, enclins à l'absolutisme comme des rois et à l'intolérance comme des inquisiteurs. Il osa dire que l'exécution de Louis XII avait été une faute et un malheur; que ce n'était pas la Terreur qui avait sauvé la Franee, mais qu'elle avait compromis la Révolution; que Robespierre et SaintJust, continuateurs de l'ancien despotisme, n'avaient lait que préparer les despotismes de l'avenir. Le livre fit grand bruit et souleva contre lauteur des animosités. Il rendit un précieux service en appliquant pour la première fois aux érénements et aux hommes de la Rérolution les règles de la eritique et en montrant que cette listoire devait ètre appréciée comme toute autre histoire. Depuis lors, beaucoup d'œuvres de valeur ont paru sur cette époque. a Camille Desmoulins et a les Dernier's Hontagnards o de Jules Claretie; l'llistoire de la République d'E. Ilamel. L'llistoire - politique s de la Rérolution, d'Aulard, a renouvelé ces études. Dans le camp des conservateurs, l'Histoire de la Terreur de Mortimer-Terneaux; l'llistoire du tribunal révolutionnaire de Wallon; « Thermidor" de Ch. d'Herieault; «la Révolution » de Taine; al'Ilistoire du Directoire de L. Sciout. Nous avons eu jusquà deux Revues de le Recolution, l'une républicaine, lautre royaliste. Le ministère de l'lnstruction publique et le Conseil municipal de Paris ont entrepris toute une série de collectinns sur cette époque. 
Signalons les belles études d'Albert Sorel sur a l'Europe et la Révolution française s; de Chuquet sur les guerres de la Révolution; de Charras sur les Campagnes de 1813 et 1815 ; d'Edgar Quinet sur Waterloo; d'Albert Vandal sur Napoléon et Alexandre Ier; d'Henry Houssaye sur 181'x et 1815.

L'histoire contemporaine. - Dans l'histoire contemporaine, qui peut se flatter d'être impartial en exposant des laits qui nous touchent de si près? Sous cette réserve, on peut signaler: sur la Restauration, l'histoire si vivante, faite au point de vue libéral d'autrefois, d'Achille de Vaulabelle; celle de Duvergier de IIauranne, écrite an point de rue libéral d'aujourd'hui; celle de Nettement, au point de vue royaliste. Sur le règne de Louis-Philippe, celles de Nouvion et Thureau-Dangin, qui sont orléanistes, celle de Louis Blanc, passionnément démocrate et même socialiste; les Mémoires de Guizot, où l'on ne peut prétendre que l'auteur se soit dépouillé de tout préjugé: la đConquẹte de l'Algérie de Camille Rousset. Sur la seconde République, l'alerte abrégé de Daniel Stern. Sur le second Empire, l'essai de Taxile Delord, et l'IIistoire de la guerre de Crimée de Camille Rousset ${ }^{1}$. Sur des événements plus contemporains, l'Histoire diplomatique de la guerre franco-allemande, d'Albert Sorel; les ourrages ou mémoires de Jules Favre, de Freycinet, Jules Simon, des généraux Faidherbe, Chanzy, Wimpffen, Vinoy, Martin des Pallières; les grandes histoires de Duquel, lieut.-eol. Rousset, Lehautevurt, sur la mime guerre; les ouvrages de Jules Ferry et de l'ambassadeur Billot sur les alfaires du Tonkin; des genéraux Faidherbe, Borgnis-Desbordes, Gallieni, Archinard, sur la conquete de linirique.

Un est toujours plus à l'aise pour exposer impartialementl'histoire ou les institutious des peuples étrangers. Nous relèverons les études de Saint-René-Taillandier sur la tévolution allemande de 18 is et sur la Serbie contemporaine; d'E. Denis, P. Matter, sur l'Allemagne du sise siècle; de $\checkmark$. Bérard sur les affaires de Turquie; I'An. Leroy-Beaulieu sur a L'Empire des tsars $\triangleright$; d'Ed. de Laboulaye (183.;) et d'A. Hoireau sur les États-Unis; l'Histoire de la guerre

1. On trouvera l'indication d'autres ouvrages ci-dessus, dans la Bibliograpble du chap xxv, p. 5 i? 
cirile aux États-Unis, du comte de Paris (187千). Mentionnons aussi le bean et savant livre d'A. Chéradame sur a l'Europe et la question d'Autriche an seuil du x. ${ }^{\mathrm{e}}$ siècle (1901).

Etudes celtiques. - En suivant le courant classique de l'histoire, nous avons laissé de côté nos origines celtiques, que notre Bretagne est presque seule aujourd hui a rappeler, et qui constituent notre parenté avec les Celtes des lles Britanniques. Les études celtiques ont eu, au début de l'ère nouvelle, un glorieux représentant: la Tour 'Auvergne, - premier grenadier de France s, qui, en 1792, partit avec son fusil de munition et sa grammaire celtique. A cette époque, comme le lien qui unit entre elles les langues indo-européennes nous échappait encore, on se faisait des idées sinsulières sur les idiomes celtiques. Tels celtisants étaient convaincus que le premier homme avait dû parler le celte. Depuis lors, ces études, qui passionnèrent si fortement llenri Martin, ont été éclairées par la grammaire comparée. N'Arbois de Jubainville et d'autres philologues ont rapproché entre eux les divers idiomes, exploré les anciens manuscrits des bibliothèques d'Écosse et d'Jrlande. Notre littérature bretonne, ses chansons épiques ou lyriques, ses contes, ses légendes, ses proverbes, ont été édités d'abord par de Villemarqué, Monin, de Courson, et, avec une critique de plus en plus rigoureuse, par Gaidoz, de Luzel. Le Braz. Entin l'archéologie gauloise doit beaucoup au fondateur du Musée de Saint-Germain. Nexanite Bertrand et à son successeur S. Reinach.

Eudes egyptiennes. - Notre plus grand égyptologue, apres Champollion, c'est Mariette, plus connu sous son titre egyptien de mariette-bey. Il a passé sa vie sur les bords du Nil, et il est mort pour ainsi dire sur le chantier, au milieu le ses fouilies. En 1850, il décourrit le temple de Sakkarah, près de l'ancienne Nemphis; en 1853. il deblaya les sables qui recourraient un temple de Memphis, appelé le Serapeum, où il trouva soixante statues des Apis ou taureaux sacrés; en 1838 , il exhuma cette merveilleuse figure du Sphinx accroupi, qui est au Louvre. Jusqu it sit mort, il n־a cessé de multiplier les foullles dans les ruines de Thèbes et le Karnak, mettant au jour d'innombrables 
momies, des statues, des pylònes, des papyrus. Il a enrichi le Musée du Lourre ou lormé pour le rice-roi d'Égyple le Musée de Boulaq, dont il fut le conserrateur. C'est à ce poste qu'il a eu pour successeur, en 1881, un autre Francais, déjà célêtre dans la science, Maspéro, qui, dans la - Vallée des Rois s, découvrit les momies de toute uue dynastie égyptienne, y compris celle du grand roi RansèsMëiamoun (qui semble devoir être identitie avec le Sisostris des Grecs). Haspéro eut pour successeurs, à la direction du Iusée de Boulaq. Grébaut et Jacques de Morgan.

Un contemporain de Mariette, $\mathbf{E}$ RodGÉ, avait publié ou traduit de nombreux textes igyptiens, comme le Rituel funéraire (1861), le joli Conte des deux Frères, le Poème de Peutaour en l'honneur de Ramsès-keïamoun.

La civilisation pharaonique, fort mal comprise ou presque ignorée des Grecs et des Romains, nous est presque aussi connue que celle de la France au temps de Louis XIV.

Etndes assyriennes, babyloniennes, persigures. médiques, etc. - C'est OPPERT qui eut l'hunneur de signaler, parmi les langres qui empruntaient l'alphabet cunèiforme. l'existence d'un idiome scythique, l'accadirn ('s:5), En 1860 , il a publié sa Grammaire assyrienne. De Sauicy, de Longpérier, Gobineau, Ménant, se sont attachés à déchiffrer les inscriptions cuneiformes sur les rochers, sur les mu. railles des temples, sur les briques qui formaient la bibliothèque des rois assyriens, sur les cachets où les lettrés d'alors faisaient graver leur nom et leur derise. E. Revillout s'est occupé des texles démotiques et de l'Érypte hellénisée. Ledrain a étudić surtout les textes sémitiques et sumériens des inscriptions cunéiformes.

RENAN, en 195\%, a pu comprendre les idiomes de la vallee du Tigre et de l'Eupurate dans son "Histoire génerale et système compraré lles langues sémitiques o.

Tout récemment, la mission SARZEC a repris les fouilles de la Babylonie; la mission Dieulafor s'est attaquée à l'ancienne Perse, surtout aux ruines de Suse, et en a rapporté de pricieux momuments, comme la firise du palais de Darius; la mission JACQUES DE MORGAN, à la suite d'une convention signce arec le shah de Perse, s'est attachee a la. Susiane et a retrouré les restes de la civilisation cirmite. 
Émdes sémiliques, syrienmes, arabes, berbères. En 18ă5, on a découvert en Syrie et transporté au Musée du Louvre le tombeau d'Eschmounazar, roi de Tyr, avec une précieuse inscription.

L'abbé Bargès, Munk, de Saulcy, ont recueilli et déchiffré les inscriptions des Phéniciens et ébauché la grammaire de leur langue. Judas a montré les rapports de cette langue avec celle des anciens Libyens (Tripolitaine); le général Faidherbe a publié des inscriptions libyques qui ont le caractère graphique qu'emploient encore aujourd'hui les Touaregs. L'abbé Bourgade, en 1856, sous le titre de - Toison d'or de la langue phénicienne ", a rassemblé les inseriptions d'Afrique et de Syrie. Le due de Luynes a étudié la numismatique des Phéniciens. Renan nous a présenté Sanchoniaton, leur philosoplie. Nous connaissons enfin ce mystérieux peuple, le premier de l'antiquité pour le commerce.

Pour les études chaldaïques, hébraïques ou syriaques, il faut citer les travaux des abbés Bertrand, Créhange, Glaire, du pasteur Bost, du rabbin Astruc, du savant israélite II. Derenbourg, de Reuss, professeur à la faculté de théologie protestante de Strasbourg, de Ledrain, de Carriere, de Pl. Berger. La Terre-Sainte et les contrées avoisinantes ont été explorées par de Saulcy (1853), qui a donné une a Histoire de l'art judä̈que s; par Renan, l'éloquent auteur de la a Vie de Jésus ๖; par le comle de Vogüé, qui a reconstitué a le Temple de Jérusalem \ (1865); par Clermont-Ganncau ( la Palestine inconnue ", 1875).

Les études sur les Arabes ont pris pour nous une importance nationale depuis que la conıuête de l'Algérie nous a mis en conlact avec cette race hérö̈que. De l'Arabie proprement dite, de l'ancien royaume de Saba, Théodore Arnaud rapporta, vers 1859 , les premières inscriptions himyarites que nous ayons connues. Lottin de Laval, en 1855, commencait l'exploration de la presqu'ile du Sinaï. Les œuvres des historiens et géographes arabes, Maçoudi, Yacout, IbnKhordalbeh, Ibn-Batoutah, Makrizi, Ibn-Khaldoun, ont été traduites par Barbier de Meynard, Pavet de Courtcille, Defrimery, de Slane; les œuvres des poètes, par St. Guyard, Barbier de Meynard; l'épopée d'Antar, par Marcel Devic. 
Pour les Arabes d'Algérie, il faut noter les travaux philologiques de Cherbonneau, Houdas, Ben-Sedira, René Basset; la publication des chroniques du Mzab par E. Masqueray; l'étude des textes législatifs applicables à l'Algćrie par Perron, Seignette, Estoublon, le présilent Zeys, etc.

Citons encore l' a Ilistoire des Arabes " de Sédillot (183̈4); la a Vie de Mahomet o de llenri Delaporte (1874); l' a Ilistoire des rapports de l'Europe avec les États arabes de l'Afrique du Nord o de L. de Mas-Latrie (1865). D'après les historiens arabes et surtout Ibn-Khaldoun, Fournel a raconté la a Conquête de l'Afrique septentrionale par les Arabes s (1875). Reinaud nous a fait connaitre leurs notions sur le monde par son antroduction à la géographie des Orientaux "(1848); Munk et Renan, leur philosophie, celui-ci par son beau livre sur a Averroës et l'Averroïsme (1852).

Un peuple apparenté avec cux, ce sont les Berbères, qui habitaient déjà l'Afrique du Nord à l'époque romaine, qui habitent encore l'Algérie, la Tunisie, le Maroc, et dont les Kabyles ne sont qu'un rameau. Le général Hanoteau a recueilli les a Poésies populaires du Djurjura (1867) et, avec le conseiller Letourneux, les a Coutumes de la Kabylie. (1873); les « Contes Kabyles s ont été publiés par René Basset, le lexique Touareg par E. Hasqueray. Les questions si importantes relatives aux confréries et ordres religieux musulmans ont èté traitées par le commandant Rinn, Le Chatellier, Coppolani et Depont, Carra de Vaux.

Les langues de l'Abyssinie, qui se rapprochent des langues berbères, ont été étudiées chez nous par Joseph Halévy et Mondon-Vidailhet.

Études persanes, arméniennes, turques, tatares. Mohl a terminé en I855 sa publication du Shah-Xamed; Defrémery a publié des fragments d'historiens et des curres de poètes persans; Charles Schefer, des textes d'historiens; A. Chodzko, sa Grammaire persane (1852). James Darmesteter a grandement contribué au progrès des études persanes.

Dulaurier a publié une Bibliothéque historique arménieme et une a listoire de l'Église arménienne s. Victor Langlois commença une collection des historiens arméniens (1868). 
Pavet de Courteille a traduit du turc-djagataï les Mémoires du Grand-Mogol Baber (1871).

Léon Cahun nous a. dans son a Introduction à l histoire de l'Asie $\triangleright$, familiarisé avec les migrations des hordes turques, tartares, mongoles, et montré leurs contre-coups sur l'histoire de lEurope (1896).

Etades indiennes. - Nous devons la traduction des Vídus à Règnier, A. Langlois, P. Regnaud; celle des fragments du Mahabaratha à Th. Pavie et E. Foucaux; celle du Ramayana et de Sakountala à Fauche et Bergaigne. Émile Burnouf nous a donné une grammaire et un dictionnaire du sanscrit. Cette langue a servi de base à de grands travaux de grammaire comparé : le plus important est la grammaire de l'Allemand Bopp, dont Michel Eréal a donné une édition française (1866). Les religions de l'Inde ont été étudiées d'abord par Eugrène Burnouf (1844), puis par A. Barth, E. Senart, Barthélemy Saint-Hilaire, Foucaux, Léon Feer: le théatre par S. Lévi; la philosophie par Jean Lahor (le docteur Cazalis).

Le tamoul, une des langues en usage sur le territoire francais de Pondichéry, a été enseignée chez nous par J. Vinson, qui a traduit des textes importants.

Etndes artrême-Orient. - Tos possessions de l'IndoChine ont été l'objet d'une véritable exploration scientifique, notamment dans le Cambodge, où habita la mystèrieuse nation des Khmers, si originale dans ses manifestations artistiques : les anciens temples des Khmers (ruines d'Angkor), leurs stèles et leurs inscriptions ont été étudiées par A. Bergaigne, Barthet, Aymonnier : celui-ci a publié un dictionnaire de la langue cambodgienne. Sous l'impulsion du gourerneur sénéral Doumer et la direction de Louis Finot, la Mission archéolo zque d'Indo-Chine tendait it devenir une véritable Ecole francrise t'Extréme-Orient. Celle-ci a été constitıée en férrier 190\%. Ses membres ont yorté leurs investigations dans les régions roisines. Naurice Courant a dressé un catalogue des manuserits de la Coré.

La langue et la littérature, les institntions chinoises ont été étudies par Kleczkowski, Deveria, H. Cordier; celles du Japon par L. de Rosny, G. Bousquet, L. Pagès, L. Bertin, G. Appert, A. Iumbert. 
Ctudes américaines. - Enfin les anciernes civilisations du Pérou, où régnèrent les Ineas, et du Mexique, où régna l'empereur aztèque Nontézuma, leurs monuments, leurs inscriptions hiératiques, leur's manuscrits indéchiffrables, ont tenté la fantaisie ou l'érudition de l'abbé Brasseur de Bourbourg, de Léon de Rosny, de Charnay. En 1875 s'est ouverte à Nancy la première session du Congrés international des Américanistes.

Ainsi, d'un bout à l'autre de la terre, reculant toujours dans des siècles plus lointains, embrassant chaque jour des régions nouvelles, la science française est à l'ouvre, interrogeant les monuments en ruines, les langues aujourl hui disparues, les littératures conservéès sur le granit, la jrique ou le papyrus. L'élargissement du monde, commencé au $\mathbf{x} v^{e}$ siècle par les grands voyages de découverte, se continue par les méthodes rigoureuses de la science.

Ecudes préhistariques. - Plus loin dans le passé que les civilisations de l'Égypte, de l'Assyrie, de l'Inde, de la Chine, plus anciennes que la plus ancienne histoire, l'autres sociétés commeṇcent à se révéler. Ce sont celles des âges préhistoriques, quand l'homme menait, sur le sol mème de ce qui est aujourd hui la France, la misérable vie des saurages australiens. Nul monument écrit n'aurait pu nous renseigner sur ces lointains ancêtres. C'est en fouillant le sol, en creusant les tertres, en sondant les cavernes, qu'on a pu retrouver les ossements de ces premiers hommes ou les vestiges de leur industrie. Ici l'histoire se confond avec lhistoire naturelle. La découverte du crâne de Cannstadt, en 1700, n'avait que peu attiré l'attention. De 1828 it 1838 sètaicnt poursuiries les explorations de Tournal, de Christol, de Joly, de Marcel de Serres, dans les cavernes de Mude, du Gard, de la Lozère. En maint endroit on avait trouvé des fragments de poterie mè's aux débris d'animaux de l'äge quaternaire. En 1833, l'Allemand Schmerling avait déconvert, dans des circonstances analognues, le crâne humain de la caverne d'Engis. Cuvier, dont l'autorité était grande alors, A. de Quatrefages lui-mème, qui devait ètre plus tard un des princes de la science nouvelle, se prononcèrent contre toute possibilité de l'existence de l'homme à l'âge quaternaire. Les préjugés religieux s'opposaient aussi 
à la reconnaissance de la haute antiquité qu'aurait dounée à notre espèce la réalité de telles découvertes. En 1838, BOUCher DE PERTHEs trouva dans les carrières d'Abbeville, en terrain quaternaire, des haches de pierre façonnées de main d'homme. Il ne fut point écouté. Il n'en publia pas moins, en 1847, le premier volume de ses a Antiquités celtiques et antédiluviennes o. C'est seulement de nos jours que la science nouvelle a pris son essor. En 1855, dans les carrières de Saint-Acheul (Somme), le docteur Rigollot découvrit quantité de silex travaillés de façon à donner des pointes de flèche ou de Jance. D'Angleterre, d'Allemagne, de Suède, on annonçait de semblables découvertes. Chez nous, en 1861, on trouvait dans la grotte d'Aurignac dix-sepl squelettes humains, qui, malheureusement, furent aussitot dispersés. En 1863, Boucher de Perthes mil au jour la mâchoire de Moulin-Quignon, qui excita une vive polémique.

C'est alors seulement qu'A. de Quatrefages se prononça pour l'existence de l'homme quaternaire. On fouilla avec une ardeur nouvelle. La Société d'anthropologie se forma. Elle eut bientôt recueilli plusieurs centaines de crânes, de nombreux squelettes; parmi ces débris figuraientle crâne d'Engis et la mâchoire de Moulin-Quignon, désormais historiques. En 1868, on trouva le squelette de Cro-Magnon (Dordogne). Dès lors, non seulement l'existence de l'homme quaternaire, contemporain chez nous du mammouth, du rhinocéros à narines cloisonnces, de l'hyène, de l'ours et des grands félins des cavernes, fut reconnue ; mais on commença à distinguer les races de Cannstadt, le Cro-Magnon, de Grenelle, de Furfooz, à collectionner les haches de pierre, les instruments de silex, les tissus, même les premiers essais artistiques sur la corne du renne ou sur l'ivoire du mammouth. L'existence d'un homme beaucoup plus ancien, de l'homme tertiaire, un moment acceptée par quelques savants (1844), considérée depuis comme inadmissible, est, aujourd'hui, ¿ propos d'ossements attribués à un pithecunthropus, de nouvean agilée. (Suppl. 3).

Une autre source de renseignements sur la vie de nos plus lointains ancêtres s'est ouverte lorsque, à partir de 18:7, Despine explora la vase du lac du Bourget (Savoie), et Chantre celle du lac de Peladru (Isire). Ils firent des 
découvertes que confirma l'exploration de la plupart des lacs de la Suisse. L'existence des cités lacustres fut désormais hors de doute. Enfin les fouilles des tumuli, des dol. mens, des allees couvertes et autres sépultures antérieures à la période gauloise complétèrent les données sur l'áge préhistorique de notre pays.

Géographie, voyages. - En Asie, nous avons à signaler les Voyages du P. Huc, de Gabet, de Grandjean, de Bonvalot, de Chaffanjon (celui-ci sur un parcours de $2000 \mathrm{ki}$ lomètres qui lui a permis de rectifier les cartes russes), de Dutreuil de Rhins et Grenard à travers le Turkestin et la Chine; cenx de Lagrée, de Dupuis, de Garnier, dans l'IndoChine, où ils ont frayé les voies à la conquête française; ceux de Wiener et autres explorateurs dans les régrions inconnues de l'Amérique du Sud.

L'Afrique, où notre inlluence et nos possessions n'ont cessé de s'étendre, est restée la carrière de prédilection pour les explorateurs français.

Sur le haut Sénégal, le haut Niger, le Tchad, ont eu lieu les voyages de Bertrand-Boccandé, de Quentin et Mage, de Gallieni, de Binger, de Crampel, de Dybowski, de Mizon, etc., qui, en général, ont précédé, dans le Soudan oceidental, la marche de nos colonnes ${ }^{1}$.

Depuis que nous possédons l'Algérie, plusieurs tentatives ont été faites pour atteindre, ì travers l'immensité du Sahara, les fertiles régions du Niger; elles ont échoué devant les difficultés naturelles on l'hostilité des Touaregs, ces pirates de l'océan de sable. En 1881, nous avons eu à déplorer le désastre de la mission Flatters dans la région de l'Asben; en 1886, l'assassinat du lieutenant Palat; en 1889 , de Camille Donls; en 1896, dı marquis de Morès. Et combien d'autres, un peu partout, lans cette Afrique dont la possession nous a coûté si cher! La mission Flamand dans les oasis de la frontière marocaine (1899), la mission Foureau-Lamy dans la direction de Zinder el du lac Tchad (1898-1900) semblent avoir rompu le charme. L'inhospitalier Maroc a dù livrer une partie de ses secrets aux

1. Voir ci-dessus, p. 582 et 601 . Voir aussi, dans l'Histoire générale, t. XI!. e chaptre su: lempire colonial francais. 
explorateurs Ch. de Foucauld (1883-1884), de la Martinière, de Segonzac, du géologue Louis Gentil (190ö-1908).

Dautres ont essayé de traverser daus toute sa largeur l'Afrique centrale, entreprise qui avait déjà coûté la vie à l'Écossais Livingstone (1873). En 1880, l'abbé Debaize, qui était parli de la cote orientale aree une escorte imposante et dans les meilleures conditions possibles de succès. est mort de maladie près du lac Tanganyika. Yous avons été plus heureux dans l'exploration du Congo.

Du côté de l'Abyssinie, Paul Soleillet, tué en 1886, a pu accomplir plusieurs voyages heureux, en rue détablir des communications assurées entre ce pays et nos possessions dOhock et de la baie de Tadjourah.

Lexploration sejentifique de Madagascar, surtoat au point de vue des sciences naturelles, a été très avancée par Allired GRANDIDIER. son tils, E.-F. Gantier et nombre d'officiers.

A côté de la société de yeorrathie sest fondée la Soenté de geographie commerciale, recomnu l'utilité publique en 1884.

Surtout depuis nos désastres le 1870 , la science géographique est en faveur chez nous. Elle a pris une place importante dans notre enseignement et provoqué la fondation de revues spéciales. Parmi les rénovatenrs. Vidal de la Blache, Marcel hubis. Cumme oure densemble, la geographie de Halie Brm a été dépassée par l'imposant travail d'Elisée Reclus. Le temps nest plus on les étrangers définissaient le Francais un a homme qui ne sait pas la géographie .

\section{L'économie politique et la sociologie.}

Léconomie politique. - L'économie politique, après les expériences faites depuis les traités de commerce de 1860 . nest plus aussi exclusivement vouée aux loctrines du libre-échange : les théories de protection ont mème repris quelque faveur. Elle est moins dogmatique, mais plutôt iclectique: elle porte son principal efiort sur l'étude des faits, sur l'état économiqute comparé des divers pays, sur la statistique. Les principaux représentants de cette science ont été chez nous Wolowski ', Joseph Garnier,

1. Wolowski, nè à Varsovie, réfugié en France après l'insurrection polonaive de 1831, professenr au Conzervatoire des Arts et Métiers, membre de 
Léon Say, Frédéric Passy, H. Baudrillart, Courcelle-Seneuil, H. Germain, E. Levasseur, Juglar, Paul Leroy-Beaulieu, Msurice Block, E. Cheysson, Octave Noël, R. Georges Léry A. Liesse. 1. de Foville.

La science sociale. - Le Play, voyageur actif et curieux qui a étudié les conditions du travail dans l'Europe presque entière, démontra que la sociologie est une science, en détermina la méthode et en constata les résultats les plus importants. Il a publié a les Ouvriers européens • (18ăs̆), - la Réforme sociale (1864) et a l'Organisation du travail, (18\%0). Le comte de Chambrun a donné une vive impulsion à ces études en fondant le Musee social'.

Ouvrages a consultell. - Ravaisson, Rapport sur les progres de la philosophie. - Damiron, Essai sui l'hist. de la philos. au XIX siècle. - Taine, Les philosophes francais au XII' siècle. - Ferraz, Etudes sur la philosophie en France au $X X^{\mathrm{e}}$ siècle. - Paul Jauet, La philosophie contenporaine. - Etudes de Mignet, Jules Simon, sur Vietor Cousin. - Pierve Leruux, Rifutation de l'eclectisme. - Etudes de do Barante, A. Philippe, Vingtain, sur Royer-Collard. - L. Liard, Notice sur Jules Simon. - Clémenceau, Augustc Comle et le positinisme. L. Lévy-Brühl, La Philos. d'Auguste Comte (1900..-I, ittré, A uguste Comte et lu philosophie positive (1:ij;. -

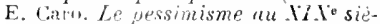
cle (1850). - Jaset, Le materialssme contemporain. - Lange, Hist. lu materialisme. - G. L. Duprat, Les causes sociales de la folie (1901). Henry S. Salt, Le's druits de l'animal considéré dans lezr rapport avec le p'ogrés social, trad. de l'anglais pa: L. Hoteln (1914).

Risports publiés, a l'occasion de
l'Expositiou de is67, sur l'etat des lettres, par de Sacy, P.Feval, Th.Gautier, Aug. Thierry; - sur les progrès des études relatives à l'Erypte et à l'Orient, par Guigniaut, de Rougé, de Saulcy, Munk, Reinaud, Defremery; - de l'archéologie, par A. Maury; - des études historiques, par Geffroy, Zeller et Thiénot;-des études orientales, par Dulaurier, Stanislas Julien, L. Feer, Nichel Breal; - dcs éludea classiques el du muyen ize, par E. Egger, Boissier, L. Dellsh, Gucssard, arbois de Jubainville, An. de Barthelemy; - de lan'hropologie, par de Quatrefages.

G. Monod, Les maitres de l'histoire: Renan, Taine, Michelet 18:1. - P. Guiraud, Fustel de Coulunges (1905).

Xavier Charmes, Le comite des tra. vaux historiqu's et scientififues (l'inLoduction). - R. de St-Alroman, Missions francaises, causorit's gèaraphiques. - Eloges apademiques: G. Picot, sur Léon Say (1900), ete. Centenaire de Le Play, dans fa $\mathrm{ft}$ forme Sociale (1907).

la Constitnnnce, de la Lérislative, du Sénat de la Rèpublique, a pubiè des ouvrages sur l'Organisation du Crédit (1849), les Banques d'Angioterre ei de France (1867), lin Lilerté commerciale (1568), etc.

Garnier, sènatear de la Réphlique, avait publié, en 1845, na Traith d'économie politique : il a donné ensuite le Droit au travail (ISis), Prin. cipe de la population (1557), Traiti de finances (1857), Elemenis de statis. sique (185\%), elc. Il fut un des fouditeuns de la Societ d'économie politique. (1847), le rédacteur en chef du Journal d'économie politique (I8:7), et to fondateur du Journal des connaissances utiles (1853).

1. On trouvera plus lain, au chapitre xxxin, l'exposé des idées et des groupements ancialistes dans les cinquante dervières années du $\mathrm{xIX}^{2}$ sicclo 


\section{CIIAPITRE XXXI}

LES ARTS

\section{L'arcinitecture, la sculpture.}

Restanrations de monments anciens. - Le mouvement commencé sous la Monarchie de Juillet s'est poursuivi de nos jours aree une passion plus éclairée et une science plus précise. Il suffit de comparer les restaurations accomplies, au mont Saint-Yichel par exemple, sous LouisPhilippe et à l'époque présente. Ballu a restauré la tour Saint-Jacques (185:?); RUPRICH-ROBERT, le château de Falaise; abadir, les cathédrales de Bordeaux, Périgueux, Angoulème; danjoy, la cathédrale de Yletz; Lance, l'abbaye de SaintDenis, les cathédrales de Sens et de Suissons: Pascal. celles de Valence et Avignon; DAumer, le château de Chantilly; NoRmand, le ehâteau de Liancourt; Marcel Lambert. le chàteau de Versailles; Émile BeswillwaLd, la calhédrale de Laon, le palais des dues de Lorraine à Nancy. l'abbave du mont Saint-llichel, sans parler du Prætorium romain à Lambèse (Algèrie) et de l'ancienne cité le Timgad, oủ les fouilles dirigees par lui ont fait revirre une opulente ville romaine, arec son forum autrefois peuplé de statues equestres des empereurs, ses temples, son théâtre, ses thermes, et jusqu'aux boutiques de ses marchands.

VIOLLET-LE-DOC, qui a dirige ou partage les travaux de Lassus à la Sainte-Chapelle, it Notre-Dame et à SaintGermain-l'Auxerrois, de Lance à Sens, de Boswillwald à Laon, s'est chargé des érlises de Vézelaý, de Montréal (Yonne), d'Amiens, de Châlons, du château de Pierrefonds, de la cité de Carcassonne, ete. 
La loi du 30 mars 18S\%, complétée par le décret du 3 janvier 1891, en vue de protéger les monuments historiques ou artistiques contre les actes de vandalisme, ne s'est pas révélée, à la pratique, complètemen i efficace.

Larchitecture contemporaine. - L'époque présente n'a certes pas créé un art nouveau; peut-être n'est-il donné qu'à des civilisations nouvelles de créer un tel art. Lart indou, grec, romain, roman, ogival, répond à quelque état de civilisation absolument original. Notre civilisation, au contraire, procède de celles qui l'ont précédèe : elle en est la résultante. Notre àge, surtout en architecture, est un âge de savoir et de critique, bien plus que d’imagination. Ce qu'on peut exiger de lui, e'est qu'il ait du moins l'intelligence de ses origines.

Voilà pourquoi nous bảtissons nos églises, tantît en style ogival, comne Sainte-Clotille, construite par GAd, et dont BALLd a fait jaillir les flèches (1850); tantôt en style byzantin, comme l'église russe de Paris, qui est de l'arliste russe Kouzmine; tantôt en style roman, ou renaissance, ou composite, c'esı-à-dire formé d'éléments divers, comme Saint-Augustin, œuvre de BALTARD (1860-1868); comme l'église du Sacré-Cour, d'ABadie; comme la Trinité, de Ballo (1867-1870); comme la cathédrale de Harseille, de Léon vauDOYER (1836) et Louis DUC.

Il en est de même de nos édifices civils : thêatres, luitels de ville, tribunaux, grands hôtels, comme le Grand llitel, l'hôtel du Louvre, le Continental, ete.

Les cuvres les plus remarquables de la période contemporaine sont le Nouveau Louvre de viscontr (1833) et LEFUEL; le Grand Opéra (1861-1874), de Charles GARNIER, commencé sous le second Empire et achevé sous la troisième République. Avec ses colonnes, son dôme, ses basreliefs, ses statues de bronze, ses obélisques égyptiens, ses marbres aux couleurs variées, il rappelle à la fois les arts de l'F́gypte, de la Grèce, de Byzance, de la Renaissance italienne.

Il faut citer encore la Grand Chambre de la Cour de cassation, de coquart; la Cour d'appel, de Daumet: le Tribunal de Commerce, de BAILLY (1860-1866); la fontaine Saint-Hichel (1860) et le theatre du Chatelet, de Davioud. Celui-ei a colla- 
boré areo BOdRDAIS au paluis di Trocadero. BALL et DUPER. THEs ont été chargés de reconstruire, dans l'ancien style, l'Hôtel de ville de Paris, incendié en 1871.

NÉNGT nous a donné la Nouvelle Sorbonne avec sa farade imposante sur la rue des Ecoles; Beruier, le nourel Opéra-Comique: Girault, le Petit Paluis; Deglane, Thomas et Louvet, le Granl Pulais, tous deux affectés au service des Beaux-Arts et inaugurés en 1900.

Un des traits caractéristiques de l'architecture contemporaine, ce sont les monuments, de proportions gigantesques, destinés à abriter des multitudes d'hommes ou à contenir un materiel immense, halles prodigieuses ou gares de chemin de fer, ceurres d'ingénieur plus encore que d'architecte, où le beau est subordonné à l'utile et oủ les charpentes en fer jouent le rôle principal, mais qu'ennohlissent la science mathématique, l'ingéniosité des moyens mis en ourre, la graudeur des difficultés vaincues, la rapidité de la cons. truction. Les trpes de cette architecture, quon pourrait appeler industrielle. ce sont les Halles centrales de Paris. construites de 1852 à 1870 par BazTard, la galerie des Machines, la tour Eiffel, les palais de l'architecte ronmige. exécutes pour l'Exposition uniserselle de 1889: le pont Alexandre 1Il, pour celle de 1900, par les ingénieurs Réral et Alby et dont le tsar Nicolas II, la tsarine et le président Faure posirent en 1896 la premiere pierre.

La scupture. - De latelier de Rude sont sortis Cain, Frémiet, Carpeaux, Cordier, Becquet, Chatrousse, Schroeder; de l'atelier de Lavid d'Angers, Cavelier. Soitoux, Petit, Aimé Millet. Schoenewerk, A. Carrier-lielleuse. André Allar; de l'atelier de Pradier, Lequesne, Eugène Guillaume, Chapu; de l'atelier d'A. Lumont, Perraud. Jules Thomas, Aizelin; de latelier de $F$. Jouffroy, moin -élebre par ses urres jersonnelles que par ses nombreux disciples, Baujaut, Cambos, Falguière, Hiolle, Ernest Barrias, Mercié, Charles Gauthier, Lanson. Tous se sont illustrès :

CAIN, par ses magnifiques Groupes danimaux; - FREMIET, par ses Combats d'hommes primitifs et de fauves, par -a statue de saint llichel, ses statues équestres de saint Georges et de Louis Xill. son Char de Pallas (qua exécuté en biscuit la manufacture de Sères); - CARPEAUX, par son 
fronton au pavillon de Flore; son groupe de la Danse, d'un mouvement si ardent (à la façade de l'Opéra); ses Saisons (à la fontaine de l'observatoire); CORDIER, par son Amphitrite, ses femmes arabes ou égyptiennes; - J. BECQUET, par son Faune (1867), son Vendangeur, son Ismaë! (an Luxembourg), sa statue de Victor Ilugo (1901), son Christ (1903); - cratrousse, par son groupe d'Héloïse el Abélard (185i), "la Renaissance et l'Antiquité ", "Wadeleine au désert » (1867); - SCHREDER, par sa Chute des feuilles (1859), sa Poésie pastorale, son "David " (à l'église de Clignancourt).

Cavelier est surtout célèbre par sa lénélope endormie (1849), sa Vérité et sa Cornélie (au Luxembourg), son groupe du Muséum à Marseille, ses sculptures de SaintAugustin, son Pascal du square Saint-Jacques; - sortoux, par sa statue de la République (1848), qui se dresse aujourd'hui devant l'Institut; - PETIT, par ses tigures de Mars, de Persée, les Muses (à l'Opéra, le cardinal de Granvelle; - aIme millet, par Ariane, par Cassandre et Pallas (au Luxembourg), les tombeaux de Mürger et de Baudin, le Vercingétorix colossal d'Alesia, le groupe d'Apollon qui surmonte l'Opéra; - SCHGNEWERE, par sa Myrto et sa a Jeune fille à la fontaine s; - A. CARRIER-BELLEdSE, par son Hébé endormie sous l'aigle de Jupiter (1869); André allar, par sa Mort d'Alceste.

LEQdesne, par son Faune dansant, son Soldat mourant (1857), sa Prètresse de Bacchus (1870); - Eucène guilladme. aussi fin critique d'art qu'admirable sculpteur, par son Faucheur, son Anacréon (1852), son groupe des Gracques, sa statue de l'archevèque Darboy $(1875)$, son fronton et ses cariatides du pavillon Turgot, son Andromaque, son Orphée, enfin par ses bustes si expressifs; - CHAPO, par sa Jeanne d'Arc à Domrémy (1870), sa figure de la Jeunesse au monument de Regnault, sa Cantate (à l'Opèra), son tombeau de Mgr Dupanloup (1887).

PERRAUD, par son bas-relief des Adieux, son groupe de l'Enlance de Bacchus, sa statue du Jour (au jardin du Luxembourg); - тнomas, par son Virgile, sa Mlle Hars, - Hippocrate et Ilysie s; - AIzenin, par sa Judith.

baujadit, par son Jeune Ganlois (1870) et le Premier Miroir (1873); - cambos, par sa Femme adultère (1866); - 
FALGuíre, par son Ophélie 1869), sa Danseuse égyptienne (18:3), sa Diane de 1887, que tant dautres Dianes ont suivie, son La Rochejaquelein, son Pasteur, son Larigerie plantant dun geste si résolu la croix sur la terre d'Afrique; - holle, jar son Arion $(1870)$; - Ernest barrias, par sa "Jeune lille de Megare " (1870), son Serment de Spartacus (1873), ses "Premières funérailles" (1878), son groupe de la Défense de Saint-Quentin, son monmment de Victor Hugo, sa "Nature se dévoilant ๖; - A. Mercis, par sa Dalila (1870), son David vainqueur de Goliath, son Génie lies arts (an nouveau Louvre), son groupe à la fois funèbe et triomphal dı Gloria virtis, son Quand même, sa Jeanne d'Are, à laquelle la France vaincue souffle les ardeurs du dévouement el du sacrilice; - Charles gauthier, par sun monument de Besançon qui représente Jouffroy l'Abbans (le second inventeur de la navigation à vapeur) et la statue du sergent Blandan à Boufarik (Algérie); - LANson, par son Age de fer (188\%), etc.

Dans la génération de statuaires qui est sortie des ateliers de ces maitres, on peut nommer : BARTHoLDI, de Colmar, élève de Falguière, l'artiste puissant qui dota sa ville natale de la statue de Rapp et du monument de Dumont-d'Lrville, qui a sculpté le rocher de Bellort en un lion gigantesque, la statue colossale de la Liberté qui se dresse à New-York, le groupe d'Amphitrite qui décore à Lyon la place des Terreaux, la statue équestre de Vercingétorix pour la ville de Clermont; - Dobols-pigalle, l'auteur de Narcisse au bain (1863), du Chanteur florentin (1865), d'Éve naissante (18:3); - IDRAC, dont le Luxembonrg a recueilli la Salammbò et le a Mercure $\triangleright$, et qui a dressé derant l'Hòtel de Ville la statue équestre d'Étienne llarcel; - Delaplanche, dont on admire, au mème musée, a Eve après le péché ๖ et a Message d'amour v; — Paul Dubors, qui nous a donné une Jeanne d'Arc et modelé une statue tombale du duc d'Aumale - guilbert, qui a exécuté plusieurs statues de Thiers, le monument de Dolet sur la place Nanbert, une figure colossale de Christophe Colomb pour la République Dominicaine; - TuRCaN, qui a dressé le groupe de a l'Avengle et le Paralytique $\triangleright(1588)$.

BARTHOLOMÉ arec son tragique a Monument aux molts ॰; - 
POECB, avec son saint Antoine de Padoue et le vigoureux buste de Jules Ferry; - Garder, l'élève et l'émule de Frémiet et de Cain pour les groupes d'animaux; - valton, élève de Frímiet et Barye et qui a également suivi les traces de ses maitres. - INJALBERT, auteur de Nymphes, de Satyres et de Bacchanales, et d'un buste populaire de la République; - de SAINT-Marceadx, d'un talent gracieux et fort; - Maraueste, auteur d'une Ève, d'une Naternilé, d'une Cigale; - GRANET, COUTAN, VERLET, G. MICHel, qui travaillèrent à la décoration du pont Alexandre 111 ; - DALOU, dont le a Triomphe de la République • fut inauguré en 1900; CARLEs, l'auteur du "Soldat expirant"; - nodIN, si origina! et si discute (Balzac, le Penseur): - A. Boucher, L. Fagel, J. HUGUES, h. LEMAIRE, A. PARIS, Math. MOREAU.

GÉRoMe, le peintre éminent, s'est exercé dans la statuaire polychrome avec sa gracieuse Tanagra musée du Luxembourg), sa Cormidable a Bellone o et même dans les statuettes polymétalliques comme son Bonaparte ou son Tamerlan équestres. Dans cet ordre d'idées il a été suivi par des artistes au talent délicat, habiles, comme les statuaires athéniens, à combiner le marbre, l'ivoire, le bronze, l'argent, l'or, les pierres précieuses, tels que Maurice Ferrary et Théodore Rivière.

Parmi les artistes en médailles et médaillons, citons chaplain, qui, Iors du voyage de Nicolas Il et de la tsarine à Paris (1896), modela leur double profil pour la médaille commémorative; Rotr, qui parmi tant dieuvres exquises, nous a donné la a Semeuse, de la nouvelle monnaie d'argent; - Daniel Dupuis, enlevé prématurément (1900); E.-F. Gaulard, l'auteur d'admirables camées; A.-G. Lambert, Lechevrel, L.-E. Houchos, Pater.

Gustave DoRí, le grand dessinateur, s’est mèlé aussi de sculpture, et on lui doit le monument d'Alexandre Irumas.

Aux siècles précédents, les rois n’autorisaient sur les places publiques d'autres statues que les leurs. La démocratie, riche, éclairée, patriote, a peuplé nos places publiques, nou seulement à Paris, mais dans les plus pelites villes, de marbres et de bronzes représentant, depuis Vercingétorix qui lutta contre César, depuis Jeanne d'Arc qui chassa les Anglais, jusqu'à Moncey qui défendit la barrière 
de Clichy, jusqu'à Chanzy qui contint sur la Loire l'invasion prussienne, tous ceux dont les exploits ont glorifié la France, et aussi tous ceux, poètes, philosophes, artistes, inventeurs, qui ont bien mérité de la France et de l'humanité.

Les monuments publics, hôtels de ville, palais de justice, théâtres, se sont déeorés de statues, de groupes, de frontons, de bas-reliel's, et e'est par cet amour de la beauté plastique que la démocratie francaise ressemble le mieux à l'antique démocratie d'Athènes.

Quant à nos sculpteurs, - e'est un fait reconnu par la critique européenne, - lemr science du dessin et de l'anatomie, leur habileté d'exécution, égalent ce qu'on a pu voir dans les siècles les plus favorisés.

\section{La peinture, les arts du dessin.}

De la splendide floraison d'artistes qui avait coïncidé avec la période romantique de notre histoire littéraire, le plus illustre des survivants, en 18'8, etait Ingres 1 (mort en 1867$)$. Il peignit \& la Source » en I861, \& l'Apothéose de Napoléon $I^{\text {er }}$ ", qui périt dans l'incendie de l'Hòtel de Ville en 1871. Il ne put tonner la dernière main à une vaste composition a l'Age d'or $v$, peinte sur une muraille du château de Dampierre (Seine-et-Oise), et qui reste cependant une de ses plus grandes œurres.

Filiation des écoles de peinture. - La génération qui atteignit sa maturité pendant le second Empire a eompté dans ses raugs Pils, Barrias, Yvon, Protais, Chenavard, Charles Muller, Laugée, Boulanger, Gérôme, Paul Baudry, Tony Robert-Fleury, llamon, Eugène Isabey, Heissonier, Frère, Fromentin, llébert, Dubufe, Paul Dubois, Cabanel, Bouguereau, Cot, llenri Regnault.

Avee Courbet, cette génération a vu les audaces de l'école réaliste; avec Manet, les témérités de l'école impressionniste; avec Bastien-Lepage, le triomphe de l'école du plein air; avec Corot, Rousseau, Millet, Daubigny, Ilarpignies, Troyon, Leleux, Anastasi. Francais, J. Breton, Cabat, liosa Bonlıeur, la renaissance de la peinture rustique et du paysage.

1. Voir ci-dessus, p. 432. 
C'est cette génération qui a formé la génération actuelle, celle des peintres de la troisième République.

\section{${ }^{\circ}$ Ides peintres dn second Empire : Ia peinture d'his-} toire. - Pour illustrer ses guerres, Napoléon III put encore emprunter le pinceau dHoRACE VERNET, qui lui donna une Bataille de l'Alma, et de PHILlpoteadx, qui peignit la charge des chasseurs à Balaclava et le Siège de Puebla.

Mais à ces artistes qui avaient vu les soldats d'Mlgérie succédèrent ceux qui, sur les champs d'Orient et d'Italie, suivirent les armées impériales : - pILS (1813-18\%5), qui peignit toute une série de Batailles de Crimée et la a Fète donnée à l'Empereur à Alger ๖. - Félix BARRIAs (né en 18.2.), à qui l'on doit les peintures de la Trinité, a fait le Debarquement en Crimée (1859). — yoon (né en 181千) les surpassa dans l'art de lancer à l'assaut zouaves et chassenrs aux jambières de cuir : après son a Premier consul descendant les Alpes $\triangleright$ et a Ney soutenant l'arrière-garde en Russie s, il donna la Prise de Malakof (185\%), Sollérino. Magenta. Il devait peindre aussi la Charge les cuirasciurs à Reichshorten (1875).

protars a exposé la Bataille d'Inkermann, la Prise du Namelon vert, le Passage de la Sésia, le a Bataillon de chasscurs avant le combat ๖ (1863), "Apris le combat •, a Yainqueurs d (1865), la Grande Halte, la Ninit de Solférino, la Capitulation de Melz (1874).

Les autres peintres d'histoive lurent: CHENAVARD, qui se tit l'historien de la Révolution (Mirabeau et Dreux-Brézé, Jugement de Louis XVI, Convention Nationale) et qui a laissè cette toile d'un symbolisme étrange et saisissant, la "Fin des religions ou la Divina tragedia (1869); - Charles Mulder, dont le jremier chef-d'cuvre, a Lady Macbeth », remonte à $18 \nmid 9$ et qui affectionne les scènes tragigues: Appel des victimes sous la Terremr (1850), Marie-Antoinette ¿ la Conciergerie, une Messe sous la Terreur. Captivité de Cralilée; - LAUGÉE, antcur de a sainte Elisabeth lavant les pieds des pauvres $>$ et de a saint Louis servant les jauvres $\mathrm{D}$; - Boulanger, qui a représenté * César au Passage du Rubicon s et a à la tête de la Dixième légion s; EÉzERT, avec sa « Malaria n (1850), le a Baiser de Judas • (1853), a les Cervaroles s (1839); - GÉRome, élive de Meli- 
roche, artiste ingénieux et élégant, qui connait l'Orient moderne comme l'antiquité ct qui a marqué chaque Salon de quelque toile a sensation ${ }^{\mathbf{1}}$; - Paul BADDRY (1828-1885), l'auteur du Supplice d'une Vestale (1847), de Thésée dans le Labyrinthe (1831), de la Perle et la Vague (1862), d'un grand nombre d'admirables portraits, et qui exécuta la Décoration de l'opéra, Jes plafonds de l'hôtel Païva et de la Cuur de Cassation ; - TONY ROBERT-FLEURY, fils du grand artiste de l'époque précédente, et qui nous a donné ces deux belles pages : a Varsovie en avril 1861 D et a le Dernier jour de Corinthe D (1870); - Hamon, qui s'est fait une spécialité des scènes familières antiques; - Eugrene ISABEY, le peintre de marine et d'histoire.

MeIssonier s'est fait une place á part par ses étonnantes miniatures: les Bourgeois flamands (183\%), Partie d’échecs (18:1), Partie de boules, le Fumeur, le Liseur, le Corps de Garde, les Bravi, Un Rève. Il a prouvé, toujours avec de petits personnages minutieusement traités, qu'il était un peintre de batailles : la Barricade (1848), Napoléon III à Solférino (1863), Napoléon Ier en 1814 (186'), Napoléon Jer à Iéna (Salon de 1891).

Parmi les peintres orientalistes, FRĖRE a traduit en pages coloríes l'Algerie, l'Égypte, la Syrie; - Fromentin, qui a exploré Ie Sahel et le Sahara algériens, en a rapporté deux livres, où il se montre grand peintre la plume à la main, et des toiles remarquables par l'originalité des types humains et la beauté des coursiers. - Henri Regnadur, tils du célèbre chimiste, et tué d'une balle allemande à Buzenval, fut le premier coloriste du siècle dans ses Bergers andalous (1868), son général Prim, Judilh et Holopherne, l'Exécution sans jugement, et surtout la Salomé (1870), éblouissante symphonie de jaunes et d'ors.

Deux élèves de Picot, cabanel et Bougueread, dans leurs

1. L'oure de Gérôme a une telle importance qu'il est néeessaire de rappeler ses principales toiles: Jeunes Grecs excitant des coqs (1847); le siecle d'Augusie (1855); Ave Cæsar ou le Salut des glaliateurs qui vont a la mort 1859); le roi Candaule; Phryne derant le tribunal; Socrate et Alcibiade chez Aspasie; les deux Augures; Louis XIV et Molière (1863); Boucher turc à Jérusalem; lalmée; Cléopitre et César; Porte de mosquée au Caire; l'Eminence grise $(19 ;)$; les peintures de Sainl-Séverin. 
sujets empruntés surtout à la mythologie, nous ont rendu Ingres par la pureté du dessin, la gracieuse élégance des formes, et l'ont surpassé par la splendeur nacrée des carnations. Le premier nous a donné la Nymphe enlevée par un Faune, la Naissance de Vénus (1868), le Paradis perdu, Thamar; - le second, le Triomphe de Vénus (15.56), Flore et Zéphyre, l'Amour désarmé (188\%), Psyché et l'Amour enfants (1890), « le Jeune Frère s (1900).

Le portrait. - L'art du portrait atteignit un degré inouï de vérité, de pénétration, d'habileté dans l'arrangement pittoresque des draperies et des accessoires avec Winterhalter, le peintre de la famille impériale, avec Delaunay, Cot, Hébert, Dubufe, Paul Baudry, L.-S. Ricard, Cabanel, Bouguereau, Paul Dubois. Au chel-d'curre d'un maitre de l'époque précédente, le portrait si étrangement révélateur de Napoléon III (1863), par Ilippolyte Flandrin, répond le premier chef-d'ceuvre d'un maitre de la période suivante, la Dame au gant (1869), de Carolus Duran.

La peinfure des vitranx. - Cet art, dans lequel excella, au xve siècle, Jean Cousin, a réalisé de grands progrès avec oudinor, un élève de Delacroix, à qui l'on doit les vitraux de Sainte-Clotilde, Saint-Jacques, Saint-Germain, la Trinité. MarÉCHaL, de Metz, mit son habileté industrielle au service des inventions des artistes.

Liécole réaliste. - C'est surtout la rogue de Cabanel et Bouguereau qui provoqua l'insurrection ríuliste, comme la domination de l'école davidienne avait suscité la révolution romantique.

Le chef du mouvement réaliste, ce fut coonbet (1819-1877), un peintre franc-comtois qu'on appela le maitre domans, qui 11 a pas eu de maitre, mais qui eut de nombreux dis. ciples; un artiste qui s'est formé lui-mème et qui s'est trouvé, dès le début, en révolte contre toutes les écoles. C'ètait une nature de paysan fruste et madré, et l'un des originaux du siècle. Il méprisait également les classiques et les comantiques. A tous il reprochait de ne pas voir la nature telle qu'elle est ou telle qu'il la royait. Des Vénus, des Nymphes, des Amours, cela n'existait pas : ce qui existe, ce sont des paysans aux costumes fripés, aux bolles crottées; des paysannes aux pieds nus, vêtues de drogruet; 
de larges figures aux rouges trognes, aux poils hirsutes: voilà ce qu'il fallait reproduire, si l'on voulait être dans le rrai.

Alors Courbet donna l'Après-dinée à Ornans, l'Enterrement à Ornans, les Paysans de Flagney revenant de la foire, les Casseurs de pierres (1830), des Baigneuses qui ne ressemblaient pas du tout à celles de Bouguereau, des Lutteurs qui n'avaient rien de la nudité et de la beauté antiques, le Retour a'une conférence de curés (1863), l'Homme à la ceinture de cuir, ete.

En même temps, il peignait les admirables paysages du Doubs, avec une réalité saisissante, une puissance étrange de vision, des eflets de neige aveuglants, des verts d'une surprenante intensité.

Courbet suscita parmi les peintres à aspirations idéales des colères semblables à celles qu'avait déchainées Delacroix parmi les peintres classiques. Si les critiques n'armaient pas ses mains d'un a balai ivre », ils l'accusaient de peindre arec sa barbe, qu'il avait fort longue et touflue. A chaque Salon, les jurys de peinture refusaient obstinément ses tableaux d'insurgé. Alors il ouvrit une exposition particulière, oì une foule accourut, les uns pour se moquer, les autres pour protester contre l'ignorance des jurés, contre lincompétence de ces a fouetteurs de erème ¿̇ la vanille.

A la suite de Courbet, il y eut, sinon une école, du moins une foule de peintres et mème de rapins, singulièrement plus mêlée que celle qui avait pris Delacroix pour portedrapeau, les uns sincères et d'un talent novateur, les autres prétendant justifier par les hardiesses du maitre leurs propres témérités, les incohérences de leur dessin ou l'étrangeté de leur coloris.

Les choses allèrent si loin que le jury, pour se justifier, et le gouvernement, pour domner une satisfaction à l'opinion, se décidèrent à ouvrir un Salon des refusés (1863). Ce second Salon fut aussi couru du public que le Salon des refus. On y vit des toiles épouvantables, devant lesquelles tout Paris s'esclaffa de rire; mais on en vil l'autres qui firent réliéchir mème les maitres, des tableanx de genre et les scines familieres d'une vérité frappante, d'une âpre poésie daus leur vulgarité. 
L'école réaliste eut donc son inflnence salutaire sur les écoles élablies, les rappelant à plus de vérité et de sincérité, et, quand ses meilleures toiles eurent désarmé les rigueurs du jury et eurent été admises aux honneurs officiels, elle renonça aux exagérations de la première heure.

Les impressionnistes. - Au Salon des refusés s'était révélée une section de l'école réaliste, qui est restée intransigeante : l'école impressionniste. Elle eut pour chef MaNET (1833-1880). La théorie impressionniste consiste à soutenir que la réalité agit sur notre appareil visuel, non par les formes, mais par des couleurs. Ce qui impressionne notre rétine, ee sout, non des contours, mais des rayons lumineux. Dès lors il est inutile de dessiner : il sulfit d'appliquer sur la toile des tons, des touches, des frottis. Comme certains impressionnistes paraissent avoir un appareil visuel conformé d'une laçon particulière, on peut arriver aux plus étranges résultats : des visages zébrés de touches violettes, jaunes, oranges: des vêtements noii's qui prennent une teinte d'azur; des arbres qui sont bleus, des cheraux violets qui s'abreuvent dans des feures vermillons. Tontefois, même les outrances de cette singulière peinture ont leur intérét; d'une part elles sont une jage de notre évolution artistique; d'autre part il y avait, mème pour les artistes les plus pondérés, quelque chose à leur emprunter, soit des hardiesses heureuses du dessin, soit le rigoureux contraste ou l'harmonie imprévue de certains lons. Aussi lorsque lÉtat, en 189\%, en vertu du legs Caillebolte. entra en possession d'un lot considérable de ces peintures, il n'hésita pas à réunir les plus intéressantes d'entre elles dans une des salles du Musée du Luximbourg. A une interpellation qu'adressa un sénateur, épris de classique, le direeteur des Beaux-Arts se contenta de répondre que l'Etat derait faire preuve d"un certain éclectisme artistique et que "la gloire samait bien reconnaitre les siens ».

Le paysage. - C'est le paysage qui, dans cette période, a éprouvé la révolıtion la plus complète et la phus salutaire. On sait combien les Français ont été longs à comprendre la nature : le genre du parsage pur était à peu près inconnu aux xvir et swire siécles, et mème à lépoque de !a 
Révolution et de l'Empire. Depuis Poussin, on n'avait pas osé exposer une forèt, une marine, sans y jeter, comme le seul motif intéressant pour le publie, un groupe historique ou mythologique. Vinrent nos lyriques de l'époque romantique, qui, mettant fin à la poésie descriptive, donnèrent une àme aux lacs, aux montagnes, aux forèts. En Angleterre, des peintres ou des aquarellistes, comme Constable, Varley, les deux Fielding, dont les cuvres firent sensation au salon de 1824, nous apprirent ce que c'est qu'un paysage. Alors parurent les belles toiles de Paul nuET, CABAT, Jules DopRÉ, qui furent vraiment des initiateurs. Vers 184x, un amant passionné de la nature, Denecourt, surnommé le Sylvain, découvrit la forêt de Fontainebleau, avec ses éboulis de roches, ses gorges sauvages, ses eavernes, ses arbres séculaires, ses sites romantiques. Dans les vingt années suivantes, les environs de la forèt, Barbison, Marlotte, commencèrent à ètre visités, bientôt envahis, par des artistes de plus en plus nombreux. Cette révélation de la nature francaise appela leur attention sur nos sites des Pyrénées, des Alpes, du Jura, des Vosges, de l'Auvergne, sur nos plages de Normandie, de Bretagne, de Provence, sur le charme plus diseret des bords de la Seine ou de la Loire, des grandes plaines, des päturages verdoyants.

Aprés conot (1796-1875), qui avait commencé par des paysages italiens et qui ne sortit plus des paysages franęais, apres ses Matins, ses Soirs, ses Solitudes, vinrent THËODoRE ROUSSEAD (1812-1867) et J.-F. MILLET (1815-187\%), qui se fixèrent à Barbison, y devinrent deux inséparables et y finirent leur vie : l'un peignant des Groupes de ehẻnes, des Clairières, des Futaies; lautre peuplant la nature de Bergers et de Bergères qui u'ont rien à roir avec ceux de Florian, de Tondeuses de moutons, de Hoissonneuses, de Glaneuses, de Cardeuses de laine, etc. L'Angelus du Soir (1867) est resté son ceuvre la plus populiare. Ce qui distingue ces deux maitres, e'est un sentiment exquis de la poèsie qui se légrge des grands bois et des scènes de la vie rurale.

Millet eut pour émules Daubigny, avec ses Plagges, ses Étangs, ses Sentiers, ses Prés, ses Bords de la Seine, de 
l'Oise; - barpignies, avec ses paysages du Nord; - Troyon (1810-1865), avec ses Foires limousines, ses Abretwoirs, ses Marchés d'animaux, ses Bøufs au labour (1863); Adolphe Leledx, avec sa Danse bretonne (1842), son Dépiquage des blés, ses Noces et Fêtes bretonnes; - ANASTASI, un élève de Corot, avec sa Vue de Bougival, ses Derniers rayons, sa Saison des foins (1852); - FrançaIS, avec son Sentier dans les blés (1855), ses Paysages du Bas-Meudon, toute une épopée de la nature agreste en toiles nombreuses; JULES BRETON, avec ses Glaneuses (1855), sa Bénédiction des blés, son Retour des champs, ses Feux de la Saint-Jean (1875), ses Jeunes filles allant à la procession (1888).

ROSA BONHEUR a compris aussi le charme de la campagne Irancaise : elle courre les landes de ses moutons et de ses taureaux, éventre la terre qui fume sous la charrue de Son a Attelage nivernais D (18'9) et, dans ses Scènes de marché, fait luire la puissante croupe de ses chevaux.

Le paysan français, en mẻme temps qu'il est appelè à la vie politique par l'extension du suftrage, entre daus la vie artistique avec sa chaumière, ses champs, son bétail, sa herse et sa charrue, ses blés et ses pommes de terre. Il a désormais, tout comme Louis XIV avait eu les siens, ses poètes ordinaires, avec les Brizeux et les Pierre Dupont, et aussi ses peintres ordinaires.

$\boldsymbol{z}^{\circ}$ Les peintres de la génération présente. - Nous serons plus sobres sur les artistes qui sont nos contemporains. Pourtant, il laut bien citer, parmi les peintres d'histoire: ÉDOdARD DETALLL, l'auteur de la Charge des Cuirassiers de Reichshotien, du Régiment qui passe, de la Sortie de la garnison d'lluningue, des Vietimes du devoir, du Retour de la revue de Chàlons (lors de la visite de Nicolas Il, 1896), et qui, dans de splendides panoramas, a fait revive les tragiques batailles de la dernière guerre; DE NEOVILLE, qui eoltabora aux panoramas de Detaille et dont l'œurre la plus populaire est peut-ètre \& les Dernic̀res cartouchies $\$(1873)$; - BERNE-BELLECoUr, l'auteur du a Coup de canon $\triangleright ;-$ armand-dumaresa, le peintre de Faidherlue et des combats de l'armée du Nord; - puvis de cravannes, aux conleurs volontairement atténuées et éteintes, mais qui entend si largement la grande décoration; - F. FLAmeng, qui 
nous a donné les Derniers jours des Girondins, la Prise de la Bastille, la Fuite en Égypte, Kléber à l'armée de Sambreet-Meuse; - MÉLingor, qui nous a montré Étienze Harcel coiffint du chaperon révolutionnaire le dauphin Charles; - LEBLANT, qui s'entend si merveilleusement à lancer à l'attaque ses Chouans ou ses Bleus; - MorEAo, de Tours, en quête des épisodes guerriers de la Révolution; - Morot, de Nancy, l'émule d'Horace Vernet pour les combats de cavalerie; - Boutigny, avec ses Scènes militaires de la Révo lution et de l'Empire; - Duez, dont le \& Miracle de SaintCuthbert s figure au Luxembourg; - BENJamin constant, qui fait rı:isseler la lumière dans ses scènes marocaines, algériennes ou orientales; - cormon, d'une inspiration épique daus son Caïn, ses Scènes de la vie primitive, ses décorations du Muséum; - Rochegrosse, qui a retrouvé les hardis empàtements et les violentes luarmonies de Delacroix dans son Andromaque, sa Jacquerie, son Nabuchodonosor, son Assassinat de l'empereur Géta, sorte de symphonie en rouge, la Joie rouge (1906); - J.-P. LAdRens, dune fantaisie sombre et d'une profondeur philosophique dans ses scènes d'histoire, le plus souvent empruntees au moyen ìge, bien qu'il ait peint " l'État-major autrichien défilant devant le corps de Marceau " (1877); - JEAN bÉRAUD, avec sa "Madeleine chez les Pharisiens », auxquels il a donné le costume et les traits de nos contemporains; - BonNat, aree son Joh sur le fumier, d'un réalisme si cru et en même temps si élevé d'inspiration; - Luc-Olivier Merson, avec son Apollon exterminateur; - cootorien, qui sait mettre aux prises la vaillance de nos marins et la furie de l'Océan; - J. Lersbvre, avec sa Mignon et sa Graziella; - PAUL BUftet, avec sa Teutation du Christ, sa Fète antique, son a Défilé de la Hache ", sujet emprunté à Salammbò, et son portrait équestre de l'empereur Ménélik. - Matgnan, arec ses Panneaux et ses Plalonds; - F.-J. Barrias, avec son "Esther se rendant chez Assuérus "; - aenri martin ("Chacun sa chimère ", "Vers l'abìme "); - TAtTEgrain (le sac de Saint-Quentin); - gervals ("Jugement de Pâris ", "Folie le Titania »); - noLL, Henri Gervex, Wencker, Brouillet, Poilpot, peintres des fètes de la République.

I'armi les peintres de genre: - BASTIEN-LEPAGE, trop tòt 
enlevé à l'art, déjà illustre par ses scènes rustiques et prar d'admirables portraits; - COMERRe, un symphoniste des couleurs dans ses portraits d'actrices; - FEYEN-PERRIN, qui répandit une lumière si pure sur ses Pècheuses; - HeNNER, qui a peint une nature de rève; - DAGNAN-BOUVERET, l'auteur de la toile si populaise des "Conscrits"; - ROYBET, qui se fit d'abord connaitre par une grande toile d'histoire, "Charles le Téméraire à Nesle ", et qui déploie dans ses scènes familières, sous le pittoresque des costumes de l'époque Louis XIII, une vie si intense et un coloris si éclatant; - M" ${ }^{\text {me }}$ DEMONT-BRETON, si sincère dans " Hommes de mer ", si graciense dans sa Vierge vêtue à la mode arabe; eNDERS, aux scènes de familles si saisissantes ; CARriére, avec ses silhouettes grises et comme voilées, Lhermitte, Lucien Simon, Friant, Agache; J. Baille, etc.

Le portrait s'est maintenu à sa perfection avec Paul Dubois, carolus-Duran, LĖon bonnat, Benjamin-Constant, Fantin-Latour, Heilbuth, Jules Machard, Gustave Courtois, Th. Chartran (l'auteur du beau portrait de Léon IIII), Marcel Baschet, Weerts. J. Blanche, et dans le senre impressionniste, avec Albert Besnard, Caro-Delvaille.

Le paysage a continué le progrès commencé naquère, avec LANSIER; avec Rapin, Vernier, Marcel Ordinaire, Isenbart, Japy, Pointelin, et toute l'école franc-comtoise; avec Barillot, René Billotte, Damoye, Petitjean, l'adnirable maitre J.-Ch. Cazin, Charles Cottet, René Mémarl, Émile Barau, Riplraël Collin, Fr. Montenard, J.-II. Zuber, Didier-Pouget, Lhermitte.

La vie de Paris a aussi ses paysages et ses paysaristes qui la suivent dans la brume du matin, sous l'ardeur de midi, à la tombée du jour, au moment où s'allument tons ses feux : Adler, Émile Cagniart, Luigi Loir.

On peut dire de la peinture ce que nous avons dit de la sculpture : jamais il n'y a. eu une entente plus grande de toutes les ressources de l'art. La peinture a d'ailleurs cet avantage que les civilisations inconnues dont l'histoire poursuit la décourerte lui apportent sans cesse, avec des sujets inédits, de nouveaux éléments de pittoresque.

Toutes les révolutions de la peinture out contribué à son progrès. Comme le dit Eugène Guillaume, "limitation 
de la nature poussée jusqu'à la servilité, les excès d'un réalisme sans mesure, ne se sont pas produits inutilement. Un frand nombre d'artistes, sans suivre les novateurs dans leurs exagérations, se sont approprie la part didies justes qui est au fond de leurs systèmes. Des audaces de quelquesuns, il est sorti des vérités dont la somme s’est répandue sur lècole entière. Ainsi les tentatives des impressionnistes, accueillies avec ironie... ont profite it toute notre peinture. Le coloris y est plus simple; la valeur des tons y est mieux observée; les sujets échappent au jour étroit de l'atelier. .

Les dessinateurs. - Un dessinateur d'un génie prodigieux, ayant l'instinct des vastes compositions, des paysages colossaux, des types étranges et fantastiques, égal à Callot pour la verve, le surpassant en idéal, et qui, s'il avait su peindre, eût été le plus grand artiste des temps modernes, c'est gustave DoRÉ (1832-183\%). Il a illustré Rabelais (185\%), les Contes drôlatiques de Balzac (1856), les Contes le fées de Perrault, la Divine comédie de Dante, la Bible, les Fables de La Fontaine, l'Arioste, Don Quichotte, la légende du Juif-Errant, avec une imagination féconde, capricieuse, débridée, servie, dans ses fantaisies les plus extravagantes, par une science prodigieuse du dessin et par une habileté incomparable dans ses contrastes d'ombre et de lumiere. Nul u'a su mieux que lui, pas même Callot, faire grouiller les monstres, les arortons, les truands, couvrir de milliers de guerriers un espace grand comme la main, rendre réels des châteaux vertigineux aux centaines de tonrs, des jardins de fées, les paysages infernaux ou paradisiaques, les mornes déserts oủ ragabondent les ombres désolées et les chevaliers errants. Ce sont aussi des maitres du crayon que Willette, Jules Cheret, Mucha, dans leurs alfiches d'un si joli dessin et de couleurs liarmonieuses en leur vivacilé, Caran d'Ache dans ses fantaisies épiques, Forain dans ses àpres caricatures politiques, Boutel de Monvel dans ses cartons dhistoire, Robida dans ses illustrations échevelées des récits les plus itourdissants, Job et Guillaume dans leurs types de troupiers ou de snobs, Léandre, dans ses caricatures puissantes, IIenriot, dans ses sobres croquis de parlementaires, de grévistes et d'électeurs. BIDA, après de longues années passées en Syrie, nous a 
donné les Évangiles illustrés et interprétés par les types, les paysages, l'architecture, les costumes de l'Orient.

Les artistes graveurs. - Jules Jacquemart, Desboutin, F. Bracquemond, Th. Chauvel, Brunet-Debaisnes, Ch. Courtry, A. et J. Jacquet, L. Flameng, Ch. Baude, A. Didier, E. Gaujean, Lecouteux, Léveillé, ont élevé la gravure française à la perfection artistique.

Les artistes lithographes. - Mouilleron fut un émule de Charlet et de Raffet. " Il a pour ainsi dire, dit Jean Gigoux, réinventé la lithographie, en la faisant participer à la fois de la peinture à l'huile et du pastel. s Sa première œuvre connue, c'est l'Auto-da-fé (18'6); son chef-d'œurre, c'est la lionde de nuit, d'après Rembrandt.

Desmaisons a donné, après bien d'autres pièces, la Galerie des représentants (1848), la Prière, le Repos, la Lecon de tambour et de flageolet, le Waitre d'école alsacien (1873). - Célestin Nanteuil, Eugène Leroux, A. Sirouy, ont été aussi des maitres éminents et de féconds artistes.

Condition nouvelle de l'art et des artintes. - Innombrables sont les sculpteurs comme les peintres de notre âge. L'art, aux siècles précédents, n'était une vocation que pour quelques-uns : en notre siècle plusieurs centaines de statuaires ou de peintres sont passés maitres dans le maniement de l'ébauchoir et du pinceau, et les œurres, mème excellentes, ne se comptent plus. Une des supériorités incontestées de la France sur tous les pays du monde, y compris l'Italie, c'est celle qu'elle a gardée dans les arts. Nombre de maitres anglais, allemands, scandinaves, russes, américains, australiens, ont étudié à Paris. A un point de vue purement industriel, l'art français est une des branches les plus importantes du travail national : de sa vie il fait vivre de nombreuses industries; il apporte un contingent sérieux au total des exportations. Les Sulons, dont nous avons vu au Xvire et au Xvire siècle les débuts, encore très espacés sous la Restauration et la Monarchie de Juillet, sont devenus annuels sous le second Empire. Sous la troisième République, leur organisation a passé des mains de l'État aux mains des artistes eux-mèmes. Puis, ils se sont sectionnés en deux sociétés, rui depuis 1898 ouvreni des Salons distincts, qui furent d'abord, l'un aux Champs- 
Élysées, l'autre au Champ de Mars. Les livrets des deux Salons annuels, rien que pour la peinture, arrivent à dépasser 3500 numéros.

L'État, pour dégager de cet immense marché des formes et des couleurs les œuvres d'une valeur supérieure, avait essayé de fonder les expositions triennales. Il est regrettable qu'elles n'aient pas duré. Du moins les Expositions universelles nous ont valu des salons décennaux et celle de 1900 une exposition centennale de la peinture qui a groupé quelques.unes des œuvres les plus éminentes des plus illustres maîtres depuis un siècle.

Donc, un des traits les plus essentiels du mouvement artistique contemporain, c'est la liberté. Le temps n'est plus où le maître exerçait sur ses élèves une inlluence jalouse, exclusive, despotique, comme celle qu'exercèrent les Le Brun ou les David, et qui rappelait la servitude des anciennes corporations industrielles. Le temps n'est plus où l'État, comme sous Lonis XIV, imposait ses prélérences artistiques. Rien de plus libre que notre enseignement de l'Ecole des Beaux-Arts. Les jurys des Salons anmuels sont élus par tous les artistes exposants. Il n'y a plus d'écoles dominantes. Chaque artiste cherche en toute indépendance la voie que lui indiquent sa nature d'esprit, son tempérament, on pourrait presque dire la conformation de ses organes visuels. C'est l'anarchie dans le sens le moins inquiétant du mot; mais c'est cela même qui rend si dilficile et si lélicat de tracer un tableau un peu exact et un peu complet de l'art au xixe siecle.

Gustave Larroumet a fait cette remarque : "Jusqu'à ces vingt-cinq dernières années (en 1895) la peinture française suivait des directions peu nombreuses et assez faciles a déterminer... De même qu'il $y$ avait eu en littérature, depuis le début du siècle, des romantiques, puis des réalistes, puis des parnassiens, puis des naturalistes, de même 1 s peintres et les sculpteurs formaient des groupes de classiques et de romantiques, de réalistes et d'impressionnistes... Puis ç'a été un émiettement de l'école française. Aujourd'hui, les groupes artistiques se comptent par vingtaines. Lindividualisme triomphe, dans l'art comme dans la littérature... Pour les uns, ce phénomène est une 
décadence qu'ils déplorent, pour les autres un progrès auquel ils applaudissent $\$$.

Les arts décoratifs. - Dans l'antiquité, au moyen àge, à la Renaissance, encore au temps du Premier Empire, le sentiment artistique se retrouvait partout, même dans la confection d'objets réservès à l'utilité la plus commune. Armes, meubles, vaisselles, même ustensiles de cuisine, étaient autant de motifs que ne dédaignait pas le génie de lartiste. on ne séparait pas ces deux notions: le beau et lutile. Platon a parlé d'une "belle marmite ". Cette tradition s'est continuée à travers les âges par uue infinité d'artistes inconnus, maitres verriers, maîtres faïenciers, maitres du meuble, par les Benvenuto Cellini et les Bernard de Palissy, par le grand peintre Le Brun et sa manufacture artistique des Gobelins, par Ime de Pompadour et sa manulacture royale de Sèvres, par Darid, le Le Brun de l'époque révolutionnaire et napoléonienue. Puur l'ameublement il y eut un style Louis XtII, un style Louis XIV, Louis XV ou Louis XVI, un style Empire. Au contraire, de la chute de Napoléon à une époque très rapproche de nous, il n'y eut plus de "style ". Sous les monarchies parlementaires, il semble s'opérer un divorce entre les deux notions de l'utile et du beau. L'artiste se cantonne dans lart proprement dit, dédaisnant ce qu'on appelle les " arts mineurs ". L'ameublement on la vaisselle ne visent qu’à la pure utilité, au solide, au "cossu" bourgeois, ou bien au bon marché, arec des lignes droites, des surfaces nues, sans fantaisie et sans gràce. L'avènement des classes bourgeoises, ensuite l'invasion des classes populaires semblaient, en cet ordre d'idées, avoir abaissé le goùt et supprimé l'idéal. Puis la démoeratie. intellectuellement émancipée, initiée au charme des arts plastiques en même temps que de la musique, réagit contre ces tendances qui eussent discrédité la société égalitaire. Le goùt de l'élégant et du beau reparut dans toutes les classes. La démocratie française tendit à reprendre les traditions de celles d'Athènes ou de Florence. Depuis 1870, l'administration des Beaux-Arts, dirigée par de Chennevières et Eugène ruillaume, s'efforça de réhabiliter les arts mineurs. Un grand artiste décorateur, P. V. Galland, 
mort en 1893, ambitionna d'être le Le Brun et le David de la troisième République. Les peintures décoratives de l'Opéra par Paul Baudry, dı Panthéon par Joseph Blanc et Puvis de Chavannes, de la Sorbonne, de l'Hòtel de Ville, de l'Opéra-Comique nous restituent l'effort combiné entre l'architecture, la scuplure et la peinture qui avait fait la splendeur de la Renaissance italienne et du siècle de Louis XIV.

Plus près de nos yeux, sous notre main, pour notre plaisir de tous les instants et l'embellissement de notre vie intime, le meuble et la vaisselle se transforment. Les arts du dessin conquièrent une place de plus en plus grande dans notre industrie, par conséquent dans notre enseignement professionnel et jusqu’à lécole primaire. Il s'est tondé une Éole des arts décoratifs et un groupe d'hommes de gon̂t, sous l'impulsion du député Georges Berger, parvient à nous doter d'un Musée des arts décoratifs, qui rivalisera bientôt avec celui de Kensington à Londres. Les motifs d'ornementation, on les emprunte un peu partout, aux tombeaux de l'Erypte, aux vases peiuts de la Grèce et de la Campanie, au Japon, à la Chine, à l'Inde brahmaniste, a l'ancien Mexique. Les cristaux de Saint-Louis et de Baccarat, les verreries imitées de Murano (iles vénitiennes), les marqueteries, les bois de senteur, les incrustations d’ivoire et d'éhène, les services de table à teintes douces, à dessin léger, du groupe industriel de Nancy (Emile Gallé, Louis Majorclle, Schuller), du groupe industriel parisien (Eugène Grasset, Louis Muller, F. Levillain) mettent partout dans nos demeures la joie de leurs reflets et l'élégance de leurs formes. L'étain est remis en honneur par Charpentier, Desbois, Carrière; les cuirs gaufrés de la Cordoue moresque, par Gruel, Marius-Michel, Martin, Meunier. Les peintres les plus en renom - Baudry, Cabanel, Bouguereau, Puvis de Chavannes, Maignan, fournissent des cartons pour les hautes tapisseries, pour les vitraux colorés, qui, pendant des siècles réservés aux seules églises, reparaissent aux fenêtres des salles à manger et aux windows des chàteaux. La céramique et la joaillerie se renouvellent par d'heureuses combinaisons de matières, par la variété des teintes, et nous avons les grès de Jean 
Carriès, des maisons Delaherche, Dalpeyrat, Lesbros, les bijoux de Lalique, les émaux translucides, cloisonnés d'or, de Thesmar. Il est impossible de suivre, dans toutes lenrs fantaisies et dans toutes leurs trouvailles, l'ingéniosité des artistes associée à l'esprit d'émulation des industriels et à la féconde invention des chimistes. Il suffit d'avoir signalé une tendance très marquée dans le mouventent artistique des trente dernières années.

\section{La musique.}

Progrès de notre éducation musicale. - Dans la seconde moitié de ce siècle, l'éducation musicale, limitée jusqu'alor's anx classes supérieures de la nation, s'est répandue dans les masses. Chaque jour, nous voyons s'accroitre le nombre des sociètés de musique vocale ou instru. mentale, chorales, fanfares, orplséons, à tel point qu'un en trouve jusque dans de petits villages. De nombreux cours, surtout du soir, se sont ouverts dans les localités de quelque importance. On peut dire que Ja musique tend, elle aussi, à se democratiser.

L'éducation musicale le la nation doit beaucoup à PASDELOOP et ì ses concerts populaires, fondés en 1563 , sans lesquels nous ne connaitrions que de nom les œurres classiques de Mozart, llaydn, Beethoven, et la plupart des œuvres de Berlioz et Waguer. Puis Colonne (1873), Lamoureux (1882), la société des a Chanteur's de Saint-Gerrais o (1892), fondatrice de la Schola cantorum, ont également organisé des concerts.

Signalons une curieuse tentative faite par Chevé, Galin et Paris pour rendre la musique lisible à tous, en remplacant les notes et les portées par des chiffres.

Pour le perfectionnement des instruments, citons Cavalllécoll, qui a fait du grand orgue un véritable orchestre.

La unusique allemande. - Parmi les auteurs doperas allemands du temps présent, on connait surtout en France FLOTOW, né en 1812 dans le llecklembourg, et dont nous arons ru si couvent rejrésenter, surtout en province, Jartha ou le Marché de Richemond (1858) et a l'Ombre o (15:0).

WAGNER (1813-1883), Saxon de naissance, mais dont on 
connait les attaches avec le roi Louis de Bavière, fut un révolutionnaire en musique. ll est remarquable par ses ingénieuses combinaisons d'instruments, par une mélodie un peu vague et nébuleuse, mais d'un charme puissant. De tous les Allemands, c'est celui que nous avons eu le plus de mal à comprendre. Son C Tannhäuser ne réussit pas à l'Opéra (1861); son a Rienzi ๖, représenté sur notre Thèâtre-Lyrique, en 1869, $\mathrm{y}$ eut un insuccès éclatant. Ce qui a encore aggravé le malentendu, c'est qu'en 1871 Wagner insulta aux souffrances des Parisiens assiégés par une plate boullonnerie, intitulée par lui a Une capitulations.

La plupart de ses livrets se sont inspirés des légendes du moyen âge allemand, comme le a Hollandais volant . ou le a Vaisseau-fantôme D (1843), đ Tannhäuser ๖ (18'5), les a Maitres-Chanteurs de Nuremberg (186s); comme les quatre pièces, empruntées à la grande épopée allemande des riebelungen, formant sa fameuse Tétralogie et pour ia représentation desquelles le roi de Bavière fit construire tout exprès un thécitre à Bayreuth. D’autres sujets, qu'il a peut-ètre crus purement germaniques, appartiennent au eycle celtique de la Table Ronde et ont dabord inspiré Chrétien de Troyes et d'autres poètes du xule siècle francais : tels sont a Lohengrin $\triangleright$, qui est notre Chevalier au cygne (1850), “ Tristan et Iseult ๖ (1865), a Parsifal \$ (1882), histoire de Perceval le Gallois et du Saint-Giaal. Sa grande originalité c'est d'avoir substitué à l'opéra le drame musicul.

La nusique italienne. - verdi, né en 1813 dans le duché de Parme, nous doit la plus grande part de sa gloire. Il avait eu des succès en Italie avec «abuchodonosor \$ (18:2), a Hernani D (184'), sujet tiré de Victor Hugo, a Mac-

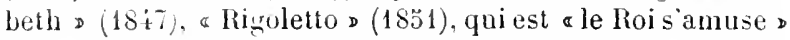
de Victor Hugo; le a Trouvère s (18333); a la Traviata D (1853), qui est a lit Dame aux Camélias o d'Alexandre Dumas fils; le a Bal masqué ๖, qui est le a Gustave III ๖ de Scribe.

La réputation européenne de Verdi a commencé quand plusieurs de ces pièces parurent sur notre Théâtre-Italien (1854-1860); surtout quand l'opéra donna, en 1847, a Jérusalem ঃ ei, en 1833 , les a Vèpres siciliennes , écrites spècia- 
lementpour la scène française, de mème que a Don Carlos s (1867); et enfin quand retentirent les trompettes d' a Aida \$ (1880), opéra égyptien à grand spectacle, représenté d'abord, sous les yeux du khédive, au théâtre du Caire. Sa messe de Requiem jour Manzoni fut exécutée it Paris presque aussitôt qu’à Milan.

La France l’a f'ait commandeur, grand officier, grand'croix de la Lérgion d'honneur, en même temps que ses compatriotes. qui avaient pris autrefois son nom pour mot de ralliement contre l'Autriche (V. E. R. D. 1. Victor Emmunuel roi d'Itulie), le faisaient sénateur du royaume nouveau. Ses lunerailles (1900) furent suivies par tout un peuple, et la plupart des parlements européens s'associèrent, par' des manilestations officielles, au deuil de l'ltalie.

Dans l'art, comme dans la politique, il fut la virante personnitication de l'union entre les irenies musicaux des deux grands pays latins, la France et l'Italie.

Les compusitenrs frangrais. - L'école française, dès le début de la seconde moitie du xixe siècle, eut a sa tête quatre grands maitres.

Félicien DAvid (1810-1876) fut un chercheur de nouveautés. b'une part, il se lanca à corps perdu dans le mouvement saint-simonien; d'autre part, il lut un adepte de la rérolution symphonique. Moins novateur ou moins proroquant que Berlioz, il fut aussi plus heureux. Né dans le pays d'Avignon, sous un beau ciel qui met la chaleur et la lumière dans les ceuvres artistiques, il alla demander un ciel encore plus pur à l'Orient, à l'Égypte, à l'Afrique. Presque lous ses sujets sont orientaux et il a créé chez nous l'oricntulisme en musique. Disciple de IIaydn, voué à la symphonie, il était cependant, par tempérament, un mélodiste: doù le dessin si net et si lranc, la gràce et le pittoresque de ses motils. Son début fut un recueil de a Mélodies orientales (1835). Puis vinrent l'Ode-symphonie du - Désert o (1844), loralorio de a Moïse au Sinä̈ o (1546), lOde-symphonie de a Christophe Colomb , le grand opéra d'a Herculanum D (185\%), les opéras-comiques de la a Perle du Brésil D (18501), de "Lalla-Roukh ๖ (186:), du * Saphir " 1865). L’ourre de Félicien David, e'est la tra. duction, en une musique ensoleillée, des vastes recherches 
par lesquelles la science française nous révélait le monde égyptien, arabe ou persan.

Ambroise THomas, né à Metz, en 1811, et qui mourut directeur du Conservatoire, a été un des tharmeurs du siècle. S'il fallait dire de qui il procède, on pourrait nommer comme son maitre François Lesueur; il dut aussi beaucoup à Ilalévy et Auber, puis à Gounod; mais il a des qualités qui sont bien à lui : un génie souple et gracieux, tendre et délicat. Nul n'a mieux su mettre en valeur une mélodie. Après des essais qui ne sont pas sans mérite, la série de ses œuvres commence en 18,9 avec a le Caïd s. Elle se continue par a le Songe d'une nuit d'été ๖ (18\%0), « Psyché , (1856), le Carnaval de Venise s (1857), a Mignon ๖(1866). En 1868, pour la première fois, il a abordé l'Opéra, avec - Hamlet s. Puis vint a Françoise de Rimini s (1882).

gounod, né à Paris, en 1828, est classé comme un disciple de Lesueur et de Ilalévy. Il surpasse le premier et égale le second, par l'ampleur, la fécondité, la variété de son génie. Il doit bien plus encore à Bach, Mozart et Schumann. Il a été le premier, en France, à écrire arec une aisance et une perlection irréprochables. II a voulu fusionner au théâtre la symphonie et la mélodie; c'est un éclectiquc de génie.

Il sait faire retentir le chant hérö̈que, traduire en harmonie colorée le fantastique des légendes allemandes, aussi bien que dessiner de spirituels couplets on lancer des strophes ailées, frémissantes comme un vol d'abeilles sous le soleil de Provence. L'opéra comique lui doit le a Médecin malgré lui • (1858), a Philémon et Bancis • (1860), a Mlireille o (186\%). Le grand opéra lui doit a Sapho ๖ (1850); - Faust • (18509), la a Reine de Saba p, \& Roméo et Julielte s (1867), a Cinq-Hars s (1877), a Polyeucte s (1878), le «Tribut de Zamora § (1881). Noublions pas ses belles méloulies, ses cantates patriotiques, comme a Gallia \$ (1871), ses Messes, ses Oratorios, ses morceaux lyriques pour la a Jeanne d'Are o de Barbier, sa a Redemplion . (1882), a Mors et Vita $>$ (1885).

Une perte cruelle pour l'art français, c'est celle de BIzET (1838-1873), mort à trente-sept ans. Il est lauteur des - Pècheurs de perles s (1863), de la a Jolie Fille de Perth 
(1867), de la a Fiancée d'Abydos $\triangleright$, des chceurs de a l'Arlésienne $\triangleright$ (18:2), de tant de belles romances et mélodies. Il a donné à notre scène comique un de ses diamants, cette - Carmon o (1875), éblouissante de coloris comme la Salomé de Rernault.

A lécole d'Ambroise Thomas, qui pourrait se définir l'école de la tradition française, se rattacheraient Victor Massí, auteur de a Galatée •(18ว̈2), a les Noces de Jean-

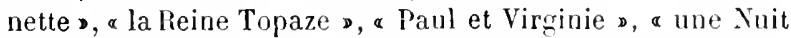
de Cléopâtre s; - Emest bodlanger, de « Don Quicholte " (1869); - bazin, de a Maitre Pathelin s, “le Voyage en Chine, (186ä); - Joncrères, de "Sardanapale p et "Dimitri ".

A lécole de Gounod se rattacheraient massenet, à qui nous devons « César de Bazan " (1873), "Manon" (1884), "Sapho ", "Cendrillon ", "Grisélidis " (1901), "le Jongleur de Notre-Dame "; les grands opéras du "Roi de Lahore " (1877), d" "Hérodiade ", du "Cid ", "Escłarmonde ", "Werther ", "Thaïs " (189'), "Roma " (1911, les chaurs et intermedes des "Erynnies" (18Ti), la musique sacrée "l" "Éve "t de "Marie-Madeleine".

SainT-SaEns, qui procède de lierlioz et Gounod, mais n est point rehelle à l'influence wagnérienne, compositeur de grande science et de grand style, nous a donné, en tous les genres, des ouvres de premier ordre. Pour le thétre, il a éerit: "Samson et Dalila " (187\%), "Élienne Harcel " " Henri Vlll ", " Proserpine ", "les Barbares " (190' f).

E. REYer, qui doit beaucoup à Wagner, sest placé au

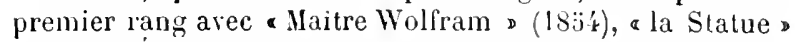
(1861), « Érostrate », le ballet de a Sacountala (1858) D, et surtout arec \& Sigurd > (1886) et a Salammbò „ (1896).

Quelque souci que nous ayons de ne pas multiplier les noms de compositeurs tout à fait contemporains, nous ne

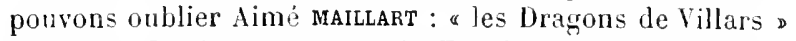
(18:56); - Louis CLAPISSON : a la Fanchonnette p (18:56); Jules conen : a José Haria o (1866) et a les Bluets » (1867); — Porse : a Bonsoir, voisin (1833) et a l'Amour médecin s; — Lalo : a le Roi d'Ys ๖ (1888); - Leo delibes : a le Roi l'a dit ๖: - Paladilae : a Patrie » (1886), sujet emprunté au drame de Sardou; - CHARPENTIRR : \& Louise >, drame lyrique (1900); - vincent D'INDY : \& W illenstein », le a Chant de la 
eloche " et "Fervaal»; - Debussy, "Pelléas et Mélisande"; - Erlanger, " le Juif Polonais "; - Benjamin Codard, " la Vivandière "; - Xavier Leroux, Guirand, Widor, Métra, à qui l'on doit les meilleurs ballets contemporains. Bien que la plupart des compositeurs écrivent pour la scène, la tendance de l'école francaise est de chercher sa voie en dehors du théátre, dans la musique de chambre, dans l'orutorio, dans la symphonie. On n'aurait qu'une idée incomplète de l'œuvre de Nassenet, Th. Dubois, Lenepreu, Delibes, Widor, Lalo, Vincent d'Indy, si l'on ne tenait compte de leurs wurres en ce geure. Saint-Saëns s'y est affirmé comme l'un des musiciens les plus complets que nous ayons en France dans ses Gratorios ( a le Dejinge s. la Lyre et la Harpe ). ses Poèmes symphoniques ( a la Danse macabre s, « Phaéton s, " le Rouet d'Omphale»), ses concertos, etc. - César Franck s'est acquis un grand nom dans l'oratorio, avec a Ruth s, a Rédemption s, a Les Béatitudes ๖, Rébecca ๖, « Psychè (1885). - Fauré (mélodies).

Un genre nonvean : l'operette. - Le xvI e siècle luimème, à côté des chefs-d'œuvre classiques, n'a-t-il pas eu " l'Enéide travestie " et a Chapelain décoiffé "? Ne nous étonnons pas si le lyrisme des "Huguenots s ou de a Faust • a été côtoyé par les gaietés de l'opérette. L'opérette est une réduction de l'opéra-comique. Elle est une création naturelle de l'esprit gaulois, aiguisé d'humour sceptique et. si l'on veut, perverti par la gouaillerie parisienne.

Ce genre, si français et surtout si parisien, c'est un compositeur né à Cologne, orfenbach. qui l'a pour ainsi dire créé chez nous, mais qui n'aurait certes pas eu l'idée de le créer en Allemagne. C'est lui qui a déshabillé les dienx de l'Olympe grec et qui les a salués non des accents tragiques auxquels ils semblaient avoir droit, mais des calembredaines de son livret et des joyeux flonflons de son orchestre. Dans ce genre, il a composé des chels-d'œure : a Orphée aux enfers ১ (1859), la a Belle Ilélène s (1864), la « Vie parisienne », la a Grande-Duchesse de Gérolstein » (1867). Avec lui, gràce à une musique ingéniense dans sa bouffonnerie, le genre opérette s'est maintenu sur les contins de l'opéra-comique, auquel offenbach est revenu dans son œuvre dernière, les " Contes d'lloffmann .. 
Après lui, parmi les ceuvres les plus typiques de lopérette, on peut bien citer la a Fille de Madame Angot " de LECoa.

Ouvrages a consulter ${ }^{\prime} \rightarrow$ Chatean, Hist. de l'architecture. Lance, Lict. des architectes. - Ch. Banchal, Nouveau dict. biog. et critique des architectes. - Vitet, Le Lowcre. - Boilean, Hist. critique de linvention en architecture.

L. de Fourcaud, Fr. Rude (1901). - IIenri Jonin, David d'Anyers. P. Narmottan, Les statues de I'aris.

G. Lafenestre, La tradition dans la peinture franeaise. - Larronmet, L'urt et lEtal (1895); Petits portraits et notes d'art; Etudes de litt. et d'urt. - Andrè Michel, Notes sur l'art moderne (1896). - Charles Blanc, Hist. des peintres (école francaise, t. II et III). - Fr. Villot, Calalorue des tableaux exposes au Museedu Lonve.

Delacroix, QEurves litteraires. Alfred de Musset, Mélanges de littérature et de critique. - Thoré, Les peintres au $\mathrm{XI}^{\mathrm{e}}$ siecle. - Chesneun, La l'einture francaise au. WIX'e sticle et Peintres ct staturares romatelyues (1579).-D. Marmottan, LE Écolefrancaise de pein ture. - Gustave Planplie, Portraits d'artistes ( 1.53 ) et Etwes sar l'Ecole fruncaise (1855). - Jean Gigun. Causeries sur los artistes de mon temps. - Th. Gautier, Hist. du rommlisme pt Portaits contemporaius. - Eng. Fromentin, Les muitres d'autrefois. - E. Michel, Les! maitres the pursage (1906\%.

Anonyme: Delacroix, sa vie et ses meves (1565): - Ph. Burty. Lettots de Delacroir et Muitres of letits

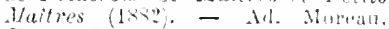

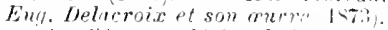

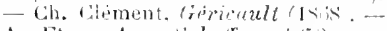
A. Etes, Ary sicheter 1rit

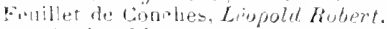
- Cinaries Blanr, Lurres, su rie et sesounmes. - 11. Delaborde 1870 Mromeja 1903, Inyres. - A. Duval, Lutclier dingres (1878).

Henri Regnault, Corrospondance et 1R. Mars, liegnanlt 1902.- Ch. Eplurussi. I'aul Bandry, sa rie et son rutre. - Sensier, Souvcnirs de Th. Rousseau et La vie ct l'curre de Millet. - Marcel, Willet (190?). A. Fournei. Les artistes contemyorains. - Ch. Blanc, Les artistes de mon tomps (15:60. - Vachon, Puvis de Charannes (1900). - Sauvageot,
Le réalisme et le naturalisme dais la litt. et l'art. - J.-L. Ennest, Jeissonier (préface par O. Gréard) (1847). Mauclair, l'Impressionisme (190').

Maxime du Lamp, Les Beaux-Arts a l'Firpos. universelle et aux Salons (1863-67). - Charles Blane, Les Beauc-Arts a l'Expos. universelle de 1sis. - J. Comte, L'art a l'Expos. univers. de 1900. - Rapports des jurys internationaux (Expos. LO00).

De Laborde, De l'union des arts et de l'industrie. - II. Havard, fict. de l'ameublement et de la dicoration. Arsène Alexandre, Hist. de l'art décoratif. - P. Rouaix, biet. des arts decoratifs. - Roger Marx, La decoration et l'art industriel(Expos. 1589. Id. Expos. 1900 - E. Maindron, Les Affiches illustries.

Fẻtis, Biographie des musiciens (1\$75-\$1). - F. Climent, Les musiciens célebres $(1-2 .-0$. Fouque, Les revolutionnaires de la musique (15.3). - 1. bituphin, Les maitres de la musique (1 soo). - Bellaigue, Un siècle de musique francaise (1857). G. Servisres, La musique frame. s,oderne $(1897)$ - Chruquet, Hist. de la musique dramatique en France (1573). - H. Lavoix, Hist. de la musique; Hist. de l'instrimentation. Audley, Franz Schubert (1851). Poucin, Schubert; Schumann.-Liszt (1579); Niecks (1590); Barbedette Is6.7). Chopin. - Wilder Is\$3; J. Chantavoine 1907), Beethover. - Blaz de Bury, Heyerbeer (1 cón). - Jinith Gautier (1882); Ernst (1857); H. Lichtenberger (1898. Richard Wraner. - Ponsin, Ferdi (1882) - Azevedo, Felicien Dovid (1865) - i. Hahive, F. Halicy (1392). - Ad. Adam, vonrenirs d'un musicien 1850 el Kowr. Sourenirs 18.89!. - Berliaz, loyga. musical en 1hmagne (184t: A travers clunts: Homoires 16.0 ; Cosresp.; Lettecs inirl. - Hippea 1R-2): Jullien (1-89): Ernat (1584): Prod'homme (1905), Berlioz. - Pulasu, Boieldieu (1875); Adam 19:\%). Jouvin (1865); Pougin (1966. Hedrol. Pigot (1886); Voss (1899, Bizet. A. Coguard (1891), E. Destranges 1897). Vincent d'lnciy 10unt. Cisar Francli. - Massenet, Soureuirs 1912

1. Rapplions qu'une parlie de eette Bibliographie se rapporte au chapitre XX (181.1-1818); voir ci-dessus, p. 445. 


\title{
CIIAPITRE XXXII
}

\author{
LES SCIENCES
}

I. Les mathématiques et l'astronomie.

Mathématiques. - Dâns les quarante ou cinquante années qui viennent de seécouler, les mathématiques ont été illustrées surtout par Ilermite, Puiseux, Ossian Bonnet, Bouquet, Serret, E. Picard, Appell, C. Jordan, Laguerre, IIalphen, IIaton de la Goupilière, de la Gournerie, l'amiral de Jonruières, le sénéral Bassot, Darboux, Poinearé (en 1890, henri polncaré a obtenu, lor's du congrés universel de mathématiques à Stockholm, la médaille d'honneur), tous membres de l'Académie des sciences. Ce qui caractérise cette période, c'est que, la science ne cessant de s'etendre, il a fallu une division de plus en plus grande du travail. On tend à se limiter dans des spécialités, dont chacune suffit à l'activité d'une intelligence. Peu de mathématiciens sont aujourd'hui des savants universels, mème en mathématiques.

Dans les mathématiques appliquées à la mécanique, se sont distingués : Bresse, Tresea, de Saint-Venant, Phillips, Resal, Maurice Lévy, Desprez, Sarrau, Beussinesq, H. Léauté, le général Sebert.

En 1872 a été fondée la Société mathématique de France.

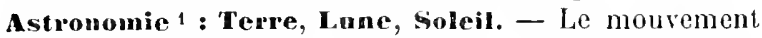
de rotation de Ia Terre sur elle-méme a été étulié, en 1851,

1. Sur le progrès de l'astronomie, voir le discours prisidentiel d'A. Comman, au congrès de I'Association britannique pour l'avancement des Sciences, 1000 (Revue scientifique, 20 oct. 1900.) 
par foucadut, qui observa les oscillations du pendule, à l'aide d'un instrument inventé par lui, le gyroscope.

L'hypothèse d'une atmosphère dans la Lune, soutenue encore au siècle dernier par quelques savants, a dû être abandonnée à la suite d'observations faites pendant une granle éclipse du Soleil (1860). Ces observations ont été confirmées à l'aide de télescopes de 60 mètres de long et d'épreuves photographiques très agrandies qui nous ont donné l'aspect de la Lune à quelques dizaines de kilomètres ${ }^{1}$. En conséquence, il n'est guère possible d’admettre à la surface de notre satellite une vie quelque peu développée, soit animale, soit végétale.

La distance du Soleil a la Terre, dans le calcul de laquelle les astronomes de la première moitié du siècle étaient forcés d'admettre une incertitude d'environ 500000 lieues, a été déterminée avec une précision preşue satislaisante, en 1862, par roucault et rIzEAu. La méthode qu’ils ont employée a pour base le calcul de la vitesse de la lumière. Cette distance a pu être ramenće par eux de $38: 00000$ lieues à environ 37 millions.

Les anciens astronomes considéraient le Soleil comme une masse incandescente, mais solide. Kant, le premier, arait osé aifirmer qu'il était une masse incandescente, mais gazense. Le problème est resté insoluble jusqu'au moment oú l'on a observé avec plus de soin ses taches. Les observations les plus curieusrs sont celles qu'ont faites deux de nos compatriotes, l'un, JANSSEN, dans l'Indoustan, l'autre, tisserand, en Indo-Chine, à loccasion d'une éclipse de Soleil (1868). Ils sout arrivés à cette conclusion que le Soleil se compose d'un globe obseur, enfermé dans une photosphère ou sphère lumineuse, dont les variations d'èclat produisent les tuches que nous apercevons. Celle sphère lumineuse ou ces corps circumsolaires, comme on les appelle, sont formés principalement d'hydrogène incandescent. Ils sont le siège de bouleversements prodigieux; des masses plusieurs centaines de fois grandes comme la Terre se déplacent et changent de forme en quelques 
minutes; des protuberances, des tourbillons de feu, des panaches de gaz flamboyants, se projettent dans l'espace à plus de 60000 kilomètres, comme de colossales éruptions volcaniques. Les variations d'intensité dans l'éclat du Soleil l'ont fait classer, par FAYE et d'autres astronomes, dans la catégorie des étoiles variables.

De 18399 d̀ nos jours, des savants étrangers, Kirchhoff, Bunsen, Angstroem, Rowland, Michelson, Lockyer, Langley, les Français Foucault, Janssen, E. Becquerel, Deslandres, se sont mis à étudier le spectre solaire pour en tirer des conclusions sur la nature du Soleil.

On sait que le speetre solaire ne présente pas seulement les sept couleurs de l'arc-en-ciel : observé avec des instruments spéciaux, il laisse, en outre, apercevoir des raies ${ }^{\text {. }}$ Or, lorsqu'on examine le spectre de lumières obtenues par la combustion de différents gaz, on voit que ce spectre présente également des raies : suirant les corps dont émanent ces gaz, les combinaisons de ces raies varient. Telle combinaison répond à l'hydrogène pur; telle autre dénonce la présence de particules métalliques dans le gaz entlammé. Les raies du Soleil, suivant leurs combinaisons, doivent donc répondre aux diverses substances qui entrent daus sa composition géologique. Au moyen de lanalyse spectrale, on a reconnu qu'il y a dans le Soleil les mèmes sulistances que dans le globe terrestre : le fer, qui forme comme a la charpente du spectre du Soleil s. l'hydrogène, le sodium, le calcium, le magnésium. le nickel, le titane, etc., plus une substance qui avait l’abord semblé spéciale au Soleil et que, pour cette raison, on a appelée hélium. C'est un gaz qui aurait une densité double de l'hydrogène. De nouvelles recherches ont prouvé qu'il n'est pas étranger à la Terre, et à d'autres corps célestes.

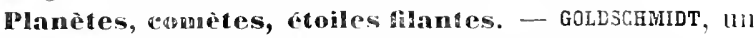
peintre allemand de Francfort, mats qui a pass sa vie à Paris, sẹprit, en suivant les cours de Le Verrjer, d'une

1. Wollaston, en 1802 , est le premier qui les ait vues, mais saus comprendre l'importanre de sa découverte. En 1S17, Frauexhofrr, opticien do Munich, compta jusqu'a 600 de ces raies dans le spectre solaire et les designa par des lettres de l'alphabet. Il etudia aussi le spectre de Mars el Vénus el de plusieurs ctoiles. 
belle passion pour l'astronomie. En 1843, il acheta une lunette chez un marchand de bric-à-brac et s'installa dans un modeste atelier d'artiste, à un sixième étage de la rue de l'Ancienne-Comédie. 11 reconnut plus de dix mille étoiles qui avaient été omises sur les cartes célestes; mais il s'occupa surtout des petites planétes; a lui seul, il en découvrit quatorze; il les appela Lutetia (1852), Pomone, Atalante, etc. D'autres avaient déjà été découvertes par Piazzi, Olbers, Hind, Hencke, etc. Comme elles sont devenues très nombreuses ${ }^{1}$, on a fini par ne plus les désigner que par des numéros. Plusieurs de ces petites planètes ont de 100 à 420 kilomètres de diametre. Dautres en ont moins de 30 : ce sont des planétules. Ainsi la planète dont Kèpler, dans ses calculs, avait pressenti l'existence, semble avoir lait place à une multitude de fragments.

En aoùt 1877, l'Américain Asaph Hall découvrit les deux satellites de Mars. Dix ans plus tard, le 9 septembre 1892, s'est révélé le cinquième satellite de Jupiter à l'astronome américain Barnard. En mars 1899 , l'Américain Ch. Pickerwig découvrit le neuvième satellite de Saturne. On connait donc six planètes escortées de satellites : la Torre (un satellite), Mars (deux), Jupiter (cinq), Saturne (neul'), Uranus (deux). Neptune (un) : au total, vingt satellites.

A la fin du xvme siècle, W. Herschel, dans l'anneau de Saturne, avait déjà distingué deux zones; en 1837 et 1838 , on en distingua cinq; depuis 1850 , on en compta une douzaine ${ }^{2}$. On a observé en outre que ces anneaux étaient sujets à des variations de forme et de lumière, et même dans la distance entre eux.

La planète Mars, si analogue à la nôtre par ses dimensions et sa proximité du Soleil, si différente d'elle par l'étrange aspect de sa surface, où l'on croit voir des canaux qui sillonnent ses continents de lignes régulieres, a ite surtont l'ohjet des travaux de l'astronome italien Giovanni Schiaparelli.

1. L'A nnnire du bureau des Longitudes de $\mathbf{I 9 0 0}$ en donne une liste de 458. La planite Eros an No 433 a été découverte en 1598 par Witt, a l'observatuire Crania, jrès de Berlin. En octobre 1:00, cinq autres petites plazètes furent derouvertes, a Heidelberg, par Max Wolf.

2. Voir ci-dessus, p. 4 í. 
Notre système planétaire, au point de vue de la mécanique céleste, a fait l'objet des travaux de Le Verrier, dans ses dernières années, de Tisserand et d'Henri Poincaré. TISSERAND a publié son ouvrage en quatre volumes, intitulé : Traité de mécanique céleste, dont Pasteur a dit quil renouvelait le Traité de Laplace, en le mettant au courant de toutes les découvertes astronomiques et mathématiques modernes. Maurice Loewy, successeur de Le Verrier, Ilouchez et Tisserand à l'Observatoire de Paris, s'est appliqué à perfectionner les instruments. Dans l'astronomie mathématique, il a fait de profondes recherches sur les orbites des planètes et comètes et déterminé les longitudes de Vienne. Berlin, Marseille, Alger, etc., par rapport à celle de Paris.

Les découvertes de comètes périodiques ont continué. Aux cinq que nous connaissions déjà 1 vinrent s'ajouter celle d'Arrest, que signala Arrest à Leipzig (1851) et qui fut étudiée de près par Villarceau: celle de Winnecke (18วั8), de Tuttle (1858), les deux de Tempel (1867 et 1878). On connaît donc aujourd'lui dix-neuf comètes périodiques, sur lesquelles quatorze ont été reconnues depuis 18301 . Périodiques ou non périodiques, on compterait par centaines de millions celles qui errent à travers linfini, et par quinze ou vingt mille celles qui ont pu. depuis seulement deux mille ans, traverser, sans sy fixer, notre systeme solaire.

FAYE et ROCHE ont démontré que les comètes, jériodiques ou non, sont impressionnées de deux manières par le Soleil : il les attire et il les repousse. Il est probable que ce double phénomène se retrouve dans les relations entre tous les corps célestes.

Les étoiles filantes ne sont, en réalité, que des boliles ou aérolithes, petites masses solides en suspension dans les espaces sidéraux. Quand elles cèdent à l'attraction de la Terre, elles s'échaufient en traversant notre atmosphère,

1. Voir ci-dessus, p. 4is-i:9. - Deux comèics, qui paraissent nouvelles sont à l'étude dans tous les obserratoires: la cumète Giacubini et la comète Borelly (1900).

Rappelons que la comite de 1811 trainait une queue ou chevelure lumineuse lonque de 76 millions de kilometres; la premiere coméle de 18 i3 avait uae queve de 320 millions de kilomètres! 
et, soit qu'elles tombent sur le sol, soit qu'elles prennent la tangente, elles laissent une trainée lumineuse. Elles ont été étudièes en France par BIGOT DE MOROGOES, qui cliercha à en dresser un catalogue, et par codlviER-GRAviER, qui a constaté que, deux fois par an, aux environs dı 10 août et du 12 novembre, il y a de véritables pluies d'étoiles filantes ${ }^{1}$; il a coustaté également que, dans une série d'années, il y a un inaximum et un minimum. - G.-A. DAdBREE a rassemblé, au Muséum, des échantillons de centaines de chutes d'aérolithes et montré que c'est le fer qui domine dans leur composition. - st. mednier a fait l'étude comparée de cette géologie céleste avec celle de notre planète.

Monde stellaire. - LADGIER, de 1851 à 1854, a dressé un noureau catalogue des étoiles; le nombre s'en est augmenté depuis, grâce à de nombreuses observations. Valz, en 18:7, Chacornac, en 18302 , ont dressé de nouvelles cartes du ciel.

L'application de la photographie à l'étude du ciel est venue apporter aux astronomes un moyen d'observation aussi puissant que les meilleurs instruments. Elle a fourni les documents à la fois sûrs et durables. La plaque pholographique, plus patiente que le regard humain, nous a révélé des étoiles jusqu'à la seizième et mème jusqu'a la dix-septième grandeur; elle fouille les profondeurs du ciel et décompose les nébuleuses. Cette innovation a pris sa grande importance, principalement, sous l'impulsion de l'amiral Houchez, directeur de l'Observatoire, el gráce aux travaux de Foucault, Fizeau, Paul et Prosper Henry, Deslandres. On a pu calaloguer des millions d'étoiles de toute grandeur.

En 1896, s'est réuni à l'Observatoire de Paris, sous Ia présidence de Tisserand, un congrès des astronomes du monde entier en vue détablir la earte photographique du

1. Herrick, de New-Haven, affirme que les étoiles filantes passent annuellement, dans notrc atmosphère, par dizaines de milliards.

L'Américain Newcomb estime qu'il ne tombe pas moins de $1.16 \mathrm{mil}-$ hards d'ètoiles filantes, par an, à la surface de la Terre, mais comme elles se fondent, se liquétient, se volalilisent, par la chaleur que développe le rottement à travers l'atmosphère, elles n'arrivent guère sur le sol que sous forme de poussière impalpatle. 
ciel, œuvre colossale pour l'exécution de laquelle un crédit annuel de près de 100000 francs est inscrit à notre budget.

Savary et villarcead se sont occupés des étoiles doubles. On en compte aujourd'hui plus de 6000 couples, sur lesquels un très grand nombre semblent formés par deux étoiles gravitant l'une autour de l'autre.

On a essayé de mesurer la distance qui nous sépare d'une étoile donnèe, en établissant sa parallaxe, c'est-àdire en construisant un triangle ayant pour sommet cette étoile et pour base le diamètre de lorbite terrestre. Or, bien que ce diamètre soit de 74 millions de lieues, dans la plupart des cas il s'est trouvé que les deux côtés du triangle se conlondaient en une seule ligne droite : tant est énorme la distance de la Terre aux étoiles! Pourtant, quelques parallaxes, où l'angle du triangle obtenu n'est jamais supérieur à un dixieme de seconde et se réduit parfois à un quntre centième de seconde, ont pu être obtenues. On a mesuré ainsi la distance à la Terre d'une vingtaine d'étoiles; il s'est trouvé qu'elle variait de 8 trillions à 170 trillions de lieues. La lumière d'une des étoiles les plus rapprochées de nous, dans la constellation du Cygne, met près de neuf ans à nous parvenir; celle de l'étoile Polaire, plus de trente-sept ans! Et pourtant la vitesse est de plus de 300000 kilomètres a la seconde. Les travaux de ce genre sont tous postérieurs à 1842; ils sont dus principalement à des astronomes étrangers, Bessel, IIenderson, Peters, Struve, Winnecke, Johnson, Auwers, hrüger, Gylden, Brumow.

Un a demontre que les étoiles fires ne sont pas fixes, mais se déplacent avec une rapidité qui. quoique prodigieuse, est insensible pour nous. La constellation de la Grande-Ourse et celle d'Orion oftraient, il $\mathrm{y}$ a cinquante mille ans, et offriront, dans cinquante mille ans, un aspect tout diffèrent de celui qu'elles présentent aujourd'hui. W. Campbell et Wright ont démontré que la Polaire n'est pas une étoile et n'est pas fixe. mais qu'elle est deux étoiles dont l'une gravite autour de l'autre, que toutes deux se déplacent dans le ciel et qu'elles tondent à se rapprocher de nous (1899). 
Le phénomène de la scintillation des étoiles a été étudié, surtout depuis 1870, par un savant belge, MoNTigNY.

Les astronomes, parmi lesquels Huggins, Rutherfurd, Secchi, Draper (1590), Pickering, Lockyer, Macclean, les Français Janssen, Cornu, Wolf, Rayet, ont cherché à conjecturer la composition des étoiles par la méthode de l'analyse spectrale. Par exemple, la présence des raies de l'hydrogène, du sodium, du magnésium, dans le spectre des étoiles Aldébaran, Sirius, Véga ${ }^{1}$, a permis de supposer la présence de vapeurs océaniques à la surface de ces globes, qui cependant ne se révèlent à nous que par un point lumineux. L'absence des raies de l'hydrogène dans le spectre de l'alpha d'Orion et du beta de Pegase, par exemple, semble indiquer l'absence de rien de semblable à notre vapeur d'ean. En général, la composition ehimique des étoiles párait assez analogue à cello du Soleil et des planètes. Nlébaran renfermerait notamment du calcium, du fer, du bismutl, du tellure, de l'antimoine, du mercure. La dilïerence de composition chimique pourrait expliquer la coloration de certaines étoiles en rouge, en vert, en jaune, etc ${ }^{2}$. L'univers serait done un tout, et la matière cosmique, partout dans l'intini, se révélerait identique à elle-même.

LAUGIER a également dressé un catalogue des nébuleuses. En 1893 on en connaissait dèjả 9369. Le nombre s'en est encore accru. De nos jours, elles ont été l'ubjet des travaux de Javer, à l'observatoire de Nice, de wolf, prolesseur à la Sorbonne. Celıi-ci admet l'existence de rébuleuses non résolubles et estime que nous sommes loin encore de pouvoir expliquer scientifiquement leur nature. Une nébuleuse résolue peut ètre, ¿̇ elle seule, tout un univers aussi vaste que celui que nous avons sous les yeux : le télescope y compte les étoiles, c'est-à-dire les soleils, par

1. Dés 1890 , plus de 10000 éloiles avaient élé soumises á cette investigation. Pickering a découvert des éloiles à la révélalion de leur spectre. A. Ditte, Les métaux dans le ciel (Soleil, planètes, cométes, éloiles filantes, étoiles, nébuleuses). Fevue scientifique, 17 nov. 1900.

2. Il faut faire une place, dans ce rapide exposé, à Camille l'Lammariox pour ses intèressants ouvrages qui ont tant contribué à la vulgarisation des notions astrononifues. 
milliers. Au delà de ces univers visibles, il y en a dinnisibles pour nos yeux aidés des plus puissants instruments; et sans doute, par delà ceux-ci, d'autres encore. La grandeur de l'astronomie, e'est de rendre sensible à nos yeux ou à notre raison l'infini ${ }^{1}$.

\section{La physique et la chimie.}

Physique : natnre de la matière. - La compressibilité des gaz avait lait déjà l'objet les travaux de Dulong et Arago : en operant à la tour du lyeée Henri IV, ils les avaient somnis it une pression de 22 atmosphères. Partant de ces expériences, DESPRETz avait démontré que les gaz sont inégalement compressibles, et que dès lors la célèbre loi d, Wariotte ne peut s'appliquer à tous en tout état de cause. Les expériences de pounlet, où la pression fut ponssée jusquà 100 atmosphères, avaient confirmé ces résciltats. Lis 1845, Michel FARADAY avait ubtenu, par la pression jusqu'i 50 atmosphères et le refroidissement jusqu'à - 100 legris, la liquéfaction de certains gaz. On vit avec surprise que ces gaz liquéfiés, chlore, acile carbonique, protoxyde d'azote, jouissent de propriétés toutes diffèrentes de celles qu'ils possèlent à l'élat gazeux. Six gaz seulement avaient résisté aux expériences de Faraday : l'hydrogène, l'oxygène, l'azote, le bioxyde d'azote, le gaz. des marais (protocarbure d'hydrogène), l'oxyde de carbone. On les con-ilérait done eumme des gaz permanents. Or, dés 1870, victor regnadt, après de sérieuses expériences, annonçait qu'on allait parrenir à les liquéfier; et, en $18 \%$, Calldetet, en France, et Pictet, en Suisse, sont arrivés à liquélier tous ces gaz. D'ARSONVAL, professeur au College de France, par la combinaison des fortes pressions et de l'extrème refroidissement (200 úegrés au-dessous de zérol, a pu obtenir un litre d'air liquétié par heure. Puis on a réussi, à l'aide de tempéralures encore plus basse",

1. Quant a la question de l'habitabililé des mondes, elle a été repris dans les ouvrages anglais de Whewell (1853) et de Brewster (185'), dans les uurages francais de Plisson (1Síi) el de Flammarion, La pluralité des mordes (1S6i). 
à solidifier l'air et d'autres gaz. James Dewar, à une température de 286 degrés au-dessous de zéro, est parvenu à solidifier l'hydrogène (sept. 1899).

Dès lor's, l'ancienne distinction des corps en solides, liquides ou gazeux a perdu de son importance; ear tous ou presque tous les corps, suivant le degré de pression ou le degré de température, paraissent susceptibles de passer par ces trois états.

Rayleigh et Ramsay (189') ont découvert, dans la composition de notre air athmosphérique, un nouveau corps simple, un nouveau gaz, l'argon, qui y entre dans la proportion de 1 p. 100. L'argon a été isolé par Maquenne. Olzewsli a trouvé moyen de le liquéfier et même de le cristalliser. Ses propriétés chimiques sont encore mal connues; peutêttre nulles : de là le mot d'argon, qui veut dire inerte.

BERTHELOT, en examinant la fluorescence et les raies du spectre de l'argon (1896), signala une relation entre elles et les phénomènes de la lumière zodiacale et des aurores boréales.

D'autres substances analogues (krypton, néon, xénon, metargon), dites a compagnons de l'argon $\triangleright$, sont à l'étude.

L’air eomprimé et l'eau comprimée ont pu ètre utilisés comme de puissants moteurs : le premier dans les horlo:es pneumaliques, les freins des chemins de fer ou des pièces d'artillerie. Avec l'ean comprimée on a pu redresser les piliers de la colossale Tour de 300 mètres. Les gaz solidiliès, pourant repasser très rapidement à l'état grazeux, constituent une force motrice, même une force de balistique, qu’on a déjà pensé à utiliser.

Chalear. - D'éminents sarants du xvile siècle, comme Laplace et Lavoisier, considéraient la chaleur comme quelque chose de matériel; mais, à cette époque déjà, d'autres savants, comme Montgolfier, commencaient à pressentir qu'elle est le résultat des vibrations intiniment rapides de l'éther 1. En d'autres termes, à l'hypothèse de la chaleurmatière on opposait déjà celle de la chaleur-mouvement, de la chaleur-dynamique.

L'invention de la thermodynamique a fait, alors, une 
révolution dans les sciences : la physique, la chimie, l'astronomie, la biologie, qui formaient autant de chapitres autrefois séparés, sont aujourd'hui reliées par des lois communes et par une commune mesure.

Cette commune mesure a été introduite en 1824 dans les sciences expérimentales par SADI CARNot, le plus jeune fils du conventionnel Carnot et oncle du lutur Président de la République, l'auteur des a Réflexions sur la puissance motrice de la chaleur o. Ce qu'il appelait puissance motrice, c'est ce qu'on dénomme aujourd'hui énergie. Carnot a du même coup énoncé les relations qui existent entre la chaleur et le travail qu'elle peut produire, et qui régrissent l'économie des machines à feu.

A l'étranger, sir WV. Thomson, Kirchhof, Helulioltz, Clausius; en France, Séguin et Hirn ont repris et continué l'œuvre de Carnot. Ces théories ont été, depuis, précisées par BERTIN, J. BERTRAND et LIPPMANN.

Lumière. - Après les études que nous avons déjà mentionnèes sur le spectre solaire, il restait à déterminer ses propriétés lumineuses, caloriques, chimiques, électriques : elles ont lait lobjet des travaux de B. Becouerel, JAMIN, DE LA PROVOSTAYE, DESAINS.

La rilesse de la lumière a été mesurce de nouveau par rIZEAJ, au moyen de miroirs tournauts. Il l'a trouvée égale à 300000 lílomètres par seconde, chiffre qui se rapproche sensiblement de celui que Roemer avait donnè dès le xrr siècle (77000 lieues). D'autres expériences, dues à rOUCAULT et à CORNo, ont permis d'arriver à une précision encole plus grande (300330 kilomètres).

L'énergie des diverses sources de lumière et des appareils lumineux peut ètre exactement mesurée au moyen d'un appareil photométrique, inveuté jar Onimus en 1 s99, et oú les chifrres s'inscrivent d'eux-mèmes sur un papier nnregistreur.

Les rayous lumineux invisibles. - Sur la nature de la lumiere les découvertes se succèdent. On a démontré que dans la lumière il y a des rayous invisibles à l'ail humain; que dans la lumière décomposée dans le spectre solaire, il y a, à droite et à gauche des sept couleurs visibles à nos regards, des rayons que nous ne voyons pas. 
Cette lumière invisible n'en exerce pas moins son action : calorique ou électrique en deçà du rouge (infrà-rouge), chimique au delì du violet (ultrit-violet $)^{1}$.

Dès avant 18ऽ6, des expériences avaient été faites par de Chardonnet et Soret sur ce qu'ils apprèrent la lumière ultra-violette, invisible à l'œil humain, parce que les humeurs de cet organe absorbent ces rayons avant qu'ils puissent toucher et impressionner la rétine. En 1886. dans une sorte de lanterne obturée par une glace mince recouverte d'argent, DE CHARDONNET, installa un arc électrique; cet arc lumineux n'était donc pas visible du delıors, puiscue l'argent intercepte tous les rayons lumineux saul les rayons ultra-violets; cependant un appareil photographique braque contre l'obturateur recut l'empreinte très nette de l'arc électrique. C'était bien la photographie de l'invisible.

Elcetricite et lumière : rayons eathodiques. - FARADAY avait découvert qu'un rayon de lumière s'altère en traversant un espace soumis à des courants magnéliques ou électriques. cLenk maxwell reprit ces études sur le ròle des milieux; il en vint a cette conclusion que les ondes lumineuses peuvent s'expliquer par des cuurants dont les alternances fréquentes produisent d'autres courants se propageant de proche en proche. "La lumière serait un ensemble de courants èlectriques caractérisés par la fréquence prodigieuse des alternances, un milliasd pendant un millionième de seconde" (Mascart). Les travaux de herTz (les ondes hertzienne's) démontrèrent que " les oscullations électriques se propagent a vec la mème vitesse que lit lumière; qu'elles donnent lieu aux mèmes phénomènes d'interférence; qu'elles se réfléchissent ou se réfractent suivant les mênes lois ". La lumière ne serait donc qu'un des phénonènes de lia force électrique. Comme l'a dit Henri Poincaré (189'), "l'identité de la lumière et de l'électricité est dès aujourd'hui autre chose qu'une hypothèse séduisante; c'est une vérité probuble, mais ce n'est pas encore une vérité demontree".

D'autre part, en 1874, crookes avait démontré que si 
l'on fait passer à travers une ampoule de verre, dans laquelle on a obtenu le vide absolu, le courant d'une bobine Ruhmkorff, des rayons se dégrạeaient du pôle négatif, dit électrode négative ou cathride, se propageant en ligne droite et produisant une phosphorescence dès quils frappaient un corps solide, le verre. par exemple. Crookes, sur ces expériences, risqua une hypothèse hardie, mais qui pourrait bien se vérifier: c’est que la matière ne se présente pas seulement à nous sous les états solide, liquile, gazeux. Il en existe peut-ètre un quatrième état : l'état radiant. Ces rayous furent dénommés rayons cathouliques.

HENRI HERTz, de Bonn (rive gauche du Rhin), étudiant ces rayons, constata qu'ils agissent sur une plaque photographique d'une façon identique aux rayons ultra-violets; que, comme eux, ils jonissent de la propriété de rendre phosphorescentes certaines substances; eufin qu'ils sont capables de traverser des feuilles de métal impénétrables à la lumière visible. $\mathrm{Ph}$. Lenard, savant hongrois, poussa très loin aussi l'ètude de ces rayons, et fut mème sur la voio (1894) de la découverte qui allait être réalisée par Rœntgen.

Les rayons X. - D'autres expériences sur ces mèmes rayons furent faites par RENTGEN, professeur à l'Université de Würtzburg. qui s’avisa (décembre 1893) d'entourer d'un papier noir l'ampoule de Crookes et constata que. malgré l'interposition de cet ubstacle, une plaque photographique n'en était pas moins impressionnée par les rayons émanés de l'ampoule, rayons qu'il dénomma rayons $X$ et qu'on appelle aussi rayons Ræntgen. Il parait bien qu'ils sont distincts des rayons cathodiques et quijls prennent naissance exactement au point ou ceux-ci viennent buter sur un obstacle. Ils ne paraissent pas davantage identiques aux rayons ultra-violets. Lorigine et la nalure des rayons $X$ ne seraient donc pas encore nettement établies.

Henri Poincaré appréciait ainsi (janvier 1896) cette découverte : a On est bien en présence d'un agent nouveau, aussi nouveau que l'étaient l'électricité du temps de Gilbert ${ }^{1}$, le galranisme du temps de Yolta ${ }^{2}$. Toutes les fois

1. Sur le livre publié par l'Anglais Gilbert en 1600, voir notre Histoire de la Cirilisation francaise, 1. 11, p. 453-45i.

2. Voir ci-dessus, p. 253. 
qu'une semblable révolution vient nous surprendre, elle réveille en nous le sentiment du mystère dont nous sommes environnés, sensation troublante qui s'était dissipée à mesure que s'émoussait l’admiration pour les merveilles d'autrefois.

Quoi qu'il en soit, les rayons étudiés par Rcentgen traversent la plupart des matières, le bois, le cuir, la chair; au contraire, ils ne traversent pas certains corps durs, tels que les métaux ou les os, qui dès lors, sur une plaque photographique très sensible (par exemple, sujette à fluorescence), impressionnée par les rayons $X$, projettent leur ombre ou, si l'on veut, leur image en noir.

On peut donc, sur cette plaque photographique, les vêtements ou les chairs d'une personne ne donnant aucune ombre, projeter l'ombre de son squelette et, avec une teinte plus foncée encore, l'ombre d'un objet métallique, soit placé dans les poclıes de ses vêtements, soit logé dans ses chairs ou dans ses os. Les mêmes projections se produisent sur un simple écran. Si donc, dans une boite en bois, remplie de chiffons, de papier, de paille, on place une bourse $\varepsilon u$ cuir contenant des pièces de monnaie ou un écrin renfermant un bijou, les rayons $\mathrm{X}$ pénètrent le bois, les chiffons, le cuir, pour impressionner la plaque pholographique; mais, arrétés par la garniture métaliique de la bourse ou de l'écrin, jar les monnaies ou les bijoux qui y sont enfermés, ils projettent uniquement l'ombre de cette garniture, de ces monnaies, de ces bijoux. Comme ces ombres sont plus ou moins intenses suivant la nature des objets frappés par les rayons $\mathrm{X}$, on peut, sans ouvrir une caisse, distinguer plus ou moins ce qu'elle contient : les métaux, très apparents; les autres substances, un peu moins visibles; un paquet de tabac se laisse entrevoir à travers son papier. A travers une enveloppe close, si elle n'est pas revêtue d'une substance (par exemple, de papier d'étain) qui arrète ces indiscrets rayons, on peut presque lire une lettre.

Il est facile de voir de quelles applications était susceptible une telle découverte. L'administration des douanes ne perdit pas de temps pour s'en emparer. Elle put, sans ouverture des colis, assurer ses vérifications. Au labora- 
toire municipal de Paris, Girard et Bordas utilisèrent les rajons $X$ pour explorer, sans y toucher, les engins explositis ou les engins suspects attribuables aux anarchistes. Dans les sciences médicales, il est infiniment précieux, sans mème déshabiller le patient, de voir l'intérieur de sou corps, tout au moins son squelette avec ses déformations pussibles. Au chirurgien les rayons $\mathbf{X}$ indiquent avec précision le point où un projectile, mème des grains de plomb, sont logés dans les chairs ou dans les os. Il semblerait méme que les rayons $X$, en traversant une poitrine affectée de inaladies pulmonaires exercent sur celles-ci une certaine action, dont la nature n'a pas encore été déterminée et dont on ne sait pas bien encore si ses eítets sont vraiment curatils et s'ils ne peuvent ètre nuisibles. Les ravons $X$ sont susceptibles d'autres applications : par exemple, ils ne traversent pas lc verre, mais ils traversent le carhone, par conséquent le diamant; donc, sans mêmo ouvrir un éerin, on peut, à l'aide des rayons $\mathbf{X}$, détermiser s'il contient un diamant de pur carbone ou un cabochon de simple cristal.

On va employer les rayons $\mathrm{X}$ à l'imprimerie (brevet Izambard, 1899). L'Anglais Kotıle les a dẻjà employés à copier, par cent copies à la fois, sur du papier sensibilisé.

La découverte de Rcentgen a été perfeclionnée ou étudiée en France par Troost, Chappuis, d'Arsonval, Londe, Radiguet, par Jean Girard, de Rochas, Dariex, Chabaud, Niewenglowsli, Ch. Henry. En moditiant la forme de l'ampoule, en employant des bobines plus puissantes, on est arrivé à réduire le temps exigé pour la pose, à produire des images. plus nettes, des ombres plus nuancées, de manière à pouvoir distinguer dans les corps vivants non seulement les os, mais les chairs, les parties molles, tous les organes, tout le réseau veineux et artériel. Les perfectionnements intéressant la médecine sont dus surtout aux doeteurs Bouchard, Lannelongue, Remy, Contremoulins. De leurs travaux est née une branche nouvelle de la médecine : la radiopathologie. Les métaux qui, sous l'action des premiers appareils, ne donnaient qu'une ombre compacte donnent aujourd hui des ombres plus nuancées: il est donc possible, dans une pièce métallique, de distinguer les soulllures, 
pailles, défauts de fonte, cause fréquente d'accidents.

Des appareils plus simples et portatifs, sous les noms de chambre noire radioscopique, eryptoscope, radioscope exploratcur, fluoroscope, lorgnette humaine, ont été construits par Radiguet, Londe, Salvioni, Edison, Seguy. En janvier 1899, Roulliès démontra que, par l'emploi simultané de deux ampoules de Crookes, on pouvait, en radiograplice, roir directement le relief des corps observés.

Recherehes diverses sur la Inmière. - En 1849. le baron de Reichenbach avait déjà essayé de saisir sur la plaque du daguerréotype ce qu'il appelait les elfluves odiques, attribuées par lui à un fluide appelé od, qui se dégageaient des corps vivants, des aimants, des composés chimiques, etc., mais qui ne seraient perceptibles que dans une obscurite absolue et seulement sur une plaque très sensible. Il serait jarrenu, assura-t-il, à obtenir des épreuves assez nettes: mais les savants de ce temps contesterent ses résultats aussi bien que l'existence de l'od ou des efthuves odiques.

Près d'un demi-siècle après, en 1996, H. Becquerel, Ch. Henry, Troost, Curie, ont démontré que certaines substances. - sels duranium, sullare de zinc, - ajpès aroir été exposées à la lumière, conservent dans l'obscurité la propriété de produire une certaine phosphorescence, de dégager un rayonnement et même, en traversant des corps cpaques, dimpressionner la plaque photographique. Elles produisent les rayons Bequerel (Rudioacticite.)

G. Le Bon a pu donner à certains phénomènes lumineux la dénomination singulière de Lumière noire, qu'il interprète par ces autres mots: Luminescence invisible, Radiations de grande longueur d'onde, Émunations métalliques, expressions qu'il serait trop long d'expliquer ici.

G. Trouvé et Foveau de Courmelles ont poursuivi des expériences en vue d'isoler la lumière rouge, la lumière froide, la lumière chimique, etc.

Les Américains Bell et Tainter, les Français Hercadier et Dussaud ont étudié la photophonie ou radiophonie, ou production de certains sons à l'aide de certains rayons lumineux : d'où le photophone.

Il sera question plus loin de la phótographie des couleurs. Quant à l'étude mème des couleur's, il convient de rap- 
peler ici les derniers travaux de chevreol. Dans son laboratoire des Golselins, il réussit à déterminer et à fixer jusqu'à $1+400$ nuances ou tons divers, tous procédant des trois coulcurs mères: rouge, jaune, bleu.

L'alectricité d'iadnetion. - Jusque vers 1855 , on ne produisait l'électricité que de deux manières. Par les machines à frottement, on dégageait un fluide doué d'une grande tension, mais en faible quantité : c'est l’électricité statique. Par les piles, on obtenait un fluide de faible tension, mais en grande quantilé : c'est l'électrieité voltä̈que on dynamique. FARADAY décourrit alors l'électricité d'induction.

En remplaçant l'action de la pile Volta par l'action de barreaux aimantés, il produisait des courants induits. II obtint ainsi, suivant l'expression de J.-B. Dumas, la troisième espèce d'èlectricité, celle dans laquelle « les qualités des deux précédentes se trouvent réunies; car, comme la première, elle lance de longues et foudroyantes étincelles; comme la seconde, elle pénètre dans l'intérieur des corps pour les échauffer, les fondre, les décomposer s.

Arago, avec de l'électricité, faisait du magnétisme : Faraday, avec des aimants, faisait de l'électricité. Il se servait de la Terre elle-même comme d'un aimant pour développer dans des fils de cuivre des courants induits.

C'est d'après les principes de Faraday que Clarke et Pixii ont construit leur machine à induction; que Ruhmkorff, en 18ว̈1, à Paris, a labriqué la bobine Ruhmkorff. Celle-ci se compose d'un cylindre de carton sur lequel s'enroulent des fils métalliques communiquant avec les pôles d'une pile. Sur certaines bobines on enroule jusqu à 30000 mètres de fil. L'électricité condensée dans cet appareil est d'une telle puissance qu'elle peut percer des lames de verre de dix centimètres d'épaisseur. Avec la machine de Ruhmkorif on a pu, en 1860 , pendant la campagne de Chine, faire sauter les forts du Peï-ho. On s'en sert aujourd'hui pour envoyer l'étincelle électrique, à d'énormes distances, dans les torpilles, dans les mines chargées de poudre ou de dynamite, dans les phares que l'on veut allumer à distance. L'empereur Napoléon 111 avait foudé, en 1852, pour la meilleure application de la pile Volta, un prix de 50000 tranes, a l'imitation de celui que le Premier Consul avait fonte 
en 1801. Ce prix fut, en 1864, décerné à Ruhmliorff.

Toutefois la production de l'électricité restait encore très coûteuse. L'application de cette force aux usages industriels, et par exemple à l'éclairagre, restait presque impossible tant qu'on ne produirait l'électricité qu'arec des moyens de laboratoire. Au lieu de la produire en brûlant du zinc dans une pile, il s'agissait de la produire en brúlant simplement du charbon sous une chandière. Le problème fut résolu par GRAmme, in rénieur d'origine belge, mais domicilie en France, qui construisit le puissantes dynamos. Les dynamos, très perlectionnées, ont permis de transformer en énergie électrique la force des chutes d'eau (la houille blanche). L'emploi des courunts triphases a permis de réaliser le transport de la force à distance.

Affinile des grandes forees de la nature. - Dès 1842 , GRove, à l'Institution royale de Londres, avail essayé d'établir que " la chaleur, la lumière, l'électricité, le magnétisme, l'affinité chimique, le mouvement ${ }^{1}$, sont corrélatils ou dans une mutuelle dépendance; que chacun d'eux peut produire tous les autres ou se convertir en eux; que la chaleur peut, médiatement ou immédiatement, produire l'électricité; que leelectricité peut produire la chaleur; el ainsi des autres forces, chacune disparaissant à mesure que la force quelle produit se développe ". faraday a repris la même théorie et l'a développée et confirmée par de brillantes expériences.

Le téléphone. - Si, au moyen du fil télégraphique, on a pu transmettre à toute distance, mème à traver's les mers, des signes et des lettres, ne pouvait-on pas transmettre également les vibrations que la parole humaine imprimerait a un appareil susceptible de vibrer? Ne pouvait-on pas transmottre la parole humaine elle-mème? En 1837, l'Américain PAGE, au moyen de son vibrateur électrique, constata quine tige magnétique soumise à des aimantations et désaimantations très rapides peut émettre des soms. En 18ă4, Charles bourseul publia son mémoire sur la transmission électrique de la parole. "On regarda cette idée, raconte Dumoncel, comme un rève lantastique; moi-

1. Mème le son. En janvier 1899, Dussaud rédigea sa première note sur la transmission du son par les rayons ulla-violets. Voir ci-dessus, p. 693. 
même, je dois l'avouer, je ne pouvais y croire $\triangleright$. Alors paru\& le tẻléphone de Philippe ReIss (1860), qui ne transportait que des sons musicaux; puis celui de Grabam BeLL (1876), qui transporte la parole liumaine. Perfectionné par Clı. Cros, Elisha Gray, Edison, Pollard et Garnier, Bréguet, Dutertre, Gouault, Varley ${ }^{1}$, l'appareil nouveau s'est vulgarisé en Europe. D'abord on s'est servi des vibrations du télé. phone pour parler d'une chambre à une autre, d'une maison à une autre, d'un quartier à l'autre d'une grande ville comme Paris. L'époque actuelle a vu réaliser cette merreille qu'un amateur, placé dans une cabine téléphonique a Marseille, pent entendre ce qu'on chante ou déclame sur la scène des théâtres de Paris. Dès janvier 1887, le président de la République française et le roi des Belges ont pu s'entretenir, par téléphone, de Paris à Bruxelles et inaugurer ainsi le service entre les deux pays.

La télephonie est venue ainsi faire concurrence à la télégraphie; nous avons, dans presque toutes les villes de France, des stations téléphoniques. Notre réseau téléphonique, chaque jour, s'étend et se complète ${ }^{2}$. Le téléphone enregistreur permet de fixer les communications dont le destinataire n'a pu avoir l'audition.

Le phonographe. - Un correcteur d'imprimerie de Paris, Léon Scotr (1836), au moyen des oscillations d'une plaque métallique vibrant à la parole lrumaine, obtint que cette parole s'inscrivit elle-méme au moyen de signes convenus. C'est ce qu'il appelait le phonautographe. Puis CE. CROS et EDISON (1877) inventèrent le phonoyraphe, qui, impressionné par la parole humaine, non seulement la conserve, mais peut la reproduire. Le phonographe emma gasine le chant de l'artiste ou les éclats de l'éloquence politique, et, des années après, en tournant une manivelle, on pent se tonner le plaisir de les entendre encore. Au début, les sons qu'il émettait étaient nasillarls et peu distincts : des incrédules prétendajent mème que ceux qui exhibaient cette machine n’étaient que d'habiles ventri-

1. D'autres perfeclionnements, dus i Gaiffe, Ducretet, Caretle, se rapportent au microphone, inventé par l'sméricain Ilughes, et qui permet de percevoir des sons trés faibles.

2. Voir ci-dessous, p. 337. 
loques. Après divers perfectionnements, le son est devenu presque aussi net, aussi naturel, aussi facile à reconnaıtre que celui que transmet le téléphone ${ }^{\mathbf{1}}$.

La télegraphie sans fil ${ }^{2}$ - - En 1842 , le physicien HeNRY avait remarqué que la décharge d'une bouteille de Leyde dans une chambre de sa maison aimantait des aiguilles dans une cave creusée à 9 mètres au-dessous. En 1880 , EDIson démontra qu'il était possible de communiquer avec un train en mouvement rien qu'en utilisant l'influence électro-stutique qui s'exerce entre un circuit installé latéralement à la voie et un circuit téléphonique posté par le train. La même année W.-H. preEce découvrait que la zone d'influence d'un courant télégraphique ordinaire peut s'étendre à une distance de 900 niètres. Le sol mème, en certains cas, sert à compléter le circuit ébauché par une ligrre télégraphique. Il en va de même pour les eaux. Les courants magnétiques, électro-magnétiques, électro-statiques, d'induction, peuvent influer, même à de grandes distances, les uns sur les autres. Preece affirmait, dès 1893, qu'il serait possible de faire des communications télégraphiques sans fil mène entre la France et l'Angleterre, même entre des îles séparées par un détroit que bouleversent des courants violents et de fortes marées.

Nous avous déjà vu henri aERTz (1888) établir que l'úlectricité se propage dans l'espace par des ondulations analogues aux ondes lumineuses : c'est la théorie des ondes hertaienns.

Le docteur Édouard Branly, professeur et doyen à l'Institut catholique de Paris, imagina de recueillir les ondes électriques, véhicule de vibrations télégraphiques projetées par un radiuteur, et de les capter dans un radioconducteur (1890).

1. Nons reuvoyons pour le détail aux ouvraces spéciaux. On y trouvera aussi des notions sur divers appareils, tels que le microphone. les parleurs microphonigurs, le microphonographe de Dussaud, le triemier phonugraphe ou enreyistren is distance de Dussaud, le télehone haut parleur de Dussaud (decembre 184, le photophone, ete. Nous aurons peut etre un jour, suivant le vou de L. Azoulay des Musees et des Archives phonographiques.

2. Il est a noter que Bfiubnuze, pendaut le sière de Paris par les Allemands (18-U-is I), arait pensé a utiliser le cours de lit Seine pour remplacer les fils hépram hiques yni nous manquaient et comuluniquer aveo le dehors. Ces experiticts palaissent aroir été abandunnes quand le siége eut pris fin. 
Celui-ci se composait essentiellement d'un tube rempli de limaille métallique (fer, or, nickel, réduits en poudre). L'étincelle d'une bobine Ruhmkorff animait cette limaille, la rendait perméable au courant électrique qu'apportaient les ondes et qui aussitôt pouvait actionner une sonnerie ou un télégraphe Morse. Cherchant jusqu'à quelle distance pouvaî̀ s’étendre l'activité de l'appareil, il fit des expériences d'abord sur quelques centimètres, puis sur quelques mètres, et, angmentant sans cesse la puissance de son appareil, constala que les messages pourraient se transmettre à des kilomètres.

Le Russe Popof (1895) et l'Anglais Lodgre s'engagèrent ensuite dans ces recherches.

Puis G. marconi, partant de celle découverte, parvint à démontrer, par des expériences faites à Salisbury et Cardiff (Grande-Bretagne) et à La Spezzia (Jtalie), qu’il était possible de communiquer sans fil lélégraphique, uniquement par les ondulations électriques, à des distances variant entre 2 et 15 kilomètres. Son appareil se composait essentiellement, au point de départ, d'un transmettcur ou radiateur; au point choisi pour l'arrivée, d'un récepteur, dans lequel s'intercale le radioconducteur de Branly. La distance parcourue par les ondes est en proportion de la lougueur de l'étincelle produite par la bobine. D'autres expériences faites à New-York (1898) confirmèrent celles de Marconi en prouvant que des navires munis de récepteurs peuvent, à une distance de 20 kilomètres, recevoir la communication. En 1899, Marconi renouvela ses expériences entre Wimereux (Pas-de-Calais) et Saint-llargaret (Angleterre), localités distantes de toute la largeur du détroit (30 kilometres); entre telle partie du littoral et tel navire en mer. Le principe de la télègraphie sans fil ètait trouvé ${ }^{1}$.

D’importantes expériences faites en France furent celles de 1)ucrétet, qui voulait s'assurer s'il était possible de communiquer par-dessus les toits d'une grande cité aussi aisément que par-dessus un bras de mer : il fit passer

1. Le premier télégramme que Marconi ait fait passer à une distance de 50 kilomètres, entre la France et l'Angleterre, fut adressé par lui à Braniy, anquel il faisait ainsi hommage do sou succès. 
des télésrammes entre le Panthéon et le Sacré-Corur, entre le Sacré-Cceur et Sainte-Anne, entre Villejuif et la rue Claude-Bernard, à des distances variant entre 4 et 7 lilomètres; - celles du lieutenant de vaisseau C. Tissot entre la côté de Bretagne de l'ile d'Ouessant, à une distance de ${ }^{2} 2$ kilomètres ${ }^{1}$. En cette même année 1899, à Vienne, des télégrammes furent échangés, à une distance le 10 kilomètres, entre un ballon libre à 1600 mètres de hauteur et un ballon captif a 150. En mai 1900, Joseph Vallot et les frères Lecornu établirent des communications du mème genre entre le mont Blanc et un ballon libre Donc il était possible, en temps de guerre par exemple, de communiquer sans fil avec un navire en pleine mer ou une ville assiégée. En 1906, on a mis en communication la Tour Eiffel et la citadelle de Belfort.

Il reste à découvrir la syntonisation, qui permettra daccorder entre eux deux appareils sans que d'autres appareils puissent déchiffrer le messare. Ciest ainsi qu'actuellement, des marconigrammes envoyés de Poldhu (Cornonailles aux trais:atlantiques qui naviguent au large sont lus par les appareils français, mẻme ceux de Port-Yendres.

Le premier emploi de la télégraphie sans fil a été fait. dans la récente guerre de Chine, par les troupes allemandes. Russes et Japonais s"en sont beaucoup servi. en mer surtout.

Et, après le télégraphe sans fil, on cherche le téléphone sans fil! (Ducrétet et Popol, 1900, le Danois Pulsen.) (V. Suppl.)

Autres applications de l'électrleité. - L'ingénieur rRoMENT a employé l'èlectricité à laire mouvoir des machines. Dans les grandes expositions de 1878 et de 1889 on arait pu voir de petits bateaux où la vapeur était remplacée par l’électricité. Dès 1879, à Berlin, sIEmens et HALKE présentèrent une locomotive électrique. Presque à la même date BonTEMPS et, plus récemment, llarcel DEPREz appliquaicnt à Paris la même idée. Aujourd'hui la traction électrique est maitresse de nos rues comme de nos routes. Elle le sera bientòt sur nos cours d'eau et sur les mers.

L'électricité se révèle déjà comme un puissant moteur,

1. Le lieutenant $\mathrm{C}$. Tissot inventa, en avil 1900, un systeme de radioconducteur qui lerfectionna la transmission 
plus énergique et plus docile que la vapeur, et dont l'usage zera un jour universel. Elle a déjà son rôle dans les analyses chimiques, les transformations des métaux L'analyse chimique prend ainsi, par l'électrolyse, l'électrochimie, l'électro-métallurgie, une énergie nouvelle. Despretz, Louis Clerc, Violle, IIéroult, A. Ninet, ont utilisé les premiers fours électriques. Avec le four clectrique de la Sorbonne, les professeurs MOISSAN ${ }^{1}$ et LEBEAd ont obtenu d'admirables résultats. On la employé aussi dans l'industrie, notamment dans les usines Bullier pour labriquer le carbure de calcium.

L'électricité est devenue un puissant auxiliaire de la métallurgie (aluminium, cuivre, nickel, etc.) et de la fabrication des produits chimiques (soude, chlorate de potasse, etc.).

berthelot, à son tour, étudia les réactions de l'étincelle et de l'eflluve électriques sur les composés organiques.

Lélectricité a son rôle dans les phénomènes les plus mystérieux de la vie et solvay, dans une lecon d'ouverture qu'il prononẹait en 1893 , à son institut de Bruxelles, a pu dire: a Les phénomènes de la vie peuvent et doivent sexpliquer par le jeu des seules forces physiques qui rérissent l'univers; et, parmi ces torces, l'etectricité joue un rôle prédominant. \$

En 1881, Marcel deprez avait trouvé le moyen, à laaide d'un fil électrique, de transporter à de grandes distances la force motrice d'une chute d'eau, d'une machine à vapeur. de l'électricité elle-mème. De Creil, par exemple, on a pu actionner des machines installées à la gare du Nord de Paris. On a employé ce procédé pour distribuer sur une vaste surface des États-Unis la force motrice de la chute du Niagara. Dans tous nos pays de montagnes, Vosges, Jura, régions alpines et pyrénéennes, Massil du Centre, les sources et cascades sont précieusement captées, domestiquées; leur force, transformée en électricité, est tratısmise à distance pour les services de télégraphie, d'éclairage, de locomotion, de métallurgie. C'est la houille blanche.

BREGET a utilise l'electricité pour dunner l'heure simul. tanément à de nombreuses horloges.

1. Lioissan, en agissant sur du carbone, a des températures de 3000 degre-, ent arrive a jroduire de petits cristaux de diamant (1900). Depuis, il a volutilist et furt distiller prescjue tous les metaus connus. 
Eonelur l'a utilisée pour perfectionner le mélipr à la Jacquard et remplacer les cartons et accessoires de l'ancien système. Avec la machine dite Électrotype, les grands journaux américains ont commencé à se composer électriquement. Cette machine, qui s'est révélée pour nous ì l'Exposition universelle de 1900, fait en 13 heures la besogne qui coûterait 1270 heures d'ouvriers typographes.

En 1879, à Sermaize (Marne), on a appliqué l'électricité au labourage : les frais de labour devaient ètre inlërieurs d'un tiers à ceux du labour avec des aitelages. En 1890 nous voyons le procédé employé en Allemagne (Saxe). En Amérique on laboure le sol, on fauche, on lie, on bat les récoltes à l'électricité.

En Amérique un est allé encore plus loin : on exécule les condamnes a morts par l'électrocution!

Nous avons déjà vu la galvanoplustie et ses dérivés ${ }^{2}$; nous pallerons plus loin de l'éclairaye électrique.

L'électricité, encore au xvrle siecle une branche si peu importante de la physique, esı devenue à elle seule toute une science. Ses applications en physique, en chimie, en physiologie, en mélecine, dans l'industrie, sont innombrables. Une des expositions internationales les plus intéressantes de ce siecle a élé l'Exposition d'èlectricité, au Palais le l'Industris, en 1081. Les Expositions universelles de 1889 et de 1900 out constaté le progrès rapide de cette science et le rapide développement de ses applications. (Voir suppl.

Météorologie ${ }^{2}$ - La météorologie, cette branche de la physique qui a pour objet lobservation des phénomènes qui se passent dans notre atmosphère, est une science relativement récente. Elle est née au xvile siècle, avec Demaison, Saussure, Dufay, Franklin, Mairan, l'abbé Nollet, Volta. Elle a pris de grands developpements en notre siècle, avec Humphry Davy, qui étudia les brouillards; Chladni, les aérolithes; Peltier, Moureaux, Bratrais, les hulos et autres phénomènes électriques de l'atmosphere; Moreau de Jonnes,

2. Voir la nutice sur les Progrès de la météorologie ue le 8 janvier 1901, pas Georges Lemoine (Revue scientifique, 16 mars 1901. 
les ouragans et les tremblements de terre; Charles SainteClaire Deville, les influences volcaniques; Coulvier-Gravier et Saigey, les étoiles filantes; Bérigny, llouzeau, Albert Lévy, l'ozone atmosphèrique; Pouillet, Violle, Crova, les phénomìnes d'actinométrie ou de rayonnement; Belgrand, l'hydrologie, la hauteur des rivières et les phénomènes des crues; Marié-Davy, la relation entre les mouvements de l'atmosphère et ceux de la mer; Foissac et Boudin, les relations de la météorologie avec l'ètat sanitaire; Boussingault et Georges Ville, ses relations avec l'agriculture.

En 1852 s'est fondéc à Paris la Société de météorologie; mais déjà de 1849 à 1832 avait paru l'Annuaire météorologique de Charles Martins. Renou, l'un des fondateurs de la Socièté, donnait en 1858 ses Instructions météorologiques et ses Tubles usuelles.

Puis se sont créés l'Otservatoire météorologique de Montsouris, avec Marié-Davy, et le Bureau météorologique, fondé par Le Verrier, développé par Mascart. Ce bureau, en relations télégraphiques avec les établissements analogues de tout l'univers civilisé, peut annoncer, parfois plusieurs jours à l'avance, la marche d'une dépression atmosphérique ou d'un ouragan. A son tour, il envoie partout des télégrammes, qui, affichés dans les mairies de toutes les communes et dans tous les ports de mer, rendent de grands services à l'agriculture et à la navigation. En 1896, s'est tenu à Paris, sous la présidence de Mascart, un Congrès internutional de mitéorologie, oì l'on s'est occupé de dresser un a Atlas du ciel s et de classer les nuages ou phénomènes analogues d'après leur origine, leur forme et leur signification météorologique ${ }^{1}$.

Citons les recherches du prince A. de Honaco, en 1905, sur les contre-alisés.

Depuis longtemps on avait essayé de protéger les plantes, au moyen de nuages artificiels, contre les grelées tardives. En 1896, Stieger, en Styrie, essaya de disloquer ou éloigner les nuées char grées de grêle à l'aide d'une artillcrie agricole d'un certain modile. Ces expériences de tir an canon contre

1. Ainsi on a distingué les nuages en cirrus, cumulus, stratus; cirrocumulus, cumulo-strutus, ete.

A consulter, l'onviage de C. Flanmarion : L'Atmosphère. 
les muages ont élé continuées par Vicenti, Pacher (Italiens), Perulet et Trabert. Elles ont donné d'excellents résullats en Styrie et Italie (1900). De même les fusées à explosion.

\section{Chimie: déconverte de nouveaux corps simples par} l'analyse spectrale ou leur radiation. - La plupart des corps simples découverts dans la seconde moitié du $\mathrm{x}^{\mathrm{e}}$ siècle l'ont été grảce à l'analyse spectrale. Après qu'on les eut devinés dans le spectre, ou du Soleil, ou des autres corps célestes, ou des flammes de nos laboratoires, il restait à les extraire des composés qui les renfermaient. C'est ainsi qu'on a obtenu le thulliun, déeouvert par Crookes, isolé par Lamy; le cæsium, le rubidium, reconnus par bunsen et Kirchhoff; le gallizm, pal Lecoq de Boisbaudran (1875); l'intium, par Richter (1863); le samarium, par Lecoq de Boisbaudran 1878): le radium de Curie et brémond (1898), qui n’a été exlrait qu'en intime quantité el dont on n'a pu encore díterminer exactement les propriétés. D'autres ont été simplement révélés par l'analyse spectrale, ou par leur ratiulion (emploi des rayons $\mathrm{X}$ ) : ainsi l'uctinium de Debierne (1900).

On comnait aujourd'hui, tant métalloüdes que mélaux, environ 80 corps simples ou élements. Nous sommes loin des qualre eléments, si cher's aux ancieus savants.

Une des découvertes les plus récentes et les plus curieuses de la climie, c'ast la production du fluor à l'ètat libre, gràce aux expériences de FRÉMY, puis de MOISSAN (1886). Ce gaz, dangereux à manier, attaque toutes les substances, saufl'or elle platine, et encore quand ils ne sont pas portés à de hautes tempèratures. Or, en 1896, Moissan et Dewar sont parvenus, sous une tempéralure de $-183^{\circ}$, à liquélier le lluor. Ses propriétés en ont été modifiées du tout au tout.

L'aluminimu. - HeNRI SAINTE-CLAIRE DEVILLE, s'emparant de la découverte de Wrehler, montra que l'aluminium est contenu en quantités immenses dans les kaolins et les argiles. Il inventa, pour l'extraire, des procédés simples et peu coúteux (1854). A l'usine de Javel, avec DEBRay, il parvint à le produire à raison de 2000 francs parkilogramme ${ }^{1}$.

1. A l'usine de Salindres (Gard), ce fut d'abord a raison de $120 \mathrm{fr}$. Par la fabrication électrique, on l'oblient aujotirdlıuı a moins de $4 \mathrm{fr}$. 
Ses premier's lingots figurèrent à l'Exposition universelle de 183̈. L'industrie, remarque J.-B. Dumas, se trouva être lotée d'un métal « léger comme le verre, presque aussi beau que l'argent, comme lui inaltérable à l'air, au feu, résistant même à la plupart des agents chimiques. Ductile, malléable, fusible, exigeant cependant pour londre une temperature assez haute et ne se volatilisant jamais, èest un metal noble de plus, prenant place à côte de l'or, du platine et de l'argent, et un métal prodigué par la nature, plis répandu que le fer dans les couclies superficielles du globe, formant comme une réserve pour les besoins des époques les plus civilisées . Non seulement on en fait des bijoux, des ustensiles divers, par exemple, des clés, tous très légers, mais, pendant le siège de Paris, on a pu en fabriquer des fusils.

Chinde orgarique. - Lart de transformer toutes matières sucrées en alcoof, toutes matières alcooliques en rinaigre, suivant la nature de la fermentation à laquelle on les soumet, a été poussé très loin chez nous, grâce surtout aux recherches de Pasteur et berthelot.

PASTeur a fait une étude approfondie de l'acide tartrique et des dillérents tartres qui entrent dans la composition du vin. C'est lui qui, le premier, a précisé les causes et fait la theorie de la fermentation alcoolique ou acétique, précisé la nature des organismes vivants, animaux ou végétaux, qui sont les agents de ces fermentations. Par li, il a rendu d'importants services à l'industrie des bières, des vins. des alcools, des vinaigres.

Le $n$ om de ce savant restera également attaché aux procédés, dits de pasteurisation, permeltant de conserver à l'abri de tout germe et de toute fermentation nuisibles (c'est-à-dire stêrilisés) le vin, la bière, le lait, etc.

BERTHELOT a pu, de toutes pièces, fabriquer de l'alcool par des procédés purement climífues.

Sur les éthers, il faut citer aussi les travaux de J.-B. DuMAs, REGNAULT, GERHARDT.

Dès lors, on a pu établir quels éthers procèdent des alcools par l'elimination, dans ces derniers, d'une certaine quantité d'cau. On a pu les diviser en ithers simples et en éthers composis. On a étudié avec plus de précision ies 
phénomènes de l'éthérisation, c'est-à-dire de l'action de l'éther sur nos organes.

Berthelot a aussi porté ses recherches sur les matières sucrées et les a distinguées en deux catégories : celles qui sont fermentescibles à la levure de bière et qu'il appelle saccharoses (comme le sucre de canne et de betterave); celles qui ne le sont pas, comme la glycérine, la manuite, la clulcite, la pinite, la quercite, ete. Il a établi l'identité chimique des alcools et des sucres, qui ne diffèrent que par leur état moléculaire.

Berthelot, après Chevreul, a également étudié les rorps grus, dont il a montré les connexions avec certains échers composés.

L'antipyrine a été découverte par Knorr en 1883.

Le caoutchouc, décrit par La Condamine dès 1751, lint analysé en 18 วั2 par PAYEN '.

Les substances explosives. - La glycérine, décourtrte au $\mathrm{XV}^{\mathrm{e}}{ }^{\mathrm{e}}$ siècle par Schrecle, est le principe doux des huiles: on l'emploie en médecine pour les pansements. Cette mine slycérine, traitée par un mélange l'acide sulfurique et d'acide nitrique, donne naissance à une substance huil use, terriblement explosive, d'un maniement fort dangeriux, car le moindre choc détermine l'explosion. C'est la nitroglycerinc, découverte en 184 par Sobrero ${ }^{2}$ et qui se récéla en 1866 par la terrible explosion du navire l'Europeen dans le port d'Aspinwal. Elle a treize fois la force expansive de la poudre. Mêléc à des matières inertes, par exempli du sable tin, procédé inventé par le chimiste allemand Nober. elle prend la consistance du beurre, devient, en these générale, insensible aux choes, d'un transport et d'un maniement très sùrs tout en conservant la mème puis. sance, el ne détonne qu'au moyen d’une capsule à luhmi-

1. Besson et Champion fabriquaient déjà des tissus tris minces en caoutchouc. De nos jours, Piattier et Guibal, important chez nous un ptrcédé de l'Auglais Makintosh, en ont fait des manteaux imperméables. Gérald a perfectionné lart de filer cette substance que le Congo français et beire, ainsi que l'Amérique du Sud, sont appelès a produire en quantité indefiaie.

2. Une année apròs la découverte du fulmi-coton par Schenbein. Lupuis cette époque, le fulmi-cotun a été chez nuus l'objet des expériences du chimiste Abel, qui apporta des perfectionnements dans sa fabrication et son emploi. Voir ci-dessus, p. 450. 
nate : e'est alors la dynamite. Copendant, il y a des dynamites mal laites dont le trarsport est hangereux : c'est une dynamite le cette sorte, appelée mataziette, qui, saisie sur des contrebandiers, a fait sauter le fort du Larmont, en 1877.

L'acide picrique ${ }^{1}$, combiné avec la potasse, lonne un sel d'une puissance explosive énorme : c'est le picrute de potıss ${ }^{2}$. Fondu, l'acide picrique constitue la mélinite.

On pourrait citer une vingtaine de produits analogues, tels que le lithofracteur, la dualine, la glycoxyline, la pantopollite, la fulgurite de R. Pictet (1895); la gelutine explosice de Nobel ${ }^{3}$, d'où procèdent la ballistite, la filite, la cordite. La mélinite, la roburite, la lydlite sont employées par l'artillerie francaise, par l'artillerie allemande, par l'artillerie anglaise.

Turpin a etudie les panclastites, explosils liquides à base d'h!moazotide. La poudre $B$, sans fumée, employée par l'armée et la marine française est due à lintrénieur Vieille; elle semble à base de fulmi-coton et de camphre.

La houille et ses prodnits. - La houille, ce résidu des forits primitives, ou் une nature plus riche et plus luxuriante avait entassé des arbres et des végétaux aux vertus puissantes, n'a pas fourni seulement le gaz d'éclairage. De la houille ou de ses résilus, par une série de réactions chimiques, on a tiré une infinité de substances aux usages les plus divers : l'ammoninque, extrait par Mallet; la benzine, dissolvant des corps gras, découverte par Mitscherlich (1833) et purifiée par Colas; l'aniline, qui, traitée de façons différenies, lonne une série de couleurs iclatantes, comme le rouge dinilme ou fuchsine ${ }^{4}$, lécouvert par IIolimann et labriqué par Verguin (1839); l'indisine, qui est un admi-

1. L'acille picrique fut découvert en 1785 par le chimiste Hausmann, qui l'intitula amer indigo. Son nom acluel lui fut domué en 1809 par Chevreul (du gre picros, qui signilie amer).

2. Rappelons que le chlorate de potasse entrait en romposition dans la poudre de Berthollet fahriquèe par ce chimiste, qui faillit périr dans l'explosion qu'elle provoqua dans la poudrière d'Essonnes.

3. Nubel, l'iuventeur de tant de produits destrueteurs, a fondé pour un million de prix destinés aux penseurs qui auraient le plus contribué à hàter lavinement de la paix nuiverselle (1900).

4. Ce mot viendrijt du fuchsia, dint la fleur a celte couleur, ou de Renard (en allemand Fuchs), fabricant lyounais. 
rable violet, inventé par l'Anglais Perkin (18.36); des teintures variant du rouge au bleu, extraites par Girard et De Laire, notamment le bleu de Lyon el le violet impérial: l'alizarine ${ }^{1}$, qui a été reconnue ètre le principe colorant de la garance, mais qu'on prélère oblenir aujourd'hui par distitlation de l'anthracine, plutôt que par la culture de la garance; la diméthylaniline, dont Lauth a extrait le violet de Paris (1861); l'acide phenique, qui est un désinfectant si énergique; l'acide picrique, avec lequel Guinon, de Lyon, a obtenu (1877) une superbe teinture janne: la créosote, un puissant corrosif, découverte par Reichenbach (1832), et dont Arnaudot et Persoz ont tiré une teiuture orange, etc.

Chimic anricole. - L'analyse des terres et des engrais, qui a pris de nos jours un développement remarquable, a été d'un grand profil pour l'agriculture. Parmi les savants qui se sonl adonués à la chimie agricole. il faut citer Boussingault, Payen, Peligot, Kuhlmann, Paul Thénard, Millon, Reiset. Georges Ville, Grandean, Dherain.

Philosophie de la chimie. - La plilosophie de la chimie consiste à rechercher la nature et la composition de la matière; le rôle des atomes et des molécules, les uns et les autres invisibles, et celles-ci comprenant un nombre plus ou moins grand de ceux-la; les proportions exactes dans lesquelles ils se combinent; la question du poids atomique; la théorie des équicalents, ilucidée par Laurent et Gerhardt; les lois stirant lesquelles un corps peul, dans une combinaison, se substituer à un autre sans que cette combinaison change de caractere. Celte branch: de la science a donué lieu amx beau travaux de J.-B. Dumas * Lecons sur la philosophie chimique s (1836), de Wurtz (186i), de Remault, de Berthelot, he Grimaux.

On doit a henri sainte cialre deville la découverte de la loi de lissicintion, un phénomène qu'il ne faut pas confondre avec celui de la léromposition des corps, bien que tous deux se produisent également par la chaleur ou l'électricité2. Il

1. Ne pas co fondre avec l'alizarine naturelle, que Robiquet et Collin avaient réısi, en 1826 , à extraire de li garance.

2. La lissociation est uue decomposition limitée et réversible, stujette a des lois déterminées. 
a réalisé au jugement de J.-B. Dumas, a une des plus belles inventions de ce siecle fécond $\triangleright$. Ses travaux ont été poursuivis par Troost, P. Hautefeuille, H. Debray, Isambert, Alfred Ditte.

\section{Les sciences naturelles.}

Voyages de naturalistes. - On ne peut énumérer tous les voyages de naturalistes accomplis de nos jours dans toutes les parties du monde. Ceux d'A. Grandider it Madagascar, qui ont eu pour résultat une précise description de cette ile au point de vue de sa faune, de sa flore, de sa géologie, marqueront parmi les plus célèlres. En. 1884 des sondages ont été entrepris, sous la direction d'Alphonse MiLNe-EDWARds, par les deux navires le Talisman et le Truacilleur. On a lait descendre la sonde it des profondenrs, jusqualors inouies, de neul mille mictres; on a ramené des mollusques, des crustacés, des poissons étranıres, habitués à vivre sous des pressions énolmes, dans des tinèbres presige completes, parfois dejourvudu sens de la vue.

D'autres sondages, aussi fécourls en lésultats, ont été entrepris par le prince Albert de Mlonaco qui, en 1899, a, dans sa capitale, inauguré un Insem octunographique et, en 1906, créé ì Paris un Institut oceanographigur.

Aux collections d'animaux vivants entreteutes au lluséum sont renues s'ajouter celles qu'a rassemblées au bois de Boulogne la socite d'acclimatntion, Condée en 18:it par Isi-

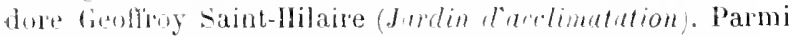
les animaux a l'acclimatation desquels elle s'est appliquée, cituns le lama, le yack, la cherre ri lngora, le rolin, oisean de Californie, plusieurs espèces lt urs a soie.

Theỏores nonvelles. - Le xvil siècle, en zonlogie, sétait surtout consacré à la deseription et à la classificutiom des animaux. La période révolutionnaire applipua i cette science les principes de l'anatomie comparee et lui douna le complément de la paléntologie. Le Xix" siecle est caractérisé, en premier lieu, par une division de plus en plus grande du traratil. En second lieu, la morphologic, c'est- 
à-dire l'étude des formes, s'est armée de méthodes plus rigoureuses. Il ne sullit pas seulement de comparer entre eux les animaux adultes; on les compare en leur germe, en leur embryon : alors nait cette branche de la science qu'on appelle l'embryologie. Les embryons, chez les animaux les plus différents, sont si semblables entre eux quon a peine, dans leur premier état, à distinguer celui dun poisson de celui d'un oiseau, celui d'un reptile de celui d'un mammifère; on a donc été amené à l'hypothèse d'une unité originelle de toutes les espèces.

Alors sest produit le système de l'Amstais Darwin ${ }^{1}$ : le transformisme, l'évolution; c'est-ḋ-dire lunitr origiuelle des espèces, leur séparation sous l'empire de ronditions dillèrentes de vie et de lutte pour la vie, le developlement d'organes spéciaux appropriés à ces conditions différentes d'existence. L'honme lui-mème ne serait arrivé à son état actuel que par un lent perfectionnement ${ }^{2}$.

Zoologie. - Dans les Suites à Buffon. qui ont paru avec la collaboration de plusieurs savants. I'aul GenvaIs a décrit les Insectes sans diles (1884). Mn lui doit anssi de nombreux ouvrages relatils à la zoologie, à la morpholonie, à la paléontologie.

LACAze-Duthiers s'est consacré à l'élude des aninaux marins, surtout des Mollusques, Zoophytes, Protozoaires. 11 a exécuté de nombreux sondages sur les cotes de la France et de l'Algéric. C'est sous sa direction quion a plitué les laboratoires zoologiques de Roscoff (Bretagne the Banyuls (Pyrénées-Orientales), où l'on étudie l'anatonie et la physiologie des Mollusques et autres animaux marins.

Georges Pouchet, directeur du laboratoire de Concarneau (Finistire), Marion, directeur de celui de Harseille, ont également lormé de nombreux élèves el rendu de wrinłs services à la zoologie maritime.

Henti MiLne-EDWARDS, mort en 1885 , âgé de quatıe-vingtcinq ans, loyen de la Faculte des soiences, étulia la

1. Lorigine des especes, 1859, trad. française de Mme C. Loyer 1862.

2. En 190i, M. li. Quinton a publié un ouvrare, L'can de mer milien organique, ou it uflime que les origines de la vie sont marins et que tout l'effort res espèces est re maintenir en elles les condition. names ndisponsables a la vie de leurs cullules. Tout ètre net qu'un appareil contenast le mileu matin dans lequel la vie se prerustar sous sa forme cellulaire primitive. 
plysiologie et l'anatomie comparée de l'homme et des animacx, et, en outre, les Crustacés, les Coraux, les Polypes. 11 lant citer les travaux de son fils, Aphonse milneEDWARDS, sur des branches analogues de la science; de BLANCHARD, sur les Insectes, les Mollusques, les Arachnides, les Crustacés; de Delage, qui. au Congrès de Rome (1899), montra que les couls microscopiques de certains animaux peurent etre divisis, chaque liaction d'ouf restant féconde, et qui, un peu plus tari, féconda au moyen de l'acide car. bonique, des cul's d'asteries; dE. PERRIER, directeur du Muséum (1900). sur les Amnélides, les Mollusques, les Zuophytes: de valldant, sur les Reptiles et les Joissons; d'A. dequatrefages, sur les Annélides, les maladies des vers à soie, les métamorphoses les insectes, lembryologie ${ }^{1}$.

Le venin des serpents et des autres reptiles a été l'objel destraraux de Phisalix, J. Bertrand, A. Calmette, qui ont recherche les moyens d'en combattre les eltets par linjection le sérums. Kaufmann, professeur à Allurt, a indiyué le pernanganate de potusse comme remede clificace contre la morsure des serpents renimeux.

L'étude des parasites, externes et interues, de l'homme ou des animaux a amené des rérélations. On a lécouver' que la fale est causé par un sarcopte; que le tournis du mouton provient d'un cénure qui, laus l'intestin du cinien, devient un tania canurus: que le cysticerque, qui cause chez le pore la maladie apjelie latrerie, levient chez l'lomme un tinia; que le rysticerque du rat, du lapin, devicnt le tinia du clrat, dn chicu; que quantités de maladies sont cansées par des hematuouives ou parasites du sang che\% l'homme on chez les animan. Les lowmatozoaires causent en particulier la fierre jazme Marchoux, Salimbeni, Simon), la fiére puludeme (Laveran), la maladie du sommeil, spriale i lifrifue. eturlice par de nombreux milerius elraugers, et, en France, par le Dr Brumpt: Ia

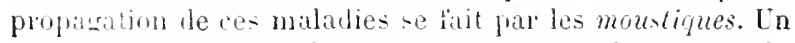
des plus ruluntables de ces parastes, cest la trichine du pore, yui so loge dans les muscles de linonme; elle est surtout friguente chez les pores allemands et americains.

1. Un evalue an ourdhui à 400000 les espéces d'animanx reconnues a la surface du globe; les Insecles eatrent lans ce total pour 290000 espèces. 
Les savants, armés de microscopes d'une puissance énorme, tels que le microscope composé et achromatique, se sont, comme PASTEUR, attaqués aux infiniment petits, bacilles, bacteridies, vibrims, a tout ce monde invisible et lormidable; nuisible quand il est l'agent des corruptions, des virus, des maladies infectieuses; nécessaire aux phénomines de la vie, quand il est l'agent des lermentations, lëcondations, translormations de toute nature.

Reculant vers des limites inespérées le champ de l'observation, les perfectionnements realisés dans la construction du microscope ont permis de scruter en ses moindres détails la structure des tissus animanx. Lhistoloyic s'est ainsi rapidement développée. Non seulement, comme nous le verrons plus loin, elle apporte un precieux concours à l'anatomie normale ou palloulogrique, mais elle a conduit les naturalistes à modifier tolalement l'ancienne conception de l'être virant, qui désormais doit être considéré comme lormé par l'associatiun, par la lëderation d'un nombre souvent considérable de parties premières (cellules, etc.) représentant autant dorganismes himentaires plus ou moins variés dans leurs formes et leurs attributs, et concourant a une fin commune. Les travaux de robin, de RANviER, de CORNIL, etc., ont particulierement contribue en France au progrès de lihistologie.

Quevion de la generation spontanee. - Les savants de l'antiquité et dı moyen âge avaient cru à la naissance spontance, c'est-a-dire sans germes préexistants, d'animaux tels que les abeilles. Aı xvir siècle, Van Helmont croyait à la génération spontanée, dans la rase d'un marécage, de grenouilles, limaces, sangsues ${ }^{\mathbf{1}}$. Redi, naturaliste italien de la fin de ce siècle, montra que mème des animaux plus petits, les mouches et les vers, ne naissent jamais que lorsqu'il existe déjà des rufs pondus par des individus de leur espece. Les partisans de la génération spontanée s'étaientréduits à ne l’admettreque pour les ani-

1. Il enseigrnait même nn moyen de provoquer la génération slıontance les souris : il sultisait de remplir de ble un vase et de le boucher avec une chemise sale. Quelque temps apres, on y tronvait une potée de souri- les grains de blé s'étant trausformés en ces animaus. On voit conbien l'observalion de fan Helmunt elat superticielle el grossiere. 
maux microscopiques: au xvin siècle, Buffon et Needham avaientsout nu cetle thèse, déjà combattue parSpallanzani. La question s'était reproduite en 18.38 : Pouchet, directeur du Muséum de Rouen, assurait avoir pris toutes les précautions imagrinables pour empècher les germes en suspension dans lair de se déposer dans certaines matières : il avait cependant obtenu la production d'animalcules vivants. Pasteur se borna à démontrer que les précautions prises par Pouchet avaient été insuffisantes; lui-mème, au moyen d'appareils inǵnieux, qui ne laissaient passer qu'un air purifié par la chaleur ou par les agents chimiques, réussit à maintenir vierges de toute génération les substances observées. An moins lans l'état actuel du monde physique et de la science, il ne convient pas d'altirmer que la matière soit capable de produire spontanément la vie.

Paléontolosia. - La paléontologie, fondée chez nous par Cuvier, a élé surtout cultivée tlepuis par ALCide dorbigny, auteur de la a Paléontologie rrancaise \$ (1840-1860) et fondateur du Comité de paléontoloyie francuise (1861); DARchiac, qui écrivit a Jilistuire des progrès de la géolowie »: PICTET, auteur de savants mémoires a la Société d'hi-toire naturelle de Genève; ALBERT GAODRY, qui, après avoir fait comnatre les curieux fossiles du gisement de Pilierni (Grice), s'est attaché à établir les liens organiques qui unissent les espèces éteintes aux especes actuelles.

Des milliers l'espèces fossiles ont été signalées.

Ilistoire naturelle de loonsue, - L'homme par ses aspects les plus nobles, appartient aux sciences morales; par d'autres, il relève de la zoologic, de l'anatomie, de la pliysinlogie. Il y a done une histoire natur lle de lhomme. Sorls te titre, Lacépède et Bory de Saint-Vincent, dès 18:7, fubliaient chacun un ouvrage. De là une science nouvelle: lanthropologie.

Les explorations des royagents lans le monde entier nous ont lait comnatre toutes les races humaines et ont permis d'en essayer une classilication. I'our préciser les points de comparaison entre elles. on s'est mis à mesurer les crânes (de là une élude nouvelle, la craniologie, et un nouvel instrument, le céphatomitre, inventé par Antelme en 183s), a ivaluer l'angle facial, a perer les cerveaux. 
Dans ces branches nouvelles de la science, il faut citer surtout les travaux de Gervais, Broca, Dupont. Joulin, Mortillet, Luys, Malhias Duval. La chaire d'anthropologie, fondée au Muséum ell 18\%:, Put occupée d'abord par rLodrens. qui étudia avec tant d'éclat les rapports du moral et du physique de l'homme, le rôle du syslème nerveux dans les phénomènes de l'intelligence, les conditions de la longévité; puis par A. de quatrefages; puis par le docteur hamy. La Societè ethnoloyique, londée en 1839, s'est dédoublée en Societé d'ethnographie et Societé d'anthropologie.

Alors des questions très hautes se sont posées. Parmi les savants, les uns, les polygénistes, estiment qu'il y eut pour l'espèce humaine plusieurs centres de création; les auires, les monoyénistes, tiennent pour un centre unique. La seconde de ces hypothèses a rallié les noms les plus illustres de la science, Linné, Bufton, Cuvier, Étienne Geofroy Saint-Hilaire, Lamarck, Humboldt, Blainville. - A. de Guatrefages déclara que a les groupes humains ne sont pas des especes différentes : ils ne sont que des races d'une seule et même espèce ๖. Il allait même jusqu'ì désigner une région de l'Asie, située à l'ouest du Platpau Central, comme le berceau commun de toutes les races humaines ${ }^{\text {. }}$

Botanique. - La botanique se partage d'abord ell deux branches principales : $1^{\circ}$ la botanique physiologique, qui étudie les plantes au point de vue de leur organisation et des phénomènes de leur existence, et qui se subdivise naturellement en oryanographic ou examen de leurs organes, phytotomie ou anutomi: végétale, physiologie ou étude des fonctions vitales; 20 la botanique phytoyrapłique, qui s’occupe de la description des végétaux, de leur groupement et le leur classitication, de la répartition des espèces a la surface du slobe ${ }^{2}$, enfin de la recherche des especes perlues ou paléontologie végetale.

L'organogruphie et l'anatomie végétale ont été, chez nous, Iobjet des travaux de Weddell, Baillon, Ed. Bureau, Germain Saint-Pierre, Charles Martins, Lestiboudois, docteur

1. Sur l'antiquité de l'espèce humaine, voir ei-dessus, p. 645.

2. On èvalue aujourd'hui a 150000 les especes de plantes reconnues à la surface du clobe. Le règne végétal serait donc moins riche et moins varié que le régue atuial. 
Clos, llenri Fabre, Van Tieghem, Decaisne, Duchartre, Gustave Regnault, Trécul, G.-A. Chatin, Cette branche de la science a dû son essor aux progrès accomplis dans la construction des microscopes, à l'emploi des réactifs chimiques et des injections colorées.

Pour la physiologie végétale, signalons les recherches de Pepin, sur l'accroissement; Arthur Guis, P. Dalimier, Duchartre, sur l'absorption et sur le rôle des eaux de pluie et de la rosée; Senebier, Th. de Saussure, Gratiolet, Boussingault, Georwes Ville, Garreau, sur la respiration; Bouchardat, Kuhlmann, Soubeiran, Grandeau, sur la nutrition; Tulasne, Charles Naudin, If. Lecoq, Gordon, Ch. Flahault, sur la fécondution et la reproduction; Dutrochet et Leclerc, sur les mouvements des plantes; Charles Royer, Fée, les deux Planchon, sur le sommeil des vécétaux; G. Bunnier, Guiguard, L. Mangin, Delactoix, E. Prillieux, G. André, sur les maladies des plantes; Délrérain, sur la physiologie veggetale appliquée à l'agricullure. On voil que le règne végétal reproduit presque tous les plrénomènes vitaux quon peut constater dans le régne animal.

D`innombrables monographies ont été consacrées à la deseription des végétaux. Les cryptogumes et lichens, ì eux seuls, nous ont valu de nombreux ouvrages dus à Cordier, G. Bonnier, Cornet, de Seynes, Marchand, etc.

Parmi les travaux d'ensemble les plus remarquables du siècle, il faut citer le a Traité général de botanique descriptive et analytique o de Le Maout et Decaisne (1869), qui ne comprend pas moins de 5500 figures; et a l'liistoire des plantes de Baillon (1865), qui comprend 8 volumes, ornés de 7000 figures.

La distribution des plantes à la surface du globe a fait l'objet de deux grandes ceuvres d'un caractère général : l'une pour l'Europe, a Études sur la géographie botanique de l'Europe »(1854-1858), de Leeoq; l'autre pour notre pays, a la Flore de France v (18:s), de Grenier et Godron. Il n'est presque pas une province de notre pays qui n'ait fait lobjet de quelque monographie considérable.

La recherche des cspèces perdues, dans le monde végétal, a èté inaugurée, dès 1837, par ADOLPHE BRONGNIART, auteur de la e Flore des vegetaux fossiles (18'9). 
Alphonse de Candolle a étudié a l'Origine des plantes cultivées $\triangleright(1883)$.

En 1854 s'est constituée la Société botanique de France; elle s'est trouvée presque aussitôt en correspondance avec de nombreuses societés locales formées dans presque toutes les parties du pays.

La Socicte d'acclimatation (1854) s'est aussi proposé de doter la France des plantes exotiques qui pourraient prospérer en nos climats. C'est grâce à elle, en partie, que nous nous sommes enrichis de nouvelles essences forestières, comme le Wellingtonia gigantea des États-Unis, le plus élevé des résineux, comme l'encalyptus de l'Australie, dont la présence assainit les terres malsaines du Languedoc, de la Corse, de l'Algérie; de nouvelles espèces médicinales, comme l'ipecaeuanha et le ricin; de nouvelles plantes d'ornement, comme les nympheias, les aralias, les ficus, les arums, les azalées, etc.

Géologie. - La géologie, en se développant, s'est également divisée en un certain nombre de branches. Les principales sont: la cristallographie, qui recherche les lois de la cristallisation ${ }^{1}$; la physique minérale, qui étudie les corps au point de vue de leurs qualités physiques, densité, élasticité, dureté, propriétés électriques, caloriques, optiques ${ }^{2}$; la chimie minerale, qui s'occupe de la composition atonique des corps; l'histoire naturelle proprement dite, on description et classification des minéraux; la stratigraphie, qui détermine la formation des couches minérales, le système des montagnes, la distribution des substances à la surface du globe, la structure des gisements métalliques.

La cristallographie, considérée dans ses rapports avec les lois mathématiques, a fait l'objet des travaux de Des Cloizeaux, Delafosse, Auguste Bravais, Baudrimonl, Pastedr: celui-ci avait débuté par des études (1818-1852) sur les cristaux des tertrates.

La physique minérale doit beaucoup aux recherches de de Sénarmont (1847), Fizeau (1862), Ilugueny, Mallard, Des Cloizeaux, qui a examiné (de 1857 à 1866) plus de 400 sub-

1. Phénomènes d'isomorphisme, de dimorphisme, de plésiomory, hisme.

2. Telles que la double rériaction, la polarisation de la lumière, etc. 
stances cristallines au point de vue de la double réfraction et de la polarisation rotatoire de la lumière; Marcel Bertrand, P. Ilauteleuille, A. Lacroix, Fournet, Michel Lévy, Jannettaz, qui se sont occupés de la coloration des minéraux; Edmond Becquerel, qui a étudié leurs propriétés phosphorescentes et magnétiques.

La chimie minérale tend a se confondre avec la chimie proprement dite. Dans cette branche de la minéralogie, il faut signaler les travaux de Niklès, Troost, Debray, Fouqué, A. Gaudry, Friedel, Damour, Delesse, Lechartier, G.-A. Daubrée. Jepérel.

De houvelles classifications ont été proposées par Charles Sainte-Claire Deville (1853), Des Cloizeaux (1862), de Chancourtois (1862).

La commission de la Carte géologique de France a fixé la classification des roches au commencement de ce siècle.

ÉLIE DE BEAUMONT a continué ses études de stratigraphie, en 10\%:, par sa "Notice sur les systèmes de montagnes ๖. Dans son « Riappont sur les Progrès de la stratigraphie (1869), il a tracé les grandes lignes de soulèvement à la suriace du globe. On vit alors sidentifier des systèmes de montarnes placés à une énorme distance les uns des autres. Sous l'impulsion d'Elie de Beaumont, toute une légron de sarants, E. Hébert, Munier-Chalmas, Fouqué, Stanislas Meunier, A. de Lapparent, Haug. Kilian, etc., s'est attachée ì la description des diverses régions. Sur la stratignohic repose en grande partie la géographie physique.

Le monde souiermin. - Les plus curieuses des études contemporaines relatives à la géologie ou mieux à la géo. graphie physique, ce sont celles que poursuit E-A. MarTeL sur les carernes, les abines, les eaux souterraines. De 1888 a 1893 , il pénétra dans 250 gouftres, parfois à plusieurs centaines de mètres de profondeur, all prix des plus grands langers. Il explora le monde souterrain non seulement en France (Causses du Languedoc, Jura, etc.), mais dans la majeure partie de l'Europe, étudiant la faune, la thore, le régine des eaux lans ces gouffres a d'où les vieilies femmes prétendent voir sortir parlois le feu de l'enter s. Il fut le fondateur de la société de spéléologie intemationule (189:). 


\section{Les sciences médicales.}

Anatonie, histologie. - Les seules découvertes qu'on ait $p u$, au xixe siccle, faire en analomie ne l'ont été qu'à l'aide du microseope : elles se rapportent plutôt à l'histologie ou étude des tissus organiques. En 1866 s'est fonlée la Société des études microscopiques. CORNIL et RANVIER ont publié, en 1869 , le a Manuel d'histologie pathologinue ». Ranvier a donné ensuite de remarquables travaux d'histologie normale.

Cependant, en anatomie pure, on pent ciler les études de LEURET et GRATIOLET sur les circonvolutions du cerveau, de MARC SÉE sur les fonctions du cueur.

Playiologie, biolowie. - En 1849 s'est fondée la Société de Biologic, dont E. Gley, en 1900, a exposé l'histoire. LONGET, médecin de Napoléon III, a éludié le système nerveux et les maladies de la moclle épinière. Son a Traité complet de physiologie \$ (1850-1839) est un des meilleurs qui ait paru en notre langue. Jules BÉCLARD a publié (1855) le a Traité élémentaire de physiologic humaine §. MArEY (1879) son \& Traité de physiologie expérimentaie s.

DUCHENNE, de Boulogne, a fait un examen approfondi de l'aciion de l'électricité sur les nerfs et sur les muscles (1839), au moyen des courants d'induction.

robiN, qui fut sénateur de la République, a publié, avec vendeIL, un a Traité de chimie anatomique et physiologique $\triangleright$; avec LITrRE, une récdition du a Dielionnaire de médecine s de Nysten; et, enfin, le a Joumal d'anatomie ot de physiologie s.

vulPian, dans ses a Lecons sur le système nerveux » (1865) et sur les a nerfs vaso-moteurs d (1873), a onvert la voie à de nouvelles découvertes. BROWN-SĖQuaRd a éludié plus spécialement la physiologie de la moelle épiniére, et les effets de l'injection de certains sérums. TRoussead a dirige, d'une facon magistrale, la clinique de l'Hôtel-Dieu. Jaccoud s'est consacré à l'étude des perturbations lans le syslème nerveux, telles que les purapligies. LANDouzy, sandras, potair, ont lait d'importantes découvertes en phrsiologie pathologique. 
Claude Bernard : les sues organiques. les fonetions de système nerveux. - CLAODE BERNARd (1813-1878) lut, a u Collège de Fralıce, à l'Académie de médecine, au Muséum, le successeur de Magendie. En 18034 , il devint professeur à la Faculté et membre de l'Acalémie des sciences. Les vues philosophiques qui le guidaient dans ses recherches, son talent d'exposition, lui ouvrirent, comme à J.-B. Dumas et Pasteur, l'Académie française (186今).

Sa première couvre fut une thèse sur le suc gastrique (18ł3). Il détermina également la nature et les propriétés du suc paneréatique (18;6). Il consacra vingt années à létude d'une propriété du foie, la propriété glycogénique, qui consiste à prołuire du sucre, substance indispensable à l'organisme, mais dont la prodnction exagrérée constitue une maladie spéciale (le dicibète). Au xvir siècle, on avait dètróné ${ }^{1}$ le foie comme facteur du sang, ne lui laissant d'autre office que d'élaborer la bile : Claude Bernard trouvait un emploi nouveau pour cet organe en disponibilité.

Reprenant les expériences de Lavoisier sur les phénomènes de combustion organique, mais avec des appareils ingénieux et des procédés d'une délicatesse extrême, il mesura la production de la chaleur dans les organes (1849).

Il étudia le nerf spinal, qu'il démontra être celui qui fait mouvoir les orranes vocaux. Il constata (1851) laction des nerfs intercostaux sur certains phénomènes vitaux. Il montra que le réseau nerveux appelé le grand sympathique forme un système autonome, indépendant du cerveau, et qui exerce une action sur la dilatation de la pupille.

Complétant la grande découverte des Servel, des Colombo, des Harvey ${ }^{2}$, il constata les circul'tions loeales. Il prouva que le cceur, lans notre organisme, n'est pas le seul agent de la circulation du sang; car, dans toutes les parties du corps, il y a des nerfs dits vaso-moteurs, les uns dilatant, les autres resserrant les artères, et qui activent les circulations locales du sang.

Notre système nerveux, sur lequel planait toujours tant d'obscurités et de mystère, fut alors exploré. Claude Ber-

2. Voir notre Hist. de la Civilis. francaise, t. ler, p. 180, et t. 11, p. 458. 
nard soumit celui des animaux à l'action des agents physiques, comme la chaleur et l'électricité. ll employa aussi des agents chimiques, comme le curare, ce poison améri. cain, qui a la singulière propriété de supprimer toute faculte de mouvement par une action directe sur la fibre musculaire, tout en laissant intacte la faculté de sentir ${ }^{1}$.

Quelques philosophes ont cherché, dans ce róle énorme que les lécouvertes de Claude Bernard assiguaient à la matière organisée en système nerveux, des argumeuts à l'appui de thèses matérialistes. Le grand savant se refusait à de telles conclusions :

- Il importe, disait-il, de séparer la physiologie des grands problèmes qui tourmentent l'esprit humain : leur étude relève de métholles différentes. La science ne saurait rien supprimer; le sentiment nabdiquera jamais; il sera toujours le premier moteur des actes lnumains. o

Il avait commencé l'étude des fermentations. Ce travail le pass: onnait. Quand il sentit ses forces décliner : a C'est dommage, dit-il, c'eùt été lien finir. Đu comnait les services que Pasteur a rendus dans cette direction.

Louis Pasten: les viras. - PASTEUR a repris la question des virus presque au point où Jenner l'avait laissée. Il monlra que les virus sont produits par le développement des bacilles, buctínidies (ainsi appelés parce qu'ils ont la forme de bâtonnets) et autres microbes. Ses premières recherches portèrent sur une maladie infectieuse connue sous le nom de charbon. Elle s'altaque aux bètes à cornes, au mouton, au cheval, à l'homme; elle peut se transmettre de l'un à l'autre de ces ètres, et être contagrieuse mème pour d'autres animaux, comme le lapin. Déjà, do $185 \mathrm{~L}$ à 1862 , Rayer et Davaine avaient constaté dans les pustules du churbon la piésence de corps en forme de bâtonnets. Pasteur reconnut également ces bacillcs. Il en commenca aussitôt la cullure : à cet effet, il préparait une série de liquides azotés, par exemple du bouillon de poule. Dans le premier liquide, il déposait quelques gouttes de sang charbonneux; dans le second liquide, une goutte 
du liquate précédent, et ainsi de suite. 11 consiata que les derniers liquides, quoique les bacilles continuassent à y pulluler, perdaient de leur virulence première. Bien plus, le liquide amené à cet état modéré de virulence, quand on l'inoculait à un animal, uon seulement ne causait pas la mort, mais, au prix d'une indisposition plus ou moins grave et toujours passagère, le rendait réfractaire pour l'avenir à l'action de liquides plus virulents et mème du virus pur. Un virus atténué produisait donc, pour cette maladie, le mème effet que le vaccin pour la petite vérole. Pasteur venait de trouver le vaccin du charbon (1881). Le nombre des animaux domestiques ainsi vaccinés, jusqu'à l'année 1900, s'élève à 13381867.

Le choléra des poules, qui fait tant de victimes dan= les basses-cours, fut l'objet des mêmes expériences : le batcille de cette maladie fut soumis à une série de cullures, et le vaccin en fut également trouvé (1859). Il en fut de même pour le vaccin du rouget des porcs.

Pasteur a mis le comble à sa renommée en créant le vaccin de la rage. Jusqu'à 1900, la méthode a été appliquée a 26631 malades, dont 99 seulement ont succombi.

Cette idée de prévenir ou de combattre les maladies virulentes par l'inoculation de virus atténués a pris, depuis les décourertes de Pasteur, mne importance capitate.

a Vous verrez, avait-il dit, comme tout cela s'agrandira plus tard. D

L'Institut Pasteur, où l'on conserve la tombe du grand savant ${ }^{1}$, a été fondé (1885), non seulement des subventions de l'État français, mais de celles qu'y ajoutèrent tous les Etats civilisés, et de souscriptions recueillies en France mème et dans le monde entier. Là, sous la direction de ses élèves, Duclaux, Roux, Martin, Grancher, Chamberland, Chantemesse, Nocard, Yersin, le Russe Metchnikof, on poursuit l'application de ses théories. Des établissements analogues se sont ensuite londés en France (à Lille arec Albert Calmette), et chez presque toutes les nations. C:est ainsi que s’immortalise le nom et se perpétue l'activité lu plus génial peut-être des savants du wixe siécle.

1. Pasteur est mort le samedi 26 septembre 1895 . 11 était aé à Lỏle lo 27 décembre 1822 . 
Sérothérapie. - Une opération distincte de la vaccination proprement dite, c'est l'injection du sirum de certains animaux ayant eux-mèmes subi certaines inoculations. C'est ce qu'on appelle la sérotherapie ". Le docteur Roux (1889), qui eut pour collaborateurs les Français Martin et Cliaillou, le docteur allemand Behring et le docteur japonais liitasato, résolut de lappliquer à la guérison du croup ou diphlérie, ce lléau si destructeur, surtout pour l'enlance. Le microbe de cette maladie était déjả reconnu "; mais c'est surtout par des sécrétions infecticuses, ou toxines $^{3}$ dégagées par les microbes que ceux-ci tuent les patients. Il fallait donc isoler cette toxine. C'est à quoi réussit le docteur Roux, aidé de Y zrsin. Le sérum de chevaux préalablcment inoculés de ce poison à doses rraduées, jusqu'à ce qu'ils fussent complètement immunises, fut, également à doses graduées, inoculé aux malades. C'est en février 1894 que le traitement fư inauguré, el dès lors les guérisons se multiplièrent.

D'autres disciples de Pasteur se sont attaqués au microbe (staphylocoque) le l'érésipèle, à la tuberculose, à la fièvie jaune, au choléra, à la fievve typhoïde, à la peste d'Orient ou bulonique, dout yersin, lor's de sa mission à Hlontr-liong (1894), décuuvit le microbe.

Le parlement francais, sur l'initiative et les raplyorts du député Audiflred, vota de larges subventions aux laboratoires de sérothérapie.

Les méthodes nouvelles de thérapeutique sont devenues d'une application si friquente qu'en France la loi $d u$ 25 avril $1895^{\circ}$ a dù réglementer la fabrication, l'emploi et le commerce des « virus atténués, sérums thérapeutiques, toxines modifiées, etc. $\$$.

On a puécrire que l'histoire de la médecine se divisait en deux périodes : avunt Pasteur, après Pastcur.

1. La première application en fut faite, en $18 S 2$, par les docteurs Ch. Richel el Héricourt, mais non a propos de la diphtérie : ils cherchaient un remède conthe le staphylocoque d'une maladie des chiens.

2. La mierobe ou bacille de la diphlérie avait été reconnu, en 1883 , par l'Allemand Klebs. Il fut ensuite isolé par un autre Allemand, Lœfller.

3. Le mol toxine est deveuu le terme générique pour les virus, que Selni appelait des ptomaines; Gautier, des leucomaïnes; Roux et Yersin, des diastases; Gamalèìn, des nucléines; Brieger, des toxalbumincs, ots. 


\section{Perturbations du système nervenx : phénomènes} d'hypnotisme. - Il se produit dans notre organisme des faits étranges et qui, jusqu'à ces derniers temps, ètaient restés inexpliqués. Notre systime nerveux, en particulier, dout on commence à peine l'exploration scientifique, est inépuisable en surprises. Déjà Laplace, Cuvier, Arağo avaient remarqué que, dans ce qu'on appelait magnétisme animal, tout ne pouvait pas s'expliquer, ou par la fraude et le charlalanisme, ou par les seuls prestiges de l'imagination. En 18:6, l'Académie de médecine, frappée des faits qui lui étaient signalés par a des observateurs exacts, probes, attentils $\triangleright$, avait nommé une commission de neuf membres pour les étudier. Cetle commission avait admis le lait mème du somnambulisme, qu'elle définissait a un élat de sommeil provoqué artificiellement ๖. Puis, en 1840, à la suite de certaines tentatives pour lui en imposer, l'Académie de médecine déclara qu'elle s'abstiendrait à l'avenir de s'occuper du magnetisme animal a de mème, disait un de ses membres, que l'Académie des sciences reluse de s'oceuper de la quadrature du cercle et du mouvement perpétuel .

Or, c'est l'année suivante (1841) que le phénomene de l'hypnotisme fut scientifiquement constaté par le médecin anglais BRAID. Il définit l'hypnotisme un sommeil nerveux accompagné d'insensibilité aux lésions, parfois de raideur cataleptique, parfois au-i d'une hypercsthesie, ou sensibilité extraordinaire de certains sens. Au lien d'agir par des passes magnetiques, comme faisaient ses devanciers, Braid produisait l'hypuotisme simplement en obligeant les sujets à fixer, pendant 20 ou 30 minutes, un corps brillant.

La découverte fut bien aceueillie en France par RabIN, Litrié, broca. Celui-ci, en 1859, employa, de concert avec velpead, l'hy!notisme pour produire l'anesthcisie, ou insensibilité, dans une opération chirurgicale. AzAm, vers 1860 , fit do ces phénomènes une description très précise. Figuren u'hésita pas, en 1861, en raison de la similitude des phénomines, ‘̀ identilier l'hypnotisme avec le somnambulisme tel que prétemiaient le produire les magnétiseurs.

A parlir de 1873, charcot, surtout dans sa clinique de la Salpètrière, fit des expériences qui excitèrent un étonne- 
ment général parmi les savants comme dans le public, mais qui ont mis hors de doute certains faits qui semblaient extraordinaires. Par lì se sont expliqués beaucoup des pliénomènes qui ont tant ému nos allètres, depuis les épidémies de sorcellerie et de démonomanie au moyen âge, jusqu'aux convulsionnaires du cimetière Saint-Mbdard et aux effets merveilleux du baquet de Mesmer.

\section{Théraputigue : progres de la medecine enrative.}

- La médecine a fait de sérieux progrés, ne lùt-ce que dans la détermination plus exacte de la nature des maladies. Par exemple, les affections du cervean out été mieux localisées et les affections de la moelle épinière ont été définies. Les fièvres continues de notre pays ont été réduites à une seule, la fièrre typhoide, qui a été reconnue comme occasionnée par une lísion de l'intestin grile. Le typhus des camps, au contraire, a été nettement séparé de la lièvre typhoïle. Les affections pseudo-membraneuses du pharynx (angine couenncuse) ou du largnx (croup) ont été raltachées a la diphtérie. Les caractères des fièvres éruptives ont été plus clairement déterminés. Une étude plus minutieuse deg tubercules dans le pommon, qu'arait reconuus Laënnec, la découverte du bacille tuberculeux, ont expliqué la nature de certaines alfections pulmonaires, ainsi que leur caractère contagieux. Le tétanos mime, daprès les récentes expériences de CORNIL el VERNEUL, est une maladie microbienne.

On a trouvé une méthode plus rationnelle et plus bardie pour le traitement de la fière typhoile, par l'eau lroide ou à une température inlérieure de quelques degrés à la température du corps.

La médecine a renoncé aux fréquentes sainnées d'autrefois, ayant bien plutút à se préoccuper de nous l'ortifier contre l'unemie et ses conséquences. Elle a renoncé aux médicameuts compliqués. Elle a marqué une préférence de jour en jour plus décidée pour l'emploi de l'eiu, soit au moyen de douches ${ }^{1}$, soit au moyen des bains de nuer

1. L'hydrothérapie a été, pour ainsi dire, fondf́e par Pnessitz, paysan allemand, nort en 1851, qui avait créé l'établiszrment de Grafeuberg (Silesie). Scoutetrin semble le premier qui ait trailé de l'eau suls le rapport hygienique et médical (1S12). Dix ans après, Fleury pubhait soa Iruite pratique et -aisonné dhyliothérapie. 
et des eaux minérales. Elle est devenue plus expectante, car elle a pris plus de contiance dans les forces réparatrices que la nature elle-même a mises en réserve dans notre organisine.

Elle a constaté la tendance qu'ont certaines maladies contagieuses à perdre de leur violence meurtrière, comme si elles s'acclimntaicnt chez nous, ou si elles avaient une tendance à s'íteindre. C'est ainsi que le choléra morbus, qui a fait tant de ravages à ses premières invasions, en 1832 , en 1840 et en 1834, s'est montré beaucoup moins redoutable lors de ses récentes apparitions ${ }^{1}$.

Elle a étudié de plus près certaines maladies allectant la composition du sang, comme l'albuminurie, le diabete, etc., que les anciens médecins classaient avec d'autres, sous la dénomination vague de a maladie de consomption.

La médecine a su tirer parti des ressourees que tant de découvertes récentes, en plyssique et surtout en électricité, en chimie, en botanique ${ }^{3}$, en mincralogie, mettaient à sa disposition. Elle fait un usage plus l'iequent du thermomètre pour mesurer la température dans les diverses parties du corps d'un mala de. Elle a employé l'analyse spectrale pour déterminer plus exactement la composition du sang. Nous avons vu quels puissants agents la chimie, surtout la chimie orqanique, avait rérélés au médecin ". bochenne, de Boulogne, a genéralisé l'emploi de l'électricité : il fut un des londateurs de l'ele trotherapie. pravaz est un des premier's qui ait pratiqué les injections sous-cutanécs. Marey et ROBINET ont perlectionné le sphygmographc, gràce auquel les mouvements du cœur et des artères s'enregistrent spontanément, en traçant des diagrammes, sur le papier:

Chirurgie. - Un illustre praticien lorme le trait d'union entre les deux générations, celle qui est antérieure et celle

1. A Paris ceulement. le choléra de 1832 a coủlé la vie á 18402 persomes; en 18\%?, a 19105 ; en 1854 , il n'a lat que 9217 vietimes. Ou prétend distinguer aujourd'hui entre le choléra asiatique, qui serail toujours importe, et le cholera nostras, forme acctimatée ou plus beinune.

2. Har exemple, les recentes applications de la d'Arsonzuisation au trattement de lartério-sclérose.

3. 'Hu cxouple, les propriélés chimiques et mëlicales de la noix de hola ont attres, dis 18y-, l'attention de lleckel.

i. Vir ci-dessus, pages 456 et 70 í.

¿. Vivir circessus, p. 163 , sur le sphyymometre. 
qui est postérieure à 1848. NÉLATON (1807-1873), fils d'un offieier tué à Waterloo, élève et aide de Dupuytren, chirurgien de Napoléon III, sénateur du second Empire, comblé d'honneurs politiques et académiques, plus célébre pour avoir soigné Garibaldi blessé au combat d'Aspromonte, fut un diagnosticien sagace, un prolesseur d'une clarté et d'une précision rares, un habile opérateur. On lui doit d'importants travaux sur la taille, sur la tubereulose des os. Il laui citer ensuite вєBERLE், qui a risqué, le premier en France, l'ovariolomie; pÉan, qui a pratiqué l'hystérotomie et l'ablation de la rate; LABBE et verneUil, qui se son distingués dans la chirurgrie de l'estomac; ollier, qui, en évi lant l'os, est parvenu à le faire se reproduire à l'intérieur du périoste; Alfred nicher, qui étudia toutes les blessures, toutes les fractures et luxations et qui, dans ses rélections de chair, refit jusqu'a des paupieres (blépharo. plastie). En 1900, l'Alsacien J. Bocckel, à hiopital de Strasbourg, a pu opérer l'ablation de l'estomae en réunissant par des sutures les tubes du système digestif qui, prar en haut et par en bas, aboutissent à cet organe. (La première opération de ce genre avait été faite à Zürich en 1897.)

Dans la chirurgie militaire, les grands noms de notre temps sont ceux de Baudens, chirurgien en chel de l'armée française dans les guerres d'Alrique et de Crimée; BÉGin, qui a étudié surtout les fractures; sÉDILLoT, qui s'est consacré à la chirurgie des os; PERRIN, qui a vulgarisé les anesthésiques; delonme, qui a, le premier, étudié méthodiquement l'action des projectiles nouveaux sur les os.

\section{Caractènes noureaux de la elnirurgie : les anticep-} tiques. - L'emploi des anesthrisiques marıue une première date dans l'histoire de la ehirurgie au xix siécle ${ }^{1}$ : "emploi des antiseptiques, environ quinze ans après, inausurè par le chirurgien écossais Listen, en marque une seconde.

Ce n'ilait pas tout que d'avoir alténué les souffrances des opélés. Wans les guerres de la République et de l'Empire, mème dans les guerres d'Afrique et de Crimée, la pourriture d'hopital et l'infection purulente tuaient plus de hlessés que les blessures mèmes. Or, les antiseptiquos

1. Voir ci-dessus, p. 466. 
sont destinés à prévenir ces complications infectieuses qui, au contact de l'air, naissent dans les plaies. Boerhaave, au xvile siècle, avait déjà signalé l'air de l'hòpital comme le plus langereux ennemi des blessés, et les travaux de PASTEUR ont mis en pleine lumière la raison de ce phénomène. Le pansement ouaté, destiné à empêcher l'arrivée des germes infectieux sur les plaies, a été appliqué, pour la première fois, avec un succès éclatant, pendant le siège de Paris, par Alphonse GuÉrin. D'autre part, en 185't, BOINET el DUROY avaient proposé, comme préservatif, la teinture diode; en 1859, COODY recommandait le permanganate de potasse; pendant la guerre de 1870 , on a employé l'acide phénique et d'autres produits dérivés du goudron. Aujourd'hui, on a recours à des substances plus efficaces encore, telles que l'iodoforme, dérivé de l'iode, le sublimé corrosif ou bichlorure de merene, dilué dans mille lois son poids d'eau, et surtont la teinture d'iode.

Par l'emploi des antisentiques, des milliers de vies humaines ont été préservées, non seulement dans les ambulances, mais dans les maternités, oú sérissait une contagion analogue et tout aussi meurtrière.

En même temps, grảce à ce préservalif, on a pu tenter des opérations dont les suites autrelois eussent été mortelles : par exemple, lablation du rein, de la rate, du larynx, de l'estomac, d'un des poumons, d'une partie du foie, etc. Mème l'opération de la taille, avec des procédés nouveaux, a pu ètre préconisée de nouveau par guyon, bien que celui-ci ait rendu la lithotritie très complète et rapide.

On a trouvé les anesthésiques locaux, qui limitent l'insensibilisation à la partie à opérer : par exemple, la cocaine, lc chlorure de méthyle, ete.

Une opération qui avait été, à l'age précédent, l'occasion de cruelles déceptions ', c'est celle de la transfusion du sang. Elle a été perfectionnée par llenri Milne-Edwards, Prévost, J.-B. Dumas, Claude Bernard, qui, en nemployant que du sang defitriné, ont réussi à diminuer beaucoup le danger.

1. Elle ètait souvent morlelle, comme on l'avail vo pour l'étndianl Legot, qui s'utait volontairement offert pour celte expérience et qui etalt mort vicline de son devouement a la science. On a donné son nom à une rue de Purs qui debouche dans la rue Soufdol. 
Branches diverses de la médecine et de la chirurgie. L'ophtalmologie est redevable de sérieux progiès à SERRE D'UzÈs, qui ètudia les phosphènes (1833), phénonènes lumineux, points ou cercles brillants, qu'on peut provoquer dans l'intérieur de l'ceil en comprimant son globe avec la ma n; Follin, qui popularisa chez nous l'ophtalmoscope, inventé par Helmholtz, de Berlin; à GIRAOD-TEULon, qui étudia lop. tique physiologique: à PH. Panas, qui publia ses Lecons sur les rélinites (1878) et son Anatomie pathologique de l'ail (1879).

Nous avons déjà parlé du daltonisme, affection qui consiste dans la confusion des couleurs et qu'on appelle alljourd'hui dyschromatopsie. Les employés de clıemin de ler, par exemple, qui en sont affectés, sont incapables de distinguer le rouge et le vert des disques. Falven, de Lyon, et REDARD ont perlectionné les appareils destinés à constater cette aberration du sens visuel.

Pour la médecine légale, Orfila a eu pour principal successeur Tardied, auteur des "Études de médecine légale sur la pendaison, la strangulation el la suffocation s (1865), de recherches sur les empoisonnements, l'aliénation mentale, etc., et, plus récemment, Brodardel, doyen de la Faculté de Paris.

Ulysse TRÉLAT, l'illustre chirurgien, et L.-F. CALMEIL ont publie sur la lolie des travaux de premier ordre.

Hygiène. - L'hygiène, qui n'est autre que la médecine préventive, doit ses progrès à Tardieu, Vernois, Alf. Becquerel, Michel Léry, Bouchardat, L. Le Fort, Proust. C'est par eux qu'elle cst devenue une science, fondée sur l'étude attentive des conditions topographiques et climatériques, des aliments, des animaux parasites, des miasmes pernicieux, des maladies contagieuses. Alors s'est créée l'hygiène speciale des villes ou des campagnes, celle du théàtre, celle de l'hôpital, celle de la manufacture, celle de la prison, celle de l'école, celle des diverses professions. On a employé les désinfectants, on a démoli les habitations insalubres, on a aéré, éclairé, purifiè. On a inventé des filtres, concus d'après les principes de Pasteur, pour débarrasser de tout élément nuisible l'eau polable.

On a signalé le rôle des moustiques dans la propagation 
des fièvres paludéennes et de la fièvre janne, des mouches dans ceile de la lievre typhoïde, des rats, souris, etc., dans celle de la peste. Autant de constatations qui éclairent la medecine preventive. On a fondé le laborutoire municipal de Paris pour analyser les aliments et les boissons.

BERTILLON el miquel ont eréé la statistique de l'hygiène.

тH. Roussel, sémateur, a bien mérité de l'humanite en proposant la loi de 1874 sur la protection des enfants en nourrice et en fondant la Societe protectrice de l'enfance.

un peut distinguer encore une hygiene militaire et une hygiène nacale. En 1826 , on avait assuré aux soldats, qui couchaient encore deux par deux, leur lit individuel; en 1832, on a mis tin, dans les casernes, à l'usage de la gannelle commune; en 18:5, on s'est fait une righle de revaceiner toutes les recrues qui arriraient au régiment; à partir de 18:\%, on a pourvu les hommes de cravates et de ceintures de laine, rétormé les coiffures lourdes et incommołtes, allégé le poils, jusqu'alor's écrasant, du sac.

MaLlot a fait connaitre la véritable nature des fièvres d'Al rérie et sauvé ainsi des millier's de soldats et de colons ${ }^{1}$. COLLIN s'est occupé des fièrres dans l'armée; BÉRANGER-FÉRAdD, ROCHARD, KERMORGaNT, des maladies coloniales (fièvres paludènnes, fiève jaune, etc.); zuBER (mort prématurément au Tonkin), des épilémies militaires et des mesures d'évacuation à prendre en temps de guerre.

C'est par l'hygiène, encore plus que par la médecine proprement dite, que la moyenne de la vie humaine, en France, s'est si notablement accrue. Au xvine siècle, elle n'élait que de vingt-trois ans: dans la période de $1823 \dot{a}$ 1830, de trente-deux ans et huit mois; depuis 1864, de trente-sept ans et six mois.

Rôle brillant des Facultés de médecine. - Du xvil au $\mathbf{x}$ vil ${ }^{e}$ siecle, presqne tout le progrès anatomique, physiologique, thérapeutique, s'est accompli en dehors de nos Facultés, mème celles de Paris et Montpellier, et a été souvent entravé par elles. Les principaux centres d'éludes mé- 
dicales, cétaient alors le Collège de France, la Société royale de médecine et l'Académie de chirurgie. La substitution aux anciennes Facultés des trois Écoles de santé, sous la Révolution, a changé le personuel, l'esprit, les méthodes. Rederenues des Facultés avec Napoléon, elles n'ont cessé d'être des agents énergiques du progrès. Celle de Paris peut s'enorgueillir d'avoir compté dans ses chaires des lommes tel; que les anatomistes Cruveilhier, Isidore Gcolliroy Saint-Hilaire, Pierre-Auguste Béclard, IIippolyte Cloquet, Laboulbène, Sappey, Mathias Duval, Farabeuf; les listologistes Robin, Ranvier, Cornil; - les physiologistes Longet, Vulpian, Gavarret, Jules Bécları, Ch. Richet; - Ies cliniciens Corvisart, Broussais, Bouillaud, Piorry, Laënnec, Bayle, Chomel, Rostan, Andral, Alibert, Rayer, Trousseau, Grisolle, Charcot, Béhier, G. Sée, Vulpian, Jaccond, Peter, Tanier, Pinard, Potain, Landolizy, llayem, Dieulafoy, Debove, Charrin, A. Fournier, Grancher, Bouchard; - les aliénistes Pinel, Ball, Tardieu, Joffroy, Raymond; - les hygiénistes Royer-Collard, IIallé, Netter, Boucliardat, Proust, - les professeurs de physique médicale, Gariel; de médecine légale, Orlila, Tardieu, Brouardel; les chirurgiens Desault, Lassus, Pelletan, Richerand; Percy, Dupuytren, Gerdy, Jules Cloquet, Jobert de Lamballe, Roux, Mralgaigne, Stanislas Laugier, Auguste Bérard, Jarjavay, Nélaton, Duplay, Lamnelongue, Labbé, Guyon, Verneuil, Ulysse Trélat, Péan, Allred Richet, Tillaux, Terrier, Le Dentu, hoyen.

Médecise vétérinaire. - L'anatomie des animaux domestiques a été étudiée surtout par LavocaT (de 1850̈ à 1864); leur physiologie, par bodley, chadvead et marey, qui ont iuventé le cartiographe pour suivre les mouvements du cœur, collin, d'Alforl, alibert. Les travaux de Dombasle sur les animaux de boucherie ont permis de modifier mène leurs formes et prouvé a l'aptitude de toutes les races domestiques à acquérir les perfections que l'homme a intérèt à leur communiquer o. charLigr a renouvelé la maréchalerie par un système plus rationnel de ferrure. NocARD a étudié la tuberculose et la tuberculine, qui en est le réactif (chez les bètes à corne). Les recherches sur les parasites et leurs métamorhoses ont permis de guérir certaines maladies 
en s'attaquant aux parasites qui les produisent : par exemple, à guérir la gale en détruisant son sarcopte. On guérit la pourriture du mouton avec lu fer, de l'écorce de saule, de la poudre de gentiane; on détruit les parasites internes ou externes avec le soufre, la benzine, l'acide plićnique. Plusieurs de ces progrès sont dus à Reynal, Rey, Gillebert, Mathieu.

Pasteur a été un grand vétérinaire, mème pour ces animaux domestiques qu’on appelle les vers à soie : il a enseigné le moyen de les débarrasser des parasites auxquels étaient dues les épidémies qui décourageaient les éleveurs du Midi.

Pharmacic. - Les progrès de la pharmacic ont marché du même pas que ceux de la chimie, qui l'a dotée de médicaments nouveaux et efficaces, tels que les alcaloïdes végétaux. L'ancien Codex pharmaceutique a été revu; on en a écarté les composés inefficaces, hizarres, d'une complication excessive: par exemple, on n'emploie plus la tète de vipère pour fabriquer la thériaque. Les vues scientiliques les plus liautes, avec Chatin, Planchon, Moissan, Bouchardat, Riche, Bourgoin, président à l'enseignement de nos Écoles de pharmacie, avec leurs cours de zoologie, botanique, physique, chimie, toxicologie, hydrologie.

Ouvrarifs a consllter. - Onviageste lluter, laye, bumas, Chevreul, Carns, Cavir, Daremberg, Hæser, Lenz, Rocharl, Parisel, cilés au ehapitre xu, 1'. 273.

Ravents rédirés a l'orencion de l'Exposition universetle de 1867. sur les prurres les siences:- de l'analyse muthématique, par J. Berlrand; - dela giométrie, jar lli. Clasies; - de la méanique appliquéc, par Combes, Philips el Collignon; - de lastronomie, par telaunay; - de la théorie de la chaleur, var Desains; - do la thermo-dynanique, par Berlin;--du magnélisme, electricilé, etc., par Quel; de la géologic expérimentale, par Daubrée; - de la straIigraphie, par Elie de Beaumont; de la mineralogie, par l)elafosse; de lit paléontolomie, par d'Arehiae; - des sciences zooloriques, par Milne-Edwards; - de la bolaninur. par Duchartre el Brongniarl; - de Ja médecine, far Bielard el Aseu- feld: - de la médecine véterinaire, par Magne; - de la chimrie, par benonviliers, Nelaton, Velpean, Guyon, Labbu: - de l'hytricone, par Buchardat, Michel Levy, Le Roy de Miricourt. - Comparer aves la série publuee al loceasion dir l'Expos. mniv.

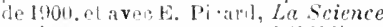
moterne et som elat actuel (1910). -

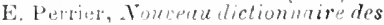
scuences et de liners applicretions.

J. linger, Hist. des mathe'matipues $1: 100$

lluzeau el Lanaster, Bibliographie seinerale de lastronomie (Isas !)!).

Vaison, La rie et les traren d'A $^{\prime} \mathrm{m}$ pere. - Th. Dumoncel. Le teliphone et le phonouraphe 1.Sy?. - A. Cazin, La chalem: litincelle électrifue (1sia) - F. Marion, Les merveilles de l'optirue. - R. Ratau, Lincoustique 1ntia). - Chassirny, Mommel throrique et matique didectriciti 19021. - A. Broca, La tiligraphie sansfil (190i). - Van Dam, La telé- 
graphie sans fil (1908). - Turpam,
les applicat. pratioues des ondes électrifues (1908). - II. Poincaré Confirences sur la tilegr. suns fil (1909). - E. Monier, La tilizr. sans fil, la télémecanique it la téliph. sans fil it la portée te tout le monde (19:1). - Coll Bonlanger et com ${ }^{\mathrm{t}}$

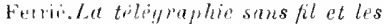
ondes electrinies 1910 . - C. Petit et Le Bouthillon, La trlétr. sairs fil, la teliph. sans fil. - l. Fournier, La tileyr. sans fil (1912).

Chrolsan, Traite de physique $(1906)$ - - O. Manvillo, Les drconcertes morlernes en plussique (1901. L. Pointare, Lil phiysinue moderne, son évolution (1906).

Radau, Le matmetism". - Hospitalier et Nontpellier, L'electricite it l'Erposition de fono. - Forean le Contmelles, Les applications te lélectricite. - Ch.tid. dilillaume, Les rayous $I^{2}$ et la photornaphie in travers les corps opranes $(1 \mathrm{~S} \% \mathrm{i})$ - G. Vitoux. Les rayons X et lu potoyraphie de l'incissble (1sati). - L. Anherl. Les rayons I't la photonraphic de l'inrisible (189S). - C. Rurckert, Lu pholographie des couleurs (1900). A. Bercet, La photogmphie des couleurs 1901): Li' Rudium at les nouvelles rulintions (rayons $\mathrm{I}$ et $\mathrm{V}$ ? (1901). - L. I'oncare, L'ilectricite 1907 - G. Dary, A travers lélectricite.

Wurtz, Hist.des theorit's chmiyues depuis Laroisier. - J.-B. Dumas, Lecons su. la phitosophie chiminus.

\section{- Fremy, Encurlopestie chiminne. -}

Wurtz, fictionnuire de chimue. Maxime llesene, La pondre is cunom et les noureaur rorps cxplosifs (1-80). - Champion, La demamite et la ni tro-ylucerine. - M. Berthelot et Jungfleiseh, Traiti pism. de chimie oryanique nomx edit, 1908).

Zurcher et Margalle, Les mitrores (1860). - L. de Latunay, La science gcoloqigue 1905 . - A. Ha Lanuarent (1906); E. Haugren cours, Truite de grologip (tous denx très specianix). A. Liaroix, Les éruptions de lie Montaqne l'elée (1904). - A. Berat, Hetrorologie et physique dic globe (1901. - Erf. sness, La face lle la tere. lladuit par L. de Nargerie, (1897.1942). - L. Vitous, drtillerite ot mitroralorie. - G. Tissandier, La honilli: les Fossiles (ISxib). - Magdeleine de saint-Agy, Histoire des scipnces maturolles 18:1).

Béclard, Elore de Clazule Bernurd, - Vallery-Radol, M. Pasteur, II istoire din suvant par un ignorant. Da méme, La rie de Pastear (j) important 1900 - beny Gochin, L'Evolution et la lie (sur les Iravaux de 1'asteur). $\rightarrow$ E. Buclanx, t'isteur (1896). - Grancher, l'testeur et la medecine contemporrine lievursciontifique, 23 avril 1893.- A. Marje, La raqe (1901). - J.-B. Dumas, Eloges de Faralay, Ballard. Ponze, V. Regubult, Istdore Geoffoy SaintIlilaire, Auguste Bérard, lés deux Brongniart, les denx Sainte-Glaire Deville, Cuvier, Flourens, ete. Eloges le savants, par Guvier, Flourens, J. Berlrand, Berthelot, ete. Biot, Melanges scientifiques 185.2). - Clande Bernard, Rappors sur les progris et la marehe de la phvisolocrit ginérale en France (1865). E. Gley, Essais de philosuplize et d'hist. de la Biologie 1900), et Rupport sur la soretet de biolorie... de 1849 a 1900 - Y. Delage, structure du protoplasma, héritite, bioloyie generale (1805). - R. Guinton, Leau de mer mileeu organirue $(190) \mathrm{t})$.

Chenu, Servicemidico-chimurgical te Crimie: Statistinue de la campagne ditule; Horlalité dans larme. - Guardia, IIst. de la médecine (1S81). - Fournip, Application des sciences a la midecine (1878). - Dechambre, Dicl. encyclopitligue des Siripnces médicules. - J. Cirasset, L'solution midirale en Franee an $\mathrm{X} / \mathrm{X}$ sificle $(\mathrm{t} !(100)$ - A. Pontier, Hist. de lie purmacie (1900). 


\section{CIIAPITRE XXXIII}

\section{LA TRANSFORMATION ÉCONOMIQUE}

\section{Les grandes applications des sciences.}

Progrès de la navigation à vapeur. - C'est en 1862 zue fut constituée chez nous la Compaynie générale transatlantique, par les frères PEREIRE. Le 14 avril, la Louisiane, un paquebot de cette Compagnie, partait de Saint-Nazaire, et, en treize jours, atteignait la Martinique.

Les perfectionnements apportés à la construction, l'adoption de l'hélice et de la chaudière tubulaire, le fer et l'acier substitués au bois, les progrès le la mécanique en toutes ses branches, permirent de donner des proportions inouies aux navires de commerce ou de gnerre. En 185s, l'Angleterre commence à construire ses paquebots géants : le Léviathan ${ }^{1}$, pourvu d'une machine de 3000 chevaux.

La France ne resta pas en arrière : sais parler de nos vaisseaux de guerre ${ }^{2}$, elle lance, en 1866, deux steamers géants, le Napoléon III, paquebot à roues, de 1500 chevanx. et le Pereire, paquebot à hélice, de 1250 chevaux; mais ces deux bitiments, avec leur jaugeage de 5 à 6000 tonnes, restaient en deçà du Great-Eastern, qui en comptait 20000.

Aujourd'hui on construit de grands paquebots, comme, chez nous, la Procence, de 191 metres le long, jaugeant 13000 tomnes ${ }^{3}$, dereloppant une vitesse de 22 mouds à

1. Appelé aussi le Greut-Eastern, deuxitme du nom.

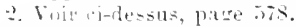

3. Ce-proprtionsont te lepassies pat les bateanx allemands; dis $190 \%$,

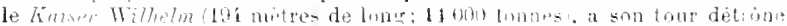

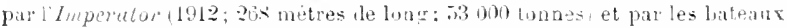
anglats (honic et Titanic 259 mitres: 43000 tonnes), le dernier coulé par un l.eberg en [ol: a son prenier royage. 
l'heure, ou la France 1912 ; 220 mitres de long, 23000 tomnes, 23 nocurs). On lianchit aujourd'hui l'dtlantique en moins de cing jours.

Notre marine marchande, en 190?, jaugeait 1400000 tonneaux, dont 800000 pour les vapeurs. Mais elle n'est plus qu'au $\tilde{5}^{\circ}$ rang, après l'Angleterre (11300000 tonneaux, dont plus de 10 millions pour les rapeurs, les btats-Unis (7 300000 tonneaux), l'Allemagne (2 800000 tonneaux), la Norvège ( 1500000 tonneaux), et celte décadence relative s’agrave, malgré les primes dunnées par lítat.

La navigation a pris sur toutes les eaux une activité prodigriense : jour et nuit, la mer est battue par les roues ou par les lidices des navires le gnerre et de commerce.

Les chaudières des bateaux à vapeur, pour produire -ette vilesse énorme, dévorent des quantités énormes de houille. Il a fallu établir partout des députs de ce combustible. Ordinairement, ils sont ouverts aux navires de toutes les natiors; mais les États militaires venlent avoir leurs dépôls is eux : voili pourquoi la France, l'Allemagne, l'Angleterre unt tenu it planter leur pavillon sur tant d'iles et tant de rivages laus toutes ies parties du monde (Voir Suppl.).

Les phares. - Il a failu songer à éclairer plus complètr:ment les cotes. Au xvil ${ }^{\circ}$ siècle, nos phares, comme ceux de lantiuuiti, n'etaient encore que des foyers de bois ou de charbon brûlant dans une cage de fer, ou des lampes firmeuses enlermées dans des lanternes de verre. En 1782, on accrut leur lumière au moyen de réflecteurs.

En 18:2, Fresnel les avait munis de lentilles à échelons qui concemtraient les rayons et projetaient sur la mer un laisceau lumineux visible à seize lieues de distarce. On les a encore perfectionnés : il y a des phares ¿ $i$ leu fixe, à feu tournaní, à éclipse, à lumière blanche ou colorée : si bien que, dans la nuit la plus obscure, un narire, da la seule vile d'un jliare, sait exactement derant quel port ou devant quel érucil il se trouve. L'emploi de la lumière électrique a centuplé leur puissance d'éclairage. Aujourd'hui, les ribes de France sont comme dessinées la nuit par une linge de 400 phares ou leux divers. Il en est de mème pour les côtes de tous les pays civilisés.

percoppenent des lignes de chemins de fer. - Les 
six graudes Compagnies, Nord, Orléans, Paris-Lyon-Marseille, Est, Ouest, Midi, furent constituées délinitivement de 18522 à 1857 : quelques-unes par la réunion de plusieurs compagnies anciennes.

Elles s'étaient bornées d'abord à construire les lignes considérées comme les plus productives : celles-ci constituent aujourd'hui l'ancien réseau. Sous le second Empire, on songea à desservir un plus grand nombre de localités : comme les Compagnies s'y refusaient, estimant que les lignes demandèes seraient peu productives, l'État intervint, accorda de plus larges subventions et garantit aux anciennes Compagnies ou à de nouvelles un minimum de revenu sur ces lignes, pendant cinquante ans. C'est ainsi que fut construit, grâce aux lois votées de 18599 à 1868, le nouveau resseau. Enfin l'État a constıuit ou racheté un certain nombre de lignes, en général peu productives, mais jugées utiles au point de vue commercial ou stratégique. Il les exploite directement : elles forment un troisieme réseau, le réseau de l'Étut. Un quatrième réscau est formé par les lignes d'interét local, à voic large ou étroite, dont les départements ont pris l'initiative.

La France a conslıuit des chemins de fer en Algérie, en Tunisie, au Sénęal, au Dahomey, à Madagascar, en Indo-Chine; l'Angleterre, dans l'Indoustan, en Australie, dans l'Afrique australe; la Russie, jusque dans les steppes du Tukestan, et, par le Transsiberien, de l'oural au golfe de Petchili. Les États-Unis ont jeté des lignes qui vont de l'Atlantique au Pacifique, et les colonies anglaises du Nord ont construit une ligne parallèle à celles-là, le Canadian Pucific, achevé en 188't. Le Transandin unit Buenos-Aires à Valparaiso. Bientôt le globe terrestre sera comme enveloppé d'un réseau de fer, qu“interrompront seulement l'Atlantique et le Pacifique, sillonnès eux-mèmes par les bateaux à vapeur.

En 18:8, nous avions en exploitation 2200 kilomètres; en 18:1, 3 35千; en 18\%0, à la clute de l'Empire, 17 \$39. La France compte aujourl'hui plus de $\$ 8000$ kilomètres de chemins de fer en exploitation, et beaucoup en construction ou en projet (trois trauspyrénéens, ligne Frasne-Vallorbe à travers le Jura, etc.). Ils ont coùté, tant ì l'État qu'aux Com- 
pagnies, une douzaine de milliards; ils donnent une recette de 1700000000 fraues et un bénélice net de 729 millions. Il y a aujourd'hui, sur la surface du globe, plus de $700000 \mathrm{ki}$ lomètres de voies lerrées. Or, en 1830, on n'en comptait que 187, dont 91 en Angleterre, 30 en France, 66 en Amérique!

Chemins de fer framçais a l'étrangrer. - Ce sont les ingénieurs français qui ont initié plusieurs des nations européennes aux bienlaits de la locomotion à vapeur. coldignon a présidé à la création des chemins de fer russes. D'autres ont doté le Portugal, l'Espagne, les pays turcs et danubiens, de leurs premières voies ferrées. La ville de Porto, par exemple, doit à EIrret son magnifique pont du chemin de fer qui, sur une seule arche de métal, lranchit l'immense ravin du Douro. C'est là une forme nouvelle de l'expansion du génie national, comme le fut en Europe, au moyen âge, la construction des cathedrales, et, depuis la Renaissance, la construction des palais et châteaux de plaisance.

Travanx dart. - Ce sont surtout les chemins de fer qui ont donné naissance aux merveilles les plus étonnantes dans l'art de construire. C'est pour eux qu'on a percé ces tunnels comme celui du Crèt d'Eau sur la ligne de Lyon à Cieneve, qui a 3900 metres de longr; celni de Blaisy-bas, qui en a 4100 ; celui de la Nerthe, qui en a 4620 ; celui de Roanne a Tarare, qui en a 6000 ; celui du mont Cenis, exécuté de 1857 a 1871 , qui en a 12 220; celui du Saint-Gothard (1882; 1:980 m.), ourre de l'ingénieur colladon; celui du Simplon $(1905 ; 19800 \mathrm{~m}$.). C'est pour eux qu'on a construit ces viaducs colossaux, plus imposants que ceux des Homains, dont les plus remarquables en France sont ceux de l'Yvelte, de Poix, de Morlaix, de Jyon, celui de Tarascon-heaucaire, œurre de l'ingrinenr desplace, celni de Chammont, qui a 696 mètres de long et 50 de hamleur, ceuvre de zeiller et DEcomble C'est pour eux que les ingénieurs anglais ont creusé des tumnels sous le lit mème de la Tamise. C'est pour eux que l'on a tracé le réseau aírien de New-York. C'est pour eux qu'on a jeté sur les fleures ces prodigieux ponts de fer, comme ceux de Bordeaux-SaintJean, d'Argenteuil, de Garibit, du Viaur, des Fades, en France, ceux de lat Severn et de la Tay en Angleterre, celui de 
Saint-Louis sur le Mlississipi, celui de Vietoria sur le SaintLaurent, qui n'a pas moins de 3144 mètres de long, comme le pont suspendu de New-York it Brooklyn (1052 mètres). Ciest pour eux quon a inventé ces ponts tubulaires, dont le premier en date, le Britannia-Bridge, a été construit entre la Grande-Bretagne et l'ile d'Anglesey par Robert STEPHENSON (18千7-1857), et dont nous possédons, dans le pont de Màcon, un spéeimen. Parmi les plus hardis projets de notre temps, citons le Mitropolitain de Paris, dont carétien a donné le premier projet en 1881. Citons aussi le projet de la traversée du Pas-de-Calais, sur une longueur de trente kilometres, soit au moyen dinn tunnel sous-marin, comme le proposa Thomé de Gamond, soit au moyen d'un immense pont de fer.

Inventions diverses. - Que de formes ingénienses a prises ce mole de locomotion! Nous avons eu, en 1859 , le chemin de fer atmospherique de Saint-Germain, initation du chemin de fer irlandais de lingstown (15'8). Un a escaladé les pentes les plus abruptes, soit par le système atmosphérifue de mékarski. SÉguter é fell: Cenis (1868). Righi (Suisse), mont Washiugton (Amérique); soit par le systène funiculaire: Vésuve (1880). Annoux a lait prévaloir son système de locomotion et de wagons articulés (pour les courbes raides. gIRARD a préeonisé son systeme hydrumlique. Un utilise aussi la traction electrique (métropolitain de Paris).

Perferionnements du matériel. - Peu à peu, on a amélioré le matériel, complété le système des signaux et avertisseurs, commencé à substituer les rails d'acier aux rails de fer. La puissance de la locomotive a été augmentée par Gillard, qui a inventé l'injecteur; par Farcot, Folleault, Charbonnier, qui ont perfectionné le régulateur de Watt; par Le Chatelier, Ricour, Fareot, qui ont créé des types nouveaux de machines.

On a construit des wagons spacieux et commodes, même des wagons-lits el des wagons-saluns. On a accéléré les vitesses, créé les trains-éclairs, et, depuis 1883, l'expressOrient fait en 75 heures le trajet de Paris a Constantinople. On a inventé les freins, soit électriques, soit atmosphériques, pour arrèter presque instantaniment les convois. Sur

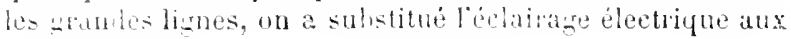


lampions lumeux. On s'est décide it chatler mème les wagons de troisième classe. (Voir Suppl.).

\section{Développement des serviees télégraphiques et télé-} phoniques. - Les essais télégraphiques, commencés en 1845 sous la direction de Foy et Bréguet, avaient pleinement réussi. Bientòt, sur les voies ferrees, sur toutes les routes importantes, se dressèrent les poteaux qui soutiennent les fils de ler, comme les lignes d'une portée de musique.

Notre riseau télégraphique de France avait, en 1:08, un developpement de 17000 kilomètres, formé par plus de 800000 hilomètres de fils de fer ${ }^{1}$. Tantôt ces fils sont fixés à des poteaux et forment le réseau aérien; tantôt ils cheminent sous la terre ou sous les eaux et forment le résertu souterrain 2 .

Les bureaux télégraphiques appartiennent soit à l'État, soit aux Cumpagnies de chemins de ler. Cienx de l'État ont expédié, en 1908 , près de $\$ 5$ millions de télégrammes, qui ont produit une recette de 55 millions et demi de lrancs. Ce service prend dannée en année plus d'importance, car, en 1876, le nombre des télégrammes n’était que de 8 millions; en 1855 , il n'ètait que de 3 millions; en $183 \% 1$, seulement de neuf mille.

Concurremment au réseau télégraphique s'est constiucé le réseau téléphonique. En 1898, il comprenait deja 17000 kilomètres de lignes, 190000 kilomètres de tils et avait lonné lieu à 138 millions de conversations. Depuis la mise en train, en 1899, des réseaux téléphoniques lépartementaux, tous ces chiffres ont pris d'énormes accroissements : 129 (60i) lim. le lignes, plus d'un million de km. de fils.

Lélectricité ne transmet pas seulement les dépèches d'un buut à lautre du continent; elle lranchit les mers. En 18301 on a pose le prumier cable sous-marin entre Dourres et Calais. En 1866 , le gigantesque paquebot Great-Eastern a posé le fremier eáble entre l'Mrlande et Terre-Neuve, cest-

1. Pour le monde entier le léveloppement, en 190s, chil de vlas de 2 millinns de kilomitres de ligues.

2. Environ 200 kilometres s.nt desservis par un systime qui ne doil rien a l'électripté : c'est le réseau pneumutqque; les telèrammes sont placédans des cylindres qui, aspires par des pompes puissantos, pareonrent l.. petits tannels cylindriques. 
à-dire entre lancien et le nouveau monde. En 1869, nous avons établi notre premier cable transatlantique entre Brest et Saint-Pierre (près de Terre-Neuve). Aujourd'hui, toutes les mers et tous les océans sont traversés par des câbles : les nouvelles se transmettent, avec une vitesse presque instantanée, de la Chine à Paris, de Paris à SanFrancisco, au Chili, à l'Afrique australe, à l'Australie ${ }^{1}$.

Perfectionnement de l'éclairage an gaz. - En 1878, Paris était déjà éclairé par 34000 becs de gaz; en 1897, par 66373 bees relevant des types les plus divers.

En 1860 , les chimistes DuMas et REgNAduT avaient réalisé un perfectionnement destiué a augmenter la puissance des appareils. Puis tessier DE MOTAY imagrina de donner plus d'éclat a la flamme en faisant arriver sur elle un courant d'oxygène : c'est l'éclairage à la lumière oxhydrique.

Vers 1878, quand le gaz fut menacé à Paris par la concurrence de l'éclairage électrique, les inginieurs Brisae, Mallet, Audouin, installerent les becs intensifs ou bccs soluires, lormés de la riunion de plusieurs becs dont un système de leutilles augrmentait le pouvoir éclairant. Ces lecs consommaient 1000 litres de gaz à l'heure. L'essai en fut fait pour la première fois, dans la rue du Quatre-Sep. tembre. L'invention des hees aver a introduit, même pour l'éclairage privé, dans la lumière du gaz, un perfectionnement nouveau : il est dù à l'introduction dans la flamme d'un manchon formé d'oxyles métalliques particuliers qui augmentent l'intensité lumineuse.

Laretylène. - Un sérieux concurrent s'est révélé pour cet éclairage, comme pour l'éclairage au pétrole; c'est I'éclairage à l'acétylèn’, gaz découvert en 18,31 par G. Davy, étudié depuis 186:- par Berthelot, el qui s'obtient au moyen du carbure de calcium décomposé par l'eau. Son pouvoir éclairant serait 10 à 15 fois celui du gaz extrait de la houille; il peut ètre obtenu, en utilisaut les chutes d'eau naturelles employées pour la production du courant électrique, à des prix extrémement bas : 30 centimes par mètre cube. Gràce à un autre procédé inventé par Ber-

1. En 1905. Les Lélegraphes sous-marins atteignaient, dans le monle entier, un developpement de $\mathbf{1 5 0} 000$ kilométres, dont 280000 de cảbles anglais. 
thelot, l'acétylène peut être converti en un alcool dont le prix reviendrait, assure-t-on, à 30 centimes le litre.

L'éclairage électrique. - En 1813, Davy, en mettant en présence deux pointes de charbon, fit jaillir entre elles la lumière électrique.

L'intensité de cette lumière électrique a été augrmentée depuis par les perfectionnements des physiciens ou ingénieurs francais Foucault (1\$+1), Fernet (1868), Serrin, Dubosq, Jamin. Elle nous a donné un nouvel et puissant agent d'éclairage. En 1878, lors de l'Exposition universelle, furent inaugurés à Paris les appareils de Jablochkolf appelés bougies électriques. Déjà REGNIER, pour les usages domestiques, arait construit une lampe, constituée par un charbon que l'électricité rendait incandescent. L'Américain EDISON et l'Anglais sWaN nous ont fait connaitre, en 1851, leurs lampes électriques, ampoules ren lermant un mince filament. La lumiere clectrique finira par itre mise à la portée de tout le monde, s'atiptant it tous les usages, alimentant la petite lampe de l'ouvriere aussi bien que les girandoles des salons, les lustres des salles de thètre, les phares des rivages, les vastes chantiers, les places publiques.

Perfertionnement de la inmpe dn mineur. - La toile métallique de la lampe Davy avait l'inconvénient de liminuer l'éclat de la lumière : souvent l'ouvrier, impatienté de ne pas voir assez clair dans son travail, déchirait le tissu protecteur, sexposant ainsi, lui et tous ses compagnons, aux plus terribles dangers. Combes et GAIFre ont construit la lampe électrique du mineur, enfermée dans un cylindre de verre, qui garde la flamme de tout contact avee le redoutable grisou.

Les aérostats. - L'aérostation, plus savante de notre temps qu'au $x$ rinle siècle, ne s'est pas inontrée moins hardie, ni mème moins téméraire. Aussi continue-t-elle à enregistrer des martyrs : Deschamps est tué à Nìmes (1853) par une rupture de son ballon. Il y a eu peut-être vingt mille ascensions. Arban, les Godard, Nadar, qui, en 1867 , construisit le Géant, se sont illustrés lans celte audacieuse carrière. L'ascension la plus tragique de nos jours a été peut-être celle de Crocé-Spinelli et Sivel. Ceux-ci, en 18\%, šétaient élevés à 7800 metres pour laire des 
expiriences physiques et météorologiques, et étaient revenus avec de précienses observations sur la raréfaction de l'air ì ces hauteurs. L'année suivante, comptant sur leur provision d'air comprimé, ils tentèrent, avec Tissandier, de s'lever plus haut; mais celui-ci redescendit seul avee les vadavres de ses denx compagnons de voyage. En décembre 189 '́ Berson s’élera jusqu'a 9100 mètrés.

Dupais, l'exploration des hautes régions de l'atmosphère a été poursuivie surtout à l'aide de ballons non montés, nommés ballons-sondes, pourvus d'appareils enregistreurs.

En 1896, une entreprise, encore plus audacieuse que toutes les précédentes, fut tentée par le Suédois Andrée, qui se faisait lort de passer par-dessus le pôle nord. Les régrions polaires sout restées muettes sur sa destinée.

Laérostation a rendu des serviees à la défense nationale comme à la seience. On se sowvient du ballon captif qui flana sur Paris assiégé pour reconnaitre et signaler les mourements de l'ennemi, et des ballons libres qui allèrent au loin listribuer, en 165000 dépèches sur papier pelure, des nouvelles de la capitale, transportèrent des messager's et mème un des chel's du gouvernement, Gambetla. A la même époque, le célèbre ingénjeur dopur DE Lome, lans le dessein de maintenir la direction de l'aérostat sensiblement en ligne droite, construisit un ballon de forme allongèe, auquel des espèces de grandes rames, actionnés prar huit hommes, donnaient une sorte de direc. tion. En 1883 les frères Tissandier firent une ascension avec un appareil analogue où la force humaine était remplatic pal la lorce électrique. Enlin, nous avons ru les efiorts les capitaines (depuis colonels) Krebs et Renard pour loter l'armée l'un ballon dirigonble. Dejà en 1s.... à J'étahlissement militaire de Chalais', avait été construit Ie ballon lit Frane, qui. par un vent modéré, put évoluer lans tontes les directions et, pour la premiere fois en navigation arienue, accomplir un circuit fermé? 2

1. Lotablistment militaire de Chalais, dans le bois de Meudon, a .lé

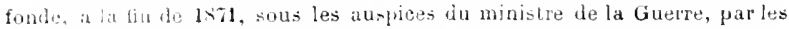
soins dia enhutel Laussedat, qui eut alors parmi ses subordonnés ef callaboratipurs kitebs et Renard.

2. En 1960. txpériences aualogues en Pussie (Dnnilerski) et en Allemagne 
Le scaphandre. - Le scaphandre, dont le non wrec signifie a homme-barque ", n'était pas inconmu des temps anciens, comme en témoigne une miniature du $\therefore v^{e}$ siècle publiée par Buthelot. Il lut réinveuté, en 1797, par l'Allemand K'lingrer et perfectionue par l'Anglitis Siebe (18:9). Le Français CABIROL (18:\%) lui a douté la forme que nous Iu connaissors. ROdQUAYRoL et IENAYRousse y ont ajouté le réservoir d'air comprimé. Puis un l'a muni d'un appareil électrique permettant au plongeu de communiquer avec le monde superaquatique.

Progrès de la photographie. - Gràce aux perfictionnemeuts apportés à l'invention de Niepce et de Wdyllere, on est arrivé à avoir des reproductions plus nelles, moins altérables à l'air et à la lumière, d'une finesse atmirable de modelé, diune réelle valeur artistique.

(comte Zeppelin). En 1905. le ballon dirireable de l'metenteul Julliot est

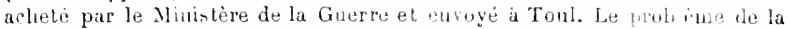
direction des ballons, depuis Monge, Neunier, Deghen, a ocrupu uolamment Lennox (183i, qui construisit l'Aigle; Peiin (1850, qui employa jusqua qualrc ballons réuis par une sorte de pont et une sorte d quilie; Delamarne (I\$i6), ' ]uj munil son aérostal de tames en forme f helives: Henri Giffard (1651), qui essaya d'utilker la vapeur. - Le Congrès d'aérustution de 1889 a donne auxballons dirigeables le nom l'aronats. - Les aéronuts, actionnés autrefois a l'ajle de furtes piles électriques atilisent mantenant des moteurs a pétrole. Ce qui caraclérize le hallon sim le ou meme muni d'un systeme de propulsion, cest quil reste, y compin ses atedesoires, plus liger que le colume d'air quill liplace. Une autre voit thas

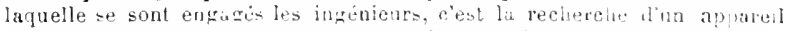
plus lourd que l'air, mais eapable, par la seule foree de son intrintsme, de se soutenir dan- l'air et de s'y diricer. D'ahort on a crastruit des appareils volauls, composés d'un parachute et d'hélipes ou lailis. Cient arec une de ces marhines que Letur: se tua en lkif et le liroof en 1574. On se mit alors a éturlier les organes qui permetteut à l'usand de voler. Ces études furent ponacées trés loin par le professem Marer. pal

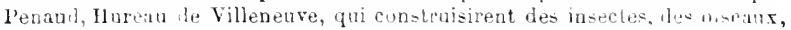
des chauves-souris qui s'èlevaient et planaient dans l'air. Ce- joucts ont élé les enbryons de l'aéroplane aetuel. (Voir Suppl.)

En somme, l'aérostal dirigeable. tels que ceux de Dupny dis Line, des flice Tisandier. de Krebs et Renard, de Santos Dnmont, du coml Zepprlin, ete., est une combuaison du balion proprement hit et dialte ou helices aclionnee par une force motrue. Ce mode de locomuliou est. $=1$ lon veut, de laviation mixte.

La France possede deja toute une lotulle de durgeables: l'Allomagne

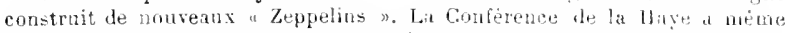
eru devoir proposer cutaines pestrietions a l'emplos maliate de ces engins. 
La photomraphie instantanée est parvenue à saisir un cheval au galop, un oiseau dans son vol, une foule en mouvement.

Des arts nouveaux sont sortis de linvention première: la photogravure ou helingrazure, ereies par Niepce de Saint-Victor et Dormé; - la phototypie, la photolithographie, par Lerebours, Lemercier, Barresvill; elles ont permis la publication d'estampes à bon marehé et donné l'essor aux publicalions illustrées; - la photographie des couleurs, qui donne des images colorées : elle est lue surtont aux recherches de Clerk Maxvell (1861), d'E. Becquerel, Ch. Cros, Ducos du llauron, qui trouverent la photographie intirecte des couleurs, par la superposition des images; puis aux recluerches dı prolesseur Lippmann, qui, par la méthode interférencielle, obtint cette photonraphie par le molle direct; - l'hélioplastie, photoglypt ie ou photoplastographie, qui donne des images en reliel, inventée par l'oiturin; - la plotographie microscopique, inventée par Dagron, perfeetionnée par Jucos du llauron, par les prolesseurs Joly et Lippmann; la photographie sous-marine, à l'aide duscaphambe, mise en pratique par Boutan, professeur it la sorhome. (Voir Suppl.)

Les applications de la photographie sont innombrables pour les sciences astronomiques, physiques, médicales, naturelles, pour les industries, pour la recherche meme des criminels (fiches anthroponétriques de Bertillon).

Une des applications les plus curienses de la plotographie est le cinemutographe, inventé par Ducos de llauron (186\%) et les l'rères Lumière (après le kinetoseope d'Edison), et qui, par une succession très rapile d'images, permet de reconstituer des scènes de la vie quotidienne, donnant l'illusion de la vie, surtout quand la collaboration du phonosraphe permet d'entendre la voix même des personnages que le cinematomraphe lait se mouvoir sous nos yeux.

Nouveaux puits artésiens. - En 1853 fut entrepris le second puits artésien de Paris, celıi de Passy, par l'entrepreneur saxon BIND. On atteignit l'eau à 578 mètres. C'est surtout en Algerie, dans la région des plateaux et dans la région salıarienne, que la possibilité de faire jaillir à la surlace du sol les eaux souterraines peut rendre d’immenses serrices; car c'est l'absence d'eau qui, dans la plu. 
part des cas, constitue le désert. C'est là qu'en 1856, sur l'initiative du général Desvaux, commencèrent les premiers forages : ils lurent exécutes par les ingénieurs Charles LAURENT et Jos, avec un matériel envoyé par la maison Degousie, de Paris. Des oasis nouvelles lurent créées, les anciennes se développèrent; une vie et une richesse nouvelles furent créées dans les solitudes arides du Sabara.

Percement de l'isthme de Suez. - Avec la dépense de charbon, la longueur du voyage a plus d'importance qu'au temps des navires à voiles. Trouver moyen d'abréger le parcours, c'est économiser au commerce des frais éuormes : si cher qu'on lui fasse payer un passage nouvellement ouvert, il y gagne encore énormiment.

C'est en 1803 que se lorma, sous la présidence de FERDINAND DE LESSEPS, la Société pour le percement de l'isthme de Suez. Sa persévérance finit, malgré la vive opposition de l'Angleterre, par obtenir l'autorisation du vice-roi d'Égyple et de son suzerain, le sultan de Constantinople. En 1858, on commenẹa les travaux, qui durèrent dix ans. En 1869 eut lieu l'inaururation solennelle. Le canal part de Port-Saïd, sur la Méditerranée, et aboutit à Suez, sur la mer Rouge. Il a 162 kilomètres de longueur, sur une largeur de 60 à 100 mètres et une prolondeur de 8 à 9 mitres. La traversée dure de treize à quatorze heures. Il permet d'aller en ringt ou trente jours de Marseille a l'Indo-Chine. La progression des recettes (navires et passagers) encaissées par la Compagnie du canal permer d'apprécier le progrès dans la fréquentation de cette voie nouvelle : en 1870 , elles ont été denviron $\$ \mathbf{~ m i l l i o n s ; ~ e n ~}$ 1880, de 37 millions et demi; en 1890, de 67 millions; eu 1909, de 120 millions. En 1909 il a passé par le canal 4239 naviles jaugeaut eusemble $1: 300000$ tonnes.

Le prercement de l'isthme de Suez a épurguc aux navires qui vont d'Europe aux Indes et a la Chine l'ohligation de faire le tour de l'Afrique. Le percement de l'isthme de Panama permettra d’éviter à ceux qui vont de l'Allautique au Pacifique l’immense détour par l'Amérique du Sud. On sait à quel desastre financier ont finalement abouti des études incompletes, des assurances mal londées et le gaspillage des ressources. Les Elats-Lnis out repris l'uuvre. 
On a également percé l"isthme de Corinthe en Grèce et songé à percer celui le Kra lans l’Indo-Chine.

\section{L'agriculture.}

Cultures. - Les progrès de l'agriculture se sont marqués surtout par ceux de la culture du froment, comparée à la culture des céréales de moindre valeur, comme l'épeautre, le seigle, le sarrasin, le millet. L'épeautre est reloulé dans le nord et le nord-est; le seigle a reculè devant les marnages et ne se maintient plus que dans le Massif ceutral, le Morbihan, la Champagne pouilleuse; le millet n'est plus guère cultivé que dans le Morbihan et le Finistère; le sarrasin s'est concentré dans la bretague, la Normandie, la Marche, le Linousin, la partie centrale du bassun dı Rhòne. Le Iroment, au lieu de 4 millious et demi d'hectares en 1815 , en oecupait en 1909 i millions et demi; an lien de $\mathbf{t} 0$ millions d'hectolitres, il en fournit en moyenne 12: millions; au lieu de 9 hectolitres par hectare, il en produit 18.

Les prairies artificiolles, trelle, luzerne, sainfoin, resce, pois, lèverole, ont lait d'énormes prosrés. La betterave, qui noecupait que 38000 hectares en 1840 , en cecupe environ $9000000^{\mathrm{i}}$. L'industrie marấchère rs! pratipuée par 1300 propriétaires, rien qu'à Paris et dans sa banlicue. Dans la culture de la vigne, on a presque partout amélioré les espèces de plants: dans le Midi, on a lutté avec courage, par toutes sortes de procédés ingénieux, nutimment par le greffage sur plants américains, contre la ruineuse invasion du phyllorera et des autres parasites de la vigne. Celle-ci, qui n'occupait ju'un million et lemi d'hectares au xrmue siècle, en occupait en 1910, malgré tant de pertes subies, 1 fit 000 . L'extension domee a la cullure du tabac, du houblon pour la bièe, du mairer prour les vers a soie, des plantes indus-

1. La betterave n'est pas seulement utilisée pour l'industrie des sucres et des alcools. Sa culture offre de telles ressources pour lélève du bétail que, dats le seul arrondicsement de Cambrai, son introduction a eu pour etfet ślever de 700 a 11000 le nombre des bêtes a cornes. 
trielles (textiles, tinctoriales, oléagineuses) est veuue encore augmenter le profit de l'agriculteur. Son verger, son potager sont mieux fournis, plantés d'espèces meilleures et plus varièes qu'au siècle précédent; son jardin s'est enrichi de fleurs inconnues à ses devancier's.

C'est surtout depuis $18: 8$ que la chimie ugricole a commencé à prêter un concours effectil à l'agriculture; que les climistes ont analysé les terres et créé des engrais artificiels; que le guano du Pérou, le noir animul, les scories, les phosphates, dont il existe en France, surtout en Algérie et en Tunisie, de nombreux gisements, sont devenus d'un usage presque courant.

Elerage. - Les dépôts de haras ont amélioré l'espèce chevaline par le croisement arec les cheraux anglais et arabes. L'espèce bovine s'est améliorée surtout par le croisement avec la race anglaise de Durliam, les races bretonnes, les races suisses. Autrefors, on laisait trainer les chariots et tirer la charrue par des bueul's, mème par des vaches; on commence à réserver le boul pour lengraissage, et on l'a remplàé, comme animal de trait, par le cheval, dont l'action est plus énergique et l'allure plus rapide. Les éleveurs de moutons ont importé les mérinos d'Espagne, qui donnent une laine plus fine, et les dixley d'Angleterre qui, en outre lu mime avantage, donnent me meilleure viande de boucherie. Dans les étables à purcs, on a introduit des races anglaises ou cochinchinoises, plus laciles à engraisser; dans les basses-cours, les poules de Crèvecœur, de Houdan, de Cochinchine ${ }^{1}$.

Ainsi toutes les parties de l'outillage agricole se sont perpectionnées, tandis que lagriculteur lui-mème, par le déreloppement de l'instruction primaire, devenait plus apte à laire un usage intelligent de cet outillage. Le paysan est mieux nourri, mieux vètu, mieux logé, et les maisons à toiture d'ardoise ou de tuile mécanique remplacent dans

1. 11 y await en France, en 1959, 3290000 chevaux, 200000 mulets, 361009 anes, li 30000,1 animax de lespere bovine, 1s 000000 moutons, donnant pour plus de 83 millinns de laine. 7500000 pores, 1500000 cherres - En 1789, Lavolsier comptiat I is1500 chevaux, 7 millions danimaux de l'espee buvine, 20 milions de moutoas, í millions de pores. Laugmentation est done considerable, surtout pour les especes chevaline et bovine. 
nos villages les cabanes couvertes de chaume, qui élaient si souvent la proie des incendies.

Institutions, lois, enseignemests agricolrs. - Pour propager les nouvelles méthodes, on a rréél'Institut national agronomique, oú des professeurs éminents enseignent l'économie rurale, la législation agricole, les sciences appiquées à l'agriculture. Depuis la loi du 3 octobre 18 \&, l'enseignement a été organisé dans les écoles nationales d'agriculture le liennes (18:9), de Grignon, de Montpellier, ete., daus q0 écoles pratiques, daus tuutes les écoles normales primaines et jurgue dans les simples éeoles primaires, lont bealucuup possedent des "champs d'expérience "; entin dans les fermes modeles établies en mn grand nombre de départements. On a institué des chaires le chimie agricole ou de botanique agricole daus presque toutes nos univer. sites. On a creie des cour's nomades, dont le protessen se trantprote de pays en pays. Les naitres de l'économie rurale ont été de nos juurs sebluzing, 1. Chanvean, Dehirais, Chr-A. Maink, P. Roux, Grandeau, Zolla, Hitier, Risler (geologie agricule). Le reboisement est poursuir avec methode : citons les travaux de Demontzay, Broillialdl.

Le lecres de juin 1852 a réolganisé l'alministration des haras et établi 23 dépôts d'étalons. Richard (du Cantal), ancien représentant du perule, a publié les - Annales des haras D. La loi du 1 禾 noit $185 \ddot{3}$ est le principal document almiuistratif sur la matiere.

En 1852, le gouvernement invita les comices agricoles à élire les délégués pour les chambres consultatives, charıées de présenter à l'administration les voux de l'asticulture. Cetle institution, si nécessaire, n'est point encore oryaticée.

La loi du $\ddot{3}$ novembre $18 \$ 4$ tendit à lavoriser la création des sociétés the crédit agricole.

La loi du 18 juillet 1866 a développé les conséquences des tois de 18:36 sur les chemins vicinaux. Celles de 1871 et 1884, concernant les conseils généranx et municipaux, assurèrent la multiplication de ees chrmins eu donnant plus d'initiative aux assemblées locales; les lois de 1868 , 1879, 1888, 1889, etc., ont aceordé à ce service, outre les

1. Voir ci-dessus, p. 701 (nétéorologiel el 713 (botanique). 
subventions budgètaires annuelles, les dotations extraordinaires s'élevant à כ̋00 millions de francs. Le réseau vicinal se complète et s'achève presque partout, et c'est sur la création de cliemins de fer et de tramways d’intétét local que les départements commencent à pouvoir reporter leurs ressources.

Une série de lois douanières, dues principalement à l'initiative et à la ténacité de Joles mÉLINE, simple député ou ministre, ont organisé la protection de la plupart de nos produits agricoles, le bétail, les céréales, les vins, les beurres et fromağes. Le droit de 5 francs par tête de bète bovine et le droit de 7 franes par heclolitre de blé ont èté particulièrement efficaces. C'est surtout dans la crise du printemps de 1898, quand les con-éifuences de la lable récolte de l'année précidente étaient encore aggravées par les accaparements qu'opéraient certains spéculateurs américains, que ert homme d'litat lit preuve d'une solidité de doctrine et d'une lemeté de caractère vraiment remarquables. Il tint a conserver au paysan le bénéfice de prix rémunérateurs, sans attemire loutefois que la hausse du pain tournît en cherté; puis il déconcerta la spéculation par une brusque suppression du droit protecteur, sans s'arrèter à la deni-mesure d'une simple réduction, et en annoncant pour le $1^{\text {er }}$ juillet le rétablissement intégral de ce droit. Une autre demi-mesure, quil repoussait comme encore plus funeste, c'était l'échelle mobile qui avait présenté tant d'inconvénients à l'époque de la Restauration; il restait opposé à tout système qui ent admis une mobilité, une incertitude queleonques dans les droits protecteurs.

Son administration de vingt-six mois (du fer mai 1896 au 15 juin 1898), conme ministre de l'agriculture et président du conseil, fut la plus féconde que le paysan le Fance ent jamais connue. Les lois quil fit roter et les mesures qu'il adopta peuvent se rattacher à cinq groupes : la protection des proluits agricoles, louverture de nouveaux débouchés à ces produits, l'organisation du travail agricole, le dégrèvement des biens ruraux, cafin la constitution du crédit agricole.

Comme il prévoyait que certaines circonstances pourraient obliger le gouvernement à modifier, sur tel ou tel 
point, son régime douanier, il fit voter la loi dite du cadenas (14 décembre 1897), en vertu de laquelle, dès qu'un projet de loi, présenté à la Chambre des députés, proposerait un relèvement des droits, ce relèvement serait immédiatement perçu sur les importations visées par la loi, sau' à être restitué aux importateurs si le projet était repoussé ou retiré.

Jules Méline entendait protéger les produits agricoles non seulement contre la concurrence étrangère, mais contre certaines fraudes ou certaines pratiques qui leur faisaient, même à l'intérieur, une concurrence déloyale. Dans l'intérèt de la viticulture, qui soufrait des vinifications artificielles, il fit voter la loi du 6 avril $189 \%$, destinée à restreindre la fabricition industrielle des vins de raisins secs. Une autre loi réprima l'abus dans l'alcoolisation et le mouillage des vins. Dans l'intérét de notre industrie du beurre naturel, il fit voter la loi contre les fraudes sur les beurres par addition ou substitution de la margarine à ce produit (16 avril 1897). Dans l'intérêt des producteurs de pommes de ierre et autres farineux, il fit relever les druils sur les lécules et amidons étrangers, ainsi que surleurs dérivés. Il prit d'autıes mesures de protection où le régime douanier n’avait rien à voir : telle ful la réorganisation du service de surveillance sur les épizoolies, notamment celle de la tuberculose. La précaution la plus essentielle a prendre contre cette maladie, c'était l'abattage et l'enfonissement des bêtes contaminées; la loi de 1893 laissait a lésirer, car, en n'assurant pas au propriètaire de l’animal infecté une indemnité suflisante, elle l'induisait à dissimuler le plus lougtemps possible la contagion qui sévissait dans son étable. Le ministre de l'agriculture fit du propriétaire lui-mème un auxiliaire zélé du service de santé en lui assurant une indemmité équivalant, selon les cas, à la moitié ou aux trois quarts de la valeur de l'animal abattu. A défaut de loi, les ariétés organisèrent la protection des oiseaux uliles à lantriculture.

Pour assmer de flus faciles débouchés et une circulation plus airée aux produits agricoles, Jules Méline ubtint te sou collècue du commerce la présentation et le rote dune loi qui portait de 3 à 10 liblos le poids maximum 
des colis postaux : cette mesure pernit au producteur d'expédier par colis postal toute sorte de comestibles. La loi sur les halles centrales de Paris tendit à supprimer les abus dont souffrait le producteur grace aux nombreux interméliaires qui s’étaient multipliés entre le consommateur et lui. La loi du 29 décembre 1897, qui tendait d la suppression des octrois, en tant quils frappaient les boissons hygiéniques et l'autres objets d'alimentation, était également concue dans l’intérêt de lagriculteur et surtout du viticulteur. Des primes d'exportation encouragerent l'écoulement des sucres lrancais a l’ètrangel et lavorisèrent dautant les cultivateurs de betteraves, cesta-dire presifue toute l'agriculture du Nord. D'autres primes lurent acoriées a la sériciculture, à la culture du chanre et du lin. Les producteurs d'alcool bénéficierent d'un nouveau et très lasge débouché lorsque la loi sur la dénafuration le l'alcool abaissa de $35 \mathrm{fr} .50$ a 3 trancs par hectolitre haxe sur les alcols denatures pour ètre emploies hans certaines industries.

C'est a Jules Méline que l'on doit le plan et la mise à exécution des canaux d'irrigation dérivés ln Rhóne qui devaient répandre la fertilité sur une vaste région. II crèa un nouveau service public, celui des améliorations pastoralis. Liorganisation des cultivateurs en syndicats ayricolcs, leur permettant de se passer d'intermédiaires pour l'achat des phosphates, engrais, semences, instruments agricoles de toute nature, fut encouragée. Le ministre avait repris, pour les développer et les élever. les idées de 1832 sur l'organisation de chambres dagriculture qui cussent ioué, pour nos industries nourricières, le même róle que les chambres de commerce pour le commerce français. Sa loi du 17 mars 1898 teudit a rendre plus rapide el moins conteuse la revision du cadastre.

Sous son administration les propriétaires de biens ruraux, surtout les petits propriétaires, bénéficièrent, en raison inverse de leur fortune, du plus large dégrèvement quils eussent jamais obtenu : vingt-six millions d'un coup dans le budget pour 1898.

Il estimail que les plus larges dégrèvements ne procurent fas à l'agrirulture un avantage comparable avec 
celui que lui assurerait la constitution d'un crédit agricole, fondè sur le principe de la mutualité, auquel la loi du $1^{\text {er }}$ avril 1898 donna ure vigueur nouvelle. Il prépara la loi du 18 juillet 1898 sur les warrants agricoles, qui permit au producteur, tout en conservant ses récoltes dans ses greniers ou ses celliers, étant constitué par la loi le gardien de son propre bien, d'emprunter sur le gage qu'offrait celui-ci. Il poussa aux organisations de banques locales, de caisses régionales, pour lesquelles il rédigea lui-mème des modèles de statuts, et auxquelles il allait assurer le concours de l'État dans une proportion jusqu'alors inconnue. En elfet, lorsque fut renouvelé le privilège de la Banque de France, celle-ci dut s'engager à mettre à la disposition de l'Éat pour la dotation des institutions agricoles, à titre de prèt non productif d'intérêts, une somme de 40 millions, plus 20 annuités de 2 millions. (Loi du 16 novembre 189i.) C'était la première lois que d'une opération financière de ce genre le paysan français était appelé à retirer le priıcipal bénéfice.

Parmi toutes les mesures énumérées ci-dessus, les unes profitaient à l'agriculture française dans son ensemble; les autres s'adressaient à telle ou telle de ses branches, à telle ou telle province de France; tour à tour les cultivateurs de betteraves dans le nord, les viticulteurs du midi, les producteurs de blé du centre. les éleveurs de l'ouest et de l'est étaient l'objet de la sollicitude du gouvernement. Toutes ces mesures, concues comme de simples parties d'un plan d'ensemble, longuement méditées et poursuivies avec constance, réalisèrent en deux années plus de progrès qu'on n'en avait accomplis en vingt-six ans de République.

Statistigue agricole. - On peut estimer la production annuelle de la France a environ cinq milliards pour les céréales, deux milliards pour les prairies naturelles ou artificielles, un milliard et demi pour les vins, cidres, poirés, etc., autant pour les cultures industrielles, deux milliards pour les forêts et les arbres fruitiers, six milliards pour les animaux domestiques.

L'agriculture occupait, en 1892, 3387000 propriétaires cultivant eux-mémes, 1428625 cultivateurs non proprié- 
taires (métayers, fermiers, colons, simples locataires), 1332174 domestiques agricoles; au tota! 6647000 personnes. Ce chiffre a été relevé à 8360000 personnes par une statistique de 1896, sans doute parce qu'elle a déterminé le plus exactement le nombre des femmes occupées aux travaux des champs. La population rurale de la France comprent donc environ 23 millions et demi d'habitants de tout sexe et de tout âge.

\section{L'industrie.}

\section{Aceroissement des populations urbaines an détri-} ment des campagnes. - Depuis le commencement du xix ${ }^{e}$ siècle s'est manifesté un phénomène démographique qui a modifié en France toutes les conditions de la vie sociale, économique et politique : c'est l'accroissement de la population des villes et bourgs au détriment de la population rurale. En 1790, d'après un document publié par ordre de la Constituante, la première comprenait 5709000 habitants et la seconde 20521000 ; la proportion étail donc respectivement de 21,76 et de 78,24 pour 100 . La France était alors surtont un pays rural et agricole.

C'est seulement en 1846 que celte statistique fut élablie avec précision (étant entendu que les agrlomérations supérieures à 2000 habitants comptaient seules comme population urbaine). Or, en 1846 , la population ur!saine était évaluée à près de 9 millions (8646 743) d'habitants, soit 24,4 pour 100 ; la population rurale à près de 27 millions (26753743), soit 75,6 pour 100. Quarante ans après, en 1876, la première s'élève à environ 12 millions d'habitants ( 11977396 ), soit 32 , pour 100; la seconde à environ 25 millions (24928392), soit 67,6 pour 100. En 1896, la première est de 15 millions, la seconde de 23487000 : soit, respectivement, 39,5 et 60,5 pour 100 . Donc les deux cinquièmes de la population totale sont agglomérés dans les villes. Il y a cent ans, ce n'était que le cinquième de la nation. Toutefois la vie rurale reste encore plus développée chez nous qu'en Angleterre, où la proportion a élé depuis longtemps renversée, el en Allemagne, où elle s"est renversée depuis environ 25 ans. 
Ce sont les plus grandes villes qui ont surtout profité de cet aceroissement. En $180 \%$, il $19 y$ arait en France que trois villes comptant plus de 100000 habitants : Paris, Lyon, Matseille. En 18:6, il n'y en a que quatre (avec Bordeaux). En 1866, il y en a huit; aujourdhui, quinze, avec une population tolale de 5800000 habitants.

Ces chifres permettent déjà d'apprécier le développement qu'ont pris en France l'industrie et le commerce.

Une statistique de 1906 évalue à 2002681 les personnes sadonnant au commerce dont 770980 femmes; sur ce nombre, 028 7't patrons.

La ciasse industrielle comprend 714580 personnes, dont 2301038 femmes. Sur ce nombre le chilfre des patrons est de $3 \pi ;$ s0 un total de plus de 7 millions, sur lequel les ouvrieres comptent à peu près pour les lpux cinquièmes.

Progrès de l'industrie. - On a vu quels nouveaux et puissants moyens daction la science a mis au service du travail : au lieu des diligences, les ehemins de ler; an lieu des galères à rames ou des navires à voiles. les bateaux à rapeur; au lieu de la lampe et de la chandelle dautrefois, le gaz, lacétylène, la lumière électrique: au lieu des lentes - messageries s, un service de postes et telégraphes d’une activité prodigrieuse; a lien de la pioche du terrassier, la dynamite; et partout, centuplantl'action des bras humains, la machine-ontil, la machine à vapeus, la machine dectrigue.

Toute la vie humaine, en notre siècle, a pris une intensité étonnante. On produit cent fois plus qu'autrelois. Au lieu de l'atelier du Xvin siècle, où un maître était assisté de quelques apprentis, on a les usines et les manulactures où une volonté unique, par l'intermédiaire d'un etat-major de contremaitres, commande à une armée douvriers.

Insirations et enseignements industriels. - Nos gramies icules scientifiques industrielles sont le Conservatoire nutional des arts et metiers, fondé en 179', et l'École centrale des arts et manufactures, londee en 18a91. Aux trois échs mutinales d'arts el metiers dejà existantes (Angers,

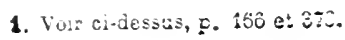


Châlons, Aix), la République ajouta celle de Lille (1881). Elle organisa les Écoles nationales professionnelles de Vierzon (1881), dite école modèle, d'Armentières et de Voiron (1882), enfin celle de Nantes, achetée à son fondateur Livet (1898). En Algérie, l'école des arts et métiers, fondée en 1866 par l'autorité militaire à Fort-National et incendiee durant linsurrection de 1571 , fut reconstituée à bellys (également en Grande-Kabylie) sous le nom d'école nationale l'apprentissage. En 1891 fut créée l'École nationale doutriers et de contrematitres de Cluny. De 1892 à $18: 19$ ont été crées trente-trois Écolcs pratiques de commerce et d'industrie. La ville de Paris a fondé les écoles Estienne (pour les industries du livre), Boulle (pour celles du menble). Dillerot (pour le travail tu fer), École de physique at chimie. ete. L'Étal subventionne les écoles nationales dhorlogerie de Cluses Haute-Siroie. depuis 18133 et de Besancon (depuis 1891 . La plupart de nos Universités possèlent un enseignement industriel.

La propriété industrielle. - De nombreux décrets, lois, ordonnances, sont venus développer les principes posés par le lègislateur de 1791, assurer à l'ingénieur et à l'artisan, comme a l'arliste et au littérateur, pour eux et pour leurs héritiers, la propriété exclusive de leurs créations, donner une nourclle sécurité et un nouveau stimulant à l'esprit d'invention et de perfectionnement. Des traités conclus avec les autres puissances ont garanti à nos inventeurs la jouissance de leurs droits de propriété même au delà de nos frontières. On ne peut utiliser une invention française, on ne peut publier un livre, reproduire une statue, jouer un morceau de musique ou une pièce de théatre, au moins dans la plupart des pays civilisés, sans que le Français qui en est l'auteur lerçoire une légitime redevance.

Les expositions internationales de rindustrie - Sous la Répulılique de 18 í tions non plus seulement nationales, mais internutionules. Tandis qu'on hésitait, en France, à appliquer cette idée, elle fut mise ḋ exécution par les Anglais, et la premiere exposition universelle ou internalionale se tint à Londres, au Palais de Cristal, en 1831. Le seconde se tint is Paris, au Palais de l'Industrie, en $18 \ddot{3}$, et attira 24000 exposants. 
Les nations les plus lointaines, la Chine, le Japon, le Pérou, le Chili, colonies anglaises d'Australie, s'y firent représenter.

Dès lors, l'institution était londée. Tour à tour ces grandes assises se réunirent à Paris, à Londres, à Vienne, à Pétersbourg, à Chicago, à New-York, en Australie.

A Paris, l'Exposition universelle de 1867 réunit environ 42000 exposants et attira la plupart des souverains de l'Europe, plus le vice-roi d'Egypte, le sultan des Turcs, le frère du taïcoun du Japon, etc.

L'Exposition universelle de 1878 nous amena un visiteur non moins extraordinaire, le premier roi de Perse qui ait visité l'Europe. Elle compta 53000 exposants, 12 millions de visiteurs, et occupa une superficie de 25 hectares. Pour ces deux expositions, il avait lallu aménager la vaste plaine du Champ-de-Nars; pour celle de 1878, sur l'autre rive de la Seine, sur la colline dı Trocadéro, on éleva l'immense palais qui subsiste encore et qui est devenu le centre de tout un Paris nouveau.

L'Exposition universelle de 1889 , qui reçut 28 millions de visiteurs, exigea de plus vastes espaces, car elle envahit l'Eulanade des Invalides. C'est alors que s'élevèrent la Tour de 300 mètres, la Galerie des Machines, les palais construits par Formigé.

Une autre statistique indiquera, au point de vue industriel, l'importance relative de ces quatre expositions : la puissance totale des machines qui y furent mises en activilé est évaluée, pour celle de 1867, à 85 t chevaux; pour celle de 1878, à 2533 chevaux; pour celle de 1889, à 5320 ; pour celle de 1900, à 3608 o.

L'Exposition de 1900, outre les espaces occupés par ses devancières, s'est annexé les deux berges de la Seine, du Pont-Royal jusque bien au delà du pont d'Jéna : au tutal une superficie de 108 hectares. Elle recut 50 millions de visiteurs. Elle devait léguer à Paris le nouveau pont Alexandre III, l'avenue Nicolas II et les deux palais les Beaux-Arts, élevés sur l'emplacement du défunt palais de I'Industrie. Elle altira 29733 exposants français. 5159 de nos colonies, 37793 étrangers. Sa caractéristique fut la magnifique a rue des Nations $\triangleright$, bordée de merveilleux 
pavillons, élevés, dans tous les styles, par toutes les puissances, petites ou grandes, des cinq parties du monde.

Indastries nouvelles. - Plus nous approchons de l'époque présente, moins il devient possible d'énumérer tant de découvertes, de perlectionnements, d'industries nouvelles ${ }^{1}$. Il faudrait dépouiller la liste des brevets d'in. vention et le catalogue d'expositions de plus en plus colossales. Cest par l'industrie que Paris, Lyon, Marseille, Lille, Naucy, ont pris de si énormes développements. et que de simples villages et bourms, comme Saint-Étienne, Tourcoing, Ronbaix, le Creusot, sont devenus de grandes cités.

Statistique de lindustrie. - Lactivitis du travail national se révele par des chilfres. La consommation de la houille peut ètre considéce comme le thermomètre du progres industriel. En 1789, elle était presigue nulle, puisquion ne consommait guère que les houilles indigènes, dont la production nétait que de 220000 tonnes; en 1815 , elle n’était que de 1 million de tonnes; en 1999. elle élait de plus de 36 millions de tonnes.

En 1826 , on produisait en France $20, ;$ s. 13 tonnes de fonte, 145519 de fer, et seulement it 91't d'acier. En 1sis, ces chiffres sélevaient respectivement à 472412,2762003 et 7 130. Ils ctaient, en 1909, de 3 \&9s 000,557000 et 2060000 . La probluction de la fonte a donc augmenté 16 lois depuis 1826 ; celle de l'acier, préféré de plus en plus an fer, a qualre fois centuple.

Denx branches de la métahlurgie ont pris, en peu l'années, un déreloppement prodigieux : les bicyclettes et les mulomoliles.

Liulustrie française, en 1910, employatit non compris les appareils des chemins de fer, tramways, antomobiles, bateaux, non compris lidrérie et les colonies), 82 2:38 machines à vapreur l'une loree totale de 2913013 chevaux.

Notre production industrielle sieleve annellement is un total te quinze milliarls.

1. Voyez ci-dessus, pages 57 et 50 ?, hes indhstries qui se sont eréées ou perfedionates arace aux decouvertes lo la physigue et de la chimie. notamment de la ehimie organique : industries de la metallargle, du meuble, de la ceranique, du vétement, le la temture, de la parfumerie, des bieres, des vins, des vinairres, des aleools, ete. 


\section{Le commerce.}

Enseignements commercianx. - L'enseignement com. mercial a pour objet l'étude " des arts et des sciences, en vue de leur application au commerce ». (L'Enseignement technique en Frunce, 1900.)

Il est donné, d'une façon générale, dans les lycées et écoles de tout ordre, mais spécialement dans les Écoles pratiques de commerce et d'industrie, dans les Écoles superieures de commerce de Paris (qui date de 1820). du llarre (187i), de Jarseille (18\%:). de Bordeaux (1874); entin, a un derer superieur, a l'École les Inutes Études commerciales de Paris, fondée en 1877, et à l'Institut commercial de Paris (1884).

Réforme des lois sur les céréales. - On avait pu se convaincre que les variations de l'echelle-mobile aggravaient les variations en hausse et en baisse dans le prix du blé. On commençait à trouver injuste que, pour favoriser le proprictaire ou le fermier, le reste des citovens fuscent contraints à payer leur pain plus cher. La loi de 1861 mit fin au régime provisoire inauguré par la loi de 1832 , et accorda la liberté absolue du commerce des grains. Ceux mêmes d'Amérique ou de Russie entrent chez nous en toute liberté, moyennant le droit de $7 \mathrm{fr} .{ }^{1}$.

Les traitén de comanerce. - Sous la République de $18: 8$, hes idées de libre-échange, préconisées par leséconomstes, avaient fail peu de progrès dans les assemblées nationales. Le 30 décembre 1850 , l'Assemblée législative rejeta un programme libre-échangiste que lui proposait Sainte-Beuve et qui fut combattu par Thiers: la majorité avait été de \$28 voix contre 199.

C'est Napoléon III qui, à Paris, le 23 févrice 1868. ronclut avec l'Angleterre un traité de commerce, le premier que nous ayons eu depuis celui de 1786. Les négociateurs avaient èté, du côté de la France, Rouher et Baroche, assistés de Michel Cheralier; du cóté de l'Angleterre, Coluden et lord Cowley. 
Par ce traité, la France levait tontes les prohibitions qui frappaient eertains produits britanniques; les droits sur les houilles, lontes, lers, aciers, tissus, s'abaissaient à moins de 25 pour 100. En échange, la Grande-Bretagne s'engageait à laisser entrer chez elle, en toute franchise, les articles de Paris et les soieries; les vins français, qui jusqu’alors étaient frappés à leur entrée en Angleterre d'un droit égal à 300 pour 100 de leur valeur, n'étaient plus grevés que d'un droit variant de 28 a 56 franes par hectolitre; nos eaux-de-vie, qui payaient autrefois 916 francs parliectolitre, n'en payaient plus que 2I8, et cela uniquement paree que les alcools anglais subissaient en Angleterre un impôt d'un chifre égal.

L'Empereur s'était fondé sur l'article 6 de la Constitution de 183 a pour conclure une convention aussi importante sans consulter les Chambres. Elle ne fut discutée à la Chambre des députés que lorsqu il s'agit de fixer précisément les tarifs, et au Sénat qu'à propos de pétitions signées par les industriels (1861). Un peu plus tard, elle fit lobjet d'une interpellation (1868). Les dispositions essentielles du traité n'en fure:at pas modifiées.

Le traité fut bien ou mal accueilli par les producteurs franças, suivant qu'il favorisait ou menacait lenr industrie. A Paris, à Lyon, à Burdeaux, à Cognac, par exemple, les producteurs d'articles de Paris, de soieries, de vins, d'alcools, se réjouirent. A Rouen, à Lille, à Roubaix, à Mulhouse, les producteurs de tissus; ailleurs, les producteurs de fers et d'aciers, s'inquiétèrent. Il y eut des régions libre-techangisles et des régions protectionnistes. Dans les unes comme dans les autres, si les productenrs n'étaient pas d'accord, les consommateurs étaient à peu près unanimes. Le traité de commerce permettait d'acheter les produits manulacturés d'Angteterre, les sucres et le café de ses colonies, à un bon marché jusqu'alors inconnu.

Le traité avec l'Angleterre fut suivi, dans les années 1861 $186 \ddot{3}$, de traités conclus avec la Belgique, l'Italie, la Suisse, la Suède, Ia Norvège, la IIollande, le Zollverein ou Union douanière des États allemands, etc. La base de tous ces traités était que la France levait les prohibitions et diminuait les droits sur certains produits de létranger, à la condition que l'étranger userait de réciprocité.

R. CJvil. Contemp. 
Autrefois, les navires étrangers étaient frappés, dans les ports français, de taxes considérables, à raison de tant par tonne : on voulait favoriser le transport par les navires nationaux; mais à l'étranger, ceux-ci étaient traités comme nous traitions chez nous les navires du dehors. La loi de 1886 supprima toutes ces taxes, toujours à la condition quon userait envers nous de réciprocité.

Par l'abolition de l'ancien régime douanier, de l'ancien régime maritime et de l'ancien régime colonial, toutes les nations civilisées sont devenues solidaires les unes des autres. En vaste courant d'échanges s'étend de l'Asie à l'Amérique, de l'Europe à l'Australie. Il s'est accompli là une révolution presque aussi considérable, dans les intérêts et dans la manière de vivre, que celle qui avait été accomplie, en 1789, dans le système politique et social.

En 185\%. la Hollande, la Belgique. l'Italie, puis l'Espagne, le Portugal, la Grèce ont adopté notre système métrique: un Bureau international des poids et mesures a été constitué à la suite des confërences de Paris en 1870 et 1872. En 1865, la Belgique, la Suisse, l'Italie, et plus tard la Grèce, l'Espagne, la Roumanie, ont accepté notre système monétaire : c'est ce qu'on appelle l'Union latine.

En Russie, en Angleterre, en Allemagne on poursuit des ètudes en vue de l'adoption le notre systime métrique.

Réforme des postes. - C'est un décret de la Constituante de 1848 qui abolit les zones postales en établissant des tarifs uniformes pour toute la France, abaissa la taxe des lettres, créa les timbres-poste : de ceux-ci on vendit en $18 \div 9$ pour 444000 francs.

En 1867, il y arait en France $\$ 876$ bureaux de poste, manipulant environ 772 millions d'objets. On vendait alors pour 15 millions de timbres-poste environ.

Tout le service a fait de grands progrès sous le ministìre d'Ad. Cochery (1878-85), notamment par la création des colis postaux, l'extension de l'union postale, l'abaissement du taux des lettres et des télégrammes.

Le proluit des postes, en 1909 , était de 230 millions, celui

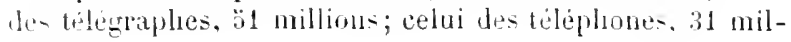
livens. 
Par le traité de Berne, en 1874, et le traité de Paris, en 1878, il a été conclu une Union postale universelle, à laquelle ont adhéré la plupart des nations les plus civilisées, non seulement de l'Europe, mais des Deux-Mondes.

Statistique du commerce. - En 1827, la France importait pour ' +1 '́ millions de marchandises étrangères; en 18't7, pour 953 millions; en 1867, pour 3027 millions; en 1887 , poul 4026 millions; en 1910, pour 7173 millons ${ }^{1}$, sans parler des métaux précieux.

Lu 1827 , elle exportait pour 507 millions; en 1845 , pour 20 millions; en $186 \pi$, pour 2826 millions; en $185 \pi$, pour 3241 millions; en 1910, pour 6234 millions, sans compter les métaux précieux.

Pour l'inportation et pour l'exportation réunies, la France est de beaucoup inférieure ì l'Angletere; elle est sensiblement inférieure à l'Allemagne et aux Etats-Lnis. Elle dépasse de beaucoup tous les autres pays.

\section{Le crédit.}

Abondance nouvelle du numéraire. - En notre siècle s'est continué l'alllux de métaux précieux qui avait commencé au $x^{r} v^{e}$ siècle avec l'exploitation des mines d'or du Pérou, des mines d'argent de la Plata. En 1848, ont été découvertes les mines d'or de la Californie, qui ont amené le peuplement de ses déserts et la richesse de San-Francisco. En 1851, ont été découvertes celles de l'Australie et de la Nouvelle-Zélande, qui ont fait grandir au milieu de solitudes les villes de Melbourne et Auckland; en 1862, ces mines avaient déjả produit 836000 kilogrammes d'or, d'une valeur de plus de quatre milliarls. Plus récemment on a découvert les mines d'or de l'Alrique australe et celles. moins facilement exploitables, du klondyke ancienne Amérique russe). Les mines d'or et d'argent de l'Oural, du Mexique, du Pérou, de la Nouvelle-Grenade, du Chili, du Brésil, continuent à fournir leur contingent.

On calcule que toutes les richesses métalliques de l'Eu-

1. Pour les chiffres, tant à l'importation qu'à l'exportation, nous prenons ceux du commerce spécial et non ceux du commerce général (qui con:prend le simple entrepót et le simple transit). 
rope entiere dans l'antiquiti et an moyen ige nownivalajent pas à un milliard. De 1300 à 1848 , les deux Amériques ont versé pour 10 milliards d'or et 17 milliards dargent. Depuis 1848 , les mines du monde entier ont toujours versé pour plus d'un milliard de numéraire par an. En 1909, la production totale de l'or a représenté une valeur de 2283 millions. Plus de la moitie de cet or est fourni par les colonies et territoires britanniques, l'Alrique du Sud comptant à elle seule pour près de 8.00 millions.

La quantité de numéraire qui circule dans le monde civilisé équivaut à 70 milliards, c'est-à-dire 70 lois la quantité d'or et d'argent qu'ont connue les Grees, les Romains et les Europèens du moyen itge. Elle serait plus considérable si l'Inde et la Chine, par l'excédent de leurs exportations sur les importations, n'en absorbaient une grande partie, qu'elles immobilisent dans leurs temples ou leurs trésors secrets, et qu'elles ne rendent plus. La quantité du numéraire circulant est encore énorme: pourtant elle est Join de suftire à la prodigieuse actirité des transactions. 11 a fallu créer les valeurs de crédit.

I.a Eanque de France. - La Banque de France, prar les décrets lu Gouvernement provisoire de 1845. absorba ses rivales de province. En revanche, elle devait constituer en province des succursales de la Banque de France. Elle acquit le droit exclusit dimeltre des billets de banque.

Elle rend au travail national trois services essentiels : elle escompte les effels de commerce, elle prete sur garantie, elle émet des billets de banque. En émettant des billets qui ont la mime valeur que l'or, elle augmente le capital en circulation : pour deux on trois milliards en especes qu'elle a dans ses caisses, il y a pour cinq milliards de billets qui circulent ${ }^{1}$. Afin de répondre aux besoins du public, elle a dù

1. Le maximum de la valeur lolale des émissions des billets le banque est fixé par la loi : il fut de 350 millions en 15 is; de 525 millious (après l'absorption des banques rivales) en $18 \mathbf{1 9}$; de 1800 millions, puis 2.100 millions en 15,0; de 3500 millions par la loi de fuanees du 30 janvier 1381; de 5 milliards par colle du 16 novembre 1897. - Ces émissions sont garanties: $1^{\circ}$ par l'encaisse métallique de la Banque : cette eneaisse alteignait, en dérembre 1909. A milliards 6nif000000 francs; 20 par le portefeuilte, comprenant les valeurs deposées dans ses coffres: durant celte mime ance 1900, ia valeur du portefeuille a varie de 5,69 a 1 un millions. 
renoncer à ne luilivrer, comme elle faisail d'abord, que des billets de 5000 , de 1000 et de 500 francs. Elle a dù, en quelque sorte, démocratiser le billet de banque, en créant des coupures de 100, de 50 francs. (En 1870, elle en émit de 25 et de 20 francs, qu'elle a retirés depuis.) Le billet de banque, presque inconnu des paysans au début de la Restauration, a pu pénétrer jusqu'au fond des campagnes.

Le chiffre d'allaires de la Banque de France et de ses succursales dans les principales villes de France a pris un développement énorme; anssi le capital primitif de 30 millions a dù ètre porté, dès 1806, à 45 millions, et, en 18\%7, à 182 millions el demi. Sur ces 182 millions, elle en a versé 100 dans les caisses de l'Étal et accepté en échange pour 100 millions de rentes. Elle est donc un rouage essentiel du crédit de l'État, comme du crédil des particuliers. Nous l'avons vue, lors du renouvellement de son privilège, en 1897, consentir à assurer l'avenir du crédit agricole.

Societes nouvelles de credit. - La Banque ne peut prêter aux particuliers que si ceux-ci lui livrent en garantie des rentes sur l'État ou d'aulres valeurs solides. Sous Napoléon III, quand les constructions à Paris el dans les granı́es villes prirent un vaste développement, les constructeurs avaient besoin de sommes considérables; ils ne pouvaient donner en garantie que des terrains, et surtout il leur lallait des emprunts à un taux plus bas. Comme la Banque de France ne pouvait répondre à ces besoins, le gouvernement autorisa, en decembre $18: 2$, la constitution d'une société nouvelle, le Crédit foncier, qui prète sur les terrains, se contente d'un intérèt modéré et consent à ètre remboursé du capital lui-mème en une série d'annuités.

En novembre de la même année, se fonda le Crédit mobilier, yui prète sur des valeurs mobilieres"; en $18 \% 9$.

1. L'ayiotayje. Les actions, émises a 500 francs, furent de suile cotèes is la Bourse 1100 puis 1400 francs, pour revenir ensuite à 875 . Aucune valeur ne favorisail autant la spéculation. "Pour la seule année 1853, a Écrit Aycard, l'ensemble des écarts mensuels entre les plus hauts et les plus bas cours ayant élé de 1622,50 , on a estimé qu'un =péculateur qui, opérant mois par mois, aurail acheté au plus bas et veadu au plus haut, aurait gagné aveo 100 actions 162250 francs; avec 1000 aclions, 1622500 franes... Trois ans plus tard, en 1366 , les variations fureat bien autrement nombreuses, désordonnées el fuadroyantes... Aussi regardaiton tout spéculateur opérant 
le Crédit industriel; en 1860, le Crédit foncier colonial; en 1863, le Crédit Lyonnais, etc. Le Comptoir d'escompte, lors de la crise du commerce parisien qui présida et suivit la révolution du 2' février 1848 , fut constitué par un décret du Gouvernement provisoire ( 7 mars), sous la garantie de l'État. Dès 1851, il put se passer de cette garantie et fonctionner comme un établissement purement privé. Il eut des sous-comptoirs au nombre le six ou sept, dont les plus importants furent celui du Bátiment, dont le credit aida grandement à la translormation de Paris, et celui des Chemins de fer.

luitiplication des valeurs en papier. - La construction du réseau des chemins de fer français et étrangers, les traraux de percement des isthmes de Suez et de Panama, les entreprises industrielles on financières de tout ordre, amenèrent la création de nombreuses compagnies, dont le capital se divise en actions et qui empruntent au public en émettant des obligations.

Les emprunts de l'État. pour faire face aux guerres ou pour accomplir de grands travaux publics, ont pris aussi une raste extension. Jusqu'au second Empire, l'État, quand il empruntait, s'adressait aux principaux financiers, qui, moyennant la constitution d'un certain nombre de titres de rente, lui fournissaient les fonds nécessaires. Napoléon III eut l'idée de s'adresser aux masses, ou, comme il disait, de rendre démocratiques les emprunts d'État. Le succès dépassa son attente. En 1864 . l'Etat ourre dans les bureaux de ses receveurs généraux un emprunt de 300 millions : le public souserit pour près de quatre milliards. En 1868, il demande $\{29$ millions : on lui offre quinze milliards répartis entre 832725 souscripteurs. Quand la troisième République, z son tour, ouvre un emprunt national de cinq milliards pour payer la contribution de guerre à la Prusse, les olfres allluent dans la même proportion. Les emprunts russes en France se sont éleves à 9 milliards environ. Il y a près d'un milliard de capitaux français dans les mines de l'Afrique australe. 
Dès lors, à chaque emprunt, des milliers de titres de rente pénètrent dans les plus humbles maisons et y remplacent les épargnes prètées à l'État. Le $\mathrm{xix}^{\mathrm{e}}$ siècle connut une catégorie de rentiers qu'a presque ignorée l'Ancien régime: l'ouvrier et le paysan. La Ville de Paris, qui en 1869 a fait son premier grand emprunt, de 465 millions, les principales villes de France, engagées elles aussi dans d'importants travaux d'assainissement et d'embellissement, recuurent aux mèmes procédés que l'État et rencontrent le mème empressement parmi les grands et petits capitalistes.

Noton's aussi le développement, chez nous, des sociétés d'assurance sur la vie, contre l'incendie, contre la grèle, contre les risques de toute sorte.

Or les rentes sur l'État, les emprunts des villes, les actions et les obligations des compagnies de crédit, de chemins de fer, de canaux, de mines, etc., forment une masse énorme de valeurs. Cette richesse mobilière peut être évaluée aujourd'hui à plus de cent milliards : elle n'existait pour ainsi dire pas au commencement du siècle; elle est la création de la société issue de la Révolution. Aussi le Code Civil, qui a été rédigé au début des temps nonveaux, n'a pu prévoir ce prodigieux développement; il tient surtout compte de la richesse immobilière.

Est-il besoin de dire que toute cette richesse mobilière repose sur le crédit, c'est-à-dire sur la confance? Dès que la société se sent menacée, il y a baisse sur toutes les valeurs, et, si le danger était sérieux, actions, obligations, rentes, mème billets de banque, disparaitraient; nous en serions réduits, comme nos pères, aux pièces d'or et d'argent, qui ne forment pas la trentième partie de cette richesse et qui elles mèmes s'enfotiiraient, comme autrefois, dans d'introuva. bles cachettes. Les utopistes qui, ébloais de ce mirage de millions, étendraient leurs mains sur eux, les verraient s'evanouir comme des fantòmes. Sous prétexte d'enrichir les paurres, ils appauvriraient tout le monde; car ils détruiraient cette immense richesse et cet immense crédit dont s'alimente le travail national et desquels dépend la subsistance mème des travailleurs. 


\section{Les classes ouvrières.}

Loi sur les coalitions : les grèves. - Nos lois, chaque jour plus imprégnées d'esprit égalitaire, tendent à atténter les inconvénients qu'entrainent pour l'ouvrier les conditions de lindustrie. Napolíon III, rompant avec les tradi-

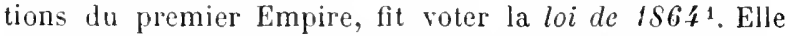
reconnait aux ouvriers le droit de se concerter pour obtenir une augmentation des salaires, et le droit de mettre en œuvre le procédé qui leur parait le plus efficace, c'est-à-dire de se mettre en gréve. Elle ne punit que les grévistes qui useraient de violences pour forcer d'autres ouvriers à déserter l'atelier. Cette loi, fondée sur le principe de la liberté du travail, a mis aux mains des ouvriers un moyen d'empêcher l'avilissement des salaires et de s'assurer une sulfisante rémunération; mais c'est une arme dangereuse qu'tle leur a confiée; il y a des grères légitimes et des grèves injustes. Lne grève est injuste quand elle a pour but l'exiger une augmentation de salaire qui n'est point jus. lifiée par la situation florissante d'une industrie. Et alors, non seulement elle impose aux ourriers de cruelles privations et aux patrons des pertes sensibles, mais, étant donné la concurrence étrangère, elle peut amener la ruine de l'industrie qui les fait virre les uns et les autres. En 189\%, on aviat compté seulement 356 grèves mettant en mouvement 68875 grévistes; en 1898 (année assez troublée), 368 grèves, avec 82000 grévistes; 46 pour 100 des grèves de $189 S$ avaien èchoué : les autres avaient abouti à des concessions julus ou moins étendues, consenties par les patrons.

Les deux années suivantes furent sigualées par une augmeutation inquiétante des glèves (dans le Doubs ct le Haut-Rhin, au Creusot, etc). Elles furent amenées moins par des litiges sur les salaires que par la poussée des passions politiques et sociales. Il y eut 739 grèves en 1899 , 809 en 1900 : les premieres mirent en mouvement 176773 grévistes et les secondes 216000. En 1908, on compla 1073 greves, mais seulement 990 t2 grevistes cl 
564 de ces grèves échouèrent. Il serait d'autant plus diffieile à nos industries d'y résister que ce sont les étrangers qui profitent de ces grèves et parfois les encouragent.

Lois sur les syndicats. - La loi du 21 mars $18 S .1$ a autorisé les divers corps de métiers, dans chaque ville, à se former en syndicats d'ouvriers et en syndicats de patrons, et à élire des chambres synclicales. Ainsi l'organisation industrielle d'autrefois revivrait en ce qu'elle arait de meilleur, la faculté d'association, mais dépouillie de toute entrare à la liberté de l'individu et à la liberté du travail : à moins que les syndicats eux-mèmes ne se fassent les oppresseurs soit de leurs propres membres, soit des ouvriers qui préfèrent n'y pas entrer. Or c'est ce résultat qu'amèneraient les décrels sur les Conseils du travail (17 sept. 1900 et 2 janv. 1901); une telle institution serait utile pour la conciliation des intérêts entre patrons et ouvriers, mais ces décrets, en refusant la qualité d'électenrs aux ouvriers non syndiqués, auraient pour conséquence d'imposer à tous l'omuipotence des syndicals. Le projet de loi sur les grèves, qui tend à les rendre obligatoires pour tous, dès qu'une majorité se sera prononcèe en leur faveur, comporte les mêmes dangers '.

Aı 31 décembre 1908, il existait en France et en Alririe 14 7it syulicats légaleneut constitués ('tit8 agricoles), comprenant 2117629 memlnes (797832 ayriculteurs).

La loidu2 juillet 1590 a supprimé les livrets d'ouvriers, you mettaient céux ei à la discrétion des patrons.

La loi du 8 juillet 1890 institua les délégrués élus par les ouvriers mineurs et chargés d'assurer leur sécurite.

La loi lu 27 décembre 1992 organisa l'artitrage fucultatif, en vue de la conciliation entre patrons et ouvriers.

Lois sur les aecidents du travail. - La loi du 9 woril $1 S 9 S$ assure aux ouvriers une indemnité pour tout accident survenu au cours du travail industriel, lors mème qu'on pourrait imputer laccident à leur propre imprudence. L'indemnité pour l'ouvrier, en cas d'incapacité absolue el permanente de travail, peut atteindre une somme annuelle égale aux deux tiers du salaire. Ea cas de mort amenéc

1. Par reaction contre cette ormanisation se sont constitués les sydicats douvriers opposés au socialisme et aux greves, les Jahnes (1902). 
par l'accident, la loi détermine l'indemnité en faveur de la veuve ou des enfants. Pour éviter que les patrons ne puissent subvenir au paiement des indemnités, la loi a organisé un système d'assurances qui, moyennant une prime annuelle, assure le paiement. Cette loi, portant sur une matiere si complexe, sst appelée à subir les remaniements que commandera l'expérience.

La loi du 30 juin 1899 a étendu le droit à l'indemnité pour les accidents résultant des machines dans le travail agricole, mais seulement des machines mues par des moteurs inanimés (vapeur ou électricité).

Lois et mesures sur la réglementation dn travail. Les principes posés par les lois de la monarchie de Juillet en vue de limiler le travail des femmes et des enfants dans les usines et manufactures ont été développées par les lois du 19 mars 1874 et du 2 novembre 1892 , qu'ont interprétées de nombreux décrets. On a essayé aussi de limiter les heures de travail même pour l'ouvrier adulte, de facon à obtenir la journée de 11 ou mêne de 10 heures. Mais c'est une matière si compliquée, grâce à la diversité mème des professions, que ces mesures, destinées à protéger les ourriers, ont parfois suscité parmi les ourriers eux-mêmes de vires protestations. Les partis socialistes n en persistent pas moins a réclamer la journée de 8 heures. Le 13 juillet 1906 a été établi le repos hebdomadaire (par romlement.

Vouvelles associations onvières. - Parmi les formes d'associalion qui ont été tolérées par les gouvernements les moins favorables à la liberté d'association en général, citons les Sociétés coopératives, nées vers 1850 dans la Saxe prussienne, et qui ont commencé à se développer en France sous le second Empire. Les unes sont dites de production, les autres de consommution. Les premières permettent aux ouvriers de travailler à leur compte: ce qui supprime entre eux et le public l'intermédiaire du patron. Les secondes leur permettent de créer des magasins d'approrisionnements : ce qui supprime entre eux et le marchand en gros et l"intermédiaire du détaillant. Dans le premier eas, ils profitent des bénéfices que ferait le patron; dans le second cas, les bénéfices que réaliserait le détaillant.

Les associations de secours mutuels, autorisées par 
la loi du 15 juillet 1850 , développées par une série de lois, entre autres celle du ter avril $1 \$ 98$, se sont fondées en vie de l'assistance dans la maladie, dans la vieillesse, etc. En 1852 on n'en comptait que 2488 avec une encaisse de

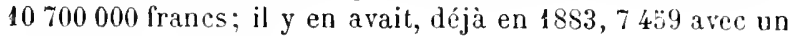
avoir de 40 millions.

On distingue aujourd'hui, entre les sociétés reconnues d't'lilité publique, les sociétés approuvées et les sociélés libres. En 1896, les premières, au nombre de 17, comptaient près de 50000 membres avec 10 millions de fonds de réserve; les secondes, au nombre de 7943 , comptaient 1381552 membres, avec une encaisse de 208 millions et demi; les troisièmes, au nombre de 3000 , comptaient près de $35 \% 000$ membres avec un avoir de plus de i.l millions. (Voir suppl.)

Créations diverses. - Des chefs d'industrie, intellicrents et jatriotes, comme JEAN DoLlrus, de Mulhouse, fondateur, en 1853, de la Societé mulhousienne des cités ouvrières, ont imaginé des combinaisons, non seulement pour assurer au travailleur un logis propre et commode, mais pour lui pernettre, en échange d'annuités modèrées, de devenir propriétaire de sa maison.

Les pouvoirs publics ont contribué aussi à améliorer le sort de l'ouvrier; on lui a rendu plus facile la tâche d'élever ses enfants que, suivant leurs âges, recueillent la salle d'asile, l'école maternelle, l'école prinaire, toutes également gratuites.

La Caisse nationale des retraites pour la vieillesse, fondée par la loi du 18 juin 1850 , sous la protection de l'Etal, comptait à la tin de 19091654247 comples (individuels ou collectils). La loi du 27 dieembre 189.30 , sur les caisses de relraites, de secours ou de prévoyance au profit les employés el ouviers, a réglementé le versement des cotisations, soit à la Crisse nationule des retraites, soit à la Caise des clepots et consigmations, et tixé l’intérêt a servir par ces leux caisses au taux des caisses d’épargne; celle du $\ddot{j}$ arril 1910 , instituant les retraites ouvrieres et puystrnnes, avec une participation tres large de l'Etat, a nécessité el nécessitera encore de iraves amenlements.

La loi du I arril 15S1 a créé les "caisses d'éparone postales ", rattachées à la "Caisse nationale d"épargne ". 
La loi du 20 juillet 1895 a domné une meilleure organisation aux caisses d'épargne.

D'autres lois, en 1893 et 1898 , ont eu pour objet de protégrer les salaires contre la saisie totale par les créanciers et de déterminer la partie qui pouvait ètre saisie.

Assistance pablique. - L'Assistance publique, qui n'est que l'application du grand principe de solidarité nationale, vient en aide au travailleur dans les moments les plus difficiles. L'assistance médicale gratuite a étė assurée par la loi du 10 juillet 1 \$93. L'assistance judiciaire lloi du 22 janvitr $1 \$ 3$ I) lui assure le concours graluit d'avoués et d'avocats et une procedure sans frais devant les tribunaux.

Le nombre des établissements hospitaliers s'élevait en 1908 is 1848, disposant de 189723 lits. On a multiplié les asiles diations, asiles de convaleseents, orphelinats, criches, ourert les asiles de nuit, instilue les médecins cantonaux pour la distrilution gratuite de la médecine et des médicaments. assuré la construction de noureaux dablissements hospitaliers, grice aux prélèvements opérés sur les fonds du parimutuel, les théâtres (droit des panves), etc.

Le buldee de l'Assistance publique, tout compris, atteint chez nous 239 millions; pour la ville de Paris seule, il s'èlève à 66 millions.

Progrès dans la condition des travailleurs. - Le sort du travailleur, dans les villes comme dans les campagnes, s'est graudement amélioré depuis 1789. La suppression des lois sur les céréales a abaissé le prix du pain. Les faciles communications avec les pays à blé rendent impossible le retour de disettes comme celle qu'on a subic encore en lannce 1817 , la a chere aunée s, suivant l'expression populaire.

Au paysan et à l'ouvrier le développement de l'industre assure des outils excellents et a bou marché. On ne peut nier que le paysan et l'ouvrier d'aujourd'hui soient cn général beaucoup mieux logés, mieux meublès, mieux vetus, mieux nourris que ceux dautrefois. Au Xirne siecle, il y arait mue dillérence prolonde, dans le costume et le genre de vie, entre l'ouvrier et le bourgeois, entre le simple paysan et le grand propriétaire rural. Ces diflérences vont culfuçant, bien plus rapidement encore qu'elles n’avaient 
commencé à le faire vers la fin de l'Ancien régime. Le travailleur d'aujourd'hui dépense plus que celui d'alltrelois, comme le prouvent les chiffres suivants. La consommation de la viande a plus que doublé depuis le commencement du siècle; celle du vin a doublé; celle du café a triplé; celle du sucre a décuplé; celle de la bière a augmenté de 70 pour 100 . Or, comme un riche ne consomme pas plus de viande, de vin, de café, de sucre, de bière, aujourd'hui qu'en 1800, ce sont don: les alitses laboricuses qui ont augmenté leur somne de jouiscances.

Le prodigieux développement des journaux et des lirres à bon marché, la multiplication des libliothèques popalaires, la gratuité de l'instruction primaire, le grand nombre des bourses d'enseignement secondaire el supérieur, ont fait marcher du même pas le progrès intellectuel. On peut dire que l'homme du peuple peut donner aujourd'hui à ses enfants toute la somme d'instruction dont ils sont capables.

Les classes laborieuses ont plus de bien-ètre et plıs l'instruction; elles sont aussi devenues plus riches. En 1847 , les caisses d’epargne ordinaires ne renfermaient que 398 millions: en 1869 , 711 millions: en 1882 , un milliarl et rö́t millions; à la fin de 1910 , les 3030 eaisses dispo-aient de trois milliurds et 933 millions représentés par 8 millions 282926 livrets; sans compter les caisses d'épargne d'Algérie et sans compter plus d'un milliard et demi de lranes dus aux déprosants de la Caisse nationale d'épargne. Or, il s'en faut, comme nous l'avons vu, que les caisses d'épargne renlerment toute l'épargne du peuple.

L'Office du Travail créé par la loi du 20 juillet 1991 eut pour mission a de recueillir, coordonner et publier toutes informations relatives au travail, notamment en ce qui concerne l'état et le développement de la production, l'organisation et lia rémunération du travail, les rapports du travail et du capital, la condition de l'ouvrier, la situation compurée du travail en France et à l'èlranger. s

\section{Paris.}

Le Paris nouvean. - a Le Paris d'aujourd'hui, disait en $18 i_{4}$ Maxime du Camp, ne ressemble guère à celui que 
nous avons connu il y a vingt ans. On peut dire, sans trop exagérer, qu'une autre ville a été construite. Nous avons supporté des dérangements et des ennuis sans nombre: qui ne les a oubliés en voyant la capitale saine, aérée, spacieuse qu'on nous a faite?

C'est d'abord sous l'impulsion de Haussmann, préfet de la Seine pendant seize années du second Empire (18531869), que Paris fut haussmannisé, c'est-ả-dire transformé et assaini. A travers les vieux quartiers, bouleversant tout, renouvelant tout sur leur passage, répandant à profu. sion l'air et la lumière, de larges voies se sont ouvertes: boulevards de Strasbourg, de Sébastopol, Saint-Michel, Port-Royal, Denfert, Saint-Germain, Montparnasse, des Invalides, Malesherbes, Haussmann, Voltaire, RicliardLenoir, ete.; avenues portant des noms de victoires et de généraux, rayonnant autour de l'arc de l'Étoile; avenue de l'Opéra, avenue du Trocadéro, avenue Nicolas II; rues Nonge, Turbigo, des Écoles, du Quatre-Septembre, etc.; squares, places des Innocents, Saint-Jacques, des Arts-etMetiers, du Temple, de lobservatoire, de Cluny arec les Thermes romains restaurés, de la Nation, de la Réjublique, d'Italie, ete.; ponts de Bercy, de l'Alma (1856) avec les belles statues de soldats par Arnaud et Diebolt, des Invalides (180\%4855) avec les victoires de Diebolt et Villain, de Sollérino (1059), Saint-Michel (1857), Alexandre IlI (1900).

On a construit les Halles centrales et de nombreux marchés, des églises, des théâtres, de vastes casernes, de grands hôpitaux. L'ancien IIôtel-Dieu a été reconstruit dans les meilleures conditions d'hygiène.

L'ingènieur BeLgRAND a restauré et purifié l'aqueduc d'Arcueil, reconstruit par Salomon de Brosse, sous Marie de Médicis. Par lui ou par son successeur, Alphand, ont été amenées à Paris les eaux de la Dhuys, de la SommeSoude, de la Vanne, de l'Avre. La canalisation pour les eaux potables avait, en 1897 , un développement de $2903 \mathrm{kilo-}$ mètres. Plus d'un million de lilomètres d'égouts ont été construits en matériaux solides et résistants, cuvre digne des anciens Romains. Ils vont aboutir aux grands collecteurs, qui sont comme des fleuves souterrains, arec leurs quais et leurs cliemins de lialage, mème leurs lignes de 
chemins de fer et leurs gares, et leur flotte de bateaux sur les flots fangeux.

Paris, en 1897, avait 2245 rues, 166 places, 42 quais, 82 boulevards, 115 avenues, d'une longreur totale de 1000 kilomètres.

Les bois de Vincennes, de Boulogne, les parcs de Monceau, de Montsouris, les buites Chammont, la butte du Trocadéro, ont été aménagés en splendides promeniules.

En 1860, les limites de Paris ont été reportées aux fortifications, annexant de nombreuses communes : le nombre des arrondissements s'est élevé de douze i vingt.

Aux anciens modes de locomotion sont venus sajouter les bateaux-mouches (depuis $1 \$ 66$ ) et les tramways, dont la premiere ligne (de Vincennes au pont de Sèvres) fut établie à Paris en 185 f et dont les voitures sont mues soit par hes chevaux, soit par la vapeur ou l'électricité.

Dans ce Paris si brillant, la Commune de 1871 a l'ait bien des ruines; mais le mouvement d'expansion a repris sous la liépublique : le Tribunal de Commerce s'est achevé, le Palais du Trocadéro, la nouvelle Sorbonne. les nouvelles Écoles de droit, de médecine, de pharmacie, se sont élevées. La reconstruction de lilotel de Ville a efracé une des plus laides taches de la guerre cirile; sur lemplacement des Tuileries verdoie et theurit un jardin; les ruines du palais de la Cour des conptes ont lait place à une spaciense gare de la compragnie d'orléans. On a réalisé l'établissement d'un chemin de lè métropolitain à traction éleetrique, en majeure partie souterrain, sur les denx rives.

Lyon, Marspille, Bordeaux, Lille, les plus petites comme les plus grandes villes ont suivi l'exemple de Paris, et si, comme la capitale, elles ont plus ou moins oberé leurs finances, elles ont gagné en étendue, en leauté, en salubrité, au grand avantage des classes populaires encore plus que des classes aisées.

\section{Les idées et les groupements socialistes.}

Enfluenre dea théories allemandes et rusmes. -

Nous arons ru comment, à la veille de la révolution de Férrier, les secles socialistes se partageaient entre les doc- 
triues communistes et les doctrines anarchistes '. Les premières avaient été vigoureusement critiquées, dénoncées comme de pures utopies par Proudhon; ce théoricien de l'an-archic ${ }^{2}$, à son tour, s'était trouvé impuissant à donuer une formule concise et pratique aux revendications des classes ouvrières. Celles-ci n'en exercèrent pas moins leur action dans les crises de l'année 1848; sur la révolution politique de Férrier se grefla bientôt la révolution sociale. Elle se manifesta dans les émeutes qui se succédèrent pendant la durée du Gouvernement provisoire et dans les premiers mois de l'Assemblée constituante. Elle atteignit son paroxysme dans les terribles journées de juin 18 \&. La sévère répression qui les suivit brisa pour longlemps la force des partis socialistes. Le coup d'Etat de décombre sembla mettre lin à la révolution sociale en même temps qu“il la révolution politique.

Le second Empire essaya des'attacher les classes ourrières, deja séduites par le rétablissement du suffrage universel, en reprenant dans les programmes socialistes les quelques idées qui pouvaient se traduire en réformes pratiques, en donnant salislaction aux intéréts matériels des travailleurs, en favorisant les associations de mutualite, les cooperatives de production et de consommation, les caisses de secours et de retraites, en encourageant les efforts que firent certains patrons en vue d'améliorer la condition de leurs travailleurs, notamment par la création des maisons ouvrières. Le pas le plus décisil qu’ait accompli daus cette voie le gouvernement impérial, ce fut l'abolition de la légrislation napoléonienne sur les grèves ${ }^{3}$.

Toutefois le progrès mème de la prospérité publique, le développement de toutes nos inclustries, les grands travaux exécutés a Paris et dans les principales villes, en grossissant les centres mbains par l'aflux toujours croissant des populations rurales, accrurent dans des proportions inouïes a les clases ouvrieres o. Elles avaient conscience de la

1. Voir ci-dessus, p. 413 et suiv.

2. L'an-archie do Ploudhon, au sens étymologique de ce mot, était simplement le contraire de l'auturité. Le mot anarchie a pris depuis un sens bearcup plus inquićlant.

3. Voir ci-dessus, p. $70^{\circ}$ í. 
puissance que leur assurait en politique leur bulletin de vote; elles estimaient que si les classes bourgeoises avaient tiré des rérolutions de 1789 et 1830 tout le parti possible, ni ces rérolutions, ni celle de 18 is n'araient donné salislaction complète aux classes ouvières. La révolution sociale leur semblait à peine commencée. Le tiers état avait triomphé en 1789; ce devait être le tour du quatricme itat. $\Lambda$ leurs yeux, l'antagonisme subsistait entre le capital et le travail, entre la bourgeoisic et le proletarint.

Pour exprimer leurs aspirations à la fois ardeutes et vagues, les utopies littéraires de Saint-Simon, Fourier, Cabet, Pierre Leroux, mème Louis Blane, leur semblaient démodées. L'anarchisme de Proudhon ne suffisait plus à des hommes qui convoitaient obscurément la conquète du capital et mème du pouvoir.

Or, en Allemagne, les idées de revendication sociale avaient commencé à se formuler avec toutes les apparcnces d'une précision scientifique. De nouvelles theories socialistes allaient sortir non pas de la masse des travailleurs, mais de la bourgeoisie elle-mème, a travailleurs intellectuels $\triangleright$, lettrés, prolesscurs, ceux qu'on appela ensuite les acialistes de la chaire .

Les créateurs de théories furent des hommes comme Rodbertus-Jagetzow, ancien ministre de l'agriculture en Prusse (1848); Karl Marx, fils d'un fonetionnaire prussien et qui avait fait de fortes études de droit et d'économie politique; Ferdinan! Lassalle, fiis d'un riche négociant et qui avait appris à l'Université le droil, la philologie et la philosophie. Les deux derniers étaient des Israélites. Tous deux avaient été compromis dans les révolutions qui suivirent en Allemagne notre révolution du 24 février 1848.

Karl Marxétait né à Trèves (1818), quatre ans après la fin de la domination française sur ce pays. Son principai ourrage, devenu comme l'évangile du nouveau socialisme, fut publié en 1867 sous ce titre : Le Capital o. Reprenant une idée de Rodbertus, enseignée d'ailleurs par d'autres économistes de grande autorité, il posa ce principe que la richrsse dérive non pas de la nature, mais du truvail, qui seul donne une valeur aux productions de la nature. Le travail est done la mesure réclle à l'aide de laquelle toute 
marchandise doit šévaluer. Il est la vraie a substance créatrice de valeur $\triangleright$.

Comme conséquence, le gain produit par le travail doit appartenir uniquement au travailleur. Tout ce que le capital entend prélever sur ce gain est une spoliation. Si la machine fournie par le capitaliste permet de produire en trois heures une valeur que la simple main-d'œurre n'aurait pu produire qu'en douze heures, peu importe. Pour l'ouvrier, la valeur de son travail équivaut exactement à celle des objets nécessaires à son entretien et à celui de sa famille. Or, słil n'a pas besoin de travailler plus de cinq ou six heures par jour pour gagner cet entretien, tout le travail que le capital exige de lui en surplus est excessif. II n'y a de juste que le travail nécessaire à la subsistance de l'ouvrier et de sa lamille. S'il lui suffit de six heures de trarail pour subvenir a ces besoins, et si on Iui impose une journée de douze heures, c'est six heures de son travail que le patron ne lui paie réellement pas. Or, a par lui-mème le capital est inerte : c'est du travail mort qui ne peut se revivifier qu'en suçant, comme le vampire, du travail vivant et qui vit et s'engraisse d'autant plus vigoureusement qu'il en absorbe davantage ${ }^{1}$. Le patron ou la compagnie qui fait travailler beaucoup d'ourriers, pratique le parasitisme en grand. Dans leur lutte contre le parasitisme du capital,

1. Il n'est pcut-ètre pas inutile de noter, dès le début, ce que la négation de tout droil au capilal a d'excessif, et à quel print tout le raisonnement ultérieur en sera fausese : $1^{\circ}$ Le capilal n'a pas été formé nécessairement par la spolialion : le plus souvent, il est le résultat du travail et de l'éparqne accumulés. Est-ce que le travail ne se propose pas comme sa récompense la formalion d'un capilal, el le travailleu. d'aujourd'hui doit-il être dènoncé comme le capitaliste spoliateur de demain? $2^{\circ}$ Le capital n'est-il pas nécessaire pour créer les entreprises oú le travail trouvera sa rémunération? Cंest si vrai que Lassalle s'adresse à l'Élat pour obtenir ce capilal nécessaire; seulement il entend que ce capital sera graluitement accordé, ne sera pas remunéré : nous indiquons plus loin le point faible de cetle canceptiun; $3^{\circ}$ Si le capital est creatcur, s'il crée les entreprises, en fournissant les machines qui rendront le travail moins penible, moins lons, moins asservissant, moins dangereux pour la santé et la vie de l'ouvrier, peut-on soutenir, avec Karl Marx, qu'il n'est que du a travail nort "vampire du capital vivant?

En outre le systeme de Marx ne tient aucun comple de cet autro capital: I'intelligeuce. 1] semble négliger la rémunération due à l'inventeur, à l'ingénieur, qui ont fondé l'industrie nouvelle, imaçiné les machines et les installations qui garantiront la santé et la vie de louvrier. 
les ouvriers de tous les pays doivent s'associer, afin que les heures de travail ne soient pas augmentées oule montant des salaires diminué par la concurrence qu'ils se feraient mutuellement. Karl Marx enseignait également que les ouvriers doivent lutter pour la conquête des pouvoirs politiques, afin de se servir de ceux-ei pour briser la prépondérance du capital.

Ferdinand Lassalle, né à Breslau (1825). tué en duel près de Carouge, non loin de Genève ( 28 août 186 í), était passionné pour l'unité allemande, très hostile à la France qui s'opposait à la réalisation de cette unité. plus tard grand admirateur de Bismarck, auquel il exposa ses idées et qui en appliqua quelques-unes.

Vers 1862, il publia deux brochures dont les titres sont significatifs : Le programme des outriers et La science ot los ourriers. Schulze-Delitzch et d'autres réformateurs s'efforçaient d'améliorer, en Allemagne, le sort des travailleurs par la création de maisons ouvrières, de caisses de secours, de coopératives de consommation, etc. Lassalle déclara que ces efforts allaient à l'encontre de l'intérît des salariés. Il formula ce qu'il appelait a la loi d'airain o. D'après cette loi, sous l'action de la concurrence pour le travail, le salaire moyen est nécessairement réduit au minimum de ce qui est indispensable à l'ouvrier pour vivre. Si les institutions philanthropiques améliorent ses conditions d'existence, le capital interviendra pour réduire d'autant son salaire. D’autre part, vainement on affirmera que l'onvrier traite librement avec le patron: Lassalle prétend qu'il subira toujours, par besoin, la loi du plus fort. Les travail. leurs ne peuvent échapper à a la loi d'airain o ni par l'effort individuel, ni par les simples coopératives de consommation. Ils ne le peuvent qu'en formant de puissantes associations, capables elles-mêmes de produire. Seulement, comme pour produire il ne suffit pas de la force des bras, comme il faut d'abord des rapitaux pour lutter contre le capital, il est nécessaire d'obtenir des subventions de l'État. Pour les lui arracher, il faut d'abord conquérir la prépondérance politique : elle ne peut se conquérir que si la classe ouvrière est en possession du suffrage universel. L'État doit aider les ouvriers à lormer des associations de pro- 
duetion où, affranchis du patronal, ils ont eux-mêmes la direction de l'entreprise avec la totalité dn bénélice. Si l'État dépense des millions de thalers à eréer des routes, des chemius de fer, des canaux, des ports, il peut bien en dépenser pour substituer au capital exploitant les associations d'ouvriers possédant en commun le capital '. $\mathrm{Au}$ fond, ces idées se rapprochent du socialisme d'Élat, tel qu'il fut pratiqué par Napoléon III et, avec plus de décision encore, par Bismareli.

Lassalle ne eroyait pas nécessaire, comme Karl Marx, de détruire au préalable les États, les trônes, les autels, la propriété privée, afin d'assurer l'avènement de la classe ouvrière. Il estimait que la transformation pouvait se faire pacifiquement et lentement. Pour Marx l'avènement de la République sociale était indispensable; Lassalle se coutentait du sufrrage universel. Il se fût accommodé d'un souverain ou d'un ministre entrant résolument dans ses vues. Il ne eherchait pas à diframer et détruire le capilal, mais à mettre aux mains des ouvriers le capital nécessaire

1. L'inlèrèt des ouvriers est certes très respectable; mais il n'est pas le seal des intéréts qu'un Etat a pour devoir de favoriser. La classe ouvrière, si nombreuse qu'elle soil, n'est pas la senle classe dans une nation. Les autres classes utiles et froductrices, les agriculteurs (beaucoup plus nompreus en France que les ouvriers), les commerçants petits ou grands, les travilleurs de la forét, les pécheurs de la mer, les marins, etc., auraient le meme lroil a réclamer les "millions de thalers " qui leur permettraicat de gaguer plus en travallaut moins. Or, ces millions, ou l'Etal les trouvera-t-il, sinon dans les poches des contribuables, agriculteurs, commergants, forestiers, pècheurs, marins? Les contributions sont prèlevies sur tous pour assurer les services publics d'un intérét évident pour tous, tels que la defense nationale, l'administrition, la justice, les voies de communication, les postes et télègraphes. les ports, l'instruction et l'assisLanee publiques, etc. Le budget de l'Elat, qui doit èlre consacré aux services intéressant la nation tout entè̀e, ne peut avoir pour objel de depouiller l'ensemble des contribuables pour avantager une selile classe de contribuables. Cefle conception du budget et de l'Étrt lui-mème est done radiealement fausse.

Dautre part, le socialisme d'État, bienfaisant si l'on maintient son action dans cerlaines limites, arriverait à des résultats monstrueux si l'on poussait jusqu'au bout les conséquences de la doctrine. ll aboutirait a établir sur tous ses sujets, sur les ouvriers eux-mênes, un despotisme dont rien dans l'histoire du passé ne saurait donner l'idée. L'arriculteur et l'ouvier seraient alors assnjetlis a un servage pire que celui da $\mathrm{xl}^{\circ}$ siécle. Le paysan serait atlaché a la glèbe de l'Étal, l'ouvier asservi á l'atelier d'Elat. Les notions de lıberte individuclle et de proprieté individuelle seratent également abolies. 
à leur émancipation. Narx était un internationaliste : Lassalle était un patriote allemand. Il n'eut guère d'inlluence sur l'èvolution des iclées françaises que par sa pittoresque formule de la a loi d'airain o et par ses prineipes d'organisation coopérative. Il fut avant tout le fondateur de l'Union des travailleur's allemands (1863). Au contraire, Marx, chef en Allemagne du Parti ouvrier social-democrate, est surtout célébre comme le fondateur de l'Internationale des travailleurs. Harx eut pour disciples en Allemagne des hommes comme Lieblinecht et Bebel; mais son action s'exeręa surtout hors des frontières du pays natal. Le marxisme fut un lait non pas senlement allemand, mais européen.

Dès 1847, dans une réunion de communistes allemands dirigée par Karl Marx, avait été formulé le programme du parti : abolition de la propriété privée; le crédit centralisé aux mains de l'État dans une banque nationale; l'agriculture pratiquée … srand, sous la direction scientifique de l'État; l'industrie remise à des ateliers nationaux, etc. (Nous avons retrouvé, dans le mouvement francais de 18 is, partiellement mise en pratique, l'idée de ces ateliers nationau.s). Le manileste se terminait par cet appel: a Prolétaires de tous les pays, unissez-vous $\mathrm{D}$.

LInternationale des travailleurs. - En 1862, pendant l'Exposition universelle de Londres, Napoléon Ill y lit envoyer, aux frais de l'Etat, un certain nombre d'ouvriers français. Ils furent bien aceueillis de leurs eamarades anglais. Les uns et les autres convinrent de s'unir et de créer des comités de travailleurs a pour l'échange de correspondances sur les questions d'industrie inter nationale . C'est le germe de la citibre Internationule de's travailieurs. A ses débuts, elle n'avait rien de révolntionnaire. Elle s'oecupait des questions de salaire, et non de politipue. On devait même, afin de diminuer les difficultés, tâcher de s'entendre avec les patrons.

L'idée prit de la consistance quand, le 28 septembre 186 ', à Saint-Martin's Jall (Londres), se réunit un grand meeling - d'ouviers de toutes les nations p. Karl Marx le dirigeait. Parmi les délégués français se tronvait Totain. alors ouvrier ciseleur, lutur deputé et sénăteur. Lagitateur ta- 
lien Mazzini s'y était fait représenter par le major Wolff; mais il n'y obtint que peu d'influence et ne tarda pas à se retirer de l'entreprise. Le meeting nomma un comité provisoire charge de rédiger les statuts de l'association et de préparer, pour l'année suivante, la réunion d'un congrès „cinéral à Bruxelles

Ce fut seulement en septembre 1866, à Genève, que se réunit le premier congrès général. Il approuva les statuts, qui avaient étè rédigés de manière à ne pas alarmer les gouveruments. Ils créaient une organisation non pas centraliste, comme l'avait fait demander Mazzini, mais lëdérale, respectant l'initiative des sections et fédérations locales. Le conseil génèral de l'Association était élu par les représentants de celles-ci. Il était presque uniquement un centre de direction et d'études; il recevait les rapports. Dans ce congrès de Genève comme dans les suivants, les Anglais et les Allemands montrèrent en général plus de sens pratique que les Français. (Plus d'une lois depuis, ils leur ont reproché les discours inutiles, les discussions violentes, leur a sabbat de sorcières, : Hexensabbat). L'assemblée décida de poursuivre partout la réduction de la journée de travail à huit lieures pour les adultes, à quelques heures pour les enfants. Des résolutions furent votées pour la suppression des armées permanentes. Dans tous les pays du monde commencèrent à se londer des journaux qui propagèrent les idees de l'Internationale.

Le deuxième congrès général se tint à Lausanne (septembre 186\%). On ne vola la suppression ni de l'héritage, ni de la proprieté individuelle, mais seulement la reprise des chemins de fer par l'Etat a afin d'anéantir le monopole des graudes compagnies $\bowtie$. Une certaine défiance se manifestait à l'égard des sociétés coopératives, a parce qu'elles temlent à constituer un quatrième ital, ayant au-dessous de lui un cinquieme ètat plus misérable encore s. Karl Marx aurait voulu limiter l'action du congrès aux questions ouvrières, écarter pour linstant celles de pure politique, ne pas intervenir dans les ellorts tentés par les classes * bourgeoises จ pour l'établissement de Républiques. On décida seulement que a l'émancipation sociale était inséparable de l'action politique.. 
Le troisième congrès se réunit à Bruxelles (septembre 1868). Francais et Allemands furent daccord pour protester contre la guerre qui, à l'occasion du Luxembourg, menaçait d'éclater entre la France et la Prusse. On emprunta la devise des a Sociétés pour la paix • Guerre à la guerie! Il fut mème question de paralyser les gourernements par une grève générale. On convint de soutenir les grèves partielles qui éclateraient dans tel ou tel pays par des souscriptions recueillies dans tous les autres. Pour la première fois, on s'attaqua violemment à la a société capitaliste s, au salariat, a celte forme moderne de l'esclavage s. Au lieu de l'ancien communisme de 18\%8, apparut l'illée du collectivisme. Ce ne sont plus seulement les chemins de fer qui doivent faire retour à l'État, mais les. mines, les carrières, les forèts, même les terres de labour : - La propriété du sol el le travail agricole doivent être traités sur le mème pied que le travail minier et la propriété du sous-sol ». Cette sorte de confiscation s'appelait nationulisation, appropriation à la collectivité, socialisation. Tolain prolesta au nom des cinq millions de petits propriétaires agricoles de France. De plus, il s’inquiétait de vcir l'individu sacrifié à la communauté. Il s inspirait ici de Proudhon qui a toujours combattu l'omnipotence de l'État, cet Élat dùt-il ètre socialiste. Au surplus, les membres du congrès ne précisaient pas ce qu'ils entendaient par la collectivite: était-ce celle de la commune, celle de la. nation, ou bien celle de l'humanité tout entière?

Au congrès de Bàle (septembre 1869) furent prises des résolutions plus graves; celle-ci, par exemple: a Le congrès déclare que la société a le droit d'abolir la propriété individuelle du sol et de laire entrer le sol dans la communauté ». Toutefois l'abolition de l'héritage nobtint que 32 oui sur 68 votants. Enfin cest à ce congrès qu'un nouvel élément se manifesta dans l'Internationale el tendit à la faire dévier: ce fut l'élément révolutionnaire russe, représenté par un ami du républicain russe Herzen : Michel Bakounine. Deja compromis dans les troubles allemands de 18'is, condamné à mort par la Prusse, déporté en Silyérie par le Tsar, évadé ensuite, errant à travers l'Europe en quête d'insurrections à soutenir, Bakounine inquieta les 
congressistes par la froide violence de ses théories. Il demanda la socialisation non seulement du sol, mais de toute richesse a moyen d'une liquidation sociale universelle ; la destruction de tous les États nationaux et territoriaux; sur leurs ruines a la construction de l'Etal international des millions de travailleurs s; la suppression de toute magistrature, de toute Eglise, de tout culte; le maintien de la commune comme seul élément organisć, et encore arec un minimum d'organisation.

En mème temps que s'accentuaient les théories de l'Internationale, l'agitation se propageait dans les masses ouvrières de tous les pays. Des grèves éclataient partont. En France, celle de la Ricamarie (Loire) lut sanglante. Le gouvernement de Napoléon Itl avait, en 1868, dirigé contre les chel's de l'Internationale des poursuites, d'ailleurs pleines de ménagements, et qui l'aboutirent qu'à des condamnations à 100 francs d'amende. Il se montra plus rigoureux dans celles de mai 1870, où fignra. parmi les accusés, Dural, un futur général de la Commune. Dans la presse qui soutenait I'Internationale, on voyait l'idée de la Iransformation sociale violente, au besoin par la rivolution, prendre le pas sur l'ilée prinnitive, qui elail simjlement le relèvement des salaires.

Au lendemain du siège prussien éclata dans Paris l'insurrection de la Commune. On ne voit pas que l'Internationule y ail participé en tant quassocialion; mais nombre de ses membres y jouèrent un ròle à titre individuel; quelques-unes de ses idées et de ses formules y sont reconnaissables ${ }^{1}$.

Le triomphe, puis la défaite de la Commune, exercerent une action dissolvante sur l'Internationale. En excitant les passions, ces érénements firent éclater la discorde, encore latente, entre les éléments relativement modérés de I'Association et ses éléments les plus violents. Quelques sections

1. Peut-étre le mot de "Communen procede t-il de la "commune autonome o de Bakounine. - Karl Marr se lint à l'èrart. 11 ne erut mẻme pas au succès de linsurrection. En revanche, Bakounine avail essayé de provoquer un mouvement a Lyon (septembre 1570). Plusieurs groupes do l'Internationale, notammont le conseil genéral de Londres, lancirent des adresses dencouragement aux incurgés ou, lius lard, témoignèrent do leurs sympathies nour les a gloricur raincus". 
de la Suisse française (Locle et Chaux-de-Fonds), dirigées par James Guillaume, se révoltèrent contre les directions " autoritaires „ de Karl Marx et formèrent la " fédération du Jura $\triangleright$. Les partisans de Blanqui opposaient la a révolution ১à sa théorie de l' a évolution ø. Enfin Michel Bakounine, dont les propositions communistes avaient été repoussées au congrès de Bảle de 1869, fonda a l'Alliance de la démocratic socialiste s. Elle se déclarait athée; elle demandait l'abolition définitive et entière des classes; l'égalité politique, économique et sociale des deux sexes; la destruction de tous les États; la socialisation de la terre, des instruments de travail, de tout capital et de toute richesse.

Cette association fut un grompencul d' a anarchistes s. Seulement l'anarchie qu'ils proliessaient différait protondément de l'an-archie de Proudhon. Elle était, en Occident, le pendant du nihilisme russe. Si les moins violents d'entre eux se contentaient de prêcher la destruction de l'État, des Égiises et même de toute religion, de l'armée, de la société, de la patrie, les énergumènes ne reculaient pas devant la a propagande par le fait s qui nes'attaquait pas seulement aux institutions, mais aux proprietes et aux personnes. Dans ses Principes de la Révolution, Baliounine écrivait: - Nadmettant aucune autre activité que celle de la destruction, nous diclarons que les formes dans lesquelles cette activité doive s'exercer peurent ètre exlrêmement variées : poison, poignard, noeud coulant. La Révolution sanctifie toul sans distinction. A A ces moyens primitits ses disciples ont pu ajouter par la suite le pétrole, la dynamite et les plus redoutables explosils; au poignard associer les armes à feu, les machines infernales et les bombes. En 1881, le congrès anarchiste de Londres recommandait à ses adhérents, l'étude de la chimie, a qui a déja rendu de grands services à la cause révolutionnaire ». De là tant d'attentats contre les propriétés, contre les personnes, mème inoffensives, contre les présidents de République aussi bien que contre les rois et les empereurs (assassinats d'Alexandre II, du président Carnot, de l'imperatrice d'Autriche, du roi d'Italie, etc.). Les exalkés du parti ont fidelement suivi cetle autre instruction de Bakou. 
nine : « Une série d'attentats et d'entreprises audacieuses, insensées même, épouvanteront les puissants... " L'universelle destruction, c'est ce qu'il appelait la pan-destruction'.

C'est au congrès de la Haye (septembre 1S72) que l'Internationale de Marx, attaquée par James Guillaume, arma son chef du droit de dissoudre les groupements rebelles; que les Blanquistes (Ranvier, Cournet, Vaillant), protesterent contre cette usurpation, en faisant scission avec éclat; que Baliounine et ses adhérents furent exclus de l'Association. Celle-ci déclara transporter son siège hors d'Europe, à New-York. L'Internationale de Marx et celle de James Guillaume, peu de temps après, tombèrent également en dissolution. Elles disparurent, moins sous la rigueur des lois édictées par les gouvernements ${ }^{2}$, qualifiées par les socialistes de a lois scélérates $\mathbf{n}$, que par les germes de discorde qui avaient rapidement grandi en leur sein.

Les idées et les partis soeialistes en France. - Le socialisme n'en continua pas moins à se développer parmi les classes ouvrières, et aussi parmi les classes bourgeoises et intellectuelles, où les ambitieux ne manquèrent pas pour l'exploiter comme un tremplin politique. Un ouvricr allemand, au congrès de Breslau (Prusse), montrant ses mains calleuses, disait : a Regardez bien ceci; c'est rare dans notre parti ". C'est peut-être aussi rare en France qu'en Allemagne.

Aux congrès généraux de l'Internationale des travailleurs succédèrent les conlërences et congrès internationaux (Gand, 1877; Coire, 1881; Paris, 1883; Paris, 1886 ; Londres, 1s88; Paris, 1889; Bruxelles, 1891; Zurich, 1893; Londres. 1896 ; Paris, 1900); sans parler d'assez nombreux congrès dits nutionaux, c'est-à-dire particulier's à la France, et d'assez nombreux congrès régionaux. C'est la résurrec-

1. Bakounine est mort à Berne, le 2 juillet 1876. Il a laissé des adhérentg en Russie, en France, en Esparne, en Italie, et partout ils eurent la main dans les attentats, les émeutes et les insurrections. En reranche l'Alliance anarchiste n'a eu aucun succès en Angleterre, ờ elle fut répudiée par lc sens pratique des ouvriers britanniques, ni en Allemagne, oú elle se beurte à la solide organisation des partis socialistes, celui de Lassalle et celui de karl Yarx.

2. Voir ci-dessus, p. $\mathbf{5 3 5}$. 
tion de l'ancienne Internationale sous le nom a d'Internationale socialiste (expression de J. Jaurès).

La dénomination de socialistes, quoiqu'elle soit sourent usurpée par des radicaux plus ou moins avancés $\triangleright$, doit être réservèe aux hommes qui se proposent ou déclarent se proposer, dans un délai quelconque et par des moyens quelconques, la substitution de la propriété et de la production socialistes à la propriété et à la production capitalistes ${ }^{1}$. 11 ne suffit donc pas de se prononcer pour des mesures ou de voter des lois tendant à l'amélioration du sort des travailleurs; car, dans cet ordre d'idées, les républicains modérés ont plus contribué que les socialistes eux-mêmes à la réalisation des réformes. Au fond, comme l'ont déclaré les représentants les plus autorisés du parti, il n'y a de véritable socialisme que le collcctivisme.

A l'extrême gauche des partis socialistes sont les anarchistes. Groupés par Bakounine, puis par son disciple le prince Kropotkine, ils ont plus d'une fois troublé la France par leurs attentats, et c'est contre eux qu'a été votée la loi sur les a associations de malfaiteurs ${ }^{2}$. Les excés commis sont d'ailleurs moins l'œuvre d'un parti que celle de déséquilibrés, de criminels par tempérament, de fanatiques exaltès, parmi lesquels surtout des étrangers, et qui en général vivent isolés ou en groupes très restreints. Cependant tous les anarchistes admettent la légitimité et la nécessité des moyens les plus violents pour hâter la substitution de la « société prolétaire จ à la a société capitaliste ». Ils sont très affirmatif's sur les théories de destruction; beaucoup moins précis sur leur plan de reconstruction sociale. Exclus de l'Internationale par Harx en 1872, ils ont été expulsés du congrès de Zürich en aoùt 1893 et du congrès de Londres en juillet 1896. Celui-ci, sur la proposition de Liebknecht et des Allemands, fit approuver la méthode d'action législative et parlementaire : a En conséquence les anarchistes sont exclus o. En 1900, à l'occasion de l'Exposition universelle, ils avaient projeté de réunir

1. Résolution de Londres (conqrès de 1896, Voir le Cinquieme congrès socialiste international (a Parıs en septembre 1900): compte rendu analycique officiel.

2. Voir ci-dessus, p. 535 . 
dans Paris, à la veille de la réunion du congrès socialiste, un a congrès ouvrier révolutionnaire international o. Il fut inlerdit par le gouvernement français, encore que celui-ci comptat deux socialistes parmi ses membres, el sans que les autres socialistes aient fait entendre la moindre protestation.

Quant aux sectes collectivistes, elles s'étaient d'abord manifestées aux congrès de Narseille (1879) et du IIavre (1880), où elles enlevèrent la direction du parti aux socialistes modérés, uniquement occupés des aríliorations pratiques dans le sort des ouvriers et qui s'étaient groupés autour de Barberet. A Marseille, les collectivistes conquirent la majorité sur ces paciliques partisans de la mutualité el de la coopération; au Havre, ils rompirent violemment avec eux el constituerent le a parti ouvrier .

Parmi les collectivistes il convient de distinguer plusieurs écoles :

1. Les intransigeants, qui, sans prêcher la destruction pour le plaisir de détruire, s'emploieraient volontiers à hâler, par la violence révolutionnaire, l'avènement de la - lélicité universelle $\triangleright$. Ils se ratlachent aux Jacobins de 1793, aux Babouristes de 1797 ', surtout à la Commune de Paris. En attendant l'occasion souhaitée, ils ont longlemps dédaigné de prendre part à la vie politique, électorale et parlementaire, qui les compromettrait arec la "république bourgeoise ". Ils tiennent pour la solution révolutionnaire ou a catastrophique $D$.

Pour amener la révolution ou la catasırophe, les uns, les Blanquistes (Vaillant, Chanvière, ete.), ne répudient pas les anciens procédés, conspirations, émeutes, barricades; les autres, les Allemanistes (Allemane, Groussier, Toussaint, Faberot, Dejeante, G. Deville, Renou, E. Guérard), amorcent le bouleversement en entretenant la lutte des classes, en préparant la gréve générale ${ }^{2}$. Au fond, les uns el les autres sont des communistes attardés, des demi-anarchistes. lls ont même tenté une fusion avec les anarchistes

1. Voir ci-dessus, p. 217.

2. L'onvrier devra alors " utiliser lomes les ressources que la science met à la portée de ceux qui onl quelque choso à détruiren. (G. I) rill.. 
sous le nom de communisme libertaire. Ils manifestent un fanatisme extrême contre tout ce qui lorme l'armature et comme l'ossature de la société, les pouvoirs publies, le patronat industriel, la magistrature, les Églises, l'armée. Ils sont violemment internationalistes. Allemane a rédigé un Catechisme du soldat où l'on peut lire: "Qu'est-ce que la patrie? - La patrie est une idée fausse et un mensonge. La patrie, c'est tout ce qui nous opprime. tout ce que nous devors haïr ${ }^{1}$.

20 Les Broussistes (Paul Brousse, Lavy, ete.) ont rompu moins avec la doctrine marxiste qu'avec la direction a autoritaire de Karl Marx. Ils répudient les moyens révolutionnaires, mème la grève génçrale, qui peut amener l'écrasement des forces prolétariennes et l'anéantissement de toute espérance. lls comptent sur la lorce des choses qui, suivant eux, amènera nécessairement la transformation collectiviste. En somme, ils semblent très proclies du sociulisme d'Etat. Leur chef ayant énoncé cette maxime: a Nous demandons que l'on fasse enfin quelque chose : le positble , leurs adversaires leur ont imposé la dénomination de possibilistes ${ }^{2}$. D'autre part, Paul Brousse, n'est pas, ou peut-être a cessé l'ètre un internationaliste. Récemment il écrivait: - La tradition du socialisme révolutionnaire français esti d'ètre patriote... Le fond de la Révolution française tient dans cette clameur : a La Patrie en danger! »

3o Mathieu Basile, plus connu sous le nom de Jules Guesde, gendre de Karl Marx, avait recu de lui en personne ses directions doetrinales. Essayant de lutter contre Brousse, il fut battu au congres de Saint-Etienne (188:) et dut réunir à Roanne ses adhérents. Il fonda le Parti ouvrier français, qui professe le plus or thodoxe marxisme. Dans son Programme de 1883, il semblait interdire à ses partisans la recherche des mandats de conseillers municipaux et de députés, abandonnant ces sièges “ aux hémorroïdes des

1. Allemane donne à sou parli la dénomination de "parti ouvrier rérolutionnaire socialiste n. Certains dépulés du parti sont tenus, sur leur indemniti parlementaire de 9000 francs, d'en verser 5000 a leur comité; certains conseillers municipaux parisiens doivent verser 2000 francs sur 6000 l'indemnité mun cipale.

2. Le nom que Brouss a ronné à sou parti est celui de Fédération de travailleurs socialistes de France. 
bourgeois de tout acabit $\triangleright$, n'entendant intervenir dans les périodes électorales que « parce qu'elles livrent à son action éducatrice la partie ia plus indifférente de la masse s. Tout au contraire, l'Almanach du parti pour 1892 propose comme objectif la conquête des pouvoirs publics par les conseils municipaux et la députation. On évite de pousser à la grève générale comme trop incertaine et trop dangereuse. On s'essaie à rassurer les petits propriétaires; on ne menace que les gros, condamnés à la "restitution", même sans indemnité. Les Guesdistes (Guesde, P. Lafargue, Chauvin, Prérost, Ferroul, Jourde, Carnaud, etc.) ont acquis une certame force à la Chambre des députés.

$4^{\circ}$ Un parti de socialistes inlépendants a été fondé, en $\mathbf{1 8 8 0 ,}$ par Benoit Malon. Ils professent les doctrines marxistes sur la socialisation, sont en général partisans de l'Élat fédéralisé et de la commune autonome. Ils sont violemment anticléricaux. lls ne reconnaissent ni discipline commune, ni direction autoritaire. Ils sont moins un groupe, moins un parti qu'une collection de persomnalités diverses (Rouanet, Fournière, Sembat, Jaurès, Viviani, Millerand, etc). Dans la masse socialiste, ils sont les plus individualistes; ils en sont les politiciens et les politiques; ils ne cachent pas leur ambitıon du pouvoir. Les crises par lesquelles a passé notre politique intérieure ont tantôt dispersé, tantòt reconstitué le groupe. Il semble anjourd'hui assez disloqué, entre internationalistes et nationalistes. Cependant la plupart se sont ralliés autour d'un cabinet qui comptait l'un d'eux parmi ses membres.

Presque tous les collectivistes ont alopté le programme formulé au congrès du Havre de 1880, où se rencontrent les propositions suivantes, sourent reproduites depuis :

$1^{\circ}$ Repos d'un jour par semaine; réduction du travail des adultes à huit heures; interdiction du travail des enfants dans les ateliers au-dessous de quatorze ans; $2^{\circ}$ Minimum légal des salaires déterminé, chaque annèe, d'après le prix local des denrées; $3^{\circ}$ Égalité de salaire, à travail égal, pour les deux sexes; $4^{\circ}$ Instruction scientifique, prolessionnelle et intigrale (?) de tous les enfants, mis pour leur entretien à la cliarge de l'Etat et des communes; $5^{\circ}$ Mise à la charge de la société des vicillards et des invalides du travail. 
$6^{\circ}$ Responsabilité des patrons en matière d'accident; $7^{\circ} \mathrm{In}$ tervention des ouvriers dans les règlements spéciaux des ateliers; $8^{\circ}$ Revision des contrats ayant aliéné la propriété publique (banques, chemins de fer, mines); exploitation des ateliers de l'État confiée aux ouvriers qui y travaillent; $9^{\circ}$ Abolition des impôts indirects et leur remplacement par un impôt progressif sur les revenus dépassant $3000 \mathrm{jr}$; suppression de l'héritage en ligne indirecte et de tout héritage en ligne directe pour la partie qui dépasse 20000 fr., etc., etc.

$0 r$, si on se rapporte (voir ci-dessus) aux lois déjà votées, on verra qu'une notable partie de ce programme a été réalisée avec le concours des partis modérés : lois sur les heures de travail, développement de l'instruction et de l'assistance publiques, caisses de retraites; loi sur les accidents du travail; loi sur les successions, en tant qu elle admet une progression dans le taril des droits à percevoir (1901); rachat de l'Ouest (1908). Le minimum de salaire, s'il n'a pu ètre imposé à tous les patrons, l'a été, par simple décret, à l'État et aux entrepreneurs qui dépendent de lui (1899).

En juillet 1889 se tinrent à Paris, simultanément, deux congrès de socialistes français, celui des possibilistes et celui des marxistes. En 1890, à la suite d'un nouveau congrès à Paris, on commenca la campagne pour les trois huit (sur vingt-quatre heures, huit heures de travail, huit heures de sommeil, huit heures de repos). Le socialiste Lafargue pensait mème, après Karl Marx, que la durée du travail pourrait se réduire à deux ou trois heures.

Enfin le $1^{\mathrm{er}}$ mai fut indiqué eomme un jour de chômage monstre où les travailleurs de toute la France devaient se livrer à une grande manifestation sur la voie publique. Elle n’eut pas lieu. La fête annuelle projetée ne passa pas en tradition. D'autres mesures tendirent à organiser la conquête des municipalités, l'embrigadement des a prolétaires intellectuels $\triangleright$, des travailleurs agricoles et des a déshérités de la mer $\triangleright$.

En mai 1896, au banquet des a municipalités socialistes , de Saint-Mandé, le députẻ Millerand prononça un discours où il déclara que a n'est pas socialiste quiconque n’accepte pas la substitution nécessaire et progressive de la propriété 
sociale à la propriété capitaliste.... C'est dire qu'il ne saurait s'agir simplement de la transformation de ces trois catégories de moyens de production qu'on peut qualifier de classiques : le crédil et la banque, les transports par voie lerrée, les exploitations minières s. Les ralfineries de sucre el d'autres grandes industries devaient être également s`cialisées. Tel fut le a programme de Saint-Mandé s, dont Millerand, devenu ministre du commerce, n'a rien reliré.

Les socialistes et, pour préciser, les collectivistes avaient déja conquis nombre de municipalités surlout daus les grandes villes, et une quarantaine de sièges à la Chambre. Pourtant ils pouvaient se croire encore éloignés du pouvoir. Le trouble qu'ils avaient aidé, à propos d'une - Afraire „ trop connue, à répandre dans l'opinion publique amena partiellement ce résultat. Lorsque se forma le cabinet Waldeck-Rousseau, deux socialistes entrèrent au ministère, et l'un d'eux, l'orateur de SaintMandé, fut placé à la tête de l'administration qui touchait par le plus de poiıts aux intérêts économiques de la France (22 juin 1899). Le 19 novembre 1899, lorsqu'on inaugura officiellement le monument élevé par le statuaire Dalou, a le Triomphe de la République ø, le parti célébra son propre triomphe : on vit se déployer librement dans la rue le drapeau rouge, emblème du collectivisme, aux plis duquel le drapeau noir des anarchistes vint audacieusement mêler ses plis.

Le congrès international de Paris en 1900. - C'est en septembre 1900, à la salle Wagram, que les collectivistes, français et étrangers, purent réunir un congrès international.

Les collectivistes purs ou marxistes (Jules Guesde, Lafargue), soutenus par les collectivistes révolutionnaires (Vaillant, ete.), s'y trouvèrent en présence des collectivistes qui se qualifiaient d'indépendants, mais qui ètaient en réatité des collectivistes ministéricls (Rouanet, Jaurès, Viviani), renforcés de toute la a jeunesse dorée o du parti, candidats fonctionnaires ou candidats ministres. Une vire discussion s'engagea sur le droit que s'était arrogé le - compagnon d Millerand d'accepter un portefeuille. Le maxiste allemand liautsliy donna sur ce sujet une consul- 
tation enveloppée de réticences : "L'entrée d'un socialiste isolé dans un gouvernement bourgeois ne peut pas ètre considérée comme le commencement normal de la conquète, mais comme un expédient forcé, transitoire, exceptionnel. C'est là une question de tactique, et non de principe. En ce cas, le ministre doit être approuvé de son parti, en rester le marıdataire: sinon il ne peut causer que la désorganisation et la confusion du socialisme militant." Le socialiste russe Plékhanol proposa une addition qui fut ainsi rédigée : an tout cas... un soeialiste doit quitter le ministère lorsque le Parti organisé reconnait que ce dernier donne des preuves évidentes de partialité dans la lutte entre le capital et le travail ๖. Après deux jour's entiers de discussion, la a motion Kautsky o fut adoptée à une forte majorité. Ainsi une question qui divisait des Français fut soumise à l'arbitrage du socialisme européen et résolue par celui-ci.

Le conglès s'elforça de réconcilier et d'unir les écoles rivales en un grand parti socialiste international, ayant pour centre un Comité permanent international, siégeant $\dot{a}$ Bruxelles, chargé de coordonner les efforts des diverses nationalités, de préparer les futurs congrès. La $12{ }^{\mathrm{e}}$ résolu. tion du congrès de septembre 1900 est ainsi rédigée: a Le congrès est d'avis que les grèves et les boycots sont des moyens nécessaires pour réaliser la tåche de la classe ouvrière; mais il ne voit pas la possibilité actuelle d'une grève générale internationale. Ce qui est immédiatement nécessaire, c’est l'organisation syndicale des masses ouvrières, puisque de l'extension de l'organisation dépend l'extension des grèves à des industries entières et à des pays entiers.

Le jour mème (28 septembre 1900) où se clótura le congrés international de Paris, souvrait, également à la salle Wagram, Je congrès des socialistes français. Il fut beaucoup moins calme que le précédent. Minislériels el anti-ministériels faillirent en venir aux coups. Il durent se séparer pour délibérer dans des salles distinctes.

Puis, le groupe guesdiste prit l'initiative d'une réolganisation unitaire lu parti tout entier (février 1901). Cette "unification " a été réalisée depuis avec le concours de 
M. Jaurès, dans la Section française de l'Internationale ouvrière, dirigée par un comité où siègent les délégués des fédérations des sections départementales. C'est comme un État collectiviste qui se créerait dans l'État francais, l'enveloppant du réseau serré de ses groupements, de son administration, de sa police.

Le parti socialiste ainsi organisé a présenté des candidats dans la plupart des circonscriptions aux élections législatives de 1906 : 54 "socialistes unifiés " ont été élus. Un certain nombre de socialistes n'ont pas accepté la discipline du parti : 20 “socialistes indépendants" ont été élus en 1906.

Parallèlement à l'action électorale socialiste, s'est exercee l'action ćconomique ouvrière, par le syndicalisme. La Conféderation Générale du travail, qui cherche à grouper dans une action commune les syndicats ou lédérations de syndicats ouvriers de toutes les professions, est une organisation révolutionnaire; elle préconise a l'action directe , (c’est-a-dire non parlementaire) et la grève générale. Sa propagande a porté surtont sur la journée de luit heures: un mouvement, préparé depuis 1902, en vue le lobtenir, à partir du $1^{\text {er }}$ mai 1906, a provoqué des grèves longues et violentes mais a échoué. Partout oủ nait un conllit entre patrons etouvriers, la Confédération soutient la résistance par ses moyens financiers et par l'action de ses délégués qui encouragent les grévistes a la violence (contrainte exercée sur hes ouvriers non grévistes, destruction de matériel, etc.). Comme conséquence, elle travaille à désorganiser l'armée, quon entendrait transformer en simples "milices citoyennes ": cela dans une Europe où les États militaires travaillent chaque jour a porter au maximum leur puissance d'offensive!

Contre la Confédération générale dn travail, s'est dressce une organisation ouvrière antisocialiste, la Fideration des Jannes, due à l'initiative d'un ouvrier horloger, M. Biètry, et d'un industriel, M. Japy. Les a Jaunes s'opposent à la a socialisation de la propriété , et veulent au contraire développer la propriété indiriduelle par une participation capitatiste des ouvriers aux entreprises.

On voit que les réformes opérẻes et les progrès accomplis dans la législation sont loin d'avoir atténué l'àpreté des "revendications". 
Ouvrages a consulter. - Statistifue armuelle de la France (alepuis $1: 27)$ - Annuaire statislipue de France (depuis 1850). - Bullitin de loffice da travait depuis $189 y^{\prime}$.

Lenseignement teehniqueen France (Miniztere du commerce, 1900).

Figaier, Exposition et Hist. Les princ. decourertes modernes (1857) et Les merveilles de la science, t. I (Chaudières et marhines à vapeur', remis a jour par $\mathrm{Max}$ de Nansouty (1909). - A. Etenand, La tiligraphie clectrique. - Thurston, Hist. de la macline a vapert 1879 . - A. Gulllemin, Les chemins te fer.-A. Hirard, 'Traité des chemins cle fer (18s:).A. de Laplarent, Le siecle du fer (1890). - F. Uujardin-Beaumetz, Histoire graphique cle l'industrie houillere en firance 18.10 .

L. de Lavergne. Economie rurale de la France $1800 \%$. - H. Bandrillart, Les populazons agricales de lit Frunce (155-93) - E. Levasseur, La population francuise (1592). Comte de Rocquigny, Les symlicats ayricoles et lear auve. - J. Meline, Le retour it lu terre et la surproduction industrielle 1905 .

1'. Menriot. Les agylomér. urbaines

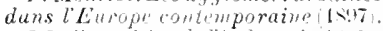
- J.Leferre Wict.delindustrie 18,99 .

- Turgan, Les yrandes usines 1505. - Al. Blanqui, Hist. cle l'econumie politique 1837 - De Foville, $L a$ France économizue (1857). - Rougier, La liberte commerciale (1878). - Richelot. Hist. de la reforme commercisle en Ampleterre. - Mongredien, Hist. dulibre-zohange en Angleterie. - L. Wolowid. La librrti commerciale et les resultuts des trartris le commerce le 1860 (1860). - Cl. Juirlar, Des crises commerciales 1 s.9.

Cunrtois, Hist. de la Banue de Franee et des principates institutions de cridit. - G. Bousquet, meme titre. - Aur. Arnaune. La Monnaie (1902.-De Fuw1!e. memetitre (1907). - Leon Say, bict. des finarees. A. Neyarari, Finances contemporaines 1905

Mlicime du Camp. A. des Cilfenls (t. Ilet 111 ). ou rages cités. - F. Bournum, l'aris, histoire, monuments, administrution. - Belerand. Les trataux souteratus de Jaris (1873-77). Ville de Parlo, Nomenclature des voies publiques et privese (1892). statistique ammelle de la ville de Puris. - Ch. Simond, Paris de foth a $1900 .-1$. Biette, Le Wétropolitain, (Rerue de Paris, Avril-Mai 1906,. -
L. Reynaud, Les trazaux publirs de la France. - D'Avenel, Le micanisme de la cio modeme (1597 sq.). - X. Mossmann, Ln industriel alsacien, Tie de J. Engel-Dollfus (1580).F. de Lesneps, Souvenirs de yuarunte ans. - Hanswnaun, Hemoires. Charles Roux, Le canil de Sue 1901 ). b. Levissem. Hist. des classes ourripes en France depuis 1789 (1903-1): (nestions ourrieres et industr. en frr. sous la $3^{\mathrm{e}}$ fipputel. Les associations professionnelles ouvrieres (Publiration de l'uftice du travail - P. Louis. Hist. du mouvement synutical en France, 1780-1906.Cissmir Periter. Les societés de coopriration 156'. - E. Cheysson, Liconomie sociale it l' Exp. univ. de 1859 . - L. de Seillac, Les congres ourriers en France (1876-1897); Les grives. - P. Hubert-Yalleroux, Les associations ouvrieres et Les associations futronales. - P. Leroy-Beaulieu, La question aurière (1871) el Le tracuil des fummes (1823). - Ch. Be-

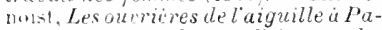
ris. - L. Sunith. Les coalitions et les greces $18>0$ ). - Pierre Lanoir, Les retraits ourvières (1899).-J. Lefort, Les caisses des retraites ourriores 1906).- Sndre, Hist.du communisme 1856. - De Laveleye, Le soczulswe contemporair $1896 \%$ - E. Villey. mème titre (1900) - H. Denis, Hist. les systèmes économiques et socialistes. - B. Malon, Hist. du socialisme (1880-85). - Zacher, llatemaiionale rouge (1885). - Ninterer, Le socalisme international 1990 . James Guillaume, LInternationale (dnc. et souv.) 1907). - G. Weill,

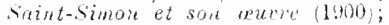
lEcole S. Simoniente (1896; Hist. dic mouvenent sacial en France 155z$1902)(1905)$. - Chamety, Hist. du Saint-Simonisme (1896-- H. Bour. gm, Fourier (1905). - J. Pradhommeaux, Icarie et son fondaten E. Cabet 1907). - P. Thomas, Pierre Lerou.c (1904). - G. Isambert, Les idées sociulistes en France de 1815 a 18.8 (1905). - P. Leroy-Beatiev. Le Collectivisme (1903. - J. Bourdeat, Lo socialisme allemand et $l \epsilon$ mililisme russe (1892). - Wyzewa, Le moucentent sacialis te en Europe (1892). - A. Liesse, La questiom sociale. - L. de Seilhac, Le nourte sociuliste (1896). - G. Goyan, Autour du catholicisme social (1597-1907). 1'. Kropotkine, La conque de pain (anarchiste). - M. Bourguin. Les sy st. sucialistes et l'évol. économ. (190). 


\section{CIAPITRE XXIIV}

\section{CARACTÉRES GÉNÉRAUX DE IA CIVILISATION MODERNE}

L'époque oi nous vivons se listingue de celles qui l'ont précédée par des caractères essentiels : $1^{\circ}$ le progrès scientifique; $2^{\circ}$ le progrès démocratique; $3^{\circ}$ le progrès économique; '́ le progris de la solidarité internationale.

Progrès scientifique. - Le moyen àge arait retardé l'essor des sciences par la prédominance de l'esprit d'autorité: or, l'autorité sur les choses de l'intelligence appartenant it l'Église, les novateur's en philosophie et en science étaient suspects, presque autant que les novateurs en religrion.

A l'autorité de l'Église s’ajoutaient d'autres autorités. Aristote, ce libre esprit de l'ancicnne Grece, était devenu au moyen àge un des geôliers de la liberté intellectuelle. Sur sa philusophie, qualors on connaissait mal, on avait édifié une sorte de philosophie officielle. Le peu de liberté que laissait au penseur l'orthodoxie religieuse lui itait enlevé par l'orthodoxie universitaire. C'est pourquoi il y eut, peudant tout le moyen àge, si peu de tentatires pour renouveler la philosophie et les seiences de la nalure.

Au xvi ${ }^{e}$ siècle, une double révolution s'opéra: la Rélorme et la Renaissance. Lautorité de l'Église cessa d'itre reconnue dans une partie le l'Europe, qui passe au protestantisme; l'autorite de l'Aristote scolastique fut détruite par le rrai Aristote, cest-à-dire par Aristote lui-même mieux connu, et par les autres philosophes de l'antiquité, notamment jar Platon.

Bientòt Bacon formula la théorie des sciences d'observation et opéra ainsi dans le monde scientifique une révolution aussi cramle que celle qu'opéraient dans le monde philosophique [laton et dans le monde religieux Luther. 
Dès lors, pour apprendre à connaitre la nature, on ne se borna plus à lire le texte des écrivains anciens : on se mit à étudier directement les phénomènes, soit par l'observation, soit par l'expérimentation.

Sans doute, l'autorité ancienne, rendue plus défiante par les échecs qu'elle avait éprouvés, surveillait encore, et mème avec plus de rigueur, les esprits indépendants. En 1632, Galilée était obligé de faire amende honorable. Descartes n'osait se déclarer ouvertement pour le vrai Système de l'Univers.

Toutefois le principe d'autorité n'était plus assez fort pour violenter l“intelligence à demi émancipée : il s'était affaibli dans le monde depuis qu'il y avait plusieurs autorites religieuses et plusieurs autorités philosophiques. Les gouvernements laïques ne permettaient plus cet asservissement de la science à la théologie : les ecclésiastiques éclairés se dégageaient eux-mèmes d'une discipline surannée. Cette liberté nouvelle en matière scientifique, bien qu'alors elle coexistât avec une recrudescence des persécutions religieuses, favorisa, au xvile et au xvili ${ }^{e}$ siècle, le premier épanouissement des sciences. Le progrès naturel de la civilisation moderne aurait assuré tôt ou tard l'émancipation complète; la Révolution française l'accéléra.

Le siècle présent a hérité de la pleine libertė religieuse, de la pleine liberté philosophique, de la pleine liberté scientifique.

C'est la science qui a éte le plus puissant agent de la transformation sociale. Ses découvertes ont renouvelé tout l'outillage du travail, de la charrue à la machine à coudre. En se rendant maitresse de deux forces de la nature jusqu'alors ignorées ou mal conaues, la vapeur et l'électricité, elle a pour ainsi dire doué l'humanité de deux facultés nouvelles. Elle a enveloppé le globe d'un réseau de plus en plus serré de fils de mètal, par lesquels circule d'un continent à lautre la pensée humaine, et donné à notre planète comme un vaste système nerveux. Elle a couvert la terre et les mers de véhicules rapides qui suscitent dans la foumilière humaine un incessant mouvement de circulation. Elle a créé les appareils qui permettent de voguer clans les airs et de respirer sous les liots. Elle 
a contraint le Soleil à devenir un artiste au service de l'homme. Elle a inventé des appareils qui transforment la nuit en un jour éclatant. Elle nous a fait réaliser, de Franklin à Edison, de Bichat à Pasteur, 'c'est-à-dire en moins d'un siècle, plus de progrès qu'il ne s'en était fait des premiers savants grees à Franklin et à Bichat, c'est-à-dire en vingt-trois siècles. Elle a augmenté la durée de notre vie moyenne et centuplé nos moyens d'action. Elle a habitué nos contemporains à des prodiges plus étonnants que ceux que la crédulité d'autrefois attribuait aux fèes, aux enchanteurs et aux sorciers; elle a rendu les choses naturelles plus merveilleuses que le merveilleux de nos pères.

Ces découvertes ont modifie si profondément les conditions de la vie qu'une société toute nouvelle a pu se former Celle-ci diffère presque autant de la société qui a produit Mirabeau et Robespierre que celle-là dillérait de la société qui avait produit saint Bernard ou saint Louis.

Non seulement il serait impossible de replacer la France dans la situation où elle était à la veille le la Révolution, mais il serait impossible de la replacer dans la situation où elle était au lendemain de la Révolution. La transformation accomplie par la science est aussi absolue que celle qui a été accomplie par les principes de 1789. Les découvertes sorties du laboratoire des savants ont renouvelé le monde aussi complètement que les lois sorties de nos grandes assemblées révolutionnaires. Si la Révolution aclieva de nous donner la pleine liberté scientifique, la science à son tour a rendu irrérocables les changements sociaux et politiques opérés depuis 1789. Si l'ouvre de nos Assemblées a duré et est demeurée indestructible, c'est que la révolution politique et sociale a coïncidé avec la révolution dans les sciences et avec la révolution dans l'èconomie politique.

Progrès démocmatique. - Le moyen âge a été le règne de l'aristocratie et du clergé; les temps modernes ont vu s'élever le pouvoir absolu des rois; la Révolution a donné la souveraineté à la nation. Dans la nation elle-mène, les classes populaires ont eu un moment le pouvoir en main lorsque le parti montagnard, avec Danton et Robespierre, 
gouvernait la France. Le gouvernement de ces classes ne dura pas plus de deux années, de 1793 à 17930 . Elles étaient alors trop ignorantes, trop passionnées, trop peu instruites des lois de la politique et de l'économie politique, pour garder longtemps le pouvoir. La Terreur, le tribunal révolutionnaire, la loi des suspects, le maximum, en un mot les excès de toute sortes, ruinèrent promptement leur prépondérance. C'est sur d'autres classes de la nation que s'appuyèrent les gouvernements suivants : le premier Empire sur les militaires, la Restauration sur les grands proprietaires fonciers, la Monarchie de Juillet sur la bourgeoisie industrielle et commerçante. La Révolution de 1848 rendit le pouvoir aux classes populaires; mais les imprudences des ouvriers et l'apathie des paysans laissirent passer la souveraineté du peuple á un nouveau César; la démocratie et le suffrage universel furent mis en tutelle. Aujourd'hui, ils sont majeurs.

Toutes les formes, monarchie de droit divin, royauté bourgeoise, empire militaire, qui voilaient plus ou moins la réalité, c'est-à-dire la souveraineté eflective de la nation, ont pris fin. La République a réalisé, sinon organisé, le gouvernement du pays par le pays : les électeurs nomment les sénateurs et les députés; ceux-ci élisent le chef de l'État et élisent les ministres, puisque les ministres sont en quelque sorte imposés au chef de l'Etat par la désignation des Chambres. Le vote de tout électeur a donc son effet direct ou indirect, mais assuré, dans la constitution du gouvernement. Chaque électeur est donc responsable de toutes les conséquences que pourront entrainer pour la France et pour la République un vote irrétléchi ou simplement son abstention daus les scrutins. Le corps électoral n'aura jamais que le gouvernement et le parlement qu'il mérite.

Un État où la collectivité des citoyens est la source même du pouvoir, où tous les citoyens ont les mêmes devoirs et les mêmes droits, s'appelle une democratie, c'està-dire le gouvernement du peuple.

Dans une démocratie, ce sont les classes les plus nombreuses qui ont le plus d'action; il est donc inévitable que toutes les lois se proposent de lavoriser leurs intéréts. 
S'il s'agrit de constituer l'armée, ces lois veilleront à ce que le devoir militaire ne pèse pas plus lourdement sur le paysan et l'ouvrier que sur le noble et le bourgeois. Les gouvernements de sulfrage restreint, la Restauration et la Monarchie de Juillet, ne pouvaient produire que des lois militaires comme celles de 1818 et de 183.2, qui, par le remplacement à prix d'argent, permettaient aux riches de se dérober aux charges communes. Un gouvernement de suffrage universel comme celui de la République actuelle devait, au contraire, aboutir aux lois militaires 1e $1572 \mathrm{et}$ de 1889 qui font peser sur tous, aussi equitablement que possible, les mèmes charcres.

Un gouvernement de sulfrage restreint, élaborant une loi sur linstruction primaire, devait naturellement écarter les principes de l'obligation et de la gratuité; un gouvernement de suffrage universel devait au contraire les consacrer, car tout citoyen, étant électeur, doit ètre obligé de s'instruire, et, puisque la loi lui en fait une obligation, elle doit, par la gratuité, lui en assurer les moyens.

Un gouvernement de suffrage restreint risque, en matière économique, de pencher pour le système protecteur. Celui de la Restauration, pour lavoriser la grande propriété loncièle, fit les lois sur les céréales, bien qu'elles eussent pour conséquence d'augrmenter le prix du pain pour les classes qui n'étaient pas investies du droit de sulfrage. Celui de la Monarchie de Juillet, pour lavoriser la bourgeoisie industrielle, devait maintenir ou imposer des Mroits considirables sur les produits manulacturés de l'etranger, bien qu'ils eussent pour conséquence daazmenter, pour les classes exclues du vote, les prix les tissus. des aciers et autres objets nécessaires à la vie. Les gouvernements de suthrag̣e universel ont dû se préoccuper de lintérêt des consommateurs, et inaugurer une politique de liberté commerciale relative, qui na pour limite que l'intérèt même du paysan et de l'ouvrier francais.

Ainsi, toutes les lois édictées par un gourernement démocratique sont nécessairement la conséquence du principe sur lequel il repose : issu de la volonté du plis srand nombre, ce sont les intérèts du plus grand nombre fu'il a mi-sion de servir. Mais pour servir ces interéts, il lutut les 
bien comprendre. Servir des intérêts ce n'est point flatter des passions et des préjugés. II peut arriver par exemple, qu'en poussant à l'excès le princifle d'égalité, on nuise à l'intérêt le plus évident de la démocratie.

Laction du principe démocratique est si puissante qu'elle s'exerce non seulement dans les lois, mais dans toutes les manifestations de la vie intellectuelle. $\mathrm{Ni}$ la littérature. ni l'art nëchappent à cette influence. Depuis que le peuple a commencé à s'instruire, des milliers de livres, des centaines de journaux, ont été écrits exprès pour lui. La révolution romantique dans la littérature et daus les arts a coïncidé avec les premiers progrès de la démocratie : la traquédie classique, par exemple, a dù céder la place au drame; le roman s'est proposé la peinture des mœur's populaires ou s'est inspiré de préoccupations sociales.

La peinture de Delacroix, avec; sa vie intense et sa couleur éclatante, la peinture de nos contemporains, arec cette recherche des sujets réels et le réalisme de l'exécution, devaientètre nécessairement plus populaires que celle des classiques. La Marseiliaise de Riude, sur l'Are de Triomphe, est un chef-d'œu vre plus intelligible aux masses que la sculpture mythologique du siècle dernier. L'architecture devait entrer également dans de nouvelles voies : ce n'était plus des palais qu'elle avait surtont à élever, mais des lieux de réunion qui répondissent aux besoins du souverain noureau : de vastes hôtels de ville, des halles immenses, des théatres et deshippodromes prodigieux.

Ce nest pas en France seulement que la liberté politique et l'égalité démocratique sont en prosrès. La Révolution française, nous l'avons vu, a eu chez tous les peuples son contre-coup. Les gouvernements absolus, après avoir longtemps résisté à l'esprit nouveau, ont fini par y céder. La Suisse, qui était une collection de républiques aristocratiques, est devenue une fédération de démocraties. Les cole. nies espagnoles et portugaises de l'Amérique du Sud se sont constituées en républiques. Des provinces asservies aux Tures, comme la Gréce, la Roumanie, la Serbie, la Bulgarie, sont devenues des États indépendants.

Le royaume des lles-Britanniques, depuis les réformes électorales de 1832. 1867, 1884, les royaumes d'Italie, de 
Belgique, de Hollande, d'Espagne, de Portugal, de Suede, de Norvège, ne sont plus que de nom des monarchies. Là aussi, e'est la nation qui se gouverne elle-même par son Parlement et par son Conseil des ministres responsables devant les Chambres. Il en est à peu près ainsi dans les États dont se conpose l'Autriche-Hongrie. L'empire allemand, bien qu'il ait gardé une monarchie toute militaire et absolue dans son principe, a cependant des assemblées élues. Si la Chambre prussienne est encore nommée au sullrage restreint, la plus importante de toutes les assemblées, le Reichstag ou parlement de l'Empire, procède du suffrage univerșel : si le sufîrage universel est encore soumis à une dure tutelle et si le Reichstag est étroitement subordonné au pouvoir impérial, les principes admis ne peuvent manquer de développer, tôt ou tard, leurs consiquences. Il n'y a plus en Europe de gouvernement alsolu : l'empire rusce, depuis 1905, a un Parlement; les "Jeunes tures ", en 1908, ont détruit le régime hamidien et réuni une Chambre. La Perse même s'est donné une Constitution et la Chine a proclamé la République!

LEurope forme un ensemble de nations qui, à toutes les époques, ont toujours fini par adopter les mèmes institutions politiques, a mesure quelles arrivaient au même degré de civilisation. Parmi toutes ces nations, la France présente aujourd'hui un caractère absolument original : elle est le seul grand État européen qui soit à la fois unitaire, democratique et républicain. Mais l'esprit de liberté et l'esprit de démocratie n'en tendent pas moins à prévaloir dans tous les autres États. La France est en avance sur toutes les nations européennes, mais elle a cessè de marcher isolée.

Progrès économique. - Le grand problème à résoudre étant le bien-ètre des masses, c'est lui que toute la politique doit avoir en vue. Aux siècles oủ les barons commanCaient en maitres, il guerroyaient pour agrandir leurs domaines, imposer l'hommage à de nouveaux vassaux, augmenter le nombre de leurs châteaux-forts et de leurs hommes d'armes. Quand l'Église fit prévaloir son autorité, elle prêcha la guerre sainte et inaugura les croisades. Quind la France fut rassemblée sous le sceptre d'un roi, 
on fit la guerre pour conquérir des provinces, affaiblir de puissants voisins, maintenir l'équilibre européen. Avec les idées nationales et démocratiques commencérent les guerres pour la propagande révolutionnaire ou l'affranchissement des peuples opprimés : telles furent la guerre d'Amérique sous Louis XVI, la plupart des guerres de la Rivolution, puis celles de l'indépendance grecque, de l'inuépendance belge, de l'indépendance italienne.

Aujourd'hui, la guerre pour les intérêts politiques ou pour les idées philosophiques tend à céder la place à la lutte pour les intérêts économiques. On a fait, pour ourrir à notre commerce de nouveaux débouchés, les guerres de Chine en 1860 et 1900, les guerres de Cochinchine et du Tonkin, celle de Tunisie, celle le Madagascar, la conquête d'une partie de l'Alrique. Si l'on acquiert aujourd'hui des colonies, ce n'est plus pour la vaine gloire d'annexer à la métropole de nouvelles provinces.

Comme le progrès de la richesse s'accommode plutòt de l'état de paix que de l'état de guerre, les relations pacifiques entre les peuples tendent à remplacer les contlits d'autrefois. La politique des conquêtes en Europe est condamrée. Celles de Napoléon for ont laissé la France plus petite. L'annexion par l'Allemagne de deux provinces françaises est pour cet empire une cause évidente d'embarras et de danger. C'est à cause de l'Alsace et de la Lomaine qu'il s'impose el impose à l'Europe des armements démesurés et des dépenses non moins écrasantes pour lui et pour elle que pour nous. C'est à cause de cette annexion qu'il est dans linquiétude continuelle d'une double guerre contre la France et la Russie; c'est à cause d'elle que l'Allemagne est privée de la pratique sincère des libertés constitutionnelles; c'est à cause d'elle que lui incombent de si lourdes charges fiscales et militaires.

La tâche de l'homme d'État d'aujourd'hui n'est pas, comme autrefois, de combiner des alliances oflensives, de préparer de secrètes et subtiles combinaisons, de mûrir des projets d'agrandissement. Elle est surtout d'assurer sans cesse au commerce national de nouveaux débouchís, de défendre lindustrie du pays contre les tarifs de douane ou la prépondérance économique des États voisins, de sur- 
veiller la balance des importations et des exportations, de préserver de toute atteinte le crédit de l'État. Les traités les plus fréquents sont aujourd'hui des traités de commerce.

Sans doute, les anciens rois se préoccupaient, jusqu'à un certain point, d'accroitrc le bien-ètre du peuple; mais c'était surtout en vue de pouvoir ensuite exiger de lui des impôts plus considérables afin d'augmenter leurs armécs, leur marine, leur puissance en Europe. Aujourd'hui, le bien-être du peuple n'est plus seulement un moyen d'arriver à un autre but: c'est le but mème de tout gouvernement libre.

La politique, la diplomatie, la gucrre elle-même, sont subordonnées à l'économie politique. Un État n'est plus mis en péril seulement par l'attaque à main armée d'un peuple voisin : il peut l'ètre par le déficit de ses budgets, la destruction de son crédit, la diminution de ses exportations, le malaise des populations. Un traité de commerce mal conçu peut être aussi désastreux pour lui yu'une bataille perdue; une banqueroute peut compromettre son indépendance: on a vu en ce siècle des États, mulsumans à la vérité, devenus insolvables et lorcés d'abandonner à leurs crẻanciers l'administration de leurs revenus, et jusqu'à la direction de leur politique. Il estimportant de considérer le chiffre des forces de terre et de mer qu'entretient une nation: mais la lermeture de certains débouchés aux produits de ses manufactures préparerait aussi assurément sa ruine que la décadence de sa marine ou de son armée.

Solidarité internationale. - Il semble que les mots de solidurite internationale n'aient jamais été moîns justiliés qu'aujourd'hui. Dcpuis les guerres de la Révolution et de l'Empire, l'esprit cosmopolite et humanitaire, qui fut celui du xvin ${ }^{e}$ siècle et qui tendait à ne faire de l'Europe qu'une seule famille, a fait place, chez tous les peuples, à un réveil violent du sentiment national. Ce sentiment, grảce à la politique de paix qui a prévalu de 1815 à 1848 , n'a pas d'aborl amené de nouveaux conflits. Mais, depuis 1841 pour l'Allemagne, depuis 1848 pour la plupart des autres nations européennes, les questions de nationalité ont occupé le premier plan. Les libertés conquises ou les constitutions octroyées presque partout semblent plutôt 
avoir aggravé cetie situation. Les peuples, devenus majeurs, ont hérité des passions, des jalousies, des liaines, qui autrefois ne divisaient que les rois. Toute guerre européenne a pris le caractère d'une lutte, non plus de cabinet à cabinet. mais de nation a nation. Surtout depuis les événements de 1866 et de 1870-18\%1, l'Europe s'est couverte, non plus de milliers, mais de millions de soldats. Par moment, on peut se eroire à la veille d'une mêlée générale des races.

$\mathrm{Si}$, dans liavenir, des gouvernements républicains se substituaient partout aux gouvernements monarchiques, si même des républiques socialistes se substituaient partout à ce que les collectivistes appellent des républiques - bourgeoises $\triangleright$, les chances de guerre n'en devien.traient pas moins fréquentes, ni les guerres moins terribles, ni les conséquences des guerres moins désastreuses. Les guerres a nationales pour l'indépendance ou pour la propagande ne furent pas moins àpres que les guerres a royales s pour l'agrandissement du domaine, ou pour le prestige, ou pour la gloire; les guerres a bourgeoises s pour l'expansion du commerce ou la conquète des gisements auriëres ne le furent pas moins. Les guerres a sociales D entre Etats c ouvriers s, pour des questions de tarifs ou de salaires, c'est-à-dire pour le pain quotidien, ou à peu près quotidien dans des soeiétés très appauvries, seraient peut-ètre encore plus acharnées. A en juger par les sanglants conflits qui s'èlèvent parfois sur les chantiers entre ouvriers français, italiens ou belges, il ne semble pas que les doctrines internationalistes soient près de réaliser l'âge d'or. Jusqu ii present les modifications dans la forme politique ou dans la constitution sociale des nations n'ont pas ete nécessairement des garanties de paix.

En dépit de beaucoup de symptômes alarmants, on ne peut nier eppendant les progrès accomplis dans les relalions internationales.

A l'époque lëodale chacun vivait sur la terre de son seigneur, entre les murs de sa ville, et bien peu osaient passer les limites de la seigneurerie ou de la commune. Avec la puissance des rois, l'borizon s'élargit jusqu'aux frontières lu royaume, et l'idée d'une Patrie prit naissance. L'Église avait conçu l’jlée un peu vague de la Chrétiente : 
c'est la diplomatie du xvie siècle qui a créé l'Europe. Depuis lors, combien le monde s'est agrandi pour nous! La eolonisation française a fait entrer dans le rayon d'aetion de la civilisation européenne le Canada, la Louisiane, les Antilles, puis l'Afrique septentrionale et occidentale, Madagascar, une partie de l'Indo-Chine et des archipels d'Océanie. La colonisation anglaise y a fait entrer l'Amérique du Nord, l'immense empire des Indes, le grand continent australien, et, avec la colonisation allemande, une partie de l'Afrique. La colonisation espagnole et portugaise y a lait entrer l'Amérique du Centre et du Sud, une partie des iles et des côtes africaines, les Philippines et d'autres archipels océaniens. La colonisation hollandaise y a fait entrer l'Afrique du Sud et les iles de la Sonde. La colonisation russe y a fait entrer l'Asie du Nord. Des États demi-barbares ou possédant une civilisation d'un type tout différent de la notre, comme la Chine, le Japon, la Perse, la Turquie, l'Égypte, le Maroc, de gré ou de force, ont dû aceepter les relations avec les peuples de notre race. L'Europe aujourd'hui n'est plus qu'une partie du monde européen, du monde civilisé. Des nations nouvelles, de sang français, anglais, espagnol, portugais, hollandais, allemand, russe, se sont formées ou sont en train de se former dans les deux Amériques, en Afrique, en Asie, en Océanie, et les principes de notre civilisation pénètrent dans les vastes régions de l'Extréme-Orient. L'homme de notre siècle considère l'univers entier comme son domaine, et l'ancien monde des Romains n'est plus qu'une faible partie du monde réel. On commence à concevoil l'idéc d'une solidarité entre tous les peuples, qu'ils soient de race blanche, jaune, noire ou brune.

Le droit des gens, qui n'obligeait autrefois que les peuples de l'Europe clrétienue, tend à régir aujourd'hui l'humanité. Les Tures, jadis exclus du concert européen, en font rartie intégrante. Les Persans, les Chinois, les Japonais, les Coréens, les Siamois, les Marocains, ont appris à envoyer et à recevoir des ambassadeurs, à signer des traités d'amitié et de commerce, á en observer à peu près les clanses, à en invoquer les garanties, à se faire représenter dans les congrès. 
Ainsi donc, il existe un droit, plus ou moins respecté, qui régit les rapports entre toutes les nations dignes de ce nom, soit en temps de paix, soit en temps de guerre.

Le droit d'aubaine de l'époque féodale s'est maintenu, avec certains adoucissements, à l'époque royale. Il fut aboli chez nous par la Révolution et ne tarda pas à disparaitre de partout.

Pour le navigateur étranger, les côtes de France furent cruellement inhospitalières dans les temps anciens. Aujourd'hui, on a perfectionné le système des phares, on a formé des sociétés et organisé des services de sauvetage, et des marins intrépides vont, par les mers les plus terribles, au secours des navires en péril, sans se demander quelle est leur nationalité. L'étranger, au lieu d'être repoussé ou traqué, est au contraire attiré, protégé, piloté, sauvé parfois de la tempête.

Les frontières d'un État étaient autrefois un obsticle sérieux à la circulation. Presque tous les objets venus de l'étranger étaient ou prohibés ou bien frappés de droits énormes, et les douaniers n'épargnaient an voyageur ni perquisitions ni vexations. Aujourd'hui, le nombre des prohibitions et le montant des droits ont diminué : la contrebande ne rapporte plus les mêmes profits et n'est plus aussi active. Vers 1820 , quiconque parconrait les trente-sept États de l'Allemagne, par exemple, pouvait voir ses malles bouleversées trente-sept fois par des douaniers aux uniformes variés. Les mêmes agréments attendaient le voyageur qui, en Italie, passait des États sardes aux États lombards-rénitiens, du duché de Parme au grand-duché de Toscane, des terres du Pape au royaumse de Naples. Presque toutes ces lignes de douanes ont été supprimées par le Zollverein ou Union des douanes de l'Allemagne. par la réorganisation du systime douanier dans l'Autriclie-IIongrie, par la réunion de l'Italie en un seul État. Aujourd'hui, on va de Paris à Pétersbourg en traversant seulement deux lignes de douanes.

Une autre vexation attendait autrefois, à toutes les frontières, le voyageur. Il ne pouvait les franchir sans un passeport pour lequel on arait multiplié les formalités et les droits fiscaux et qui, à la fin du rovage. était noir de tous 
les visas et de tous les timbres des États civilisés. Les Anglais, le peuple le plus libre d'alors, et de tout temps le plus pratique, supprimèrent les premiers l'obligation d'un passeport pour entrer chez eux. Le gouvernement impérial de France, quelque absolu et défiant qu'il l'ît, les imita. L'exemple gagna de proche en proche. Aujourd'hui, it part la Russie et la Turquie, l'Europe entière peut ètre parcourue sans passeport.

Nous avons vu à quel point l'Union postale universelle, l'adoption, par certains Etats, de notre système métrique et monétaire tendent à favoriser les relations.

Tandis que tombent quelques-unes des barrières qui séparaient les peuples, les liens qui les unissent vont se multipliant. Chaque jour, quelque nouvelle ligne de télégraphe, on de cable sous-marin, ou de chemin de fer, ou de paquebots, vient resserrer le réseau de communications qui enveloppe le monde civilisé. Dans toutes les entreprises de chemins de fer ou d'industrie, dans tous les emprunts nationaux ou municipaux de Belgique, d'Espagne, d'Italie, de Russie, il y a une quantité énorme de souscriptions francaises, tandis que des masses de capitaux belges, anglitis, allemands, américains, sont placées dans les entreprises et dans les emprunts francais. La richesse de l'Angleterre et celle de la France sont, en particulier, si étroitement associées que la Bourse de Paris suit tous les mouvements de la Bourse de Londres, que les faillites d'Angleterre provoquent des désastres sur les marchés financiers de Paris, de Lyon, de Marseille, de Lille, de Bordeaux, que la guerre déclarée entre ces deux puissances amènerait chez les deux peuples la mème dépréciation des valeurs et le mème désarroi du crédit. Tant de liens d'alfaires et d'intérèts les unissent qu'une guerre entre ces deux nations, qui se sont porté autrefois tant de coups terribles, semble aujourd'hui une impossibilité. Ce sont les frères siamois de l'économie politique.

Aucune des grandes entreprises du siècle n'a pu étre conduite par une seule nation : il a fallu que l'Italie et la France fussent associées pour le percement du mont Cenis, l'Allemagne, la suisse et l'itáiz pour le percement du Saintfrothard. i Angleterre et l'Anerique pour te y'emier câble 
transatlantique : c'est surtout, mais non uniquement, arec des capitaux francais qu'a été ouvert le canal de Suez.

La science du $\mathrm{x}^{\circ}{ }^{\circ}$ siècle est une science qui n'est ni française, ni anglaise, ni amérieaine, ni allemande : elle est avant tout la science. Le savant ne travaille plus, comme autrefois, isolé dans son laboratoire: des centaines de Revutes tiennent le clercheur français au courant des travaux et des cxpériences de ses confrères étrangers. Des congrès internationaux, pour toutes les branches de la science, l'appelient a se mettre en relation directe avec eux. Aucune grande découverte n'a été réalisée sans que le génie primesautier de la France, l'esprit pratique des Anglais, l'excellente organisation scientifique de l'Allemagne, la ténacité et l'ingéniosité américaines, n'aient tour à toní concouru au succes. - C'est un Français, Papin, qui découvre la force expansive de la vapeur; c'est un Anglais, Watt, qui construit la première machine à vapeur; c'est un Américain, Evans, qui construit la première machine à haute pression. - Le Francais Jonfîroy d'Abbans dirige le premier bateau a vapeur; les Américains Fitch et Fulton reprennent son idée et l'anènent à un résultat pratique. - La locomotive de l'Anglais Stephenson n'atteint son maximum de puissance que lorsque le Francais Seguin l'a dotée du système tubulaire. L’Anglais Grey découvre la transmission de lélectricité par le contact; le Hollandais Musschenbrock imagine la bouteille de Leyle; l'Iméricain Franklin dresse le premier paratonnerre; l'ltalien Volta construit la première pile; le Danois OErsted fonde l'électro-magnétisme; les Français Arago et Ampère trouvent le principe du télégraphe éleetrique.

Ce qui a dominé dans les temps anciens, ce furent surtout les cuvres qui divisent les nations : la guerre et la conquête. Ce qui finira peut-être par dominer dans les temps noureaux, ce sont les ceurres qui réclament le concours pacifique et ! ¿anulation reonde de tous les peuples : celles de lindustric, du conmerce, de la science, de la philanthropie. 



\section{NOTES SUPPLENENTAIRES}

\section{l.age 562.}

Une nouvelle conférence s"est réunie à la llaye en 1907, sur l'invitation du président des États-Unis. Le programme était plus restreint, presque exclusivement relatil' a la gruerre maritime : on précisa les droits et devoirs des neutres fourniture de matériel de guerre, séjour, droit de visite ou eapture dans eaux neutres, etc.); on prescrivit des limites au bombardement des côtes et à l'emploi des mines sousmarines, on institua une Cour internationale des prises. La limitation des armements fut une fois de plus écartee. Quarante-auatre États s’ètaient fait représenter.

Page 580.

Les cuirassés tendent à devenir de plus en plus grands; les frégates cuirassées de la flotte que le second Empire laissa à la République déplaçaient de 6 à 7000 tounes; ceux de 1881, euviron 10000 ; les derniers mis à flot (1908), de 15 à 16000 ; ceux en construction, 19 à 20000 tonnes. Cependant, en 1004, sous Port-Arthur, le cuirassé amiral russe Pétropavlovsk, ayant touché deux torpilles, coule en trois minutes; le cuirasse japonais Hatsusé, iorpille également, disparait en cinquante secondes. A la bataille de Tsou-Sima, la flotte russe est hors de combat au bout de quarante minutes de leu.

\section{Page 6 it.}

En 1908, M. Marcellin Boule a fait connaitre les ossements, trouvés à la Chapelle-aux-Saints (Corrize) par labbé Bouyssonie, d'un homme de l'époque moustérienne, assez voisin des grands singes anthropoïles. C'est l'homme le plus ancien comnu. 
Page 699.

La Tour Eiffel a pu communiquer avec les navires de guerre français en croisière sur la côte du Haroc et avec le corps expéditionnaire de Casablanca; elle recoit les télégrammes de la station américaine de Nantucket. Presque tous les navires de guerre et beaucoup de transatlantiques possèdent la T. S. F. (pour employer une abréviation courante) et s'en servent pour communiquer entre eux et avec la côte. Au commencement de 1909, le transatlantique Republic, abordé en pleine mer et coulant bas, a pu appeler d'itutres navires et assurer le sauvelage de ses passagers.

\section{Page 701.}

L'èneratie électrique, produite à bon marché par la houille blanche, est en train de révolutionner la métallurgie de l'acier, du cuivre, de l'aluminium. - La telautographie permetira la reproduction à distance, par le fil du télégraphe élecirique, de dessins, photographies, etc.

\section{Page 733.}

Progrès des divers motenrs. - Parmi les moteurs hydrauliques, le bilier hydraulique de Montgolfier a été très perfectionné : il sert à l'élèvation de l'eau ou à la compression le l'air (ainsi au tunnel du Mont-Cenis). Les turbines, qui permettent d'utiliser les moindres chutes d'eau, mème celles à débit irrégulier, tendent partout à remplacer les anciennes roues hydrauliques.

De mème la lorce du vent, mal utilisée autrefois par les moulins il rent, actiome des aérumoteurs de plus en plus nomlireux dans les exploitations agricoles.

Les moteurs tonnants, utilisant comme force motrice l'explosion derrière un piston d'un gaz comprimé (gaz d'échitiage, gaz des loauts lourneaux, vapeurs de pétrole ou d'alcoul, caz pauvre), prennent de jour en jour plus d'extension. en raison de leur rapidité de mise en marche, de leurs dimensions réduites, de leur légèreté de plus en plus 
grande et de leur lacilité de conduite. Outre beurs applications à la unarine, à l'aéronautique, aux voitures autonobiles, i l'aviation, ils permettent aux plus petits ateliers d'avoir de la force motrice, et commencent à ètre utilisés dans les machines agricoles.

Dans la navigation à vapeur, les chandières à tubes d'eau et a tirculation, bien plus économiques et moins encombrantes que les cylindriques, les machines à triple et quadruple expansion, utilisant bien mienx la vapeur, l'emploi des hélices doubles ou triples, ont permis les grands prourés actuels. Enfin, sur les navires trés rapides, les turbines a vapeur tendent à remplacer les machines alternatives.

\section{Page 73\%.}

Voitures automobiles. - Les noitures automobiles, dont les premiers spécimens à vapeur ont été construits jar Serpollet et pas de Dion et Bonton, ont pris un essor prodigienx grace aux motems à explosion el a l'invention des bandages pnoumatiques. Elles peuvent dépasser $100 \mathrm{~km}$. à l'heure.

Outre les tricycles et les motocyelettes, ontre les voitures particulières si répandues actuellement, de nombreux services de diligences automobiles, sur les routes de France, d'Algérie, de Tunisie, des colonies, font revivre, mais combien plus rapides et plus eonlortables, les anciennes roitures publiques.

Des trains automobiles (train Scott, train Renard), constituent sur route de réritables trains sans voie ferrée. Ainsi notre magnifique réseau routier, abandonné par le roulare lepuis les chemins de fer, reprend une vie nouvelle.

Jans les arandes villes, les omnibus automobiles (vulgairement autobus), remplacent les anciens omnibus à chevaux. Les camions automobiles, dont quelques-uns appartiement à l'armée, transportent les poids lourds.

\section{Page 740.}

Aéroplanes. - Les aéroplanes ou appareils d'aviation, commencent à donner des résultats très intéressants, gráce a la legèreti des moteurs à explosion, qui arrivent à l'heure 
actuelle à ne peser que 2 lilogrammes par cheval-vapenr développé; c’est ainsi que les aéroplanes des frères Voisin se sont grandement perfectionnés entre les mains de Farman et de Delagrange. L'aéroplane Bléıiot a réalisé, le 31 octobre 1908, le premier circuit lermé et, le premier aussi, a franchi la Manche (25 juillet 1909). Citons encore les aéroplanes d'Esnault-Pelterie et ceux des frères Wright, Américains.

Les premiers aéroplanes, comme l'Avion, d'Ader, étaient constitués par un seul plan (monoplans) commeles anciens cerfs-volants; puis, initant les cerfs-volants du type cellulaire, on eut les biplans et les triplans. On a dépassé la hauteur de $5000 \mathrm{~m}$., la vitesse de $160 \mathrm{~km}$. à l'heure, et eflectué sans escale un vol de plus de 1000 kilomètres.

\section{Page 742.}

Actuellement les usines françaises mettent en vente des plaques permettant tiès facilement la photographie des couleurs (plaques autochromes de Lumière, plaques omnicolores de Jougla on de Gulay).

\section{Page 767.}

Au 31 décembre 1903, ces sociétés étaient ensemble 16297 arec plus de 3 millions de membles et pres de $40 \pi$ millions ale fonds, 19 de res societés étaient reconumes d'utilité publique, 11078 appronves, 3209 libres, 1997 scolaires.

()UVRages a CONSUlter. - A. Ernat. Limere de la se cunfítence de la pati. $1909)$.

J. Signorel. L'électrification des (frumles lignes decheminsde fer (1910).

C. ${ }^{\text {es }}$ de la Vaulx, Le triomphe do la naxiyution aèrienne (191?). - J. Lecomu, La nariqation a rieme (1910). - Co:ne Boutlieaux, La marif. aer. par brallons tirigeables (1910). E. G rald et A. de linurille. Les batlons clirigeables 1909). - Capil.
Sazerac de Forge, La conquête de lair drrigeables (1910). - Capit. Ferber, L'aviation (1910). - Comt Renurd, Le vol mécanique, les aéroplanes 1912 ?

H. Larose, Rapport sur létat aetuel de la tileigraphie sous-marine (1909). J. Finanee. Les syrdicats professionnels devant les tribunaux et le Parlement depuis 1884 (1911). (i. Salatin. Les retraites onvieres et paysanne's (1911). 


\section{INDEX ALPHABÉTIQUE}

Abattolrs, $223,319$.

Académies, - leur suppression, 168 , - leur rétablissement, 370. Voyez Ixstitur.

Acclimatation, - des animaux, 708 ; - des plantes, 715 ; - des maladies, $72 \%$.

Acte additionnel de $1815,40,322$.

Actes de l'état civil, 8i, 120, 5 í6.

Acleurs. - Yoỵez Comédiens.

Acoustique. 4\%9, 695 (nole).

Administration, 62 \%2, 337-340, 545546 ; - Ecole d ), 589, 594.

Administratif (droit). - Travaux sur ce Iroul, 100, 630 .

Aérostation militaire, 246, 250, 574, $7 ; 0$.

Aérostats, Aéronats, Aéroplanes, Aviation, 730-740, 246, $250-251$, $479,574,739-741.793,819$.

Affranchissement, - des paIsans, 4, 9. 14. 274-27; - des nègres, 13 , 159-I60, 360, 755 ; - des juifs, 131133, 354, 554; - des protestanis, 7, 129-130; - des peuples opprimés, 12-1.i, 133-138, 557, 797; - de l'agrimulture, $27 \cdot-277 ;-$ dellindustrie. $2 \% 9$.

Afrique, - colonies francaises. 160 , $366^{\circ}, 583,600,802 ;-$ nos troupes indigènes d'Afrique, $575-576 ;-$ républiques hollindaises d'Afrıque, $55 \pi, 802$; voyages scientifiques, $40 \%, 41 \%, 458.583,600,61 \%$; ourrages y relatifs, $197,407,459$. $639,70 \leq$.

Agiatage, $302,3 ! 1,490,761$.
Agraires (lois), 217, 27i-277.

Agriculture, - émapcipation sociale, 27a-2is; -- progres de l'outillage, 481, 75: - institutions agricules, 481-42.746; - réformes et projets Meline, $7 \boldsymbol{h} ;$; enseignements agricoles, 4\&.?, 746; - sciences agricoles, 7i6; - botanique agricole, $746 ;$ - chimie a@ricole, $25 \%$, 700,$75 ;-$ nuétéorolozie a cricole, $702 ;-$ artillerie agricole : tir contre les nuages, 702. - Travaux arricoles a lelectricite, $70 \mathrm{i},-$ Statistique de la population agricole, 750-75: : - des produits agricoles, 745, 751 .

Alcaloïdes organiques, $256,454,456-$ $457,467-405,409,724,72 \mathrm{~S}$.

Alcools, - législation, 9?, 258, 348, -is9, 737; - travaux des rhimistes, 257. 2S2, 455, 456, 704, 738.739.

Algérie, $357,358-359,360,365,366$, $412,458,574-575,58 \%, 557,617$, 802 ; - dans la littérature, 623 , $142-$ 643 ; - dans les arts, $428,434,058$; - Ecoles supérieures d'Alger, 900 .

Aliénés (médecine des), 72, 26;, 269$270,469,722,727,729 ;-$ (theories sur les;, 625-626.

Allemands, - infuence sur nous de leur littérature, 200-202, 383, 626; - de leur philusophie, 209, 398 399 ; - de leurs idées socialistes, 773 et s. - de leur musique. $\mathbf{2} 40$, $498-410,443,671-622$; - ĕrudits, 210,407 ; - sarants et inventeurs, $249,559,204,447,448,453,456$, 457 , 17. $571-522,573,623,645$, $679-730,740$, S05; - soldats au service de Fiage, 148-149, 155$15 \%, 360-3031$. 
Allumettes chimiques, 486 .

Aluminium, 453,813 .

Amérique, - colonies franerises. 15\%1-101, 595-587: - voyatio liitéraires seientifiques, 199,260 , 412. 45- 460, 601, 647 - publications y relatives, 617 : - mines d'Amérique. 739 ; - découvertes seientitiques ou inventions industrialles far des Américains, 252$253,255,470474,475,477,455$ 571, 678-730. 805; - Etats nouveaux en Amerique, 12, 557,797. - Voyez Etats-Unis.

Analyse mathématique, $2: 6,4 ; 6,678$. Anaiysc spectrale, $680,685,68 \%$ W.'; - du sann, 22.'.

Anarchie anarchistes, 417, 771,779 . TSi, is.

Anatomie $265-266,461,717,727,729$; - des unmaux, ${ }^{20 s ; ~-~ d e s p l a n t e s . ~}$ 713.

Anciens, Antiquitė grecque et ro maine, - travanx qui leur ont elé consilcres, 210-211, 40:-403, 601, $631-1335$

Anestiejsique $455,46-457,462,167$, 468,$725 ;-10 \mathrm{caus}, 457.726$.

Anglais, - littérateurs, 185, 201, 383; 330 ; - philosophes, 209, 210, 218, 395: - sconomistes, $218,413,756$, artiste- 662: - savants, 249,251 , $254,255,257-259,205.440-450,455$, 46x. 66். 679-790. 720. 805; inventenr's, 253, 286-287, 470,472. $471,476,481,739,805 ;-$ commerce avee eux, 2\$y-290, 489, 499, 723; 756. S04, - Anglais chez nous, $2-9,279,283,3 \cup 7,753$. Nos litiges colonaus avec eur. 582-583; - solidarite d'intèréts économiques. S04. - Socıalisme angluis, iti.

Anglomanie, $493-500$.

Animaux, - lois et institutions protectrires a leur exard, $6: 9-630$; stati-ique des animaux utiles, 75 . - Mederine appliquee aux animaux, 71!. 720, 729. - Voy. Zooi.OG 18 .

Antisepticues, 725-720, 752.

Antipyrine. 705 .

Anthropologie, 615-1546, 712-713, $11 \%$.

appel - Vogez Thibinaciet Cours.
Appel comme d'abus. 11S, $12 \mathrm{i}$.

Arabie, Arabes, $213,40 \Omega-403,612$. 633.

Archives natiouales, 160, 229-2?4.

Arcs de triomphe, 219-22', $\$ 19-420$ 423.

Architecture, 218-224, 419-422, 650. $652,7 \% 0$.

Archéologie, - préhistorique, 645biz: - orecque et romaine, 210211, 219-221, 402-103, 601, 631-(35: - celiare, gallo-romaine, 640. Voyez Etudes égyptiennes, assyriennes, etr.; - Ecoles darchéologie, 374, 5ะs, 614 .

Argon. 687 .

Armée (recrutement de l'), - sous liancien rerme, 110 ; - sous la Révolution, 13:-149; - sous l'Empire, $140,150-157$; sous la Restauration, 359-3.11; - sous LouisPhilippe. $361-365 ;$ - sous Napoléon 111,56 i -567 ; - sous le reigime actuel, 567-576:- attaquéc par les sectes sociahstes, 779 et suiv.

Armes, - des àges préhistoriques, 6:4-626. - Voyez Antillerie, Elsil, Mitrallleuse, Revolveh.

Arrondissements, - remplaçant les districts, 64, 77; conseils d'arrondissement, 69, 339, 545-546; arrond. de Paris, 71, 339, 546, 721.

Artillerie, - sous la Révolution, 14́s, 2í; - sous l'Empire. 152-153, $155 ;$ - de Is1' a 1s4s, 363-364; depuis 1848, 570-573; - corps de l'artillerie de marine, 15:, 366 ; devenue coloniale, 576 ; - matériel d'artillerie le la marine, 152,570 $573 ;$ - écoles d'artillerie. 107, 266 , 574-575; - musèe dartllerie, 167; - artillerie agricole, 702 .

Arts. - Voyez Architecture. SGulpturf, Peinture, Dessin, Gravure, Lithoghaphie, Caricature. MusiQLe, Décoratifs (Arts). VétérlNare (Art), Culinaire (Art), ete.

Arts et métiers (Écoles d'). - 370 . 37 i, 75\%-753; - (Conservatoire d", 166. 420 .

Asie. - colonies franpaises, 160,306 , $586-5 \times 7,802 ;-$ nuis troupes undigenes d'Asie, 5io; - rapports avec les Elats de J'Asie, 561. 802 ; - voyages seientiliques, 213-214, 112, 600-601, 617; - ouvrages y 
reiatifs, 213-214, 407-411, 641-6i5. Asile (salles d'), - 369, 597, 767.

Assemblées nationales. - Voyez Constitutions. - A l'ètranger, 16-21, 515, 797-79S.

Assemblées provinciales, 5 ; - comment remplacées, $62-63$. - Voyez Aoministration.

Assignats, 96, 98-99, 294. 302, 311.

Assistance judiciaire, 768 .

Assistance médicale, 768 .

Assistance publique, $11-12,72,342-$ $343,549,768$.

Astronomie, astronomes, - de 1789 a 1s1 $1,249-250 ;-$ de 1814 a 184 , 447-419; - depuis 1848, 678-636.

Aubaize (Wruit d"), - splprimr, zos. so3.

Automobiles, 809 .

Aveugles (institutions en fareur ros 7.. 409 .

Avocats, s3-81, 345-340.395, 610, 76s. - Fummes avocits, 5it. Avoues, si,

Bacilles, Bactèridies (Revherches sur les), 70', 711, 719-721.

Bagnes, - supprimés, 549.

Banque de France, 295-29f, 490, $760-$ 761 ; - banques de provinet, 401. 760 ; - banques privees. 9: billets de banque. 290, i.jo, 700-763 - Avantaces ru'elle fait a l'agriculture, 750.

Baromètre, 449.

Bateaux à vapeur, 253-25í, 47t-473, $575-580,732-733,505$.

Bateaux-mouches, 495,711 .

Bibtiotheque nationale, 166, $\{21$; Sainte-tisnevieve, $4: 1 ;-$ pedarorique, 598 ; - popularres, 592.

Blère, 704, 769.

Bobine Ruhmkorft, 694-695.

Botanique, - suus la Révolution et lempire, $26 ;-264 ;-$ de 1814 a $1848,459-460:-$ depuis 1848,694 , 713-715, 721, 746.

Bourgeoisie, - son róle politique, $2,5,20,274,302,320,360-361$, $362-963,368,323,436,514-515.733-$ 795 ; - ses goùts littéraires et artistiques, $273,380,41,493,496-$ 497, 515, 797.

Bourse, 223, 295, 420, S04.

Budget, - de l'Elal, 11, 96, 348, 549550 ; - des dẹartements, 3 19, 549 . car: ; - des conmmnes, 349, 549 , 602; - de Puris, To8.

Bureau des longitudes, 106.

Cabinet noir 42, 34't.

Câbles, - sous-marins, 737, 80t.

Cadastre, 89-90, 347-345, 749.

Café, $990,302,457,757,569$.

Catèine, 457.

Cafès, 34, 296, 312, 317-315, fi?.

Caisses, - d'eparrne, 4 0 , 767-769; - de retraites four les ouvriers, 767, 755: - do secours mutuels, 76-709; - de prévoyance sous lis Convention, $72 ;-$ - des inslituteurs, $372 ;-$ des écoles, 506 .

Calendrier républicain, $30 \%$

Canaux, - en France, 993. 179; de Suez, 723, 743, $805 ;$ - d $\mathrm{Pa}$ nama, 744 .

Caoutchouc, 292, 454, 455, 705.

Capacités (ajjonction des), 327-323. Carabiniers, 15\%, 153, $3, \mathrm{i}, 5.5$.

Carbonarisme ou Charbonnerie, 504 .

Caricature, $145,331,336,362,435-$ $436,455,493,49,660$.

Cens. - Voyez Electorat (uroit).

Censure, - au theitre, 180-15\%, 381; - sur les publicalious, 53, 5-61, 12i, 330-333, \$36.

Chambres, lègislatives, voyez CoxsTitutions; - d'ayriculinre, 狧, 74S; - de commerce, itt; - syndicales, $605 ;-$ de tiocipline, pour les ofticiers ministerets, is.

Chansons, 195-197, 309, 34, 611-61:.

Chauts patriotiques, 181, 191-19?, 235. iti, till.

Chapeaux, 300, 184, -191-49.1.

Charbon de terre. 458, 693, 706, 733, 755.

Chapitres, - de cathédrale, 101, 117. 
Charte, - anglajse, 17; - francaise de 181i, 321-32i, 526; - de 1830, $321-325,526$.

Chasseurs à pied, $366^{\prime}-365,569,575$. Chasseurs d'Afrique, $365,569,575.576$. Chaux hydraulique, 486 .

Chemins, - vieinaux, 292-893, 48148?, 746-747.

Chemins de fer, $473-477,697,733-735$, $7 i 5,80$ i-805; - organisation militaire, 574; - visés par les eollee. tivistes, 776. - Voyez DaltoNISME.

Chimie, - sous la Revolution et l'Empire, 24i-2\}5, 255.259; - de 1814 à $1848,452-458 ;-$ depuis 1848, 703-708, 724; - agricole, 707,76 ; - révolutionnaire, 781.

Chine, 411, 561, 576, 584-585, 601, $614,670-671,699,799,80$ ?.

Chloroforme, 455, 468.

Choléra, 26\%, 511, 221, 724; - des poules, 720 .

Cinèmatographe, 742.

Cités lacustres, 646-647.

Citoyens, - aetifs. Voyez Electoral (droit); - appellation de eitoyen, $31,304,313$.

Civilisation, - sous l'ancien régime, 8-9, 792 et s.: - moderne et eontemporaine, ibid.; ourrages sur les eivilisations des divers templs et des divers pays, 211-214, 401-411, 631 et s.

Civisme (certificat de), 30 í.

Clergé, - sous la Révolution, 97-115; - sous Napoléon 1er, 115-129; - sous les Monarebies parlementaires. 349-35; ; - sons Napoleon 111, 551 et s.; - sous le récrme actuel, 551 et s. - Rôle daus l'enseignement, 588 et s., - puissance daus le passé, 792 et s.

Cloche à plongeur, 479-480.

Cloches, $\rightarrow$ fondues pour faire des canous, 2if; - sonnerie interdite, 113-11'.

Clubs, 51-52, 329-330, 532-534.

Codes, - de la Révolution, 87; eivil, 87, 346, 516-549, 763; - de procéture, $88 ;-$ pénal, 52 , 86 , $88,329,340-347,547-549 ;-$ de commerce, $s 8,3$ i 6 ; - d'iustruction criminelle, 88, 346-347, 517-519;rural, $546 ;-$ militalre, 143,548 ; forestier, 3'6.

Coalitions (lois sur les), 51, 280, 281, $764-765$ - Voyez GRẼVS.

Coilfure, 299-300, 303-304, 309-310, $315,491-494$.

\section{Collectivisme. Voyez Socialisme.}

Collège de France, 167, 171, 410, 446, $591,593,599,717,729$.

Collèges, - universitaires, 162, 164, $169,170-171,319,373,593 ;-$ de jeunes filles, 598 ; - des jisuites, :53-354, 368, 553 ; - électoraux. Voyez Electoral (droit).

Collodion, 455.

Colonies Irançaises, - leurs aeeroissements, 366, 583-585, 720, 802 ; regrme social, 158-161, 366, 585; polilirue, 586-587; - économique, $585-586 ;-$ troupes eoloniales, 365 , 576 ; colonies étrangères, $12,803$.

Colonnes, - triomphales, 220-2?2, 221, 120-421, 位4.

Comédie, 177-184, 189-191, 385-386, 603-608.

Comédiens, Comédiennes, 17\%, 181, $153,186,383-384,607$.

Comices agricoles, $482,746$.

Comités, - pendant la Révolution, $25 ;-$ de Salut publie, 25-25; de Süreté générale, 27; de l'instruction publique, $128, \mathrm{t} 62 ;-$ e"clésiastique, $99-100$; - socialistes, 777 et $\mathrm{s}$.

Commerce, - de 1789 à 1814, 288$293 ;-$ de $18 \mathrm{t} 4$ à $1-48,488-490$; depuis 1848, 756-759; - eode de conmerce, 88,346 ; - tribuuaux de commeree, $76,7 s, 3$; ; - femmes électeurs pour ces trihunaux. 57:; - chambres de commerce, 7i9; - traités de commerce, 285, 289, 756-759, 798-80.4; - impóts sur le eommeree, 90-9', 348, 5\%0; - théories sur le commerce, 290,413 , 489, 586, 747, 756 .

Communaux (bicns), 277.

Commune de $1871,42 \%, 433,523,535$, $651,656,721,750-781,781$.

Communes, - comment elles sont alministrées, pendant la Révolutirn th l'Empire, 6i-72; - de 1814 a $1518,337-340$; - depuis 1848 , 
546; - budget des communes, 339 , 549, 602, 768 .

Communistes (thérries). - 216218 , $413-418,649,771$ et s. - Voyez Socialisme.

Comprimés (eau, air, autres gaz) 686687.

Comptoir d'escompte, 762 .

Conciles, - du clergé constitutionnel, $115 ;-$ sous Napoleon, $125 ;-\mathrm{du}$ Vatican, 551-555.

Concordat, - de François 1er, 116; - de 1801, 116-121; - de 1813, 123 ; - comment le Concordat a été pratiqué depuis, 349-35\%, 551-555.

Confection (maisons de), $4 \$ 5$.

Confèrence de la Haye, 560-562.

Conférences, - diplomatiques internationales, 558-562, 758, 804, 807 ; - sorialistes, 752.

Confréries, - musulmanes, 643.

Congrégations. - sons la Rérolntion, 124-1:9; - sons l'Empire, 129;de 1814 a $1818,352-354,368,553-$ 55í, 596, 620; - la Conqrégation, 350,504 .

Congrés, - des deux Chambres francuices. 52', 526; - européens, 350$358,555-563$; soeialistes, 778 et s.; - scientifiques, 645, 083, 702, 805 .

Conscription, 147-148, 150, 359-361; $565-570$.

Conseil d’État, $35,42,59,69,76,87$, $85,118,121,132,345,518$.

Conseils, - législatifs sous le Directoire, 28-30; - des mir istres, 17, $322,517,522,526-527$; - gènèraux de départements, darrondissements, municipaux, voyez AbmtNistration; - de préfecture, 69 ; - supérieur de l'1nstruction publique, 169. $367,589,591,59 i, 595$ : - general des facultés, 600 ; - academiques, $169,590,595$; départementaux, 598 ; - de guerre, 5 1, 143, 290, 548; - de l'ordre res a vocats, Si, 346 ; - coloniaux, 586 : de prudhommes, 281 ; - du travail, 765 .

Conservatoire, - do musique, 10\%: - des Arts et Netiers, 166, 420, 752.

Conspirations, 26, 43, 501-505; boulangiste, $5 \% 0^{\circ}-$ socialistes, 734 .
Constitutions, - de 1791, 20-2i; de 1793, 27-25; - de l'an 111, 28$30 ;-$ de l'an VI11, 3.4-37; - de l'an $\mathrm{X}, 37-39$; - de l'an X11, 3944; - charte de 1814, 221-324; acte additionnel de 1815,322 ; eharte de $1530,321-325 ;-$ constitution de 1848, 516-525: - de 18.2, 518; - du second Empire, 519-5:3; - de la troisième Répu. blique, $523-529$; - anglaise, $16-20$, 322. 526, 797-798; - amèriraine, 20,$516 ;-$ dautres pays, 12, 14, 17, $797-798$.

Consulaire (justice). - Voyez TRIBUNACX DE COMMERCE.

Consulat, 3i-39, et passim.

Contes, - pour les enfants, 392,618 ; - bretons, 640 ; égvptiens, 641 ; kabyles, $6 \mathbf{4 3}$.

Contributions, - directes. \$9-92, 9i$95,3 \cdot 7-348,549$ el $s . ;-$ indirectes, $9293,34,549$ et s.; en Angleterre, 757.

Corps d'armée, 153, 569 .

Corvées, - abolies, 27i, 29\%.

Costume, - sous la Rérolution, 31, $145,217-300,303,309,311 ;-$ sous l'Empire, 15\%, 283, 315-316; - sous les deux monarchies parlementaires, 491-494; depuis 1848, 493-

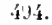

Coton, 285-257, 290, 481-485, 487.

Couleurs de teinture, 257, 25?, 457458, 4Si, 485, 643-69i, 700-707.

Cour (a), - de Napoléon, 313-315; - de Louis XV11, 497; - de Charles X, 497; - de Louis-Philippe, $497-498$.

Cour de cassation, 47, 76-77, 315 .

Cour des compies. 95-97.

Cours d'appe1, i7, 74, $7 \%-75$.

Cours martiales ou prévôtales, 5i, 1if, 290. - Voyez Cosseils DE GUERRE.

Course, Corsaires, 158, 559-569.

Courses de chevaux. 500. - loyez 1'A.I MUTUEL.

Coutumes. - Voyez Maurs.

Crâniologie, 712 .

Crédit (institutiıns de), 295-296, 49 , 759-763; - crédit de l'Etat, 291$296,490,762.764,800-804$. - agri- 
cole. 747 , 750 ; foncier, 761 ; mobilier, 762 .

Cristaux. - Voyez Verre, MinéraLOGIE.

Critique, - littéraire, 200, 393, 619; -artistique, 393, 619.

Cuirassẻs (navires), 57S-581. \$07.

Cuirassiers, 153, 575.

Cuisine, Culinaire (A rt), 193, 317, 499.

Cultes, - eatholique, voyez CLergé: - protestant, 139-131,354, 551, 55't, - israelite, 131-13', 35', 554; - musulmans et divers, $55 \dot{4}, 643$.

Curare, 719.

Daguerréotype 452-453, 480. Voyez PHOTOGRAPHIE.

Daltonisme, 727 .

Danoís, - artistes, 225 ; - savants, 451, 805 .

Danses, 309, 317, 498.

Darwinisme, 626, 709.

Décoratifs (arts), 669-6i1.

Démocratie, - son intluence sur la ve sociale et politique, $51 \mathrm{i}-515$, 791-79s; - : ar les lettres, les arts. les sciences, 515, 652, 656, 671, 797-798; - sos prontes en Flunce et dars le monde, 1: $-1 \mathrm{i}$. 791 et $\mathrm{s}$.

Départements, - ministériels, voyez Misistéres; - maritintes, $30 \%$ $360^{\circ}$; - administralifs, lenr création, 9,02 ; - leur mode darmipistration, 62, 336-340, 349, 545-546.

Dépenses, - de l'htat, des départements, des communes. roy. BupGET.

Despotisme, - des rois de France, 24,27 - de la Connention, 24-27; - de Napolion ler a: - de NapoJéoo 111, 51 - $-20,-31,533,536 ;-$ Eta's despotiques en Europe, ou hors d'Europt, 1:-14, 5\%2, 798, 801 .

Dessin, dessinateurs, 233-23i, 13\%$496,666-60 \%$.

Dette publique, $96,29 i-295,550,800$. Diamant, - verifié par les rayous $\mathbf{X}$. Qyz: - fabrum it lelectricile, 700.

Dilligences, $93,293$.

Diplomatie, 562, 799-800.

Districts, 62-69, 72-77.
Divorce, $\$ 5-\$ 6,87,311,346,546$.

Domaine, 98.

Douanes (systimes de), $888, .90,498$ $490,586-587,747,756$ et s., 803 ; - bataillons de douaniers, 569.

Drame, - historique. 3iS-3S4, 592, (6) $2-605$; - populaire ou bonrgeois, 186-1S9, 38-1-385, 605.

Drapeau, - tricolore, 10, 136, 142, 717 ; - rouge, 788 ; - noir (anarchiste), 758.

Droit, voyez LoIs, Codes. - Onvrages sur le droit, $100-401,630$; sur le droit nusulman, 643 .

Droit des gens, 135-139, 355-359, 556, 558 et s., 721, 802 et s.

Droits reunis. Voyez Contributions.

Droits seigneuriaux, - suptrimé.

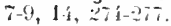

Duels. 172, 301-302, 503-501.

Dynamite, 705-706, 752, 781.

Dynamos, 695.

Echelle mobile, 1s:, :4, 750.

Eclairage, - it la limpe, 252.283, 955,$46 ;-$ a la boumie, $4.5,44$ - an gaz, 2-1, 175-14, 513, 514 738; - a linetrlone, 738 ; - a l'électricite, $055,73 \div, 75:$, 79'.

Eclectisme, - en philosophie, $397-$ $399,621-627$; - dans les arts, 431 , 651, 668; - en éonomis polttique, 618.

Ecole centrale, 370, 任, 752.

Ecole coloniale. ssi.

Ecole dadministration $58,594595$.

Ecole d'aérostation militaire, 5í. 7i0, 741.

Ecole d'application du génie. 16:, \&i6.

Ecole des beauz-arts, 603 .

Ecole des Chartes, 3\%0.

Ecole des hautes ètudes, 593.

Ecole des langues orientales vivantes, 166 .

Ecole des mines, 167

Ecole des pants-et-chaussées, 167.

Ecole lorestière, 370, $\$ 80$. 
Ecole libre des solences politiques, $59 \div-595$.

Ecole militaire, 167, 171-172.

Bcole navale, 167, 366 .

Ecole normale supérieure, 165, 171, $370,374,446,591$.

Ecole polytechnique, 165-166, 171, $370,4: 16$.

Ecole supérieure de guerre, 575.

Ecoles (autres) relevant du ministère de la guerre, 5/4-575.

Ecoles relevant du ministère de la marine, $577-578$.

Ecoles, - petites ou primaires, 162$161,169-170,368-369,370-373$, 589602,767 ; - primaires supérieures, 371,595 ; - normales primaires, $170,369,373$.

Ecoles, - de droit, 164-165; - de médecine, 165, voyez Facultés; - de pharmacie, 730; -- d'Alger, 600 .

Ecoles, - d'Athènes, 374, 600-601, 6:2; - de Rome, 600; - du Caire, $600 ;-$ d'Extrème-Orient, 644.

Ecoles, - d'ag!ıculture, 746; - d'industrie, 752-753; - de commerce, 756.

Rcoles centrales. - sous la Révolution, $16 \%$.

Ecoles normales supérieures, - de Sèvres, 599; - de Fontenay, 597; - de Saint-Cloud, 59s ; - de Cluny, 593.

Economie politique, 208, 238-292, $413,488-490,648,747,756,775$, 798.

Ecrouelles, 463.

Education (théories sur l'), 162, 306.

Eglise, - catholique, voyez Clergé, Pape, Congrégations.

Eglises, - coustruction d'églises, $419-429,650$; - restauration des ancienues, 421-422, 650-651.

Egouts, - de Paris, 511, 770.

Egyptologie, - 213, 406-407, 600, $640-641$.

Egypte (gout pour l'), - dans le mobilier, 316, $170 ;$ - au thédtre, 655,673 (Aida); - obélisque de Loug=0r, 407,509 .
Election, - du chef de l'Etat, 517, 52 ', $531,795$.

Elections, - aux Assemblées nationales, voyez Electoral. (droit); aux administrations dèpartementales et municipales, voyez Anm1Nisthation; - aux conseils universitaires, et scolaires, voyez ConSEILS; - des juges, voyez MaglsTrats; - des officiers militaires, voyez ArMÉE.

Electoral (droit), - pendant la Révofution et l'Empire, 4'́49; - sous les deux monarchies parlemeataires, 325-329; - depuis 1548, 529, 532; - en Angleterre, 20, 328; - en d'autres pays de l'Europe, 798.

Electricité, 253-255, 450-452,470,477, 689-701; - ses applications, 463, 477, 689-701; - en physiologie et medecine, 719,$721 ;$ - en navigation et focomotion, 699-700, 733; - en inétallurgie et aulres industries, 700-701, s08; - en agrjeulture; 701; - en telegraplup. 737 738; - pour l'écluraze, 723, 73:. 752 ; - pour les aerostitts, 710.

Electrocution (en Amérique), 701.

Electro-magnétisme, 451-45\%, 694, S05.

Electrothèrapie, 72 '.

Eloquence, - de la chaire, 395; ru barreau, 395, 619; - politique, 204-206, 395-396, 620-622; - militaire, $266-207$.

Embryologie, 709.

Emprunts, 760-763 ; - forces, 96, 216 .

Enfance, enfants, - lois et institutions protrctrices à leur t́mard, 14, 487-488, 549, 728; - médecine et byritue, 463, 726; - travail des enfants, 766, 778. - Voyez EcoLEs, ASILE (salles d'), Covites.

Enregistrement (droits d'), 93-9', 550

Enseignement, voyez ECoLES. - L Lberte de l'enseleuement, 169, 353$354,367-398,573,374,5 \$ 3,592,593$.

Epopée, poésie épique, 193-195. 375, 3ธ6-3\$9,609; - epopées de l'lade $213,410,614$.

Erudition, 402-403,406-411,631 et $\mathrm{s}$.

Esclavage. esclaves, aux colonies, $13,153-160,366,585$.

Escrime, 301-38\%. - Voym DUEL. \&ٔif 
Fspagnols, 12-13, 18i, 797, 802.

Essentielles (huiles). 45 ', 457.

E ablissements scieutiliques - Voyez College de France, Nuseum, ObGervatolres.

Etat Tiers). - Voyez Bourgeoisie et PEUPLE.

Etat (Quatrième). - Voyez SociALISME.

Etats généraux, 1, 16, 4 í.

Etats provinciaux. - Voyez Asse.MbLéES PRovinciales.

Etats-Unis, leur constitution, 21, 516. - loyez Amérique.

Etrangers, - leur situation lécale en Frauce, $288,36,547$ - troupes étrangères au service de la France $148-179,155-157,359-360,576$; Franmis a l'étranger, 173-174, 215, $240,422,735 ;$ - influeace de la France et de la Révolution à l'étranger, 12, 14, 797-798.

E.udes, - éryptiennes, $213,400-407$, $600,640-611$; - acsyilennes, babyloniennes, 407-408, 641; - persiques, mèdiques, 213,641 ; sénutiques, arabes, berbères, 213, 408-i09, 6i2; - persanes, arménienves, tatares, turques, chinoses, japonaines, 409, 4li, ti33-6it; indiennes, 213 , 410,$644 ;-$ amèricaines, $6 \%$; - reltiques, 640 ; - préhistoriques, 645-6:\%.

Explosives (substances), 45 -455, 692, $703-706,72,781-782,781$.

Exposition publique (peine de l'), $86,85,545-54 \%$.

Expositions, - nationales, 280, 282, 483, 753; - internationales, 753$755 ;$ - des beans-arts. 167, 298, $230,427,429,667-668$; deleetrieite, 701 .

Facultés, - de théologie, eatholignes, 171, 5.2., 583-584: - de driti, 171, 599,630 ; de medrecine, 171, 205 , 599, 728; des s.iences. 171, 369; des lettres, 171, 210, 369-370. 398. - Voyez Univensité.

Facultés, instifuts ou écoles catho liques, 59 i- $3 \%$.

Faiences, 301.

Féeries, 608-609.
Femmes, - situation légale, Si-86, $87,311,346,546-547$; leur wluc tion, 372, 373, 590-591, 593, 597599 ; - leur róle en liıtiratıre, 197-198, 200, 208, 212, 348, 391392 ; - dans les sciences, 4i7, 709; - dans les arts, 633, 665. - Voyez Costume, Mobilier, Maurs.

Fer, fonte, aeier, 283, 483-485, 489, 499-500, 680 (dans les astres), 755 , 757.

Fermentations (recherehes sur les), $701-705,719$ et $\mathrm{s}$.

Fèodalité. - Voyez Droits seigneurians.

Fêtes, - sous la Révol fion, 306307: - sous Napoleon, 313, 318; - sons les monarchies parlementaires, 497 et s.; $\rightarrow$ sous lin troisieme Republique, 664, 787-788.

Fiacres, 293, 494-495.

Finances. - Voyez Contributions, Budget, Coun des Comptes, CréDit, Dette publique, Assignats, Mandatsterhitoriaua, Fimprunts, Grand-LlVRe, Douanes, Tabac, Domaine, Timbre, Enregistrement, Postes, Telégraphes.

Fluor, 703; - fuorescences, 691.

Forêts, 488; - code lorestier, 346, $4 \$ 0 ;-$ éeole forestìre, 370,480 , - chasseurs forestiers (armet), 569.

Fortilications, - nouvelles, 567; de Paris, 509, 721.

Franc-mạonnerie, 504.

Fulmi-coton, 455, 705.

Eulminates, 573 .

Fusées à la Congrève, 578.

Gabelle. - Voyez SEL.

Galvanoplastle, 451, 486.

Garde impérlale, - sous Napoléon Ior, 153-15.5; - sous Napoleon 111, 565.

Garde mobile, de ISis, 50 i; - de $1858,566-567$.

Garde nationale; - sous la Revolulion, líl-142; - sous NapoleonJer, 1.00-151; - sous la Restauration, :30-361; - sons Louis-Philippe, 302-303; - depuis 1848, 541 et s.

Garde républicaine, 363. 
Garde royale, - suus la liestauraration. $\$ 59-360$.

Gènération spontanée iquestion de Ja), $620,711-712$.

Génie, - militaire, voyez Ecole flapplication, Fortifications; troupes du getnie, 14s; - genie civil, voyez Travaux pUblics, INGÉNIEUNS.

Géographie, 410, 111-\$12, 600-601, $6.47-64$.

Géologic, 201-265, 460, 715-716.

Géométrie, Géomètres, 2i6-249, 446, $4 \pi, 6.5$.

Grâce (droit de), 21, 39.

Grand-Livre de la detle publique. $2 y+2.5$.

Gravure, Graveurs, 23:-239, 436, 667.

Grèves, - (législation sur les), 51, $2801-281,764-765 ;-$ grèves partielles, menaees de "grève générale ", 779-790.

Guerre. - Voyer. Droit des Gens, ArMÉE, Marine.

Gutta-percha, 454, 455-4\$6.

Baras, 482, 745-710.

Hébertisme, - en religion, 109-110; - eu lictéralure, 182.

Hélice, - des navires, 473, 578, 732; - des aérostats, 739-740.

Bèliogravure, Hélioplastie, 742 .

Histoire. Historiens, 210-213, 401-406. $631+i ; 0$.

Bistoire naturelle. - Voyez ZooLogie, Anthropologie, Paléontologie, Darwinisme, Botantque, Gélogie, Stratigraphie, MixéRALOGIE.

Histologie, - zoologique, 7\%1; botanique, $713 ;-$ medicale, 266 , $461-462,717,729$.

Bomoeopathie, 40't- $\mathbf{6 5}$.

Forlogerie, 281, 306, 753 ; - èlectrique, 701.

Bydrothèrapie, 467, 723 .

Bygiène, 469, 511. 727-729, 770 .

Bypnotisme, 500, 721-723.
Illuminès. Illuminisme, 500-501.

Impôts. - Voyez Contmbutions.

lmpressionnistes, - en peinture, 661; - en litterature, 610 .

Imprimerie, 55-56, 59, 284, 330, 334$335,540-543$; - par les rayous $X$, 692 ; - par l'électricité, 701.

Inde, 211, 110, 614.

Industrie, - sous la Révolition et l'Fompire, 279.287; - di 181'́ à 1848, 493-488; - depuis 1849,699701. 703-707, 751-705; vues des socialistes sur l'ındustrie. $771-790$; sociélés industrielles, 761-i63.

Ingénieurs, 478-480, 48\%, 484, 486, $733-756$.

Infanterie, 142-157, 359-365, 561-576; - de marine ou coloniale, 310,576 .

Institut de France, 168, 17:3, 175, $370,37 i$.

Institut commercial, 756 .

Institut national agronomique, 746 .

Instruction publique. - V'oy. EcoLES, ENSEHGNEMENT, CONSEILS, Asile (salles d'). Femmes, Enfants.

Internationale (des travailleurs), 777 et s. - (socialiste), $282-783$.

Italiens, - influence sur nous de leur lillérature, 201; - de Jenr musique, 210-242, 437, 4î-41, 672-673: - de leur statualie, 225; - de leurs savanls, 253-264, 463, 681,695 ; - de leurs mours poliliques, 504; - de leurs économistes. 413; - Italiens au service de la france, 148-149, 155-157, 361365. - Voyez Etrangers.

Jansénistes, 99.

Japon, Japonais, 411,561, 64t, 609$670,721,802$.

Jardin du roi. - Voyez MUséum. Jardins publics, 260, 301, 311-313, $512,770-731 ;$ d'acelimatation, 708,715 .

Jésuites, 109, 350, 353-354, 369, 392, $535,553-554,596,62)$.

Jeux - de hasard, 499; - de billard, 318.

Journaux, 53-61, 330-336, 535-54:3 ; à cari itures, 33', 336, 666; illustrès, 436; - scieatifig̨tes, 463 
542, 717; - socialistes, 413-115. 778,780 ; - religieu $x, 350,368,373$.

Juges, - mode de recrulement, 7381 ; - inamovibilité, 81-82, 34'́-345.

Juils, - émancipés, 131-133, 354. 554: - leur role dans les arts, $437,439$. 413,444; - en philosophie, 625; dans l'érudition, 642 ; - dans l'industrie, 475-476, 732; - dans la presse, 541 ; - dans le socialiswe, 773.

Jarisconsultes, $76,87,400-401,613$, $615,619,430$.

Jury, - daccusation, 75, 77; - de jugement, $42,75-76,77-75,325-330$, 333, 5i7-itis; - en matiëre de presse. 330 et s., 535 et s.; correctionuel, 76 .

Justice. - Voyez Cours, Tribunaux, Conseils, Juges, Justice to paix.

Justice de paix, 73-75, 77, 78, 79, 81, 82,34 .

Babyles, - d'Algérie, 365, 643.

Ealéidoscope, 450.

Bola (noix de), 724.

Lampes, - perfectionnées, 282-283, 285,$486 ;-$ du mineur, 25s, 478, 739 ; - électriques, 739.

Lanciers, 153, 154, 156; - leur suppression, 575.

Langues, - francaise, ses développements, $376,597595,603$ et s.; recherches sur sa formation, $625-$ 626 ; - étrangères, dans l'enseigaement, $599 ;$ - latine et grecque, 164, 170, 599; - orientales, 213, 406-4l1, 641-645; - ecole des langues orientales, 166.

Lègion d'honneur, $151,156,175,247-$ $\because$ is.

Légions, - départementales. 360 ; etrangère, 361,576 ; - de la garde nationale, voyez Garde nationale.

Lettres de cachet, 7, 42 .

Libertés, - de jètition, 33, 50, 51, 329, 532: - dassociation et de réunion, 8, 51-53, 329-330, 532-535; - de la presse, 7-8, 53-61, 330-334, 535-540; - des cultes, 7, 111-115, 129-134, 551-5í4; - de l'Eglise gallicane, $119,125,400-401,551-552$.
Librairie, Libraires, 59, 60, 294, 330. ¿03.

Libre-échange, 288-292, $413,488-490$. 585-586, 648, 756-758, 797.

Lithographie, 436, 667, 742 .

Lithotritie, 467, 726.

Livre (école du), -553 .

Locomotives, 252-2:3, 473-475, 805; - élestrique, 699-700.

"Loi d'airain ", 75-777.

Lois. - civiles, $10,84-86,346,546-$ 547 ; - pénales, 14, 86-87, 88, 346$347,547-549$.

Loterie, 499.

Lumière. branche de la physique, 251-252, 449-450, 688-69i; - électrique, $739.752,79 ;$; - des étoiles, 655 ; - lumière noire, rouge, froide, chimique, etc., 693.

Lycées, 169-171, 369, 373, 589-599; - de filles, 598 ; - de Galata-Seraí, 593.

Machines, - pneumatique, 449; electrique, $253,694,752$; - à vapeur, 252-253, 470-471, 578, 732,753754. $755 ;-$ industrielles. $986-287$, 752 ; - de Richard-Lenoir, Girard, 234-2 $\$ 6$; - de Jaequard, 250. 484, 701 ; - agricoles, 481, 701, 747; à coudre, 485; - à imprimer, 333$334,540-541,692,701$.

Magnètisme, 657. Voyez ElectroMAGNÉTISME.

Magnétisme animal, 500, 721-722. Voyez HYPNOTISME.

Maillechort, 483.

Malthusianisme, 218.

Mandats territeriaux, 294 .

Mariage, 10, 8́t-86, 87, 108, 133, 311, $540-347$.

Marine, - sous la Révolution et l'Empire, 157-158; - de 1814 a $1848,365-366$; - depuis 1848,573 , 576-581; - ministere de la marine 157 ; - troupes de marine, 158, 368, devenues troupes coloniales, 5\%6; - écoles relevant de la marine, 167 , $366,577-578$.

Marque (peine de la), 86, $88,346$.

Marxisme. Voyez Socialisme.

Maternelles (écoles), 598, 767. 
Maternités, 469,726 .

Mathèmatiques, Mathématiciens, sous la Pévolition et l'Empire, 246-

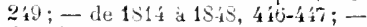
depris 1518,678; - appliquées aux arts et travaux, 487.

Maximum (loi du), 291, 302, 795.

Mécanique (science de la), 478, 678.

Médailles, Mèdaillistes, 655 .

Médecine légale, 268-269, 469, 727, 729.

Médicales (sciences), - sous la Révolution et l'Empire, 265-273; de 1814 a 1848, 401-469:- depuis 1848, 717-730. - Voyez ANatome, Histologie, Physiotogie, Thérapeutique, Chirubie, Ophtalmo. logie, Hygiène, Maternités, AliéNĖs, Médecine légale.

Mélinite, 700.

Messageries, 93, 293, 752.

Mètallurgie, 244, 253, 25?, 454, 471474, 15-455, 700-701, 703-704, 733734,755 .

Métaux. - nouvellement découverts, $25-253,452-453,763-704 ;$ - précieus, 739-740.

Météorologie, 599, 701-703.

Microbes, 704, 711-711, 719-721.

Microphone, 69i.

Microscope, 710, 714.

Microscopiques (auimaux). - Voyez MICROBES.

Minéralogie. 264-265, 460, 715-716.

Ministère public, 7\$, $\$ 2-83$.

Ministres, - supprimés, $2 j$; - puis rétablis. 29; - de la guerre, $139-$ $140,360-361,559 ;$ - de la marine, 157 ; - de l'agriculture, 4S2, 7i7750 ; - de rinstruction publique, $354,370,37 \dot{4}, 592-600$.

\section{Mitrailleuse, $5 \% 2$.}

Mobilier, - sous la Révolution, 221222, 232-281, 295-301; - mobilier Empire, 316-317; - de 1814 a 1818 , 494; - sous la troisieme Republique, 669-571. - Ecole du meible (Boille), 753. - Recherehes sur le mobilier ancien, 636.

Modes, Modistes. - Voyez Costume.

Mqurs, 297-319, 496-50S.
Monnaies, 759; _- artistiques, 655 ; - union monétaire, 758, 804.

Monts-de-piété, 295 .

Monuments. - Voyez Aachitecture. - Restauralion d'anciens monuments, 421-422, 601, 636, 650-651.

Morale; Moralistes, 210, 399, 606,

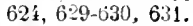

Morphine, 456, 468.

Moteurs, 733, 808 .

Mouches (hitean), 195, 771.

Mouches (insectes nuisibles), $72 \%$ 728.

Municipalitẻs. - Voyez Communes.

Musée social, 649; - Pédagogique, 598.

Musées, 166-167, 418, 419, 423, 601.

Mu séum, 166, 171,260, 262, 591, 593, $599 ;$ - océanographique de Nonaco, 708 .

Musique, - sous la Révolution et l'Empire, 234-242; - de 1314 i $1848,437-446 ;-$ depuis 1848,671 677 ; - des Grees. 625; - de l'anejenne France, 636.

Mutilation, - du poignet, 86,88 , 346.

Nationalités (politique des), -358 359, 556-558, 797-798.

Naturaliste (école), - en littérature, 614-615; - en peinture, 659-661.

Négres, 13, 159-160, 366, 585 .

Neutralisations, 558-559.

Neutres, 139.

Nitroglycérine, 705.

Notaires, 83-84.

Observatoires, 599,678-686; - de météorologie, 599, 702.

Océanie, - colonies françaises, 366 , 584,802 ; - voyages scientifiques, 260,458 .

Olficiers, - grands officiers de le couronne, 40 ; - dans l'armée système éleetif, 14's, 147, 151; officiers ministériels, 83-\$4.

Omnibus, 495, 509.

0ndes hertziennes, 6\$9-690. 
Ophtalmo.ogie, Ophtalmoscope, 260 , $469,72 \%$.

Opéra, 651, 675.

Opérette, 676 .

Optique, 25l-252, $149-150,688-691,742$.

Oratorio, 676 .

Ordres religieux. - Voyez Covgrégations.

Orfẻvrerie, orfèvres, : $83,317,486$.

Ouvriers, - snus la Révolution, 279280, 287, 79'-795; - sous l' $\mathrm{En}^{-}$ pire, 280-282; modifications apportẻes dans leur sort par les machines. 287, 486-487; - leurs associations anciennes, 506, et nouvelles, 766 767 ; - leurs conditions actuelles d'existence. 764-769; - leurs relations avec les sectes socialistes, 413-418, 771-790, 801.

Paléont logie, 262-263, 459, 712; $\nabla$ trét ile, 713-715.

Pamphlets, 54-58, 195, 207-21)8, 39'395.

Panama (isthme de), Ti3.

Papauté, pape, - ses rapports avec la Révolution, 103-101; - avec Napoléon Itr, 116-117, 121-126; avec les gouvernements suivauts, $349-350,551-553 ;-$ infaillibilité du pape, $551-552$.

Papler (industrie du), 283-281, 484; - papiers peints, 284, 301 .

Papier-monnaie. - Voyez Assignats, Mandats tenritoriaux, Banque iblllets de).

Pari mutuel (fonds du), 768.

Paris, - pendant la Révolution, $311-313$; sous Napoléon 1er, 317 319; - sous les derax monarchies parlementaires, 49-490, 509-513; - depuis 184, 752, 769-771; son régime administratif, voyez Communes; - ses monumeots voyez Ponts, JARdins, Egouts A RCHIteCture, etc.

Parlement, - représentation nationale, - en France, voyez ConstiтLтіохs; - en Angleterre, 16-21; - da 1 les autros pays de l'Europe, $12-14,797-798$.

Parlements, ancienues cours de justice; - supprimès, 9-10, 71-75,77.
Paysans, - leurs couditions actuelles d'existence, 744-752, 795-796; visés par les socialistes, 776,779 , 787. - Voyez Agriculture.

Pècheurs, Pècheries, 576-5;7, 776, 787. - Pèches scientifiques, sondages, 708.

Peinture, Peintres, - sous la Révolulion et l'Empire, 167, 168, 175, 225-2:3, - sous la Restauration, 418-13\%; - sous Louis-Phil ppe, 418, 425-426, 433-435, 493, 716:sous Napoleon III, 656-663; sous le régime actuel, 653-669.

Peluche, 484.

Perruques, Perruquiers. 291, 299-300, 303,315 .

Perse, 213, 407, 409, 511, 601, 611, $6 \mathbf{1 3}, 802$.

Peuple, 31, 32-34. - Voyez Ouvalers, Paysans, Plébiscite.

Phares, 449-150, 689, 733, 803.

Pharmacie, 25i, 273, 453, 456-457, $469,706,719,730$.

Phénol, acide phénique, 707, 720.

Philosophie, - sensualiste, 208-209; - éclectique, 209-210, 397-399, 624627 ; - positiviste, $399-400,610627-$ 629 ; - matérialiste, 209, 719; des Grecs et des Romains, 624, 631; - du moyen àge et eartésienne, 624, 629; - des Hèbreux, 409, 624; - de l'Inde, 624, 64.

Phonographe, 696-697.

Photographie, 453, 455, 480,741-742; - des corps cèlestes, 679 el s., 683-684; - de l'invisible, 689; des rayons $X$ el autres radialions, 689-693; - instantanée, microscopique, sous-marine, 74\%; - photographie des couleurs, 752,810 .

Photogravure, Phototypie, Photolithographie, Photoglyptie, Photoplastographie, 7\%.

Photophonie, Photophone, 693, 695.

Physiologie, - animale, 709; 一 végé1iale, 713-714; - médicale, 266-267. $462,717-729$.

Physique, - sous la Révolution et l'Empire, 250-255; - de $181 . \mathbf{i}$ à 184, $149-452 ;-$ depuis $1848,686-$ 701. - Voyez Acoustique, LuMtìre, Optique, Electricité, MaGNétisme, VAPEUR, MÉTÉo ROLOGIE. 
Pile électrique, 253-255, 257-259, 450-452, 4\$6, 691-695.

Pithécauthropus, 646.

Fisciculture, $1 \$ 2-4 \$ 3$.

Plaisirs (lienx de), 301, 311, 317-319, 498-199.

P1ébiscites, 28, 36-37, 41, 49, 322, 518, 519, 521-522.

Pneumatique, - machine, 449; tubes, 737.

Poésie, -- lyrique, 191-192, 195-197, 3๖(6-3s9, 6099-611; - épique, 193$191,386-3 \$ 9,609-611,-$ hèroì-eomique, 19i-195; - deseriptive, $192-193$.

Polémique, 207-208, 39'-395, 539-540.

Police, - sous la Révolution, 25-27, $58,75,1811-183,217,303,304 ;-$ sous Napoléon Ier, 42, 59, 61, 71, 125, 183-194; - sous la monarehie parlemeotaire. 339-311, 504. 509; - sons Napoléon $111,517,519,532$ $533,536,538$.

Ponts, 892-293, 319, 479, 509; - de for, 4-7.7-736; - ponts-riadues, 479,735 .

Porcelaine, 284, 483.

Ports (travanx dans les), 366, 179.

Postes. 313-311, 550, 758-759; - Union postate, 759, 801 .

Presse. - Voyez lmprimerie, LIbrairie, Jourinaux, Libertés.

Prisons, 生, 107, 304, 307, 340-342.

Prophèties, 212, 500.

Propriété, 8 ; - morcelèe par la Révalution, 271-275; - attaques eontre son primipe, 216-218, $113-118,771$ et s.; - proprieté industrielle, litteraire, artistique, 279, 753.

Protestants. - Voyez Affranchissement, Cultes.

Proverbe (eomédie-), 385.

Prud'hommes (conseils de), 281.

Psychiatrie. - Voyez Alí̇NÉs.

Puits artésiens, 478, 742-743.

Question ou torture, - abolie, 86 . Quinquina, Quinine, 457.

Radiant (état de la matière), 690.

Radiation, Radioscopie, 688-69i, 703 .
Radiopbonie, 693, 695.

Radium, 703.

Rayons, - cathodiques, 689 et s.; Kant gen, 690 et s.; - Beequerel, 693.

Réalisme, Réalistes, - en litter., 613 et s., - dans les arts, 659 et s.

Religions (science des), 213-214, 408411), 624, 640,642; - musee des religions, 601 .

Représentants des colonies au parlement, 587.

Républiques, - au dehors, 12-14, 797. 798, 801.

\section{Revolver, 574.}

Revues, - littéraires ou s"entinges, $336,542,629,805$; - an theilre, 609.

Romans, 196-200, 336, 389-3.3,6!?-619.

Romances, 197.

Romantisme, - en littérature, 201$203,355-3 \times 3,656 ;-$ dancles arts,

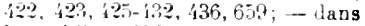
le mobilier, 491.

Routes, 292-?93.

Russes, Russie, - musique, 437 ; róle dans les sciences, 477,153 ; - dans le promrès du droit des cens, 560-562; - dans le nouvement soeialiste et anarchiste, 779783 ; - dansla eivllisation cénirale, 802 ; - des chemins de fer, 73i-735; - nos rapports avec eux, 1:-13,199200,560 ; - Régime soejal ti politique, 12-13, 798; - obligation des passeports, 803-804; - puissance et population, 563 .

Salons, 49r-197; - de peinture, 165,

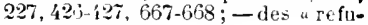
sés ", 661)-661. - Voyez ExposlTIONS.

Salpêtre, 214-245.

Sauvetage (sociélés et apparells de), 803.

Scaphandre, 7i1, 7i2.

Sciences. - Voyez Mathé.MatipUes, Astronomie, Physique, Chimicete. - Serviees rendus a la déf nuse nationale, 214, $245,290,567,5 \% 1-75$, 704, 740-741; 一 a l'aerenture, 256-257, 626; 761, 702, 707, 7 \% -746, - à l'ind strie, $256-257.282,455$. 
457, 704-70\%,735-739, 752-755; leur rule dais le monde moderne, 7)2-79i.

Sciences morales et politiques. Voyez Philosophie, Morale, HisTOIRE, ECONOMIE POLITIUUE, SOCIOLOGie, Religions, Juhisconsultes, LOIS, THÉORIES.

Sculpture, - sous la Révolution et l'Empire. 224-225; - de 1814 a $1818,422-125,716 ;-$ depuis 1848 , $597,652-650$.

Sel (impít sur le), 90.

Sels organiques, 454-456, 704-705.

Sénat, - sous Napoléon Ior, 34-44. $47-49,61,81,150,175,177,575-$ 576: - sous Napoléon 111, 518520 ; - républicain, $22,524-52$, 546,$627 ;$ - aux Etats-Unis, 22, 516 ,

Serfs, - leur atranchissemeat, en France, 8-9, 274, - en Russie, 13, 798

Sérothérapie, 721 .

Socialisme. Socialistes, 216-21S, 388, $392,413-418,771$ et $\mathbf{s}$.

Sociétés, - secrètes. 329, 504-505, $533,53 \%$ : - cooperatives, 766 , $775,775,790 ; \rightarrow$ de cecours mutuels, 766-767: - d'industrie nationale, 282 ; - d'agriculture, 279 ; - d'artistes, $667-668 ; \ldots$ de musique, 498,671 ; - scientifiques, 649, 609670 ; - de géographie, 412,648; d'économie politique, $649 ;-$ de sauvetace, 803 ; - protectrice des animaux, 629-630; - protectrice de l'enfance. 728 ; - de sciences médicales, 272, 461, 462, 717; d'acclimatation, 708, 715.

Sociologie, 208, 649-619. - Voyez SOCIALISNE.

Soie. Soieries, 279, 283, 2\$6, 315, ist-155, 459.757; - vers a soie, 730, 7ín.

Somnambulisme. - Voyez HypnoTISME.

Sorcellerie, 500-501.

Soude, 256-257, 282, 289, 453-454.

Sourds et muets (institutions en faveur de:, 72.

Sous-marins (bateaux), 580-581.

Souterrain (monde), 716.
Souveraineté nationale, $8-9, \mathbf{1 3 5}$, 321,795 .

Spahis, - algériens, 365, 576; sénéralais, soudanais, 576 .

Spectre, spectrale (analyse); - so. laire, 680, 658-689; - des étoiles, $685 ;-$ du sang, 724; - des diverses substances, 703.

Spiritisme, 500 .

Statistique, - agricole, 745, 750751 ; - industrielle, 751-752, 755; - commerciale, 751-752, 759; médicale, 728.

Stratigraphie, 460, 715-716.

Sucres, - législation, 290, 302, 550, $5 \$ 6,769 ;-$ production, 279, 2S4, 4\$3, 744,749; - travaux des chimistes, 454, 455, 704-705.

Suffrage, - universel. Voyez ÉlecTORAL (droit).

Suisses, - au service de la France, voyez ETRANGERs. - Lettrés, artistes, savants, $246,420,686,712$.

Suédois, - savants, 259; - aéronautes, 740 .

Suez (isthme de), 743-744, 805.

Superstitions, 500 .

Supplices. - Voyez Lots pÉNales.

Syndicats (lois sur les), 765. - (Abus des), 765, 790.

Système décimal. 246, 250, 292, 306, 758,804 .

Tabac, 92-93, 348, 457, $491,493,550$, 714.

Téléphone, 574, 695-697; - réseau téléphonique, 690. 737; - téléphone sans fil, 697 .

Télégraphes, - aérien. 243-244;electrique, 255, 452, 477, 574.689. $737,793,804 ;$ - optique, 574 : télégraphe sans fil, 697-699, 8 心

Temples, - antiques, 422, 632-633, 650,671 ; sous la Révolution et l'Empire, 218, 222-223; - protestants ou israélites, 110 .

Terreur (1a), 25-27, 52, 56, 67, 80, J08-112, 173-17- $302-308,638,795$; - Terreur blanche, 501 .

Théatre, - sous la Révolution et l'Empire, 176-191; - de 1814 a 1848, 378-386; - depuis 1848,603, 
609. -- Thèatres antiques, 623, 650 ; - constructions de théatres. 222-224, 421, 65l, 797. - Voyez Tragénie, Drame, Coméde. NivSIQUe.

Théologie (facultés de), - leur création, 171; - suppression des facullés de théolngie catholique, $55 \%$ : - facultés libres de theologie, 552, 594. - La théologie dans li: pascé. 797 et s.

Théories, - sur la Révolation, 212,638 ; - sur l'Falise, 215-210, $359-351,394,551-552 ;-$ sur la propriété et la société, voyez SoCIALISME.

Thérapeutique, 267-270, 462-465, 719T:y,

Thermo-dynamique, 68;-683.

Thermo-électricitè, 69'-695.

Thermomètre, 251, 449, 724.

Timbre (droits de), 53, 58,93-9i, 5\% .535 .550 .

Tirailleurs, - de Vincennes, voyez 1.HAsseurs a pled; - algériens, 305,570 ; - siduriens, seneralais, soudanais, haoussas, annaniles, tonkinois, maleaches, canaques,576.

Tissus, 252-236, 481-185. - Voyez Draps, Snie, Velours, Peluche, GOTON.

Tolerance religieuse. - Voyez CrLTLS.

Torpille. Torpilleurs, 580 581, 694.

Trageddie, 184-:86, 393, 602.

Traités de commerce, 285, 289, 756$758,797,79 \%, 800$.

Transportation aur colonies. 549 .

Tramways, 73f, 7i7, 7\%1.

Travaux publics, - Voyez Ponts. Pohts, Router, Canaux, Chemins DE FER. - Lis sur les travaux publics, 479, 746-747.

Tribunat, 3t-41, 47-49, 51 .

Tribunaux, - de district, 7i-75, 78; - remplacés par ceux de premitre instance, 77, 78-80; - d'appel, voyez Coths D'APPEL; - de cas- sation, voyez Cour de Cassation; - de conmerce, $76,78,345 ;-$ révolutionnaire, $26,80,619, \tau 95$.

Tubulaire (ohaudière ou sy-tème), 171, 474-475, 800.

Tunnels, $479,735-736 ;-$ sous le Manche, 736 .

\section{Turcos. - Voyez Tiralleeurs al-} GÉRIENS.

Turquie, Turcs, $411,557,561,593$, $637,643-644,743,797-798,804$.

Université de France, 123, 169-1:2. 353-354, 367-368, 363-374, 589-60:2.

Untversités (loi sur les), 599-600.

Vaccins, - de la variole, 268, 675 , 682 ; - de Pasteur et deses disciples, 719-721; - loi sur les vaccins, 721 .

Val-de-Grâce, 172, 272, 575.

Vapeur, 25:-253, 470-477, 573-581 732-735, 740, 793, 505 .

Vaudeville. - Voyez ComÉde.

Véhicules. - Voyez Vortures, MrsSAGERIES, THAMWAYS, OMNIBUS, Bateaux, Chemins de fer.

Velours, 484.

Verre, Verrerie, 284, 4\$3, 669-671.

Vétérinaire (art ou science), 469, $7: 99-730$.

Vins, - production, 279,605 , 744$7 \mathrm{i5}$; consonmation, $769 ;-$ lisislation, 92, 291, 499, 7is; - 1rA. raux des chimistes, 256,455 , 204 705 .

Vitraux, 659 .

Voitures, 92, 293. 494-495, 75:.

Voyages, - de découvertes ou do sciences, 250, 417, 412, 458,601. 647-648. - Voyez Asie, Afrique, AmÉRIQUe, OcÉanie.

Zoologie, 260-263, 458-459, 709-713.

Zouaves, $365,575-576,657$. 



\section{TABLE ANALYTIQUE}

Prérace.........................................

\section{LIVRE PREIIER}

\section{LES GOUVERNEMENTS RËVOLUTIONNAIRES}

\section{LA REVOLUTION - LE GONSULAT - L'EMPIRE}

(1789-1814).

CHAPITRe PREMIEP. - Les Principes de 1 789 et la Révolution............................. 1

L'œuvre accomplie par l'ancienne monarchie (1). - L'œuvre accomplie par la Révolution (2). - La Révo'uliun aurait-elle pu être évitée? (4). - Les principes de 1789 (6). - Souveraineté nationale $(6)$. - Principes nouveaux de liberté (7). - Principes noureaux d'égalité (8). - Les privilèges des provinces et des villes abulis (9). - Principes nouveaux de justice et de législation (9). - Principes nouveaux d'organisation militaire (10). Principes nouveaux d'organisation financière (10). - Principes nouveaux d'enseignement national (11). - Principes nouveaux d'assistanec publique (11). - Expansion des principes de 1789 dans le moade............................ 12

CHaf'lfre II. - Les Constitutions, le droit electoral. 15

I. La Constitution de 1791 . - Principes fondamentaux de nos Constitutions (10). - La Constituante (16). - Exemple que nous otfrait la Cunstitution anglaise (16). - Pourquoi on n'a pas adopté la Constitution anglaise $(\because 0)$. - La Constitution de 1791 (21). - La Législative........................ 24

Il. Les Constilutions républicaines. - La Convention (24). - La Constitution de 1793 (27). - La Constitution de l'an III (28). Les mœurs parlementaires pendant la période violente de la Piévolution............................ 30

III. Les Constitutions napoléoniennes. - La Constitution de l'an VIII (34). - La Constitution de l'an X (37). - La Constilution de l'an XII (39). - Suppression du Tribunat (41). - Abus des sénatus-consulies (41). - Despotisme impérial (42). - Instabilité des institutions impériales..................... 42 
v. Le droit élecloral. - Les élections de 1789 (44). - Systène électoral de la Constituante (44). - Système électoral de la Législative (46). - La Convention nationale : son prenier système électoral (46). - Son deuxième système èlectoral (46). - Système électoral de la Constitution de l'an VIII (47). - Système électoral du Consulat à vie et de l'Empire........... 48

CHAPITRE III. - Les libertés publiques........... 50

Ce qu'on entend par les libertés publiques (50). - Le droit de pètition (51). - Le droit d'as*ociation et de réunion (51). - Son histoire : 10 Pendant la Rérolution (51). - 20 Sous le Consulat et l'Empire (52). - La liberté de la presse (53). - Son histoire : 10 Sous la Constituante (54). - $2^{\circ}$ Sous la Législative et la Convention (55). - $3^{\circ}$ Sous le Directoire $(5 i)-4^{\circ}$ Sous le Consulat et l'Empire.............................. 58

CHAPITRE IV. - L'administration département:a le et eomnunale $\ldots \ldots \ldots \ldots \ldots \ldots \ldots \ldots \ldots \ldots \ldots, 62$

Problèmes que soulève cette administration (62). - Système de la Constituante : $1^{\circ}$ Departements et districts (62). - 20 Mlunicipalitès (64). - Inconvénients de ce système (65). - Système de 1793 (66). - Système de l'an III (67). - Système du Consulat et de l'Empire (69). - L'assistance publiţue............ 72

CHAPITRE V. - Les tribunaux et les lois.......... 73

I. Les tribunaux. - Organisatiol des tribunaux par la Constituante (73). - Organisatiou des tribunaux par Napoléon (77). - Recrutement des magislrats : 10 Système de la Constituante : l'élection (78). - Avantages et incouvénients de l'élection (79). - 20 Système napoléonien : la nomination par le pouvoir $(8 \mathrm{t})$. - Inamovibilité des magistrats (81). - Réorganisútion lat ministire public (82. - - Les a vocats et les officiers ministériels......... 83

Il. Les lois. - La Revolution : $1^{\circ}$ Lègisiation civile (84). - 20 Légistation pénale (86). - Ligratation napoléonienne : les Codes. 87

CHAPITRE VI. - Lew dinabces................ 89

Contributions directes (89). - Contributions indirectes (92). Enregistrement et timbre (93). - Mlode de percention des impöts (9'). - Organisation du service des contributions directes (95). - La cour des Comptes (9.). - Les budrets.......... 96

CHIPITRE VII. - Les cultes................. 97

i. Le clergé catholique sous la Constituante. - Rüle du clergé au debut de la liévulution (97). - I'reuieres réformes de la Constituante (97). - Le Comité ecclésiastipue (99. - La Constitution civile du clergé (100). - Pissistances uppusies à la Constitution civile (103). - Décret qui impose le seraent constitutionnel 
(104). - Exécution des décrets (105). - Le nouveäu clergé cons titutionnel (105). - Trouble profond apporté par les décrels (106). - Dernier décret de la Constituante............ 106

II. Le clergé catholique après la Constituante. - Décrets de la Législative (107). - Décrets de la Convention contre les réfractaires (108). - L'Église constitutionuelle sous la Convention (108). - Le culte de la Paison et la persécution hébertiste (109). - Robespierre et le culte de l'Être suprème (111). - Derniers temps de la Convention; la liberté des cultes (113). - Pulitique du Directoire............................ 114

III. Le clergé catholique sous Napoléon. - Politiqne de Bonaparte (115). - Le Concordat de 1801 (116). - Les arlicles organiques (117). - Mise à exécution du Concordat (t20). - Comparaison de la situation du clersé catholique sous le nouveau Concordat et sous l'ancien régime (120). - Appréciation du Concordat (121). - Politique de Napoléon à l'égard de la papauté (121). - Politique de Napoléon à l'égard de l'Église de France (123). - Ambitions impolitiques de Napuléun................. 126

IV. Les congrégations religieuses. - Décrets de la Constituante (126). - Décrets de la Législative (128). - Législation consulaire et impériale....................... 129

V. Les culles non calholiques. - Les protestants et la Révoluiion (129). - Les protestants et Napoléon (130). - Les juifs et la Révolution (131). - Les juifs et Napoléon (132). - Organisation du culte israelite....................... 133

\section{CHAPITlE VIII. - Le droit des gens, l'armée, la marine,} les eolonies.......................... 135

I. Le clroit des gens. - Le droit des gens pendant la Rèvolution (135). - Le druit des gens sous le Consulat et l'Empice... 138

II. L'armée pendaAt la Révolulion. - Ministres de la guerre (139). - Idees nouvelles sur l'armée (140). - Pouvoirs du roi sur la force armée (140). - La garde nationale (141). - Le drapeau tricolore (142). - L'armée régulière sous la Constituante (1 12 ). La Législative : les enrólements volontaires (144). - La Convention : l'amalgame (146). - La réquisition, la levée en masse (147). - Le Directoire : Ja conscription (147). - Création de nouveaux corps (148). - Les trouyes étrangères pendant la Révolu-

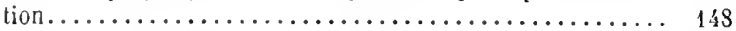

III. L'armée sous Xapoléon. - Abus de la conscription sous l'Empire (150) - La garde nationale sous l'Empire (150). - Les grades, la Légion d'honneur, les dotations (151). - L'organisation é l'armement (152). - La garde impériale (153). - Les troupes ètrangères sous l'Empire...................... 155

R. GNIL. CONTENP. 
IV. La marine el les colonies. - La marine (157). - Les colonies................................ 158

CHAPITRE IX. - L'inst ruction publique........... 162

I. L'instruction publique pendant la Révolution. - Projets de la Colvention (162). - 10 Enseignement primaire (162). $-2^{\circ}$ Enseignement secondaire : les écoles centrales (164). - $3^{\circ}$ Enseignement supérieur (16\%). - $4^{\theta}$ Créations scientifiques, littéraires, artistiques (165). - 50 L'Instilut de France (168). - Sous le Direcloire............................... 168

II. L'instruction publique sous Napoléon. - Fondation de l'Université (169). $-1^{\circ}$ Enseignement primaire (169). - $2^{\circ}$ Enseignement secondaire : les lycées et collèges $(170)$. $-3^{\circ}$ Enseignement supérieur; les facultés (171). - 4 Réfurmes et créations diverses (171). - 5 L'Institut de France mutilé........ 172

CHAPITPE X. - Les lettres.

I. Caractères généraux. - Influence de la Révolution sur l'esprit francrais (173). - Influence de l'Limpire (174). - Caractere classique de la lıttèrature........................... 176

II. Le théutre. - Le théâtre de la Révolution (177). - La censure sur le théatre pendant la Pévolution (180). - Régime du thèàtre sous le Consulat et l'Empire (183). - La tragédie (184). - Le drame (186). - La comédie.................... 189

III. Les autres genres lilléraires. - La poésie lyrique (191). - La poésie descriptive ( 192 . - La poésie épique et liéroĩ-comique (193). - La satire, la chauson, la ronance (195). - Le roman (197). - La critique littéraire (200). - Les origines du mouvement romantique (201). - Fécondité littéraire de la période ı́volutionnaire et impériale................... 203

IV. La tritune et la presse. - L'èloquence pulitique (204). - La presse, la polémique....................... 207

V. Les sciences morales et politiques. - La philosoplie (208). L'histuire (210). - Les éludes orientales (213). - La science des religions $(213)$. - Les théories politiques $(213)$. - Les théories sociales (216). - Babeuf et les Babonvistes (217). - Autres écoles socialistes 217$)$. Le Vilthnianisne......... 218

CHAPITRE XI. - Les arts ................. 219

I. Larchitecture, la sculpture - Caractère classique (219). - Caractère de grandeur; vastes projets de Napoléon (219). - Les arcs de triomphe, les colonmes $(220)$. - Le Temple de la Gioire (222). - Palais et édifices publies (223). - Les sculpteurs francais 224. - Les grand's sulptents étrangers 223). - Caraclieres de la sculpture...................... 223 
I. La peinture, les arts du dessin. - Filiation de nos écoles de peinture (225). - Première genération : David, Regnault, Lethière, Prud'hon, Carle Vernet (226). - Denxième génération : Isabey, Gérard, Gros, Girodet, Guérin (229). — La gravure. 233

III. La musique. - Les compositeurs de la génération pricédente (234). - Les compositeurs de la génèration révolutionnaire (235). - Les chants patriotiques (236). - L'opéra (236). L'opéra comique (238). - Influence des Allemands et des Italiens sur la musique française..................... 240

CHAPITRE XII. - Les scienres................ 243

Services rendus par la science à la défense nationale (243). - Le télégraphe aérien (243). - Aérostation militaire, canons, aciers, poudres, salpêtres, etc..................... 244

I. Les math'matiques et lastronomie. - Mathématiques et mathématiciens (246). - L'astronomie............... 249

II. La physique et la chimie. - Physique : les gaz, lez aérostats (250). - La lumière, l'optique (251). - La chaleur (252). - La vapeur (252). - L'électricité (253). - Chimie........ 255

III. Les sciences naturelles. - Voyages de naturalistes (260). Zoologie (260). - Paléontologie (262). - Botanique (263). Géologie............................. 264

IV. Les sciences médicales. - Anatomie (265). - Physiologie (266). - Thérapeutique (267). - Psychiatrie (269). - Chirurgie (270). - Pharmacie............................ 273

CIAPITRE XIII. - L'agriculture, l'industrie, le commerce, le crédit........................... 274

I. L'agriculture. - Lois agraires de la Constituante (274) - Lois agraires de la Législative (275) - Lois agraires de la Convention (276). - Multiplication des propriétés rurales (277). - Progrès de l'agriculture........................... 278

II. L'industrie. - L'industrie pendant la Révolution $(279)$. - L'in. dustrie sous Napoléon : la réglementation (280). - Progrès de l'industrie (282). - Philippe Lebon (284). - Richard-Lenoir (284). - Philippe de Girard (285). - Jacquard (286). — L'avènement des machines............................ 286

III. Le commerce. - Le régime donanier : $1^{\circ}$ Pendant la Révolution 288). - $2^{\circ}$ Sous le Consulat el l'Empire (289). - Régime intérieur du commerce : $1^{\circ}$ Pendant la Révolution $(291) .-2^{\circ}$ Sous le Consulat el l'Empire (291). - Unité des poids et mesures (292). - Routes, ponts, canaux (292). - Moyens de lueomotion: diligences, fiacres....................... 293 
IV. Le crédit. - Les assigats (29k). - Les mandats territoriaur (294). - Le Grand-Livre (294). - Le tiers consolidé (295). Le crédit public sous Napoléon (295). - La Banque de France. 295

CHAPITRE XIV. - Les usages et les mours......... 297

I. Pendant les premières annees de la Révolution. - La vie dans la rue (297). - Le costume, le mobilier (298). - Les plaisirs (301). - Les duels............................... 301

Il. Pendant les années sombres de la Révolution. - La vie pendant la Terreur (302). - Le calendrier républicain (306). - Cérémonies, fêtes $(306)$. - Les prisons, l'échafaud.......... 307

III. Après Thermidor. - La réaction thermidorienne (309). - Le costume (309). - L'agiotage (311). - Mariages et divorces (311). - Les plaisirs (311). - Paris pendant la Revolution..... 312

IV. Sous le Consulat et l'Empire. - La cour (313). - Le costume Empire (315). - Le mobilier Empire (316). - L'art culinaire (317) - Les plaisirs (317). - L'opinion (318). - Paris capitale d'un

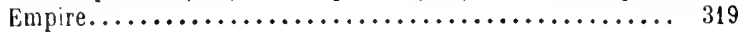

\section{LIVRE II}

\section{LES GOUVERNEMENTS DE SUFFRAGE RESTREINT}

\section{LA RESTAURATION, LA MONARGHIE DE JUILLET} (1814-1848).

\section{CHAPITPE XV. -- Les Constitutions, le droit électoral, les} libartés............................. 320

1. Les Constitutions. - Caractères des deux monarchies (320). - La Charte de $1814(321)$. - L'Acte additionnel de 1815 (322). - Modifications à la Charte de 181 4 (322). — La Charte de 1830... 324

11. Le droit électoral. - Système de la Restauration (325). - Système de la IIonarchie de Juillet (326). - La question de la réforme é ectorale et parlementaire............... 327

IIl. Les libertés publiques. - Le droit de pétition (329). - La liberté d'assuciation et de réunion (329). — La liberté de la presse : 10 Sous la Restauration (330). - $2^{\circ}$ Sous la Monarchie de Juillet (333). - Développement de la presse sous les monarchies parler entaires.............................. 334

CHAPITRE XVl - L'administration, la justice, les cultes........................... 337

I. L'administration. - Caractères de notre organisation dars la période contemporaine (337). - L'administration départementale et municipale (338). - La police (340). - Réforme des prisons (340). - L'assistance publiquue (342). - Péforme des postes. . 343 
II. Les tribunaux el les lois. - Nomination des magistrats (34k). Importance nouvelle de la Cour de Cassation (343). - Esprit de la magistrature (3ł⿱艹)). - La législation civile (346). - La législation pénale............................. 346

III. Les finances. - Les impóts (347). - Le budget de l'État (348). - Le budget des départements et des communes (348). - Lorganisation finan ière..................... 349

IV. Les cultes. - La pratique du Concordat (349). - Esprit du clergé $(350)$. - Lois religieuses sous la Pestauration (3ว̆1). - Politique de Louis-Philippe à l’ègard du clergè (3.ّ2). - Les congrigations (352). - Les protestants et les juifs................ 354

\section{CHAPITPE XVII. - Le droit des gens, l'armée, la mariue,} les colonies.......................... 355

I. Le droit des gens. - Les Congı̀̀s de $1813 ̈$ à 1823 (30̈3̆). - Les guerres de la Restauration (3̈̈6). - La politique ètrangère sous Louis-Philippe (356). - Caractère essenticllement pacifique de la vériorle parlementaire....................... 3.5

U. L'armée. - L'armée sous la Restauration (359). - Là garde nationale sous la Restauration (360; - L'armée sous la Monarchie de Juillet (361). - La garde nationale sous la Jlonarchie de Juillet (362). - Progrès de l'artilleric (363). - Rerfectionnement du fusil (36't). - Corps nouveaux ou modifications des anciens 36 '

III. La marine el les colonies. - La marine (365). - Lescolonies. 366

CHAPITlE XiII. - Linstruction publique......... 368

I. Sous la Restauration. - L'Université (367). - Enseignement primaire (368). - Autres ordres d'enseignement.......... 369

II. Sous la Monarchie de Juillet. - Enseignement primaire (370). - La lui de 1833 (371). - Progrès réalisès (372). - Enseignement sceundaire (373). - Enseignement supérieur....... 374

CILPITPE XIX. - Les Iettres................ 375

1. Caractères généraux. - Le siècle de Victor Hugo (375). - La langue (376). - La versification................ 377

II. Le théatre. - La révolution du théatre (378). - La Prèface de Cromwell (378). - La Bataille d'Hernani (380). - Le théâtre de Victor Ilugo (331). - Influence du théàtre étranger (382). - Les dernieres tragedies (383). - Acteurs el actrices cèlèbres (383). Le drame listorique (38\%). - Le drame bourgeois (384). - La comédie historique (385). - La comédie-proverbe (335). - Le

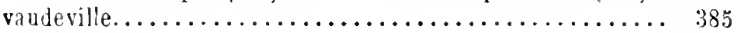

III. Les autres genres litteraires. - La poèsie épique et lyrique (385). - La clıanson (389). - Le roman (359). - Là critique ittèraire (393). - La polémique (394). - L'èloquence... 39ă 
CHAPITRE XX. - Les sciences morales et politiques. 397

I. La philosophie et le droit. - L'ẻcole ćclectique (39i). - L'ècole positiviste (399). - Le droit................. 400

Il. L'histoire, les langues, la géographie. - Idèes nourelles sur l'histoire (401). - Les àges classıques (402). - Le moyen àge français ('403). - L'histoire des temps modernes (40t). - L'histoire de la Piévolution et de lEmpire (403). - Les provinces nouvelles de l'histoire (406). - Études égyptiennes (406 - Études assyriennes, babyloniennes, persiques, médiques (407). - Études sèmitiques (408). - Études persanes et arméniennes 409$)$. - Études indiennes $(410)$. - Éludes tatares, turques, chinoises, japontises (411). - Geographie, voyages................. 411

III. L'économie politique ot la sociologie. - L'économse politique (413). - Les thejories communistes et collectivistes (413). - Les théories anarchistes....................... 417

CHAPITRE XXI. - Les arts................ \&t9

I. L'architecture, la sculpture. - L'árchitecture de la liestauration (419). - L'architecture de la Monarchie de Juillet (420). - Caractères généraux de la sculpture française (422). - Les sculpteurs............................... 423

11. La peinture, les arts du dessin. - Les rèvolulions de la peinure (42.5). - Les peintres de la Restauration: classiques et romantiques (426). - Les peintres de la Monarchie de Juillet (433). - Les dessinateurs (435). - Les artistes graveurs (436). - Les artistes lithographes............................ 436

III. La musique. - Prugrès de la musique au xixe siècle 437 ). La musique allemande et son influence sur la notre (439). - La musique italienne et son infuence (440). - Les compositeurs francais.............................. 441

CHAPITPE XXII. - Les sciences............... 446

1. Les mathématiques et l'astronomie. - Nathématiques (46). Astronomie........................... 447

11. La physique et la chimie. - Plyssique : acoustique, lumière $(4 \dot{49)}$. - Électricité : les piles (4ว0). - Électro-magnètisme (451). - Chimie : décourerte de noureaux corps simples (402). - La soude (43). - Les composés nouveaux (45). - Chimie organique............................

III. Les sciences naturcllcs. - Voyages de paturalistes (458). Zuologie (458). - Botanique (459). - Minèralogie, gẻologie. 460

IV. Les sciences médicales. - Anatomie, histologie (161). - Physiologie (462). - Thèrapeutique (462). - Homœopathie (464). - Chirurgie (465). - Caractères nouveaur de la chirurgie : le 
anesthésiques (466). - Branches diverses de la médecine et de la chirurgie (469). - Pharmacie............... 468

CHAPITRE XXII. - La transformation éonomique... 470

I. Les grandes applications des sciences. - La vapeur $\langle 470\rangle$. - Les machines industrielles à vapeur (471). - La navigation à vapeur (4i1). - Les chemins de fer (473). - La télégraphie électrique (477). - L'éclairage au gaz (477). - La lampe du mineur ('78). - Les puits artésiens (48). - Progrès de la mécanique (478). - Les travaux publics (478). - Les aérostats, la cloclie á plongeur, l'aur comprimé (479). - Le daguerrèotype et la photographie ............................. 480

II. L'agriculture. - Les résultals de la Révolution consacrés (480. - Irogrès de l'agriculture : méthodes, instruments (4S1). Institutions et enseignements agricoles (481). - Pisciculture. 482

III. L'induslrie. - Les expositions nationales (483). - L'industrie sous la Restauration (48.3). - L'industrie sous la Monarchie de Juillet (484). - Modification dans le sort de la classe ouvrière (486). - Lois sur le travail des enfants............ 487

IV. Le commerce et le crédit. - Les lois sur les cèrèales (488). Le système douanier ( $\$ \$ 9 \%$ - Le crèdit............ 490

CHAPITRE $X X I V$. - Les usages et les mours....... 491

I. Le costume et le mobilier. - Le costume (491). - Le mobilier (494). - Les véhicules.................... 494

II. La vie de societé. - Les salons (496). - La cour (497). - Les plaisirs ('98). - La loterie, les jeux de hasard (499). - L'anglomanie (499). - Le magnétisme animal et le spiritisme... 500

III. La vie publique. - Les haines de partis (501). - Les duels (503). - Les sociétés secrètes ( $50 \%)$. - Les complots sous LouisPhilippe (505). - L'apothéose de Napoléon (503). - Les anciennes associations dourriers.................. 506

IV. Paris. - Accroissement et embellissement de Paris (509. Aspect de la capitale.....................

\section{LIVRE III}

LES GOUVERNEMENTS DE SUFFRAGE UNIVERSEL - LA SECONDE REPUBLIQUE, LE SECOND EMPIRE - LA TROISIĖME RÉPUBLIQUE

(depuis $18: 8$ jusqu’à nos jours.)

CHAPIT RE XXV. - Les Constitutions, le droit électral, les libertés............................. 
I. - Les Conslilulions. - Caractères génèraux de celte période (כั1千). - Le Gouvernement provisoire de $184 \$^{\circ}(.316)$. - La Constituante et la Constitution de 1848 ( 316$)$. - Le Prince-Prèsident et l'Assemblèe Législative (5t7). - La Constitution de 1852 (51S). Pithblissement de l'Empire (519). - Modifications apportées au régime impérial (\$20). - Décret du 24 novembre 1860 (520). Décret du 19 janvier 1867 (521). - Sénatus-consulte du $S$ septembre 1869 (521). - L'Empire libèral (522). - Le Gonvernement de la Défense nationale (:923). - L'Assemblée nationale de 1871 (523). - La Constitution Rivet (523). - Le Septennat (324). - La Conslitution du 24 février 1875 et ses récentes modifications (524). - Mécanisme de notre Constitution actuelle...... 326

II. Le droit électoral. - Le suffrage universel décrétẻ (ă29). - Le suffrage universel menacé par l'Assemblée législatice (329). - Le suffrage universel rétabli par le coup d'État (530). - Rèsumé de l'histoire de notre droit électoral (531). - État actuel du droit de suffrage ................................. 531

III. Les libertés publiques. - lee droit de pétition (532). - La liberté d'assuciation et de réunion. Son histoire: $1^{\circ}$ Sous la liépublique de 1848 (532). - 20 Sous le régime du coup d'État (533). $3^{\circ}$ Suns l'Empire libèral (334). $-4^{\circ}$ Sons le régime actuel (534). - La liberté de la presse. Son histoire $: 1^{\circ}$ Sous la Reepublique de 18 's (335). - 2o Sous le régime du coup d État (536). - 30 Sous

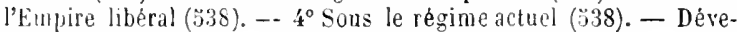
loppenent énorme de la presse............... 540

\section{CHAPITRE XXVI. - L'administration, la législation, les} finanees, les cuites................. 5 ; 5

Laiministration arant 1871 (543). - L'adninistalion depuis 1871 (5:5). - La légrislation contemporaine : droit civil ( $\$ 46)$. - Droit péual (547). L'assistance publique : enfunts (549). Les linances (549). - L'organisation tinancière (550). - L'exécution du Concordat (551). - Les congregations (553). - Les cultes non catholiques..................... $5 . ; 4$

\section{CHAPITRE XXVII. - Le droit des gens, l'arnée, la marine,} les colonies........................ 530

I. Le droit des gens. - Les nationalités (5:56). - Droit des peuples à disposer d'eux-mèmes (558). - Congrès, conférences, arbitrages, neutralisations (5\%8). - Le droit des gens pendant la guerre (559). - La diplomatie (:562). - Situation de la France en Europe.......................... 563

II. - l'armée. - la garte nationale el l'armèe après 18 ís (564). La farde nationale et l'armée sous le second Empire (56't). L'armée sous le régime actuel (567). - P'erfectionnement de l'artillerie (570). - Perfectiounement du fusil (573). - Transfor- 
mation de la taclique : la guerre scientilique (574). - Corps nouveaux ou modifications des anciens............ $57 \%$

III. La marine. - Recrutement de l'armée de mer (576). - Le nouveau matériel flottant (578). - Torpilles, bateaux-torpilleurs, sous-marins (580) - Puissance de la flotte française.... 581

IV. Les colonies. - Accroissement de nolre empire colonial (582). Abolition de l'esclavage ( 5857 . - Émancipation économique ( 383 ). - Émancipation politique (586). - Représentation coloniale. 587

CHA ITPE XXVIII. - L'instruetion publique....... $\$ 89$

I. Sous la seconde République. - Projet Carnot (589). - Loi

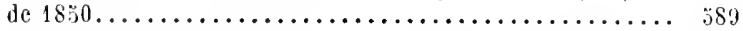

Il. Sous l'Empire. - Régime du conp d'Élat (591). - Ninistère de Victor Duruy : $1^{\circ}$ Mesures réparatrices (592). - $2^{\circ}$ Enseignement primaire (592). - $3^{\circ}$ Enseignement secondaire (592). - $4^{\circ}$ Enseignement supérienr...................... 593

III. Sous la Répullique achuelle. - to I'renieres lus sur les Conseils et sur la Liberté de l'enseignement (594). - Lois Ferry sur les Conseils et la Liberté d'enseignement (593). - $2^{\circ}$ Enseignement primaire (:i96). - Lois Ferry sur l'enseiguement primaire (596). - Autres lois sur l'enseignement primaire (598). - 30 Enscignement secondaire (598). - $4^{\circ}$ Enseignement supérieur (599). $5^{\circ}$ Ilusées nouveaus (601). $-6^{\circ}$ Budget de l'instruction publique.............................. 601

CHAPITRE XYIX. - Les lettres............... 603

1. Le théatre. - Tendance à la confusion des diver's genres dramatiques (603). - Le drame historique (603). - Le drame populaire (605). - La comédie de mœurs et de caractères (60.3). - Le vaudeville, la comèdie fantaisiste (607). — La féerie, la revue. 608

II. Les autres genres littéraires. - La poésie épique et lyrique (609). - La chansun (61t). - Le roman (612). - La critique littéraire et artistique (619). - L'éloquence du barreau (619). - L'éloquence poltique.............................. 620

CHAPITPE XXX. - Les sciences morales et polidiques. 624

I. La philosophie el le droit. - Plailosophie : l'école éclectique (62't). - La philosophie et les sciences (62k). - L'école positiviste (627). - Ine branche nouvelle de la morale (629). - Le droit. 630

II. L'histoire, les langues, la géographie. - L'bistoire (631). - Les áges classiyues (631). - Le moyen dge francais (625). - L'histoire des temps mudernes (637). - L'histoire contemporaine (639). - Etndes celtiques (640). - Études égyptiennes (640). Etules assyriennes, babyloniennes, persiques, médiques (641). Etules sémitiques : syriennes, arabes, berbères (641). - Elurles 
persanes, arméniennes, turques, ta!ares (6:3). - Études indiennes 64t). - Etules l'lxtrême-Orient (644). - Eludes américaines 643). - Études prèhisturiques (6'5). - Gèugraphie, voyages. $6: 7$

11I. - L'économie politique et la sociologie. - L'économie politique $(648)$. - La science sociale................ 649

CHAI'ITPE XXII. - Les arts............... 6.30

I. L'architecture, la sculpture. - Restauration des monuments anciens (6⿱艹0). - L'architecture contempraine (6ว̈). - La sculpture............................... 6

11. La peinture, les arts du dessin. - Filiation des écoles de peinture (6.56). - $1^{\circ}$ Les peintres da second Empire : la peinture d'histoire (657). - Le portrait (659). - La peinture des vitraux (659). - L'école réaliste (659). - Les impressionnistes (661). Le paysage $(66 \mathrm{t})$. - 20 Les peintres de la gẻnération prèsente (663. - Les dessinateurs (666). - Les artistes graveurs (667). - Les artistes lithographes (667). - Condition nonvelle de l'art et des artistes (667). - Les arts décorat!fs........... 669

İl. La musique. - Progrès de notre éducation musicale (671). La musique allemande (671). - La musique italieme (672). Les composileurs français $(673)$. - Un genre noureau : l'opérette................................... 676

CHAPITRE XXXII. - Les seiences.............. $67 \mathrm{~s}$

I. Les mathématiques et l'astronomie. - Mathẻmatiques (678). Astronomie : Terre, Lone, Soleil (678). - Planètes, comètes, étoiles filantes $(6 \varsigma 0)$ - Monde stellaire.............663

II. La physique et la chimie. - Physiqne : nature de la matière (686). - Chaleur (687). - Lumiere (688). - Les rayons lumineux invisibles (682). - Electricité et lamière : rayons cathodiques (6ৎ9). - Les rayons X (690). - Tiecherches diverses sur la lumiere (693). - L'électricité d'índuction (694). - lfinité des grandes forces de la nature (69:). - Le téléplune (695). - Le plonographe (696). - La télègraphie sans til (697). - Autres applications de l'électricite (699). - Météurolorie (70I). - Chimie : découverte de nouveanx corps simples par l'analyse spectrale on leur radiation (703). - L'aluminium (703). - Climie organique 70 ). - Les substances explosives (705). - La houille et ses probuits (706). - Chimie agricole (707). - Ihilosuphie de la cluimie............................ 707

III. Les sciences naturelles. - Voyages de naluralistes (708). Thèories nouvelles (708). - Zoolugie (708). - Question de la génération spontanée (711). - Paléontologie (712). - Histuire naturelle de l'homme (712). - Botanique (713). - Géulogie (715). - Le monde souterrain.................... 718 
IV. Les sciences mélicales. - Anatomie, histologie (717). - Pbysiologie, biologie (717). - Claude Bernard : les sucs organiques, les fonctions du systeme nerveux (717). - Louis Pasteur : les virus (719). - Serothérapie (721). - Perturbations du systéme nerveux : phenomenes d'hypnotisme (721). Thèrapeutique : progrès de la médecine curative (723). - Chirurgie (724). - Caractères noureaux de la chirurgie : les antiseptiques (725). Branches diverses de la médecine et de la chururgie (727). Hygiene (727). - Rijle brillant des facultés de médecine (723). — Hédecine vètérinaire (729). — Pharmacie.......... 730

\section{CHAPITRE XXXII. - La transformation économique. $\mathbf{i} 32$}

I. Les grantes applications des sciences. - Progrès de la navigation à vapeur (732). - Les phares (73'). - Dèveloppement des ligues de chemins de fer (73i). - Chemins de fer francais à l'ètranger (73:). - Travaux d’art (733). - Inventions diverses (736). - Perfection dn matèriel (736). - Développement des lignes tẻlégraphịues (73\%. - Perfectionnement de l'èclairage au gaz (73s) - L'acètylène (738). - L'éclairage èlectrique (738). - Perfectionnenent de la lanpe du mineur (739). - Les aérostats (739). - Le scaphandre (74). - Prugrès de la jholographie

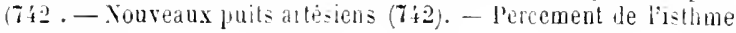
de Suez............................. 743

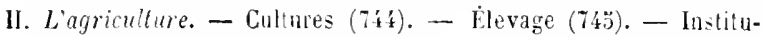
tions, luis, enseignements agricules (746). - Statistique agricole.............................. 70

III. L'inchustrie. - Accroissement des popuhatious urbaines a uètriment des camplagnes (731). - Progrès de l'industrie 752. Instilutions et ensergnemeuts industriels (732). - La propriete industrielle (753). - Les expositions internationales de l'industrie (733). - Industries nouvelles (70. - Statistique de l'inin:tre...............................

IV. Le commerce. - Enseignements commerciaux (7äb). - Rèforme des lois sur les céréales (70̈6). - Les traités de commerce (706). - Péforme des postes : union postale universelle (7.38). - Statistique du comnerce.................... 739

v. Le crédit. - Abondance nouvelle du numéraire (739. - La Banqute de France (760). - Sociétés nouvelles de crèdit (761. Multiplication des valeurs en pupier............. T02

VI. Les clinses ourrieres. - Loi sur les coalitions : les grèves $(\mathbf{7 0} \mathbf{4})$. - Loi sur les syrdicats (706). - Lois sur les accidents du tra vail (263). - Lois et mesures sur la réglementation du travail (766. - Nouvelles associations onvrières (766). - Ciéations diverses (767). - Assistance publique (768). - Progres dans la conditio ina trapilleurs..................... 65 
VII. Paris. - Le Paris nouveau................ 769

VIII. Les illes et les groupements socialistes. - Influence des théories allemandes ei russes (771). - L'Internationale des travailleurs (777). - Les idees et les partis socialistes en France (782). - Le congrès international de l'aris en $1900 \ldots \ldots \ldots \ldots .788$

CHAPITRE XXXIV. - Caractères généranx de la civilisa. tion moderne $\ldots \ldots \ldots \ldots \ldots \ldots \ldots \ldots \ldots \ldots, 792$

Prugrès scientifique (792). - Progrès démocratique (794). - Progrès ieunuminue (798). - Sulidarité internationale..... 800 Nutes supplimentaires..................... 807 
, 
Histoire de la Civilisation française, drpuis les Origines justuia mes jouts, par II. Alfred Ranbaco, de l'Institut, professeur à l'l nicersité de Paris. Les deux volumes in-18 jésus de 1.300 pages, lrochés.

\section{Histoire politique de la Révolution fran-} çaise. Origines et llewhopement de lu Démocratie ot de la lifipulligue (17S9-1804), par M. A. Aul.and, professeur it l'Luiversité de Paris. Ln vol. in-8 raisin de 816 pages, broche

Relié demi-chagrin, tite dorén .... 16 fr.

\section{Histoire politique de l'Europe contem-} poraine, Evolution des partis et des formes politipues 1814-1896, par M. Ch. Selgnoros, professemr à l'Ĺniversití le l'aris. Un rolume in- $8^{\circ}$ cavalier de $8: 0$ pages, broché

Relie demi-chagrin, tête doree. . . . $16 \mathrm{fr}$.

(Ou'raye couronné par l'Academie française)

\section{Histoire générale du IV siècle à nos jours,} publiée sous la direction de Ernest Lavisse, de l'Académie française, professeur ì l'Université de Paris, et Alfred hambaud, de l'Institut, professeur à l'Université de Paris.

\section{OUVRAGE COMPLET EN DOUZE VOLUMES}

1. Les Origines (395-11195).

11. L'Earope féodale; les Croisades (109-127i1).

111. Formation des grands États $11270-1492$.

IV. Renaissance et Réforme; les non-

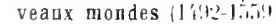

Les Guerres de Religion (1)

Louis XIV (|17i3-171.i).
V11. Le XVIII siècle $(1715-17 \times 8)$.

rill. La Révolution française (178!-1799!).

1X. Napoléon 1800-1815).

X. Monarchies constitutionnelles $181,-18,2$

Xl. Revolutions et Guerres natio-

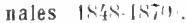

Xil. Le Monde contemporain $1150-1900$ 


(2) 


$$
1
$$

